

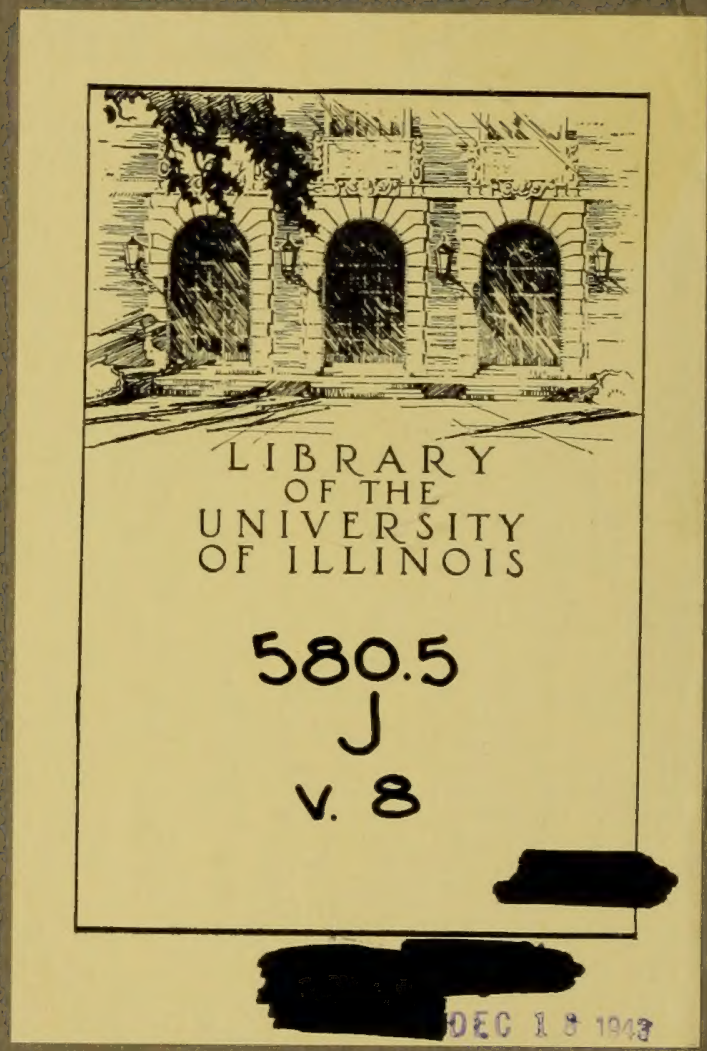




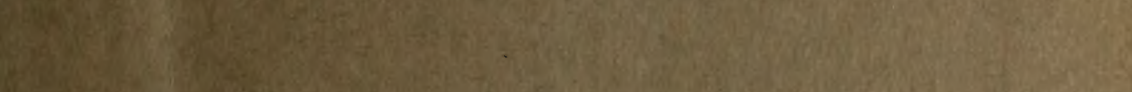

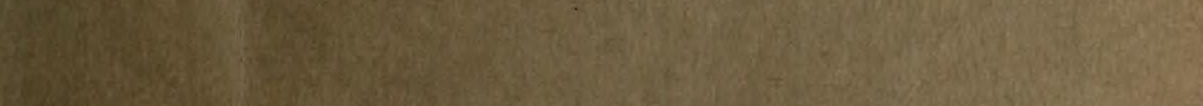

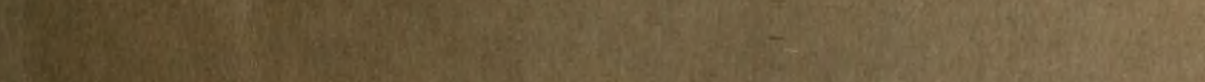

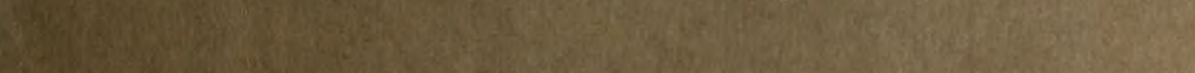

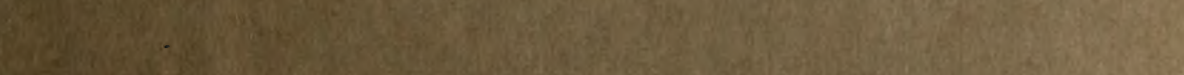

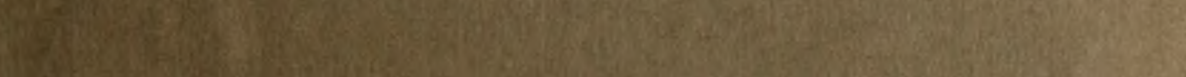







\section{JAHRBUCHER'}

für

\section{wissenschaftliche Botanik.}

Herausgegeben

von

\section{Dr. N. Pringsheim.}

Achter Band.

Mit 38 zum Theil colorirten Tafeln.

\section{Leipzig 1872.}

Verlag von Wilh. Engelmann. 



\section{0.}

J v. 8

\section{I n h a 1 t.}

I. Entwickelung des Vorkeimes von Osmunda regalis L. . . . . 1

1. Bau der Sporen. . . . . . . . . . . . . 1

2. Entwickelung des Vorkeimes . . . . . . . . 3

3 Entwickelung der Antheridien . . . . . . . . . 9

4. Entwickelung der Archegonien . . . . . . . . . 10

Erklärung der Tafeln I, II u. III . . . . . . . . . . . . . . 14

E. Pfitzer. Beiträge zur Kenntniss der Hautgewebe der Pflanzen, mit Taf. VI 16

III. Ueber die mehrschichtige Epidermis und das Hypoderma. . 16

Erklärung der Tafel VI . . . . . . . . . . . . 73

N. J. C. Müller. Die Anatomie und die Mechanik der Spaltöffnungen (als Fortsetzung zu: Diffusion der atmosphärischen Gase u. s. f.) . . . . . . 75

III. Wirkung der Wärme innerhalb der Temperaturgrenzen des gewöhnlichen Lebens, mit Taf, IV. u. V . . . . . . . 75

J. Peyritsch. Ueber Bildungsabweichungen bei Cruciferen, mit Taf. VII-IX 117

Erklärung der Abbildungen . . . . . . . . . . . 128

G. Kraus. Die Entstehung der Farbstoffkörper in den Beeren von Solanuma

Pseudocapsicum, mit Taf. X . . . . . . . . . . . 131

Erklärung der Taf. X . . . . . . . . . . . . 147

A. Dodel. Der Uebergang des Dicotyledonen-Stengels in die Pfahlwurzel mit

Taf. XI-XVIII . . . . . . . . . . . . . 149

Der Vasalstrangverlauf . . . . . . . . . . . . . . 153

Vasalstrangverlauf des hypocotylen Stengels und der Hauptwurzel . 154

Verlauf der primordialen Bastpartieen ........... 159

Anatomischer Bau der verschiedenen Elemente . . . . . . . . 161

Basaltheil der Hauptwurzel . . . . . . . . . . . . . . . . 179

Erklärung der Abbildungen Taf. XI-XVIII . . . . . . . . . 184

W. Pfeffer. Zur Blüthenentwickelung der Primulaceen und Ampelideen, mit

Taf. XIX-XXII . . . . . . . . . . . . . 194

Erklärung der Abbildungen Taf, XIX-XXII. . . . . . . . . 214

B. Frank. Ueber die Veränderung der Lage der Chlorophyllkömer und des

Protoplasmas in der Zelle, und deren innere und äussere Ursachen . . . 216

I. Trennung der Zellen vom Körper . . . . . . . . . 220

II. Luft . . . . . . . . . . . . . . . . 250

III. Temperatur. ............. . . 261 
IV. Verminderung des Wassergehaltes der Zelle ... : . . 266

V. Das Medium . . . . . . . . . . . . . . 269

VI. Periodicität . . . . . . . . . . . 271

Das Protoplasma ist das Bewegende. . . . . . . . . . 282

Allgemeine Ergebnisse . . . . . . . . . . . . . 289

Nachträgliche Bemerkungen . . . . . . . . . . . 302

J. Klein. Zur Kenntniss des Pilobolus . . . . . . . . . . . . 305

I. Entwickelung des Pilobolus . . . . . . . . . 306

1. Das Mycelium . . . . . . . . . . . 306

2. Anlage zum Fruchtträger . . . . . . . . . . . 310

3. Fruchtträger und Sporangium . . . . . . . . 313

4. Das Abschleudern des Sporangiums . . . . . . 326

5. Chemische Reactionen . . . . . . . . 334

6. Geformte Inhaltskörper . . . . . . . . . . . 337

7. Ausnahmsweise Erscheinungen . . . . . . . . 339

II. Formen des Pilobolus . . . . . . . . . . . . . 343

III. Pleomorphie des Pilobolus . . . . . . . . . . . 362

Erklärung der Abbildungen Taf. XXII-XXX . . . . . . . . . 377

L. Jurányi. Ueber den Bau und die Entwickelung des Pollens bei Ceratozamia longifolia Miq. . . . . . . . . . . . . . . . . . . . . 382

Erklärung der Abbildungen Taf. XXXI-XXXIV . . . . . . . 398

K. Sanio. Ueber die Grösse der Holzzellen bei der gemeinen Kiefer. (Pinus silvestris) . . . . . . . . . . . . . . . 401

G. Kraus. Ueber eigenthümliche Sphärokrystalle in der Epidermis von Coccu-

lus laurifolius) . . . . . . . . . . . . . . . 421

Ueber Eiweisskrystalloide in der Epidermis von Polypodium ireoides Lam. 426

Erklärung der Abbildungen Taf. XXXV . . . . . . . . 428

W. Pfeffer. Untersuchungen über die Proteinkörner und die Bedeutung des

Asparagins beim Keimen der Samen . . . . . . . . . . . . 429

Proteinkörner ohne Krystalloide . . . . . . . . . . . 434

Proteinkorner mit Krystalloiden . . . . . . . . . . 450

Die Einschlüsse . . . . . . . . . . . . . . 4464

Die Grundmasse . . . . . . . . . . . . . . . . 478

Allgemeines . . . . . . . . . . . . . . . . . 486

Die Ursachen der Löslichkeit der Proteinkörner . . . . . . . . . 491

Die Proteinkörner von Paeonia . . . . . . . . . . . 499

Bildung der Proteinkörner . . . . . . . . . . . . 506

Silybum marianum . . . . . . . . . . . . . 511

Lupinus polyphyllus und luteus . . . . . . . . . 513

Phaseolus vulgaris . . . . . . . . . . . . 515

Ricinus communis . . . . . . . . . . . . . 516

Veränderung der Proteinkörner beim Keimen . . . . . . . . 525

Die Bedeutung des Asparagins beim Keimen. . . . . . . . 530

Historisches . . . . . . . . . . . . . . 565

Erklärung der Abbildungen. Taf. XXXVI-XXXVIII . . . . . . 571

J. Wiesner. Untersuchungen über die Farbstoffe einiger für chorophyllfrei ge-

haltenen Phanerogamen . . . . . . . . . . . 575

Erklärung der Figurentafel ............... 594 


\section{JAHRBÜCHER}

\section{für \\ wissenschaftliche Botanik.}

Herausgegeben

von

Dr. N. Pringsheim.

Achter Band. Erstes Heft.

Mit 10 zum Theil farbigen Tafeln.

Leipzig, 1871.

Verlag von Wilb. Engelmann. 


\section{Inhalt der ersten sechs Bände.}

N. Pringsheim. Beiträge zur Morphologie und Systematik der Algen.

I. Morphologie der Oedognnieen, mit Taf. I-VI.

W. Ilofmeister. Neuere Beubachtungen über Embryobildungen der Phanerogamed, mit Taf. VII-X

N. Pringsheim. Teber das Austreten der Sporen von Sphaeria Scirpi aus ihren Schläuchen; hierzu Taf. XXIV. A.

H. Scharht. Ueber die Pflanzenbefruchtung, mit Taf. XI-XV.

Joh. Ilausteiu. Ueber den Zusammenhang der Blattstellung mit dem Bau des dicotylen Holzringes, mit Taf. XVI-XVIII.

N. Pringsheim. Beitı äge zur Morphologie und Systematik der Algen.

II. Die Saprolegnieen, mit Taf. XIX-XXI.

dl. Braun. Ueber den Blüthenbau von Delphinium, mit Taf. XXII und XXuI.

L. Cienkowsky. Die Pseudogonidien; hierzu Taf. XXIV. B.

R. Caspary. Die Hydrilleen (Anacharideen End) mit Taf. XXV-XXIX.

J. Gröntand. Einige Worte über die Bastardbildungen in der Gattung Aegilops, mit Taf. XXX.

․ Pringsheim. Beiträge zur Morphologie und Systematik der Algen

III. Die Choleochateen, mit Taf. I-VI.

c. Sanio. Vergleichende Untersuchungen über den Bau und die Entwickelung des Korkes, mit Tafel VII-XIII.

H. Schacht. Ueber den Bau einiger Pollenkörner, mit Taf. XIV-XVIII.

d. de Bary. Einige neue Saprulegnien, mit Taf. XIX-XXI.

M. Wichurn, Beiträge zur Physiologie der Laubmoose.

N. Pringsheim. Beitrage zur Morphologie und Systematik der Algen.

IV. Nachtrïge zur Morphologie der Saprolegnieen, mit Taf. XXII-XXV.

W. Hofmeister. Ceber die Beugungen saftreicher Pflanzentheile nach Erschitterung.

II. Hoffmann. Tntersuchungen über die Keimung der Pilzsporen, mit Taf. XXVI bis XXXII.

J. Sachs. Physiologische Untersuchungen über die Abhängigkeit der Keimung von der 'lemperatur.

W. Ilofmeister. Ueber die Entwickelung der Sporen des Tuber aestivum Vittad., mit Taf. XXXIII-XXXV.

Joh. Hansteìn. Versuche über die Leitung des Saftes durch die Rinde und Folgerungen daraus,

N. Pringsheim. Nachtrag zur Kritik und Geschichte der Untersuchungen über das Algengeschlecht.

A. Wiegand. Zur Morphologie und Systematik der Gattungen Trichia und Arcryria, mit Taf. I-III.

F. Hildebrand. Anatomische Untersuchungen über die Farben der Blüthen, mit Taf. IV.

W. Hofmeister. Ueber die durch die Schwerkraft bestimmten Richtungen von Pflanzentheilen.

A. Wigand. Ueber die Deorganisation der Pflanzenzelle, insbesondere über die physiologische Bedeutung von Gummi und Harz, mit Taf. V-VII.

J. Sachs. Ueber die Stoffe, welche das Material zum Wachsthum der Zellhänte liefern.

W. Hofmeister. Zusätze und Berichtigungen zu den 1851 veröffentlichten Untersuchungen der Entwickelung böherer Kryptoganen, mit Taf. VIII.

N. Pringshein. Ueber die Vorkeime und die nacktfissigen Zweige der Charen mit Taf. IX-XIII.

L. Cienkowsky. "Zur Entwickelungsgeschichte der Mixonyceten.

II. Schacht Ueber die Zellstofffiticn in der vorderen Aussackung des Embrjosackes von Pedicularis sylvatica, mit Taf. XIV und XV.

Ueber ein neurs Secretionsorgan im. Wurzelstock von Nephrodium Filix mas, mit Taf. XVI.

W. Kabsch. Untersuchungen über d.e chemische Beschaffenheit der Pflanzengewebe.

L. Cienkowsky. Das Plasmodium. mit Taf. XVII-XXI.

II. Sehacht. Ueber die Yeländerting durch Y'ilze in abgestorbenen Pflanzenzellen, mit Taf. XXII-XXIII.

N. Pringsleiol. Zur Morphologie der Salvinia natans, mit Taf. XXIV-XXIX.

II. Sehacht. Die Blüthe und die Brfichtung von Santalum album, mit Taf. I-IV.

F. Thomas. Zur verglcichenden Anatomie der Coniferen-Laubblätter.

L. Kıy. Beitıäge zur Entwickelungsgeschichte der laubigen Lebermoose, mit Taf. V-VII. 


\section{I n h a 1 t}

des vorliegenden Heftes 1, Bd. VIII.

L. Kny. Beiträge zur Entwickelungsgeschichte der Farrnkräuter, mit Taf. I.

II. III.

I. Entwickelung des Vorkeimes von Osmunda regalis. L. . . 1

1) Bau der Sporen . . . . . . . . . . . . 1

2) Entwickelung des Vorkeimes . . . . . . . . 3

3) Entwickelung der Antheridien . . . . . . . . - 9

4) Entwickelung der Archegonien. . . . . . . . 10

Erklärung der Tafeln I. II. u. III. . . . . . ... 14

E. Pfitzer. Beiträge zur Kenntniss der Hautgewebe der Pflanzen, mit Taf. VI. 16

III. Ueber die mehrschichtige Epidermis und das Hypoderma . . 16

Erklärung der Tafel VI. . . . . ... . . . 73

N. J. C. Müllor. Die Anatomie und die Mechanik der Spaltöffnungen . . 75

(Als Fortsetzung zu: „Diffusion der atmosphärischen Gase

u. s. f.")

III. Wirkung der Wärme innerhalb der Temperaturgrenzen des gewöhnlichen Lebens, mit Taf. IV. u. V. . . . . . 75

J. Peyritsch. Ueber Bildungsabweichungen bei Cruciferen, mit Taf. VII.

VIII. IX. . . . . . . . . . . . . . . . . 117

Erklärung der Abbildungen . . . . . . . . . . 128

G. Kraus. Die Entstehung der Farbstoffkörper in den Beeren von Solanum

Pseudocapsicum, mit Taf. X. . . . . . . . . . . . . . 131

Erklärung der Taf. X. . . . . . . . . 147 



\section{Beiträge zur Entwickelungsgeschichte der Farrnkräuter. \\ Von}

Dr. L, Kny.

\section{Entwickelung des Vorkeimes von Osmunda regalis. L. ')}

1) Bau der Sporen.

Die reifen Sporen von Osmunda regalis zeigen, wenn frisch aus dem Sporangium entnommen und in Wasser untersucht, nahezu regelmässige Kugelgestalt. (Taf. I., Fig. 1.) Ibre Membranen sind wasserhell und durchscheinend. Auf drei, am Scheitel $\mathrm{zu}$ sammenlaufenden flachen Kanten, welche den Berührungslinien mit je zweien ibrer Schwestersporen innerhalb der Mutterzelle entsprechen, erheben sich niedrige, bis fast zum Aequator verlaufende Leisten. Mit Ausnahme dieser drei Linien ist die Oberfläche der Exine überall mit kleinen, wellig hervortretenden Prominenzen bedeckt. Bisweilen sind dieselben im Grundriss kreisrund; meist sind sie länglich, gewunden und dabei nicht selten verzweigt. Beiderlei Formen kommen auf derselben Spore fast immer nebeneinander vor. (Taf. I., Figg. 1 u. 2).

Die Differenzirung der Sporenhaut in eine äussere und innere Membran ist ohne Anwendung von Reagentien nicht deutlich erkennbar; dagegen tritt die Anordnung des Inhaltes bei der Farblosigkeit der Exine sehr klar hervor. Auffallend ist der reiche Gehalt an Chlorophyll (Taf. I., Fig. 1). Dasselbe ist in wolkigen Massen um den centralen, als heller Fleck erscheinenden Zellkern versammelt und strahlt von hier an mehreren Punkten gegen die Peripherie der Sporenzelle aus, ohne dieselbe indess zu erreichèn.

1) Gegenwärtige Untersuchung wurde auf Anregung meines Freundes, des Herrn Prof. Dr. Milde in Breslau unternommen. Am 21. Januar 1868 gab ich der Gesellschaft Naturforschender Freunde in Berlin einen kurzen Bericht über die gewonnenen Resultate. Eine Uobersicht derselben findet sich in Milde's Monographja generis Osmundae p. 49 abgedruckt.

Jahrb. f. wiss. Botanik, VIIT. 
Die zwischenliegenden Parthieen des Inhaltes und der Wandbeleg sind farblos.

Uebt man auf reife Osmundasporen einen allmälig gesteigerten, zuletzt ziemlich energischen Druck mit dem Deckglase, so platzen sie, meist an den durch die drei vorspringenden Leisten bezeichneten Linien, und der zähe protoplasmatische Inhalt tritt als wurstförmige Masse aus dem Spalt hervor. Nur selten fand ich das Chlorophyll schon in deutlich umschriebenen Körnern darin vor; ihre Form war dann gewöhnlich elliptisch, mit lang ausgezogenen Enden. In der grossen Mchrzahl der Fälle bildete es amorphe, wolkige Massen (Taf. I., Fig. 2). Ausserdem enthälı das Proto. plasma noch eine grosse Zahl farbloser, glänzender Tröpfchen, welche unter Einwirkung von Kalilauge, Schwefelsäure, Alkohol und Aether zu grösseren Tropfen zusammenfliessen und sich bei Behandlung mit den letztgenannten Reagentien noch überdiess grün färben. Eine Lösung durch Alkohol und Aether wurde nicht beobachtet. Es bleibt also unentschieden, ob der Stoff wirklich den fetten Oelen angehört, denen er sich durch sein optisches Verhalten nähert. Stärke konnte ich nie mit Sicherheit nachweisen.

Bei aufmerksamer Durchmusterung des durch Druck befreiten Sporeninhaltes gelingt es nicht selten, den in der unverletzten Spore als heller Fleck sichtbaren Zellkern wiederzufinden. Derselbe stellt ein zart contourirtes Bläschen von kugeligem oder eiförmigem Umriss dar; sein grösster Durchmesser ist 2-4 mal kleiner, als der der Spore. Mitten im feinkörnigen Inhalt tritt ein grosses kugeliges Kernkörperchen sehr deutlich hervor. Die beschriebenen Verhältnisse sind besonders klar, wenn man den Zellkern durch Zusatz verdünnter Jodlösung schwach braun färbt. (Taf. I., Fig. 2.)

Schwefelsäure von mässiger Concentration giebt der Exine eine intensiv rothbraune Färbung, welche bei längerer Einwirkung des Reagens (16 Stunden) in eine șchwärzlich violette übergeht. Eine innere Schicht derselben grenzt sich dabei in scharfen Contouren nach aussen und nach innen gegen dic Intine $a b$, welche ihrerseits nicht deutlich hervortritt. Die Prominenzen gehören, wie man jetzt erkennt, allein der Aussenschicht der Exine an. Legt man Osmundasporen in concentrirte Schwefelsäure, so sieht man die Aussenhaut der Exine ausserordentlich stark, bis zum vollständigen Verschwinden der äusseren Contour, aufquellen und dabei fast augenblicklich eine blassere Färbung annehmen. 
Die Innenhaut ist resistenter und behält ihre dunkler rothbraune bis violette Färbung längere Zeit bei.

Concentrirte Kalilauge ertheilt der Exine eine lebhaft goldgelbe Färbung; dabei quellen deren Häute weniger stark, als in Schwefeläure, während die Intine sammt dem Zellinhalt bedeutend an Volumen zunimmt und bäufig als geschlossene Blase aus einem klaffenden Riss der Exine hervortritt. Wäscht man solche Präparate vorsichtig aus und fügt nun concentrirte Schwefelsäure zu, so sieht man die goldgelbe Färbung der Exine durch schmutzigweiss in bräunlich-roth übergehen und überzeugt sich nun, dass die intensiver gefärbte, beiderseits scharf contourirte Innenschicht wirklich der Exine angehört, was vorher zweifelhaft geblieben war.

Die warzenförmigen Prominenzen der Aussenhaut bleiben selbst bei Kochen in Aetzkali unverändert.

Eine Blaufärbung der Intine konnte weder durch Chlorzinkjodlösung noch aurch Jod und Schwefelsäure erreicht werden.

Alte Sporen von Osmunda zeigen eiu von den frischen sehr abweichendes Aussehen. Ihr Inhalt ist geschrumpft und die Membran an einem, seltener an mehreren Punkten gleichzeitig eingesunken. Die ölartigen Tröpfchen sind im Innern der Spore zu einem oder mehreren grösseren Tropfen zusammengeflossen; ein Theil derselben ist durch die Membran hindurchgetreten und hängt den Warzen der Exine an. Die Zeichnungen und Angaben Fischer's von Waldheim (Jahrbücher für wissensch. Botanik IV. p. $372 \mathrm{ff}$. Taf. 27, Fig. 28-39) beweisen, dass er nicht mit frischem Material gearbeitet hat. Seine Beschreibung ist desshalb in vielen Punkten verfehlt.

Die Grösse der Sporen ist sehr verschieden. Nach einer grossen Zahl von Messungen schwankt der Durchmesser zwischen 0,0868 und $0,0491 \mathrm{Mm}$., gewöhnlich beträgt er 0,061-0,078 $\mathrm{Mm}$.

Die Sporen von Osmunda spectabilis, welche ich ebenfalls frisch untersuchte, stimmen in Form, Grösse und chemischem Verhalten mit denen von Osmunda regalis genau überein.

2) Entwickelung des Vorkeimes.

Die Zartheit der Exine und der reiche Gehalt an Chlorophyll, welche die Sporen von Osmunda vor denen der Polypodiaceen auszeichnen, machten es von von vornherein wahrscheinlich, dass ihre Keimfähigkeit keine langandauernde sein werde. Um hierin sicher zu gehen, klopfte ich das reife Sporenpulver aus dem Frucht- 
wedel direct auf das zur Aufnahme bereite Substrat. Als besonders geeignet erwies sich eine Mischung von Torf und Haideerde; auf ihr habe ich wedeltragende $\mathrm{P} f$ änzchen bis zu ziemlicher Grösse erzogen. Die ersten Stadien der Keimung wurden auch auf Brunnenwasser und feuchtem Sande beobachtet.

Eine nothwendige Bedingung für den Eintritt der Keimung ist Licht von genügender Intensität. Wurden die Sporen auf Torf oder Wasser in möglichst vollkommene Dunkelheit gebracht, so blieben sie über eine Woche lang unverändert. Im diffusen Tageslicht traten die ersten Anzeichen der Keimung schon am zweiten Tage nach der Aussaat hervor.

Aeusserlich macht sich die Fortentwickelung der Spore durch eine Volumenzunahme des Inhaltes bemerklich, welcher die Exine nur kurze Zeit durch Dehnung zu folgen rermag. Mit Beginn des dritten Tages berstet sie, gewöhnlich genau am Scheitel, und spaltet sich, indem die drei hier zusammenlaufenden Kanten der Länge nach halbirt werden, in ebensoviele bis zum Aequator oder darüber hinausreichende Lappen. Die von der Intine umgebene Sporenzelle tritt nun in Form eines abgerundet konischen Wärzchens aus dem Spalt hervor (Taf. I., Fig. 3).

Schon zu dieser Zeit, wo die Innenzelle von der Exine noch fast allseitig umschlossen ist, tritt die erste Theilungswand in ihr auf. Dieselbe ist zur Richtung des vorhergegangenen Längenwachsthums immer genau senkrecht und trennt die warzenförmige, mit hyalinem Protoptasma erfüllte Hervorragung als erstes Wurzelhaar von der Mutterzelle des Prothalliums ab. In ersterem treten keine weiteren Theilungen mehr auf; dafür ist seine Längsdehnung durch Scheitelwachsthum der Membran sehr beträchtlich. In der Jugend stellt es einen wellig gebogenen, an der Spitze gerundeten Cylinder dar, welcher rom jungen Vorkeim mit verbreiterter Basis entspringt (Taf. I., Figg. 4-8); später hat es durch Anschmiegen an die Unebenheiten des Substrates seine regelmässig cylindrische Gestalt eingebüsst und ist an vereinzelten Stellen knorrig aufgetrieben (T'af. I., Figg. 16, 17).

Die Mutterzelle des Prothalliums vergrössert sich vornehmlich in Richtung ihrer Längsachse und theilt sich, bald nach ihrer Abtrennung vom ersten Wurzelhaar, durch eine horizontale, der erstentstandenen parallele Scheidewand (Taf. I., Figg. 3, 4). In jeder der beiden übereinanderliegenden Tochterzellen tritt nun fast immer je eine vertikale Wand auf; die obere Zelle eilt der unteren 
hierin voraus (Taf. I., Figg. 5, 6). Der junge, eiförmige oder nahezu kreisrunde Vorkeim besteht jetzt, abgesehen vom ersten Wurzelhaar, aus vier, nach Art von Kreisquadranten zu einer Fläche geordneten Zellen. Eine der beiden oberen wird darauf meist schon jetzt, seltener erst nach vorangegangener Theilung durch eine vertikale oder horizontale Scheidewand (Taf. I., Fig. 11), zur Scheitelzelle des Vorkeimes. Die weiteren Theilungen in ihr folgen genau dem für Metzgeria und Aneura bekannten Gesetz: Die Scheidewände sind den beiden ebenen Seitenflächen abwechselnd nahezu parallel und einander stufenweise aufgesetzt. Dabei nimmt die Scheitelzelle in jeder folgenden Theilungsgeneration eine etwas spitzere Form an, die sich von der ursprünglichen eines Kreisquadranten zuletzt merklich entfernt (Taf. I., Figg. 14, 15).

Mit der wiederholten Verjüngung der Scheitelzelle halten die Theilungen in den nach rechts und links von ihr abgegliederten Randzellen nicht nur gleichen Schritt, sondern eilen ihr häufig voran. Die zuerst in ihnen entstehende Theilungswand ist stets senkrecht $\mathrm{zu}$ ihrer Längsachse gerichtet und der freien Aussenwand parallel; die folgenden wechseln, besonders gegen den Rand hin, meist rechtwinkelig mit einander ab (Taf. I., Figg. 9 u. ff.). Es werden auf diese Weise sanft gebogene, hinter der Scheitelzelle in spitzem Winkel zusammentreffende Zellreihen gebildet, die sich gegen den Rand des Vorkeimes fächerförmig in mehrere Reiben spalten. Die Scheitelzelle selbst kommt, bei den lebhaften Theilungen der von ihr abgetrennten Randzellen, allmälig is eine sanfte Einbuchtung zu liegen (Taf. I., Figg. 15, 16).

Die drei übrigen Quadrantenzellen des Vorkeimes, die wir einstweilen unberücksichtigt gelassen hatten, nehmen einen von der Scheitelzelle abweichenden, unter sich ziemlich übereinstimmenden Entwickelungsgang. Meist treten zuerst längsgerichtete Scheidewände in ihnen auf (Taf. I., Figg. 9, 10, 11, 13). Die weiteren Theilungen stimmen im Allgemeinen mit denen der von der Scheitelzelle abgetrennten Randzellen überein; sie sind etwas weniger zahlreich, als in diesen, das Wachsthum der Theilzellen dafür aber entsprechend intensiver. Diesem Umstande ist es zu danken, dass selbst in ziemlich entwickelten Vorkeimen sich die Entstehung der Zellgruppen aus vier Quadrantenzellen oft noch mit grosser Schärfe erkennen lässt. Das kleinzellige Gewebe der zur Scheitelzelle ersten Grades gewordenen oberen Quadrantenzelle grenzt sich gegen die grossen benachbarten Zellen, besonders nahe dem 
Rande, meist sehr deutlich ab. (Taf. I., Figg. 16 u. 17, bei $x$ und y.) $^{-}$

Die Scheitelzelle, welche ihrer ersten Anlage nach eine seitliche Stellung am oberen Ende des Vorkeimes einnahm (Taf. I., Fig. 14), wird sehr bald genau terminal, indem die sekundären Wurzelhaare besonders zahlreich ihr gegenüber, zuerst am Rande, später auch auf der Unterseite des auf dem Substrat sich flach niederlegenden Vorkeimes hervortreten. Jedes Wurzelhaar ist eine einfache Verlängerung der Zelle, aus welcher es seinen Ursprung nimmt. Es gliedert sich nicht, wie z. B. am Vorkeim von Aneimia, durch eine Querscheidewand von ihr ab.

Die Verjüngung der Scheitelzelle durch schiefe, einander wechselweise aufgesetzte Scheidewände ist cine begrenzte. Nachdem sich der Vorgang im jungen Vorkeim fünf bis sieben mal wiederholt hat, theilt sich die Scheitelzelle letzter Generation durch eine zu ihrer Längsachse senkrechte Scheidewand in eine Randzelle und eine Flächenzelle (Taf. I., Figg. 17, 18). Die Randzelle zerfällt darauf durch eine Längswand in zwei gleichwerthige Randzellen, welche von ihren Nachbarzellen zur Rechten und Linken in Nichts verschieden sind. Das weitere Längenwachsthum des Vorkeimes ist demjenigen der Laubachse von Pellia durchaus analog: es erfolgt durch mehrere in der Einbuchtung am Scheitel nebeneinanderliegende gleichwerthige terminale Randzellen ('Taf. II., Fig. 1).

Schon zur Zeit, wo der junge Vorkeim erst aus 8-12 Zellen besteht, treten Theilungswände parallel zur Ober- und Unterseite auf, zunächst in der dem primären Wurzelhaar benachbarten Zelle und ron da in weiterer Folge gegen den Scheitel hin. Die Seitenränder des Prothalliums nebmen an dieser Art der Zellbildung keinen Antheil. In der Längsachse des jungen Organes wiederholen sich die Theilungen durch horizontale Wände am häufigsten; nach beiden Seiten hin werden sie allmälig sparsamer. Es entsteht auf solche Weise eine den Vorkeim seiner ganzen Länge nach durchziehende Mittelrippe (T'af. II., Fig. 2), welche rechts und links in die einschichtige Laubfläche allmälig übergeht. An alten Vorkeimen fand ich sie bis 12 Zellschichten dick. Ihre Zellen sind in der Richtung der Längsachse des Vorkeimes stark. gestreckt.

Der Vorkeim von Osmunda regalis besitzt in hohem Grade die Fähigkeit, sich durch Adventivsprosse zu vermehren. Dieselben 
erscheinen, besonders bei gedrängtem Wachsthum der Vorkeime, oft sehr zahlreich neben einander. Soweit meine Beobachtungen reichen, treten sie am Rande, nicht in der Mitte der Laubfläche hervor. ${ }^{1}$ ) Eine Randzelle wölbt sich über ihre Nachbarinnen deutlich nach aussen. Ihr freier äusserer Theil trennt sich entweder durch eine dem Rande parallele Wand vom inneren ab (Taf. II., Fig. 3); oder es tritt schon jetzt eine schiefe, gegen die Längsachse des zukünftigen Adventivsprosses geneigte Wand auf (Taf. II., Fig 4), deren Entstehung sonst erst den zweiten Theilungsschritt darstellt. Der ersten seitlich geneigten Wand setzt sich stets eine $\mathrm{zweite,} \mathrm{entgegengesetzt} \mathrm{geneigte} \mathrm{auf;} \mathrm{und} \mathrm{in}$ der oberen Zelle, welche hierdurch die charakteristische Form einer Scheitelzelle gewinnt, wiederholt sich derselbe Vorgang in demselben Sinne mehrmals hintereinander (Taf. II., Figg. 5, 6). Indem die nach rechts, und links abgegliederten Randzellen sich ihrerseits in derselben Weise theilen, wie es für den Hauptspross des Vorkeimes angegeben wurde, verbreitert sich die Basis und besonders der obere Theil des Adrentivsprosses und letzterer erhält eine dem Hauptspross ähnliche Form; nur ist sein Vorderrand meist weniger gebuchtet (Taf. II., Fig. 7). Auch im Adventivspross erreicht die Verjüngung der Scheitelzelle gesetzmässig ihren Abschluss; auch hier geschieht diess, indem statt einer schiefen eine zur Längsachse des Sprosses seukrechte, dem Vorderrand parallele Scheidewand sich bildet, der sich sofort eine Längswand rechtwinkelig aufsetzt. Das weitere Längenwachsthum findet ganz ebenso durch mehrere gleichwerthige terminale Randzellen statt, wie im Hauptspross des Vorkeimes (Taf. II., Figg. 7, 8). Durch Theilungen parallel zur Laubfläche bildet sich auch in den Adventivzweigen eine Mittelrippe aus. Dass sich dieselbe an die Mittelrippe des primären Vorkeimes durch nachträgliches Dickenwachsthum der zwischenliegenden Parthie des Randes ansetzte, wie dies an der Frons von Metzgeria zuweilen der Fall ist ${ }^{2}$ ), habe ich nie beobachtet. Häufig dagegen sah ich Adventivsprosse im Begriffe, sich von ihrem Mutterspross abzulösen, um sich selbstständig fortzuentwickeln.

1) Nur ein einziges Mal sah ich aus der unteren Seite der Mittelrippe eines schon erwachsenen Vorkeimes einen Spross parallel dem Hauptspross hervortreten, dessen Seitenränder an der Mittelrippe flügelartig herabliefen. An letzterer hatten sich 2 wischen den beiden parallelen Laubflächen zahlreiche Archegonien entwickelt. Die Entstehungsart dieser Abnormität ist mir unbekannt.

2) Hofmeister, Vergleichende Untersuchungen p. 22 unten. 
Das Chlorophyll, welches in der reifen Spore den centralen Zellkern in amorphen, wolkigen Massen umgab (Taf. I., Fig. 1), sondert sich aus dem Protoplasma schon im ersten Stadium der Keimung in Form ovaler Körner aus. Anfangs ist ihre Contour gegen den farblosen Theil des Inhaltes nicht sehr deutlich abgegrenzt; später ist sie scharf gezeichnet. Im jungen Vorkeim, solange derselbe noch wenigzellig ist, sieht man das Protoplasma in Form von Schleimsträngen, die sich verzweigen und mit einander anastomosiren können, vom centralen Kern gegen den geschlossenen Wandbeleg ausstrahlen. In diesen Strängen bilden die Chlorophyllkörner perlschnurartige Reihen (Taf. I, Fig. 8). An älteren Vorkeimen findet sich diese Anordnung des Zellinhaltes nur in solchen Zellen wieder, welche noch in lebhafter Theilung begriffen sind, wie am eingebuchteten Vorderrande und an der Ober- und Unterseite der Mittelrippe; doch hat der Zellkern in letzterem Falle eine wandständ'ige Lage angenommen und die chlorophyllführenden Protoplasmastränge strahlen nur einseitig von ihm aus. In den älteren Flächenzellen des Vorkeimes ist das Protoplasma auf einen continuirlichen Wandbeleg reduzirt, welchem sämmtliche Chlorophyllkörner in einfacher Schicht eingebettet liegen. Jedes Chlorophyllkorn hat die Form einer planconvexen Linse angenommen, deren gekrümmte Fläche dem Innenraum der Zelle zugekehrt ist. Meist sind sie so zahlreich im Wandbeleg vorhanden, dass sie sich an ihren Rändern gegenseitig polygonal abplatten.

Ihre Theilungen halten mit der Ausdehnung der Zelle gleichen Schritt, so dass sie den Primordialschlauch fast überall lückenlos auskleiden. Die Anordnung der Theilkörner ist dabei eine durchaus regellose, da sich die aus wiederholter Z $\mathbf{Z}$ weitheilung nach derselben Richtung hervorgegangenen Reiben gegenseitig verschieben und durchbrechen. Desto leichter ist es, eine Regelmässigkeit in der Aufeinanderfolge der Theilungsrichtungen in solchen Zellen nachzuweisen, deren Chlorophyll sich, bei beschränktem Lichtzutritt, nur sparsam bildet. Diese Bedingung ist bei solchen Vorkeimen erfüllt, welche sehr gedrängt neben einander wachsen. Am 'Grunde der einschichtigen Laubfläche sind die Zellen hier stark in die Länge gedehnt und zeigen ihre Chlorophyllkörner gewöhnlich in Form verzweigter, mit einander anastomosirender Reihen angeordnet (Taf. III., Fig 9). Häufig sind diese Reihen durch gegenseitige Staung mehrfach gebogen. Da, wo sie auf 
weitere Strecken regelmässig und ungehindert verlaufen, überzengt man sich leicht, dass sie nach Art der Zellreihen eines Nostoc durch intercalare Theilungen, welche alle in demselben Sinne erfolgen, in die Länge wachsen, nebenbei aber das Vermögen selbstständiger Verzweigung besitzen. Einzelne Chlorophyllkörner verlängern sich, statt in Richtung der Hauptachse der ganzen Reihe, in einem rechten oder spitzen Winkel zu ihr. Der Verlängerung folgt sehr bald eine ringförmige Einschnürung senkrecht zur Wachsthumsrichtung. Hiermit ist die erste Anlage zu einer Zweigreihe gegeben, deren weitere Entwickelung mit derjenigen der Hauptreihe vollkommen übereinstimmt ${ }^{1}$ ) (Taf. III., Fig. 9). Von der eben beschriebenen echten Verzweigung sind nachträgliche Verbindungen von Chlorophyllreihen wohl zu unterscheiden. Beide kommen häufig genug neben einander vor.

3) Entwickelung der Antheridien.

Antheridien erschienen schon fünfzig Tage nach der SporenAussaat in grösserer Zahl am Grunde der Vorkeime. Die meisten entspringen auf der Unterseite der Laubläche, mit Ausschluss der Mittelrippe; doch treten sie auch am Rande stets sehr zahlreich auf (Taf. III., Fig. 1). Für das Studium der Entwickelung sind letztere besonders geeignet.

Eine der Randzellen wölbt sich über ihre Nachbarinnen nach aussen und theilt sich durch eine dem Rande parallele Scheidewand. Die äussere der beiden Zellen ist die Mutterzelle des Antheridiums. In ibr tritt zunächst eine schiefe Scheidewand auf, welche sich der letztentstandenen in seichter, nach innen gekrümmter Bogenlinie aufsetzt und gegen die Längsachse geneigt ist; alsbald folgt ihr eine entgegengesetzt geneigte, ebenfalls nach innen concave Wand. Beide nach aussen abgetrennte Zellen sind bestimmt, sich an der Zusammensetzung der Antheridium-Wandung zu betheiligen. Die innere und gleichzeitig obere theilt sich nun durch ein auf der Längsachse des Antheridiums annähernd senkrechte, nach seiner Basis concav gekrümmte Scheidewand, welche sich den beiden erstentstandenen allseitig ansetzt, in die

1) Reihen von Chlorophyllkörnern mit echter Verzweigung habe ich auch in den Oberhautzellen der Wedel von Osmunda regalis, in den Zellen des Vorkeimes mehrerer Polypodiaceen und besonders schön im Blatt von Isoëtes II alinverniana beobachtet. 
Centralzelle und die Deckelzellc. Die Centralzelle wird durch eine Reihe von Theilungen, in welchen es mir nicht gelingen wollte, eine bestimmte Regel zu finden, zu den Specialmutterzellen der Spermatozoiden. Die Deckelzelle zerfällt in drei bis vier Zellen, welche annähernd in gleicher Richtung über den Scheitel des Antheridiums hinweglaufen. Sie setzen, da dic beiden unteren Wandzellen, wie ich gefunden, stets ungetheilt bleiben, die Antheridienwandung zum grösseren Theil zusammen (Taf. III., Fig. 2, 3); durch späteres ungleichmässiges Flächenwachsthum erhalten sie meist wellige Contouren.

Während die Centralzelle und alle aus ihr hervorgehenden Zellgenerationen durch reichen Gehalt an trübem, körnigem Protoplasma ausgezeichnet sind, füllen sich die 7ellen der Wandung zum grösseren Theil mit wässrigern Zellsaft. Doch bleibt der Zellkern, welcher der nach innen gekehrten Membran platt anliegt, bis nach dem Bersten des Antheridiums deutlich sichtbar.

Auch die aus Flächenzellen herrorgegangenen Antheridien werden zum grösseren Theil durch Theilungen nach zwei Richtungen angelegt. Oft sieht man sehr deutlich, wic eine der beiden unteren Wandzellen die andere mit ihren Rändern umfasst und wie beide um die Centralzelle (oder deren Theilzellen) zusammenschliessen. Doch glaube ich mich in mehreren Fällen mit Bestimmtheit überzeugt zu haben, dass in der Antheridium-Mutterzelle hier auch Theilungen nach drei Richtungen auftreten können. Die successiven Wände divergiren dann in Winkeln ron $120^{\circ}$.

Ueber den Bau und die Bewegung der Spermatozoiden werde ich bei anderer Gelegenheit Näheres mittheilen.

\section{4) Entwickelung der Archegonien.}

Archegonien sah ich erst 14 Tage nach den ersten Antheridien auftreten. Sie entstehen in grösserer Zabl (an sehr alten Vorkeimen oft zn mehreren Hunderten) auf der Unterseite der Laubfläche und bilden hier zwei parallele Längsbänder zu beiden Seiten der Mittelrippe, wo diese etwa 6-7 Zellschichten dick ist (Taf. III., Fig. 1); zwischen den beiden Archegonieureihen, genau unterhalb der Längsachse, entspringen zahlreiche Wurzelhaare, welche stets aus dem der Basis des Vorkeimes zugekebrten Theile der Aussenzellen ihren Ursprung nehmen. Im Allgemeinen erfolgt die Ent- 
wickelung der Archegonien, dem Längenwachsthum des Vorkeimes entsprechend, von der Basis nach vorn, so dass nahe dem Scheitel die jüngsten Anlagen zu finden sind; doch trifft man häufig dicht neben älteren, schon abgestorbenen Archegonien noch jugendliche Entwickelungszustände.

In der Mutterzelle des Archegoniums tritt, noch ehe sie sich über ihre Nachbarinnen bedeutend hervorgewölbt hat, eine der freien Aussenfläche parallele Scheidewand auf. Während die innere der beiden Tochterzellen zunächst ungetheilt bleibt, setzt sich in der äusseren eine meist nach der Längsachse des Vorkeimes orientirte Wand der vorigen senkrecht auf. Ihr folgt beiderseits eine zur Längsachse des Vorkeimes und zur letztgebildeten Scheidewand senkrechte Membran (Taf. III., Fig. 4). Die vier nach Art von Kreisquadranten gruppirten Aussenzellen wölben sich gemeinschaftlich über die Unterseite der Mittelrippe hervor (Taf. III., Fig. 5). In jeder tritt ohngefähr gleichzeitig je eine Querwand auf, welche auf der Richtung ihres intensivsten Längenwachsthums senkrecht steht, also gegen die Längenachse des jungen Archegoniums geneigt ist (Taf. III., Fig. 6a). Indem sich diese Theilungen in der je oberen Zelle der vier Reihen mehrfach wiederholen, entsteht der Halstheil des Archegoniums (Taf. III., Fig. 7). Bei der Reife ist derselbe ohngefähr 8 Zellen hoch.

In demselben Maass, als sich die Zellreihen des Halstheiles nach oben vergrössern, weichen sie am Grunde allmälig auseinander. Es müsste hierdurch ein Intercellularraum gebildet werden, wenn nicht die Basalzelle den Zwischenraum durch entsprechendes Längenwachsthum ausfüllte. Sie drängt sich zwischen den vier Zellreihen des jungen Halstheiles aufwärts, bis sich der obere, stark verschmälerte Theil von dem unteren durch eine Scheidewand abgliedert. Diese Scheidewand, welche die Centralzelle ron einer oberen Zelle abtrennt, ist, wie bei Salvinia, stark nach unten gebogen. Ihr folgt in der oberen Zelle bald eine zweite (selten noch eine dritte), ebenfalls stark nach unten convexe Wand. Damit findet die Neubildung von Zellen im Halskanal ihren Abschluss (Taf. III., Figg. 5, 6a, 7).

Die Centralzelle sowohl, als die zwei (oder drei) nach oben folgenden Kanalzellen sind durch ihren trüben, an Stärkemehl reichen Inhalt vor den sie seitlich umgebenden Zellen ausgezeichnet. Auch die eine oder zwei Zellen unterhalb der Centralzelle führen Amylon (Taf. III., Fig. 7.) In den Zellen des Halskanals 
wird die Stärke, ron oben wach unten fortschreitend, allmälig gelöst, ihre Membranen verflüssigt. Der Schleimstrang, welcher auf diese Weise entsteht, übt, wahrscheinlich durch gesteigerte Wasseraufnahme, einen immer bedeutenderen Druck auf den Scheitel des Archegoniumhalses, dem die sich lockernden Zellen zuletzt nicht mehr zu widerstehen vermögen. Es erfolgt plötzlich eine gewaltsame Oeffnung. Die Zellreihen des Archegoniumhalses trennen sich an der oberen Hälfte ron einander und schlagen sich einzeln zurück. An der Innenseite jeder der abgerundeten Zellen ist der von grünen Körnchen umgebene Zellkern sehr deutlich sichtbar. (Taf. III., Fig 8.) Der Schleim tritt zum Theil aus der Oeffnung hersor und die Centralzelle rundet sich nach oben ab. Innerhalb dersclben sieht man einen hellen Fleck im trüben, stärkehaltigen Protoplasma. Aller Wahrscheinlichkeit nach entspricht derselbe einem centralen Zellkern; ihn als Keimbläschen zu deuten, liegt nicht der geringste Grund vor.

Es war mein Wunseh, den Befruchtungsakt zu beobachten. Bei der körnigen Beschaffenheit des Inhaltes der Centralzelle und dem reichen Cbloropliyllgehalt der umgebenden Zellen musste das Unternehmen leider als hoffnungslos aufgegeben werden.

Als Resultat meiner Untersuchung ergiebt sich, dass die Entwickelung des Vorkeimes ron Osmunda in einigen wesentlichen Punkten von den bei den Polypodiaceen beobachteten Bildungsvorgängen abweicht.

Bei Osmunda wird, wie bei Equisetum, das primäre Wurzelhaar durch die erste in der keimenden Spore auftretende Scheidewand abgegliedert; seine Wachsthumsrichtung ist der des jungen Prothalliums genau entgegengesetzt. Am Vorkeime der Polypodiaceen dagegen ist das erste Wurzelhaar, gleich allen späteren, seitlichen Ursprungs.

Bei den Polypodiaceen und Schizaeaceen hebt die Entwickelung des Vorkeimes mit Bildung einer einfachen Zellreihe an, die, bei manchen Arten früher, bei anderen später, am Vorderende allmälig in eine einfache Zellfläche übergeht. Bei Osmunda dagegen führen schon die allerersten Theilungen zur Anlegung einer Zellfläche. 
Eine der beiden oberen Quadrantenzellen des jungen OsmundaVorkeimes wird zur Scheitelzelle ersten Grades, die sich durch eine Reihe successiver Theilungen nach abwechselnd zwei Richtungen verjüngt. Die Polypodiaceen bieten zwar ebenfalls Beispiele für ein gesetzmässiges Längenwachsthum durch eine Scheitelzelle, wie ich mich bei Polypodium leiorrhizon, Adiantumprionophyllum, Blechnumbrasiliense?, Asplenium marinum, A. caudatum, A. alatum, Aspidium melanocaulon, Microlepia trichosticha, Denstaedtia davallioides, D. tenera, Cibotium Schidei, Ceratopteris thalictroides und bei einer unbestimmten Species deutlich überzeugt; doch tritt dasselbe, wo es vorkommt ${ }^{1}$ ), erst in etwas späteren Entwickelungszuständen auf.

Die Verjüngung der Scheitelzelle ist eine begrenzte; sie findet ihren Abschluss im Auftreten einer Querwand, welche eine Flächenzelle ron. einer Randzelle abtrennt. Alles weitere Längenwachsthum des Vorkeimes wird durch dic Vermehrung gleichwerthiger terminalor Randzellen vermittelt. Hierin stimmt Osmunda mit den oben genannten Polypodiaceen überein.

Charakteristisch für Osmunda ist die mehrschichtige Mittelrippe, welche den Vorkeim vom Grunde bis zum Scheitel durchzieht und beiderseits mit zahlreichen Archegonien besetzt ist. Bei den Polypodiaccen ist dieselbe auf ein (sclten mehrere) Gewebepolster unterhalb der terminalen Einbuchtung des erwachsenen Vorkeimes reduzirt.

Die Entwickelung des Antheridiums ist bei Osmunda eine durchaus eigenthümliche. Die für die Polypodiaceen und Schizaeaceen charakteristischen Ringzellen ${ }^{2}$ ) fehlen hier rollständig. Die Basis der Antheridienwandung besteht aus 2 (seltener 3) Zellen, denen sich mehrere aus der Theilung der Deckelzelle hervorgegangene obere Zellen aufsetzen.

Der Bildungsgang des Archegoniums schliesst sich im Wesentlichen an den von Pringsheim für Salvinia nachgewiesenen an. Der Halskanal ist Anfangs von zwei (seltener drei) Zellen ausgefüllt, welche mit der Centralzelle gleichen. Ursprung haben und ihre Querwände bei der Reife des Archegoniums verflüssigen.

1) Der Vorkeim von Aneimia hirta zeigt von Anfang an Marginalwachsthum.

2) ef. L. Kn y: Ueber Bau und Entwickelung des Farrnantheridiums. (Monatsber. der Königl. Akad. đ. W. in Berlin. Mai 1869.) 
Ein besonderes Keimbiäschen ist innerhalb der Centralzelle nicht vorhanden. In allen diesen Punkten stimmt Osmunda mit den Polypodiaceen ${ }^{1}$ ) überein; eigenthümlich ist nur der reiche Gehalt der Centralzelle und der ihr nach oben und unten benachbarten Zellen an Amylon.

Berlin, im Dezember 1868.

\section{Erklärung der Figuren.}

\section{Tafel I.}

Fig. 1. Reife, frisch aus dem Sporangiuı entnommene Spore, in Wasser; $287 \mathrm{~m}$. vergr.

Fig. 2. Reife Spore, durch Druck geöffnet und mit Jodlösung behandelt, um den Zellkern deutlich zu machen; $287 \mathrm{~m}$. vergr.

Fig. 3. Keimende Spore, drei Tage nach der Aussaat. Das primäre Wurzelhaar ist abgegliedert und die Mutterzelle des Vorkeimes durch eine horizontale Wand getheilt. a. in frischem Wasser; b. in Zuckerwasser; $287 \mathrm{~m}$. vergr.

Figg. 4-7. Junge Vorkeime auf den frühesten Entwickelungsstufen; 112 m. vergr.

Fig. 8. Junger Vorkeim, das Exosporium am Scheitel tragend, auf Brunnwasser gezogen, 6 Tage nach der Aussaat. Die Cblorophyllkörner sind reihenförmig den vom Zellkern ausstrahlenden Protoplasmasträngen eingebettet; $287^{\circ} \mathrm{m}$. vergr.

Figg. 9 und 10. Junge Vorkeime, 9 Tage nach der Ausssat. Scheitelzelle bei $\mathrm{v}$; $112 \mathrm{~m}$. vergr.

Fig. 11. 9 Tage alter Vorkeim mit Theilungs-Schema (b); $112 \mathrm{~m}$. vergr.

Fig. 12. Gleich alter Vorkeim. a. von der Fläche; c. bei fast mittlerer

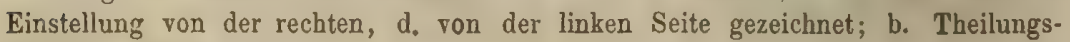
Schema; $112 \mathrm{~m}$. vergr.

Fig, 13. 10 Tage alter Vorkeim; $112 \mathrm{~m}$. vergr.

Fig. 14. 13 Tage alter Vorkeim mit Theilungsschema (b); $112 \mathrm{~m}$. vergr.

Fig. 15. 22 Tage alter Vorkeim; $112 \mathrm{~m}$. vergr.

Fig. 16. 23 Tage alter Vorkeim. Die Scheitelzelle (v) hat sich sechsmal verjüngt; $120 \mathrm{~m}$. vergr.

Fig. 17. 23 Tage alter Vorkeim. Die Anordnung der Zellen nach vier Quadranten ist deutlich erkennbar. Der obere Quadrant, welcher zur Scheitelzelle ersten Grades wurde, grenzt sich durch seine kleineren Zellen scharf gegen das grössermaschige Gewebe der benachbarten Quadranten ab (bei x und y). Nachdem sich die Scheitelzelle fünfmal verjüngt hat, ist in derjenigen letzten Grades soeben eine Querwand aufgetreten, welche eine terminale Randzelle von einer Flächenzelle abtrennt; $120 \mathrm{~m}$. vergr.

Fig. 18. Scheitelgruppe von Fig. 17 mit Theilungsschema (b); $240 \mathrm{~m}$. vergr.

1) cf. Strassburger, die Befruchtung bei den Farrnkräutern (Mém. de l'acad. d. sc. de St. Petersb.) p. 5 ff. Die Abhandlung wurde mir erst nach Abschluss meiner Untersuchung bekannt. 


\section{Tafel II.}

Fig. 1. 41 Tage alter Vorkeim. Das Längenwachsthum erfolgt durch terminale Randzellen; $92^{3 / 2} \mathrm{~m}$. vergr.

Fig. 2. Längsschnitt durch die Mittelrippe eines 45 Tage alten Vorkeimes; $98 \mathrm{~m}$. vergr.

Fig. 3. Anlage eines Adventivsprosses an einem $51 / 2$ Monate alten, Vorkeim. Die erste Wand in der Mutterzelle ist dem Aussenrande parallel; $168 \mathrm{~m}$. vergr.

Fig. 4. Junger Adventivspross, wie voriger. Schon die erste Wand in der Mutterzelle ist hier schief gerichtet; $168 \mathrm{~m}$. vergr.

Fig. 5. Etwas weiter entwickelter Adventivspross mit einer terminalen Scheitelzelle; $168 \mathrm{~m}$. vergr.

Fig. 6. Noch weiter vorgeschrittener Entwickelungszustand; $162 \mathrm{~m}$. vergr.

Fig. 7. Ziemlich erwachsener Adventivspross, dessen Scheitelzelle ihre bisherige gesetzmässige Theilung durch abwechselnd nach rechts und links geneigte schiefe Wände abgcschlossen hat. Sie ist durch eine borizontale Wand in eine Flächenzelle und eine Randzelle zerfallen, welche sich ihrerseits bereits weiter getheilt haben; $162 \mathrm{~m}$. vergr.

Fig. 8. Scheitelgruppe von Fig. 7, mit Theilungsschema (b); 332 m. vergr.

\section{Tafel III.}

Fig. 1. Erwachsener, 8 Monate alter Vorkeim; $4 \mathrm{~m}$. vergr.

Fig. 2. Junges Antheridium vom Rande eines Vorkeimes, Die Deckelzelle hat sich erst durch eine Wand getheilt; $332 \mathrm{~m}$. vergr.

Fig. 3. Halbreifes Antheridium, von aussen gezeichnet. Die Deckelzelle ist in 4 Zellen zerfallen; $332 \mathrm{~m}$. vergr.

Fig. 4. Jüngste Anlage eines Archegoniums, auf dem Längsschnitt durch einen Vorkeim. Die vier Mutterzellen des Halstheiles sind bereits gesondert; $325 \mathrm{~m}$. vergr.

Fig. 5. Etwas weiter entwickelte Archegonium-Anlage. Die Mutterzellen des Halstheiles beginnen sich eben hervorzuwölben und die untere Zelle zwischen sie hineinzuwachsen; $325 \mathrm{~m}$, vergr.

Fig. 6. Gruppe von zwei Archegonien, auf dem Längsschnitt durch einen 7 Monate alten Vorkeim. a. zeigt die Mutterzellen des Halskanales nach der ersten Theilung; b. ist in Folge unterbliebener Befruchtung abgestorben; die Centralzelle ist sammt dem Plasma des Ausführungskanales stark gebrăunt, die oberen Zellen des Halstheiles sind desorganisirt; $325 \mathrm{~m}$. vergr.

Fig. 7. Der Reife nahes Archegonium. Die Centrazelle, die unter ihr liegenden Zellen und die beiden Kanalzellen enthalten reichlich Stärke; $325 \mathrm{~m}$. vergr.

Fig. 8. Reifes Archegonium, unmittelbar nach dem Aufplatzen; $325 \mathrm{~m}$. vergr.

Fig. 9. Einige Zellen am Grunde eines schmächtigen, sehr gedrängt gewachsenen Vorkeimes. Die Chlorophyllkörner sind in verzweigten Reihen angeordnet; $325 \mathrm{~m}$. vergr. 


\title{
Beiträge zur Kenntniss der Hantgewebe der Pflanzen.
}

Von

\author{
Dr. E. P f itzer.
}

Privat-Docent in Bonn.

\section{Ueber die mehrschichtige Epidermis und das Hypoderma. ${ }^{1}$ )}

Es ist eine für die klare Auffassung und Begrenzung des Begriffs der Epidermis hochwichtige Frage, ob, abgesehen von denjenigen Pflanzen und Pflanzentheilen, welche überhaupt die deutliche Sonderung einer Oberhaut nicht crkennen lassen, diese stets die eine, äusserste Zellschicht bilde, oder ob sie in einigen Fällen als mehrschichtig betrachtet werden müsse. In neuester Zeit ist die letztere Ansicht, nachdem sie viele Vertreter unter den älteren Phytotomen gefunden, wieder lebhaft bekämpft worden, während andererseits auch nambafte Forscher an derselben festhielten, ohne sie jedoch durch umfassendere Untersuchungen neu zu begründen. Es war zu vermuthen, dass für die morphologische Auffassung der in Rede stehenden Schichten blattgrünfreier uud häufig in der Wand verdickter Zellen, welche unmittelbar unter der äussersten Zelllage von Blättern und Stämmen so oft vorkommen, die Entwicklungsgeschichte eine hervorragende Bedeutung haben werde. Da dieselbe bisher nur in sehr wenigen Fällen, und dabei stets ohne besondere Rücksicht auf die hier zu behandelnde Streitfrage untersucht worden war, unternahm ich eine Reihe von darauf bezüglichen Beobachtungen und will deren Ergebnisse an dieser Stelle mittheilen. Zuvor möge jedoch noch eine gedrängte Uebersicht derjenigen Angaben Platz finden, welche

1) I. u. II. siehe Bd. VII. p. 532 u. 561 . 
die Literatur bis jetzt darbietet. Es hat zwar schon Thomas ${ }^{\mathrm{T}}$ ) eine ähnliche Zusammenstellung gegeben, doch sind dabei einmal einige der wichtigsten Veröffentlichungen übersehen worden und andererseits ist der Standpunkt, von welchem aus die geschichtliche Entwicklung des Gegenstandes dort dargestellt worden ist, ein von dem meinigen durchaus verschiedener. Dies mag entschuldigen, dass ich dieselbe hier noch einmal verfolge - es sollen dabei in dieser Einleitung nur die für die Auffassung im Ganzen wichtigen Stellen erwähnt werden, während ich die zahlreichen Angaben über Einzelnheiten bei Gelegenheit meiner eigenen Untersuchungen anzuführen beabsichtige.

Nachdem 1805 Franz Bauer, ${ }^{2}$ ) wie uns L. C. Treviranus ${ }^{3}$ ) mittheilt, zuerst von einer mehrfachen Oberhaut der Gewächse gesprochen hatte, bestätigte zunächst der letztgenannte Forscher bei mehreren Pflanzen das Vorkommen einer solchen und gab an, dass meistens die Schichten derselben aus um so kleineren Zellen gebildet seien, je näher der Oberhaut sie lägen. Treviranus, ${ }^{4}$ ) wie wenig später Ad. Brongniart ${ }^{5}$ ) definirten den neuen Begriff folgendermaassen: als inehrfache Oberhaut sind zu bezeichnen alle diejenigen an der Aussenfläche grüner Pflanzentheile gelegenen Schichten, deren Zellen sich durch feste Verbindung unter einander, durch Verdickung ihrer Wände und namentlich durch Mangel des Chlorophylls dem unterliegenden Parenchym gegenüber auszeichnen. Doch nahm Treviranus dabei fälschlich Luft als Inbalt der Epidermis an. Brongniart unterschied ferner eine aus lauter gleichgeformten Zellen bestehende mehrfache Oberhaut, und eine solche aus theilweise abweichend gestalteten Zellen. Beide Forscher traten demnach der Auffassung Bauer's vollkommen bei. Dieselbe wurde dagegen von Meyen ${ }^{6}$ ) für die meisten Fälle Anfangs verworfen, da die Zellen der äussersten Schicht, der „wahren Epidermis" gewöhnlich sehr von den zunächst darunter liegenden in ihrer Gestalt abwichen, und nur die feste Verbindung dieser verschiedenen Schichten der Annabme einer doppelten Oberhaut

1) Zur vergleichenden Anatomie der Coniferen-Laubblātter. Pringsh. Jahrb, IV. S. 33.

2) Tracts relative to botany. London 1805.

3) Ueber die Oberhaut der Gewächse, Vermischte Schriften. IV. S. 11.

4) A. a. 0. S. 17 .

5) Recherches sur la structure et sur la fonction des feuilles. Annal. d. scienc. natur. 1830. Tome XXI. S. 426.

6) Phytotomie 1830. S. 114.

Jahrb. f. wiss. Botanik, vLur. 
zur Stütze dienen könne; man müsse, fügt Meyen hinzu, dann selbst eine drei- und vierfache zulassen und „das würde zu nichts. führen". Nur bei den Blättern von Pandanus crklärte derselbe sich geneigt, zur Epidermis auch die ron aussen zweite Schicht zu rechnen, da er in dieser letzteren den Spaltöffnungen analoge Gebilde beobachtet zu haben glaubte, eine Bemerkung, die sich aus den in meinem Aufsatze über das Hautgewebe der Gramineen mitgetheilten Beobachtungen erklärt. Meyen machte ferner aufmerksam auf die häufig dicht unter der Oberhaut vorkommenden bastähnlichen Zellen, die er, ohne sie jedoch genügend rom wahren Bast zu unterscheiden, als Faserzellen, Pleurenchym, bezcichnete ${ }^{1}$ ). Seine Bedenken gegen die Bauer'sche Auffassung wurden im Allgemeinen getheilt von Herrmann Krocker, ${ }^{2}$ ) der die weiteren Einwände geltend wachte, dass auch im Iuneren ron Pflanzen blattgrünfreie Gewebe rorkämen, die man doch keinenfalls zur Epidermis zählen könne, und dass an nicht grünen Theilen die Bron. gniart'sche Unterscheidung überhaupt kcine Anwendung fände, obwohl dieselben doch auch eine Epidermis besässen. Doch vermochten diese, noch neuerdings als "sehr natürliche bezeichneten Gründe nicht, der Ausbreitung der durch sie bestrittenen Ansicht Einhalt zu thun, und dies um so weniger, als auch Krocker einen Ausnahmefull zuliess, indem er den Blättern einiger Cycadeen wegen der Aehnlichkeit ihrer beiden äussersten Zelllagen unter einander und deren gemeinsamer Verschiedenheit vom inneren Blattgewebe eine doppelte Oberhaut selbst zuschrieb. Unger ${ }^{3}$ ) und Bischoff ${ }^{4}$ ) sprachen sich ganz entschieden für Bauer's Auffassung aus, Mohl ${ }^{5}$ ) nahm keine bestimmte Partei. Letzterer wies zuerst auf die Aehnliehkeit der Zellform mancher zur mehrfachen Oberhaut gerechneten Schichten mit dem Collenchym der Rinde hin, während gleichzeitig Treviranus ${ }^{6}$ ) noch einmal die Ansicht vertheidigte, dass derartige Schichten nicht gut anders unterzubringen. scien, als bei der Epidermis. Meyen ${ }^{7}$ ) selbst gab seinen Widerstand 1835 auf und nahm nur hinsichtlich des oberfächlichen

1) A. a. 0. S. $131 \mathrm{ff}$.

2) De plantarum epidermide observationes. Dissert. Vratislaviae 1833. S. 2.

3) Die Exantheme d. Pflanzen 1833. S. 26, 29, Grundzüge d. Anatomie 1846 S. 66 und Anat。 u. Phys. d. Gewächse 1855. S. 183.

4) Allgemeine Botanik II. Band S. 11.

5) Ueber die Verbindung der Pflanzenzellen. Diss. Tübingen 1835. S. 20.

6) Physiologie d. Gewächse 1835. I. $449 \mathrm{f}$.

7) Ueber die neuesten Fortschritte d. Anatomie u. Physiol. d. Gewăchse 1835. In Verhand. v. d. Teylers Tweede Genootschap. Harlem 1836. S. 68. 373. 
Sklerenchyms der Cycadeenblätter, in welchem Falle Krocker gerade eine Ausnahme zu Gunsten der Mehrschichtigkeit der Oberhaut zugegeben hatte, noch Anstand, dieselbe anzuerkennen, da, wie er wenig später genauer ausführte, ${ }^{1}$ ) hier die Zellen nicht in regelmässigen Schichten lägen. Meyen fügte ferner dem Fornenkreise der blattgrünfreien Schichten unter der Epidermis die hier bei einigen Orchideen von ihm gefundenen Spiralfaserzellen hinzu, ${ }^{2}$ ) sowie das an derselben Stelle bei den Cacteen so häufig vorkommende eigenthümliche Collenchym, ${ }^{3}$ ) welches er, wie später Schleiden $^{4}$ ) zur Rinde rechnete, während Brongriart ${ }^{5}$ ) in einem wenig characteristischen Falle dasselbe zur Epidermis stellte, wie es später auch Unger ${ }^{6}$ ) that. Meyen machte dann auch die wichtige Beobachtung, ${ }^{7}$ ) dass bei Begonia umbellata bisweilen an Stelle einer der umfangreichen Oberhautzellen des Blattes zwei über einander gestellte von halber Grösse vorkämen. Es war dies die erste bestimmtere Hindeutung auf ein Entwicklungsgesetz, welches erst 1839 von demselben Forscher mit Klarheit ausgesprochen wurde. In seiner in diesom Jahre erschienenen Arbeit ${ }^{8}$ ) über die "Gummikeulen" (Traubenkörper Schacht, Cystolithen Weddell) gab Meyen auf das Bestimmteste an, dass die 4-5 farblosen Zelllagen, welche die Oberseite ausgewachsener Blätter von Ficus elastica nach aussen begrenzen, durch Theilung aus einer anfangs einfachen Epidermis herrorgehen. Meyen behält dabei den von Bauer aufgestellten Begriff bei, wählt aber ein neues Wort „Epidermalschicht" und unterscheidet deren äusserste Zelllage, falls sie in ihrer Form von den übrigen wesentlich abweicht, als die „wirkliche Epidermis". Der erstere Ausdruck wurde auch von Unger ${ }^{9}$ ) angenommen. Mohl ${ }^{10}$ ) rechnete auch jetzt die ron aussen zweite, stark verdickte Schicht der Blätter einiger Bromeliaceen nicht zur Oberhaut, ebensowenig Schleiden ${ }^{1}$ ) ähnliche Zellen bei Banksia,

1) Ueber die Epidermis der Gewächse. Wiegmanns Archiv 1837. S. 213.

2) Uéber die n. Fortschritte u. s. w. S. 173.

3) Neues System der Pflanzenphysiologie 1837. I. S. 41.

4) Beiträge zur Anatomie d. Cacteen. 1839. In mém. prés. p. div. sav. à l'Acad. d. St. Petersbourg IV. 1845. S; 348.

5) A. 2. 0. S. 453.

6) Grundzüge der Anatomie 1846. Fig. 32.

7) Ueber d. n. Fortschr. u. s. w. S. 274.

8) Müller's Archiv fo Anat. u. Phys. 1839. S. 264.

9) Grundzüge u. s. w. . Erklắr. izu Fig. 32.

10) Ueber die Cuticula d. Gewăchse. Linnaea 1842. Verm. Schriften S. 265.

11) Grundzüge d. wissensch. Botanik. III. Aufl. Band I. S. 275. 
währeud Goldmanu ${ }^{1}$ ) sich in anderen hichtor gehörigen Fälen für dicse Annahme anssprach. Sulleiden ${ }^{2}$ ) bildete dagegen einen neuen, unfassenderen Begriff, indem er die Epidermis sammt ibren Anhangegebilden (einschliesslich Epiblema u. s. w.) und den Kork als "Epidermoidalgewebe", tela epidermoidea zusammenfasste, wofür dann Lnger ${ }^{3}$ ) später etwa in demselben Sinne die Worte "Epidermoidal-Bildungen oder-Gebilde", tegumenta cpidermoidalia brauchte, während er für Meyen's „Epidermalschicht" noch „Stratum epidermaticum" einfülırte. Schacht spricht im Allgemeinen ron einer mehrfachen, bei einigen Bromeliaceen aber von einer "scheinbar mehrfachen" Oberhaut, ohne dass der Unterschied scharf angegeben wäre. ${ }^{*}$ ) Durselbe Forscher wiederholte dann Meyen's Beobachtungen bei Ficus, ${ }^{5}$ ) kam aber nicht zu bestimmten Resultaten hinsichtlich der Eutwicklungsgeschichte der "Epidermalschicht", welche er seinerseits "Oberhautschicht" nennt. Jedoch "schienen" ihı die Angaben Meyen's über die Entstehung derselben richtig. Später bezcichuete $\mathrm{er}^{6}$ ) im Gegensatz zu dieser Erklärung doch wieder nur die äusserste Zelllage bei Ficus elastica und anstralis als Oberhaut, so dass auch diese bis dahin einzigen entwicklungsgeschichtlichen Resultate entweder ganz in Frage gestellt, ocler doch in ganz anderer Weise, als früher, gedeutet waren. Dafür wurden zwei neue Fälle von tangentialer Theilung der Zellen der Epidermis ron Sanio aufgefunden: so 1860 bei Buxus, ${ }^{\circledR}$ ) 1864 beim Stamm der Peperomia blanda. $\left.{ }^{8}\right)$ Gleichzeitig unterzog Metterius") die so häufig dicht unter der Oberhaut rorkommenden bastähnlichen Zellen (Meyen's Plourenchym p. p.) als "Sklerenchym" einer eingehenderen Betrachtung.

In den Jahren 1865 und 1866 erschienen dann zwei Abhandlungen von Thomas und Kraus, welche die ganze Frage wieder in den Vordergrund treten liessen. Thomas ${ }^{10}$ ) fand bei verglei-

1) Botanische Zeitung 1848. S. 357 f.

2) A. a. 0. S. 270 .

3) Anatom. u. Physiol. d. Gewächse 1865. S. 182.

4) Die Pflanzenzelle 1852. S. 229, 230.

5) Al,handl. d. Senkenberg. Gesellsch. z. Frankfurt a. M. 1854. I. S. 135.

6) Lehrbuch d. Anatom. u. Physiol. I. S. 31. 283.

7) Botanische Zeitung 1860. S. 212.

8) Botanische Zeitung 1864. S. 195.

9) Die Hymenopbyllaceen in Verhancll. d. Sächs. Gesellschaft d. Wissenschaften zu Leipzig. 1865. Math. Phys. Klasse Band VII. S. 432.

10) Yur vergleichenden Anatomie der Coniferen-Laubblätter. Pringsheim's Jahrbücher IV. S. $33 \mathrm{ff}$. 
chender anatomischer Untersuchung der Laubblätter von Coniferen, dass die hier unter der Epidermis fast allgemein vorhandenen sklerenchymatischen Schichten deutliche Uebergänge zu den in Chlorophyll führenden Diachym zerstreuten dickwanäigen Zellen, sowie zu dem grünen Parenchym selbst zeigten. Er schloss daraus, dass man jene Schichten nicht zur Oberhaut, sondern zum Grundgewebe des Blattes rechnen müsse. Wir wcrden schen, dass dieser Schluss wohl einer wesentlichen Modification bedarf. Als ein Irrthum wird es sich dagegen herausstellen, dass Thomas die weitere Folgerung zieben zu dürfen glaubte, dass dieses, an sich schon nicht durch die Entwicklungsgeschichte bekräftigte Resultat, auf alle blattgrünfreien Schichten unter der Epidermis überhaupt auszudehnen sci. Da Thomas bei sciner Aufzählung derartiger Fälle auch Ficus, Begonia und Peperomia nennt, so ist wohl zu vermuthen, dass er die seiner Auffassung entgegenstehenden Angaben von Meyen, Schacht und Sanio nicht gekannt hat.

Ebenfalls etwas zu einseitig behandelte bald darauf dieselbe Frage Kraus ${ }^{1}$ ) bei Gelegenheit seiner anatomischen Bearbeitung der Blattfiedern der Cycadeen. Er ging von der Beobachtung aus, dass oftmals im Blattstiel ein unmerklicher Uebergang zwischen dem blattgrünfreien Gewebe an der Oberfläche der Blattspreite und dem Collenchym der Rinde stattfinde. Er folgerte daraus, dass das letztere durch den petiolus in die Lamina übertrete und dass demnach die „mehrfache Epidermis" der älteren Phytotomen bei Begonia, Peperomia u. A. als aus Umwandlung des Collenchyms der Rinde hervorgegangen $z u$ betrachten sei, nicht aber zur Oberhaut gehöre. Kraus wurde in dieser Ansicht bestärkt dadurch, dass es ihm nicht gelang, sich durch Nachuntersuchung der Peperomia blanda von der Richtigkeit der von Sanio dabei geltend gemachten Auschauungsweise zu überzeugen. Abgesehen von diesem ungegründeten Widerspruch gegen eine auf thatsächlich richtigen Beobachtungen beruhende Angabe scheint mir hier zunächst ein Missverständniss des Begriffs „Collenchym" vorzuliegen, insofern Kraus denselben als gleichbedeutend mit ,äusserer Rindenschicht" (Schleiden) „Aussenrinde“ (Sanio) gebraucht. Collenclyym, ursprünglich von Link für die stark quellbaren Membranen der Mutterzellen des Pollens in Vorschlag gebracht, hat aber bisher in der maass-

1) Ueber den Bau der Cycadeenfidern. Pringsheim's Jahrb. IV. S. 304. 
gebenden botanischen-Literatur cinen solchen vergleichend morphologischen Sinn nicht gehabt, sondern sich, wie es auch die Bedeutung дез Wortes fordert, einzig und allein auf eine gewisse Verdickungsform der Zellwände bezogen. Wo diese letztere, wie bei der mehrfachen Oberhaut fast sämmtlicher Peperomien und Begonien, nicht rorhanden ist, ta kann von Collencbym und auch von "umgewandeltem Collenchym" nicht die Rede sein. Andererseits aber bcruht der Schluss von Kraus noch auf der irrigen Prämisse, dass Gewebe, zwischen denen man im entwickelten Zustand keine Grenze erkennen kann, als morphologisch gleichwerthig betrachtet werden müssten. Es wird gleich nachgewiesen werden, dass gerade bei den angefübrten Pflanzen die betreffenden Schichten nicht der Aussenrinde des Stammes, sondern der Oberhaut analog sind, da sie aus dieser hervorgehen. Diese Thatsache zeigt an sich, dass das Beweisverfahren, durch welches Kraus zur Annahme des Gegentheils geführt wurde, nicht richtig sein kann. Da Kraus nun durch die Verwechslung der bildlichen Auffassung, dass das Gewebe eines Pflanzentheils sich aus dem eines anderen "herausbilde" mit einer wirklich stattfindenden Entwicklung die Verwandschaft der sogenannten „mehrfachen Epidermis" - ausschliesslich ihrer äussersten Zelllage - mit der farblosen Rinde naclgewiesen zu haben glaubte, so bezeichnete er, unter Verwerfung der Bauer'schen Annahme, die in Rede stehenden blattgrünfreien Zelllagen der Blattspreite als "Blattrinde, Hypoderma". Wenn. sich nun gegen den letzteren dieser beiden Ausdrücke, der weiter nichts, als die Lage jener Schichten andeutet, wenig einwenden lässt, vorausgesetzt, dass dieselben aus dem Grundgewebe des Blatts ihren Ursprung nehmen, so muss der erstere in um so höherem Grade Widerspruch erregen. Wir verstehen kei höheren Pflanzen unter Rinde allgemein die ausserbalb des Gefässbündelkreises gelegenen Gewebe bis zur Epidermis. Wollen wir demnach überhaupt von einer Blattrinde sprechen, so müssen wir Alles das unter diesem Ausdruck begreifen, was zwischen Oberhaut und Gefässbündeln liegt. Da hierfür aber bereits die Worte Mesophyll und Diachym vorhanden sind, so scheint mir kein Grund für die Einführung eines neuen Ausdrucks rorzuliegen. Nur in denjenigen Fällen könnte meines Erachtens die Kraus'sche Bezeichnung möglicherweise Anwendung finden, wo im Blatt ein wahrer Gefässbündelkreis vorkommt, der ein „Blattmark" von einer "Blattrinde" trennt, wie beispielsweise bei Portulacea und anderen sogenannten 
Fettpflanzen. Doch wäre selbst da, wie ich glaube, eine solche Terminologie nicht empfehlenswerth, da sie die Gefahr falscher Analogieen zu nahe legt. In dem von Kraus selbst vorgeschla. genen Sinne möchte ich den Begriff keinenfalls annehmen, weil man doch auch da, wo bei Stämmen ein innerer Chlorophyll führen. der und ein äusserer farbloser Rindentheil sich unterscheiden lassen, beide zusammen, nicht aber den äusseren blattgrünfreien allein als "Rinde" bezeichnet.

Ziemlich gleichzeitig mit den eben besprochenen beiden Arbeiten erschien dann eine Abhandlung von Leitgeb ${ }^{1}$ ), in welcher derselbe, bei Gelegenheit der Schilderung der Entstehung der Wurzelbülle der Orchideen und Aroideen aus der Epidermis des Wurzelkörpors, den Gedanken ausspricht, dass die Oberhaut durch tangentiale Theilung - wenigstens in dem von ihm betrachteten Falle - als solche fortzubestehen aufhört. Wir werden später zu untersuchen haben, ob diese Anschauungsweise einer umfassenderen Anwendung fähig ist. Im Jahre 1867 machte dann Hofmeister ${ }^{2}$ ) noch einmal auf die Beobachtungen ron Meyen und Schacht über Ficus aufmerksam und gab den Sachverhalt richtig an.

Eine neue Gestalt erhielt darauf die ganze Frage durch Sachs. ${ }^{3}$ ) Derselbe fasste unter dem Namen der "Hautgewebe" ausser dem, was Schleiden zu den "Epidermoidalbildungen" gerechnet hatte, noch etwaige durch Theilung der Epidermis entstandene Schichten, sowie alles Das zusammen, was Kraus Hypoderma genant hatte. Sachs bezeichnete aber diese letzteren. Schichten im Gegensatz zu Kraus mit dem sonst gleichbedeutenden Ausdruck der "subepidermalen". Während demnach Kraus und Thomas diese letzteren Gewebe alle zum Grundgewebe gestellt hatten, finden wir sie nun insgesammt mit der Oberhaut verbunden, deren Vorhandensein Sachs auch bei unterirdischen und untergetauchten höheren Pflanzen annimmt. Der Letztere schloss endlich an die „Hautgewebe“6 auch die als eigenartig differenzirt erkennbaren äusseren Schichten der Muscineen und Thallophyten an.

Ich beende hiermit die Schilderung des Entwicklungsganges der zur Zeit über die Mehrschichtigkeit der Epidermis bestehenden

1) Die Luftwurzeln der Orchideen. Denkschriften d. Acad. zu Wien. Math.Phys. Klasse 1865. XXIV. S. 253.

2) Lehre von d. Pflanzenzelle. S: 180 Anm.

3) Lehrbuch d. Botanik. 1868. S. $76 \mathrm{ff}$. 
Ansichten. Manches mag auch mir noch entgangen scin; soviel aber können wir aus dieser Uebersicht entnehmen, dass die Fragestellung vor Allem auf folgende Punkte zu richten ist:

1) Theilen sich bisweilen wirklich die Zellen der Oberhaut tangential und geben so melireren blattgrünfreien, oberfächlichen Schichten"die Entstehung?

2) Gehen ähnliche Schichten bei anderen Pflanzen aus dem Grundgewebe hervor?

3) Ist es möglich und zweckmässig, diese beiden Reihen von Fällen auf Grund der Ver'schiedenheit der Entwicklung scharf zu trennen?

Diese Fragen erhalten noch eine besondere Bedeutung durch den neuerdings von Hanstein ${ }^{1}$ ) ausgesprochenen, auf Beobachtungen bei zahlreichen Phanerogamen gegründeten Satz, dass schon im Vegetationspunkt selbst das Meristem der Oberhaut, das "Dermatogen" von dem des Grundgewebes gesondert sei, dass demnach die letztere eine weit grössere Selbstständigkeit besitze, als bisher angenommen wurde. Es weist Hanstein auch selbst anf die Beziehung dieses Satzes, welchen ich in vielen Fällen bestätigen kann, zur Lehre von der mehrfachen Oberhaut hin, sowie auf die Mangelhaftigkeit unserer Kenntnisse über deren Entwicklungsgeschichte, und fordert zur Untersuchung der letzteren auf.

Wenden wir uns also zunächst zu dem ersten der oben aufgestellten Fragepunkte und beginnen mit der Prüfung der ältesten Angaben, derer über die Blätter von Ficus. Die blattgrünfreien Schichten wurden hier 1821 entdeckt von Treviranus bei F. bengalensis ${ }^{2}$ ), Meyen fand dieselben bei $\mathrm{F}$. elastica ${ }^{3}$ ), der jüngere Krocker bei F. ulmifolia ${ }^{4}$ ), Payen bei F. reclinata, ferruginea, Carica, laurifolia, Neumanni, nymphaeifolia ${ }^{5}$ ), Schacht bei F. austra-

1) Festschrift der Niederrheinischen Gesellschaft für Natur- und Heilkunde zum 50 jährigen Jubiläum der Universität Bonn. S. 109.

2) Vermischte Schrift. IV. S. 11. Payen, mémoire sur le dévéloppement des végétaux in Mém. prés. à l'acad. d. sciences pas div. savants. Tome IX. Taf. V. 9.

3) Phytotomie S. 311, Müllers Archiv. 1839. S. 264, Payen a. a. 0. Taf. II., Schacht in Abhandl. d. Senkenberg. Gesellschaft in Frankfurt 1854, S. 133 f., Lehrbuch d. Anatomie u. Physiologie I. 283, Unger, Anatomie u. Physiologie S. 190, Hofmeister, die Pflanzenzelle S. 180.

4) a. a. 0. Fig. 51, Schacht in Senkenb. Abhandl. S. 133 f-

5) a. a. 0. Taf. III. IV. V. VI. 
lis, lutescens ${ }^{1}$ ), Weddell bei F. salicifolia ${ }^{2}$ ) auf. Da nach den Abbildungen ron Schacht und Weddell zu vermuthen war, dass F'icus australis besonders lehrreiche Resultate geben werde, so wählte ich diese Art zur Untersuchung. Wie Schacht richtig angiebt, ist schon vor dem Abfallen der Stipulen eine deutliche aber einfache Epidermis vorhanden, welche sich durch stärkeren Gehalt an Plasma, Mangel des Chlorophylls und Bildung zahlreicher Haare als solche charakterisirt. Die letzteren sind auf beiden Blattseiten schon vor der tangentialen Theilung der Oberhautzellen sehr entwickelt, einige dünnwandig und vielzellig, andere, die namentlich auf der Blattunterseite zahlreich auftreten und nur aus einer langen Zelle bestehen, haben ihre Zellwand, soweit sie frei bervorragt, bereits mächtig verdickt. Ebenso sind Anlagen von Cystolithen schon vor der Theilung vorhanden; die sie enthaltenden Oberhautzellen sind noch ebenso gross als die übrigen, der Zellstoffzapfen reicht von aussen her bis etwa zu ihrer Mitte, auch weiter. Nun erst tritt die Theilung in den nicht Cystolithen führenden Zellen der Epidermis ein: die innere Tochterzelle wird meist schon bei ihrer Entstehung von der äusseren an Grösse übertroffen. Die letztere theilt sich bald noch einmal und diescr Vorgang wiederholt sich dann anf der Blattoberseite fast immer, seltener auch auf der Unterseite in der äussersten Zelle, so dass die fertige Oberhaut oben 4 , unten 3 Schichten stark zu sein pllegt. Seltener bildet auch die erste innerste Tochterzelle noch eine tangentiale Scheidewand: meist wächst sie nur stark senkrecht zur Blattfäche. Die ersten beiden Theilungen fand ich in zahlreichen Zellen eingetreten schon bei Blättern, die noch fest von ihren Stipulen umhüllt waren, im Gegensatz zu einer Angabe Schacht's über die Zeit des Auftretens der "Epidermalschicht" - nach dem Hervortreten des Blattes war die Entstehungsweise der mehrfachen Epidermis auf der Oberseite schon nicht mehr deutlich erkennbar, während sich die Oberhautzellen der Blattunterseite erst eben getheilt batten. Die Cystolithen führenden umfangreichen Zellen sind bei F. australis einfach stark gewachsene und ungefächert gebliebene Zellen der Epidermis - seltener findet man einen Cystolith in einer äusscren Tochterzelle. Die von mir beobachtete Folge der Scheidewände stimmt mit derjenigen überein, die Meyen bei F. elastica an.

1) In Senkenb. Abhandl. S. $133 \mathrm{f}$.

2) Annales d. scienc. naturelles IV. Ser. Tome H, S. 271. 
giebt. Da das Blatt nach seiner Entfaltung noch sehr stark in die Fläche wachsen muss, um seire volle Grösse zu erlangen, so theilen sich alle Schichten desselben sehr oft radial d. h. senkrecht zur Spreitenebene, wodurch die genetische Verwandschaft der einzelnen Zellen unter einander bald aufhört, sich in der Anordnung derselben zu erkennen zu geben. Ganz besonders reichlich treten diese radialen $W$ ände in der äussersten, schliesslich ziemlich kleinzelligen Schicht der mehrfachen Epidermis auf, von da nach innen ihre Zahl vermindernd.

Nach den Abbildungen von Krocker, Schacht, Payen und Weddell ist anzunehmen, dass auch die Blätter der vielen anderen oben genannten Arten der Gattung Ficus in derselben Weise ihre Oberhaut vervielfältigen - nur bei F. elastica liegen noch bestimmte Angaben (Meyen, Hofmcister) vor. Andere Formen behalten stets ihre ursprüngliche einfache Epidermis aut beiden Blattseiten (F. lutescens, ulmifolia). ${ }^{\text {') }}$

Was die Peperomien betrifft, deren mehrfache Oberhaut Treviranus ${ }^{2}$ ) ebenfalls entdeckte, so ist zunächst die Angabe Sanio's aufrecht zu erhalten, dass bei P. blanda H. B. K. sich die Zellen der Epidermis des Stamms tangential theilen. Diese Beobachtung ist ohne alle Schwierigkeit zu wiederholen, da die Theilung, wie schon Sanio ${ }^{3}$ ) bemerkt, verhältnissmässig spät eintritt; sie geschieht mehrere Internodien hinter dem Stammscheitel und dabei in verschiedenen Zellen noch zu verschiedener Zeit. Kraus bezweifelt dieselbe daher durchaus mit Unrecht. Auch am Blattstiel wird bei der genannten Pflanze die Oberhaut in derselben Weise wie am Stamm verdoppelt; eine weit höhere Entwicklung erreicht sie aber auf der Blattspreite. Schon 1821 fand Treviranus (a. a. 0.), dass sich anf der Oberseite derselben bei Piper pellucidum $=\mathbf{P e}$ peromia pellucida H. B. K. eine aus vielen Zelllagen bestehende Oberhaut finde, während dieselbe auf der Unterseite einfach sei, und dehnte dann 1835 diese Beobachtung noch auf Pep. magnoliifolia Dietr. und Chavica maculata Miq. aus. ${ }^{4}$ ) Pasen ${ }^{5}$ ) fügte Artanthe colubrina Miq. hinzu. Ich fand denselben Bau, ausser

1) In Abhandl. v. Senkenberg. Gesellschaft 1854 S. 142.

2) Vermischte Schriften IV. S. 11.

3) Botan. Zeitung 1862 S. 213.

4) Physiologie s. Gewächse I. S. 449.

5) a. a. 0. Taf. VI, 4. 
bei den beiden erstgenannten Arten, noch bei Peperomia blanda H. B. K., peireskiifolia H. B. K., rubella (Hook.) Miq., galioides H. B. K., polystachya Dietr., incana Dietr., arifolia Miq., obtusifolia Dietr., argyracea hort. Bonn, und habe mich bei mehreren dieser Formen auf das bestimmteste überzeugt, dass ursprünglich auch auf der Blattoberseite eine einfache Epidermis vorhanden ist. Bei den Blättern der Pep. blanda theilt dieselbe sich schon bei noch geringer Blattlänge (3mm.) zum ersten Mal tangential, dann (bei etwa $6 \mathrm{~mm}$. ), die innere unterdessen stark senkrecht zur Spreitenfläche gewachsene Tochterzelle noch einmal ebenso, Diese Scheidewandbildung beginnt.in der Mittellinie des Blattes und schreitet von da gegen den Rand hin fort. Nahe dem letzteren findet man auch noch an ziemlich weit entwickelten Blättern bisweilen ungetheilte Oberhautzellen, häufig Paare von solchen, deren genaue Uebereinanderlagerung sie deutlich als durch tangentiale Theilung entstandene Schwesterzellen erkennen lässt. Auf dem grössten Theil der Blattspreite wird dies Verbältniss hingegen bald dadurch getrübt, dass die äussere Lage zablreichere radiale Wände bildet, als die innere; jene wird dadurch viel kleinzelliger und zeigt nach vollendetem Flächenwachsthum des Blattes keine genetische Beziehung mehr zu den ihr innen angrenzenden Schichten grosser blattgrünfreier Zellen gleichen Ursprungs. Die letzteren vermehren sich oft noch weiter, indem die innerste der durch die zweite tangentiale Theilung entstandenen Tochterzellen diesen Vorgang noch einmal wiederholt.

Unmittelbar unter der so entstandenen 2-4schichtigen Epidermis, deren Zellen nach Beendigung ihrer Entwicklung wässerige Flüssigkeit mit äusserst wenigen Einlagerungen führen, befindet sich bei P. blanda zunächst eine Lage stark Chlorophyll führender, karz cylindrischer, zur Blattfäche senkrecht gestellter Zellen, welche dem „pallisadenförmigen Parenchym" (p. supérieur Brongn.) der meisten Laubblätter entsprechen $(P)$ und bei anderen Peperomien mehrere Schichten bilden (Taf. VI. Fig. 1 und 4). Dann folgen einige Lagen locker aneinander gefügter, bedeutend grösserer Zellen, welche weniger Blattgrün, in alten Blättern aber viel Stärke enthalten und in ihrer Gesammtheit das ,schwammige $\mathrm{Pa}$ renchym" (p. caverneux ou spongieux Brongn.) darstellen (S). Dann endlich die einfache untere Epidermis (Eu). Auf beiden Blattseiten sind kurze kopfförmige und vielzellige langkegelförmige Haare reichlich vorhanden. Dieselben entstehen nur zum "kleinsten Theil, 
namentlich gegen die Blattränder hin, vor der tangentialen Theilung der Oberhautzellen. - Dic allermeisten bilden sich erst nach derselben aus der äusseren Tochterzelle, nachdem diese inzwischen oft schon mehrere radiale, d. h. zur Fläche der Spreite senkrechte Wände gebildet hat.

Einen ganz ähnlichen Bau zeigen die erwachsenen Blätter von P. polystachia und argyracea; bei $O$. arifolia ist die Epidermis der Oberseite meist nur zweischichtig, die Entwicklung derselben durch tangentiale Theilung einer Zelllage noch am fertigen Blatt ziemlich deutlich. Bei demjenigen ron $\mathbf{P}$. incana sind die oberen, farblosen Schichten schon 7-8 Zellen stark und ihr Gesammtdurchmesser übertrifft bereits den des ganzen Chloropbyll führenden Gewebes; die Anordnung der Zellen in zur Blattfäche senkrechte Reihen ist sehr rerwischt. Ungemein deutlich ist dieselbe dagegen bei P. peireskiifolia: cin Stück eines Blattquerschnitts dieser Pflanze stellt Taf. VI. Fig. 1 dar. Die beiderseits äusserste Zelllage besitzt hier stark verdickte, mit Chlorzinkjod sich gelb färbende Aussen und Seitenwände (Taf. VI. Fig. 2 am oberen Rande E), während die inneren, blattgrünfreien Schichten der Oberseite (F) keine irgend erhebliche Verdickung zeigen und sich mit Chlorzinkjod leicht bläuen. Auch bei dieser Art habe ich die Entwicklungsgeschichte untersucht und auch hicr am ganzen Umfang des Blattes ursprünglich eine einfache Epidermis gefunden, welche schon vor ihrer ersten tangentialen Theilung zahlreiche Kopfhaare bildet. Diese tritt hier verhältnissmässig spät ein, bei einer Blattlänge von etwa $7 \mathrm{~mm}$. (Taf. VI. Fig. 3). Die äussere Tochterzelle entwickelt dann entweder zuerst eine zur Fläche der Lamina senkrechte, und dann in jeder der so gebildeten Tochterzellen eine tangentiale Wand, oder sogleich eine solche der letzteren Art - es entsteht dadurch die schliesslich äusserste, später stark verdickte und cuticularisirte Zelllage. Die innere Tochterzelle ersten Grades theilt sich dann noch einmal parallel zur Blattfläche, worauf nach Streckung der Zellen die mehrfache Oberhaut bereits dem Chlorophyll führenden Gewebe an Dicke gleich kommt. Dieser Zustand bleibt mit geringen Abweichungen (Taf. VI. Fig. 5) bestehen bis das Blatt etwa $\frac{5}{5}$ seiner definitiven Länge erreicht hat $(2 \tilde{0}-50 \mathrm{~mm}$.). Dann beginnt eine lebhafte Zellbildung in der innersten, dem pallisadenförmigen Parenchym nächsten Zelle, indem immer wieder die jeweilig innerste, dem pallisadenförmigen Parenchym und somit dem Heerdo der Assimilation nächste 
Tochterzelle sich wieder theilt (Taf. VI. Fig. 4), ohne dass das Auftreten von Scheidewänden in weiter nach der Oberfläche hin liegenden Zellen ganz atisgeschlossen wäre. Die so entstandenen zahlreichen Zellen sind anfangs tafelförmig, meist viel breiter als hoch, erst schliesslich strecken sie sich gewaltig senkrecht zur Blattfäche und stellen dann ein massenhaftes farbloses Gewebe dar, welches bis siebenmal dicker ist, als das ganze Mesophyll. Auf dem Umstand, dass hier die meisten Theilungen erst nach beinahe vollendetem Flächenwachthum der Spreite stattfinden, beruht die äusserst regelmässige Anordnung der Zellen, deren genetische Reihen man noch an alten Blättern oft durch die ganze Dicke der mehrfachen Oberhaut hindurch leicht verfolgen kann.

So umfangreich wie bei $P$. peireskiifolia habe ich die letztere im Verhältniss zum Mesophyll bei keiner anderen Art gefunden; sie fältt dagegen noch mehr in die Augen bei P. rubella und galioides wegen der Kleinheit des Blattes und der glasartigen Durchsichtigkeit der farblosen Schichten, welche, namentlich bei P. galioides, gestattet, dass man von oben her durch jene hindurch den im pallisadenförmigen Parenchym verlaufenden Blattnerv deutlich wahrnimmt. Bei P. rubella, wo ich die Entwicklungsgeschichte verfolgt habe, geschieht die erste tangentiale Theilung der ursprünglich einfáchen Oberhaut schon ungemein zeitig (Taf. VI. Fig. 8), viel früher noch als bei $P$. blanda, jedoch bereits nach Anlegung einiger Kopfhaare. Im weiteren Verlaufe der Entwicklung wird dann das Anfargs wenig gekrümmte Blatt durch stärkeres Flächenwachsthum der Unterseite löffelförmig (Querschnitt Taf. VI. Fig. 7) und schmiegt sich vermöge dieser Form eng an die jüngeren, zu einer sphäroidalen Knospe zusammengedrängten Blätter an. Wenn es dann aber, etwa $7 \mathrm{~mm}$. lang, sich frei zurückbiegt, so steigert sich die Vermehrung und Streckung der Zellen der bis dahin vom Mesophyll noch an Dicke übertroffenen mehrfachen Oberhaut so sehr, dass die löffelförmige Höhlung der Blattoberseite nicht nur vollständig ausgefüllt wird, sondern lass das Blatt vielmehr einen biconvexen Querschnitt erhält (Taf. VI. Fig. 6). Der grau gehaltene Theil deutet in Fig. 6 und 7 das Mesophyll, der farblose die mehrfache Epidermis an.

In den bisher beschriebenen Fällen sind alle Schichten der letzteren - mit Ausnahme der äussarsten bei P. peirekiifolia dünnwandig, namentlich obne allen collenchymatischen Bau. Dieser findet sich dagegen hier in $3-4$ oberflächlichen Lagen bei $P$. 
magnoliifolia recht schön und weniger deutlich ausgebildet auch bei P. obtusifolia und nach Payen's Abbildung bei Artanthe colubrina. Zu einer vollständigen Entwicklungsgeschichte fehlte es mir bei diesen beiden Arten an geeignetem Material, doch konnte ich bei der erstgenannten soviel feststcllen, dass gegen den Rand eines jungen Blattes hin Paare deutlich superponirter farbloser Zellen, augenscheinlich durch tangentiale Theilung eine Oberhautzelle entstanden, unmittelbar neben einem erst zweizelligen Kopfhaar vorhanden waren. Es ist demnach im höchsten Grade wahrscheinlich, dass die dicken blattgrünfreien Schichten, obwohl sie später eine sehr unregelmässige Anordnung der Zellen zeigen, auch hier aus der ursprünglich einfachen Epidermis hervorgehen.

Hinsichtlich des Inhalts der mehrfachen Oberhaut sämmtlicher untersuchter Peperomien will ich noch bemerken, dass der mehrfach zu deren Bezeichnung angewandte Ausdruck ,blattgrünfreie Schichten" zwar relatir, aber nicht in aller Strenge richtig ist, indem ich bisweilen spärliche kleine Chlorophyll-Körner in denselben beobachtet habe. Sonst kommen ausser wässrigem, schwach sauer reagirendem Saft in diesen Zellen, welche in ihrer Jugend Zellkerne und reichliches Plasına führen, später nur sehr zerstrcute Stärkekörnchen und vereinzelt grosse, manche kleineren Zellen fast ganz ausfüllenfle Tropfen aromatischen Oels ror. Die Anwesenheit plasmatischer Stoffe ist kaun nachzuweisen. Nichts destoweniger kann auch in diesen Zellen selbst bei alten Blättern eine lebhafte Neubildung eintreten, wic ich unten zeigen werde. Die letzteren scheinen dabei lange Zeit an der Pflanze zu bleiben - ich fand ihre Oberfläche oft mit kleinen einfacheh Algen bedeckt, wie Leitgeb das von den Luftwurzeln tropischer Orchideen angiebt. ${ }^{1}$ )

Die silberglänzenden Flecken auf der Blattoberseite von $P$. argyracea werden, wie bei den Begonien u. s. w., durch l'ıftführende Zwischenzellräume verursacht, welche in diesem Fall rom palli. sadenförmigen Parenchym her zwischen die inneren grossen Zellen der mehrfachen Oberhaut bis etwa zu deren halbem Durchmesser eindringen.

Die letztere bildet in keinem Falle Spaltöffnungen - dieselben werden vielmehr bei allen untersuchten Arten ausschliesslich auf

1) a. 2. 0. S. 187. 
der Blattunterseite gebildet, wie 'dies schon Rudolphi' ${ }^{1}$ ) bei $P$. blanda, obtusifolia fand, und zwar werden sie durch nach drei Richtungen der Fläche fortschreitende Theilungen angelegt. ${ }^{2}$ )

Eine zweite Pflanzengruppe, welcher man eine vielfache Epidermis zugeschrieben hat, sind die Begonien. Eine darauf bezügliche Beobachtung Meyen's bei B. umbellata habe ich bereits erwähnt (S. 6); ziemlich gleichzeitig fand Treviranus ${ }^{3}$ ), dass bei B. heracleifolia an der unteren Seite des Blatts zwei, an der oberen drei Oberhautschichten vorhanden seien, welche nach aussen zu kleinzelliger würden, und dass die Gesammtdicke derselben eine im Verhältniss zu dem $\mathrm{zwischen}$ ihnen liegenden Mesophyll sehr bedeutende sei. Auf die Grösse der in ihnen gelegenen Athemhöhlen machte Meyen ${ }^{4}$ ) bei B. nitida aufmerksam und gab eine darauf bezügliche Abbildung. Payen ${ }^{5}$ ) fand die Oberhaut bei den Blättern von B. undulata, Unger ${ }^{6}$ ) bei denen von B. manicata, Hildebrand ${ }^{7}$ ) beim Stamm der B. tomentosa mehrschichtig. Kraus $^{8}$ ) kann sieh bei B. umbellata dieser Anschauung "nicht anschliessen".

Ich habe die Entwicklung bei Blättern von B. manicata (Taf. VI. Fig. 9) untersucht. So lange dieselben noch von ihren Stipulen umhüllt sind, haben sie beiderseits eine einfache Epidermis, welche im Allgemeinen $3-4$ blattgrünführende Schichten umschliesst; nur auf der Unterseite an den Nerven sind noch ausserdem zahlreiche, an Chlorophyll arme Zellen vorhanden. Die Oberhautzellen wachsen senkrecht zur Lamina, bis das Verbältniss ihrer Höhe und Breite an der Oberseite etwa $5: 1$, an der unteren $3: 2$ ist - nur an den Nerven bleibt dasselbe ungefähr 1:2. Die Theilung: tritt, ziemlich zur Zeit des Hervortretens des Blattes und zwar zuerst an der Oberseite ein, deren Zellen dann zwar, im Durchschnitt eben so breit als die der Unterseite, aber $3-4$ Mal so

1) Anatomie $S$.

2) Vgl. Strassburger, Ein Beitrag z. Entwicklungsgeschichte der Spaltöffnungen in Pringsheim's Jahrb. V. S. $297 \mathrm{ff}$.

3) Physiologie d. Gewăchse I. S. 450.

4) Neues System d. Pflanzenphysiologie I. S. 264. $\Delta$ bb. Taf. V. 5.

5) a. a. 0. Taf. VI. 3.

6) Anat. u. Physiol. S. 184.

7) Untersuch. über die Stämme d. Begoniaceen S. 20. Die Entstehung durch Theilung ist nicht angegeben, Vgl, Sachs Lehrbuch S. 79.

8) a. a. 0. S. 316 . 
hoch sind: die innere Tochterzelle übcrtrifft stets die äussere an Grösse. Schon vor der Theilung sind zahlreiche Kopfhaare vollständig entwickelt. Später bildet häufig die innere Tochterzelle noch eine tangentiale Wand - schliesslich ist die Dicke der oberen Epidermis beträchtlicher, als die des Blattgrün führender Mesophylls, dessen oberste Zellschicht sich zu einem kurzzelligen pallisadenförmigen Pareuchym entwickelt. Das Letztere zeigt auch bei B. manicata die von Kraus') bei B. umbellata beobachtete Eigenthümlichkeit, dass seine Zellen in ihrem oberen Theil kein Chlorophyll enthalten (Taf. VI. Fig. 9). Besonders schön ist dieselbe Erscheinung bei B. Drègei zu finden.

Die Verhältnisse an der Blattunterseite erhalten dadurch ein besonderes Interesse, dass hier bei gleichfalls dopppelter Oberhaut Spaltöffnungen gebildet werden. Während des lebhaften zur Sprëtenfläche senkrechten Wachsthums der Zellen der Epidermis bemerkt man, dass manche derselben sich minder stark verlängern. Von diesen kürzeren Zellen wird ein Theil zu Kopfhaaren, ein anderer zu Urmutterzellen von Spaltöffuungen. Die ersteren, von schmälerer Gestalt, bleiben an ihrem unteren Theil in fester Verbindung mit dem Blattgrün führenden Gewebe. Ihre Spitze liegt in einer flach trichterförmigen Vertiefung, welche später in ihrer Mitte die obere, kopfförmige Anschwellung des Drüsenhaars zeigt, während die Fusszelle, wclche rings von anderen Oberhautzellen umschlossen ist, sich mehrfach theilt und eine am fertigen Blatt zwischen die sehr grossen Zellen der inneren Oberhautschicht eingeschaltete Gruppe kleiner, stark mit körnigem Inhalt gefüllter Zellen bildet. Ueber die Entwicklungsweise der zweiten Art kürzerer Zellen der Epidermis zu Spaltöffnungen babe ich schon früher ${ }^{2}$ ) gesprochen: hier nur noch die Bemerkung, dass erst nach Eintritt der Theilungen der Mutterzelle nach drei Richtunger des Raumes die Fächerung der übrigen Oberhautzellen durch eine tangentiale Wand erfolgt.

Obwohl bei dem sehr bedeutenden Flächenwachsthum der in Rede stehenden Blätter noch nach der tangentialen sehr viele zur Spreite senkrechte Theilungen aller Schichten eintreten, bleibt die genetische Beziehung der beiden zur Epidermis gehörigen doch selbst am erwachsenen Blatt ziemlich, stellenweise sogar vollkommen deutlich (Taf. VI. Fig. 9).

1) a. a. 0. S. 327 .

2) Ueber das Hautgewebe des Gramineen, Diese Jahrb. Band VII. 
Andere Arten, wie B. sanguinea, ricinifolia, peltata haben an ihren Blättern eine vier bis fünf Zellen starke mehrfache Oberhaut, B. Drègei, Fischeri an Blatt und Stamm eine einfache, die jedoch am ersteren aus sehr grossen Zellen besteht. Einfach und kleinzellig ist dieselbe am Blattstiel der B. manicata; nur vereinzelt kommen hier tangentiale Scheidewände in ihr vor. Darunter befindet sich in diesem Theil der Pflanze ein schönes Collenchym, ăhnlich wie es Sachs') abgebildet hat; die eigenthümliche Verdickung erstreckt sich auch auf die inneren Ecken der Oberhautzellen. Dasselbe kommt auch an den grossen Blattnerven vor und es zeigt sich, dass die Epidermis beim Debergange über den nach unten weit vorspringenden Rücken des Nervs nach dessen höchster Kante hin immer kurzzelliger wird, an der letzteren selbst findet man flache ungetheilte Oberhautzellen. Es ist hier bei genauer Verfolgung der einzelnen Gewebe möglich, sich schon allein durch Betrachtung des fertigen Zustandes von der Unrichtigkeit der oben erwähnten Hypothese zu überzeugen. Ner Collenchym entsteht, wie gewöhnlich, aus dem Grundgewebe des Blatts - seine Verdickung hat schon vor der Verdoppelung der Oberhaut begonnen, so dass man dann deutlich die einfache Epidermis über das bereits als solches erkennbare Collenchym fortgehen sieht und die Unabhängigkeit beider von einander erkennen kann.

Mögen die bisher gernachten Mittheilungen, da sie nur drei Familien umfassen, auch nur einen kleinen Theil der vorkommenden Erscheinungen erschöpft haken, so genügen sie doch, um zunächst zu beweisen, dass die oben gestellte Frage, ob die Epidermis sich bisweilen durch tangentiale Theilung vervielfältige, ohne Zweifel mit ja zu beantworten ist. Es zeigt sich ferner, dass der von Nägeli und Schwendener ${ }^{2}$ ) aufgestellte, schon von Hofmeister ${ }^{3}$ ) auf Grund eigener Beobachtungen bei Ficus und der meinigen bei Peperomia als nicht zutreffend bezeichnete Satz, dass erst nach Aufhören der tangentialen Theilungen in der äussersten Zellschicht Trichome entstehen, in vielen Fällen unrichtig ist. Es ist endlich bervorzuheben, dass bei der Bildung zahlreicher Schichten aus der ursprünglich einfachen Epidermis das Meristem zu deren Ent-

\section{1) Lehrb. d. Botanik. S. 24.}

2) Nägeli und Schwendener, das Mikroskop. II. S. 593.

3) Allgemeine Morphologie. S. 416. Bei Acanthostachys sind die Verhältnisse andere, wie weiter unten gezeigt werden soll. 
wicklung bald zunächst dem Mesophyll (Peperomia, Begonia), bald in der äussersten Zelllage sich befindet (Ficus), dass mithin nach Sanio's Bezeichnungsweise die Theilungsfolge bald centripetal, bald centrifugal ist.

Was nun die Deutung der eben beschriebenen Erscheinungen anbelangt, so sind drei Formen der Anschanung moglich. Entweder 1) man bezeichnet nur die äusserste Zelllage als Épidermis, wie das Meyen und Schacht versucht haben, die Gesammtheit der blattgrünfreien Schwesterzellen aber mit einem eigenen Ausdruck; oder 2) man nimmt an, dass nach der Theilung überhaupt keine Oberhaut mehr vorhanden sei, sondern ein durchweg eigenartiges Gewebe. Oder man fasst 3) alle durch Theilung einer einfachen Oberhaut entstandenen Zellschichten unter dem Namen der ${ }_{n}$ mehrfachen Oberhaut" zusammen.

Die erste dieser drei Hypothesen scheint auf den ersten Blick viel für sich zu haben. Zunächst muss ich in allen von mir beobachteten Fällen das ron Treviranus ausgesprochene Gesetz bestätigen, dass die äusseren Schichten des durch Theilung aus der Epidermis hervorgegangenen Gewebes kleinzelliger sind, als die inneren. Bisweilen, wie bei Begonia manicata, Peperomia peireskiifolia setzt sich auch die äusserste Zelllage hinsichtlich ihrer Form recht scharf gegen die innen ihr angrenzenden farblosen Zellen ab. Ausserdem zeigt nur diese äusserste Lage Cuticularisirung ihrer oberflächlichen und zum Theil auch seitlichen Zellwände, nur sie allein kann Haare und Spaltöffnungen entwickeln. Es kommt dabei noch besonders der Umstand in Betracht, dass bei den Peperomien mit behaarten Blättern ein Theil der Trichome vor der Theilung aus den ursprünglichen einfachen Oberhautzellen, eine viel grössere Menge aber (nach derselben) aus den äussersten Tochterzellen entsteht. Die verschiedenen Haare sind demnach, wenn wir nicht die jeweilig äusserste Zellschicht allein als wirkliche Epidermis betrachten, entwicklungsgeschichtlich nicht gleichwerthig; sie gehen aus Mutterzellen verschiedenen Grades hervor. Dasselbe gilt von den Spaltöffnungen der Begonien. Während die Urmutterzellen der ersten Stomata, deren Entwicklung ich früher beschrieben habe, einer ungetheilten Oberhautzelle entsprechen, werden bei fortschreitendem Flächenwachsthum des Blatts zahlreiche weitere Spaltöffnungen nachgebildet, indem in einem Theile der inzwischen entstandenen äusseren Tochterzellen der Epidermis nach drei Richtungen der Fläche gerichtete Wände auftreten. Die inneren farb- 
losen Zellen betheiligen sich an der Anlegung dieser Stomata nur insofern, als sie schon, ehe noch die eigentlichen Mutterzellen der letzteren vorhanden sind, durch Auseinanderweichen die Athemhöhle entwickeln. Es scheint demnach auch hier, als ob man nur die in jedem Augenblick oberflächliche Zelllage der ursprünglichen Oberhaut gleich achten, nur sie als "wirkliche Epidermis", das innere farblose Gewebe aber etwa nach dem Vorgange von Oudemans") als „intermediäres" bezeichnen müsse.

Nichtsdestoweniger lässt sich diese Auffassung nicht durchführen. Was zunächst die auf die äusserste Zellschicht beschränkte Haarbildung betrifft, so hat schon Leitgeb ${ }^{2}$ ) mit Recht darauf hingewiesen, dass sie eben nur hier möglich sei und dass daher ihr Auftreten nicht eine specifische Verschiedenheit der oberflächlichen Lage von den inneren beweisen könne. Ausserdem habe ich einen Fall beobachtet, in dem die innere von zwei durch Theilung einer ursprünglich einfachen Epidermis entstandenen Schichten durch Spitzenwachsthum ihrer Zellen nach dem Parenchym zu, wenn auch natürlich nicht wahre Trichome, so doch bedeutende kegelförmige Verlängerungen bildet, welche ein Freund paradoxer Ausdrücke leicht als eine "Haarbildung nach innen" bezeichnen möchte (Taf. VI. Fig. 11). Die Epidermis der Blattoberseite von Arbutus Unedo besteht anfangs aus kurz prismatischen, oben und unten flach endenden Zellen, welche ein in der Entwicklung begriffenes pallisadenförmiges Parenchym überdecken. Später beginnen die meisten derselben sich spitz nach innen zu wölben (Taf. VI. Fig. 10) und treiben so endlich zwischen die unter ihnen liegenden Zellen lange conische Fortsätze hinein, während sie sich zugleich tangential theilen. Die Fortsätze enthalten nie Chlorophyll und fallen daher auf jedem Durchschnitt des Blatts sehr in die Augen. Da andere Oberhautzellen sich ebenso verlängern, aber ungetheilt bleiben und namentlich die Verlängerungen schon lange vor der Bildung der tangentialen Scheidewand sich zu entwickeln beginnen, so können wir doch nicht umhin, dieselben zur Epidermis zu rechnen, und den Zellen der letzteren in diesem Falle eine ähnliche Thätigkeit nach innen zuzuschreiben, wie sie bei der Haarbildung nach aussen stattfindet. Trotzdem möchte ich, um Begriffsverwirrung zu ver-

1) Ueber den Sitz der Oberhaut bei den Luftwurzeln der Orchideen. Abh. d. Acad. z. Amsterdam. Math. Phys. Klasse 1861.

2) Die Luftwurzeln der Orchideen. Denkschriften d. Akad. zu Wien. 1865. S. 213. 
meiden, die betreffenden spitzen Aussackungen nicht als "Haare" bezeichnen. Dieselbe Erscheinung zeigt sich auch, jedoch viel schwächer, bei Maranta zebrina. Der eben beschriebene Fall ist übrigens nicht nur ein Argument gegen die begriffliche Trennung der äusseren und inneren Tochterzellen der Oberhaut, sondern auch gegen den Beweisgrund, welchen Thomas ${ }^{1}$ ) dafür geltend macht, dass die sclerenchymatischen Zellen der Coniferen-Laubblätter zum Grundgewebe zu rechnen seien. Er beruft sich zu diesem Behufe auf die Thatsache, dass einzelne dieser Zellen, welche bei Cephalotaxus pedunculata unter der Oberhaut der Blätter eine „nicht geschlossene Schicht" bilden, Aeste zwischen die Zellen des Pallisaden-Parenchyms hinabsenden, wodurch der Charakter einer "Schicht", der doch für Oberhautgebilde wesentlich sei, ganz verloren gehe. Wir baben gesehen, dass bei Arbutus Achnliches bei einer unzweifelhaften Epidermis rorkommt - die Argumentation ist daher nicht zutreffend, wenn auch das Resultat, wie sich später zeigen wird, im Wesentlichen richtig ist.

In anderer Weise möchte nach meiner Ansicht auch eine von mir bei Begonia manicata gemachte Beobachtung gegen diese begriffliche Scheidung der äussersten Schicht vom übrigen aus der Oberhaut hervorgegangenen Gewebe sprechen. Es scheint nämlich hier die innere farblose Zellschicht insofern indirekt bei der Entwicklung der nach der tangentialen Theilung entstandenen Trichome mitzuwirken, als aus ihr, nachdem die äussere Tochterzelle das eigentliche Haar gebildet hat, eine Fusszellgruppe hervorgeht (vgl. S. 29) ganz ähnlich derjenigen, welche bei den zuerst auftretenden Trichomen aus der Mutterzelle des Haares ihren Ursprung nimmt. Wenigstens müssen wir auch bei Begonia manicata der grossen Zahl der am fertigen Blatt vorhandenen Kopfhaare wegen, welche sich durch blosses Auseinanclerrücken der vor der Theilung der Oberhaut entstandenen nicht erklären lässt, annehmen, dass auch bei ihnen, wie bei den Spaltöffnungen, eine Nachbildung stattfinde. Andererseits zeigt sich uns aber schliesslich bei einem jeden solchen Trichom eine Gruppe kleiner Zellen, welche vom Mesophyll zum kugelförmigen Kopfe des Haares geht. Es scheint mir dies die oben gemachte Folgerung zu rechtfertigen.

Auch die entwicklungsgeschichtliche Ungleichwerthigkeit der Urmutterzellen der Spaltöffnungen ist kein vollgültiger Beweis,

1) ล. ล. 0. S. 35 . 
weil man überhaupt von dem Grundsatz, als seien dieselben sonst stets aequivalent, absehen muss. Bei der Entwicklung der Stomata der Begonien tritt, ganz wie es Strasburger ${ }^{3}$ ) bei Sedum spurium beschrieb, oft in einer der bei der spiralig fortschreitenden Theilung der Urmutterzelle gebildeten Dauerzellen eine neue solche Theilung auf, welche ebenfalls einer normalen Spaltöffnung die Entstehung giebt und dieser Vorgang kann sich noch wiederholen. Die Urmutterzelle des einen Stoma ist dann aus der des andern hervorgegangen und mithin auch hier von Gleichwerthigkeit nicht die Rede. Auch aus diesem Grunde sind wir demnach nicht genöthigt, nur die Gesammtheit der jeweilig äussersten Zellen für die Oberhaut zu halten.

Diese Auffassung verliert weiter an Wahrscheinlichkeit durch die Erwägung, dass bei manchen Begonien und Ficus-Arten eine einfache, bei anderen eine doppelte und mehrfache Epidermis vorkommt, und dass auch an demselben Blatt eine solche Verschiedenheit zwischen Ober- und Unterseite bestehen kann. Am entscheidensten aber ist der Umstand, dass bisweilen in einer im Allgemeinen einfachen Oberhaut einzelne tangential getheilte Zellen, und in einer mehrfachen einzelne ungetheilte sich finden. Einige Fälle der Art habe ich bereits erwähnt: das erstere kommt am Blattstiel der Begonia manicata, das letztere am Stamm der Peperomia blanda und am Blatt von Arbutus Unedo vor. Die Blätter von Cyanotis (Tradescantia) zebrina zeigten uns ebenfalls einzelne tangential getheilte Zellen unter den sonst einfachen, aber sehr grossen, an Ausdehnung senkrecht zur Spreite das Mesophyll übertreffenden Oberhautzellen. Beim Blatt von Pittosporum Tobira (Taf. VI. Fig. 12), undulatum, beim Stamm von Ephedra altissima, monostachya, Elegia nuda treffen wir in der Epidermis ziemlich gleichmässig untermischt getheilte und ungetheilte Zellen neben einander; auch diejenigen der Ficus-Blätter, welche Cystolithen führen, sind im Verbältniss zu den übrigen, mehrfach gefächerten Oberhautzellen dieser Pflanzen hierher zu rechnen.

Wenn wir nun den Begriff der Epidermis auf die jeweilig äusserstc Zelllage beschränken, so müssen wir einmal eine auf das bunteste aus ungleich grossen Zellen zusammengesetzte Oberhaut annehmen, und ausserdem behalten wir eine grosse Anzahl zerstreuter Zellen, nämlich die sämmtlichen inneren Tochterzellen,

1) a. a. 0. S. 321. 
übrig, die wir nicht gut zum Mesophyll zählen können und die als ein eigenes Gewebe zu benennen doch wohl auch nicht angemessen wäre, namentlich in den Fällen, wo sie ganz rereinzelt auftreten. $\mathrm{Da}$ bei allen den genannten Pflanzen die Entwicklung der tangentialen Scheidewand so ganz ohne erkennbare bestimmte Regel bald erfolgt, bald unterbleibt, so müssen wir uns vielmehr auf den schon auf anderen Gebieten namentlich von Hofmeister vertretenen Standpunkt stellen, und annehmen, dass die Fächerung der Oberhautzellen lediglich eine secundäre Folge ihres Wachsthums sei, bestimmt, um dem Produkt des Letzteren eine grössere Widerstandsfähigkeit gegen äussere Einflüsse zu geben; dass es daher mehr darauf ankommt, wie die Zellen der Epidermis gewachsen sind, als wie viele Scheidewände sie gebildet haben. Wir treffen nun aber ganz ähnliche Mittelstufen, wie ich sie eben zwischen einfacher und doppelter Oberhaut beschrieben habe, axch zwischen zwei- und dreifacher: so an der Blattoberseite von Begonia manicata, Escallonia grandiflora, und drei- bis vielfacher (Peperomien) und so fort. Ist daher im ersteren Falle eine Trennung der durch ungleich oft erfolgte Theilung, aber gleichnässiges Wachsthum aus der Epidermis entstandenen Schichten unzulässig, so ist sie es auch in den übrigen: wir müssen daher die sämmtlichen aus Theilung der Oberhaut hervorgegangenen Gewebe als ein Ganzes betrachten.

Es bleibt nun noch der zweite Punkt zu erledigen, ob dann dieses Ganze fortfahren dürfe, Epidermis zu heissen, oder ob die Letztere, wie Leitgeb ${ }^{1}$ ) bei der in gleicher Weise entstandenen Wurzelhülle der Orchideen annimmt, „durch Theilung ihrer Zellen als solche fortzubestehen aufhört". Ich glaube zunächst aus dem Zusammenhang entnehmen zu dürfen, dass Leitgeb diesen Satz so scharf nur aufstellt, um gegenüber den früheren irrigen Annahmen über die Lage der Oberhaut an den Lútwurzeln seine richtige Ansicht, dass die wahre Epidermis derselben „durch die Theilung in die Wurzelhülle übergegangen" sei, deutlich auszudrücken, dass er dem oben ausgesprochenen Gedanken selbst eine allgemeine Ausdehnung nicht geben wollte. In den von mir oben beschriebenen Fällen, wo in einer einfachen Oberhaut einzelne tangential getheilte Zellen vorkommen, und umgekehrt, kann derselbe schon darum keine Anwendung finden, weil er uns zu der Annahme

1) a. a. $0 . S, 213$. 
zwingen würde, als sei die Epidermis stellenweise unterbrochen und durch ein eigenartiges Gewebe ersetzt, oder zu dem Satz, dass durch tangentiale Theilung einer Oberhautzelle auch die übrigen ihre Eigenschaft als solche verlören. Aehnliche Fälle der Untermischung tangential getheilter und ungetheilter Zellen kommen auch auf dem von Leitgeb bearbeiteten Gebiet vor ${ }^{1}$ ), doch hat derselbe sich über deren Beziehung zur Theorie der Epidermis nicht näher geäussert.

Nach alledem glaube ich schliessen zu dürfen, dass die einzige naturgemässe Anschauungsweise die ist, dass wir alle Schichten, welche durch Theilung aus der Oberhaut hervorgehen, nur als eine Abänderung der gewöhnlichen einfachen Form derselben zusammen als Ganzes mit dem Namen der „mehrfachen oder mehrschichtigen" Oberhaut belegen. Die letztere kann dann ibre Zelllagen in eben so mannigfacher Weise von innen nach aussen fortschreitend eigenartiger gestalten, wie dies in der einfachen Epidermis mit den Zellwänden einer Zelle geschieht.

Als einen besonderen Fall müssen wir endlich noch die „Wurzelhülle" der Orchideen und Aroideen hierher rechnen. Die Entstehung derselben durch Theilung der ursprünglichen Oberhaut der Wurzel können wir als sicher festgestellt betrachten, da Leitgeb ${ }^{2}$ ) und Nicolai ${ }^{3}$ ), welche gleichzeitig und von einander unabhängig diesen Gegenstand untersuchten, zu genau den gleichen Ergebnissen gelangt sind. Nicolai hat aber ferner eine ähnliche Bildung bei einer Erdwurzel, der von Crinum bracteatum gefunden; ich habe dasselbe bei C. americanum beobachtet. Die äusseren, in verschiedener Weise, ähnlich wie bei den Orchideen, in der Wand verdickten Zellschichten, welche nach Nicolai ebenso entstehen, wie die luftführenden Wurzelhüllen der eben genannten Pflanzen, enthalten aber bei Crinum, wie dies bei einer Wasser aus dem Boden aufnehmenden Wurzel natürlich ist, Flüssigkeit. Wir haben hier demnach einen unmittelbaren Uebergang zwischen dem "velamen" der Luftwurzeln und der Wasser führenden mehrfachen Oberhaut der Stämme und Blätter, und werden so darauf hingewiesen, dass auch das erstere nur als eine mehrschichtige Epider-

1) a. a. 0. S. 214 .

2) 2. ล. 0 . S. 210.

3) Das Wachsthum der Wurzel in Schriften d. physic. oecon. Gesellsch. zu Königsberg in Pr. 6. Jahrgang 1865. S. 73. 
mis zu betrachten sei. Vorausgesetzt ist dabei freilich, dass die äusserste Zellschicht der Wurzeln, Schleiden's Epiblema von der der oberirdischen Pflanzentheile nicht wesentlich verscbieden sei. Letzteres glaube ich aber annehmen zu dürfen; Leitgeb spricht ohne Weiteres von einer Epidermis der Wurzeln.

Eine gewisse, wenn auch entfernte Beziehung hat ferner die mehrfache Oberhaut zum Kork, indem hier wieder die bald absterbende und Luft führende Wurzelhülle allenfalls als Mittelglied betrachtet werden könnte, wenn auch die Entwicklung und Function derselben gewichtige Gegengründe an die Hand geben. Die Annahme, dass man die, besonders bei Peperomia peireskiifolia, so regelmässige Bildung tafelförmiger Zellen aus einer cambialen Schicht der Epidermis ohne Weiteres der in ähnlicher Weise erfolgenden Korkbildung parallel stellen dürfe, muss zurückgewiesen werden, weil die betreffenden Zellen keine der charakteristischen Eigenschaften des Korkes zeigen. Sie werden später lang säulenförmig, führen bis zum Lebensende des Blattes Flüssigkeit und ihre Wände bläuen sich mit Chlorzinkjod. Auch vertrocknen diese Schichten sebr schnell, wenn man sie nach aussen frei legt, sind demnach für Wasser in Gasform leicht durchdringlich, was sie gleichfalls vom Kork unterscheidet. Sie sind endlich der Neubildung dauernd fähig. Durchschneidet man ein erwachsenes Blatt der $P$. peireskiifolia quer, senkrecht zur Blattfläche, während dasselbe am Stamm verbleibt, so tritt in allen Zellen unmittelbar unter denen, die durch den Schnitt verletzt wurden und den nächst angrenzenden, eine Korkbildung so schnell ein, dass die Schnittfläche nicht einmal merklich ihren Umfang durch Austrocknung und Zusammensinken der Ränder vermindert. Es ist hier dann sehr leicht, den Unterschied zwischen den Zellen der mehrfachen Oberbaut und den durch Theilung derselben entstandenen Korkzellen mittelst Chlorzinkjod deutlich zu machen: erstere werden damit behandelt blau, letztere gelb.

Anders verhält sich dagegen die Sache, wenn dieselbe Verletzung dem Blatt in seiner Jugend zugefügt wird, zu einer Zeit, wo auf dessen Oberseite erst wenige farblose Zellschichten aus der Epidermis entwickelt sind. Ich beobachtete mehrfach Blätter, die am Rande mehr oder weniger tief gehende Beschädigungen erfahren hatten, so dass unregelmässige Stücke der Lamina fehlten. Der Augenschein deutete aaf einen frühen Verlust dieser Theile durch irgend welche planzenfressende Thiere. Die genauere 
Betrachtung zeigte, dass, während diese Blätter im Allgemeinen die obere Epidermis in ihrem gewöhnlichen, bedeutenden Umfang entwickelt hatten, nach dem Verletzungsrande hin die Zahl der Schichten farbloser Zellen abnahm bis auf 3 oder 4. Es schien demnach, als ob die mehrfache Epidermis hier etwa ebenso viele Lagen behalten habe, als zur Zeit der Beschädigung vorhanden gewesen waren. Die mikroskopische Untersuchung bestätigte diese Vermuthung und zeigte (Taf. VI. Fig. 4), dass die Zellen aller Gewebetheile zahlreiche zur Wundfläche parallele Wände gebildet hatten; mit guten optischen Hülfsmitteln waren auch in der die letztere bedeckenden braunen Masse noch die abgestorbenen, zusammengesunkenen Reste von Korkzellen erkennbar. Diejenige Erscheinung aber, welche den vorliegenden Fall vor den gewöhnlichen Korkbildungsvorgängen auf Wundflächen sehr auszeichnet, besteht darin, dass hier zwar der äussere Theil der entstandenen tafelförmigen Zellen, wie sonst, zu luftführendem schnell absterbendem Gewebe wird, dass aber der innere nicht nur dauernd lebens. fähig bleibt, sondern seine äusserste Zelllage sogar in einer Weise gestaltet, die einer Reproduction der Epidermis mindestens sehr nahe komint. Wir finden nämlich, dass die Aussen- und Seitenwände der unmittelbar unter der braunen todten Masse gelegenen Zellen genau ebenso verdickt sind, wie die der wahren Oberhautzellen (Taf. VI. F. 5, $\mathrm{N}$ u. E) und dass zwischen diesen beiden auf so verschiedene Weise entstandenen Zelllagen nicht nur diese auffallende Aehnlichkeit der Form besteht, sondern dass dieselben auch unmerklich in einander übergehen. Gleichzeitig beweist die Behandlung mit Chlorzinkjod, dass die wahrem Kork so ähnlichen tafelförmigen Zellen innerhalb der verdickten Lage in ihrem Verhalten nicht mit dem Kork, sondern vielmehr mit den inneren Oberhautzellen übereinstimmen; ibre Wände werden rein blau nur die Verdickungsschichten der falschen, nachgebildeten Epidermis (N) färben sich gelb, genau wie es bei denen der wahren, ursprünglichen (E) der Fall ist. Die Annahme, dass wirklich eine Verwundung stattgefunden habe und nicht etwa nur eine selbstständige unregelmässige Entwicklung des unbeschädigten Blattrandes vorliegt, scheint schon nach dem Taf. VI. Fig. 4 gezeichneten Präparat kaum zweifelhaft; ein zur vollkommenen Sicherstellung dieser Thatsache unternommener Versuch hat sie inzwischen bestätigt. Ein am 6. Januar 1870 quer durchschnittenes junges Blatt des Peper. peireskiifolia zeigte am 1. Februar schon aufs 
schönste etwa 6 Lagen von normalen Korkzellen auf der Wundfläche und darunter mehrere Schichten ähnlicher tafelförmiger Zellen, deren Wände sich aber mit Chlorzinkjod bläuten. Diese letzteren waren, obwohl mit den ersteren in denselben deutlichen zur Wundfläche senkrechten Reihen gelegen und somit ohne Zweifel aus denselben Mutterzellen wie die Korkzellen hervorgegangen, von diesen schon ohne Anwendung von Reagentien verschieden dadurch, dass ihre Wände nicht solche scharfe, schwarze Linien darstellten und nicht so farbig irrisirten, wie die Zellhäute des Korkes es in dem vorliegenden Falle thun. Die Grenze zwischen diesen beiden Geweben gleicher Entstehung war schon jetzt eine ganz scharfe. Am 15. Octb. waren die Korkzellen abgestorben und die darunter befindlichen wie in Figur 4 und 5 verdickt. Nach alledem bleibt uns wohl nichts übrig, als zuzugestehen, dass hier sowohl alle Schichten der Oberhaut, als des Blattgrün führenden Parenchyms im Stande sind, in der Jugend des Blattes erlittene Wunden durch eine 7ellbildung auszuheilen, welche unter einer schützenden Lage von Korkzellen eine der äussersten Lage der normalen Epidermis durchaus ähnliche Zellschicht hervorbringt, unter Einschaltung eines farblosen Gewebes, welches in seinem ganzen Verhalten mit den inneren Zelllagen der mehrfachen Oberhaut die grösste Uebereinstimmung zeigt. Bei der grossen Seltenheit der Reproduction im Pflanzenreich ist dieser Fall wohl bemerkenswerth, wenn auch hier nicht, wie es zu einer Wiederbildung nothwendig wäre, das ganze verloren gegangene Stück ersetzt wird, sondern die Wundfäche sich nur gewissermaassen mit einer neuen Epidermis bekleidet. Da die Verdickung auch in der wahren Oberhaut erst zu einer Zeit beginnt, welche einer weit grösseren Entwicklung des Blatts entspricht, als sie nach der Schichtenzahl des Taf. VI. Fig. 4 gezeichneten Blattquerschnitts zu schliessen - im Augenblick der Beschädigung vorhanden war, so findet die vollkommene Verschmelzung der wahren und falschen Oberhaut darin ihre natürliche Erklärung, dass erst nach Entstehung der die letztere zusammensetzenden Zellen gleichzeitig in ihnen und in den ursprünglich äussersten Zellen des Blatts die Verdickung der Aussenwände ihren Anfang nimmt. Wie vollkommen der Uebergang schliesslich ist, zeigt Taf. VI. Fig. 5, eine stark vergrösserte Darstellung der oberen linken Ecke des Fig. 4 zu Grunde liegenden Präparats.

Aehnlich gebaute, auf ihren Aussenflächen stark verdickte 
wahre Korkzellen, aber ohne Anschluss an eine wirkliche Epidermis und ohne Cellulose-Rcaction ihrer Innenwände hat Sanio ${ }^{1}$ ) bei Salix an jungen Zweigen beschrieben; auch bei Pinus kommen ähnliche Bildungen nach Sachs ${ }^{2}$ ) vor.

Erfolgt die Verletzung bei Peperomia peireskiifolia am erwachsenen Blatt, so tritt, wie schon erwähnt, nur eine gewöhnliche Korkentwicklung ein - findet sie in einem mittleren Zustand statt, so scheinen ausserdem die unter dem Kork liegenden Zellenschichten ihre Wände gleichmässig collenchymatisch zu verdicken. Zur genaueren Feststellung fehlte es mir hierfür an geeignetem Material.

Was die Beziehung der oben mitgetheilten Erscheinungen zur Theorie der mehrfachen Oberhaut betrifft, so beweisen sie meines Erachtens nur, dass eine ungewöhnliche sowohl im Haut- als im Grundgewebe eintretende Zellbildung Schichten hervorbringen kann, die jener sehr ähnlich sind, nicht aber eine unmittelbare Analogie der mehrschichtigen Epidermis und des Korks, wenn sie auch als ein Bindeglied zwischen diesen beiden Gewebeformen wohl gelten können.

Ich bleibe demnach bei der S. 39 ausgesprochenen Auffassung und will im Anschluss an das Vorige nur noch darauf aufmerksam machen, dass eine rein pathologische tangentiale Fächerung der Oberhautzellen in Folge des Eindringens einer Zoospore von Synchytrium in eine benachbarte Zelle von Woronin ${ }^{3}$ ) beschrieben worden ist.

Durch die hier mitgetheilten Untersuchungen halte ich die erste der am Anfang dieser Abhandlung gestellten Fragen für unzweifelhaft in der Affirmative beantwortet, also für bewiesen, dass die Epidermis durch tangentiale Theilung die Zahl ihrer Schichten vermehren könne. Ich wende mich daher jetzt zu der zweiten: Können ganz ähnliche blattgrünfreie, oberfächliche Zellschichten auch aus dem Grundgewebe hervorgehen?

Auch diese Frage ist zu bejahen. Ich beginne die Reihe der hierher gehörigen Beispiele mit der Tradescantia (Rhoeo) discolor, bei welcher die betreffenden farblosen Zelllagen zuerst von Krocker jun. ${ }^{4}$ ), dann nach einer falschen Darstellung von Link ${ }^{5}$ ),

1) Untersuchungen über den Kork. Pringsh. Jahrb. II. S. 64.

2) Lehrbuch d. Botanik. S. 88.

3) Botanische Zeitung von Mohl u. de Bary. 1868. S. 100.

4) a. a. 0. Fig. 12.

5) Jcones anatom. Fasc. I. Taf. VIII. 4. 
auch von Mohl') beobachtet wurden, während Treviranus²) ähnliche bei $\mathbf{T}$. crassula fand.

Der Querschnitt des Blatts, Taf. VI. Fig. 13, gleicht auf den ersten Blick dem von einer dickblättrigen Begonia. Ein Diachym, welches aus etwa 4 Lagen schwammigen und 2 Lagen pallisadenförmigen Parenchyms besteht, ist jederseits von 2-4 Schichten grosser, blattgrünfreier Zellen umschlossen, deren Gesammtdicke an der Blattoberseite dem des Diachyms etwa gleich, an der Unterseite geringer ist. Wie bei den Begonien sind an der ersteren die Zellen der inneren Schicht kurz säulenförmig, meist höher als breit, die der äusseren viel niedriger, tafelförmig; an der zum Boden gewandten Blattseite sind die Zellen beider Lagen einander an Grösse ziemlich gleich, grösstentheils mit rothem Safte erfüllt. Ein wesentlicher Unterschied von dem Bau der Begonien-Blätter zeigt sich darin, dass bei Trad. discolor die Zellen der beiden oberflächlichen, im Allgemeinen blattgrünfreien Lagen an der oberen wie unteren Blattfäche keine Andeutung einer senkrechten Opposition wahrnehmen lassen, sondern vielmehr regelmässig alterniren. Eine zweite Verschiedenheit ist die, dass rings um die Athemhöhlen die Zellen der zweiten Schicht von aussen nicht farblos sind, wie sonst, sondern reich an Chlorophyll und oft unregelmässig gestaltet. Sowohl jene Alternation, als diese Unterbrechung der farblosen inneren Schicht durch Zellen mit grünem Inhalt, deutet auf eine von dem bei Begonia herrschenden Gesetz abweichende Entwicklungsweise.

Die Vergleichung jüngerer Zustände bestätigt diese Vermuthung durchaus. Niemals, vom eben dem Wachsthumscheitel entsprossen. den Blatthöcker bis zur Vollendung des Blatts tritt eine Theilung der Oberhautzellen ein. Die beiden später so ähnlichen äussersten Zelllagen sind genetisch von einander vollkornmen unabhängig. Die Verfolgung der Blattentwicklung bis zur ersten Anlage ist hier leichter als gewöhnlich, da noch im Vegetationspunkt selbst alle Zellen verhältnissmässig sehr gross sind. Ein Dermatogen im Sinne Hanstein's ist deutlich erkennbar. Die unmittelbar darunter liegende Schicht ist dagegen nicht der zweiten ron aussen im Blatte direkt gleichwerthig, sondern nimmt auch an der Bildung des inneren Blattgewebes noch Theil. Die Zellen der auf der

1) Ueber die anatomischen Verhältnisse des Chlorophylls. Diss. 1837. Verm. Schriften S. 352.

2) Physiologie der Gewächse. 449. 
Blattaussenseite unter der Epidermis liegenden Schicht, - welche ich, wie die entsprechende an der Oberseite als "hypodermatische ${ }^{*}$ bezeichnen will, - sind lange Zeit unter einander vollkommen gleich. Erst mit dem Auftreten der Spaltöffnungen entwickeln sich die durch ihr Auseinanderweichen die Athemhöhlen bildenden Zellen besonders: sie erhalten Blattgrün, die übrigen führen nur wässrigen Saft. Eine genauere Untersuchung zeigt auch, dass der Inhalt der Epidermis von dem der hypodermatischen Schicht etwas verschieden ist - nur die Zellen der ersteren zeigen in Präparaten schnelle Bräunung ibres Zellinhalts. Die der letzteren theilen sich häufig einmal durch eine zur Blattfäche parallele Wand; oft hinter einander tritt derselbe Vorgang nur am Grunde der Spreite ein, wo sich diese vom Scheidentheil trennt. Hier entstehen, indem immer wieder die der Oberhaut nächste, von aussen zweite Zelle sich theilt, zahlreiche bypodermatische Schichten. ${ }^{1}$ ) Zu bemerken ist dabei noch, dass zwischen den Zellen der Epidermis und dem Hypoderma und zwischen den einzelnen Zellen der letzteren keine luftführenden $\mathrm{Z}_{\text {wischenzellräume auftreten, wäb- }}$ rend dieselben im Diachym dagegen bäufig sind: am erwachsenen Blatt findet man dort schwache collenchymatische Verdickungen, der Berührungskanten, hier zum Theil ein fast schwammiges Gewebe.

Wenn in dem eben beschriebenen Fall die farblosen Schichten im entwickelten Zustande einige Aehnlichkeit mit den anders entstehenden gleichen Alters von Begonia erkennen lassen, so finden die Peperomien mit ihren so gewaltigen wasserführenden oberflächlichen Geweben ein genetisch sich abweichend verhaltendes Seitenstück in manchen Bromeliaceen. Es gilt dies namentlich von der Acanthostachys (Hohenbergia) strobilacea Lk, von deren Blatt Taf. VI. Fig. 14 einen Querschnitt schematisch darstellt; das grüne Gewebe (grau gezeichnet) erreicht hier nur den dritten Theil des Durchmessers des farblosen. Beinahe eben so stark ist das Letztere an der Oberseite der Blätter von Tillandsia acaulis, vittata, wo auch an der Unterseite einige von Chlorophyll freie Zelllagen vorkommen. Bei Pitcairnia speciosa ist die Gesammtheit derselben immer noch stärker als das Mesophyll, auch bei Billbergia

1) Bei Canna indica entsteht am Blattgrunde in derselben Weise ein umfangreiches Gewebe, in welchem sich aber Gefässbündel differenziren, ähnlich wie in dem sekundären Cambium des Stammes von Yucca, Dracaena u. s. w. 
zebrina, vittata, amoena, bei Aechmea fulgens finden sich ähnlicho farblose Schichten, jedoch von geringerer Ausdehnung.

Zur entwicklungsgeschichtlichen Untersuchung wählte ich Acanthostachys strobilacea. Die wahre Epidermis dieser Pflanze (Taf. VI. Fig. 16) zeichnet sich dadurch aus, dass sie ihre Zellen auf der Innenseite stärker verdickt, als auf der äusseren; zunächst unter ihr liegt eine Lage enger, oft fast bis zum Verschwinden des Lumen verdickter, sklerenchymatischer Zellen. Schon die Abbildung der jüngeren Krocker ${ }^{1}$ ) von Bromelia Karatas deutet Aehnliches an; klar erkannte es $\mathrm{Mohl}^{2}$ ) bei Bromelia Ananas und Billbergia zebrina und wurde dadurch bewogen, an der Innenseite der Oberhautzellen eine Cuticula anzunehmen, welche irrige Auffassung dann Wigand ${ }^{3}$ ) berichtigte. Dieselbe Vertheilung der Verdickung in den Oberhautzellen fand Schacht ${ }^{4}$ ) noch bei Hechtia planifolia und stenopetala, Tillandsia fasciata und usneoides, schreibt aber mit Unrecht den Bromeliaceen im Allgemeinen diese Eigentbümlichkeit zu, welche nach seiner eigenen Abbildung von Dasylirion graminifolium, ${ }^{5}$ ) sowie nach der, welche Unger von D. oblongifolium giebt, diesen beiden doch zu derselben Familie gehörigen Arten nicht zukommt. Eine genaue Verfolgung der Porencanäle zeigt übrigens bei Acanthostachys, dass in der Zellreihe solche auch nach aussen, gegen die Oberhautzellen verlaufen, ohne dass ihnen von dort entsprechende entgegenkämen (vgl. Taf. VI. Fig. 16), sowie dass auch die Aussenwände der dritten, noch immer klcinzelligen Lage (III.) sehr bedeutend in die Dicke gewachsen sind. Dann folgen an der Blattoberseite deutlich in senkrechte Längsreihen geordnete, säulenförmige grosse Zellen voll wässriger Flüssigkeit. Dieses, um es kurz zu bezeichnen, Wassergewebe, hat auffallender Weise keiner der oben genannten Forscher erwähnt: Mohl und Schacht bemerkten dagegen wohl die Lage verdickter Zellen unmittelbar unter der Epidermis. Letzterer sagt mit Bezug

1) A. a. 0. Fig. 22.

2) Ueber die Cuticula der Gewächse. Vermischte Schriften. S. 265. Taf. X. Fig. 33.

3) Intescellularsubstanz und Cuticula 1850. S. 62.

4) Lehrbuch d. Anatomie u. Physiologie, der Gewächse I. S. 274.

5) A. a. O. Taf. IV. Fig. 9. Die Abbildung Taf. III. 29, nach S. 442 Hechtia stenopetala passt auch schlecht zu dieser Angabe; die betreffende Figur wird auch einmal (S. 273) als zu Dasylirion gehörig bezeichnet.

6) Anatomie u. Physiologie d. Gewächse. S. 192. 
darauf, die Oberhaut bestände bei Hechtia und Tillandria fasciata "scheinbar aus zwei, auch wohl aus drei Zellreihen."

Die Grenze zwischen dem farblosen und dem grünen Theil des Blatts ist zwar scharf, aber nicht ganz glatt gezogon - oft springen reichlich Chlorophyll führende Zellen in den ersteren hinein vor. Auf der Blattunterseite, wo ausschliesslich sich Spaltöffnungen finden, ist die Weite der Zellen der von aussen zweiten Schicht beträchtlicher und zwischen ihr und dem grünen Gewebe finden wir nur eine Reihe blattgrünfreier, ziemlich kleiner Zellen eingeschaltet.

Die entwicklungsgeschichtliche Untersuchung, welche nicht ohne Schwierigkeiten ist, da alle jüngeren Blätter sehr weich und kleinzellig sind, lehrt, dass auch bei Acanthostachys die Epidermis sich niemals tangential theilt, dass vielmehr sowohl das umfangreiche Wasser führende Gewebe, als die Reihe sklerenchymatischer Zellen aus dem Grundgewebe ihren Ursprung nehmen (Taf. VI. Fig. 17). Schon sehr frühzeitig theilen sich die unmittelbar unter der Epidermis gelegenen Zellen zum ersten Mal tangential, parallel zur Blattläche. Die äusseren Tochterzellen bilden dann viele radiale Wände und bringen so die - im erwachsenen Blatt ron aussen zweite - Lage später so stark verdickter Zellen hervor. Auf der Blattunterseite werden auch die inneren Tochterzellen nur noch durch radiale Theilungen vermehrt und geben so die unmittelbar an das grüne Mesophyll stossende, dritte Schicht von aussen. In beiden Fällen wird diese erste Theilung durch das weitere Wachsthum des Blatts und das Auftreten der radialen Scheidewände bald unkenntlich; nur Querschnitte sehr junger und namentlich Längsschnitte dicht über dem Grunde etwas älterer Blätter erlauben die Nachweisung dieser ersten tangentialen Fächerung. Viel leichter ist dagegen zu beobachten, dass auf der Blattoberseite die zablreichen später nur Wasser führenden, in zur Blattfläche senkrechte Reihen geordneten Zellen sich grösstentheils aus der nunmehr dritten Schicht von aussen, d. h. also aus den inneren der bei der ersten tangentialeu Theilung entstandenen Tochterzellen entwickeln. Dieselben bilden zunächst noch eine der Blattfläche parallele Wand: die äusseren so gebildeten Zellen theilen sich radial und werden so zu der verhältnissmässig kleinzelligen definitiv von aussen dritten (in Taf. VI. Fig. 16 mit III. bezeichneten) Schicht; die inneren entwickeln aus sich durch weitere tangentiale Theilungen die Hauptmasse des Wassergewebes. Die 
letzteren erfolgen vorzugsweise in der jeweilig äusseren Tochterzelle, kommen jedoch auch in den nach innen abgeschiedenen Zellen vor. Auch die ursprünglich von aussen 3 te und 4 te Zellschicht geht bei Acanthostachys noch mit in die Bildung des Hypoderma ein. Auch bei dieser Pflanze zeichnen sich, wie bei Tradescantia, diejenigen Gewebe, welche sich zu farblosen Schichten entwickeln werden, stets durch den Mangel Luft enthaltender Zwischenzellräume aus, welche dagegen in dem später mit Chlorophyll erfüllten Parenchym schon zeitig auftreten und beständig erhalten bleiben. Taf. VI. Fig. 17 stellt im Querschnitt einen Theil der Oberseite eines jungen, noch scharf zusammengefalteten Blattes dar, des innersten des auf Taf. VI. Fig. 15 schematisch gezeichneten Knospendurchschnitts. Die Zelle $\mathrm{T}$ lässt die erste tangentale Theilung als erst vor kurzem eingetreten erkennen; die $\mathbf{3}-\mathbf{4}$ Reihen ohne schwarze (d. h. luftführende) $\mathrm{Z}_{\text {wischenzellräume ent- }}$ wickeln sich zu dem später oft 10-12 Schichten starken Hypoderma, in dessen Zellen ausser wässeriger Flüssigkeit schliesslich nur noch einzelne Bündel grosser nadelförmiger Krystalle vorkommen. Ein pallisadenförmiges Parenchym ist im Mesophyll der Blätter von Acanthostachys nur unvollkommen gesondert: die obersten grünen Zellen sind zwar in zur Blattfläche senkrechter Richtung mehr gestreckt, als die weiter nach der Blattunterseite $2 u$ gelege nen, führen aber nicht merklich mehr Chlorophyll und haben ziemlich ebenso grosse lufterfüllte Lücken zwischen sich, als jene.

Ich halte hiermit den Nachweis für geführt, dass dünnwandige, parenchymatische, im fertigen Zustand nur oder fast nur Wasser enthaltende Gewebe an der Oberfäche von Pflanzen nicht allein aus der Epidermis, sondern auch aus dem Grundgewebe hervorgehen können. Hinsichtlich der collenchymatischen, so oft unmittelbar unter der Oberhaut vorkommenden Gewebe ist die Möglichkeit der letzteren Entwicklungsweise meines Wissens nie bestritten worden. Im Gegentheil hielt man sie eher für zu allgemein verbreitet, obwohl nur wenige genaue Untersuchungen vorlagen jedoch hat Sanio wenigstens beim Stamm von Euonymus latifolia') und Peperomia blanda ${ }^{2}$ ) die Entstehung des Collenchyms aus der primären Rinde nachgewieser. Ich will hier noch zwei Beispiele von collenchymatischen Zellschichten der Blattspreite geben, welche

1) Botanische Zeitung 1863. S. 263.

2) Botanische Zeitung 1864. S. 210. 
demselben Entwicklungsgesetz folgen. Es finden sich solche bei Nerium Oleander und Ilex Aquifolium.

Das Hautgewebe der ersteren Pflanze hat schon sehr früh die Aufmerksamkeit der Phytotomen auf sich gezogen. Bereits Malpighi ${ }^{1}$ ) entdeckte die an der Unterseite der Blätter vorhandenen tiefen Gruben; der ältere Krocker ${ }^{2}$ ) erklärte dieselben für Stomata, Rudolphi ${ }^{3}$ ) für Drüsenöffnungen. Amici ${ }^{4}$ ) fand dann in deren Grunde die wahren Spaltöffnungen auf, was der jüngere Krocker $^{5}$ ) und Meyen $^{6}$ ) bestätigten, während Brongniart ${ }^{7}$ ) sich noch 1830 dagegen aussprach. Letzterer gab eine im Allgemeinen gute Darstellung des Blattquerschnitts und der farblosen oberflächlichen Zellschichten. Auf die collenchymatische Verdickung der letzteren machte $\mathbf{M o h l}^{8}$ ) aufmerksam, ihren Bau untersuchte dann Wigand ${ }^{9}$ ) näher, während Kraus $^{10}$ ) fand, dass das Collenchym des Blaltstiels unmittelbar in die verdickten Zellen unter der Oberhaut der Blattspreite übergehe. Die Entwicklungsgeschichte wurde wohl noch nicht verfolgt.

Das fertige Blatt von Nerium Oleander zeigt auf seiner Ober. seite meist drei, seltener vier oder zwei farblose Zellschichten, deren innerste häufig durch Reihen blattgrünführender Parenchymzellen unterbrochen wird, eine Erscheinung, welche man seltener auch bei der weiter nach aussen liegenden Schicht beobachtet; im letzteren Falle berührt dann die Oberhaut unmittelbar das grüne Gewebe. Am Rande und über den Nerven des Blatts nimmt die Zahl der Schichten ohne Chlorophyll erheblich zu. Auf der Unterseite findet man deren meist zwei bis drei, es ist aber hier ein allgemein gültiges Gesetz, das im Grunde und an den Seitenwänden der tiefen Gruben, in welchen die Spaltöffnungen verborgen sind, die hypodermatischen Schichten ganz fehlen, so dass an die-

1) Anatome plantarum. Lugduni Batavor. 1687. S. 52. T. XX. 106.

2) De plantarum epidermide. Halae 1800. S. 40.

3) Anatomie der Pflanzen. 1807. S. 94.

4) Ausgesprochen in einem Brief an Mirbel 1829. Vgl. Ann. d. sc. nat. XXI. S. 438.

5) A. 2. 0. S. 13.

6) Physiologie I. S, 292.

7) A. 2. 0. S. 438, Taf. XVI.

8) Ueber die Verbindnung der Pflanzenzellen. Diss. Tübingen 1835. S. 20.

9) A. a. 0. S. 23.

10) a. ล. 0. S. $309 \mathrm{f}$.

Jahrb. f. wiss, Botadik, VIII . 
sen Stellen stets die einfache Oberhaut und das grüne, lockere Parenchym in unmittelbarer Berührung stehen. Alle diese Erscheinungen deuten darauf hin, dass dio collenchymatischen, farblosen Zellen den Chlorophyll enthaltenden des Diachyms gleichwerthig sind. Die Entwicklungsgeschichte bestätigt diese Vermuthung durchaus. Am Wachsthumsscheitel ist ein einfaches Dermatogen vorhanden, dessen Zellen sich sowohl hier, als später auf den Blättern durch alle Altersstufen nur durch zur Fläche senkrechte, nie durch ibr parallele Wände theilen. Das letztere gilt dagegen von der von aussen 2 ten Zelllage des Vegetationspunkts nur an der äussersten Spitze des Stammes: weiter abwärts und namentlich in den ganz jungen Blättern sind tangentiale Theilungen dieser Schicht sehr häufig, und zwar auf beiden Blattseiten, so dass wir dem Hypoderma des Oleanders kein ihm ausschliesslich eigenes Meristem zuschreiben dürfen. Das Blatt entwickelt anfangs ganz vorwiegend seinen mittleren Theil, die Lamina bleibt lange ein sehr schmaler Streifen an jeder Seite des schon weit ausgebildeten Mittelnervs. Noch Blätter von 6 Mill. Länge zeigen alle Zellen der Blattspreite in Theilung; namentlich kommen noch auf beiden Seiten tangentiale Wände in der von aussen 2 ten und 3 ten Schicht vor. Blätter von 13 Mill. Länge, im Querschnitt Fig. 18 auf Taf. VI. entsprechend zeigen an der Oberseite die beiden hypo. dermatischen Schichten differenzirt durch beginnende Verdickung ihrer Wände und Mangel luftführender Zwischenzellräume; weniger auffallend, aber schon merklich, ist die Verschiedenheit des In. halts. An der Unterseite, wo bis dahin alle Zelllagen unter der einfachen Epidermis gleichwerthig gewesen waren, beginnt nun die Entwicklung der Gruben (Taf. Vl. Fig. 19.) In der von aussen zweiten Schicht treten stellenweise tangentiale Theilungen auf, die sich mehrfach wiederholen und auch in der ursprünglich von aussen dritten Zelllage häufig stattfinden. Dadurch werden netzförmig verbundene Stellen der Oberfläche der Blattunterseite gewissermassen in die Höhe gehoben, während andere in der bisherigen Ebene verbleiben, wodurch die Höhlen angelegt werden. Ihre weitere Entwicklung schreitet ziemlich langsam fort - noch bei Blättern von 3 Centim. Länge sind nur ganz vereinzelte Spaltöffnungen gebildet. Andererseits findet man oft kleinere Blätter, die beim Eintritt in die Ruhezeit der Pflanze, ohne ihre volle Grösse nur entfernt erreicht zu haben, Höhlen vollständig ausbilden, in deren Grunde man wenige, bisweilen nur eine Spaltöffnung 
bemerkt, doch sind diese Fälle eben als Hemmungen des normalen Ganges anzusehen.

Ebenso wie bei Nerium lässt sich auch bei Ilex nachweisen, dass die an der Blattoberseite unter der Epidermis befindliche Schicht grösserer, schwach collenchymatisch verdickter, farbloser Zellen aus dem Grundgewebe entsteht. Dieselbe wurde zuerst von Treviranus, ${ }^{1}$ ) später von Goldmann, ${ }^{2}$ ) der sie zur Oberhaut rechnete, und von Thomas ${ }^{3}$ ) bei I. Aquifolium, von letzterem dann auch bei I. balearica, Calamistra und Cassine Maurocenia, von Kraus $^{4}$ ) bei Ilex ovata beobachtet. Bei Cassine ist ihre Verdickung besonders schön collenchymatisch. Die Entwicklungsgeschichte habe ich bei I. Aquifolium untersucht und dabei niemals in den verschiedensten Alterszuständen des Blatts bis zu den allerjüngsten hinab eine tangentiale Theilung der Epidermis wahrnehmen können. Im Vegetationspunkt bilden die beiden äussersten Zellschichten nur zur Aussenfläche senkrechte! (radiale) Wände, während weiter nach innen nach allen Richtungen des Raumes Theilungen erfolgen. Man darf aber trotzdem auch hier nur ein einfaches Dermatogen annehmen, weil allein die äusserste, sich zur wahren Oberhaut entwickelnde Schicht auch bei der Anlegung von Blättern ausschliesslich radiale Wände zeigt. Die zweite ist ebenso wenig hier, als beim Oleander als ein eigenes Meristem des Hypoderma aufzufassen, da ihre Zellen sich bei der Entwicklung eines Blatthöckers tangential und selbst schief theilen und somit auch zur Bildung des Mesophylls wesentlich beitragen. Auf den grossen Nerven und nach dem Rande hin findet man mehr als eine, bis drei Schichten von collenchymatischem Hypoderma. An der Blattunterseite ist nur eine Lage ähnlicher Zellen vorhanden und zwar wird dieselbe so vielfach von grünen Zellen unterbrochen, dass man ihr kaum den Namen einer Schicht beilegen kann. Am Blattrande selbst findet sich ausserdem noch eine andere Form hypodermatischen Gewebes, nämlich ein Strang von langen sklerenchymatischen Zellen, wie dies schon Mettenius ${ }^{5}$ ) angab. Dieselben sind scharf gegen das Collenchym abgegrenzt; sie entstehen eben-

1) Beitrăge zur Pflanzenphysiologie 1811. Taf. II. Fig. 13.

2) Botanische Zeitung 1848. S. 861.

3) 2. a. 0. S. 33 .

4) 2. 2. 0. S. 321 .

b) a. 2 , 0. S. 439 . 
falls aus dem Grundgewebe, und zwar erst spät, an etwa 2 Cent. langen Blättern aus bis dahin weitzelligem unverdicktem Gewebe.

Wir sehen demnach, dass auch collenchymatische und normal sklerenchymatische Schichten unabhängig von der Oberhaut sich entwickeln können: für diese letztere Behauptung habe ich einen zweiten Beleg schon weiter oben bei Acanthostachys gegeben; Sanio $\left.{ }^{1}\right)$ wies auch bei dem Sklerenchym unter der Epidermis von Ephedra dieselbe Entstehungsweise nach.

Die Letztere kommt gleichfalls vor bei denjenigen hypodermatischen Geweben, welche zu den von Sachs ${ }^{2}$ ) neuerdings an das Sklerenchym angeschlossenen Zellformen gerechnet werden können. Ein solches Gewebe findet sich beispielsweise in den unteren, bräunlich gefärbten Internodien der zu den Restionaceen gehörigen Elegia nuda. Während die oberen Theile des Stammes dieser Pflanze unter einer durch tangentiale Fächerung verdoppelten Epidermis ein Chlorophyll führendes Gewebe zeigen, finden wir weiter nach unten die Zellen der Oberhaut ungetheilt, aber stark hartwandig verdickt und gebräunt. Diese Eigenschaften kommen auch noch den zwei his drei zunächst der Epidermis liegenden Schichten $z u$, ohne dass cine ganz scharfe Grenze gegen das unveränderte Grundgewebe vorhanden wäre. Die Verhältnisse sind im Ganzen dieselben, wie etwa bei dem Kajselstiel eines Laubmooses; nur eine allmählich von innen nach aussen sich steigernde Verdickung und Bräunung der Zellon charaktcrisirt das Hantgewebc. Auch bei Elegia lässt sich der Ursprung dieser Schichten (deren Zellen überdies nach oben hin Uebergänge zu Chlorophyll enthaltenden zeigen und mit denen der Oberhaut alterniren) aus dem Grundgewebe leicht feststellen.

Blicken wir auf die bisher geschilderte Reihe der Erscheinungen zurück, so kann es nicht „zweifelhaft sein, dass die bisher einerseits als „mehrfache Oberhaut", andererseits als „Hypoderma“ unter einen Begriff zusammengefassten Gewebe entwicklungsgeschichtlich in zwei Gruppen zerfallen, unterschieden durch ihren Ursprung aus der Epidermis und aus dem Grundgewebe. In morphologiscber Hinsicht ist demnach eine Trennung derselben geboten und ich glaube, dass die Terminologie sich am einfachsten gestaltet, wenn man die Bezeichnung, mehrfache oder mehrschich-

1) Botanische Zeitung 1863. S. 371.

2) Lehrbuch der Botanik S. 87. 
tige Obcrhaut" nur auf diejenigen Schichten anwendet, welche aus einer ursprünglich einfachen Epidermis hervorgehen, wenn man dagegen in den übrigen Fällen den Namen der Oberhaut nur der einen äussersten Zellschicht beilegt, und die sich ihr innen anschliessenden, blattgrünfreien, aus dem Grundgewebe entstandenen Schichten "Unterhautgewebe, Hypoderma ${ }^{1}$ " nennt. Andererseits könnte man sich allerdings versucht fühlen, den Begriff der mehrfachen Oberhaut in dem Umfange festzuhalten, in welchem ihn seine Begründer, Bauer, Treviranus und Brongniart aufgestellt haben. Man müsste ihn dann auf die beiden eben genannten Gruppen ausdehnen und etwa die farblosen Schichten, deren Zellen alle gleichen Ursprung haben, (Peperomia, Ficus u. s. w.) als gleichwerthige oder homogene (gleichen Ursprungs), die der übrigen als ungleichwerthige (heterugene) mehrfache Oberhaut bezeichnen. Ich habe dagegen das Bedenken, dass dadurch der Begriff des Epidermis im Allgemeinen eine zu grosse Weite und eine zu unbestimmte Begrenzung erhalten würde. Wir finden in den allermeisten Fällen die Oberhaut so scharf gegen das Grundgewebe abgesetzt, dass es mir höchst wünschenswerth erscheint, auch den Begriff derselben so weit als irgend möglich klar und rein zu halten, zumal da uns die Hanstein'sche Theorie, die ja auch durch die vorliegende Abhandlung wieder bei mehreren Pflanzen bestätigt worden ist, die Möglichkeit vor Augen stellt, durch den allgemeinen Nachweis eines Dermatogens wenigstens bei den angiospermen Phanerogamen die Definition der Oberhant sehr einfach zu gestalten. Es kommt dazu die Erwägung, dass wir zu den Abänderungen der Epidermis mit dem vielgestaltigen Hypoderma noch ein Seitenstück desselben bei der Wurzel zählen müssten, nämlich die sogenannte Endodermis. Dieselbe ist bei den Orchideen schon lange bekannt und neuerdings namentlich von Oudemans und Leitgeb (a. a. O.) untersucht worden. Sie ist ausgezeichnet durch die feste Vereinigung ihrer Zellen, welche oft Aehnlichkeiten mit denen der Schutzscheide $^{2}$ ) zeigen, und durch den Mangel luftführender Räume zwischen ihnen und der wahren Oberhaut der Wurzel und hat nach

1) Ich ziehe diesen Ausdruck dem von Sachs (Lehrbuch S. 85) in Vorschlag gebrachten ,subepidermale Schichten“ vor, weil er älter und kürzer, auch grammaticalisch richtiger gebildet ist, wenngleich ihn Kraus in zu weitem Sinne anwandte.

2) Aehnliches beobachtete ich auch bei der von aussen zweiten Zellschicht des Stammes von Linaria Cymbalaria. Nur diese zweite Lage und die Schutzscheide führten rothen Saft. 
Nicolai') eine sehr allgemeine Verbreitung. Man kann die Endodermis nun zwar nicht mit dem Hypoderma vollkommen rereinigen, da jene stets ibre eigenen Mutterzellen im Vegetationspunkt hat, was bei diesem noch nicht nachgewiesen und sogar bei $\mathrm{Ne}$ rium und Ilex gewiss nicht der Fall ist - aber ein entschiedener Uebergang wird vermittelt durch diejenigen collenchymatischen Gewebe, welche, wenn auch unter dem Stammscheitel, so doch aus der einen unmittelbar unter der Oberhaut gelegenen Zellschicht. hervorgehen. Es hat dies Sanio bei Peperomia und Euonymus nachgewiesen. Ausserdem ist aber namentlich noch zu bedenken, dass, wenn wir die Zellen des Hypoderma, die erst spät aus dem Grundgewebe der Epidermis beigegeben werden, ohne Weiteres zu dieser rechnen, dies noch mit viel grösserem Rechte bei den Zellen der Endodermis geschehen muss, die schon im Augenblick ihrer Entstehung sich der Oberhaut anschliessen. Da demnach die Aufnahme des Hypoderma unter den Begriff der letzteren diesen so unverbältnissmässig ausdehnen würde, so ziche ich vor, bei der oben gegebenen Bozeichnungsweise zu bleiben, mithin nur eine solche Epidermis als mehrschichtig zu betrachten, welche aus einer ursprünglich einfachen durch Fächerung hervorgegangen ist. Hingegen möchte ich vorschlagen, diese drei so nahe verwandten Gewebe Epidermis, Hypoderma und Endodermis als eine Unterabtheilung der Hautgewebe zusammen mit dem Namen der ,oberhautartigen epidermidalen ${ }^{2}$ ) Schichten " zu belegen.

Die eben vertheidigte Trennung von Epidermis und Hypoderma wird dadurch nicht erschüttert, dass diese beiden Gewebe oft nach vollendeter Entwicklung kaum von einander zu unterscheiden sind. Die Natur erreicht eben oft dieselben $\mathrm{Z}$ wecke mittelst verschiedener Organe, welche sie nur der Verrichtung gemäss gestaltet. Ich brauche nur an die wurzelartigen Gebilde zu erinnern: die meisten Pflanzen nehmen das ihnen nothwendige Wasser mittelst abgeänderter Axengebilde, Salvinia mit Hülfe eines Blattes, noch andere durch Trichome auf; alle diese Organe erscheinen dem ersten Blick gleichwerthig und sind es doch in morphologischer Hinsicht nicht. Ebensowenig dürfte man Blätter, Phyllodien und flache

1) a. a. 0. S. 67 .

2) Von den verschiedenen schon bestehenden Adjectiven epidermal, opidermidal, epidermoidal, epidermoid, epidermatisch schien mir das Gewählte das relativ richtigste. 
Zweige olme Weiteres zusammenwerfen. Wenn aber auch von dieser rein theoretischen Seite ber gegen die oben versuchte Sonderung nichts einzuwenden ist, so bewegen mich doch praktische Gründe auch rom physiologischen Standpunkt aus eine Gruppenbildung zu versuchen. Zunächst empfiehlt es sich für diejenigen noch sehr zahlreichen Fälle, in denen man die Entwicklungsgeschichte noch nicht kennt, die Möglichkeit einer bestimmten Bezeichnung zu schaffen. Nach der S. 54 gegebenen Auseinandersetzung wäre nun hier der Ausdruck „oberhautartige Schichten", da er nichts hinsichtlich der Entstehung präjudicirt, stets anwendbar. Es erweist sich die Einführung eines solchen umfassenderen Begriffs namentlich auch zweckmässig bei denjenigen Pflanzen, bei welchen die Entscheidung schwierig ist, ob in einem gegebenen Augenblick die äusserste Zellschicht bereits als eine Epidermis zu betrachten sei, oder nicht, d. h. also namentlich für Gymnospermen und höhere Kryptogamen. Ein Dermatogen dürfen wir bei den letzteren unter keinen Umständen annehmen, da sie mit einer Scheitelzelle wachsen und auch bei den Coniferen sprechen die Beobachtungen von Hofmeister ${ }^{1}$ ) und meine gleich anzuführenden eigenen Untersuchungen dagegen. Es giebt nun aber auch bei Farren Blätter mit mehreren oberhautartigen Schichten (nach Kraus $^{2}$ ) bei Aspidium coriaceun, Niphobolus Lingua - ich kann N. pertusus hinzufügen) und ebenso bei Coniferen und Cycadeen. Entwicklungsgeschichtliche Beobachtungen, die ich bei Abies pectinata DC., Picea excelsa und Pinus Pinsapo angestellt habe, beweisen, dass die sklerenchymatischen Schichten, welche wir unter der Epidermis der Blätter dieser Pflanzen finden, zwar aus der äussersten Zelllage hervorgehen; dass aber die erste tangentiale Theilung derselben zu einer Zeit eintritt, in der man zweifelhaft sein kann, ob diese äusserste Schicht schon vom Grundgewebe differenzirt sei. Bei ganz jungen Blättern, deren Länge ihre Breite noch kaum übertrifft, kann man, sowohl an dünnen Längsschnitten, als auch (nach Behandlung dickerer Schnitte mit Kali) durch Einstellung des Mikroskops auf die Median-Ebenen der Blatthöcker sich überzeugen, dass alle Zellen der zu dieser Zeit äussersten Zellschicht nach innen zu mindestens je eine deutlich ihnen oppo-

1) Beiträge zur Kenntniss der Gefässkryptogamen in Ahhandt. d. Sächs. Gesellschaft in Leipzig, 1857. Math. Physic. Klasse. Bd. III. s. 643.

2) a. a. 0. S. 321 . 
nirte Schwesterzelle besitzen. Ls ist aber gleichzeitig ersichtlich, dass die tangentiale Theilung; durch welche dieselbe entstanden ist, schon in den ersten Stadien der Entwicklung des Blattes stattfindet. Indem dann dieses Letztere sich stark in die Länge zu strecken beginnt, wird die genetische Bezichung zwischen der von aussen zweiten und der äussersten Schicht bald undeutlich: in den Zellen der ersteren beobachtet man aber häufig ein starkes Längenwachsthum und eine weitere Zerfällung durch eine zur Aussenfläche des Blattes parallele Wand. Da demnach die beiden oberflächlichen Zellen aus einer ursprünglich äussersten hervorgehen, so müssen wir schliessen, dass auch das Sklerenchym, welches später unmittelbar unter der Epidermis sich findet, in dieser äussersten Schicht seine Mutterzellen hat und aus ihr, wenn auch nicht ohne zahlreiche vermittelnde Theilungen, hervorgeht. Es ist aber auch im höchsten Grade wahrscheinlich, dass, da die tangentiale Theilung in der äussersten Zellschicht der Blattanlagen auch ausserhalb der Medianebene derselben vor sich geht, auch schliesslich Blattgrün führenàes Parenchym denselben Ursprung haben wird, dass demnach dic ihnen gemeinsam als Mcristem dienendo oberflächliche Zelllage nicht als eine junge Epidermis zu betrachten sei. Auch die Uebergänge, welche Thomas') zwischen den grünen und dem sklerenchynatischen Gewebe beobachtete, sprechen dagegen. Andererseits ist nicht zu läugnen, dass die Gesammtheit der Innenwände jener äussersten Zelllage eine ziemlieh regelmässige, dem Gesammtumriss der Blattanlage parallele Fläche bildet, und dass"auch die gemeinsame tangentiale Theilung und die Abwesenheit schiefer Wandbildung dieselbe als ein Ganzes erscheinen lässt. Ein eigentliches Dermatogen am Vegetationspunkt möchte ich den Coniferen keinenfalls zuschreiben, da die Umgrenzung der äussersten Schicht der Stammspitze nach innen wenig Regelmässigkeit zeigt und auch nahe dem Scheitel tangentiale und schiefe Theilungen vorkommen, welche letztere vielleicht eine Beziehung zur Blattentwicklung haben. $\mathrm{Ob}$ aber die oberflächlichen Zellen des Blatthöckers im Augenblick der tangentialen Scheidewandbildung ein differenzirtes Ganzes sind oder nicht, ist sehr schwer zu sagen. Jedenfalls muss man dic Thatsache der oberflächlichen Entstehung des Sklerenchyms im Auge behalten, wenn man auch die Ansicht von Thomas, dass dasselbe zum Grundge-

1) a. a. 0. S. 34 . 
webe gehöre, anvimmt. Es ist dies die Modification derselben, auf welche ich oben (S. 21) hindeutete.

Unter allen Umständen lässt auch dieser zweifelhafte Fall es sehr wünschenswerth erscheinen, einen Begriff aufzustellen, der mehrfache Epidermis und Hypoderma gleichzeitig umfasst und daher auch bei denjenigen Pflanzen anwendbar ist, welche alle Gewebe aus einer Scheitelzelle entwickeln, und bei denen immer schwer zu entscheiden sein wird, ob eine Epidermis schon gebildet sei oder nicht. Es empfichlt sich dann ferner, diesen auf physiologischen Eigenschaften beruhenden Begriff nach dem gleichen Eintheilungsgrunde weiter zu zerlegen, wenn auch die so gebildeten Untergruppen nicht scharf vou einander gesondert sind.

Ehe ich aber hiermit zu einer Aufzählung der bisher bekannt gewordenen Fälle vom Vorkommen mehrerer oberhautartiger Schichten übergehe, muss ich noch zwei ausscheiden, bei welchen dasselbe ohne Grund behauptet worden ist: die betreffenden Pflanzen sind Rochea falcata und Agave americana.

Bei der ersteren rührt die irrige Angabe von Brongniart') her. Derselbe wurde getäuscht durch die allerdings schr eigenthümlichen einzelligen Haare der Blätter der Rochea. Diese Trichome sind von kurz tonnenförmiger Gestalt, oben flach und nur mit einem schmalen Fusse zwischen den viel kleineren Oberhautzellen befestigt - ihre Wände sind stark verdickt und zeigen schöne Schichtung. Indem diese Haare sich eng aneinander drängen, flachen sie sich seitlich zu Prismen ab und können, da sie wie ein geschlossenes Pflaster, nur an den Spaltöffnungen bildenden Stellen der Epidermis unterbrochen, über der Blattfäche stehen, leicht für eine äussere zweite Schicht der Oberhaut gehalten werden. Schon 1830 gab Bischoff $^{2}$ ) eine kleine, aber richtige Zeichnung davon; ich komme darauf nur zurück, weil noch neuerdings dic Rochea falcata wieder unter den Pflanzen mit doppelter Epidermis aufgeführt wurde. Aehnliche Bildungen beobachtete Meyen ${ }^{3}$ ) bei Aloe perfoliata.

Den Blättern der Agave americana schrieb zuerst Treviranus, ${ }^{4}$ ) dann Unger ${ }^{5}$ ) eine zweifache Oberhaut zu; Meyen ${ }^{6}$ ) er-

1) a. a. 0. S. 435 . Taf. $X$.

2) Handbuch d. bot. Terminol. u. Systemkunde Taf. XLVI.

3) Phytotomie Taf. III. Fig. 11. 12.

4) Verm. Schrift. IV. S. 217.

5) Grundz. d. Anat, und Phys.

6) Pflanzenphysiologie I. Taf. V. Fig. 3. S. 438. 
kannte wahrscheinlich bereits den wirklichen Sachverhalt. Es sieht nämlich die Grenze zwischen dem stark verdickten und dem dünn bleibenden Theil der Seitenwände der Zellen der einfachen Epidermis auf dem Querschnitt der letzteren bei ungenauer Einstellung des Mikroskops einer tangentialen Scheidewand sehr ähnlich. Ich habe jedoch eine solche auch bei alten Blättern nie gefunden.

Im Anschluss an die oben beschriebenen Fälle einer späten Theilung der Oberhautzellen durch tangentiale Wände will ich noch daraut aufmerksam machen, dass bisweilen auch eine Fächerung in dazu senkrechter Richtung vorkonmt, welche die Umrisse der einzelnen vor dem Eintritt derselben rorhandenen Zellen nicht verwischt. Schon Malpighi ${ }^{1}$ ) bildet eine solche "gefächerte Epidermis" vom Stamm der Portulaca oleracea $a b$, Sachs ${ }^{2}$ ) fand Aehnliches beim sich streckenden hypocotylen Glied von Helianthus annuus. Besonders schön ist diese Erscheinung an den erwachsenen Blättern von Dracaena reflexa zu beobachten; eine Flächenansicht der Oberhaut derselben ist auf Taf. VI. Fig. 21 dargestellt. Die Zellen derselben enthalten zahlreiche, ihrer Aussenwand eingelagerte Krystalle, vermuthlich von oxalsaurem Kalk; ${ }^{3}$ ) die Fächerung tritt erst ein, wenn die Stomata bereits ihre Spalte geöffnet haben. Ebenfalls spät erfolgt diese nachträgliche Theilung auch bei Ilex Aquifolium; erst Blätter, die im Juni beinahe ibre volle Grösse erreicht hatten, zeigten den Beginn der Fächerung. Bei Camellia japonica scheint auf den ersten Blick Aehnliches geschehen zu sein - in Wirklichkeit haben aber nur die Aussenflächen der Oberhautzellen nach innen vorspringende Leisten, die den Zellraum nicht ganz durchsetzen.

Eine Combination der "gefächerten" mit der mehrfachen Epidermis kommt bei manchen Cacteen vor. Bei Cereus peruvianus theilen sich die Oberhautzellen, ohne ihren Unriss zu verlieren, erst radial und dann häutig noch tangential. Bereits Meyen ${ }^{4}$ ) giebt eine hierauf bezügliche Abbildung; im besonders hohem Grade scheint Aehnliches bei Rhipsalis funalis stattzufinden; ${ }^{5}$ ) ich habe letztere Pflanze leider nicht vergleichen können.

1) Anatome plantarum Tab. I.

2) Lehrbuch d. Botanik S. 106.

3) Ungemein kleine Krystalle finden sich auch in Masse eingestreut in den Aussenwänden der Epidermis der Ephedren.

4) Physiologie I. Taf. I Fig. 1.

5) Vergl. Wigand a. a. O. Taf. II Fig. 95. 
In der Liste von Pflanzen mit epidermidalen Schichten, zu welcher ich nun übergehen will, werde ich die Arten und Citate nur bei denjenigen geben, welche bisher nicht erwähnt wurden, sonst aber auf die betreffende Seite dieses Aufsatzes zurückrerweisen. Ein Stern deutet an, dass ich die Angabe bestätigt gefunden habe, $\mathbf{E}$, dass eine wahre mehrfache Oberhaut, $\mathbf{H}$, dass ein Hypoderma nachgewiesen worden ist. Hinsichtlich des Vorkommens einer Endodermis bei Wurzeln sind nur die Beobachtungen von Leitgeb und Nicolai vorhanden, welche a. a. 0 . zu vergleichen sind.

\section{Oberhautartige Schichten.}

(Strata epidermidalia.)

\section{I) Normal sklerenchymatische.}

${ }^{*}$ L a u b m o o se (Kapselstiel), Is o et a ce a e ${ }^{1}$ ) (Blätter der landbewohnenden Arten), *Equisetaciea ${ }^{2}$ ) (Stamm aller bekannten Formen), ${ }^{*}$ Polypodiaceae ${ }^{3}$ ) (Stamm und Blatt vieler Arterı), ${ }^{*}$ Cycadaceae ${ }^{*}$ ) (Stamm und Blatt), *Coniferae ${ }^{5}$ ) (Blatt, E? H? vgl. S. 55f. und vermisst bei Torreya und Taxus), *Gnetaceae (Stamm H. vgl. S. 52), *Gramineae (Blattscheide von Phragmites ${ }^{6}$ ), Blätter von Elymus, Festuca ovina, rubra u. A., Aera flexuosa, Nardus, Spartina cynosuroides), Cy p'e racea e (Blatt von Scirpus lacustris, $\left.{ }^{7}\right)$ ), * Bromeliacea e (Blatt H. vgl. S. 46 ff, Dasylirion oblongifolium, ${ }^{8}$ ) graminifolium $\left.{ }^{9}\right)$ ), ${ }^{*} \mathrm{Orchidaceae}$ (Blatt von *Renanthera coccinea), *Pandanaceae (Blatt von Pandanus odoratissimus ${ }^{0}$ ), *graminifolius), *Palma ${ }^{11}$ ) (Blatt von

1) Al. Braun im Monatsber. d. Berlin. Academie 1863. S. 588.

2) Bischoff, Kryptogam. Gewächse I. Taf. V. Duval Jouve, Histoire nat. des Equisetum de France.

3) Vgl. Mettenius, die Hymenophyllaceen a. a. 0. S. $4.36 \mathrm{ff}$.

4) Vgl. S. 4. 5. u. Kraus a. a. 0.

5) Meyen, Phytotomie Taf. VI. Fig. 2, Thomas a. a. 0.

6) Meyen in d. Haarlemer Preisschrift Taf. IV. A. 2. Treviranus, Physiologie I. S. 192.

7) Phytotomie Taf. VI. 1.

8) Unger, Anatomie u. Physiologie S. 192.

9) Schacht, Lehrbuch d. Anatomie u. Physiol. I. Taf. IV. 9.

10) Meyen, Phytotomie Taf. VIII. (?).

11) Treviranus Physiologie I. S. 192. 
Oenocarpus utilis'), *Phoenix dactylifera), Potaniae (Blattstiel Potamogeton natans $\left.{ }^{2}\right)$ ), Berberidaceae $\left(\right.$ Stamm $\left.^{3}\right)$ ), Aquifoliaceae (Blatt H vgl. S. 51), *Casuarinaceae ${ }^{4}$ ) (Stamm wohl aller Arten), *Cupuliferae (Blatt von Quercus coccifera am Rand), Umbelliferae (Stamm von Chaerophyllum bulbosum ${ }^{5}$ )), Proteaceae (Blatt von Dryandra floribunda $\left.{ }^{6}\right)$ ), Papilionaceae $\left(\right.$ Stamm $\left.^{2}\right)$ z. B. Spartium monospermum).

In den meisten Fällen werden diese Gewebe von ungefächerten langen bastähnlichen Zellen gebildet; doch haben Jochmann bei Úmbelliferen ${ }^{8}$ ), Mettenins und Kraus ") bei Cycadeen eine mehrfache Quertheilung dieser Zellen beobachtet, entsprechend der zweiten vou Mettenius aufgestellten Form des Sklerenchyms. Es bietet uns diesclbe einen Uebergang zu den Geweben, welche wir unterseheiden können als

\section{2) Parenchymatisch-sklerenchymatische.}

*Equisetaceae (Rhizom), *Polypodiaceae (Rhizom), * Restiouaceae (vgl. S. 52).

Sehwer davon zu trennen sind, da in der Quellungsfähigkeit und Härte der Verdickungsschichten so vicl Abstufungen vorkommen, die mehr oder weniger deutlich collenchymatischen Gewebe. Ich nenne hier auch diejenigen, welche auf der Grenze zu den vorigen stehen, halte dagegen nicht eine Aufzählung der Pflanzen für geboten, deren einjährige Stämme oder Blattstiele Collenchym unter der Epidermis besitzen, da diese Erscheinung so sehr verbreitet ist und schon Schleiden ${ }^{10}$ ) so viele Fälle aufführte. Die folgende Liste entbält nur diejenigen Gewächse, deren assimilirende Theile, blattlose Stämme oder Spreiten, derartige Gewebe zeigen.

1) Karsten, Vegetationsorgane d. Palmen.

2) Meyen in d. Haarlem. Preisschrift Taf. IV. B. 4.

3) Mettenius a. -a. O. S. 439.

4) Sanio in Pringsh. Jahrb. II Taf. XIII, Loew de casuarin. caulis foliique evolutione et structura Diss. Berol. 1865. S. 32, Thomas a. a. 0. S. 83.

5) Jochmann, de umbelliferar. structura Diss. Vratislav. 1854. S 8.

6) Meyen in Haarlem. Preisschr. Taf. V. B. 3.

7) Mettenius a. a. 0. S. 439.

8) a. a. 0. Taf. I. Fig. 8.

9) a. a. 0. S. 322 .

10) Grundzüge d. wissenschaftl. Botanik 3, Aufl. II. S. 152. 


\section{3) Collenchymatische.}

*Polypodiaceae (vgl. S. 55), *Gnetaceae (Stamm E vgl. S. 37), *Restionaceae (Stamm E. H. Hautg. II S. 576), * P a nd anaceae (Blatt P. graminifolius), * P a lmae (Blatt Phoenix silvestris, *dactylifera, farinifera, Livistonia australis, Chamaerops excelsa und humilis $\left.{ }^{1}\right)$ ), La biata e (Blatt Rosmarinus officinalis ${ }^{2}$ )), *A p o cynaceae (Blatt H. vgl. S. 49f.), Dipsacaceae (D. silvestris Blatt $\left.{ }^{3}\right)$ ), *Rhodoraceae (Blatt E.vgl. S. 35), *Berberidaceae (Blatt Mahonia Fortunei $\left.{ }^{4}\right)$ ), ${ }^{*} \mathrm{R}$ hamnaceae (Stamm ${ }^{*}$ Colletia serratifolia), *Aquifoliaceae (Blatt H. vgl. S. 51), *Pittosporaceae (Blatt E. vgl. S. 37), I uglandaceae (I. regia Blatt ${ }^{5}$ )), *Cactacea 0 (Stamm H? Cactus phyllanthoides $\left.{ }^{6}\right)$, glaucescens, ${ }^{7}$ ) peruvianus, E. H ${ }^{8}$ ), viele Arten bei Schleiden ${ }^{9}$ )), ${ }^{*}$ Urticaceae (Blatt E. *Ficus vgl. S. $24 \mathrm{ff}$., Morus nigra, Conocephalus naucleiflorus $\left.{ }^{10}\right)$ ), Cupuliferae (Blatt Quercus glabra $\left.{ }^{11}\right)$ ), *Saxifragaceae (Blatt E. vgl. S. 38), "Proteaceae (Blatt Banksia sp., ${ }^{12}$ ) *B. Cunninghamii, Stenocarpus sinuatus? $\left.{ }^{13}\right) *$ Myrtaceae (* Metrosideros). Auch manche Begonien und Peperomien zeigen collenchymatischen Bau ibrer mehrfachen Oberhaut.

Indem dann die Verdickung der Zellwände mehr und mehr schwindet, kommen wir zu oberhautartigen Schichten, die wir bezeichnen können als

\section{4) Dünnwandige wasserführende.}

Wir finden hier alle Uebergänge von solchen, welche einen im Verhältniss zum Mesophyll nur unbedeutenden Durchmesser haben, bis zu den umfangreichen der Peperomien u. s. w.

1) Kraus a. a. 0. S. 321.

2) Thomas a. a, 0. S. 33 .

3) Schleiden a. a. 0. I. S. 337, Schacht, Lehrbuch d. Anat. u. Physiol. I. S. 274.

4) Thomas a. a. $0 . \mathrm{S}, 33_{2}$

5) Payen a a. 0, Taf. III, 1-3.

6) Brongniart a, a. 0. Taf. 11.

7) Payen a. a. 0. Taf. V. 7.

8) Unger, Grundzüge d. Anatomie d. Gewächse.

9) Beiträge zur Anatomie d. Cacteen a. a. 0. vergl. auch dies. Aufs, S. 6.

10) Payen a. a. 0. Taf. IV. 1.

11) Thomas a. a. 0. S. 33.

12) Schleiden, Grundzüge I. S. 275.

13) Kraus a. a. 0. S. 321. 
*Commelinaceae (Blatt E. und H. vgl. S. 43 f.), *Bromeliaceae (Blatt H. vgl. S. 45 f.), *Cannaceae (Blatt ${ }^{*}$ C. indica, ${ }^{1}$ ) * Maranta zebrina, ${ }^{2}$ ) ${ }^{*}$ discolor), ${ }^{*}$ Zingiberaceae (Blatt * Costus speciosus), *Musaceae (Musa * paradisiaca, ${ }^{3}$ ) Ensete, ${ }^{*}$ ) ${ }^{*}$ Urania speciosa, ${ }^{3}$ ) *Strelitzia Reginae), *Araceae (Blatt * Philodendron cannifolium, *Anthurium membranuliferum), *Cyrtandraceae (Blatt Aeschynanthus sp., $\left.{ }^{6}\right),{ }^{*}$ A. ramosissimus), * Serophulariaceae (Blatt *Veronica speciosa $\left.{ }^{6}\right)$, *Lindleyana), *Piperaceae (Blatt und Stamm E. rgl. S. $26 \mathrm{f}$ ), *Urticaceae (Blatt *Urtica crassifolia), *Begoniaceae (Blatt und Stamm E. vgl. S. 31 f.).

Nur durch die eigenthümliche Form ihrer zarten Wandverdickung sind von den eben genannten verschieden die bei manchen Orchideen beobachteten epidermidalen Schichten, die

5) Netz- oder schraubenförmig verdickten, wasserführenden.

*Orchidaceae (Blatt und Stamm Stelis sp. ${ }^{7}$ ), Blatt Pleurothallis ruscifolia ${ }^{8}$ ), Lepanthes cochlearifolia und Physosiphon Loddigesii $\left.{ }^{9}\right)$; ebenso bei einer unbestimmten Art des Bonner Gartens).

Ihnen in der Form ähnlich, aber durch die Natur ihres Inhalts im fertigen Zustand verschieden, ist dann die mehrfache Oberhaut der Luftwurzeln. Crinum (vgl. S. 39) vermittelt den Uebergang dazu, zu den

\section{6) Wurzelhüllen.}

* Orchidaceae, *Araceae, *Amaryllidaceae.

Die Grenze bildet dann auf dieser Seite der Kork, luftführend wie die Wurzelhüllen, aber oft anderer Entstchung und namentlich stets anderer Verrichtung dienend, während auf der anderen die sich in Grundgewebe vereinzelnden sklerenchyma-

1) Treviranus, Verm. Schriften S. 11.

2) Meyen, Phytotomie Taf. III. Fig. 3.

3) Treviranus a. a. 0. S. 11.

4) Wittmack, Musa Ensete, Diss, Berol. 1867. (in Linnaea Bd. XXVI. Taf. XII. Fig. 21).
5) Meyen a. a. O. S. 92. Taf. VII. Fig. 2.
6) Kraus a. a. 0. S. 321.
7) Meyen, Haarlem. Preisschrift S. 173.
8) Meyen, Wiegmanns Archiv 1837 S. 424 u. Schleiden obenda 1838. S. 51.
9) Trécul in Ann. d. sc. natur. Botan. IV. Série II. S. 338.


tischen Zellen (Pachycysten Caspary), welche ja bei den Coniferen nach Thomas ${ }^{1}$ ) Uebergänge zu dem Hypoderma zeigen, uns über den Umfang des Begriffs der oberhautartigen Schichten und selbst der Hautgewebe hinausführen.

Versuchen wir zum Schluss noch uns der Beantwortung der Frage zu nähern, welche Rolle die menrfachen epidermidalen Schichten im Haushalt der Pflanze spielen. Wir werden zu diesem Zweck hauptsächlich in's Auge fassen müssen, in welcher Weise das Vorkommen derselben an der einzelnen Pflanze und im Pflanzenreich vertheilt ist.

Wir finden nun solche Gewebe ganz besonders häufig an del Ob erseite von Blättern: in den allermeisten Fällen sind sowohl mehrfache Oberhaut als Hypoderma auf diese Blattläche beschränkt, selten kommen sie beiden, niemals, so weit bekannt, der unteren allein zu. Es verhält sich damit also etwa umgekehrt, wie mit den Spaltöffnungen, doch kann deren Anwesenheit an der Blattunterseite nicht als unmittelbar das Auftreten von epidermidalen Schichten ausschliessend betrachtet werden, da ja beide Gebilde sich bei Begonia a. A. gleichzeitig finden. Die früher den verdickten, starren Formen dieser Gewebe zugeschriebene Bedeutung, dass sie nämlich die Festigkeit der Blätter vermehren sollen, ist, wie Thomas ${ }^{2}$ ) nachwies, zwar nicht so zu verstehen, dass alle festen Blätter solche Schichten besitzen, doch kann eine Wirksam. keit der letzteren in dieser Richtung wohl kaum bezweifelt werden. Ferner scheint es mir, als ob auch der spiegelnde Glan\% vieler Blattoberseiten wenigstens häufig auf der Anwesenheit blatgrünfreier oberflächlicher Gewebe beruhe. Man kann zwar wieder nicht behaupten, dass alle glänzenden Blätter solche besitzen -wohl aber möchten alle von derartigen Schichten begrenzten Blatt. oberseiten das Licht stark reflectiren, sofern nicht Behaarung, Athemhöhlen dies beeinträchtigen. Es wäre dann die starke Entwicklung verdickter blattgrünfreier Schichten auf die Intensităt des ins Chlorophyll enthaltende Gewebe eindringenden Lichts einen merklichen Einfluss üben. Ganz besonders möchte diese Bemerkung Anwendnng finden auf die die Sonnenstrablen so sehr stark zurückwerfenden Blätter vieler Begonien, Cyanotis u. A.

Doch kommen bei den letzteren Formen, da hier die Wasser-

1) a. a. 0.5 .35 .

2) a. a. 0 . S. 31.32 . 
gewebe auch auf der Blattunterseite rorkommen, noch andere Gesichtspunkte in Betracht, welche ausschliesslich massgebend da sind, wo blattgrünfreie Schichten ganz im Innern des Gewebes sich finden. Es ist dies der Fall bei den Phyllodien mancher Acacien und den gleichfalls lederartigen und senkrecht gestellten Blättern von Callistemon, bei welchen Beiden die abweichende Richtung des Blattes zur Beleuchtung für die Lage des farblosen Gewebes bedingend sein mag. Ein sehr umfangreiches Wassergewebe in Mitten ilurer Blätter zeigen auch manche Fettpflanzen (Mesembryanthemum, Aloo). Wir werden bei diesen uns darauf beschränken müssen, anzunehmen, dass dic Aufspeicherung von Flüssigkeit als solche für diese Gewächse von Vortheil sei. Es ist dies auch leicht begreiflich, da dieselben gauz vorzugsweise die dürrsten Gegenden bewohnen. Meist tritt dabei keine Sonderung von assimilirendem und nur Flüssigkeit führendem Gewebe ein (Dischidia, Crassula, Sempervivum, viele tropische Orchideen); bei anderen Pflanzen ist dieselbe sehr scharf, und zwar liegt, wie schon bemerkt, das Wassergewebe bald im Innern, bald dicht unter der Oberfläche. Einen schönen Uebergang zwischen diesen beiden Verhältnissen bieten dic Blätter mancher Mesembryanthema und namentlich von Aloe cuspidata, planifolia, tessellata, atrovirens. Dieselben besitzen ein mittleres, sehr ausgedehntes Wassergewebe, welches, wie der Blattquerschnitt von Aloe cuspidata, Taf. VI. Fig. 20 lehrt, nur ron ciner ganz dünnen (grau gezeichneten) Schicht Chlorophyll enthaltender Zellen umgeben ist. Dieselbe ist aber noch vielfach durchbrochen und an diesen, von aussen dem blossen Auge grau erscheinenden Stellen reicht dann das farblose Gewebe von der Mitte des Blattes bis zur Oberhaut. Wenn wir nun auch nicht immer einsehen könuen, von welchen Ursachen die Vertheilung des Wassergewebes im Blatt bestimmt wird, so ist doch die Bedeutung desselben im Haushalt der Fettpflanzen eben durch deren Standort klar. Es liegt nahe zu untersuchen, in wie weit auch diejenigen Gewächse, welche starke wasserführende epidermidale Schichten besitzen, durch ihre Lebensweise auf die Bildung derselben angewiesen sind.

Wir finden nun solche Gewebe von in Verhältniss zum Mesophyll erheblichem Umfang bei Commelinaceen, Scitamineen, Bromeliaceen, Orchidaceen, Cyrtandraceen, Piperaceen und Begoniaceen. Alle diese Pflanzen gehören heissen Climaten an: nur die wenigsten. sind Steppenbewohner, aber auch bei den übrigen zeigt 
sich eine Beziehung zwischen Standort und Bau. Es scheinen nun dieselben dabei sich gut unter zwei Gesichtepunkte zu ordnen.

Zu der ersten Gruppe rechne ich die Gattungen Maranta, Canna, Costus und andere Scitamineen. Es sind das Gewächse mit sehr grossen, dünnen Blättern von meist zartem Gefüge, meist Bewohner lichter Waldstellen und feuchter Wiesen $\left.{ }^{1}\right)$. Wir dürfen bei ihnen wohl annehmen, dass die wasserreichen epidermidalen Schichten, aufgebaut mit wenig organischer Substanz, aber oft an beiden Blattseiten dem sehr dünnen Mesophyll an Umfang gleich, die Blätter durch bedeutende Vermehrung ihrer Dicke widerstandsfäiger machen. Ausserdem aber steht namentlich zu vermuthen, dass bei der ungemein starken Verdunstung, welche diese grösstentheils frei der tropischen Sonne ausgesetzten Pflanzen vermöge ihrer grossen, zarten Blätter erleiden müssen, das oberflächliche Wassergewebe im Stande sein wird, für eine Weile den Bedarf der assimilirenden Schichten zu decken, wenn einmal die Transpiration über die Wurzelkraft das Uebergewicht bekommen sollte. Eine vermittelnde Stellung zwischen dieser Gruppe und den S. 63 besprochenen Pflanzen nehmen nach dem allgemeinen Bau und nach der Vertheilung des Wassergewebes die Musaceen ein, deren riesige, mehr lederartige Blätter nur auf ihrer Oberseite einigermassen erhebliche farblose Schichten besitzen.

Die zweite Reihe, zu welcher gerade die durch die gewaltigsten, bisweilen dem Mesophyll siebenmal an Dicke überlegenen, oberflächlichen Wassergewebe ausgezeichneten Gewächse gehören, scheint auf den ersten Blick kaum etwas Gemeinsames zu bieten. Und doch verbindet auch sie eine bestimmte Lebensweise: es sind wie ich gleich zeigen werde, vorzugsweise Felsbewohner und Epiphyten.

Begiunen wir diesen Nachweis mit den noch verhältnissmässig die schwächsten Wassergewebe besitzenden Formen, den Begonien und Tradescantien. Es stehen diese gleichzeitig wegen ihrer grossen, leicht welkenden, also sehr stark verdunstenden Blätter und des Vorkommens der farblosen Schichten auf beiden Blattseiten noch der vorigen Gruppe sehr nahe - andererseits sind sie durch ibren Standort verschieden. Leider kommt gerade bei ihnen der geringe Umfang unserer Kenntnisse von der Lebensweise tropischer Pflanzen uns recht zum Bewusstsein. Von denjenigen diesen Gattungen

1) Vergl. Spix u. Martius, Reisen in Brasilien III. S. 20.

Jahrb. fo wiss. Botanik. VIII. 
angchörigen Arten, welche ich selbst zu untersuchen Gelegenheit hatte, habe ich nur bei einer einzigen eine bestimmte Angabe gefunden. Wir bleiken also daraut angewiesen, die allgemeinen Wohnorte der Gattung ins Auge zu fassen.

Von Tradescantia discolor und Cyanotis zebrina sind solche nicht bekannt; ${ }^{1}$ ) doch spricht der schlaffe Habitus der letzteren, ihr Wachsthum in unseren Gewächshäusern und ihr Reichthum an Luftwurzeln für Epiphytismus. Andere Cyanotis-Arten bewohnen nachweislich Baumstämme. ${ }^{2}$ )

Von der Lebensweise der Begonien giebt Martius ${ }^{3}$ ) folgende Schilderung: „Multae humiditatis sunt indiguae, ob laxam compagem et succorum turgescentiam. Huic usui pleraeque satisfaciunt statione humida, opaca. Sunt tamen nonnullae, quae locis apricis super arida saxa crescunt, ita mexicana Begonia peltata... rupium graniticarumcalidalateravestit. B. parvifolia montium sicca cacumina incolit, pleraeque vero ...... per loca uda, densa et vaporosa umbra fota propter scaturigines et rivulos in pingui et fragosa humo radicantur, aliae rupibus applicitae, aliae vetustarum arborum radici. bus aut super ligna putrida radicantes. "Er fügt hinzu, dass manche Arten bis 20 Fiss über dem Erdboden auf den Bäumen vorkämen. De Candolle ${ }^{4}$ ) führt bei seiner Aufzählung von 349 sicheren Begoniaceen nur bei $72 \mathrm{mehr}$ an als das Vaterland. Von diesen 72 Angaben sind:

$$
\begin{aligned}
& 45\left\{\begin{array}{l}
22=\text { in silvis, in nemoribus, } \\
15=\text { in silvis umbrosis, densis u. s. w., } \\
8=\text { in humidis, ad fossas, in paludibus u. s. w., }
\end{array}\right. \\
& 27\left\{\begin{array}{l}
8=\text { locis rupestribus, praeruptis u. s. w., } \\
5=\text { in saxosis, petrosis siccis u. Aehnl., } \\
8=\text { in saxis, ad rupes, } \\
6 \text { ad truncos arborum, }
\end{array}\right.
\end{aligned}
$$

es entsprechen demnach 27 von 72 d. h. $\frac{3}{8}$ der oben gemachten Behauptung und dabei sind die 37 ersten Standortsangaben so unbestimmt, dass man sie kaum überhaupt rechnen kann. Da aber die Unvollständigkeit unserer Kenntnisse bei dieser Familie so weit

1) Vergl. Walpers Annales III. 661, Kunth Enumeratio IV. 85.

2) $" \quad$ VI. 164.

3) Flora brasiliensis Fasc. XXVII. S. 394.

4) Prodromus system, natur. vegetab. XV. S. 266. 
geht, dass von $\frac{1}{5}$ aller Arten gar nichts über die Art und Weise ihres Vorkommens bekannt ist, so ist hier kaum ein Schluss möglich. Die B. peltata, welche Martius oben als einen Bewohner der trocknen, heissen Granitfelsen nennt, habe ich untersucht; sie hat von allen Begonien, die ich sah, die stärkste mehrfache Oberhaut. -

Günstiger gestaltet sich die Sache bei den nun folgenden Formen, welche zum grössten Theil durch den Umfang ihrer Wassergewebe förmlich fleischige Blätter haben.

Bei den Bromeliaceen kann es nicht zweifelhaft sein, dass die meisten Epiphyten sind. Martius ${ }^{1}$ ) sagt von ihnen: sie „treten bald parasitisch an Bäumen auf, bald einzeln oder in zahlreichen Haufen über F'elsen und den kahlen Erdboden verbreitet" und an einer anderen Stelle ${ }^{2}$ ) gerade ron den Gattungen, zu denen die von mir untersuchten Arten gehören „Pitcairniae, Billbergiae, Aechmeae, Tillandsiae, Hohenbergiae aliaeque imprimis inveniuntur in cavis locis truncorum ramorumque qui in directum aut obliquum ascendunt." Unter den 18 Arten aus diesen Gattungen, welche R. Schomburgk ${ }^{3}$ ) nennt, sind 14 Epiphyten; eine Art bewohnt Granitfelsen und Bäume, eine erstere ausschliesslich und 2 felsige Stellen. Kunth ${ }^{4}$ ) bezeichnet die Tillandisien als „herbae saepissime parasiticae ", Olaf Swartz ${ }^{5}$ ) nennt bei allen von ihm aufgeführten Arten als Standort Baumstämme, während nach denselben beiden Beobachtern die Pitcairnien auch an Felsen viel vorkommen. Obgleich nun aber nach alledem die Thatsache, dass die genannten Gattungen rorwiegend Epiphyten enthalten, nicht zweifelhaft sein kann, finden wir doch bei vielen einzelnen Arten keine Standortsangaben, vielleicht gerade deshalb, weil der Epiphytismus von Billbergien u. s. w. den Sammlern so selbstrerständlich erschien, dass sie darüber keine weitere Bemerkung machten. In der Aufzählung der Bromeliaceen bei Schultes ${ }^{6}$ ) habe ich hinsichtlich der von mir untersuchten Arten nur eine Angabe

1) Reiso III. S. XVII.

2) - Tabulae physiognomicae explicatae S. LII.

3) Reisen in Britisch Guyana III. S. 903, 1067, 1121.

4) Synopsis plantarum aequinoctialium, quas in itinere ..... colleg. Humboldt et Bonpland. Tomus I. S. 294.

5) Flora Indiae occidentalis I. S. $578 \mathrm{ff}$.

6) Linnaei Systema Vegetabilium. Tom. VII. 2. S. 1252. 
gefuudev, bei Hohenbergia (Acanthostachys) strobilacea: in campis alpestribus Prov. Minas Geraes. In seiner Schilderung der Camposflora des Hochlandes dieser Provinz - denn deren baumreiches Gebict ist doch mit den obigen Worten sicher gemeint und nicht etwa Alpenwiesen - nennt Martius, ${ }^{1}$ ) der die Pflanze zuerst fand, dieselbe nicht. Doch dürfen wir wohl auch auf sie die gerade von ihrem Entdecker gegebene Charakteristik der Standorte der Hohenbergien (vgl. oben) beziehen.

Die Peperomien nennt der Prinz ron Neuwied ${ }^{2}$ ) als gewöhnliche Zierden der Baumstämme in Brasilien, Miquel, ${ }^{3}$ ) ibr Monograph, bezeichnet sie im Allgemeinen als , aut terrestres aut supra arborum truncos vetustos rupesque madidas muscosasque luxuriantes", auch R. Schomburgk*) nennt mehrere als Epiphyten. Miquel zählt 190 Arteu auf, ron welchen 71 , d. h. beinahe $\frac{2}{3}$ mit Standortsangaben versehen sind; 23 davon sind unbestimmt: in silvis u. s. w. Es finden sich: 11 species in locis scopulosis, in saxosis, 8 ad saxa, 10 ad truncos, 17 ad truncos et $s a x a$, 2 intes muscos. Es kommen also von den, nur irgend in ihrer Lebensweise bekannten 71 Arten die Hälfte (35) an Felsen und Baumstämmen, 11 an felsigen Orten vor, so dass im Ganzen etwa i nachweislich der gemachten Hypothese genügen. Dieselbe wird aber, ausser durch dies günstige Verbältuirs, noch dadurch unterstützt, dass gerade über die untersuchten Peperomicu einige Angaben vorhanden sind. P. blauda nent Kunth, $\left.{ }^{5}\right)$ P. pollucida Martius $^{6}$ ) und Schomburgk ${ }^{7}$ ), P. magnoliifolia Schomburgk ${ }^{7}$ ) als baumbewohnend; letztere komint nach Perottet ${ }^{8}$ ) auch an Felsen vor. P. incana ist nach Martius ${ }^{9}$ ) ,heliophila " und findet sich ,in rupibus graniticis apricis." 10 )

Die Gattung Aeschynanthus lebt durchaus epiphytisch. Wo bei den von De Candolle aufgeführten Arten eine Angabe über

1) Reise. Band II. S. 463 .

2) Reise in Brasilien II. S. 253.

3) Monographia Piperacearum I. S. 64.

4) a. a. 0. S. 1074.

5) a. 2. 0. I. S. 120.

6) Flora brasiliensis Fasc. XI. S. 10.

7) a. a. 0. S. 1129.

8) Bei Miquel a. a. 0. S. 98.

9) Flora brasiliensis Fasc. XXVII. S. 394.

10) Flora brasiliensis Fasc. XI. S. 24. 
den Standort gemacht ist ( $\frac{1}{3}$ der spec.) sind als solcher Baumstämme genannt; nur von einer Art wird gesagt, dass sie auch an der Erde vorkomme. Ae. ramosissima Wallich, welche ich untersuchte und welche ein bedeutendes Wassergewebe besitzt, wird bezeichnet als "super arbores rupesque radicans".

Von den vier Orchideen, bei denen starke epidermidale Schichten nachgewiesen sind, ist Pleurothallis ruscifolia nach Schomburgk, ${ }^{1}$ ) Lepanthes cochleariifolia nach Olaf Swartz ${ }^{2}$ ) ein Baumbewohner. Welche Art von Stelis Meyen untersuchte, ist nicht bekannt, ein genauer Nachweis des Standorts daher nicht möglich. Doch nennt Kunth ${ }^{3}$ ) die Formen dieser Gattung im Allgemeinen „Herbae parasiticae, rarius bulbiferae". Ueber Physosiphon habe ich keine Angabe finden können.

Ich glaube damit den Nachweis, dass die Gewächse mit umfangreichen oberflächlichen Wassergeweben vorzugsweise an Bäumen und Felsen vorkominen, so weit geführt zu haben, als dies bei der Mangelhaftigkeit unseres Wissens über die Lebensweise tropischer Pflanzen überhaupt zu erwarten stand. Dass aber gerade die Bewohner derartiger Standorte, auch wenn die sic umgebende Luft sehr feucht ist, besondere Veranlassung haben, sich für den Nothfall mit Wasser zu versorgen, indem sie solches bei günstigem Wetter in ihren Geweben ansammeln, scheint mir klar; auch hat bei den Orchideen schon Sachs ${ }^{5}$ ) eine hierauf bezügliche Bemerkung gemacht. Die Pflanzen sind ja nach den Untersuchungen von Unger ${ }^{6}$ ) nicht im Stande, gasförmiges Wasser sich anzueignen. Die epiphytischen und an Felsen lebenden Gewächse werden aber, da bei der Abschüssigkeit und der geringen oder mangelnden Erdbedeckung ihrer Wohnorte tropf bares Wasser schnell abfliesst, nur zeitweilig in der Lage sein, mittelst ihrer Wurzeln solches aufzunehmen. Es ist aber ferner von Unger nachgewiesen worden, dass welke Pflanzen, wenn nur ihre Verdunstung beschrankt wird, ilıre Straffheit und Frische dadurch wieder gewinnen, dass die Wände der Zellen dem Inhalt derselben Flüssig-

1) Prodromus IX. S. 260.

2) a. a. 0. S. 904.

3) a. a. O. III. S. 1563.

4) a. a. I. S. 294 .

5) Experimentalphysiologie der Pflanzen S. 197.

6) Sitzungsher. d. Wiener Acarlemie IX. S. 885. 
keit entziehen. Bei den mit umfangreichen Wassergeweben ausgestatteten Gewächsen wird dieser Vorgang sich, namentlich in der feuchten Atmosphäre des Urwaldes, sehr oft wiederholen können, da eine so bedeutende Menge Flüssigkeit ausserhalb der assimilirenden Schichton und in deren unmittelbarer Nähe vorhan. den ist.

Was die Beschränkung der eine erhebliche Dicke errei chenden Wassergewebe auf die Blattoberseite betrifft, so glaubeich, dass diese, allen beobachteten Fällen gemeinsame Erscheinung daranf berubt, dass Spaltöffnungen bei den betreffenden Pflanzen nur an einer Blattseite entwickelt werden. Wir können aber Letzteres wieder dadurch erklären, dass ihnen eine sehr grosse Verdunstung ihres Standorts wegen leicht gefährlich werden könnte. Dies zugestanden, muss man es aber wohl als die passendste Anordnung bezeichnen, wenn die Stomata an der der Sonne abgewandten Blattfäche, das assimilirende Gewebe ihnen zunächst und die Wasser führenden Schichten an der Blattoberseite liegen. Die letzteren können gerade hier selbst noch von unmittelbarem Nutzen sein. Vermuthlich hindert nämlich ibre beträchtliche Dicke - bis 2 Millim. - zwar den Zutritt des Lichts zum grünen $\mathrm{Pa-}$ renchym nicht merklich, wohl aber den der strahlenden Wärme. Hinsichtlich der ersteren Behauptung genüge es darauf hinzuweisen, dass die starken epidermidalen Schichten der Blattoberseite in keinem bekannten Fall dunkel gefärbte Säfte enthalten, was an der Unterseite häufig vorkommt. Auch die S. 29 von Peperomia galioides und rubclla angeführte Thatsache beweist, dass die Durchsichtigkeit der Wassergewebe, auch bei bedeutendem Durchmesser, eine sehr grosse ist und selbst die dünnen Sklerenchymlagen von Acanthostachys u. s. w. möchten dieselbe kaum wesentlich beein. trächtigen. Dagegen wissen wir, dass schon eine eiren halben Millimeter dicke Schicht reinen Wassers je nach den Wärmequellen $\left.{ }^{1}\right)$ nur 8,7 bis $25,1 \mathrm{pCt}$. der auf sic einwirkenden Wärmestrahlen durchlässt, und dass die Menge der nicht absorbirten Strahlen bei einer 2 Millimeter dicken Wasserschicht auf 3,2 bis 13,9 pCt. sinkt. Da nun gleichzeitig alle Flüssigkeiten sehr schlechte Wärmeleiter sind, so liesse sich wohl denken, dass durch das Vorhanden

1) Die Versuche sind mit irdischen Wärmequellen angestellt; die Zahlen würden wohl aber auch für Sonnenwärme nicht sehr anders werden. Vergl, MüllerPouillet, Lehrbuch d. Physik 6. Aufl. II. S. 740. 
sein eines epidermidalen Gewebes von der bezeichneten Dicke der Einfluss der strahlenden Wärme auf die assimilirenden Zellen und somit auch die Verdunstung ganz erheblich gemildert werde, namentlich wenn, wie bei vielen der betreffenden Pflanzen, gemäss ibren Standorten angenommen werden kann, dic Insolation nur zeitweilig und nicht lange andauernd ist. Die Anwesenheit der Zellwände möchte dabei der zahlreichen Reflexionen wegen eher förderlich als schädlich sein. Ich will hier auf die Bedeutung dieser Verbältnisse nur hindeuten; nur umfassende Versuche können dabei volle Klarheit geben. Auffallend bliebe es immer, dass die anscheinend so vortheilhafte Sonderung des Wassergewebes nicht bei den fleischigen Blättern weiter verbreitet ist.

Dass übrigens bei den Orchideen diese letzteren und bei den dünnblättrigen Arten derselben Familie die Bulbi Wasserbehälter für den Nothfall seien, vermuthet bereits Martius.') Auch d:e nach S. 39 in den Kreis der mehrfachen Oberhaut gehörigen Wurzelhüllen haben in dieser Hinsicht Bedeutung. Man schreibt denselben meist nur die Fähigkeit zu, als poröse Körper Wasserdünste zu verdichten. Sollten sie aber nicht im Stande sein, sich bei dem mit so grosser Gewalt ${ }^{2}$ ) fallenden Regen der Tropenländer mit Wasser zu erfüllen und dieses dann wie ein Schwamm längere Zeit in der Nähe der - wie Leitgeb ${ }^{3}$ ) wohl mit Recht vermuthet - wasseraufnehmenden dünnwandigen Zellen der Endodermis zu erhalten? So würde dem allzuschnellen Abfliessen des Regenwassers doch einigermassen Einhalt gethan.

Auch sind die bisher angeführten nicht die einzigen Waffen, welche den Epiphyten im Kampf um ihr Dasein mit den äusseren Verhältnissen und den Mitbewerbern zu Gebote stehen. Manche baumbewohnende ${ }^{4}$ ) Aroideen (Philodendron cannifolium) haben ausser den Luftwurzeln noch dickfleischig angeschwollene, wassererfüllte Blattstiele. Viele Bromeliaceen sammeln nach Martius ') in ihren zu einer festen Röhre zusammengeschlossenen Blättern, oder in den tiefe und weite Höhlen bildenden einzelnen Blattachseln grosse Mengen von Thau und Regen auf und erhalten sich dies Wasser selbst in der trocknen Jahreszeit. Dabei ist

1) Reise Tabul. physiognom. explicatae S. XXXIV.

2) Vergl. Reise III. Band Cap. I.

3) a. a. 0. S. 215.

4) Reise Tabul. physiognom. explicatae S. XLIX. 
noch zu bemerken, dass, soweit meine Untersuchungen reichen, gerade die Billbergien und Aechmeen, die vermöge ihres Baues zu dieser Art der Wassererwerbung besonders geeignet sind, $\mathrm{schwache}$ epidermidale Schichten, die Tillandsia acaulis, vittata und die Acanthostachys dagegen, deren Blätter keine Röhren oder Höhlen bilden, umfangreiche Wassergewebe besitzen.

Der Gesammterfolg dieser vielen schützenden Vorrichtungen ist nicht gering anzuschlagen. Von den Bromeliaceen berichtet Martius, ${ }^{1}$ ) dass sie auch in den Monaten der Dürre, wenn die sie tragenden Bäume blattlos dastehen, den Glanz ihres Laubes nicht verlieren, und sogar reichlich blühen. ${ }^{2}$ ) Von einer, mit zahlreichen langen Bulbis und grossen fleischigen Blättern versehenen Orchidee aber, der Aërides odorata, versichert Loureiro, ${ }^{3}$ ) dass sie in freier Luft aufgehangen, durch viele Jahre hindurch wachse und blühe, ohne je von Aussen Wasser zu empfangen.

Wir haben nach alledem wohl anzunehmen, dass die physiologische Bedeutung der epidernidalen Wassergewebe hauptsächlich darin liegt, dass sie eines der vielen Mittel darstellen, durch welche Bewohner ungünstiger Standorte sich den letzteren anpassen. Eine denselben Zweck erreichende, aber auf anderen Grundsätzen beruhende Vorrichtung haben wir in dem im vorigen Heft dieser Jahrbücher enthaltenen Aufsatz über das Hautgewebe der Restionaceen kennen gelernt.

1) Reise Band III. S. XVII.

2) Reise Tab. physioga explic. S. XXXTV.

3) Flora Cochinchinensis II. S. 642. 


\section{Erklärung der Tafel VI.}

Fig. 1-5. Peperomia peireskiifolia.

Fig. 1. Theil eines Blattquerschnitts bei schwacher Vergrösserung. Eo obere, Eu untere Epidermis, F das durch Wucherung aus der ersteren entstandene umfangreiche Wassergewebe. P Pallisaden-Parenchym, S schwammiges Parenchym.

Fig. 2. Theil eines Querschnitts eines jungen Blatts bei starker Vergrösserung. Bezeichnung wie in Fig. 1. Die obere Epidermis erst ein- bis zweimal getheilt.

Fig. 3. Aehnlicher Schnitt aus einem etwas älteren Blatt mit schon 5-6 Zellen starkem Wassergewebe F.

Fig. 4. Querschnitt eines in der Jugend am Rande verletzten Blatts bei schwacher Vergrösserung. Die Wundfläcke (in der Figur links) ist durch eine oberhautähnliche Neubildung geschützt. Vgl. S. 40 des Textes.

Fig. 5. Die linke obere Ecke der vorigen Figur bei starker Vergrösserung. E Zellen der äussersten Oberhautschicht, $\mathbf{N}$ ähnliche Zellen der Neubildung.

Fig. 6-8. Peperomia rubella.

Fig. 6. Wenig vergrösserter Querschnitt durch ein erwachsenes Blatt. S schwammiges Parenchym, Eo die zu einem dicken Wassergewebe entwickelte mehrfache Oberhaut.

Fig. 7. Querschnitt eines jungen Blatts derselben Art mit noch nicht so dicker mehrfacher Epidermis.

Fig. 8. Erste tangentiale Theilung der letzteren, sichtbar am Querschnitt von der Oberseite eines ganz jungen Blatts. $\mathrm{P}$ die Mutterzellen des Parenchyms.

Fig. 9. Begonia manicata.

Fig. 9. Theil eines Blattquerschnitts. E obere, $E_{\text {u }}$ untere Epidermis, beide durch Theilung mehrere Zelllagen stark. $\mathrm{P}$ pallisadenförmiges, $\mathrm{S}$ schwammiges Parenchym.

Fig. 10-11. Arbutus Unedo.

Fig. 10. Querschnitt von der Oberseite eines noch jungen Blatts mit noch einfacher Epidermis $\mathbf{E}_{0}$.

Fig. 11. Gloicher Schnitt von einem erwachsenen Blatt: die Epidermis hat durch Theilung zwei Schichten E und F gebildet.

Fig. 12. Pittosporum Tobira.

Fig. 12. Querschnitt durch die, stellenweise durch Theilung verdoppelte Oberhaut der oberen Blattseite.

Fig. 13. Tradescantia discolor.

Fig. 13. Theil eines Blattquerschnitts. E die stets ungetheilt bleibende Oberhaut, W aus dem Grundgewebe entstandenes Wassergewebe, A Athemhöhle. 


\section{Fig. 14-17. Acantbostachys strobilacea.}

Fig. 14. Wenig vergrösserter Blattquerschnitt. W das dem Grundgewebe entstammende umfangreiche Wassergewebe.

Fig. 15. Querschnitt durch zwei sich umfassende jnnge Blätter derselben Pflanze.

Fig. 16. Querschnitt durch die Oberhaut und die nächst benachbarten Zellschichten der Oberseite eines erwachsenen Blatts.

Fig. 17. Aehnlicher Schnitt ron einem jutigen Blatt. T ror Kurzem getheilte Zelle der von aussen zweiten Schicht.

\section{Fig. 18-19. Nerium Oleander.}

Fig. 18. Wenig vergrüsserter Querschnitt eines jungen Blatts.

Fig. 19. Theil eines Quersehnitts von der Unterseite eines solchen: Entstehung der Gruben, in deren Grunde später die Spaltöffnungen auftreten werden.

Fig. 20. Aloe cuspidata.

Fig. 20. Blattquerschnitt. W farbloses Gewebe.

Fig. 21. Dracaena reflexa.

Fig. 21. Oherhaut, des Blatts von der Fläche gesehen, mit gefächerten Zellen. 


\section{Die Anatomie und die Mechanik der Spaltöffnung.}

(Als Fortsetzung zu ,Diffusion der atmosphärischen Gase u. s. f. ")

Von

Dr. N. J. C. M üller.

Docent der Botanik in Heidelberg.

(Mit Tafel IV und V.)

\section{Wirkung der Wärme innerhalb der Temperatur- grenzen des gewöhnlichen Lebeps.}

In einer an ausgezeichneten Experimenten reichen Abhandlung bat Hugo von Mohl zuerst die Mechanik des Oeffnen und Schliessens der Spaltöffnungen dargelegt. Die Fragen, welche sich iber die Bedeutung derselben am Pflanzenkörper aufwerfen lassen, sind zum Theil beantwortet, wenn man über die Ursache derjenigen Bewegung im Klaren ist, welche beim Oeffnen und Schliessen ron den Schliesszellen vollführt wird. In der Mohl'schen Abhandlung, welche ich als Ausgang zu den vorliegenden Untersuchungen ansehe, wurde an einigen Monocotyledonen der Bau des Spaltöffnungsapparates demonstrirt und diejenigen Formen als Untersuchungsmaterial gewählt, welche der experimentellen Erforschung an zugänglichsten waren. Es besitzen die dort untersuchten Pflanzen sehr grosse Spaltöffnungen.

Da die meisten der Untersuchungen microscopische sind und eine starke Vergrösserung erforderten, war es nöthig, den Apparat bis in die kleinsten Einzelheiten zu beschreiben.

Nach der Mohl'schen Benennung kann man die Messungen behufs der Beobachtung über Oeffnung und Schliessung des Interzellularraums an folgenden Linien anstellen:

1) An der Einfügungsstelle der Sc.liesszelle an die augrenzende Epidermiszelle. aa. Fig. 12.

2) An der Grenze des Cuticularbügels der Vorhofsspalte nach der Fläche der Epidermis hin. c Fig. 10. 11.

3) An der Vorhofspalte. e. Fig. 10. 11.'12.

4) An dem Spalte sclbst. Fig. 2. 7. 11. 12.

Dieselben Messungen können an ähulichen Linien der Unterseite (Wundfläche) angestellt werden. 
Die v. Mohl'schen Messungen beziehen sich auf die Weite des Spaltes.

Durch eine Reihe einfacher Experimente weist $\nabla$. Mohl nach, dass der Spalt bei Berührung der Zellen mit Wasser geschlossen wird; so die Mehrzahl der untersuchten Pflanzen. Als geeignetstes Demonstrationsobjekt wurde Amaryllis formosissima angewendet. Bei wenigen Pflanzen öffnet oder erweitert sich der Spalt bei Berührung mit Wasser; so die Orchideen und Liliumarten.

In diesem auffalligen Verhalten ist die Einwirkung des Wassers als eine Ursache der Bewegung der Schliesszcllen unverkennbar. Welcher Art diese Wirkung ist, scheint mir aber nicht möglich nach den v. Mohl'schen Experimenten zu entscheiden und die v. Mohl'sche Darstellung eines Antagonimus zwischen Epidermiszellen und Schliesszellen, welcher in verschiedener endosmotischen Spannung der Zellinhalte seine Ursache haben soll, einer Prüung bedürftig. Die v. Mohl'schen Experimente sind die folgenden:

1) Die geschlossenen Spalten öffinen sich bei Amaryllis im Wasser, wenn die Nachbarzellen der Schliesszellen durch Anschneiden geöffnet sind.

2) Die vorher offenen Spalten derselven Pflanzen schliessen sich, wenn das unverletzte Blatt in Wasser gelegt wird.

3) Zuckerwasser bringt die im ersten Experimente geöffneten Spalten zum Schliessen; Anwendung von Wasser öffnet biernach den Spalt wieder. Dies sind die Beobachtungen bei den Amaryllideen.

4) Die Spalten unverletzter Blätter und der abgezogenen Epidermis öffnen sich in Wasser, mag der etwaige endosmotische Druck der angrenzenden Epiderminzellen eliminirt scin oder nicht, bei Lilium tigrinum, candidum und den Orchideen.

5) Dieselben schliessen sich, wenn Zuckerwasser angewaudt wird und öffnen sich wieder, wenn man mit Wasser nachspült. Hieraus schliesst v. Mohl zunächst, dass bei Amaryllis, der Einfluss vom Wasser die Spalten immer öffnen würde, wenn nicht der durch Wasseraufnahme bewirkte Druck der Epidermiszellen manchmal hindernd wirkte. Dies zugegeben, wäre nach der Differenzmethode, wenn sie streng durchgeführt wird, noch ein Umstand zu suchen, welcher nicht beiden Gruppen von Spaltöffungen gemein ist; nämlich den Liliumarten, Orchideen einerseits und Amaryllideen und der Mehrzahl der untersuchten Pflanzen andererseits. Dieser Umstaud ist gefumlen in der verschiedenen Lage 
(von Mohl macht hierauf schon aufmerksam) der Sehliesszellen zu den Epidermiszellen.

Die Ergebnisse der Mohl'schen Untersuchungen lassen folgende inductive Behandlung $\mathrm{zu}$ :

Die Spalten der einen Gruppe: Amaryllis, Zea, Haemanthus und andere (s. v. Mohl) schliessen sich unter Umständen, unter welchen die Spalten der anderen Gruppe sich öffnen (Orchideen Liliaceen).

Erste v. Mohl'sche Voraussetzung: Das Wasser wirkt allein dadurch formändernd auf die Schliesszellen, dass diese dasselbe einsaugen, weil sie endosmotisch kräftiger wirkende Zellinhalte führen als die Epidermiszellen.

Zweite v. Mohl'sche Voraussetzung: Die Spaltöffnungen der ersten Gruppe und die der zweiten unterscheiden sich nur durch einen Umstand. Derselbe ist in der anatomischen Lage der Schliesszellen gefunden.

Folgerung: Die Verschiedenheit der Lage der Schliesszellen oder deren Folge ist die Ur'sache oder cin Theil der Ursache des verschiedenen Verlaufes einer und derselben Reaction bei den 2 Gruppen.

Prüfung der 2. Voraussetzung. Der Umstand, welcher die beiden Gruppen unterscheidet, wird beseitigt, indem das erste Mohl'sche Experiment angestellt wird, oder dadurch, dass man ein wasserentzielendes Mittel anwendet, welches den seitlichen Druck der Epidermiszellen allein entfernt, ohne die endosmotische Wirkung der Schliesszellen zu lähmen. Der Erfolg ist nach v. Mohl: Die Gleicheit der in Betracht kommenden Eigensehaften bei beiden Gruppen von Apparaten und demnach gleicher Verlauf der Reaction mit Wasser: Die Spalten beider Gruppen öfinen sich nämlich.

Dies ist das Ergebniss der Mohl'schen Untersuchung, was den Einfluss des Wassers anbelangt.

Es ist auf diese Weise leicht möglich, einzusehen, dass der wichtigste 'Theil einer crneuten Bearbeitung des Gegenstandes die Prïfung der ersten Prämisse ist.

Der auf endosmotischer Wirkung beruhende Antagonismus zwischen Schliesszellen und Epidermiszellen bei Amaryllis wurde noch ron v. Mohl mit einem weiteren Experimente nachgewiesen. Abgewelkte Blätter dieser Pfanzen zeigen anfangs den Spalt geschlossen, in Wasser gelegt öfnet sich derselbe, also unter Umständen, wo er bei der frischen Pflanze geschlossen wird, wenn er 
vorher offen war. v. Mohl nimmt au, die Schliesszellen seien jetzt vorzugsweise wasserarm im Zelleninhalt. Durch Einlegen in Wasser vermögen sie durch raschere Wasseraufnahme den Druck der eben. falls Wasseraufnehmenden Epidermiszellflüssigkeit zu überwinden; der Spalt öffnet sich. Das Ende der Erscheinung ist nun aber "Schliessen der Spalten." Nach der Mohl'schen Auffassung erreichen die Epidermiszellinhalte später diejenige Füllung, welche es möglich maeht, dass die nach Erweiterung strebenden Schliesszellen zum Zusammenliegen ihrer deın Spalte zugekehrten Ränder gezwungen werden. Man sollte denken, damit, ich meine mit der letzten Schliessung, müsste jede weitere Aenderung des Apparates aufgehoben und dies die definitive Gleichgewichtslage sein. Ich werde später zeigen, dass das nicht der Fall ist.

Ich wende mich zu der zweiten der von v. Mohl entdeckten Ursachen.

Mit einer weiteren Experimentenreihe zeigt v. Mohl, dass das Bestreben der Schliesszellen auseinander zu weichen durch die Einwirkung von Licht und Wärme gesteigert wird.

Im Allgemeinen beobachtete $\nabla$. Mohl eine Erweiterung der Spalten bei allen den genannten Pflanzen in Folge der Insolation. Für Amaryllis, dem wichtigsten hier rorliegenden Untersuchungsobjekt, soll das folgende Verhalten gelten. Eine kurze Dauer der Einwirkung des Sonnenlichtes, wie sie bis zur ersten Hälfte des Vormittags möglich ist, soll den Epidermiszelleninhalten ein endosmotisches Uebergewicht verschaffen. Die Spalten schliessen sich, wenn sie in Wasser gebracht werden.

Eine 6stündige Insolation im dunstgesättigten Raum (Schnittfläche im Wasser) soll nun aber den Schliesszellen das endosmotische Uebergewicht vorschaffen, dadurch, dass in Folge der Lichtwirkung im Chlorophyll der Schliesszellen endosmotisch wirksame Körper neu gebildet werden: die Spalten haben nun das Maximum ihrer Weite und schliessen sich in Wasser nicht.

„Wenn ein Fall, in welchem die zu erforschende Naturerscheinung eintrifft, und ein Fall, worin sie nicht eintrifft, alle Umstände, mit Ausnahme eines einzigen, gemein haben, und dieser cine nur in dem ersten Fall vorkommt, so ist der Umstand, durch welchen allein die zwei Fälle sich unterscheiden, die Wirkung oder Ursache, oder ein nothwendiger Theil der Ursache der Naturerscheinung." Diese, in den experimentellen Wissenschaften jeden Moment angewandte Regel, können wir bei den nachfolgenden 
Beobachtungen gewissermassen als Prüfstein für alle Aussagen, einfachsten, wie complicirten Inhaltes anwenden. Nach derselben sind die Mohl'schen Experimente oben zusammengestellt und ist dieselbe dazu benutzt, an den zwei von Mohl gewählten Beispielen Amaryllis und Orchis latifolia (s. von Mohl a. a. O.) die Ursache des verschiedenen Verhaltens zu Wasser zu finden. Wir habeu gesehen, dass v. Mohl nur die 2. Prämisse geprüft hat mit 2 Instrumenten, welche oben genannt sind, dass die Prüfung der ersten Prämisse mit die wichtigste Aufgabe war, braucht nach der $\mathrm{Zu}$ sammenstellung nicht erst gesagt zu werden.

Was geschicht, wenn wir ein wasserentziehendes Mittel in die Nähe einer geschlossenen Zelle bringen? Die Zellwand verliert in jedem Raumelement Wasser, welches nach aussen wandert, und von dem Zellinbalte tritt Wasser in die Zellmembran. Die Zellwand wird also wasserärmer, und man weiss aus zahlreichen Untersuchungen, dass ein solcher [Eingriff die Ursache zu eigenthüm. lichen Bewegungserscheinungen werden kann. Auch der Zelleninhalt wird endlich ebenfalls wasserärmer und dadurch wird das Volum der Zelle kleiner. Die Bewegungserscheinungen, die an dem Spalt dadurch beobachtet werden, dass wir den ganzen System Wasser entziehen, können Folge sein der 2 Veränderungen, die durch die Wasserentziehung an dem System hergestellt wurden. Und hier kann wiederum nur die Differenzregel angewandt werden. Doch ist diese Aufgabe gerade sehr schwierig, wenn nicht unlösbar. Immerhin lautet die Folgerung unserer Betrachtung der Mohl'schen Ergebnisse: Die Veränderung des Systems kann in endosmotischer und in Spannungsveränderung gleichzeitig oder aber in jeder einzelnen allein ihre Ursache haben. Sind beide Eigenschaften gleich, so kann nur die anatomische Lage allein noch die Ursache des verschiedenen Verlaufs der Erscheinung sein.

Man kann von auffälligen Lagerungsarten der einfachsten Art bei den von mir untersuchten Monocotylenpflanzen wohl drei unterscheiden:

1) Die Schliesszellen liegen so, dass sie mit einer im Querschnitt planen Wand an die benachbarten Epidermiszellen gränzen, dahin gehören die Liliumarten a a.... Fig. 7. Der Hauptzug in der Flächenansicht solcher Spaltöffnungen ist die grosse Leichtigkeit, mit welcher bei starker Vergrösserung alle die Contours a a c c d d e e der Figur 7 (u. a. bei v. Mohl) gesehen werden, ohne Verschiebung der verticalen Einstellung des Microscops. 
2) Die Schliesszellen ragen, wie v. Mohl für Amaryllis und bei Clivia gezeigt, in die Epidermiszellen mit einer convexen Wand binein (s. a. Fig. 8 bis 11), so bei Haemathus puniceus und Amarylis und liegen, etwas tiefer wie dic freie Aussenfläche der Epidermis, sind aber so eingefügt, dass der durch die Vertiefang gebildete Trichter, welcher an die Vorhofsspalte gränzt, nahezu gleich demjenigen isi, welcher an die Hinterhofspalte gränzt.

Für diese beiden Arten der Einfügung sind die beiden Ansichten (freie Aussenfläche nach oben oder Wundfläche der abgezogenen Epidermis nach oben) nahezu (bis auf kleine Details in der Cuticula der Oberseite begründet) die gleichen. Hierher gehört denn auch mit Berücksichtigung der letzten Noten die Spaltöffnung der Aloearten Fig. 6.

3) Die Schliesszellen liegen nach innen gerückt, so bei Allium altaicum, dem besten Demonstrationsobject für diese Lagerung. Der Hinterhofstrichter ist kürzer und breiter als der Vorhofstrichter (Fig. 3, Fig. 1.2). Von Interesse ist ferner die Dicke und Ausdehnung der cuticularisirten Schichten am Schliesszellenaparate. Ich habe für diese Verhältnisse auf die Erklärung der Mohl'schen Zeichnungen zu verweisen.

Das zweite wichtige Verhältniss in unserer Untersuchung ist die Bestimmung des endosmotischen Vermögens der Schliesszellen zweier verschiedener Pflanzen A. und B. (s. oben) und dasjenige der Schliesszellen zu den Epidermiszellen. Im Allgemeinen sind, wie Mohl angegeben und wie leicht in jedem speciellen Fall nachgewiesen werden kann, die Schliesszellen reicher an Protoplasma und endosmotisch wirksamen Körpern, wie die angrenzenden Epidermiszellen. Um Anhaltspunkte bezüglich des Urtheils über das Einsaugungsvermögen der Inhalte der Schliesszellen zu gewinnen, bediente ich mich einer Scale, welche in verschieden verdünnten Glycerin oder Zuckerlösungen bestand. Der Nullpunkt der Scale ist destillirtes Wasser. Die erste Nummer ist ein Raumtheil Glycerin oder ein Gewichtstheil Zucker in einem bestimmten Raumtheil Wasser, dic 2 te Nummer 2 Raumtheile Glycerin in demselben Volum Wasser u. s. f. Diese aus 10 -20 Nummern bestehende willkürliche Scale ist vorräthig und wird von Zeit zu Zeit erneuert. In der Anwendung derselben wurde folgendermassen verfahren: Es wurde aus einem grösseren rechteckigen EpidermisStreifen eine genügende Anzahl schmalerer Läppchen geschnitten und in einer dünnen Wasserschicht auf Objectträgern vertheilt und 
zu je einem solchen Präparat in der Reihenfolge der Nummern der Scale die betreffende Glycerinlösung gefügt, bis die zu beobachtenden Erscheinungen eiutreten, nämlich: Schliessung resp. Oeffnung der Spalten oder Contraction des Protoplasma. Aus der bei einer niederen oder höheren Nummer erfolgenden Contraction des Protoplasma kann auf die endosmotische Capacität des Inbaltes der vorliegenden Zellen geschlossen werden.

Die dritte Methode, die wir noch zu betrachten haben nach der obigen Formel ist diejenige, welche zur Entdeckung der Verschiedenheit in der Spannung zweier verschiedenen Schichten in einem Flächenelemente der Epidermis, führen sollte.

Die abgezogene Epidermis verkürzt sich, zeigt dabei eine mehr oder weniger starke Krümmung, die sich beim Einlegen in Wasser verstärkt oder schwächt. Man hat zu bestimmen die Richtung der Krümmung. - Bei diesen Beobachtungen kommt es nicht nur an auf die Krümmung derjenigen Platte der Epidermiszellen, welche nach aussen liegen und cuticularisirt sind, sondern auch auf die Krümmung der ganzen Epidermis. Um sich zu überzeugen, ob es diese äussere Zellenwand ist, fertigt man an der abgezogenen Epidermis am besten Wiegeschnitte an, indem man sich bestrebt, ein rundes Scalpell möglichst in einer senkrecht zur Oberhautfläche stehenden Ebene hin und her zu wiegen. Es gelingt leicht (und leichter wie mit jeder anderen Methode), so dünne Schnitte herzustellen, dass diese sich umlegen auf die scharfe Kante der Epidermisfläche. Man fertigt auf diese Weise, sich dem Zufall überlassend, eine grosse Anzahl schmaler Streifchen an, von welchen die schmälsten dis zartesten Querschnitte durch die Epidermis sein können. Diese Wiegeschnitte sind entweder nach der Wundfläche oder nach der freien Aussenfläche concav oder starr und gerade. Es ist mir auf diese Weise gelungen, aus Spaltöffnungen eine mittlere dünne Lamelle Fig. 2, $7,8,9,10,11$ herzustellen, so aber, dass die eine Hälfte derselben an einem gerade neben dieser Lamelle belegenen Epidermisstreifen noch sichtbar war. Diese Gelegenheit wurde benutzt, um die genannten Zeichnungen herzustellen.

Bei Messungen kommt es nicht allein darauf an, die Weite des Spaltes zu bestimmen, sondern es muss auch Rücksicht genommen werden auf alle übrigen Contours, aus deren Veränderlichkeit auf eine Volumänderung der Zelle geschlossen werden kann.

Grössere Schwierigkeiten haben mir in dieser Hinsicht die Jahrb. f. wiss. Botanik. VIII. 
für die Behandlung der Mohl'schen Experimente unerlässlichen Amaryllideen gemacht. Bei diesen ist der Apparat, und namentlich bei Haemanthusarten, mit soviel Contours in der Fliachen. ansicht überladen. dass man bei Messungen die äusserste Vorsicht anwenden muss, un Irrthumer zu vermeiden. Meine Ergebnisse an Haemanthus weichen von den v. Mohl'schen etwas ab. Es sind die folgenden:

Bei hoher Einstellung werden beobachtet: der äusserste Contour a a Fig. 5 der Zellwand a. Fig. 4; weiter nach innen die Leiste, die da vorhanden ist, wo diese Wand in die freie Aussenfläche eingefügt ist b F'ig. 10; enơlich der äusserste Rand c c und der innere d d eines in den Figuren im Durchschnitt dargestellten Caticularhügels. (Fig. $11 \mathrm{zu}$ vergleichen mit Fig. 12.) Diese beiden Ränder sind meist nicht scharfe Linien, sondern körnig unterbrochen oder gezackt. Noch weiter nach innen beobachtet man bei derselben Einstellung als scharfe Linie den meist geöffneten Vorhofspalt e, F'ig. 10 bis 12.

Bei derjenigen tieferen Einstellung, bei welcher der wirkliche Spalt mit scharfem Contour zu sehen ist, wird keine der genannten Contours scharf gesehen als der äusserste, der nuu doppelt erscheint. In den Figuren sind die Verhältnisse so dargestellt, dass cin Missrerstchen nicht möglich ist. Bei der Messung der Querdurchmesser ee, a a, c c, dd etc. bediente ich mich eines Ocularglasmicrometers bei den gleichen optischen Theilen am Microscop, so dass die Einheit der unten folgenden Masse für alle Messungen die gleiche ist. Auf die Angabe absoluten Maasses legte ich kein Gewicht. Wer sich dafür interessirt, findet in den Mohl'schen, jedenfalls viel genaueren Messungen, das Gewünschte.

Es wird vor Allem darauf ankommen, die Veränderung der beiden Flächen (der Ober- und Unterseite) zu beobachten, welche eintritt, wenn der geöffnete Spalt geschlossen wird. Dies kann nur durch vergleichende Messung der Querdurchmesser a a, b b, c c etc. geschehen und erhält man durch solche die Verkürzung oder Verlängerung der Flächen ie, ed, a Fig. 11 für die Oberseite, welche in der Zweizahl symetrisch um eine senkrecht auf der Oberfläche der Epidermis stehende, und mit der grossen Axe des Spaltes zusammenfallende Ebene liegen. Man wird vor allem zu constatiren haben, welche in der Flächenansicht sichtbaren Flächen verändern in Folge der Oeffnung und Schliessung ihre Lage und Grösse so, dass die senkrechte Projections-Ebenen der 
genannten mannigfach gekrümmten Flächen eine Veränderung erleiden (s. von Mohl a a. 0., S. 718).

Ich glaube in dem vorstehenden die Methoden so dargestellt zu haben, dass ein Jeder, der sich nur wenige Mühe geben will, den Mohl'schen und den nachfolgenden Untersuchungen zu folgen, sich leicht durch Wiederholung der einfachen Experimente über die beiden dirergirenden Ergebnisse ein selbständiges Urtheil bildeu kann; ich glaube auch ferner in der Darlegung der zu lösendeu experimentellen Fragen, diejenige Form angewandt zu haben, welche ohne einen zu grossen beschreibenden Apparat, die Prüfung der Schlüsse aus jedem einzelnen Experiment Jedem leicht möglich macht und von mir begangene Fehler in dieser Richtung dem Prüfenden am leichtesten blosstellt, und wende ich mich nach diesem zu der Prüfung der Mohl'schen ersten Prämisse. Ehe ich mich jedoch zn dem Experimente selbst wende, will ich hier die Zusammenstellung der Eigenschaften geben, welche nach den oben angewandten Forneln rorgeschlagen und mit den 3 genannten Instrumenten srforscht werden. Dabei soll, was die anatomische Lage anbelangt, auf die Mohl'schen und meine Zeichnungen verwiesen sein. Der Grad der Scale soll sich auf die eben eintretende Contraction des Protoplasma in der Schliesszelle beziehen und die nachfolgende Krümmung soll den Zustand der Spannung in der Membran kennzcichnen.

Die Erscheinungen, welche bei den Gruppen A und B. beobrchtet worden, sind verschieden (s. oben, und bei $v$. Mohl), und sehen wir, dass, wenn man alle übrigen Eigenschaften in den 2 Gruppen als gleich ansehen muss, dieselben nur in $2 \mathrm{Um}$ ständen von einander abweichen.

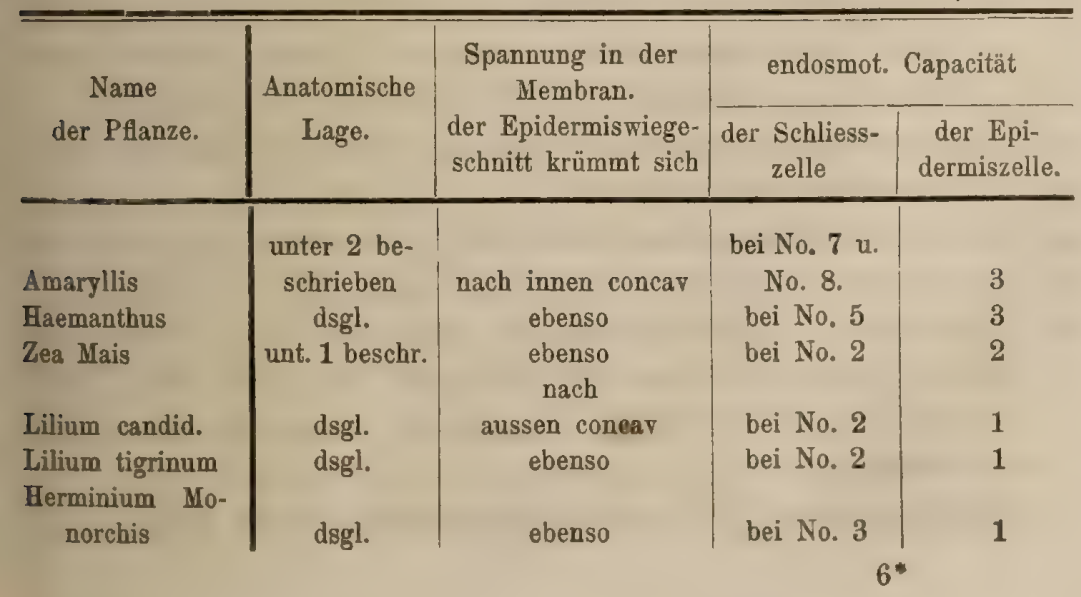


Man wird bei dem ersten Versuch mit dem Wiegeschnitt constatiren, dass bei Lilium und den Orchideen 2 Zellhautplatten nahezu gleiches Ausdehnungsstreben besitzen, so aber, dass die geringe Differenz eine Krümmung in einem Sinne herbeifubrt, während bei den Aqmarillideen diese Krümmung in viel auffälligeren Maass in entgegengesetzter Richtung erfolgt.

Um hier noch mit mehr Vorsicht zu prüfen, sei bemerkt, dass in beiden Gruppen die Wasserwirkung, was das endosmotische Einsaugen anbelangt, nur eine graduell verschiedene ist. In beiden Gruppen wird das Volum der Zellfüssigkeit der Schliesszellen vermehrt. Die ungleiche Richtung der Bewegung der Wände, welche in dem einen Fall Oeffuen, im anderen Schliessen bewirkt, kann daher, wie es die Folgerung aussagt, selbstrerständlich nur entweder in der anderen Erscheinung der ungleichen Biegung in Folge anderer Spannung oder in wesentlich verschiedener Stellung der Schliesszellen ihre Ursache haben.

Wir kommen damit zum schwierigsten Theil der Untersuchung zu dem Theil, wo der Entscheid nur ron der Beobachtungsgabe abbängt. Dic Frage ist die: Wclchen Antheil hat die endosmo. tische Wirkung und welchen Antheil hat die Spannuugswirkung bei der Bewegung an einer und derselben Spaltöffnung? Diese Frage kann nur auf experimentellem Wege gelöst werden. Es ist, glaube ich, aber nöthig, dass ich einige allgemeingültige Sätze über Gewebespannung hicr dem Leser ins Gedächtniss rufe; dicselben sind die folgenden, wenn ich Bezug nehme auf die in den anatomischen Abbildungen ersichtichen Verhältnisse.

1) Wenn ein Flächenelement derjenigen Schliesszellhautfläche, welche an den Spalt grenzt, das Bestreben hat, sich nach innen oder aussen concav zu biegen, so wird gemeiniglich diese Concavität stärker sein, wenn Wasser an die Fläche als wenn ein wasserziehendes Mittel an dieselbe grenzt.

2) Dasselbe Bestreben kann sich an dem freiliegenden Theil der Schliesszelle äussern.

3) Das Maximum der Cuncavität in der einen oder anderen Richtung wird dann eintreten, wenn auch die Zellflüssigkeit am wasserreichsten ist, wenn die Schliesszelle am prallsten gefüllt ist. Das Minimum, wenn die Zellfüssigkeit am wasserärmsten ist und die Membran nur schlati spannt.

Man kann nun die Oeffnung und Schliessung an der abgezogenen 
Epidermis bewirken dadurch, dass man dieselbe abwechselnd mit Wasser oder einer der nummerirten Glycerinlösungen in Berührung bringt, und bekommt eine Vorstellung von der Veränderung der Lage der Wände der Sshliesszellen durch Messungen verschiedener Durchmesser vor und nach der Reaction.

\section{Experimente in der Gruppe A.}

(Herminium, Lilium candid, Lilium tigrin.)

1. Experiment. Von dem Blatt einer im Schatten befindlichen Pflanze (Lilium tigrinum) werden Epidermisstreifen geschnitten und in destillirtes Wasser gelegt. Alle Spalten erweitern sich. Es wird No. 1 der Glycerinscale angewandt. Es tritt Schliessen des Spaltes unter den Augen dos Beobachters ohne eine merkliche Plasmacontraction ein. Bei Anwendung von No. 2 auf einen 2 ten Streifen tritt sofortiges Schliessen ein und wenige Secunden später ein langsames Zurückziehen des Protaplasma. Dieses Experiment wurde $3 \mathrm{mal}$ wiederholt mit demselben Erfolg.

2. Experiment. Aehnliche Epidermisstreifen werden von einer beschatteten Herminium Monorchis genommen. Die Spalten sind in Wasser offen.

Bei No. 1 der Scale keine Veränderung.

Bei No. 2 der Scale keine Veränderung oder langsames Schliessen ohne Plasmacontraction.

- No. 3 - - Schliessen unter dem Auge des Beobachters viel später (5-10 Secunden) eintretende Plasma. contraction.

3. Experiment. Mit denselben Epidermisstreifen von Lilium und Herminium, wird abwechselnd No. 2 (für Lilium), No. 3 der Scale (für Herminium) und Wasser angewandt.

Die Erscheinungen sind: Schliessen und Contraction des Protoplasma (so, dass sich der Spalt längst geschlossen, ehe das Protoplasma zurückzieht), in den Nummern der Seale, und Wiedererlangung der normalen Lage der Protoplasmamasse und Oeffnung der Spalten bei Anwendung von Wasser, wobei deutlich beobachtet wird, dass der Spalt sich nicht merklich erweitert, ehe das Protoplasma seine normale Lage zeigt. Die Abwechselung kann beliebige Male wiederholt werden.

4. Experiment. Ein Epidermisstreifen von Herminium wird eine Stunde lang in destillirtes Wasser gelegt. Die Schliessung 
und Contraction der Spalten trat jetat schon bei No. 2 ein. Dies Experiment wurúe an 3 Streifen wiederholt.

5. Experiment. Dieselben Beobachtungen an Lilium und Herminium werden sowohl an rings von geschlossenen Epidermiszellen umgebenen als auch an solchen gemacht, deren Nachbarzellen nach der Mohl'schen Methode geöffnet sind.

6. Experiment. Um zu erfahren, welcher Art die Gestaltsänderung der Schliesszellen bei den Pflanzen der Gruppe $\mathbf{A}$ ist, wurden folgende Messungen angestellt:

Länge des breitesten Querdurchmessers des Spaltes im geöffneten Zustand ii Fig. 7. 12., und die Breite des Vorhofspaltes $\mathrm{e}^{1} \mathrm{e}^{1}$ Fig. 7. Zieht man daun die Breite $\mathrm{ji}$ von der Breite $\mathrm{e}^{1} \mathrm{e}^{1} \mathrm{ab}$, so hat man die Breite der Summe der 2 Böschungen, welche von i nach $\mathrm{e}^{1}$ sich hinziehen.

Diese Messungen wurden gemacht zur Zeit, wo die Spalte offen ist, sodann wurde durch Anwendung einer Nummer der Scale der Spalt geschlossen und an derselben Spalte die Messungen der Querdurchmesser ee und ca wiederholt.

Lilium candidum (an der Oberseite).

\begin{tabular}{l|l|l|l}
\hline $\begin{array}{c}\text { Weite } \\
\text { des Spaltes }\end{array}$ & $\begin{array}{c}\text { Weite des } \\
\text { Vorhofspaltes }\end{array}$ & $\begin{array}{c}\text { Breite einer } \\
\text { Schlieszelle. }\end{array}$ & \\
\hline 5 & 6 & 10 & vor der Schliessung od. Verengung. \\
0 & 5 & 11 & nach der Verengung. \\
3 & 5,5 & 10 & vor der Schliessuug. \\
0 & 6 & 10 & nach - \\
4 & 1,5 & 11 & vor - \\
0 & 4 & 10 & nach - \\
5 & 4 & 13 & vor - \\
0 & 5 & 12 & nach - \\
5 & 6 & $\mathbf{1 4}$ & vor - \\
0 & 8 & $\mathbf{1 2}$ & nach - \\
4 & 5 & 13 & vor - \\
0 & 6 & $\mathbf{1 3}$ & nach - \\
\hline
\end{tabular}

Diese Messungen wurden in der Weise wiederholt, dass der Spalt ii Fig. 7, der Vorhofspalt $e^{1} e^{1}$ und die Breite $e^{1} a^{1}$ gemessen wurden vor und nach der Schliessung durch eine Nummer der Glycerinscale. 


\begin{tabular}{|c|c|c|c|}
\hline $\begin{array}{c}\text { Breite } \\
\text { des Spaltes. }\end{array}$ & $\begin{array}{c}\text { Breite des } \\
\text { Vorhofspaltes. }\end{array}$ & $\begin{array}{c}\text { Breite der Zelle von } \\
\text { Vorhof bis Rand } \\
\left(e^{t} \text { bis } a^{t} .\right)\end{array}$ & \\
\hline 2 & 9 & 13 & vor der Schliessung. \\
\hline 0 & 9 & 13 & nach - \\
\hline 3 & 11 & 10 & vor - \\
\hline 0 & 10 & 10 & nach - \\
\hline
\end{tabular}

Herminium monorchis.

\begin{tabular}{r|l|l|l|}
2,5 & 11 & 11 & vor der Schliessung. \\
9 & 14 & 10 & nach - \\
2,5 & 12 & 15,5 & vor - \\
0 & 10 & 12 & nach - \\
3 & 16 & 8 & vor - \\
0 & 13,5 & nach -
\end{tabular}

Man ersieht, dass an der Verschiebung bei den Liliumarten die Wand c c nicht Theil nimmt und nur die Böschung i ${ }^{1}$ Fig. 7steiler oder flacher wird; steiler bei der Oeffnung; flacher bei der Schliessung. Die Vorhofspalte wird dabei nicht oder nur wenig verändert; ebenso bleibt die Fläcbe $e^{1}$ a ziemlich unverändert. Etwas verschieden davon ist Herminium, wo bei der Gestaltänderung die genannte Böschung immerhin die Hauptrolle spielt, der Vorhofspalt und die Fläche $e^{1}$ a aber auch eine geringe Veränderung erleiden.

Es ist für die hierhergehörigen Versuchsobjecte wohl nur eine Vorstellung zulässig, nämlich die, dass die Wände, welche dem Spalt zugekehrt sind, stärker convex gegen den Spalt gekrümmt sind; alsdann ist derselbe geschlossen; oder schwächer, alsdann ist er offen.

Geringste Krümmung dieser Wand, Offensein der Spalte, und Maximum des Wassergehalts des Zellinhaltes sind Erscheinungen, die zusammengehören einerseits, so wie stärkste Krümmung, Geschlossensein des Spaltes und Minimum des Wassergehaltes andererseits.

Ein Antagonismus, beruhend in einer endosmotischen Spannung zwischen Epidermiszellen und Schliesszellen ist nirgends in den Untersuchungsobjecten angetroffen worden. 


\section{Experimente mit der Gruppe B.}

(Amarylliden.)

Die wichtigsten Mohl'schen Experimente erfordern, dass der geschlossene Spalt bei Amaryllis und Haemanthus sich öffnet, wenn man die Epidermiszellen anschneidet, oder wenn man einen solchen Grad der Scale anwendet, dass, wie sich v. Mohl vorstellt, den Epidermiszellen mit wässerigerem Inhalt das Wasser entzogen wird, während den Spaltöffnungszellen dadurch von der umgebenden Flüssigkeit zugeführt wird.

Beide Arten den geschlossenen Spalt zu öffnen sind mir vollständig bei Haemanthus missglückt, selbst bei mehrfacher Wiederholung.

7. Experiment. Um der Möglichkeit des Misslingens in Folge unrichtiger Concentration vorzubeugen, wurden $10 \mathrm{Abschnitte}$ mit dem Blattparenchym in 10 verschiedene Fläschchen mit den Flüssigkeiten No. 1 bis No. 10 gegeben. Nach Verlauf einiger Stunden wurde eine Nummer nach der andern untersucht: Es waren alle Spalten geschlossen und zwar in derjenigen Stellung der Schliesszellen, in welcher sie ron oben ein Oral darstellen (das Oval bb der Fig 4). Diese Weise zu experimentiren, wurde 3 mal mit demselben Erfolg wiederholt.

8. Experiment. Die Spalten sind geschlossen, es werden an 10 nach der Mohl'schen Methode hergestellten Streifen Beob. achtungen angestellt, während eines halben Tages. Es wurde keine Offnung constatirt.

9. Experiment. Wiederholung der Experimente in der Weise, dass man die Scalentheile der Glycerinscale nach und nach auf Streifen mit geschlossenen Spalten anwendet und dabei die Contraction der Plasmamassen beobachtet: Es ergab sich Contraction der Plasmamassen der Schliesszellen zwischen 8 und 10 und ebensolche (wenn überhaupt wahrnehmbar) bei den Epidermiszellen zwischen No. 2 und No. 3.

Es lässt sich, wie $\nabla$ : Mohl hinlänglich bestimmt nachgewiesen, und wie ich später noch zu bestätigen habe, wahrnehmen, dass die Oeffnung des Spaltes bei Amaryllis und Haemanthus mit dem Zustand der Schliesszellen zusammenfällt, in welchem die Wand a a, Fig. 4, Fig. 10 in das Innere der Epidermisconvex gewölbt ist, mit- 
hin der Abstand a b, Fig. 11. 12 in der Flächenansicht der grösste ist, auch lässt sich zeigen, dass dann die Contraction der Plasmamasse der Schliesszellen zwischen No. 4 und No. 5 derselben Scale liegt. Es lässt sich aber daraus noch nicht vorstellig machen, dass, wenn wir im geschlossenen Zustand, wo a b sehr klein ist, der Epidermiszelle durch No. 3 der Scale Wasser entziehen, die Schliesszellen rasch genug von dieser Lösung aufnehmen, um sich mit. Flüssigkeit so zu füllen, dass a von $\mathrm{b}$ hinweg rückt.

Eine andere Art, den geschlossenen Spalt der Amaryllideen zurn Oeffnen zu bringen, besteht nach v. Mohl darin, dass man Blattabschnitte in Wasser legt und insolirt oder die ganze unverletzte Pflanze insolirt.

Die nachfolgenden Experimente sollen zeigen, dass die $\mathrm{Er}^{-}$ scheinung des Oeffnens der Spalten von Abschnitten in Wasser, welches insolirt wird und diejenige, welche bei der insolirten Spalte an der ganzen Pflanze beobachtet wird, wesentlich verschiedene Erscheinungen sind.

10. Experiment. Wird die ganze Pflanze insolirt, so öffnet sich der Spalt auf eine sehr geringe Weite, ohne eine merkliche Vorbreiterung des ganzen Apparates. Bei der in Wasser eintretenden Schliessung wird auch der ganze Apparat wenig verschmälert. Nach der Insolation der ganzen Pflanze, beobachtet man am besten in der Weise, dass man die Epidermis mit einem Scalpell abträgt mit einer einzigen Zellenlage. Der Spalt schliesst sich sehr bald in Wasser (5-10 Minuten), ohne dass die Breite a a oder b b merklich verändert wird. Dieses Experiment ist leicht anzustellen und hat an und für sich und in seinen Folgerungen gar nichts mit dem folgenden zu thun. Die wesentlichen Merkmale des Zustands der Oeffnung der Spalten nach diesem Experiment sind: wenn der Schnitt parallel der Epidermisfläche eben der lebenden Pflanze entnommen ist oder die abgezogene Epidermis in Wasser unter dem Deckglas liegt, Vorhofspalte, Spalte und Hinterhofspalte führen Luft; der ganze Apparat ist ein Oval, dessen grosse Axe mit der grossen Axe des Spaltes zusammenfällt, Fig. 4, 9. Die Oeffnung des Spaltes ist sehr klein, 1-2 der Theilstriche des ron mir gewählten Messinstruments. Der Schnitt schliesst sich bald in Wasser, ohne merkliche Veränderung aller Contours oder Verkürzung aller Querdurchmesser, mit Ausnahme des Spaltes Fig. 11 stellt den Zusand des geöffneten Spaltes nach dem fraglichen Experimente dar, Figur 10 die Schliessungsstellung. Un 
eine Uebersicht zu erlangen über die Gestaltänderung wird am besten gemessen, vor und nach dem Schliessen, die Weite ii des Spaltes.

- e e des Vorhofspaltes.

- ba oder a a, Fig. 11, 12.

\section{Messungen (an Amaryllis formosissima)}

des durch Insolation der lebenden Pflanze erweiterten Spaltes.

\begin{tabular}{|c|c|c|c|}
\hline Weite i i & Weite e e & Breite ba & \\
\hline 4 & 6 & 12 & vor der Schliessung. \\
\hline 0 & 4 & 11 & nach - \\
\hline 5 & 5 & 13 & vor - \\
\hline 0 & 4 & 12 & nach - \\
\hline 6 & 7 & 14 & vor - \\
\hline 0 & 3 & 13 & nach . \\
\hline
\end{tabular}

11. Experiment. Um zu zeigen, dass die im Experiment 10 beobachtete Schliessung und die nach ron Mobl auf einem Antagonismus beruhende Schliessung der Spalten (s. o. a. a. O. S. 714) nicht der letzte Zustand ist, in welchen ein Abschnitt beim Einlegen in Wasser gerathen kann, und dass weitere Veränderungen an solchen Abschnitten nicht ron dem Lichteinfluss abhängen, wurden Abschnitte, an welchen die Spalten geschlossen waren, in 2 Bechergläser mit Wasser seluracht und zwar so, dass ein Theil der Blattfläche unverrückbar unter Wasser, der andere über das Wasser ragte. Beide so hergerichtetc Apparate wurden mit einer Glasplatte bedeckt, durch welche ein Thermometer in das Wasser tauchte. Der eine Apparat wird 2-3 Stunden in directes Sonnenlicht, der andere in ein dunkles Blechluftbad gesetzt, in welchem das den Blattabschnitt umgebende Wasser auf den in dem insolirten Wasser beobachteten Tempcraturgrad (annähernd) erwärmt wird. Nach zwei bis drei Stunden werden die beiden Apparate erkalten gelassen und die Spalten an der abgezogenen Epidermis der 4 Stellen (der 2 untergetauchten insolirten und nicht insolirten und der 2 nicht untergetauchten, sonst aber wie die 2 ersten behandelten) untersucht. Die 4 Stellen verhalten sich alle gleich, die Spalten aller sind aufs Aeusserste erweitert. Aber die Gestalt ist in allen 4 Fällen auch so verändert, dass ein nicht 
geübter Beobachter den ganzen Apparat nicht als den im Experiment 10 geöffneten wiedererkennen würde. Der Contour a a um. schreibt jetzt ein breites Oval, dessen grosse Axe senkrecht auf derjenigen des Spaltes steht. Die wichtigeren Formänderungen sind die folgenden: Vorhof, Spalte und Hinterhof sind mit Wasser gefüllt, die Böschung ci hat das Maximum ihrer Abflachung die Böschungen di i d (Fig. 11, 12) das Maximum der Steilheit erreicht. Der Spalt bleibt Stunden, ja Tage lang in Wasser geöffnet. Die Contraction des Plasma in den Schliesszellen tritt bei No. 4 der Scale ein; bei derselben Einwirkung schliesst oder verengt sich der Spalt, jetzt aber (abweichend von dem Vorgang der Schliessung im Experiment 10) mit Zurückziehung der Wand a a nach b b hin, so dass a b kleiner wird (Fig. 4). Die Figur 8 sucht den Zustand dieser Oeffnung zu demonstriren, nach Messungen der genannten Querdurchmesser ausgeführt. Die Temperaturerhöhung allein bewirkte also zunächst Benetzung der Wände, Oeffnung des Spaltes unter Gestaltänderung des ganzen Apparates, und Verdünnung des Inhaltes der Schliesszellen von No. 7 oder No. 8 der Scale auf No. 4 oder No. 5 derselben.

Messungen an der Oberseite von Haemanthus pumiceus.

Oeffnung bewirkt durch Erwärmen Schliessung durch Erkalten oder Glycerinzusatz No. 5 der Scale.

\begin{tabular}{l|c|c|c|l}
\hline \hline $\begin{array}{c}\text { Weite des } \\
\text { Spaltes. }\end{array}$ & $\begin{array}{c}\text { Weite des } \\
\text { Vor- } \\
\text { hofspaltes. }\end{array}$ & $\begin{array}{c}\text { Breite c c } \\
\text { Fig. 11 u. } \\
12 .\end{array}$ & $\begin{array}{c}\text { Bür eine einzelne } \\
\text { Zelle also c b. } \\
\text { Fig. 11 u. 12. }\end{array}$ & \\
\hline I. $\left\{\begin{array}{l|c|l}4 \\
4\end{array}\right.$ & $5,1 / 2$ & 16 & 5 & vor der Schliessung. \\
1,5 & 5 & 15,5 & nach 4,5 & nach \\
3 & 6 & 17 & 6 & vor, \\
0 & 6 & 16 & 5 & nach \\
6 & 12 & 17 & 4 & vor, \\
0 & 5 & 12 & 4 & nach \\
4 & 9 & 17 & 4 & vor, \\
0 & 6,5 & 17 & 4 & nach \\
3 & 5 & 16 & 6 & vor, \\
0 & 5 & 16 & 6 & nach
\end{tabular}

Es ergiebt sich aus diesen Messungen, bei welchen der Länge der Zeit halber, die eine Messung in Anspruch nimmt, die letzte Weite a b für eine Zelle nicht ins Auge gefasst wurde, dass die geringsten $V$ eränderungen in Folge der Sshliessung auf den Vor- 
hofspalt den ganzen Cuticularhügel und gar keine auf die Fläche zwischen diesem und der Einfügungsstelle der Wand c f kommt, wenn die Schliessung durch Erkalten oder Einlegen in kälteres Wasser erfolgte. Messungen I, II, IV, V. Eine bedeutende Veränderung in der Weite des Vorhofspaltes und c c wurde dagegen bei der Schliessung durch Glycerin No. 5 bewirkt, bei Messeung III.

\section{Wiederholung derselben Messungen bei Haemanthus.}

Oeffnung bewirkt durch das Experiment 5. Schliessung durch Glycerin No. 2 der Scale.

\begin{tabular}{l|c|c|c|l}
\hline $\begin{array}{c}\text { Weite des } \\
\text { Spaltes. }\end{array}$ & $\begin{array}{c}\text { W.d. Vor- } \\
\text { hofsp. }\end{array}$ & $\begin{array}{c}\text { Cutic- } \\
\text { hügel ce. }\end{array}$ & Breite c b. & \\
\hline & & 16 & 4 & vor Schliessuug. \\
2,5 & 6 & 15 & 4 & nach \\
0 & 5 & 16 & 4 & vor \\
5 & 6 & 15 & 4 & nach \\
0 & 5 & & &
\end{tabular}

Diese Messungen zeigen, dass für langsame Schliessung, durch Erkalten oder Zusatz rerdünten Glycerins nur die Böschung, welche an den Spalt gränzt, verändert wird.

\section{Messungen an der Unterseite:}

Oeffuen des Spaltes durch Experiment 11 bewirkt, Schliessung durch Glycerin No. 4 und No. 8 der Scale, erstere unter I., letztere unter II.

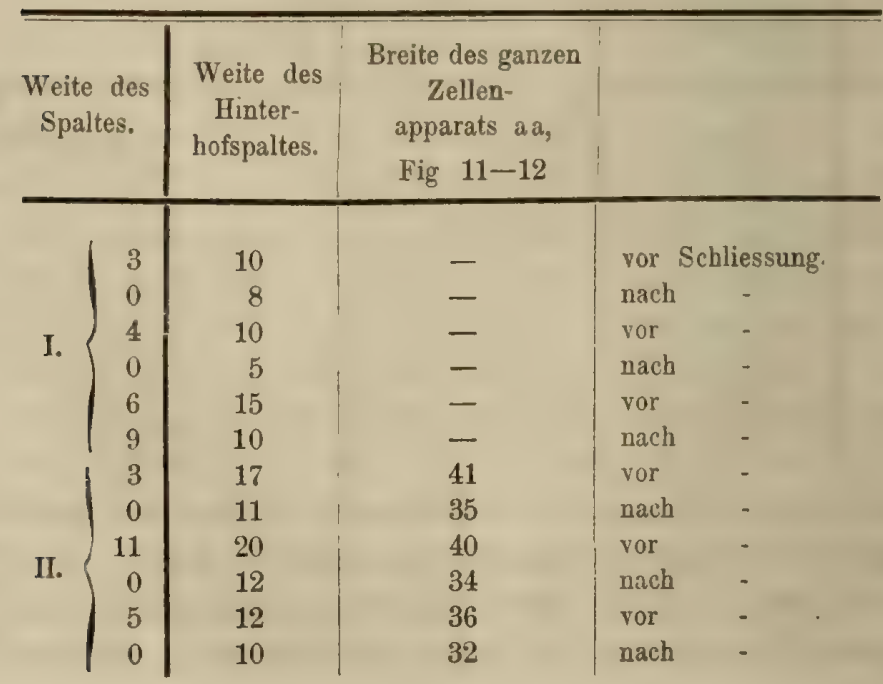


Aus diesen Messungen geht hervor, dass während die nicht dem Spalt zugekehrten Flächen der Oberseite nur geringe Aenderungen erleiden, die sämmtlichen benannten Flächen der Unterseite beträchtliche Verschiebungen erleiden müssen, durch den Einfluss wasserentziehender Medien, und die darauf folgende Schliessung.

Um auch bei den Amaryllideen die Mitwirkung der Spannungserscheinungen zu betrachten, hat man sich wieder vorzustellen, dass das zusammenfallende Erscheinungen sind: Das Maximum des Bestrebens eines Flächenelements an der Spaltenfläche sich nach innen concar zu krümmen, Maximum des Wassergehaltes der Schliesszelleninhalte und Offenstellung des Spalts.

Soviel aus den müherollen Beobachtungen der Wiegeschnitte und der Messungen hervorgeht, ist im Zeitpunkt dieser Erscheinungen die Zellhautfläche, welche dem Spalt angränzt, am stärksten nach dem Spalt convex gekrümmt. Nimmt man an, dass die endosmotische Ueberfüllung die Ursache sei für die endliche Oeffnung des Spaltes, so ist in den Wabrnehmungen der Gestaltänderungen auch hier kein Hinderniss bereitet, die in der Membran herrschende Spannung als bei dem Mechanismus mitwirkend zu betrachten. Der ron Mohl gefundene Antagonismus zwischen Epidermiszellen und Schliesszellen findet nach meinen Untersuchungen folgenden Ausdruck: Wird dem in Folge von Wärmezufuhr wenig geöffneten Spalt Wasser zugeführt, so schwellen die Schliesszellen Wasseraufnehmend an, pressen die Zellfüssigkeit der Epidermiszellen, und bewirken dadurch ein Schliessen des Spaltes. Dieselbe Pressung bewirkt aber, dass die Schliesszellen sich endlich ausdehnen und nach mehrstündiger Benetzung und Erwärmung öffnet sich der Spalt und bleibt offen. Bis rascher Temperaturwechsel ein plötzliches oder langsames Erkalten ein langsames Schliessen herbeiführt, ohne dass das Volum der Zellenflüssigkeit der Schliesszelle kleiner wird.

Wenn ich versuche, die Ergebnisse der vorstehenden Untersuchung zusammenzustellen, so geschieht dies nur mit dem Vorbehalt nach weiterer eingehenderer Studien in diesem schwierigen Gebiet und bis jetzt ohne die Erlaubnissnahme einer Folgerung über die Rolle des Apparates im gewöhnlichen Leben. Allgemein kann ich sagen, wenn die 2 Schliesszellen nur unter sich verbunden wären, so wie sie in der Natur sind, sonst aber frei, so würde 
sich der Spalt bei Wasser und Wärmezufuhr immer schliessen, wenn nicht die freie Aussenfläche der Schliesszellen cuticularisirt, d. b. alle Flächenelemente der Schliesszellen gleichartig wären. Es wäre gar kein Grund vorhanden, warum zwischen den Wänden, welche dem Spalt zugekehrt sind, ein Höhlram entsteht. Da aber nicht allein wegen der einseitigen Cuticuba, sondern auch wegen der Backenartigen Verdickungen oberhalb und unterbalb der Spaltenflächen bei den meisten der beobachteten Spalten nicht alle Flächenstückchen unter sich gleich sind, so ist der bewegende Apparat in dieser Anordnung zu suchen; so dass man saven kann, die endosmotische Wasseraufnahme vermehrt das Volum der Zellfüssigkeit und damit den hydrostatischen Druck und die Spannung in jedem Flächenelement der cuticularisirten Schliesszellenfläche; der hydrostatische Druck erfährt ron den verschicdenen Flächen verschiedenen Widerstan?, die Folge daron ist die Gestaltänderung, die wir bei der Oeffnung des Spaltes wahrnehmen. Spalten, bei welchen allein diese Verhältnisse ron Belang sind, sind die der Orchideen und Liliaceen und aller der Pflanzen, welche einen so einfachen Bau im Spaltöffnungsapparat zeigen, wie die genannten. Nur zwei Stellungen der betrachteten Wandstücke kennzeichnen sich hier im Schliesszellenapparat in der Flächenansicht. Die Ansicht des geschlossenen und die Ansicht des offenen Spalts. Ein Antagonismus ist hier nur möglich zwischen hydrostatischem Druck und der Elasticität der Membrantheile in den Schliesszellen. Ist die Anordnung hingegen der Art, dass die Schliesszellen sich nicht ausdehnen können, ohne das Volun der Nachbarzellen zu verkleinern, so wie dies in der Natur der Fall ist bei den Amaryllideen, so wird der Mechanismus complicirterund es ist hier ein Verhältniss zu betrachten, welches von Wichtigkeit zu sein scheint. Es ist die Veränderung der grossen Axe des ganzen Spaltenapparats mit dem Uebergang aus der Schliessungs, in die Oeffnungsstellung. Ein anderes yleichzeitig eintretendes Verhältniss ist das der hydrostischen Pressung, welche bei den Amarylliden in Folge der sich wölbenden und abplattenden Scheidenwand eintritt, und über welches ich meine Experimente oben mitgetheilt habe.

Bei den Amarylliden sind drei Stellungen für den Apparat in der Flächenansicht direct wahrnehmbar, die ich nach sorgfältiger Beobachtung in den Figuren 8 bis 12 dargestellt habe: Der $\mathrm{Zu}$ stand geringen Wassergehaltes, der Spalt ist immer geschlossen, 
Pig. 9, wo dic Wand aa. auf das auffälligste eingestülpt sein kann.

er Zustand der Ueberfüllung und der Schliessung des Spaltes, ig. 10, welcher unter dem Auge des Beobachters eintritt mit dem rerschwinden der besagten Einstülpungen, und endlich der Zustand ler Ueberfüllung mit gleichzeitiger Oeffnung des Spaltes, Fig. 8 Ind 11. Die letzten zwei können durch Wasser und Wärmezufuhr us dem ersten hergestellt werden, obne Tödtung der Epidermis. Inders aber mit dem ersten; diese Stellung, Fig. 9, findet sich in ler Natur und kann dadurch herbeigeführt werden, dass man zu len Spalten in den letzteren Stellungen starke, wasserentziehende üsungen setzt. Ich beobachtete aber, dass dabei der Spaltenpparat die Fähigkeit verliert, sich wieder zu öffnen.

\section{Reizungserscheinungen durch plötzlichen Temperaturwechsel.}

Mit dem Nachweis, dass an der Mechanik des Oeffnens und Schliêssens sich nicht nur der hydrostatische Druck, sondern auch lie Spannung betheiligt, die in den isolirten Membranelementen lachweisbar ist, wurde ich auf Versuche geführt über die Reizbarreit des Apparates in einer seiner Stellungen. Es glückten mir lie nachfolgenden Experimente auch vollständig und beweisen die. selben zum mindesten, dass es die Beschaffenheit der Membran st, deren moleculare Veränderung die merkwürdige Bewegung hereiführt, wenn auch, so viel ich beurtheilen kann, bis jetzt nicht ntschieden werden kann, wieviel der Wirkung auf die Permeabiliät oder Expansionsänderung der Membrantäche kommt. Wie bei Gelegenheit der Darlegung der früheren Experimente will ich auch ier diejenigen einfachsten Versuche vorführen, bei welchen die zu veobachtende Erscheinung ganz unzweidentig waren.

12. Experiment. - Das Experiment 11 wird wiederholt. Epidermisstreifen ron Lilium candium, tigrinum, croceum, Hermiaium Monorchis, Amaryllis formosissima, Haemanthus puniceus, Ricinus communiss u. $\nabla$. a. werden in einem Luftbad, in dunstgeättigter Atmosphäre oder in Wasser längere Zeit $\frac{1}{2}-2$ Stunden oclassen, bei einer Temp. von $30^{\circ}-35^{\circ} \mathrm{C}$. Alle Spaltöffnungen öffnen sich, die Amarylliden zuletzt, alle bleiben geöffnet, die Amarylliden am längsten, bei halb oder eintägigem Verweilen.

13. Experiment. - Die ganzen Blattabschnitte werden in Wasser denselben Bedingungen ausgesetzt; es tritt der gleiche 
Effect ein und die Intercellularräume des Blattes injiciren sich mit Wasser.

14. Experiment. - Von den Streifen im Experimente 12 (nach der eingetretenen Oeffnung der Spalten) werden mehrere unter dem Deckglas in Wasser in ein Luftbad gebracht, in welchem eine Kältemischung die Luft auf $-3^{\circ}$ bis $-7^{\circ} \mathrm{C}$. erkältet hält. Nach 5 Minuten ist das Wasser des Objecttragens gefroren. Die Spalten sind noch offen (Lilium tigrinum), nachdem man bei gewöhnlicher Temperatur langsam aufthauen liess.

15. Experiment. - Dasselbe Experiment, dieselben Ergebnisse, Herminium Monorchis.

16. Experiment. - Diẻselben Streifen ron L. tigrinum, Amaryllis und Haemanthus, nach dem Exp. 1 werden in der Kältemischung 10-15 Minuten belassen. Das Wasser ist gefroren; die Spalten sind geschlossen. Bleiben unmittelbar nach dem Aufthauen geschlossen. Sind geöffnet nach halbstündigem Verweilen bei ge. wöhnlicher Temp. $\left(26^{\circ}-27^{\circ}\right.$ C. $)$ Die Protoplasmamassen der Schliesszellen sind in keinem der genannten Zustände contrahirt.

1i. Experiment. - Dieselben Objecte verbleiben 20-30 Minuten in der Kältemischung $\nabla$ on $-10^{n}$ C. Die Spalten sind nach dem Aufthauen geschlossen. Das Protoplasma contrahirt. Dieselben bleiben für immer geschlossen bei gewobnlicher Temperatur.

18. Experiment. - Die Streifen (aus No. 12) werden 2030 Minuten in der Kälte belassen und unmittelbar in das Luftbad (auf $30^{\circ}-40^{\circ}$ C.) gebracht: die Spalten bleiben für immer geschlossen, das Plasma contrahirt. Bemerkenswerth ist, dass bei den Amarylliden in allen diesen Versuchen, wie bei der Schliessung der Uebergang aus der Stellung äusserster Wasserüberfüllung (Fig. 8) in die des Wassermangels (Fig. 2) beobachtet wurde.

\section{Reiz durch den electrischen Schlag.}

Um die Empfindlichkeit des geöffneten Spaltenapparats gegen den electrischen Schlag zu untersuchen, wurden diese durch das Experiment 11 zum Oeffnen gebracht. Schaltet man nun einen langen Epidermisstreifen auf dem Objectträger unter dem Micros. cop in die Leitung des Inductionsstroms ein, so beobachtet man bei allen Pflanzen, nach Anwendung schwacher Oeffnungs- und Schliessungschläge, eine Schliessung des Spaltes. Es tritt die Schliessung bei einer und derselben Stromstärke bei verschiedenen 
Pflanzen nach verschiedener Zeit ein. Ich benutzle ein kleines Bunsensches Element und einen kleinen, Inductionsapparat (wie er in physiologischen Laboratorien Anwendung findet). Die beste Zusamenenstellung für derartige Untersuehungen wäre wohl die, bei welcher an mehreren gleichzeitig eingeschalteten Objecten an ebensoviel Microscopen die Einwirkung der Schläge gleicher Intensität beobachtet werden. Da mir diese Vorrichtung und Hülfeleistung in der Beobachtung abgingen, musste ich den folgenden Weg einschlagen. Zwei in geeigneter Weise verschiebbare Klemmen führen plattenförmige Platinelectroden auf den auf dem Objecttisch liegenden Objectträger. Auf diese kommt der Epidermisstreifen zu liegen. Die Electroden stehen mit der inducirten Spirale in Verbindung. Die Unterbrechungsvorrichtung am Batteriestrom ist ein bequem zu haudbabendes Quecksilbernäpfchen neben dem Micros* cop aufgestullt. Der magnetische Hammer am Inductionsapparat bekummt für alle Versuche die gleiche Stellung. Vergleichende Versuche an den Spaltötinungen verschiedener Pflanzen konnten bequem in so kurzer Zeit ( $1 / 2$ bis 1 stunde) angestellt werden, dass die Verändcrlichkeit der Stromstärke in der inducirenden Schliessung vernachlässigt werden konnte. $\mathrm{Da}$ bei den untersuchten Ptlanzen an einem kleinen Streifen selbst nicht alle Spalten die gleiche Oeffiungsstellung zeigen, nusste ein Präparat stets so lange unter dem Microscop bleiben, bis die zu betrachtende Erscheinung eingetreten war, was diese Beobachtungen selostverständlich sebr zeitrauberd machte.

Die Stellung der ausgezogenen Inductionsspirale ist bei den vergleichenden nachfolgenden Experimenten, wenn nicht des Näheren angegeben, ist für alle Versuche dieselbe. Alle von mir untersuchten Objecte zeigten nach langerer oder kürzerer Zeit eine Schliessung des Spaltes. Die Schliessung derselben tritt unter dem Auge des Beobachters cin. Die untersuchten Ptauzen sind: Amaryllis formosissima, Haemanthus puniceus, Lilium candiuum, tigrinum, croceum, Herminium Munorchis, Ricinus cummunis, Caladium, Calocasia-Arten u. a. In. Ich suchte nun zu ermitteln, wie gross die Auzahl der Sulhlage ist, damit der Spalt geschlossen werde. Das folgende Experiment wiess wich aut aie Vermuthung, dass die buptinulichkeit gegen die electrischen Reize in eiuem bestiunten Verhaltniss zu der endosmritischen hialt der Schliesszelleninhalte stehen müsse, oder zu dem Verhältuiss dieser Kraft zu dem Bestreben 
der Membran sich zu krümmen. In der endosmotischen Spannung stehen die Pflanzen in der Reihenfolge:

1) Lilium tigrinum, croceum, candidum No. 2 oder 2 wischen 1 und 2 der Scale.

2) Herminium Monorchis No. 3 od. zw. No. 2 u. No. 3 der Scale.

3) Haemanthus puniceus No. 8 od. zw. No. 7 u. No. 8 der Scale.

4) Amaryllis formosissima No. 9 od. 2 w. No. 9 u. No. 8 der Scale.

Nach der Wandztärke und Stärke der Krümmung isolirter Wiegeschnitte fast in derselben. (Soweit das nach nicht exacten Beobachtungen möglich ist.)

1) Hermininm,

2) Lilium,

3) Haemanthus,

4) Amaryllis.

19. Experiment. - Der durch Experiment 11 geöffnete Spalt schliesst sich bei derselben Stellung der inducirten Schliessung nach 2 Secunden unter dem Auge des Beobachters, bei Lilium candidum. I lie ebenso geöffnete Spalte von Amaryllis famosissim schliesst sich erst nach 5 Sec. lange dauernder Reizung.

Im 20. Experiment suchte ich zu ermitteln, bei welcher Dauer der Iuductionsschläge gleicher Intensität die folgenden verschiedenen Pflanzen ihre Spalten an abgezogenen Epidermisstreifen schliessen. Die Streifen wurden dabei vorher hergestellt, die dazu nöthigen Präparate auf Objectträger im Wasser auf eine Tafel zurechtgelegt und ein Präparat nach dem andern eingeschaltet. Alle Streifen waren von gleicher Länge zwischen den Electroden am Objecttisch. In der beifolgenden Tafel sind in der ersten Colonne die Namen der Pflanzen, in der zweiten die Zahl der Secunden während welcher der Batteriestrom geschlossen wurde, bis der vorher offene spalt geschlossen war; in der dritten einige Beobachtungen nach dem Experiment notirt.

Temperatur des Wassers, in welchem die Streifen aufbewahrt lagen, $22,5^{\circ} \mathrm{C}$.

Temperatur des Wassers, in welchem die Blattabschnitte, von welchen die Streifen genommen, während $1^{1 / 2}-2$ Stunden verweilten, $30^{0}-32^{\circ}$ C. Stellung der inducirten Spirale No. 3. 


\begin{tabular}{|c|c|c|c|}
\hline $\begin{array}{c}\text { Name } \\
\text { der Pflanze. }\end{array}$ & $\begin{array}{l}\text { Dauer der } \\
\text { Inductions- } \\
\text { schläge in } \\
\text { Secunden. }\end{array}$ & $\begin{array}{c}\text { Ruhe nach der Reizung } \\
1 \text { Stunde. }\end{array}$ & $\begin{array}{l}\text { Ruhe nach der Reizung } \\
4 \text { Stunden. }\end{array}$ \\
\hline $\begin{array}{l}\text { Terminium Mo- } \\
\text { norchis. }\end{array}$ & 3 & $\begin{array}{l}\text { Die Spalten sind ge- } \\
\text { schlossen, Protoplasma } \\
\text { geschrumpft. }\end{array}$ & $\begin{array}{l}\text { Spalten geschlossen, Plasma } \\
\text { stark contrahirt. }\end{array}$ \\
\hline ilium candidum & 10 & $\begin{array}{l}\text { Spaiten ebenso, Plasma } \\
\text { nicht contrahirt. }\end{array}$ & $\begin{array}{l}\text { Spalten geschlossen, Plasma } \\
\text { eben contrahirt. }\end{array}$ \\
\hline $\begin{array}{l}\text { Haemanthus pu- } \\
\text { niceus. }\end{array}$ & 10 & $\begin{array}{l}\text { Spalten ebenso, Plasma } \\
\text { nicht contrahirt. }\end{array}$ & $\begin{array}{l}\text { Spalten ebenso Plasma } \\
\text { kaum merklich contra- } \\
\text { hirt. }\end{array}$ \\
\hline $\begin{array}{l}\text { Amaryllis formo- } \\
\text { sissima. }\end{array}$ & 12 & $\begin{array}{l}\text { Spalten ebenso, Plasma } \\
\text { nicht contrahirt. }\end{array}$ & $\begin{array}{l}\text { Spalten ebenso Plasma stark } \\
\text { contrahirt. }\end{array}$ \\
\hline Lilium tigrinum & 15 & $\begin{array}{l}\text { Spalten ebenso, Plasma } \\
\text { wenig contrahirt. }\end{array}$ & $\begin{array}{l}\text { Spalten, ebenso Plasma con- } \\
\text { trabirt. }\end{array}$ \\
\hline
\end{tabular}

Im 21. Experiment wurde Experiment 20 in allen Massregeln wiederholt, nur dass die Inductionsspirale auf No. 6 ausgezogen wurde (die Intensität der Schläge somit schwächer war).

\begin{tabular}{|c|c|c|c|}
\hline $\begin{array}{c}\text { Name } \\
\text { der Pflanze. }\end{array}$ & $\begin{array}{l}\text { Dauer der } \\
\text { Induc:ions- } \\
\text { schläge in } \\
\text { Secunden. }\end{array}$ & Ruhe hienach 1 Stunde. & Ruhe hienach 4 Stunden. \\
\hline ilium candidum & 10 & $\begin{array}{l}\text { Spalten z. Th. offen, } \\
\text { Plasma nicht con- } \\
\text { trahirt. }\end{array}$ & $\begin{array}{l}\text { Spalten } z \text {. Th. offen, Plasma } \\
\text { nicht contrahirt. }\end{array}$ \\
\hline $\begin{array}{l}\text { Hermin. Monor- } \\
\text { chis }\end{array}$ & 15 & $\begin{array}{l}\text { Spalten geschl, Plasma } \\
\text { contrahirt. }\end{array}$ & $\begin{array}{l}\text { Spalten geschlossen, Plasma } \\
\text { stark contrahirt. }\end{array}$ \\
\hline $\begin{array}{l}\text { Haemanthus pu- } \\
\text { niceus }\end{array}$ & 25 & $\begin{array}{l}\text { Spalten geschl, Plasma } \\
\text { nicht contrahirt }\end{array}$ & $\begin{array}{l}\text { Spalten geschlossen, Plasma } \\
\text { nicht contrabirt }\end{array}$ \\
\hline Lilium tigrinum & 30 & $\begin{array}{l}\text { Spalten z. Th. offen, } \\
\text { Plasma kaum meık- } \\
\text { lich contrahirt. }\end{array}$ & $\begin{array}{l}\text { Spalten geschlossen, Plasma } \\
\text { kaum merklich contrahirt. }\end{array}$ \\
\hline $\begin{array}{l}\text { Amaryllis formo- } \\
\text { sissima }\end{array}$ & $35-40$ & $\begin{array}{l}\text { Spalten geschl., Plasma } \\
\text { deutlich contrahirt. }\end{array}$ & $\begin{array}{l}\text { Spalten geschlossen, Plasma } \\
\text { contrahirt. }\end{array}$ \\
\hline
\end{tabular}

22. Experiment. Ich strebte nun dahin, durch möglichst schwache Schläge die Schliessung zu bewirken und dabei das Minimum der Dauer der Reizung zu bestimmen, welches nöthig 
ist, um den Spalt zum Schliessen zu bringen. Die Schwierigkeiten solcher Experimentenreihen sind aber sehr bedeutende. Ich musste zunächst einen sehr schwachen Inductiousatrom anzuwenden suchen und für je eine Pflanze den Strom von Zeit zu Zeit unterbrechen, je nachdem durch das Microscop beobachteten Effect. Ich verfuhr dabei folgendermassen: Die Epidermisstreifen der Pflanzen einer Versuchsreihe wurden (durch Wärmewirkung präparirt) bereit gehalten; ein schwäclıster noch wirksamer Strom durch das jeweilig eingeschaltete Object geleitet, und die Schliessung der Spalten an einem Ocularmicrometer abgeschätzt. War nach einer an der bereit liegenden Secundenuhr bestimmten Dauer des Inciuctionsstroms ein langsames Zusanmenziehen merklich, so wurde die Schliessung des Batteriestroms unterbrochen, bis eine weitere Verengung der Spaltöffnung niclıt mehr wahrzunehmen war; alsdann wird der Batteriestrom wieder so lange geschlossen, bis die gewünschte Wirkung herrorgebracht war, alsdann wieder geöffnet und so fort, bis eben eine rollständige Schliessung beobachtbar war. Die rerschiedenen Zcitdauer der Schliessung deз Batteriestroms stehen in der nachfolgenden Tabelle in der zweiten Colonue.

\begin{tabular}{|c|c|c|}
\hline Name der Pflanze. & $\begin{array}{l}\text { Gesammtda uer } \\
\text { der Induction in } \\
\text { Secuuden. }\end{array}$ & \\
\hline $\begin{array}{l}\text { Herminium Monorchis } \\
\text { Lilium candidum } \\
\text { Lilium tigrinum } \\
\text { Haemanthus puniceus } \\
\text { Amaryllis formorissima }\end{array}$ & $\begin{array}{r}45 \\
60 \\
70 \\
300 \\
145\end{array}$ & $\begin{array}{l}\text { Bei dem Experiment stand der } \\
\text { Index der Inducirten Spirale auf } \\
\text { No. 9. Die übrigen Theile hatten } \\
\text { dieselbe Anordnung wie in den } \\
\text { früheren Experimenten. }\end{array}$ \\
\hline
\end{tabular}

Die weiteren Beobachtungen, die ich über die Ruhezeit der Präparate nach Reizung anstellte, gehören mit zu den Hauptschwierigkeiten der Untersuchung, welche nur gehoben werden können, wenn mehrere Beobachter gleichzeitig zur Verfünung stehen. Die Gründe dafür sind die folgenden: 1) Da ein Beobachter nur immer bei einer Reizung eine Spaltöffnung beobachten kann, an einem Streifen aber verschiedeu reizbare Spaltöffungen sind, und bei dem Versuch, wie der letzte, dus Minimum des reizenden Agens angewandt werden soll, f hlt dem einen Beobachter die Möglichkeit der Bestimmuog der Mittelwerthe. 
2) Können sich mehrere zu vergleichende Prä arate mit geötfnetem Spalt, da die Beobachtungszeit immerhin für 1 Präparat gegen eine halbe Stunde dauern kann, nicht in einem und demselben Znstand des Wärmereizes befinden.

3) Müsste zu einer exacten Behandlung des Zusammenhangs zwischen endosmotischer Capacität der Schliesszellen Spannung der Membranelemente einerseits, und Reizbarkeit des geöffneten Spaltenapparates durch den electrischen Schlag andererseits, jedem der Experimente $(19-21)$ Bestimmungen der relativen endosmotischen Capacität mit der Methode der Scale, die ich früher beschrieben, und Bestimmung der Krümmungsbestreben der Wiegeschnitte vorausgehen und nachfolgen. Zu eirem Vergleich brauchbarer Mittelwerthe aus einer solchen Versuchsreihe für zwei Pflanzen müssten demnach drei Beobachter gleichzeitig thätig sein. Ich hielt es für Pflicht, diesen Plan darzulegen. Da meine Kräfte nicht bis dalin reichen, dürte sich vielleicht in einer planzenphysiologisehen Schule Gelegenheit zur Prüfung und Ausführung desselben finden.

Konnte ich nach dem Vorstehenden nicht mit Boffnung auf Erfolg die gleichzeitige Behandlung aller der v. M(hl und mir gewählten Versuchspflanzen durchführen, so war mir gleichwohl nicht der Weg. abgreschnitten, wenigstens einiges zur Prüfung der ersteren Experiment? zu thun. Ich versuchte je zwei der Versuhspflanzen bezüglich d"r Reizbarkeit durch den electrischen Sclilag zu veryleichen. Dabei wandte ich eine verdünntere, empfirdlichere Scale und sehr schwache Inductionsschläge an. In deın vachfolgenden Täf lchen sind mehrere Spaltöfnungen mit der Glycerinscale behandelt und andere derselben Pflanze und desselben Blattes dem Inductionsschlag ausgesctzt. Die Vursuche kınnten für die Veryleichung $z$ weier Pflanzen in 4 bis 5 Stunden ausgeführt werden. Dabei wurde in jeder Weise erst mit der Scale, sodann mit dem Inductionsschlag der Spalt zun Schliessen gebracht. 


\begin{tabular}{|c|c|c|c|c|}
\hline Name & der Pflanze. & $\begin{array}{l}\text { Nummer } \\
\text { der Glycerin- } \\
\text { scale. }\end{array}$ & & $\begin{array}{l}\text { Dauer der In- } \\
\text { duction in Secun- } \\
\text { den. Spirale anf } \\
\text { No. } 6 \text { ausgezogen }\end{array}$ \\
\hline \multirow{4}{*}{\multicolumn{2}{|c|}{ Lilium croceum }} & 4 & $\begin{array}{l}\text { Schliessung ohne Con- } \\
\text { traction des Proto- } \\
\text { plasma. }\end{array}$ & 29 \\
\hline & & 5 & desgl. & 25 \\
\hline & & 5 & desgl. & 30 \\
\hline & & 6 & $\begin{array}{l}\text { Schliessung mit Con- } \\
\text { traction derselben. }\end{array}$ & 25 \\
\hline \multirow[t]{4}{*}{ Lilium } & candidum & 3 & $\begin{array}{l}\text { Scbliessung ohne Plas- } \\
\text { macontraction. }\end{array}$ & 40 \\
\hline & desgl. & 4 & $\begin{array}{l}\text { Schliessung mit PJasma- } \\
\text { contraction. }\end{array}$ & 45 \\
\hline & desgl. & 4 & desgl. & 40 \\
\hline & desgl. & 3 & $\begin{array}{l}\text { Schliessung ohne Plas- } \\
\text { macontraction. }\end{array}$ & 45 \\
\hline \multirow{2}{*}{\multicolumn{2}{|c|}{$\begin{array}{l}\text { Herminium Monorchis } \\
\text { desgl. }\end{array}$}} & 4 & desgl. & 25 \\
\hline & & 5 & $\begin{array}{l}\text { Schliessung mit Plasma- } \\
\text { contraction. }\end{array}$ & 30 \\
\hline & desgl. & 5 & $\begin{array}{l}\text { Schliessung ohne Plas- } \\
\text { macontraction. }\end{array}$ & 30 \\
\hline & desgl. & 6 & $\begin{array}{l}\text { Schliessung mit Plasma- } \\
\text { contraction. }\end{array}$ & 35 \\
\hline
\end{tabular}

Man kann aus diesen Beobachtungen mit Berücksichtigung der Nutizen in der zweiten Colonne für die Vergleichung der endosmotischen Capacitat des Plasma der Schliesszellen die folgenden Mittelwerthe annehmen.

Lilium croceum: Schliessung durch Glycerin No. 5 der Scale. Dauer des Inductionsstroms 27 Secunden.

Lilium candidum: Schliessung durch No. 4 der Scale. Dauer derselben 4: Sekunden.

Herminium Monorchis: Scbliessung durch No. 5 der Scale. Dauer derselben 30 Sekunden.

Es ergiebt sich aus dieser Zusammenstellung, dass eine Proportionalität in der Anwendung der beiden Agentien nicht besteht. Noch auffalliger zeigt das die folgende Experimentenreibe. 


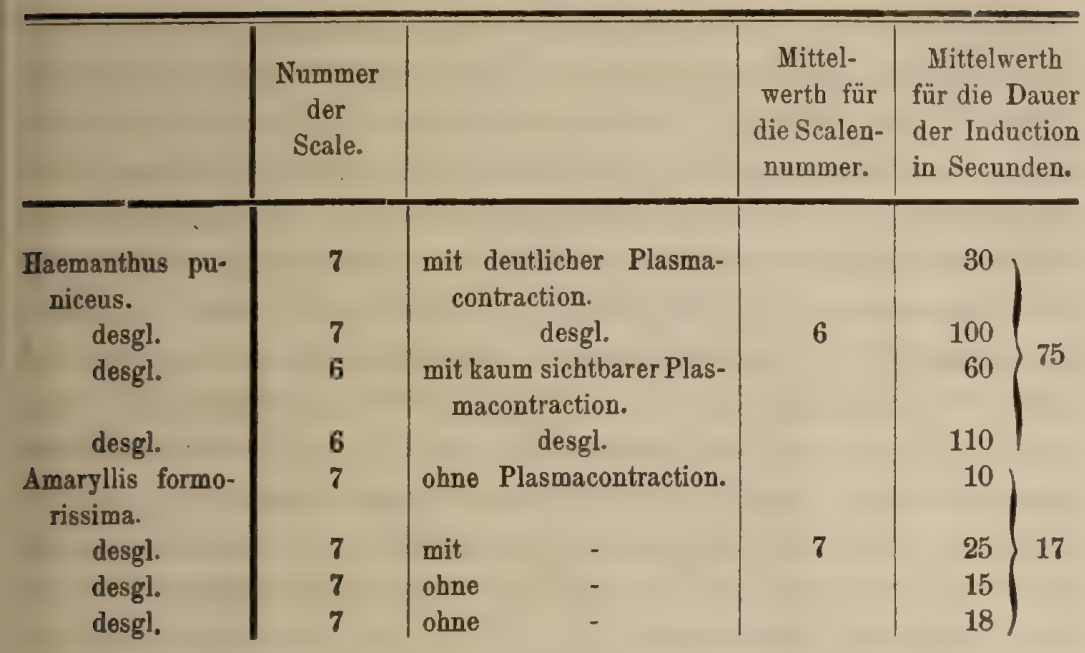

Die Bestimmung der Scalenmittelwerthe kann eine nur näherungsweise sein. Die grossen Unterschiede in der Dauer der electrischen Erschütterung mit der letzten Experimentenreihe deutet darauf hin, dass ein unmittelbarer Zusammen ang zwischen dem endosmotischen Verhalten der Protoplasmamassen und der Energie, mit welcher der Spalt geöffnet bleibt, nicht besteht. Um so mehr ist die Hypothese nahe gelegt, dass die Schliessung des Spaltes durch diesen Reiz nicht unmittelbar $d$ arauf beruhe, dass dies endosmotische Verhalten des Plasma eine Aenderung erleide, sondern dass mit der Membran zunächst eine Umänderung eintrete, sei es, dass dieselbe schlaffer wird und in Folge davon die Gestaltänderung eintritt, sei es, dass sie permeabeler für Wasser wird, wodurch ein Theil der Flüssigkeit der prall gefüllten Schlicsszellen austritt, und eine Volumverringerung die Schliessung herbeiführt.

\section{Nachweis der Wegsamkeit durch Manometerversuche.}

Nachdem im vorigen Abschnitt gezeigt wurde, dass ein Theil der Ursache der Bewegung der Schliesszellen in Spannungerscheinungen der Zellnembran lestehe, karn es mir darauf an, die am Microscop gewonnenen Resultate mit eiver anderen Methode zu prüfen. Der von mir eingeschlagene Weg führt zu Experimenten am lebenden Pflanzenblatte und zu sehr einfachen Fragen, die ich mir über die Wegsamkeit der Spaltöftnung vorlegte. Ich habe ge- 
legentlich der Betrachtung des Gasaustritts aus einem Intercellularraum schon früher eines einfachsten Apparats gedacht ${ }^{1}$ ), wie er in der Natur nicht rorkommt. Das Blatt der Phanerngamen stellt ein complicirtestes System vieler cinzelner solcher Apparate dar. Mein Bestreben ging nun dahin, das gebotene Intercellularraumsystem so zu behandeln, dass die Atınosphäre in ihnen unter einen höheren Druck gelangt, als der Baronieterstand und ein Gasetrom rom Inuern der Pflanze nach Aissen bewirkt wird; oder umgekehrt. Bei der Erforschung der Function der Spaltoffnung ist dies die erste und wichtigste Art zu experimentiren. Man hat im Experiment Berlingungen herzustellen, welche in der Natur als die Pflanze beeinflussende bekannt sind. Die Frage, die ich mir bier stellte, ist die folgende. Bewirkt die Erwärmung des Intercellularranmsystems eine Erleichterung des Gasstroms durch die Spultöffnung?

Ich suchte die Geschwindigkeit eines in allen Versuchen gleichen Gasstromes aus dem Innerlu der Pflanze zu bestimmen, bei rerschiedenen Temperaturen und Buleuchtungen des Pfanzenblattes und dessen Umuebung. Der Apparat, dessen ich mich bediente, wurde nach folwenden Principe construirt. Es sollten alle communicirenden Intercellularräume eines Lulthlattes mit cinem geschlossenen gasführeaden Recipienten commuriciren, und durch die feinsten Intercellularen und Spaltöffurgen mit einem zweiten geschlossenen Recipienten, und es soll die Geschwindigkeit gemessen werden, mit welcher ein und derselbe Druckunterschied zwischen beiden durch das Blatt getrennten Recipienten sich aus. gleicht, bei verschiedener vorheriger Beeinflussung des Pflanzenblattes. Der Apparat ist iu T'af. V. dargestellt. An einem massiven eisernen Stativ sind nittelst verschiebbarer Klummen die beiden Glascylinder A und B befiestigt. Der Cylinder A führt zwei ihn verschliessende Coutchoucpfropten, von welchen der obere dreimal durchbohrt ist und in die Durchbohrungen aufuimint, ein Ventil c, ein Thermometer t, ein Ahzugsrolir b; der untere Pfropf ist zweimal durchbobrt und nimmt in die Durchhohrungen auf: Die Mündungen eines [Differentiulnanometer's M M, dessen einer Quecksilberspicgel mit der Atmosphäre im Recipienteu A, dessen anderer mit dem Innern des Pflanzenblattes communicirt. Der letztere Schenkel des Differentialmanometers ist an einer

1) Pringsheim, Jahrbücher. VI. S. 497. 
Stelle spindel:g erweitert und hat an dieser Stclle zwei Glasröhren angelöthet, von welchen eine $b^{1}$, nach dem Innern des Recipienten $\mathrm{B}$, die andere $\mathrm{b}^{11}$ nach einer Pumpe $\mathrm{P}$ führt. Der Recipient $\mathrm{B}$ hat ausserdem noch in dem oberen Coutchouepfropf ein Thermometer $t^{1}$ und ein Ventil $c^{1}$, und in dem unteren cine nach oben zugeschmolzene graduirte Röhre D, welche dem Coutchoucpfropf luftdicht schliessend aus- und eingezogen werden kann. Die Rolire b und $b^{11}$ führen zu einem Wurtzschen Ruhr b ${ }^{111}$, welches unmittclbar mit der Sprengelschen Pumpe communicirt. Die ersteren führen die Hähne $\mathrm{c}^{11}, \mathrm{e}^{111}$, durch welche die Communication mit Pumpe leicht hergestellt und unterbrochen werden. Bei der Herrichtung zu einem Versuch bleiben die folgenden Theile an dem Statir befestigt. Der Recipient B mit allen Theilen verbunden mit deın Differentialmanometer $\mathbf{M ~ M}^{1}$ und dem unteren Coutchoucpfropf des Recipienten A. Dieser mit den Röhren im obcren eingefügt bluibenden Propf wird abgenommen urd das Blatt dem Manometerarme $\mathbf{M}$ eingelügt. Es sind nur solche Blätter vcrwendbar, wulche nahezu kreisrunden Querschnitt am Blattstiel zeigen, und bei welchen die Capillaren eine nicht zu beträchtliche Enge besitzen. Die Blätter wurden befestigt mittelst eines Contchoucschlauches, welcher den Blattstiel nıfasst. Die Einfügung an dem Manonneterschenkel M. ist haufig mit grössten Schwierigkeiten verbunden. Die Piöfung des luftuichten Verschlusses wurde folgendernaassin angestellt. Es wurde um die Einfügnngsstelle des Blattes in die Mündung ein Behälter aus Mndellirwachs gebildet, welcher erlaul,te, dass man Wasser bis über die Verbandstelle geben konnte, so dass dieselhe sichthar war. Al-darn wurde durch Blasen an dem anderen Schenkel in demselben die Quecksilher:äule um soriel gesenkt, als man etwa vermuthete, dass die im Versuch angewendete Druckdifferenz betrage, dann wurde der letzte Schenkel wieder geöffuet und beobachtet, ob ir das Wasser des besagten Behälters au Modellirwachs Gasbläschen austraten. Geschah dies nicht, so wurde zu dem Beginne der Versuche geschritten: Die Electroden e e ${ }^{1}$, welche durch den untern Coutchoucpfropf des Recipienten A gingen, wurden an dem Blatte befestigt, der Recipient A dem Pfropf eingefügt. Es bleibt jetzt nur noch die leicht zu bewerkstelligende Prüfung der Verschlüsse der Recipienten durch die Coutchoucpfropfen. Zu dem Behufe wird um die obern Ränder beider Recipienten ein Cartonhülse ge..lebt, welche über dic Pfropfen und deren röhrenumfassende Bohrlöcher 
hervorragt, und nachdem dieser Behälter mit Sublimatlosung bestrichen mit Quecksilber gefüllt. Durch die Ventile $\mathrm{c}$ und $\mathrm{c}^{1}$ wird Wasser in A, Quecksilber und Wasser in B, einige Millimeter auf die unteren Pfropfe geschichtet. Der Apparat ist damit zum Versuch hergerichtet. Zur Verständigung der nachstehenden Experimente ist nur noch folgendes nöthig: Betrachtet man die beschriebene Zusammenstellung wie sie in Taf. V. dargestellt ist, so sind alle Apparattheile unter dem Druck des Barometerstandes b, wenn geöffinet sind die Ventile $\mathrm{c}$ und $\mathrm{c}^{\prime}$ (geschlossen mögen sein die Hähne $\mathrm{c}^{11}$ und $\mathrm{c}^{111}$ ). Bei dieser Stellung zieht man den Stempel D aus, so weit als möglich, und schliesst die sämmtlichen. Ventile und Hähne. Jetzt noch stehen die beiden Spiegel im Differentialmanometer $\mathbf{M} \mathbf{M}^{1}$ gleich, auf dem 0 Punkt der Scale. Schiebt man jetzt den Stempel D in den Recipienten B hinein, so wird die Atmosphäre im Innern des Recipienten B und des Blattes comprimirt. Der Spiegel in $\mathbf{M}$ sinkt. Der Spiegel in $\mathbf{M}^{1}$ steigt. Wird der Druck, unter welchem nach Einschieben des Stempels D die Atmospluäre beider Recipienten steht, b genannt, so steht für einen kleinen Zeitraum, während welcher das Blatt noch als impermeabel gelten möge, die Atmosphäre in B unter den Drucke b $+\mathbf{n}$ (millim. Quecksilber); in A und den Hohlräumen des Blattes unter dem Drucke $b-n^{1}$, wo $n$ and $n^{1}$ an der Scale des Manometers $M_{M^{1}}$ abgelesen werden $\left(n+n^{1}\right)=n^{11}$ ist die Druckdifferenz für den Zeitpunkt und ist für alle Versuche mit einem und demselben Blatt constant. Der Zeitpunkt der Ablesung wird nach der Secuudenuhr notirt, und gewartet, bis die Spiegel beider Schenkel auf dem Nullpunkt stehen. Der Zeitpunkt dieser Ablesung wird ebenfalls nach der Uhr notirt.

Eine Hauptbedingung eines jeden Versuchs ist die annähernde Gleichheit der Temperatur in jedem Recipienten. Jedem Versuch geht voraus und folgt eine Thermometerablesung an $t$ und $t^{1}$.

Bei dem geschilderten Versuch geht ein Luftstrom durch die Intercellularen und Spaltöffnungen aus dem Innern des Blattes in den Recipienten A. Um ungekehrt einen solchen aus dem Recipienten $\mathbf{A}$ durch bcnannte Raume in den Recipienten B treten zu lassen, wird in der Hundhabung von D umgekehrt verfahren, nämlich: D eingeschoben, $\mathrm{c}$ und $\mathrm{c}^{1}$ geöffnet, alsdann $\mathrm{c}$ und $\mathrm{c}^{1}$ und alie Hähne geschlossen, D ausgezogen und die vorgenannten Ablesungen notirt.

23. Experiment. Es wird ein Blatt von Caladium esculen- 
tum in dem Recipienten B befestigt, nachdem dasselbe einen halben Tag in Wasser in einem finstern Recipienten gestanden. Der Recipient A wird mit einer undurchsichtigen Blechhülse umgeben und mit einem schwarzen Tuch behängt.

\section{Der Strom von innen nach aussen.}

1) Die Druckdiffererz von $50 \mathrm{~mm}$. Quecksilber ist ausgeglichen in 195 Secunden. Die Temperatur im Recipienten $\mathrm{A}$ ist $23,4^{\circ}$, die Temperatur im Recipienten B $23,2^{\circ}$. Beobachtungszeit Abends um $11 \mathrm{Uhr}$.

2) Der Apparat bleibt in dem oben beschriebenen Zustande stehen bis zum nächsten Tag um $10 \mathrm{Uhr}$ in der Sonnenseite eines durch Vorhange beschatteten Zimmers. Die Temperatur in beiden Recipienten stieg bis 10 Uhr früh in $\mathrm{A}$ auf $27,4^{\circ}$, in $\mathrm{B}$ auf $27,1^{\circ}$. Dieselbe Druckdifferenz wird jetzt ausgeglichen in 100 Secunden.

24. Experiment. Ein ähnliches Blatt von Caladium esculentum, welches von einer den Tag über besonnten Pflanze genommen war, wird Abends $5 \mathrm{Uhr}$ in den Apparat gebracht und der Versuch wenig später begonnen. Der Apparat steht im Dämmerlicht in Schatten. Der Strom geht von innen nach aussen.

1) Die Druckdifferenz von $50 \mathrm{~mm}$. wird ausgeglichen in 150 Secunden. Temperatur im Recipienten B $27,5^{\circ}$, im Recipienten B $27,2^{\circ}$.

2) An dem Recipienten B wird ein Thermostat angebracht, mittelst dessen die Temperatur annähernd auf $30^{\circ} \mathrm{C}$. erhalten wurde, während vier Stunden. Die nächste Ablesung wurde nach sechs Stunden vorgenommen (Nachts $11 \mathrm{Ubr}$ ), die Temperatur im Recip. war $27^{\circ}$. Die im Recip. A $26,8^{\circ}$ C. der Ausgleich derselben Druckuifferenz ging in 1:0 Secunden von statten.

Diese Versuche würden dem Experimentator, selbst wenn die im früheren Abschnitt erhaltenen microscopischen Resultate nicht vorhanden waren, Andeutungen sein, dass es nicht die leuchtende Kraft der Insolation allein ist, welche die Spalten öffnet.

Un zu diesen Andeutungen experimentelle Belege gewichtigerer Natur zu geben, wandte ich eine zweite Methode an, welche die Häufung der Experimente ohne zu grossen Zeitverlust erlaubte. Die Methode besteht in folgendem: Das Blatt wird, wie früher, in dem Recipienten befestigt. In dem Recipienten B wird 
eine wasserdunstgesättigte Atnısphäre dadurch hergestellt, dass derselbe mit Glasscherhen gefüllt wird, welche mit Wasser benetzt werden, der Stempel D bekommt für eine Rcihe von Versuchen eine constante Stellung. Die erforderliche Druckdifferenz zwischen dem Reripienten A und B wird durch Auspumpen durch eine Sprengelsche Pumpe besnrgt. Dicse steht durch den Bahn $\mathrm{c}^{11}$ mit dem Recipienten A, durch $\mathrm{c}^{111}$ mit dern Recipienten B in Verbindung. Wird $\mathrm{c}^{11}$ geöffuet, $\mathrm{c}^{111}$ geschlossen, während die Pumpe evacuirt, so hebt sich der Quecksilherspiegel in $\mathbf{M}^{\mathbf{1}}$, der in $\mathbf{M}$ sinkt, und es wird ein Gasstrom aus dem Recipienten B durch das Innere der Pflanze in den Recipienten A veranlasst.

Wird dagegen $\mathrm{c}^{111}$ geöffnet, $\mathrm{c}^{11}$ geschlossen unter sonst gleichen Ünständen, so hebt sich der Spiegel in $\mathbf{M}$, der in $\mathbf{M}^{1}$ sinkt und ein Gasstrom aus dem Recipienten A durch das Innere der Pflanze nach dem Blattstiel und dem Recipienten B wird veranlasst.

Bei den nachfolgenden, an Allium altaicum gemachten Versuchen konnte nur der Strnm vom Innern der Pflanze nach dem Recipienten A benutzt werden.

Es wurde dabei so verfahren: Ehe die Pumpe C, Taf. $\nabla$., in Bewegung gesetzt wurde, wird das Ventil $c^{1}$ geöffiet, nun allo Bahne geschlossen, bis auf $\mathrm{e}^{11}$, solann evacuirt, bis auf die gewünschte Mruckdifferenz. In dem Moment, wo unan diese hergestellt hat, ist der Druck in B gleich dem Barometerotand, im Recipienten A hingegen gleich diesem minus $\left(n+n^{1}\right)$, wo $n$ die Zahl der Scalentheile unter 0 von $\mathbf{M}$ und $\mathrm{n}^{1}$ dicjunigen ütrer 0 ron $\mathbf{M}^{1}$ bedeuten. Schliesst man in dem Zeitpunkt der hnreichenden Evacuation von A den Hahn $\mathrm{c}^{11}$, so hat man nur noch zwei Ablesungen an dem Schenkel $M^{x}$ des Monometers zu machen und die $\mathbf{Z}$ eit derselben zu notiren. Der Ausgleich der Druckdifferenz geht aber rascher vor sich, wenn von dem Moment der ersten Ablesung der Recipient B wieder gesclilossen wird; und dieser Uustand macht gerade die letztere Zusammenstellung des Apparates äusserst bequem. In dem Augenblick nach der Schliessung des Ventils $\mathrm{C}^{1}$ ist das constante Volum Luft im Recipienten B unter dem Drucke des Barometerstandes. Der Strom dieser Atmosphäre dauert so lange, bis die Druckdifferenz ausgcglichen ist dadurch, dass ein Theil der Atmosphäre ron B nach A fliesst. Ist dies eingetreten und sind die nöthigen Ablesungen gemacht, so werden die beiden Ventile $c$ und $c^{1}$ geóffnet, und alle Räume 
bis zur Anstellung einer neuen Ablesung unter dem Drucke des Barometerstandes gelassen.

25. Experiment. - Ein Blatt von Allium altaicum wurde an einem sonuigen septembertag 3 Stunden vor dem Einsetzen in den Apparat von einer insolirt gewesenen Pflanze genommen und im Schatten bei einer Temperatur von $24^{\circ} \mathrm{C}$. in wasserdunstgesättigtem Raume aufbewahrt und während $24-36$ Stunden die folgenden Ablesungen gemacht.

1) Tageszeit (Abends $\Varangle \quad \mathrm{Uhr}$ ), Temp. im Recipienten A $21,5^{0}$ C. Teup. im Recipienten B $21,3^{\circ} \mathrm{C}$.

Ausgleich des Druckunterschieds von $20 \mathrm{~mm}$. auf $10 \mathrm{~mm}$. Quecksilber in 600 Secunden.

2) Tageszeit (Abends 10 Uhr), Temp. im Recipienten A $20^{\circ}$ C. , im Recip. B $19,7^{\circ}$ C. Ausgleich derselben Druckdifferenz in 660 Secunden.

Der Apparat wurde nach diesen Ablesungen auf die oben angegebene Weise verfinstert und die Nacht über unter dem Druck der Atmosphäre in allen Räumen belassen.

Die Temperatur sank von $10 \mathrm{Uhr}$ ab und erreichte $16,5^{\circ} \mathrm{C}$. morgens um 3 Uhr, stieg und hatte um 9 Uhr $20^{\circ}$. Die Pflanze verweilte aber jedenfalls längere Zeit bei einer Temperatur unter der am vorhergehenden Abend abgelesenen. Um 9 Uhr geschahen die folgenden Ablesungen:

3) Tageszeit (Morgens $9 \mathrm{Uhr}$ ), Temp. in A 21,50 C., in B $21,2^{\circ}$ C. Dieselbe Druckdifferenz wird in $1010 \mathrm{Se}$ cunden erst ausgeglichen.

Von nun ab werden wahrend zwei Stunden mittelst zweier Thermostaıen die beiden Recipienten $\mathrm{A}$ und $\mathrm{B}$ auf $26^{\circ} \mathrm{C}$. erwarmt und nach dieser Zeit auf die gewöhuliche Temperatur erkaltet, nach dieser Operation wird die folgende Ablesung gemacht.

4) Tageszeit (12 Uhr Mittigs), Temp. in A $22^{\circ} \mathrm{C}$; in B $21,7^{\circ} \mathrm{C}$. Dieselve Druckuffferenz glich sich aus in 810 Secunden. Wiederholung derselben Ablesung ergiebt 870 secunden. Mittel hieraus 855 Secunden.

Die PHanze verblieb von nun ab bis Abends beschattet und rerdunkelt, die Temperatur des Zimmers ist $20^{\circ}-21^{\circ}$.

5) Tageszeit (Abends $y$ Uhr), Temp. in A $20^{\circ}$ C. In B 19,6 C. Dieselbe Druckuifferenz gleicht sich in $1140 \mathrm{Se}-$ cunden aus.

Noch an demselben Abende wurde der Recipient A auf $30^{\circ} \mathrm{C}$. 
während zwei Stunden erwärmt und um Mitternacht die folgende Ablesung gemacht, nachdem der Apparat erkaltet war.

6) Tageszeit (Mitternacht), Temp. in A $20,3^{\circ}$, in B $20^{\circ} \mathrm{C}$. Dieselbe Druckdifferenz ist ausgeglichen in 920 Secunden und in 960 Secunden. Mittelwerth 940 Secunden.

Die Pflanze verblieb wiederum den Rest der Nacht im Finstern bei einer Temperatur, die unter $18^{\circ} \mathrm{C}$. sank, und ergab bei der letzten Ablesung:

7) Tageszeit (Morgens $7 \mathrm{Uhr}$ ), Temp. in A $20^{\circ} \mathrm{C}$, in B $19,7^{\circ} \mathrm{C}$., den Ausgleich derselben Druckdifferenz in 1020 Secunden aus zwei Ablesungen als Mittelwerth.

Was bei allen hier einschlägigen Versuchen auffält, ausser der Unabhängigkeit des Wechsels der Wegsamkeit von der Beleuchtung, ist die stetige Verlangsamung wàhrend der zwei Tage der Dauer der Experimentenreibe, und es ist hier wohl der Ort, daran zu erinner, dass dies nichts gegen den ersten Nachweis aussagt. Die Ursache dieser Verlangsamung, die auf eine stetige Verengung des Spaltes schliessen lassen, sind die folgenden: das dem Apparat eingefügte Blatt verliert dadurch, dass aus dem Recipienten A immer dunstgesättigte Luft genommen wird, fortwahrend Wasser, welches ihm höchst wahrscheinlich nicht in dem Maass durch die nasse, aus dem Recipienten B strömenden Gase zugelührt wird, dass die Maxima und Minima der Turgescenzschwankungen und diejenigen der endosmotischen Spannung denjenigen der Pfanze im natürlichen unverletzten Zustand gleichkommen.

Um den Nachweis zu liefern, dass die Spaltöffnungen an dem ganzen Blatt, nachdem sie durch Warme zum Oeffnen gebracht waren, durch den electrischen Schlag geschlossen oder verengt werden, kam es darauf an, eine bedeutende Verlangsamung im Ausgleich der Druckdifferenz, nach dem Einfluss dieser Reizung zu beobachten. Zu solchen Versuchen ist die Apparatzusammenstellung in unserer Figur wiedergegeben. Um den Recipienten B wird ein Hohlcylinder von Messingblech gegeben, welcher deuselben allseitig umschliesst und welcher einen dicken Streifen Blech angeniethet trägt, dessen Ërwärmung mittelst der Weingeistoder ventilirten Petroleumlampe den Messingblechcylinder erwärmt. Durch den unteren Coutchoucpfropf des Recipienten A gehen zwei an beiden Enden mit Haken versehene Kupferdrähte, deren innere Haken die Platin-Electroden e und $e^{1}$ führen, welche die Pflanze 
zwischen Blattstiel und Ende der Lamina einschliessen, deren äussere Enden nach der inducirten Spirale eines Inductionsapparates führen. Zwei kleine Bunsen'sche Elemente genügen zu diesen Versuchen. Es kam mir, um jeder Täuschung vorzubeugen, bei diesen Versuchen darauf an, aus mehreren Ablesungen genügend bestimmte Mittelwerthe zu bekommen.

26. Experiment. - Ein Blatt von Allium altaicum wird in dem Recipieuten A untergebracht und während 12 Stunden beobachtet. Es ergaben sich aus vier Ablesungen am Morgen die folgenden Angaben: die Druckdifferenz von $40 \mathrm{~mm}$. Quecksilber ist bei annähernd constanter gewöhnlicher Temperatur ausglichen in

180, 200, 165, 175 Secunden. Der Mittelwerth ist 180 Secunden.

$\mathrm{Um} 11 \mathrm{Uhr}$ wurde der Batteriestrom geschlossen und $15 \mathrm{Se}-$ cunden lang die Schläge durch die Pflanze geschickt. Die nächsten Ablesungen ergeben den Ausgleich erst in folgenden Zeiten:

240 Secunden nach 15 Secunden langer Wirkung der inducirten Schläge.

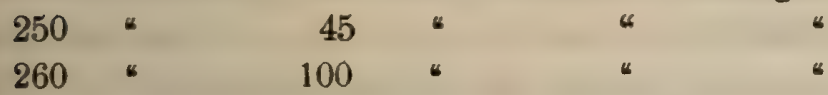

270 Secunden nach 160 Secunden langer Dauer der Schläge.

$\begin{array}{llllll}300 & \text { " " } & 200 & \text { " } & \text { " } & \text { " } \\ 300 & 260 & \text { * } & \text { * } & \text { " }\end{array}$

Diese Ablesungen waren innerhalb 11/2 Stunden gemacht und zeigen, dass eine Verengung der Spalten eingetreten ist. Um zu zeigen, dass der Reiz ein vorübergehender sein kann, wurde der Recipient A auf $35^{\circ} \mathrm{C}$. während 3 Stunden erwärmt, und nach dem Lrkalten die folgenden Ablesungen gemacht: Dieselbe Druckdifferenz ist ausgeglichen in 270, 260, 250, 265 Secunden. Mittelwerth hieraus 261 Secunden.

27. Experiment. - Ein Blatt der Saxifraga maxima ist das Object: Die constante Druckdifferenz ist $60 \mathrm{~mm}$. Quecksilber. T. i soll die T'emperatur im Recipienten B; T. e diejenige im Recipienten A bedeuten. 


\begin{tabular}{|c|c|c|c|c|}
\hline T.e & T. i & $\begin{array}{l}\text { Zeitdauer } \\
\text { des Aus: } \\
\text { gleiches in }\end{array}$ & $\begin{array}{l}\text { Nummer der } \\
2 \text { gleichzeiti- } \\
\text { gen Abesun- } \\
\text { gen und Mittel }\end{array}$ & $\begin{array}{l}\text { Der Versuch I. wurde um } \\
8 \text { Uhr Morgens gemacht; der } \\
\text { Versuch II., nachdem die Pflanze }\end{array}$ \\
\hline Grad & Grad & cunden. & & \\
\hline $\begin{array}{l}22,8 \\
-\end{array}$ & 22,4 & & 107,5 I. & och längerer \\
\hline 22,8 & 22,4 & 1 & 22.5 & to. \\
\hline$\overline{22,4}$ & $\overline{21.0}$ & & & wöhnlichster Temperatur und er- \\
\hline- & - & & 220 & folyter "2ten Reizung von $3 \mathbf{M i}$ - \\
\hline$\stackrel{20,2}{-}$ & 20 & & 160 IV. & $\begin{array}{l}\text { nuten. } \nabla \text {. nach weiterer } 8 \text { stün* } \\
\text { diger Ruhe und Erwärmen auf }\end{array}$ \\
\hline $\begin{array}{c}20,2 \\
-\end{array}$ & 20 & & $117,5 \mathrm{~V}$. & $30^{\circ} \mathrm{C}$. VI. unınittelbar nach V. \\
\hline 20,2 & 20 & $\begin{array}{l}150 \\
160\end{array}$ & 155 & Inductionsschläge. \\
\hline
\end{tabular}

28. Experiment. - Vou Xanthosoma appendiculata wurde ein Blatt in den Recipicnten A gebracht. Druckdifferenz ist $50 \mathrm{~mm}$. Quecksilber.

\begin{tabular}{|c|c|c|c|}
\hline $\begin{array}{l}\text { Ti. } \\
\text { Grad }\end{array}$ & $\begin{array}{l}\text { Te. } \\
\text { Grad }\end{array}$ & $\begin{array}{l}\text { Dauer bis zum } \\
\text { Ausgleich } \\
\text { in Secunden. }\end{array}$ & $\begin{array}{l}\text { Nittelwerth und } \\
\text { Nummer } \\
\text { der Versuche. }\end{array}$ \\
\hline 22 & $\begin{array}{l}22,4 \\
-\end{array}$ & $\begin{array}{l}300 \\
300\end{array}$ & 300 I. \\
\hline & 21,5 & $\begin{array}{l}210 \\
220\end{array}$ & 215 II. \\
\hline $\begin{array}{l}21,6 \\
-\end{array}$ & 22 & $\begin{array}{l}260 \\
250\end{array}$ & 245 UI. \\
\hline $\begin{array}{l}20,5 \\
-\end{array}$ & $\begin{array}{c}20,8 \\
-\end{array}$ & $\begin{array}{l}200 \\
220\end{array}$ & 210 IV. \\
\hline $\begin{array}{l}21,8 \\
-\end{array}$ & 22 & $\begin{array}{l}380 \\
400\end{array}$ & $390 \quad \mathrm{~V}$. \\
\hline 20,8 & 21 & $\begin{array}{l}360 \\
350\end{array}$ & $355 \quad$ VI. \\
\hline
\end{tabular}

Die sechs Mittelwerthe, aus je zwei unmittelbar auf einanderfolgenden Ablesungen wurden erhalten nach dem folgenden Verfahren: Das Blatt wurde morgens um 10 Uhr eingesetzt und ohne vorherige Erwärmung die zwei ersten Ablesungen (deren Mittelwerth in I ist) gemacht. 
Die Ablesungen, deren Mittelwerth unter II angegeben, wurden remacht, nachdem der Recipient von $11 \mathrm{Uhr}$ früh bis $2 \mathrm{Uhr}$ Nachnittags auf $35^{\circ} \mathrm{C}$. erwärmt war, um $5 \mathrm{Uhr}$ bei gewöhnlicher Temperatur. Nun blieb der Apparat bei gewöhnlicher Temperatur stehen bis 9 Uhr Abends, zu welcher Zeit die Ablesungen, deren Mittelwerth unter III. gegeben, gemacht wurden. Nach einer wiederholten Erwärmung von zwei Stunden wurden um Mitternacht, achden die Temperatur wieder die der äusseren Atmosphäre war, die Ablesungen unter IV. gemacht und unmittelbar darauf lie Pflanze electrisch erschüttert. Die Ablesung $V$ zeigte die Folgen dieser Behandlung Es bat sich die Dauer des Druckausgleichs nach einer Dauer der Inductionsschläge von 30 Secunden, von 220 auf 380 , und nach einer Daver ron 100 Semnden auf 400 vermehrt. Der Apparat blieb bis um $10 \mathrm{Uhr}$ früh les nächsten Tages stehen, zu welcher Zeit die Ablesungen unter VJ gemacht wurden, welche ergeben, dass die Pflanze im Begriff war, sich von dem Reize zu erholen.

29. Experiment. - Ein Blatt von Allium altaicum wird in Jen Recipienten A gebracht, und während drei Stunden' beobachtet vei einer Temperatur von $20^{\circ} \mathrm{C}$. in beiden Recipienten. Der Ausgleich von $80 \mathrm{~mm}$. Druckdifferenz zwischen A und B, der Gasstrom geht aus dem Innern der Pflanze in die Atmosphäre, wird beobachtet in 40 Secunden,

50
45
48

Nach Anstellung der lutzten Strömung werden beide Recipienten, $\mathbf{A}$ und $\mathbf{B}$, mit 2 wei Blechbülsen mit doppelter Wandung versehen, welche mit einer Kältemischung aus Eis und Kochsalz augefüllt ist. Die Temperatur in den Recipienten A und B sinkt rasch auf $4^{\circ}$ nachdem die Kältemischung 5 Minuten lang applicirt war, wurde sie entfernt und dieselbe Druckdifferenz von $80 \mathrm{~mm}$. hergestellt. Dieselbe gleicht sich jetzt aus in

120 Secunden,

130 "
125
127

Nun wird der Apparat unter dem Atmosphärendruck in allen Theilen belassen, wähend 2 Stunden. Die Temperatur ist jetzt Jahrb. f. wisk. Botanik. VIII. 
$18^{\circ} \mathrm{C}$. in beiden Rucipienten. Derselbe Drucknnterscbien wird jetzt ausgeglichen in

80 Secunden,
75
70
78

Nach einer weiteren Ruhe von 4 Stunden geht derselbe Druckausgleich in 60, 55, 50, 58 Secunden vor sich.

30. Experiment. - Mit einem anderen Blatt derselben Pflanze wird ähnlich rerfahren, die Kältemischung bleibt 15 Minuten. Der Ausgleich einer Druckdifferenz ron $80 \mathrm{mim}$. wurde vor der Kältemischung beobachtet in 60 Secunden, 65, 70, 73 Secunden, nach derselben in 310 Sec., 350, 325, 340 Sec., nach zweistündiger Ruhe und Temperaturerhöhung ron $-10^{\circ}$ auf +15 in 200, 260, 300 Secunden.

31. Experiment. - Ein ähnlicher Versuch. Temperatur: For der Anwendung der Kältemischung $18^{\circ} \mathrm{C}$., während einer halben Stunde der Wirkung dieser $-10^{\circ} \mathrm{C}$, nach 4 Stunden Ruhe, nach derselben $18^{\circ}$. Die Ablesungen ergeben die Druckdifferenz von $80 \mathrm{~mm}$., ausgeglichen

in $90,96,93,97$ Sec., zuerst vor der Erkältung, $600,650,630,610$, unmittelbar nach derselben, $500,540,510,500,4$ Stunden nach derselben.

Aus allen Versuchen ergiebt sich das übereinstimmende Resultat, dass die Verengung und Erweiterung der Spaltöffnung von der Wärme abbängt Man würde aber sehr fehlen, wollte man aus den Versuchen schliesseu, die Spaltöffnungen vermögten längere Zeit an der Pflanze zu functioniren, ohne den Einfluss des Sonnenlichtes. Dieses ist leicht zu erweisen, wenn man allein beachtet, dass die Zellinhalte der Schliesszellen wasseranziehend wirken, gegenüber den Zellen der Epidermis. Jede Oeffoungsstellung des Spaltöffnungsapparates ist Folge einer vorhergehenden $W$ asseraufnahme. Das Wasser, oder die wässrige Lösung, welche aufgenommen wird, kann nu r osmotisch schwächer wirken, wie die Zellinhalte der Schliesszellen. Bei jeder Schliessung, namentlich bei jeder Schliessung in Folge rascherer Temperaturschwankungen, wird ein Theil der Lösung aus der Schliesszelle hinausgepresst. Dadurch muss der Vorrath an Colloiden in der Schliesszelle allmählich abnehmen. Der Wiederersatz dieses Verlustes wird nun durch die Arbeit der Sonnenstrablen besorgt, und zwar kann dies nur dadurch geschehen, dass 
liese Schliesszellen selbst Assimilatoren sind. In der That führen die neisten von mir beobachteten, einpfindlicher reizbaren Spaltöffnunyen Chlorophyllkörper. So namentlich diejenigen der jüngeren noch rischgrünen, zarten Blätter, an welchen gemeiniglich auch die yrösste Empfindlichkeit gegen Wärmereiz beobachtet wird.

Die Arbeit, welche durch die assimilatorische Function der hlorophyllhaltigen Schliesszelle geleistet wird, kann nun auch selbstverständlich dadurch geleistet werden, dass die Pflanze in alge der Erwärmung verdunstet. Der geöffnete Schliesszellenapparat wird sich verengen, wenn in Folge der Verdunstung die Zellinhalte wasserärmer werden. Die Verdunstung wird somit der Hauptregulator der Mechanik der Spaltöffnung sein, insofern die ereits mit colloidalen Massen gefüllten Schliesszellen wasserärmer der wasserreicher werden. Würde aber in Folge häufiger Wiederolung von Schliessung und Oeffnung der Zellinhalt der Schliesselle inmer ärmer an colloidalen Massen, so müsste schliesslich lie bewegende Kraft des Apparats verschwinden und die Bewegung in demselben mit einer Oeffnungs- oder Schliessungsstellung abschliessen für alle Zeiten. Die Ursache dafür, dass dies nicht eintritt, kann nur einfach und allein in der Wirkung der Sonnenstrahlen begründet sein. Diese liefern die Kraft zur Assimilation im Chlorophyllkörper der Schliesszellen. Bei den älteren Blättern rerschwindet das Chlorophyll in denselben. Der einzige Regulator des Apparates kann jetzt nur die endosmotische Differenz sein; mithin ist die Temperatur bei älteren Blättern die bewegende Kraft des Apparates, insofern diese allein einen Ausgleich der endosmotischen Differenz zwischen Schliesszelle und Epidermiszelle verhindern kann, wenigstens für kurze Zeit. Wir erhalten hieraus folgende allgemeine Form der Deduction für die bewegenden Kräfte an unserem Apparat.

1) Hebung von Wasser aus einem Reservoir bis in dio Schliesszellen erfordert eine Arbeit, welche durch die endosmotische Differenz geleistet wird. Diese öfnet den Apparat.

2) Verschwinden des Wassers aus der Schliesszelle erfordert eine Arbeit, welche durch die allgemeine Wärmequelle die Sonne geleistet, diese schliesst den Apparat.

3) Das Reservoir, welches in den Schliesszellen liegt, und die endosmotische Differenz herbeiführt, wird erneuert durch die Arbeitsleistung der Sonnenstrahlen. 
4) Die Oeffnungsstellung, welche einem Ausgleich der endosmotischen Differenz näherliegt, ist dann noch deswegen einem Arbeitsvorrath in dem Apparat gleichzusetzen, weil in ihr die Membranplatten der Schliesszellen so gestellt sind, dass Arbeit verschwinden musste, um diese Stellung herbeizuführen. Die gekrünmtun cuticularisirten Membranplatten sind zwei fer?ernden Spiralen zu rergleichen, welche durch Verbrauch von Kraft zusammengedrückt sind, und in dieser Stellung durch einen Mechanismus dauernd erhalten sind, welcher selbst wieder durch den Verbrauch einer kleineren Kraft entfernt werden kann, wodurch der Arbeitsrorrath in den Spiralen ausgelöst und die Spaltöffnung zum Schliessen gebracht wird.

5) Die Oeffunngsstellung ist die normale Stellung des Apparates, die Schliessungsstellung ist die Reizstellung. Die Ḱraft, welche den Mechnnismus auslöst, von welchem in 4) die Rede war, ist der Inductionsschlag, oder der plötzliche Temperaturwechsel innerhalb weiter Grenzen. Beide sind als Reizungserscheinungen anzusehen. Die Eigenschaft einiger Spaltöffıungen, sich zu schliessen, wenn der Pflanzentheil in Wasser gelegt wird (Amaryllideen, und nach v. Mohl die Mehrzahl der Phauerogamen) wird man ebenfalls als einen vorübergehenden Reiz anzusehen haben, nachdem ron mir gelieferten Nachweis, dass die Spaltöffnungen aller Pflanzen bei Zufuhr von Wärme und Wasser sich öffnen. 


\title{
Ueber Bildungsabweichungen bei Cruciferen.
}

Von

\author{
Dr. J. Peyritsch.
}

Die an Cruciferen beobachteten Abweichungen rom normalen Typus der Blüthe beruhen grösstentheils auf Umbildungen ron Gliedern eines oder mehrerer Wirtel in andere, nach Bau und Verrichtung verschiedene Blüthentheile, oder in laubartige Blätter mit oder ohne Durchwachsung des Blüthenstiels und Entwicklung ron Axillarsprossen, in anderen Fällen auf Vermehrung oder Verminderung der Zahl der Wirtelglieder, seltener auf regelwidriger Verwachsung oder Trennung derselben.

Indem ich die Betrachtung der gefülltel. Blüthen übergehe, will ich die in zweiter Linie erwähnten Abnormitäten, soweit sie sich auf die Staubgefässe bezichen, einer eingehenden Besprechung würdigen. Die Blüthen der weitaus meisten Arten dieser Familie sind bekanntlich mit sechs Staubgefässen versehen, von welchen die zwei kürzeren und unteren lateral, die vier längeren und oberen paarweise median gestellt sind. In mehreren Gattungen findet constant die paarweise Verwachsung der Filamente der median stehenden Staubgefässe statt und letzture tragen bei Atelanthera ausnahmsweise einfächerige Antheren. Bei einigen Arten von Lepidium zeichnen sich die Blüthen durch eine grosse Variabilität in der Zahl und Stellung der Staubgefässe aus, indem bald nur 2, jedoch auch 3, 4 und 5 Staubgefässe in denselben vorkommen. Sind nur zwei vorhanden, was bei Lepidium ruderale die Regel ist, so stehen sie in der Mediane, ebenso in den dreimännigen Blüthen, wobei das eine Staubgefässpaar, wie in den fünfmännigen, bald dem vorderen, bald dem hinteren Kelchblatte gegenübersteht. In den viermännigen Blüthen nehmen die Staubgefässe paarweise mediane Stellung ein, oder es sind $\mathrm{zwei}$ lateral und zwei median 
stehende Staubgefässe vorhanden. Sehr selten wird in den drei-, vier- und fünfmännigen Bluthen nur ein einziges lateral stehendes Staubgefäss angetroffen').

Diese Fälle sind wohl als Ausnahmen, jedoch nicht als eigentliche Abnormitäten aufzufassen. Dies gilt auch ron einigen Fällen vermehrter Zahl der Staubgefässe in den zehnmännigen Blüthen der apetalen Abart der Capsella Bursa pastoris und den vielmännigen der Megacarpaea polyandra. Auch abnormer Weise kommen Blüthen mit nur vier, mit den Petalen alternirenden Staubgefässen vor; oder es ist ein lateral stehendes Staubgefäss und eines der paarweise gestellten abgängig, wodurch die Blüthe ebenfalls viermännig erscheint, dann findet man jedoch, wie in vielen Fällen, wenn nur füuf Staubgefässe vorhanden sind, dass vom Kelch oder Blumenkronwirtel Glieder abgängig seien. Fehlt eines der lateralen Kelchblätter, so ist damit gewöhnlich der Abortus des diesem gegenständigen Staubgefässes combinirt. Anderseits erscheinen Blüthen auch scheinbar fünfmännig, wenn die Staubgefässe des einen median stehenden Paares mit einander verwachsen. In einzelnen abnorm gebildeten Blüthen hat man mehr als sechs Staubgefässe angetroffen, so fand Buchenau ${ }^{2}$ ) bei Jonopsidion acaule siebenmännige Blüthen, in welchen das überzählige Staubgefäss in der Mitte zwischen den beiden grösseren eines median stehenden Paares stand, einmal sah er bei derselben Art eine Blüthe mit nur fünf Staubfäden, wovon jedoch der eine in der Mediane stehende sechs Loculamente trug. Derseibe Beobachter ${ }^{3}$ ) fand in einer Blüthe von Brassica Rapa $z$ wei überzäblige Staubgefässe, welche die Stelle eines fehlenden Blumenblattes einnahmen. In den abnorm achtmännigen Blüthen stehen die Staubgefässe entweder paarweise den Kelchblättern gegenüber ${ }^{4}$ ), oder es ist ausser den sechs an normaler Stelle befindlichen noch ein in der Mediane stehendes vorderes und binteres Staubgefäss ${ }^{5}$ ), das danu mit den lateral stehenden auf gleicher Höhe inserirt ist,

1) Vgl. Eichler, Ueber den Blüthenbau der Fumariaceen, Cruciferen und einigen Capparideen. (Sonderabdruck der Fl. 1865. S. 33 fg.)

2) Einige Beobachtungen aus der Geschichte der Pflanzenteratologie in Botan. Zeitg. (1862.) S. $127 \mathrm{fg}$.

3) Ebendaselbst.

4) Bei Cheiranthus Cheiri beobachtet von Lestiboudois nnd Séringe nach Eichler a. a. O. S. 35.

5) Ebendaselbst bei Cheiranthus Cheiri beobachtet von C. Presl in Flora (1838) Bd. I. S. 133. 
vorhanden, oder die Achtzahl der Staubgefässe kommt dadurch zu Stande, dass eine Spaltung der lateral stelienden Staubgefässe in zwei je eine einfächerige Anthere tragende Theile stattgefunden hat ${ }^{3}$ ).

Diese verschiedenen Torkommnisse lassen sich leicht dem von Eichler ${ }^{2}$ ) aufgestellten Schema der Cruciferenblüthen, dem zufolge die Blüthe mit Ausnahne der viergliederigen Corolla nach regelmässig binärem Typus gebaut ist, einreihen. Die Staubgefässe stehen nach seiner Ansicht in zwei Wirteln, der untere Wirtel enthält die zwei seitlichen, bisweilen abortirenden Staubgefässe, der obere die median gestellten, welche bei Lepidium ruderale einfach sind, bei Atelanthera sich spalten, bei den übrigen als freie oder mit ihren Filamenten mehr minder verwachsene Doppelstaubgefässe auftreten, wobei die Spaltung derselben bei Megacarpaea und in einzelnen abnormen Fällen, zum Beispiel bei Jonopsidion, in noch mehrere Theile erfolgen kann. Seltener wird Dedoublement der lateral stehenden Staubgefässe beobachtet. Während keine einzige Crucifere normal diklinische Blüthen besitzt, so ist auch bei Abnormitäten ein vollständiger Abgang der Staubgefässe selten wahrgenommen worden, man findet dann die Blüthentheile mehrerer Wirtel sehr verkümmert oder sie bilden sich eben nicht als Staubgefässe aus. Hieher gehört eine an Cheiranthus Cheiri oft beobachtete, in Candolles Prodromus als var. gynanthera angeführte Abnormität, bei welcher man eine normale Schote von einer aus sechs Klappen bestehenden, an der Spitze meist offenen, übrigens keimfähige Samen tragenden Kapsel umschlossen findet. Auch Wichura ${ }^{3}$ ) beobachtete an einer Barbarea vulgaris eine ähnliche Abnormität.

Ein Exemplar von Arabis alpina, das ich im Dolomitgerölle der Kerschbaumeralpe am 7. August 1862 auffand, zeigte eine dem Cheiranthus Cheiri gynantherus analoge Bildungsabweichung. Sämmtlichen Blüthen fehlten vollständig die Blumenblätter und die Staubgefässe, auch der Fruchtknoten hatte manche Eigenthümlichkeiten im Baue aufzuweisen. Die Pflanze machte sich durch die starr abstehenden, von sinander entfernten, blumenblattlosen Blüthen und den dadurch bedingten fremdartigen Habitus von Weitem

1) Moquin Tandon Pflanzenteratologie, übersetzt von Schauer, S. 284.

2) a. a. 0. S. $51 \mathrm{fg}$.

3) Nach einer Angabe Schauer's in Moquin Tandon a. a. 0. S. 212 . Es war mir nicht möglich, die Originalquelle dieser interessanten Mittheilung zu finden. 
bemerkbar: Der Stengel und die Laubblätter normal, der Blü. thenstand reichblüthig; deckblattlos; der Kelch vierblättrig, die Blättchen eiförmig-länglich stumpf. Blumenblätter, Staubgefässe, Drüsen, wie erwähnt, rollkommen feblend, nirgends Rudimente derselben anzutreffen. Fruchtknoten lineal. Die Schoten 2-, 3-, 4. klappig, an der Spitze offen, oder die zweiklappigen meist, seltener die dreiklappigen geschlossen. Die zweiklappigen Schoten sind den normalen ähnlich, nur stehen häufig die Klappen auf ungleicher Höhe, indem im letzteren Falle der Fruchtstiel sich rechts oder links von der Mediane ober der Basis der längeren Klappe eine Strecke weit verfolgen lässt. Die Lappen der Narbe stehen, wie es normaler Weise der Fall ist, nach vorn und binten oler sie sind den Klappen parallel. In den dreiklappigen Schoten steht meist die eine Klappe nach hinten, die beiden übrigen seitlich, in den vierklappigen, welche mit zwei Narben versehen sind, stehen die Narben den seitlichen Kelchblättern gegenüber. Bei den dreiklappigen, an der Spitzc klaffenden Schoten sieht man, wenn man die Klappen loslöst, drei Samenknospenträger, welche sich im oberen Viertel oder Fünftel, oder voch höher in zwei Aeste spalten, von welchen jeder Gabclast init dem liächstgelegenen des an. deren Samonknospenträger's an der Spitze verbunden ist und einen dicken abgerundeten, bisweilen etwas lappigen Narbenkörper bilden hilft. Der Fruchtknoten oder die Schote hat nun drei ron einander abstehende, somit getrennte Narben, zwischen denen man die Einsicht in das Innere des Fruchtknotens gewinnt. In einem derartig beschaffenen Fruchtknoten stehen dit Narben parallel mit den Fruchtklappen und letztere füllen den freien Raum zwischen den Samenknospenträgern aus.

Bei einer vierklappigen Schote fand ich einmal vier Samenknospenträger, von denen die $z$ wei einander entgegengesetzten schmäleren wie im vorigen Falle sich in je zwei Gabeläste trennten, während die breiteren, welche zugleich von mehr fleischiger Consistenz waren, ungetheilt bis an das Ende verliefen und an der Spitze mit den entsprechenden Gabelästen der schıäleren Samenknospenträger zu einer undeutlich dreilappigen Narbe verwuchsen. Diese Schote hatte somit zwei Narben, die Klappen füllten die Zwischenräume zwischen den Trägern aus und waren an der Spitze entsprechend gekrümmt. Auch hier konate nan in die Höhlung des Fruchtknotens hineinsehen. Die dünne durchscheinende Membran, welche im normalen Fruchtknoten eine vollständige Scheide- 
wand bildet, wurde in den letzteren Fällen meist nur als eine mehr minder breite, jedoch doppelte Leiste an jedem Samenknospenträger aufgefunden. Eine zahlreiche Menge von tauben Samen war mit ihrem horizontal vom Samenknospenträger abstehenden Nabelstrange an demselben befestigt.

Weitere Abnormitäten im Baue des Fruchtknotens werden durch die tiefere oder höhere Spaltung einzelner oder sämmtlicher Samenknospenträger in je zwei Gabeläste begründet. Sehr häufig wurde im Innern der Schote, indem von einem Samenknospenträger ein Ast nach Innen bog und zum Fruchtstiel wurde, ähnlich wie bei Cheiranthus Cheiri eine zweiklappige Schote angetroffen, deren Klappen an der Spitze zusammenhängend, jedoch meist schraubig gedreht waren.

Bei den unteren Blüthen der Inllorescenz entsprangen auf dem Blüthenboden in der Achsel der Kelchblätter gestielte Blüthen, die im Baue den beschriebenen olichen, jedoch nur zweiklappige Schoten besassen oder auf den Fruchtknoten reducirt waren; in einem Falle waren ausser dem centralen noch sechs peripher stehende vorhanden, welche eine den Staubgefässen älınliche Stellung einnahmen. Den oberen Blüthen der Traube fehlten nicht selten die Kelchblätter gänzlich. Folgende Fälle sah ich öfters: Es war nur ein gestielter Fruchtknoten vorhanden, dessen Stiel in eisem Falle an seinem oberen Ende ein Deckblatt trug, aus dessen Achsel eine gestielte Blüthe mit vier Kelchblättern und einem zweiklappigen Fruchtknoten entsprang; an der Spitze des Fruchtstiels standen zwei einander opponirte oder blos ein einziger Fruchtknoten; in einem anderen Falle sah ich vier in ihrer unteren Hälfte verwachsene, an einer Seite jedoch getrennte Carpellarblätter, von denen jedes mit zwei randständigen Gefässbündeln versehen war, welche an der Verwachsungsstelle der Carpellarblätter zu einem promenirenden Strange sich vereinigten und daselbst Samenknospen trugen.

Einige der beschriebenen Schoten, welche zumeist den unteren Blüthen der Tranbe angehörten, unterschicdeu sich somit von normal gebauten durch die vermehrte Anzahl der Klappen, das Verhalten der Samenknospenträger und der Dissepimente, endlich durch die relative Lage der Narben zu den Klappen. Nur bei der Gattung Tetrapoma und bei Molargidium, einem Subgenus von Draba, sind die Schoten normal vierklappig, während in abnormen Blüthen eine vermehrte Zahl der Klappen, ausser dem erwähnten Cheiran- 
thus Cheiri') und der Barbarea, öfter gefunden wurden. Man hat sie bei Lepidium sativum, Diplotaxis muralis ${ }^{2}$ ), Lunaria rediviva '), Thlaspi arvense ${ }^{4}$ ), Capsella Bursa pastoris, Brassica oleracea ${ }^{5}$ ), Erysimum cheirifolium und anderen Arten angetroffen. Das Verhalten der Dissepimente ist nun sehr verschieden, indem sie entweder im Centrum zusammenstossen, wodurch so viel centrale Winkel gebildet werden als Dissepimente vorhanden, wie ich dies an 3-5klappigen Schötchen der Capsella Bursa pastoris beobachtete und ähnliche Fälle bei Erysimum cheirifolium, Cheiranthus Cheiri etc. beschrieben wurden ${ }^{6}$ ), oder sie sind von einem Samenknospenträger zum nächst gelegenen ausgespannt und stellen gewissermassen die Chorden zu den von den Klappen gebildeten Kreisbögen dar, wodurch ausser den peripheren noch ein centrales, so viel Kanten als Dissepimente vorhanden, enthaltendes leeres Fach gebildet wird, wie sie zum Beispiel bei Lepidium sativum von De Candolle ${ }^{8}$ ), an Cheiranthus Cheiri ron Godron ${ }^{8}$ ) beschrieben worden sind; in anderen Fällen sind die Dissepimente unvollständig und verlaufen als mehr minder breite einfache oder doppelte Leisten am Sameuknospenträger. Sehr selten verlaufen sie parallel, wie man sie in den von Go. dron ${ }^{9}$ ) dargestellten Grundrissen mehrklappiger Schoten von Brassica oleracea dargestellt findet. Bei Arabis alpina fand ich die Dissepimente niemals im Centrum zusammenstossend und centrale Winkel bildend, bei den dreiklappigen, an der Spitze geschlossenen Schoten wurde die Höhlung wie bei Lepidium sativum in drei periphere und ein centrales Fach getheilt; jene Schoten, welche an der Spitze mehr minder klafften, hatten in der Regel unvollständige gefensterte Septa.

Im normalen Fruchtknoten verlaufen die Klappen, wie bereits erwähnt, der Narbe nicht parallel, sondern es stehen die Lappen der letzteren nach vorne und hinten, während die ersteren rechts und links von der Mediane einander opponiren. Die Lappen der Narbe sind als eine direkte Fortsetzung der Samenknospenträger anzusehen.

Betrachten wir jene Fruchtknoten, die an der Spitze geöffnet

1) 2) 3) 4) 5) Vgl. C. Schimper in Flora (1829), II. Bd. S. 433.

6) Flora (1841) S. 266. Tab. II. C. Fig. 1-3.

7) P. und A. De Candolle Monstruosit. vég. (1841) S. 13.

8) Ann. sc. nat. Serie V. Vol. II. (1864) S. 178. Tab. 18. Fig. 8-9.

9) ล. 2. 0 . 
sind, oder den zuletzt erwähnten Fall mit noch weiterer Lösung der Carpellarblätter, so stellen sie sich entsprechend der Anzahl der Fruchtklappen aus 2, 3, 4 Carpellarblättern zusammengesetzt dar. Jedes derselben ist mit zwei randständigen Gefässbündeln versehen, welche an der Stelle, wo die Carpellarblätter ein geschlossenes Rohr bilden, sich wieder vereinigen, ähnlich den die Corolle der Compositen oder den verwachsen blätterigen Kelch vieler Gattungen durchziehenden Nerven. Durch die weitere Massenzunahme der randständigen Gefässbündel verwachsen nun die einander zunächst gelegenen an ihrer Spitze und stellen den mehr minder verdickten, oft ein wenig gelappten Narbenkörper dar, während der andere Theil desselben $z u$ den prominirenden Samenknospenträgern sich verdickt, welche in Folge der weiteren Differenzirung der Gewebe des Fruchtknotens bei der Fruchtreife von den Klappen sich loslösen und zu freien Organen werden. In dem Falle nun, wenn die Spitzen der Fruchtblätter von einander, wenu auch unmerklich, getrennt erscheinen, verwachsen je zwei randständige Gefässbündel, die demselben Fruchtblatte angehören, an der Spitze und stellen eine der Klappe parallele Narbe dar. Bei der normalen Bildung gleicht der Fruchtknoten in den ersten Entwicklungsstadien einem an der Spitze abgestutzten offenen Rohre, die Spitzen der Carpellarblätter sind somit nicht getrennt, es ver. balten sich die ihnen angehörigen randständigen Nerven ähnlich jenen, die die Blumenkronröhre der Compositen durchziehen, indem je zwei verschiedenen Fruchtblättern angehörige Nerven in einen zusammenfliessen, einerseits die Samenknospenträger, anderseits an der Spitze den compacten Narbenkärper bilden, dessen Lappen nun eine zu den Fruchtklappen krenzwcise Stellung einnehmen. Für die Anschauung, dass die Samenknospenträger nur weiter differenzirte und bei der Fruchtreife frei gewordene randständige Nerven der Carpellarblätter seien, spricht auch der Umstand, dass man in jenen Fällen von Chlorosen, in denen der Fruchtknoten in zwei Blätter sich auflöst, diese letzteren von zwei randständigen, an der Spitze sich oft vereinigenden Nerven durchzogen finciet, während etwa vorhandene Samenknospen oder deren morphologische Aequivalente diesen inserirt sind. Einen solchen Fall von Chlorose ') habe ich gerade wieder an einer Arabis alpina, die ich am 28. August 1860 auf dem Erzberg in Steiermark

1) Literatur der Chlorosen, so weit sie mir bekannt:

1) C. Schimper: in Fl. (aus einem Schreiben an Dr. Hoppe in Regensburg) 
in einer Höhe von $3000^{\circ}$ auf eisenhaltigem Kalkboden fand, zu beobachten Gelegenheit gehabt.

Obwohl ähnliche abnorme Formen bei dieser Species bereits Heyland und Seringe gesehen haben, so mag eine kurze Beschreibung derselben Platz finden, um eine Vergleichung der verschiedenen Formen und des Baues der Fruchtkucten beider Abnormitäten anzustellen.

Die Tracht der Ptlanze röllig abweichend, die Blüthentrauben deckblattlos, die unteren Blüthen derselben normalen ähnlich, und es findet ein allmäliger Uebergang $z u$ den abnorm gebildeten statt. Kelch 4 blättrig, normal. Blumenkrone mehr minder grünlich; Staubgefässe 6, deren Insertion und Form wie in normalen Blüthen, der Pollen jedoch schlecht entwickelt. Fruchtknoten lang gestielt, unit einem $\frac{1}{2}-1$ Zoll langen Stiele, herzförmig, ab-

(1829). Bd. II. S. 433 fg. (Erysimum officinale, Barbarea vulgaris, Peltaria alliacea, Raphanus sativus u. A.)

2) C. B. Pres 1: Einige Metamorphosen der Blumentheile des Sisymbrium officinale. Linnaea Bd. VI. (1831.). S. 599. T. IX.

3) Engelmann: de Antholysi prodromus (1832).

4) Ad. Brongniart: Exam. de quelques cas de monstrousités végét. Arch. du Nuseum Bd. IV. (1833). Tab V.A. S. (Brassica Napus) und über dieselbe Pflanze in Ann. sc. nat. Serie III. Bd. II. (1840). S. 29.

5) Prochnow an Hornschuch in Flora (1834), Bd. I. S. 20. (Brassica oleracea, Turritis glabra).

6) Wiegmann: $\bar{u}$. Bastardpflanzen u. einige Missbildungen von Gewächsen Fl. (1834) Bd. II. S. 61. (Brassica Rap.)

7) Schultz: über eine Monstrosität von Nasturtium in dem bot. Garten, Fl. (1834)。 Bd. II. S. 121.

8) Klinsmann: ̈̈. eine Monstr. von Hesperis matronalis Linnaea. Bd. X. (1835). S. 604. T. V.

9) Fresenius: ü. Pflanzenmissbildungen in Mus. Senkenb. Bd. II. (1837). S. 27. (Sisymbrium officinale).

10) Reissek: ü. das Wesen der Keimknospe. Linnaea Bd. XVII. (1843). S. $656 \mathrm{fg}$. T. XX. (Sisymbrium Alliaria).

11) A ch. Guillard: sur deux Chloranthies in Bull. soc.jbot. de France. (1857). S. $761 \mathrm{fg}$. (Sinapis arvensis).

12) Wydler: Beschreibung einiger Blüthenanalysen von Alliaria officinalis in Regensb. bot. Denkschr. (1859). S. 79. T. VII.

13) Fleischer: ü. Missbildungen verschiedener Culturpflanzen und einiger anderer landwirthschaftlicher Gewächse. Esslingen 1862. S. 1 fg. 'T. J. u. II. (Brassica Napus).

14) Godron: sur l'inflores. et les fleurs des Crucifères in Ann. sc. nat. Serie V. (1864) S. 281. T. XVIII. (Cardamine pratensis, Hesperis matronalis).

15) Baillon: sur fleurs monstr. de Sinapis arvensis in Adansonia Bd. III. S. 351-353. T. XII.

Ausserdem vgl. Moquin Tandon's oben citirtes Werk a. a. 0 . und Maxwell T. Masters: Vegetable Teratologie. London, 1869. S. 250, 252, 261, 280. 
gestutzt, ausgerandet, seltener eiförmig spitz, von der Seite zu. sammengedrückt, einfächerig. Narbe zweilappig, in der Ausrandung sitzend. Sämmtliche grüne Theile als Kelch, Aussenfläche der Blumenblätter, Stempelträger und Fruchtknoten sternförmig behaart. Samenknospenträger zwei, wandständig, in die Fruchtknotenhöhle vorspringend. An denselben entspringen zahlreiche, etwas abstehende, kurz gestielte, oblonge, grüne, sternförmig behaarte Blättchen mit undeutlicher fiederiger Nervatur. An der Basis der Samenknospenträger sah ich öfters Blüthenknospen mit langem, von letzterem horizontal abstehendem Blüthenstielcherı. An den obersten Blüthen der Traube trug der durchgewachsene Blüthenstiel statt eines Fruchtknotens 1-3 Blüthen. Die seitlichen derselben entsprangen aus der Achsel von Bracteen, häufig fehlten jedoch die letzteren. Einmal sah ich zwei einander opponirte, ziemlich dicke Blättchen, deren jedes mit einem centralen und zwei randständigen Gefässbündeln versehen war. Die randständigen Nerven trugen Samenknospen und vereinigten sich unter der Spitze jedes Blättchens. Die am durchgewachsenen Blüthenstiel befindlichen Blüthen stellen Mittelbildungen $\mathrm{zwischen} \mathrm{normalen} \mathrm{und}$ den beschriebenen Formen dar, der Fruchtknoten derselben kurz gestielt, an der Basis etwas verbreitert.

Beide Anomalien bieteu merkwürdige Beispiele weit gehender Differenz der Gestaltung einer und derselben Art angehörenden Pflanzen dar, und man könnte beim ersten Anblicke einzelner Blüthen oder Frücbte derselben verleitet werden, jede für sich als Typus einer anderen Gattung aufzustellen, während keine bis jetzt bekannte eine ähnliche Fruchtform aufzuweisen hat.

Es sei mir noch gestattet, einige Bemerkungen über die der Carpellarnath oder den randständigen Nerven der Carpellarblätter angehefteten Gebilde anzuschliessen.

Während es bei der zuerst beschriebenen Anomalie evident ist, dass an den verdickten randständigen Gefässsträngen der Carpellarblätter die Samenknospen angeheftet sind, so findet man in anderen Fällen abnormer Bildung des Carpells an der sogenannten Naht, die durch die Verwachsung der randständigen Nerven derselben gebildet wird, bald Samenknospen, bald aber Gebilde, dereu erste Entwicklungsstadien noch jenen der Samenknospe gleichen, nach vollendetem Wachsthum flache blattähnliche oder verschieden geformte röhrige Bildungen darstellen. Letztere tragen an irgend einer Stelle ibrer Innenfläche, jedoch niemals einem Nerven 
aufsitzend, ein zelliges, kegelförmiges Wärzchen, das mit dem $\mathrm{Nu}$ cleus einer Samenknospe sich vergleichen lässt; in anderen Fällen kommen aber anscheinend als unzweifelhafte Blätter zu deutende Gebilde vor, denen jenes Wärzchen fehlt; in sehr seltenen Fällen erscheinen eigenthümlich gestaltete Blüthen, die mit der Samenknospe die Anheftungswaise und den Verlauf des Funiculus und der Raphe, die äussere Hülle derselbeu gemein haben, während man von dieser einzelne monströse, jedoch noch als Staubgefässe oder Fruchtknoten erkennbare Gebilde eingeschlossen findet. Bisweilen kömmt es jedoch vor, dass auch Laubknospen den randståndigen Nerven aufsitzen.

Diess fübrt zur Erörterung eines oft abgehandelten Themas, nämlich der morphologischen Bedeutung der Samenknospe. Es muss nun, um Irrthümer zu vermeiden, die morphologische Bedeutung des Nucleus, der das Wesentliche der Samenknospe ist, indem er in seinem Innern den Embryosack ausbildet, von der seiner Hüllen, von denen sich, wie bekannt, in vielen Pflanzenfamilien zwei, in anderen nur eine vorfindet, welche jedoch auch constant fehlen können, unterschieden werden.

Man findet nun das Analogon des Nuclcus weitaus in den meisten Fällen abnormer Bildung auf der Innenfläche eines statt der Samenknospe angehefteten flachen oder röhrigen, blattähnlichen Gebildes, scltener auf der Oberfläche eines unzweifelhaften Zahnes des Carpellarblattes selbst, in einzelnen Fällen in der Achsel zwischen dem randständigen Nerven des letzteren und dem diesem angehefteten Blättchen. Kein Fall berechtigt zu der Annahme, dass der Nucleus hlattartig ausgewachsen wäre.

Es entsteht nun die Frage, ist die Bildung dieses Wärzchens als Neubildung am Blatte zu erklären, stellt es ein Axenorgan dar, clas dann der jenes Blatt erzeugende Spross sein kann, oder ist es als verkümmerter Axillarspross zu deuten? Für die erste Ansicht spricht sowohl der Abgang des Nucleus als wie die in grösserer Anzahl sich vorfindenden, dem Nucleus vergleichbaren Wärzchen an einzelven der Carpellarnaht angehefteten Blättchen. Den ersteren Fall habe ich bei der Chlorose der Arabis alpina, den letzteren bei Salix Caprea zu beobachten Gelegenheit gehabt, hier ist die Annahme, dass dieses Blättchen an der durch den Nucleus repräsentirten Axe entstanden, ganz abzuweisen. Dass der Nucleus unabhängig von dem dem randständigen Nerven inserirten Blatte oder Blattauswuchse entstehen kann, beweisen die 
freilich seltenen Fälle vom Vorkommen desselben in der Achsel zwischen jenem Blättchen und dem randständigen Nerven des Carpellarblattes oder den Zähnen des letzteren. Gewöhnlich ist der einem Blättchen aufsitzende Nucleus nackt, seltener ist er mit einem Integumente versehen, das dann dem inneren der normalen Samenknospe analog ist. Dies bezieht sich jedoch nur auf die Umwandlung von anatropen oder amphitropen, der Carpellarnaht angehefteten Samenknospen, während bei einem Falle abnormer Bildung einer orthotropen, am Grunde des Fruchtknotens befindlichen Samenknospe, die ich an Rumex scutatus beobachtete, die beiden röhrigen oder scheidigen durch ein mehr minder langes Internodium von einander entfernten Integumente augenscheinlich an einem und demselben Stiele, der mit dem Nucleus abschliesst, inserirt sind. Bewahrt somit der Nucleus in diesen pathologischen Fällen seine mit der Norm übereinstimmende Gestalt, ohne dass er sich jemals zu einem Laubspross oder Blatte zu entwickeln im Stande ist, so wird hier die Entscheidung der morphologischen Natur desselben nicht leichter sein, als bei der normalen Samenknospe selbst. In sehr seltenen Fällen scheint er auf kurze Zeit entwicklungsfähig bleiben zu können und Blattgebilde hervorzubringen, indern nur durch diese Annahme die Entstehung der vorher schon erwähnten, mit Funiculus, Raphe und Integument versehenen Blüthe sich erklären lässt. Ueber die den randständigen Nerven der Carpellarblätter inserirten Blättchen oder blattähnlichen Sprossungen ist zu bemerken, dass sie keineswegs eine dem Carpellarblatte eigenthümliche Bildung darstellen und dass in vielen Fällen stärkerer Ausbildung und Verdickung der Nerven Blattsubstanzproductionen auf denselben beobachtet werden. Sie sind eigentlich nicht einem Blatte gleichwerthig, sondern als Auswüchse, (Sprossungen) zu betrachten, ebenso wenig wie man die an den Blättern des Blumenkohls zuweilen vorkommenden trichterförmigen, glockenförmigen oder blattartigen Auswüchse als selbstständige Blätter ansieht. 


\section{Erklärung der Abbildungen.}

\section{Tafel VII. Arabis alpina.}

Fig. 1. Eine der untersten Blüthen der Traube mit vier Kelchblättern und dreiklappigem, an der Spitze klaffenden Frucbtknoten. Aus jeder Axilla eines Sepalums entspringt eine gestielte Blüthe mit vier Kelebblättern und zweiklappigem Fruchtknoten. 3 mal vergr.

Fig. 1. Der dreiklappige Fruchtknnten der vorigen uach Entfernung der Klappen. pl. = Placenta. st. = Stigma. gm. = gemmula. Man lemerkt zwischen beiden vorderen Placenten die Scheidewand als durclbrochene Membran ausgespannt. $8 \mathrm{mal}$ vergr.

Fig. 3. Das Gerüste (die Samenknospenträger) eines dreiklappigen, an der Spitze klaffenden Finchtknotens einer mittleren Blüthe der T'raube Die zwischen den Placenten ausgespannte Membran ist durcbbrochen und verläuft nach oben als schmale, endlich aufhörende Leiste. (Letzteres tıitt in der Figur nicht deutlich hervor, um viele Linien zu vermeiden, damit das Gerüste und der eingeschlossene Fruchtknoten deutlich zur Auschanung kommen.) Im Innern des Fruchtknotens bemerkt man einen zweiten, dessen Stiel mit dem auf der rechten Seite gelegenen Samenkmospenträger etwas unter der Mitte desselhen sich verbindet. st. = Stigma zweihörnig. $6 \mathrm{mal}$ vergr.

Fig. 4. Ein vierklappiger Fruchtknoten. 3 mal vergr

Fig. 5. Derselbe von der Seite. 3 mal vergr.

Fig. 6. Die Klappen desselben 3 mal vergr.

Fig. 7. Das Gerüste eiues vierklappigen Fruchtknoteus nach Loslösung der Klappen. pl. a. Der sich in zwei Aeste spaltende, vordere Samenknospenträger. pl. l. der seitliche, etwas dickel'e ungetheilt bleibende Samenknospenträger Im Innern bemerkt man einen zweiklappigen Fruchtknoten, dessen Klappen nach vorne und hinten stehen. $8 \mathrm{mal}$ vergr.

Fig. 8. Eine Narbe mit den angränzenden Stücken der Samenknospenträger von Fig. 7.

Fig. 9. Das Gerüste eines dreiklappigen, an der Spitze klaffenden Fruchtknotens nach Loslösung der Klappen, letztere standen auf ungleicher Höhe. 3 mal vergrössert.

Fig. 10. Das Gerüste eines vierklappigen, an der Spitze fast geschlossenen Fruchtknotens nach Loslösung der Klappen, die vordere Ǩlappe kürzer als die übri. gen. 6 mal vergr.

Fig. 11. Eine obere Blüthe der Traube mit vier Kelchblättern und dreiklappigem, an der Spitze geschlossenem Fruchtknoten, die Klappen losgelöst 4 mal vergrössert.

Fig. 12. Eine der obersten Blüthen der Traube, rechts an der Spitze des Blüthenstiels bemerkt man einen sitzenden zweiklappigen Fruchtknoteu, links einen aus vier Carpellarblättern bestehenden. Letztere nur in ihrer unteren Hälfte verwachsen, die beiden vorderen durch einen Spalt bis auf die Basis getrennt. pl. = Placenten. Je zwei verschiedenen, einander zunächst zugekehrten ('arpellarblättern angebörige randständige Nerven tragen an ibrer etwas vorspringenden Vereinigungsstelle, welche die Placenta darstellt, die Samenknospen (gm.). 12 mal vergr. 


\section{Tafel VIII. Chlorose der Arabis alpina.}

Fig. 1. Eine Blüthe aus der unteren Hälfte der Traube. 3 mal vergr.

Fig. 2. Eine Blüthe, das vordere Kelchblatt entfernt. 3 mal vergr.

Fig. 3. Ein kürzeres Staubgefäss. $6 \mathrm{mal}$ vergr.

Fig. 4. Der Fruchtknoten der Blüthe (Fig.1) der Länge nach durchschnitten. Im Grunde bemerkt man zwei Blüthenknospen und an der vorspringenden Carpellarnaht (Sameuknospenträger) zahlreiche, in zwei Längsreihen angeheftete, lanzettliche Blättchen. $6 \mathrm{mal}$ vergr.

Fig. 5. Ein Fruchtknoten von eiförmiger Gestalt. 3 mal vergr.

Fig. 6. Obere Blüthe der Traube, der Blüthenstiel durchwachsen, trägt an seiner Spitze zwei Samenknospen trageude Blätter und zwei Blüthenknospen. $6 \mathrm{mal}$ vergr.

Fig. 7. Der oberste Theil von Fig. 6 nach Entfernung der zwei Blüthen. $75 \mathrm{mal}$ vergr.

Fig. 8. Ein Stück aus dem links gelegenen Carpellarblatt der vorigen Figur. pl. = Placenta. $\mathrm{gm} .=$ Gemmula. $30 \mathrm{mal}$ vergr.

Fig. 9. Eine obere Blüthe der Traube mit durchgewachsenem Blüthenstiel an seiner Spitze zwei Bracteen und drei Blüthenknospen tragend. $3 \mathrm{mal}$ vergr.

\section{Tafel IX. Verbildete Samenknospen und an der Carpellarnaht ange- heftete blattartige Sprossungen bei Cruciferen and anderen Familien.}

Fig. 1. Eine von der vorspringenden Leiste eines einfächerigen, verbreiterten Fruchtknotens von Arabis hirsuta abgelöste verbildete Samenknospe. $20 \mathrm{mal}$ vergr.

Fig. 2, Fig 3, Fig. 4. Verbildete Samenknospen von Sisymbrium Alliaria, einem lang gestielten, sehr verbreiterten, von der Seite zusammengedrückten Fruchtknoten entnommen. $\mathrm{n}=$ nucleus, Die dem Mittelnerv des Blattes von Fig. 4 aufsitzende Anschwellung ist hohl, im Grunde derselben sass der von einem Intugumente umgebene Nucleus. $10 \mathrm{mal}$ vergr.

Fig. 5. Längsschnitt durch ein etwas verbreitertes gestieltes Ovarium von Cheiranthus fruticosus, mit aufgehängter monströser Blüthenknospe, dieselbe enthielt in ihrem Innern einige ganz verbildete monströse Staubgefässe und einen Fruchtknoten. 3 mal vergr.

Fig. 6. Funiculus und äusseres Integument einer ähnlichen monströsen Blüthe, einem anderen Fruchtknoten entnommen. 3 mal vergr.

Fig. 7. Längsschnitt durch ein an der Bauchnaht offenes Ovarium von Trifolium repens. Man sieht zwei am randständigen Nerven desselben inserirte Blättchen, und in der Achsel des unteren den lang zugespitzten Nucleus (n.). 12 mal vergrōssert.

Fig. 8. Ein Stück vom Rande eines verbreiterten, an der Bauchnaht offenen Fruchtblattes der vorigen Pflanz.e. a sitzt mit breiter Basis dem randständigen Gefässbündel auf, welcher letztere auf ungleicher Höhe zwei Nervenzweige nach a aussendet, die Flächen desselben sind nach rechts und links gewendet. $b=$, das untore Blāttchen gestielt, ohne Nucleus, 20 mal vergr.

Fig. 9. Ein Stück rom Rande eines anderen Fruchtknotens derselben Pflanze. $a$ und $b$ ohne Nucleus.

In dieser wie in der vorigen Figur bedeutet die punktirte Linie den hinten gelegenen freien Rand des Fruchtblattes. $30 \mathrm{mal}$ vergr.

Fig. 10. Ein im Innern des Fruchtknotens von Salix Caprea von der Carpellarnaht abgelöstes Blättchen, das zwei Nuclei trägt. 12 mal vergr. 
Fig. 11. Grundständige Samenknospe mit der Lãnge nach klaffendem ãusse. rem Iutegumente, das Internodium zwischen äusserem und innerem Integumento sichtbar. Einem blattartig verbreiterten Fruchtknoten von Rumex scutatus entnommen. 6 mal vergr.

Fig. 12. Das Innere von Fig. 11. Der Nucleus (n) etwas zusammengeschrumpft, an der Basis umgeben von wallartigem inneren Integumente. $24 \mathrm{mal}$ vergrössert.

Fig. 13. Dütenförmiges, oben durch ein Membran geschlossenes Gebilde. In der Mitte der Membran ist ein hobles kegelförmiges Röhrchen eingesetzt. 6 mal vergrōssert.

Fig. 14. $a=$ integumentum externum, $b=$ integumentum internum. Beide Integumente durch ein dünnes solides Internodium von einander entfernt.

Dieses so wie das vorige Gebilde (Fig. 14 u. Fig. 13) am Grunde eines blattartig verbreiterten, an der Spitze dreilappigen Fruchtkuotens vou Rumex scutatus stehend. $16 \mathrm{mal}$ vergr. 


\section{Die Entstehung der Farbstoffkörper in den Beeren von Solanum Pseudocapsicum}

von

\section{Dr. Gregor Kraus.}

Diese kleine Untersuchung über die eigenthümlich geformten Farbstoffgehilde in den Früchten von Solanum Pseudocapsicum wurde der Hauptsache nach bereits im Winter 1864 gemacht. Eine Wiederholung und kurze Darlegung derselben an diesem Orte schien mir nicht überflüssig, da über die Entstehung dieser Formen bis in die jüngste Zeit andere und, wie ich glaube, ganz unrichtige Ansichten verbreitet worden sind.

Ich gebe zunächst meine eigenen Beobachtungen und knüpfe daran die nöthige Discussion über die Angaben Anderer.

\section{Die fertigen Farbstoffkörper.}

Die Wand der reifen Beeren der genannten Solanee besteht aus etwa 20-30 radialen Zellagen, in denen allen, von der Epidermis angefangen, orangerothe Farbstoffkörper liegen, dichter in den äussern kleinern Zellen, weniger dicht in den grössern innern.

Die meisten dieser Körper sind von der vielerwähnten ') zweioder dreispitzigen Gestalt; doch ist das nicht die einzige Form derselben, dieselbe ist vielmehr in verschiedenen Regionen der Beere verschieden und gesetzlich geregelt.

In den äussersten Zellen (Taf. X. Fig. 1) sind dieselben von der Form der gewöhnlichen Chlorophyllkörner, von oben gesehen kreisrund oder etwas oval, von der Seite wie jene platt, in der That also linsenförmig; wo zahlreiche Körner zusammenliegen, an den anliegenden Seiten abgeplattet. Ihre Grösse beträgt 0,0048 bis 0,0080 , im Mittel $0,0064 \mathrm{~mm}$.

1) H. v. Mohl, Veg. Zelle 1851 S. 206. - Unger, Anat. u. Phys. d. Pfl. 1855 S. 111, Fig. 23 c. - Trécul, Ann. scienc. nat. S. IV. T. X. 1858 p. 150 bis 158, pl. 5. - Hildebrand, Pringsh. Jahrb. III. S. 64, Taf. IV. Fig. 7. Weiss, Sitzb. d. Wien Acad. Bd. XLIX. 1864. S. 1 ff. und Bd. LIV. 1866. S. 157 ff. - Hofmeister, Lehre *. Pfl. Zelle 1867. S. 376-378. 
Ihre Substanz habe ich bei den stärksten Vergrösserungen (Hartnack Immers. IX, Bénèche Obj. 11) niemals homogen gefunden, sondern den ältern Chlorophyllkörnern gleich, fein gekörnelt und den Farbstoff ${ }^{1}$ ) innerhalb dieser feinkörnigen Grundsubstanz gauz gleichmässig rertheilt. Nicht selten sieht man darin auch grössere Körnchen zu 2, 3 und mehr, die sich durch Jodreaction als Stärke erweisen.

In andern Fällen ist dagegen der Farbstoff auf bestimmte Stellen des Korns beschränkt und der übrige Theil desselben fast oder ganz farblos. Derselbe liegt z. B. auf einer Hälfte, am dichtesten an der Peripherie und nimmt gegen die andere farblose ganz allmählig $a b$; oder ist auf 2 Seiten meniskenartig vertheilt, wobei die Mitte farblos bleibt. Fig. 2.

Damit nicht zu verwechseln sind in denselben Zellen vorkom. mende, für das folgende sehr wichtige Farbstoffvertheilungen, die durch Vacuolenbildung im Korn hervorgerufen sind und $j o$ nach der Lage, Grösse und Anzahl der Vacuolen dem gefärbten Theile desselben eine sehr eigenthümliche Gestalt verleihen.

Innerhalb des runden Korns erscheint eine centrale kug. liche Vacuole von verschiedener Grösse, und die gefärbte Substanz bildet einen breitern oder schmälern Ring (Fig. 3 a). Oder die Vacuole im Centrum ist oval, dann erscheint die farbige Substanz als ein Doppelmeniscus Fig. $3 \mathrm{~b}$; liegt endlich die Vacuole einseitig, so erscheint das Korn (von oben gesehen) als Ring, der aber auf der einen Seite fadenartig dünn, auf der andern meniskenartig gestaltet ist (Fig. 3c). Der fadenartige Theil ist gewöhnlich farblos.

Gar nicht selten kommen im Korn 2-3 Vacuolen vor, wie in Fig. $3 \mathrm{~d}$, dann ist die gefärbte Masse biconcav, 3-, 4spitzig u.s.w.

Dass man es dabei mit wirklichen Vacuolen zu thun hat, das

1) Der mit Alcohol ausgezogene Farbstoff bildete eine klare goldgelbe Flüssigkeit, die, wie bereits Hofmeister (Zelle S. 377) bemerkt, nicht fluorescirt, durch verdünnte $\mathrm{SO}_{3}$ und Alkalien keine Farbenänderung erlitt, durch $\mathrm{HCl}$ aber nach einiger Zeit spangrün wurde. Aus ihr setzten sich flockige (unkrystallinische) Massen von der Farbe der reifen Beere ab, die durch Conc. $\mathrm{SO}_{3}$ (von der die Flüssigkeit stets nur gebräunt wurde) unter Tropfenbildung und Zerfliessen prächtig indigblau wurden, eine Färbung, die bekanntlich auch die Farbkörper der Beere zeigen, so aber, dass die Färbung mit einem schmutzig Braun-Grün beginnt und allmählich in die bezeichnete übergeht. Jod färbt die Körner grün (Weiss a. a. 0.), die Lösung gar nicht. Vgl. über andere durch $\mathrm{S}_{3}$ sich bläuende gelbe Farbstoffe De Bary, Morph. u. Phys. d. Pilze u. s. w. S. 11. Anm. 
ergibt sich einmal aus der ausserordentlich scharfen membranartigen Umgrenzung der genannten Stellen, dann aus der völligen Gleichheit dieser Gebilde mit den später zu beschreibenden, an normalem Chlorophyll künstlich hervorrufbaren unzweifelbaften Vacuolen. ${ }^{1}$ )

Diese vacuolenhaltigen Körner nehmen von den äussern gegen die innern Zellen an Häufigkeit zu und finden sich besonders reichlich zwischen den Farbstoffkörpern der zweiten Art, die sich etwa in der 5.-6. Zellage von Aussen allgemein einstellen.

In diesen Zellen liegen die Farbstoffkörper theils als Spindeln, theils als sichelförmig gekrümmte Körper ron derselben Farbe und dem gleichen innern Bau wie die Körner, dazwischen aber auch andere, sehr interessante Formen Fig. 3 e. Gewöhnlich sind es einfache, gleichmässig gefärbte rothe Spindeln oder Sicheln von $0,0064-0,0096 \mathrm{~mm}$. Länge, welche sehr gewöhnlich, aber nicht immer die vielerwähnten haarförmigen Fortsätze haben. Nicht selten hängen 2, sehr selten 3 solcher Spindeln mit ihren feinen Fäden an einander und liegen entweder in einer Linie, oder sind hufeisenförmig gekrümmt, stossen unter spitzem oder stumpfem Winkel zusammen, Fig. 3f, oder sind Sförmig geschwungen, Fig. $3 \mathrm{~g}$. Die Verbindungsstelle der Doppelspindeln ist da und dort ziemlich dick, oft nur eine kleine Einschnürung, wie in Fig. $3 \mathrm{f}^{1}$. - Neben diesen zweispitzigen Gestalten erscheinen drei- und vierspitzige mit concaven Seitenflächen Fig. $3 \mathrm{~h}$. und die oben genannten Ringe, Menisken u. s. w. allerorts häufig.

In den innersten Parthien der Beere endlich, besonders in den Theilen, dia an die Samen stossen, in den Zellen um die Gefässbündel, und in dem Samenträger selbst sind die Farbstoffkörper durchgängig nadelfeine Spindeln von 0,0128 - 0,0192 gewöhnlich $0,0160 \mathrm{~mm}$. Länge.

Alle diese Gebilde liegen, den Chlorophyllkörnern gleich, Im Protoplasma der Zelle, gewöhnlich an der Wand, theils unregelmässig in Gruppen oder zerstreut, sehr gerne den Zellkern überdeckend. Wo, wie in den innern grössern Zellen, das Plasma strangartig das Zelllumen durchsetzt, folgen die Spindeln mit Vor-

1) Dass dieselben in diesem Falle hier nicht Kunstproducte sind, dafür bürgt die Art der Untersuchung, die, wie alle folgenden, nie in Wasser, sondern nur im Safte des Schnittes selbst vorgenommen wurde. 
liebe diesen Strängen, oft $z u$ dicken Bündeln in einem Strang nebeneinander gelagert, Fig. 4, oder von haarfeinen Plasmasträngchen fadenartig aneinander gereiht. In den rundlichen Zellen sind solche Aordnungen gewöhnlich ohne bestimmte Orientirung, die Reihen in gewundenen oder spiralig geordneten Figuren '), in den gestreckten Zellen aber der Längsdurchmesser parallel dem Längsmesser der Zelle. Es kommen auch federartige Gruppirungen der Farbekörper vor.

Eine sehr merkwürdige Lagerung der Körner sowohl als der Spindeln, welche Anlass zu irrthümlichen Ansichten über die Entstehung der Farbstaffgebilde geworden, ist die innerhalb grösserer oder kleinerer Vacuolen und wasserreicher Protoplasmabällchen, ${ }^{2}$ ) oder, was gar nicht selten ist, innerhalb des eigenthümlich veränderten Zellkerns.

Man sieht häufig in den Zellen Kugeln von $0,015-0,048 \mathrm{~mm}$. Grösse schwimmen, Fig. 5 und 6, die, wie die genauere Betrachtung zeigt, gewöhnlieh nichts anderes als mit wässerigem Safte erfüllte Hohlräume sind, und eine Hülle von Plasma besitzen, sei es, dass diese nur eine membranartige Haut um sie darstellt, oder an bestimmten Stellen dicker in Form eines regelmässigen $\mathrm{Me}$ niscus oder in unregelmässigen klumpigen Massen ansitzt. A uf dieser Hülle oder in ihrer Masse, seltener im Hohlraum derselben, liegen bald mehr, bald weniger dicht Farbstoffkörper, unitunter sogar der Zellkern, und geben der ganzen Erscheinung das täuschende Ansehen, als ob man es mit „Bläschen“ eigner Art zu thun habe, in denen Farbkörper sich vorfinden oder gar entstehen. Der Anlass zu einer solchen Täuschung wird noch mehr gegeben dadurch, dass nicht selten der Zellkern im Alter die ursprünglich auf seiner Oberfläche gelegenen (und da häufig bleibenden) Farbstoffkörper in sein Inneres aufnimmt und (an dem sehr leicht zu übersehenden Kernkörperchen immer erkennbar) neben diesen $\mathrm{Va}$ cuolen im Zell aft umherschwimmt. Fig. 7.

Eine der Entstehung nach von dieser Erscheinung wohl zu unterscheidende, äusserlich aber sehr ähnliche Art des Vorkom-

1) Weiss, a. a. 0. Bd. XLIX. Taf. II. Fig. 20.

2) Ich bezeichne im Folgenden diese Bildungen stets als Vacuolen, obgleich nicht selten vorkommt, dass dieselben nach Innen nicht membranartig abgegrenzt und nur zellsafthaltig sind, sondern wasserreiches Protoplasma enthalten, das ohne scharfe Grenze gegen Ausseu dichter wird, also in der That Protoplasmabällchen darstellen, die man sich äbrigens, wie die Vacuolen, durch Ablösung aus dem Plasma entstanden zu denken hat. 
mens von Farbkörpern ist folgende: In den mittleren Zellen finden sioh nicht selten kleine, die gewöhnlichen Farbstoffkörner höchstens um das $2-3$ fache übertreffende farblose Kugeln aus Plasma, die im Innern sehr kleine, etwa den 4.-6. Theil der gewöhnlichen messende runde oder spindelige Farbkörperchen bergen. Man könnte geneigt sein, diese für jugendliche Entwicklungszustände obiger grösserer Kugeln zu halten - und es ist dies in der That geschehen - allein die unten anzuführenden Thatsachen machen es wahrscheinlich, dass jede solche Kugel einem einzigen eigenthümlich veränderten Farbkörper (Chlorophyllkorn) gleichzusetzen ist, und mit einem Aggregat von Farbkorper, wie es die obigen grossen Vacuolen sind, nichts zu thun hat. Fig. $3 \mathrm{~m}$.

\section{Entstehung.}

Obwohl sich aus den geschilderten verschiedenen Formen und ihrem Nebeneinandervorkommen in den reifen Zellen schon manche Schlüsse auf die Art ihrer Entstehung ziehen liessen, so soll doch der grössern Sicherheit halber die Entwicklung derselben von der grünen Beere aus verfolgt werden.

Zur Zeit, wo die Beere eben ausgewachsen, aber noch rein grün ist, findet man in den Zellen derselben nur grünes Chlorophyll, aber auch hier Aussen und Innen etwas verschiedener Art.

In den äussern deutlich grün gefärbten und später die runden Farbkörper haltenden Schichten der Beere liegen Chlorophyllkörner der gewöhnlichen Art, aussen dicht die ganze Wand bedeckend, innen zerstreut oder gruppenweise in den Zellen; ihre Grösse variirt zwischen $0,0032-0,0064$, selten $0,0080 \mathrm{~mm}$. Einzelne Körner sind länglich, andere, offenbar in Theilung begriffen, bisquitformig eingeschnürt; ihre Substanz bald homogen, bald fein granulirt, ${ }^{1}$ ) weicht von der gewöhnlicher Chlorophyllkörner in nichts ab, im Innern finden sich gewöhnlich Stärkekörnchen. Fig. 8.

In den weisslich gefärbten innern Partien der Beere liegen die Chlorophyllkörner immer zerstreut an der Wand einher und sind geringerer Grösse 0,0032-0,0024 mm. Nicht selten findet man ausserordentlich schwach, fast ungefärbte Körner, in denen

1) Die Grundsubstanz des Chlorophyllkorns wird bald homogen (Năgeli, Zeitsch. f. wiss. Bot. Heft 3-4 1846 S. 116. - Sachs, Lehrb. d. Bot. 1868, S. 49), bald feinkörnig (v. Mohl, Bot. Ztg. 1855 S. 109) genannt; ich fand beides, ganz jugendliche Körner aber stets homogen. 
ein oder mehrere kleine scharf umschriebene Körnchen liegen, die ihrem ganzen Ansehen wie den vielfachen Uebergängen nach zwischen ihnen und ächten Chlorophyllkörnern für Chlorophyllkörner zu halten sind, in denen der Farbstoff in der eigenthümlichen Art vertheilt ist.

Zuinnerst endlich sind um diese Zeit die Zellen noch ganz farblos, sehr selten kaum gefärbte Chlorophyllkörner, denen der letzten Schicht gleich, vorhanden.

Demnach sind in der grünen Beere die spätern Farbstoffkörper als gewöhnliche Chlorophyllkörner vorhanden: in der äussern Schicht nach Grösse und Form bereits fertig: an Stelle der mittleren Spindeln und sonstigen Formen finden sich zur Zeit theils gefärbte, theils ungefärbte ebenfalls linsenförmige Chlorophyllkörner; im innersten Theil endlich sind nur schwache Andeutungen der nadelförmigen Spindeln gegeben.

Wenn die Beere ausserlich pomeranzengelb erscheint, findet man in den äussern Gewebelagen die Körner nach Gestalt und Grösse ungeändert, nur gelbgrün, gelb oder röthlich gefärbt, ${ }^{1}$ ) die Grundsubstanz stets körnig, die Contouren mehr weniger granulirt aber scharf.

In den innern Reihen dieser Lagen, noch mehr aber in den weiter innen gelegenen für's blosse Auge gelblich erscheinenden Parthien der Beere sieht man jetzt, was ursprünglich nicht der Fall war, den gelb gewordenen Farbstoff mehr und mehr nach einer Seite des Korns gerückt, so dass derselbe an der einen Peripheriehälfte am intensivsten gegen die andere farblose ganz allmählich abnimmt, Fig. 9. Oder derselbe sammelt sich auf einer oder zwei entgegengesetzten Seiten des Korns ausschliesslich und auf der Gegenseite, beziehungsweise in der Mitte erscheint eine kleinere oder grössere Vacuole. Fig. 10.

In den innersten Zellen ist noch keine Weiterbildung bemerklich. Bemerkenswerth ist es, dass unter all' diesen bereits gelb oder röthlich gefärbten vacuoligen Körnern immer noch selur kleine homogene rein grüne Chlorophyllkörnchen vorhanden sind, nicht selten in Einschnürung begriffen. Sie ändern sich bei der Reife einfach in rothe Körnchen um. Andrerseits findet man aber auch die oben erwähnten Chlorophyllkörner, deren sehr wasserreiche,

1) Der Unfärbungsprocess geht in den Körnern derselben Zelle ungleichen Schritt. 
farblose Grundmasse einige grün gefärbte Körnchen einschliesst, und die später die kleinen, mit rothen Körperchen versehenen Plasmakugeln darstellen.

In der Weise, wie die Beere sich röthet, findet man den ursprünglich grünen Farbstoff oraugeroth werden, und damit weitere Aenderungen in der Körnerform eintreten.

In den äussersten Reihen bleiben die Körner meist ungeändert, in den mittleren erscheint dagegen der Farbstoff nun allgemein auf eine oder 2 Seiten gedrängt, die Mitte oder Seite durch eine grosse Vacuole eingenommen, oder deren mehrere seitliche vorhanden und in Folge dessen die Formen, wie Fig. $3 \mathrm{~d}$ e.

Bei der definitiven Reife endlich sind die eben angegebenen Formen an Zahl bedeutend zurückgetreten, statt deren zahlreiche sichelförmige Körner, aneinanderhängende Doppelsicheln, S förmig geschwungene Körner, offece Ringe, endlich geradgestreckte einfache oder Doppelspindeln, Drei- und Vierspitzer vorbanden. Fig. 3.

Diese ganze Reihe von auf-und nebeneinander vorkommenden Formen ron dem einfachen linsenförmigen Korn bis zur exquisiten Spindel oder Sichel kann nicht anders gedeutet werden als eine Entwicklungsreihe. Man muss annehmen, dass die letztern Formen aus den erstern hervorgehen: Zunächst lagert sich in manchen Körnern, die vorher gleichmässig vertheilten Farbstoff besassen, der letztere peripherisch einseitig so, dass die eine Hälfte des Korns farblos wird, oder 2- und mehrseitig so, dass die Mitte frei bleibt. Weiterhin treten in den so veränderten (oder auch noch unveränderten) Körnern Vacnolen auf, in verschiedener Zahl, Grösse und Lagerung; gewöhnlich eine einzige centrale oder seitliche grosse, weniger häufig mehrere seitliche kleine. Wachsen diese Vacuolen nun bis zu einer bestimmten Grösse, so müssen Zerreissungen der Körner an den dünnsten Stellen der Oberfäche eintreten, die je nach Anzahl und Lage der Vacuolen - wie man leicht sieht zu den verschiedenen Formen der Farbstoffkörper sühren.

Begreiflicher Weise lässt sich das Einreissen der Körner nicht, oder nur höchst selten unmittelbar beobachten, dass aber diese Entstehungsweise dennoch die richtige und allein mögliche ist, wird aus dem Zusammenhalt aller Umstände völlig klar.

Sind die genannten Gebilde wirklich durch Einreissen vacuoliger Körner entstanden, so stellt die Länge einer Spindel oder 
Sichel (in einigen Fällen der Doppelsichel oder -Spindel) die Peripherie des frühern Korns dar, und es müssen Spindeln u. s. w. mit einiger Genauigkeit die 3 fache Länge des Durchmessers der früberen Körner haben. Dies ist in der That der Fall, wie der Vergleich der oben angegebenen Grösse der Körner mit der der Spindeln sehr rein darthut.

Wollte man annehmen, die nicht runden Formen seieu nicht die Abkömmlinge der Körner, so müssten die letztern zur Zeit der Reife noch eben so reichlich als vor derselben vorhanden sein und gleichzeitig eine absolıte Vermehrung der Farbstoffkörper stattgefunden haben. - Beides ist nicht der Fall; vielmehr zeigt sich, wie oben bemerkt, in der reifen Beere die Zahl der Körner sehr verringert, und eine absolute Zunahme der Farbkörper ist nicht vorhanden.

Man kann auch nicht annehmen, dass die spitzen Formen aus den runden auf eine andere als die angegebene Weise entstehen, etwa durch ein ,eigenthümliches Spitzenwachsthum “, denn dagegen beweist einfach die Thatsache, dass während der ganzen Entwicklung des Farbstoffs keine Uebergangsstufen zwischen runden und spitzen Formen aufgefunden werden können. (Weiteres in der "Literatur*.)

Leider war es mir - aus Mangel an passendem Material nicht möglich, über die Entstehung der allerinnerstgelegenen nadelförmigen Spindeln völlig ins Reine zu kommen. Wie oben erwähnt, finden sich in den innersten Zellen der grünen Beere gar keine Andeutungen von Farbstoffkörpern oder ausserordentlich blasse, kaum sichtbare linsenförmige Bällchen. In spätern Stadien sah ich solche Körper mit einseitigem, sehr dünnem Farbstoffmeniscus - aber auch gleichzeitig lange, Protoplasmafäden ähnliche gelbliche Stränge, und es blieb mir ungewiss, ob die hiesigen Formen allein durch Zerfall der runden Körper oder auch vielleicht durch Auftreten von Farbstoff in Plasmasträngen entstehen.

Endlich muss noch zweier möglicher Entstehungsweisen von spindeln und kleinen Körnern gedacht werden, die vielleicht in manchen Beeren vielfach, in andern (wie bei den von mir untersuchten) selten oder gar nicht vorkommen.

Fig. $3 \mathrm{k}$ finden sich Körner, in denen sich der Farbstoff sehr bestimmt in Sichel- oder Spindelform auf gewisse Stellen concentrirt hat, während die zwischenliegenden Parthien ganz farblos sind. Es ist möglich und wahrscheinlich, dass solche Körner 
schliesslich zerbrechen und die Fragmente, als selbstständige spindelige oder dreieckige Farbkörper, frei werden.

Die in Fig. $3 \mathrm{~m}$ dargestellten Körper, die ebenfalls mitunter vorkommen, balte jch für gewöhnliche Farbekörper, deren Pigment auf kleine Kugeln geballt ist, und (mit oder ohne protoplasmatischer Grundlage) durch Auflösung der sehr wasserreichen umhüllenden Plasmagrundsubstanz vielleicht frei werden kann.

Vielleicht, dass eine solche Bildungsweise kleiner Farbkörper stellenweise häufig ist.

Werfen wir nun noch einen Blick auf die sichtbaren Aenderungen, welche Protoplasma und Zellkern während der Reife eingehen.

Der Zellkern der unreifen Beere bietet nichts Abweichendes dar; er ist wandständig, linsenförmig, scharf aber einfach conturirt, im Innern homogen oder feinkörnig, mit ziemlich grossem, gewöhnlich etwas einseitig gelagerten Kernkörperchen versehen. Auch das Plasma bietet keine Besonderheiten vor dem anderer Zellen.

Mit der Reifung müssen aber beide Objecte eine eigene schleimartige, klebrige und gegen Wasser ausnehmend empfindliche Consistenz annehmen.

Man sieht nemlich die Farbkörper, die den Zellkern schon als Chlorophyllkörner um- und überlagern, später auf demselben merkwürdig fest haften, wie sich beim Bewegen derselben durch Druck auf das Deckglas constatiren lässt, und während dieselben anfänglich nur aufliegen, allmäblich da und dort sogar im Innern desselben erscheinen, wobei gewöhnlich auch Vacuolen auftreten, das Plasma auf eine Seite zurückweicht und das Kernkörperchen unförmlich wird, Fig. 7. In gleicher und noch folgereicherer Weise ändert das Protoplasma seine Beschaffenheit. ${ }^{1}$ ) Anfänglich der Wand angelegen, zeigt dasselbe bald zahlreiche Stränge und Fäden, in welche die Farbkörper bündelweise eingelagert oder durch sie fadenartig aneinander gereiht sind. Es erscheinen nun die oben beschriebenen zellsafterfüllten Kugeln, die, wie bemerkt, bald mit einer dünnen, bald dicken Plasmahülle umgeben sind, in dieser Farbkörper tragen und frei umherschwimmen. Diese Kugeln, die vielfach für "Bläschen" sui generis gehalten worden sind,

1) Vielleicht bängt diese eigenthümliche Beschaflenheit des Plasmas mit einem beträchtlichen Gehalt desselben an Pectinstoffen zusammen; diese Körper sind be- 
zeichnen sich vor gewöhnlichen Vacuolen nur dadurch aus, dass sie sich frei in der Zelle bewegen können, indem sie nicht allein nach Innen, sondern auch nach Aussen durch eine hautartige Schicht abgegrenzt, kurz, individualisirt, und nicht einfache Hohlräume des Plasmas sind. Ich glaube nicht, dass dieses berechtigt, sie für besondere organische Bildungen, „Bläschen" eigner Art, dem Zellkern u. s. w. vergleichbar zu halten, zumal, da man ganz analoge, wo nicht identische Erscheinungen künstlich an dem Plasma jeder beliebigen grünen Zelle hervorrufen kann.

Legt man nemlich Zellen der unreifen Beere in einen Tropfen Wasser, so treten unter Zurückweichen des Plasma ron der Wand und mitunter unregelmässigem Zerfall desselben Vacuolen mancherlei Art in demselben auf. Diese sind bald einfach begrenzt, und als typische Vacuolen von einer hautartigen Schicht umgrenzte Hohlräume des Plasmas, Fig. 11. Bald aber von einer dicken, regel- oder unregelmässigen Plasmahüllc umgeben, die auch gegen Aussen hautartig abgeschlossen ist, und den ganzen Körper gegen das umgebende Plasma mehr oder minder scharf abgrenzt. Gar nicht selten erscheinen sogar diese Vacuolen vollständig frei, Fig. $12 \mathrm{a}$, wie von einem doppelten Contour umgeben, täuschende Ebenbilder der oben in der reifen Frucht gesehenen Kugeln, wie sie auf und in der Wand Farbkörper und den Zellkern tragen, oder ins Innere einschliessen.

Man gewahrt dabei auch, dass die Chlorophyllkörner, besonders wenn sie aus dem Protoplasma frei ins Wasser treten, Veränderungen darbieten, die für die Auffassung der Reifeerscheinun. gen von Bedeutung sind, ich meine die sonst schon vielfach ${ }^{1}$ ) beschriebenen Quellungserscheinungen derselben. Mitunter granuliren die Körner beim Austritt ins Wasser bloss und erscheinen wie aus zahllosen winzigen Körnchen zusammengesetzt, wenn sie gleich vorher ganz homogen waren, und ihr scharf umschrieben bleibender Contour wird körnelig. Häufiger jedoch tritt Folgendes ein: Im Moment des Austritts in Wasser hebt sich plötzlich von der granulirenden Gesammtmasse eine feine Membran ab, die sich

kanntlich normale Begleiter vieler Fruchtsäfte, bei Capsicum ist nach Berzelius Pectinsäure vorhanden, und auch für Solanumarten derartige Körper wabrscheinlich, vgl. Rochleder, Phytochemie 1854. S. 145-146.

1) H. v. Mohl, a. a. 0. S. 97; S. 107; S. 109-111. - Nägeli u. Uramer, Pfl.-Phys.-Unters. Heft I. 1855. S. 9-14. - Nägeli und Schwendener, Mikr. 1867. S. 552-554. - Hofmeister, Zelle 1867. S. 369. 
mehr und melur bläht, und die geballte Chlorophyllmasse sackartig umgibt. Auch in diesem Falle treten Aehnlichkeiten mit den Reifeerscheinungen noch nicht hervor. Es geschieht aber sehr bäufig, dass in dem Korn sehr rasch eine oder mehrere Vacuolen hervortreten, und diese geben dann jene obigen Uebergangsstadien der Körner zu den Spindeln täuschend wieder: man sieht Körner durch eine centrale Vacuole zu Ringen geworden, solche, die eine längliche Vacuole haben und die gefärbte Grundmasse zu beiden Seiten derselben meniskenartig tragen, andere mit einer seitlichen grossen Vacuole und einem seitlichen Farbstoffmeniscus, endlich solche, in denen mehrere Vacuolen die Grundmasse drei- und vierspitzig zusammendrängen. Fig. 13.

Diese Erscheinungen des Chlorophylls wie des Plasmas bekräftigen die oben gegebene Auffassung des ganzen Vorgangs der Farbkörperbildung, wie die der Farbkörper haltigen Bläschen; sie geben aber auch zugleich einen Wink, wie man sich rielleicht die Ursachen dieser Aenderungen in beiden Objecten bei der Reife vorzustellen hat. Die überraschende Aehnlichkeit beider Processe lässt die Vermuthung nicht ungerechtfertigt erscheinen, dass beide auf wesentlich derselben Ursache, auf einer Wasseraufuahme (Imbibition) des Plasmas und des Chlorophylls beruhen. Eine Stütze dieser Vermuthung scheint es nur zu sein, dass die Beeren bei der Reifung allmählich einen sehr hohen Wassergehalt erreichen. ${ }^{1}$ )

Bekanntlich enthalten auch andere zahlreiche Früchte (Lycium barbarum, Lonicera etrusca, Pyrus aucuparia und americana, Asparagus verticillatus nach Trécul, Solanum capsicastrum, Capsicum baccatum, Lycopersicum esculentum, Samenmantel von Evo-

1) Ich fand denselben für die entkernten Beeren (bei $110^{\circ}$ C.) zu $89,1 \%$. Bei unserm Beeren- und Kernobst beträgt derselbe nach Fresenius durchschnittlich über $85 \%$; der Eiweissgehalt nicht ganz $1{ }^{0} 0$ Ein Verhältniss, das besouders auffallend wird, wenn man den Wasser- und Eiweissgehalt in andern Pflanzentheilen, 7. B. den Blättern, damit vergleicht. Nach Fresenius beispielsweise enthält die Weinbeere 79,977\% Wasser (der geringste Gehalt ähnlicher Früchte), 0,832\% Eiweiss; die Blätter derselben Pflanze nach Boussingault 74,4\% Wasser, 6,08 \% Eiweiss. (vgl. Fr. Schulze, Lehrb. d. Chemie f. Landw. II., 2. S. 380 und 381.) Es verhalton sich demnach die Eiweissstoffe zum Wasser

in der Beere wie $1: 96,1$,

in den Blättern wie $1: 12,3$. 
nymus europaeus nach Weiss) wie gelbe und orangefarbige Blüthen (Strelitzia Regina nach Mohl und Hildebrandt, Geum montanum, Lilium bulbiferum, Tydaea u. s. w. nach Weiss) ähnliche 2 wei- und mehrspitzige Farbstoffkörper. Obwohl ich nun die Entstehungsweise nur für eine einzige Pflanze beobachtet habe, so lässt sich doch aus den von Trécul und Weiss gegebenen Abbildungen mit Sicherheit eine gleiche Entstehungsweise auch für die übrigen Pflanzen erschliessen, da hier dieselben Uebergänge von vacuoligen Körnern, Ringen u. 8. w. beobachtet worden sind. Vgl. Trécul a. a. O. pl. 5. Fig. 38. Lycium barbarum; Fig. 39. Lonicera etrusca. - W eiss a. a. O. Bd. XLIX. Taf. I. Fig. 8. Lyciun barbarum; Taf. II. Fig. 20. Solanum capsicastrum; Fig. 23. Evonymus europaeus; Fig. 24. Capsicum baccatum; Fig. 25. Asparagus verticillatus; für die Blüthen Weiss a. a. O. Bd̀. LIV. Fig. 18-19. Geum montanum; Fig. 27. Lilium bulbiferum; Fig. 29. Tydaea hybr. gigantea.

\section{Literatur.}

Die geschilderte Bildungsweise der verschieden geformten Farbstoffkörper durch Zerfall vacuolig gewordener Körner drängt sich dem Beschauer so unmittelbar auf, dass schon der Erste, der über die Entstehung dieser Gebilde geschrieben hat, Trécul'), sie in der genannteu Weise auffasste.

Derselbe beschreibt unter Anderm die Farbkörper von „Capsicum Pseudocapsicum" und fährt dann fort: Quand ces vésicules sont arrivées à leur complet développement et que la matière colorée est inégalement répartie au pourtour de la vésicule, la membrane se rompt au point resté mince et incolore; elle se dresse peu à pou et l'on a alors des corps fusiformes plus ou moins grêles, qui présentent quelquefois des granules rouges dans leurs interieur, en sorte qu'ils constituent eux-mêmes des vésicules fusiformes. Cette structure vésiculaire se voit surtout parfaitement dans les cellules du fruit du capsicum Pseudocapsicum. Dans les vésicules gg. fig. 30. pl. 5. le protoplasma coloré, même avant l'ouverture de le vésicule arrondie, était déja adhérent aux deux

Mögen immerhin diese Zahlen nicht das richtige Verhältniss des freien Zellwassers zum Plasma angeben, jedenfalls darf nach ibnen ein weit grösserer Wassergehalt des Plasmas in der Beere als in sonstigen Theilen angenommen werden.

1) Annal. sciene. nat. S. IV. T. X. 1858. p. 150. ss. 
pellicules écartées laissant un espace vide et incolore entre elles. Quand la vésicule arrondie ou mère est restée mince sur deux points opposés, il se fait dans ce cas deux vésicules fusiformes, qui peuvent rester fixées l'une à l'autre par une de leurs extremités après la rupture d'une des parties amincies." p. 155. s.

Diese richtige, aber ohne alle Beweise vorgetragene Ansicht über die Entstehung der Spindeln blieb unbeachtet, zumal da dieselbe in einer Arbeit versteckt liegt, deren sonstige Anschauungen und Resultate von Niemand getheilt werden.

In einer Arbeit von Ad. W eiss, "Untersuchungen über die Entwicklungsgeschichte des Farbstoffs in den Pflanzenzellen " "), wo zahlreiche Farbkörper von Solanum-Arten und andere spindelförmige Farbstoffkörper beschrieben und abgebildet werden, geschieht weder dieser Ansicht Trécul's (obwohl dessen sonstige Ansichten vielfach citirt und adoptirt werden), noch überhaupt der Entstehnng dieser Gebilde Erwähnung. Erst in der Fortsetzung derselben ${ }^{2}$ ) wird ihrer einfach mit den Worten gedacht, „dass durch das Zerreissen der dünnsten Stellen aus rundlichen Formen spindelförmige zweispitzige entstehen, kann man ziemlich häufig beobachten (?), und die Mehrzahl derselben bildet sich ganz sicher auf diese Weise;" und darauf wird ohne weitere Beweise diese Bildung im Resumé.(S. 205) definitir ausgesprochen: „Die zweispitzigen eigenthümlichen Gestalten entstehen durch Zerreissen runder Formen an ihren dünnsten Stellen." Hinsichtlich der feinen Fortsätze der Spindeln, die, wie wir sahen, die dünnsten Stellen des früberen racuoligen Korns sind, heisst es dort: „Die zweispitzigen Farbstoffgebilde haben häufig farblose schleimige Fortsätze, welche oft mehrere verbinden. Diese Fortsätze sind die Reste ursprünglicher Protoplasmastränge." Das ist, wie oben gezeigt wurde, nur hinsichtlich der Verbindungsstränge zahlreicher Spindeln richtig.

Eine von der unsrigen ganz abweichende Ansicht über die Entstehung der Spindeln wird von Hofmeister geäussert, ${ }^{3}$ ) (Zelle, S. 377): „Manche der gelbroth oder gelb gewordenen Chlorophyllkörner zeigen ein auffallend gesteigertes Längen- oder viel-

1) a. a. 0. Bd. XLIX.

2) a. a. O. Bd. LIV.

3) Dieselbe ist auch in das so vorzügliche Lehrbuch der Botanik von Sachs 1. Aufl. S. 49-50; 2. Aufl. S. 49. übergegangen. 
mehr Spitzenwachsthum. Die der peripherischen Gewebe ron Ly. copersicum esculentum sind langgestreckt mit stumpfen oder spitzen, in letzterm Falle oft ungefärbten Enden. Viele (nicht alle) Farbkörperchen der Fruchtwand von Capsicum cerasiforme, Lycium barbaium, Solanum capsicastrum, Asparagus verticillatus, des Arillus von Evonymus europaeus wachsen an einer Stelle oder an zwei einander gegenüberliegenden Puncten (bei länglichen Körnern an den Enden) oder an 3 verschiedenen Orten zu eft sehr lang werdenden Fortsätzen aus; die Körnchen werden spindelförmig oder selbst dreistrahlig. Wenn diese Sprossungen der Körnchen besondere Länge erreichen (wie bei den erwähnten Solanaceen), so bleiben sie farblos."

Während nach unserer Erklärung diese Formen einem eigen. thümlichen, meist durch Vacuolenbildung eingeleiteten Zerfallen der Körner, einer Degradation derselben, ihre Entstehung verdanken, wird hier ein ,gesteigertes Spitzenwachsthum ", Sprossung »der Körner“, angenommen.

Wie oben bemerkt, ist ein solches Spitzenwachsthum deshalb nicht zulässig, weil bei der Entwicklung durchaus alle Uebergänge von den runden zu den spindeligen Körpern fehlen, die doch sicherlich nicht überseben werden könnten.

Es ist aber auch an sich unwabrscheinlich, dass in eisem Organ wie der reifenden Frucht, in dem kein Elementartheil der Zelle mehr Wachsthum, vielmehr nur Zerfall, Degradation zeigt, gerade die Chlorophyllkörner eine so merkwürdige Steigerung ihrer Lebensthätigkeit erfahren sollten; merkwürdig besonders des. halb, weil dieses Wachsthum bei verschiedenen Körnern ein höchst verschiedenes sein müsste: das eine Korn müsste Spitzen. wachsthum an zwei Enden, das andere an drei oder vier, wieder ein anderes tangentales Wachsthum der Peripherie zeigen, damit die bekannten Ringe entstünden u. s. w. - gewiss ein sehr complicirter und unwahrscheinlicher Vorgang, dem gegenüber die obige Erklärung höchst einfach und natürlich crscheint. - -

Zu den merkwürdigsten Irrthümern über die Entstehung der Farbstoffgebilde haben die oben erwähnten, farbkörperhaltigen Vacuolen Anlass gegeben, Irrthümern, die, wie Hofmeister treffend bemerkt, eine ganze Literatur haben.

Der Leser erinnert sich, dass nebeu den oben beschriebenen grossen, freischwimmenden, farbkörperhaltigen Vacuolen in den mittleren und innern Parthien des Pericarps nicht selten etwas 
grössere Chlorophyllkörner vorkommen, deren Farbstoff in Form kleiner Kügelchen der farblosen Grundmasse eingelagert ist, und dass hier zu verschiedener, und ziemlich später Zeit schwach fast ungefärbte Chlorophyllkörper vorkommen. Diese ganz heterogenen Dinge wurden (in der umgekehrten Reihenfolge) in genetischen Zusammenhang gebracht und aus den farblosen Körnern die grossen farbkörperhaltigen Vacuolen allmählich entstehen lassen. Es sollte das eine zweite Art der Entstehung von Chlorophyll- und Farbkörpern innerhalb „Bläschen“ eigner Art sein, Bläschen, die bald als vésicules pseudo-nucléaires (wenn sie farblos) oder vésicules chromulifères (wenn sie farbkörperhaltig) (Trécul), bald als „Farb- und Mischbläschen" (Weiss), bald als „Physalide* (Hartig) bezeichnet wurden.

Am ausführlichsten hat über diese Gebilde Trécul (a. a. 0 . p. 127-135 und p. 147-150) gehandelt. Er fand in den reifenden Früchten verschiedener Pflanzen, besonders der SolanumArten (Solanum nigrum pl. 4. fig. 1-14; Solanum Dulcamara pl. 4. fig. $31-43$; Solanum villosum pl. 4 . fig. $56-57$.) die oben genannten 3 Formen von "Bläschen": kleine farblose (seine vésicules pseudo-nucléaires), grössere mit kleinen Farbkörnchen und grosse mit zahlreichen grossen Farbkörpern (grünen oder gefärbten); er nimmt an. dass es die aufeinanderfolgenden Entwicklungsstufen einer in "Bläschen" geschehenden F'arbkörpererzeugung seien, und lässt also hier die Farbkörper in farblosen Bläschen sich bilden. In einem andern Falle lässt er eine wesentlich ganz gleiche Reihe von Dingen nicht aus farblosen Bläschen, sondern aus einem Chloroplyyllkorn der gewöhnlichen Art Entstehung nehmen, pl. 5. fig. $6-11$.

Diese (erstgenannte) Entstehungsweise von Farbkörpern wurde auch von Weiss adoptirt und (a. a. O. Bd. XLIX. S. 3-5. Taf. I. Fig. 3-5. für Lycium barbarum, Fig. 26. für Asparagus verticillatus) illustrirt. Die Vacuolen heissen „Farbbläschen“, wenn sie nur Farbkörper, „Mischbläschen“, wenn sie nebenbei auch einmal einen anderen Farbstoff (Anthokyan) einschliessen. - Ein Gleiches thut M a schke, Bot. Ztg. 1859. S. $193 \mathrm{ff}$.

Nachdem ich oben gezeigt habe, dass diese „Blasen" einfache, Farbstoffkörper einschliessende Vacuolen sind, halte ich .einen weitern Beweis für die Unrichtigkeit dieser Annahme farbkörpererzeugender Bläschen für ganz unnöthig; nicht die farblosen Bläschen sind, wie wir gesehen, das Primäre und die Farbkörper darin 
secundär erzeugt, sondern die zuerst vorhandenen Farbkörper werden in nachträgliche $\nabla$ acuolenbildungen eingeschlossen. Wo aber farblose "Bläschen", vésicules pseudo-nucléaires, vorkommen, haben sie mit den farbkörperbaltigen Vacuolen gar nichts zu thun, sie sind entweder wenig gefärbte Chlorophyllkörner, wohl auch kleine Vacuolen der obigen Art, die zufällig keine Farbkörper eingeschlossen haben. Die "Farbbläschen" und vésicules chromulifères aber sind Dinge zweierlei Art: da, wo sie im Innern kleine grüne Körnchen von geringer Grösse als dies gewöhnliche Chloropbyll bergen, und dieses selbst nur um ein Unbedeutendes übertreffen, sind es eigenthümlich entwickelte (degradirte) Chlorophyllkörner, so entstanden, wie es Trécul, pl. 5 . fig. 4 ff., ') will; wo dieselben aber bedeutende Grösse erreichen und gewöhnliche Chlo. rophyll- oder Farbkörper einschliessen, sind es die beschriebenen Vacuolen, wie sich schon daraus ergibt, dass sie gar nicht selten zugleich den Zellkern ${ }^{2}$ ) mit umschliessen.

Schliesslich sei noch bemerkt, dass Hartig's Physalide (Entwicklungsgeschichte des Planzenkeims, 1858. S. 10 ff.), soweit sie "Chlorophyllbläschen" werden oder enthalten, die oben genannten Vacuolen sind.

Leipzig, 2. Januar 1869.

1) In dieser Reihe gehören aber Fig. 9 und 10 offenbar nicht zu den übrigen; sie sind chlorophyllhaltige Vacuolen.

2) Weiss hat a. a. 0. Bd. LIV. Taf. IV. Fig. 55-57. bei Hyoscyamus niger sehr grosse Zellkerne gefunden, die Plasmaströmung und eisengrünenden Gerbstoffenthalten und deren Kernkörperchenganz das Anseben eines kleinen Cytoblasten hat." Ich vermuthe, diese Kerne sind vom übrigen Plasma losgetrennte Plasmamassen der obigen Art, und ihr "cytoblastenäbuliches Kernkörperchen" ist der Cytoblast selbst. 


\section{Erklärung der Tafel $\mathbf{X}$.}

Fig. 1-3. Die Farbstoff körper der reifen Beere von Salanum Pseudocapsicum, mit Hartnack's Immers. IX. gesehen.

1-2 aus den äusseren, 3 aus den inneren Zelllagen der Beere. 1 a eine ganze Zelle bei geringerer Vergrössernng.

Fig. 4-6. Dieselben bei 300 facher Vergrösserung, eingeschlossen in Plasmastränge (4), und Vacuolen (5 u. 6).

Fig. 7. Zellkern mit Farbstoff körpern im Innern. (Immersionssyst.)

Fig. 8. Zelle der grünen Beere mit normalen Chlorophyllkörnern.

Fig. 9 u. 10. In der Umfärbung begriffene Chlorophyllkörner.

Fig. 11 u. 12. Chlorophyllhaltige Zellen in Wasser liegend.

Fig. 12a. Vacuole, in einer chlorophyllhaltigen Zelle durch Wasserzusatz entstanden.

Fig. 13. Chlorophyllkorn intact, und in Wasser verquollen. 

R. Caspary. Bemerkungen über die Schutzscheide und die Bildung des Stammes und der Wurzel; hierzu Taf. VIII und IX.

A. Weiss. Untersuchungen über die Zahlen- und Grössenverhältnisse der Spaltöfnungen.

J. Hanstein. Die Befruchtung und Entwicklung der Gattung Marsilia, mit Taf.X-XIV.

Th. Wulf: Beiträge zur Entwicklungsgeschichte der Orchideen-Blüthe, mit Taf. $\mathrm{XV}-\mathrm{XVIII}$.

Gr. Krans. Ueher den Ban der Cycadeenfiedern, mit Taf. XIX-XXIII.

A1. Fischer v. Waldheim. Ueber die Entwickelung der Farnsporen, mit Taf. XXIV bis XXVII.

F. Buchenan. Der Blüthenstand der Juncaceen, mit Taf. XXVIII-XXX.

S. Rosauofl Zur Kenntniss des Baues und der Entwicklungsgeschichte des Pollens der Mimoseae, mit Taf. XXXI-XXXII.

r. Ilildebrand. Ueber die Befruchtung der Silviaarten, mit Hülfe von Insecten, Taf. XXXIII.

Th. Geyler. Zur Kenntniss der Sphacelarieen, mit Taf. XXXIV-XXXVI.

Alex. v. Wolkulf. Einige Untersuchungen über die Wirkung des Lichtes von verschiedener Intensität anf die Ausscheidung der Gase durch Wasserpflanzen, mit Taf. I-III.

A. Yogl. Beiträge zur Kenntniss der Milchsaftorgane der Pflanzen, mit Taf. IV.

S. Rosanoff. Morphologisch-embryologische Studien, mit Taf. V-VII.

Gr. Kraus. Ueber den Bau trockner Pericarpien, mit Taf. VIII-XI.

J. Walz. Beitrag zur Morphologie und Systematik der Gattung Vaucheria DC, mit Taf. XII-XIV.

A. B. Frank. Ueber die anatomische Bedeutung und die Entstehung der vegetabilischen Schleime, mit Taf. $X V-X V I$.

A. de Bary. Ueber die Keimung einiger grosssporiger Flechten, mit Taf. XVII-XIX.

Max Reess. Zur Entwicklungsgeschichte des Polypodeaceensporangiums, mit Taf. XX-XXII.

C. Mũlier. Untersuchung über den Sitz des Alcaloide in der Cinchonarinde, mit Taf. XXIII-XXIV.

N. J. C. Miller. Das Wachsthum des Vegetationspunktes von Pflanzen mit decussirter Blattstellung, mit Taf. XXV-XXXIV.

E. Strasburger. Ein Beitrag zur Entwicklungsgeschichte der Spaltöffnungen, mit Taf. XXXV-XLII.

F. Ilildebrand. Ueber die Befruchtung von Aristolochia Clematitis und einiger anderer Aristolochia-Arten, mit Tafel XLIII.

F. Bildebrand. Ueber die Nothwendigkeit der Insektenhülfe bei der Befruchtung von Corydalis cava.

L. Kny. Ueber Bau und Entwickelung der Riccien, mit Taf. XIIIV-XLVI

§. J. C. Miiller. Untersuchungen über die Vertheilung der Harze, ätherischen Oele, Gummi und Gummiharze, und die Stellung der Secretionsbehälter im Pflanzenkörper, mit Taf. XLVII - LIII.

A. Famintzin. Die Wirkung des Lichtes auf Algen und einige andere ihnen nahe verwandte Organismen, mit Taf. I-III.

Die Wirkung des Lichts auf das Ergrünen der Pflanzen.

Die Wirkung des Lichts und der Dunkelbeit auf die Vertheilung der Clorophyllkörner in den Blättern von Mnium sp.?

1月. Th. Geyler. Ueber den Grfässbündelverlauf in den Laubblattregionen der Coniferen, mit Taf. IV-IX.

11. Reess. Zur Entwickelungsgeschichte der Stammspitze von Equisetum, mit Taf. X-XI.

X. J. Müler. Die Entwickelungsgeschichte der Kapsel von Ephemerum mit Taf. XII-XIV.

F. fildebrand. Nykologische Beiträge, mit Taf. XV-XVII.

G. liilgers. Leber das Auftreten der Krystalle von oxalsaurem Kalk in Parenchym einiger Monocotylen.

E. Pfitzer. U(ber die Sclutzscheide der deutschen Equisetaceen, mit Taf. XVIII-XX.

$P$ 6. Loient?. Grundlinien zu ciner vergleichenden Anatomie der Laubmoose, mit Taf. XXI-XXVIII.

E. Loen. Ceber Demation pullulans de Bary, mit Taf. XXIX und XXX.

N. C. Miiller. Untersuchungen uber die Diftusium der aımosphärischen Gase in der Pflauze und die Gasausscheidung unter verschiedenen Beleuchtungsbedingungen, mit Tif. XXXI.

Hermaun Graf' zu inoms-Laubah. Ueber den Bau und die Entwickelung der Ernührungsorgane parasitischer Phanerogameu, mit Taf. XXXII-XXXIX. 


\section{Inhalt des vorliegenden Heftes 1, Band VIIr.}

L. Kny. Beiträge zur Entwickelungsgeschichte der Farrenkräuter mit Taf.I - III.

E. Phitzer. Beiträge zur Kenntniss der Hautgewebe der Pflanzen mit Taf. VI. III. Ueber mehrchichtige Epidemis und das Hypoderma.

N. J. C. Müllır. Die Anatomie und Mechanik der Spaltöffnungen mit Taf. IVu. V. III. Wirkung der Wärme innerhalb der Temperaturgrenzen des gewöbnlichen Lebens.

J. Peyritsch. Ueber Bildungsabweichungen bei Cruciferen mit Taf. VII-IX.

G. Krius. Die Entstebung der Firbstoffkörper in den Beeren von Solanum Pseudocapsicum mit Taf. X .............. 131

\section{Inhalt von Band VII.}

J. Baranetzky. Beitrag zur Kenntniss des selbstständigen Lebens der Flechteu. gonidien, mit Taf. I. - Fr. Buhlienul. Leber die Richtung der Samenknospe bei den Alismaceen, mit Taf. II. - C'ur. Lue'ssen. Zur Controverse über die Einzelligkeit oder Mehrzolligkeit des Pollens der Onaqrariern, Cucurbitaceen und Corylaceen, mit Taf. IV.-VI. - A. Fischer 1. Waldheim. Beiträge zur Biologie und Entwickelungsgeschichte der Ustilagineen, mit Taf. VII-XII. - N. J. C. Müller, Untersuchungen über die Diffusion atmosphiurischer Gase in der Pfanze und die Gasausscheidung unter verschiedenen Beleuchtungsbedingungen, II. Theil, mit Taf. III. - N. J. C. Mliller, Ueber den Durchgang von Wasserdampf durch die guschlossene Epidermiszelle - .. J. c. Miiller, Notiz über die Farhstoffe im Chlorophyll. - (i. Kiras. Ueber die Ursachen der Formänderungen etiolirender Pflanzen. - Julius iclurödel. Beitrag zur Kenntniss der Frübjahrsperiode des Ahorns (Acer platanoides) mit 'Iat. XIII-XX. - EI. Bor cow. Ueber gegitterte Parenchymzellen in der Rinde des Stenge!s von Ceropegia aphylla und deren Beziehung zu den Milchsatturefassen, mit Tafel XXI. - II. Leitreli. Neue Saprolegnicen, mit Taf. XXII-XXIV. - li. Ntrisburger. Die Befruchtung bei den Farrenkräutern, mit Taf. XIV und XXVI - E. Strasburger, Die Geschlechtsorgane und die Befruchtung bei Marchantia polymorpha, mit Taf XXYII und XX'III - F. Itildelınd. Ceber die Betaubungsvorrichtungen bei den Fumariaceen, mit Taf. XXIX-XXXI. - E. Loew. Zur Entwicklungsgeschichte von Penicillium mit Tafel XXXI-XXXIV. - G. Kraus. Einige Beobachtungen uber den Einfluse des Lichts und der Wirme auf die Stärkeerzengung im Chlorophyll, mit Tafel XXXV. - F. Pfitzer Beiträge zur Kenntniss des Hautgewehes der Pflanzen, mit Taf. XXXVI-XXXVII. 1. Ueber die Spaltöffungen der Gräser nebst einigen Bemerkungen über die ersteren im Allgemeinen. Il. Ueber die Hautgewebe einiger Restionaceen.

Die ,.Jahrbücher für wissenschaftliche Botanik" erscheinen in unterzeichneter Verlagsbuchhandlung in zwangloseu Heften von 8-12 Bogen Text mit Abbildungen, und wird der Verleger bestrebt sein, die typographische wie artistische Ausstaltung der Zeitschrift zu einer miglichst vollkommenen zu gestalten.

Vier Hefte bilden einen Band, doch kann jedes Heft auch einzeln bezogen werden und richtet sich der Preis jedes einzelnen Heftes nach Umfang und nach Anzahl der beigegebenen Tafeln.

Geeignete Beiträge wolle man gefälligst an den Herrn Herausgeber (in Berlin, Bendlerstrasse 13 ) oder an den unterzeichneten Verleger senden, welcher letztere alle zur Aufnahme angenommenen Aufsätze mit 10 Thlr. pro Druckbogen homorirt.

Bestellungen auf die „Jahrbücher für wisseuschaftliche Botanik“ nehmen alle Buchhandlungen des In- und Auslandes entgegen.

Leipzig, im October 1864.

\section{Die Verlagshandlung. Wilhelm Engelmann.}

Redigirt unter Verantwortlichkeit von Dr. Wilh. Engelmann in Leipzig. 


\section{JAHRBÜCHER}

für

\section{wissenschaftliche Botanik.}

Herausgegeben

von

Dr. N. Pringsheim.

Achter Band. Zweites Heft.

Mit 12 Tafeln.

Leipzig, 1871.

Verlag von Wilh. Eugelmann. 


\section{Inhalt der ersten sieben Bände.}

1. Pringsheim. Beiträge zur Morphologie und Systematik der Algen. I. Morpho. logie der Oedogonieen, mit Taf. I-VI. - W. Hofimeister. Neuere Beobachtungen über Embryobildungen der Phanerogamen, mit Taf. VII-X. - N. Pringsheim. Ceber das Austreten der Sporen von Sphaeria Scirpi aus ihren Schlauchen hierzu Taf. XXIV. A. - H. Srhacht. Uepber die Pflanzenbefruchtung, mit Taf $\mathbf{X I}-\mathbf{X} \nabla$. - Juh. Hanstein. Ueber den Zusammenhang der Blattstellung mit dem Bau des dicotylen Holzringes, mit Taf. XVI-XTIII. - N. Pringsheim. Beiträg zur Morphologie und Systematik der Algen. II. Die Saprolegnieen, mit Ti XIX-XXI. - Al. Braun. Ueber den Blüthenbau von Delphinium, mit Taf. XXII und XXIII. - L. Cienknwsky. Die Pseudogonidien; hierzu Taf. XXIV. B. k. Caspary. Die Hydrilleen (Anacharideen End) mit Taf. XXV-XXXX. - J. Grïllaud. Einige Worte über die Bastardbildungen in der Gattung Aegilops, mit Taf. XXX. - N. Prinsshrim. Beiträge zur Morphologie und Systematik der Algen. III. Die Choleochateen, mit Taf. I-VI. - C. Silnio. Verglechende Untersuchun gen über den Bau und die Entwickelung des Korkes, mit Tafel VII-XII. H. Schacht. Ueber den Bau einiger Pollenkörner, mit Taf. XIV.-XVIII. 1. de Bary. Einige neue Saprolegnien, mit Taf. XIX-XXI. - M. Wicluma. Beiträge zur Physiologie der Laubmoose. - N. Pringsheim. Beiträge zur Morpholo gie und Systematik der Algen. IV. Nachträge zur IIorphologie der Saprolegnieen mit Taf. XXII-XXV. - W. Hofmeister. Ueber die Beugungen saftreicher Pflar zentheile nach Erschitterung. - H. Rolfmann. Untersuchungen über die Keimun der Pilzsporen, mit Taf. XXVI bis XXXII. - J. Sachs. Physiologische Untersuchungen über die Abhängigkeit der Keimung von der Temperatur. - W. Pot meister. Ueber die Entwickelung ler Sporen des Tuber aestivum Vittad., mi Taf. XXXIII-XXXV. - Joh. Hanstein. Versuche uiber die Leitung des Safte durch die Rinde und Folgerungen daraus, - I. Pringsheim. Nachtrag zur Kriti und Geschichte der Untersuchungen viber das Algengeschlecht. - A. Wiegat Zur Morphologie und Systematik der Gattungen Trichia und Arcryria, mit Taf I-III. - F lilldphrand. Anatomische Untersuchungen über lie Farben der Bl then, mit Taf. IV. - W. Hofneistel. Ueber die durch die Schwerkraft bestimuten Richtungen von Pflanzentheilen. - 1. Wigand. Ueber die Deorganisation de Pflnzenzelle, insbesondere über die physiologische Bedeutung von Gummi uni Harz, mit Taf. V-VII. - J. Sachs. Ueber die Stoffe, welche das Material zun Wachsthum der Zellbänte liefern. - W. Hofmeister. Zusätze und Berichtigung zu den 1851 veröffentlichten Untersuchungen der Entwickelung höherer Krypto gamen, mit Taf. VIII. - N. Pringsheim. Ueber die Vorkeime und die nacktfussigen Zweige der Charen mit Taf. IX-XIII. -- L. Cienkowsky. Zur Entwic lungsgeschichte der Mixomyceten. - If. Schacht Ueber die Zelistofffäden in de vorderen Aussackung des Embryosackes von Pedicularis sylvatica, mit Taf. XIV und XV. - H. Schacht. Ueber ein neues Secretionsorgan in: Wurzelstock Nephrodium Filix mas, mit Taf. XVI. - W. Kabsch. Untersuchungen über de chemische Beschaffenheit der Pflanzengewebe. - L. Cienknwsky. Das Plasmodium mit Taf. XVII-XXI. - H. Sehacht. Ueber die Veränderung durch Pilze in ah gestorbenen Pflanzenzellen, mit Taf. XXII-XXIII. - N. Pringsheim. Zur Mor ihologie der Salvinia natans, mit Taf. XXIV-XXIX. - H. Schacht. Die Blüthe und die Befruchtung von Santalum allum, mit Taf. I-IV. - \&. Thomas. Zur vergleichenden Anatomie der Coniferen-Laubblätter. - L. Kny. Beiträge zur Entwickelungsgeschichte der laubigen Lebermoose, mit Taf. V-VII. - R. Caspary. Bemerkungen tiber die Schutzscheide und die Bildung des Stammes und der Wurzel; hierzu Taf. VIII und IX. - A. Weiss. Untersuchungen über die Zahlenund Grössenverhältnisse der Spaltöffnungen. - J. Haustein. Die Befruchtung unc Entwicklung der Gattung Marsilia, mit Taf. X-XIV. - Th. Wolf. Beiträge zur Entwicklungsgeschichte der Orchideen-Blüthe, mit Taf. XV-XVIII. - Gir. Kraus: Ueher den Bau der Cycadeeufiedern, mit Taf. XIX-XXIII. - Al. Fischer v. Waldhein. Ueber die Entwickelung der Farnsporen, mit Taf. XXIV bis XXVII. F. Burhenan. Der Blüthenstand der Juncaceen, mit Taf. XXVIII-XXX. - S. B :sauoff. Zur Kenntniss des Baues und der Entwicklungsgeschichte des Pollens der Mimoseae, mit Taf. XXXI-XXXII. - F. Hildebrand. Ueber die Befruchtung der Salviaarten, mit Hülfe von Insecten, Taf. XXXIII. - Th. Geyler. Zur Kenntniss der Sphacelarieen, mit Taf. XXXIV-XXXVI. - Ilex. v. Wolknff. Einige Untersuchungen über die Wirkung des Lichtes von verschiedener Intensität auf die Ausscheidung der Gase durch Wasserpflanzen, mit Taf. I-III. A. Vogl. Beiträge zur Kenntniss der Milchsaftorgane der Pflanzen, mit Taf. IV. - s. Rosanoff. Morphologisch-embryologische Studien, mit Taf. V-VII. - Gir. Kraus. Ueber 


\title{
I n h a $\mathbf{l}$ t
}

\author{
des vorliegenden Heftes 2, Bd. VIII.
}

A. Dodel. Der Uebergang des Dicotyledonen-Stengels in die Pfahl-Wurzel mit Taf. XI-XVIII . . . . . . . . . 149

Der Vasalstrangverlauf . . . . . . . 153

Vasalstrangverlauf des bypocotylen Stengeis und der Hauptwurzel . . . . . . . . . . . . . 154

Verlauf der primordialen Bastpartieen . . . . . . . 159

Anatomischer Bau der verschiedenen Elemente. . . . . 161

Basaltheil der Hauptwurzel . . . . . . . . . . 179

Erklärung der Abbildungen。 Taf. XI-XVIII _. . 189

W. Pfeffer. Zur Blüthenentwickelung der Primulaceen und Ampelideen mit

Taf. XIX-XXII . . . . . . . . . 194

Erklärung der Abbildungen. Taf. XIX-XXII . . . 214

B. Frank. Ueber die Veränderung der Lage der Chlorophyllkörner und des

Protoplasmas in der Zelle, und deren innere und äussere Ur-

sachen . . . . . . . . . . . 216

I. Trennung der Zellen vom Körper. . . . . . 220

II. Licht. . . . . . . . . . . , 250

III. Temperatur . . . . . . . . . . . 261

IV. Verminderung des Wassergehaltes der Zelle . . 266

v. Das Medium . . . . . . . . . 269

VI. Periodicität . . . . . . . . . 271

Das Protoplasma ist das Bewegende . . . . . . . 282

Allgemeine Ergebnisse . . . . . . . . . . 289

Nachträgliche Bemerkungen . . . . . . . . 302 



\title{
Der Uebergang des Dicotyledonen-Stengels in die Pfahl-Wurzel.
}

\author{
Von
}

\section{Dr. A. Dodel.}

Die anatomischen Differenzen zwischen Wurzel und Stengel der Gefässpflanzen sind - wenigstens zum Theil und in den allgemeinsten Zügen - schon längere Zeit bekannt. Genaueres hierüber verdanken wir, namentlich in Hinsicht der Entwicklungsgeschichte dieser Organe, der Arbeit Nägeli's: „das Wachsthum des Stammes und der Wurzeln bei den Gefässpflanzen und die Anordiung der Gefässstränge im Stengel" (Beiträge zur wissenschaftl. Botanik 1. 1858).

Nägeli entdeckte zuerst die Thatsache, dass die Entwicklung der ersten Vasalstränge in der Wurzel in centripetaler Richtung erfolgt, ganz abweichend ron der Entwicklung diesser Elemente im Stammtheil: „In ihren ersten Stadien bieten die Wurzeln eine "constante und charakteristische Verschiedenheit gegenüber den "Stammtheilen dar. Dieselbe besteht im Allgemeinen darin, dass „die Gefässbildung (im Cambium überhaupt oder wenigstens in , einem äussern Kreis von Cambiumsträngen) an der Peripherie ,beginnt und nach dem Centrum der Wurzel fortschreitet, und "dass das zu diesen centripetalen Vasalbündeln gehörige Cam„bium oder Cambiform nicht in radialer Richtung ausserhalb oder "innerhalb, sondern in tangentialer Richtung neben oder zwischen , denselben liegt, während in den Stammtheilen der Phanerogamen - die Gefässbildung centrifugal ist und das Cambium oder Cam,biform ausserhalb der Gefässe (oder wenigstens der ersten der-

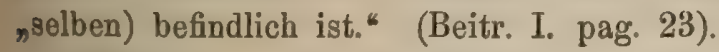

Wir haben gründliche Untersuchungen über Anatomisches und Physiologisches mancher Wurzeln, von verschiedenen Botanikern herrührend; die interessanteste derselben ist neuern Ursprungs: „Entstehung und Wachsthum der Wurzeln von C. Nägeli und H. Leitgeb." (Beitr. IV. 1868.) Die schwierigsten Themata sind berührt, zum Theil gelöst, zum Theil derart angeregt, dass eine Jahrb. f. wiss, Botanik. VIIl. 
vollstäıdige Lösung in nicht allzu ferner Zcit der wissenschaftlichen Botanik einverleibt sein wird. Bis heute blieb eine Frage noch unberührt: Wie rerhalten sich die Elemente des Stengels und der Wurzel beim Uebergang vom ersteren in die letztere?

Bei den Dicotyledonen, wo in der Regel der Stengel seine direkte Verlängerung in der Hauptwurzel hat, muss der Uebergang des erșteren in die letztere in Hinsicht auf die Differenzen zwischen diesen Organen interessante Erscheinungen darbieten, da ja die Vasalbündel im Stengel centrifugale, in der Wurzel dagegen centripetale sind und ohnedies auch die Bastelemente zu den $\mathrm{Va}$ salmassen in diesen rerschiedenen Organen auch rerschiedene Anordnung zeigen.

Es ist bekannt, dass bei den Monocotyledonen von einer Pfahlwurzel nicht die Rede sein kann, sondern dass deren Wurzeln ohne Ausnahme Adrentivwurzeln sind. Es fallen demnach zur Beantwortung der oben berührten Frage die Monocotỵledonen von vorn herein ausser den Bereich dieser Untersuchungen.

Das Nachfolgende enthält die Erstlingsuntersuchungen über diesen Gegenstand, und soll den Uebergang rom Stengel in die Pfahlwurzel charakterisiren, wie er bei den Phaseolus-Arten un. tersucht worden. Es ist der Anfang einer grössern Arbeit, welche lediglich den Zweck verfolgt, die Erscheinungen in den Haupttypen klar zu machen, welche sich beim Uebergang rom Stengel in die Pfahlwurzel der Dicotyledonen überhaupt darbieten.

Zuerst einige Bemerkungen über die Art und Weise, wie die nachstehend mitgetheilten Resultate gewonnen wurden: Es handelte sich vorerst um den Fibrovasal-Verlauf von der Wurzel an bis in diejenige Region, wo der typische Stengel-Charakter klar zu Tage tritt. Dieser zeigt sich bei den Phaseolus-Arten ohne Ausnahme erst über den Cotyledonen, somit war der Verlauf der Fibrovasalmassen bis ins erste (unmittelbar über den Cotyledonen stehende) Internodium zu verfolgen. $\mathbf{Z u}$ diesem $\mathbf{Z}$ wecke wurden zahlreiche Keimpflanzen in den verschiedensten Stadien auf successiven Querschnitten, die oft die Zahl 200 überschritten, untersucht und von mehreren Exemplaren aus verschiedenen Stadien oft 40-60 Querschnitte gezeichnet, was in den gegebenen Fällen unbedingt nöthig geworden. Auf diesen Querschnitten von derselben Pflanze wurde der Verlauf der Vasalstränge verfolgt und auf die abgewickelt gedachte Cylinderfläche des Gefäss- und Holz- 
körpers projicirt, wodurch die Systeme der Vasalstränge von der Wurzel an bis über die Cotyledonen hinauf in ihrem Längsverlauf anschaulich wurden. Zur Controle wurden auch verschiedene Längsschnitte (tangentiale und diametrale), in manchen Fällen mit concentrirter Schwefelsäure, in andern Fällen mit Kalilauge behandelt, auf den fraglichen Vasalverlauf untersucht, was namentlich für die Stellen des Stengels nöthig wurde, wo die Cotyledonen abgehen, da dort auch die Blattspurstränge, aus dem ersten Internodiun kommend, sich unmittelbar an die Vasalstränge des hypocotylen Stengels anlehnen. Das Verfahren war ein mühsames, führte aber allein und am sichersten zum Ziel. In zweiter Linie war der Bau der sämmtlichen Gewebepartieen im unterirdischen und oberirdischen Axenorgan zu untersuchen und die Art des Ueberganges von einem Theil in den andern auf Quer- und Längsschnitten schrittweise zu verfolgen. Dass die Resultate am leichtesten und sichersten gewonnen wurden, wenn die Untersuchung in der Richtung der Entwicklungsgeschichte vorschritt, braucht wohl kaum besonders begründet zu werden.

Von den drei untersuchten Phaseolus-Arten besitzt die eine, PL. multiflorus, einen sehr verkürzten hypocotylen Stengel. Die dicken Cotyledonen der Keimplanze werden nicht, oder nur sehr wenig über die Erde gehoben, während bei den beiden andern Arten, $\mathrm{Ph}$. vulgaris und $\mathrm{Ph}$. erectus (var. nanus), der hypocotyle Stengel eine beträchtliche Höhe, meist die Länge eines der untern Stengel-Internodien, erreicht. Die dicken fleischigen Cotyledonen fallen nach vollendeter Streckung des hypocotylen Stengelgliedes, nachdem sie ihre Reservenahrung an den Keimling vollends abgegeben haben, als weiterhin unnütze Organe zu Boden. Auf den ersten Blick erscheinen sie am Stengel der Keimpflanze in opponirter Stellung; allein in manchen Fällen sind sie bedeutend verschoben, so dass der eine Cotyledon oft $\frac{1}{2}$, ja bis einen Centimeter tiefer am Stengel sitzt, als der andere. Von den vielen un. tersuchten Keimpflanzen, deren successive Querschnitte in dieser Stengelregion ich hinsichtlich des Gefässverlaufes verfolgte, waren wenige, bei denen die Gefässe des hypocotylen Stengels auf demselben Querschnitie gleichartig in die Cotyledonen ausbogen, sondern meistens differirte die Ausbiegun einen Cotyledon um mehrere Stengelquerschnitte von derjenigen für den andern Cotyledon.

Mit den Cotyledonen alterniren in vertikaler Richtung die 
Primordialblätter mit opponirter Stellung. Das zwischen Cotyledonen und Primordialblättern liegende Internodium ist je nach der indiriduellen Entwicklung der Pflanze bald länger, bald kürzer, bei allen 3 Phaseolus-Arten immer einige Centimeter lang. Bei Phaseolus erectus, rar. nanus, beginnt die wiederholte Verzweigung des Stengels meist unmittelbar über dem ersten Internodium, während sie bei den beiden andern Phaseolus-Arten erst eintritt, wenn die Pflanze eine beträchtliche Höhe erreicht hat. Selten treten Verzweigungen in den Achseln der Cotyledonen auf; somit ist der Stengel unterhalb der Primordialblätter bei allen Phaseolus. Arten nach dem Abfallen der Cotyledonen meist ohne Seitenorgane, was die Verfolgung der Fibrorasalmassen wesentlich erleichtert. Das hypocotyle Stengelglied übertrifft an Dicke alle übrigen Stengeltheile, jedech nur um Weniges; nicht selten ist es bei Phaseolus vulgaris und Phas. erectus auch länger, als das erste Internodium. In Niveau des Bodens hat das hypocotyle Glied die grösste Dicke, um sich beim Uchergang in die Hauptwurzel rasch $\mathrm{zu}$ verjüngen. Diese Verjüngung beginnt unterhalb des Abgangs der ersten Nebenwurzeln und ist ein Hauptcharakter des Basaltheiles der Hauptwurzel. Letzterer bildet somit einen bald kürzern, bald längern gestutzten Kegel, der mit der Basis auf dem untern Stengeltheil ruht. Der Basaltheil der Pfallwurzel zeichnet sich ausserdem durch zahlreichere Nebenwurzeln von den übrigen Theilen der Hauptwurzel aus. In der Regel kommen an letzterer 4 Längsreihen von Nebenwurzeln vor, während im Basaltheil oft 5, 6 oder gar 7 Längsreihen beobachtet werden. Während die Hauptwurzel unter dem Basaltheil meistens im Vergleich zu den Nebenwurzeln von geringem Durchmesser ist und früh von ihrer Hauptrolle zurücktritt, entwickeln sich um so mehr die obersten Nebenwurzeln, die vom Basaltheil der Hauptwurzel abgehen. Die ausgewachsene Pflanze zeigt also bei den Phaseolus-Arten einen Wurzelkomplex, entstanden durch zahlreiche Verzweigungen 1., 2. und 3. Ordnung, in welchem die Hauptwurzel weder durch Länge noch grösseren Durchmesser dic stärksten Nebenwurzeln übertrifft. Die gleiche Erscheinung bieten auch andere Dicotyledonen. Die grosse physiologische Bedcutung der Pfahlwurzel beschränkt sich somit auf die allerersten Stadien der jungen Pflanze. Erst nachdem eine gewisse Anzahl von Nebenwurzeln gebildet ist, erträgt die Pflanze allfälige Verletzungen (oder andere Hindernisse zur weitern Entwicklung) der Hauptwurzel. 
Die Nebenwurzeln 1. Ordnung zeigen uberhaupt in Wesentlichen dieselben Erscheinungen wie die Hauptwurzel; sie rer$\mathrm{zweigen} \mathrm{sich} \mathrm{ebenfalls} \mathrm{wie} \mathrm{diese,} \mathrm{nur} \mathrm{mit} \mathrm{dem} \mathrm{Unterschied,} \mathrm{dass}$ die dünnsten Nebenwurzeln erster Ordnung statt 4 Längsreihen von Tochterwurzeln deren blos 2 besitzen. Diese Verzweigungen wiederholen sich mehrfach und immer in derselben Weise bis $\mathrm{zu}$ den zarten Nebenwürzelchen 4 , und 5 . Ordnung.

\section{Der Vasalstrangverlauf,}

im Stengel sowohl (oberhalb und unterhalb der Cotyledonen), als auch in der Wurzel, ist im Wesentlichen bei allen 3 untersuchten Phaseolus-Arten derselbe, ausgenommen, dass bei Phaseolus multiflorus, wo der hypocotyle Stengel sehr verkürzt ist und sich nicht, oder nur sehr wenig über die Erde erhebt, die Erscheinungen, welche der Bau des hypocotylen Stengels von Phaseölus vulgaris und $\mathrm{Ph}$. erectus bietet, auf eine kurze Strecke zusammengedrängt sind. Die Darstellung der anatomischen Verbältnisse, wie sie im Nachfolgenden gegeben wird, bezieht sich auf die letztgenannten Phaseolus-Arten mit gestrecktem hypocotylen Stengel.

Wenn auch der Vasalverlauf bei den verschiedenen PhaseolusArten im Allgemeinen derselbe ist, so finden doch bei den verschiedenen Individuen mehr oder weniger Abweichungen statt, die zwar die Hauptzüge nicht wesentlich verändern, aber dennoch zu berücksichtigen sind. Diese Abweichungen beziehen sich ausschliesslich auf den hypocotylen Stengel und den ältesten Theil der Pfahlwurzel, während sie ohne Einfluss sind auf den Stengel oberhalb der Cotyledonen und die jüngsten Theile der Hauptwurzel ron der ausgewachsenen Pflanze.

Im ersten Internodium über den Cotyledonen haben wir hinsichtlich der Vasalstränge in der Regel folgende Verhältnisse:

Von den zwei opponirten Primordialblättern besitzt jedes einen Medianstrang ( $m . m$ in Fig. 1.2.3. 4 und 6), der sich durch das ganze Internodium herabzieht. In der Höhe der beiden Cotyledonen theilt sich jeder dieser Medianstränge, um die beiden Hälften an die benachbarten Vasalstränge des hypocotylen Stengels anzulehnen (Fig. 1.2. 3. 4. und Fig. 6 und 7). Ausser dem Medianstrang erbält jedes Primordialblatt noch zwei mal zwei seitliche Stränge, die wir im Gegensatz zu jenem Lateralstränge 
nennen wollen. Diese bilden im ersten Internodium zusammeu zwei mal zwei vereintläufige Spurstränge (1.1.1.1. in Fig. 1, 2, 3, 4 und 6). Beim Abgang der Primordialblätter theilt sich jeder. dieser vereintläufigen Spurstränge in zwei Theile, die eine Hälfte in das zunächstliegende, die andere Hälfte in das andere Primordialblatt absendend, wodurch die in Fig. 3 dargestellte Verschrän. kung der Lateralstränge entsteht. Die rereintläufigen Lateralstränge ziehen sicb, parallel mit den Mediansträngen der Primordialblätter, durch das ganze Internodium hinunter und lehnen sich beim Abgang der Cotyledonen an die Vasalstränge, die aus den letztern in das hypocotyle Glied niedersteigen. Zwischen den genannten Blattspursträngen des ersten Internodiums ziehen sich diejenigen aus der Region über den Primordialblättern hin; sie sind weniger stark entwickelt, bedeutend schwächer als die Spurstränge der Primordialblätter, und setzen sich in der Höhe der Cotyledonen meist an jene an (0.0.0.0 in Fig. 1 und 3).

Sämmtliche Blattspurstränge des Stengels über den Cotyledonen lehnen sich somit in der Höhe der letztern zum Theil gegenseitig an einander an, zum Theil münden sie in die Spuren der Cotyledonen, oft mit diesen vereint noch eine Strecke weit in den hypocotylen Stengel niedersteigend; nie aber reichen sie bis zu den Wurzeln und nie sind sie im bypocotylen Sten. gel als selbstständige Blattspurstränge anzutreffen.

\section{Vasalstrangverlauf des hypocotylen Stengels und der Hauptwurzel.}

Das einfachste Verhältniss findet sich in Fig. 1 dargestellt. In jeden Cotyledon geht ein Paar Stränge, dic längs der Verticalen, welche parallel zur Längsaxe des Stengels durch die Ansatzstelle des betreffenden Cotylcdons geht, sich durch das ganze hypocotyle Glied hinziehen. Wir nennen sie das Medianstrang. paar des Cotyledons. Die beiden Stränge desselben Paares bleiben sich durch den ganzen hypocotylen Stengel genähert.

Mit den zwei opponirten Medianstrangpaaren (II. und IV. Fig. 1) alterniren zwei andere Paare von Strängen (I. und III. Fig. 1), die im ganzen hypocotylen Stengel sich ähnlich verhalten, wie die erstern.

Je die zwei Stränge eines dieser Paare bleiben sich rom $\mathrm{Ba}$ - 
saltheil des Stengels an bis in die Nähe der Cotyledonen genähert; beim Abgang der letztern geht jedoch der eine Strang in den einen Cotyledon, während der andere Strang in den andern Cotyledon ausbiegt. Es erlıält demnach jeder. Cotyledon vier Vasalstränge, nämlich ein Paar Medianstränge und zwei Lateralstränge, deren einer dem einen, der andere dagegen dem andern Lateralstrang. paare angehört.

Ucber den Lateralstrangpaaren liegen die Medianstränge der Primordialblätter, welche sich in der Höhe der Cotyledonen in zwei Hälften spalten, um sich an die Lateralstränge des hypocotylen Stengels anzulegen $\left(\mathrm{m}^{1}\right.$ und $\mathrm{m}^{2}$ in Fig. 1).

Der hypocotyle Stengel der Phaseolus-Arten zeigt somit in den meisten Fällen mindestens 4 primordiale Vasalstrangpaare, die in ihrom Verlauf von den Cotyledonen an bis zur Wurzel hinsichtlich ihrer gegenseitigen Lage keine wesentlichen Veränderun. gen erleiden.

Jedes dieser 4 Vasalstrangpaare vereinigt sich beim Uebergang des Stengels in die Wurzel zu einem einzigen Strang, indem die zwei zusammengehörigen Stränge des hypocotylen Stengels hier sich langsam nähern und endlich, nach Absendung zahlreicher Nebenwurzeln, vollständig zusammenrücken, in ihrer Vereinigung einen primordialen Vasalstrang der Wurzel bildend.

Entsprechend den 4 primordialen Vasalstrangpaaren des hypocotylen Stengels Laben wir also in der Hauptwurzel der Pha. seolus-Arten 4 einzelne Primordialstränge, die sich gleichmässig auf dem Querschnitt vertheilen.

Während bci 2 opponirten primordialen Vasalsträngen der Wurzel die Richtung ihrer Verlängerung im Stengel durch die Ansatzstellen der Cotyledonen geht, entsprechen die 2 andern den mit diesen letztern decussirten Primordialblättern. Sämmtliche 4 primordiale Vasalstränge der Wurzel besitzen durch die ganze Länge der letztern dieselbe Lage, sowohl zur Wurzelaxe, als unter einander und endigen in der gleichen Höhe in der Wurzelspitze.

Der Strangverlauf, wie er in Obigem angegeben worden, bietet die einfachsten der bei Phaseolus beobachteten Erscheinungen. Von den vielen, vielleicht über 100 untersuchten Exemplaren der verschiedenen Phaseolus-Arten ist mir indess nur eine einzige Keimpflanze zu Gesicht gekommen, die im hypocotylen Stengel und in der Wurzel nur die angeführten Vasalstränge aufwies. Das Gefässsystem in dieser einfachsten Form ist in Fig. 1 dargestellt. 
Es wurde letztere aus den successiren Querschnitten construirt, die von jenem Exemplar (Phaseolus erectus, rar. nanus) entnommen-waren.

In der Regel finden sich im hypocotylen Stengel zwischen den genannten 4 Paaren primordialer Vasalstränge noch weniger starke $\mathrm{Z}$ wischenstränge, die ebenfalls sämmtlich in die Cotyledouen ausbiegen. Ihre Zahl und ilure Stellung zu den Hauptstrangparen bietet die rerschiedensten Verhältuisse, doch nie wurden solche Zwischenstränge $z$ wischen den einzelnen Theilen eines zusammengehörigen Strangpaares beobachtet. Ihre Zabl und Stellung, sowie ihre Entwicklung ist kcine gesctzmässige. Bald findet sich zwischen je zwei Hauptstrangpaaren ein Zwischenstrang, so dass dann auf der ganzen Peripherie des primären Fibrorasalringes deren 4 vorhanden sind; bald sind statt cines einzigen zwei oder gar drei solcher Zwischenstränge auf demselben Quadranten des Querschnittes, während sie in einem andern Quadranten fehlen ( $x, y, z$ und 5 in Fig. 4, ferner $z$ in Fig. 2 und 3, 7. 10).

Nicht selten, wenu auf dem (Quadranteu zwischen zwei Hauptstrangpaaren mehr als $1 \mathrm{Zwischenstrang}$ vorhauden ist, sind zwei derselben einander in derselben Weise genähert, wie die Hanptstränge, wozu, wie ich später zeigen werde, noch andere Eigenthümlichkeiten des Baues und der gegeuseitigen Lage hinzukommen.

In diesem Falle vereinigen sic sich im Basaltheil der Hauptwurzel zu einem einzigen Vasalstrang, der an diescr Stelle dieselben Eigenschaften darbietet, wie die Vereinigung zweier Hauptstränge des Stengels zu einem Vasalstrang der Wurzel. Es kaun nämlich, was häufig geschieht, hier eine 5 te Längsreihe von Nebenwurzeln, oder wenn ein 2 tes Zwischenstrangpaar vorhanden, eine sechste Längsreihe von Nebenwurzeln abgehen (Fig. 2 u. 3); oder es kann die Absendung von Nebenwurzeln bei dem einen Zwischenstrangpaare auch unterbleiben (Fig. 4). Diese nicht gesetzmässig vorhandenen Nebenwurzelreihen am Basaltheil der Hauptwurzel will ich die überzähligen nennen. Jede derselben enthält meist nur wenige Nebenwurzeln, oft blos cine, meist aber zwei oder drei, selten mehr. Unterhalb des Abganges der überzähligen Nebenwurzeln sind die Zwischenstrangpaare dos hypocotylen Stengels vereinigt zu je einem $Z$ wischenstrang der $W$ ur. zel, der sich meist nach kurzem Verlauf im Gefäss- und Holzkörper der letztern verliert, ohne sich an den einen oder andern der 
benachbarten primordialen Vasalstränge anzulehren. Oft aber lassen sich solche $Z$ wischenstränge, die selbstverständlich mit den Primordialsträngen alterniren, im weitern Verlauf der Hauptwurzel auf grosse Strecken hin verfolgen; immer aber endigen sie blind und bedentend früher, als die Hauptwurzel in die Länge zu wachsen aufhört. Zichen sicł mehrere solcher Zwischenstränge durch die Hauptwurzel, so reicht der eine oft einige Centimeter weiter, als der andere; selten schliessen sie ihr Längenwachsthum auf gleicher Höhe ab, wie dies gesetzmässig bei den Primordialsträngen der Wurzel geschicht.

Die übrigen isolirten Zwischenstränge des hypocotylen Stengels verlieren sich in der Regel (ohne Absendung von Nebenwurzeln) im Holzkörper des Basaltheiles der Hauptwurzel, ebenfalls ohne sich an die benachbarten Stränge anzulehnen (Fig. 4. x u. z).

Der Vasalstrangverlauf in den Nebenwurzeln ist im Allgemeinen rur eine Wiederholung der Verhältnisse in der Hauptwurzel. Die stärksten Nebenwurzeln der ersten Ordnung (mit Ausnahme derjenigen, die am Basaltheil der Hauptwurzol entspringen), sowie die stärkern Nebenwurzeln der 2. und folgenden Ordnungen besitzen 4 primordiale Vasalstränge, die im Querschnitt ein regelmässiges Kreuz bilden, ähnlich wie im Querschnitt des dünnern Theils der Hauptwurzel. Sie verlaufen, wie die primordialen Vasalstränge der letztern, parallel durch die ganze Nebenwurzel und endigen in gleicher Höhe in der Wurzelspitze.

Anders verhalten sich manche der rom Basaltheil der Hauptwurzel abgehenden Nebenwurzeln 1. Ordnung, indem dieselben oft im untersten, d. h. der Hauptwurzel zunächst liegenden Theil statt 4 Vasalsträngen deren 5,6 oder 7 und nóch mehr enthalten. In weitern Verlauf, je mehr man sich vom Mutterorgan entfernt, treten jedoch einige dieser überzähligen primordialen Vasalstränge zurück, indem sie sich im Holz- und Gefässkörper der Nebenwurzel verlieren, bis endlich ihre Zahl sich auf 4 reducirt hat, und somit auch diese Nebenwurzeln in ihrem weitern Verlauf die regelmässig dominirenden Verhältnisse bieten.

Die dünnsten Nebenwurzeln der 1. und aller folgenden Ordnungen enthalten dagegen meistens 2 primordiale Vasalstränge, die sich, im Querschnitt diametral liegend, durch die ganze dünne Wurzel hinziehen und ebenfalls auf gleicher Höhe endigen. Am seltensten ist das Vorkommen von 3 primordialen Vasalsträngen.

Der Ansatz der primordialen Vasalstränge von den 
Nebenwurzelı sämmtlicher Ordnungen (mit Ausnahme derjenigen, die am Basaltheil der Hauptwurzel entspringen) an die Gefässe des Mutterorgans bietet folgende Verhältnisse. Sämmtliche primordiale Vasalstränge der Nebenwurzel setzen sich an einen einzigen Vasalstrang der Mutterwurzel an, und zwar crgeben sich für die verschiedenen Verhältnisse folgende Regeln: Sind in der Nebenwurzel 4 primordiale Vasalstränge vorhanden, so setzen sich zwei (opponirte) derselben direkte an den Mutterstrang an, indem sie in jener Ebene verlaufen, die zugleich durch die Axc der Mutterwurzel und diejenige der T'ochterwurzel geht. Von den übrigen 2 primordialen Vasalsträngen der Nebenwurzel liegt der eine rechts, der andere links ausserhalb jener gemeinsamen Axenebene (Fig. 5).

Indem sich die sämmtlichen 4 stränge der Nebenwurzel dem primordialen Fibrovasalkörper der Mutterwurzel nähern, beschreiben sie schwach gewölbte Bogen, deren convexe Seite der Axe der Nebenwurzel zugekehrt ist. Während aber jene zwei, in der gemeinsamen Axenebene von Mutter- und Tochterorgan liegenden Vasalstränge der Nebenwurzel direkt auf den Gefässstrang der Mutterwurzel zugehen, müssen die 2 seitlich licgenden Vasalstränge der Nebenwurzel, auf einem gewissen Punkte angekommen, plötzlich von ihrer Richtung abspringen, um die Ueberbrückung zum Vasalstrang der Mutterwurzel bilden zu können. Dieses plötzliche Abbiegen finclet in der Peripherie jenes Kreises statt, der durch die Ansatzstellen der zwei erstgenannten Vasalstränge der Nebenwurzel geht und tangential zum Vasalkörper der Mutterwurzel liegt. Beide seitlichen Stränge erreichen in derselben Höhe der Mutterwurzel den betreffenden Vasalstrang der letztern, während ron den 2 andern Vasalsträngen der Nebenwurzel (in der gemeinsamen Axenebene liegend) der eine nothwendigerweise etwas höher, der andere etwas tiefer sich an den Mutterstrang anlehnt (Fig. 5).

Sind in der Nebenwurzel blos zwei primordiale Vasalstränge vorhanden, so liegen sie immer in der gemeinsamen Axenebene von Mutter- und Tochterwurzel und setzen sich dem entsprechend auch in der oben beschriebenen Weise an den Vasalstrang der Mutterwurzel an. (Nie beobachtete ich, dass diese wenigen Vasalstränge der Nebenwurzel etwa seitlich der gemeinsamen Axenebene liegen.)

Zählt die Nebeuwurzel mehr als 4 primordiale Vasalstränge, 
so liegen immer zwei derselben in jener gemeinsamen Ebene, die übrigen seitlich davon.

Etwas abweichend gestaltet sich der Ansatz der primordialen Vasalstränge jener Nebenwurzeln, die am Basaltheil der Hauptwur. zel ihren Ursprung haben, w's je zwei zusammengehörige Hauptstränge des hypocotylen Stengels sich gegenseitig nähern und während dieser langsamen Vereinigung jene obersten starken Neben. wurzeln abschicken. Die primordialen Vasalstränge dieser oft so verschieden gebauten Nebenwurzeln setzen sich nämlich nicht an einen einzigen Strang, sondern an die zwei Stränge des Mutterorgans an, die sich allmälig zu einem einzigen Strang der Hauptwurzel vereinigen.

Wenn diese Nebenwurzeln 1. Ordnung, die am Basaltheil der Hauptwurzel entspringen, auch da, wo ihr Querschnitt in Zahl und Anordnung der Vasalstränge Abweichungen vom gewöhnlichen Typus bietet, Nebenwurzeln 2. Ordnung tragen, so entspringt jede der letzteren an einem einzigen Vasalstrang der unregelmässig gebildeten Nebenwurzel 1. Ordnung, und zeigt überhaupt nichts Abweichendes von den übrigen Ncbenwurzeln, die anderswo ihren Ursprung haben.

\section{Verlauf der primordialen Bastpartieen.}

Jeder Blattspurstrang des ersten hypercotylen Stengelgliedes besitzt auf der peripherischen Seite des Fibrovasalkörpers eine der Gefäss- und Holzmasse entsprechende Phloempartie, bestehend aus dickwandigem Bast- und Weichbast. Der Anzahl der primordialen Vasalstränge entspricht dort in gleicher Anordnung die Zahl der zugehörigen ersten Baststränge. In der Höhe der Cotyledonen legen sich die letztern in gleicher Weise an die primordialen Baststränge des hypocotylen Stengels an, wie die primordialen Gefässstränge des 1 . Internodiums sich mit den Cotyledonarspuren vereinigen. Im hypocotylen Stengel entsprechen den 4 Paar Hauptsträngen primordialer Gefässe 4 breite Lamellen primären Bastes. Die den Gefässsträngen zugehörigen primären Baststränge bilden hier nicht, wie im Stengel über den Cotyledonen, isolirte Phloempartieen, sondern sie verbreiten sich auf der ganzen Peripherie des Fibrovasalkörpers, mit Ausnabme jener Stellen, die ausserhalb der Ueberbrückungen zweier zusammenge- 
höriger, eijander genäherter Vasalstränge liegen. Die Phloempartie eines jeden Primordialstranges bildet mit derjenigen des nächstliegenden Stranges, welcher zum benachbarten Hauptstrang. paar gehört, eine ununterbrochene Lamelle, die beinahe den 4 ten Theil der Peripherie einnimmt. Se'ustrer'ständlich schliesst eine solche Lamelle auch die Phloemparticen der Zwischenstränge, die auf demselben Kreisquadranten liegen, in sich ein, allein wenn

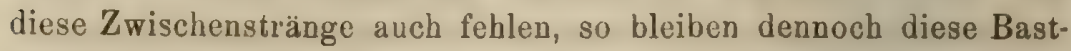
lamelley ununterbrochen, ein Beweis, dass die Zwischenstränge auf den Bau des primären Phloemkörpers in der Regel keinen Einfluss ausüben. Im 'Basaltheil der Wurzel, wo die einzelnen Vasalstränge jedes Paares sich zu einem Vasalstrang der Wurzel vereinigen, ändert sich im Verlauf der primordialen Phloempartieen im Wescntlichen Nichts. Wie im hypocotylen Stengel, so bleiben auch hier die Phloemparticen in Querschnitt auf 4 Quadranten vertheilt, dic zwischen den 4 primordialen Gefässpartieen liegen. Wir baben somit auch in der Wurzel 4 Bastlamellen, von deren jeder die eine Hälfte dein einen, die andere Hälfte dem andern benachbarteu primordialen Vasalstrang angehört (Fig. 5. 15). Die punktirten Linien in Fig. 1 bezeichnen die Mittellinien der 4 primordialen Bastgruppen. Ausnahmsweise kann die primäro Phloemmasse im hypocotylen Stengel durch die Anwesenheit eines 5 ten Strangpaares, in der Wurzel durch einen 5. Primordialstrang in 5 Partieen zerfallen. Von den vielen untersuchten Exemplaren junger Keimpflanzen beobachtete ich bei zweien, dass im Basaltheil und dem unmittelbar darauf folgenden Theil der Hauptwurzel ausserhalb eines Zwischenstranges die entsprechende Phloempartie sich in zwei Theile trennte, um in acropetaler Richtung beim Verschwinden des $\mathrm{Z}$ wischenstranges sich wieder zu einem einzigen Strang zu vereinigen.

In den Nebenwurzeln verhält sich der Verlauf der primordialen Phloempartieen ganz ähnlich, wie in der Hauptwurzel. Wenn 4 Stränge vorhanden sind, so liegen, da sie mit den Vasalsträngen alterniren, 2 rechts und 2 links von der Ebene, die durch die Nebenwurzel und ihr Mutterorgan gedacht wird. Sie legen sich an die.nächstliegenden Baststränge des Mutterorgans, und zwar selbstverständlich einerseits die Stränge der rechten, andererseits die der linken Seite (Fig. 5). Es sind diese Verhältnisse namentlich an jungen Organen durch Längs- und Querschnitte leicht zu ermitteln. 


\section{Anatomischer Bau der verschiedenen Elemente.}

a. Im Stengel über den Cotyledonen.

In der ausgewachsenen Pflanze ist bei sämmtlichen PhaseolusArten der Stengel bohl, indem während der Streckung der jungen beblätterten Axe, vor eintretender Verholzung der rerhältnissmässig mächtige Markcylinder in seinem Innern zerreisst und hier das weitmaschige paremchymatische Gewebe zerstört wird. Der Markkörper bildet also im ausgewachsenen Stengel einen paremchymatischen Hohlcylinder von geringer Mächtigkeit, dessen änssere Peripherie im Querschnitt durch die in denselben hineinragenden Blattspurstränge unterbrochen wird. Die innersten Markzellen sind die weitesten, während die äussersten, im Querschnitt isodiametrisch erscheinend, im Durchmesser den benachbarten Holz- und Gefässzellen so ziemlich gleich stehen. Die Zellen des Markparenchyms stossen mit Intercellularräumen an einander und sind im Längsschnitt des ausgewachsenen Stengels langgestreckt; ihre Länge übertrifft den Querdurchmesser um das Mehrfache.

Der Markcylinder wird vollständig umschlossen rom $\mathrm{Holz}$ und Gefässring, aus welchem heraustretend dic Blattspurstränge in den Markkörper hineinragen. Sämmtliche Vasalstränge des Stengels über den Cotyledonen sind streng centrifugal angeordnet (Fig. 6), d. h. die engsten, zuerst entstandenen Gefässe eines Stranges liegen dem Centrum des Querschnittes am nächsten. An sie lehnen sich nach einander in radialer Richtung nach Aussen die successiv neu hinzugekommenen, weiteren Gefässe an, deren Durchmesser in dem Grade zunimmt, als sie sich vom allerersten Gefässe entfernen. Ein Querschnitt durch das erste Internodium (Fig.6) zeigt die Blattspurstränge von verschiedener Mächtigkeit. Sowohl Medianstränge (n. Fig. 6), als Lateralstränge (11 1 l) erweisen sich auf den-crsten Blick als vereintläufig. Von den Mediansträngen der Primordialblätter (m. m Fig. 6) theilt sich jeder in der Höhe der Cotyledonen in zwei gleiche Theile ( $s p^{1}$ und $s p^{2}$ ), um die eine Hälfte ( $s p^{1}$ in Fig. 6 und 7) an den einen Lateralstrang (hp ${ }^{1}$ in Fig. 7), die andere Hälfte sp ${ }^{2}$ Fig. 6 und 7) an den andern Lateralstrang 
(hp ${ }^{2}$ Fig. 7) anzulebnen. Dass diese Medianstränge ( $\mathrm{m} \mathrm{m}$ ) der Primordialblätter, wie sie uns der Querschnitt durch das erste Stengelinternodium zeigt, zusammengesctzt sind, erkennen wir insofern aus dem Bau derselben, als sie nicht aus einer einzigen, radial angeordneten Reihe von Gefüssen gebildet sind, sondern aus zwei gleichmässig ausgebildeten, in centrifugaler Richtung entstandenen Vasalsträngen bestehen, dic in ihrer Vereinigung auf dem Querschnitt einen spitzen Winkel bilden, dessen Scheitel dem Centrum des Stengels zugekehrt ist, dessen Schenkel aber auf der innern Peripherie des Holzkörpers ruhen. In gleicher Weise verhalten sich die Lateralstränge (1. l. I. I) der Primordialblätter, wäh. rend die Blattspurstränge, dic ans dem 2 teu Internodium kommen, schwächer entwickelt sind ( 0 o 0 o Fig. 6).

Auf die an der axilen Seite rou zartwandigem, parenchymatischem Gewebe eingeschlossenen Blattspursträange folgt nach Aussen der völlig geschlossene, uächtige Holzring, sciner Hauptmasse nach aus mehr oder weniger dickwandigen Holzzellen bestehend, die meist in radialer Richtung in regelmässige Reihen angevidnet sind; diese letztern sind aber oft durch weitlichtige, ebenfalls verholzte poröse Gefäise unterbrochen. - Die den Gefässen zunächst liegenden Holzzellen sisd in der Regel die zucrst verholzten und stärker verdickt, als dic übrigen. Ebenso zeichnen sich durch stärkere Verdickung dic an der inneru Peripherie des Holzkörpers liegenden Zellen, die primären Holzzellen, aus.

Auf den Holzring folgt nach Aussen der geschlossene Cambiumring, dessen Zellen ebenfalls radial angeordnet sind, eine Erscheinung, welcher dieselbe Anordnung der ganze Holzkörper verdankt. Es ist der Cambiumring im Stengel der P'haseolusArten einige Zellschichten mächtig und producirt dersello bis zum Absterben der Pflanze nach Innen fortwährend Holz- und Gefässmasseu in beträchtlicher Menge, wähend der Phloemkörper durch ihn wur noch um Weniges zunimint. Der letztere besteht aus Weichbast und dickwandigeu Bastlamellen, die, mit Unterbrechungen, die Peripherie des Fibrovasalkörpers einnehmen. Der Weichbast, die Zone zwischen den dickwandigen Bastlamellen und dem Cambiumring eiunehmend, besteht zum Theil aus paremchymatischem Gewebe, in welchem kleinere Zellgruppen eingebettet sind, die im Durchmesser viel kleiner, als die umliegenden zartwandigen Zellen und während der ganzen Lebensdauer mit trübem Zellinhalt erfüllt sind. Wir treffen diese isolirten klei- 
nen Zellgruppen .durch alle untersuchten Pflanzentheile. Im Längsschnitt sind es äusserst zarte, langgestreckte Zellen, deren Form denen des dickwandigen Bastes entspricht; wir nennen sie die Weichbaststränge. Ausser diesen kommen als charakteristische Elemente des Phaseolus-Stengels in der Zone des Weichbastes noch zahlreiche Gerbstoffgefässe vor, die in der Jugend stets mit einem durch Kali sich rothbraunfärbenden Inhalt erfüllt sind. Sachs hat in seiner physiologischen Abhandlung „über die Keimung der Schminkbohne" (Ph. multiflorus, Wien 1859) diesen Zellinhalt untersucht und Gerbstoff nachgewiesen. Während der Zeit der Keimung, bis zum $\Delta$ bfallen der Cotyledonen, bilden die Gerbstoffgefässe ununterbrochene Zellreihen, die sich von der Stengelbasis an durch alle Theile der Pflanze, mit Ausschluss der Wurzel, verfolgen lassen. Nach vollendeter Streckung findet man aber die Querwände resorbirt und sämmtliche Zellen eines solchen Gefässes unter einander in direkter Communication. Diese weitlichtigen Gerbstoffgefässe sind immer isolirt, nie berühren ${ }_{2}$ wei einauder direkt; ebenso finden keine Anastomosen unter denselben statt. Es sind die im Keimling zuerst scharf diffurenzirten Elemente. Man erkennt sie nach Sachs schon im ruhenden Keim. So viel ich beobachtet, $\sin$ d sie jedenfalls schon mit dem charakteristischen Inhaltc gefüllt, ehe die ersten Spiralgefüsse eine sichtbare Differenzirung erhalten. Es sind somit die Gerbstoffgefässe primordiale Gebilde des ersten Cambiumringes (Procambium ron Sachs). Der sekundäre Cambiunring, der nach Innen fortwährend $\mathrm{Holz}$ und nach Aussen Phloem erzeugt, bildet keine weitern Gerbstoffgefässe mehr.

Der Fibrovasalcylinder wird rings von einer Zellschicht umschlossen, die Sachs in seiner Abhandlung über die Keimung ron $\mathrm{Ph}$. multifiorus Stärkeschicht genannt. Schon Sachs drückt dort die Vermuthung aus, dass diese Schicht von Zellen, welehe in der jungen Pflanze durch Behandlung mit Kalilauge viel deutlicher hervortritt, als in spätern Stadien, mit der Schutzscheide von Caspary identisch sei. Durch verschiedene Manipulationen ist es mir gelungen, diese Vermuthung unzweifelhaft zu bestätigen; indem sich die fragliche Zellschicht in ihrem anatomischen Bau ganz ähnlich verhält, wie die von Caspary bei verschiedenen Pflanzen beschriebene Schutzscheide (vergl. Pringsheim's Jahrb. 1864). Die Schutzscheide im Stengel von Phaseolus ist eine dichtgeschlossene concentrische Schicht von Zellen, die so an einander 
gereiht sind, dass ihre Begrenzungswände im Querschnitt radiale Richtung haben. Diese radial gestellten Wände sind gewellt. Zwischen den Schutzscheidezellen finden sich keine Intercellularräume. Im Stengel verwischt sich der Charakter der Schutzscheide mehr oder weniger im Verlauf der weitern Entwicklung, während derselbe in der Wurzel am ausgeprägtesten hervortritt. Auf die Schutzscheide folgt nach Aussen die mehrschichtige primäre Rinde, aus paremchymatischen Zellen bestehend, die mit luftführenden Intercellularräumen an einander schliessen. Die äusserste Zellschicht bildet die mit hakenförmigen Trichomen versehene Epidermis, deren Wande radial gestellt sind, wie bei der Schutzscheide. Ihre Zellen sind in Querschnitt bedeutend kleiner als die Rindenparenchymzellen und schliessen ebenfalls ohne Zwischenzellräume an einander.

\section{b. Im hypocotylen Stengel}

verhalten sich Mark- und Rindenparenchym, sowie die Epidermis und Schutzscheide im Wesentlichen gleich, wie in cben beschriebenen Querschnitt über den Cotyledonen. Anders verhalten sich hier die Fibrovasalstränge. Während die-Blattspurstränge über den Cotyledonen olne Ausnahme sich in centrifugaler Richtung entwickeln, finden wir im hypocotylen Stengel bedeutende Abweichungen.

Im ganzen hypocotylen Stengel erfolgt die Entwicklung der Hauptvasalstränge im Allgemeinen in tangentialer Richtung.

Die engsten zuerst entstandenen Gefässe der beiden Stränge eines Paares sind einander zugekchrt und zeigen somit die geringste Entfernung, während die darauf folgenden Gefässe in tangentialer Richtung sich an diese anschliessen und dadurch einander immer ferner rücken (Fig. 9 und 1(1). Die meisten Gefässe der Hauptstränge im hypocotylen Stengel sind Spiral- und Ringgefässe, nur die weitesten derselben sind poröser Natur, und diese letztern liegen bereits im Holzkörper, während die ersten, zum Theil isolirt stehenden Ring- und Spiralgefásse eines jeden dieser Hauptstränge, von zartem Gewebe umgeben, etwas in den Markkörper hereintreten. Diese schwache Abweichuug der im Querschnitt durch den hypocotylen Stengel so charakteristisch angeordneten Primordialgefässe von der innern Peripherie des Holzkörpers ist am stärksten im obersten Theil des hypocotylen Stengels, wo 
die engsten Gefässe sich mehr dem Centrum des Querschnitts näherv, die weitern dagegen mehr nach Aussen treten (Fig. 7. hp. hp.). Es kann sogar die Richtung der Gefässentwicklung eine stärkere Andeutung zur centrifugalen Richtung sein, wie dies jedoch nur $\mathrm{in}^{\mathrm{n}}$ unmittelbarer Nähe der Cotyledonen beobachtet wird ( $\mathrm{hp}{ }^{1}$ und $\mathrm{hp}^{2}$ ). Hier lehnen sich auch die aus einander tretenden Theile der Medianstränge, welche von den Primordialblättern an bis zu den Cotyledonen vereintläufig sind, an dieser Stelle aber je zwischen die zwei zusammengehörigen Lateralstränge hereintreten, an diese letztern an, und zwar in der Art, dass der centrifugale Blattspurstrang des hypercotylen Gliedes mit dem in beschrieben $r$ Weise angeordneten Lateralstrang hier einen Winkel bildet, dessen Scheitel mehr oder weniger in das Markparenchym hereinragt, dessen einer Schenkel - centrifugal - dem aus der Laubblattregion kommenden Gefässstrang, dessen anderer Schenkel aber - in der Richtung oben beschriebener Sekante liegend dem betreffenden Lateralstrang des hypocotylen Stengels entspricht ( $h p^{1}$ und $s p^{2}$, ferner $h p^{2}$ und $s p^{2}$ in Fig. 7; ferner $s p^{1}$ und $s p^{2}$ in Fig. 6).

Im untern Theil des hypocotylen Stengels sind die Hauptstränge regelmässig streng tangential angeordnet; es ist diese Richtung ein wesentlicher Charakter der Hauptstränge im grössten Theil des hypocotylen Stengels der Phaseolus-Arten, und verdient ganz besonders hervorgehoben zu werden.

Anders verhält es sich mit den unregelmässig vorkommenden $\mathrm{Z}$ wischensträngen, die auf allen Querschritten von der Wurzel an bis in die Cotyledonen hinauf sich in streng centrifugaler Richtung entwickeln und darin den Blattspursträngen über den Cotyledonen gleich kommen ( $\mathrm{zz}$ in Fig. 7 und 10).

Die Zwischenstränge des hypocotylen Stengels sind weniger stark entwickelt, als die Hauptstränge; sie werden zu gleicher Zeit mit, oder mindestens in sehr kurzer Zeit $n$ ach den letztern im Keimling angelegt, zählen aber meist blos die Hälfte der Gefässe eines Hauptstranges (Fig. 10, z). Wenn zwischen zwei Hauptstrangpaaren mehr als 1 Zwischenstrang vorkommt, so können im hypócotylen Stengel zwei Zwischenstränge eben so genähert sein, wie die zwei Theile eines Hauptstrangpaares und dieselbe tangentiale Anordnung besitzen, wie diese. In diesem Falle haben wir dann im Querschnitt durch den hypocotylen Stengel statt 4 Strangpaaren deren 5 mit tangentialer Gefässentwicklung; viel seltener 
findet sich noch ein zweites Zwischenstrangpaar in derselben Weise entwickelt.

Haupt- und Zwischenstränge ruhen, in Querschnitt betrachtet, mit ihrem jüngsten Ende, das die weitesten Gefässe trägt, auf dem Holzring. Dieser ist im hypocotylen Stengel ron gleichem Bau, wie im Stengel über den Cotyleçonen. Auch hier sind die Holzzellen radial angeordnet und in denjenigen Partieen, die den wenigen eingestreuten porösen Gefässen zunächst liegen, stärker verdickt und weniger regelmässig angeordnet, als die üirigen Holzzellen.

Cambiumring und Weichbastzone bieten dieselben Erscheinungen, wie im Stengel über den Cotyledonen. Auch im hypocotylen Stengel bildet das Cambium in derselben Weise sekundäre Bastelemente, wic ober'balb der Cotyledonen. In diesem sekundären Bast rerdicken sich in einem späten Stadium, wo der Holzkörper schon eine bedeutende Mächtigkeit erreicht hat, einige isolirt stehende Zellen; es sind die sckundären dickwandigen Bastzellen, die (innerhalb der Gerbstoffgefässe und der kleinen, aber zahlreichen Stränge des Weichbastes liegend) nicht hlos durch ihre Lage und jhre gcringe Zahl, sondern auch durch den bedeutend kleinern Durchmesser und ihre verhıältnissmässig geringe Länge sich von den primären dickwandigen Bastzellen unterscheiden. Im Stengel von noch jungen Pflanzen, die jedoch bereits bis zuın Blühen gediehen waren, konnte ich im Bastring noch keine dieser sekundären, dickwandigen Bastzellen erkennen; nur bei einigen alten, getrockneten Exemplaren von Phaseolus erectus (var. nanus): die mir dies Frühjahr durch die Freundlichkeit des hiesigen Garten-Inspektors, Herrn Kolb ${ }^{1}$ ), zukamen, erhielt ich jene fraglichen Elemente zu Gesicht. So sehr auch der Holzkörpor durch den geschlossenen Cambiumring verdickt wird: der sekundäre Bast bleibt im Vergleich zu jenem von sehr geringer Mächtigkeit.

Dass die primären dickwandigen Bastzellen, welche im Stengel unmittelbnr unter der Schutzscheide liegen, sich in vier breiten Lamellen zwischen den 4 Hauptstrangpaaren ausbreiten, haben wir früher bei der Betrachtung des Baststrangverlaufes ge-

1) Anmerk. Ich erachte es als angenehme Pflicht, an dieser Stelle der grossen Zuvorkommenheit dankend zu erwähnen, mit der Herr Inspector Kolb mir während der ganzen Zeit dieser Untersuchung das nöthige Material bereitwilligst besorgen liess. 
sehen. In radialer Richtung sind diese Bastlamellen 2-4 Zellen mächtig. Die Verdickung der Zellen - das Lumen meist auf ein Mininum reduzirend - tritt mit der Verholzung der ersten Gefässe, nach vollendeter Streckung des Stengels ein.

Ehe wir zur Betrachtung der nächstfolgenden Partie, dem Basaltheil der Hauptwurzel (C) übergehen, besprechen wir erst die anatomischen Verbältnisse der

\section{d. Wurzel im weitern Verlauf.}

Dio Hauptwurzel der Phaseolus-Arten hört in einem gewissen Stadium auf, in die Länge zu wachsen, indess das Dickenwachsthum während der ganzen Lebensdauer der Pflanze vor sich geht, sofern die Hauptwurzel nicht durch schädliche Einflüsse zerstört und dann durch die stark entwickelten Nebenwurzeln, die im Basaltheil entspringen, ersetzt wird. Es versteht sich daher von selbst, dass ihre Mächtigkeit in verschiedenen Höhen eine verschiedene sein muss, je nach dem Alter des fraglichen Theiles. Nehmen wir an, wir untersuchten die ganze Pfahlwurzel in dem Stadium, wo sie (bei normaler Entwicklung) aufhört, in die Länge zu wachsen, so werden uns die Querschnitte von der Wurzelspitze an bis zum Basaltheil : ach einander das Bild geben von der Entwicklungsgeschichte des ältesten Theiles. Was sich in den jüngern Theilen der Wurzel ron diesem Stadium an bis zum Absterben der Pflanze noch weiter entwickelt, ist dasselbe, was wir jetzt schon in den Querschnitten durch die dem Basaltheil der Wurzel zunächst liegenden Partieen entwickelt sehen. Um daher den Bau der Hauptwurzel kennen zu lernen, werden wir am besten thun, von der Spitze an gegen die Basis hin vorzuschreiten, und so die Entwicklung der Elemente in der Betrachtung der Querschnitte aus verschiedenen Höhon uns vorzuführen.

Der Scheitel der Wurzel trägt die aus zahlreichen Zellschichten bestehende, über dem Vegetationspunkt die grösste Dicke besitzende Wurzelhaube. Letztere zeigt bei unserer Pflanze keine besondern Eigenthümlichkeiten.

Unter der Wurzelhaube liegt der Vegetationspunkt, ein Complex von Zellen, die in sehr rascher Theilung begriffen sind und als Urmeristem bezeichnet werden.

Aus dem Urmeristem der Wurzelspitze differenziren sich nach einander die verschiedenen Elemente der Wurzel, und zwar am 
schnellsten die primäre Rinde, als grnsszelliges Parenchym mit luftführenden Intercellularräumen, die bis in die nächste Nähe des Vegetationspunktes verfolgt werden köunew. Die primäre Rinde umgibt den centralen Cambiumcylinder: cin zartes Gewebe enger Zellen, die mit Plasmastoffen reichlich angefüllt sind und sich dadurch deutlich rom Rindenparenchym abheben, dass sic nicht mit luftführenden Intercellularräumen an einander grenzen, sondern ein dicht zusammenschliessendes Bildungsgewebe darstcllen. Wenige Schnitte unterhalb des Vegetationspunktes erkennt man in diesem zarten Cambiumcylinder auf 4 peripherischen Punkten je eine, später mehrere Zellen, im Querschnitt als dunkler conturirt erscheinend: es sind dies die ersten Gofässzellen. Diese 4 ersten Vasalelemente liegen jeduch nicht vollständig an der Peripheric des interstiticnlosen centralen Gewebcylinders, sondern es zeigen sich zwischen dem Rindenparenchym und den ersten Gefässzellen stets noch zwei oder mehr Zellschichten, die im Querdurchschnitt aus dieser Region noch den gleichen Charakter wie das centrale Cambium besitzen.

Wir sind durch mancherlei Gründe veranlasst, dieses fragliche Gewebe (nach Nägeli und Leitgeb: „Entstehung und Wachs. thum ler Wurzeln", Beitr. IV. 1868) Pericambium zu nennen. Schreiten wir basipetal weiter, so zeigen uns die Querschnitte in ihrer successiven Entfornung rom Wurzelscheitel eine stets zunehmende Anzahl von Gefässzellen, die innerhalb der ersten 4 sich in centripetaler Folge an einander anlehnen. Auf diese Weise heben sich also $4 \mathrm{~V}$ asalstränge aus dem Cambium heraus und zwar, wie auf den ersten Blick zu sehen, in ihrer Gefässbildung gegen das Centrum hin fortschreitend. Die Gefässe, welche der Peripherie zunächst liegen, sind die engsten und zuerst verdickten, während diejenigen, welche dem Centrum des Querschnittes zunächst liegen, deren Wände sich ihrer jugendlichen Zartheit wegen noch wenig ron den benachbarten Cambiumzellen ableben, den grössten Durchmesser besitzen.

Zu gleicher Zeit mit den ersten Gefässzellen zeigt sich an der Peripheric desselben Kreises, dem diese angehören, zwischen je zwei Vasalsträngen im Cambium eine Gruppe dunkler erscheinender Zellen, die alle ziemlich gleichen Durchmesser haben. Ihre Wände verdicken sich in dem Maasse stärker, als man basipetal fortschreitet. Es sind dies die mit den primordialen Vasalsträngcu alternirenden, zu gleicher Zeit angelegten 4. Stränge pri- 
märer dickwandiger Bastzellen. Weiter basipetal vorschreitend, bemerken wir, dass die Gefässbildung, auf einem gewissen Punkte in ihrer centripetalen Richtung angekommen, nun eine andere Richtung einschlägt. Es gewinnen nämlich die Vasalstränge, je mehr sich die fortschreitende Gefässbildung dem Centrum der Wurzel nähert, an Breite um endlich nach rechts und links, in tangentialer Richtung ausbiegend, gegenseitige Ueberbrückungen zu bilden, so dass nun im Fibrovasalcylinder die dem Centrum zunächst liegenden Gefässe ein regelmässiges Viereck bilden, dessen Ecken gegen die Peripherie in scharfe Spitzen ansgezogen sind. An den Enden dieser letztern liegen die allerersten Gefässe.

Ein Querschnitt in dieser Höhe der Differenzirung, ca. 25 bis 30 Millimeter unterhalb der Wurzelspitze, zeigt deutlich das relative Alter der nach einander aufgetretenen Gefässe, indem die 4 peripherischen Gruppen der engen Primordialgefässe bereits verholzt und daher dunkel conturirt sind; die weiter nach Innen liegenden Gefässe dagegen besitzen ein weiteres Lumen und sind noch weniger verholzt, die Zellwände weniger verdickt, und endlich die zur gegenseitigen Ueberbrückung der Primordialgefässe tangential angelegten Gefässe zeichnen sich unter allen als die weitesten aus und sind zum Theil noch gar nicht verholzt, so dass sie sich blos durch ihr weiteres Lumen von den benachbarten Cambiumzellen unterscheiden. Die Verholzung der Gefässzellen geht somit parallel mit dem Alter derselben; ihre Richtung ist dieselbe, wie diejenige der Aufeinanderfolge der Gefässe: von den Primordialgefässen aus schreitet sie centripetal nach lnuen und biegt dann von der centripetalen Richtung rechts und links auf die T'angente aus.

Meistens liegt im Mittelpunkt des Querschnittes ein einziges grosses, poröses Gefäss (Fig. 14), rings umgeben von den inner. sten Gefässen der Primordialstränge und den in tangentialer Richtung entstandenen grossen porösen Gefässen - oder an der Stelle dieses einen grossen porösen Gefässes findet sich eine Anzahl von Holzzellen und kleinerer Gefässe (Fig. 12).

Mit dieser weitern Ausbildung des Vasalkörpers geht auch die schärfere Differenzirung der übrigen Elemente Hand in Hand. Es besitzen dieselben in dem Querschnitt, der ca. 4 Centimeter unter dem Scheitel der Wurzel liegt, folgenden Charakter (Fig. 12): 
Die Zellen der dickwandigen Bastbündel zeigen äusserst stark verdickte Wände, so dass ihr Lumen auf ein Minimum reduzirt ist. Es geht diese Verdickung der Bastzellen zu gleicher Zeit vor sich, wie die Verholzung der Primordialgefässe, eine Erscheinung, die bereits vom primären dickwandigen Bast des Stengels ebenfalls constatirt ist.

Im Querschnit haben die dickwandigen Bastlündel der Wurzel in ibren gröbsten Conturen längliche Eiform, deren Hauptaxe tangential liegt und 6 bis 10 Zellen fasst, während die Mächtigkeit der Bastbündel im radialen Durchschnitt nur 3-5 Zellen beträgt.

Die dickwandigen Bastbündel sind umgeben von Weichbast, in welchem sich namentlich die kleinen Zellgruppen, die wir schon im Stengel in der Zone des Weichbastes beobachtet haben, durch den trüben Inhalt der Zellen und den äusserst geringen Durchmesser der letztern auszeichnen. Sio bleiben während der ganzen Lebensdauer der Pflanze zartwandig. Mancher dieser Weichbaststränge nimmt im Querschnitt denselben Raum ein, wie eine der benachbarten Parenchymzellen und zeigt auch dieselben Um. risse, so dass wohl mit Sicherheit geschlossen werdeu durf, es seien diese isolirten kleinen Zellkornplexe je aus einer einzigen Cambiumzelle hervorgegangen. Es berühren sich jedoch oft zwei derselben unmittelbar, so dass sie dann in ibrer Gesamıtheit eiven doppelt so grossen Zellkomplex bilden (Fig. 12 und 13).

Sämmtliche Phloem-Elemente bilden zusammen eine um den Holzkörper liegende Zone, dic nur durch die an 4 Punkten des Querschnittes heraustretenden Primordialgefässe unterbrochen wird (Fig. 12 und 15).

Innerhalb des Phloems befindet sich das fortwährend th atige Cambium, durch die 4 nach Aussen keilförmig zugespitzten primordialen Vasalstränge in 4 Gruppen getheilt. Aus ihm entstehen die spätern Bildungen des Fibrovasalkörpers.

Das Phloem ist rom Pericambium umgeben, einer concentrischen Schicht zartwandiger Zellen, deren grösster Durchmesser denjenigen der Cambiumzellen um ein Bedeutendes übertreffend, im Allgemeinen radiale Richtung hat (Fig. 12, 13, 17 pp.). In dieser Höhe der Entwicklung ist das Pericambium über den Phloempartieen meist einschichtig, während es, soweit meine Untersuchungen reichten, bis in die Nähe der Wurzelspitze über den 4 Primordialsträngen wenigstens 2, und meist 3 Zellschichten 
zählt. Es ist dieses lebensfähige Gewebe die Bildungsstätte der ersten Anlagen aller Nebenwurzeln.

Ich habe zwar weder auf Längs- noch Querschnitten die Entwicklungsgeschichte dieses Gewebes in einer Weise verfolgen können, wie lies $\mathrm{Naegeli}$ und Leitgeb bei der Untersuchung von Wurzeln böherer Kryptogamen und einiger Phanerogamen gelungen ist (Entstehung und Wachsthum der Wurzeln, Beitr. IV.), wo die Entstehung des Pericambiums aus den Segmenten der Scheitelzelle abgeleitet werden konnte. Allein die bisher gemachten Beobachtungen veranlasseu genugsam, jenen Namen auch für dies Gewebe in den von mir untersuchten Phanerogamen-Wurzeln zu acceptiren.

Bei den Phaseolus-Arten zeichnet sich das Pericambium auch schon dadurch vor dem eigentlichen Cambium aus, dass es, wie aus gelungenen axilen Längsschnitten durch die Wurzelspitze hervorgeht, in der Höhe, wo die ersten Verdickungen der Gefässzellwände auftreten, noch von plasmatischen Stoffen bis zum Strotzen angefüllt ist, was bei den übrigen Geweben nicht mehr stattfindet. Solche Schnitte, mit verdünnter Kalilauge versetzt, lassen die Pericambiumschichten bis in die unmittelbare Nähe des Vegetationspunktes verfolgen. Ihre Zellen sind in der Richtung der Längsaxe kürzer, als in der Richtung de`s Radius und liegen in Längsreihen äber einander. Die Querwände sind zum Theil schief, zum Theil horizontal liegend, wodurch sich die Pericam. biumzcllen ebenfalls von den benachbarten Schutzscheide- und Rindenzellen unterscheiden (Fig. 11 und 12). Es ist wohl anzunehmen, dass in einer gewissen Höhe der jungen Wurzel (mehr scheitelwärts als die ersten Gefässwandverdickungen) das Pericambium eine einzige concentrische Zellschicht bildet, die durch Zelltheilung über den 4 ,rimordialen Vasalsträngen bald mehrschichtig wird.

Das Pericambium ist rings von einer Zellschicht umschlossen, die bis in den Stengel hinauf verfolgt werden kann, wo wir sie bereits als Schutzscheide kennen gelernt haben. Im Querschnitt durch die junge Wurzel (Fig. 12, 13 und 17) bietet die Schutzscheide folgenden Charakter: Je zwei Wände einer jeden Zelle liegen im Radius des Querschnittes und schliessen ohne Intercellularräume an einander. In ganz gelungenen Schnitten zeigt jede dieser radial gestellten Wände rechts und links dunkle Partieen, wie sie Caspary für die Schutzscheide der Knollenwurzel 
von Ficaria ranunculoides (Pringsheim's Jahrb. 1864) dargestellt hat. Die Zellen der Schutzscheide sind in tangentialer Richtung gestreckt, was namentlich an nachträglich verdickten und rerholzten Wurzcln besonders auffält. Meist werden ihre Mem. branen durch einen Zusatz ron etwas Kalilauge hellyrün gefärbt. Immer machen die einzelnen Zellen, selbst im schönsten Querschnitt, den Eindruck, als seien sie schief durchschnitten, da durch die Wellung der sämmulichen $W$ ände stets ti:fer liegende Partieen der letztern in das Zelllumen hereinragen. Auf einern mit Kalilauge behandelten tangentialen Längsschnitt zeigen die in der Längsaxe der Wurzel verlängerten Zellen der Schutzscheide zierlich geschlängelte Wande (Fig. 8), yanz ron glcichem Charakter, wie dies Caspary an den radialen Wänden der Schutzscheidezellen ron Elodea canadensis (Priugsh. Jlub. 186t) dargestellt hat. Die Betrachtung der Schutzseheidezellen von Pliaseolus nach allen möglichen Richtungen führte zu dem Resultate, dass sämmtliche Wände gewellt sind, diss aber diese Wellung nicht eine parallele, sondern eine unregelmässige ist. Jedenfalls haben wir hite das nämliche Organ ror uns, dus iu manchen Phauerogamen-Wurzeln als stark verdickte, schützende Zellschicht den Fibrovasalkörper umgibt und diesen nach Aussen deutlich ron der primären Rinde, die wohl bei den meisten Phanerogamen-Wurzeln sehr hinfälig ist, als dicht geschlossenen Mantel abgrenzt.

Die primäre Rinde erscheint auf dem Querschnitt als ein Gewebe von isodiantetrischen Zelleu, die zum Unterschied von allen übrigen Zellen dieses Qucrschnittes mit luftfuhrenden Intercellularräumen an einander grenzen. Die Zahl diescr unregelmässig über einander liegenden Zellschichten schwankt in der Hauptwurzel der verschiedenen Individuen zwischen 6 und 18, je nach der üppigen oder weniger kräftigen ersten Entwicklung. Es ist das Rindenparenchym wohl das allererst differenzirte Dauergewebe der Wurzel. Die Zellen desselben vermehren sich in sebr geringer Entfernung vom Vegetationspunkte der Wurzel schon nicht mehr.

Die Zellen der innersten Rindenschicht sind nicht, oder nur wenig grösser, als diejenigen der Schutzscheide, erscheinen aber, wie alle übrigen Rindenparenchymzellen auf dem Querschnitt mit hellern Conturen, als jene, da ihnen die für die Schutzscheidezellen charakteristische Wellung der Wände fehlt. Auch mangelt ihnen die regelmässige Anordnung, da zwischen der Lage 
ihrer Wände und dem Radius des Querschnittes keine gesetzmässige Beziehuug herrscht (Fig. 12 und 17). Die nach Aussen liegenden Zellen des Rindenparenchyms nehmea an Durchmesser im. mer mehr zu, je weiter sie vom Fibrovasalcylinder entfernt sind, um dann gegen die Epidermis hin wieder abzunehmen (Fig. 12, 13, 15). Ein Unterschied $\mathrm{zwischen}$ innerer und äusserer Rinde ist in anderer Hinsicht nicht wahrzunehmen.

Die Rinde wird umgrenzt ron der einschichtigen Epidermis mit radial gestellten $W$ änden, wie bei der Schutzscheide und ohne Intercellularräume. Mebrere Millimeter vom Scheitel der Wurzel entfernt, bildet die Epidermis zahlreiche Wurzelhaare.

Soviel über die Erscheinungen, die uns die successiven Querschnitte von der Wurzelspitze an bis ca. 4 Centimeter weiter basipetal bieten. Wir haben in dem bisher Dargestellten den Entwicklungsgang einer jeden Hauptwurzel, sowie auch der stärkern Nebenwurzeln, wie er sich in der ersten Zeit stets gestaltet. Was beim weitern Dickenwachsthum noch hinzukommt, bieten uns die grundwärts auf einander folgenden Querschnitte. Es ist in Kurzem Folgendes:

Die im ersten Stadium cuntripetale Gefässentwicklung, die, auf einem gewissen Punkte angekommen, tangential ausbiegt, und so auf einer längern Strecke des jüngern Theils von der Hauptwurzel dem Holzkörper eine 4eckige Gestalt gibt, ändert nun nochmals ibre Richtung, indem nach vollendeter Ueberbrückung der Partieen zwischen den primordialen Vasalsträugen die nächstfolgenden Gefässe in der Richtung gegen die primordialen dickwandigen Baststränge, also centrifugal auftreten (Fig. 14). Kurz nachher beginnt die Bildung der Holzzellen auf der ganzen Peripherie des Gefässkörpers, indem der Theilungsprocess in den cambialen Zellen auch die über den primordialen Vasalsträngen liegenden Pericambiumpartieen ergreift. So entsteht ein geschlossener Ring von producirendem Gewebe, der aus zweierlei Elementen hervorging und auch dem entsprechend verschiedene Produkte liefert: der grössere Theil des Ringes besteht aus ächten, langgestreckten Cambiumzellen und entspricht den 4 zwischen primärem Phloem und dem ersten Gefässkörper liegenden Cambiumpartieen, die nach der Differenzirung der ersten Elemente übrig geblieben sind. Diese Theile des Ringes liefern nun nach Innen Holz- und Gefässzellen (Xylem), nach Aussen secundäres Phloem. Dagegen sind die 4 über den Primordialgefässen liegenden Par- 
tieen des producirenden Ringes aus dem Pericambium herrorgegangen. Daher sind im Längsschnitt ihre Zellen sehr kurz und die daraus hervorgehenden Produkte - die 4 grossen Markstrahlen - parenchymatisch; sie verholzen jedoch ebenso, wie die Produkte des eigentlichen Cambiums. Nie finden sich in den Derivaten des Pericambiums Gefässzellen; eben so wenig sind die peripherischen Produkte desselben, welche die Zone des primären und secundären Pbloems unterbrechen, Bastelemente im engern Sinne des Wortes, sondern dünnwandige parenchymatische Gewebe-Partieen, in denen ich auf dem Querschnitt nie dickwandige Zellen beobachtet habe. Die im Querschnitt $\mathbf{z w i s c h e n}$ den grossen Markstrahlen liegenden breiten Holzlappen der ausgewachsenen Wurzel (Fig. 14) zeigen in Bau und Struktur denselben Charakter, wie der Holzkörper in Stengel. Die Holzzellen sind auch hier radial angeordnet und schliessen verhältnissmässig nur wenige poröse Gefässe ein. Auch in der Wurzel verholzen stets die diesen Gefässen zunächst liegenden, weniger regelmässig angeordneten Zellen zuerst und meist stärker, als die übrigen, radial angeordneten.

Mit dem Dickenwachsthum der Wurzel werden die Elemente des primären Phloems in tangentialer Richtung ausgedehnt. Es werden daher die kleinen Weichbaststränge in Querschnitt un. deutlich, indem sie ihre fruhern Conturen verlieren, während die Stränge primären dic'iwandigen Bastes durch dic ganze Wurzel so ziemlich denselben Querschnitt beibehalten. Im secundären Phloem treten erst spät (wie in Stengel) stark verdickte Zellen auf, die isolirt und zer treut von einem Markstrahl zum andern meist in geringerer Zahl vorkommen (Fig. 14).

Mit dem primären Phloem werden auch die über denselben liegenden Pericambiumzellen in tangentialer Richtung ausgedehnt, wodurch sie ebenfalls ihren früheren Charakter verlieren, indem sie flach gedrückt und in der Richtang der Tangente verzogen werden. Sie bleiben zartwandig während der ganzen Lebensdauer der Pflanze, indess die Schutzscheidezellen verkorken und die primäre Rinde zu Grunde geht. Während letztere im jüngsten Theile der Hauptwurzel noch von der Epidermis bedeckt und unversehrt ist, bieten uns die Querschnitte durch den ältern Theil der Hauptwurzel nur noch fetzenartige Ueberreste des zerrissenen Rindenparenchyms. Die Schutzscheide, deren Verkorkung durch chemische Agentien leicht nachzuweisen ist, leistet 
nach dem Abwerfen der primären Rinde der Wurzel genügenden Schutz gegen äussere Einflüsse und vertritt in dieser Hinsicht die Rolle der früher vorhandenen Epidermis.

Noch bleibt uns übrig, ein Wort über den Charakter der Gefässe und den Bau der $\mathbf{Z}$ wischenstränge zuzufügen. Die ersten Gefässe eines primordialen Vasalstranges sind immer Spiralgefässe; in den Phaseoluswurzeln habe ich bis jetzt noch nie Ringgefässe zu Gesicht bekommen. Die Zahl der Spiralgefässe in einem Primordialstrang schwankt zwischen 2-4, wodurch - und namentlich auch durch ihren geringen Durchmesser - das Auffinden derselben in Längsschnitten erschwert wird. Zudem sind sämmtliche Gefässe der Wurzel ohne Ausnahme nicht abroll. bar. Nie ist mir gelungen, eine abgelöste Spiralfaser aus der Wurzel zur Ansicht zu erhalten. Durch die physiologische Abhandlung von Sachs ( über die Keimung der Schminkbohne"), in welcher die Anwesenheit von Spiralgefässen in der Wurzel verneint wird, sah ich mich veranlasst, Wurzeln von sämmtlichen 3 Phaseolus-Arten ganz besonders auf den Charakter der Gefässe zu untersuchen. Von der Anwcsenheit der Spiralgefässe kann man sich am leichtesten im jüngsten Theil der Wurzel überzeugen, während es ungleich schwieriger ist, solche in der verholzten Wurzel zu Gesicht zu bekommen, da sie hier meist so von porösen Gefässen und Holzzellen umgeben sind, dass sie bei ihrem kleinen Durchmesser leicht der Beobachtung entgehen. Auch im jüngsten Theil der Hauptwurzel gelangt man nicht immer leicht zum Ziel; denn es besitzen die engster porösen Gefässe der primordialen Vasalstränge den gleichen Durchmesser, wie die weitesten Spiralgefässe, und da letztere nicht abrollbare Spiralleisten besitzen, so sind bei der Zartheit der Gefässe leicht Verwechslungen möglich. Selbst zarte, mit Kalilauge behandelte Längsschnitte lassen über die Natur der Verdickung oft im Zweifel. Dagegen bietet concentrirte Schwefelsäure ein willkommenes Mittel, hierüber in's Klare 'zu kommen. Die concentrirte Schwefelsäure löst nämlich in kurzer Zeit alle dünnwandigen Zellen auf, so dass von Parenchym und Cambium lange nichts Störendes mehr zu sehen ist, wenn die Vasalstränge noch unversehrt sind; sie scheint auf die Gefässzellen nicht so schnell und zerstörend einzuwirken, wie Kalilauge, und dennoch schneller die Weichgewebe aufulösen, als die letztern. Zudem bietet die Behandlung mit Schwefelsäure den grossen Vortheil, dass die Spiralleisten und 
porösen Verdickungen sich intensir färben und dadurch scharf hervortreten, wodurch Verwechslungen weniger möglich werden.

Die äussersten, zuerst entstandenen zwei bis vier engen Gefässe eines jeden primordialen Vasalstranges sind Spiralgefässe; an sie schliessen sich die mehr axil gelegenen porösen Gefässe, die in der Folge an Durchmesser stets zunchmen, während sie umgekehrt an Länge einbüssen. Die läugsten porösen Gefässzellen sind eben so lang, als die zuletzt entstandenen Spiralgefässzellen; die kürzesten dagegen bleiben in ihrer Länge um das Melirfache hinter jenen zurück; es sind dies diejenigen, welche in centrifugaler Richtung sich jı Holzkörper entwickeln als sekundäre Gebilde des Cambiums.

Anders als bei den primordialen Vasalsträngen verhalten sich die Gefässe der Zwischenstränge. Der Querschnitt lässt darïber zwar im Zweifel nnd manchmal gewährt er selbst den Anschein, als ob die Zwischenstränge, wie die Hauptstränge angelegt würden und aus den nämlichen Gefässen beständen.

Eine genauere Untersuchung dicser Verbältnisse durch das Herauspräpariren der Zwischenstränge und deren Untersuchung in der Längsansicht, sowie die Verfolgung derselben vom Basaltheil der Wurzel an bis an ihr jüngstes Ende, führte jedoch zu dem Resultat, dass sie unterhalb des Basaltheiles der Hauptwurzel, wo keine Nebenwurzeln mehr von ihnen abgehen, nie Spiralgefässe enthalten, dass die erstentstandenen porösen Gefässe bald rom gleichen Durchmesser, wie die Spiralgefässe des prinordialen Vasalstranges, bald aber weitlichtiger sind, und dass die engsten Gefässe des Zwischenstranges bald an der peripherischen, bald an der axilen Seite, bald in der Mitte zwischen den übrigen Gefässen liegen. Ohnedies reichen diese $\mathrm{Z}$ wischenstränge, wie schon früher bemerkt, imıer etwas weniger weit gegen die Spitze der Wurzel, als die Hauptstränge und verlieren sich meist sehr bald im dünnern Theil der Hauptwurzel vollständig.

\section{Die Anatomie der Nebenwurzeln}

bietet in Allgemeinen nur eine Wiederholung der Verhältnisse in der Hauptwurz l. Primäre Rinde, Schutzscheide und Pericambium verhalten sich ohne Ausnahme wie in der Hauptwurzel; dagegen können im Fibrovasalkörper insofern Abweichungen eintreten, als bei den schwächsten Nebenwurzeln statt 4 Primordial- 
strängen deren blos zwei vorhanden sind, während sonst die Verbältnisse ganz dieselben bleiben, wie in der Hauptwurzel. Dass bei diesen zarten Nebenwurzeln die Zahl der verschiedenen Gewebezellen viel kleiner ist, als in stark entwickelten Wurzeln, braucht kaum besonders betont zu werden. Es sind mir sogar Querschnitte von Nebenwürzelchen zu Gesicht'gekommen, die bloss ein einziges centralns Gefäss besassen, deren Rindenschichten sich auf zwei reduzirten; immer aber waren das Pericambium und die Schutzscheide, sowie Bastzellen deutlich unterscheidbar.

Die Nebenwurzel-Anlagen entstehen, wie früher bemerkt, im Pericambium der Mutterwurzel. Ich hatte Gelegenheit, Anlagen von Nebenwurzeln in mancherlei Stadien, auf Quer- und Längsschnitten, zu sehen; gleichwohl kann ich mit Bestimmtheit über die ersten Anfänge der Nebenwurzeln nur folgendes Wenige mittheilen: Da, wo sich eine Nebenwurzel bilden soll, strecken sich die dem betreffenden Primordialstrang der Mutterwurzel zunächs liegenden Pericambiumzellen erst in radialer Richtung, so dass nach Aussen eine Anschwellung der Gewebepartie entsteht (Fig. 13); hierauf treten in den radial verlängerten Zellen tangentiale Wände auf, nachher solche, die scheinbar ohne Regel nach allen Seiten gerichtet sind. So vergrössert sich die Wurzelanlage als hügelige Anschwellung immer mehr, und zwar geschieht dies in räumlicher Hinsicht auf Kosten des darüber liegenden Rindenparenchyms, dessen Zellen bei der Ausdehnung der Nebenwurzelanlage zuerst nach Aussen zusammengedrückt werden, um nachhe zu verschwinden. Hat die hügelige Anschwellung des Pericam biums eine gewisse Höhe erreicht, so tritt auch Zelltheilung in den darüber liegenden Schutzscheidezellen der Mutterwurzel ein; gleichzeitig erhalten aber sämmtliche Zellen der Nebenwurzelanlage ein undurchsichtiges Plasma, und stellen sehr bald ein kleinmaschiges Gewebe dar, das den Charakter besitzt, wie in der Spitze der Mutterwurzel. Die successiven Processe, von der ersten Zelltheilung im Pericambium an bis zur Bildung der Wurzelhaube in der jungen Nebenwurzel, zu verfolgen und Schritt für Schritt zu deuten, war mir bis jetzt nicht möglich. Ein Querschnitt durch die Mutterwurzel, so geführt, dass er zugleich radialer Längsschnitt der jungen Nebenwurzel war, zeigte nach wochenlangem Liegen in Glycerin die in Fig. 16 und 17 dargestellten Ansichten. Wurzelhaube, primäre Rinde und Cambiumcylinder sind zwar noch nicht scharf unterscheidbar, obschon zu- 
nächst dem primordialen Vasalstrang der Mutterwurzel die Gefässbildung im Körper der Nebenwurzel bereits begonnen hat; jedoch so viel ist mit Sicherheit zu sehen, dass die Wurzelhaube der Nebeuwurzel in 5-3 Zellen mächtiger Schicht bis zur Schutzscheide der Mutterwurzel herabreicht. Aus den Umstand, dass die Schutzscheidezellen der letztern in einem gewissen Stadium der Nebenwurzelanlage ebenfalls mit in den Theilungsprocess hineingezogen werden, und dass die Wurzelhaube der bis zur Epidermis der Mutterwurzel rorgeriickten Nebenwurzel in allen mir zu Gesicht gekommenen Quer- und Längsschnitten •in direktem Zusammenhang mit der Schutzscheide der Mutterwurzel zu stehen schien, möchte ich geneigt sein, zu schliessen, es wären die über deın primordialen Vasalstrang liegenden Schutzscheidezellen jeweilen das Bildungsgewebe für die allererste Wurzelhaube der Nebenwurzel. In vielen Fällen schien mir sogar die über der Schutzscheide liegende innerste Rindenschicht bei dieser Bildung bethätiget, wie dies auch aus Fig. 17 geschlossen werden möchte. Wegen mangelnder Beobachtungen der Stadien, die zwischen den in Fig. 13 und 16 dargesteliten liegen, wage ich jedoch nicht, eine Behauptung aufzustellen, an deren Wahrscheinlichkeit ich zwar nicht zweifle, dio aber doch mit genügenden Beweisen unterstützt werden soll. Ich lasse darun die Eutscheidung der F'rage noch dahingestellt, ob die Wurzelhaube der Nebenwurzel im ersten Stadium das Produkt der Schutzscheide allein, oder der Schutzscheide und innersten Rindenschicht der Mutterwurzel zusainmen, oder ob sie ebenfalls vom Pericumbium abzuleiten ist. Dass bei manchen Phanerogamen die Wurzelhaube der Nebenwurzel zum Theil oler ganz aus der innersten Rindenschicht hervorgeht, ist zuerst von Nägeli und Leitgeb (Beitr. IV.: „Entstchung und Wachsthum der Wurzeln ") thatsächlich nachgeviesen worden; dass ähnliche Verbältnisse bei Phaseolus vorwalten, bezweifle ich nicht, und hoffe den Beweis noch zu liefern.

Nachdem wir die auatomischen Verhältnisse im Stengel und in der Wurzel im weitern Verlauf betrachtet haben, gehen wir endlich zum 


\section{Basaltheil der Hauptwurzel}

über. Hier finden sich die verwickelten Verhältnisse, welche dem Uebergang vom Stengel der Phaseolus-Arten in die Pfahlwurzel eigen sind.

Das Erste, was den Basaltheil der Hauptwurzel von der Wurzel im weitern Verlauf und ron den Nebenwurzeln ganz besonders unterscheidet, ist das Vorhandensein des Markes (Fig. 18). Das. selbe bildet einen mehr oder weniger hohen Kegel ron parenchymatischem Gewebe, dessen Ende wenig mehr scheitelwärts liegt, als der Querschnitt, auf dem wir den ausgesprochenen Wurzelcharakter an den 4 centripetal angeordneten primordialen Vasalsträngen erkennen. Die Basis des Markkegels ruht dagegen auf dem Markcylinder des hypocotylen Stengels. Wenn der letztere in der ausgewachsenen Pflanze hohl ist, so ragt diese Höhlung zum Theil auch in jenen Markkegel der Wurzel hinein.

Um diesen Markkegel licgt der Fibrovasal-Mantel, dessen einzelne Theile sich folgendermassen verhalten. Die im hypocotylen Stengel tangential angeordneten Hauptstränge, dort schon einander paarweise genähert, rücken beim Uebergang in die Wurzel nach und nach immer mehr zusammen, bis die engsten, einander zugekehrten Gefässe eines Hauptstrangpaares sich völlig vereinigen. Diese aus zwei. Theilen entstandene Gefässgruppe zeigt an der Vereinigungsstelle noch tangentiale Anordnung; in der Mitte derselben befinden sich die engsten primordialen Gefässe, von denen aus nach rechts und links die weitlichtigen porösen Gefässe folgen. Die erstern schliessen sich jedoch in manchen Fällen nicht unmittelbar an einander, sondern liegen im Querschnitt zerstreut, allein in der Entwicklung immer die angegebene Richtung befolgend. Tiefer wurzelwärts ordnen sich die Gefässe allmälig so, dass die ganze Gruppe einen Winkel bildet, dessen Scheitel der Peripherie zugekehrt ist, während die Schenkel des Winkels, von der Tangente abweichend, mit ihren äussern Enden sich immer mehr dem Centrum des Querschnittes nähern. Die im hypocotylen Stengel tangential liegenden Stränge eines Paares rücken also in der Weise zusammen, dass sie in ihrer Vereinigung erst einen flachen, dann einen stumpfen Winkel und nach und nach einen immer spitzern Winkel bilden und somit zuletzt eine Gefäss- 
gruppe darstellen, deren engste und äiteste Gefässe sich aussen befinden. Auf diese Weise erfolgt die Vereinigung Ger 4 Hauptstrangpaare des hypocotylen Stengels im Basaltheil der Wurzel zu den 4 centripetal angeordneten primordialen Vasalsträngen der letztern. Ganz ähnlich vereinigen sich die $\mathrm{Z}$ wischenstrang. paare des hypocotylen Stengels, wenn sie sich in letzterem den Hauptstrangpaaren gleich rerhalten, im Basaltheil der Hauptwurzel zu je cinem $\mathbf{Z}$ wischenstrang, ler jedoch untcrhalb der letzten von ihm abgehenden Nebenwurzeln keine Spiralgefässe mehr besitzt und überhaupt den Charakter eines Primoldialstranges verliert, oft sogar schon im Basaltheil der Wurzel blind endiget.

Die übrigen $\mathrm{Z}$ wischenstränge des hypocotylen Stengels, welche sich in centrifugaler Richtung entwickelten, verlieren sich ebenfalls blind im Holzring des Basaltheiles.

Weil in der Regel im hypocotylen Stengel mit den Hauptstrangparen die schwäshern Zwischenstränge alterniren, und beiderlei Elemente sich ziemlich gleichzeitig anlegen und ausbildon, so ergibt sich für den Basaltheil der Hauptwurzel hinsichtlich der Bildung des ersten Gefäss- und Holzringes eine Abweichung von derjenigen in den übrigen Wurzeltheilen, indem die sekuudäre Gefässbildung nicht blos von den 4 Haupt-Gefässgruppen, sondern zu gleicher Zeit anch von den Zwischensträngen ansgeht. Diese weitere Gefässbildung im Basaltheil der Hauptwurzel ist bis zur völligen Umschliessung des Markkegels durchweg eine tangentiale. Ist der Gefäss-Ring geschlossen, so crfolgt dic Holz- und Gefässbildung in centrifugaler Richtung.

Merkwürdige Verhältnisse bietet der Bastköıper im Basaltheil der Hauptwurzel. Der primäre dickwandige Bast des hypocotylen Stengels, der sich je in einer breiten Lamelle ron einem Vasalstrangpaar zum andern hinzieht, verschwindet in der Basis des hypocotylen Stengels- Erst mehrere Querschnitte tiefer treten im Basaltheil der Wurzel, ebenfalls zwischen den 4 primordialen Gefässgruppen jene dickwandigen Bastbündel auf, die als 4 Stränge von gleicher Mächtigkeit durch die ganze Wurzel hinzichen. Mit den dickwandigen primären Bastzellen des hypocotylen Stengels verschwinden wurzelwärts auch die Gerbstoffgefässe, um aber in der Wurzel nicht wieder zu beginnen. Die letzten derselben sind noch in jenem Querschnitt zu sehen, wo die primärer dickwandigen Bastbündel der Wurzel ihren Anfang nehmen. Die übrigen Elemente des primären Weichbastes erleiden im Basaltheil 
der Wurzel keine Veränderung, sondern setzen sich vom Stengel aus durch denselben unmittelbar in die Wurzel fort, was namentlich recht deutlich an den kleinen Weichbaststrängen beobachtet wird.

$\mathrm{Da}$, wo die dickwandigen Bastlamellen des hypocotylen Stengels, in einzelne Zellgruppen zerfallend, sich wurzelwärts verlieren, erkennt man im Querschnitt bereits auch den einschichtigen Pericambium-Mantel, welcher der Wurzel eigen ist und sich stengelwärts da verliert, wo im Basaltheil der Wurzel ein primordialer Vasalstrang sich in zwei Schenkel spaltet. Das Pericambium setzt sich aber an 'den 4 Partieen der Peripherie, welche, den 4 primordialen Vasalsträngen' der Wurzel entsprechend, im Basaltheil des Stengels sich je zwischen zwei zusammengebörigen Hauptsträngen befinden, noch etwas weiter stengelwärts fort, als auf den übrigen Theilen der Peripherie, die den Bastlamellen entsprechen. Dort treffen wir auch - über der Erde - immer noch einige mehr oder weniger entwickelte Nebenwurzelanlagen, die, unregelmässig zerstreut, dem besagten Theil des Stengels oft das knorrige Ansehen geben.

Die Schutzscheide verhält sich im Basaltheil der Wurzel nicht anders, als in den übrigen Theilen der Hauptwurzel. Hat der Holzkörper eine gewisse Mächtigkeit erreicht, so verkorkt sie sich; es stirbt sodann die primäre Rinde ab und geht zu Grunde.

Was die Producte des Cambiumringes betrifft, so unterscheidet sich der Holzkörper des Basaltheils von demjenigen der übrigen Wurzel nicht. So weit das Pericambium reicht, finden sich auch im Basaltheil der Wurzel jene 4 grosson Markstrahlen, die über den primordialen Vasalsträngen liegen. Die Holzelemente sind dieselben, wie in der früher beschriebenen Wurzel und im Stengel.

Im secundären Bastkörper reichen die dickwandigen Bastzellen der Wurzel, die sich insgesammt erst sehr spät verdicken, nicht bis zu denjenigen des hypocotylen Stengels, sondern auch zwischen diesen Elementen findet beim Uebergang des Stengels in die Wurzel eine Unterbrechung statt. An den alten Exemplaren von Phaseolus erectus, die im Vorjabre geblüht und Früchte getragen, habe ich in dem sehr stark verholzten Basaltheil der Wurzel, beim Uebergang der Bastelemente vom Stengel in diesen letztern, immer beobachten können, dass $z$ wischen den dick. wandigen Bastelementen vom Stengel und der Wurzel 
- den secundären sowohl als den primären - kein dirokter Zusammenhang. sondern eine kurze Unterbrechung besteht.

$\mathrm{Da}$ die meisten Gefässe der primordialen Vasalstränge im hypocotylen Stengel Spiralgefässe sind, während in der Wurzel jedem Primordialstrang deren höchstens 4 zukommen, obschon er eigentlich durch das Zusammentreten zweier Vasalstränge des Stengels entstanden ist, so müssen die meisten Gefässe beim Uebergang aus dem Stengel in die Wurzel ihre Natur verändern. In der That ist es sehr leicht, auf Längsschnitten die Verwandlung der spiraligen Verdickung in die poröse bei der Mehrzahl der Gefässe zur Ansicht zu bringen.

Wir haben früher schon hervorgehoben, dass im Basaltheil der Wurzel eine grosse Zahl von Nebenwurzeln abgeht. Dadurch wird die Untersuchung dieses Theiles wesentlich erschwert, da die Bastelemente, das Pericambium, sowie Schutzscheide und Rinde hier mehr als anderswo durchbrochen sind, was die Verfolgung der einzelnen Gewebepartieen manchmal fast unmoglich macht.

Noch in anderer Beziehung bietet die Entwicklungsgeschichte des Basaltheiles der Hauptwurzel ein eigenthümliches Verhalten dar. Die Radicula des Embryo vergrössert beim Keimen ihre Länge erst um das Drei- bis Vierfache, ehe in derselben die ersten Spiralgefässe auftreten. (Im trockenen Embryo zeigt die genaueste Untersuchung weder in der Plumula, noch in der Radicula, noch in den Cotyledonen etwelche charakteristische Verdickung der Gefässzellwände.) Das hypocotyle Glied hat im trockenen Samen von Phaseolus vulgaris eine Lănge von 3-4 Millimeter; erst wenn dasselbe die Länge von 11-12 Millimeter erreicht hat, treten in der Nähe der Cotyledonen und in der Plumula Gefässe mit spiraliger Verdickung auf. Zahlreiche Untersuchungen ergaben, dass die ersten Spiralleisten der Gefässzellen da sichtbar werden, wo die Cambiumpartieen des hypocotylen Stengelchens in die Cotyledonen ausbiegen. Von dort schreitet die Gefässbildung einerseits im Stengelchen abwärts, andererseits in die Cotyledonen hinein. Zu gleicher Zeit, oder unmittelbar nachdem diese ersten Spiralgefässe an der Insertionsstelle der Cotyledonen auftreten, finden sich auch solche an den Insertionsstellen der Primordialblätter und gleich nachher in der ganzen Länge des Gliedes über den Cotyledonen.

Da die Gefässbildung von den Samenlappen abwärts fort- 
schreitet, so beginnt sie in dem Basaltheil der Wurzel später, als im hypocotylen Stengel, aber sie nimmt dann daselbst so sehr überhand, dass wir dort zuerst einen geschlossenen Gefäss- und Holzring antreffen, lange bevor im hypocotylen Stengel irgend eine Zelle verholzt. Jener geschlossene Gefäss- und Holzring ist im Basaltheil der Hauptwurzel schon zu bedeutender Mächtigkeit angewachsen, ehe im hypocotylen Stengel die Streckung vollendet ist.

Die Verholzung der Gewebe erfolgt zuerst im Basaltheil der Hauptwurzel und schreitet von da in die nächstliegenden Theile der letztern, hier mit der Gefässbildung Hand in Hand gehend; erst bedeutend später schreitet sie vom Basaltheil der Hauptwurzel in den Stengel vor. Während die Spiralgefässbildung im hypocotylen Stengel sich von den Cotyledonen an abwärts bewegt, crfolgt die Verholzung dieser Gefässe vom Basaltheil der Wurzel an aufwärts. Zu gleicher Zeit mit dieser Verholznng tritt auch die Verdickung der primordialen Holzzellen ein, welche den ersten Holzring bilden, und beginnt der Cambiumring die Production der sekundären Gefäss- und Holzmassen, welche Bildung ebenfalls von der Wurzelbasis gegen die Cotyledonen hinauf vorschreitet. Dagegen zeigt das primäre Phloem ein eigenthümliches Verhalten, indem die Verdickung der primären dickwandigen Bastzellen nicht von Unten nach Oben, sondern von den Cotyledonen an abwärts schreitet. Immer habe ich die ersten dickwandigen Bastzellen in der Nähe der Cotyledonen bemerkt, ehe die fast zu gleicher Zeit angelegten Bastzellen im Basaltheil des hypocotylen Stengels nur eine Spur von Verdickung zeigten. Während in der Wurzel mit der Verdickung und Verholzung der primordialen Vasalmassen die Verdickung der primären Baststränge gleichen Schritt hält, sehen wir also im hypocotylen Stengel diese beiden Processe rücksichtlich ihres Ausgangspunktes getrennt und entgegengesetzte Richtungen einschlagen.

Fassen wir die wesentlichen Erscheinungen beim Uebergang des Stengels in die Hauptwurzel der untersuchten Phaseolus-Arten kurz zusammen, so ergibt sich Folgendes:

1. Im Basaltheil der Hauptwurzel geht der Markcylinder des Stengels in einen Kegel über, dessen Scheitel nur wenig in den übrigen Theil der Wurzel hereinragt.

2. Dem entsprechend spitzt sich das ganze Organ pfahlförmig zu.

3. Im Basaltheil der Hauptwurzel vereinigen sich je 2 Haupt- 
stränge des Stengels in einen Primordialstrang der Wurzel (resp. zwei genäherte Zwischeustränge des hypocotylen Stengels in einen Zwischenstrang der Wurzel).

4. In der Regel endigen die $\mathrm{Z}$ wischenstränge des hypocotylen Stengels nach kurzem Verlauf im Basaltheil der Hauptwurzel blind, oder

5. Wenn ein Zwischenstrang sich in die Hauptwurzel fortsetzt, verwandeln sich im Basaltheil der letztern die sänmtlichen Spiralgefässe desselben in poröse Gefässe.

6. Die meisten Spiralgefässe der Hauptstränge im Stengel rhalten im Basaltheil der Pfablwurzel poröse Verdickungen.

7. Die Gefässe der im hypocotylen Stengel tangential angerdneten primären Vasalstränge verändern beim Uebergang in die Wurzelstränge ihre Lage in der Weise, dass sie centripetal angeordnet erscheinen.

8. Entsprechend den im hypocotylen Stengel oft vorhandenen Zwischenstrangpaaren gehen im Basaltheil der Hauptwurzel nicht selten statt 4 Längsreiben von Nebenwurzeln deren 5 oder sogar $6 \mathrm{ab}$.

9. Die Nebenwurzeln, welche von der stengelsichtigen Partie des Basaltheils abgehen, legen ihre Gefässe nicht blos an einen einzigen Strang, sondern an zwei zusammengehörende Vasalstränge des Mutterorgans an.

10. Die stärkern Nebenwurzeln, welche dem Basaltheil der Hauptwurzel entspringen, zeigen meist in ihrem dem Mutterorgan zunächst liegenden Theile in Zahl und Anordnung der primordialen Vasalstränge Abweichungen, die bei den übrigen Nebenwurzeln nicht vorkommen.

11. Durch die Anwesenheit der Zwischenstränge bildet sich der primäre Holz- und Gefässring im Basaltheil der Hauptwurzel durch in tangentialer Folge entstebende Gefässe nicht blos von 4 (wie in der übrigen Wurzel), sondern von 5-8 Punkten der Markscheide aus.

12. Die Schliessung des primären Gefäss- und Holzringes geschieht hier zuerst und schreitet zunächst abwärts in den übrigen Theil der Wurzel fort, und bewcgt sich erst viel später aufwärts in den Stengel.

13. Der primäre dickwandige Bast des hypocotylen Stengels verliert sich im Basaltheil der Hauptwurzel vollständig, ohne in 
Verbindung mit den äquivalenten Bastträngen der Wurzel zu stehen, welche hier ihren Anfang nehmen.

14. Die sekundären dickwandigen Bastzellen des hypocotylen Stengels einerseits und der Wurzel anderseits verlieren sich ebenfalls im Basaltbeil der Hauptwurzel, ohne in einander überzugehen.

15. Die zahlreichen Gerbstoffgefässe des Stengels endigen blind beim Uebergang in die Hauptwurzel, um in letzterer nicht wieder aufzutreten.

16. Das Pericambium nimmt als integrirender Theil der Wurzel im Basaltheil seinen Anfang.

17. Die primäre Rinde, welche während der ganzen Lebensdaver der Pflanze die oberirdischen Axenorgane bekleidet, geht im Basaltheil der Wurzel zuerst zu Grunde, während die Schutzscheide auch hier zuerst verkorkt. Von hier aus schreitet dieser Process in die Wurzel fort und ist dieser eigenthümlich.

\section{Nach trag.}

\section{Einiges über zeitliche und räumliche Verhältnisse in der Entwicklungsgeschichte.}

Es ist schon lange bekannt," dass die Wurzeln hauptsächlich an der Spitze in die Länge wachsen. Nach der bisherigen Ansicht jedoch sollte die Längsstreckung, wenn auch nur in geringem Maasse, auch den nicht mehr ganz jungen Wurzeltheilen zukommen, in welchen selbstverständlich die scharfe Differenzirung der Elemente, also auch die charakteristische Zellwandrerdickung der Gefässe angenommen werden musste.

Durch zahlreiche Messungen der betreffenden Elemente bin ich zu dem Schluss gelangt, dass in den Wurzeln von Phaseolus keine einzige Gefässzelle sich nachträglich noch in die Länge streckt, sobald in ihr charakteristische Verdickungen der Wände auftreten, dass somit die Wurzeln der Phaseolus-Arten nur an demjenigen Theile in die Länge wachsen können, der vom Scheitel der Wurzel an bis zur ersten spiraligen Verdickung der primordialen Gefässe reicht. 
Wenn schon der Nachweis des Vorhandenseins von Spiralgefässen in einer zum Theil schon verholzten Wurzel auf Längsschnitten oft nicht leicht ist, so wurde es noch viel schwieriger, den Beweis zu leisten, dass die Gefässzellen der Wurzel, nachdem ihre Differenzirung aus dem Cambium durch die charakteristische Verdickung ihrer Wände sichtbar geworden, sich nicht mehr in die Länge dehnen, da es nnumgänglich nothwendig erscheint, die Gefässzellen in ihrem jüngsten und in ihrem spätesten Stadium zu messen, d. h. isolirte Gefässzellen von einem Ende bis zum andern in ihrer ganzen Länge zu Gesicht zu bekommen, was in hundert Fällen vielleicht nur ein Mal gelingt und immerhin vom glücklichen Zufall abhängt. Es gelingt dies bei den porösen, weitlichtigen, meist kürzern Gefässzellen weit eher, als bei den seltenen, sehr engen Spiralgefässen. Ungleich leichter sind die secundären Gebilde des Cambiums auf ihre Länge zu untersuchen, da sie um das Mehrfache kürzer sind, als die primordialen Ellemente. Bei den Spiralgefässen kommt freilich ein Umstand für die fragliche Entscheidung trefflich zu Hülfe. Sollte es auch gar nicht gelingen, Spiralgefässzellen der ganzen Länge nach sicher messen zu können, so dürfen wir doch aus der Aṇzahl der auf die Längeneinheit treffenden Knötchen schliessen, ob sich eine Spiralgefässzelle seit der Verdickung ihrer Wände bis zur völligen Verholzung noch in die Länge gestreckt hat, oder nicht. Jene Knötchen werden durch die spiraligen Verdickungsleisten der Gefässwände gebildet. Streckt sich eine Spiralgefässzelle nachträglich noch in die Länge, so müssen diese Spiralbänder nothwendig aus einander rücken. Dieser Umstand erleichtert die Entscheidung über die Frage der Streckung, kann aber nur dadurch zum schlagenden Beweis verhelfen, dass zahlreiche Messungen vorgenommen werden, da die Spiralgefässzellen von gleichem Alter, ja von gleichem Durchmesser und in derselben Höhe nicht genau gleich eng gewundene Spiralleisten besitzen, auch in den verschiedenen Individuen derselben Species in dieser Hinsicht mehr oder weniger variiren. Auch muss erwähnt werden, dass dieselbe Zelle auf verschiedenen Stellen in ihrer Längsansicht bald mehr, bald weniger Knötchen zeigt, indem oft eine einläufige Spirale in eine doppelläufige übergeht und umgekehrt. Es können auch zwei, sich unmittelbar an einander reihende, und zum gleichen Gefäss gehörende Zellen von verschiedenem Durchmesser und von verschiedener Länge sein.

In manchen Eällen ist mir auf guten Längsschnitten durch die 
Wurzelspitze gelungen, die letzte sichtbare spiralige Verdickung der primordialen Gefässzellen in einer Höhe zu bemerken, die blos um 800 oder 1000 , oder 1200 Micromillimeter vom Wurzelscheitel abstand. Von hier stammen die Messungen an den jüngsten Gefässzellen.

Im Folgenden gebe ich die Zusammenstellung der Resultate aus den zahlreichen Messungen, deren einzelne Details hier mitzutheilen ich für unnöthig erachte.

1. Die Anzahl der Knötchen auf je 32 Micromillimeter in der Längsansicht der Spiralgefässe variirt bei den ersten sichtbaren Verdickungen von 8-13.

2. Dieselbe Anzahl von Knötch'en findet sich auf derselben Strecke bei alten Spiralgefässen.

3. Der Durchmesser der Spiralgefässe, sobald man sie als solche erkennt, variirt von 5,1 bis 12,8 Micromillimeter; im arithmetischen Mittel beträgt dersejbe 9-9,5 Micromillimeter.

4. Zahlreichere Messungen von alten, ausgewachsenen Spiralgefässen ergaben ebenfalls ein Variiren ron 5,1-12,8 Micromillimer (in einem einzigen Fall 15 Micromillimeter), im arithmetischen Mittel 9-9,5 Micromillimeter.

5. Die Länge der in der Wurzel gemessenen Spiralgefässzellen variirt bei einem Durchmesser von 5,1 bis 12,8 Micromillimeter von 70,4 bis 700 Micromillimeter an 14 Zellen, deren Durchunesser im arithmetischen Mittel 9,5 Micromillineter und deren Länge im arithmetischen Mittel 335 Micromillimeter betrug.

6. Die Länge der engern porösen Gefässzellen, deren Durch. messer von 10-51 Micromillimeter gemessen, variirt an 14 Zellen von 153 bis 586 Micromillimeter. Das arithmetische Mittel aus den verschiedenen Durchmessern beträgt 29,2 Micromillimeter und dasjenige aus den verschiedenen Längen 337 Micromillimeter.

7. Von vielen gemessenen dickwandigen Bastzellen ergibt das arithmetische Mittel aus 9 verschiedenen Längen (variirend von 235 bis 866 Micromillimeter) - die gleiche Länge jeweilen an verschiedenen Zellen beobachtet - eine durchschnittliche Länge von 337.7 Micromillimeter, also die nämliche, wie bei den primordialen Spiral- und porösen Gefässen.

Aus diesen Thatsachen folgt mit Evidenz:

I. Die Spiralgefässe der Wurzel von Phaseolus dehnen sich nicht mehr, weder in die Dicke, noch in 
die Länge, sobald die charakteristischen Verdickungen der Zellwände sichtbar werden.

II. Die dickwandigen primären Bastzellen, die Spiralgefässe und die engsten porösen Gefässe der Wurzel werden zu gleicher Zeit angelegt; denn sie haben alle die gleiche durchschnittliche Länge.

III. Die Länge der primordialen Gefässzellen in der Wurzel steht zu ihrem Durchmesser in keiner Beziehung, wie dies im Stengel der Fall ist, indem dort die engsten Gefässe die kängsten, die weitern dagegen in der Regel die kürzern sind.

Die spiralige Verdickung der Primordialgefässwände in der Wurzel erfolgt in derselben Zelle nicht auf allen Stellen zugleich, sondern schreitet vom basiscopen Ende der Gefässzelle acropetal fort, was mehrere instruktive Längsschnitte durch die Wurzelspitze unzweifelhaft anschaulich machten. Es konnte nämlich in derselben Gefässzelle am basiscopen Ende die junge Spiralleiste deutlich gesehen werden, während sie in acropetaler Richtung an Deutlichkeit immer mohr einbüsste; dem entsprechend erschienen auch die Knötchen am basiscopen Ende in deutlichen Umrissen von der primären Zellwand abstehend, während sie in acropetaler Richtung immer kleiner und undeutlicher wurden und sich endlich in die unverdickte Wand der Zelle verflachten. Es rückt also die Spiralverdickung in den primordialen Vasalzellen langsam und continuirlich fort, nicht ruckweise von einer Zelle auf die ganze Länge der folgenden überspringend. Es hängt dies verschiedene Verhalten der Theile einer und derselben Gefässzelle wohl mit der Verschiedenhoit der umliegenden Gewebe zusammen. Während das eine Ende der primordialen Vasalzelle bereits Spiralleisten zu bilden beginnt, und von mehr oder weniger ausgebildeten Cambiumzellen umgeben ist, liegt das andere Ende der gleichen Zelle viel näher am Vegetationspunkt der Wurzel, wo alle Zellen noch in lebhafter Theilung und im Wachsthum begriffen sind. Dieses acroscope Ende der Gefässzelle wächst wohl noch bedeutend in die Länge, während das basiscope Ende mit eintretender Spiralleistenbildung sich nicht mehr dehnt. 
Wir haben früher schon erwähnt, dass im jungen Keimling die ersten Spiralgefässe sichtbar werden, wenn die Radicula 10-12 Millimeter lang geworden. Da im ausgewachsenen Zustande der hypocotyle Stengel eine Länge von 9-16 Centimeter besitzt, so folgt hieraus, dass sich die primordialen Gefässe des hypocotylen Stengels seit ihrer scharfen Differenzirung noch um das 10-20 fache in die Länge dehnen. Daraus erklärt sich, dass die primordialen Gewebe im hypocotylen Stengel sämmtlich ungleich mehr in die Länge gezogen sind, als in der Wurzel. Aus verschiedenen Messungen an Stengeltheilen geht hervor, dass auch hier die primären dickwandigen. Bastzellen sich zu gleicher Zeit aus dem Cambium differenziren, wie die primordialen Spiral- und Ringgefässe, während die secundär aus dem Cambium entstandenen Elemente bedeutend kürzer sind.

\section{Erklärung der Abbildungen.}

Fig. 1. Taf. XI. Darstellung des primordialen Gefässsystems von der Wurzel an bis in das erste Stengel-Internodium. Einfachster Fall, wie er an einer jungen Keimpflanze von Phaseolus erectus (var. nanus) beobachtet worden. Die Gefässstränge sind auf die eben gelegte Cylinderfläche des Fibrovasalkörpers projicirt und letzterer in Stengel und Wurzel von gleichem Durchmesser gedacht.

1. 2. 3. 4 - PrimordiaIstränge der Hauptwurzel.

B - Basaltheil der Hauptwurzel.

I. II. III. IV - die 4 Strangpaare des hypocotylen Stengels.

N. N N. N - Nebenwurzeln.

II. und IV - die Medianstrangpaare.

I. und III - die Lateralstrangpaare.

b. b. b. b. - die Mittellinien der Bastpartieen.

C. C. - Cotyledonen-Ansatz.

m. m - die Medianstränge der Primordialblätter.

$m^{1}$ und $m^{11}$ - die Theile eines Medianstranges, wie sie zwischen die Lateralstränge des hypocotylen Stengels treten und sich an dieselben anlehnen.

1. 1. 1. 1 - die Lateralstränge der Primordialblätter.

0. 0. 0. 0. - die Blattspurstränge aus der Region über den Primordialblättern.

Fig. 2. Darstellung des Gefässsystems einer jungen Keimpflanze von PhaseoIus vulgaris.

Bezeichnung wie in Fig. 1.

z. z - zwei Zwischenstrangpaare des hypocotylen Stengels, die nach Absendung einiger Nebenwurzeln im Basaltheil der Hauptwurzel blind endigen. 
Fig. 3. Darstellung des primordialen Gefässsystems der Hauptwurzel, des hypocotylen Stengelchens und des ersten Internodiums von einer jungen Keimptlanze (Phas. rulgaris), in der ein Zwischenstrangpaar $z^{1}$ nach Absendung einer Nebenwurzel im Basaltheil der Hauptwurzel blind endigt, während ein zweites Zwischenstrangpaar $z^{11}$ sich in einem Zwischenstrang der Hauptrurzel bis zur Wurzelspitze fortsetzt. Das erste Stengel-Internodium ist noch sehr rerkürzt.

P P - Ansatz der Primordialblätter.

Die übrigen Bezeichnungen wie in den vorhergehenden Figuren.

Fig. 4. Taf. XII. Darstellung des primordialen Gefässsystems einer jungen Keimpflanze ron Phas. vulgaris, die im Basaltheil der Hauptwurzel bereits einen goschlossenen Gefäss- und Holzring besass.

A. B. C bis V - die verschiedenen Höhen, aus welchen die Querschnitte stamm ten, nach welchen dies System construirt wurde.

B - Basaltheil der Hauptwurzel, von E bis $\mathrm{M}$ reichend.

5 - ein Zwischenstrangpaar, ron welchem 3 Nebenwurzeln abgehen.

y - ein Zwischenstrangpaar ohne Nebenwurzeln.

$\mathrm{x}$ und $\mathrm{z}$ - eiufache $\mathrm{Z}$ wischenstränge mit centrifugaler Gefässanordnung.

Sämmtliche Zwischenstränge verlieren sich im Holz- und Gefässring des Basaltheiles der Hauptwurzel, der hier durch Schraffirung angedeutet ist.

Fig. 5. Taf. XII. Schematische Darstellung des Ansatzes der primordialen Vasal- und Baststränge einer Nebenwurzel an diejenigen der Mntterwurzel.

P. P.. P. P. - die primordialen Vasalstränge der Mutterwurzel.

$\mathrm{B} \mathrm{B}$ - - - - Baststränge

$\mathrm{p}^{1} \mathrm{p} \mathrm{p}^{1} \mathrm{p}$ - die primordialen Vasalstränge der Tochterwurzel, von denen zwei, nämlich $p^{1} p^{1}$, in der gemeinsamen Axen-Ebene der LItter- und Tochterwurzel sich an den primordialen Vasalstrang der Mutterwurzel anlegen, während von den übrigen zwei der eine rechts, der andere links im Fibrovasalkörper der Mutterwurzel sich erst gegen den nächstliegenden Baststrang der letztern hin bewegt, um dann plötzlich, einen Winkel bildend, gegen den primordialen Vasalstreng abzubiegen. p p.

b. b. b. b - primordiale dickwandige Baststränge der Tochterwurzel, von denen zwei rechts und zwei links der gemeinsamen Axen-Ebene liegen und in sanften Bogen sich an die primären Baststränge der Mutterwurzel anlegen.

Fig. 6. Taf. XILI. Vergrösserung $\underset{\mathrm{f}}{2 n}$. Querschnitt. durch das erste, noch wenig verholzte Stengelglied über den Cotyledonen von Phaseolus vulgaris.

m m - Medianstränge der Primordialblätter.

1. 1. 1. 1. - Lateralstränge.

o. 0. o. o. - Blattspurstränge aus der Region über den Primordialblättern.

pr. R - Primäre Rinde.

d B - dickwandiger Bast.

GG - Gerbstoffgefässe.

M - hohler Markcylinder.

Fig. 7. Taf. XIII. ${ }_{1}^{2 n}$. Querschnitt durch den hypocotylen Stengel in der Nähe der Cotyledonen, von derselben Pflanze, wie das Objekt zu Fig. 6.

dB - dickwandiger primärer Bast, von einem Hauptstrangpaar bis zum andern reichend, in 4 Lamellen die Peripherie des Fibrovasalkörpers einnehmend.

hp. hp. hp. hp. - die Hauptstränge des hypocotylen Stengels, deren Gefässe in ihrer Anordnung etwas von der Tangente abweichen.

z z z z - Zwischenstränge des bypocotylen Stengels mit streng centrifugaler Anordnung. 
sp. sp. sp. sp. - Blattspurstränge aus der Region über den Cotyledonen, sich

an die Hauptstränge des hypocotylen Stengels anlehnend.

$\mathrm{sp}^{1}$ - die eine Hälfte des Medianstranges $\mathrm{m}$ in Fig. 6.

$\mathrm{sp}^{2}-$ die andere -

GG - Gerbstoffgefässe im primären Weichbaste.

Der Holzring ist bereits geschlossen; die Pfeile geben die Richtung an, in der sich die Vasalstränge entwickelt haben.

Fig. 8. Taf. XII. $\frac{332}{1}$. Fragment eines mit Kalilauge behandelten, tangentialen Längsschnittes aus dem Basaltheil des hypocotylen Stengels, die zierlich geschlängelten Zellwände der Schutzscheide darstellend.

Fig. 9. Taf. XIV. $\frac{86}{1}$. Fragment eines Querschnittes durch den hypocotylen Stengel eines sehr alten Exemplars von Phas. erectus (var. nanus), in halber Höhe des hypocot. Stengelgliedes.

M - Markparenchym, in welches die tangential angeordneten primordialen Ge-

fässe eines Hauptstrangpaares hereinragen.

GG - Gerbstoffgefässe.

dB - dickwandiger primärer Bast.

wB - Weichbaststränge.

Der Holzkörper ist von beträchtlicher Dicke, während der Phloemtheil nur wenig zugenommen hat.

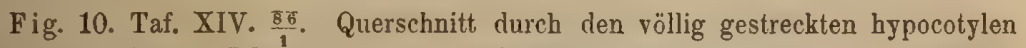
Stengel einer jungen Pflanze von Phas. vulgaris, in derselben Höhe, wie für Fig. 9.

P - tangential angeordneter primordialer Hauptstrang.

z - centrifugal angeordneter Zwischenstrang.

C - Cambium.

hh - Holzring.

wB - Weichbaststrănge.

GG - Gerbstoffgefässe.

dB - dickwandiger primärer Bast.

sch - Schutzscheide.

Fig. 11. Taf. XV. $\frac{205}{1}$, Radialer Längsschnitt durch einen primordialen Vasalstrang der jungen Phaseolus-Wurze], in der Nähe des Basaltheiles, wo bereits der Uebergang der centralen Holzzellen zum Markparenchym stattfindet. Erklärung vereint mit derjenigen für folgende Fig.

Fig. 12. Taf. XV. ${ }^{205}$. Querschnitt durch dieselbe Wurzel in derselben Höhe, wie der in Fig. 11 fragmentarisch dargestellte Längsschnitt; für Fig. 11 und 12 ist die Bezeichnung dieselbe.

$\mathbf{R}$ - primäre Rinde.

$\mathrm{pa}^{\mathrm{I}}, \mathrm{pa}^{2}$ und $\mathrm{pa}^{3}$ - die 3 innersten Rindenschichten.

st. st - Schutzscheide.

p p - die zwei über dem primordialen Vasalstrang liegenden Pericambiumzellschichten.

1. 2. 3. 4. 5. 6 - die in Fig. 12 centripetal auf einandor folgenden Gefässe des Primordialstranges, die im Längsschnitt (Fig. 11) wieder zu erkennen sind.

1 und 2 sind Spiralgefässe, die übrigen dagegen porös.

hhh - verholzte Zellen im Centrum der Wurzel, den Uebergang zum parenchymatischen Markgewebe bildend.

1 in Fig. 11 - luftführender Intercellulargang.

ccec in Fig. 12 - Cambiumzellen, die auch an dem in Fig. 11 dargestellten 
Längsschnitte bei höherer oder tieferer Einstellung als langgestreckte, an beiden Enden zugespitzte Zellen, die Gefässe umlagernd, erkannt werden.

wB in Fig. 12 - Weichbaststränge.

$\mathrm{dB}$ - primordiale dickwandige Baststränge.

Fig. 13. Taf. XVI. $\frac{205}{1}$. Fragment eines Querschnittes durch die junge Hauptwurzel mit beginnender Nebenwurzelanlage. Vergl. Fig. 20.)

st. st - Schutzscheide.

pppp - Pericambium über dem Primordialstrang der Hauptwurzel, durch einige

Zelltheilungen bereits nach Aussen bügelig angeschwollen.

Pc. Pe. Pericambium ausserbalb jener Wurzelanlage.

Fig. 14. Taf. XVIII. $\frac{86}{1}$. Querschnitt durch die Hauptwurzel eines sehr alten Exemplars von Phas. erectus.

Die primäre Rinde, pr. $R$, zum Theil vollständig verschwunden, nur noch in einzelnen Fetzen der Wurzel adhärirend.

sch - verkorkte Schutzscheide, noch unversehrt.

$\mathrm{dB}$ - primärer dickwandiger Bast.

sB - sekundärer dickwandiger Bast.

M. St - Markstrahlen, innerhalb welcher die primordialen Vasalstränge der Wur-

zel liegen. Im Centrum des Querschnittes liegt der erste Gefässkörper.

NW. - Nebenwurzel.

Fig. 15. Taf. XII. $\frac{30}{1}$. Querschnitt durch die Hauptwurzel von Phaseolus vulgaris. Uebersichtliche Darstellung des ganzen Schnittes, der in Fig. 12 nur fragmentarisch gezeichnet ist.

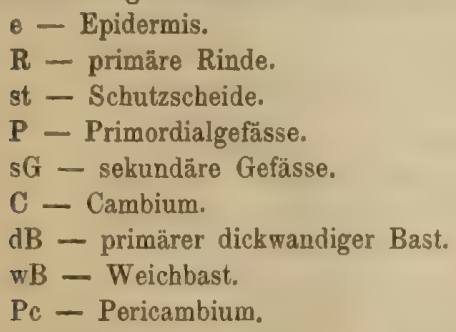

Fig. 16. Taf. XVI. $\frac{30}{1}$. Fragmentarischer Querschnitt durch die junge Hauptwurzel von Phas. vulgaris, mit einer jungen Nebenwurzel, welche bereits bis zur Epidermis der Hutterwurzel vorgedrungen ist. Die Zeichnung wurde nach einem mehrere Wochen in Glycerin gelegenen Objekt angefertigt, das den Zusammenhang der Wurzelhaube der Nebenwurzel mit der innersten Rindenschicht und der Schutzscheide der Mutterwurzel fast mit Sicherheit schliessen liess.

Wh. Wh - Wurzelhaube der jungen Nebenwurzel.

$\mathbf{v}-$ Vegetationspunkt

$\mathrm{xx}-$ die Uebergangsstellen der innersten Rindenschicht und der Schutzscheido der Mutterwurzel in die Wurzelhaubenschichten der Nebenwurzel.

ii - innerste Rindenschicht der Mutterwurzel.

p p. - Pericambium

ss - die Schutzscheidezellen der Mutterwurzel, die an der Basis der Nebenwurzel noch unzweifelhaft den erlittenen Zelltheilungsprocess zu erkennen gaben, wie erhellt aus folgender Figur.

Fig. 17. Taf. XVII. $\frac{200}{1}$, Die Basis der in Fig. 16 dargestellten Nebenwurzel hier stärker vergrössert und Zelle für Zelle nach dem Prisma gezeichnet. 
Wh. Wh - die bis zur innersten Rindenschicht ii und zur Schutzscheide ss der Hauptwurzel herabreichenden Zellschichten der Nebenwurzelhaube.

pp. - Pericambium der Matterwurzel.

Ueber den äussersten Primordialgefässen der Hauptwurzel hat bereits die Gefassbildung in der Nebenwurzel begonnen.

Fig. 18. Taf. XVIII. $\frac{30}{1}$. Querschnitt durch den Basaltheil der Hauptwurzel einer jungen Keimpflanze von Phas. vulgaris (Höhe K. Fig. 4), deren hypocotyler Stengel, noch wenig entwickelt, kaum die halbe Länge erreicht hatte. Hier findet sich schon ein geschlossener Holz- und Gefässring um den Markkörper, während im Stengel erst die primordialen Spiral- und Ringgefässe scharf differenzirt, aber noch nicht verholzt sind. 


\title{
Zur Blüthenentwicklung der Primulaceen und Ampelideen.
}

\author{
Von \\ Dr. W. Pfeffer.
}

Der ersten entwicklungsgeschichtlichen Untersuchung der Primulaceenblüthe begegnen wir bei $\mathrm{D}$ uchartre ${ }^{1}$ ), dem es besonders um den Nachweis der Axennatur der Placenta zu thun war. Ausserdem fand aber dieser Beobachter, dass die Corolle am Grunde eines früher angelegten Höckers sich bildet, welcher selbst direkt zum Staubgefässe wird. D u chartre spricht desshalb Corolle und Andröcum als einen Blattcyclus an und lässt ibre Entstehung durch „Dedoublement" zu Wege kommen. Später erklärte sich auch Wigand ${ }^{2}$ ) für einen genetischen Zusammenhang zwischen Blumen und Staubblatt; doch ist es diesem Forscher wahrscheinlicher, dass zuerst die Corolle entsteht und aus dieser die Staubgefässe als appendiculäre Organe entspringen. Die beiden eben erwähnten Anschauungen konnten in das herrschende morphologische Schema nicht wohl eingepasst werden und fielen um so mehr der Vergessenheit anheim, als späterhin Corolle und Andröcum der Primulaceen von $\mathrm{Payer}{ }^{3}$ ) und (ramer ${ }^{4}$ ) übereinstimmend als selbständige und acropetal aufeinanderfolgende Blattcyclen dargestellt wurden. Zweifeln an dieser Auffassung begegnen wir erst in jüngster Zeit bei $\mathrm{Hofmeister}{ }^{5}$ ), der, freilich nur auf Analogien hin vermuthet, dass die Blumenblätter nach dem Auftreten der Staubgefässe an der Blüthenachse intercalar. eingeschaltet werden.

Die gewöhnliche morphologische Betrachtung der Primulaceenblüthe werde ich später berühren ${ }^{6}$ ), hier sei aber noch einer Ar-

1) Annal. d. scienc. natur. 1844, 3 Ser. Tom II., p. 279 ff. u. Taf. VII. u, VIII.

2) Grundlegung der Pflanzenteratologie 1850, p. 21 Anmerkung.

3) Traité d'organog. comp. d. 1. fleur, 1857, p. 611 u. Taf. 153.

4) Bildungsabweichungen 1864, p. 132.

5) Allgem. Morphologie 1868, p. 504.

6) Erklärungen, wie sie für superponirte Wirtel von Agardh (Lehrbuch übers. v. Creplin 1832, II. p. 304) und Krause (Bot. Ztg. 1846, p. 1 ff.) versucht wurden, übergehe ich hier. 
beit von van Tieghem ${ }^{1}$ ) erwähnt, in welcher Staub- und Blumenblätter aus rein anatomischen Gründen für nur einen Blattwirtel angesprochen worden. Die absolute Unmöglichkeit Achse und Blatt nach der Anordnung der Gefässbündel in einen Kreis oder in eine Ebene zu unterscheiden, wie es in der citirten Arbeit geschieht, bedarf keiner weiteren Worte, selbst nicht für den, welcher Achse und Blatt für andere als durch willkührliche Definition abzugrenzende Organe hält.

Für die Ampelideen, bei denen Corolle und Andröcum gleichfalls superponirt sind, liegt nur Payer's ${ }^{2}$ ) Arbeit vor, welche auch hier selbständige und acropetal entstehende Blüthenwirtel vorführt.

Aus dem eben Gesagten erhellt, dass die Blüthenentwicklung der Primulaceen noch nicht als abgeschlossen zu betrachten war. Speciell für Corolle und Andröcum war die zeitliche Succession festzustellen, und traten die Blumenblätter später auf, so fragte es sich weiter, ob sie einen intercalaren Wirtel repräsentiren, oder zusammen mit den Staubgefässen nur einen Cyclus bilden. Ferner war die Bedeutung der sogenannten Staminodien, welche sich bei nur wenigen Primulaceen finden, zu ermitteln. Diese letzteren wurden, um hier gleich das Historische beizufügen, meines Wissens bisher ausschliesslich als ein episepaler mit Corolle und Andröcum alternirender Blattkreis angesprochen, welcher bei der Mehrzahl der Primulaceen abortire. ${ }^{3}$ )

Hanstein's Arbeit über die Scheitelzellgruppe im Vegetationspunkt der Phanerogamen veranlasste mich um so mehr meine Untersuchungen auf den ersten Ursprung der Organe im Gewebe zurückzuführen, als ich hoffen durfte, die fraglichen Punkte bestimmter beantworten zu können. Bei der Anfertigung dünner Schnitte wendete ich eine Methode an, welche sich so vortrefflich bewährte, dass ich nicht unterlasse, dieselbe hier zunächst anzugeben.

Die jugendlichen Inflorescenzen, von Blättern und Stengeln möglichst befreit, werden in eine Mischung von Alkohol und Glycerin (etwa 3:1 dem Volumen nach) gebracht und mindestens einige Tage zurückgestellt. Hat man eine grössere Menge Flüssigkeit angewandt, oder erneuert man dieselbe nach einiger Zeit,

1) Récherches sur la structure du pistill, in Annal. d. scienc. natur. 1868, p. $130 \mathrm{ff}$.

2) L. c., p. 457 u. Taf. 34.

3) So A. Braun, Verjüngungen p. 100. 
so lässt sich das Material beliebig lange conserviren und eignet sich eben so gut als frische Blüthen zum Studium der EntwickIungsgeschichte. Indem man den Alkohol freiwillig verdunsten lässt, bettet man die Inflorescenz in Glycerin ein, ohne dass hierbei die zartesten Gewebe beschädigt würden. Nun werden Blüthen entsprechenden Alters abgesucht, um sic in Gummi einzukleben. $\mathrm{Da}$ sie aber in diesem nur schwierig sichtbar sein würden, so färbt man dieselben vortheilhaft durch Zubringen von Anilinblaulösung, nimmt dann das Glycerin hinweg und setzt Gummischleim hinzu; alles Operationen, welche sich bequem und schnell auf einem Objektträger ausführen lassen. Ich verwende immer eine dicke Gummilösung, die mit einer geringen Menge Glycerin versetzt wurde, wodurch nicht nur das Sprödewerden ganz verhindert, sondern auch das Schneiden wesentlich erleichtert wird. Beim Einbetten der Blüthen in Gummi, welches in bekannter Weise ausgeführt wird, bringe ich jene in eine bestimmte Lage, welche ich genau markire, um beim Schneideu eine bestiminte Richtung einzuhalten.

So weitläufig diese Operationen erscheinen mögen, sie führen dennoch schneller zum Ziele, als das unsichere Schneiden durch ganze Blüthenstände, abgesehen davon, dass Schnitte von einer Feinheit, wie ich sie hier mit Sicherheit erziele, auf andere Weise nur durch Zufall zu erhalten sind. Wesentlicher aber ist die genaue Orientirung über die Lage des Schnittes, die bei successivem Abtragen genauest $z u$ ermitteln ist. Dabei sind die Gewebe so wenig collabirt, dass ein geringer Ammoniakzusatz ausreicht, um die natürlichen Formen wieder völlig herzustellen. Wiederholte Behandlung mit Kali und Salzsäure wird nur für dickere Schnitte erforderlich, deren Anfertigung übrigens, neben dünneren, wie Hanstein mit Recht hervorhebt, für die Untersuchung durchaus nothwendig ist.

Die Blüthen von Lysimachia quadrifolia - auf diese Pflanze bezient sich speciell die folgende Darstellung, wofern ich nicht andere Primulaceen namentlich anführe, - stehen ohne Vorblätter in der Achsel von Deckblättern, welche nach $\frac{3}{8}$ Divergenz an der Inflorescenzachse angeordnet sind. Wie es von Hanstein allgemein für den Ursprung seitlicher Sprossungen an Axen der Phanerogamen gezeigt wurde, ${ }^{1}$ ) wird auch die Anlage der Blüthen-

1) In Betreff des Scheitelwachsthums der Phanerogamen schliesse ich mich ganz der Auffassung Hanstein's an (die Scheitelzellgruppe im Vegetationspunkt der Pha- 
achse unserer Pflanze durch eine Allerwärtstheilung im Periblem der Inflorescenzachse eingeleitet, und zwar meist in Zellen der ersten, zuweilen indess auch gleichzeitig der zweiten Schicht dieses Gewebecylinders. Während die Blüthenachse als Hügel sich erhebt, theilt sich die Epidermis ausschliesslich durch Wände, welche senkrecht auf ihrer Innen- und Aussenfäche stehen. Die anderen Zellen des Hügels sind zuuächst noch ordnungslos gruppirt, scheiden sich aber weiterhin in den Pleromcylinder und das Periblema, welches als ein- bis zweischichtige Kappe jenen überzieht. Das Periblem theilt sich nun, ganz so wie es Hanstein zeigte, fast nur durch Wände, die zu seiner Innen- und Aussenfläche senkrecht gestellt sind, während diesen Flächen parallele Theilungen nur sehr vereinzelt getroffen werden. Auch die Gruppirung des Pleromgewebes in Reihen, welche gegen die Achseninitialen convergiren, stimmt mit Hanstein's Darstellung so überein, dass ich füglich auf dessen citirte Schrift verweisen kann.

Die Blüthenachse nimmt weiterhin cylindrische oder cylindrisclkeulenförmige Gestalt an, während noch geraume Zeit vor Anlage des Kelches sich einzelne Drüsenhaare an ihr entwickeln. Auf

nerogamen 1868). Die hiergegen von Pringsheim (Monatsb. d, Berl. Akad. 1869, p. 11.2) geltend gemachten Bedenken kann ich namentlich nach den neuen Arbeiten Hanstein’s (Monatsb. d. Niederrheinischen Gesellschaft, Sitzung voun 5. Juli und 2. Augnst 1869) nicht theilen. Die Bildungsvorgänge am Embryo und nicht minder das Wachsthum der Wurzeln finde ich nach eigener Untersuchung in der That so beweisend, dass ich eine andere als die Hanstein'sche Auffassung nunmebr für unmöglich halten muss. $\mathrm{Ob}$ nun, wie es übrigens wahrscheinlich, alle Plianerogamen in gleicher Weise wachsende Vegetationspunkte hahen, werden ausgedehnte Intersuchungen zu entscheiden haben; auch bei den Coniferen ist an den Axen eine Scheitelzelle vorhanden. Aber selbst der Nachweis einer Scheitelzelle bei irgeud welchen angiospermen Pflanzen würde durchaus nicht gegen Hanstein's Auffassung sprechen, eben so wenig, wie das gar nicht unmögliche Fehlen einer Scheitelzelle bei einzelnen Gefässcryptogamen Veranlassung geben kann, das bekannte Scheitelwachsthum anderer zu bezseifeln. Bei Lycopodiuzo ist aber eine Scheitelzelle noch nicht über allen Zweifel erhaben, und vielleicht wachsen die Wurzeln von Isoetes in ähulicher Weise wie die angiospermer Gewächse. Für die Wurzeln von Isoetes wird sogar von Nägeli und Leitgeb die Möglichkeit eines anderen Wachsthums als vermittelst Scheitelzelle ventilirt, und nur durch Analogien wurden diese Forscher zurückgehalten, eine der Hanstein'schen gleiche oder ähnliche Auffassung zu acceptirel. "Solche Ansichten, sagen sie (Beiträge z. wiss. Botanik Hft. IV., p. 136) würden vielmebr die Vermuthung nahe legen, als ob über dem selbständig fortwachsenden Cambiumcylinder zwei bedeutende Schichten sich befänden, deren innere die innere Rinde bilden würde, während aus der üusseren sich äussere Rinde mit Epiderwis und Wurzelhaube entwickeln könnte." 
dem Querschnitt ergicbt sich meist ein cylindrischer, selten cin etwas elliptischer Umfang, in welchem letzteren Falle die kleinste Achse mit der Medianebene der Blüthen und Inflorescenzachse zusammenfältt. Vermuthlich veranlasst ein geringer Druck, welchem gelegentlich die Blüthe zwischen Deckblatt und Inflorescenzachse ausgesetzt ist, diese leichte Compression, der wir übrigens in aufallender Form bei Glaux begegnen werden.

Die Anlage der Kelchblätter wird gleichfalls ron einer allseitigen Zelltheilung beglcitet, welche zumeist nur in der ersten Periblemschicht anhebt. Dic Herrorwölbung des Kelches und überhaupt aller Blattorgane der Blüthe wickelt sich dann allen wesentlichen Zügon nach in gleicher Weise ab, wie ich es eben für die Axe skizzirie; in allen Fällen überzicht die Epidermis als continuirliche Zellschicht die Sprossung. Die Differenzirung des inneren Blattgewebes in Periblem und Plerom aber unterbleibt entweder gänzlich, oder ist wenigstens so wenig ausgesprochen, dass ich es vorziehe, hier und bei anderen Blattorganen der Blüthe einfach ron Plerom zu reden.

Die Anlage der cinzelnen Kelchblätter folgt schr rasch aufeinander. Kaum sind alle fünf Blätter nach 2 Divergenz erschienen, da werden auch subon zwischen den ohnedies dicht aneinander grenzenden Blättern die trenuenden Stücke der Achse überbrückt (Taf. XXI. Fig.1 u.2). A uf dem nun geschlossenen Walle finden wir die Kelchblätter als fünf tangential gestreckteHöcker, deren relative Grösse meist unschwer die zeitliche Succession verräth(Taf.XXI.Fig.2). Uebrigens ist Duchartre's') Annahme, dass die Kelchlappen aus dem zuvor sich hervorschicbenden Ringwall ihren Ursprung nehmen, sehr erklälich, da der Turnus der Kelchblattanlage rapid durchlaufen wird und es schon einigen Suchens nach Entwicklungsstadien, welche nur ein oder cinige Blätter angelegt zeigen, bedarf.

Das crste Kelchblatt nimmt fast immer an der rechten Seite des Deckblattes seinen Ursprung und dic anderen folgen in linksläufiger Richtung. Ausser diesem trifft man übrigcus zuweilen auch rechtsumläufige Entstelıngsfolge, wobei dann das erste Kelchblatt am linken Ranie des Deckblattes zu liegen kommt. Solche Blüthen nehmen übrigens keine bestimmte Stellung ein, sonderu finden sich gelegentlich zwischen anderen, deren Blätter in rechtswendiger Succession entstehen.

1) L. c., p. 283. 
Die von dem eben angelegten Kelche umschlossenc Blüthenachse zoigt sich uns als cin sanft gewölbter Hügel mit ziemlich gleichförmig gekrümmter Oberfläche (Taf. XXI. Fig. 2). Der Scheitel des Hügels sistirt jetzt sein Längenwachsthum, während eine peripherische Zone als ein Ringwall emporschwillt, der in die Blüthenmitte allmählich verläuft, nach dem Kelche hin steiler abfällt (Taf. XXI. Fig. 3 bei $x$ ). Von der Fläche gesehen scheint zwar dieser Ringwall gleichförmig hoch zu sein, Längsschnitte zeigen indess, dass bereits die vol den Kelchbuchten liegenden Partien ein klein wenig im Wachsthum gefördert sind (Taf. XIX. Fig. 3 u. 4 bei st.n). Während sich an diesen fünf Stellen bald halbkugelige Höcker bemerk. bar machen, erheben sich die vor den Kelchlappen liegenden Stücke nicht weiter über das Niveau der Blüthenachse. Uebrigens springt die Blüthenachse in die Buchten des Kelches ein wenig hervor, so dass ihre Horizontalebene die F'orm einer schwach fünflappigen Scheibe zeigt, auf deren der Blüthenmitte fcrnsten Partien die vorgenannten Höcker ihren Ursprung nehmen (T'af. XXI. Fig. 4). Diese fünflappige Form der Blüthenscheibe tritt bei Primula acaulis und Androsace septentrionalis ein klein wenig markirter hervor als bei unserer Lysimachia.

Die vorerwähnten Höcker sind Blattprimordien, deren apicaler Theil ohne Aenderung der Wachsthumsrichtung zum Staubgefäss wird, während sich die Blumenblätter am Grunde der Aussenscite der Höcker als Auszweigung bilden, und zwar erst dann, wenn dic Primordien bereits anschnliche Grösse erreichten (Taf.XIX. Fig.2). Es erheben sich dann zu gleicher Zeit an allen Primordien, nahe über der Insertion des Kelches, tangential gestreckte Wülste, die in ihrer Mitte am weitesten hervorgeschoben sind, während sie nach beiden Seiten allmählich verlaufen, ohne dass übrigens zu dieser Zeit die trennenden, etwas tiefer liegenden Stücke der Blüthenaxe überbrückt wären, wie man sich an Längsschnitten leicht vergewissern kann.

Doch kehren wir nun zunächst noch einmal zu dem Ringwall zurick, welcher sich, wie wir sahen, baldigst nach Anlage des Kelches bildet. Stets wird die Anlage des fraglichen Walles durch eine allseitige Zelltheilung eingeleitet, welche gleichzeitig im ganzen Umfang der Blüthenachse, sowohl vor den Lappen als den Buchten des Kelches stattfindet (Taf. XIX. Fig. 3 bei x u. st.n). Gewöhnlich sicht man zuerst auf dem Längsschnitte zwei hintereinanderliegende Zellen der äusseren Periblemschicht durch ordnuigslos gestellte 
Wände getheilt, zuwcilen sind indess gleichzeitig Zellen der zwciten Periblemschicht in Mitleidenschaft gezogen worden. Die vor den Kelchlappen liegenden Stücke des Walles erheben sich fernerhin nicht weiter üher das Niveau der Blüthenachse, und hier trifft man denn auch, sobald die Primordien einige Böbe erreicht haben, ein mehr oder weniger dentliches ein- his zweischichtiges Periblema, dessen Zellen sich fast ausachliesslich durch Wände theilen, welche den Seitenwänden parallel gerichtet sind (Taf. XIX. Fig. 4 bei $x$ ).

Die Theile des Walles, welchen dic fünf Primordien entspringen, sind, wie gresagt wurde, schon unmittelbar nach dessen krscheinen ein klein wonig hö' er herrorgewölbt und hier theilen sich die Zellen lebhaftest weiter, wälurend Her Höcker hervorgeschoben wird. In diesem sind zunächst die Zellen noch ordnungslos gruppirt, stellen sich aber weiterhin in Reihen, welche gegen eine Initialgruppe, zuweilen rielleicht auch eine cinzelne Initiale conrergiren, die unmitteliar unter der Epidermis am Scheitel des Primordiuns gelegen ist (Taf. XIX. Fig. 5). Diese reibenförmige Anordnung der Zellen cntspringt als nothwendige Folge aus der Stellung neu auftretender Theilungswände. Es ist nämlich in dem Meristemhügel die bei weitem überwiegende Zahl aller Theilungen senkrecht gegen dessen Wachsthumsaxe gerichtet, während eben mit dieser parallel laufende Wände nur vereinzelt auftreten und in Folge dessen natürlich die Zabl der 7ellen auf dem Querschnitt nur langsam zunimmt. Dicse Zellreihen reichen aber herab bis auf das Niveau der Insertion des Kelclies, bis wohin sich also gleiche Wachsthumsbestrebungen thätig zeigen. Hieraus sind nun freilich niclıt dic Mittel zu zichen, ein Primordium schärfer zu begrenzen, als dies der äusseren Form nach möglich ist; indess haben wir doch hier eine weitere Bestätigung der Auffassung, welche die Gestalt dor fraglichen Primordien bei Primulaceen fordert, dass nämlich der Insertionsatrufien des Kelches lie untere äussere Begrenzung bildet. Dann aber sind die Blumenblätter ihrem morphologischen Werth nach Blattstrahlen, wic aus dem früher Gesagten folgt und wie wir es auch jetzt wieder sehen werden, wo wir die bei der Anlage thätigen Zelltheilungen betrachten wollen.

Es wurde schon gezeigt, dass die Blumenblätter nahe über dem Kelche als tangential gestreckte Wülste auftreten, und zwar zu einer Zeit, wo das Primordium bereits ansehnliche Höhe erreichte. Vor Anlage der Blumenblätter treffen wir auf axilen 
Längsschnitten, welche durch den Scheitel des Primordiums geführt wurden, die Zelles in mehr oder weniger deutliche Reihen geordnet (Taf. XIX. Fig. 5).

Etwas später sehen wir auf Längsschnitten an dem Ur'sprungsorte der Blumenblätter eine cinzelne oder $z$ wei übereinanderliegende Zellen allseitig getheilt (Taf. XX. Fig. 1, p.n). Diese Zellen liegen unmittelbar unter der Epidermis und gleichzeitig wird in dem ganzen Gewebestreifen, welchem die Blumenblätter entspringen, die Allerwärtstheilung in Scene gesetzt. Während sich nun die Blumenblätter schnell als deutliche Wülste hervorarbeiten, ergreift die allseitige Zelltheilung auch weiter nach Innen und auf ungefähr gleichem Querschnitt liegende Zellen des Primordiums. So finden wir denn die gleichsam nur hervorgestülpte Epidermis einen Wulst überziehen, welcher aus ordnungslos nebeneinanderliegenden Zellen gebildet wird, die sich aber auch hier, wie bei anderen Neubildungen, beim weiteren Heranwachsen der Blumenblätter in deutliche Längsreihen anordnen (Taf. XX. Fig. 2-4). Die unmittelbar unter der Epidermis gelegenen Initialen des Pleroms bilden längs des ganzen Randes des Blumenblattes eine continuirliche Zone, welche sich zu den scheitelständigen Initialen kegelförmiger Vegetationspunkte etwa so verhält, wic dic einzelne Scheitelzelle zu den Scheitelzellreihen bei Muscineen und Gefässcryptogamen.

Das Wachsthumsstreben der eben ins Lcben tretenden Blumenblätter ist mehr oder weniger senkrecht gegen die Axe des Primordiums gerichtet; während der weiteren Ausbildung krümmt sich indess die Corolle schnell aufwärts, indem die Zellen der Unterseite öfters durch zu den Aussenflächen senkrechte Wände getheilt werden, als dies auf der Oberseite stattfindet. Während dessen wird aber die Wachsthumsrichtung des Primordiums nicht wesentlich abgelenkt und dessen ganze übrige Partie zur Bildung des Staubgefässes verwerthet (Taf. XX. Fig. 4).

Ein Eingehen auf die weitere Ausbildung von Corolle und Andröcum liegt ausserıalb meines $Z$ weckes und es genügt, hier uur noch zwei Punkte kurz zu berühren. Die seitliche Verschmelzung der Blumenblätter geschieht durch Ueberbrückung der trennenden und etwas tiefer liegenden Achsenstücke, welche gleichfalls durch eine allseitige Zelltheilung im Peribleme der betheiligten, übrigens kurzen Strecken eingeleitet wird (Taf. XX. Fig. 4 bei p.u). Der Zeitpunkt dieses Vorganges tritt bei den Primulaceen mit langer Röhre (Primula acaulis) etwas früher als bei den kurzröhrigen ein. 
Wesentlich später werden dann anch Corolle und Andröcum auf gemeinschaftlichem Picdestal cinporgeschoben, ein Vorgang, der keiner weiteren Erörtcrung bedarf, da man, wic ich es gleich zeigen werde, die Corolle den stipulis adnatis, wenn man vou deren Zahl und Stellung absicht, vergleichen kann.

Es wurde schon gezeigt, wic die Wachsthumsrichtung der Primordien bei Ausbildung der Staubgefässe nicht abgelenkt wird, und wie also die Blumenblätter reine monopodiale Auszweigungen, Blattstrahlen, sind. Spccicller kann man aber die Corolle Stipularbildungen rergleicheu, wenn man die Hypericinee» zu Hülfe nimmt. Es ist nämlich für mich nach eigenen beiläufigen Untcrsuchungen an Androsacmum Rugellianum so gut wie gewiss, dass hicr Corolle und Andröcuın den gleichnamigen Organen der Primulaceen morphologisch gleichwerthig sind und auch Payer's ${ }^{1}$ ) Abbildungen lassen bei unbefangener Betrachtung kaum eine andere Deutung für die mit fünf Staubgefässbündeln versehenen Hypericineen zu. Bei dicsen aber nimut zunächst das Blumenblatt aus dein Grunde des Primordiums seinen Ursprung, und dann erst werden die Staubgefässstrahlen in basipetaler Folge angelegt. Das ist aber, wonn man Zahl und Lage ausser Acht lässt, dic Entwicklung cines mit Nebenblättern versehenen getheil. teu Blattes. Mit der Anlage der Corolle ist das Primordium in Ober- und Unterblatt gegliedert, ${ }^{2}$ ) an welchem ersteren ja auch die Blattstrahlen nicht bilateral gestellt sind, wic es bei zertheilten Laubblättern Regel ist, sondern nur auf der Rückenseite, wic bei der Melızahl verzweigter Staubgefässe ibren Ursprung nehmen. Wenn aber bei den Hypericineen Corolle und Andröcum einem getheilten Blatte mit freien Nebenblättern entsprechen, so darf man bei den Primulaceen dieselben Blüthentheile als Analoga ungetheilter Blätter mit sogenannten stipulis adnatis ansprechen.

Dic Entwicklungsgeschichte zeigt die faktisch spätere Anlage der Corolle $^{3}$ ) so evident, dass ich die gegentheiligen Angaber

1) L. c., Taf. I.

2) Eichler, zur Entwicklgesch. d. Blattes 1861, p. 8, 34 u. a. Ich halte mich hier an die leste Arteit über Blattentwiclilung, obgleich ich, was übrigens hier gleichgültig ist, mit Eichler's Ansichten üher Ober- um Unterblatt nicht ganz cinverstauden bin. Vergl. auch Wretschko in Sitzber. d. Wiener Akad. 1864: Entwickl. getheilter und gefiederter Blattformen.

3) Nach Caspary (Schrft. (1. phys.-ökon. Gies, zu Körigsberg 1861, p. 66) solleı auch bei Capsella bursa pastoris die Blumenblätler erst nach den Staubge- 
nicht weiter zu widerlegen brauche. Aber auch gegen die von Hofmeister ${ }^{1}$ ) ausgesprochene Vermuthung, die Corolle sei ein intercalarer Wirtel, muss ich dic vorgetragene Ansicht aufrecht halten, auf Grund der aus Form und Wachsthumsstreben entlehnten und vorhin angeführten Gründe. Da wir hier die Corolle aus den der Achse (mit Einschluss des Ringwalles) aufgesetzten Primordien ihren Ursprung nehmen sahen, so kann auch der Ringwall, den wir früher kennen lernten, die genetische Beziehung zwischen Staubgefäss und Blumenblatt nicht in Frage stellen. Der fragliche Wall ist nicht einmal eine specifische Eigenthümlichkeit der Primulaceen, soudern auch bei manchen anderen Pflanzen, z. B. Labiaten und Scrophularineen, schwillt der Insertionsring der Staubgefässe gleichzeitig mit deren Anlage wallförmig an. Auch den Ringwall, der bei Primulaceen nach Anlage des Kelches sich bildet, betrachte ich nur als eine Anschwellung der Achse, wobci es gleichgültig ist, ob diese, wie es wahrscheinlich, sich mit aktivem Wachsthum betheiligt oder nur gewissermassen passiv hervorgehoben wird. Ein gefördertes Höhenwachsthum ringförmiger Zonen findet sich aber an Blüthenachsen häufig genug, um die namentliche Anführung von Beispielen unnöthig zu machen.

Wie früher gezeigt wurde, wird die Erhebung des Ringwalles von einer allseitigen Zelltheilung in einer entsprechenden Strecke des Periblemas begleitet. Allein die Allerwärtstheilung ist ja nur als nächste Folge einer Wachsthumsbestrebung, die sich in anderer als der bisherigen Richtung geltend macht, aufzufassen; sie wird also eben so gut eintreten, wenn eine ringförmige Zone der Blüthenachse sich hervorwölbt, als wenn eine Neubildung sich hervorzuarbeiten beginnt. ${ }^{2}$ ) Selbstverständlich ist man nur dann berechtigt, in einer allseitigen Zelltheilung die erste sichtbare Anlage einer Sprossung anzusprechen, wenn es gelingt, jene gene-

fässen angelegt werden. Hier ist jedenfalls eine nochmalige Prüfung wünschenswerth, da auch bei anderen Cruciferen das Wachsthum der angelegten Blumenblätter zunächst in auffallender Weise gehemmt zu sein scheint (Iberis und Cheiranthus nach Eichler in Flora 1865, p. 518).

1) Allg. Morphol. p. 504.

2) Bei der sehr regelmässigen Theilung des Periblemas durch zur Aussen- und Innenfläche senkrechte Wände, mit denen nur seltenst den genannten Flächen parallele wechseln, ist anzunehmen, dass überall dort, wo sich Theilungswände allseitig stellen, wenn nicht Neubildung, so doch ein verändertes Wachsthumsstreben begann. Uebrigens bemerkt man fast immer gleichzeitig mit der Allerwärtstheilung eine, wenn auch nur leichte Heranwölbung an der Blüthenachse. 
tisch mit unzweifelhaften Entwicklungsstufen der Neubildung zu verknüpfen.

Dass die Corolle der Primulaceen einen anderen morpholugischen Werth als bei der Mehrzahl der Blüthenpflanzen hat, kann Bedenken gewiss nicht crregen, da es geradezu überflüssig wäre, aus der vegetativen Region Fälle anzufübren; wo morphologisch ungleichwerthige Organe denselben physiologischen Funktionen vorstehen und umgekehrt. Gleiches gilt aber auch für die Blüthe und rermuthlich weit häufiger: als bis jetzt bekannt ist. Es genüge, hier übrigens an Achsen und Blattpistill, an die terminalen Antheren von Mercurialis ${ }^{1}$ ), Casuarina ${ }^{2}$ ), Najas ${ }^{3}$ ) und Typha ${ }^{7}$ ) zu erinnern und nur die Familien zu bezeichnen, bei welchen mit grösserer oder geringerer Wahrscheinlicbkeit eine gleiche Entwicklung, wie bei den Primukaceen, für Andröcum und Corolle zu rermuthen ist. Für die den Primulaceen nächst verwandten Myrsineen sind mir keine Untersuchungen bekannt, hingegen stimmen die Plumbagineen wach Untersuchungen an Statice clongata, was Bildung von Andröcum und Corolle betrifft, mit den Primulaceen überein. Für die Plumbagineen hat übrigens Griesebach ${ }^{5}$ ) schon vor langer Zeit die Corolle als appendiculäres Organ nach entwicklungsgeschichtlichen Studien angesprochen und deshalb sogar diese Familie zu den Apetalen gestellt ${ }^{6}$ ). Ausser bei den schon vorhin besprochenen Hypericineen, dürften vielleicht auch bei Tiliaceen, Hermannieen und Lasiopetaleen Andröcum und Corolle zusammen einen Blattwirtel ausmachen. Für alle diese Familien gibt Payer acropetale Folge der Wirtel an, während Hofmeister ${ }^{2}$ ) in der Corolle einen intercalaren Blattwirtel siebt. Mir selbst stehen nur für Hermannia ${ }^{8}$ ) (venosa) unvollständige Beobachtungen zu Gebote, bei welcher Pflanze, wenn überhaupt Corolle und Andröcum auf einen Blattwirtel zurückzuführen sind, das Primordium sich dichotomisch verzweigen dürfte.

1) Roөper, Enumerat. Euphorbiar. 1824.

2) K auffmann, Bullet. d. l. Soc. Imp. Imp. de Moscou 1868, p. 374.

3) Magnus. Bot. Ztg. 1869, p. 769, Beiträge zur Kenntniss d. GattungNajas, 1870.

4) Rohrbach, Sitzb. naturf. Freunde in Berlin, 16. Nov. 1869.

5) Spicileg. florae Rumeliae et Bithynicae 1844, p. 295.

6) Barnéoud (Comptes rendus 1844, p. 262) und Payer (L. c. Taf. 153) geben hier gleichfalls acropetale Entstehung an.

7) Allgem. Morphologie, p. 467 u. 505.

8) Baillon (Adansonia Tom II., 1861, p. 176) bringt nichts Neues zu dem bereits durch Payer Bekannten. 
Bekanntlich nehmen zahlreiche Morphologen bei superponirten Blüthenwirteln das Fehlschlagen eines alternirenden Blattkreises an, welcher nach A. Braun ') bei den Primulaceen ein Blumenblattkreis sein soll, wie nach der verwandten Jacquinia (Theophrastaceen) und den Sapoteen geschlossen wird. Uebrigens erklärt sich C. C. Schimper ${ }^{2}$ ) ausdrücklich in solchen Fällen gegen die Schwindekreise, lässt vielmehr die superponirten Wirtel durch den Ausfall der Prosenthese entstehen.

Wie die Theophrastaceen haben auch einzelne Primulaceen (Samolus Valerandi, Lysimachia ciliata) fünf, zwischen den Staubgefässen der Blumenröhre inserirte corollinische Gebilde, sogenannte Staminodien, die, um es gleich vorauszuschicken, einen intercalar eingeschalteten Blüthenwirtel ${ }^{3}$ ) repräsentiren.

Bei Lysimachia ciliata treten die Staminodien erst dann in's Leben, wenn die anderen Blüthenwirtel nicht nur angelegt, sondern bereits weit entwickelt sind (Taf.XXI. Fig. 5 bei sta). Es beginnt danu eine allseitige Theilung in der unmittelbar unter der Epidermis liegenden Zellschicht, welcher die Erhebung von Höckern auf den Fuss folgt, die in tangentialer Richtung ein klein wenig gedehnt und auf gleichem Kreisbogen und alternirend mit den Staubgefässen gestellt sind: Die Staminodialböcker reichen bis an die Verschmelzungsstücke der Blumenblätter, ohne dass diese jedoch bei der ersten Anlage jener in irgend welcher Weise betheiligt wären, wenn wir auch bald die Staminodien dem kurzen Tubus der Corolle inserirt finden.

Ungleich früher treten die Staminodien bei Samolus Valerandi auf, und deren Vereinigung mit dem Tubus der Corolle tritt auch erst lange nach ihrer Anlage ein. Die Staminodien werden bestimmt erst nach Erhebung des Fruchtknotenwalles angelegt und nicht etwa, wie es Payer angibt, früher als dieser (Taf. 153 Fig. 20). Uebrigens sind Payer's Figuren, was die Stellung der Staminodien zu den Staubgefässen wenigstens anbetrifft, genau; nur trifft man dann und wann die Staminodialhöcker der Blüthenmitte ein klein wenig mehr genährt als die Staubgefässe. Bei dieser Pflanze kann

1) Verjüngung, p. 100. Ebenso $D$ öll in Flora v. Baden.

2) Geiger's Magazin für Pharmacie 1835, Bd 29, p. 41.

3) Intercalare Wirtel sind in den Blüthen nicht selten und meist auch von Payer richtig abgebildet, z. B. Zygophylleen, Geraniaceen, Oxalideen u. a. Auch bei Tropaeoleen sehe ich trotz Rohrbach's neuesten Erörteruugen (Bot. Ztg. 1869, No. 50 u. 51) nur einen intercalaren Wirtel. Vgl. Sachs, Lehrb. II. Aufl., p. 498. 
von eincm genetischen Zusammeuhang ron Corolle und Staminodialanlageu gar nicht die Rede sein, da zur Zeit, wo diese erscheinen, dic Blumenblätter eben erst gebildet wurden, untereinander aber noch nicht zusammenhängen, und ein die Staminodien durehschneidender Radius der Blüthenachse also crst am Kelch auf andere Blattorgane der Blüthe stösst. Aber auch mit dem Fruchtknoten stehen die Staminodien in keinem organischen $\mathrm{Zu}$ sammenhang; sie sind vielmehr ein selbständiger, intercalar gebildeter Blüthenwirtel. Als solcher brauchen die Staninodien in Bezichung auf die Staubgefässe weder einen äusseren, noch eineu inneren Wirtel darzustellen, ja ihr Auftreten zwischen deu Staubblättern w̦ird bei der gedrängten Stellung der Blüthenwirtel naturgemäss zu Stande kommen, wenn nicht durch entsprechendes intercalares Wachsthum neuer Raum an der Blüthenachse geschaffon wird, was aber hier, wenigstens in auffälliger Weise, nicht der Fall ist.

Es wurde schon angeführt, dass bei Samolus die Staminodialaulagen zuwcilen der Blüthennitte ein wenig näLeł stchen als die Staubgefässe; diese Stellungsdifferenz ist indess zu gering, um auf sic einigen Wcrth legen zu kömnen. Fänden wir aber bei nahe verwandten Pflanzen einen, den Staminodien entsprechenden Kreis hoher au der Achse inserirt oder gar durch einen acropetal ange. legten Wirtel rertreten, dann wären wir völlig berechtigt, die Staminodien der Primulaceen als cinen in Beziebung auf das Andröcum inneren Kreis zu betrachten, welchem seine Position zwischen den Staubgefässen durch dic Raumverhältnisse aufgedrängt wurde. Ich nuss mich jedoch mit üiesem Hinweis begnügen, da gerade für die Theophrastacecn, welche möglicherweise hier entscheidend wcrden können, entwicklungsgeschichtliche Untersuchungen fehlen. Das leuchtet jedoch ein, dass ein den Staminodieu entsprechender Kreis aller Wahrscheinlichkeit nach höher an der Blüthenachse auftreten wird, wenn er bei Pflanzen, welche Corolle und Andrö. cun in gleicher Weise wie dic Primulacecu bilden, aus dem Insertionsring der Staubgefässe rückt.

Bei Samolus und Lysimachia ciliata alterniren die Staubgefässe mit den Fruchtblättern ${ }^{1}$ ), ganz so wie bei anderen Primulaceen; was übrigens von vorn herein zu crwarten war, da ein

1) Wenigstens nach deu Fruchtklappeu zu schliessen; den Fruchtknoten fand ich hier nur als Ringwall angelegt. 
intercalarer Wirtel auf den Ursprung früher angelegter Kreise natürlich keinen Einfluss haben kann. ${ }^{1}$ )

Die weitere Entwicklung der schliesslich epigynisch werdenden Blüthe von Samolus ist von Payer ausreichend dargestellt. Hicr führe ich nur noch an, dass die Staminodion bei Samolus nicht nur relativ grösser als bei Lysimachia ciliata sind, sondern auch von cinem Gefässstrang durchzogeu werden, der bei letzterer Pflanze fehlt; frühere Anlage und höhere Ausbildung gehen also in diesem Falle Hand in Hand.

Die dargestellte Entwicklung der Staminodien und die nachgewiesene genetische Beziehung zwischen Andröcum und Corolle machen die Ansicht, die Staminodien seien der bei den meisten Primulaceen fehlschlagende, zwischen Staub- und Blumenblattwirtel liegende Kreis, zur Unmöglichkeit. Uebrigens füge ich noch hinzu, dass bei anderen Primulaceen (Primula acaulis, Lysimachia quadrifolia, Androsace septentrionalis) der Staminodialwirtel überbaupt nicht, auch nicht durch allseitige Zelltheilung (Lysim. quadrifol.) zu irgend einer Zeit angelegt wird. ${ }^{2}$ )

Nunmehr wende ich mich zu der blumenblattlosen Glaux, deren auch anderweitig interessante Blüthenentwicklung ich etwas eingehender behandeln muss.

Die Blüthen von Glaux maritima stehen in der Achsel ge-

1) Beachtenswerthe Stelluugsverhältnisse der Blüthe bieten uns die Hermanniaceae (Hermannieen und Lasiopetaleen). Das Blüthenschema der Hermannieen stimmt, wenigstens in der Stellung der Blattwirtel, ganz mit dem der Primulaceen überein, bei den Lasiopetaleen hingegen findet sich ein mit den Staubgefässen alternirender Kreis staminodienartiger Gebilde, der nach Payer (Traité d'organog. Taf. 9) acropetal angelegt wird, und mit diesem alterniren die Fruchtblätter, deren Ursprungsort also, gegenüber den Hermanuicen, um ibre halbe Divergenz seitlich verschoben ist. Vielleicht lernen weitere Untersuchungen bei den Lasiopetaleen oder anderen Familien sogar Wirtel kennen, die bei der einen Pflanze acropetal, bei einer anderen intercalar angelegt werden; Wirtel, deren Stellungsverhältnisse zu den Fruchtbläıtern besoñderes Interesse bieten würde.

2) Nach ran Tieghem (Anual. d. scienc. natur. 1868, p. 130 ff.) sollen die gegen die Buchteı der Corolle aufsteigenden Bündel eigentlich einem zwischen Blumenkrone und Staubgefässen liegenden und mit diesen alternirenden Wirtel zukommen, bei dessen Fehlschlagen aber für die Corolle verwerthet werden. Bei Samolus, wo der fragliche Schwindekreis, die sogeuannten Staminodien, vorhanden sei, soll das Gefässbündel auch diesem allein wirkjich zugehören. Diese Angabe ist aber faktisch unrichtig, da ganz wie hei anderen Primulaceen gegen jede Bucht der Corolle cin Bündel aufsteigt, sich unterhalb dieser gabelt und in jeden angrenzenden Kronenlappen cinen längs des Randes verlaufenden Strang sendet, hier aber noch zugleich einen anderen Strang in die der Corollenröhre inserirten Staminodien abgibt. Für Weiteres verweise ich auf van Tieghem's preisgekrönte Arbeit. 
wöhnlicher Laubblätter, an welchen sich eben so wenig, wie bei anderen Primulaceen, Vorblätter finden. Eine senkrecht zur Längsachse gelegte Ebene wird schon an der jugendlichen Blüthenachse nicht ron einem Kreise, sondern einer Ellipse unschrieben, deren längste Achse senkrecht gegen dic durch Deckblatt und Inflores. cenzachse g.legte Medianebene steht (Taf. XXII. Fig. 1). Diese Gestalt ist offenbar die Folge eines Druckes, welcher von der rinnenförmigen Inflorescenzachse einerseits und dem Deckblatt anderseits ausgeübt wird, ein Druck, der auch Ursprung und Entwicklung der Kelchblätter thätig beeinflusst.

Dic Anlage des Kelches wickelt sich, abgesehen von den gleich anzuführenden Stellungsabweichungen, wic bei Lysinachia quadrifolia ab. Das erste Kelchblatt kommt aber eben so oft an den rechten als an den linken Rand des Deckblattes zu liegen und so sind links- und rechtswendige Entstebungsfolge gleich häufig. Ess sind diese aber in keiner Weise von der Stellung der Blüthen zum Erdradius bedingt; denn an aufstrebend wachsenden Pflanzen fanden sich beide Wendungen ebensowohl, als an hingestreckten, und bei diesen war es für die Entstehungsfolge gleichgültig, ob die Blüthen auf einer dem Zenith, der Erde oder dem Horizont zugewandten Seite der Inflorescenzachse standen.

Das erste Kelchblatt steht vermöge seines Ursprungs gegen den Rand eines Deckblattes hin, an einer Partie der Blüthenachse, welche weder ron dem Deckblatt, noch von der Achse eng um. fasst wird. Das zweite Kelchblatt nimmt an der anderen nicht umfassten Partie der Blüthcuachse seinen Ursprung, was ohne Aenderung der Divergenz nur dann möglich ist, wenn die Achse schmächtiger bleibt, als es in der Regel der Fall ist, wo $\frac{2}{5}$ und mehr ihres Umfangs der rinnenförmig ausgehöhlten Inflorescenzachse angedrückt liegt. $\mathrm{Da}$ aber dennoch die erwähnte Stellung des zweiten Kelchblattes mehr oder weniger yollständig realisirt wird, so finden wir dieses um einen grösseren Divergenzwirtel als $144^{\circ}$ vom ersten Kelchblatt entfernt (Taf. XXII. Fig. 1 u. 2). In Folge dessen stehen nun die Kelchblättex 3 und 5 um weniger als $72^{\circ}$ sowohl von einander, als von 1 und $2 \mathrm{ab}$, während jedes dieser letzteren durch eine grössere Divergenz als $\frac{1}{5}$ vom vierten Kelchblatt entfernt ist. Ganz wie bei anderen Primulaceen verschmelzen die Kelchblätter baldigst nach ihrer Anlage mit ihren Seitenrändern; gleichzeitig beginnt aber das erste und zweite Kelchblatt den anderen so sehr in der Entwicklung vorauszueilen, wie es bei 
anderen Pflanzen derselben Familie vie vorkommt. Da die zurückbleibenden Kelchblätter aber diejenigen sind, welche dem von Deckblatt und Inflorescenzachse ausgeübten und in der Gestalt der Blüthenachse seinen unmittelbaren Ausdruck findenden Drucke ausgesetzt sind, so liegt die Vermuthung nahe, dass durch den Einfluss dieses auch das Wachsthum der fraglichen Kelchblätter aufgehalten wird. Dass aber in der zeitlichen Succession der Kelchblätter nicht allein die Ursache ihrer ungleichen Grösse liegen dürfte, wird weiter dadurch wahrscheinlich, dass die Grössendifferenz $z$ wischen den drei letztentstandenen Kelchblättern das bei anderen Primulaceen gewöhnliche Maass nicht überschreitet.

Auch an den Staubgefässen treten uns Verhältnisse entgegen, welche zur Bestätigung des mechanischen Druckeffektes dienen können. Wie bei den anderen Primulaceen schwillt nach Anlagre des Kelches eine peripherische Zone der Blüthenachse ein wenig wallförmig an, während gleichzeitig die Erhebung von fünf Höckern beginnt, welche den Primordien ganz entsprechen, hier aber nie Blumenblätter aus sich heraus bilden. Diese Höc'zer entstehen simultan und ziemlich genau vor den Kelchbuchten ${ }^{1}$ ), sind deshalb also gleichfalls durch ungleiche Divergenzen von einander entfernt, und zwar muss die seitliche Entfernung für die zu beiden Seiten des vierten Kelchblattes liegenden Staubblätter am grössten sein (Taf. XXII. Fig. 2). Das zwischen dem dritten und fünften Kelchblatt seinen Ursprung nehmende Staubgefäss kommt mehr oder weniger genau in die Mediancbene der Blüthe zu liegen, welche Ebene zugleich die Richtung der rom Deckblatt und Inflorescenzachse ausgeübten Pression bezeichnet. Das eben genannte Staubgefäss ist meist schon seiner Anlage nach etwas kleiner als die übrigen, gegenüber denen es im Verlauf seiner weiteren Entwicklung gewöhnlich noch merklicher zurückbleibt; der Regel nach trifft man die Anthere in der Knospenlage, seltener auch noch nach dem Aufblühen, wesentlich kleiner (Taf. XXII. Fig. 4B). Die übrigen rier Staubgefässe zeigen keine auffallenden Grössenunterschiede, stehen aber auch so an der Blüthenachse angeordnet, dass sie gleich intensiven Druckverbältnissen unterworfen sein dürften.

Da nach dem Aufblühen Blüthenachse und Kelch mehr oder weniger Cylindergestalt und die Saumlappen annähernd gleiche

1) In Kocb's Synopsis und Hofmeister's Morphologie (p. 458) werden irrthümlicher Weise die Staubgefässe opponirt (superponirt) genannt. 
Grösse haben, so müssen nothwendig verschicdenc Stellen der Blüthe ungleich stark gewachsen sein. Wie aber aus den angeführten Stellungsverhältnissen von Kelch und Staubgefässen folgt, muss namentlich auf der Deckblattseite ein überwiegendes Wachsthum in tangentialer Richtung an Blüthenachse und Kelch thätig gewesen sein.

Bei Glaux werden, wie ich schon sagte und auch Hofmeister ${ }^{1}$ ) hervorhebt, die Blumenblätter nic angelegt. Die fünf Höcker, welche endlich zu den Staubgefässen werden, gleichen hier in jeder Weise, sowohl der äusserlichen Form, als dem inneren Baue nach, den entsprechenden Primordien anderer Primulaceen, bis auf den Punkt, dass bei Glaux auch nicht einmal cine allseitige Zelltheilung auf Anlage der Blumeublätter schliessen lässt, dass sich das ganze Primordium zum Stanogefässe umbildet (Taf. XXII. Fig. 3).

Der Fruchtknoten erhebt sich bei Glaux immer als gleich hoher Ringwall, wie es übrigens auch meist bei Lysimachia quadrifolia der Fall ist, bei welcher man indess zuweilen auch drei, selten vier oder fünf Particen des Walles höckerartig hervorstelıen sicht. Noch augenfäliger tritt dies gelegentlich bei Primula elatior und chinensis herror, bei welchen kein $\mathrm{Z}$ weifel bleiben kann, dass man es hier mit fünf, mit den Staubgefässen alternirenden Blattorganen $\mathrm{zu}$ thun hat. Indem ich hier noch bemerke, dass auch die Anlage des Fruchtknotens der Primulaceen mit einer allseitigen Zelltheilung in der ersten Periblemschicht anhebt, dass dessen Plerom weiterhin von einer ringförmigen Zone von Initialen gekrönt ist, verweise ich auf Duchartre's und Payer's mehrfach citirte Arbeiten, welche die Entwicklung von Fruchtknoten und axiler Placenta ausführlich behandeln. ${ }^{2}$ ) Ueber dic ovula, die hicr den morphologischen Werth eines ganzen Blattes haben, sind wir durch Cramer $^{3}$ ) ausführlich unterrichtet; ich füge nur noch hinzu, dass auch die Anlage der Eichen mit ciner Allerwärtstheilung im Periblema anhebt.

Bei Glaux alterniren also sämmtliche drei Blattwirtel der Blüthe. Indem nun das bei dieser Pflanze zum Staubgefäss wer-

1) Allg. Morphologie, p. 547. Anmerkung.

2) Lestibudois' Versuch, die Placenta der Primulaceen als aus Blätern verschmolzen zu betrachten, darf man wohl mit Stillschweigen übergehen. Compt. rendus 1869 , p. $845 \mathrm{ff}$.

3) Bildungsabweichungen 1864. 
dende Primordium eine Auszweigung, das Blumenblatt, producirt, kommen wir zun Blüthenschema der Mehrzahl der Primulaceen, das bei wenigen Pflanzen dieser Familie noch um den zwischen den Staubgefässen intercalar gebildeten Wirtel, dic sogenannten Staminodien, vermehrt wird.

\section{Ampelopsis hederacea.}

Die Inflorescenzachse der Robe ist nicht, wie seit Turpin allgemein angenommen wurde, sympodialen Ursprungs, sondern, wic Nägeli $\left.{ }^{1}\right)$ zeigte, ein monopodial, aber olıne Deckblatt entstehender Spross. Hingegen ist die zusammengesetzte Blüthentraube ein Syıpodium. Dic Achse schliesst mit einer Blüthe $a b$, die von einem Deckblatt und zwei, selten auch drei oder vier Vorblättern gestützt wird; jedes Vorblatt wird zum Deckblatt einer nenen Blüthenachse, deren Vorblätter dasselbe Spiel wiederholen.

Die Blüthenentwicklung von Ampelopsis stimmt wesentlich mit der Weinrebe, wєlche Payer ${ }^{2}$ ) behandelte, überein. Ich kann mich deshalb kurz fassen, indem ich nur Corolle und Andröcum, welche hier als zwei acropetale und superponirte Wirtel gebildet werden; sorgfältiger behandle.

Die Anlage der Blüthenachse wird, wie bei Primula, von einer allseitigen Zelltheilung, die meist gleichzeitig Zellen der ersten und zweiten Periblemschicht trifft, begleitet. In der heranwachsenden Achse sind die gegen die Initialen hinzielenden Reihen des Pleromkörpers in die Augen springender, als bei Primula, und auch zwei, selten drei Lagen von Periblem sind meist deutlich abgegrenzt zu bemerken.

Die Zelltheilungen bei Anlage des Kelches treffen Zellen der ersten, zuweilen auch gleichzeitig der zweiten Periblemschicht. Die einzelnen Kelchblätter folgen nach $\frac{2}{5}$ Divergenz auf einander und verschmelzen unmittelbar nach ihrem Erschoinen.

Nach Anlage des Kelches ist die Blüthenachse ein sanft gewölbter Hügel, an dem nun dicht vor dem Kelche und alternirend mit dessen Blättern die fünf Blumenblätter ihren Ursprung nehmen (Taf. XXII. Fig. 5 u. 7). Es bilden diese tangential gestreckte Wülste,

1) Beiträge z. wiss. Bot. I., p. 88, Mikroskop 1867, p. 605 .

2) Traité d'organogénie Texte p. 157 und Taf. 34. 
welche wit ibren Seitenrändern sich $z$ war fast berühren, nie aber mit einander verschmelzen (Taf. XXII. Fig. 7). Wenn die Blumenblätter bereits ansehnlich herrorgewachsen sind, erscheint vor jedem derselben ein halbkugeliger Höcker, der angenscheinlich seinen Ursprung aus der Blüthenachse nimmt und in keiner genetischen Beziehung zu rlem Blumenblatt steht (Taf. XXIJ. Fig. 6 u.7). Dies zeigt sich dann bei näherem Eingehen auch völlig begründet. Die Blumenblätter beginnen 'mit einer allseitigen Zelltheilung, ganz wie das beim Kelch der Fall ist, ihre Aulage und wachsen dann schnell hervor, während sich dentliche, wach dem Scheitel convergirende Zellreihen ausbilden. Unmittelbar vor len Blumenblättern aber bleibt das Gewebe der Achse ungestört; auf zwei meist sehr markirte Periblemschichten folgen gegen das Plerom undeutlich abgegrenzte Zelllagen. In der ersten und oft auch gleichzeitig in der zweiten Poriblemschicht beginnt nun die allseitige, die Staubblätter anlegende Theilung, und zwar in Zellen, welche von dem Wachsthumsbestreben des Blumenblattes in keiner Weise afficirt wurden (Taf. XXII- Fig. 8).

Während bei einer grösseren Zahl von Pflanzen die Staubgefässe, einmal angelegt, schneller als die Corolle wachsen, eilt hier diese jenen auffallend voraus. Anstatt des im Wachsthum zurückbleibenden Kelches scheint hier die Blumenkrone die Rolle des Schutzes für die geschlechtlichen Blüthentheile zu übernehmen, was sie um so vollständiger erreicht, als ihre Blätter an der Spitze nach rorn umschlagen, mit den eingeschlagenen Partien sich an einander legen und endlich durch eine schleimige Masse fest verbunden werden.

Später, wenn schon die Staubgefässe zu ansehnlicher Höhe herangewachsen sind, beginnt in einer der Blüthenmitte näher liegenden ringförmigen Zone des Pcriblema's eine allseitige Zelltheilung (Taf. XXI. Fig. 6), und ihr auf den Fuss folgt die Erhebung des Fruchtknotens in Gestalt eines aus zwei Stücken gebildeten Ringwalles. Für Weiteres rerweise ich auf Payer, bei welchem auch nachzusehen ist, wie der drüsige Discus sich erst späterhin am Grunde des Fruchtknotens bildet. Hier sei uur noch bemerkt, dass ein zwischen Blumenblättern und Staubgefässen liegender, alternirender Wirtel, der nach A. Braun ${ }^{1}$ ) ein Staubfadenkreis sein soll, auch ảurch allseitige Zelltheilung niemals angedentet wird.

1) Verjüngung, p. 100. Ebeuso auch Döll in Flora von Baden 1862, p. 1188. 
Wie bei den Ampelideen dürften auch bei Rhamneen, ferner bei Santalaceen, Chenopodeen, Proteaceen u. a. superponirte Wirtel acropetal entstehen, eine Vermuthung, die freilich erst durch specielle Untersuchungen zu bestätigen oder zu widerlegen ist. ${ }^{1}$ ) Wenn nun hier-auch eine Ausnahme von der Regel der Wirtelalternation vorliegt, so ist doch am wenigsten die Berechtigung gegeben, durch willkührliches Einführen von Schwindekreisen allgemein gültige Gesetze aus blossen Regeln zu construiren. Ueberdies ist die Zulassung eines materiellen, aber sich unsichtbar abwickelnden Abortus, zu dem schon De Candolle als letzte Instanz seine Zuflucht nahm, von einer auf Empirie zu gründenden Morphologie durchaus unzulässig. Eine andere bestimmte Bedeutung wird aber dem Abortus vom Standpunkt der Descendenztheorie zu Theil. Eben so gut, wie von dieser Seite zugegeben werden muss, dass einzelne Glieder, Wirtel u. s. w., die früher gar nicht vorhanden waren, auftreten konnten, eben so gut muss auch zugestanden werden, dass vorhandene Glieder, Kreise u. s. w. unterdrückt werden konnten. Hierbei konnte natürlich die Unterdrückung eine so vollständige sein, dass auch nicht die leiseste Spur einer Wachsthumsbestrebung übrig blieb, dass die Glieder faktisch verloren gingen. ${ }^{2}$ ) Natürlich können morphologische Gesetze und Regeln auch nicht auf theoretischen Betrachtungen dieger Art, sondern nur auf dem Boden der Thatsachen errichtet werden.

Es eriibrigt nur noch, Herrn Professor Wigand, meinem verehrten Lehrer und Freunde, für die freundliche Unterstutzung, die er mir bei Ausfuhrung dieser Arbeit angedeihen liess, meinen besten Dank auszusprechen.

Marburg, Ende Juli 1869.

1) $\mathrm{Zu}$ vergleichen Payer's Traité d’organogénie und für Santalaceen auch Baillon, Traité du développement d. 1. fleur et du fruit. I. Livr. 1868.

2) Aehnliches ist zu wiederholten Malen von Sachs (Lehrbuch, II. Aufl.) in den vortrefflich behandelten Kapiteln über Morphologie ausgesprochen; so z. B. p. 200 u. 495 . 


\section{Erklärung der Abbildungen.}

Sämmtliche Figuren sind mit Hülfe der Oherhäuser schen Camera entworfen. Bei allen bezeichnet: sp. Kelchblatt, p. Blumenblatt, st. Staubgefäss, g. Fruchtknoten und sp.n., p.n., st.n, g.n. die hei Aulage genannter Blïtbenorgane allseitig getheilten Zellen; sp.u. und p.u. die Verschmelzungsstïcke der Kelch- und Blumenhlätter, c. Placenta, b. Braktee, ax. Blüthenachse, ax.i. Inflorescenzachse.

\section{Taf. XIX. Lysimachia quadrifolia.}

Fig. 1. Eine schon weiter entwickelte Blüthe nach Entfernung des Kelches schräg ron der Seite gesehen. Die einzelnen Blumenblätter sind zu dieser Zeit noch nicht verschmolzen.

Fig. 2. Längsschnitł durct eine Blüthe, an welcher eben die Blumenblätter auftraten. Der rechte Höcker ist genau median, der linke an einem Seiteurande durchschnitten.

F́ig. 3. Dünner Längsschnitt durch die Mediane einer Blüthe, an welcher eben der Ringwall sich zu bildeu beginut. Vor den Kelchbuchten (sp.u.) sowohl, als vor den Kelchlapnen hat eine allseitige Zelltheilung stattgefunden (bei st.n. und X.).

Fig. 4. Weiter entwickelte Blüthe als 3. im Längsschnitt.

Fig. 5. Längsschnitt durch einen weiter entwickelten Höcker vor Anlage des Blumenblattes.

\section{Taf. XX. Lysimachia quadrifolia.}

Fig. 1. Längsschnitt durch einen Höcker, in welchem das Blumenblatt ehen durch allseitige Zelltheilung angelegt wird.

Fig. 2. Weiter entwickeltes Stadium als Fig. 1. Das Blumenblatt ist schon als Höcker hervorgewölbt, der Fruchtknoten wird durch allseitige Zelltheilung angelegt.

Fig. 3. Ein noch älteres Stadium als Fig. 2. - Das Blumenblatt ist bereits ansebnlich gewachsen.

Fig. 4. Ein sehr gelungener Längsschnitt durch eine Blïthe, in welcher alle Organe bereits ziemlich weit entwickelt sind und die Verschmelzungsstücke der petala eben mit einer allseitigen Zelltheilung ihre Entstehung beginnen.

\section{Taf. XX . Lysimachia quadrifolia.}

Fig. 1. Blüthenachse, an welcher das erste und zweite Kelchblatt angelegt sind und an welcher der Ursprungsort des dritten gerade bemerklich wird, von oben gesehen.

Fig. 2. Der Kelch ist fertig angelegt und die einzelnen Blätter sind mit ihren Seitenrändern verschmolzen. 
Fig. 3. Der Ringwall hat sich gebildet; der Kelch ist zurückgelegt.

Fig. 4. Der Kelch ist ausgebreitet; die fünf mit dessen Zipfeln alternirenden Höcker sind erschienen.

\section{Lysimachia ciliata.}

Fig. 5. Der Kelch ist weggeschnitten, ebenso sind die Staubgefässe, deren Filament sich eben abzugrenzen beginnt, weggebrochen (bei st.). Zwischen den Staubgefässen erscheinen die Staminodien sta.

\section{Ampelopsis hederacea.}

Fig. 6. Dünner Längsschnitt durch eine Blüthe. Der Kelch murde nicht gezeichnet, die Blumenblätter (p.) sind bereits weit entwickelt; vor den Staubblättern beginnt die Anlage des Fruchtknotens mit einer allseitigen Zelltheilung (bei g.n.). y

\section{Taf. XXII. Glaux maritima.}

Fig. 1. Blüthenachse, an welcher alle Kelchblätter angelegt sind, von oben gesehen.

Fig. 2. Ebenso nach Hervorbildung der Staubgefässe.

Fig. 3. Ein schon ziemlich weit entwickelter Staubblatthöcker im Längsschnitt. Von einer Blumenblattanlage ist nichts bemerkbar.

Fig. 4. Querschnitte einer mittelalten Knospe. - A. Dicht über der Insertion von Kelch und Staubgefäss an der Achse. - B. Durch den freien Saum des Kelches und die Antheren.

\section{Ampelopsis hederacea.}

Fig. 5. Die Blüthenachse nach Anlage des Blumenblattes median durchschnitten.

Fig. 6. Wie vorher nach Anlage der Staubblätter.

Fig. 7. Eine Blüthe, an welcher der Kelch abgeschnitten ist und Blumenblätter und Staubgefässe aufgetreten sind, von oben gesehen.

Fig. 8. Theil eines medianen Längsschnittes. - Vor den Blumenblättern werden die Staubgefässe durch eine allseitige Zelltheilung angelegt. 


\section{Ueber die Veränderung der Lage der Chlorophyll- körner und des Protoplasmas in der Zelle, und deren innere und äussere Ursachen.}

Von

B. Frank.

Früher galt es für eine feststehende Thatsache, dass die Chlorophyllkörner ausser in denjenigen Fällen, wo sie durch ein in Rotation begriffenes Protoplasma mitbewegt werden, ihre Lage

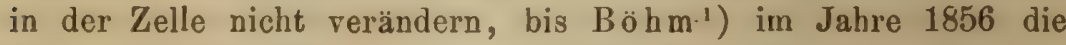
Beobachtung publicirte, dass in den Blattzellen verschiedener Crassulaceen die Chlorophyllkörner sich binnen Kurzem zu einer Gruppe vereinigen, wenn die Pflanzen oder auch nur Präparate davon zur Mittagszeit den direkten Sonnenstrahlen ausgesetzt werden. Ferner wurde vor einigen Jahren von Famintzin ${ }^{2}$ ) die Entdeckung gemacht, dass in den Blattzellen einer Mnium-Art die Chlorophyllkörner bei Beleuchtung unter der oberen und unteren Wand der Zelle liegen, bei Verdunkelung aber auf die schmalen Seitenwände sich begeben, mit welchen die Zellen unter sich im Verbande stehen, und diese Lage so lange beibehalten, als sie sich in der Dunkelheit befinden, bei Wiederbeleuchtung aber wieder in die alte Lage rücken. Und daran schlossen sich alsbald Borodin's ${ }^{3}$ ) Angaben, nach denen die gleiche durch den Wechsel von Licht und Dunkelheit bedingte Wanderung der Chloro. phyllkörner auch in den Zellen mancher Farnprothallien, sowie der Brutknospen von Marchantia polymorpha zu beobachten ist. Auf der Versammlung deutscher Naturforscher und Aerzte zu

1) Beiträge zur näheren Kenntniss des Chlorophylls. Sitzungsber. d. K, Akad. der Wissensch. 22. Wien 1857 , p. 510-512.

2) Pringsheim's Jahrbücher IV. p. $49 \mathrm{ff}$.

3) Bull, d. lacad. imp. de St. Petersbourg. Tom IV. (1867), p. 482. 
Dresden im Jahre 1868 wurde von A. Braun die Mittheilung gemacht, dass Kny eben solche Bewegungen an den Vorkeimen von Osmunda aufgefunden habe, und ich machte daselbst darauf aufmerksam, dass sie auch den Blattzellen folioser Jungermannien eigen sind und an diesen sogar von völlig etiolirten Körnern ausgeführt werden können, worauf ich die Vermuthung gründete, es möchten diese Lagenveränderungen wohl im Grunde nichts als plasmatische Bewegungen sein. Schon kurz vorher war aber eine ähnliche Vermuthung über die Ursache dieser Bewegungen von Sachs ${ }^{1}$ ) ausgesprochen worden, welche in den folgenden Mittheilungen ihre Bestätigung finden wird. Sie lautet: "Da nun die Chlorophyllkörner in dem farblosen Protoplasma eingebettet sind, so wird wohl... diese Wanderung der Chlorophyllkörner auf einer vom Lichtwechsel veranlassten Bewegung des letzteren beruhen, durch welche die grünen Körner passiv mit fortgeführt werden."

Die vorhandenen Kenntnisse über die Wanderung der Chlorophyllkörner schienen mir in hohem Grade einer Erweiterung fähig zu sein. Denn einmal musste die von $S$ achs ausgesprochene Vermuthung die Anregung geben, die Beziehungen der Chlorophyllbewegungen zum Protoplasma genauer zu untersuchen. Dann giebt es hinsichtlich der Ursachen dieser Bewegungen noch viele offene Fragen: die Beobachter, die sich bis jetzt mit diesem Gegenstande beschäftigten, hatten nur die Wirkung des Lichtes im Auge; es ist noch nicht die Frage gestellt worden, ob nicht auch andere Agentien ähnliche Wirkungen auszuüben im Stande sind. Ja es fehlt auch nicht an Angaben, welche sich den Anschauungen, die man sich gegenwärtig von der Sache gebildet hat, nicht recht fügen wollen. So giebt, was von allen späteren Schriftstellern unberücksichtigt gelassen worden ist, $\mathrm{B} \ddot{o} \mathrm{hm}^{2}$ ) an, dass die Vereinigung der Chlorophyllkörner in Gruppen, wie er sie an den den direkten Sonnenstrahlen ausgesetzten Crassulaceen beobachtete, auch an Präparaten nach mehreren Stunden erfolgte, während dieselben in einem vollkommen dunkeln Raume sich befanden.

Derartige Fragen und Bedenken mögen es rechtfertigen, dass dieser Gegenstand nochmals zur Untersuchung vorgenommen worden ist. Die Ergebnisse derselben sollen im Nachfolgenden mitgetheilt werden.

1) Lehrbuch der Botanik, Leipzig 1868, p. 568.

2) 1. c. p. 511. 
Wenn es sich überhaupt um Bewegungen ron Chlorophyllkörnern handelt, bei welchen die letzteren ihre Distanzen unter sich und von gewissen fixen Punkten der Zelle verändern, so gehören dazu noch mehr Erscheinungen als diejenigen, mit denen wir uns hier speciell zu beschäftigen haben. So vor Allew die Erscheinung, wo die Chlorophyllkörner an einer dauernd fortgehenden Rotation oder Circulation ${ }^{1}$ ) des Protoplasmas betheiligt sind. Ferner sind selbst in solchen Zellen, deren Protoplasma keine derartigen Bewegungen erkennen lässt, bisweilen die Chlorophyllkörner in eigenthümlichen im Allgemeinen sehr trägen und daher oft nur aus dem Erfolge zu crschliessenden Ortsveränderungen begriffen. Diese letzteren Bewegungen sind dadurch charakterisirt, dass zwar die Gesammtauordnung der Chlorophyllkörner in der Zelle nicht gestört wird, dass aber die einzelnen Körncr dauernd ibre Lage unter einander verändern, indem sie ohne bestimmte Regel, ein jedes in selbständiger Weise in kleinen Distanzen hin- und herrutschen. Die Vaucheria-Schläuche sind zur Beobachtung dieser Erscheinung besonders geeignet. In ilınen bilden die Chlorophyllkörner bekanntlich eine wandständige Schicht, welche meist nicht vollständig ist, indem hin und wieder chlorophyllfreie Stellen von unbestimmter Gestalt und Ausdehnung die Chlorophylllage unterbrechen. Dort kann man an den Rändern der letateren solche kleine Bewegungen der Chlorophyllkörner besonders deutlich wahrnebmen. Hat man eine bestimmte Stelle am Rande, wo die Körner weniger dicht stehen, eingestellt und die Anordnung derselben genau aufgezeichnet, so wird man das Bild wesentlich verändert finden, wenn man etwa nach einer halben Stunde das Objekt von Neuem betrachtet. Behält man die Stelle eine Zeit lang in Auge, so kann man die Lagenveränderungen auch direkt verfolgen. Man sieht z. B. zwei Körner, die Anfangs noch in ziemlicher Entfernung standen, sich einander nähern, bis sie sich berühren, oder aneinander vorbeirutschen oder auch eins über das andere hinweggleiten. Unterdessen sind auch andere Körner von ihrer Stelle gerückt, und das anfängliche Bild der Vertheilung ist bald ein ganz anderes geworden. In der Regel sind diese Bewegungen selir träge, vielfach kaum direkt wahrnehmbar; doch werden unzweifel-

1) Die Bezeichnungen: Rotation und Circulation des Protoplasma werden hier und im Folgenden nach den von Sachs (Lehrbuch der Botanik, p. 41) festgesetzten Begrifisbestimmungen gebraucht. 
haft manche Körner rascher bewegt als andere: gewöhnlich fallen von den im Gesichtsfelde befindlichen Körnern eins oder einige durch deutlichere Bewegungen auf, während die übrigen scheinbar momentan in Ruhe sich befinden. Nach einiger Zeit werden wieder andere Körner die beweglichsten. Die Richtung der Bewegung folgt durchaus keiner Regel; weder zu den Dimensionen der Zelle, noch zu den Bewegungsrichtungen der übrigen Körner stehen sie in einem bestimmten Verhältnisse. Die Bahnen sind im Allgemeinen sehr kurze, sie übertreffen den Durchmesser der Körner böcbstens u!̣ wenige Male. Auch kommen rückläufige Bewegungen ror, wodurch ein Chlorophyllkorn seiner anfäuglichen Lage wieder genähert werden kann. Man beobachtet sowobl geradlinige wie krummlinige Bahnen, ohne eine bestimmte Regel. Auch an Binncnstellen des Chlorophyllwandbeleges lassen sich solche Bewegungen erkennen. Die kirschoinung ist am nächsten verwandt mit kleinen Protoplasmacirkulationen, unterscheidet sich aber von diesen ausser durch die grosse Trägheit der Bewegungen doch vornehmlich dadurch, dass man keine eigentliche Strömung von Plasmasträngen, welche die Körner fortbewegten, entdeckt, und dass eben jedes Chlorophyllkorn ganz selbständig in seiner Bewegungsrichtung ist. Es scheint also hier eine Bewegung von Protoplasma stattzufinden, welche nur in stellenweisen, von einander unabhängigen Dimensionsänderungen der inneren Masse desselben besteht, die eben darum nicht den Ausdruck einer nach einem bestimmten Plane geordneten Strömung annelımen können. - Es giebt aber auch Zellen, in denen die Chlorophyllkörner mit Sicherheit ihre Lage dauernd unveränderlich behalten. So die Stengelzellen der Nitellen; in denen die in einer einschichtigen Lage stehenden Chlorophyllkörner dauernd eine Stellung in seicht spiraligen einander parallelen Längsreihen behalten, wobei sie polygonale Gestalt annehmen und mit den Seiten genau an einander liegen.

Eine wesentlich andere Erscheinung ist es, wenn in polyedrischen Zellen die Chlorophyllkörner nur an bestimmten Zellwänden, ausschliesslich oder in grösster Menge, angeordnet sind, unter gewissen Umständen aber von dort weg nach wiederum bestimm. ten anderen, bisher von Chlorophyllkörnern ganz oder nahezu entblössten Zellwänden sich begeben oder sonst irgend eine bestimmte neue Orientirung annehmen, in welcher sie dann, so lange jene Umstände obwalten, wiederum dauernd verbleiben. Zum Unter- 
schiede von anderen Bewegungen der Chlorophyllkörner wollen wir diese Erscheinungen, die den Gegenstand der vorliegenden Arbeit bilden, als Wanderung der Chlorophyllkörner bezeichnen.

Es giebt, wie im Folgenden gezeigt werden wird, eine Reihe innerer wie äusserer Anlässe, welche eine solche Wanderung der Chlorophyllkörner herrorbringen. Es sind aber die Wirkungen dieser an einer und derselben Pflanzenart nicht überall einander gleich, und auch eine und dieselbe Action hat bei den einzelnen Pflanzenarten, von denen solche Wanderungen bekannt geworden sind, zum Theil rerschiedene Wirkung. Daher sollen die einzelnen Ursachen in ihren Wirkungsweisen je nach den Pflanzenarten gesondert betrachtet werden.

\section{Trennung der Zellen vom Körper.}

Wir pflegen unsere Kenntnisse von den Zuständen der Zellen in einer intakten vielzelligen Pflanze aus der Betrachtung von Präparaten zu gewinnen, welche durch $\mathrm{Ab}$ - oder Herausschneiden der betreffenden Zelleu aus dem Körper der Pflanze hergestellt wcrden. Die Walurnchmung, dass die Zellen solcher Präparate, während diese in Wasser liegen, meist lange Zeit sich lebendig erhaltev, reranlasst uns, die in dem Präparate sichtbaren Zustände der Zellen für diejenigen binzunehmen, welche auch in der Gutakten Pflanze herrschen. Zu diesem Schlusse sind wir aber streng genommen nicht berechtigt; denn es kann nicht verkannt werden, dass eine oder mehrere Zellen, die aus dem natürlichen Verbande mit der Pflanze gelöst und nur von Wasser oder feuchter Luft umgeben sind, nicht mehr denjenigen Einwirkungen unterliegen, welchen sie ansgesetzt waren, so lange sie ein integrirendes Stück der ganzen Pllanze bildeten. Die neuen Verhältnisse müssen auch neue Wirkungen herbeifuhren, und es ist sehr wohl denkbar, dass diese Veränderung irgend einen sichtbaren Ausdruck in den Zuständeu der Zelle findet. Das Folgende wird zeigen, dass dies wirklich in hohem Grade der Fall ist.

\section{Mnium rostratum Schwaegr.}

Die sehr weiten polygonalen Blattzellen dieses Mooses sind für Untersuchungen über die Vertheilung der Chlorophyllkörner 
besonders geeignet. Die Individuen dieses Mooses, welche ich zu diesen und den folgenden Versuchen benutzte, standen während des Herbstes in einer mit einer Glastafel bedeckten Kultur am Fenster eines Zimmers, sie befanden sich fortdauernd in kräftiger Vegetation.

Zuvörderst will ich bemerken, dass bei dieser Art, oder wenigstens bei meinen Individuen, selbst die langen Herbstnächte nicht hinreichten, um die Nachtstellung der Chlorophyllkörner in der von Famintzin beschriebenen Weise herbeizutühren. Sowohl mitten in der Nacht als auch am Morgen bei Tagesanbruch sah ich die Körnchen immer nur in vollständiger Tagesstellung. Erst mehrtägige constante Verdunkelung brachte die Nachtstellung hervor.

In erwachsenen, völlig lebenskräftigen und frischen Blättern bildet das Protoplasma eine zusammenhängende peripherische Schicht unmittelbar unter der Membran. Die Chlorophyllkörner liegen in der Protoplasmaschicht der breiten freiliegenden Zellwände, welche die obere und die untere Seite des Blattes aus. machen. Hier bilden sie eine einfache Lage, indem sie immer eins neben dem andern liegen, so dass sie einander berühren oder in geringen, aber gleichmässigen Entfernungen von einander stehen, derart, dass die genannten Zellwände an allen Punkten gleichmässig mit einem Ueberzuge von Chlorophyllkörnern bedeckt sind. Dabei liegen sie alle mit ihrem grösseren Durchmesser - sie sind abgeplattet kugelförmig - parallel der Zellwand, an welcher sie stehen. Ein Unterschied $z$ wischen der oberen und unteren Zellwand ist hierin nicht aufzufinden. Unter den schmalen Seitenwänden, mit welchen diese Zellen unter sich im Verbande stehen, enthält das Protoplasma kcine Chlorophyllkörner, oder man findet daselbst höcbstens hin und wieder ein isolirtes Körnchen, welches dann dem Beschauer seine schmale Seite zuwendet.

Der eben beschriebene Zustand herrscht in den noch mit der Pflanze zusammenhängenden Blättern ebenso wie in abgetrennten oder in einzelne Stücke zerschnittenen Blättern alsbald nach dieser Operation, wenn dieselben in Wasser liegen. Dass derselbe aber an abgeschnittenen Theilen unter sonst gleichbleibenden Verhältnissen nach einiger Zeit mit einem anderen vertauscht wird, ergab sich mir aus folgendem Versuche. Es wurden Blätter dieses Mooses in kleinere und grössere Stücke zerschnitten, so dass jedes derselben noch eine grössere Anzahl unverletzter Zellen enthielt. In diesen befanden sich die Chlorophyllkörner in der be- 
schriebenen Stellung. Die Stücke wurden auf einem Objektträger mit Wasser unter ein Deckglas gebracht. Das Ganze stand, vor Verdunstung geschützt, am Fenster, so dass die Objekte während des ganzen Tages sich im Lichte befanden. Unter solchen Verhältnissen bleiben diese Zellen lange Zeit lebendig. Nach zwei Tagen war schon cine Veränderung an der Stellung der Chlorophyllkörner bemerkbar: die gleichmässige Ordnung derselben an den freicn Wänden war insofern gestört, als sie meistens nicht mehr dicht nebeneinander standen; der grüne Wandbeleg war etwas lückig geworden, indem an manchen Orten die Körnchen etwas weiter von einander gerückt waren, dafür aber an manchen sich auch melr gehäuft hatten, so dass wohl zwei über einander lagen oder manche ihre schmale Seite nach aussen kehrten. Es befand sich aber auch an den Seitenwänden eine Anzahl Chlorophyllkörner, die Aufangs dort nicht zu sehen gewesen waren. In der Folge schritt die Veränderung in diesem Sinne weiter: die Zahl der an den Aussenwänden stehenden Chlorophyllkörner wurde stärker gelichtet, während an den Scitenwänden immer mehr dergleichen sich einfanden. Dies war jedoch nicht in allen Blattstücken und auch oft nicht in den einzelnen Zellen desselben Stückes in gleichem Grade der Fall. In manchen Zellen waren dic Aussenwände nur noch sehr spärlich mit Chlorophyllkörnern besetzt, während die letzteren in grösserer Menge die Seitenwände ringsum bedeckten. In anderen befanden sich zwar solche auch an den Seitenwänden, die Mehrzahl derselben batte aber ihren Platz an den Aussenwänden noch inne, freilich einen in seiner Gleichmässigkeit immer gestörten, lückigen Ueberzug bildend. Zu einer vollständigen Unlagerung der Chlorophyllkörner nach den Seitenwänden kam es jedoch nicht, auch nicht bei wiederholten Versuchen: das schliessliche Absterben der Zellen machte, ehe dies erfolgt war, dem Versuche ein Ende. Die unter gleichen Verhältnissen danebenstehenden unverletzten Pflanzen zeigten in der Vertheilung ihres Chlorophylls keine Veränderung. Dieser Ortswechsel der Chlorophyllkörner ist offenbar demjenigen gleich, welchen Famintzin an seinen Mniumpflänzchen bei Entzichung des Lichtes beobachtete. Die denselben Erfolg erzielende Wirkung der Abtrennung des Gliedes von der Pflanze ist nach dem Mitgetheilten nur weniger effektvoll als die Wirkung der Verdunkelung; sie ist aber auch gerade bei dieser Pflanze 
von weit geringerem Effekt, als bei anderen, wie das Folgende zeigen wird.

\section{Radula complanata Dumort.}

In den Blattzellen dieses Tiebermooses bildet das Protoplasma ebenfalls einen gleichmässigen Wandbeleg, welcher abermals nur unter den breiten freiliegenden Zellwänden Chlorophyllkörnchen in dichter Stellung und in einer einfachen gleichmässigen Schicht enthält, an der unteren wie oberen Zellwand in ziemlich gleicher Weise. An den Seitenwänden liegen keine Körnchen. Das Innere des Zellraumes wird fast völlig von dem grossen, unregelmässig gestalteten, opaken Inhaltskörper, wie er den meisten Jungermannieen eigen ist, ausgefüllt.

Lebhaft vegetirende Triebe aus einer Kultur, in welcher diese Pflanze im Herbste gezogen wurde, wurden in Stücke zerschnitten und in ganz derselben Weise bchandelt, wie es eben ron den Mniumpflänzchen angegeben worden ist. Die Objekte standen neben der Kultur, welche die unversehrten Individuen enthielt.

In den ersten Tagen zeigten sich an den Präparaten noch durchaus keine Veränderungen. Als sie aber am fünften Tage untersucht wurden, war in sämmtlichen Zellen die Stellung der Chlorophyllkörner eine andere geworden. Die beiden breiten Wände der Zellen waren von solchen ganz oder nahezu entblösst; dafür sassen dieselben in gedrängter Stellung ringsuun an den Seitenwänden: die Mitte der Zelle mit ihrem grossen Inhaltskörper war jetzt deutlich sichtbar, nur im äussersten Umfange stand der grüne Kranz von Chlorophyllkörnern. Hin und wieder war die neue Stellung in diesem vollständigen Grade eingetreten. In anderen Zellen standen wohl noch einige Körner an den breiten Wänden, aber es fanden sich doch immer auch an den Seitenwänden Chlorophyllkörner, und dort war in der Regel ihre Stellung am dichtesten. Es war dies also offenbar wiederum die analoge Vertheilung der Chlorophyllkörner, welche Famintzin an seinen Mniumblättern zur Nachtzeit beobachtete.

Pfänzchen aus der danebenstehenden Kultur, welche jetzt auf die Stellung ihrer Chlorophyllkörner untersucht wurden, zeig. ten die letzteren überall in der vollständigsten Tagstellung. Im Laufe des Tages wurde die neue Anordnung, in welcher sich die 
Chlorophyllkörner der Präparate befanden, nicht wieder aufgegeben. Für die folgende Nacht aber wurde die normale Kultur künstlich lichtdicht verschlossen, um sie bis zum nächsten Morgen unmittelbar vor der Untersuchung der Pflanzen in der Verdunkelung zu erhalten. Es zeigte sich auch hierauf noch keine irgend merkliche Veränderung der Vertheilung der Chlorophyllkörner, und es geht daraus hervor, dass auch bei dicsen Pflanzen die Verfinsterungsdauer einer Nacht nicht hinreichte, um die Nachtstellung des Chlorophylls herbeizuführen. Es konate also auch in den zerschnittenen Theilen der Pflanze die Aenderung der Chlorophyllvertheilung nicht eine Wirkung der nächtlichen Dunkelheit sein. Auch wurde dieselbe nicht wieder aufgehobeu, trotzdem dass die Präparate jeden Tag über sich ununterbrochen am Lichte befanden.

\section{Farnprothallien.}

Zu den folgenden Versuchen wurden Prothallien nicht näher bestimmter Polypodiaceen verwendet, wie sie in den Gewächsbäusern zu haben sind. In den hier zu besprechenden Erscheinungen verhalten sich dieselben in der Hauptsache einander gleich. Die beiden Lappen des Vorkeimes bestehen aus einer einzigen Zelllage, nur in der Mitte sind sie mehrschichtig. Jene Zellen sind polygonal, ziemlich dünn tafelförmig, aber in den Richtungen der Vorkeimfäche sehr weit; nur an dem am vorderen Ende liegenden Einschnitle, wo die jüngsten und kleinsten Zellen liegen, nimmt die Weite allmählich ab. Diese Gestalt ist der Klar. heit der Anordnungsweise der Chlorophyllkörner besonders günstig. Auf unverletzten, unter normalen Verhältnissen gehaltenen Individuen sind die beiden grossen freien Aussenwände der Zellen mit einem gleichmässigen Ueberzuge von Chlorophyllkörnern bedeckt, in welchem die letzteren in einfacher Lage eins neben dem andern lückenlos so angeordnet sind, dass ihre breiten Seiten der Wand parallel liegen. Die schmalen Wände aber, mit welchen dic Zellen unter sich im Verbande stehen, sind nicht mit Chlorophyllkörnern bedeckt, oder es sind daselbst nur hin und wieder spärliche vorhanden. Im Inneren der Zellhöhle sind ebenfalls keine grüven Körner sichtbar. In den Zellen, welche den Rand des Prothalliums einnehmen, liegen die Chlorophyllkörner ausser 
an den beiden Aussenwänden auch an der Kante, in welcher beide auswärts zusammentreffen; die drei einwärts gekehrten an die Nachbarzellen stossenden Wände sind davon entblösst. Dieser Typus ist bis in die kleineren jungen Zellen in der Nähe des Prothalliumeinschnittes erkennbar, soweit nur die Enge der Zelle noch eine derartige Regelmässigkeit in der inneren Anordnung gestattet.

Von einer Kultur, welche unter gewöhnlichen Verbältnissen am Zimmerfenster stand, wurden einige Individuen, in denen die Chlorophyllkörner die eben beschriebene Anordnung hatten, in eine Anzahl verschieden grosser Stücke regellos zerschnitten. Letztere wurden in der mehrfach beschriebenen Zurichtung neben der Kultur aufgestellt und waren hier wie diese der täglichen Beleuchtung ausgesetzt. Wiederholte fortgesetzte Beobachtungen zeigten zunächst, dass in den unverletzten Individuen der Kultur die normale Anordnung der Chlorophyllkörner unverändert blieb; auch die allnächtliche Verfinsterung vermochte keinen Einfluss zu äussern. Gleiches wurde auch an solchen unverletzten Individuen beobachtet, welche daneben in einem Glassgefässe in Wasser lagen. In den zerschnittenen Prothallien war aber schon in den nächstfolgenden Tagen an den schmalen Seitenwänden der Zellen eine zusammenhängende Schicht von Chlorophyllkörnern vorhanden, und dafür war die Gleichmässigkeit des Chlorophyllüberzuges der freien Aussenwände mehr oder weniger gestört. Es verhielten sich hierbei aber die Zellen der einzelnen Stücke, ja selbst diejenigen eines und desselben Stückes nicht genau einander gleich. In manchen war die Zahl der noch an den Aussenwänden sitzenden Chlorophyllkörner eine sehr geminderte; in anderen befanden sich dort noch die meisten, aber ihre Stcllung daselbst war lückig und entweder ganz unregelmässig oder gegen die Ränder der Zelle zu auffallend dichter als in der Mitte, wo bisweilen schon fast alles leer war. Nachdem die Präparate eine Woche lang sich in diesen Verhältnissen befunden hatten, wurden jene Veränderungen in einem noch viel höheren Grade vorgefunden. An den Seitenwänden lag überall, an den jüngeren wie au den älteren grossen Zellen, ein dichter Kranz von Chlorophyllkörnern, an den Aussenwänden aber standen in den meisten Zellen nur noch vereinzelte, in manchen allerdings auch noch eine grössere Anzahl in unregelmässig lückiger Ausbreitung; nirgends aber wurden an den Seitenwänden zablreiche Körnchen vermisst. In den 
Randzellen der Vorkeimfläche hatten die Chlorophyllkörner mehr oder weniger die Aussenwände sowie die Kante, welche beide nach aussen bilden, verlassen, und sich mehr ins Innere der Zelle zurückgezogen; am dichtesten standen sie an den drei inneren schmalen Seitenwänden. Dieses ist also wiederum dieselbe Vertheilung des Chlorophylls, welche Borodin an den Farnorkeimen bei Verdunkelung eintreten sah. Die unverletzten Prothallien zeigten, zur nämlichen Zeit untersucht, den normalen $\mathrm{Zu}$ stand auf das Vollständigste.

\section{Sagittaria sagittaefolia.}

Die Primordialblätter der Laubsprosse der Sagittaria, welche bekanntlich lange linealische Gestalt haben und submers bleiben, bestehen mit Ausnahme der Nerven nur aus zwei zusammenhängenden Zellschichten, den Epidermen beider Seiten. Zwischen beiden enthält die Blatemasse luftführende Intercellularräume, die nur hin und wieder durch cinfache Reihen von Zellen unterbrochen sind, welche eine unvollständige dritte Zelllage ausmachen und die Epidermis der Ober- und Unterseite verknüpfen. Die Epidermiszellen haben ungefähr parallelepipedische Gestalt, sind ziemlich breit und lang, aber weniger tief. Sie grenzen also mit der einen breiten Wand an die äıssere Umgebung, mit der anderen gleichgrossen an die Intercellularluft; nur mit den vier schmalen Seitenwänden stehen sie mit ihren Nachbarzellen im Verbande. Bei der Geräumigkeit ihres Lumens ist auch der Typus der Anordnung der Chlorophyllkörner, des Protoplasmas und des Zellkernes deutlich ausgeprägt. Diese Pflanze war es, an welcher ich zuerst darauf aufmerksam wurde, dass Trennung der Zellen vom Körper eine Veränderung in der Vertheilung des Protoplasmas und der Chlorophyllkörner zur Folge hat, und sie zeigt dies auch auf das Ausgeprägteste. Nach von.Mohl') werden die Chlorophyllkörner und selbst der Zellkern in den genannten Zellen von kleinen Protoplasmaströmchen, welche an den Zellwänden hinkriechen, fortbewegt. Es wird sich sogleich zeigen, dass dieser Zustand schon die Wirkung der durch die Herstellung des Präparates verursachten Auf-

1) Botanische Zeitg. 1846, p. 91 u. 93. 
hebung des natürlichen Zusammenhanges der untersuchten Zellen mit ihrem Blatte ist.

Der Umstand, dass wenn ich durch Flächenschnitte Stücke der oberflächlichen Zelllagen abgetragen hatte, zahlreiche und wiederholte Beobachtungen in den Blattzellen unserer Pflanze unter gleichen äusseren Verhältnissen in verschiedenen Fällen sehr verschiedenartige Anordnungen der Chlorophyllkörner erkennen liessen, veranlasste mich zu genaueren Untersuchungen. Ich fand bald, dass dafern ich nur sofort nach der Präparation die Objekte unter dem Mikroskope betrachtete, die Anordnungsweise des Zelleninhaltes in allen Fällen wenigstens im Wesentlichen einen und denselben Typus repräsentirte, und ich konnte dann schon nach wenigen Minuten an dem Präparate eine durchgreifende Veränderung in der Vertheilungsweise von Protoplasma und Chlorophyllkörnern sich vollziehen sehen. Wenn nämlich solche Schnitte sogleich nach der Präparation mit möglichster Eile für die Beobachtung hergerichtet werden, so findet man in der Regel die Chlorophyllkörner nur in der Protoplasmaschicht, welche die vordere und hintere breite Zellwand überzieht. Sie bilden hier eine einfache gleichmässige Lage, indem sie in gleichen Entfernungen ziemlich nahe bei einander stehen, so dass ihre breiteren Durchmesser der Zellwand parallel sind. Bewegungen lassen fsich an den Chloro. phyllkörnern jetzt keine beobachten, ibre gegenseitige Stellung bleibt zunächst auf das Bestimmteste unverändert. Auch Proto. plasmaströmchen konnte ich in solchen Zuständen nicht entdecken, will jedoch ihre Existenz nicht bestreiten, denn der gleichmässig über die ganze breite Wand der Zelle sich erstreckende Chlorophyllüberzug erschwert einen Einblick in tiefere Stellen des Zellenlumens beträchtlich. Der Nucleus ist hier sehr deutlich, er liegt immer an der hinteren Wand, meistens vollständig, bisweilen aber auch dem Rande derselben genahert, fast die Kante zwischen dieser Wand und einer der Seitenwände einvehmend.• Auf den vier Seitenwänden finden sich in der Regel keine Chlorophyllkörner, eben so wenig weiter im Inneren des Zellraumes. Zwar fand ich diese Anordnungsweise in manchen Fällen auch nicht so vollständig, indem die Zahl der an den breiten Wänden liegenden Körnchen eine geringere war und dafür entsprechend mehr Körnchen den Seitenwänden anlagen, doch sollen diese Erscheinungen zunächst noch ausser Acht bleiben. DasEolgende bezieht sich nur auf solche Zellen, in welchen die Chlorophyllkörner auf das Vollständigste nach dem 
vorhin beschriebenen Typus angeordnet waren. Die Beobachtungen geschahen im hohen Sommer, bei Tage; die Objekte befanden sich unter Deckglas in Wasser und wurden mittelst durchfallenden Lichtes beleuchtet. Nachdem die ursprüngliche Stellung der Chlorophyllkörner zunächst noch eine kurze Zeit constant geblieben ist, beginnt, in der Regel schon nach wenigen Minuten die Veränderung. Es kommt zunächst Unordnung in die bisher regelmässige Vertheilung der Körnchen; die geschlossene Stellung derselben wird immer mehr gelichtet. Dafür sammeln sich immer mehr Körnchen an den Seitenwänden, wo alsbald eine rings um die ganze Zelle gehende Zone dicht zusammenhockender Chlorophyllkörner sich gebildet hat. Nach ein bis zwei Stunden ist die Veränderung vollständig: von der äusseren wie von der hinteren breiten Wand sind die Chlorophyllkörner gänzlich verschwunden, oder es finden sich ihrer nur noch vereinzelte, und dann häufiger an der Hinterwand als an der Aussenwand. Dagegen hat die grüne Schicht an den Seitenwänden ihre grösste Mächtigkeit erreicht. Es sind also offenbar alle, oder doch die weitaus grösste Mehrzahl der Körner von den breiten Zellwänden nach den schmalen Seiten gewandert. Der Zellkern liegt bisweilen noch auf der Hinterwand und ist dann deutlich sichtbar; meistens ist er aber ebenfalls dem Rande genähert oder sitzt geradezu ảuf einer Seitenwand.

Dauernde genaue Betrachtung einzelner solcher Zellen lässt auch die unmittelbaren Vorgänge der Bewegung verfolgen. Man sieht anfänglich die Körnchen in kleine träge Bewegungen gerathen, wodurch sie, zunächst ohne bestimmtes Ziel, aus ihrer Lage etwas verrückt werden. Aber bald wird die Bewegung lebhafter und ihr Ziel bestimmter. Es rutschen ein oder zugleich mehrere beisammenliegende Chlorophyllkörner mit ziemlicher Geschwindigkeit nach den Seitenwänden. Nun zeigt sich aber stets, dass die in Bewegung begriffenen Chlorophyllkörner in Protoplasmaströmchen von gleicher Richtung eingebettet sind. Der Plan aller dieser gleichzeitig und nach einander eintretenden Strömungen des Protoplasmas ist jedoch ein keineswegs einfacher. Hin und wieder fliesst von der breiten Wand nach einer Seitenwand ein dunnes Strömchen mit ziemlicher Lebhaftigkeit. Bisweilen bringt ein solches ein oder mehrere Chlorophyllkörner mit und treibt sie gegen die Seitenwand. Dort werden diese meist durch andere schon dort liegende Körner aufgehalten, während der Plasmastrom immer noch fortfliesst. Häufig gehen die Ströme 
nicht an der Zellwand hin, sondern nehmen ihren Weg zum Theil quer durch den Innenraum der Zelle in serader Linie von irgend einem Punkte der breiten Wand nach einer bestivmten Höhe an einer Seitenwand. Vorzugsweise gehen ron der hinteren Wand nach verschiedenen Höhen der Seitenwände solche dünne, auch Chlorophyllkörner mit fortführende Ströme. Häufig fliesseu sie statt in radialer in schiefer Richtung gegen deu Umfang der Zclle, ja es kommt vor, dass ein Strom auf der breiten Wand in der Nähe des Randes parallel dem Umfange der Zelle fortgetricben wird, oft auf lange Strecken. Die Chlorophyllkörner, dic er fortbewegt, werden endlich irgendwo am Rande aufgehalten. Oder man sieht auch Chlorophyllkörner, welche schon an einer Seitenwand angelangt waren, plötzlich wieder flott werden und nach der Hinterwand treiben, indem sie mit einem quer durch den Zellraum von der Seitenwand nach der Hinterwand fliessenden Plasmastrome sich fortbewegen. Dort angelangt, werden sie entweder von daselbst noch liegenden anderen Körnchen aufgehalten oder bis nach der gegenüberstehenden Seitenwand weiter getrieben. Oft werden aber auch grössere Massen von Chlorophyllkörnern zusanımen fortbewegt. So sieht man nicht selten den Zellkern sammt einem Chlorophyllkörnerklumpen, von welchem er bisweilen eingeschlossen ist, in drehende Bewegung gerathen und dann gegen die Seitenwand hingewälzt werden. Dort bleibt er entweder, oder er wird wieder nach seinem alten Orte zurückbewegt, und dic Körnchen werden erst später noch einmal in ihrer Vereinigung, oder cinzeln nach den Seitenwänden gebracht. Biswcilen werden nämlich solche Klumpen von Chlorophyllkörnern aufgelöst und eine Anzahl Körnchen nach dieser, eine andere nach jener Richtung gegen den Umfang der Zelle getrisben. Endlich sieht man auch Protoplasmaströmchen von den Seitenwänden zur Mitte der breiten Wände gehen, welche keine Chlorophyllkörner enthalten; sie fliessen bald in centrifugaler, bald in centripetaler Richtung. Aber auch die bereits definitiv an den Seitenwänden liegenden Chlorophyllkörner sind häufig in einer Bewegung begriffen. Diese geht läng's der Seitenwände hin, und bisweilen laufen in verschiedenen Höhen dieser Wände mehrere solcher Ströme in entgegengesetzten Richtungen. Diesen Zustand der Zelle hat offenbar v. Mohl vor sich gehabt, als er die Protoplasmabewegungen der Sagittariablätter untersuchte. 
Weun dicses Spiel der Beweyungen einige Zcit gedauert hat, so ist, wie schon bemerkt, alsbald der Punkt crreicht, wo die Umlagerung der Chlorophyllkörner auf dic Seitenwände vollständig oder nahezu rollständig gesehehen ist. Wie bei den angefülırten Cryptogamen, so bleibt nun auch hier die neuc Stellung der Chlorophyllkörner constant. Ich habe solche Präparate wochenlang in Wasser unter dem Deckgläschen lebendig erhalten, ohne dass an dieser neuen Anordnung der Chlorophyllkörner zu irg nnd einer Zeit sich etwas geändert hätte, obgrleich die Präparate neben den ganzen Pflanzen der täglichen Beleuchtung ausgesetzt waren. In den Blättern aber, von welchen dic Präparate genommen worden waren, selbst in der Nahe der verletzten Stellen, zeigte sich zu der Zeit, da in den Präparaten die Stellungsänderung der Chlorophyllkörner vollständig eingetreten war, keine Störung der normalen Anordnungsweise. Lis wird also durch die Veränderung äusserer kinwirkungen, wie sic aus der Trennung der Zelle aus ihrem natürlichen Verbande resultirt, ein neuer Zustand in dieselbe eingeführt, welcher in der Unlagerung des Protoplasmas und zumal der Chlorophyllkörner sowie des Zellenkernes seinen Ausdruck findet und der, einmal hergestellt, constant bleibt, so lange eben die reränderten Einwirkungen andauern, cbenso wie der Zustand, welcher in Ger intacten Pflanze herrscht und in der entgegengesetzten Anordunngsweise der Chlorophyllkörner seinen Iusdruck findet, gleichfalls im Allyemeinen constant bleibt, so lange die Zelle sich in uatiirlichen Verbaude mit der Pflanze befindet. Jene Bewegungen aber, bei welchen die Chlorophyllkörner innerhalb dünner Protoplasmaströmehen nach verschiedenen Richtungen in der Zelle um. hergefülırt werden, sind nur vorübergehende Erscheinungen, sie sind das Uebergangsstadium von dea einen Zustande zu den anderen, der Ausdruck cines gestörten, aber sich wiederherstellenden Gleichgowichtes zwischen den verschicdenen Actionen, welche unter entgegengesetzten Umständen auf den Protoplasmakörper einwirken.

Wenn in solchen Präparaten die Chlorophyllkörner vollständiyo in ihre neue Stellung gekommen sind, so dauern dennoch die strömenden Bewegungeu des Protoplasmas fort, nur mit dem Unterschicde, dass die Strömchén jetzt keine Chlorophyllköruer mehr mit sich fülıren, indem diese jetzt dauernd in Ruhe an den Seiten- 
wänden liegen bleiben. Da jetzt vor den bruiten Wäuden der Zellen keine Chlorophyllkörner mehr liegen, so sind diese zarten Protoplasmaströmchen besonder's deutlich. Nach Form, Richtung und Geschwindigkeit sind sie anscheinend nicht verschieden von den bisherigen Strömen; man sicht jetzt sehr deutlich, lass sie bald schneller, bald langsamer ihre Lage verïndern: oft rutscht ein solcher Strang, der an beiden Enden an den Zellwänden ansitzt, mit ziemlicher Geschwindigkeit in der Zelle hin, wobei er sich nicht selten in zitternder welliger Bewegung befindet, wie ein schlaff ausgespanntes, in Schwingungen rersetztes Seil - die bekannten Erscheinungen des strömenden Protoplasmas. Diese Bcwegungen konnte ich so lange wahrnehmen, als überhaupt die Zellen der Präparate am Leben blieben.

Es ist auf den ersten Blick nicht so leicht und einfach, die Lagenveränderungen der Chlorophyllkörner zu den Bewegung'cu des Protoplasmas in nähere Bezichung zu bringen, wenn man bedenkt, dass während dieser Vorgang stattfindet, ausser den Plasmaströmchen, welche Chlorophyllkörner vou deu breiten Wänden nach den Seitenwänden schaffen, auch solche von der entgegengesetzten Richtung beobachtet werden, welche mitunter auch Chlorophyllkörner bewegen, und vor allen Dingen, wenn man erwägt, dass auch, nachdem die Chlorophyllkörner sämmtlich in ihre neue Stellung gekommen sind, das Spicl der Protoplasmaströmungen noch immer dauernd in einer Weise fortgeht, welche keinen Unterschied gegen die früheren Bewegungeu erkennen lässt, ohne dass dadurch die Chlorophyllkörner jetzt aus ihrer Stellung gebracht werden können. Immerhin aber wird nach deu eben dargclegten Beobachtungen gerade an dieser Pflanze auf das Unzweideutigste die Annabme von Sachs bewiesen, dass bei der eigentlichen Wanderung der Chlorophyllkörner das Bewegende dasjenige Protoplasma ist, in welchem die Körner zunächst eingebettet sind, und dass die letzteren also nur passiv mit fortgeschwemmt werden. Wic man sich den schliesslichen Stillstand der Chlorophylliöruer an den Seitenwänden trotz der Fortdaucr der Plasmaströmungen zu erklären hat, darüber soll unten eine Vermuthung ausgesprochen werden.

lch habe mich noch gefragt, ob gewisse äussere Kräfte in nachweisbarer Weise einen Einfluss auf die durch Trennung der Zellen von der Pflanze herbeigeführten Stellungsveränderungen der 
C'hlorophlyllkörner ausüben. In Präparaten, die ich sogleich nach ihrer Herstellung iu cinen dunkeln Raum einschloss, war die Veränderung ebenfalls erfolgt, als ich sie nach einigen Stunden wieder an's Licht brachte und sogleich unter dem Mikroskope untersuchte. Hicraus sowie aus dor Thatsache, dass bei den oben beschriebenen Vcrsuchen dic Präparate sich ununterbrochen am Lichte bcfanden, während in ihren Zellon die Chlorophyllkörner ihre Wanderungen rollzogen, geht hervor, dass bei dieser Erscheinung dew Lichte kein merklicher Wirkungsantheil zukommt.

L.s war ferner der Beachtung werth, dass bei allen diesen Untersuchungen die Zellen in ciner ganz bestimmten Lage zum Horizoute sich befanden. Auf dem stets horizontal stehenden (1)jektiträger lagen die Zellen so, dass ihre breiten Wände horizontale Stcllung einnahmen; die Anssenwand war zenithwärts, die Hinterwand nach abwärts gekehrt. Um zu ermitteln, ob die neue Stellung der Chlorophyllkörner in anderer Weise sich ausbilden würde, wenn die Zelle wälırend der inneren Veränderungen in einer anderen Lage zum Horizonte sich befindet, legte ich solche l'rïparate derart auf Objektträger unter Deckgläser, dass bei den cincu die Aussenwand der Zellen, bei den anderen dic Hinterwand olscn lag. Die Objektträger wurden dann sogleich in einen dunkelen Raum gebracht und blieben dasclbst in horizontaler Stellung 24 Stunden stehen. Hierauf wurden sie zur Beobachtung rorgennmmen, die rerkehrtliegenden Schnitte wurden zunächst umgewendet, weil sich in dieser Lage die Epidermiszellen besser beobachten lassen.

In denjenigen Präparaten, welche mit der Aussenfläche nach oben gukelurt gewesen waren, fand sich unter der Aussenwand der muisten Zellen nicht ein cinziges Chlorophyllkorn; dicse standen an den Sciteuwänden und eine Anzahl an der Hinterwand. Dagegen waren in den Schnitten, welche in verkehrter Stellung sich belunden hatten, fast in jeder Zelle noch einige Chlorophyllkörner untè der Aussenwand anzutreffen. Besonders laäufig sah man sulche in dem Winkel zwischen der Aussen- und den Seitenwänden sitzen, viclfach so, dass sie noch auf dem Rande der Aussenwand lagen. Ws sah aus, als ob der treibende Protoplasmastrom nicht übcrall die uöthige Kraft gehabt hätte, um das Chlorophyllkorn vou der jetzt unten liegenden Aussenwand nach der Seitenwand cmporzuheben. Dieses Ergebniss deutet mit Bestimmtheit 
auf die schon a priori arzunehmende Thatsache, dass hei protoplasmatischen Bewegungen der durch das Gewicht der in Bewegung zu setzenden Massen gegebené Widerstand üborwunden werden muss, und es würde der vorliegende Fall direkt anschaulich machen, wie durch jenen Widerstand unter Unständen das Resultat der Bewegungen bis zu einem gewissen Grade beeinträchtigt, resp. verändert werden kann.

\section{Elodea canadensis.}

Die kleinen, in dreigliederigen Quirlen stehenden Blättchen dieser Pflanze bestehen mit Ausnahme der vielzelligen Mittelrippe und des eine einzige Zellreihe bildenden Randes nur aus zwei Zellschichten, welche bis auf zwischen den Kanten sich hinzichende ziemlich enge Intercellulargänge mit einander im Verbande stchen. Die der Oberseite angehörigen Zellen haben parallelepipedische Gestalt; der rechtwinklig zur Blattfläche stehende Durchmesser ist der kleinste; der Längsdurchmesser ist dem Breitedurchmesser gleich oder grösser als dieser. Die Zellen sind ziemlich geräumig, doch nimmt ihre Weite gegen den Rand und gegen die Spitze des Blattes zu ab. Die die Unterseite bildenden Zellen haben im Wesentlichen die gleiche Gestalt, sie sind ungefähr eben so lang, aber höchstens halb so breit. In allen finden sich zablreiche Chlorophyllkörnchen; die Anordnung derselben ist jedoch in den Oberzellen, wegen der grösseren Weite derselben, viel deutlicher als in den schmalen Zellen der Unterseite, und darum beziehen sich die folgenden Untersuchungen vornehmlich auf die ersteren.

Zur mikroskopischen Betrachtung dieser Zellen genügt es bei der Dünne dieser Objekte. abgeschnittene Blätter ohne weitere Präparation so unter ein Deckglas zu legen, dass die Oberseite nach oben gekehrt ist. Sofort nach der Operation findet man dic Chlorophyllkörner auch hier in einer lückenlosen einfachen Lage in der Protoplasmaschicht der Aussenwand, bald in dichtgedrängter Stellung, so dass sich die Körnchen mit ihren Rändern fast berühren, bald mehr zerstreut stehend, aber dann immer so, dass die Abstände der einzelnen Körnchen gleich gross sind. Stets liegen sie mit ihrem grösseren Durchmesser der Zellwand parallel, und sie befinden sich in vollständigster Rube. Auf den Scitenwänden gibt es keine Chlorophyllkörner, oder nur ausnahmsweise 
hicr oder da eins, welches dann seine schmale Seite dem Beobachter zuwendet und gleichfulls bewegungshos ist. Die Hinterwand ist hier ebenfalls leer oder auch mit einigen wenigen Körnchen ordnungslos bedeckt. Auch in Blättern, welche mit der Pflanze noch zusammenhängen und die sich in dieser Weise unschwer der direkten mikroskopischen Bcobachtung unterwerfen lassen, werden die nämlichen Zustände gefunden.

In der Regel schon wenige Minuten nach Herstellung des Präparates bemerkt man Bewegung in die Chlorophyllkörner und Unordnung in ihre Stellung gerathen. Man sieht an einer oder einigeu Stellen der Aussenwand einige Körner weiter von einander rücken und anderen entsprechend sich nähern. Auch rutschen manche Kömchicn schon jelzt auf einc Scitenwand, meistens aber werilen z:unächst an der Aussenwand die Chloroplyllkörner an gewissun Stellen zusammengescliwemmt, bald rorwicgend in einen, bald in melurese, aber nicht schart umschriebene Hanfen, bald auch mehr in Quer-oder in einem Lüngsstreifen; oder es sind solche Haufen nach einer oder mehreren Seiten hin zu cinem Streifen verdüunt. Ls ist üheraus deutlich, dass diesen Anhäufungen ron Chlcroplyllkörneru eine Häufung schleimigen Protoplasmas an dicsen Stellen cntepriclit: os zichen sich unverkennbar T'heile des bis dahin glcichmässig verbreiteten Protoplasmas zu dünneren oder dickeren Ballen oder zn Strängen zusammen, und die eingebetteten (hlorophyllkörner werlen dabei passir mit von ihrer Stelle gerückit. Man sicht num aher auch in diesen Strängen eine innere Strömung beginnen, durch welehe die Chlorophyllkörner mit fortlowegt werden Dabei ist os überaus dentlich, wic ausnahmslos lie Richtung, in welcher die Körner sich bewegen, dieselbe ist, wie die, in weleher der Protoplasmaschlein fliesst. Die Ströme rerïndern daucrnd ihre Lage, manche verzwcigen sich, andere rerschwinden, während wieder neue auftreten. Die Lage und Richtung der Ströme ist eine schr mannichfaltige: manche gehen unter der Aussenwand querüber von einer Seitenwand nach der gegenüberstehenden in gerader oder schicfer Richtung; ineist aber senkt sich der Strom ron einer Stelle der Aussenwand anhebend in sehicfer Richtung in tiefere Gegenden der Zelle, nach der Hinterwand oder ungefäh nach der Kante zwischen dieser und einer Scitenwand. In allen solchen Strömen werden rielfach auch Chlorophyllkörner mit fortisewegt, und zwar entsprechend der wechselnden Richtung und Lage dieser Ströme zunächst ohne 
bestimmtes Ziel. Zu ciner gewissen Zeit werden z. B. eine Anzahl Körnchen nach einer Seite hin oder nach der Hinterwand geschwemmt; während bald darauf durch einen neu entstandenen Protoplasmastrom andere oder vielleicht diesclben Körnchen wieder an die Aussenwand zurückgetrieben werden. So geschicht es auch zuweilen, dass vorübergehend einmal alle Chloroplyllkörucr von der Aussenwand verschwunden sind; nach kurzer Zeit werden aber wieder welche dahin gebracht, um daselbst eine Zeit lang ruhig zu liegen oder umhergetrieben zu werden, und so kann sich auf einer schon leer gewesenen Aussenwand wieder eine riemliche Anzahl Körnchen ansammeln. In dieser Weise geht das Spiel der Bewegungen eine Zeit lang fort, bis endlich nach 1 bis 2 Stunden ein neuer Zustand angebahnt wird. Unverkennbar wird nämlich dic Anzahl der momentan an der Aussenwand befindlichen Chlorophyllkörner im Allgemeinen immer geringer, während sich dieselben an den Seiten- und Hinterwänden immer mehr anhäufen. Fine genauere Betrachtung lehrt aber auch, dass die Strömchen unter der Aussenwand seltener werden. Man sieht nämlich, wie dieselben ihre Lage entweder so verändern, dass sic sich der um die Seitenwände vertheilten Protoplasmamasse cinlagern, oder wie diejenigen Strömchen, welche von der Aussenwand nach der Seite odcr nach hinten fliessen, rückwärts aufhören und also ebenfalls von der an der Seite oder auf der Hinterwand liegenden Masse des Protoplasmas vollständig aufgenommen werden. In dem Maasse uun, als dieses Flichen des Protoplasmas und der Chlorophyllkörner von der Aussenwand vollständiger wird, beginnt in den jetzt an den Seiten der Zelle angehäuften Massen eine neue Erscheinung, nämlich eine ringsherum laufende Rotation des Protoplasmawandbcleges sammt den darin eingebetteten Chlorophyllkörnern, in gleicher Weise, wie es ron der Vallisneria schon längst bekannt ist. Die Rotation bildet sich aber erst allmählich aus: zunächst sieht man nur an diesem oder jenem Punkte des Umfanges der Zelle schwache Ansätze einer solchen hervortreten, dic an eincr sehr trägen Fortbewegung dieses oder jenes Chlorophyllkornes parallel der Seitenwand der Zelle sichtbar wird. Es gerathen aber in der Folge immer mehr Körner in gleiche und gleichsinnige Bewegung, und die letztere wird immer beschleunigter, bis endlich alle an den Seiten der Zelle liegenden Chlorophyllkörner in je nach der Höhe der Temperatur verschieden lebhafter Rotation begriffen sind. Dabei ist es höchst deutlich, dass die den Scitenwänden 
aunlegende, in strömender Bewegung begriffene Protoplasmaschicht, in welcher die Chlorophylliörner mit fortgeführt werden, jetzt gerade rclativ sehr mächtig geworden ist. Es sei noch besonders herrorgehoben, dass die einzelnen Chlorophyllkörner nicht sofort in Rotation kommen, sobald sie auf der Seitenwand angelangt sind, denn es befinden sich daselbst schon lange ror Eintritt dieser Erscheinung zahlreiche Chlorophyllkörner, aber sie liegen dort ruhig, oder beschreiben doch wenigstens kcine Rotation, wie denn anch um diese Zeit das dasclbst rorhandene Protoplasma eine derartige Bewegung noch nicht zeigt. Es tritt vielmehr die Rotation bestimmt erst in einer späteren Periode allmählich ein, und ihr Anfang fallt zusammen mit dem rollständigeren Fliehen des Protoplasmas und der Chlorophyllkörner von der Aussenwand der Zelle. Ist aber dic Rutatiou einmal in vollem Gange, so benerkt man anch keine an der Aussenwand oder durch die Zellhöhle hingehenden Protoplasmaströmehen mehr. Bis dahin sind aber auch in der Regel sämmtliche Chlorophyllkörner von der Aussenwand rerschwunden, orler es ist wohl noch eins oder das andere daselbst sitzen geblicben, aber diese liegen dann dauernd in Ruhe. Auf der Hinterwand bemerkt man gewöhnlich eine grössere Anzahl ron Köruchen, dic unregelmässig gehäuft oder rerstreut liegen; anch diese sind unbeweglich.

Ist die Rotation cinmal im Gange, so bleibt sie es danernd, ebenso wie anch die Chlorophyllkörner in ihrer nunmehrigen Anordnungsweice unverändert, verharren. Es wird also übcrhaupt der Zustanl der Zelle, wie or sich beim Eintritte der Rotation auslildel, cin constanter. In ahreschnittenen Blättern, welche in Wasser unter Deckglas lagen, erhiclt ich die Zellen vicle 'Tage lang am Lehen, und eben so lange blieb auch der Zustand ihres Inhaltes unrerändert.

In selteneren Fällen erfolgte die nene Anordnung des Protoplasmas unil der Chlornphyllkörner nach cinem etwas anderen Typus. Das Gemeinsame mit der vorigen Erscheinung bestand zwar anch in dem Verschwinden der Chlorophyllkörner von der Aussenwand; dieselben gruppirten sich aber sämmtlich oder zum grösseren Theile in eincn grossen auf der Hinterwand ruhenden und weit in den Raum der Zelle rorragenden dichten Klumpen. An den Seitenwänden war auch melır oder weniger deutlich eine Rotation von Protoplasina erkennbar, aber die strömende Masse war hier, offenbar weil das meiste Protoplasma auf der Hinter- 
wand stand, merklich dünner, und sie führte keine oder nur vereinzelt dort liegende Chlorophyllkörner mit. Auch diese Form blieb, einmal hergestellt, constant. Dass sie nicht wesentlich von der vorigen verschieden ist, geht daraus hervor, dass auch bei jener an der Hinterwand Chlorophyllkörner sich meist reichlich vorfinden. Der Unterschied ist also eigentlich nur ein relativer.

Die beschriebenen Veränderungen treten in der Regel nicht genau gleichzeitig in allen Zellen des abgeschnittenen Blattes ein. Wenn auch nicht in jedem Falle mit vollständigster Evidenz, so lässt sich doch im Allgemeinen hierin folgende Regel erkennen. Den Anfang machen die der Wundstelle zunächst gelegenen Zellen, während die der Spitze des Blattes näher liegenden etwas später nachfolgen Auch in den Querzonen des Blattes befinden sich die Zellen im Allgemeinen nicht in ganz gleichen Stadien: die der Mittelrippe zunächst stehenden beginnen die Veränderung früher als die nach dem Rande zu liegenden.

In allen Zellen des nämlichen Blattes erfolgen die Veränderungen nach einem und demselben Typus. Wo also z. B. die neue Stellung der Chlorophyllkörner in der soeben beschriebenen anderen Form sich ausbildet, da verhalten sich auch alle Zeller des Blattes in dieser Weise. Eine anderweite nähere Beziehung der Anordnung, resp. der Bewegung des Chlorophylls zu den gleichen Erscheinungen der übrigen Zellen ist nicht aufzufinden. Insbesondere besteht hinsichtlich der Rotatiossrichtung keine bestimmte Beziehung zwischen den benachbarten Zellen: sowohl zwei seitlich als auch zwei in logitudinaler Richtung verbundene (die Zellen sind ziemlich regelmässig in Längsreihen geordnet) können gleichsinnige wie entgegengesetzte Rotation haben, so dass es eben so gut Zellwände giebt, auf deren beiden Seiten die Protoplasmaströme gleichgerichtet sind, wie solche, an denen dieselben in entgegengesetzten Richtungen fliessen.

Die Elodea eignet sich besonders zur Untersuchung des Einflusses, welchen das Zerschneiden der Pflanze auf die betreffenden Theile ausübt. Wenn in einem abgeschnittenen Blatte die Chlorophyllkörner vollständig in die neue Stellung gekommen und in Rotation begriffen sind, so findet man in anderen Blättern desselben Stengels, von welchem jenes Blatt entlehnt worden war, wenn sie jetzt abgeschnitten und sofort untersucht werden, die Zellen alle im normalen Zustande. Selbst wenn mehrere Blätter zugleich abgeschnitten worden sind, ist dies in der Regel der 
Fall. - An einem sonst unverletzten Triebe schnitt ich von eivem Blatte die acropetale Hälfte ab und brachte sie sogleich mit Wasser unter ein Deckglas zur Beobachtung, während der Trieb selbst im Wassergefässe verweilte. In allen Zellen des Präparates befanden sich zunächst dic Chlorophyllkörner auf das Vollständigste in normaler Anordung. Nach ciner Stunde hatte die Ortsreränderung dersellen ihre Endschaft nahezu crreicht, die Rotation hatte bereits begounen. Jetzt wurde die an der Pflanze stehengebliebene basale $\mathrm{Halfte}$ des durchschnittenen Blattes abgeschnitten und sogleich untersucht. Mit Ansnahme der in der Nähe des früheren Wundrandes stehenilen befanden sich alle Zellen in völlig nornalem Zustande, so wie die Zellen der acropetalen Hälfte sofort nach deren Abtrennung. In jenen unmittelbar vor dem Wundrande stehenden Zel!en war aber mehr oder weuiger Unordnung in die Stellung der Chlorophyllkörner gerathen, und zum Theil war auch der Anfang der Rotation zu erkennen. Dieser Zustand ging in den Zeilen üher und unmittelbar neben der Mittelrippe augenscheinlich etwas weiter blatteinwärts, sonst war er strenger auf die am Wundrande gelegenen Zellen beschränkt. Erst nach einiger Zeit begann auch an diesem alogeschnittenen Präparate in allen Zellen die Veränderung der Chlorophyllstellung $\mathrm{u}$. $\mathrm{S}$.w. in der gewöhnlichen Weise. - Ferner zerschnitt ich rinen Elodea-Stenge! so in Querstücke, dass jedes Stïck nur aus einem cinzigen Blattquirle bestand. Sofort nach der Operation bestand in allen der normale Zustand der Zellen (die Untersuchung geschah ohne Verletzung der Stücke). Nachdem dic Otıjekte in eincm Gefässe mit Wasser unter gewöhnlichen Umständen 24 Stunden gelegen hatten, war in allen Blättern dic Ortsveränderung der Chlorophyllkörner, wenn auch nicht ganz in der Vollständigkeit, wic in für sich isolirten Blättern, eingetreten. Bei eiuem anderen Versuche verwendete icl, ein aus 3 Blattquirlen bestehendes Stengelstück, von dessen oberem und und unterem Quirle je cinem Blatte die acropetale Halfte abgeschnitten wurde. Das Stengelstück, wie die abgeschnittenen Theile blieben in cinem Gefässe mit Wasser unter gewöhulichen Verhältnissen 24 Stunden liegen. In den abgeschnittenen Blattstücken standen die Chlorophyllkörner sofort nach der Opcration in normaler Stellung. Später fand ich nicht nur in den abgetrennten Blattstüeken, sondern auch in den verschnittenen Stumpfen sowie in den übrigen Blättern der verletzten Quirle die Chlorophyllkörner mehr oder weniger in die entgegen- 
gesetzte Stellung versetzt; das Gleiche, nur in etwas minderem Grade, war auch in dem zwischenliegenden unverletzten Quirle erfolgt.

Die vorstehenden Ergebnisse lassen sich dahin zusammen. fassen, dass eine Lösung der Zellen nder Glieder der Pflanze aus ihrem natürlichen Verbande mit dem Hauptkörper in den abgetrennten Theilen einen Zustand vernichtet, welcher durch die normale Anordnung des Protoplasmas und der Chlorophyllkörner angezeigt wird, und zwar um so entschiedencr, ein je klcinerer Theil der ganzen Pllanze das abgeschnittene Stück ist.

Um die etwaige Bethciligung äusserer Einwirkungen bei der Herstellung des neuen Zustandes in den von dem Hauptkörper getrennten Gliedern zu ermitteln, stellte ich noch folgende Versuche an. Zurächst braclite ich abgeschnittene Blätter, die ich mit Fliespapier abgetrocknet hatte, unter Deckgläscr ohne Zusatz von Wasser. Die Vorrichtung wurde vor Verdunstung geschützt am Fenster dem Tageslichte ausgesetzt. Das Objekt war auf diese Weise lediglich von Luft umgeben; die Zellen enthielten Saft ohne Luftblasen; Protoplasma und Chlorophyllkörne: befanden sich anfangs in natürlicher Stellung. Auch unter solchen Umständen sah ich die Veränderung sehr bald in der gewöhnlichen Weise eintreten, und nach etwa einer Stunde war die neue Anordnung des Zelleninhaltes fertig.

Auch Anwesenheit oder Abwesenleit des Lichtes übt anf diese Erscheinungen keinen Einfluss; ich sah sic an Präparaten, die sofort nach ihrer Herstellung verdunkelt worden waren, in der gewöhnlichen Form eingetreten.

Die Gravitation macht ihren Einfluss in äbnlicher Weise bemerkbar, wie bei Sagittaria. Es muss jedoch vorausgeschickt werden, dass hier die Hinterwand nicht gleichwerthig ist derjenigen bei Sagittaria: dort liegt sie frei am Intercellularraume und ist in der ne,uen Stellung der Chlorophyllkörner von letzteren entblösst; hier steht sie mit anderen Zellen im Verbande und wird von Chlorophyllkörnern überzogen. Von einem Elodea-Triebe wurde eine Anzahl Blätter abgeschnitten, und zunächst, constatirt, dass in den Zellen derselben das Chlorophyll in der normalen Vertheilung sich befand; alsdann brachte ich sogleich die Präparate auf horizontale Ohjektträger mit Wasser unter Deckgläser, und zwar so, dass die eine Hälfte der Blätter mit der morphologischen Oberseite nach oben gekehrt war, die anderen aber in umgekehrter 
Lage sich befanden. Nach 5 Stunden hatte bereits in allen Blättern die Veränderung in Zelleninhalte in der gewöhnlichen Wcise mehr oder weniger begonnen, wobei jedoch in den verkehrt liegenden Blattern unrerkenubar mehr Körnchen auf der Aussenwand vorhanden waren als in den anderen. Nachdem die Präparate noch weitere 15 Stunden in der bisberigen Lage zugebracht hatten, war die Differenz noch weit grösser geworden. In den mit der morphologischen Oberseite nach oben gekehrten Blättern war die Aussenwand der Zellen entweder ron Chlorophyllkörnern ganz leer, oder es fanden sich daselbst nur einige wenige Körner, die dann meist der Seitenwand genähert waren. In den rerkehrt gelegenen Blättern stand zwar auch die Mchrzahl der Chlorophyllkörner auf den Scitenwänden und auf der Hinterwand, allein es waren im Allgemeinen auf den Aussenwänden entschieden melir vorhanden als in den anderen Blüttern, was schon ohne Zählung bei der oberfächlichsten Verglcichung mit jenen unzweideutig herwortrat. Zwar gab es Zellen, welche nicht mehr Chloroplyllkörner auf der Aussenwand trugen als die meisten Zellen jener Blätter; indessen war dic Zahl derjenigen mit entschieden zahlreicheren Körnern an der Aussenwand die weitaus grössere; ja in dem einen der verkehrt gelegenen Blätter fand ich sogar in den meisten Zellen an den Aussenwänden dic Chlorophyllkörner noch in einer fast dem normalen Zustande gleichkommenden Anzahl sowic in ähnlicher allwärts gleichmässiger Verthcilung über die ganze Wand. Nach Beendigung der Untersuchungen wurden nun die bisher vorkehrt gelegenen Blätter unter den nämlichen Umständen in umgewendete Lage gebracht, wobei also die Aussenwände der Oberzellen aufwärts zu liegen kamen. Als sie dann nach 6 Stunden wicder untersucht wurden, ergab sich, dass die Chlorophyllkörner jetzt zum allergrössten Theile die Aussenwand verlassen hatten, und dass nun in dem Aussehen der Zellen kein Unterschied mehr von denjenigen der un rerändert in natürlicher Stellung gelegenen Blätter aufzufinden war. Daraus ergiebt sich denn abermals in zwingender Weise, dass bei diesen Umlagerungen der Inhaltsbestandtheile der Zelle die Gravitation ihren Einfluss in merklicher Weise geltend macht. 


\section{Vallisneria spiralis.}

Das Blatt der Vallisneria ist auf beiden Ssiteu mit einer Epidermis überzogen, welche aus ziemlich flach tafelförmigen, viereckigen, im Verhältniss zu den Mesophyllzellen sehr kleinen Zellen besteht. Diese enthalten ziemlich zahlreiche Chlorophyllkörner, welche, obgleich die Enge der Zelle eine scharf ausgeprägte Anordnung derselben erschwert, an der unverletzten Pflanze ungefähr folgende Vertheilung crkennen lassen. Es liegen entweder alle oder doch die meisten der freien Aussenwand an; bisweilen sieht man auch cinige an den Seitenwäaden oder auch an der Hinterwand. Das letztere kaun eben wegen der sehr flachen Gestalt der Zelle leicht geschehen. Denn wenn auch in manchen Fällen die Chlorophyllkörner unter der Aussenwand eine einfache zusaınmenhängende Lage bilden, so sind sie doch dasclbst oft dichter gehäuft; man sieht sie nicht selten einen nur die Mitte der Zelle einnchmenden, der Aussenwand anliegenden Haufen bilden, der dann in der Regel auch bis an die Hinterwand reicht. Protoplasmarotation bemerkt man in diesen Zellen an der unverletzten Pflanze nicht.

Das Mesophyll besteht aus sehr grossen und weiten parallelepipedischen Zellen, welche im Allgemeinen drei Schichten bilden. Von diesen sind nur die unter den beiden Epidermen liegenden vollständig; die mittlere Schicht bestcht nur aus einzelnen einfachen Zellreihen, welche theils in longitudinaler, theils in transversaler Richtung angeordnet sind, und dadurch Veranlassung zur Bildung grosser viereckiger Lufträume geben. Die breiten Seiten der letzteren werden also von den inneren Wänden der beiden äusseren Mesophyllzellschichten, die schmalen Seiten von den Seitcnwänden der mittleren Mesophyllzellen begrenzt. Ès verhalten sich also auch die äusseren und die mittleren Zellen hinsichtlich ihrer Umgebung ungleich: die letzteren stehen ausser an den Querwänden an den der Blattfläche parallelen Längswänden mit Nachbarzellen in Berührung; bei ersteren dagegen sind dies ausser den Querwänden die beiden rechtwinklig zur Blattfäche gerichteten Längswände. Mit den übrigen Seiten stossen die Mesophyllzellen an die Intercellularräume, eventuell an die Epidermis. Es mögen 
der Kürze wegen im Folgenden diejeuigen Zellwände der Mesophyllzellen, an welchen sie mit anderen ihres Gleichen in Verbindung stehen, Fugenwände, und diejenigen, wclche an die lntercellularräume grenzen, freic Wände genannt werden. Diese Zellen sind es, in welchen die scit langem bekanute Rotation des Protoplasmas, die zugleich die Chlorophyllkörner in Bewegung setzt, zu beobachten ist. Man findet diese Erscheinung in den Schriften der Physiologen folgendermassen dargestellt ${ }^{1}$ ). Der cine gcschlossene Bahn beschreibende und den Zellenkern sowie sätnmtliche Chlorophyllkörner mit sich führende Protoplasmastrom geht nur über die beiden Fugenwände und über die Querwände. E3 steht also die Ebene, in welcher der Strom kreist, in den beiden äusseren Mesophyllzcllschichten der Fläche des Blattes parallel, in den mittleren Zellen dagegen rechtwiuklig dazu. Von diesen Vorgängen, die an den Präparaten mit aller Evidenz zu beobachten sind, wird stillschweigend angenommen, dass sie auch in den Zellen der intakten Pflanze in gleicher Form stattfinden.

Zwar ist es den Beobachtern nicht entgangen, dass in der Regel unmittelbar nach der Präparation in den Zellen keine Strömung stattfindet und erst einige Zeit nachher beginnt. Man hat hierbei, und dies mit allem Rechte, daran gedacht, dass mechanische Eingriffe, wie sie z. B. auch durch den Schnitt des Präparirmessers bewirkt werden, thatsächlich die Bewegungen des Protoplasmas vorübergehend aufheben ${ }^{2}$ ) Darnach liegt es aber nahe, anzunehmen, dass das Bild, welches die Zelle im Präparate nach dem Wiedereintritte der Plasmaströmung darbietet, deın vor der Präparation in der Pflanze bestehenden Zustande entspricht. Nach dem, was ich über den Erfolg der Verwundung an den Blättern der Elodea etc. ermittelt habe, schien mir dies jedoch zweifelhaft. Die nähere Untersuchung führte in der That zu eincm gegentheiligen Resultate.

Wenı man von Blattstücken durch einen Flächenschnitt die Epidernis ncbst der darunter liegendeu Zellschicht abträgt und die Stücke dann mit der Schnittfläche nach obeu auf den Objekt-

1) Vergl. z B. die ausführliche Beschreibung bei Mleyen, Neues System der Pflanzenphysiologie II. p. $228-234$ und dazu die Abbildung auf Tafel VIII. Fig. 4.

2) Vergl. Meyen, l. c. p. 234. - Hofmeister, die Lehre von der Pflanzenzelle p. 50. 
träger legt, so werden an den vorliegenden Mesophyllzellen die in Rede stehenden Erscheinungen mit Deutlichkeit sichtbar. Dic Hinterwand der geöffneten grossen Intercellularräume wird von den subepidermalen Zellon der entgegeugesetzten Blattseite gebildet, und diese kehren dem Beobachter unmittelbar ihre freicn Wände zu. Stellenweise sieht man die mittleren Mesophyllzellen, welche dic Lufträume von einander scheiden, und diese sind mit ciner Fugenseite dem Beobachter zugewendet. Haben solche Präparate eine Zeit lang mit Wasser benetzt gelegen, so sieht man das Protoplasma in lebhafter Rotation, und zwar in allen Zellen über die Fugenwände hinströmen. In der Regel schwement es ausser dem Zellenkern auch sämintliche Chlorophyllkörner der Zelle mit fort; mit anderen Worten, es haben diese Körper ihren Platz an den Fugen- und Querwänden. Dies ist besonders deutlich an den Zellen, welche den Hintergrund der Lufträume einnehmen; hicr sind die freien Wände dem Beschauer in ihrer ganzen Aus. dehnung zugewendet, und auf diesen findet man in der Regel nicht ein cinziges Chlorophyllkorn. Rings um die Seitenwände aber ist der Plasmastrom in Rotation, und in demselben stecken im Allgemeinen in lückeuloser Lage, nur stellenweise stärker angehäuft, sämmtliche Chlorophyllkörner, desgleichen der Zellenkern. Es besteht also hier eine Anordnung des Zelleninhaltes, welche dem Zustande in den Zellen abgeschittener Elodeablätter einige Zeit nach der Präparation durchaus analog ist.

Wesentlich anders ist das Bild, welches die nämlichen Zellen unmittelbar nach der Präparation darbieten. Wenn man cincm unverletzten, noch mit der Pflanze in Verbindung stehenden Blatte an ciner Stelle in der eben bezeichneten Weise die Epidermis sanmt der darunter liegenden Zellschicht wegschneidet, und sofort enlweder das Präparat oder das Blatt selbst an der operirten Stelle unter das Mikroskop schicbt, so dass man durch die geöffueten Lufträume dirckt die im Hintergrunde derselben lie? genden Zellen erblicken kann, so findet man in den letzteren in der Regel das Protoplasma in Ruhe, oder doch nur in sehr träger Rotation auf den Fugenwänden hinströmen. Aber die Chlorophyllkörner sitzen, wenigstens der Mehrzahl nach, an den freicn Wänden. Und während in jenem Falle auf den Fugenwänden die Chlorophyllkörner in einer zusammenhängenden gedrängten Lage rersammelt sind, sicht wan jetzt daselbst deren nur einzelne zerstreute oder wenige in kleinen, isolirten 
Häufchen. An den freien Wänden stehen die Chlorophyllkörner allerdings nicht in einer continuirlichen Lage, sondern angemessen ihrer im Vergleich zu der ausserordentlichen Grösse dieser Zellen geringen Anzahl, in Entfernungen von cinander, und zwar oft ziemlich ungleichmässig: an manchen Stellen weitläufiger, an manchen näher bei einander, ohne irgend eine bestimmte Regel. Der Zellenkern liegt in den ıncisten Fällen an einer der Fugen- oder Querwände, doch findet man ihu auch in manchen Zellen an der freien Wand. So oft ich auch diese Probe an verschiedenen Blättern wiederholte, war das Resultat dasselbe. Diese wesentlich andere Anordnung der Chlorophyllkörner unmittelbar nach der Präparation kann kaum aus einer momentanen Aufhebung der Protoplasmabewegung erklärt werden, denn es wäre schwer cinzusehen, warum dic bis dahin in dem strömenden Protoplasma eingebetteten Chlorophyllkörner in dem Augenblicke, wo in Folge des Schnittes die Bewegung stockt, von den Seitenwänden auf die freie Wand sich begeben sollten. Wenn man aber unzweifelhaft beweisen will, dass in der That die zuletzt beschriebene Anordnung der Chlorophyllkörner die in der intakten Pflanze normal herrschende ist, so muss man diese unverletzt untersuchen. Während man die Pflanze selbst im Wasser stehon lässt, beugt man ein Blatt derselben heraus und legt es behutsam über cinen Objektträger, der unter dern Mikroskope liegt, und bedeckt eine Stelle des Blattes unter Vermeidung ron Druck mit einem hinreichend grossen Deckglase. Bei günstiger Beleuchtung lässt sich dann durch die chlorophyllhaltige kleinzellige Eipidermis hindurch die darunter liegende Zellschicht wenigstens so weit erkennen, dass man ihre Chlorophyllkörner wahrnimmt. Sorgt man dafür, dass das Blatt fortwährend genügend benetzt ist, so kann es lange ohne Schaden in dicser Lage blciben, und man kann dic Beobachtung längere Zeit fortsetzen. In den subepidermalen Zellen sicht man hier die Chlorophyllkörner in gleicher Vertheilung wie in einem soeben der Pflanze entnummenen Präparate Die dem Bcobachter abgewendete freie Wand der Zelle ist mit zerstreut stelenden Chlorophyllkörnern besetzt. . Fixirt man diese einige Zeit, so bemerkt man, dass sie langsam ihren Ort verändern, aber nicht in einer bostimmten Bahn continuirlich fortschreitend, sondern auf kürzere Strecken, nach jeder beliebigen Richtung hin. und herrutschend, ohne eine bestimmte Regel. Oft scheinen Körnchen längere Zeit still zu stehen, hernach kommen sie aber in Bewegung, um dann vielleicht wieder eine Zeit lang 
in Ruhe zu gerathen. Zwar lassen sich verschiedene Geschwindigkeiten unterscheiden, doch sind alle diese Bewegungen auffallend träg, und sie stimmen überhaupt in jeder Hinsicht mit den Erscheinungen überein, die Eingangs dieser Arbeit für andere Wasserpflanzen angegeben worden sind. Bisweilen rutschen Chlorophyllkơnner wohl auch bis an den Rand der Zelle, aber sie kehren entweder alsbald wieder zurück oder es rutschen andere für sie an die freie Wand. So bleibt doch die letztere dauernd mit Chlorophyllkörnern besetzt. Die Fugenwände dagegen sind, wenn auch nicht geradezu von Chlorophyllkörnern entblösst, so doch nur mit wenigen bedeckt; das Protoplasma aber, welches diese Wände überzieht, befindet sich in Rotation. Es ist nun zwar weit schwieriger, unter diesen Umständen die im Profil zugekehrten Fugenwände auf die an ihnen liegenden Körper zu untersuchen, als dies bei den querrorliegenden freien Wänden möglich ist. Allein man findet bei einigem Suchen leicht solche Stellen, wo ein, wenn auch kurzes Stück des Randes einer Mesophyllzelle mit aller Deutlichkeit sichtbar ist, und wo man mit Leichtigkeit den an der Fugenwand hinkriechenden Protoplasmastrom beobachten kann. Dies genügt, um die Beschaffenheit des Zelleninhaltes im ganzen Umfange der Zelle zu ermitteln. Denn da der ganze Protoplasmabuleg der Seitenwände in einem geschlossenen Strome sich fortbewegt, so müssen nach und nach alle Stellen desselben unter dem der Beobachtung zugänglichen einen Punkte des Randes vorüberpassiren. Man sieht nun in der strömenden Masse von Zeit zu Zeit einzelne Chlorophyllkörner mit vorüberkommen, bisweilen auch mehrere beisammen liegende zuglęich, häufig befinden sich auch einige in der Begleitung des Zellenkernes. Sie stehen in der Regel in ziemlichen Entfernungen von einander: es fliesst oft ein langes Stück des Stromes vorüber, ehe wieder ein Chloro. phyllkorn kommt. Jedenfalls ist die Zahl derselben sehr gering im Vergleich zu der zahlreichen Menge überall gedrängt stehender Körner, welche in einem mehrere Stunden gestandenen Präparate dem rotirenden Protoplasmastrome eingebettet sind. Demgemäss muss man den in der Zelle unmittelbar nach der Präparation sichtbaren Zustand auch als den in der intakten Pflanze bestehenden ansehen, mit der einzigen Ausnahme, dass dort das Protoplasma der Seitenwände vorübergehend unbeweglich geworden ist. Wenn man nun soeben gefertigte Präparate längere Zeit beobachtet, so kann man die Vertauschung des anfänglichen Zustandes Jabrb. f, wisn. Botanil. VIII. 
mjt der definitiven neuen Anordnungsweise der Chlorophyllkörner direct verfolgen. Nach kurzer Zeit kommt zunächst das Protoplasma auf den Fugen- und Querwänden wieder allmählich in Bewegung, oder dieselbe wird lebhafter, wenn sie nicht ganz erloschen war. Dann beginnen auch die an der freien Zellwand stehenden Chlorophyllkörner ihre früheren langsamen Rutschbewegungen wieder. Diese nehmen aber jetzt sehr bald ein bestimmtes Ziel an: es rutschen die Körner rorwiegend den Rändern der Zelle zu, um entweder sogleich sich dem dort rotirenden Protoplasma anzuschliessen, oder abermals mehr oder weniger weit zurückzukehren. So wird allmählich, indem die Zahl der in den Protoplasmastrom aufgenornmenen Körner grösser ist, als die der wieder zurückkehrenden, die freie Zellwand immer mehr von Chlorophyll entblösst. Ebenso wirl auch der Zellenkern, wenn derselbe an der freien Wand lag, sogleich oder nach wiederholten Ansätzen ron dem Seitenwandstrome aufgenommen. Endlich sind alle Chlorophyllkörner von der freien Zellwand geflohen, w:d man hat nun dasjenige Bild, in welchem die bisherigen Beobachter die Vallisneriazellen dargestellt haben.

In den Epidermiszellen, deren normaler Zustand oben beschrieben worden ist, stellt sich nach der Abtrennung rom Blatte ebenfalls eine Veränderung in der Vertheilung der Chlorophyllkörner ein. Auch hier weichen dieselben von der freien Wand der Zelle zurück und ordnen sich an der Hinterwand und an den Seitenwänden. Indessen ist hier der definitive Zustand nicht durchweg ein gleicher. In manchen Zellen stehen die Chlorophyllkörner zum grösseren Theile an den vier Seitenwänden, so dass eine zusammenhängende grüne Schicht die fast chlorophylllose Mitte umgiebt. In anderen Zellen liegen die Chlorophyllkörner auf der Hinterwand, und auch intermediäre Zustände werden häufig angetroffen. Bisweilen stellen sich auch Protoplasmabewegungen ein: dann ist bald nur der Seitenwandbeleg in Rotation begriffen, während die in der Mitte der Zelle stehenden Chlorophyllkörner auf der Hinterwand ruhen; bald rotiren aber von diesen wenigstens die dem Rande genäherten ebenfalls mit; bald auch befindet sich der ganze Inhalt der Zelle in drehender Bewegung, wobei der Mittelpunkt der Hinterwand das Drehungscentrum ist.

Die Zeit, welche erforderlich ist, um an den von dem Hauptkörper getrennten Zellen die neue Anordnung der Chlorophyllkörner herbeizuführen, lässt sich nicht allgemeingültig angeben. Es kom- 


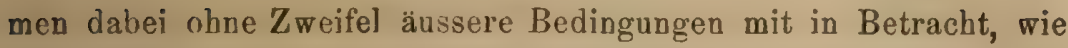
z. B. die beschleunigende Wirkung eines gewissen gunstigen Tem. peraturgrades nicht zu verkennen ist. Unter solchen Umständen kann die Veränderung schon nach viertel- bis halbstündiger Dauer eingetreten sein. Jedenfalls wird man nicht länger als einige Stunden darauf zu warten brauchen.

Es sei noch bemerkt, dass diese Erscheinungen bei der Vallisneria sich denjenigen bei Elodea canadensis auch insofern gleich verhalten, als dabei ebenfalls das Licht ohne Wirkung zu sein schernt, indem die Chlorophyllkörner in den präparirten Zellen ihre neue Stellung ebenso einnehmen, wenn das Präparat dauernd im Dunkeln gehalten wird, als wenn es sich im Tageslichte befindet.

\section{Crassulaceen.}

Nach Böhm's oben bezeichneten Angaben verhält es sich mit der Lage der Chlorophyllkörner in den Mesophyllzellen der Crassulaceenblätter in über hundert von ihm untersuchten Arten übereinstimmend folgendermassen. Stehen die Individuen „,im Freien“, so liegen die Chlorophyllkörner zerstreut über die Zellwände, werden sie aber den directen Sonnenstrahlen ausgesetzt, so ziehen sich jene in eine der Zellwand anliegende Gruppe zusammen. Dies finde sowohl an der unverletzten Pflanze, als auch an Präparaten, welche im Wasser oder auf feuchtem Filtrirpapier liegen, statt. Die Erscheinung wird als eine Wirkung der directen Sonnenstrahlen aufgefasst (p. 510). Es sind aber von Böhm noch einige andere Beobachtungen angeführt worden, welche mit dem eben Gesagten nicht recht in Einklang zu bringen sind. So soll auch das zerstreute Sonnenlicht nicht obne Wirkung sein, und man müsse daher die Pflanze, deren Chlorophyllkörner sich in einer Gruppe vereinigt haben, wenn dieselben wieder ihre anfängliche Vertheilang annehmen sollen, wenigstens einen halben Tag in einen finstern Raum stellen (p. 512). Ausserdem wird aber auch angegeben, dass an Präparaten die Gruppirung der grünen Körner zu einem Hanfen auch im vollkommen finstern Raume nach einigen Stunden eintrete.

Ich finde die Vertheilung der Chlorophyllkörner in den im Freien oder im Zimmer unter gewöhnlichen Umständen gehaltenen 
Pflanzen in einer von den Angaben Böhm's abweichenden Weise; glaube aber. dass derselbe die nämlichen Erscheinungen vor Augen gehabt hat, nur nicht zur Erkenntniss ihrer Gesetzmässigkeit gekommen ist. Es dienten mir zur vorläufigen Orientirung verschiedene Scdum- und Sempervivum-Arten, und da ich bei allen ein gleiches Verhalten beobachtete. so setzte ich die weiteren Untersuchungen an Sempervirum Funkii Braun, Requienii DC., ruthenicun Lchm. fort, als denjenigen Arten, die für Präparation und Beobachtung am günstigsten erschienen.

Um dic Gesetzmässigkeit der Chlorophyllvertheilung in•den Mesophyllzellen der Crassulaceen in Worte zu fassen, muss man sich zuuächst über die Form und die gegenseitige Verbindung dieser Zellen klar werden. Diese sind, ohne vollständig gleiche Grösse zu haben, ungefähr ron tonnenförmiger Gestalt. Die obere und untere Wand rincr jeden Zelle ist nämlich eben, und an diesen Wänden stehen die Zellen in festem unlösbarem Zusammenhange, indem die beiderseitigen Membranentheile zu einer cinfachen Platte innig verwachsen sind und an dieser Stelle also keinen Intercellularraum bilden. Es sind hiernach die Mesophyllzellen in Longitudinalreihen geordnet, welche der Längsachse des Blattes parallel laufen. Diese Reihen liegen in radialen Streifen und sind in dieser Richtung auch zienlich fest verbunden, indem die Zellen an ihrer vorderen und hinteren Wand, wenigsteus in einem mittleren Streifen in eben solcher Weise mit den Nachbarzellen zusammengewachsen sind, wie an den Querwänden. Aber die in tangentialer Richtung nebeneinanderliegenden Zellenstreifen stehen in der Regel nirgends im Zusammenhange: die linken und rechten Wände der Zellen sind nämlich ziemlich convex und in ihrer ganzen Ausdehnung frei, kaum dass sie in der erhabensten Mitte ein wenig zusammenhängen. Es liegen also continuirliche, ziemlich weite, lufthaltige Intercellulargänge radial $\mathrm{zwischen}$ den einzelnen Zellreihen. Daher kommt es, dass, wenn man nach Entfernung der Epidermis tangentiale Längsschnitte durch die Blattmasse anstcllt, jede abgetragene Lamelle sogleich in parallele Längsfasern auseinanderfährt, die eben aus jenen einfachen Zellreihen bestehen. An Individuen, welche soeben von ihrem natürlichen Standorte genommen sind oder auch im Zimmer am Fenster im diffusen Tageslichte gestanden haben, findet man sogleich nach der Präparation dic Chlorophyllkörner im Allgemeinen nur an den beiden freien radialen Längswänden; die Vorder- und Hinterwände 
und zumal mit aller Strenge die beiden Querwände sind nicht damit besetzt. Auch das Innere der Zellhöble enthält nichts da. von. Die Chlorophyllkörner bekleiden die freien Seitenwände entweder in deren ganzer Ausdehnung gleichmässig oḍcr doch den grösseren Theil derselben und bilden eine einfache Lagé, indem eins neben dem andern und jedes mit seiner breiten Seite der Zellwand parallel steht. Wenn der Schnitt etwas dick ist, so geschieht es leicht, dass sich die radialen Zellstreifen auf ihre breite Seite leger, und da dann die Zellen die mit Chlorophyllkörnern bedeckten breiten Seitenwände dem Beobachter zukehren, so kann aus solchen Bildern allein ohne genauere Untersuchung der im Profil zu sehenden Zellwände leicht die Vorstellung erzeugt werden, als stünden die Chlorophyllkörner allenthalben an den Wänden vertheilt. Hiernach fallen auch diese Zellen hinsichtlich des Typus der Vertheilung ihrer Chlorophyllkörner bei normalen Verhältnissen unter denselben Gesichtspunkt wie die Zellen der bisher betrachteten Pflanzen: denn wir sehen die Körner nur diejenigen Zellwände einnehmen, welche aussen frei sind, nämlich nicht mit anderen Zellen im Verbande stehen. - Ich will noch bemerken, dass Gleiches auch in den Blättern von Sedumarten $\eta_{u} u$ sehen ist, und glaube daher, dass sich überhaupt die Crassulaceen in dieser Weise verhalten. Sehr lehrreich war mir eine Erscheinung, die ich an Sedumarten beobachtete. Dic Mesophyllzellen zeigen hier bisweilen einen Ansatz zur Sternfolm, indem sie an jenen freien Seitenwänden an einer gewissen Stclle in kurze gegeneinander gerichtete Auswüchse verlängert sind. An diesen ringsum freiliegenden Wandstellen fand ich besonders viel Chlorophyllkörner.

Wenn man. solche Präparate, mit Wasser benetzt, einige Zeit stehen lässt, so wird die Vertheilung der Chlorophyllkörner allmählich eine andere. Es ist dabei gleichgültig, ob die Präparate sich mit Wasser unter einem Deckglase befinden, oder ob sie nach Böhn's Methode auf feucht gehaltenem Filtrirpapiere liegen. Die Veränderung tritt ziemlich rasch ein: wenigstens ist sie nach cinigen Stunden, oft schon nach einer halben Stunde bemerklich. Man sieht zunächst die Chlorophyllkörner sich an den Seitenwänden in mehrere Gruppen zusammenziehen, die in ziemlichen Entfernungen von einander liegen. Diese bestehen aus einer verschieden grossen Anzah] von Chlorophyllkörnern, welche alle eine einfache Lage bilden, indem eins unmittelbar an das andere anstösst; die ganze 
Gruppe ist daher scharf umschrieben; die übrigen Stellen der Zellenwand sind dann ron Chlorophyll entblösst. In der Regel vereinigen sich die Gruppen, indem sie sich mehr nach den beiden Querwänden hinziehen; bisweilen begeben sich auch die Chlorophyllkörner einzeln dorthin. Hier kommt es nun zu einer oft sehr dichten Anhäufung, und bisweilen findet man sämmtliche Chlorophyllkörner an diesen beiden Wänden, indem sie ron einem scharf umschriebenen dichten Haufen solcher ganz bedeckt werden. Doch geschieht es auch, dass die Wanderung unvollstängdig ist, indem noch an anderen Zellwänden Gruppen oder einzelne Chlorophyllkörner zerstreut zurückbleiben. Das Resultat ist dasselbe, gleichgültig ob die Präparate in Lichte oder im Dunkeln gehalten werden.

\section{Licht.}

Dass lediglich dauernde Entziehung des Lichtes an einer in normaler Vegetation begriffenen Pflanze die Vertauschung der gewöbnlichen Vertheilung der Chlorophyllkörner in der Zelle mit der entgegengesetzten bewirken kann, ist zunächst für Moose durch Famintzin's Untersuchungen an einer nicht näher bestimmten Species von Mnium erwiesen worden. Das Gleiche hat Borodin ${ }^{1}$ ) bei Funaria hygrometrica beobachtet. Ich habe diese Untersuchungen an den Blättern von Mnium rostratum Schwaegr. wiederholt, im Wesentlichen mit dem gleichen Erfolge. Das Morphologische der Erscheinung ist dasselbe wie das in Folge der Abtrennung der Zellen zu beobachtende. Bisweilen ist die Veränderung der Stellung die denkbar vollständigste, d. h. es liegen sämmtliche Chlorophyllkörner an den Seitenwänden, kein einziges befindet sich an den breiten Zellwänden. So vollständig geschieht aber die Umlagerung nicht in allen Zellen, selbst nicht nach mehrwöchentlicher dauernder Verdunkelung. In manchen Blättern bleiben noch mehr oder weniger Chlorophyllkörner auf den breiten Wänden sitzen. Auch giebt es in einem und demselben Blatte Zellen mit vollständigem und solche mit unvollständigem Stellungswechsel; zumal stehen oft in den weitesten Zellen, die in der Nähe der Mittelrippe sich befinden, noch einige Chlorophyllkörner an den breiten

1) 1. c. p. 446 . 
Wänden, während in den mehr nach dem Rande und nach der Spitze zu liegenden engeren Zellen die neue Stellung in vollständigerer Weise eingetreten ist. Umgekehrt geschieht aber die Wanderung der Chlorophyllkörner aus der Dunkelstellung in die normale Anordnung stets vollständig: wenn die längere Zeit in Dunkeln verweilten Pflanzen wieder ans Licht gebracht werden, so verlassen in allen Zellen sämmtliche Chlorophyllkörner die Seitenwände und nehmen ihre Stellung auf den beiden breiten Wänden ein.

Unter den foliosen Jungermannieen dürfte die Erscheinung weit verbreitet sein. Ich beobachtete sie an Radula complanata Dumort., Mastigobryum trilobatum N. ab E. und Lophocolea bidentata N. ab E. Die Form des Vorganges ist in Nichts verschieden von der Erscheinung nach Abtrennen und Zerschneiden der Blätter, wie sie oben von Radula complanata besclirieben worden ist. Der Stellungswechsel bei Verdunkelung ist hier in der Regel vollständiger, doch sind ebenfalls manche Eigenheiten gewisser Theile zu beobachten, von denen weiter unten ein Weiteres. Auch hier erfolgt die Rückwanderung der Chlorophyllkörner aus der Dunkelstellung in die natürliche Anordnung, sobald die Pflanze wieder ins Licht gebracht wird, und zwar gleichfalls mit grösster Vollständigkeit.

Auch den Farnprothallien kommt diese Erscheinung zu, wie Borodin an denjenigen von Allosorus sagittatus und Aspidium spinulosum, sowie an anderen unbestimmten Vorkeimen aus Gewächshäusern gezeigt hat. An solchen habe ich den Vorgang ebenfalls beobachtet; er ist wiederum den schon oben an diesen Organen dargelegten Veränderungen gleich. Die Vorkeime verschiedener Farne verhalten sich in dieser Beziehung verschieden: in manchen tritt die Erscheinung schneller und vollständiger ein als in anderen. Auch ist hier in vielen Zellen die Veränderung der Chlorophyllstellung im Dunkeln nicht vollständig, worauf ebenfalls Borodin ${ }^{1}$ ) schon aufmerksam gemacht hat.

Auch in den Epidermiszellen der Oberseite der submersen Blätter von Sagittaria sagittaefolia gerathen die Chlorophyllkörner sowie das Protoplasma in die oben beschriebene neue Stellung, wenn nur die ganze unverletzte Pflanze einige Zeit dauernder Verfinsterung ausgesetzt wird. Es bekleiden sich die Seitenwände mit einer zusammenhängenden Schicht gedrängt stehender Chlorophyll-

1) l. c. p. 443. 
körner, und wenn ein Zellkern deutlich sichtbar ist, so liegt er ebenfalls auf einer Seitenwand. Die breiten Aussenwände dagegen sind entweder ganz leer oder nur mit rereinzelten Körnchen bcdeckt; die Hinterwand trägt gewöhnlich noch cine grössere Anzahl. Um diese Anordnung nahezu vollständig herzustellen bedurfte es im hohen Sommer bei dem einen Versuche einer con. stanten Verfinsterung vou vier Tagen, bei einem zweiten von fünf Tagen. Werden so gehaltene Individuen wieder dem Tageslichte ausgesetzt, so begeben sich die Chloroplyllkörner und das Protoplasma wieder in die gewöhnliche Stellung. Schon nach fünfzehn Stunden war die Veränderung weit fortgeschritten, in manchen Zellen nahe vollendet, in vielen aber auch noch schr iı Rückstande, uberall jedoch wenigstens der Anfang bemerklich. Wegen dieses versfliedenen Verhaltens der einzelnen Zellen zu gleichen Zeiten rermochte ich denn auch kein bestimmtes Zeitmass als das für die Rückwanderung bei erneuter Beleuchtung erforderliche anzugeben.

Auf Eloclea canadensis ist die Wirkung der Verdunkelung eine entschieden schwächere als auf die rorgenannten Pflanzen. Die Resultate der in dieser Richtung angestellten Versuche waren nicht sämmtlich cinander gleich. In einem Falle konnte ich selbst nach sechswöchentlicher constanter Verfinsterung nur eine geringe Veränderung in der Stellung der Chlorophyllkörner beobachten. Diese waren bis jetzt noch nicht desorganisirt: sie besassen noch die gesunde grüne Farbe und waren sogar noch mit Stärkeeinschlüssen versthon; dagegen waren die unterdessen neugebildeten Blätter vollständig rergeilt. Die Chlorophyllkörner bekleideten noch in gleichmässiger einfacher Schicht die Aussenwand, zum Theil lagen sie an der Hinterwand. In manchen Zellen war dies in einer Weise der Fall, die keinen Unterschied von der Stellung des Chlorophylls unter gewöhnlichen Verhältnissen crkennen liess. In anderen Zellen war allerdings dic Zahl der an der Aussenwand sitzonden Körner eine etwas geringere: diese standen entfernter, aber doch in gleichmässigen Abständen von einander. Die Cultur wurde nun noch vicr Wochen lang in constanter Dunkelheit gehalten. Jetzt erst war die Veränderung erheblicher geworden. Die Pflanzen waren noch vollständig am Leben, sie sahen auffallend hellgrün aus (die in der Dunkelheit erzeugten Theile natürlich gelb); die Chlorophyllkörner hatten noch ihre grüne Farbe, aber die Stärkeein. schlüsse waren verschwunden, und der Durchmesser der Körner 
war um das Mehrfache geringer geworden'). In manchen Blättern befand sich nicht ein einziges Chlorophyllkorn auf den freien Wänden der Zellen; diese sassen sämmtlich an den Seitenwänden, einige auch auf der Hinterwand. In anderen Blättern war die Veränderung noch nicht so vollständig: es befanden sich auf der Aussenwand noch einige wenige Körnchen, wclche dort in gleichen Abständen von einander über die ganze Wand verbreitet lagen. Die Zahl dieser Körnchen war dann in der Spitze des Blattes am grössten und nahm nach abwärts von Zelle zu Zelle ab, in den untersten Zellen war wohl auch die Veränderung schon vollständig hergestellt. Rotation war nirgends zu sehen, wohl aber machten sich selbst in solchen Zellen, in denen kein einziges Chlorophyllkorn mehr an der Aussenwand sich befand, daselbst strömende und ihren Ort verändernde Protoplasmastränge bemerkbar, welche quer unter der Wand oder schief von derselben ins Innere der Zelle verliefen, aber niemals Chlorophyllkörner fortbewegten. Es scheint dies anzudeuten, dass bei dieser Pflanze das Protoplasma durch Entziehung des Lichtes weit weniger als in Folge der Trennung von dem Hauptkörper der Pflanze veranlasst wird, seine Anordnung in der Zelle mit der entgegengesetzten zu vertauschen, und es würde sich so erklären, warum auch die Chlorophyllkörner unter diesen Verhältnissen erst nach so langer Zeit in die neue Stellung gerathen. Die Pflanzen wurden dann wieder ins Tageslicht gesetzt. Schon nach einigen Tagen fand sich kein Chlorophyllkorn mehr an den Seitenwänden, einige an der.Hinterwand, die meisten aber sassen an der Aussenwand und bildeten hier eine die Mitte derselben einnehmende Gruppe, welche durch innerlich strömende dünne Protoplasmafäden mit dem peripherischen Protoplasma zusammenhing. Bei mehreren anderen Versuchen zeigten die Chlorophyllkörner bereits nach ein- oder wenigwöchentlicher Verfinsterungsdauer, und zwar als sie noch ihre Stärkeeinschlüsse besassen, eine merklich veränderte Stellung: es waren viele derselben auf den Hinter- und Seitenwänden zu sehen; indessen fehlten sie auch an der Aussenwand nicht gänzlich: man sah daselbst noch einige Körnchen entweder einzeln in gleichen Distanzen von einander oder an einer bestimmten Stelle gehäuft, eines neben dem anderen, oft eine quer-

1) Diese Verringerung des Durchmessers der Chlorophyllkörner in Folge von Entziehung des Lichtes ist kürzlich schon von Micheli (Quelques observations sur la matière colorante de la chlorophylle. Arch, d. sc. de la bibliothèque universelle de Genève 1867) gelehrt worden. 
über liegende Gruppe bildend, während daun der ganze übrige Theil der Aussenwand meist keine Körnchen weiter trug. An den zur Untersuchung abgeschnittenen Blättern trat aber ausnahmslos die Follständige Lagenveränderung auch hier rach kurzer Zeit in der gewöhnlichen Weise ein.

Endlich wurden auch Individuen verschiedener Sempervivum. Arten diesem Experimente unterworfen. Vorher war constatirt worden, dass ihre Chlorophyllkörner in der oben beschriebenen Weise die beiden radialen Seitenwände der Mesophyllzellen beklei deten. Nach dreitägigem Verweilen in einem dunkeln Raume bei gewöhnlicher 'Zimmertemperatur' wurden sie untersucht. Die Chlorophyllkörner hatten sich zicmlich gleichmässig über alle Zellwände verbreitet: es waren nämlich die beiden radialen Wände immer noch mit einigen zer'streuten Chlorophyllkörnern besetzt; die übrigen aber hatten sich auf die andereu Zellwände begeben und standen dort ebenfalls meist einzeln in Distanzen von einander. Doch waren manchmal auch Gruppen von Chlorophyllkörnern daselbst sichtbar. Nachdem die Pflanzen noch weitere neun T'age unter constanter Dunkelheit zugebracht hatten, zeigte sich noch immer derselbe $\mathrm{Zu}$ stand, es war kein weiterer Fortschritt erfolgt. Nun wurde die Kultur Vormittags wieder ans Tageslicht gebracht. Schon als sie nach sieben Stunden wieder untersucht wurde, war die normale Stellung der Chlorophyllkörner beinahe wieder eingetreten: wenn auch von den Quer- und den Vorder- und Hinterwänden die Chlorophyllkörner noch nicht ganz verschwunden waren, so hatten doch unverkennbar die meisten in ziemlich dichter Stellung an den beiden Seitenwänden Platz genommen. Späterhin wurde die regelmässige Stellung vollständig.

Es war nun noch die Frage übrig, ob bei den Crassulaceen das direkte Sonnenlicht eine andere Vertheilung der Chlorophyllkörner bewirkt als das zerstreute, da ja Böhm eine Gruppirung derselben bei direkter Insolation beobachtet haben will. Ich setzte die Pflanzen, die zu den eben beschriebenen Versuchen gedient hatten, nachdem im zerstreuten Tageslichte die normale Vertheilung ihrer Chlorophyllkörner wieder hergestellt war, einige Stunden lang dem direkten Sonnenlichte aus. Ich fand alsdann nichts weiter als die bisherige regelmässige Anordnung des Chlorophylls, die allerdings jetzt einen auffallend hohen Grad von Vollständigkeit angenommen hatte: alle Zellwände bis auf die beiden radialen waren meistens von Chlorophyllkörnern durchaus entblðsst; 
letztere hatten einzig und allein die freien Stellen der beiden gegenüberstehenden radialen Seitenwände eingenommen und bildeten hier einen ziemlich gleichmässigen lückenlosen Ueberzug, eines neben dem anderen in einer einfachen Schicht beisammenstehend. Diese in direkten Sonnenlichte durch ihre Vollständigkeit auffälligere Versammlung der Chlorophyllkörner an den zwei entgegengeselzten Seitenwänden jeder Zelle hat wahrscheinlich die an sich sehr unbestimmt gehaltene Angabe Böhm's über eine Gruppirung der Chlorophyllkörner veranlasst.

Ueber die entgegengesetzten Wirkungen von Licht und Dun. kelheit auf die Lage der Chlorophyllkörner in der Zelle lassen sich noch folgende allgemeine Sätze aufstellen. Zunächst sind diese Wirkungen hinsichtlich der Schnelligkeit, mit der sie erfolgen, und der Vollständigkeit des Effektes specifisch verschieden. Nach Famintzin genügt bei der von ihm untersuchten Mniumart eine vier-bis fünfstündige Verdunkelung, um die Chlorophyllkörner an die Seitenwände treten zu lassen. Solche Pflanzen würden also in ihren natürlichen Verhältnissen allnächtlich die Stellungsveränderung der Chlorophyllkörner vornehmen. Bei keiner der von mir untersuchten Pflanzen habe ich eine solche Lebhaftigkeit beobachtet; für sie muss ich es in Abrede stellen, dass sie in unseren Gegenden bei ihrem natürlichen Vorkommen durch die nächtliche Verdunkelung zu einer irgend erheblichen Veränderung der Chlorophyllstellung gelangen können, weil die Dauer derselben in unseren Breitengraden für diese Wirkung nicht ausreicht. Ich verschloss Individuen von Lophocolea bidentata N. ab E. und Mastigobryum trilobatum N. ab E. lichtdicht und liess sie so von Abends $7 \mathrm{Uhr}$ bis zum nächsten Morgen $9 \mathrm{Uhr}$ bei gewöhnlicher Zimmertemperatur stehen. Darauf zeigten beide nur in wenigen Zellen die Aussenwände von Chlorophyllkörnern, nahezu entblösst, die Seitenwände reichlich damit besetzt. In. den meisten Zellen waren noch zahlreiche Chlorophyllkörner an den Aussenwänden vorhanden, und überhaupt meistens keine Veränderung bemerklich. Erst nach weiteren drei Tagen war die Veränderung bei Lophocolea vollständig eingetreten, während Mastigobryum auch jetzt noch nicht diesen Punkt orreicht hatte. In Farnprothallien, welche von Abends 7 Uhr bis zum nächsten Morgen $9 \mathrm{Uhr}$ lichtdicht verschlossen gehalten worden waren, konnte ich noch keine Veränderung bemerken; erst am nächsten Tage waren die Anfänge der. selben eingetreten, und erst in den folgenden Tagen wurde Voll- 
ständigkeit erreicht. Bci Mnium rostratum bedurfte es zwei Tage langer Verdunkelung ehe die Chlorophyllkörner bis auf einige noch an den Aussenwänden sitzende an die Seitenwände getreten waren. Ebenfalls mehrerer Tage bedurfte es, wie schon oben erwähnt, um den gleichen Erfolg an den Blattzellen der Sagittaria herbeizuführen. Noch weit langsamer gehen die Veränderungen bei Vallisneria und Elodea, bei welcher letzterer, wie oben angegeben, crst nach einer zehnwöchentlichen Verfinsterung dic Chlorophyllkorner zu nahezu vollständigem Stellungswechsel gekommen waren. - In allen Fällen geschicht aber die Rückwanderung der Chlorophyllkorner in die anfängliche Lage beim Wiedereintritte der Beleuchtung rascher als die entgegengesetzte. So hat sie Fa. mintzin an seiner Mniuuart schon nach einer Stunde vollendet geschen. Die nämlichen Farnprothallion, welche erst nach mehreren Tagen die Dunkelstellung der Chlorophyllkörner erreicht hatten, zeigten mir schon nach eintägigem Lichtgenusse (von einem Mittage zum anderen, die nächtliche Verfinsterung eingerechnet) das Chlorophyll wieder in der normalen Vertheilung. Lophocolea bidentata gebrauchte hierzu zwei Tage (von Mittag zu Mittag), Sagittar'a etwa eincn. Am deutlichsten tritt diese Differenz in der Dauer der beiderlei Wanderungen bei Elodea hervor, deren Chlorophyllkörner erst nach zehn Wochen in die Dunkelstellung eingetreten waren und diesc auch dann noch nicht allgemein vollständig crreicht hatten, bei Wiederbelenchtung aber schon nach einigen Tagen in der vollständigsten Weise wieder in die normale Stellung sich begeben hatten.

Ausser diesen specifischen Verschiedenheiten giebt es aber auch individuelle. Mit einer je grösseren Zahl von Individuen man gleichzeitig und unter gleichen Verhältnissen solche Versuche anstellt, desto mehr wird man finden, dass sich nicht alle einander gleich verhalten, indem manche hinter den anderen mehr oder weniger weit zurückbleiben. Bei allen eben mitgetheilten Versuchen wurde dies beobachtet, und die obigen Angaben über die Geschwindigkeit der Wanderung bei den einzelnen Arten beziehen sich auf diejenigen Individuen, in welchen die Veränderungen am zeitigsten eintreten. In besonders hohem Grade zeigen sich auch individuelle Verschiedenheiten unter den einzelnen Zellen tines und desselben Organes. Und zwar zunächst unter Zellen von yleichem Alter: so ist es fast Regel, dass in Moosblättern, z. B. bei Mnium, die einzelnen Zellen mit verschiedener Geschwin- 
digkeit und Vollständigkeit die Stellungsänderung der Chlorophyllkörner vornehmen. Häufig bleiben die in der Nähe der Mittelrippe gelegenen weitesten Zellen hierin gegẹn die nach dem Rande zu gelegenen zurück. Aber auch Zellen, die an gleichem Orte liegen, verhalten sich oft verschieden; und es kommt häufig vor, dass an ganz beliebigen, im voraus gar nicht $z u$ bezeichnenden Stellen die Veränderungen langsamer und unvollständiger geschehen. Es ist etwas ganz Gewöhnliches, dass man z. B. an Epidermisschnitten aus den submersen Blättern von Sagittaria Zellen trifft, welche hinter den übrigen bemerklich zurückbleiben oder auch ihnen vorauseilen. Ferner richtet sich aber auch der Effekt nach dem Alter der Zelle, und hier kann es im Allgemeinen als Regel gelten, dass in älteren Zellen die Wanderungen langsamer erfolgen und nament. lich einen geringeren Grad von Vollständigkeit erreichen. Dies zeigt sich sehr deutlich an den Farnprothallien, wo die dem älteren Ende genäherten Zellen inmer relativ trägere Chlorophyllkörner enthalten und diese meistens gar nicht vollständig in die Dunkelstellung übergehen lassen. Bei Moosen und Jungermannicen giebt sich diese Altersschwäche blattweise zu erkennen: die dem jungen Ende der Triebe fernsten Blätter bleiben hinter den jüngeren weiter zurück und gelangen wohl uberhaupt nie zu einer vollständigen Veränderung der Chlorophyllstellung. Bedenkt man, dass in den ersten Lebensstadien der Zelle eine bestimmte Vertheilung von chlorophyllführendem Protoplasma noch nicht existirt (s. unten), so ist nach dem Vorstehenden eigentlich nur ein gewisses mittleres Lebensalter, freilich von ziemlich weitem Spielraume, als das eigentlich der Chlorophyllbewegung günstige zu betrachten.

Im Anschlusse an diesen Gegenstand mag noch über eine andere Erscheinung Mittheilung gemacht werden, die zwar nicht zu denjenigen Wanderungen der Chlorophyllkörner gehört, von denen wir hier gesprochen haben, die aber auch als eine durch das Licht verursachte Bewegung der Chlorophyllkörner in der Zelle hier einen Platz finden darf. Wie es bis jetzt nur von freien grünen Organismen bekannt war, dass das Licht eine anziehende (beziehendlich abstossende) Wirkung auf sie zusübt und eine entsprechende Ortsveränderung veranlasst, so habe ich die gleiche Erscheinung auch an den in Zellenräumen eingeschlossenen Chlorophyllkörnern beobachtet, indem ich fand, dass dieselben an derjenigen Seite per Zelle sich anhäufen, welche gerade der Quelle intensivsten Lichtes zugewendet ist. Es ist von vornherein selbst- 
verständlich, dass sich ein solcher Vorgang nur da wird deutlich beobachten lassen, wo die räumlichen Verhältnisse der Zelle dies hinreichend gestatten, und wenn sich meine Beobachtungen hierüber zunächst auf gewisse Glieder nur zweier Pflanzenarten, welche diesen Bedingungen besonders entsprechen, erstreckten, so geht daraus nicht hervor, dass jene Fähigkeit nicht den Chlorophyllkörnern allgemein zukommt.

Die weiten, etwas tafelförnigen Epidermiszellen in der Oberseite der submersen Blätter von Sagittaria sagittaefolia sind dieser Chlorophyllbewegung besonders günstig. Ich wurde an diesen zuerst auf die Erscheinung aufmerksam, indem ich fand, dass an einer am Fenster in einem Glasgefässe stehenden Kultur, die von der Sonne beschienen wurde, in vielen Präparaten die Chlorophyllkörner anstatt gleichmässig über die beiden breiten Wände vertheilt zu sein, auffällig einem bestimmten Rande der Zelle, der in sämmtlichen Zellen des Präparates nach einer und derselben Richtung gekehrt war, sich genähert hatten. Dort standen sie so dicht beisamınen, dass sie häufig zu mehreren übereinander lagen; nach der Mitte der Zellwand zu wurde die Lage dünner und die Stellung der Körner nebeneinander immer lückenhafter; an den übrigen Stellen gab es entweder gar keine Chlorophylikörner mehr, oder am entgegengesetzten Rande deren noch eine geringe Anzahl. Als ich diese Orientirung der Chlorophyllkörner mit der Richtung, in welchen an den einzelnen von der Sonne beschienenen Stellen der Blätter die Lichtstrahlen auftrafen, in Vergleich zog, ergab sich sofort die gesetzmässige Abhängigkeit jener von der Richtung der Beleuchtung. An solchen Stellen, wo die Ebene des Blattes ungefähr mit.der Richtung der Sonnenstrablen zusammenfiel, war jenes Bild am deutlichsten. Stets hatten sich die Chlorophyllkörner an demjenigen Rande angehäuft, welcher der Sonne zugekehrt war, gleicngültig ob dies einer der beiden seitlichen oder der acropetale, oder der basipetale wax.

Noch ausgeprägter ist die Erscheinung in den Zellen der seitlichen Lappen der Vorkeime von Farnen. Diese Zellen sind verhältnissmässig sehr weit und ihre grössten Durchmesser liegen in der Richtung der Vorkeimfläche; die breiten Wände aber sind mit den Chlorophyllkörner bedeckt. Da sich diese Pflänzchen besonders zu hier einschlagenden Versuchen eignen, so suchte ich an diesen die Erscheinung auch experimentell festzustellen. Auf den Boden eines Glasgefässes brachte ich eine Anzahl Farnvor- 
keime in ihre natürliche horizontale Stellung. Das Gefäss wurde mit einer lichtabschliessenden Umhüllung versehen, welche nur an der einen, dem Fenster zugekehrten Seite in der unteren Hälfte einen schmalen Längsausschnitt hatte, durch welchen allein zerstreutes Tageslicht auf die Pflänzchen fallen konnte. Letztere standen so, dass bei den einen der Prothalliumeinschnitt dem Lichte zu-, bei den anderen abgekehrt war. Nachdem die Vorrichtung mehrere 'Tage in dieser Stellung unverändert sich befunden hatte, hatten in den meisten Zellen die Chlorophyllkörner eine Orientirung angenommen, welche in bestimmter Beziehung zu der Richtung der Lichtstrablen stand. Die meisten Zellen zeigten Folgendes. An der oberen freien Zellwand standen die Chlorophyllkörner an dem lichtwärts schauenden Rande vereinigt oder wenig. stens am dichtesten. In den ausgeprägtesten Fällen war die der Lichtquelle abgewendete Hälfte dieser Wand vom Rande bis zur Mitte ganz von Chlorophyll entblösst; die nach dem Lichte gekehrten Ränder mit einer dicken rückwärts immer dünner und spärlicher werdenden Lage von Chlorophyllkörnern bedeckt. Die Form der Zelle war hierbei ganz gleichgültig: die Versammlung der Körner an dem lichtwärts schauenden Rande war unabbängig davon, ob der letztere eine Längsseite oder eine schmale Seite oder eine Kante der Zelle war. Auch die Richtung des jungen Prothalliumendes gegen das Licht oder vom Lichte ab war gleichgültig. Auf der unteren freien Wand hatten dagegen die Chlorophyllkörner die gerade entgegengesetzte Vertheilung: an dem der Lishtquelle abgewendeten Rande wax dieselbe am dichtesten und wurde nach dem gegenüberstehenden zu immer spärlicher. Die Orientirung der Chlorophyllkörner an der oberen und unteren Wand war stets auf das Vollkommenste antagonistisch. Wenn nämlich die obere Wand unter dem Mikroskope eingestellt war, und es wurde darauf durch Hebung des Objekttisches die untere Wand in den Focus gebracht, so entsprach stets der Stelle grösster Entblössung der Oberwand die stärkste Anbäufung an der Unterwand, und umgekehrt. Ausnahmslos aber fand ich, dass die ungleichmässige Vertheilung der Chlorophyllkörner an der unteren Wand minder ausgeprägt war als an der oberen, und darin machte sich sogar eine gewisse Proportionalität geltend, indem da, wo die Orientirung an der Oberwand den höchsten Grad von Vollständigkeit angenommen hatte, auch an der unteren Wand die entgegengesetzte Vertheilung wenn auch etwas schwächer, doch höchst 
ueutlich erkennbar war, während da, wo die Oberwand eine wenig entschiedene Orientirung ibrer Chlorophyllkörner zeigte, die Vertheilung derselben an der Unterwand wohl gar keine merkliche Störung erfabren hatte. Ich glaube, das man dieses antagonistische Verhalten beider Zellwände leicht auf folgende Weise erklären kann. Wenn in ungefähr horizontaler Richtung auf dem Boden eines Glasgefässes stehende Vorkeime von der einen Seite her durch eine Längsspalte allein Licht erhalten, so tritt das 公

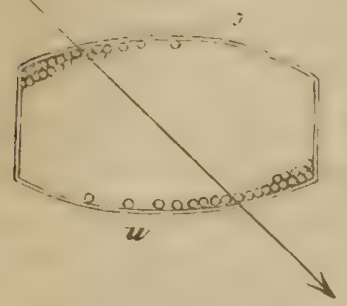

letztere vorwiegend in schiefer Richtung in die Zellen ein, so wie es die beistehende Figur versinnlicht, welche eine solche Vorkeimzelle im Profil mit dem Chlorophyllwandbelege der oberen und unteren Wand darstellt. Die schief durchgehende Linie bedeutet die Richtung, in welcher die Lichtstrahlen

die Zelle durchdringen. Es ist nuи selbstverständlich, dass für die Oberwand o der nach der Lichtquelle $L$ hinschauende Rand derjenige ist, von welchem her das intensirste Licht kommt, und dort sammeln sich denu auch die Chlorophyllkörner an. Der dadurch gebildete dichte Haufen wirft aber seinen Schatten unter sich, und darum ist die darunter stehende Zellwand $u$ offenbar an dem entgegengesetzten Rande am stärksten beleuchtet, weil über diesem keine schattenwerfenden Körperchen sitzen. Da sich nun auch wirklich die Chlorophyllkörner der Unterwand an dieser Stelle ansammeln, so darf die einfache Annahme, dass die Chlorophyllkörner stets die stärkste Beleuchtung aufsuchen mit den Beobachtungen im Einklange befindlich betrachtet werden. Es wird so aber auch erklärlich, warum immer an der Unterwand die ungleichmässige Vertheilung der Chlorophyllkörner etwas minder ausgeprägt ist als an der Oberwand. Für Wiederholer des Experimentes will ich noch bemerken, dass in Prothallien, deren Fläche stark uneben oder sogar am Rande wellenförmig gefaltet ist, sich nicht alle Zellen einander gleich verhalten, offenbar weil sie wegen jenes Umstandes in verschiedenen Richtungen zur Lichtquelle sich befinden. So trifft man an gewissen Stellen die Chlorophyllkörner in gleichmässiger Verbreitung über die ganze Fläche beider Aussenwände, an anderen wiederum dem Rande derselben genähert, und 
zwar an beiden Wäuden an derselben Seite, nämlich an der der Lichtquelle zugekehrten. Es begreift sich leicht, wie es zu solchen Anordnungen kommen muss, je nachdem die Lichtstrahlen ungefähr rechtwinklig auf die Aussenwände treffen, oder denselben ungefähr parallel die Zelle durchdringen.

Man kann auch die einseitige Gruppirung der Chlorophyllkörner beliebig ändern, wenn man dem Vorkeime eine andere Stellung zur Lichtquelle giebt. Eir solcher wurde, nachdem in Folge einseitiger Beleuchtung seine Chlorophyllkörner die beschriebenc Anordnung in sehr ausgeprägter Form angenommen hatten, so gestellt, dass nun der bisher lichtwärts gewendete Rand nach der entgegengesetzten Seite gerichtet war. Als er nach mehrtägigem Verweilen in dieser Stellung wieder untersucht wurde, hatten die Chlorophyllkörner unverkennbar den neuen Beleuchtungsverhältnissen entsprechend, zum Theil ziemlich vollständig, ihre Lage geändert, indem sie von dem einen Rande der Zelle nach dem entgegengesetzten gewandert waren. An anderen ebenfalls cinseitig beleuchtet gewesenen Vorkeimen mit entsprechender Vertheilung der Chlorophyllkörner wurden zunächst die letzteren durch mehrtägigen vollständigen Lichtabschluss in die Dunkelstellung gebracht. Hierauf wieder einer einseitigen Beleuchtung ausgesctzt liessen die Vorkeime ihre Chlorophyllkörner abermals die einseitige Gruppirung an den Aussenwänden annehmen, - Weitere Mittheilungen in dieser Richtung behalte ich mir für eine andere Gelegenheit vor*).

\section{Temperatur.}

Die Frage, ob unter übrigens gleichen Verhältnissen gewisse Veränderungen der Temperatur ebenfalls die in Rede stehenden Vorgänge in der Zelle veranlassen können, zerfällt in zwei besonders zu beantwortende Theile. Da subald alle übrigen Bedingungen gegeben sird bei gewöhnlicher Temperatur Protoplasma und Chlorophyllkörner ihre normale Anordnung in der Zelle beibehalten, so wird es sich fragen, ob einerseits bei Erniedrigung andererseits bei Erhöhung der Temperatur ein Punkt erreicht wird, wo der entgegengesetzte Zustand in die Zelle einkehrt.

*) Dieselben sind schon vor dem Erscheinen dieser Arbeit in der Botanischen Zeitung 1871 No. 14 veröffentlicht worden.

Jahrb. f. wiss. Botanik, VIII. 
Hinsichtlich der Wirkung der Temperaturerniedrigung fand ich bei wiederholten Beobachtungen, dass wenn die in Rede stchenden Moose und Lebermoose, sowie, die Elodea auch nur bei wenigen Graden über dem Nullpunkte längere Zeit am Tageslichte sich befinden, die Stellung ibrer Chlorophyllkörner nicht verändert wird. Es konnten also überhaupt nur Temperaturen von $0^{\circ}$ und darunter in Frage kommen. Ich brachte einige Individuen von Mnium rostratum und Radula complanata, von denen ich mich zurörderst überzeugt hatte, dass ihre Chlorophyllkörner in der gewöhnlichen Anordnung sich befanden, in ein leeres, innen etwas befeuchtetes und mit einem Korkpfropf leicht verschlossenes Probirgläschen. Dieses wurde zur Tageszeit in langsam schmelzenden Schnee gesteckt, dergestalt dass es horizontal lag und rollständig davon umgeben war. Die bedeckende Schneeschicht war mässig dick, sie ermöglichte eine ziemlich intensive rein weisse Beleuchtung innerhalb des Probirgläschens. Nach zweistündigem Verweilen in diesen Verhältnissen wurden die Pflanzen wieder untersucht. Es bestand zwar noch im Allgemeinen bei allen der normale Zustand, indessen war doch eine Anhäufung von Chlorophyllkörnern an den Seitenwänden, die zuvor nicht beobachtet wurde, unverkennbar. Ich liess daher die Pflanzen in dem Probirgläschen noch bis zum Mittage des dritten Tages (noch 48 Stunden lang) im Schnee stehen. Als ich sie jetzt abermals untersuchte, fand ich die Chlorophyllköruer fast sämmtlich in der neuen Stellung. Am überraschendsten war dies in den Blattzellen von Radula, in denen, zur vollen Mittagszeit, alle Chlorophyllkörner in einem dichten Kranze sich ringsum an die Seitenwände gelagert hatten, während die breiten freien Zellwände ganz leer oder nur mit einigen zerstreut stehenden Körnern bedeckt waren. In den Mniumblättern war die Veränderung im Allgemeinen noch etwas weiter von ihrem Ziele entfernt; es hatte sich zwar auch an den Seitenwänden eine Lage ron Chlorophyllkörnern angesammelt, es befand sich indessen mebr oder weniger noch eine wenn auch relativ geringe Anzahl von Körnern an den breiten Wän. den. Uebrigens waren auch hier diese Zustände in verschiedenen Blättern und in verschiedenen Individuen verschieden, ebenso wie wir dies schon oben rücksichtlich der Lichtwirkung constatiren mussten. Zur Controle wurden nun zur nämlichen Zeit solche Individuen beider Pflanzen, welche bisher im Zimmer gehalten worden waren, untersucht. In diesen herrschte die normale Stellung der Chlorophyllkörner auf das Vollständigste. Es konnte also bei 
jenen Versuchspflanzen die entgegengesetzte Anordnung der Chlorophyllkörner nur eine Folge der Erniedrigung der Temperatur auf $0^{\circ}$ sein. Hierauf brachte ich das Probirgläschen mit den Versuchspflanzen ins geheizte Zimmer, nachdem ich es mit einer Hülse weissen Papieres umgeben hatte, welche die bisher durch die Schneebedeckung geschaffene Beleuchtungsweise recht gut nachahmte. Nachdem die Pflanzen hier zwei Tage zugebracht hatten, war in den Radulablättern die gewöhnliche Chlorophyllstellung fast vollständig wieder eingetreten. In den Mniumblättern, in welchen um diese Zeit nur erst geringe Veränderungen erfolgt waren, wurden doch, rachdem die Pflanzen noch weitere vier Tage unter diesen Verhältnissen gehalten worden waren, wenigstens in den jüngeren noch kräftig vegetirenden Blättern die Chlorophyllkörner wieder vollständig oder doch nahezu in normaler Stellung gefunden; die Zellen der älteren Blätter hatten wenig Veränderung erfahren, sie waren auch offenbar dem Absterben nahe, stellenweise schon humificirt. In den Radulapflanzen war dagegen nach dieser Zeit die gewöhnliche Chlorophyllstellung wieder auf das Vollständigste erreicht.

Da in den Mniumindividuen des vorstehend beschriebenen Versuches die Chlorophyllkörner sich ziemlich träge verhielten, so wurde das Experiment mit anderen Individuen nochmals in etwas abgeänderter Weise wiederholt. Ich setzte die Pflanzen, an denen ich zuvor wiederum die gewöhnliche Chlorophyllstellung constatirt hatte, in einer inwendig etwas angefeuchteten, mit einer Glastafel bedeckten weissen Glasbüchse am Tageslichte heftiger Winterkälte aus und liess sie in diesen Verhältnissen 24 Stunden lang, von einem Mittage zum andern, während welcher Zeit das Thermometer sich niemals über $0^{0}$ erhob. Nach dieser Zeit hatten die Chlorophyllkörner in den jüngeren noch in kräftiger Vegetation befindlichen Blättern nahezu vollständig die neue Stellung eingenommen: in vielen Zellen standen sämmtliche Körner an den Seitenwänden, in anderen waren sie wenigstens denselben sehr genähert. In den übrigen Blättern war im Allgemeinen je nach deren Alter die neue Stellung unvollständiger, in den älteren nur in sofern angebahnt, als die Gleichmässigkeit der Verbreitung der Chlorophyllkörner an den breiten Wänden alterirt war und eine stärkere Häufung derselben gegen die Ränder der Zelle hin sich bemerklich machte. Das Gefäss wurde nun unter Vermeidung zu plötzlichen Tempe. raturwechsels ins geheizte Zimmer an das Fenster gestellt. Nach 
zwei Tagen war in allen lebenskräftigen Blättern die normale Anordnung der Chlorophyllkörner auf das Vollständigste hergestellt; in den meisten Zellen befand sich nicht ein einziges Korn auf den Seitenwänden, und an den Ausseuwänden standen die Chlorophyll. körner dichtgedrängt in gleichmässiger lückenloser Lage. In älteren Blättern war dagegen keine merkliche Veränderung eingetreteu.

Dieser Versuch wurde mit den genannten Pflanzen, denen auch noch Individuen der erwähnten Farnprothallien beigcgeben wurden, später nochmals wiederholt, und zwar standen die Pflanzen von 9 Uhr Morgens bis Nachmittag 3 Uhr, also bei dauernder Beleuchtung, in einer Temperatur ron mehreren Graden unter dem Gefricrpunkte. Unmittelbar vor Beginn des Versuches befanden sich in allen Individucn die Chlorophyllköruel vollständig in der normalen Stellung. Nachmittags 3 Uhr hatte die Acnderung derselben in allen Individuen bereits sehr beträchtliche Fortschritte gemacht. Insbesondere sah man in den Farnrorkeimen die Zahl der Chlorophyllkörner an den Aussenwänden sehr gelichtet, vielfach war die Mitte derselven ganz leer und die Körner gegen den Rand zusammengedrängt, auch as den Seitenwänden selbst waren dergleichen schon vorhanden. In den Randzellen hatten sich die Chlorophyllkörner auf clas Deutlichste von der Aussenkante und den breiten Wänden nach einwärts zurückgezogen. Die Pflanzen wurden dann noch 24 Stunden lang in der Winterkälte steheu gelassen, worauf die Veränderung der Chlorophyllvertheilung noch vollständiger geworden war. Dann wurden sie wieder ins geheizte Zimmer gebracht und zeigten hier nach weiteren 48 Stunden die Chlorophyllkörner wieder nahezu in der regelmässigen Stellung.

Aehnliche Versuche mit Elodea canadensis bewiesen, dass diese Pflanze in dieser Beziehung sich den vorgenanuten analog verhält. Ein Spross, in dessen Blättern der normale Zustand herrschte, wurde in ein mit Wasser gefülltes Probirglas gebracht, und dieses in geneigter Stellung am Tageslichte zur Mittagszeit in Schnee gesteckt. Nach zweistündigem Verweilen daselbst wurden Blätter von der Pflanze abgeschnitten und sofort untersucht. Die Chlorophyllkörner waren fast vollständig von den freien Aussenwänden nach den Seiten- und Hinterwänden gewandert. Die Pflanze zeigte keine wachtheilige Veränderung, sie blieb auch fernerhin am Leben. Bei einem anderen Versuche wurde ein Elodea-Spross in einem mit Wasser gefüllten Probirgläschen zur Tageszeit 3 Stunden lang heftiger Winterkälte ausgesetzt, so dass das Wasser binnen Kurzem 
unter $0^{\circ}$ ahgekühlt war und zum Theil in Folge der Erschütterung erstarrte als nach jener Zeit von der Pflanze ein Blatt zur Untersuchung abgeschnitten wurde. In diesem zeigte sich sofort nach der Operation die Stellung der Chlorophyllkörner vollständig verändert; die meisten befanden sich auf der Hinterwand und auf den Seitenwänden, während an der freien Zellwänden keine oder höchstens wenige einzeln oder in einem kleinen Klumpen zusammen. stehende Körner zu sehen waren. Rotationen des Protoplasmas an den Seitenwänden konnte ich nicht entdecken, ebensowenig wie kleinere Plasmaströmchen oder Bewegungen an den Chlorophyll. körnern selbst zu dieser Zeit erkannt werden konuten. Eine Tödtung hatte aber keineswegs stattgefunden. - Bei beiden Versuchen wurden die Pflanzen, nachdem das Wasser allmählich erwärnt worden war, ins geheizte Zimmer gebracht. Hier liess sich nach 24 Stunden der Anfang der Rückwanderung der Chlorophyllkörner in die normale Stellung beobachten: es waren schon mehr oder weniger derselben wieder an den freien Zellwänden erschienen. Nach weiteren vier Tagen aber befand sich alles wieder auf das Vollständigste in der früheren Ordnung.

Auch bei den Sempervivumarten ist die Erniedrigung der Temperatur ron ähnlicher Wirkung wie die Abtrennung der Zellen und wie die Entziehung des Lichtes, nur in noch höherem Grade. Individuen von S. Funkii Braun und ruthenicum Lehm, die bei starker Winterkälte eine Zeit lang im Freien sich befunden hatten, und deren Blätter zum Theil hartgefroren waren, zeigten ihre Chlorophyllkörner in zwei oder auch in einer einzigen klumpenartigen Gruppe, während in der ganzen Zelle kein einziges Chlorophyllkorn weiter vorhanden war. Wo zwei Klumpen sich fanden, da lagen diese häufig an den beiden Querwänden, nicht selten aber auch an den Längswänden, immer aber so dass sie ungefähr diametral entgegengesetzte Stellung zu einander einnahmen. Die Haufen waren ziemlich dick, indem mehrere Körnchen übereinander lager, und meist scharf umschrieben. Darauf wurden die Pflanzen unter allmählicher Erhöhung der Temperatur in ein geheiztes Zimmer gebracht, wo sie wiederum dem zerstreuten Tageslichte ausgesetzt waren. Schon nach einigen Stunden hatten sich die Klumpen ziemlich aufgelöst; die Körner hatten sich mehr vertheilt und standen entweder ziemlich regellos über die Wände verbreitet, oder waren meistens noch an den Vorder- und Hinter- sowie an den Querwänden dichter gehäuft; doch hatte sich immer auch an den bei- 
den Seitenwänden schon eine Anzahl Körnchen vertheilt. Späterhin wurde die normale Stellung wieder vollständig erreicht.

Hinsichtlich der Wirkung der T'emperaturerhöhung bin ich bei Elodea canadensis, welche ich in Wasser langsam erwärmte, nur zu dem Resultate gekommen, dass erst wenn die Temperatur diejenigen Grade erreicht hat, welche überhaupt tödtlich wirken, d. h. worauf nach einiger Zeit stets die Todessymptome cintreten (Vergl. Sachs Experimentalphysiologie p. 65), die Chlorophyllkörner aus der bisherigen normalen Stellung zicmlich vollstäudig in die cntgegengesetzte übergehen. Es darf daraus geschlossen werden, dass jedenfalls vor dem Tode die Lage der Chlorophyllkörner geändert wird. Bei Mnium rostratum erfolgte auch bei sehr langsamer Erwärmung immer sogleich Vacuolenbildung und offenbar Erstarrung des Protoplasmas, und darum konnte es wohl überhaupt nicht zu einer eigentlichen Wanderung der Chlorophyllkörner kommen; nur ihre gleichmässige Verbreitung an den Aussenwänden wurde wegen der Schrumpfung und der Vacuolenbildung des Protoplasma alterirt. $\mathrm{Ob}$ es an anderem hierzı vicllcicht tauglicherem Materiale gelingt, die Umlagerung der Chlorophyllkörner bei einer Temperaturerhöhung zu erzielen, die noch nicht tödtlich wirkt, bleibt hiernach noch eine offene Frage.

\section{Verminderung des Wassergehaltes der Zelle.}

$\mathrm{Da}$ die in Rede stehenden Lagenveränderungen der Chlorokörner jedenfalls mit Protoplasmabewegungen nahe verwandt sind, und da der Hofmeister'schen Hypothese, wonach alle Bewegungen des Protoplasmas durch gewisse Veränderungen des Wassergehaltes desselben hervorgebracht werden, der höchste Grad ron Wahrscheinlichkeit zuzuerkennen ist, so lag mir die Frage nahe, ob die Wirkungen, welche durch eine bis ' zu einem gewissen Grade fortschreitende Wasserentziehung in der Zelle hervorgebracht werden, nicht auch in der Vertheilungsform des Protoplasmas und seiner Einschlüsse einen sichtbaren Ausdruck gewinnen können.

Versuche, durch Einwirkung wasserentziehender chemischer Mittel einen Erfolg zu erzielen, scheiterten an der viel zu kräftigen und raschen Wirkung dieser Agentien, selbst wenn sie nur langsam und in grosser Verdünnung zugelassen werden. Der Erfolg ist immer eine gleichmässige Contraction des gesammten Protoplasına- 
leibes oft unter Vacuolenbildung, wobei seine geformten Inhaltsbestandtheile der Verringerung seines Volumens entsprechend ihre absoluten und relativen Stellungen verändern, ohne dass in der Form dieses Vorganges sich etwas anderes als eine directe Folge jener nach Form und Grad zunächst zufälligen Contractionen des Gesammtleibes erkennen liesse. In dem Masse, wie das Protoplasma schrumpft, werden auch die darin enthaltenen Chlorophyllkörner mehr und mehr einander genähert und zusammengehäuft, ohne dass sich irgend eine bestimmte Regel, welche an die bisher besprochenen Erscheinungen erinnerte, ausspräche.

Einen besseren Erfolg ergab ein sehr langsames Eintreten des Welkwerdens in Folge erhöhter Transpiration. Ein Spross von Elodea canadensis, an welchem ich zuvor den normalen Zustand in den Blattzellen constatirt hatte, wurde in einem verkehrt stehen. den Glastrichter so aufgehängt, dass er im Innenraume desselben mit allen seinen Theilen frei in der Luft hing. Die Mündung des Trichters ruhte auf einigen auf dem Tische liegenden Klötzchen, so dass von unten her Luftein- und austritt ermöglicht war. Die Vorrichtung befand sich bei gewöhnlicher Temperatur im Tageslichte. Unter diesen Umständen erfolgte die Verdunstung durch die Blätter sehr laugsam; nach Verlauf von 3 Stunden gab sich der Wasserverlust derselben durch geringe Unebenheiten - Anfänge des Einschrumpfens - namentlich an den Blattspitzen, zu erkennen. Da eine Tödtung der Zellen vermieden werden sollte, so wurde der Versuch alsbald unterbrochen, und die Pflanze untersucht. Die Zellen der Blätter waren vollständig am Leben, mit Ausnahme derer in einigen Blattspitzen, die etwas stark eingeschrumpft waren, in welchen das Protoplasma sammt den Chlorophyllkörnern zu einer unförmlichen Masse sich zusammengezogen hatte. In allen lebendigen Zellen aber, selbst solcher Blätter, die noch gar keine Schrumpfung erlitten hatten, befanden sich die Chlorophyllkörner sämmtlich an den Seiten- und Hinterwänden, und zwar an den ersteren mit dem Protoplasma in lebhafter Rotation. Die Pflanze wurde sogleich wieder ins Wasser gelegt; eine schädliche Folge des Experimentes machte sich an ihr in der Folge nicht bemerkbar. Am nächsten Tage wurde sie wieder untersucht: der normale Zustand war zwar noch nicht wieder eingetreten, seine Herstellung aber unverkennbar in Werke, denn es hatte schon wieder eine Anzahl Chlorophyllkörner an den Aussenwänden Platz genommen. Und als die Pflanze nach einigen Tagen abermals untersucht 
wurde, befand sich alles wieder auf das Vollständigste in der früheren Ordnung.

Individuen von Mnium rostratum, in deren Blattzellen die Chlorophyllkörner in normaler Anordnung standen, wurden während des Tages bei gewöhnlicher Zimmertemperatur in eine leere trockene weisse Glasbuchse gebracht, welche mit einer Glasplatte derart unvollständig bedeckt wurde, dass eine sehr limitirte Verdunstung des Mooses möglich war. Nach 4 Stunden waren die Blätter ziemlich stark cingesclırumpft; der Vorgang wurde absichtlich bis zu diesem bohen Grade fortgesetzt, weil die Ztellen der Moose bekanntlich starken Wasserverlust ertragen können ohne getödtet zu werden. In diesenı Zustande mit Wasser unter ein Deckglas gebracht und untersucbt zeigten die Blattzellen in rer. schiedenem Grade die anfïngliche Anordnung der Chlorophyllkörner gestört. Es war mindestens die régelıässige Verbreitung derselben an den Ausseuwänden aufgehoben; sie waren mehr oder weniger den Seiten genähert, in manchen Zellen, namentlich in den jüngereu, so, dass die Mitte der breiten Wände ganz leer stand; in älteren Blättern war die Veränderung minler vollständig. Hierauf brachte ich die Pflanzen in eine mit Wasserdunst geschwängerte Atmosphäre, in welcher sic thre Blätter bald wieder vollständig ausbreiteten. So blieben sie bis zum nächsten Tage stehen und wurden dann wieder untersucht. Die Chlorophyllkörner hatten ihre regelmässige Stellung zwar noch nicht wieder eingenommen, sich derselben aber unverkennbar genähert. Nach wciterem dreitägigem Verweilen in der mit Wasserdunst geschwängerten Luft und unter Einwirkung der täglichen Beleuchtung waren sie wieder auf das Vollständigste in ihre natürliche Lage getreten. - Aus dem Vorstehenden dürfte es sich erklären, warum an Herbarienexemplaren von Laub. und Lebermoosen die Chlorophyllkörner in der Regel die Seitenwände einnehmen. Famintzin') glaubte die Erklärung hierfür in der Wirkung der Verdunkelung suchen zu müssen, welcher die Pflanzen heim Trocknen zwischen den Papierbogen ausgesetzt werden. Erwägt man aber, dass es sicher in den meisten Fällen einer ziemlich langen Verfinsterungsdauer be darf, um die Chlorophyllkörner in dic entgegengesetzte Stellung zu bringen, dass aber gerade diese Pflanzen in der kürzesten Zeit so vollständig trocken werden, dass ihr Protoplasma in den starren

1) 1. e. p. 54 . 
Zustand übergeht, so scheint die hier gegebene Erklärung den Vorzug zu verdienen, indem das 'Trockenwerden, welchem ja eben die Herbarienexemplare anheimfallen, hierzu vollständig genügt.

\section{Das Medium.}

Es schicn mir die Frage ron Wichtigkeit zu sein, ob an der normalen Vertheilungsweise đer Chlorophyllkörner in der Zelle, während sonst alie Bedingungen derselben gegeben sind, durch Veränderungen des Mediums Modificationea herbeigeführt werden können, und dies um so mehr, als wir es bier theils mit entschiedenen Wassergewächsen, theils mit ausgeprägten Aërophyten zu thun haben.

Zur Prüfung des Eiıflusses, welchen bei einer submersen Wasserpflanze eine dauernde Vegetation in Luft auf die in Rede stebenden Zustände ausübt, ist Elodea canadensis die geeignetste Pflanze. Ich setzte Triebe derselben so in eine Glasbüchse, dass sie vom Boden derselben anfrecht emporragten und in dieser Richtung fortwachsen konnten. Auf den Boden wurde etwas Wasser gegossen, in welchem die Pflanzen mit ihren untersten Theilen standen. Durch Bedeckung der Büchse mit einer Glastafel wurde in Innern derselben die Luft dauernd derart mit Wasserdunst geschwängert erhalten, dass die Pflanzen nicht nur ohne jeden Nachtheil cin halbes Jahr lang, vom Sommer bis mitten in den Winter in diesen Verhältnissen zubrachten, sondern auch während dieser Zeit zu weiterem Wachsthume gelangten. Die in der Luft neu erzeugten Stücke zeigten nichts Abweichendes, als höchstens, dass die Blätter nicht so wie die übrigen, gerade rom Stengel abstanden, sondern in verschiedenem Grade vorwärts demselben angedrückt waren. Während dieser Zcit wurden wiederholt Blätter abgeschnitten, ohne Wasserzusatz unter ein Deckglas gebracht und so untersucht. Stets traf ich die Chlorophyllkörner in vollständig normaler Stellung, und auch nach Zusatz von Wasser zu dein Präparate blieb dies unverändert; wohl aber trat an diesem immer nach kurzer Zeit die gewöhnliche Veränderung der Iage des Chlorophylls in der oben beschriebenen Weise ein.

Individuen von Mnium rostratum, Radula complanata und Farnvorkeime liess ich in einer offenen Glasbüchse in Wasser liegend längere Zeit am Lichte stehen. Sie blieben ebenfalls lebendig und 
die Chlorophyllkörner behielten auf das Vollständigste ihre normale Stellung bei.

Es geht daraus hervor, dass die Vertanschung des natürlichen Mediums der Pflanze mit dem entgegengesetzten keine Veränderung an der Vertheilung des Protoplasmas und der Chlorophyllkörner bewirkt, solange dabei nicht überhaupt schädliche Einflüsse auf den Organismus ausgeübt werden. Ferner schien es mir von Wichtigkeit, den Einfluss zu beobachteu, den ein Fernhalten oder ungenügender Zutritt atmosphärischen Sauerstoffes in dem Medium der Pflanze auf jene Verhältnisge ausübt. Zu dem Ende steckte ich einen Spross von Elodea canadensis, in dessen Blättern das Chlorophyll in der nor. malen Stellung sich befund, in ein Probirglas, welches mit unmittelbar vorher ausgekochtem Wasser gefüllt war. Alsdann wurde auf das Wasser cine Oelschicht gegossen und die Vorrichtung bei gewöhnlicher Temperatur im Zimmer dem Tageslichte ausgesetzt. Nach zwei Tagen wurde die Pflanze herausgenommen und einige Blätter zur Untersuchung abgeschnitten. In diesen zeigten sich bei sofortiger Betrachtung sämmtliche Chlorophyllkörner vollständig in der neuen Stellung. Eine Rotation aber war weder an den Chlorophyllkörnern noch am Protoplasma zu entdecken; nur in den schmalen Zellen, welche über dem Nerven liegen, und etwa in den nächstbenachbarten weiteren Mesophyllzellen wurde äusserst lang. same Rotation bemerkt, von der es jedoch nicht unwahrscheinlich war, dass sie eben erst jetzt in Folge der Berührung mit sauerstoffhaltiger Luft, sich herzustellen begann. Denn nach einer Stunde war auch in den übrigen Zellen die Rotation eingetreten und in ziemlich lebhaftem Gange. Dies steht im Einklange mit der bekannten Thatsache, dass bei Abwesenheit oder ungenügender $\mathrm{Zu}$ fuhr von Sauerstoffgas die protoplasmatischen Bewegungen aufgehoben werde:I. Dadurch aber, dass bei Zutritt von Sauerstoffgas die Rotation wieder eintrat, wurde bewiesen, dass in dem vorliegenden Falle das Verweilen der Pflanze in den abnormen Verhältnissen nicht tödtlich gewesen war, wohl aber genügt hatte, um das Protoplasma und die Chlorophyllkörner zum Aufgeben ihrer normalen Stellung zu veranlassen. Nun wurde die Pflanze wieder in gewöhnliches und nicht mit Oel bedecktes Brunnenwasser gesetzt, welches in dem nämlichen Zimmer sich befand, und verblieb unter sonst den nämliohen Verhältnissen. Schon am folgenden Tage waren die Chlorophyllkörner auf der Rückwanderung in die regelmässige Stellung begriffen. Es lagen zwar noch viele Körner 
an den Seiten- und Hinterwänden, allein es hatten sich doch schon ziemlich viele wieder an der Aussenwand eingefunden. Uebrigens waren die Zellen von Plasmafäden durchzogen, welche in deutlicher Bewegung sich befanden und hin und wieder Chlorophyllkörner mit fortführten. Es war also offenbar der Zelleniohalt im Begriffe seine frühere Anordnung wieder einzunehmen. Und in der That fand ich in Blättern, welche nach einigen Tagen von der Pflanze genommen wurden, die anfängliche Vertheilung der Chlorophyllkörner wieder vollständig hergestellt.

Gleiche Versuche mit Mnium rostratum, Radula complanata, sowie mit Farnprothallien ergaben weniger bestimmte Resultate. An der erstgenannten Pflanze vermochte ich dadurch niemals eine Veränderung in der Vertheilung der Chlorophyllkörner zu erzielen. An den übrigen blieben auch bisweilen die Veränderungen aus, in anderen Fällen aber waren doch wenigstens die Anfänge der Wanderung der Chlorophyllkörner mit Sicherheit nachzuweisen: so hatten einmal bei Radula complanata fast alle Chlorophyllkörner die Seitenwände eingenommen und an einem Farnprothallium waren in einem Falle in manchen Zellen viele grüne Körner an den schmalen Seiten sichtbar geworden, wenngleich die Mehrzahl noch an den Breitwänden vertheilt war. Die im Allgemeinen geringe Wirkung einer solchen Luftabsperrung auf diese Pflänzchen dürfte erklärlich werden, wenn man erwägt, dass grüne Pflanzen, die im Lichte gehalten werden, vermöge der Assimilation, bei welcher sie die in den Geweben vorhandene noch unverarbeitete Kohlensäure zersetzen, - sich selbst etwas Sauerstoff liefern können. Gerade diese Pflänzchen sind aber an Chlorophyll relativ überaus reich, während bei ihrer Kleinheit ihr Bedarf an Sauerstoff ein ausnehmend geringer sein wird.

\section{Periodicität.}

Wenn in dem Vorausgehenden gesagt worden ist, dass im naturlichen Verbande mit der Pflanze und unter den gewöhnlichen äusseren Verhältnissen in der Zelle eine nach einem bestimmten Typus sich richtende regelmässige Anordnung des Protoplasmas und der Chlorophyllkörner besteht, so bezog sich das zunächst auf den Zustand der fertig ausgebildeten und zugleich noch völlig lebenskräftigen Zelle. Da dieser aber sur ein Stadium im ganzen 
Leben der Zelle bezeichnet, so gewinnt die Frage Interesse, wie sich die letztere in dieser Beziehung in anderen Perioden ihres Lebens verhält. Besonders werden die Jugendzustände der Zelle in Betracbt koinmen müssen, weil $\mathrm{ja}$ in diesen erst in einer gewissen Periode die Bildung der Chlorophyllkörner erfolgt und auch das Protoplasma Anfangs inancherlei Veränderungen unterliegt.

Bekanntlich erfüllt das Protoplasma die jungen Zellen Anfangs gleichmässig und nimmt erst beim Heranwachsen derselben in Folge der Bildung von Vacuolen seine wandständige Vertheilung an. Wenn die Chlorophyllkörner schon vor dieser definitiven Orientirung des Protoplasmas sich bilden, so liegen sie zunächst ziemlich ordnungslos in demselben eingebettet, und während dieses später sich ansschliesslich an der Innenseite der Zellmembran ausbreitet, ordnen sich auch die Chlorophyllkörner an den freien Zellwänden an. Der Beobachtung am günstigsten sind hier die Blattzellen der Elodea canadensis. In den Zellen ganz junger Blätter findet man gleichmässig körniges Protoplasma, in welchem alsbald die späteren Chlorophyllkörner als grössere Protoplasmakörnchen sichtbar werden. Diese sind zunächst noch farblos und vielmal kleiner als die ausgebildeten Chlorophyllkörner, und erscheinen gleichmässig im Protoplasma zerstreut. Zugleich werden nun auch im Innern des letzteren eine oder einige grosse runde Vacuolen gebildet. Dies ist der Anfang der Erzeugung von Protoplasmasträngen, welche jetzt über die Wände und durch das Lumen der Zelle ausgespannt sind. Auch in diesen Strängen liegen dann noch die jungen Chlorophyllkörner gleichmässig zerstreut oder ohne bestimmte Regel hier und da etwas mehr zusammengedrängt. Man findet ferner eine Anzahl derselben an den Seitenwänden sitzen und auch an der Aussenwand sind solche vorhanden, bald gleichmässig zerstreut, bald hin und wicder regellos aggregirt. Erst wenn die Chlorophyllkörner grösser werden und ihre grüne Farbe deutlicher wird, sammeln sie sich allmählich alle an der Aussenwand an und nelmen hier die beschriebene gleichmässige Vertheilung an. Es stehen also die Chlorophyllkörner nicht ursprünglich in derjenigen Ordnung in der Zelle, in welcher sie in erwachsenen Zustande derselben augetroffen werden; sie begeben sich vielmohr erst in einer bestimmten Entwickelungsperiode in jene Stellung. Diese Wanderung tritt also ein, ohne dass eine Veränderung der äusseren Einflüsse stattfindet, sie ist eine auf inneren Motoren beruhende, durch die periodische Entwickelung der Zelle 
gegebene Erscheinung. Wohl aber steht sie unter denselben auf äusseren Einwirkungen beruhenden Bedingungen wie die normale Vertheilung des Chlorophylls in den ausgebildeten Zellen. So vermögen die Chlorophyllkörner, wenn die Zelle denjenigen Entwickelungszustand erreicht hat, in welchem dieselben normalmässig in ihre definitive Stellung sich begeben müssen, diese Wanderung nicht vorzunehmen, wenn die Pflanze im Dunkeln steht. Dieser Satz hat wenigstens für diejenigen Pflanzen Geltung, bei denen das Licht eine sehr entschiedene Wirkung auf die Stellung der Chlorophyllkörner ausübt. So sieht man bei Jungermannieen, welche eine Zeit. lang im Dunkeln verweilt und unterdessen jüngere Blätter zur vollständigen Ausbildung gebracht haben, in allen Entwickelungsstadien der jungen Blätter, soweit man noch die ersten Spuren sich bildender Chlorophyllkörner zurückverfolgen kann, diese an den Seitenwänden der Zellen liegen. - Und dass jene Erscheinung an der jungen Zelle sich auch nur insofern vollzieht, als diese mit dem Hauptkörper der Pflanze in Verbindung steht, geht daraus hervor, dass wenn junge Blätter von Elodea in dem Stadium, wo die Chlorophyllkörner eben die normale Anordnung einzunehmen in Begriffe sind, abgeschnitten werden, das Protoplasma sammt den Chlorophyllkörnern nicht nur in der früheren Lage dauernd verbleibt, sondern auch diejenigen Körner, welche schon an der Aussenwand angekommen waren, sich wieder für immer zurückziehen.

Aber auch in senescirenden Zellen besteht ein Zustand, welcher von demjenigen der im Böhepunkte ihrer Entwickelung begriffenen Zellen abweicht und in einer veränderten Vertheilung der Chlorophyllkörner, auch unter gewöhnlichen Umstäuden, einen sichtbaren Ausdruck gewinnt. An den längeren Trieben der Elodea finden sich häufig aın unteren Ende älteste Blätter, welche unzweifelhaft dem Absterben nahe sind. Sie haben immer eine blässer grüne Farbe oder sehen auch blassröthlich aus, oder sind wohl auch ganz verbleicht; aber sie sind noch vollständig am Leben, wie nicht nur der straffe turgescende Zustand beweist, vermöge dessen sie wie die übrigen Blätter geraue vom Stengel abstehen, sondern wie auch aus der mikroskopischen Untersuchung hervorgeht. Das Protoplasma befindet sich nämlich in Rotation um die Seitenwände, und ihm sind die weitaus meisten Chlorophyllkörner eingebettet; nur einige liegen auch an der Hinterwand, die Aussenwand ist leer. Die Chlorophyllkörner sind in diesen Zellen sehr klein, stärkefrei und besitzen keine rein grüne Farbe mehr: sie sehen gelblich oder 
gelbröthlich aus, in manchen Zellen sogar schön roth wie in rothen Beeren und von dem nämlichen F'arbentone wie in diesen. Nicht selten ist eine Anzahl solcher rother Köruchen in einem kugeligen Klumpen dicht zusammengeballt, der dann mit den einzelnen übrigen Körnchen in dem Strome des Protoplasmas fortgeschwemmt wird. Intermediäre Zustände repräsentiren die nächstfolgenden Blätter, in denen die Chlorophyllkörner noch weniger von ihrem grünen Farbentone verloren haben und in dem Aufgeben ihrer normalen Stellung erst begriffen sind.

Wenn die Pflänzchen des Mnium rostratum neue aufwärtswachsende und grüne Blätter tragende Sprosse treiben, so werden die bisherigen grünen Sprosse abgelegt. Dann vertauschen die Blätter derselben schon einige Zeit vorher ihre intensiv grüne Färbung mit einer blässeren, bisweilen etwas bräunlichen. Solche Blätter sind aber noch vollkommen lebendig: sie haben noch die natürliche Turgescenz, und das Protoplasma steht noch überall an den Zellwänden, die einzige Abweichung von dem früheren $\mathrm{Zu}$ stande besteht in einer der normalen Anordnung entgegengesetzten Lage der Chlorophyllkörner. Diese Veränderung ist oft auf das Vollständigste hergestellt, indem alle Chlorophyllkörner die Seitenwände bedecken und auf den breiten Wäuden gänzlich fehlen. Häufig ist sie aber insofern unvollständig, als noch mehr oder weniger Körner die breiten Wände einnehmen. Diese Zustände herrschen dann in der bezeichneten Periode in allen Blättern des Sprosses, wenngleich die Pflanzen die alltägliche Beleuchtung geniessen and sich auch in jeder anderen Beziehung unter den Bedingungen der normalen Chlorophyllstellung befinden und während die letztere auch in den kräftig vegetirenden neuen Sprossen besteht. Auch früher, wenn die Sprosse dem Absterben noch ferner sind, findet man nicht selten, dass schon in den ältesten Blättern der eben beschriebene Zustand eingekehrt ist, während in den jüngeren Blättern noch die regelmässige Ordnung herrscht.

Aus Vorstehendem geht hervor, dass sich im Leben der Zelle drei Perioden unterscheiden lassen, deren jede durch eine bestimmte Ordnungsweise der Chlorophyllkörner bezeichnet ist: der juvenile Zustand, der Höhepunkt der Entwickelung und die Senescenz. Der erstere ist charakterisirt durch den Mangel einer ausgeprägten Vertheilung der Chlorophyllkörner an bestimmten Zellwänden; der zweite durch diejenige Anordnung, die wir im Bisberigen als die normale bezeichnet haben, und der dritte durch 
die entgegengesetze Vertheilungsform, die in anderen Perioden des Zellenlebens nur die Folge abnormer Umstände zu sein pflegt.

Ausserdem scheint aber auch während des Höhestadiuns der Entwickelung ein gewisser continuirlich in kurzen Zeiträumen wiederkehrender Zustandswechsel in der Zelle zu herrschen, welcher aber nur in gewissen F'allen einen wirklich sichtbaren Ausdruck, und zwar wiederum in der analogen Vertheilungsweise des Protoplasınas und der Chlorophyllkörner, gewinnt. Dass es überhanpt an der Zelle Erscheinungen giebt, die einer nach kurzen Zeiträumen bemessenen Periodicität unterliegen, ist mehrfach bekannt. Die Kraft, mit welcher die aufsaugenden Wurzelzellen das Wasser im Stamme aufwärts pressen, die Verdunstung, die Gewebespannung, die Athmung und die damit verbundene Selbsterwärmung bieten hierfür Belege. Wenn wir hier an sehr verschiedenen Erscheinungen die Lebensthätigkeit der Zelle in einem allem Anscheine nach von äusseren Einflüssen bis zu einem gewissen Grade unabhängigen Steigen und Sinken begriffen sehen, so ist es schon an und für sich nicht unwahrscheinlich, dass auch die inneren Bedingungen der Anordnungsweise des Protoplasmas und des Chlorophylls ähnlichen Veränderungen unterliegen können. Ich glaube, dass die unbekannten inneren Kräfte, auf welche in letzter Instanz die Bewegungen des Protoplasmas und der Chlorophyllkörner zurückzuführen sind, wenigstens in gewissen Pflanzen in einem periodischen Steigen und Sinken begriffen sind, und dass da, wo sie den äusseren $\mathrm{Mo}_{0}$ toren jener Bewegungen überlegen sind, sich der Rhytmus dieses Wechsels in einem Vor- und Zurückgehen der normalen Vertheilung von Plasma und Chlorophyll kundgiebt. Beobachtungen, die ich ane den submersen Blättern von Sagittaria sagittaefolia machte, schienen mir nicht anders als auf diese Weise zu deuten zu sein.

An der genannten Pflanze findet man bei manchen Individuen, welche unter gan\% normalen sich gleichbleibenden Verbältnissen gehalten werden, nicht selten mitten am Tage die Chlorophyllkörner der Nachtstellung mehr oder weniger genähert. Dass dieses nicht eine individuelle Abweichung in dem stetigen Verhalten des Chlorophylls, sondern das Resultat einer bei unveränderten Verhältnissen stattfindenden Wanderung der Chlorophyllkörner ist, geht z. B. aus folgender Wahrnehmung hervor. Zwei Individuen, welche zur Sommerszeit, nachdem sie in constanter Dunkelheit ibre Chlorophyllkörner alle an die Seitenwände bewegt hatten, 
wieder ans Licht gebracht worden waren und daselbst nabezu die frühere Vertheilung des Chlorophylls augenommen hatten, wurden nun weiter der täglichen Beleuchtung ausgesetzt. Nach mchreren Tagen untersuchte ich sie Nachmittags abernals und fand in allen Präparaten, die ich mehreren Blättern beider Pflanzen in Gestalt je eines kleinen Flächenschnittes entnahm, an den Seitenwänden sehr viele, ja beinahe sämmtliche Chlorophyllkörner, desgleichen überall den Zellenkern, auf den beiden breiten Wänden dagegen keine oder sehr spärliche Chlorophyllkörner; und doch war weder in der Beleuchtung noch in der gewöhnlichen Temperatur, noch sonst in irgend einer Beziehung eine Veränderung der äusseren Umstïnde erfolgt. Nach etwa halbstündicer Dauer bemerkte ich aber an den Präparaten entgegengesetzt der sonst dabei zu beobachtenden Erscheinung, eine Anzahl Chlorophyllkörner an die breiten Wände, namentlich an die Hinterwand treten, und in manchen Zellen rutschte auch der Zellkern dorthin. Als nun sogleich von der Pflanze, die unterdessen daneben gestanden hatte, neben den Stellen, an welchen jene Präparate hcrauggeschnitten wa:en, neue dergleichen entnommen wurden, so fand sich auch hier alles in der Lichtstellung und zwar weit rollständiger als es in jencn Prä. paraten geworden war. Die Aussenwand war ganz mit Chlorophyllkörnchen überzogen, auch an der Hinterwand befanden sich viele. Die annähernde Dunkelstellung der Chlorophyllkörner mitten am Tage, nachdem die Planze vorker schon wieder den normalen $\mathbf{Z u}$ stand erlangt hatte, und die in kurzer Zeit erfolgende Aenderung der Chlorophyll- und Zellkernstellung macht es im höchsten Grade wahrscheinlich, dass dabei lediglich innere Kräfte der Zelle bethejligt waren. Diese vermochten sogar in den Präparaten die durch die Trennung der Zelle von der Pflanze herbeigeführte entgegengesetzte Wirkung zu paralysiren, ja zu überwinden. Dass aber diese letztere Wirkung wie sonst ausnahmslos, so auch hier sich geltend machte, wurde dadurch bewiesen, dass in den Präparaten die Lichtstellung der Chlorophyllkörner hinter den während der gleichen Zeit eingetretenen Zuständen in der Pflanze selbst bemerklich zurückblieben. Es geht aber ferner auch hieraus hervor, dass die Zelle in ihrer Periodicität mit den ubrigen Zellen selbst dann noch gleichen Schritt hielt, als sie gar nicht mehr mit ihnen zusammenhing. Man muss also annehmen, dass allen Zellen ein gewisses gleichartiges Befinden zukommt, welches die Quelle der Kräfte, die die späteren Zustände erregen, schon in sich trägt. 
Um noch andere Individuen auf diese Erscheinung zu prüfen und ein vollständigeres Bild von dem Gange derselben zu gewinnen, nahm ich Mitte Juni einige kräftige Exemplare, die eben erst von ihrem natürlichen Standorte geholt worden waren, in Untersuchung. Sie befanden sich dabei in einem gläsernen Wasserge. fässe hinter einem nach Nordwesten schauenden Zimmerfenster, wo sie während des ganzen Tages der Belcuchtung ausgesetzt waren. An jedem Individuum wurden drei Blätter für die Untersuchung bestimmt. Aus der Mitte derselben wurde jedesmal von der Oberseite ein kleines Stückchen Epidermis durch einen Flächenschnitt herausgelöst; jeder nächste Schnitt wurde in einiger Entfernung von den alten angestellt. Durch solche kleine Verwundungen wird an den Blättern durchaus keine Veränderung der inneren Zellenzustände herbeigeführt. Die Untersuchung wiederholte sich alle zwei Stunden, und jedesmal kamen die einzelnen Blätter in derselben Reihenfolge daran. Es dauerte jedesmal ungefähr eine Stunde, ehe alles durchuntersucht und der Befund protokollirt war. Somit kam also doch jedes Blatt ungefähr alle zwei Stunden zur Untersuchung. Späterhin wurden die Pausen etwas grösser angenommen. Die folgende Tabelle giebt in gedrängter Form das Protokoll der Beobachtungen. Die einzelnen Individuen der Versuchspflanzeu sind der Reihe nach aufgeführt. Die Abkürzungen AW., HW. und SW. bedeuten Aussenwand, Hinterwand und Seitenwände der Zellen.

No. 1.

\begin{tabular}{|c|c|c|c|}
\hline & Erstes Blatt. & Zweites Blatt. & Drittes Blatt. \\
\hline $\begin{array}{l}8 \mathrm{Uhr} \\
\text { Vor- } \\
\text { mittag. }\end{array}$ & $\begin{array}{l}\text { AW. Sehrwenige, ein. } \\
\text { zeln stehende Körner. } \\
\text { HW. Ganz mit Kör- } \\
\text { nern bedeckt. Zellkern. } \\
\text { SW. Keine oder we- } \\
\text { nige Körner. }\end{array}$ & Wie das erste Blatt. & $\begin{array}{l}\text { AW. Ganz mit Körner } \\
\text { bedeckt. } \\
\text { HW. Ebenfalls, aber } \\
\text { etwas spärlicher. Meist } \\
\text { Zellkern. } \\
\text { SW. Keine oder we- } \\
\text { nige Körner. Selten Zell- } \\
\text { kern. }\end{array}$ \\
\hline $\begin{array}{l}10 \mathrm{Uhr} \\
\text { Vor- } \\
\text { mittag. }\end{array}$ & $\begin{array}{l}\text { Ebenso, aber SW ot- } \\
\text { was mohr besetzt. }\end{array}$ & $\begin{array}{l}\text { AW. Wenige oder } \\
\text { keine Körner. } \\
\text { HW. Mit Körnern be- } \\
\text { dekt, aber spärlicher } \\
\text { als vorher. Zellkern } \\
\text { oft am Rande. } \\
\text { SW. Zahlreiche Kör- } \\
\text { ner, oft Zellkern. }\end{array}$ & $\begin{array}{l}\text { AW. Spärlicher be- } \\
\text { setzt als vorher. } \\
\text { HW. Reichlich be- } \\
\text { deckt. } \\
\text { SW. Keine oder einige } \\
\text { Körner. }\end{array}$ \\
\hline
\end{tabular}


Zw eites Blatt.

Drittes Blatt.

Wie das erste Blatt.

AW. Ziemlich besetzt.

HW. Reichlich he-

deckt. Zellkern.

SW. Leer oder mit einer im Allgemeinen nicht sebr bedeutenden Anzahl Körner besetzt.

AW. Verschieden reichlich besetzt.

HW. Reichlich bedeckt.

SW. Leer oder wenige Körner.

AW. Bald reichlich bald spärlich besetzt.

HW. Immer reichlicher als $\mathrm{AW}$ besetzt. SW. Bald reichlich bald spärlicher besetzt.

\section{No. 2.}

$8 \mathrm{Uhr}$

Vormittag.

10 Uhr Vormittag.
Wie das erste Blatt, nur im Allgemeinen etwas mehr Körner auf $H W$, etwas weniger auf SW.

Wie das erste Blatt, nur noch etwas mehr Körner und häufig auch der Zellkern auf HW.
AW. Keine oder wenige Körner.

HW. Ziemlich , bedeckt; meist Zellkern. SW. Ziemlich viel Körner; bisweilen Zellkern. AW. Fast leer. HW. Spärliche Körner, oft den SW genähert.

SW. Dicht bedeckt, meist Zellkern.
Ebenso, aber die SW entblösst.

AW. Im Allgemeinen mit wenigen Körneru.

HW. Etwas reichlicher als $A W$ besetzt.

SW. Reichlich besetzt, meist auch Zellkern.

AW. Reichlich bedeckt.

HW. Noch reichlicher als AW bedeckt. Mleist Zellkern.

SW. Wenige Körner.

\section{Euenso.}

Ebenso.

AW. Spärliche Körner. HW. Ziemlich reichlich bedeckt; meist Zellkern. SW. Ziemlich viel Körner; bisweilen Zellkern.

AW. Spärliche Körner. HW. Ziemlich viel Körner, meist auch Zellkern, oft beide den SW genähert; bisweilen auch in geringerer Anzahl.

SW. Ziemlich viel Körner, bisweilen Zellkern. 


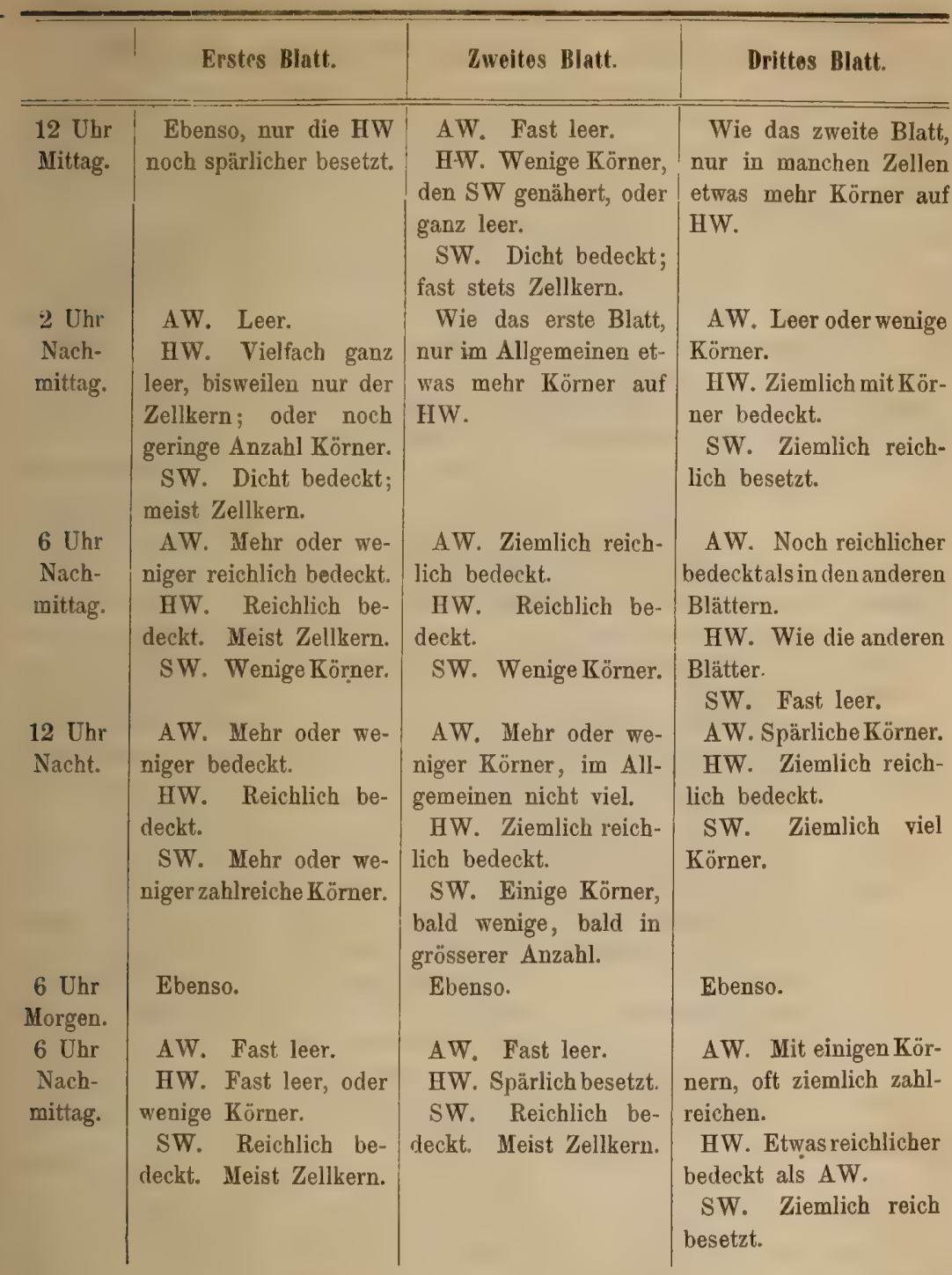

No. 3.

\begin{tabular}{|c|c|c|c|}
\hline $\mathrm{ar}$ & $\begin{array}{l}\text { AW. und HW. Mehr } \\
\text { oder weniger bedeckt, } \\
\text { in vielen Zellen sehr } \\
\text { wenig Körner. } \\
\text { SW. Reichlich be- } \\
\text { setzt; meist auch Zell- } \\
\text { kern. }\end{array}$ & $\begin{array}{l}\text { AW. Sehr spärlich } \\
\text { besetzt. } \\
\text { HW. Reichlicher be- } \\
\text { deckt; oft Zellkern. } \\
\text { SW. Ziemlich viel } \\
\text { Körner, oft Zellkern. }\end{array}$ & $\begin{array}{l}\text { AW. Sehr spärlich } \\
\text { besetzt. } \\
\text { HW. Meist reichlich } \\
\text { bedeckt; meist auch } \\
\text { Zellkern. } \\
\text { SW. Mit einigen Kör- } \\
\text { nern besetzt. }\end{array}$ \\
\hline
\end{tabular}




\begin{tabular}{|c|c|c|c|}
\hline & Erstes Blatt. & $Z$ weltes Blatt. & Drittes Blatt. \\
\hline $\begin{array}{l}10 \mathrm{Uhr} \\
\text { Vor- } \\
\text { mittag. }\end{array}$ & $\begin{array}{l}\text { AW. Spārlich besetzt. } \\
\text { HW. Häufig fast leer; } \\
\text { beiweilen noch eine } \\
\text { grössere Anzahl Kör- } \\
\text { ner. Oft Zellkern. } \\
\text { SW. Reichlich be- } \\
\text { deckt; bisweilen Zell- } \\
\text { kern. }\end{array}$ & Wie das erste Blatt. & $\begin{array}{l}\text { AW. Im Allgemeinen } \\
\text { spärlich besetzt. } \\
\text { HW. Ziemlich viel } \\
\text { Körner. } \\
\text { SW. Meist mit zabl- } \\
\text { reichen Körnern besetzt. }\end{array}$ \\
\hline $\begin{array}{l}\text { 12 Uhr } \\
\text { Mittag. }\end{array}$ & $\begin{array}{l}\text { Ebenso, aber der Zell- } \\
\text { kern meist auch an } \\
\text { SW, und die HW im } \\
\text { Allgemeinen noch spăr- } \\
\text { licher besetzt. }\end{array}$ & $\begin{array}{l}\text { Wie das erste Blatt, } \\
\text { nur etwas mehr Körner } \\
\text { an der HW, daselbst } \\
\text { auch nicht selten der } \\
\text { Zellkern. }\end{array}$ & Ebenso. \\
\hline $\begin{array}{l}2 \mathrm{Ohr} \\
\text { Nach- } \\
\text { mittag. }\end{array}$ & $\begin{array}{l}\text { AW und HW im All- } \\
\text { gemeinen fast leer. } \\
\text { SW. Reichlich be- } \\
\text { deckt; meist Zellkern. }\end{array}$ & $\begin{array}{l}\text { Wie das erste Blatt, } \\
\text { aber an der HW etwas } \\
\text { mehr Körner. }\end{array}$ & Ebenso. \\
\hline $\begin{array}{l}6 \text { Uhr } \\
\text { Nach- } \\
\text { mittag. }\end{array}$ & $\begin{array}{l}\text { AW. Ziemlich reich- } \\
\text { lich bedeckt. } \\
\text { HW. Noch reicher, } \\
\text { dicht bedeckt. } \\
\text { SW. Leer. }\end{array}$ & Wie das erste Blatt. & $\begin{array}{l}\text { AW. Mit wenig Kör- } \\
\text { nern besetzt. } \\
\text { HW. Ziemlich reich- } \\
\text { lich und dicht besetzt. } \\
\text { SW. Wenige oder } \\
\text { keine Körner. }\end{array}$ \\
\hline $\begin{array}{l}12 \text { Uhr } \\
\text { Nacht. }\end{array}$ & $\begin{array}{l}\text { AW. Im Allgemeinen } \\
\text { spärlich besetzt. } \\
\text { HW. Ziemlich reich- } \\
\text { lich, aber lückenhaft } \\
\text { besetzt. } \\
\text { SW. Reichlich be- } \\
\text { setzt. }\end{array}$ & $\begin{array}{l}\text { AW. Mitmässiger An- } \\
\text { zahl Körner berleckt. } \\
\text { HW. Reichlicher, doch } \\
\text { lückenhaft besetzt; oft } \\
\text { die Körner den SW } \\
\text { genähert. } \\
\text { SW. Mehr oder we- } \\
\text { niger reich bedeckt. }\end{array}$ & $\begin{array}{l}\text { AW. Spärlich oder } \\
\text { mässig besetzt. } \\
\text { HW. Ziemlich reich- } \\
\text { lich bedeckt. } \\
\text { SW. Mit einigen Kör- } \\
\text { nern besetzt. }\end{array}$ \\
\hline $\begin{array}{c}6 \text { Uhr } \\
\text { Morgen. }\end{array}$ & Ebenso. & $\begin{array}{l}\text { AW. Mässig oder spär- } \\
\text { lich besetzt. } \\
\text { HW. Ziemlich viele } \\
\text { Körner, oft lückig. } \\
\text { SW. Mit mässiger An- } \\
\text { zahl Körner. }\end{array}$ & $\begin{array}{l}\text { AW. Spärlich besetzt } \\
\text { oder leer. } \\
\text { HW. Meist ziemlich } \\
\text { reichlich besetzt, oft ot- } \\
\text { was lückenhaft. } \\
\text { SW. Bald dicht be- } \\
\text { setzt, bald etwas spär- } \\
\text { licher. }\end{array}$ \\
\hline $\begin{array}{l}6 \text { Uhr } \\
\text { Nach- } \\
\text { mittag. }\end{array}$ & $\begin{array}{l}\text { AW. Fast leer. } \\
\text { HW. Wenige Körner, } \\
\text { meist dem Rande ge- } \\
\text { nähert. } \\
\text { SW. Sehr reichlich } \\
\text { und dicht bedeckt. }\end{array}$ & $\begin{array}{l}\text { AW. Spärlich oder } \\
\text { etwas reichlicher be- } \\
\text { setzt. } \\
\text { HW. Ziemlich besetzt, } \\
\text { aber meist sehr lücken- } \\
\text { haft. } \\
\text { SW. Meist reichlich } \\
\text { bedeckt. }\end{array}$ & $\begin{array}{l}\text { AW. Leer. } \\
\text { HW. Ziemlich reich- } \\
\text { lich bedeckt, oft lückig. } \\
\text { SW. Im Allgemeinen } \\
\text { reichlich besetzt. }\end{array}$ \\
\hline
\end{tabular}


No. 4.

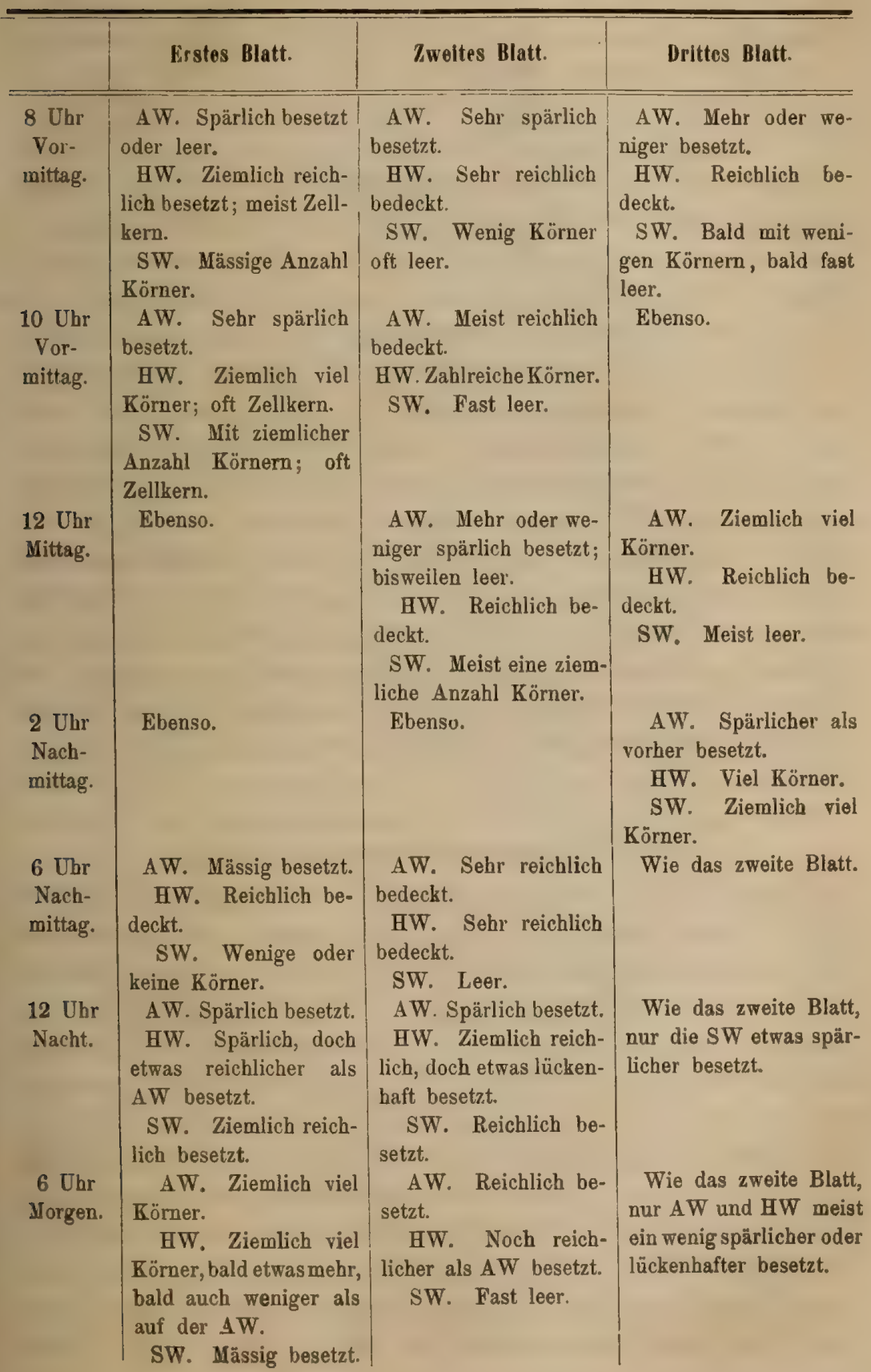




\begin{tabular}{c|c|c|c}
\hline & Erstes Blatt. & Zweites Blatt. & Drittes Blatt. \\
\hline $\begin{array}{l}\text { Nach- } \\
\text { mittag. }\end{array}$ & $\begin{array}{l}\text { AW. Ziemlich reich- } \\
\text { HW. Noch reichlicher } \\
\text { bedeckt als AW. Meist } \\
\text { Zellkern. } \\
\text { SW. Leer oder mit } \\
\text { wenigen Körnern. }\end{array}$ & Ebenso. & $\begin{array}{c}\text { A Wr. Mehr oder we- } \\
\text { niger reichlich besetz.t. } \\
\text { HW. Etwas reichlicher } \\
\text { als AW besetzt. } \\
\text { SW. Mehr oder we- } \\
\text { niger, oft ziemlich reich- } \\
\text { lich besetzt. }\end{array}$ \\
\hline
\end{tabular}

Die vorstehenden Angaben zeigen, dass bei unserer Pflanze periodenweise die Chlorophyllkörner ihre gewöhnliche Stellung in verschiedenem Grade, bald nur annäherungsweise, bald vollstän. diger mit der entgegengesetzten auf einige Zeit vertauschen, und dass dieser Wechsel weder an sich eine bestimmte Regelmässigkeit zeigt, noch auch zu der Beleuchtung oder zu den Tageszeiten in einer festen Beziehung sich befindet. Sie zcigen auch, dass rielfach nicht nur die einzelnen Blätter eines und desselben Individuums, sondern selbst die einzolnen Individuen unter einander bis zu einem gewissen Grade bei jenem Wechsel gleichen Schritt halten. Sie zeigen aber auch, dass Blätter und Individuen zur nämlichen Zeit, und während sie sich unter gleichen äusseren Verhältnissen befinden, sehr wesentlich verschiedene Chlorophyllvertheilungen annehmen können. Es ist daher wahrscheinlich, dass jene verschiedenen Befunde zum Theil wenigstens der Ausdruck eines nicht weiter bekannten periodischen inneren Zustandswechsels sind.

\section{Das Protoplasma ist das Bewegende.}

Gegenüber der bekannten Thatsache, dass die Chlorophyllkörner in dem allgemeinen Protoplasma der Zelle eingebettet sind, ist die Bezeichnung Wanderung der Chlorophyllkörner zweideutig, denn es ist ebensowohl denkbar, dass innerhalb des Protoplasmas als eines passiven Mediums die Chlorophyllkörner selbständig sich fortbewegen, als auch dass das Protoplasma in Bewegung geräth und die in ihm steckenden Chlorophyllkörner mit fortführt. Die erstere Annahme würde sich auf gewisse analoge Erscheinun. gen berufen können, indem wir z. B. in den Schwärmsporen, in den Diatomeen und Oscillarien ähnliche selbständig bewegliche Organismen vor uns haben, wobei zunächst die Frage, ob sichtbare Bewegungsorgane vorhanden sind, in zweiter Linie steht. Dem Protoplasma würde immer ein Flüssigkeitsgrad zugestanden 
werden können, welcher diese Bewegungen gestattet. Dass auf die Ortsreränderungen der Chlorophyllkörner das Licht einen wesentlichen Einfluss ausübt, dass dieselben sogar, wie ich gezeigt habe, unter Umständen in der Zelle direkt nach der Seite stärkster Beleuchtung hin wandern, würde erinnern an das ähnliche Verhalten jener frei beweglichen grünen Organismen, deren Bewegungsrichtung ja ebenfalls durch das Licht bestimmt wird. Die andere Annahme würde aber ihre wesentliche Stütze in dem Umstande finden, dass überhaupt das Protoplasma vielfache Bewegungen in der Zelle vornimmt, und dass ja positiv Fälle bekannt sind, wo durch ein strömendes Protoplasma die Chlorophyllkörner mit in Bewegung gesetzt werden. Für die letztere Ansicht hat sich wie oben erwähnt, bereits Sachs ausgesprochen. Und wenn wir das, was über die Wanderung der Chlorophyllkörner bereits bekannt war, mit demjenigen zusammenfassen, was aus dem Vorstehenden sich ergeben hat und was ich im Folgenden noch bierüber mitzutheilen habe, so müssen wir dieser Ansicht auf das Entschiedenste beipflichten.

Es lässt sich dies durch folgende Momente begründen. Voran steht die Thatsache, dass es in einigen Fällen auf das Unzweideutigste sich beobachten lässt, wie bei diesen Ortsveränderungen der Chlorophyllkörner auch wirklich das Protoplasma in denselben Bewegungen sich befindet. Wir haben oben bei Sagittaria, Elodea und Vallisneria gesehen, dass die in der Ortsveränderung begriffenen Chlorophyllkörner in strömenden Protoplasmasträngen oder auch in grösseren gestaltloseren beweglichen Protoplasmamassen enthalten sind und von diesem Medium mit forthewegt werden; wir haben ferner gesehen, wie bei Elodea gegen die Zeit hin, wo die neue Anordnung ihrer Vollendung nahe kommt, die an den Aussenwänden sich zeigenden Protoplasmastränge seltener werden und die letzten schliesslich so eingezogen werden, dass sie in die die Seitenwände überziehenden Partien übergehen. Ferner kann man auch bei diesen Pflanzen wahrnehmen, wie wenn die neue Anordnung der Chlorophyllkörner fertig ist, die mit den letzteren auf den Seitenwänden befindliche Schicht von Protoplasma weit dicker ist als vorher, und dieses Verhältniss findet einen weiteren Ausdruck darin, dass wo ein Zellkern deutlich sichtbar ist, wie bei Sagittaria und bei Vallisneria, dieser sich jetzt in der Regel gleichfalls an einer Seitenwand befindet, während er im normalen Zustande wenigstens häufig auf der Hinterwand angetroffen wird. Man darf sich hierbei aber uicht vorstellen, dass in der neuen 
Vertheilung alles Protoplasma auf den Seitenwänden sich befindet, und die Aussenwand geradezu darnn entblösst ist, sondern es besteht auch dann noch die allyeneine Organisation des Protoplasmas, wonach allerwärts unter den Zellwänden eine Lage desselben auggebreitet bleibt, welche an ihrer äusseren Grenze die dichtere Beschaffenheit der sogenannten Hautschicht repräsentirt. Davon kann man sich überzeugen, wenn Zellen, deren Protoplasma und Chlorophyllkörner in der neuen Anordnung sich befinden, mit was. serentziehenden Mitteln behandelt werden, indem dann immer noch ein Gesammtprotoplasmaleib, der auch an der Aussenwand anliegt, contrahirt wird. Dies ist besonders deutlich, wenn die Volumverminderung nicht überall gleichmässig erfolgt: es bleibt dann die peripherische Plasmaschicht stellenweise noch an der Innenfläche der Aussenwand hängen in Form von Zipfeln, um welche herum das Uebrige sich schon abgehoben hat. Diese auch dann noch an der Aussenwand ausgebreitete Protoplasmalage wird also von re. lativ geringerer Dicke anzunehmen sein. Die vormals daran sicht. baren beweglichen Strängo u. s. w. waren offenbar dickere Stellen, und ihr Verschwinden daselbst eben das Anzeigen der Verminderung des Protoplasmas an diesem Orte. - Was die Wanderung selbst anlangt, so ist schon oben daranf hingewiesen worden, dass so bestimmt auch der Ausgangszustand sowohl wie das Endziel der Bewegungen ist, doch der Vorgang der letzteren selbst, wenigstens bei einigen Pflanzen, als ein ziemlich complicirter sich darstellt. Denn es fliessen z. B. bei Elodea die Protoplasmaströmchen, welche die Chlorophyllkörner fortführen, keineswegs allein von der Aussenwand nach den Seiten- und Hinterwäden, sondern auch in umgekehrter Richtung und bringen dadurch oft wieder die Chlorophyllkörner vorübergehend an die Aussenwand. Dass trotzdem die Zahl der letzteren hierselbst immer geringer wird und sie sich entsprechend an den übrigen Stellen anhäufen, wird sicher in der Thatsache seine Erklärung finden, dass eben auch das Protoplasma an den letzteren Orten sich anhäuft und an der Aussenwand immer spärlicher wird. Wahrscheinlich sind die nach der Aussenwand zurückfliessenden Strömchen nicht nur an Zahl geringer, sondern auch dünner, substanzärmer als die anderen; sie würden also auch eine geringere bewegende Kraft entfalten müssen, als die letzteren, und minder leicht schwere Körper, als welche sich hier die Chlorophyllkörner den Strömchen gegenüber erweisen, forttreiben können. Und wenn man in den Zellen der Sagittariablätter sowie, wenigstens 
bei Einwirkung der Dunkelheit auch in denen der Elodea canadensis, nach vollständiger Herstellung der neuen Anordnung noch immer die circulirenden Bewegungen dünner Protoplasmaströmchen in verschiedenen Richtungen durch die Zellhöhle und unter der Aussenwand beobachtet, während die Chlorophyllkörner und der Zellkern dauernd ihre neue Lage bewahren, so nöthigt uns dieses zu der Annabme, dass zu dieser Zeit eine entschieden geringere Protoplasmamenge in jener circulirenden Bewegung bugriffen ist als vordem und dass daher ibre Strömchen jetzt nicht mehr die Kraft besitzen um Körper wie die Chlorophyllkörner von ihrem Orte zu rücken.

Solche Fälle, wie die hier bezeichneten, in welchen die direkte Beobachtung ohne jede Schwierigkeit die Identität der Bewegungen wandernder Chlorophyllkörner mit gleichen Bewegungen des Protoplasmas constatiren kann, gestatten einen Schluss auf diejenigen Pflanzen, bei deneu es wegen der Homogeneïtät des Protoplasmas schwieriger ist das Verhalten desselben während der Wanderung der Chlorophyllkörner zu beobachten, wie bei den Moosen, Lebermoosen und Faı cprothallien. Es steht nichts der Annahme entgegen, dass auch bei diesen Pflanzen das Protoplasma durch die bezeichneten Ursachen zu einer Veränderung seiner Vertheilung in der Zelle veranlasst wird und dabei die Chlorophyllkörner mit sich nimmt. Hier sind diese Bewegungen auch viel einfacher, wie man aus der Richtung, welche die Chlorophyllkörner nehmen, schliessen darf. Denn diese rutschen hier gerades Weges oder doch ohne irgend erhebliche Umwege, insbesondere ohne in circulirenden Plasmaströmchen zunächst eine Zeit lang ziellos in der Zelle umhergeführt zu werden, unmittelbar nach den Seitenwänden, und kehren bei der entgegengesetzten Wanderung auch wieder in dieser Weise in ihre frühere Lage zurück.

Es lässt sich aher die Annahme, dass das Protoplasma das Bewegende ist, auch noch durch den Umstand erweisen, dass wenn in solchen Zellen die Chlorophyllkörner durch Körper anderer Art ersetzt sind, diese dann die gleichen Ortsveränderungen zeigen wie jene, dass also die Bewegung nicht an die specifische Natur der Chlorophyllkörner geknüpft ist, sondern an jedweden Formelementen, sofern sie im Protoplasma solcher Zellen eingeschlossen sind, sich vollzieht. Folgende Beobachtungen mögen dies bestätigen.

In einer Cultur von Lophocolea bidentata N. ab E., welche ich 17 Tage lang in constanter Dunkelheit stehen gelassen hatte, 
waren die Srosse an der Spitze beträchtlich weiter gewachsen; es batte sich an den meisten in der Dunkelheit eine Anzahl neuer bereits fertig ausgebildeter Blätter erzeugt, welche vollständig weiss aussahen, etiolirt waren. Die älteren Blätter enthielten ihr unverändertes Chloropbyll, sic waren wie Anfangs grün gefärbt. In den grünen Blättern befanden sich die Chlorophyllkörner auf das Vollständigste in der Dunkelstellung. Die etiolirten jüngeren Blätter enthielten statt der Chlorophyllkörner kleinere farblose Kügelchen protoplasmatischer Natur, die offenbar als die Grundsubstanz der Chlorophyllkörner, an welcher eben die Bildung des grünen Farbstoffes unterblieben war, sich erwiesen; denn in den ältesten der vergcilten Blätter, welche noch eine schwache Grïnfärbung besassen, zeigten diese Kügelchen mehr oder weniger einen grünen Anflug. Auch diese Körper nahmen dieselbe Stellung ein, wic die Chlorophyllkörner in den grünen Blättern. Die Cultur wurde nun wieder, zur Mittagszeit, ins Tageslicht gesetzt. Am Mittage des folgenden Tages war bereits eine Veränderung an der Stellung der Chlorophyllkörner sowohl wie der entschieden vergeilten Körnchen zu bemerken: einige von ihnen hatten ihre Stellung an den Seitenwänden verlassen und mehr oder weniger an die freien Wände sich begeben. Am $\mathrm{z}$ Weiten Tage waren die genannten Körper ihrer Lichtstellung überall sehr nahe gekommen, und am dritten Tage befanden sich alle auf das Vollständigste in der normalen Anordnung. Um diese Zeit war aber eine Ergrünung der vergeilten Chlorophyllkörner noch nicht wahrzunehmen, diese trat bestimmt erst später ein, nachdem dieselben schon ihre Stellung an den freicn Zellwänden vollständig eingenommen hatten. Es wurde also hicr die Wanderung auch von Körpern ausgeführt, welche noch nicht als eigentliche Chlorophyllkörner betrachtet werden können ${ }^{1}$ ).

Das Gleiche lässt sich auch an den noch farblosen Chlorophyllkörnern ganz junger Blätter von Elodea canadensis nach Abtrennung rom Stengel beobachten. In den Zellen solcher Blätter sind, wie oben schon erwähut, die kleinen farblosen oder ganz schwach grünlichen Kügelchen, wclche die Anfänge der Chlorophyllkörner darstcllen, noch ziemlich gleichmässig im Protoplasma zerstreut, und dicses beginnt eine oder mehrere Vacuolen zu bil-

1) Diese Beobachtung habe ich bereits auf der Versammlung deutscher Naturforscher und Aerzte zu Dresden im Jahre 1868 mitgetheilt. 
den, an deren Umfange dann die farblosen Kügelchen mehr zusammengedrängt sind. Einige Zeit nach der Präparation sieht man schon in diesen Zuständen der Zelle eine analoge Veränderung in dem Protoplasma erfolgen, wie in ausgebildeten Zellen. Dasselbe rückt mit seinen farblosen Ćhlorophyllanfängen mehr von der Aussenwand weg nach den Rändern der Zelle zu, indem die Vacuolen genauer unter der Aussenwand ihren Platz nehmen, auch zu eiuer einzigen daselbst liegenden grossen Vacuole zusammenfliessen, wenn deren mehrere vorhanden waren, und wohl selbst durch eigene Vergrösserung das Protoplasma seitwärts zurückdrängen. Auch in denjenigen etwas älteren Zuständen der Zelle, wo die Chlorophyllkörner zwar ergrünt sind, aber noch keine Stärkelsörner wie die ausgebildeten enthalten, auch ihre volle Grösse noch nicht erreicht haben und sich noch nicht alle in der normalen Stcllung befinden, sieht man kurze Zeit nach der Abtrennung des Blattes diejenigen Körnchen, welche bereits an der Aussenwand lagen, sich nach den Seitenwänden zurückziehen.

Die bei längerer Cultur in constanter Dunkelheit erzeugten und zur vollständigen Ausbildung gediehenen Blätter der Elodea sind vollständig rergeilt, sie enthalten fast farblose Körner, welche ähnlich wie die grünen Chlorophyllkörner nach langer Verdunkelung nur unvollständig in der normalen Anordnung sich befinden: viele stehen an den Seiten- und Hinterwänden, meistens aber auch einige an der Aussenwand. Die letzteren verändern ihre Stellung gleich echten Chlorophyllkörnern, wenn das Blatt von der Pflanze abgeschnitten worden ist.

Die Elodea bietet auch noch eine andere Erscheinung dar, die an dieser Stelle zu erwähnen ist. Die untersten fast der Blattachsel angehörigen Zellen der Blattoberseite enthalten statt der eigentlichen grünen stärkeführenden Chlorophyllkörner sehr grosse farblose oder nur schwach grün gefärbte Stärkekörner in der gleichen Anordnung wie sonst jene. Besonders in den jüngeren Blättern längere Zeit im Dunkeln gehaltener Pflanzen sind die grossen Stärkekörner dieser basalen Zellen wirklich farblos. Auch diese Körper begeben sich bald nachdem das Blatt abgeschnitten worden ist, nach den Seitenwänden, an denen sie alsbald von dem in Rotation übergehenden Protoplasma mit fortbewegt werden.

Dass das Protoplasma in Wechsel seiner Stellung sich befindet und dadurch die Anordnung der Chlorophyllkorner bedingt, 
geht endlich aus dem Zustand ganz junger Blätter, die in ununterbrochener Dunkelheit erzeugt worden sind, hervor. In den oben erwähnten Culturen rerschiedener Jungermannieen in constanter Dunkelheit, während welcher neue Blätter sich erzeugt hatten, waren in den jüngsten dieser letzteren die eben sichtbar werdenden ersten Anlagen der hier etiolirt bleibenden Chlorophyllkörner auch nur an den Seitenwänden vorhanden. Es erfolgte also hier auch schon die Entstehung der Chlorophyllkörner an diesem Orte. Vergleicht man damit die Bildung der Chlorophyllkörner in Blättern, die unter Einwirkung des Lichtes sich entwickeln, so bemerkt man an den Aussenwänden eben sichtuar werdende Chloro. phyllanfänge, indem hier wenigstens eine Auzahl Chlorophyllkörner sogleich an der Aussenwand entsteht. Da aber überhaupt nur im Protoplasma Chlorophyllkörner gebildet werden, so muss, wenn ihre Entstehung das eine Mal an den Seitenwänden, das andere Mal an den Aussenwänden beobachtet wird, in beiden Fällen das sie erzeugende Protoplasua eine verschiedene Vertheilung in der Zelle haben.

Noch mag ein Einwand gegen die Erklärung der Wanderung der Chlorophyllkörner durch protoplasmatische Bewegungen, den man vielleicht aus den vorstehenden Ergebnissen ableiten könnte, entkräftet werden. Man könnte daran Anstoss nehmen, dass die Chlorophyllkörner zu einer Wanderung veranlasst werden durch Einwirkungen, welche nachweislich die Bewegungen des Protoplasmas lahm legen, wie z. B. durch starke Temperaturerniedrigung und durch Entziehung sauerstoffhaltiger Luft. Dies dürfte sich aber wohl einfach dahin erklärer lassen, dass diese Bewegungen ausgeführt werden, noch ehe der Zeitpunkt eingetreten ist, wo jene Agentien ihre das Protoplasma lähmendon Wirkungen zur Geltung bringen. Denn es ist ja bekannt dass dieselben erst nachdem sie einige Zeit gedauert haben, allmählich ihre Wirkung äussern.

Wenn man die abwechselnde Stellung der Chlorophyllkörner an bestimmten Zellwănden als eine Folge der Aenderung der Protoplasmavertheilung betrachtet, so muss wohl dieselbe Anschaungs. weise auch nothwendig auf die directe Hinwanderung der Chlorophyllkörner nach der Quelle intensirster Beleuchtung innerhalb der Zelle übertragen werden. Zwar haben diese Erscheinungen sehr viel Aehnliches mit der lichtswärtsgehenden Schwärmsporenbewegung, wie sie Treriranus, Thuret, Nägeli, Cohn, Famintzin in einem an Fenster stehenden Teller, in theilweise ver- 
finsterter Glasröhre etc. beobachtet haben; allein man wird doch auch hier wohl nicht die Cblorophyllkörner mit jenen frei beweglichen Organismen identificiren können. Denn sie befinden sich ja nicht wie diese in einem wie das Wasser an sich trägen $\mathrm{Me}$. dium, sondern sind im Protoplasma eingebettet. Nun sieht man gewöhnlich, dass wo ein Zellenkern deutlich bemerkbar ist, wie bei Sagittaria, dieser dann mit den Chlorophyllkörnern an die der Lichtquelle zugekehrte Zellwand gerückt ist. Es scheint also, als ob die Chlorophyllkörner nicht als solche, sondern nur insofern sie im Protoplasma stecken, der lichtwärtsgekehrten Zellwand zubewegt werden. Zudenı weiss man ja auch in einigen Fällen, dass pflanzliches Protoplasma in seiner Bewegungsrichtung durch das Licht beeinflusst wird. So ist es bekannt, dass das Plasmodium von Aethalium septicum sich vor dem Lichte zurückzieht; und nach den Bcobachtungen Borscow's und Lürssen's zieht sich in den Brennhaaren von Urtica das Protoplasma von einem mit rothem Lichte beleuchteten Punkte der Zelle zurück, während es von blauem Lichte angezogen $z u$ werden scheint.

\section{Allgemeine Ergebnisse.}

Im Vorstehenden ist für eine Reihe von Pflanzen gezeigt worden, dass in ihren chlorophyllhaltigen Zellen das Protoplasma oder wenigstens der die Chlorophyllkörner und den Zellenkern unmittelbar einschliesende Theil desselben einer zwiefachen Vertheilung in der Zelle fähig ist, indem beide Male verschiedene aber bestimmte Zellenwände es sind, an welchen sich dasselbe ausschliesslich oder doch in weitaus grösster Menge ansammelt. Das Morphologische dieser Orientirung lässt sich unter einen allgemeingültigen Gesichtspunkt bringen. Es besteht ein Gegensatz zwischen denjenigen Stellen der Zellhaut, welche mit anderen Zellen in Verbindung stehen, und denjenigen, welche frei liegen, sei es dass dieselben die Oberfläche des Pflanzentheiles einnebmen, sei es dass sic an intercellulare Räume angrenzen. Die beiden entgegengesetzten Typen der Protoplasmavertheilung sind dadurch charakterisirt, dass die chlorophyllführende Hauptmasse des Protoplasmas bei dem einen die freien, bei dem anderen die Fugenwände der Zellen bekleidet. Unter dieses:einfache Gesetz lassen sich auch wirklich alle bei den oben betrachteten Pflanzen erkannten Erscheinungen 
bringen. Bei den einschichtigen Zellenkörpern der Laubmoos- und Jungermannieenblätter, sowic der Faruprothallien nehmen dic Chlorophyllkörner in dem einen Falle die beiden auswärts gekehrten breiten Wände, in dem anderen die schmalen Fugenwände ein; und in den Marginalzellen, welche nur drei Fugenwände haben und mit der cinen Kante freiliegen, ist bei der einen Stellung auch die letztere sanmt den breiten Zellwänden besetzt, bei der entgegengesetzten dagegen sind diese Theile entblösst und nur die drei Fugenwände überzogen. In der oberen Zellschicht der Blätter von Elodea giebt es an den parallelepipedischen Zellen nur eine freie Zellwand: die oberflächliche; die Hinterwand sowie die vier schmalen Seitenwände stehin mit anderen Zellen im Connexe. Hier ist der eine Typus durch ausschliessliche oder vorwiegende Versammlung der Chlorophylliörner an jener einen freien Wand, der entgegengesetzte durch die Vertheilung derselben an den Hinter- und Seitenwänden charakterisirt. Die ebenso gestalteten Epidermiszellen der submersen Blätter von Sagittaria betinden sich hinsichtlich ihrer Umgebung in anderen Verhältnissen: nur die rier schualen Seitenwände stehen mit anderen Zellen im Verbande, die beiden breiteu Wände liegen frei, die vordere ist die oberflächliche, die hintere grenzt an einen lufthaltigen Binnenraum des Blattes. Dem entspricht es auch, dass in dem eiuen Falle an beiden breiten Wänden, im ançeren an den vier schmalen Wänden die Chlorophyllkörner sich anordnen. Wiederum in anderen Verhältnissen befinden sich die grosscn Mesophyllzellen des Vallisneriablattes: die subepidermalen haben nur eine freie Wand, und diese grenzt an den Intercellularraum; dio mittleren, welche die subepidermalen hin und wieder verbinden, haben zwei gegenüberstehende freie Seitenwände, welche ebenfalls an den Binnenräumen liegen. Auch hier befinden sich die Chlorophyllkörner das eine Mal an der oder den freien Wänden, das andere Mal an den gegenüberstehenden Fugenwänden. Dass endlich selbst die Mesophyllzellen höherer Landpflanzen sich auch unter dieses Gesetz fügen, beweisen diejenigen der Crassulaceen. Hier sind dic freien Zellhautstellon diejenigen, welche an die Intercellulargänge stossen, und da die letzteren bei den obengenannten Pflanzen noch eine ziemlich gesetzmässige Anordnung haben, so bietet auch die Stellung der Chlorophyllkörner nocb eine leicht zı übersehonde Regelmässigkeit: sie nehmen die radialen Längswände, als die an die Intercellularräume grenzenden Hautstellen ein, die übrigen 
Wände, dic alle mit Nachbarzellen verwachsen sind, sind leer. Der Gegensatz dazu ist die Verbreitung der Chlorophyllkörner an allen Wänden oder vorwiegend an den oberen und unteren Querwänden oder gar ihre Vereinigung in einen einzigen contrahirten Klumpen. Dieser Fall bietet die Brücke zu den Mesophyllzellen aller übrigen höheren Landpflanzen und gestattet auch diesen die Erscheinung zuzuschreiben, die sich dann als eine ganz allgemeine betrachten lässt. Dass sie bei diesen nicht sehr in die Augen fallen kann, liegt eben in den hier allenthalbon gegebenen Verhältnissen, indem bei den Mesophyllzellen der meisten Pflanzen der Gegensatz zwischen den an Intercellulargänge grenzenden und den mit Nachbarzellen verwachsenen Stellen so wenig distinct und regelmässig ist, dass auch wenn das Protoplasma eine Unterscheidung dieser Stellen anstrebt, dies in der Regel nicht einen so augenfälligen Ausdruck wird gewinnen bönnen, wie in den verhältnissmässig wenigen Fällen, welche dem Zustandekommen dieser Erscheinung besonders günstig sind. Dass aber darum in jenen Zellen nicht die gleichen Kräfte thätig sind wie hier, geht daraus nicht hervor. Im Gegentheil gelang es mir z. B. in den Zellen des schwammigen Mesophylls von Stellaria nemorum die wandständigen Chlorophyllkörner im Allgemeinen, und oft mit grosser Deutlichkeit, an denjenigen Kanten, Ecken und Wandstreifen aufzufinden, welche den Intercellulargängen angrenzen, während die übrigen Stellen, namentlich breitere mit Nachbarzellen verwachsene Streifen durchaus leer waren.

$\mathrm{Da}$ die beiden Vertheilungstypen des Protoplasmas in allen Pflanzen, soweit bekannt, die gleichen sind, so ist es schicklich, ihnen der Kürze wegen ein für alle Mal bestimmte Bezeichnungen beizulegen. Der Zustand, in welchen das chlorophyllführende Protoplasma an die freien Stellen der Zellwand vorgerückt ist, mag Epistrophe, derjenige, in welcher es sich an die Fugenseiten zurückgezogen hat, Apostrophe heissen. Beide Erscheinungen sind Symptome gewisser Zustände des Protoplasmas, welche nachgewiesener Massen sowohl innere als äussere Ursachen haben könven. Zunächst wechseln diese Zustände auch unter gleichen äusseren Verhältnissen normal in bestimmten Lebensstadien der Zelle. Aus einer zur Jugendzeit herrschenden im Allgemeinen indifferenten Vertheilung des chlorophyllbergenden Protoplasinas stellt sich allmählich die Epistrophe her, welche während der Dauer der Entwickelungshöhe der Zelle sich erhält. Gebt letztere in die Senescenz 
über, so schwindet jene unwiederbringlich, und dic Apostrophe tritt an ihre Stelle.

Es giebt ferner gewisse äussere Einflüsse, welche die A postrcphe auch zu jeder anderen Zeit bewirken können. Und darum hat denn auch die Epistrophe ihre bestimmten äusseren Bedingungen, die eben die gegentheiligen von jenen sind. Dagegen ist die normal zur Alterszeit eintretende Apostrophe durch äussere Einflüsse nicht irritabel.

Die äusseren Einflüsse, welche die Apostrophe herbeiführen, sind specifisch sehr verschieden, doch stimmen sie alle darin überein, dass sie bei irgend dauerndem Bestande dem Pflanzenleben überhaupt ungünstig sich erweisen. Trennung der Zelle rou Haupt. körper der Pflanze, Entzichung des Lichtes, Ueberschreitung der gewöhnlichen vitalen Temperaturgrenzen, Verminder ung des Wassergehaltes unter ein gewisses Minimalmaass, Entziehung des respirabeln Sauerstoffes sind alles Zustände, welche nicht als normale gelten können.

Nach alledem scheint es, als sei die Epistrophe der Ausdruck eines völlig normalen, kräftigen Lebenszustandes, eines, wenn der Ausdruck erlaubt ist, ungetrübten Woblbefindens; die Apostrophe dagegen das Symptom einer geminderten Luebensenergie, eines Schwächezustandes, einer Erschlaffung. Ein solcher Schwächezustand kann durch jene ungünstigen Vegetationsbedingungen herbeigeführt werden, und solange noch keine inneren Bedingungen für denselben gegeben sind, kann er wieder vernichtet werden, sobald jene äusseren Umstände sich ändern. Ist aber die Zelle in die Senescenz eingetreten, so haben sich innere Bedingungen für jene Erschlaffung eingefunden, die dadurch zu einer wirklichen Altersschwäche geworden ist, und darum können auch die Optima der Vegetationsbedingungen den eingetretenen Zustand nicht mehr rückgängig machen.

Unabhängig von äusseren Einflüssen kann aber auch während der Höhezeit des Zellenlebens ein periodisches Steigen und Sinken der Lebensenergie und damit eine periodische Annälerung an die Apostrophe statthaben. Dass dieselbe sichtbaren Ausdruck gewinnen kann, ist eben an Sagittaria gezeigt worden. An anderen Pflanzen habe ich etwas Derartiges nicht beobachtet; es ist daher zweifelhaft, ab bei diesen überhaupt kein solcher periodischer Zustandswechsel besteht, oder ob er nur keinen sichtbaren Ausdruck gewinnt. 
Wenn angenommen wird, dass die Vertheilungsweise des chlorophyllfuhrenden Protoplasmas ein Symptom gewisser Zustände der Zelle ist, so wird es erklärlicher, warum so verschiedenartige Einflüsse jedesmal dieselbe Vertheilung des Protoplasmas veranlassen. Denn während sie wahrscheinlich alle direct nur die Lebensenergie der Zelle beeinflussen, ist die bestimmte Orientirung des Protoplasmas erst die nothwendige Folge, das äussere Anzeichen jenes Allgemeinbefindens. Freilich sind wir über das Nähere dieser Vorgänge noch in jeder Beziehung im Unklaren. Insbesondere vermag ich mir auch nicht im Entferntesten zu erklären, wie gerade die freien Wände und die Fugenwände der Zelle dazu koınmen, hierbei eine Rolle zu spielen. Dass ein ausserhalb der Zelle liegendes direct anziehendes oder abstossendes Agens, wie es etwa bei der directen Wanderung der Chlorophyllkörner gegen eine besonders intensive Lichtquelle so deutlich ist, hierbei nicht angenommen werden kann, versteht sich von selbst. Aber dainit ist noch sehr wenig gewonnen. Ich glaube auch, dass es dermalen verfrüht ist, nach irgendwelchen Vermuthungen zu suchen.

Wohl aber haben wir einige Kenntnisse davon, welche Eigenthümlichkeiten und gegenseitigen Beziehungen die Wirkungsweisen der einzelnen äusseren Einflüsse bei den verschiedenen Pflanzen zeigen. Zunächst sind individuelle Verschiedeuheiten nicht zu verkennen. Wenn man an einer grösseren $\mathrm{Zahl}$ von Individuen bestimmter Pflanzen Glieder vom Hauptkörper trennt, so findet man, dass sich nicht alle einander gleich verhalten hinsichtlich der Geschwindigkeit und der Vollständigkeit, mit welcher die Apostrophe eintritt. Bei der Wirkung der Lichtentziehung ist oben Aehnliches berichtet worden. Es verhalten sich sogar die einzelnen Zellen eines und desselben Gliedes nicht immer einander gleich; auch in ihnen tritt oft die Apostrophe verschieden rasch ein und erreicht verschiedene Vollständigkeit. Dies ist besonders bäufig an den gegen die Blattspitze zu liegenden Zellen der Elodea der Fall, welche nicht selten gegen die übrigen Blattzellen bemerklich zurückbleiben. Allein selbst ganz und gar gleichwerthige Zellen können ein verschiedenes Verhalten zeigen, wovon man fast an jedem Präparate sich überzeugen kann, und was auch bei der durch Lichtentziehung erfolgten Apostrophe etwas ganz Gewöhnliches zu sein pflegt. Individuelle Verschiedenheiten sind daher sogar in den einzelnen Zellen anzunehmen.

Grösser als die individuellen Verschiedenheiten sind die speJahrb. fo wiss. Botanik. VIIJ. 
cifischen. Die Wirkungen eines und desselbens Agens sind bei den verschiodenen Pflanzen von sehr verschiedener Energie. Dies zeigte sich am entschiedensten bei der Trennung der Glieder aus ihrem natürlichen Verbande und bei der Einwirkung der Dunkelheit. Während die erstere Operation an den Zellen von Elodea, Sagittaria, Vallisneria schon nach ein oder wenigen Stunden, oft selbst nach noch kürzerer Zeit die Apostrophe bewirkt, gehört z. B. bei Mnium rostratum hierzu eine Reihe ron Tagen, ja Wochen. Auch mannichfache Abstufungen zwischen diesen beiden Extremen sind zu finden, wie die Crassulaceen, die Jungermannieen, die Farnprothallien beweisen. Auch hinsichtlich der Wirkung der Dunkelheit liegen die Extreme ziemlich weit auseinander. Bei Jungermannieen, bei Farnprothallien, bei Mniumarten genügen ein oder wenige Tage (nach Famintzin in gewissen Fällen noch kürzere Dauer), um die Apostrophe zu bewirken; während Elodea zehn Wochen im Dunkeln stehen musste, ehe die Chlorophyllkörner in einigermassen grösserer Anzahl ihre Stellung wechselten. -- Es verdienthierbei aber anch hervorgehoben zu werden, dass diese einzelnen Wirkungen hinsichtlich ihrer Energie je nach Arten in einem verschicdenen Verhältnisse unter einander stehen, dass also wenn das eine Agens auf eine gewisse Pflanze nur eine schwache Wirkung äussert, ein anderes nicht etwa gleich schwache Wirkung auf die nämliche Pflanze zu haben braucht. Während z. B. bei Elodea canadensis die Lösung der Zellen von dem Hauptkörper oder eine beträchtliche Temperaturerniedrigung oder Entziehung von Wasser eine äusserst kräftige Wirkung ausüben, ist diejenige der ununterbrochenen Dunkelheit an der nämlichen Pflanze auffallend schwach. Ungekehrt ist bei Mnium rostratum, bei Radula complanata, bei Farnprothallieu die Entziehung des Lichtes, die Erniedrigung der Temperatur, die Entziehung von Wasser von schnellerer und eingreifenderer Wirkung als die Aufhebung des Verbandes der Zellen mit der Pflanze. Bei Sempervivum dagegen zeigt sich eine grössere Annäherung in der Energie der Wirkungen dieser verschiedenartigen Einflüsse. Ich schliesse hieraus, dass das Protoplasma der verschiedenen Pflanzen verschieden empfindlich gegen gewisse Einflüsse ist. Und wenn die Lösung der Zellen aus ihrem Verbande in manchen Fällen einen sehr schwachen Effekt hervorbringt, so scheint dies zu beweisen, dass solche Zellen einen besonders hohen Grad von Individualität besitzen; und gerade bei den Cryptogamenorganen, von denen jenes gilt, ist ja auch dies in höherem Grade 
der Fall, als bei anderen vielzelligen Organen, zumal den Blättern der Phanerogamen, wo die Individualität der Zelle ganz in dem höheren Individuum des Organes aufgegangen ist.

Von weiteren Eigenthümlichkeiten der Wirkungsweise der ge. nannten Agentien sei noch F'olgendes als von allgemeinerem Interesse hervorgehoben. Im Allgemeinen kann man sagen, dass die Epistrophe nur solange besteht, als alle ihre äusseren Bedingungen gegeben sind, dass sie in die Apostrophe übergeht sobald eine dieser Bedingungen schwindet, d. h. wenn eins jener abnormen Agentien sich geltend macht. Daraus folgt eigentlich, dass auch die Apostrophe nur dann in die Epistrophe sich verwandelt, wern alle ibre äusseren Bedingungen geschwunden sind. Eine Ausnahme hiervon geht aus folgender Beobachtung hervor. Individuen von Mnium rostratum und Farnprothallien, welche unter Genuss der täglichen Beleuchtung 30 Stunden lang in einer stets unter dem Gefrierpunkte sich haltenden Temperatur verweilt hatten, waren sehr vollständig in Apostrophe übergegangen. Sie wurden dann, noch während sie sich in der Kälte befanden, lichtdicht verschlossen und so erst allmählich in höhere Temperatur versetzt, aber dabei dauernd im Dunkeln gelassen. Und zwar geschah dies sowohl mit den ganzen Pflauzen, als auch mit Präparaten, die von ihnen genommen und mit Wasser unter ein Deckglas gelegt worden waren. Nach 24 Stunden ans Licht gebracht und augenblicklich untersucht zeigten die Zellen in beiden Fällen ziemlich vollständige Epistrophe. Es waren also hier die Chlorophyllkörner sobald nur die Temperatur wieder einen gewöhnlichen günstigen Grad erreicht hatte, wieder an die Aussenwände hervorgekrochen, obgleich sie vollständig vor dem Einflusse des Lichtes geschützt und auch die Blätter zum Theil von der Pflanze getrennt waren. Einen Widerspruch mit den sonst bekannten Thatsachen wird man hierin nicht finden, wenn man bedenkt, dass bei den genannten Pflanzen die Entziehung des Lichtes eine längere Dauer als 24 Stunden haben muss, um ihre apostrophische Wirkung geltend machen zu können. Es war also hier offenbar der Zeitpunkt noch nicht gekommen, wo wegen Lichtmangels eine Epistrophe unmöglich ist. Wohl aber geht hieraus unbestreitbar hervor, dass man dem Lichte eine Nachwirkung in der Zelle zugestehen muss, vermöge welcher auch dann, wenn dasselbe eben zu wirken aufgehört hat, auf einige Zeit hinaus noch die molekularen Bewegungen fortgehen, welche durch das Licht bewirkt worden waren und welche vielleicht erst 
die directen Erreger derjenigen Vorgänge sind, welche man schlechthin als Wirkungen des Lichtes in der Zelle bezeichnet. Ebenso hat zumal die Erscheinung nichts Auffalliges, dass bei dem eben beschriebenen Experimente auch an den Präparaten die Epistrophe im Dunkeln sich wiederherstellte: weder die Dunkelheit noch die Trennung des Blattes von der Pflanze waren in ihrer Wirkung auf das Protoplasma soweit gediehen, um die Epistrophe zu verhindern. -

Das Protoplasma setzt, wenigstens solange es im Höhezustande seines Lebens sich befindet, den zur Apostrophe führenden Bewegungen einen grösseren Widerstand entgegen als den ungekehrten, mit anderen Worten es bekundet einen gewissen Widerwillen gegen jenen Zustand, cine Vorliebe für die Epistrophe. Man darf dies daraus schliessen, dass z. B. bei Einwirkung der Dunkellieit die Wanderung der Chloroplıyllkörner in die Apostrophe immer mit einer gewissen Trägheit geschieht, während nach vollständigem Eintritte derselben bei erneuter Beleuchtung dic entgegengesetzte Bewegung immer mit grösserer Schnelligkeit erfolgt. Schon bei den Farmurothallien, bei den Moosen und Lebermoosen sowie bei Sempervivum ist dies sehr deutlich, den höchsten Grad erreicht es aber bei Elodea, wo zehn Wochen erforderlich waren um die Apostroplse herbeizuführen, während alsdann wenige Tage genügten un den entgegengesetzten Zustand vollständig wieder herzustellen. Allerdings hat auch das Protoplasma bei seinem Rückzuge an die Fugenseiten der Zellc einen Widerstand in der Nachwirkung des Lichtes zu überwinden, welcher bei der entgegengesetzten Wanderung wegfällt, allein dies würde doch bei so langer Verfinsterung, wie sie die Elodea nöthig hat, schwerlich als ausreichend betrachtet werden können, um die grössere Geschwindigkeit zu erklären, mit welcher das Protoplasma in Epistrophe zurückkehrt.

Wenn das Protoplasma aus der indifferenten Vertheilung in den jugendlichen Zellen bei deren allmählicher Ausbildung sich nach und nach in die Epistrophe begiebt, so vermag es dies auch nur sobald die allgemeinen äusseren Bedingungen dieses Zustandes gegeben sind, während beim Eintritte der Senescenz die Apostrophe erfolgt, auch wenn keine einzige der äusseren Bedingungen derselben gegeben ist. Es kann daher die junge Zelle, wenn sie den Entwickelungsgrad erreicht hat, in welchem sich die Epistrophe einzustellen pflegt, hieran verhindert und unmittelbar zur Apostrophe 
veranlasst werden, sobald eine der Beỏindungen jener, z. B. Licht, danernd fern gehalten wird. Ja es kommt dann sogar die Zelle zu ihrer soweit hier überhaupt möglichen vollständigen Ausbildung, wenngleich sic niemals während ihrer Entwickelung in der Epistrophe sich befunden hat.

Wenden wir uns nun zu dem näheren Verhalten des Protoplasmas während seiner beiderlei Zustände, so ist zunächst hervorzuheben, dass nicht etwa sämmtliches Protoplasma unter Entblössung der uibrigen Stellen der Zellhaut sich allein an den betreffenden Zellwänden ansammelt, sondern dass nur eine relativ grössere Menge und zwar nur der die Chlorophyllkörner unmittelbar einschliessende Theil desselben jene Stellungen einnimmt. Das allgemeinste Bild der Anordnung des Protoplasma, wonach ein ringsum über alle Zellwände gehender Sack, auswendig in der hautschichtartigen Verdichtung, in der Zelle sich findet, ist hiernach in beiderlei Protoplasmazuständen unverändert. Ausser dieser blossen Verrückung des chlorophyllführenden Theiles an verschiedene Zellwände machen sich aber wenigstens in einigen Fällen noch andere Verschiedenheiten am Protoplasma während seiner beiderlei Zustände bemerklich. In den Epidermiszellen von Flodea beobachtet man vor der Trennung des Blattes sowie alsbald nach derselben solange die Chlorophyllkörner in der Epistrophe sich befinden, keinerlei strömende Bewegungen in dem Protoplasma, insbesondere ist das an den Seitenwänden stehende spärliche Plasma in Ruhe, wie man namentlich dann deutlich sieht, wenn ein Chlorophyllkorn in demselben sich befindet. Dagegen ist das Protoplasma während der Apostrophe auf den Seitenwänden mit den Chlorophyllkörnern in lebhafter Rotation begriffen und bleibt es solange jener Zustand anhält. Diese Erscheinung zeigt sich am Protoplasma, gleichgültig durch welchen Einfluss die Apostrophe verursacht worden ist, vorausgesetzt, dass dieses specielle Agens überhaupt nicht bei irgend längerer Einwirkung protoplasmatische Bewegungen vereitelt. Darum wurde die Rotation beobachtet nicht nur bei der Apostrophe an abgeschnittenen Blättern, sondern auch wo dieselbe an den unverletzten Pflanzen in Folge von Wasserverminderung, sowie an den in die Senescenz eingetretenen Blättern sich erzeugt hatte. Dass das Protoplasma starr war in solchen Zellen, welche in Folge der Entziehung sauerstoffhaltiger Luft sowie in Folge der Einwirkung einer sehr niedrigen Temperatur apostrophisch geworden waren, ist nach dem, was wir über die 
Bedingungen der protoplasmatischen Bewegungen wissen, nicht anders zu erwarten. Als nach vielwöchentlicher Verdunkelung die Apostrophe an Elodeaindividuen cndlich eingetreten war, befand sich das die Chlorophyllkörner einschliessende Protoplasma doch. nicht in Rotation; dahingegen wurden an der Aussenwand verlaufende und von da aus durch den Zellraum gehende feine Plasmastränge beobachtet, welche in strömender Bewegung begriffen waren, aber keine Chlorophyllkörner mehr führten. Es ist immerhin denkbar, dass dicses abweichende Verhalten des Gesammtprotoplasmas während der Apostrophe auch nur eine directe Wirkung des Lichtes war. Wenn Entzichung des Lichtes auch nicht gerade Protoplasmabewegungen überhaupt lähmt, so ist doch möglich dass es die Form seiner Bewegungen zu verändern strebt, und hier an Stelle der Rotation die Circulation setzte. - Auch bei Sagittaria ist das Protoplasma während der Apostrophe noch durch das Eintreten einer besonderen Bewegung ausgezeichnet. Es ist hier eine durch den Zellraum und unter den breiten Wänden hingehende Circulation in höchst feinen netzförmig verbundenen, Ort, Form und Richtung verändernden Strängen, welche keine Chlorophyllkörner fortbewegen.

Was endlich die Wanderung des chlorophyllführenden Protoplasmas aus ciner Stellung in die andere selbst anlangt, so ist ihre Art und Weise nach Species rerschieden. In geraden Bahnen direct dem Ziele zu und immer unter der Zellwand hin rutschen die Chlorophyllkörner bei den Moosen, Lebermoosen, Farnprothallien und wahrscheinlich auch bei den Crassulaceen. Sehr verschieden hiervon und weit complicirter sind die Vorgänge bei Elodea, Vallisneria und Sagittaria, bei denen, wie oben gezeigt wurde, die Chlorophyllkörner zunächst eine Zeit lang in besonders sich bildenden, Ort, Form und Richtung ändernden Plasmaströmen in der Zelle ziellos umhergeführt werden. Später nimmt ein Chlorophyllkorn nach dem andern seine Stellung an den Fugenwänden dauernd ein, ohne wieder zurückzukehren. Dabei sicht man eutweder, wie bei Elodea, auch jene Protoplasmastränge dem Protoplasma der Fugenwände dauernd sich einverleiben, oder aber dieselben erhalten sich, wie bei Sagittaria, auch während der Apostrophe, nur mit dem Unterschiede, dass sie keine Chlorophyllkörner mehr führen. Man könnte dies, wie es oben schon angedeutet wurde, dadurch erklären, dass die während der Apostrophe strömende Protoplasmasse dünnere, substanzärmere Strömchen bildet, welche nicht 
mebr hinreichende Kraft besitzen, um die Chlorophyllkörner von ihrem Orte zu rücken. Oder es könnte auch daran gedacht werden, dass jedes Chlorophyllkorn gewissermassen von einer eigenen Atmosphäre von Protoplasma ein für alle Mal umhüllt ist, und dass dieses letztere in einer gewissen Selbstständigkeit hinsichtlich seiner Bewegungen dem übrigen Protoplasma gegenüber sich befindet. Man würde dann jene Erscheinung so zu erklären haben, dass man annähme, es geriethe zu einer gewissen Zeit nur dieses die Chlorophyllkörner unmittelbar einhüllende Protoplasma auf den Fugenwänden in Ruhe und betheilige sich von da ab nicht mebr an den Strömungen des übrigen Protoplasmas, dafern nicht auch dieses letztere die Circulation aufgiebt, wie bei Elodea. Welche dieser beiden Erklärungen die richtige ist, dürfte sehr schwer zu entscheiden sein.

Indem wir die bier dargelegten Erscheinungen auf Protoplasmabewegungen zurückführen, gelangen wir zu der Annahme einer Form derselben, für die bisher noch kein Analogon bekannt war. Diese Bewegung, vermöge deren Protoplasma nach morphologisch bestimmten Zellwänden sich orientirt, ist von der gewöhnlichen Rotation oder Circulation wesentlich verschieden; am nächsten kommen ihr solche Bewegungen, welche man schon längere Zeit unter dem Namen Protoplasmawanderungen kennt, wie z. B. die Vereinigung des Protoplasmas in den wachsenden Enden schlauchförmiger Zellen, eine namentlich in Pilzhyphen gewöhnliche Erscheinung, wobei immer ein Nacbrücken des Protoplasma hinter dem Scheitel der Zelle erfolgt. Auch die Erscheinungen bei der Copulation, z. B. der Spirogyren, könnte man als eine entfernte Aehnlichkeit hierher ziehen. Indessen springt doch hier immer auch der wesentliche Unterschied von jenen Bewegungen in die Augen. Trotzdem wird das Eigenthümliche derselben nicht hindern können, auch sie mit unter die Theorie zu begreifen, welche Hofmeister für die Erklärung der protoplasmatischen Bewegungen überhaupt begründet bat; und wonach durch Aenderungen der Imbibitionsfähigkeit bestimmter 'Theile des Protoplasmas für Wasser das Volunen und die Distanzen derselben geändert und somit innere Bewegungen herbeigeführt werden können. Hält man an dem Gedankengange der Hofmeister'schen Theorie fest, die als bekannt vorausgesetzt werden darf, so scheinen die vorliegenden Bewegungen, insofern sie einen sehr einfachen Fall repräsentiren, gerade mit besonderer Klarheit die Fundamentalanschauung, welche 
jener Theorie zu Grunde liegt, zu erläutern und zu bestätigen. Wenn das die Chlorophyllkörner einschliessende Protoplasma auf den in der Regel relativ grosseu freien Zellwänden so verbreitet ist, dass alle Chlorophyllkörner in einer einfachen Schicht eines neben dem andern und mit ibren breiten Durchmessern in einer Ebene liegend, die ganze Wand überkleiden, so befindet sich offenbar dieser 'Theil des Protoplasmas im höchsten Grade der Vertheilung, d. h. es haben die Distanzen seiner einzelnen Molecüle ein Maximum erreicht. Sitzt dagegen dieser nämliche Theil auf den meist kleineren Fugenwänden, so dass daselbst wie gewöhnlich die Chlorophyllkör'uer dichtgedrängt übereinander hocken, so befindet er sich in cinem hohen Grade der Zusammenziehung, die Distanzen sciner Molecülc betragen ein Minimum. Und unter den letzteren Gesichtspunkt lässt es sich auch bringen, wenn bei Sempervirum beim Eintritte der Apostrophe die Anfangs in gleichmässigen Distanzen über dic freien Wände verbreiteten Chlorophyllkörner sich häufig in eine Anzahl scharf umschriebener dichter Gruppen zusammenziehen. Wir wissen nun, dass Vergrösserung der Dimensionen des Protoplasmas auf einer Steigerung seines Wassergehaltes, Verminderung derselben auf einer Ausstossung von Wasser berulien. Hiernach dürfen wir annehmen, dass in dem epistrophischen Protoplasma dic Imbibition für Wasser in zwei bestiminten Richtungen (parallel der anliegenden Zellwand) ihr Maximum erreicht hat, dagegen in dem apostrophischen Protoplama auf' das Minimum reducirt ist. Aus dieser Annahme würde sich aber unmittelbar ergeben, dass dic V'ertauschung beiderlei Zustände auf einer Veränderung des Grades dieser Imbihitionsfähigkeit beruht. Die Beziehung diescr Vorgänge zu den morphologisch bestimmten Zellwänden ist offenbar cine Frage für sich, die zunäcbst nicht in Betracht kommt wenn es sich nur darum handelt, den molecularen Fundamentalvorgang der Erscheinung festzustelleu. Es würde hier der Ort sein, eine Bcobachtung mitzutheilen, welche mich noch ausserdem von der Richtigkeit der hier entwickelten Anschanungsweise in hobem Grade überzengt hat. Herausgeschnittene Epidermisstücke aus der Oberseite submerser Blätter von Sagittaria wurden mit Wasser unter Deckgläsern liegend 24 Stunden in einem dunkeln Raume gehalten. Hierauf am Tageslichte untersucht zeigten sie ausser der schon beschriebenen Eigenthümlichkeiten hinsichtlich der Chlorophyllstellung noch folgendes Abwcichende von dem gewöhnlichen Zustande. Der Zellenkern 
besass bei kleinerem Volumen grössere Deutlichkeit als sonst: er war schärfer umschrieben und hatte stärkeres Lichtbrechungsvermögen, ja bisweilen zeigte er dabei eine fein körnelige Structur im Innern. In den meisten Zellen lagen um den Zellenkern viele Chlorophyllkörner versammelt und bildeten eine scharf begrenzte Gruppe; ja oft waren sämmtliche Chlorophyllkörner der Zelle mit dem Zellenkern in einen grossen runden scharf umschriebenen Klumpen vereinigt. Diese Chlorophyllkörnergruppen lagen an einer Seitenwand, oder am Rande der Hinterwand. Offenbar war dies ein besonders hoher Grad von Apostrophe, dessen bedeutungsvolle Eigenthümlichkeit in der maximalen Contraction des die Chlorophyllkörner und den Zellenkern einschliessenden Protoplasmas, sowie namentlich auch in dem Aussehen des Zellenkernes selbst lag, Erscheinungen von denen wir wissen, dass sie der Ausdruck einer Verringerung an imbibirtem Wasser sind. Als nun die Präparate einige Minuten lang am Lichte sich befanden, fuhren die Chlorophyllkörner wieder auseinander und verbreiteten sich auf den Seitenwänden und zum Theil auf der Hinterwand. Dies erfolgte mit sichtbarer Geschwindigkeit, ja oft mit einem Schlage: man sah plötzlich Leben in die bisher bewegungslose Masse gerathen, die Chlorophyllkörner fuhre山 mit grosser Geschwindigkeit nach verschiedenen Richtungen auseinander. Bisweilen schossen aus einem Haufen plötzlich mehrere Körner in radialer Richtung heraus, und blieben darnach in einer langen Reihe stehen. Meistens wurde aber der Haufen gleichmässig gelöst und die Körner verbreiteten sich mehr allseitig. $\mathbf{Z u}$ gleicher Zeit verlor aber auch der Zellkern seine bisherige Deutlichkeit. Unter Vergrösserung des Durchmessers wurde sein Lichtbrechungsvermögen geringer, die körnige Structur zerstört, seine Ränder mehr verwaschen, so dass er oft nur noch als leere runde Stelle in der Chlorophyllgruppe erkennbar war. Vielfach war aber auch die Wirkung nicht so plötzlich, jene Veränderungen erfolgten ganz allmählich. Es giebt also Uebergänge in der Geschwindigkeit bis zu der gewöhnlichen Erscheinung, dass das Licht erst nach geraumer Zeit die Bewegung der Chlorophyllkörner auslöst. Dass es nicht zu eigentlicher Epistrophe kommen konnte, verstand sich von selbst, da die Objecte ja Präparate waren. Aus diesen Wahrnehmungen geht unleugbar herror, erstens dass hier das licht eine oft sehr plötzliche Steigerung der Imbibitionsfähigkeit des Protoplasmas und des Zellenkernes für Wasser hervorruft, wäh- 
rend dieselbe vorher durch die Wirkung der Dunkelbeit vermindert worden ist; zweitens dass diese Aenderungen der Imbibitionsfähigkeit des Protoplasmas die Dimensionen des letzteren um das Vielfache verändern und damit Bewegungen derjenigen Formelemente veranlassen, die in ihm eingeschlossen sind. Und dies scheint mir denn gerade diese Bewegungsform des Protoplasmas in der überzeugendsten Weise in den Rahmen der Hofmeisterschen Vorstellungen von dem Vorgange aller protoplasmatischen Bewegungen uberhaupt zu bringen. - In der durch Wasserausstossung bewirkten Verkleinerung des Zellenkernes bei Entziehung des Lichtes haben wir ohne Zweifel einen Anknüpfungspunkt an die von Micheli benbachtete Thatsache, dass die Chlorophyllkörner in der Dunkel. heit ihre Durchmesser verringern. Beide Vorgänge gehören gewiss unter einen Gesichtspunkt, und daraus würde folgen, dass alle diese Erscheinungen als Folgen eines und desselben Fundamentalvorganges in der Zelle zu betrachten sind.

Iseipzig, im Februar 1870.

\section{Nachträgliche Bemerkungen.}

Seit der Ablieferung des Manuscriptes der vorstehenden Arbeit sind mir weitere Mittheilungen Borodin's, die auf unseren Gegenstand Bezug haben, bekannt geworden. In einer Abhandlung ,Ueber die Wirkung des Lichtes auf die Vertheilung der Chlorophyllkörner in den grünen Theilen der Phanerogamen" (Bullet. de l'acad. imp. des sciences de St. Pétersbourg. T. XIII. 1869. p. 571 ff.) kommt genannter Forscher zu dem Resultate, dass im directen Sonnenlichte die Chlorophyllkörner ebenfalls die Dunkelstellung annehmen, und dass somit nur das diffuse Licht die entgegengesetzte Vertheilung bewirke, sowohl bei einigen Phanerogamen (Lemna trisulca, Callitriche verna, Stellaria media) als bei den Cryptogamen. Es ist aber Borodin die Fähigkeit der Chlorophyllkörner im directen Lichte innerhalb eines gewissen Bereiches bestimmter Zellwände eine unmittelbare Lichtwärtswanderung ähnlich wie gewisse freilebende grüne Organismen zu beginnen, noch nicht bekannt gewesen. Ich bin daher überzeugt, dass die Art der Chlorophyll- 
vertheilung, die sich unter diesen Umständen ausbildet, jene mehr oder weniger einseitig entstellte Epistrophe, die dann allerdings wohl mitunter durch eine entfernte Aehnlichkeit mit Apostrophe täuschen kann, Veranlassung zu Borodin's Meinung, soweit diese sich wenigstens auf die auch von mir untersuchten Pflanzen beziehen, gegeben hat. Dies umsomehr, als Borodin mehrfach, zumal nach längerer Dauer der Insolation Gruppirungen der Chlorophyllkörner an gewissen Stellen gesehen hat, welche ein Bild orzeugten, von dem er sich hat sagen müssen, dass es erheblich von der eigentlichen Dunkelstellung verschieden sei (vergl. z. B. l. c. p. 571-572). - Ferner hat Borodin auf der Naturforscher-Versammlung zu Moskau 1869 berichtet, dass in den Blättern der Elodea canadensis bei intensiver Insolation die Chlorophyllkörner von den äusseren auf die seitlichen Wandungen der Zellen hinüberwandern. Ich muss dem auf das Bestimmteste widersprechen. Wenn ich die genannte Pflanze einige Zeit ununterbrochen intensiver Insolation aussetze und dann abgeschnittene Blätter mit aller Eile unter das Mikroskop zur Beobachtung bringe, so finde ich Epistrophe, jedoch wiederum von etwas verändertem Aussehen: Sämmtliche Chlorophyllkörner sind an der Aussenwand $z u$ einer Gruppe zusammengeschwemmt, die entweder ungefähr auf der Mitte der Wand oder mehr nach diesem oder jenem Rande zu gelegen ist, wobei bisweilen über grössere Flächen des Blattes, die einzelnen Zellen hinsichtlich dieser Richtung gleichsinnig sich verhalten. Dieser Zustand dauert aber in dem Präparate nicht lange. Es scheint, als trete hierbei die durch die Abtrennung des Pflanzengliedes bewirkte apostrophische Erschlaffung des Protoplasmas, welche Borodin unbekannt war, besonders rasch ein: in kurzer Zeit sinkt jetzt entweder der ganze Chlorophyllklumpen auf die Hinterwand nieder, um sich dort zu vertheilen, oder die Körner rutschen nach verschiedenen Richtungen hin unmittelbar auf die Seitenwände. 

den Bau trocknex Pericarpien, mit Taf. VIII-XI. - J. Walz. Beitrag zur Morphologie und Systematik der Gattung Viucheria DC., mit Taf. XII-XIV. A. B. Frank. Ueber die anatomische Bedeutung und die Entstehung der vegetabilischen Schleime, mit Taf. XV-XVI. - A. da Bary. Ueber die Keimung einiger grosssporiger Flechten, mit Tat. XVII-XIX. - Max Keess. Zur Entwicklungsgeschichte des Polypodeaceensporangiums, mit Taf. XX - XXII. c. Millier. Untersuchung über den Sitz des Alcaloide in der Cinchonarinde, mit Taf. XXIII-XXIV. - N. J. C. Miiller. Das Wachsthum des Vegetationspunktes von Pflanzen mit decussirter Blattstellung, mit Taf. XXV-XXXIV. - E. Strashurrer. Ein Beitrag zur Entwicklungsgeschichie der Spaltïffnungen, mit Taf. XXXV-XLII. - F. Aildebrand. Ueber die Befruchtung von Aristolochia Clematitis und einiger anderer Aristolochia-Arten,mit Tafel XLIII. die Nothwendigkeit der Insektenbülfe bei- der Befruchtung von Corydalis cava. - L. Kuy. Ueber Bau und Entwickelung der Riccien, mit Taf. XLIV-XLVI. - I. J. C. Miller. Untersuchungen über dic Vertheilung der Harze, ätherischeu Oele, Gummi und Gummiharze, und die Stellung der Secretionsbehälter im Pflanzenkorper, mit Taf. XLVII-LIII. - A. Famintzin. Die Wirkung des Lichtes auf Algen und einige andere ihnew nahe verwandte Organismen, mit Taf. I-III. - . Famiutzin. Die Wirkung des Lichts auf das Ergrünen der Ptlanzen. 1. Famiutzin. Die Wirkung des Lichts und der Dunkelheit auf die Vertheilung der Clorophyllkürner in den Blittern von Mnium sp.?. - H. Th. Gityler. Ueber den Gefässbündelverlanf in den Laubblattregionen der Coniferen, mit Taf. IV-IX. - M. Kerss. Zur Entwickelungsgeschichte der Stammspitze von Equisetum, mit Taf. X-XI. - I. J. Miillap. Die Entwickelungsgeschichte der Kapsel von Ephemerum, mit Taf. XII-XIV. - F. Hildebrand. Mykologische Beiträge, mit Taf. $\mathrm{XV}$-XVII. - G. Iilgers. Ueber das Auftreten der Krystalle von oxalsaurem Kalk in Parenchym einiger Monocotylen. - E. Pfitzer. Ueber die Schutzscheide der deutschen Equisetaceen, mit Tat. XVIII-XX. - P. 6. Lorentz. Grundlinien zu einer vergleichenden Anatomie der Laubmoose, nit Taf. XXI-XXVIII. E. Loew. Ueber Demation pullulans de Bary, mit Taf. XXIX und XXX. V. C. Miller. Untersuchungen über die Diffusium der atmosphürischen Gase in der Pflanze und die Gasansscheidung unter verschiedenen Beleuchtungsbedingungen, mit Taf. XXXI. - Hermann fraf' zu solıs-Laularh. Ueber den Bau und die Entwickelung der Ernihrungsorgane parasitischer Phanerogamen, mit Taf. XXXII-XXXIX - I. Baranetzky. Beitrag zur Kenntniss des selbstständigen Lebens der Flechtengonidien, mit Taf. I. - Fr. Buchentu. Ueber die Richtung der Samenknospe bei den Alismaceen, mit Taf. II. - Clir. tuersseft. Zur Controverse über die Einzelligkeit oder Mehrz-lligkeit des Pollt'ns der Onagrariern, Cucurbitaceeu und Corylaceen, mit Taf. IV. - VI. - A. Fischer 1. Waldhein. Beiträge zur Biologie und Entwickelungsgeschichte der Ustilagineen, mit Taf. VII-XII. - X. J. C. Miiller, Untersuchungen über die Diffusion atmospharischer Gase in der Pflanze und die Gasausscheidung unter verschiedenen Beleuchtungsbedingungen, II. Theil, mit Taf. III. - N. J. C. Miller, Ueber den 1)urchgang von Wasserdampf durch die geschlossene Epidermiszelle - K. J. C. Miiller, Notiz über die Farbstoffe im Chlorophyll. - G. Krals. Ueber die Ursachen der Formänderungen etiolirender PAanzen. - Julius Schröder. Beitrag zur Kenntniss der Frühjahrsperiode des thorns (Acer platanoides) mit Taf. XIII-XX. - El. Bor cow: Ueber gegitterte Parenchymzellen in der Rinde des Stengels von Ceropegia aphylia und deren Beziehung zu den Milchsaftgefässen, mit Tafel XXI. - li. Leitgeb. Neue Saprolegnicen, mit Taf. XXII - XXIV. - k. Strasburger. Die Befruchtung bei den Farrenkräutern, mit Taf. XXV und XXVI. - E. Strasburger, Die Geschlechtsorgane und die Befruchtung bei Marchantia polymorpha, mit Taf. XXVII und XXVIII - F. llidehrand. Ueber die Betäubungsvorrichtungen bei den Fumariaceen, mit Taf. XXIX-XXXI. - E. Loew. Zur Entwicklungsgeschichte von Penicillium mit Tafel XXXI-XXXIV. - G. Kraus. Einige Beobachtungen über den Einfluss des Lichts und der Wärme auf die Stärkeerzeugung im Chlorophyll, mit Tafel XXXV. - E. Pfitzer. Beiträge zur Kenntniss des Hautgewebes der Pflanzen, mit Taf. XXXVI-XXXVII. I. Ueber die Spaltöffnungen der Gräser nelsst einigen Bemerkungen üher die ersteren im Allgemeinen. II. Ueber die Hautgewebe einiger Restionaceen. 


\section{Inhalt des vorliegenden Hefts 2, Band VIII.}

A. Dodel. Der Uebergang des Dicotyledonen-Stengels in die Pfahlwurzel, mit Taf. XI-XVIII . . . . . . . . . . . .

W. Pfoffer, Zur Blüthenentwicklung der Primulaceen und Ampelideen, mit

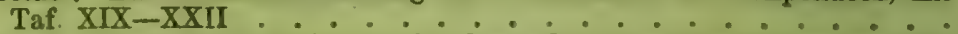

B. Prank. Ueber die Veränderung der Lage der Chlorophyllkörner und des Protoplasmas in der Zelle, und deren innere und aussere Ursachen

\section{Inhalt des vorhergehenden Heftes 1, Band VIII.}

L. Koy Beiträge zur Entwickelungsgeschichte der Farrenkräuter mit Taf I - Seite.

E. Pfitzer. Beiträge zur Kenntniss der Hautgewebe der Pflanzen mit Taf. VI. 16 III. Ceber mehrchichtige Epidemis und das Hypoderma.

N. J. C. Muller. Die Anatomie und Mechanik der Spaltöfnungen mit Taf. IV u. V. $\quad 75$

III. Wirkung der Wärme innerhalb der Temperaturgrenzen des gewöhnlichen Lebens.

J. Peyritsch. Ueber Bildungsabweichungen bei Cruciferen mit Taf, VII-IX. 117

G. Kraus. Die Entstehung der Farbstoflkororper in den Beeren von Solanum

Preudocapsicum mit Taf. X .............. 131

Die ,Jahrbücher für wissenschaftliche Botanik" erscheinen in unterzeichneter Verlagsbuchhandlung in zwanglosen Heften von 8-12 Bogen Text mit Abbildungen, und wird der Verleger bestrebt sein, die typographische wie artistische Ausstattung der Zeitschrift zu einer möglichst vollkommenen zu gestalten.

Vier Hefte bilden einen Band, doch kann jedes Heft auch ein zeln bezogen werden und richtet sich der Preis jedes einzelnen Heftes nach Umfang und nach Anzahl der beigegebenen Tafeln.

Geeignete Beiträge wolle man gefälligst an den Herrn Herausgeber (in Berlin, Bendlerstrasse 13) oder an den unterzeichneten Verleger senden, welcher letztere alle zur Aufnahme angenommenen Aufsätze mit 10 Thlr. pro Druckbogen honorirt.

Bestellungen auf die „Jahrbücher für wissenschaftliche Botanik " nehmen alle Buchhandlungen des In- und Auslandes entgegen.

Leipzig, im October 1864.

\author{
Die Verlagshandlung. \\ Wilhelm Engelmann.
}

Redigirt unter Verantwortlichkeit von Dr.Wilh. Engelmann in Leipzig. 


\section{JAHRBÜCHER}

\section{wissenschaftliche Botanik.}

Herausgegeben

ron

Dr. N. Pringsheim.

Achter Band. Drittes Heft.

Mit 12 Tafeln.

Leipzig, 1872.

Verlag ron Wilb. Engelmann. 


\section{Inhalt der ersten sieben Bände.}

i. Pringsheim. Beiträge zur Morphologie und Systematik der Algen. I. MorphoIogie der Oedogonieen, mit Taf. I-VI. - W. Hofmeister. Neuere Beobachtungen üluer Embryobildungen der Phanerogamen, mit Taf. VII-X. - I. Príngsheim. Ceber das Austreten der Sporen von Sphieria Scirpi aus ihren Schliuchen; hierzu Taf. XXIV. A. - II. Schacht. Ueber die Pflanzenbefruchtung, mit Taf. $\mathrm{XI}-\mathrm{X} \mathrm{V}$. - Jh. Hanstein. Ueber den Zusammenhang der Blattstellung mit dem Bau des dicotylen Holzringes, mit Taf. XVI-XVIII. - X. Prinrsheim. Beiträge zur Norphologie und Systematik der Algen. II. Die Saprolegnieen, mit Tif. XIX-XXI. - Al. Brnun. Ueber den Blüthenbau von Delphinium, mit Taf. XXII und XXIII. - L. Cientiowsky. Die Pseudogonidien; hierzu Taf. XXIV. B. B. Caspary. Die Hydrilleen (Anacharideen End) mit Taf. XXV-XXIX. - J. GrönIand. Einige Worte über die Bastardbildungen in der Gattung Aegilops, mit Taf. XXX. - 1. Primshleim. Beiträge zur Morphologie und Systematik der Algen. III. Die Choleochateen, mit Taf. I-VI. - C. Sanio. Verglechende Lintersuchungen über den Bau und die Entwickelung des Korkes, mit Tafel VII-XIII. ii. Srhacht. U'eber den Bau einiger Pollenkörner, mit Taf. XIV-XVIII. 1. de larry. Einige neue Saprulegnien, mit Taf. XIX-XXI. - M. Wichura. Beiträge zur Phrsiologie der Laulumoose. - N. Prinusheiıi Beiträge zur Morphologie und Srstematik der Algen. IV. Nachträge zur II orphologie der Saprolegnieen, mit Taf. XXII-XXV. - W. Unfueister. Ueber die Beugungen saftreicher. Pflnzentheile nach Erschitterung. - II Hofluann. Untersuchungen über die lieimung der Yilzsporen, mit Tilf. X.IVI bis XXXII. - J. Sachs. Physiologische Lntersuchungen über die Abhüngigkeit der Keimung ron der Temperatur. - W. Ilofmeister. Leber die Entwickelung der Sporen des Tuber aestivum Vittad., mit Taf. XXXIII-XXXV. - Juh. Hanstrin. Versuche über die Leitung des Saftes durch die Rinde und Folgerungen daraus, - X. Pringsheim. Nachtrag zur Kritik und Geschichte der Untersuchungen über das Algengeschlecht - 1 . Wiegand. Zur Morphologie und Systematik der Gattungen Trichia und Arcryria, mit Taf. I-III. - F. Ilidelırad. Anatomische Untersuchungen über die Farben der Bluthen, mit Taf. IV. - W. Hofmeister. Ueber die durch die Schwerkraft bestimmten Richtungen von Pflanzentheilen. - A. Wirand. Ueber die Decrganisation der Pflanzenzelle, insbesondere über dje physiologische Bedeutung ron Gummi und Harz, mit Taf. V-VIr. - J. Silchs. Ueher die Stoffe, welche das Material zum Wachsthum der Zellhänte liefern. - W. Ilofmeister. Zusätze und Berichtigungen zu den 1851 veröffentlichten Untersuchungen der Entwickelung höherer Kryptoganen, mit Taf. VIII. - N Pringsheim. Ueber die Vorkeinic und die nacktfussigen Zweige der Charen mit Taf. IX-XIII. - L. Cieshowsky. Zur Entwicklungsgeschichte der Mixomyceten. - II. Schacht Ueher die Zellstofffiden in der vorderen Aussackung des Embryosackes von Pedicularis sylratica, mit Taf. XIV und XV. - H. Schacht. Ueber ein neues Secretionsorgan in? Wurzelstock von Nephrodium Filix mas, mit 'Tif. XVI. - W. Kabsch. Untersuchungen über die chemische Beschaffenheit der PHanzengewebe. - L. (ienkowsky. I)as Plasmodium. mit 'Jaf. XVII-XXI. - Il. Sehacht. Ueber die Veränderung durch I'ilze in abgestorbenen Pflanzenzellen, mit Taf. XXII-XXIII. - N. Pringsheim. Zur Morphologie der Salvinia natans, mit Taf. XXIV-XXIX. - II. Sichacht. Die Blüthe und die Befruchtung von Santalum album, mit Taf. I-IV. - F. Thomas. Zur vergleichenden Anatomie der Coniferen-Laubblätter. - \%. Kuy. Beitıäge zur Entwickelungsgeschichte der laubigen Lcbermoose, mit Taf. V-VII. - R. Cinspary. Bemerkungen über die Schutzscheide und die Bildung des Stammes und der Wurzel; hierzu Taf. VIII und IX. - A. Ireiss. Untersuchungen über die Zahlen. und Grössenverhäitnisse der Spaltöfnungen. - J. llanstein. Die Befruchtung und Entwicklung der Gattung Marsilia, mit Taf. X-XIV. - Th. Wolf'. Beiträge zur Entwicklungsgeschichte der Orchideen-Blüthe, mit Taf. XV-XVII. - fr. Kraus. Uelier den Bau der Cycadcenfiedern, mit Taf. XIX-XXIII, - Al. Fischer v. Waldheim. Ueber die Entwickelung der Farnsporen, mit Taf. XXIV his XXVII. F. Buhlenan. Der Blüthenstand der Juncaceen, mit Taf. XXVIII-XXX. - S. Rosanofi. Zur Kenntniss des Baues und der Entwicklungsgeschichte des Pollens der Mimoseae, mit Taf XXXI-XXXII. - F. llildebraul. Ueber die Befruchtung der S:lviairten, mit Hulfe von Insecten, Taf. XXXIII. - Th. Geyler. Zur Kenntniss der Sphacelarieen, mit Taf. XXXIV-XXXVI. - Alex. v. Wolkoff, Einige Untersuchungen über die Wirkung des Lichtes von verschiedener Intensität auf die Ausscheidung der Gase durch Wasserpflanzen, mit Taf. I-III. A. Yogl. Beiträge zur Kenntniss der Milchsaftorgane der Pflanzen, mit Taf. IV. - S. Kosauoli. Morphologisch-embryologische Studien, mit Taf. V-VII. - Gr. Kraus. Ueber 


\section{I n h a l t}

des vorliegenden Heftes 3, Bd. VIII. '

J.

J. Klein. Zur Kenntniss des Pilobolus . . . . . . . . . . . 305

I. Entwickelung. des Pilobolus . . . . . . . . 306

1) Das Mycelium . . . . . . . . . 306

2) Anlage zum Fruchtträger ......... . 310

3) Fruchtträger und Sporangium . . . . . . . , 313

4) Das Abschleudern des Sporangiums ...... 326

5) Chemische Reactionen ......... . 334

6) Geformte Inhaltskörper . . . . . . . . . . 337

7) Ausnahmsweise Erscheinungen . . . . . . . . . 339

II. Formen des Pilobolus : . . . . . . . . . . 343

III. Pleomorphie des Pilobolus . . . . . . . . , 362

Erklärung der Abbildungen. Taf. XXIII - XXX . . . . 377

L. Jurányi. Ueber den Bau und die Entwickelung des Pollens bei Ceratozamia longifolia Miq. . . . . . . . . . . . . . 382

Erklärung der Abbildungen. Taf, XXXI-XXXIV . . . . 398

K. Sanio. Ueber dio Grösse der Holzzellen bei der gemeinen Kieter (Pinus silvestris) . . . . . . . . . . . . . . 401

G. Kraus. Ueber eigenthümliche Sphaerokrystalle in der Epidermis von Cocculus laurifolius . . . . . . . . . . . . . . . 421

- - Ueber Eiweisskrystalloide in der Epidermis von Polypodium ireoides Lam. 426

Erklärung der Abbildungen. Taf. XXXV . . . . . . 428 



\title{
Zur Kenntniss des Pilobolus.
}

Von

\author{
Julius Klein.
}

(Mit Taf. XXIII-XXX).

Der Begründer der Gattung Pilobolus ist J. Tode. Er entdeckte diesen Pilz im Jahre 1784 und gab zuerst eine richtige Beschreibung desselben'). Später wurde der Pilobolus wiederholt beobachtet, so dass er eine nicht unbedeutende Literatur besitzt. Die zwei letzten, grösseren Arbeiten sind von $\mathrm{Cohn}^{2}$ ) und Coe$\mathrm{mans}^{3}$ ). Letzterer hat in seiner Monographie des Pilobolus auch die Literatur gesammelt, weshalb ich hier dieselbe übergehe und auf Coeinans verweise. Ich wurde durch Herrn Prof. Nägeli, meinen hochverehrten Lehrer, zum Studium des Pilobolus angeregt und es gereicht mir zu grossor Freude, hier meinen Dank aussprechen zu könuen für die Güte, welche Herr Prof. Nägeli mir während meiner Arbeiten in seinem Laboratorium erwiesen hat. - Wenn ich nun hier abermals die Entwickelung des Pilobolus vorbringe, obgleich sie schon in den letzten Arbeiten gegeben wurủe, so geschieht es deshalb, weil es mir gelang selbst da noch einige Punkte aufzufinden, die bis jetzt noch gar nicht oder nicht ganz richtig erkannt wurden und welche sich im Zusammenhang am besten besprechen lassen. Ich werde dabei auch nur die von mir aufgefundenen Punkte ausführlicher behandeln und ist bezüglich mancher anderer Einzelheiten die Arbeit von Coemans nachzusehen. Nach der Entwickelung des Pilobolus werde ich die

1) Schriften d. Naturf. Berlin. Gesell. V. p. 46.

2) N. A. A, C. L. N. C. XXUI.

3) Monographie du genre Pilob. in Mem. des savants étrang. Acad. Brux. Tom. XXX.

Jahrb. 1. wiss, Botanik. VIII. 
Formen desselben besprechen und zuletzt seine Pleomorphie. Ich cultivirte den Pilobolus immer im Zimmer unter einer Glasglocke und zwar auf Pferdemist. Auf anderen Substraten fand ich ihn noch nicht ${ }^{1}$ ) und ebenso hatte ich noch keine Gelegenbeit ihn im Freien zu beobachten. -

\section{Entwickelung des Pilobolus.}

Bringt man frischen Pferdemist ins Zimmer und bält mau ihu auf einem Teller unter einer Glasglocke etwas feucht, so erscheinen auf demselben, gewöhnlich nach 6-7 Tagen, eine Menge von $\mathrm{Pi}$ lobolus-Pflänzchen. Das Mycelium dieses Pilzes ist in dem Substrate ausgebreitet und an demselben bilden sich die Anlagen zu den oberirdischen Fruchtträgern dadurch, dass gewisse Myceliumäste stark anschwellen, sich mit Inhalt füllen, dass dann diese Anschwellung vom Mycelium durch Scheidewände getrennt wird und selbst nach oben zum Fruchtträger auswächst, der das schwarze Sporongium trägt. Dieses wird zur Zcit der Reife abgeschleudert und bleibt dabei geschlossen, so dass die Sporen erst später aus demselben frei werden.

Aus dieser kurzen Uebersicht der Erscheinungen bei der Entwickelung des Pilobolus ergeben sich zugleich die Hauptpunkte für die năhere Betrachtung und zwar

\section{Das Mycelium.}

Ueber das Mycelium des Pilobolus wurde bisher ziemlich wenig gesagt, da die meiste Aufmerksamkeit dem Fruchtträger zufiel, der zuerst durch seine Eleganz und Eigentbümlichkeit den Beobachter fesselt; dann aber ist es nicht immer leicht grössere, zusammenhängende Partien des Myceliums aus dem Substrate heraus zu prä. pariren, um daran seine Eligenthümlichkeiten zu erkennen. Für eine deutliche Einsicht in dieselben ist es gut vorerst die fertigen Zustände ins Auge zu fassen und will ich die Entstehung des Myceliums aus der Spore an einem anderen Orte geben. Grössere zusammenhängende Partien des Pilobolus-Myceliums erhielt ich dadurch, dass eine ältere Cultur desselben ziemlich feucht gehalten

1) Nachträglich brachte ich Ziegenmist von einer Alpe (im bayerischen Gebirg) mit und darauf erschien bereits schon nach fünf Tagen der Pilobolus crystallinus und zwar spontan und in grosser Anzahl. 
wurde. Das Mycelium wuchs dabei aus dem Substrate in die Mistjauche, in welcher letzteres lag und erzeugte daselbst auch Fruchtträger. Daraus liess es sich leichter unversehrt erhalten und Fig. 1 zeigt eine Partie des jüngeren, fortwachsenden Myceliums, das noch keine Fruchtträger erzeugt hatte. Dasselbe ist besonders an den Enden reich verzweigt und lässt leicht dickere mit Inhalt erfüllte Bauptäste (Fig. 1, a, a, a) unterscheiden. Diese zeigen im normalen Zustand keine Scheidewände und auch später bilden sich auf normale Weise keine; dieses Mycelium verhält sich also anders als bei Mucor, wo das Mycelium auch Anfangs ohne Querwände erscheint, später aber solche in allen Aesten auftreten. Diese Aeste am Pilobolus-Mycelium bilden gleichsam ein verzweigtes, communicirendes System von Hauptästen, welche gegen das Ende auch in dünnere $\mathrm{Z}_{\text {weige }}$ sich theilen, ausserdem aber noch Seitenäste tragen, welche gleich Anfangs durch Scheidewände von den Hauptästen getrennt sind (Taf. XXIII, Fig. 1, b, b, b). Die Scheide- wände dieser Aeste treten aber nie hart an der Abzweigungsstelle auf, sondern etwas weiter davon und nicht selten folgen sich zwei derselben kurz hintereinander; im weiteren Verlauf zeigen aber auch diese Aeste keine Scheidewände mehr.

Das System der Hauptäste ist der Ort, wo sich später die Anlagen zu den Fruchtträgern bilden und nie findet man dieselben an den Zwe:gen, welche durch Scheidewände von den Hauptästen getrennt sind. Bei älteren Pilobolus Culturen bildet das Mycelium oft ein ausgebreitetes Ganze, an welchem dann mehrere Fruchtträger zugleich entstehen und wenn man dann den Hauptästen nachgeht, so sieht man, dass sie von einer Anlage zur andern ohne Scheidewände sind, und somit frei communiciren. So lange noch keine Anlagen zu den Fruchtträgern im Mycelium auftreten, zeigen die Hauptäste desselben nur spärliche Verzweigung und meist auch nicht viel Seitenzweige. Mit der Ausbildung der Fruchtträger-Anlagen aber bildet sich auch das Mycelium weiter aus und erscheint oft mit sehr vielen meist aher kurzen Seitenzweigen besetzt, die erst zur Zeit, wo die Anlagen sich bilden, entstehen. Eine ältere Partie des Pilobolus-Myceliums zeigt Fig $2 \mathrm{a}$ und $2 \mathrm{~b}$ Taf. XXIII; daran erkennt man einen dicken Hauptast h, h, welcher beiderseis zu Fruchtträgern führt, und ausserdem noch verschiedene Seitenzweige: der Ast $\mathrm{h}^{1}$ gehört zum System der Hauptäste und führt auch zu einem Fruchtträger; dann sind die hürzeren Aeste a, a, a, welche von dem Hauptast meist durch Scheidewände ge- 
trennt sind und ausserdem noch die Aeste b, b, b und $b^{\prime}, b^{\prime}$. Diese sind nachträglich durch Ausbuchtung der Membran des betreffenden Astes entstanden, denn sie sind an der Abgangstelle eingeschnürt, was bei den andern Aesten nie vorkommt; sie werden meist bur kurz und wachsen auch später nicht weiter aus. Sie zeigen keine Scheidewände und sind auch nicht durch solche ron dem Hauptast getrennt. Bei meist unbedeutender Länge erscheinen sie Anfangs einfach (XXIII 2a und 2b, b, b), später weiter ausgebildet sind sie seitlich ausgebuchtet $\left(b^{1}, b^{1}\right)$ und erhalten dadurch einen verhältnissmässig grossen Umfang, wodurch sie befähigt werden mehr und schneller den Nahrungssaft aus der Umgebung aufzunehmen. Dieser gelangt, durch keine Scheidewand gehindert, unmittelbar in den Hauptast des Myceliums und durch diesen zur Fruchtträger-Anlage. Diese Aestchen findet man daher auch meist nur an solchen Stellen des Myceliums, wo in der Nähe eine Fruchtträger-Anlage gebildet wird, doch auch da nicht immer oder nicht gleich zahlreich. -

Diese Zustände wie sie Fig. 1 und 2 darstellen, können als Typus für das Pilobolus-Mycelium galten, und wenn sie auch vicht immer, zumal nicht bei jungen, beginnenden Culturen so ausgeprägt erscheinen, so lässt sich doch anch das junge Mycelium auf diesen Typus zurückführen. So zeigt Fig. 3 Taf. XXIII ein junges Mycelium, das bereits einen ausgebildeten Fruchtträger (A) und eine Anlage (B) gebildet hat. Dasselbe ist ganz aus einer Spore hervorgegangen, in sich geschlossen $d$. $h$. nirgends abgerissen oder verletzt. An demselben erkennt man nun leicht das verzweigte System der Hauptäste $(h, h, h)$, welches keine Scheidewand zeigt, dann die Zweige a, a, a, die gleich Anfangs durch normale Scheidewände von den Hauptästen getrennt sind und dann noch die zahlreichen kurzen Aestchen, welche nachträglich mit der Bildung der Fruchtträger-Anlagen entstehen. An diesem Mycelium fand an den Orten 0 , o das stärkste Wachsthum statt; hier ist die Verzweigung am reichlichsten. Bei weiterer Ausbildung erscheinen dann auch hier die schon jetzt angedeuteten communicirenden Hauptäste mit ihren Seitenzweigen und den Fruchtträger-Anlagen. -

Die Membran des Myceliums ist nur an älteren Theilen etwas dicker und deutlich doppelt contourirt; sie wird an den jüngeren Aesten dünner und gegen die Zweigenden hin ganz dünn und einfach, zumal bei den noch fortwachsenden, dagegen ist sie bei schon ausgewachsenen Aesten selbst an der spitze doppelt contourirt. 
Die Aeste des Myceliums sind selten oder gar nicht cylindrisch und gerade, sondern unregelmässig gcbogen und ihre Membran wellig.

Der Inhalt des Myceliums ist farbloses Plasma, welchem meist sehr kleine Körnchen eirgelagert sind. Diese sind theils farblos oder sie zeigen eine gelbe bis rothe Färbung und je nach ihrer Farbe und der Menge in der sie vorhanden sind erscheint auch der Inhalt fast farblos bis roth. In älteren dickeren MyceliumAesten, besonders in den Hauptästen sind die Körnchen so zahlreich, dass der Inhalt ganz roth erscheint; in jungen $\mathrm{Z}$ weigen und gegen die Enden derselben werden sie immer spärlicher und kleiner, bis in den feinen Verzweigungen der Inhalt farblos erscheint. Die Farbe des Inhaltes wechselt selbst in verschiedenen Mycelien, - was wohl von der Ernährung abhängt, - denn während sie in einem mehr blass ist, obgleich die Körnchen in grosser Zahl vorhanden sind, ist sie in anderen melir roth. Der Inhalt der Fruchtträger-Anlagen ist selbst bei Mycelien mit blassem Inhalt im reflectirtem Licht gelb bis orange und die Körnchen müssen hier nicht nur in grosser Zahl vorhanden sein, sondern haben wahrscheinlich auch ihre Farbe geändert. Bei Verletzungen treten aus dem Inhalt oft grosse, glänzende, ölartige Tropfen aus und diese zeigen eine blass. bis goldgelbe Farbe; ebenso fliesst der Inhalt durch Salzsäure in glänzende gelbe Massen zusammen; es ist fettes Oel, das früher im Inhalt in feinen Theilchen suspendirt war. -

Neben der Querwandlosigkeit der Hauptäste des Myceliums, ist für die Entwickelung der Pilobolus-Fruchtträger ferner von Bedeutung: die Bewegung, welche der Inhalt des unverletzten Myceliums zeigt. $\nabla$ on der keimenden Spore an findet man nämlich in allen Theilen des Myceliums den Inhalt in strömender Bewegung und diese wird nur in den feinen Endverzweigungen unkenntlich. Wie erwähnt sind besonders die Hauptäste dicht mit Inhalt erfüllt und hier nun sieht man die zahlreichen Körnchen im Inhalt in lebhafter Bewegung. Sie fliessen in vielen Strömchen nicht bloss nach einer, sondern nach entgegengesetzten Richtungen und zwar so dicht neben und durcheinander, dass es oft schwer hält ein Strömchen längere Zeit im Auge zu behalten. In weniger erfüllten Theilen sicht man dagegen ein Körnchen eine Strecke weit nach einer Richtung strömen, dann aber von einem in entgegengesetzter Richtung fliessenden aufgehalten und selbst in dieser Richtung fortgeführt werden. Andere Körnchen tanzen von zwei entgegenge- 
setzten Strömchen bewegt an einer Stelle eine Zeit lang herum, um bald von der überwiegenden Strömung nach einer Richtung fortgeführt zu werden. Es ist klar, dass bei der Querwandlosigkeit des grössten Theils des Myceliums, der Bewegung der Körnchen ein grosser Spielraum gegeben ist. Sie fliessen entweder nach den Orten, wo sie verwendet werden - denn die Bewegung dient hier dem Stofftransport -, oder wenn dies nicht geschieht, kehren die Körnchen wieder um und setzen ibre Bewegung fort bis sie theils an den Querwänden von Seitenästen oder überhaupt an den Enden der Mycelium-Zweige abermals zur Umkehr genöthigt werden. - Der Inhalt ist in den Hauptästen am dichtesten und hier ist auch die Bewegung am lebhaftesten, gegen die dünneren $\mathbf{Z}$ weige hin werden sowohl die Körnchen spärlicher, als auch ihre Bewegung langsamer. Oft ist die Dichtigkeit des Inhalts in den Hauptästen so gross, dass man nur ein Fliessen sieht ohne die einzelnen Strömchen unterscheiden zu können und hier kann man nicht entscheiden, ob die Bewegungen nur in einer Wandschichte oder durch das ganze Zelllumen stattfindet; in andern Mycelien aber mit mehr blassem Inhalt und weniger zahlreichen Körnchen, kann man nicht nur die einzelnen Strömchen deutlich unterscheiden, sondern man sieht auch, dass sie durch das ganze Zelllumen sich bewegen, denn bei jeder Einstellung innerhalb der Dicke des Mycelium-Fadens sind im Gesichtsfeld deutliche Strömchen zu sehen. Doch kann man auch hier keine Plasmafäden erkennen, in welchen sich die Körnchen bewegten, sondern diese fliessen vielmehr durch einen homogenen farblosen Zellinhalt. - In jungen Keimschläuchen aus Pilobolus-Sporen, sowie in manchen $\mathrm{Z}$ weigen des erwachsenen Myceliums treten im Imbalt auch Vacuolen auf und hier ist oft deutlich zu sehen, dass sich die Körnchen nur in einer Wandschichte bewegen. - Da das Mycelium verzweigt ist, so müssen sich auch die Strömchen an diesen Stellen trennen und von einander abzweigen; man sieht daher oft in den Hauptästen an den Verzweigungsstellen eine grössere Anhäufung des Inhalts, weil hier gleichsam eine kleine Stauurg eintritt, bevor sich die Strömchen nach divergirenden Richtungen sondern. -

\section{Anlage zum Fruchtträger.}

Bei einer gewissen Ausbildung des Myceliums bilden sich an demselben die Anlagen zu den Fruchtträgern und zwar indem die Mycelium-Schläuche nach allen Richtungen wachsen und sich im 
Substrate ausbreiten, häuft sich der Inhalt in gewissen Aesten mehr an und dieselben schwellen an einer Stelle an. Dies geschieht nur an Aesten, welche mit den Hauptästen frei communiciren und meist an solchen, die mehr an der Oberfäche liegen. Hier wird durch grössere Verdunstung und Stoffverbrauch ein Wachsthum mehr in die Dicke eingeleitet und dem entsprechend muss dann der Inhalt aus den communicirenden Theilen des Myceliums vorwiegend nach dieser Richtung strömen. Man sieht dann auch die Strömchen des Inhaltes meist nach jenen Orten fliessen, wo Fruchtträger-Anlagen sich bilden sollen und je näher dem Orte, desto langsamer wird die Bewegung. Der Stofftransport wird hier also wirklich durch die Strömchen ausgeführt, denn dafür spricht, dass sie bei Bildung von Fruchtträger-Anlagen vorwiegend nach dieser Gegend strömen und dass sich nur wenig zurückkehrende Strömchen finden, diese aber sind immer und in allen Theilen vorhanden. Die erste Andeutung zur Bildung von Fruchtträger-Anlagen besteht nun darin, dass manche Stellen der Mycelium-Schläuche sich dichter mit Inhalt füllen (Fig. 4, Taf. XXIII), dabei dehnen sie sich immer mehr aus, schwellen an und füllen sich immer mehr mit Inhalt (5, XXIII); und zwar erfolgt die Anschwellung des betreffenden Mycelium-Astes gleich in der ganzen Länge, in welcher auch später die fertige Anlage erscheint, und ist nicht, wie Coemans sagt ${ }^{1}$ ) und abbildet, Anfangs rund oder oval um sich dann später in die Länge zu strecken. Bei weiterer Ansammlung des Inhaltes tritt dann bald eine Sonderung ein, indem sich die Hauptmasse im oberen Theil der Anschwellung anhäuft und besonders dicht in der Mitte erscheint, wo sich der dunkle Inhalt nach unten von einem minder dichten scheidet (a. 6, XXIII). An der Stelle nun, wo die Sonderung des dichteren Inhalts von dem minder dichten am deutlichsten ist (a.6, XXIII), tritt später eine Scheidewand auf (7, XXIII) und diese scheidet die Anschwellung des MyceliumAstes in eine obere, dicht mit Inhalt erfüllte Partie und einen untern ins Mycelium übergehenden Theil, der unmittelbar nach Anlegung der Scheidewand weniger dicht mit Inhalt erfüllt ist, später aber sich wieder mehr füllen kann. Diese dicht mit Iuhalt erfüllte Anschwellung des Mycelium-Astes, welche durch die Scheidewand rom übrigen Mycelium getrennt ist, bildet die Anlage zum Fruchtträger; sie ist mit dem Auftreten der Scheidewand fertig

1) a. a. 0. p. 29 . 
und ändert ihre Gestalt nicht weiter; ausser insofern, dass sie später zum Fruchtträger auswächst. Die Gestalt der Anlage kann verschieden sein, am meisten elipsoïdisch und ebenso kann der Myceliumtheil, dem die Anlage aufsitzt, entweder unmerklich in das übrige Mycelium übergehen, oder er ist etwas angeschwollen und zeigt dann meist eine obconische Gestalt (7,3 und 8).

Die Fruchtträger-Anlage kann sich nun ganz am Ende eines Mycelium-Astes bilden (3, 7 XXIII) oder sie entsteht etwas unterhalb desselben (4, 5, 6 XXIII) und trägt daher schon der Anlage nach oben eine Mycelium-Fortsetzung; ja der Ast aus welchem sie entsteht kann gleich ursprünglich verzweigt sein $(4,5 \mathrm{XXIII)}$ und somit erscheint auch die Anlage im fertigen Zustand mit seitlichen Schläuchen besetzt. Coemans bildet dieselben nicht ab und auch Cohn nur je einen an zwei Exemplaren, sie sind aber oft sehr zahlreich und von beträchtlicher Länge, dabei communiciren sie mit der Frucbtträger-Anlage und zeigen meist keine Scheidewände. In anderen Fällen fehlen diese Schläuche ganz oder sie können selbst nachträglich entstehen; indem sich die Membran der Anlage an manchen Stellen ausstülpt. Ich habe es nie beobachtet, dass die seitlichen Schläuche an der fertigen Anlage wieder zu einem Mycelium auswachsen würden, sie bleiben viclmehr kurz und stellen gleichsam nur Wurzelhaare dar, welche später nach dem Auswachsen der Anlage zum Fruchtträger mit derselben zu Grunde gehen. Der Myceliumtheil aber, dem die Anlage aufsitzt, verhält sich auch später wie das Mycelium: seine Seitenzweige können weiter auswachsen und wieder neue Anlagen bilden. Die fertigen Anlagen aber, selbst aus einem Mycelium entstanden, sind nun zu eigenen Organen geworden, welche später nur zu Fruchtträgern und nie zu einem Mycelium auswachsen. -

Die Fruchtträger-Anlagen entstehen an einem ausgedehnten, älteren Mycelium auch zu mehreren zugleich, so z. B. an einem ausgebildeten gut ernährten ron ungefähr ein Quadratzoll Ausdehnung fanden sich sieben fertige Fruchtträger, zwei die schon das Sporangium abgeschleudert hatten und drei Anlagen, aber immer durch ein grosses Stück Mycelium von einander getrennt und an verschiedenen Seitenzweigen des Systems der Hauptäste. An jüngeren Mycelien dagegen entstehen sie meist nacheinander und nur selten, bei grossem Nahrungsvorrath, findet man sie in unmittelbarer Nähe und in gleicher Entwickelung (8 XXIV). Oefter dagegen findet man sie in ungleicher Entwickelung, wo wie in 
Fig. 3, XXIII bei A bereits ein ausgebildeter Fruchtträger, bei B aber erst eine Anlage zu finden ist. Ebenso findet man oft an den Mycelien neben den jungen Fruchtträger-Anlagen andere Aeste, die bereits angeschwollen sind aber noch wenig Inhalt zeigen und wahrscheinlich erst später zur weiteren Entwickelung gelangen, wenn die benachbarten Fruchtträger-Anlagen bereits ihre Ausbildung erreicht haben.

Alle diese Erscheinungen und noch andere später zu erwähnende, finden ihre Erklärung in der offenen Communication des grössten Theils der Mycelien-Aeste. Hat nämlich an einem noch jungen Mycelium die Bildung einer Fruchtträger-Anlage bereits begonnen, so strömt der Inhalt aus den benachbarten Theilen vorwiegend nach diesem Orte und erst wenn dieselbe durch das Auftreten der Scheidewand als fertig rom Mycelium abgesondert wird, kann der Inhalt wieder einer andern Stelle zufliessen. Bei Nahrungsüberfluss können sich aber selbst in unmittelbarer Nähe doch zwei Anlagen fast zugleich bilden (8 XXIV) oder an entfernteren Theilen desselben Myceliums. Nacheinander können sie sich aber selbst in unmittelbarer Nähe gut bïlden, da das Mycelium immer Nahrung aufnimmt und wenn es dieselbe zuerst einer Anlage zugeführt und dieselbe versorgt hat, kann es nachher wieder die Bildung einer zweiten Fruchtträger-Anlage ermöglichen.

Die Anlagen finden sich meist in der oberen Partie des Substrates, theils bedeckt, theils offen liegend und dem blossen Auge dann als gelbe bis orange gefärbte Körper sichtbar; ausnahmsweise findet man sie selbst ganz tief im Substrate.

Der Inhalt der fertigen Fruchtträger-Anlage ist wie der des Myceliums feinkörnig; die Körnchen sind hier in solcher Menge angehäuft, dass die Anlage im durchgelassenen Licht mehr oder minder dunkel gelb- oder rothbraun erscheint; im reflectirten Licht zeigt sie eine gelbe bis orange Farbe. Der Inhalt ist am untern Theil viel dunkler, er wird gegen die Spitze lichter und oft etwas röthlich gefärbt. Bei Verletzungen treten auch hier im Wasser grosse glänzende, ölartige Tropfen aus dem Inhalt und werden durch Zusammenfliessen immer grösser; ebenso durch Schwefelsäure und Alkohol.

\section{Fruchtträger und Sporangium.}

Nach der Ausbildung der Fruchtträger-Anlage beginnt das Auswachsen derselben zum Fruchtträger und zwar meist sogleich, so 
dass wenn die Anlage durch die Scheidewand rom Mycelium getrennt wird, nachher nicht etwa eine längere Pause eintritt, sondern die weitere Entwickelung geht gleich vor sich. Dieselbe wird dadurch eingeleitet, dass an der Spitze der Anlage ein undeutlich umschriebener, lichterer Raum kenntlich wird. Derselbe lässt sich unter dem Mikroskop bei abgewendeten Spiegel als Vacuole erkennen (3 B XXIII). Es wird also Wasser aufgenommen, welches ermöglicht, dass das in der Anlage angehäufte Material weitere Bildungen eingehen kann, wie es auch bei der Keimung der Sporen in analoger Weise stattfindet. Die Vacuole wird nun immer grösser und kenntlicher ( 8 XXIV A), während die Anlage zugleich an dieser Stelle zu einem dicken Schlauch auszuwachsen beginnt ( 8 XXIV B), der später zum Fruchtträger wird. Dieser Schlauch verhält sich nun ganz anders, als die anderen seitlichen Schläuche, welche an der Fruchtträger-Anlage noch vorkommen können, denn während die letzteren nur dünn sind und Mycelium-Charakter haben, ohne aber weiter zu wachsen, ist der erstere bedeutend dicker und zeigt das entschiedene Bestreben nach oben zu wachsen und sich über das Substrat zu erheben. Man findet nämlich die FruchtträgerAnlagen manchmal ganz tief bis einen Zoll im Substrate und wenn nun dieselben dort einen Schlauch treiben, der zum Fruchtträger werden soll, so durchdringt derselbe die ganze Schichte des Substrates, welche ihn von der Oberfäche trennt, um über dieselbe. hervorzutreten. Lir bleibt auf der ganzen Strecke im Substrate ebenso dick oder noch dicker, als wenn er gleich Anfangs ausser dem Substrate gewachsen wäre; auch verzweigt er sich nicht noch zeigt er seitliche Schläuche, wie sie an Ner Fruchtträger-Anlage vorkommen. - Werden Fruchtträger-Anlagen, die bereits einen Schlauch übor das Substrat getrieben haben, etwa so gelegt, dass die Spitze des Schlauches tiefer in's Substrat kommt und nach unten gekehrt wird, so wächst der Schlauch nicht etwa im Substrat fort, sondern er krümmt sich, um alsbald über der Oberfläche zu erscheinen, oder er stirbt ab und die Anlage treibt an einer andern Stelle einen neuen, nach oben gerichteten Schlauch. Die Mycelium-Schläuche, welche sich oft schon bei der Bildung der Fruchtträger-Anlagen und oft an der Spitze derselben vorfinden, sah ich dagegen nie über das Substrat hervorwachsen und sich dann etwa anders ausbilden, ebenso ist mir auch der Fall nicht vorgekommen den Coemans (a. a. O. p. 54) erwähnt, wo die Fruchtträger-Anlage statt zu einem einfachen dicken Schlauch, 
in einen vielfach verzweigten auswächst, dessen Enden Conidien abschnüren sollen. -

Man könnte vielleicht das Auswachsen der Fruchtträger-Anlage zu einem Schlauch, der zum Fruchtträger werden soll, vergleichen mit einer in bestimmter Weise vorsichgehenden Keimung einer grossen Spore, welche aber hier, einer Azygospore ähnlich, durch einen obconischen Suspensor noch mit dem Mycelium zusammenhängt (9 und $10 \mathrm{XXIV}$ ); und diese Anschauungsweise wird dadurch noch einigermassen gerechtfertigt, dass die Fruchtträger-Anlage, einmal fertig gebildet, vom Mycelium selbst ganz getrenn乞 werden kann und sich nichtsdestoweniger zum vollständigen Fruchtträger in ganz normaler Weise ausbildet.

Ebenso hat man auch das Recht, auf Grundlage der Entwickelung, die Fruchtträger-Anlage nicht als untere Anschwellung des Fruchtträgers zu betrachten, sondern denselben erst von da an zu rechnen, wo er aus der Anlage hervorgewachsen ist. Diese Stelle ist nun meist sehr kenntlich, theils dadurch, dass sich die Fruchtträger-Anlage dort deutlich in den Fruchtträger verjüngt, theils, dass an der Anlage nur bis zu dieser Stelle seitliche Schläuche vorkommen; in anderen Fällen aber fehlen diese letzteren ganz oder die Anlage ist nicht bedeutend angeschwollen, so dass das Auswachsen derselben mehr wie eine Verlängerung der ganzen Anlage, denn als ein Austreiben eines Schlauches erscheint. In diesem letzteren Falle erscheint denn auch beim fertigen Pilobolus die Trennung $z$ wischen der ursprünglichen Anlage und dem Frucht. träger meist nicht so scharf ausgesprochen, als wie im $\in$ rsten Fall, aber doch immerhin kenntlich.

Indem nun bei weiterer Entwickelung theils durchs Mycelium, theils durch die Anlage selbst und ihre seitlichen Schläuche immer mehr Wasser aufgenommen wird, wächst auch der Schlauch, der zum Fruchtträger werden soll, immer mehr in die Länge. Die Vacuole vergrössert sich nicht nur in der Richtung, in welcher der Schlauch wächst, sondern sie dehnt sich auch in der Anlage immer mehr aus. Die fortwachsende Spitze des Schlauches erscheint hell (14 und 9 XXIV) darunter ist eine kleine röthlich-braune Anhäufung des Inhalts und der übrige Theil zeigt einen feinkörnigen mehr oder minder dicken Wandbeleg von gelb- bis röthlichbrauner Farbe, in der Mitte aber eine farblose Zellfüssigkeit die Vacuole. Mit dem Wachsthum des Schlauches wandert natürlich auch der Inhalt von unten nach oben; bald aber hört das Spitzenwachs- 
thum des Schlauches auf, während die Emporschaffung des Nah. rungsmaterials aus der Anlage noch immer fortdauert. Dasselbe wird sich also unter der Spitze des Schlauches ansammeln, diese verliert ihre helle Färbung und rundet sich ab (10) XXIV). Dies geschieht später immer mehr, so wie die Anhäufung des Inhaltes sich vermehrt (11 XXIV). I॥ Folge dieser Wanderung des Inhaltes aus der Anlage nach dem Schlauchende wird derselbe in der ersteren immer lichter, dagegen in dem letzteren immer dunkler und dichter. Im weiteren Verlauf beginnt das Schlauchende kugelig anzuschwellen und diese Anschwellung wird später zum Sporangium, der andere Theil des Schlauches aber zum eigentlichen Träger des Sporangiums. Diese Anscbwellung ist Anfangs klein unä nur durch eine schwache Einschnürung. ron dem Fruchtträger gesondert; später wird sie bedeutend grösser und erscheint als ein mit dichtem Inhalt erfülltes Köpfchen (12, 13 XXIV). Der Fruchtträger bildet mit der Anlage immer eine Zelle und wenn ich trotzdem beide unterscheide und letztere nicht als untere Anschwellung des ersteren betrachte, so geschieht es, wie oben erwähnt, auf Grund der Entwickelung und mit demselben Recht, wie auch anderwärs gesonderte Theile einzelliger Pflanzen besonders benannt werden, falls Entwickelung und morphologische Bedeutung dazu führen. -

Aus der Anlage wandert so nach und nach fast aller Inhalt in das angelegte Sporangium und in der ersteren, so wie im Fruchtträger findet man nur einen mehr oder minder dünnen Wandbeleg, der übrige Raum wird von wässeriger Flüssigkeit eingenommen. Diese reicht nicht bis in das angelegte Sporangium, sondern ist deutlich an der Stelle begrenzt wo dasselbe beginnt (15 XXIV). Kurz nach diesen Vorgängen wird dann das dicht mit Inbalt erfüllte Köpfchen durch eine Scheidewand als Sporangium rom T'räger getrennt $(33 \mathrm{XXV})$. Beide aber sind lamit noch nicht fertig, sondern gehen noch verschicdeue Veränderungen bis zur völligen Ausbildung ein.

Bevor ich das Sporangium weiter bespreche, will ich vorher noch die Vorgänge im Fruchtträger erwähnen und zwar sowohl die Bewegung seines Inhaltes, durch welche das, in der Anlage angehäufte Bildungsmaterial emporgeschafft wird zu dem sich bildenden Sporangium, als auch die Veränderungen, welche er nach Anlegung desselben bis zu seiner vollkommenen Ausbildung noch erleidet. -

Wir haben gesehen, dass das Auswachsen der Fruchtträger- 
Anlage zum Fruchtträger damit begann, dass Wasser aufgenommen wurde, welches als Vacuole in der Spitze der Anlage sich erkennen liess. Die Menge des Wassers ist bedeutend und wird zum Theil auch ausgeschieden, wodurch dann die an Pilobolus bekannten Wassertröpfchen entstehen. Sie erscheinen schon sehr früh, an noch ganz kurzen Schläuchen, welche eben über das Substrat hervorragen und noch ein zugespitztes Ende zeigen (14 XXIV). Nahe demselben sind sie Anfangs klein, werden nach unten immer grösser und zahlreicher und ebenso vermehren sie sich bei der weiteren Ausbildung des Fruchtträgers und erscheinen selbst an jungen Sporangium. Wie nun mit der Wasseraufnabme weitere Bildungen überhaupt eingeleitet werden, dass nämlich vor Allem die Anlage zu einem Schlauch auswächst, so wird dadurch auch wieder die strömende Bewegung des Inhaltes ermöglicht, welche wir schon im Mycelium kennen gelernt und welche bei der Bildung der Fruchtträger-Anlage gleichsam zur Ruhe gelangt, hier im jungen Fruchtträger wieder auftritt, um wie im Mycelium, so auch hier dieselbe Rolle zu übernehmen, nämlich die Transportirung von Bildungsmaterial: im Mycelium für die Fruchtträger-Anlage, hier für das sich bildende Sporangium. Während aber im Inhalt des Myceliums eine strenge Sonderung zwischen einern plasmatischen Wandbeleg und einer centralen Zellflüssigkeit meist nicht erkennbar ist,- sondern hier die Körnchen in dem wässerigen Plasma durch das ganze Zelllumen verlaufen, tritt diese Sonderung gleich bei dem beginnenden Fruchtträger ein, um bei seiner weitcren Ausbildung auch imfner deutlicher zu werden. Eine farblose Zellflüssigkeit nimmt die Mitte des Inhaltes ein, an der Zellwaud aber ist ein mehr oder minder dicker feinkörniger Wandbeleg von gelb- bis röthlichbrauner Farbe. In demselben nun kann man an den kleinen Körnchen, welche ihm eingelagert sind, deutlich eine strömende Bewegung wahrnehmen und zwar finde ich sie nur in dem Wandbeleg, nicht aber auch durch das Zelllumen hin, wie es Cohn angiebt (a. a. 0. p. 509). Die Bewegung ist Anfangs in dem zum Frucht. träger auswachsenden Schlauch gar nicht oder nur schwer sichtbar, theils weil der Inhalt noch $\mathrm{zu}$ dicht, theils weil auch die Bewegung noch zu schwach, um sie an den kleinen Körnchen leicht wahr. nehmen zu können. Später aber wenn noch mehr Wasser aufgenommen und dadurch der Wandbeleg lichter wird, besonders aber wenn der Fruchtträger an seiner Spitze zum Sporangium anschwillt, wird die Bewegung immer deutlicher und lebhafter. Das ändert 
sich natürlich auch mit der Grösse des jungen Fruchtträgers. Ist sie aber einmal sichtbar, so zeigt sie sich darin, dass eine Menge Körnchen dicht neben einander dahinfliessen. Die Richtung ist vorwiegend nach oben und sich gleichbleibend; nur selten finden sich $\mathrm{z}$ wischen den vielen aufwärtssteigenden Strömchen auch zurückkebrende, aber einzelne sind immer vorhanden. - So wird auch hier, wie im Mycelium, durch die aufsteigenden Strömchen selbst der Inhalt aus der Anlage fortgeschafft zur Bildung des Sporangiums. Im untern Theil des Fruchtträgers und in der Anlage selbst ist die Bewegung schneller, da hier das Wasser unmittelbar aufgenommen wird, nach oben zu wird sie etwas langsamer, da sich hier die körnigen Massen immer mehr anhäufen und im angelegten Sporangium wird sie ganz unkenntlich. Durch grössere Wasserzufuhr wird sie deutlicher und etwas rascher, denn bringt man eine Anlage, welche breits zu einem Fruchtträger ausgewachsen und oben schon zum Sporangium angeschwollen ist, vorsichtig unter Deckglas, so sieht man gleich Anfangs die feinen Körnchen dicht neben einander, fast ausschliesslich nach oben strömen; nach einiger Zeit aber wird die Erscheinung viel deutlicher und lebhafter. Es wird nun nicht bloss durchs Mycelium und durch die Anlage Wasser aufgenommen, sondern auch durch die Wand des Fruchtträgers. Der Inhalt desselben wird etwas lichter und lässt die feinen Strömchen deutlicher und die Bewegung lebhafter erscheinen. Sie geht selbst unter Deckglas oft Stunden lang ganz ungestört und ungeändert vor sich.

Ist nun auf die Weise aus der Fruchtträger-Anlage fast aller Inhalt in das sich bildende Sporangium geströmt und hat sich derselbe dann durch eine Querwand vom Fruchtträger, oder Träger schlechtweg gesondert, so hört die Strömung des Inhaltes damit keineswegs auf, während sie aber bisher vorwiegend nach oben gerichtet war, so stellt sich jetzt mehr eine Circulation ein, indem die Strömchen im Ganzen in geringerer Zahl vorhanden fast in gleicher Zahl nach oben, wie nach unten strömen und unter einander anastomosiren. -

Der Träger des Sporangiums ist nach Abtrennung des letzteren durch die Scheidewand, entweder von unten bis oben ziemlich gleich dick oder unter dem Sporangium etwas erweitert. Von dem Mycelium aber und der Anlage wird immer noch eine Menge Wasser aufgenommen, welches theils durch die Membran in vielen Wassertröpfchen ausgeschieden wird, theils aber weitere Veränderungen 
an dem Träger und der Scheidewand, welche denselben vom Sporangium trennt, hervorruft. Mit der steigenden Wasseraufnahme wird der Träger durch Druck und gleichzeitiges Wachsthum unter dem Sporangium mehr oder minder stark kugelig ausgedehrt; während die Scheidewand sich auch ausdehnt und dabei kegelförmig ins Sporangium wölbt. Coemans ${ }^{1}$ ) glaubt, dass diese Querwand gleich anfangs gewölbt erscheint und sich unter dem Drucke scines "courant crystallin" bildet; aber dieser oder die centrale Zellflüssigkeit crscheint zu der Zeit, als die Querwand angelegt wird nach oben ganz eben abgegrenzt (15 XXIV) und äussert also keinen Druck, welcher die Bildung einer gebogenen Querwand bedingen könnte, sonst müsste die Zellfüssigkeit auch in einer gebogenen Linie nach oben begrenzt erscheinen, was später bei noch schwach gewölbter Querwand wirklich der Fall ist (16 XXIV). Die angelegte Querwand ist aber anfangs sehr zart und wenn man sie nun durch Contraction des Inhalts mittelst Schwefelsäure nachweisen will, so wird dabei der Inhalt des Sporangiums in den Träger gedrückt; die Querwand muss zerreissen und alles wird unkenntlich. Durch Schwefelsäure wird also die Membran erst kenntlich, wenn sie bereits stärker und nach oben gewölbst ist; ich sah aber in manchen Fällen ohne Schwefelsäure eine flache Querwand und ebenso sieht man später, dass dieselbe anfangs nur schwach und erst nachträglich stärker gewölbt erscheint (16, 18 XXIV). Sie bildet so die für die Mucorinen charakteristische Columella, welche im ausgebildeten Zustand mehr oder minder stark kegelförmig erscheinen kann. - Der Träger erscheint im ausgebildeten Zustand dem freien Auge wie ein wasserhelles Bläschen, das nach unten sich verjüngend in einen meist deutlich gesonderten mehr oder minder langen Stiel übergeht, der sich von der Fruchtträger-Anlage entweder kenntlich absetzt oder auch in dieselbe unmerklich übergeht. - Der Irbalt des Trägers besteht gleich nachdem das Sporangium sich durch eine Querwand von demselben abgesondert hat, aus einem gleichmässigen nicht immer gleich dicken, feinkörnigen Wandbeleg, von meist schmutzig gelber Farbe im durchgelassenen, und fast farblos im reflectirtem Licht. Mit der Veränderung, welche der Träger erleidet, verändert sich auch der Wandbeleg und dieser kann dann in dem ausgebildeten Träger verschieden sich zeigen. In der Fruchtträger-Anlage und im Stiel des Trägers ist er oft unkenntlich, weil

1) a. a. 0. p. 32 . 
farblos und sehr dünn, und nur durch chemische Reagentien sicher nachzuweisen, in anderen Fällen aber durch ihm eingelagerte Körnchen deutlicher sichtbar. In der blasenförmigen Anschwellung des Trägers erscheint er aber oft roth gefärbt von ihm eingelagerten feinen Körnchen, und zwar finden sich dieselben entweder ziemlich gleichmässig eingelagert oder an gewissen Stellen mehr angehäuft. Dies geschieht gewöhnlich in einer ringförmigen Zone gleich unter dem Sporangium und dann an der Stelle, wo die Anschwellung des Trägers in den Stiel übergeht. An der ersteren Stelle wird die Anhäufung meist nicht bedeutend, dagegen erscheint sie an der letzteren oft als ein rothes Querband (19 XXIV), das nach oben und unten theils scharf abgesetzt erscheint, theils aber nach einer oder nach beiden Seiten allmählich weniger dicht und weniger roth wird. An der letzteren Stelle hat Coemans (a. a. 0. p. 31) eine Membran angenommen zwar nicht aus Cellulose, sondern blos aus Plasma und zwar nur auf Grund des dichteren und stärker roth gefärbten Querbandes. Dieses ist aber nicht wur in'sehr vielen Fällen gar nicht vorhanden, sondern ist selbst, wenn es scharf als Querband erscheint, nur eine ringförmige, stärkere Anbäufung von rothem Inhalt und geht nicht als Platte durch die Zelle. Es kann aber eintreten, dass indem mit dem Wasser, welches durch Mycelium und Anlage aufgenommen wird, auch noch Nahrungsstoffe in den Träger gelangen, der Wandbeleg dadurch stärker wächst, während es der Träger nicht mehr thut; dann stülpt sich der Wandbeleg an jener Stelle ringförmig nach innen, wobei er sich an dieser Stelle zugleich ron der Membran abhebt (17 XXIV). Meist ist aber dann bei mittlerer Einstellung des Mikroskops sicbtbar, dass der Wandbeleg nur als ringförmige Leiste nach innen ragt und sich nicht zu einer ganzen Querplatte vereinigt. Immerbin ist aber hier die Möglichkeit dazu gegeben, dass sich eine solche Querplatte von Plasma hier bilden könnte, mit Bestimmtheit konnte ich das aber nur einige Male ermitteln; eine Cellulose-Membran aber habe ich an dieser Stelle nie beobachtet.

Ist nun der Inhalt in der Anschwellung des Trägers so angeordnet, dass er unter dem Sporangium und beim Uebergang in den Stiel eine roth gefärbte Anhäufung zeigt, so. hängen beide natürlich zusammen, denn es sind ja nur stärker mit rothen Körnchen eingelagerte Partieen desselben Wandbeleges. Derselbe kann nun zwischen diesen beiden Orten theils farblos oder nur schwach mit rothen Inbalt eingelagert sein oder man findet einfache, rothe 
Längstreifen (34 XXVI), die selbst unregelmässig netzartig untereinander verbunden sein können.

Ausser diesem ruhenden, stellenweise mit rothen Inbalt eingelagerten Wandbeleg, finden wir an der innern Fläche desselben zarte, vielfach unter einander verbundene Fäden farhlosen Plasmas, dem feine Körnchen nicht in gar grosser Zahl eingelagert sind. An diesen kann man nun wieder und hier oft sehr deutlich und lebhaft, besonders im Stiel des Trägers, eine strömende Bewegung wahrnehmen. Da der Wandbeleg im Stiel nur dünn und farblos ist, da die Plasmafäden oft deutlich sichtbar und die ihnen eingelagerten Körnchen nicht zu zahlreich sind, so lässt sich die Bewegung an den Körnchen sehr schön und oft Stunden lang unter dem Deckglas verfolgen. Obgleich die Plasmafäden nur dünn sind, so kann man doch sehen, dass oft in demselben Plasmataden die Körnchen nach entgegengesetzten Richtungen an einander vorbeifliessen, sich gegenseitig aufhalten können oder eins das andere mitreisst. Ein einzelnes Körnchen fliesst meist schnell dahin, begegnen sich mehrere, so beginnt ein Drängen und Stossen, bis sich jedes seine Bahn bricht und weiter fliesst. - In andern Fällen ist die Bewegung aber minder auffallend, da die Plasmafäden oft sehr zart und die ihnen eingelagerten Körnchen sehr klein sind, so dass man sehr aufmerksam sein muss um die Bewegung zu finden, obgleich sie selbst in diesem Falle ziemlich lebhaft ror sich geht. In manchen grossen Trägern aber mit langen, dünnen Stiel ist sie sehr deutli 2 h und zwar erfolgt sie, da die Plasmafudden anastomosiren, in verschiedenen Richtungen, von denen keine als etwa überwiegend zu erkennev ist, sondern die Bewegung giebt sich als Circulation kund. Sie ist nicht nur im Stiel vorbanden, sondern geht nach unten bis in die Anlage und nach oben in die Anscbwellung des Trägers, wo sie etwas langsamer wird, da sie sich auf eino grössere Fläche zertheilt. Ueberall aber erfolgt sie nur an der innern Fläche des Wandbeleges; das Innere des Trägers enthält eine wässerige Flüssigkeit in welcher weder f ine Körnchen noch eine Strömung sichtbar sind. $\mathrm{Cohn}^{1}$ ) erwähnt die strömende Bewegung in dem Fruchtträger des Pilobolus, dagegen sah er sie nicht im Mycelium; Coemans ${ }^{2}$ ) aber referirt Cohn's Angabe und sagt dann: er könne keine strömende Bewegung zugeben.

1) N. A. A. C. L. N. C. XXIII. p. 509.

2) a. a. 0. p. 34 .

Jahrb. f. wiss. Botanik. VIII. 
Ich kann nun auf das bestimmteste angeben, dass dic Bewegung des Inhaltes nicht nur im Fruchtträger, sondern auch im Mycelium $\mathrm{zu}$ finden ist, natürlich muss man diese Theile in möglichst unversehrtem Zustand untersuchen um dic Bewegung zu sehen.

Jetzt will ich die weiteren Veränderungen des angelegten Sporangiums betrachten. Wir sahen, dass nachdem sich dasselbe dicht mit Inhalt erfüllt hatte, eine Sclieidewand angelegt wurde, welche es vom Fruchtträger trennte. Diese Scheidewand ist an. fangs eben und wölbt sich, wic schon erwähnt, erst spüter kegelförmig ins Sporangium. Dasselbe erscheint alsdann in reflectirten Licht als cin orange-gelb gefärbtes Köpfchen und zwâr rührt die Farbe allein vom dichten Inhalt her, denn die Membran des Sporangiuıns ist anfangs farblos und wie die des Trägers, in welche sie übergeht doppelt contourirt und mit derselben gleich gebaut. Später aber beginnt das Sporangium an seinom oberen Theil sich dunkler zu färben und zwar ist es jetzt die Membran desselben, welche nach und nach eine dunkel blau-schwarze Fürbung annimmt. Im oberen Theil beginnt die Färbung nicht nur zuerst, sondern sie wird dort auch an intensirsten, gegen den Grund des Sporangiums aber wird sie allnählich lichter, und sclbst im ausgebildeten Zustand zeigt sie einen mehr orler minder breiten, lichter gefärbten Saum, der sich aber nicht scharf gegen den übrigen Theil absetzt, sondern allmählich in den zuletzt ganz dunkel schwarzblauen oberen Theil übergeht. Mit dieser Färbung der Membran treten in derselben zugleich feine schwarze Pünktchen, als sehr kleine Wärzchen auf und zwar bedingen nicht etwa sie die schwarze Fürbung, denn sie können auch fohlen, obgleich auch dann die Membran schwarz erscheint. Diese Wärzchen sieht man besonders deutlich im lichteren Rand der Sporangium-Membran (18 und $20 \mathrm{XXIV}$ ), und sie treten nur so weit als dieselbe reicht, nämlich bis zu der Stelle, wo die Columella angeheftet ist und wo die Sporangium-Membran in die farblose nicht warzige $\mathbf{M c m}$. bran des Trägers übergeht $(18,20 \mathrm{XXIV})$. Mit dieser Färbung ist keine besondere Verdickung derselben rerbunden, wic Cocmans (a. a. 0. p. 23) sagt, sondern sie bleibt in ihrer ganzen Ausdehnung mit der Membran des Trägers, in welche sie übergeht, von ganz gleicher Dicke.

Zugleich mit diesen Veränderungen der Membran des Sporangiums gehen solche auch im Inhalt desselben vor sich. Die Färbung der Membran sowie die Dichtigkeit des Inhaltes erlauben 
aber nicht dieselben zu beobachten. Man weiss nur das Resultat dieser Veränderungen: es bilden sich nämlich aus den gesammten Inhalt des Sporangium die Sporen des Pilobolus, und zwar scheinen sie recht bald nach Bildung des Sporangiums zu entstehen, denn angelegt findet man sie schon, nachdem die Sporangium-Membran sich bereits schwarz zu färben und der Träger unter dem Sporangium anzuschwellen beginnt. Wahrscheinlich entstehen die Sporen auch hier, wie bei andern Mucorinen durch "Theilung ohne Scheidewandbildung" $\left.{ }^{1}\right)$, d. h. der ganze Inhalt des Sporangiums zerfällt simultan in eben so viele und so grosse Partien, als spätcr Sporen vorhanden sind. Diese erscheinen nun bei Pilobolus kurz nach ihrer Anlegung als zart umschriebene Bläschen, mit spärlichem, feinkörnigem Inhalt, - noch von derselben Beschaffenheit, wie er vorher das ganze Sporangium erfüllte - und in demselben eine bis mehrere oft ziemlich grosse Vacuolen; von einem Zellkern ist nichts zu sehen (40a und $b \mathrm{XXVI}$ ). Diese Sporen müssen bis zu ihrer völligen Ausbildung noch wesentliche Veränderungen eingehen: so müssen vor allem die Vacuolen kleiner werden, es wird also durch Verdunstung Wasser abgegeben, dann muss der Inhalt dicliter mehr homogen und ölartig und die Membran stärker werden.

Die zuletzt besprochenen Vorgänge bej Pilobolus, welche nach dem Auftreten der Scheidewand unter dem angelegten Sporangium vor sich gehen, finden ziomlich gleichzeitig statt, und zwar so, dass während einerseits, durch die Aufnahme von Wasser durch Mycelium und Anlage, die Anschwellung des Trägers unter dem Sporangium und damit die kugelförmig ins Sporangiun ragende Columella sich bildet, andererseits wieder sich dic SporangiumMembran schwarz färbt und in ihrem Innern darauf die Sporen entstehen. In diesem Stadium erscheint uns dann der Pilobolus-Fruchtträger, wie ihn Fig. 19 Taf. XXIV, ohne den unteren Theil darstellt. Die Sporangium-Membran ist besonders im oberen Thoil dunkel schwarz gefärbt und geht nach unten in eine hier ziemlich breite immer lichter gefärbte Partie über, durch welche man im Innern die Sporen erkennen kann. Der Träger des Sporangiums zeigt die blasenförmige Anschwellung und ihr Inhalt unter dem Sporangium eine schwächere Anhäufung röthlichen Inhaltes, und unten an der Uebergangsstelle in den Stiel eine noch viel stärkere, welche

1) de Bary, Morph. u. Physiol. d. Pilze etc. p. 121. - Coemans hat die Sporenbildung bei Pilobolus noch als freie Zellbildung aufgefasst; ebenso Cohn. 
in der Mitte als ein Querband erscheint, dasselbe ist eine ringförmige Ansammlung von rothen Inhalt. Fig. 20 XXIV zeigt einen Theil des Sporangiums von dem Pilobolus bei stärker Vergrösserung: man sieht hier deutlich die Sporangium-Membran durch die schwächer gefärbte Partie bei a in die farblose Membran des Trägers übergehen; sie ist in ihrem ganzen Verlauf doppelt contourirt und gleichmässig dick. Bei a ist die Anheftungsstelle der Columella, welche hier steil in das Sporangium sich erhebt. Die Sporen liegen hier nicht hart an der Sporangium-Membran, sonsind in Folge längeren Liegens im Wasser von derselben zurückgetreten (siehe weiter unten).

Das ganze Pflänzchen ist in diesen Stadium mit zahlrcichen Wassertröpfenen bedeckt, welche zeigen, dass die Wasseraufnahme durch Mycelium und Anlage noch immer ungestört vor sich geht. Sie bewirkt nicht nur, dass dic Anschwellung des Träger immer grösser und praller mit Wasser gefüllt wird und dass die Columella sich immer stärker ins Sporangium wölbt, sondern durch eben dieses Fmpordrängen der letzteren wird auch ein Druck au die Sporen und die Sporangium-Membran ausgeiibt. Diese letztere reisst nun in Folge dieses Druckes an der Stelle, wo sie an den Träger befestigt ist rund berum glatt ab und wird von den Sporen, welche bis jetzt von der Columelle gegen die Sporangium-Membran gedrückt wurden und nur nach Abreissen der letzteren diesem Drucke nachgeben können, etwas in die Höhe gehoben (17, 21 XXIV).

So bleibt die Sporenmasse oben von der schwarzen Membran kappenartig bedeckt auf der Columella sitzen. Dieses Stadium gewährt uns zugleich eine nähere Einsicht in den innern Bau des Sporangiums. Fig. 21 Taf. XXIV zeigt einen Theil desselben in diesem Stadium bei stärkerer Vergrösserung. Wir sehen oben die schwarze Membran der Sporenmasse aufsitzend und am untern Theil von derselben abstehend; bei a ist die Stelle, wo sie früher an den Träger befestigt war. Von a aus steigt die Columella in die Sporenmasse hinein; dieselbe aber wird von einer zarten, ziem. lich dicken Membran, der Sporenhülle umschlossen, diese ist farblos und von homogen gallertartiger Beschaffenheit. Sie erstreckt sich unter die schwarze Membran und wenn es gelingt, - wie es manchmal der Fall, die schwarze Membran mit einer Nadel von der Sporenmasse so abzulösen, dass die letztere von der Sporenhülle ganz umschlossen auf der Columella sitzen bleibt, so kann man die Sporenhülle oben um die ganze Sporenmasse unversehrt 
verfolgen, sie ist also nicht an die schwarze Membran befestigt, sondern haftet ihr meist nur sehr stark an. Ebenso umschliesst sie auch nach unten continuirlich die Sporenmasse, denn dieselbe löst sich oft - besonders nach längerem Liegen im Wasser unter Deckglas ganz glatt von der Columella ab, so dass an derselben keine etwa abgerissenen Membranstücke haften bleiben, noch auch dass die Sporenhülle zerreissen und die Sporen austreten würden. Ebenso verhält es sich, wenn man, was nicht selten gelingt, das Sporangium mit einer Nadel vom Träger abhebt oder abstreift. - Die Sporenmasse wird also von der Sporenhülle ganz umschlossen; oben ist die schwarze Membran koppenartig aufgesetzt und das ganze Sporangium ist nun mit der Columella durch keine Membran verbunden, sondern sitzt derselben nur auf. Diese ragt in die Sporenmasse hinein und haftet mehr oder minder stark mit derselben zusammen. - Die Sporenhülle quillt in ihrem unteren Theil im Wasser auf, was schon dann sichtbar wird, wenn die schwarze Membran noch an dem Träger befestigt ist (20 XXIV), wo dann nach längerem Liegen im Wasser die Sporenmasse von derselben sich zurückzieht; der Raum zwischen der Sporenmasse und der schwarzen Membran wird nun von der aufgequollenen Sporenhülle eingenommon, welche sich oft stellenweise von der letzteren als zarte Linie ablöst (bei a 20 XXIV) und selbst da wo sie der Columella aufliegt als zarte Linie erscheint (b 20 XXIV). Die Sporen liegen der innern Fläche der Sporenhülle dicht an und erscheinen von cem innern Contour derselben in einer zarten Linie begrenzt. Die Sporenhülle quillt nur in ibrer unteren Partie auf, gar nicht aber in ihrer oberen, was sich auch schon früher deutlich beobachten lässt bevor noch die SporangiumMembran vom Träger abgerissen ist. So besonders bei einem sonst ganz normal entwickelten Pilobolus, dessen Sporangium. Membran aber sich gar nicht schwarz färbte; man sieht hier, wie Fig. 16 und 18 Taf. XXIV zeigen, dass im untern Theil des Sporangiums, dessen farbloge aber fein warzige Membran noch an den Träger befestigt ist, die Sporen von derselben abstehen, wäbrend sie im oberen Theil derselben eng anliegen.

Durch wasserentziebende Mittel wird die Sporenhülle unmerklich zusammengezogen, so z. B. durch alkoholische Jodlösung, dabei färbt sie sich zugleich schwach gelblich.

Den eben beschriebenen Bau des Sporangiums hat Coemans nicht richtig erkannt (a. a. O. p. 23), indem er noch eine "membrane 
médiane annimmt, welche farblos sein und die schwarze Membran an die Columella befestigen soll. Ich finde dieselbe nicht und wie gesagt ist das Sporangium in seiner Ausbildung durch keine Membran an die Columella befestigt, sondern sitzt derselben meist nur ziemlich fest auf. Es gelingt aber auch gar nicht selten in dem Stadium kurz vor dem Abschleudern des Sporangiums, dasselbe mit einer Nadel so abzuheben, dass es nicht nur ganz geschlossen bleibt, sondern auch der Träger mit der Columella ganz unversehrt stehen bleibt; ich habe es Dutzend Male mit dem gleichen Erfolg ausgeführt und niemals blieb an der Columella stwa eine abgerissene Mcmbran, wie es der Fall sein müsste, wenn die "membrane médiane" ron Coemans existiren würde. Er scheint den äusscren Contour der aufgequollenen Sporenhülle, welcher sich oft eng an die schwarze Membran anlegt, für seine „membrane médiane gehalten zu haben, den innern Contour aber für die Sporenhülle, weil or ron der letzteren sagt, dass sie als feines Häutchen dic Sporen eng umgiebt. Es ist aber leicht sich zu überzengen, dass hier die schwarze Menbran durch keine andere Membran an dic Columella befestigt ist, da man das Abreissen derselben von der Stelle, wo sie an den Träger ursprünglich befestigt ist, deutlich unter dem Mikroskop sehen kann, und ebenso siebt man dann, dass die Sporenhülle in ihrem untern Theil aus einer homogenen, ziemlich breiten, aufgequollenen Membran besteht, welche mit ihrem inneren Contour den Sporen eng anliegt und deren äușerer Contour nach oben zu unter der schwarzen Membran sich fortsetzt; wo sich dic Sporenhïlle zugleich verschmälert (22b XXIV).

\section{Das Abschleudern des Sporangiums.}

Mit den zuletzt beschriebenen Veränderungen erreicht der Fruchtträger des Pilobolus seine vollständige Ausbildung: der 'Träger, mit sciner blasenförmigen, prall mit Flüssigkeit erfüllten Anschwellung, endigt oben in der kegelförmigen Columella, auf derselien sitzt die Sporenmasse, umschlossen von der Sporenhülle und oben von der schwarzen Sporangium-Membran kappenartig bedeckt. - Jetzt erfolgt das bei Pilobolus längst bekannte Fortschlcudern des Sporangiums ${ }^{1}$ ). Es wird näılich von Mycelium und Anlage immer noch Wasser aufgenommen und in den Frucht-

1) Vergl. Coemans a. a. O. p. 38 ff. und de Bary, Morph. und Physiol.d. Pilze etc, p. 146. 
träger gepresst, welcher unter demselben Einfluss sich bisher oben blasenförmig ausgedehnt hat. Nun aber hört das Wachsthum und dio Ausdehnung des Trägers auf, seine Membran kann dem immer steigenden Drucke, welchen das aufgenommene Wasser auf sie ausübt, nicht lange Widerstand leisten, sondern reisst, und die Columella mit dem aufsitzenden Sporangium werden durch die gleichzeitig damit aus dem Träger hervorspritzende Flüssigkeit fortgeschleudert. Der Riss in dem Träger ist glatt und ringförmig, er erfolgt immer an der Stelle, wo die Columella an denselben befestigt ist oder wo frübcr die schwarze Membran sich von der Membran des Trägers getrennt hatte. Diese Stelle ist daher gleich nach dem Abreissen der Sporangium-Membran von dem Träger, als scharfe Linie sichtbar und entspricht der Rissstelle bei den Ascis der Discomyceten (21a XXIV). Lässt man das Fortschleudern des Sporangiums unter Deckglas vor sich gehen, wie ich es ofter beobachtet, so wird dasselbe theils unter demselben hervorgeschleudert, meist aber bleibt es unter demselben in einiger Entfernung von dem geplatzten Träger liegen. Man findet dann in dem Raum zwischen beiden verschiedene festc Inhaltstheile des Trägers ausgestreut, besonders in der Nähe des Sporangiums und das beweist, dass beim Durchreissen des Trägers derselbe sich, da er vorher gespannt war, contrahirt und so einen Strahl von Inhaltsflüssigkeit herausspritzt, welcher die festen Inhaltstheile mitreisst.

Mit dem Fortschleudern des Sporangiums fällt der Träger gewöhnlich zusammen, manchmal aber bleibt er stehen und aus seiner Oeffnung quillt ein Tropfen Inhaltsflüssigkeit heraus. In dernselben iieht man dann oft verschiedene Inhaltstheile aus dem Träger eine drehende Bewegung ausführen. Diese erfolgt bei horizontal stehendem Träger senkrrecht auf die Längsrichtung derselben und ist von der Verdunstung abhängig. Denn lässt man einen Träger, an welchem diese Erscheinung zu sehen ist, offen auf einem Objectträger unter den Mikroskop liegen, so ist die Bewegung sichtbar, deckt man aber ein Uhrglas darauf, so hört sie momentan auf um beim Wegnehmen desselben sogleich wieder zu beginnen und das kann man mit demselben Erfolge öfter wiederholen. Manchmal reisst die Inhaltsanhäufung des Wandbeleges, welche sich im oberen Theil des Trägers befindet, von dem übrigen Wandbeleg ab und rotirt als rother Ring in dem Wassertropfen. Anfangs ziemlich schnell, dann etwas langsamer, um später noch- 
mals schneller zu rotiren, bis die Bewegung ganz aufhört. Der Tropfen bleibt ziemlich lange sichtbar, oft über eine Stunde, wird aber immer kleiner, indem das durch Mycelium und Anlage aufgenommene Wasser nicht hinreicht, um den Verlust durch Ver- dunstung zu decken, bis der Träger auch zusammensinkt.

Das Fortschleudern der Sporangien bei Pilobolus hat schon Tode fast richtig crkannt; es findet sich ausführlich beschrieben bei (oemans ${ }^{1}$ ) und hat dann de Bary ${ }^{\bar{T}}$ ) gezeigt, dass dieser Vorgang mit der Ejaculation der Sporen bei den Discomyceten analog ist; Hofmeister ${ }^{3}$ ) aber und nach ihn Sachs ${ }^{4}$ ) orwähnen nur die unrichtige Ansicht Cohn's und scheinen die Arbeit von Coemans nicht gekannt zu haben. Nach Coln soll das Fortschleudern der Sporangien dadurch geschehen, dass sich die Columella ins Sporangium hineinwölbt und dadurch einen Druck auf Sporen und Sporangium-Membran ausübt; in Folge dessen reisst die letztere an ihrem Grunde ab und damit soll zugleich das ganze Sporangium fortgeschleudert werden. Dic Sporangium-Membran reisst nun wirklich, wie ich gezeigt habe, von dem Träger ab, aber ohne dass dabei das Sporangium fortgeschleudert werden würde. Ja in den Fällen, wo sich, wie oben erwähnt, das Sporangium ganz leicht von der unversehrten Tragzelle abheben lässt, ohne sich dabei zu öffnen, musste es also nur ganz schwach der Columella angeheftet und die Sporangium-Membran sich bereits vou dem Träger abgetrennt haben, aber es wurde dennoch nicht fortgeschleudert. Später aber erfolgte jedesmal das Durchreissen des Trägers, so dass dann die Columella allein von demselben fortgeschleudert wurde, wie es sonst gewöhnlich mit dem ihr aufsitzenden Sporangium geschicht und dass die Columella somit, selbst wenn das Sporangium sich nicht mehr auf ihr befindet, nicht an dem Träger bleibt, wie es Cohn meinte. - Ja es kann selbst stattfinden, dass das Sporangium abgeschleudert wird, ohne dass die Columella mit geht, also ohne dass der Träger durchreisst. So habe ich es unter dem Mikroskop beobachtet. Der PilobolusFruchtträger befand sich natürlich im Wasser unter Deckglas und die Sporangium-Membran war nocb an den Träger befestigt. Das Abwerfen geschicht nun in diesem Fall durch das Aufquellen der

1) a. a. 0. p. 38 .

2) Morpb. u. Physiol. d. Pilze etc. p. 146.

3) Pflanzenzelle p. 290 u. Flora 1862.

4) Physiologie p. 503 . 
Sporenhülle. Der untere Theil derselben muss natürlich durch Berührung mit Wasser aufquellen; dadurch wird ein Druck ausgeübt, sowohl auf die Columella, als auch auf die Sporangien. Membran. An der ersteren wird er aufgehoben, da sie durch die Zellflüssigkeit des Träger's unter einem noch stärkeren Druck sich befindet; in Folge des Druckes auf die Sporangium-Membran aber wird dieselbe nicht nur von dem Träger abreissen ${ }^{1}$ ), sondern wenn das Sporangium der Columella nicht zu fest anhaftet wird dasselbe dabei - zumal wenn das Aufquellen plötzlich geschieht selbst auf eine kleine Strecke fortgeschleudert. Dieser Fall wird auch in der Luft eintreten, wenn der Träger dicht unter dem Sporangium - dasselbe scheidet im ausgebildeten Zustand keine Wassertröpfchen aus - Wassertröpfchen ausscheidet, durch welche die Sporenhülle zur Aufquellung gebracht wird, und so findet man auch zeitweise auf dem Pferdemist Träger ohne Sporangium noch durch die Columella geschlossen. - Es kann aber auch eintreten, dass die Sporangien, welche zu dieser Zeit der Columella oft nur schwach anhaften, vom Beobachter unbewusst abgestreift werden, oder dass sie selbst von einem andern vorbeifliegenden und anschlagenden Sporangium abgerissen werden und dass so der Träger mit der Columella unversehrt zurückbleibt. Ich habe vielmal absichtlich die Sporangien von den Trägern abgestreift und dann jedesmal gefunden, dass später die Columella allein fortgeschleudert wird. In gewöhnlicher Weise aber erfolgt, wie oben gesagt, das Abschleudern der Sporangien in Folge des Durchreissens des Trägers, wobei Janu stets die Columella mit dem Sporangium mitgeht und demselben anbaftet. -

Nach dem Abschleudern bleibt das Sporangium geschlossen und sieht dann ähnlich aus, wie kurz vorher als es noch auf der Columella und mit derselben dem Träger aufsass: die Sporen wer-

1) Im normalen Verlauf der Entwickelung, nämlich in der Luft, wird aber, wio früher gesagt, das Abreissen der Sporaugium-Mlembran durch das Empordrängen der Columella bewirkt und nicht durch das Aufquellen der Sporenbülle, diese ist vielmehr, in der Luft betrachtet, ganz dünn und nicht aufgequollen. Die Columella muss daher eine eigene Beschaffenheit haben, da sie eben kein Wasser ins Sporangium difundiren lässt, und es ist dies um so auffallender, nicht nur da die Columella in nichts sich von der übrigen Membran des Trügers unterscheidet, ja vielmehr noch etwas dünner als diese ist, sondern auch weil bei Pilobolus das Wasser ziemlich stark in den Träger gepresst wird, und somit anch auf die Columella einen Druck äussert. Während aber die Membran des Trägers einen Theil des Wassers in Tropfen ausscheidet, lässt die Columella dasselbe nicht durch, weshalb auch am ausgebildeten Sporangium keine Tropfen $z u$ finden sind. - 
den ringsum von der Sporenhülle umgeben, welche in ihrem unteren Theil aufgequollen erscheint (22a und 22b XXIV). Bei Fig. 22a ist sie stark aufgequollen und ihr äusserer Contour setzt sich unmittelbar an die Sporangium-Membran - welche hier farblos ist an; dagegen ist bei $22 \mathrm{~b}$ die Sporangium-Membran etwas abstehend und hier sicht man die Sporenhülle nach oben unter der Sporangium-Membran immer schmäler werden. Oben sitzt der Sporenmasse die Sporangium-Membran auf und an ihrer unteren Fläche ist in der Mitte die Columella eingesenkt; sie wird beim Zerdrücken des Sporangiums leicht gefunden und ist bei ınittlerer Einstellung (22a XXIV) als lichtere Stelle in der Sporenmasse zu erkennen, auch sicht man zugleich die Sporenhülle als zarte Linie an dieser Stelle sich hineinziehen. Aus dem geschlossenen Sporangium werden dann die Sporen erst durch Aufösung der Sporenhülle frei, was bei der gallertartigen Beschaffenheit derselben in Feuchten leicht geschieht, während die Sporaugium-Membran und die Columella noch lange erhalten bleiben. -

Das Fortschleudern der Sporangien geschicht mit ziemlicher Gewalt und sie gelangen dadurch in rerhältnissmässig bedeutende Höhen, so nach Coemans bis über ein Meter. In dem Moment, wenn der Träger durchreisst und so das Sporangium fortgeschleudert wird, hört man ein schwaches knisterndes Geräusch und fängt man das Sporangium an einem Glase auf, indem man etwa das Substrat mit dem Pilobolus mit einer Glasglocke überdeckt, so hört man jedesmal einen feinen Tun, so oft ein Sporangium an das Glas anschlägt. Dabei bleibt das Sporangium meist an dem Glase baften und zeigt die schon von Coemans erwähnte Erscheinung, dass es gewöhnlich seinen ursprünglich unteren Theil dem Glase zukehrt und zwar selbst wenn es in verschiedenen Höhen aufgefangen wird. Diese Erscheinung erklärt sich, wie mir scheint, einfach aus der Beschaffenheit des Sporangiums. Die schwarze Sporangium-Membran verhält sich nämlich wie eine $\mathrm{Cu}$ ticula, sie ist glatt und nicht leicht oder gar nicht mit Wasser benetzbar, und hat man ein abgeschleudertes, geschlossenes Sporangium in einem Wassertropfen auf dem Objektglas und zwar so dass es seine untere Scite dem Glase zukehrt, so ist es schwor das Sporangium umzudrehen; nicht nur weil es in seinem oberen Theil kugelig ist, sondern weil die schwarze Membran sich nicht benetzen lässt und somit klappt es immer in seine frühere Lage zurück, wenn man es umzudrehen versuclit. Schlägt nun das 
Sporangium mit seiner oberen Seite an das Glas, so bleibt es entweder gar nicht daran haften, sondern fällt wieder hinab, oder wenn es in etwa am Glase vorhandene Feuchtigkeit gelangt, kann es sich vielleicht darin so umwenden, dass es mit seiner unteren Partie, wo die gallertartige Sprenghülle unter der SporangiumMembran hervorkommt, das Glas berührt und so an dasselbe befestigt wird. Gelangt nun aber das Sporangium gleich anfangs mit seiner unteren Fläche ans Glas, so bleibt es gleich haften, vermöge der gallertartigen Beschaffenheit der Sporenhülle, welche unten noch zugleich durch die beim Fortschleudern aus der Trag. zelle hervorspritzenden Zellfüssigkeit befeuchtet ist. Zugleich schlägt das Sporangium mit ziemlicher Gewalt ans Glas, was die Befestigung noch inniger macht und wenn dann nachträglich die Sporenhülle eintrocknet, so ist das Sporangium ziemlich stark am Glase befestigt und kann ohne Verletzung nicht leicht davon losgemacht werden. Es wäre noch möglich, dass indem das Durchreissen des T'rägers einseitig beginnt, dem Sporangium dadurch neben der fortschreitenden Bewegung auch noch ein Anstoss zur rotirenden ertheilt würde, und so für gewisse Entfernungen die grössere Möglichkeit gegeben wäre, dass die Sporangien mit ihrer unteren Fläche an das Glas gelangen; immerhin finden wir sie aber nur deshalb meist mit ihrer untern Fläche dem Glase anhaften, weil diese durch ihre gallertartige Beschaffenheit das leichtere Anhaften ermöglicht In freier Natur werden die Sporangien ähnlich, wie hier aı Glase, an anủere Gcyenstände haften bleiben an die sie ebeu anschlagen, oder sie fall:n einfach zu Boden, wo sie wahrscheinlich auch mit der unturn jeite auflegen und hier wird dann die gallertartige Sporenhülle noch dazu dienen möglich viel Wasser aufzunehmen und so die Keimung der Sporen zu befördern.

Die gallertartige Beschaffenheit der Sporenhülle wäre somit auch eine von den zweckmässigen Einrichtungen im Pflanzenreich ${ }^{1}$ );

1) Man könnte auch das Fehlen der Querwände im grössten Theil des Myceliums und die strömende Bewegung des Inhaltes, als zweckmässig für die schnelle Entwickelung des Pilobolus betrachten. Ebenso die Bildung einer Fruchtträger-Anlage, ja diese erscheint, eben wegen der obigen Eigenthümlichkeiten des Myceliums als notbwendig; es muss sich iler mit Inhalt erfüllte Mycelinu-Ast durch eine Scheidewand, als Anlage, von dem übrigen Mycelium trennen, damit der angehäufte Inhalt nicht wieder fortgeführt werden kaun, falls sich an einem andern Orte des Myceliums ein grösserer Stoffverbrauch kundgeben sollte. Ein Analogon finden wir dafür, wie mir scheint, darin dass bei den übrigen Mucornen mit oder vor der Fruchtbildung Querwănde in dem bis dahin derselben entbehrenden Mycelium auftreten. 
und zwar ist es hier um so auffallender, dass die Sporenhülle diese aufquellbare Beschaffenheit nur in ibrer äusseren Partie zeigt, während der Theil unter der Sporangium-Membran dieselbe nicht zeigt. Das Haftenbleiben der Sporangien kann aber zweckmässig sein, weil dadurch vielleicht rlie Sporen an Orten bleiben, wo sie ihre weitere Entwickelung durchmachen können und nicht leicht ron dnrt wieder fortgeführt werden. Wie denn überhaupt das Fortschleudern der Sporangien, wie mir scheint, nicht blos deshalb geschieht, um dieselben von dem Träger zu befreien, denn wir haben gesehen, dass sie vor dem Abschleudern der Columella nur aufsitzen und sich von derselben oft trennen lassen, sondern es geschieht vielmehr um die Sporangien von dem Pferdemist, der sie erzeugt hat, wieder auf frischen gelangen zu lassen, da die Sporen auf demselben leicht keimen, was auf dem alten Substrate gar nicht oder weniger leicht erfolgt. Die Sporangien fallen aber auch deshalb schon weniger leicht auf dasselbe Substrat, weil sie bei der heliotrophischen Krümmung des Trägers meist nicht senkrecht in die Höhe, sondern in einen mehr oder minder grossen Bogen fortgeschleudert werden, und so in einen ziemlich weiten Umkreis ausgestreut werden. Gelangen die Sporen dabei auf frischen Pferdemist, so keimen sie bald wieder; aber es wäre mög. lich, dass sie selbst auf ein anderes Substrat kommen und auf demselben eine Entwickelung durchmachen, welche sich vielleicht mit der im Pferdemist zu einem Generationswechsel zusammenschliesst. -

Ich habe nun die Entwickelung des Pilobolus geschildert wio sie in normaler Weise gewöhnlich ror sich geht und wenn ich sie noch einmal kurz zusammenfasse so ergiebt sich folgendes: der Pilobolus erscheint spontan auf Pferdemist; sein Mycelium ist in demselben ausgebreitet und besteht aus rerzweigten Schläuchen, deren grösster Theil unter einander frei communicirt, indem die Querwände fehlen. Der Inllalt zeigt eine ziemlich lebhafte strömende Bewegung. Indem nun das Mycelium sich immer mehr ausbreitet, gelangen dabei gewisse Aeste näher an die Oberfläche des Substrates. In denselben wird damit eine stärkere Verdunstung cingeleitet und dadurch der Anstoss gegeben, dass die strömende Bewegung des Mycelium-Inhaltes vorwiegend nach dieser Stelle sich richtet Dahin strömt so aus allen benachbarten, communicirenden Theilen des Myceliums der Inhalt und sammelt sich bier immer mehr an. Der betreffende 1st debnt sie dabei immer mehr 
aus und bildet sich zuletzt, wens er dicht mit Inhalt erfüllt ist zur Fruchtträger-Anlage aus, indem er sich vom übrigen Mycelium durch eine Querwand absondert. Die Bildung der FruchtträgerAnlagen erfolgt gewöhulich im Laufe des Vormittags. Nachmittags zwischen 3 und $4 \mathrm{Uhr}$ sieht man dann aus dem Substrate eine Menge kle̊iner, gelber Spitzen herrorragen. Es beginnen nämlich die Fruchtträger-Anlagen Schläuche zu treiben, die später sich $z u$ den Fruchtträgern ausbilden. Der in der Anlage angehäufte Inhalt wandert nach oben und zwar in oft deutliche sichtbaren Strömchen, wo or zur Bildung des Sporangiums verwendet wird. Dasselbe wird am Abend angelegt, trennt sich später durch eine Scheidewand vom Träger und bildet sich während der Nacht weiter aus, indem sich seine Membran schwarz färbt und sich die Sporen in demselben bilden ${ }^{1}$ ). Damit zugleich bildet sich die blasenförmige Anschwellung des Trägers und am nächsten Morgen erscheint der Pferdemist bedeckt von den schimmernden Pilobolusfruchtträgern, welche fast ihre vollständige Ausbildung erreicht haben. Der 'Träger hat sein Wachsthum beendet; er zeigt neben einem ruhenden Wandbeleg an demselbeu Plasmafäden mit strömender Bewegung, die nun als Circulation auftritt und in Innern eine klare Inhaltsflüssigkeit. Dieselbe wird durch das von Mycelium und Anlage aufgenommene Wasser immer vermehrt und übt einen Druck auf die Membran des Trägers, welche dadurch gespannt wird. Zugleich wird damit die Columella immer mehr ins Sporangium gedrückt und die Membran desselben reisst in Folge dessen vom Träger ringsum glatt ab und bedeckt so kappenartig die auf der Columelle sitzende, von der Sporenhülle ganz umschlosseno Sporenmasse. Zwischen 8 und 10 Uhr Morgews wird der Druck der Zellfüssigkeit im Träger auf die Membran desselben so gross, dass sie endlich an der Stelle, wo sie mit der Columella zusammenhängt, ringförmig durchreisst und indem sich dabei der gespannt

1) Die Sporenbildung fällt hier gewöhnlich in die Nacht und Sachs (Physiologie p. 31) führt das als eineu Fall an, wo Neubildung im Dunkeln vor sich geht; es ist hier noch zu bemerken, dass wenn ausnahmsweise am Tage sicb Sporangien bilden, hier das Schwarzwerden der Sporangien-Membran an früheren Stadien erfolgt, als sonst. Sobald nämlich das Sporangium angelegt ist, wird es schwarz, es bilden sich die Sporen, während die Anschwellung des Trägers erst nachträglich entsteht. Worden die Sporangien am Abend angelegt, so beginnt die Bildung der Trägeranschwellung etwas früher als das Schwarzwerden der Sporangium-Membran, ja letztere kann selbst farblos bleiben, wie ich es beobachtete, aber die Sporen werden in der Nacht gebildet und sah ich die Fruchtträger mit farbloser SporangiumMembran nie am Tage entstehen. - 
gewesene Träger coutrahirt spritzt aus demselben ein Theil der Inhaltsflüssigkeit heraus und wird dadurch das Sporangium fortgeschleudert.

Die ganze Entwickelung des Pilobolus-Fruchtträgers wird also in einem Tage (24 Stunden) beendigt und die Aufeinanderfolge der Erscheinungen wiederholt sich dabei täglich (ungefähr $\mathrm{zwei}$ Wochen hindurch) oft mit der grössten Regelmässigkeit. Eine Störung tritt ein, wenn man den Pilobolus im Dunkeln cultivirt, wo die Entwickelung langsamer durchlaufen und besonders das Abschleudern der Sporangien verzögert wird'), oder bei üppiger Ernährung, wo dann oft alle Stadien zur selben Zeit sich vorfinden.

Dieses täglich sich wiederholende Erscheinen der Fruchtträger bei Pilobolus hängt auch mit den Eigenthümlichkciten des Myceliums zusammen. Denken wir uns 2. B. ein Mycelium, das bereits so weit ausgebildet ist, dass es Fruchtträger-Anlagen erzeugen kann, so wird beim Anstoss zur Bildung der Anlagen der meiste Inhalt aus dem Mycelium in dieselbe wandern und wenn diese sich durch eine Querwand vom Mycelium getrennt hat, enthält dasselbe meist nicht mehr so viel Inhalt um sogleich die Bildung einer zweiten Anlage zu ermöglichen. Während nuu die gebildete Anlage zum Fruchtträger auswächst, wird vom Mycelium wieder neuer Inhalt erzeugt, welcher sich nun wieder zur Bildung einer Anlage ansammeln kann, und diese ist dann gewöhlich schon fertig, wenn die erste bereits einen ausgebildeten Fruchtträger entwickelt und derselbe das Sporangium schon abgeschlendert hat (3 XXIII). Bei üppiger Ernährung aber und zumal bei grösserer Ausbreitıng des Myceliums - welches, da die Anlagen hier am Ende der Aeste entstehen, durch die querwandlosen Hauptäste auf weite strecken zusammenhängt und daher aus einer grossen Umgebung Nahrung erhält, welcher leicht nach bestimmten Punkten geschafft werden kann - ist es möglich, dass gleich nach Bildung der ersten Anlage eine zweite sich bilde, da genügender Inhalt dazu vorhanden ist und so finden wir denn verschiedene Entwickelungsstadien zu gleicher Zeit beisammen. -

\section{Chemische Reactionen.}

Nachträglich will ich noch einige chemische Reactionen mittheilen und zwar zuerst an der Membran des Pilobolus. Diese ist

1) Coemans a. a. 0. p. 45. 
mit Ausnahme der feinsten Mycelium-Enden sonst überall doppelt contourirt und zeigt keine besonders bedeutende Verdickungen. Bei Behandlung mit Jod in einer Jodverbindung zeigt sie nun die für die Mucorinen charakteristische weinrothe Färbung. Ich benutzte Jod in Jodwasserstoff. Es ist hierbei auffallend, dass sich Verschiedenheiten insofern zeigen, als die Färbung oft nicht an allen Theilen der Membran gleichzeitig und gleich stark auftritt. So wird manchmal die Membran cles Fruchtträgers sogleich nach Zusatz obigen Reagens in ihrer ganzen Ausdehnung weinroth gefärbt; in anderen Fällen aber verhält es sich anders, obgleich das Reagens reichlich zugesetzt wurde. Es tritt nämlich zuerst eine schwache weinrothe Färbung auf und nur am Stiel des Trägers, während die übrigen Theile ganz ungefärbt oder gelblich erscheinen und erst nach längerem Liegen und Eintrocknen auch eine weinrothe Färbung zeigen oder diese tritt stellenweise gar nicht ein, so besonders an der Anschwellung des Trägers. Färbt sich die Membran gleich nach Zusatz des Reagens weinroth, so wird nach längerem Liegen und Eintrocknen diese Färbung oft sehr intensir und zwar nicht blos an der Membran des Fruchtträgers, sondern auch der Anlage und aller Mycelium-Schläuche; aber am Stiel des Fruchtträgers beginnt die Färbung stets zuerst.

Die schwarze Sporangium-Membran wird durch concentrirte Salpetersäure rothbraun und später schmutzig gelb; ebenso wird sie durch Schwefelsäure kirschbraun und später schmutzig gelb. braun. Sie quillt dabei nicht auf; die Membran des Trägers nur unbedeutend, während die Membran der Fruchtträger-Anlage und der Mycelium-Schläuche bedeutend aufquillt. Keine der Membranen aber wurrie durch concentrirte Schwefelsäure aufgelöst, nur bei der Sporenhülle tritt es ein.

Der Inhalt des Pilobolus zeigt mit Schwefelsäure ganz eigenthümliche Reactionen. Wird eine Fruchtträger-Anlage, die ganz mit Inhalt erfüllt ist und deshalb dunkel gelbbraun erscheint, mit Schwefelsäure behandelt, so wird sie alsbald glänzend gelb. Es scheiden sich nämlich aus dem Inhalte gelbe, glänzende, ölartige Tropfen aus und diese häufen sich in der Mitte zusammen; rund herum bleibt ein dünnerer Wandbeleg von Plasma, welcher durch Schwefelsäure rosenroth wird. Die innere, gelbe Masse macht folgende Farbenwandlungen durch: sie wird lichter gelb, dann grünlich, bläulich und zuletzt entfärbt. Auf Zusatz von Schwefelsäure platzt gewöhnlich die Anlage - nachdeın zuror die gelben 
Tropfen sich im Innern ausgeschieden haben und der Wandbeleg rosenroth wurde - und damit tritt der Inhalt heraus. Das rosenroth gefärbte Plasma behält dabei längere Zeit scine Färbung, die gelben Oeltropfen aber werden grünlich, dann blau und zuletzt entfärbt; die grünliche und blaue Farbe tritt oft in grossen Tropfen nur in einzelnen Flecken auf. Diese Farbenwandlungen erfolgen aber nicht immer gleich und nicht bei allen Tropfen gleichreitig; man findet oft gelbe, grüne, blaue, farblose und selbst rosenrothe Tropfen gleichzeitig in demselben Objekt beisammen; nach längerem Liegen wird alles entfärbt.

Der Inhalt der Mycelium-Schläuche sowie der obconischen Erweiterung derselben, auf der die Anlage sitzt, wird durcb Schwefelsäure meist schön rosenroth gefärbt. Es ist das Plasma, welches diese Färbung zeigt und es fragt sich nur ron welchem Stoff diese Färbung herrührt: ist es Cholosterin, wie Coemans meint, oder wäre es möglich, dass diese Färbung die Gegenwart ron Zuckel anzeigt, der mit Schwefelsäure das Plasma rosenroth färbt (siehe weiter unten).

Die rothe Inhalts-Anbäufung im Träger wird durch concentrirte Schwefelsäure erst orangegelb, dann grünlich und zulctzt blan, aher noch später farblos. Dabei treten keine ölartigen Tropfen aus dem Plasma; der farblose Wandbeleg wird hier auch blass rosaroth. - In den gelben Sporen wird durch Schwefelsäure der gelbe Farbstoff in Tropfen ausgeschieden und das Plasma erscheint farblos, wird aber später rosaroth, während die gelben T'ropfen durch grünlich ins bläuliche übergehen; zuletzt ist wieder Alles farblos. - Bemerkenswerth ist noch dass die Reactionen mit Schwefelsäure nicht immer in gleicher Weise vor sich gehen.

Jod in Jodwasserstoff färbt den gelbbraunen Inhalt der Frucht. träger-Anlage erst grünlich, dann aber dunkel rothbraun; wie die letztere Färbung auch bei den Mucorinen eintritt. Wenn aber Coemans sagt, dass del Inhalt durch Chlorzinkjod - das ja mit obigem Reagens gleich wirkt - nur grünlich wird und im Innern gelb bleibt, so hat er entweder zu wenig von dem Reagens zugesetzt oder es nicht lange genug wirken lassen. Die Sporen werden durch obiges Reagens auch erst grüulich und dann rothbraun gefärbt, während die Sporenhülle schwach gelb wird. Salpetersäure entfärbt die Sporen und den rothen Inhalt des Trägers, letzteres geschieht auch bei längerem Liegen in Wasser. Gelangen die gelben Sporen durch Zerreissen der Columella in den unver- 
sehrten Träger, so werden sie darin auch farblos; der Inhalt ist also sauer wie es auch die Wassertröpfehen sind, welche vom Träger ausgeschieden werden.--

\section{Geformte Inhaltskörper.}

Im Inhalte dos Trägers finden sich ausser dem formlosen Plasma mit dem ihm eingelagerten kleinen Körnchen noch zweierlei Stoffe, die in bestimmten Formen auftreten.

a. Krystalloïde. In den Trägern des Pilobolus findet man gewöhnlich farblose, mattglänzende, krystallähnliche Körper. Sie sehen Octaëdern oder quadratischen Pyramiden ähnlich, zeigen aber nicht immer ganz ebene Kanten und so viel sich nach blossem Ansehen sagen lässt auch nicht immer gleiche. Winkel. Sie sind meist sehr klein und uur selten erreichen einzelne eine Grösse, wie sie die Fig. 23 XXIV bej 455 facher Vergrösserung zeigt. Nicht in jedem Träger kommen sie in gleicher Anzahl vor, oft sind sie aber sehr zahlreich vorhanden, so dass es auffallend ist, dass sie bis jetzt noch von Niemanden beobachtet wurden. Meistens finden sic sich in der Fruchtträger-Anlage und im Stiel des Trägers, aber auch in der Anschwellung desselben. Einzeln kommen sie schon in der noch nicht ausgewachsenen Anlage ror, ebenso im jungen, besonders zahlreich aber im ausgebildeten Fruchtträger. Ueber ihre krystallographischen Verhältnisse lässt sich bei ihrer Kleinheit nichts sagen und ebenso hatte ich nicht Gelegenheit die Wirkung auf polarisirtes Licht zu untersuchen. Wenn ich sie aber Krystallö̈de nenne, so bestimmten mich dazu die Erscheinungen, welche sie unter Einwirkung gewisser chemischer Reagentien zeigen. Und zwar: in Kali werden sie gelöst; alkoholische Jodlösung färbt sie gelb bis braun und dabei schrumpfen sie beträchtlich zusammen, sie sind also imbibitionsfähig; Schwefelsäure allein färbt sie rosaroth, oft besonders deutlich, wenn sie noch im Zellinhalt sich befinden aber auch ausserhalb desselben, wo sie sich dann im ausgespritzten also diluirten Inhalt befinden. Die Reaction von Jod spricht dafür, dass die Krystalloïde eiweissartige Verbindungen sind, ebenso dic Reaction mit Schwefelsäure, wenn man zugleich das Vorhandensein von Zucker im Zellinhalt annimmt. Wir haben gesehen, dass sich das Plasma des Pilobolus mit Schwefelsäure allein schön rosaroth färbt; entweder wirkt hier Zucker mit oder es giebt noch einen andern Stoff, welcher mit Schwefelsäure zusammen eiweissartige Stoffe rosaroth färbt oder aber die Krystal- 
loìde bestehen aus einem Stoff, welcher durch Schwelsäure allein rosaroth gefärbt wird und dieser ist auch dem Plasma eingelagert. Aus welchem Stoff sie aber auch bestehen mögen, so sind sie den bisher bekannten Krystalloïden doch analog, schon deshalb, weil sie durch alkoholische Jodlösung zusammenschrumpfeil und somit keine echten Krystalle sein können.

b. Oxalsaurer Kalk. Neben den Krystalloïden finden sich noch im Inhalt des Trägers Körper von oxalsaurem Kalk. Sie erscheinen theils als sehr kleine, an beiden Enden etwas keulige Stäbchen (24 XXIV); in anderen Fällen werdın sie grösser und an beiden Enden breiter; sie sehen dann wic gewisse Pilzhüte aus. Es können beide Enden oder nur das eine so erscheinen ( $27 \mathrm{XXV}$ ). Meist sind diesc Körper einzeln, aber es kommen auch Vereinigungen ron zwei bis mehr ror, theils sind sie aneinander gereiht (25f XXIV), oder es sind zwei solchor Körper kreuzförmig oder in anderer Weise rerbunden ( $26 \mathrm{XXY}$ und a, b, c $25 \mathrm{XXIV}$ ). Ein solcher Körper von der Form der Fig. e 25 XXIV erscheint ron oben ge. sehen wie 25d; er zeigt eine helle Mitte, welche dem Stiel entspricht und cinen dunkleren of ziemlich gezackten Rand, welcher der keuligen Erweiterung entspricht.

Diese Körper sind dunkel berandet, ron granlich-weisser Farbe, in der Mitte hell und glänzend. Sie werden durch Salzsäure lang. sam und obne Gasentwickelung aufgelöst, daher oxalsaurer Kalk. Die Lösung erfolgt von aussen nach innen und liegeu diese Körper dabei in der Zelle, wo sie meist dem Wandbeleg anhaften, so bleibt ihre Form erhalten, gleichsam wie im Plasma eingedrückt. Liegen sie frei, so bleibt jhr Unriss während der Auflösung auch als zarter Contour erhalten, verschwindet dann aber gänzlich. -

Diese Körper fand ich nicht in allen Fruchtträgern, in andern sind sie nur einzeln vorhanden, kommen manchmal aber auch zahlreicher vor und besonders, wie es scheint, wenn der Pilobolus im Junkeln cultivirt, also seine Entwickelung und seine Lebensthätigkeit verlängert wird. Пas stimmt auch gut mit Hilgers'1) Ausicht, dass die Oxalsäure ein „Entwickelungsprodukt des assimilirten Lebenssaftes" sei; denn je länger der Pilobolus-Fruchtträger lebensfähig bleibt - was im Dunkeln der Fall ist - desto mehr Nahrung nimmt er auf; diese wird, da der Fruchtträger im Dunkeln sich stark verlängert, zu Zellstoff und Plasma verwendet und

1) In Pringsheim's Jahrbücher, VI. p. 296 
dabei zugleich Oxalsäure gebildet, die mit dem überall vorhandenen Kalk sich zu oxalsaurem Kalk verbindet. - Ich fand diese Körper von oxalsauren Kalk meist nur in ausgebildeten Fruchtträger und in den Schläuchen, die zum Fruchtträger auswachsen besonders dann, wenn diese durch Verletzung ihrer Spitze in der Entwickelung verzögert wurden.

Cohn') meint vielleicht ähnliche Körper, wenn er sagt: nicht selten zeigen sich im Inhalı des Pilobolus säulenförmige Krystalle. Currey ${ }^{2}$ ) scheint sie auch beobachtet zu haben und ebenso auch Coemans, aber beide hielten sie sonderbarer Weise für unvollkommene Sporen.

Nach de Bary ${ }^{3}$ ) findet man oxalsauren Kalk bei Pilzen ziemlich häufig, aber er fand ihn nur bei zweien im Innern von Zellen. Obiger Fall wäre alsı ein drittes Beispiel und wenn der oxalsaure Kalk hier anch nicht in wirklichen Krystallen auftritt, so zeigt er doch ausgesprochene Formen.

Krystalloüde sind bei den Pilzen bis jetzt noch nicht gefunden worden und sind die oben besprochenen der einzige Fall dafür. -

\section{Ausnahmsweise Erscheinungen.}

Im Vorhergehenden habe ich die Erscheinungen bei der Entwickelung des Pilobolus so dargestellt, wie sic in normaler Weise als Regel vor sich gehen; es kommen nun ausserdem einige, ausnahmsweise auftretende Abweichungen ron dieser Regel vor und zwar an den verschiedenen Theilen des Pilobolus je in ibrer Art.

Wir laben früher gesehen, dass die sogenannten Hauptäste des Myceliums mit ihren Verzweigungen querwandlos sind. Ausnahmsweise können nun auch hier Wände auftreten und zwar theils in Folge von Verletzungen und Absterben eines Theils des Iuhaltes, dessen noch lebcnder Theil sich dann durch eine Querwand vom übrigen sondert, theils nach Zerreissung eines Hauptastes. Dabei tritt dann oft aus dem Inhalt ein grosser glänzender, ölartiger Tropfen heraus und verschliesst gleichsam die Oeffnung eines Schlauches. An dem Tropfen nach innen befindet sich eine Partie körigen Plasmas und weiter davon geht die Strömung des übrigen Inhaltes ganz ungestört und in normaler Weise vor sich. Bei solchen Abreissungen des Hauptastes kann es nun geschehen, dass

1) a. a. 0. p. 524 .

2) Citirt bei Coemans a. a. 0.p. 51.

3) Morph. u. Physiol. d. Pilze etc. p. 13. 
er sich durch eine Querwand nach aussen abschliesst. Diese ent. steht natürlich nicht dicht am abgerissenen Ende des Schlauches, sondern etwas nach Innen (b $28 \mathrm{XXV}$ ). Es kann dabei auch vorkommen, dass diese Querwand wieder nach aussen zu einem Mycelium-Schlauch auswächst wie es Fig. 28 bei a zeigt und hier hat sich zugleich die Membran bei a stark verdickt, wo ursprüng. lich die Querwand war; ebenso stülpt sich auch bei b die Querwand nach aussen und wäre vielleicht auch später ausgewachsen. Diese Querwände entstehen nur in kräftig regetirenden Schlauchen und lassen sich leicht, als nicht in normale Weise gebildet, erkennen, theils durch ihre Dicke und theils an ihrer Umgebung, indem nämlich von einer Seite ein abgestorbener Theil ihr angrenzen muss. -

Die Bildung der Fruchtträger-Anlage geht immer in normaler Weise vor sich und es kann höchstens eintreten, dass eine Anlage sich bereits zu bilden begonnen hat, aber nachträglich ihren Inhalt verliert, weil wahrscheinlich unterdessen an cinem andern Orte des Myceliums ein grösserer Stofferbrauch eingetreten ist, wohin nun vorwiegend der Inhalt strömt; so findet man dann angesehwollene Mycelium-Schläuche mit spärlichen, vacuolenreichen Inhalt. Gewöhnlich wächst diesclbe Anlage zu einem Fruchtträger aus, aber in manchen Fällen kann dieselbe Anlage zu zwei bis drei Fruchtträgern gleichzeitig oder nach einander auswachsen (29 XXV), wobei aber meist nicht jeder bis zur Sporangien-Bildung gelangt.

Wenn die Anlage in einen Schlauch, den werdenden Frucht. träger auswächst, so kann es vorkommen, dass diese verletzt wird und deshalb oder auch, bei unverletztem Zustand, ans einer andern Ursache nach der begonnenen Richtung nicht weiter wächst, sondern sich unten durch eine Scheidewand abgrenzt und die Anlage wächst dann gewöhnlich gleich daneben zu einem neuen Fruchtträger aus. Gewöhnlich befindet sich die Anlage der Oberfläche des Substrates so nahe, dass der zum Fruchtträger auswacbsende Schlauch gleich über dasselbe gelangen kann; wo dies aber nicht der Fall ist, wo also die Anlage tief im Miste steckt, wächst der Schlauch nicht etwa zu einem Mycelium aus, sondern dick und einfach dringt er durch das Substrat bis er über dasselbe gelangt und sich dort zum Fruchtträger entwickelt. In diesem Falle ist der Theil des Fruchtträger's der im Substrate sich befindet etwas anders als der oberirdische; er ist dicker und an der Stelle eingeschnürt und dünner werdend, wo er aus dem Substrate heraus- 
trat. Man kann diesen Fall auch absichtlich erzeugen. So brachte ich eine Anlage, welche bereits zu einem dicken, aber noch zugespitzten Schlauch ausgewachsen war (30 XXV), mit dem Miste in welchem sie lag derart ins Wasser, dass der Schlauch bis auf seine Spitze mit Wasser bedeckt war. Derselbe starb nicht ab, aber er wuchs auch nicht in der begonnenen Weise fort, sondern am nächsten Tage war aus ihm geworden, was Fig. 31 XXV darstellt. Er hatte also an seiner Spitze einen dünneren Fortsatz über das Wasser getrieben und verhielt sich gleichsam wie eine Fruchtträger-Anlage. Bis zum folgenden Tag hatte sich nun der Fortsatz zu einem vollständigen Fruchtträger mit Sporangium und ausgebildeten Sporen entwickelt wie es Fig. 32 XXV zeigt. Dieser Vorgang konnte hier vor sich gehen, weil das Schlauchende noch im Fortwachsen begriffen, noch hell und spitz war; ist dasselbe aber bereits abgerundet und zeigt es schon eine kleine Inhaltsanhäufung, so gelingt obiger Versuch nicht mehr.

Eine andere abweichende Erscheinung sehen wir an Fig. 33 XXV. Hier hat sich der Fruchtträger zu einer Schlinge zusammengedreht, was wahrscheinlich dadurch bervorgebracht wurde, dass der zum Fruchtträger auswachsende Schlauch durch Hindernisse im Substrat nicht unmittelbar nach oben wachsen konnte. -

In der Regel ist der Fruchtträger einfach, er kann aber in gewissen Fällen eine Verzweigung zeigen, welche jedoch nur bei gestörtem Verlauf der gewöhnlichen Entwickelungsweise eintritt. Ist nämlich die Anlage bereits zu einem Schlauch, den werdenden Fruchtträger ausgewachsen, so tritt es ein, dass wenn derselbe verletzt wird, er natürlich in der begonnenen Richtung nicht fortwächst. Es trennt sich vielmehr der verletzte Theil von dem unverletzten durch eine Wand $a b$ und der letztere wächst unter der Wand seitlich wieder aus und kann es selbst bis zur SporangienBildung bringen. So entsteht eine scheinbare Verzweigung, aber in diesen Fällen ist dann ein Ast immer abgestorben. So einen Fall zeigt Fig. $29 \mathrm{XXV}$; hier ist nicht nur dieselbe Anlage zu zwei Fruchtträgern $a$ und $b$ ausgewachsen, sondern $b$ wurde im oberen Theil verletzt, deshalb bildete sich bei o eine Wand und unter derselben wuchs wieder ein Fruchtträger d mit einem jungen Sporangium aus. So erscheint der ursprüngliche Fruchtträger $b$ oben verzweigt aber der Ast c ist abgestorben.

Etwas anders erscheint es, wenn der werdende Fruchtträger keine sichtliche Verletzung zeigt und doch aufgehört hat sich in 
begonnener Weise auszubilden. So rcigt Fig. 34 XXVI ein verzweigtes Pilobolus-Pfänzchen; der $\mathbf{A s t}$ a ist der frühere, er sah woch nicht abgestorben aus, hatte aber aufgehört sich weiter zu entwickeln. Dafür war aber au seinem unteren Theil ein Ast b ausgewachsen, der sich bis zum vollständigen Sporangium entwickelt hatte. An der Abzweigungsstelle war hier keine Scheidewand, der Ast b zeigte dort nur eine kleine Einschnürung, was cben dafür spricht, dass er erst nachträglich aus a herrorgewacbsen war. - Einen noch interessanteren Fall zeigt Fig. 35 XXV. Hier hatte der werdende Fruchtträger aufgehört sich an der Spitze a weiter zu entwickeln, unter derselben aber bildeten sich zwei Aeste, welche sich ganz gleich zu vollständigen Fruchtträgern ausbildeten.

Wie oben gesagt wurde färbt sich die Membran des Sporangiums mit dessen Entwickelung schwarz und der ausgebildete Fruchtträger trägt über einer wasserhellen Blase - wie die Anschwellung des Trägers dem blossen Auge erscheint - ein schwarzes Köpfchen. Ich fand eiuigemale sonst ganz normale PilobolusFruchtträger mit orangegelbon Köpfchen. Hier war nämlich die Sporangium-Membran gar nicht oder so schwach gefarbt, dass die Sporenmasse durch dieselbe hindurchlcuchtete und das ganze Köpfchen somit orangegelb erscheinen liess. Sonst war alles normal, die Sporangien wurden auch wie gewöhnlich abgeschleudert und blieben am Glase haften. Ihre Membran allein war farblos, dabei aber zeigte sie auch, wie die schwarzen Sporangium-Meıbranen, feine Wärzchen, welche sich als sehr kleine schwarze Punkte dem Auge darbieten und das bestätigt, was schon oben gesagt wurde, dass die schwarze Farbe der Sporangicn-Membran nicht durch dicse Pünktchen bedingt wird, denn sie..können vorhanden sein und die Membran dabei doch farblos erscheinen. - Wodurch dieses Farblosbleiben verursacht wurde, ist schwer zu sageu, zumal diese Fruchtträger mit farbloser Sporangium-Membran in einer Cultur erscheinen, in welcher seit einer Woche uur solche mit schwarzen Sporangien sich bildeten und nachher fanden sich cinige Tage hindurch zwischen den letzteren auch einzelne, wo die SporangienMembran farblos war und das Köpfchen des Fruchtträgers somit orangegelb erschien; später verschwanden diese wieder. Die Fig. 16, 18, 22 a und 22 b Taf. XXIV zeigen solche Sporangien und sicht man bei Fig. 16 und 18 durch die hier durchsichtige SporangienMembran, dass die Sporen derselben im oberen 'Theil eng anliegen, während sie, in Folge längeren Liegens im Wasser, im unteren 
von ihr abstehen, was von der Sporenhülle bewirkt wird, die blos in ihrem unteren Theil aufquellbar ist.

In einigen solcher Sporangien fand ich «wischen den Sporen, welche die für die betreffende Pilobolus-Form zukommende Gestalt zeigten, noch andere von ganz sonderbarer Gestalt, wie sie überhaupt bei Pilzen nicht vorkommen. Sie waren zugleich verhältnissıässig gross und während die meisten übrigen Sporen die Form und Grösse von Fig. 36a Taf. XXVI hatten, zeigten sie die verschiedensteu Formen, wareu mannigfaltig gelappt und ausgebuchtet, wie einige Fig. 36 zeigt, obgleich die Zahl der verschiedensten Formen noch bedeutend hätte vermehrt werden köunen. Dic Form dieser Sporen hängt wohl kaum nit der farblosen SporangiumMembran zusammen, deun man findet abweichend gestaltete, weun auch nicht so grosse Sporen selbst in Sporangien mit schwarzer Membran. Die Entstehung dieser Sporen ist wohl nur su zu betrachten, dass mehrere Sporen bei ihrer Anlegung theilweise oder gänzlich mit einander verschmolzen sind. Der Inhalt zeigte bei diesen Sporen viele lichte Flecken, während solche bei den normalen Sporen höchstens in der Zahl von 1-4 vorkounmen, was auch dafür spricht, dass hier mehrere Sporen verschmolzen sind. -

\section{Formen des Pilobolus.}

Indem ich zur speciellen Betrachtung der Pilobolus. Formen ubergehe, werde ich dabei zugleich noch manches zu erwähnen haben, was in der allgemeinen Entwickelung unbeachtet blieb, da es sich hier viel besser besprechen lässt: so die deu einzelnen Formen eigene Variation in der allgemeinen Entwickelung, dann die Form der einzelnen Theile und besonders die Sporen nach Inhalt und Form, sowie ihre Veränderungen, die sie sowohl im Sporangium als auch bei der Keimung durchmachen.

Von den fünf Arten, welche in der Gattung Pilobolus aufgestellt wurden, sind nach Coemans ${ }^{1}$ ) nur zwei als solche zu betrachten, nämlich $P$. crystallinus und $P$. oedipus. Die erstere stammt von J. Tode ${ }^{2}$ ), während die letztere von Montagne ) aufgestellt wurde und sich besonders durch die runden Sporen von der ersteren

1) 2. a. 0. p. 65 .

2) Schriften d. Naturf. Berlin. Gesellsch, V.

3) Mém. de la Soc. Lin. de Lyon 1828. 
unterscheidet, welche elipsoïdische Sporen besitzt. Ich habe beide Formen beobachtet und zwar auf demselben Substrat, nämlich Pfordemist, und kann zugleich sagen, dass beide Formen genetisch zusammenhängen. Ausserdem aber habe ich noch eine dritte Form auch auf Pferdemist gefunden, welche sich durch ganz charakteristische Merkmale auszeichnet und welche ich bei keiner der bis jetzt aufgestellten Pilobolus-Arten erwähnt finde. Ich babe diese Form in meiner kleinen Notiz in der Bot. Ztg. ') als Pilobolus microsporus bezeichnet und will auch hier diesen Namen beibehalten.

Das Mycelium zeigt mehr oder weniger bei allen F'ormen denselben Typus; unterscheidende Merkmale bietet die Bildung der Fruchtträger-Aulage, der Fruchtträger selbst das Sporangium und die Sporen.

Die erste Form, welche ich Gelegenheit hatte zu beobachten, erschien im November 1868 spontan auf l'ferdemist, welcher im Zimmer gehalten wurde. Dic Fruchtträger bedeckten in grosser Anzahl das Substrat; sie waren alle ron ganz gleichem Bau und variirten höchstens in der Grösse von 2-5 Mm, selten etwas grösser. Die fertigen Fruchtträger-Aulagen sassen auf nur einer obconischen Mycelium-Erweiterung und waren meist mit kurzen seitlichen Schläuchen besetzt(XXIII 3, XXIV 8). Sio wuchsen zu einem Fruchtträger aus, welcher immer einen deutlichen Sticl zeigte (XXV 34 b). Dieser war unten von der Anlage deutlich gesondert und ging oben allmählich in die blasenförmige Anschwellung über; an dieser Stelle war der Inhalt mehr oder weniger angebäuft, oft in Form eines rothen Querbandes (XXIV 17, 19), oder in einer nicht scharf begreuzten Zone, welche beiderseits allmählich in den dünueren Waudbeleg übergeht (XXVI 34b). Die Columella war hoch, breit und steil kegelförmig (XXVI 37). Das Sporangium erscheint, so lange die schwarze Membran noch an der Tragzelle befestigt ist, hoch, mehr als halbkugelig (XXIV 19, XXVI 34), später nach Abreissen derselben steht diese mehr oder minder stark ab und so erscheint das Sporangium in der Mitte etwas in die Breite gezogen, während unten zugleich die Sporen sichtbar werden (XXIV 17). Die Sporangium-Membran ist schwarz, besonders oben und gelit nach unten in einen verschieden breiten, lichteren Saum ganz allmählich über (XXIV 19, 20). Die Membran ist stets fein warzig (XXIV 18, 20, 22). Die Sporen waren

1) Bot. Zeitg. 1870, p. 386. 
in diesem Fall bei allen Exemplaren ziemlich gleich von elipsoïdischer Gestalt und zwar 0,0055-66 $\mathrm{Mm}$. breit und 0,011-15 $\mathrm{Mm}$ lang. Ihr Inhalt war gelb, fast homogen und verlieh den Sporen ein ölartiges, glänzendes Aussehen, zumal bei oberer Einstellung, wo die Sporen dunkel berandet erscheinen. Bei mittlerer Einstellung erscheint ihr Contour einfach nicht dunkel und die Membran der Sporen ist dünш, vom Inhalt nicht gesondert. Alle Sporen zeigten ausserdem in der Mitte einen lichten Flcck (XXVI 41).

Diese Form entspricht wohl der bis jetzt als P. crystallinus beschriebenen, und stimmt dem Aeusseren nach noch an meisten

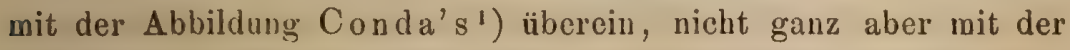
von Coemans${ }^{2}$ ), besonders nicht in Bezug auf das Sporangium.

Ueber zwei Wochen erneucrte sich diese Form täglich in derselben Weise; anfangs zahlreich, später abnehmend, bis sie zuletzt ganz verschwand. Ein andermal beobachtete ich auch einen P. crystallinus - eberfalls spontan auf Pferdemist erschienen - der ganz mit obigem übereinstimmte, nur zeigten hier die Sporen nicht in der Mitte einen lichten Fleck sondern meist an beiden Enden je einen (XXVI 42) und diese Form scheint dem Coemans'schen P. crystallinus noch am meisten zu entsprechen, mit dem Unterschied, dass die Sporangien bei ihn kleiner waren.

Die abgeschleuderten Sporangien dieser Form bleiben am Glase haften, womit das Substrat bedeckt war. Sie befanden sich dabei theils im Trocknen, theils in niedergeschlagenen Wassertropfen. Während nun in manchen Sporangien die Sporen fünf Monate hindurch fast ganz unverändert erschienen, haben sie dagegen in anderen Sporangien ihre Form verändert und sich dabei vergrössert. Aus den elipsoïdischen, meist doppelt so langen als breiten Sporen wurden nach und nach breiter elipsoïdische (XXVI 44a) bis ganz kugelrunde Sporen (XXVI 44b), so dass sie nun einen Durchmesser besassen, der ihrer früheren Länge gleich kam oder selbst etwas grösser war (XXVI 44 b, c). Zugleich damit wurde der lichte Fleck in den Sporen grösser und der Inhalt etwas körnig. Diese Sporen hatten ein ganz normales und gesundes Ausseher, erhielten sich lange so und keimten selbst nach fünf Monaten gut. Ausser diesen

1) Icones VI. Tab. 2 Fig. 10 und 12.

2) a. a. 0. Taf. II. Fig. 7. - Coemans' Abbildung stellt den Pilobolus so dar, wie er in Luft betrachtet unter dem Mikroskop aussieht; meine Zeichnungen sind nach benetzten Objekten gemacht, wobei man die Farbe und Anordnung des Inhaltes deutlicher sieht. - 
Sporen fanden sich in den Sporangien oft auch einzelne, die bereits ohne Inhalt waren oder derselbe war lockerer und im Verschwinden begriffen, wo daun nur die leereu Sporenmembranen zurückblieben. In manchen Sporaugien waren selbst alle Sporen verschwunden und statt derselben fand man nur eine Menge farbloser Amoeben. - Bei den älteren Sporangien wird dic schwarze Membran stets lichter und durchsichtiger. -

Die Keimung dieser Sporen kann auf zweierlei Art erfolgen. Säet man nämlich viele Sporeu zugleich auf ausgekochten Pferdemist, so äıdern sie dabei ihre Gestalt nur weuig. Sie bleiben elipsoïdisch, wer'en höchstens etwas breiter und damit wird der lichte Fleck etwas grösser uud heller, bis er später deutlich als Vacuole zu erkennen ist. - Ich halte daher den lichten Fleck, der schon anfangs in der Spore sichtbar ist für eine Vacuole und nicht für den Zellkern. - Der Inhalt wird nachher farblos, es treten in demselben einige Körnchen auf und bald keimt die Spore in einen dünnen Keimschlauch aus (XXVI 43 a, b, c, d).

Bei der zweiten Art der Keimung durchgehen die Sporen dieselben Veränderungen, wie sic schon iun Sporangium eintreten: sie werden nämlich rund. Dabei bleibt es aber meist noch nicht, sondern im weiteren Verlauf zur Keinung, werden sie noch bedeutend grösser (XXVI $44 \mathrm{c}$ ), mit einem Durchmesser von 0,015-19 Mm. Ihr Inhalt wird lichter und in demselben treten gelbe bis orange Körnchen auf, während zugleich der frühere lichte Fleck sich vergrössert und als Vacuole sichtbar wird. Nun treibt dic Spore einen meist bedeutend dickeren Keimschlauch, als im früheren Fall (XXVI 44 e, $d, f)$; sie zeigt jetzt meist eine grosse Vacuole in der Mitte und einen plasmatischen Wandbeleg (XXVI 45) oder es treten mehrere kleine Vacuolen auf (XXVI $44 \mathrm{e}$ ). Diese finden sich auch oft in den jungen Keimschläuchen und ausserdem sieht man bei dieser Keimung die kleinen Körnchen in Inhalt schon bei ganz jungen Keimschläuchen in strömender Bewegung, wie sie dem Pilobolus-Mycelium im Pferdemist eigenthümlich ist. Diese Art der Keimung beobachtete ich im Wasser (XXVI 45) und im Fruchtsaft, sie wird aber wahrscheinlich auch im Pferdemist so erfolgen, wenn die Sporen in geringer Zahl vorhanden sind.

Werden nun die Sporen dieser Form in grosser Menge auf ausgekochten Pferdemist ausgesäet, so keimen sie, wie erwähnt, auf die erste Art (XXVI 43); die wenig veränderten Sporen treiben dünne Keimschläuche mit blassen Inhalt. Indem diese weiter 
wachsen, werden sic immer dicker, ihr Inhalt wird immer mehr röthlich, durch die ihm eingelagerten Körnchen, welche zugleich die strömende Bewegung zeigen. So cntsteht ein Mycelium, welches 6-7 Tage nach der Aussaat die ersten Fruchtträger entwickelt, die eine zweite Pilobolus-Form geben. Sic sind in den ersten Tagen sehr klein, dem freien Auge nur schwer sichtbar und bedecken in grosser Anzahl das Substrat. Sie haben meist nur eine Länge von $\frac{1}{2}-1 \mathrm{Mm}$. und zeigen meist die Gestalt wie sie Fig. 46 Taf. XXVI darstellt. Der Fruchtträger sitzt auf einer meist nur schwach obconischen Mycelium-Erweiterung; die Anlage ist nicht deutlich und meist ohne seitliche Schläuche. Ein Sticl ist entweder gar nicht zu erkennen oder undeutlich kurz und sowohl nach unten in die Anlage, als nach oben in die Anschwellung des Trägers unmerklich übergehend. Der Inhalt des letzteren ist blass roth und entweder überall gleichmässig oder höchstens schwach an der Stelle angehäuft, wo der Stiel in die Anschwellung übergeht. Die Columella ist steil kegelförmig (XXVI 37) und trägt ein hohes, mebr als halbkugeliges Sporangium. Dasselbe hat eine schwarze Membran, auch mit feinen Wärzchen und einen verschieden breiten, lichtern Saum, wie es gasz gleich auch bei der zuerst beschriebenen Form vorkommt. Die Sporen aber sind hier ganz anders, als bei der ersten Form, von welcher diese Form doch abstammte. Sie waren nämlich verhältnissmässig grösser und an Form und Grösse selbst in demselben Sporangium sehr verschieden; meistens rund mit einem Durchmesser von $0,0066--0,017 \mathrm{Mm}$, breit elipsoïdisch, $0,0066-0,015^{\mathrm{Mm}}$. breit und 0,0087-0,026 Mm. lang, oder noch anders geformt. Ihr Inhalt war dunkel gelb, orange bis fleischfarben, mchr körnig und ölartig, und zeigte 1 - 4 lichtere Flecken oder diese fehlen auch ganz. In einzelnen Fällen konnte man hier die Sporeumembran rom Inhalt unterscheiden. Fig. 47 Taf. XXVI zeigt einige Sporen dieser Form, wie sie oft in demselben Sporangium vorkommen. -

Bei andern Aussaaten der Sporen der ersten Form erschienen in den ersten Tagen auch eine grosse Anzahl sehr kleiner Fruchtträger von $\frac{1}{2}-1 \mathrm{Mm}$. Länge, aber diese zeigten trotzdem schon eine deutliche Sonderung in Anlage, Stiel und Anschwelluvg (XXVI 48), dabei aber vorwiegend runde Sporen, mit Inhalt wie die vorigen. Jedesmal aber folgten sich paar Tage hindurch nur sehr kleine Fruchtträger in grosser Anzahl, später aber nahm die Zahl etwas ab und ihre Grösse zu; damit trat zugleich die Sonderung in An- 
lage, Stiel und Anschwellung immer deutlicher hervor (XXVII 49) und nach einigen Tagen waren die Fruchtträger ganz so, wie bei der ersten Form (XXIV 17 und 19). Sie hatten cine bedeutendere Grösse erreicht $-2-5^{\mathrm{Mm}}$. Länge - und der Träger zeigte einen deutlichen Stiel, Anlage und Anschwellung und in Inhalt an der Uebergangsstelle von Sticl in Anschwellung oft eiue rothe Inhaltsanhäufung. Das Sporangium aber und die Sporen blieben gleich, diese waren auch jetzt ganz oder vorwiegend rund. Selten fand man in einzelnen Sporaugicu nur elipsoïdische Sporen, diese waren dann aber grösser - $0,0066 \quad 0,011 \mathrm{Mm}$. breit und $0,013-0,017 \mathrm{Mm}$. lang - als bei der ersten Form, hatten auch dunkleren, etwas körnigen Inhalt und zeigten nie den für die erste Form charakteristischen lichten Fleck in der Mitte, sondern entweder gar keinen, oder dann an einem oder an beiden Enden je einen (XXVI 42).

Ein andermal wurden uur wenig Sporen der ersten Form auf ausgekochten Pferdemist ausgesäet und nach cinigen Tagen erschienen einige Fruchtträger von $1-2^{M m}$. Läge, von der Form, wie sie Fig. 50 Taf. XXVII zeigt, wit deutlichem Stiel an dem Träger. Hier waren die Sporen alle ganz rund aber von verschiedevem Durchmesser. Ihr Inhalt war fast flejschfarben, körnig und die Membran deutlich vom Inhalt unterscheidbar.

Diese Pilobolus-Form, welche man bei der Aussaat der Sporen der crsten spontan entstandenen Form erhält, entspricht der von Cocunaus als Pilobolus oedipus beschricbenen. Denselben sollen besonders die runden, viel grösseren und dunkler gefärbten Sporen auszeichnen; Coemans aber und auch $\mathrm{Cohn}{ }^{\prime}$ ) gaben nur lauter runde Sporen an, während ich zwar auch eine Form mit lauter runden Sporen beobachtet habe, sonst aber meist in einem Sporangium neben runden, auch elipsoïdische und anders geformte Sporen fand. Da Cohn's Pilobolus, den Coemans für P. oedipus erklärt hat, dem Aeusseren wach mit meiner $z$ weiten durch Aussaat erhaltenen Form übereinstimmt, so halte ich dieselbe auch für den P. oedipus. Ich habe nun gezeigt, dass aus den Sporen des echten P. crystallinus in zweiter Generation der P. oedipus werden kann, somit müssen beide Formen, da sie genetisch zusammenhängen, auch vereinigt werden und ist für den ganzen

1) Cobn bat diese Form als P. erystallinus beschrieben und sie entspricht mehr, als Coemans sein P. oedipus, meiner zweiten Form, da bei Coemans die Sporangien sehr flach sind, während sie bei mir und Cohn hoch sind. Cohn's Pilobolus wurde von $\mathrm{C} 0$ emans für $\mathrm{P}$. oedipus erklärt. 
Formencomplex, der aus den Sporen des spontan erschienenen P. crystallinus hervorgeht, der Name P. crystallinus in erweiterter Bedeutung beizubehalten.

Coemans hat zur Zeit seiner Monographie den P. oedipus nicht auf Pferdemist beobachtet, sondern auf Strassenkoth und nur allein, dagegen sagte er in einer späteren Arbeit'), dass er den P. oedipus auf allen Stationen des P. crystallinus gefunden habe. Ich fand auch auf demselben Pferdemist ganz gleiche Fruchtträger, die einen mit lauter elipsoïdischen, die andern mit vorwiegend runden Sporen; die letzteren konnten nun durch Aussaat der Sporen der ersteren Fruchtträger entstanden sein oder da beide gleich anfangs gleichzeitig erschienen, so muss es dieser Pilobolus-Art eigen sein elipsoïdische und runde Sporen zu erzeugen. - Sonst wurde die Pilobolus-Form mit ganz runden Sporen auf Schlamm, Strassenkoth, faulenden Algen (Cobn) und noch andern faulenden Stoffen beobachtet; es ist daher wahrscheinlich, dass sie auf diesen verschiedenen Substraten auch etwas variiren mag. Es kann auch sein, dass sie auf andern Substraten ihre kurze, gedrungene Gestalt länger beibehält, während sie au: Pferdemist diese nur in den ersten Tagen ihres Erscheinens zeigt, später aber nach dem Aeusseren, ganz in den P. crystallinus auct. übergeht, obgleich die Sporen dabei vorwiegend rund bleiben. Ebenso sah ich diese Form nie in ihrer kurzen, gedrungenen Gestalt spontan auftreten, sondern ich erhielt sie in dieser Form nur nach Aussaat der Sporen des spontan erschienenen $P$. crystallinus auct., und es würde sich noch darum frageu, unter welchen Verhältnissen der P. crystallinus (mihi) gleich mit runden Sporen auftritt. Bei anderen Culturen, wo auf Pferdemist zuerst der P. microsporus spontan auftral, erschienen später Fruchtträger von P. crystallinus mit gross-elipsoïdischen Sporen, und noch später auch solche mit thcilweise runden und breit-elipsoïdischen Sporen. Diese sind also nicht bloss der kleinen Form, die als P. oedipus bekannt ist, eigenthümlich, sondern kommen auch bei der Form vor, die dem Aesseren nach ganz P. crystallinus auct. ist. Und ausser den Sporen stimmen beide Formen in andern Merkmalen überein, nämlich in der warzigen Sporangien - Membran und der steil - kegelförmigen, farblosen Columella, welche Theile bei P. microsporus anders beschaffen sind.

1) Bullet. acad. Belg. 2. Séc. Tom. XVI. p. 71. 
Diese Erscheinung, dass nämlich die Sporen des P. crystalli nus auct, bei ihrer Keimung auf Pferdemist eine etwas andere Form geben, welche besonders durch die Sporen versch:eden ist - und zwar erhielt ich bei allen Aussaaten nie eine Forın, deren Sporen den ausgesäeten ganz gleich gewesen wären - könnte man als eine Art Pleomorphie betrachten, welche bei andern Pilzen bis jetzt noch gar nicht oder wenig bekannt ist, obgleich sie auch anderwärts vorkommen könute. In gewissem Sinne ein Analogon dafür dürfte vielleicht die Erscheinung bieten, dass bei einigen Discomyceten zweierlei Fruchtträger vorkommen, solche mit kleinen und andere mit grösseren Sporen, die sich auch bei der Keimung verschieden verhalten, so bei Peziza Duriaeana Tul. ${ }^{1}$ ). Ebenso beobachtete ich bei einem noch nicht bestimmten Ascobolus auf Pterdemist ${ }^{2}$ ) auch zweierlei Fruchtträger, die sich auf einander folgten. Die ersten waren in grosser Auzahl vorhauden und enthielten kleinere Sporen $-0,0098^{\mathrm{Mm}}$. breit und 0,1121 $1^{\mathrm{mm}}$. lang. Einige Tage aber nachdeu die ersten Fruchtträger bereits verschwunden waren erschienen bloss einzelne riel grössere, den vorigen sonst gleiche und diese enthiclten Sporen, welche bedeutend grösser - 0,032 $\mathrm{Mm}$ breit und $0,06 \mathrm{I}^{\mathrm{Mm}}$. lang - sonst aber gleich gestaltet und gefäbt waren. Die keirung der sporen habe ich nicht beobachtet, es wäre abor hier möglich, dass die letzteren Fruchttraiger aus den Sporen der ersten entstanden wären.

Bei Yilobolus sind hierbei auch noch dic Veränderungen in Betracht zu ziehen, welche die Sporeu des P. crystallinus auct. schon in Sporangium eingehen: dass sie nämlich, wic oben erwähnt, aus der elipsoïdischen Form in eine vollkommen kugelige übergehen können, wo sie dunn den Sporen des P. oedipus sehr ähnlich sind. Die Sporen des P. crystallinus auct. haben also höchstens unter dem Einfluss von Feuchtigkeit die Fähigkeit schon in ihrem Sporangium kugelig zu werden und ausgesäet entwickeln sie dann Fruchtträger mit vorwiegend oder ganz runden Sporen.

Die Sporen der zweiten Generation des P. crystallinus zeigten ausser der runden Gestalt auch einen noch mehr ölartigen, etwas körnigen Inhalt, von dunklerer Farbe, als die spontan entstandenen.

1) de Bary, Morph. u. Phys. d. Pilze etc. p. 201.

2) Dieser Ascobolus hatte eine braune Rinde mit parenchymatischer Zeichnung, farbloses Mark und ein gelbgrünes Hymenium - wodurch die Farbe hervorgerufen wurde weiss ich nicht -; in den Ascis elipsoïdische schon dunkel violette Sporen mit glatter Membran. 
Die Veränderungen die jene im Sporangium noch durchmachen sind auch etwas anders. Zuerst bleiben sie nicht so lange normal und keimfähig wie die früher besprochenen. Aus ihrem Inhalt scheidet sich oft der gelbe Farbstoff in Tropfen aus, während der übrige Theil farblos bleibt; der Inhalt wird auch ganz farblos, homogen etwas farblos, zieht sich von der Membran etwas zurück und verschwindet zuletzt ganz. Die Membran bleibt entweder zurück oder wird auch aufgelöst. - In anderen Fällen wurden die Sporen etwas grösser, ihr Inhalt körniger, blass gefärbt; in demselben traten eine bis melirere Vacuolen auf und zuletzt verschwand der Inhalt ganz.

Jede dieser Veränderungun entspricht der Vorbereitung dieser Sporen zur Keimung. In Fruchtsaft nämlich werden die Sporen erst ganz farblos und dann keimen sie aus. Im Pferdemit dagegen vergrössern sie sich, ilır Inhalt wird blasser gefürbt und zeigt deutliche Körnchen und Vacuolen. Erst dann keimen sie aus und die Keimung kann im Pferdemist auch in zwcierlei Weise erfolgen. Sind viele Sporen vorhanden, so treiben sic nur dünne Schläuche (XXVII 51) mit homogenem Inhalt, diese werden erst bei weiterem Wachsthum auch dicker und zeigen in ihrem Inhalt Körnchen. Im andern Fall treiben die Sporen gleich anfangs dicke Schlänche mit vacuolenhaltigem Inhalt und deutlichen gelb bis röthlich gefürbten Körnchen (XXVII 52). Diese zeigen wieder die strömende Bewegung in schönster Weise, welche bei weiterer Ausbildung der Schläuche zum Mycelium und der gleichzeitigen Vermehrung der Körnchen immer auffallender wird. Nach 6-10 Tagen entstehen an dem Mycelium aus diesen Sporen wieder neue Fruchtträger von derselben Beschaffenheit wie die, von denen sie stammen und es wiederholen sich dabei die oben beschriebenen Erscheinungen, wie sie nach Aussaat der Sporen von der ersten Form auftreten. Die ersten Fruchtträger sind klein (XXVI 46, 48. XXVII 49), werden aber später grösser. Ihre Sporen sind auch vorwiegend rund und nur einzelve Fruchtträger zeigen lauter elipsoïdische Sporen aber nie ganz gleich mit denen der zuerst beschriebenen Form, welche ich nur bei spontanem Auftreten fand. -

Dem eben beschriebenen Formencomplex des P. crystallinus, in dem von mir erweiterten Sinne, ist die oben gegebene Entwickelung des Pilobolus entnommen, um dabei das Typische derselben zu zeigen. Bei P. microsporus erfolgt nun die Entwickelung im Wesentlichen gleich, $d$. b. es bilden sich hier dieselben 
Theile wie bei P. crystallinus, nämlich ein Mycelium mit Hauptästen, dessen Inhalt strömende Bewegung zeigt, eine FruchtträgerAnlage, welche zum Fruchtträger auswächst, ein oben angeschwollener Träger; oben durch die Columella geschlossen, auf welcher auch ein schwarzes Sporangium ron gleichen Bau wie bei P. crystallintis sitzt und das auch zur Zeit der Reife abgeschleudert wird; aber die Art der Entwickelung dieser Theile weicht in manchen Punkten ab und der fertige P. microsporus ist durch so charakteristische Merkmale ausgezeichnet, dass er vom P. crystallinus sehr leicht zu unterscheiden ist.

Zuerst beobachtete ich den $\boldsymbol{P}$. microsporus im Januar 1869 auf Pferdemist, der von der Strasse ins Zimmer gebracht wurde und wo or, wie auch noch später einigemal spontan erschien. Seine Fruchtträger sind im Allgemeinen schon unter normalen Verhältnissen viel grösser, als die ron $\mathrm{P}$. crystallinus, meist $2-8^{\mathrm{Mm}}$ lang, ausnahmsweise aber auch 11,12 ja selbst bis $35 \mathrm{Mm}$. lang. Sie zeigen einen langen dünnen Sticl, oben eine grosse wasserhelle Anschwellung, auf der ein verhältnissıässig sehr kleines Sporangium sitzt. Ist neben dem P. microsporus zugleich auch der P. crystallinus auf demselben Substrat, wie es meist geschieht, so kann man beide schon mit dem blossen Auge unterscheiden. Durch sein yrosses Sporangium fällt sogleich der $P$. crystallinus auf und dann erscheint dorselbe, mit P. microsporus verglichen, immer etwas gelblich gefärbt, während der letztere ganz krystallhell aussieht.

Bei P. microsporus gelang es mir nicht, so grosse zusammenhängende Partien des Myceliums zu erhalten, wie bei $\mathbf{P}$. crystallinus, aber soviel ich gesehen, zeigt es auch hier denselben Typus, nämlich stärkere Hauptäste, stets ohne Querwände und diese sind auch hier im ganzen Mycelium selten; oft treten hier sehr reichlich die auf pag. 308 beschriebenen kurzen Aeste auf.

Ebenso gelang es mir auch nicht die Bildung der FruchtträgerAnlagen vollständig zu beobachten: in fertigen Zustand sehen sie aus wie es Fig. 53 Taf. XXVII bei b zeigt; eine dicht mit Inhalt erfüllte Anschwellung wird von zwei obconischen Mycelium-Erweiterungen getragen. Abgesehen von den seitlichen Mycelium.Schläuchen, welche die Anlage meist trägt, sieht dieselbe in diesem $\mathrm{Zu}$ stande einer Zygospore nicht unähnlich und man könnte vielleicht durch diese Aehnlichkeit leicht verleitet werden, auch an eine den Zygosporen ähnliche Bildung zu denken. Aber obgleich ich bemüht war der Sache auf den Grund zu kommen, so fand ich doch 
trotz tagelangen Präparirens keinen Fall, welcher entschieden dafür gesprochen hätte. Die Bildung der Anlage ist daher vielmehr ander's aufzufassen. Die Anlagen entstehen nämlich auch hier nur innerhalb der Hauptäste und diese schwellen bei der Bildung der Anlagen in ihrem Verlauf an und wachsen an einem Ende immer weiter, dafür spricht der einzig beobachtete Fall in Fig. 53 Taf. XXVII bei a. Diese Anschwellung füllt sich nun ganz dicht mit Inhalt und scheidet sich dann beiderseits durch Scheidewände ab. Diese werden wahrscheinlich innerhalb der Anschwellung auftreten, so dass neben denselben das Mycelium obconisch erweitert erscheint und die Anlage wie eine Zygospore von zwei Suspensoren getragen wird. Wir sahen auch bei P. crystallinus (pag. 312), dass die Anschwellung zur Bildung der Fruchtträger-Anlage nicht immer ganz am Ende eines Mycelium-Astes entstand, sondern über sich noch eine Mycelium.Fortsctzung zeigt (4, 5 XXIII und 6 XXIII); diese aber wächst nicht weiter und trennt sich auch nicht durch eine Scheidewand von der Anlage. Einmal sah ich, dass sich bei P. crystallinus ein Ast durch eine Wand von der Anlage getrennt hatte, er wuchs aber weder weiter, noch war er neben der Scheidewand obconisch erweitert, was auch dafür spricht, dass bei P. microsporus die Scheiảewände innerhalb der zur Anlage sich ausbildenden Anschwellung auftreten und nicht erst dort, wo diese aufhört, um dann erst nachträglich sich zu erweitern, was ja auch bei P. crystallinus nicht geschieht (XXIII 6, Scheidewand entsteht bei a). Bei P. microsporus wächst aber auch nur der Hauptast weiter, also bei 53 a Taf. XXVII nach $x$, während die seitlichen Schläuche, welche schon bei Bildung der Anlage an dem betreffenden Stück des Hauptastes sich finden, nicht weiter auswachsen, obgleich sie mit dem Inhalt der Anlage frei communiciren.

Während nun bei $\mathbf{P}$. crystallinus das Mycelium auf grosse Strecken ein zusammenhängendes Ganze bildet (1 XXIII), an welchem die Anlagen immer nahe dem Ende von Hauptästen so entstehen, dass der übrige Theil des Myceliums noch immer frei communicirt (3 XXIII); wird bei P. microsporus, durch die Bildung der Anlagen im Verlauf der Hauptäste, das Mycelium in kleine Partien getheilt, die immer durch Anlagen unterbrochen sind (53 XXVII). Diese kommen oft sehr nahe an einander zu liegen, so dass das dazwischen liegende Mycelium-Stück sehr kurz wird. Damit steht im Zusammenhange, dass hier das Mycelinm oft mit sehr zahlreichen, kurzen, vielfach ausgebuchteten Aesten besetzt ist, Jahrb. f, wiss. Botanik, VIII. 
welche die Nahrungsaufnahme erleichtern und so ermöglichen, dass trotz der geringen Ausdehnung des zwischen zwei oder drei Anlagen befindlichen Mycelium-Stückes, dieses doch wieder neue Anlagen bilden kann. Von den zwei Mycelium-Erweiterungen, welche die Anlagen tragen, ist gewöhnlich eine etwas kleiner (Fig. 53 XXVII) und wahrscheinlich diejenige, die nach der Richtung liegt, nach welcher der Hauptast weiter gewachsen. In manchen Fällen kanu aber dieser nicht bedeutend wachsen, sondern bleibt kurz und so wird die zweite Mycelium-Erweiterung unscheinbar; ja die Anlage zeigt selbst, jedoch selten, bloss eine einzige solche. Dieser Fall tritt besonders, jedoch wur sehr spärlich, gegen das Ende der Cultur ein und die Fruchtträger dieser Anlagen sind verbältnissmässig klein, sonst aber mit den Merkmalen des P. microsporus. Ebenso findet man auch Anlagen, die sogar von drei MyceliumErweiterungen getragen werden (54 XXVII) und hier muss sich die Anlage gerade an einer Verzweigungsstelle des Hauptastes gebildet haben. Die beiden letzten Fälle sind selten und als Regel zeigt die Anlage zwei obconische Mycelium-Erweiterungen.

Das Auswachsen der Anlage geschieht hier ganz so wie bei P. crystallinus; es wird Wasser aufgenommen, das als Vacuole erscheint, an welcher Stelle sich zugleich cine kleine Ausbuchtung bildet (54 XXVII), die im späteren Verlauf immer grösser wird (55 XXVII) und zuletzt zu einem ziemlich langen Schlauch auswächst $(56,57 \mathrm{XXVII).} \mathrm{Dieser} \mathrm{ist} \mathrm{unten} \mathrm{immer} \mathrm{scharf} \mathrm{von} \mathrm{der}$ Anlage als ein aus derselben hervorgewachsener Theil gesondert (57 XXVII). Anfangs in seiner ganzen Länge gleich dick und oben mit zugespitztem, farblosem Ende fortwachsend (56 XXVII), besteht sein Inhalt nur aus einem dünnen Wandbeleg und einer centralen Flüssigkeit. Bei der beträchtlichen Länge des Schlauches zeigt sich hier schon die Bewegung der Körnchen im Wandbeleg sehr deutlich. Der Schlauch hört nun auf an der Spitze zu wachsen, dieselbe rundet sich $a b$ und das Ende des Schlauches beginnt auf einer Strecke anzuschwellen (57 XXVII), während sich zugleich der Inhalt unter der sich immer mehr abrundenden Spitze anzusammeln beginnt ( $58 \mathrm{XXVIII).} \mathrm{Jetzt} \mathrm{strömt} \mathrm{der} \mathrm{Inhalt} \mathrm{immer} \mathrm{stärker}$ aus der Anlage nach oben und da wo die Erweiterung des Schlauchendes beginnt, sondert sich die Körnchenmasse oft in dichtere Stränge (59 XXVIII), in welchen die Bewegung besonders lebhaft erfolgt und die hier nicht bloss an der Peripherie, sondern durchs ganze Lumen verlaufen, aber alle parallel neben einander nach 
oben gerichtet und ebenso strömen die Körnchen vorwiegend ja fast ausschliesslich nach oben. Während im untern Theil, wo der Schlauch nicht angeschwollen ist, die Körnchen sich in einem gleichmässigen Wandbeleg fortbewegen, beginnen sie nach oben zu sich in Stränge zu sondern, die ganz fein anfangen nach oben breiter und dichter werden und zuleizt in den oben zum Sporangium sich ansammelnden Inhalt zusammenfliessen. Ich beobachtete lange unter dem Mikroskop die Bewegung der Körnchen und sah dass sich diese Stränge langsam ändern, sowohl in ihrer Breite, als in ihrer gegenseitigen Lage. So wird auch hier, wie bei Pilobolus allgemein, durch die strömende Bewegung der Stofftransport besorgt, wie er wohl schöner nirgeuds bekannt ist. Aller Inhalt wandert aus der Anlage nach oben und beginnt später sich nach unten schärfer abzugrenzen (60 XXVIII), bis er sich zuletzt durch eine Querwand als Sporangium vom Träger sondert (61 XXVIII).

Bei P. crystallinus erscheint das Sporangium nach seiner Anlegung als kugeliges Köpfchen, und während der Träger zu der Zeit gar nicht oder nur wenig angeschwollen erscheint, sondern vielmehr in seinem ganzen Verlauf ziemlich gleich dick ist (15 und $33 \mathrm{XXV}$ ), so geschieht es bei P. microsporus etwas anders. Hier ist mit der Bildung des Sporangiums auch zugleich ein Theil unterhalb angeschwollen (59-61 XXVIII), und der ganze Fruchtträger erscheint mehr keulig und trägt nicht ein als scharf gesondertes Köpfchen sich darbietendes Sporangium. Dieses ist jetzt noch flach wie es Fig. 61 Taf. XXVIII zeigt, wo es bis a reicht und durch eine flache Querwand vom unteren Theil getrennt ist; von a bis $b$ aber ist schon jener Theil vorgebildet, aus welchem später die blasenförmige Anschwellung hervorgeht und ist auch schon durch die chemische Reaction als solcher angedeutet. Denn wie im fertigen Zustand am Pilobolus-Fruchtträger meist blos der Stiel durch Jod in Jodwasserstoff weinroth gefärbt wird, während die Anschwellung ungefärbt oder höchstens gelblich erscheint, so geschieht es auch hier. In dem Stadium wie es Fig. 61 XXVIII darstellt wird die Membran durch obiges Reagens bloss bis b weinroth, nach oben zu aber nicht; ja selbst schon in jüngeren Stadien (57 XXVII und 58 XXVIII) wird der obere angeschwollene Theil höchstens gelblich gefärbt.

Hat der Fruchtträger des P. microsporus die Ausbildung erlangt, in der ihn Fig. 61 XXVIII zeigt, dass nämlich das Sporangium durch eine Querwand sich vom Träger gesondert hat, so gehen 
nun die weiteren Veränderungen in derselben Weise wie bei P. crystallinus vor sich. Die hier schon angedeutete Anschwellung des Trägers wird durch Wachsthum und den Druck des von Mycelium und der Anlage aufgenommenen Wassers immer grösscr, bis sie im ausgebildeten Zustand als wasserhelle Blase erscheint, dic sich hier von dem immer deutlich vorhandenen, dünnen langen Stiel in einen Winkel scharf von demselben absetzt. An dieser Stelle ist zugleich immer der Inhalt in einem rothen, scharf begrenzten Querband angehäuft, jedoch nur als Ring und nicht durch das Lumen durchgehend (62, $65 \mathrm{XXVIII).} \mathrm{Ausserdem} \mathrm{ist} \mathrm{der} \mathrm{Wandbeleg} \mathrm{in}$ den übrigen Theilen des Trägers nur dünn, farblos und höchstens unter dem Sporangium kommt manchmal noch eine schwache röthliche Inhaltsanhäufung vor. An der inneren Fläche des Wandheleges sind auch hier Plasmaströmchen in denen kleine Körnchen, die schon oben besprochene Bewegung zeigen, und diese ist hier meist sehr deutlich und lebhaft, da sowohl der Wandbeleg dünn und farblos, als auch der Träger meist grösser als bei P. crystallinus ist.

Mit der Bildung der Anschwellung im oberen Theil des Trägers wird natürlich auch die anfangs flache Querwand unter dem Sporangium gewölbt und als Columella in dasselbe hineingedrängt. Aber diese bleibt hier nur niedrig und schwach gewölbt (65 XXVIII), dagegen zeigt sie eine für P. microsporus charakteristische Eigenthümlichkeit, sie ist nämlich schwärzlich-blau gefärbt, von demselben T'on, wie die schwarzblaue Färbung der Sporangien-Membran. Diese Färbung der Columella ist bei allen Exemplaren des P. microsporus zu finden, während bei $P$. crystallinus mihi die Columella immer farblos ist. Durch Schwefelsäure erhält die Columella des P. microsporus einen scliwachen carminrothen 'Ton.

Das angelegte Sporangium, wiees Fig. 61 XXVIII reigt, wird ferner weder grösser, noch ändert es seine Form bedentend; aber zugleich mit den eben beschriebenen Vorgängen fürbt sich seine Membran und wird zuletzt dunkel schwarz-blau, während zugleich im Innern des Sporangiums die Sporen sich bilden: Die schwarze Färbung erstreckt sich über die ganze Membran, und diese ist am Rande in einer nur sehr schmalen Partie blasser gefärbt, was nur an der von dem Träger und den Sporen befreiten Membran sichtbar ist, sonst aber am unversehrten Fruchtträger nicht bemerkbar wird, weshalb man auch hier nicht, wie bei P. crystallinus, im unteren Theil des Sporangiums die Sporen durchleuchten sieht. Die Spor- 
angium-Membran des $P$. microsporus ist glatt und es fehlen ihr die feinen Wärzchen, welche dem ganzen Formencomplex des P. crystallinus eigen sind. Durch Schwefelsäure erhält die schwarze Membran des P. microsporus einen carminiothen Ton, während der schwarze Ton nach und nach verschwindet und zuletzt erscheint die Membran bloss chocoladefarbig.

Nach den eben beschriebenen Vorgängen ist der Fruchtträger ausgebildet und erscheint uns wie ihn Fig. 62 und 63 (in Luft gesehen) XXVIII zeigen. Weiter erfolgt nur noch das Abreissen der schwarzen Sporangium-Membran von dem Träger, wobei das Sporangium etwas breiter wird und sich in die Höhe zieht (64 XXVIII). Die Sporen aber werden mit emporgeschoben und werden auch jetzt noch nicht sichtbar, was bei P. crystallinus der Fall ist (17, $21 \mathrm{XXIV).} \mathrm{Bringt} \mathrm{man} \mathrm{einen} \mathrm{Fruchtträger} \mathrm{in} \mathrm{diesem} \mathrm{Zustand} \mathrm{ins}$ Wasser, so quillt die Sporenhülle unter der schwarzen Membran hervor und wird als zarter Contour vom Rande des Sporangiums bis zur Stelle, wo aie gefärbte Columella an den Träger befestigt ist, sichtbar (64 XXVIII a). Sie ist im unteren Theil ziemlich breit und umgiebt auch hier die ganze Sporenmasse, welche letztere wie bei P. crystallinus oben von der schwarzen Membran kappenartig bedeckt, auch nur der Columella aufsitzt. -

Zuletzt werden auch hier die Sporangien auf dieselbe Weise wie bei $P$. crystallinus abgeschleudert und bleiben, von einem Glase aufgefangen, mit ihrer unteren Fläche an demselben haften. Die Sporangien werden hier viel früher abgeschleudert als bei P. crystallinus und überhaupt zeigt der P. microsporus eine sehr regelmässige Periodicität in seinem Erscheinen. Die Fruchtträger erscheinen Nachmittags zwischen 3 und $4 \mathrm{Uhr}$, als dünne, spitze Schläuche und sind durch ihre blasse, gelbe Farbe schon mit blossem Auge von den mehr orangegelben Schläuchen des P. crystallinus zu erkennen. Noch am Abend werden die Sporangien angelegt und am andern Morgen sind die Fruchtträger ausgebildet und schleudern schon um $8 \mathrm{Uhr}$ ihre Sporangien ab, während die gleichzeitig auf demselben Substrate befindlichen Fruchtträger des P. crystallinus dasselbe erst gegen $10 \mathrm{Uhr}$ thun.

Unregelmässigkeiten, wie sie bei $\mathbf{P}$. crystallinus eintreten, dass nämlich alle Entwickelungsstadien zugleich vorhanden sind, habe ich bei P. microsporus nicht beobachtet und das hängt, wie ich glaube, auch mit der Art wie sich hier die Fruchtträger-Anlagen bilden, zusammen. Indem diese im Verlauf der Hauptäste ent- 
stehen, wird hier das Mycelium in kleine Partien getheilt und diese sind kurz nach der Bildung der Anlage ziemlich inhaltsleer, da sie aber nicht, wie bei $\mathbf{P}$. crystallinus mit andern Theilen des $\mathbf{M y}$ celiums frei communiciren, sondern von denselben durch schon gebildete oder schon abgestorbene ') Anlagen getrenut sind, so müssen sie erst aus ihrer nächsten Ungebung neuen Nahrungstoff wieder sammeln, bevor sie zur Bildung einer neuen Anlage gelangen und diese wird erst während der Zeit fertig, in welcher cine vorher gebildete Anlage zum Fruchtträger ausgewachsen ist.

In den Sporangien des P. microsporus finden sich eine grosse Anzahl sehr kleiner Sporen. Sie sind alle elipsoïdisch, 0,0021-43 $\mathrm{Mm}$. breit und $0,0043-76^{\mathrm{Mm}}$. lang, und in demselben Sporangium alle fast gleich gross. Ihr Inhalt ist homogen und sehr blass, so dass sie einzeln fast farblos erscheinen, während sie in grosser Menge beisammen liegend, schmutzig gelb aussehen. In einer Cultur beobachtete ich den P. microsporus mit Sporen, die alle in der Mitte einen lichten Fleck zeigten (66 XXVIII), in einer andern Cultur zeigten die Sporen diesen Fleck nicht und waren dabei unmerklich kleiner (67 XXVIII). In ersteren Fall waren auch die Sporangien etwas höber (63 XXVIII) als im letzteren ( $62 \mathrm{XXVIII),} \mathrm{aber}$ sonst stimmten sie in Allem überein. Die Keimung der Sporen konnte ich bis jetzt noch nicht beobachten, ebenso fand ich an den Sporen, welche seit fünf Monaten im Sporangium am Glase haften, noch keine Veränderungen, nur die Sporangium-Membran ist etwas blasser geworden, dagegen hatte die Columella noch immer ihre Farbe behalten. -

Die oben (pag. 334) angegebenen chemischen Reactionen gelten, mit Ausnahme der auf Sporangium-Membran und Columella bezüg. lichen, auch für den P. microsporus. Ebenso fand ich im Fruchtträger desselben sowohl die oben genannten Krystalloïde als auch die Körper von oxalsaurem Kalk.

Das Mitgetheilte wird genügen, um sowohl die Gattung Pilo. bolus in der Familie der Mucorini, als auch ihre Formen zu charakterisen. Nach meinen Beobachtungen haben wir bei Pilobolus zwei nicht genetisclı zusammenhängende Formen, also wenn man will, zwei Arten, nämlich: P. crystallinus als Formencomplex und P. microsporus. Und will man die charakteristischen und bis jetzt

1) Nachdem nämlich der Fruchtträger das Sporangium abgeschleudert, geht er mit der Anlage zu Grunde und so werden zwei Myceliumtheile, die vorher nur durch Anlagen zusammenhingen, ganz getrennt. 
durchgreifenden Kennzeichen der Mucorini und ihrer beiden Gattungen zusammenstellen, so sind es folgende:

\section{F a m. Mucorini.}

Saprophytische Pilze, deren verzweigtes Mycelium in oder auf dem Substrate wuchert; zur Fruchtbildung schickt dasselbe aufrechte Fruchtträger über das Substrat, welche oben kugelige, hlasenförmige Sporangien tragen. Diese sind von dem Träger durch eine anfangs flache, später ins Spurangium gewölbte Querwand, die Columella, abgegrenzt. Sporen einfach, bewegungslos, zu vielen durch "simultane Theilung ohne Scheidewandbildung“ entstehend. Ausserdem bei einigen Formen Pleomorphie bekannt.

1. Gattung. Mucor. Mycelium zur Zeit der Fruchtbildung septirt; Fruchtträger fadenförmig, aus gewöhnlichen, nach oben gewachsenen Zweigen des Myceliums gebildet; Sporen von der einfachen, farblosen Sporangium-Membran umschlossen.

Unterscheidbare Arten sind nach de Bary ${ }^{1}$ ) folgende: Mucor Syzygites und stolonifer mit Zygosporen; M. Mucedo Fres. mit drei his vier verschiedenen Fruchtformen; M. Phycomyces Berk., M. nıacrosporus Corda und M. fusiger Lk. Hierher gehören wohl auch die von Hildebrandt2) aufgefundenen Syzygites ampelinus und echinocarpus, die aber nur in der Zygosporen-Form genauer bekannt sind, während es noch nicht sicher entschieden ist, zu welchem Mucor sie gehören.

2. Gattung. Pilobolus. Mycelium selbst zur Zeit der Fruchtbildung der Querwände fast ganz entbehrend und diese nur spärlich und vereinzelt an gewissen Seitenzweigen vorhanden. Am Mycelium ist ein System von Hauptästen zu unterscheiden, in diesem bilden sich Anschwellungen, die sich mit Inhalt füllen und als Fruchtträger-Anlagen sich vom übrigen Mycelium durch ein oder zwei Wände sondern. Aus den Anlagen wächst der Fruchtträger hervor, dieser besteht aus einem gestielten, oben blasenförmig erweiterten Theil, dem eigentlichen Träger, und dem schwarzen Sporangium. Im demselben sind eine Menge Sporen von einer farblosen, unten aufquellbaren Sporenhülle umgeben und ausserdem bedeckt von einer schwarzen Sporangium-Membran. Zur Zeit der Reife sitzt das Sporangium der Columella nur auf und wird mit derselben in Folge des Durchreissens des Trägers fortgeschleudert.

1) Abhandl. d. Senkenberg. Gesellschaft. Bd. V. p. 365.

2) in Pringsheim's Jahrb. VI. p. 270. 
Der Inhalt des Myceliums und des Fruchtträgers zeigt strömende Bewegung.

Enthält zwei Arten:

P. crystallinus KI. Die Fruchtträger-Anlagen bilden sich am Ende der Hauptäste und werden im ausgebildeten Zustand von nur einer obconischen Mycelium-Erweiterung getragen (3 B XXIII). Der Stiel des Trägers nach oben allmählich in die Anschwellung übergehend ( 34 XXVI b). Columella farblos, steil kegelförmig, oft oben etwas erweitert (XXVI 37, 38 und 39). Sporangium-Membran schwarz, fein warzig. Sporangium hoch, mehr als halbkugelig. Sporen gelb, orange bis fleischfarben; ellipsoïdisch bis rund. Lässt folgende Formen unterscheiden.

a. Sporen alle ellipsoïdisch - 0,0055-0,011 $\mathrm{Mm}$. breit und $0,011-0,017 \mathrm{Mm}$. lang - in demselben Sporangium fast gleich gross, gelb, theils in der Mitte theils an einem oder an beiden Enden je einen lichten F'leck zeigend (XXVI 41, 42). P. crystallinus auct., spontan auf Pferdemist erscheinend.

b. Sporen alle rund; Grösse selbst in demselben Sporangium sehr verschieden; Inhalt orangegelb bis fleischfarben, $1-4$ lichte Flecken zeigend; Fruchtträger meist kleiner und gedrungener als bei voriger Form. P. oedipus auct. (XXVII 50).

c. Sporen in demselben Sporangium von verschiedener Form - ellipsoïdisch, rund und anders geformt - und von sehr verschiedener Grösse, Inhalt gelb bis orange, 1-4 lichte Flecken zeigend; Fruchtträger meist klein (XXVI 46, 48, 49). Entspricht vielleicht der Varietät des P. oedipus auct., die Coemans ${ }^{1}$ ) intermedia nennt. - Form b und c erhielt ich auf Pferdemist durch Aussaat der Sporen von der Form a; dagegen hat Coemans die Form b auf Strassenkoth und Cohn auf faulenden Algen, spontan auftretend, gefunden. (Siehe Nachtrag.)

P. microsporus Kl. Die Fruchtträger-Anlagen bilden sich im Verlauf der Hauptäste und werden im fertigen Zustand in der Regel von zwei obconischen Mycelium-Erweiterungen getragen (XXVII 53 b, XXVII 55), selten von dreien (XXVII 54) oder bloss von einer. Stiel des Trägers nach oben nicht allmählig in die Anschwellung übergehend, sondern von derselben in einem Winkel gesondert. Columella niedrig, ziemlich flach gewölbt, blass schwärzlich-blau gefärbt (XXVIII 65). Sporangium-Membran

1) in Bullet. acad. Belg. 2 Sér. Tom. XVI. p. 71. 
blau-schwarz, nicht warzig; Sporangium verhältnissmässig klein und flach (XXVIII 62, 63); Sporen alle ellipsoïdisch sebr klein $0,0021-43^{\mathrm{Mm}}$. breit und $0,0043-76^{\mathrm{Mm}}$. lang _, einzeln fast farblos, beisammen schmutzig gelb; in der Mitte einen lichten Fleck zeigend (XXVIII 66) oder dieser fehlt (XXVIII 67).

Erscheint spontan auf Pferdemist, oft mit der Form a. des P. crystallinus zugleich.

Ich will noch hier erwähnen, dass ich einmal zweierlei Pferdemist von der Strasse ins Zimmer brachte: der eine sah dunkel aus, er war von einem gesunden Pferd, welches gut rerdaut hatte, auf demselben erschien der P. microsporus in grosser Menge zwei Wochen hindurch; der andere war bedeutend heller, er stammte von einem alten Pferd, mit nicht ganz guter Verdauung, und auf demselben erschienen im Ganzen nur vier bis sechs Fruchtträger des P. microsporus. Der letztere Pferdemist wurde ausgekocht und darin ausgesäcte Sporen des P. crystallinus entwickelten sehr zahlreiche Fruchtträger. -

Anmerkung. Da dic Sporen des P. crystallinus im Fruchtsaft einen Mucor geben, wie im Folgenden gezeigt wird, und somit allen zu den Mucorini gehörenden Pilzen die Mucorform gemeinsam ist, so dachte ich anfangs, dass es zweckmässig wäre, alle diese Pilze unter Mucor zusammenzufassen. Ich habe aber hier dennoch die Gattungen der Mucorini noch so belassen, wie sie bis jetzt genommen wurden; denn jede Aenderung wird so lange nur eine vorläufige sein, als man nicht die ganze Naturgeschichte der betreffenden Pilzformen vollkommen kennt. Dann aber besitzt der Pilobolus in seiner bis jetzt bekannt gewesenen Fruchtform so charakteristische Eigenthümlichkeiten, dass er nicht nur jetzt, sondern vielleicht auch künftig sich als Typus einer Gattung behaupten dürfte, zumal da es ja möglich ist, dass ihm neben einer Mucorform auch noch eine eigenthümliche Zygosporenform zukömmt. Wenn aber diese letztere etwa selbst fehlon sollte, so müsste die Pilobolus-Form als Fructification aufgefasst werden und diese würde sich gegenüber den Mucorformen mit Zygosporen sehr gut generisch unterscheiden lassen. -- Für die Gattung Mucor dürfte künftig der Name Syzygites substituirt werden, unter welchem dann, falls Pilo- 
bolus auch ferner als eigene Gattung bleibt, der Mucor desselben nicht inbegriffen ist. -

\section{Pleomorphie des Pilobolus.}

Auf Pleomorphie bezügliche Angaben bei Pilobolus. finden wir nur bei Coemans und zwal erwähnt er zweierlei Conidien '); eine zweite Art kleiner, morgensternförmiger Sporangien und zweierlei Chlamydosporen ${ }^{2}$ ). Die Natur der Conidien ist sehr zweifelhaft und für die andern Organe ist weder der Zusammenhang mit dem Pilobolus-Mycelium, noch die Identität, des sie tragenden mit dem letzteren, noch auch die Zusammengehörigkeit durch Aussaat-Versuche nachgewiesen, ja nicht einmal wahrscheinlich gemacht, da diese Organe nur den Standort mit Pilobolus gemein haben. Ueber eine Art seiner Chlamydosporen werde ich noch weiter unten sprechen.

Ich habe auf eine andere Art die Pleomorphic des Pilobolus zu prüfen gesucht, nämlich durch Aussaat der Sporen auf andere Substrate, als die ron welchen sie stammten und ich habe so eine $\mathrm{zweite}$ Art von Fruchtorganen für Pilobolus aufgefunden, die ich uun im Folgenden beschreiben werde. Es gelang mir bis jetzt nur für P. crystallinus und seine Formen dieselben nachzuweisen, während bei P. microsporus bisher nicht einmal die Keimung der Sporen gelang.

Zuerst wurden die Sporen der Form a. des P. crystallinus, welche spontan auf Pferdemist erschienen war, in den unverdünnten Fruchtsaft von eingesottenen $Z$ wetschen (wie sie in Haushaltungen verwendet werden) ausgesäet. Die Sporen dieser Form sind, wie schon erwähnt, in dem eben abgeschleuderten Sporangium alle ellipsoïdisch und in der Mitte mit einem lichten Fleck. Im Fruchtsaft durchgehen die Sporen dieselben Veränderungen, welche auch sonst in den meisten Sporangien erfolgen, was aber im Sporangium nur in einiger Zeit erfolgt, geschieht hier sebr bald. Die Sporen gehen nämlich schon am andern Tage nach der Aussaat aus der anfangs schmal ellipsoïdischen Form in eine breitere über (XXVI 44 a), wobei zugleich der Inhalt etwas körnig wird und in der Mitte der lichte Fleck sich etwas vergrössert. Diese

1) Coemans, Monograph. d. genre Pilob. a. a. O. p. 54.

2) Coemans in Bullet, acad. Belg. 2. Sér. Tom. XVI. p. $72 \mathrm{ff}$. 
Veränderung geht in derselben Richtung weiter (XXVI 44 b), bis die Sporen rund geworden sind und nun meist einen Durchmesser von der ursprünglichen Länge der Sporen besitzen. Weiterhin werden die Sporen noch allseitig etwas grösser, der Inhalt wird lichter und lässt deutliche, verschieden grosse, oft kenntlich gelb gefärbte Körnchen und in der Mitte noch den vergrösserten lichten Fleck erkennen (XXVI 44 c). In diesem Stadium keimen die Sporen aus, in Form eines zarten, farblosen Fortsatzes (XXVI 44 d), wobei der Inhalt der Spore gegen das vorige Stadium nicht geändert erscheint. So wie aber der Keimschlauch grösser wird, verschwindet der lichte Fleck im Inhalt und es treten ein bis mehrere deutlich umschriebene Vacuolen auf, welche auch im Inbalt des Schlauches erscheinen, der sonst ganz homogen und farblos ist, während er in der Spore Körnchen enthält, die verschieden gross und die grösseren von gelber Farbe sind (XXVI 44 e). Diese Körnchen befinden sich in dem blassen etwas graulichen Plasma und zeigen in diesem oft eine strömende Bewegung, womit auch eine deutliche Veränderung der Vacuolen verbunden ist; diese werden an manchen Orten kleiner, verschwinden selbst ganz, während an andern Stellen wieder neue auftauchen. Die strömende Bewegung sah ich bei der Keimung im Fruchtsaft nur an ganz jungen Keimstadien (XXVI 44 e), besonders deutlich bei im Wasser ausgekeimten Keimschläuchen (XXVI 45), und ist dieselbe im ausgewachsenen Mycelium, das bei dieser Keimung im Fruchtsaft später entsteht, nicht wahrzunehmen.

Obige Veränderungen ${ }^{1}$ ) und das Auskeimen der Sporen im Fruchtsaft wurden unter Deckglas lückenlos beobachtet und es zeigt sich dabei, dass die Keimung durch Aufnahme von Wasser eingeleitet wird; denn der lichte Fleck in der Spore, die Vacuole, wird grösser, der Inhalt lichter und Körnchen aufweisend, während die ganze Spore ausgedehnt wird. Durch die Wasseraufnahme wird der Stoffumsatz möglich, wie es die Bewegung der Körnchen und die Vacuolenbildung zeigen. Das Auskeimen erfolgt nur auf Kosten des Sporeninhaltes und erst der junge Keimschlauch beginnt Nahrung aufzunebmen; fehlt ihm aber diese, wie es beim Keimen im Wasser der Fall ist, so wird der Inhalt sehr dünn und in der Spore wie in den Schläuchen treten grosse Vacuolen auf (XXVI 45),

1) Es ist zu bemerken, dass diese Veränderungen nicht an allen Sporen gleich schnell vor sich gingen, ja bei manchen gar nicht erfolgten, und auch dass nicht alle dieselbe Grösse erreichten bevor sie auskeimten. 
aber die Beweyung der Körnchen ist hier sehr lebhaft, da sie mit dem Wassergehalt des Plasmas zusammenuängt. Nach dem Aus. keimen zeigen die Sporen natürlich einen dunkleren Contour als die Schläuche und dieser ist oft selbst doppelt. In manchen Fällen kann man auch das Episporium deutlich erkennen, zumal wenn die Spore mehr keinen Inhalt hat. Es ist ein sehr feines blass bräunlich gefärbtes Häutchen, welches theils die Spore lange umgiebt - sie erscheint dann in einem bräunlichen Ton -, theils ganz oder nur theilweise abgestreift wird, und so als zartes Häutchen neben der Spore liegt oder derselben noch lange anhaftet und dann leicht $z u$ erkennen ist (XXIX $2 \alpha$ bei a). Im Allgemeinen wird es selten gefunden oder seiner Zartheit halber leicht übersehen. Hat die Spore bereits einen Keimschlauch getrieben, so wächst dieser in der Folge ziemlich rasch und fängt auch bald an sich zu verzweigen (XXIX 1). Ganz in derselben Weise wie unter Deckglas erfolgte die Keimung auch im Uhrglas, wo die Sporen des Pilobolus ausgesäet waren, und die Identität der Produkte der Keimung liess sich unzweifelhaft feststellen, da im Uhrglas ausser den Pilobolus-Sporen keine andern sich fanden, welche ausgekeimt hätten.

Im Uhrglas entwickelten sich die Keimschläuche der PilobolusSporen sehr rasch, sie verzweigen sich stark und bilden sich bald zu einem starken und ausgebreiteten Mycelium aus. Dieses ist aber aber noch querwandlos und bleibt sehr lange mit der Spore in Verbindung. Diese enthält lange Zeit hindurch noch Inhalt, der feinkörnig aussieht, während er gegen die Schlauchenden homogen wird und oft zahlreiche Vacuolen enthält. -

Am vierten Tage nach der Aussaat der Sporen ragten im Uhrglas über die Flüssigkeit gestielte Köpfchen empor; es waren Sporangien, wie es schon eine schwache Vergrösserung zeigte. Ich war nun gleich das erste $\mathrm{Mal}$ so glücklich mit der Pincette ein solches Sporangium mit dem ganzen ihm zugehörenden Mycelium bis zur ursprunglichen Spore ganz rein herauszuziehen. Von diesem Präparat sind die Figuren $2 \alpha-2 \delta$ auf Taf. XXIX und ich will nun davon die Theile desselben näher besprechen. Von der ursprünglichen Spore ( $2 \alpha$ a) ausgehend konnte man durch das ganze Mycelium bis zum Sporangium den Zusammenhang zwischen der ersteren und dem letzteren ersehen. Die Spore war deutlich zu erkennen, da ihr noch das Episporium als zartes, bräunliches, hier dreilappiges Häutchen anhaftete $(2 \alpha \mathrm{a})$; sie hatte einc doppelt 
contourirte Membran, aber keinen Inhalt mehr. Ein einziger Kcimschlauch war ursprünglich aus derselben hervorgewachsen $(2 \alpha$ b), welcher sich bald, scheinbar dichotomisch, zu verzweigen begann und durch fortgesetztes Wachsthum und Verzweigung ein ausge. breitetes Mycelium lieferte. Denkt man sich bei Fig. $2 \alpha$ die abgerissenen Myceliumenden ( $\mathrm{x}, \mathrm{x}, \mathrm{x}) \mathrm{zu}$ geschlossenen Schläuchen, wie c ausgeführt, dabei die Querwände feblend, die Membran einfach und den Inhalt aus lebenskräftigem Plasma gebildet, so erhält man genau das Bild von Keimungsstadien, wie sie unter Deckglas aus den Pilobolus-Sporen erhalten wurden (z. B. wie 1 XXIX). Es ist mir deshalb und aus der sehr genauen Verfolgung aller Verhältnisse bei der Keimung der Pilobolus-Sporen unzweifelhaft, dass das im Uhrglas - in welches die Pilobolus-Sporen gesäet waren - erhaltene Mycelium mit den Sporangien, die es trug, nur aus den ausgesäeten Sporen von Pilobolus entstanden sein kann, wo. für auch noch spricht, dass öfter wiederholte Aussaaten immor dasselbe Resultat lieferten.

Im ausgebildeten Zustand zeigt das Myceliun unregelmässig auftretende und nicht zu zahlreiche Querwände, welche, wie mir scheint, schon vor der Sporangienbildung auftreten können. Alle Theile des Myceliums zeigen eine doppelt contourirte Membran, diese ist wellig, so dass das Mycelium ziemlich unregelmässig aussieht. Der Inhalt war in den Theilen nahe der Spore und dieser selbst (XXIX $2 \alpha$ ) bereits verschwunden oder nur in spärlichen Körnchen repräsentirt, in anderen Theilen war er noch theilweise vorhanden, doch schon abgestorben und farblose Oeltropfen zeigend. Gegen die Enden des Myceliums war er reichlich vorhanden und lebenskräftig, theils feinkörnig und dicht, theils homogen und mit Vacuolen. Ueberall war er farblos, etwas graulich aussehend. Das ganze Mycelium war stark verzweigt und zeigte an manchen Stellen ausser den gewöhnlichen Aesten noch andere kürzere, welche nachträglich durch Ausstülpung entstanden sind, da sie an ihrer Abgangsstelle immer eingeschnürt erscheinen (XXIX $\left.2 \beta \mathrm{c}, \mathrm{c}, \mathrm{c}^{1}\right)$. Sie sind theils einfach $(c, c, c)$ theils vielfach ausgebuchtet $\left(c^{1}\right)$ und erinnern sehr an ähnliche Zweige, die oben (pag. 308) am Pilobolus-Mycelium im Pferdemist beschrieben wurcien; in ihnen spricht sich also auch noch die beiderseitige Verwandtschaft aus. -

Gegen das Ende des Myceliums werden die Scheidewände

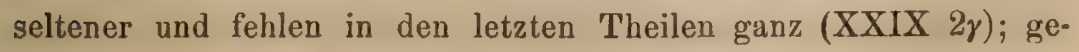
wisse Aeste wachsen bedeutend in die Länge, ohne sich dabei 
stark zu verzweigen (XXIX 2y). Nach diesen Endäaten ist aus dem Mycelium der meiste Inhalt gewandert, und sie sind damit ganz dicht erfüllt. Immer rasch in die Länge wachsend, nehmen einzelne Aeste endlich einen schief gegen die Oberfläche der Flüssigkeit gerichteten Verlanf an (XXIX $2 \gamma$ e). Diese wachsen weiter über dieselbe empor, richten sich dabei senkrecht auf und werden so zur Fruchthyphe, welche oben ein kugeliges Sporangium, mit den charakteristischen Merkmalen eines Mucorsporangiums, bildet. -

Fig. $2 \gamma$ und $2 \delta$ Taf. XXIX $^{1}$ ) zeigt uns das Ende eines Myceliumtheiles, an welchem ein Ast (e) zur Fruchthyphe (f) mit einem Sporangium ausgewachsen war. Ausserdem sind noch zwei andere lange Aeste da, aber der ganze Myceliumtheil ohne Querwände und ausser den kleinen, gewöhnlichen Astanlagen ( $d, d, d$ ), nur noch die später durch Ausstülpung entstandenen unten eingeschnürten Zweiglein (c, c, c) zeigend. Der Ast e zeigt auf der Strecke, wo er sich noch in Flüssigkeit befand, eine wellige Membran, so wie er aber als Fruchthyphe über die Flüssigkeit tritt, wird er nicht nur dünner, sondern auch cylindriscb ( $2 \gamma$ und $2 \delta \mathrm{f}$ XXIX). Die Fruchthyphe und auch der Theil dessen Verlänge. rung sie darstellt, sind anfangs dicht mit Inhalt erfullt; erstere wächst in einer Spitze anfangs fort, wclche sich spätcr abrundet, kugelig anschwillt, sich dicht mit Inhalt fült und sich endlich zum Sporangium ausbildet. Selbst zu dieser Zeit ist die Fruchthyphe, so wie das ihr angrenzende Mycelium ohne Querwände.

Die Fruchthyphe ist unter dem Sporangium zu einer breiten Apophyse erweitert $(2 \delta$ XXIX) und wird nach oben durch die halbkugelige Columella begrenzt, die schon am unversehrten Sporangium kenntlich ist. Auf der Columella sitzen die Sporen, durch die farblose, glatte Sporangium-Membran deutlich zu erkennen. Das fertige Sporangium erscheint dunkel, bräunlich und nur an der Stelle lichter, wo die Columella in dasselbe hineinrragt, wo zugleich die Sporen nur in einer einfachen Schicht sich vorfinden. Sporangium mit Apophyse stellen ein kugeliges Köpfchen dar, welches bei g g $2 \delta$ XXIX eine scharfe Linie, die Ansatzstelle der Columella zeigt. -

Im reifen Zustand zerfällt die Sporangium-Membran in Stücke, welche in Wasser gebracht sogleich verschwinden, ohne sich dadarbot.

1) Der Inhalt ist so gezeichnet wie er sich nach längerem Liegen im Wasser 
bei zuerst in Körnchen aufzulösen. In Luft befindlich bleiben die Sporen, oft selbst nach dem Zerfallen der Sporangium-Membran, noch in der ursprünglichen Lage der Columella aufsitzen und nur bei Berührung oder im Wasser fallen sie ganz auscinander, wo dann die Columella frei sichtbar wird ( 4 XXIX). Diese ist, wie scbon gesagt, halbkugelig und zeigt manchmal eine netzartige Zeichnung auf ihrer Oborfläche, welche von den Sporen herrührt, denen sie stark angepresst gewesen sein muss (4 XXIX). - Die Sporen sind ziemlich gross, von kugeliger oder ellipsoïdischer Gestalt, mit etwas polygonalem Umriss (a 3 XXIX) oder sie zeigen

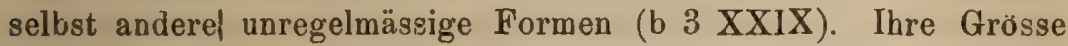
schwankt, sie sind $0,0087-0,013 \mathrm{Mm}$. breit und $0,013-21 \mathrm{Mm}$ lang. Sie besitzen meist eine dicke, schwach bräunliche Membran und einen körnigen, dunkel bräunlichen Inhalt. Ihre Keimung erfolgte schnell in Wasser und Fruchtsaft, wobei ein Episporium als faltiges, bräunliches Häntchen die Spore umgab, aber nicht abgestreift wurde. Die Keimung gelangte hier nur bis zur Bildung von kurzen höchstens einmal verästelten, noch querwandlosen Schläuchen, welche sich nicht weiter entwickelten.

Nachträglich erwähne ich noch, dass hier die Fruchthyphen meist einfach sind und immer aus den Enden der Hauptäste des Myceliums hervorgehen, selten nur findet man welche, die nahe an ihrem Grunde, aber noch über der Flüssigkeit 1-4 Mal verzweigt sind, wo dainn jeder Ast ein Sporangium trägt. - Ausserdem fand ich noch einige Mal Fruchthyphen auf demselben Mycelium, welche an ihrem Ende vielfach in kurze Aeste getheilt waren, einzelne derselben, besonders dic unteren waren an ihrem Ende wie zu einem; Sporangium angeschwollen (5 XXIX). Ich fand leider keine ausgebildeten Stadien, und an den beobachteten sah ich weder Columella noch Sporen. Diese Anschwellungen waren uur dicht mít feinkörnigen Inhalt erfüllt. Dabei aber kleiner, als die besprochenen Sporangien.

Wie oben erwähnt geben die Sporen der Form a. des P. crystallinus auf ausgekochten Pferdemist ausgesäet Fruchtträger mit Sporen, welche von den ausgesäeten verschieden sind. Die Sporen der zweiten Generation sind nämlich nicht blos im allgemeinen grösser und vorwiegend von kugeliger oder breit-ellipsoïdischer Gestalt, sondern auch ihr Inhalt ist dunkler, consistenter und von mehr ölartiger und körniger Beschaffenheit (XXVI 47).

Diese Sporen wurden nun auch ausgesäet und zwar in Frucht- 
saft von Johannisbeeren und Zuckerlösung; es entwickelte sich aus ihneu auch ein Mycelium mit Mucorsporangien, aber rerschieden von den eben beschriebenen. Hier wurde die Keimung bis zur Sporangienbildung lückenlos auf dein Objektträger beobachtet. Es wurden zu diesem Zwecke die schwarze Sporangium-Membran der betreffenden Pilobolus-Form mit einigen Sporen, welche ihr theils noch anhaften, theils in ihrer unmittelbaren Nähe sich befanden, unter Deckglas in Fruchtsaft gebracht; die schwarze Membran erleichterte das schnelle Auffinden derselben Sporen, die beim Aussäen genau betrachtet wurden.

Die Veräuderungen, welche diese Sporen bei der Vorbercitung zur Keimung durchmachen, sind verschieden ron denen im zuerst beschriebenen Fall. Die anfangs gold- bis orangegelb gefärbten Sporen werden nämlich nach einiger Zeit blasser und dann plötzlich ganz farblos, mit homogenem und etwas glänzendem Inhalt; die Sporen haben sich dabei wenig oder gar nicht vergrössert. In diesem Zustand keimen sie aus und zwar in ein bis zwei ziem. lich dicken Schläuchen (XXIX 6, 14). Die Spore zeigt einen dunklen Contour - ein Episporium wurde hier nicht abgestreift, ist aber wahrscheinlich auch vorbanden - während die Schläuche sehr zart erscheinen. Der Inhalt bleibt in den Schläuchen, wie in der Spore lange homogen und farblos und enthält in den Schläuchen zahlreiche Vacuolen, während in der Spore sich nur eine von bedeutenderer Grösse findet, welche den Inhalt bis auf einen Wand. beleg verdrängt hat (XXIX 6, 14 sp.). Die Schläuche sind gleich anfangs ziemlich dick und wellig, sie beginnen sehr bald sich zu verzweigen (XXIX 6) und dies selbst in unmittelbarer Nähe der Spore (XXIX 14); ebenso treten schon sehr zeitig Scheidewände auf, meist in grösseren Entfernungen von einander oder am Ende der Aeste mehrere in gleichen Abständen auf einander folgend (XXIX 6, 14). Durch diese letzten Scheidewände werde nanfangs cylindrische Zellen, welche sich nachträglich dicht mit Inhalt füllen, sich abrunden und so sich zu den noch später zu besprechenden, von mir Conidien genannten Organen ausbilden. Diese Vorgänge gehen unter dem Deckglas vor sich; die anfangs schwach verzweigten Schläuche geben nach und nach ein junges Mycelium, das sich unter dem Deckglas ausbreitet. Die einen Aeste bilden am Ende Conidien, andere wachsen rasch weiter und verzweigen sich immer stärker. Diese gelangen endlich an den Rand des Deckglases, wachsen unter demselben hervor, verbreiten sich hier schnell 
und bilden bald darauf an senkrecht emporragenden Seitenzweigen die Mucorsporangien, welche man also hier in Verbindung mit den unter Deckglas befindlichen ursprünglichen Sporen sehen kann.

In ein Uhrglas ausgesäete Sporen gaben nach 3-4 Tagen dasselbe Resultat. Es hatte sich cin stark ausgebreitetes Mycelium gebildet, das zahlreiche Fruchthyphen mit dunkeln Sporangien über die Flüssigkeit emporschickt. Wir sahen schon unter Deckglas an jungen Keimschläuchen Querwände auftreten, am fertigen Mycelium sind sie ziemlich zahlreich vorhanden, jedoch ganz unregelmässig vertheilt und oft auf lange Strecken fehlend. Das Mycelium ist stark und unregelmässig verzweigt; neben den gewöhnlichen, wellig gebogenen, im Allgemeinen meist gleich dicken Aesten, findet man noch andere, die gegen ihre Enden sich in immer dünnere, haarfein ausgezogene Acste theilen, wie sie auch bei anderen Mucorformen rorkommen. - Der Inhalt ist farblos, feinkörnig, manche Partien ganz dicht erfüllend, in anderen Theilen viele Vacuolen zeigend. Beim Absterben scheiden sich aus demselbeh oft grosse, farblose, ölartige Tropfen aus und im älteren Zustand wird er oft gelb bis braun.

Die Membran des Myceliums ist doppelt contourirt und zeigt mit Jod in Jodwasserstoff behandelt eine weinrothe Färbung, wie sie den Mucorformen eigen; der Inhalt wird rothbraun.

Die Fruchthyphen entstehen hier nicht aus der direkten Verlängerung von Hauptästen, sondern indem diese weiter wachsen erhebeu sich gewisse Seitenzweige über die Flüssigkeit und bilden am Ende das Sporangium. Anfangs sind sie gewöhnlich nur einfach, später verästeln sie sich in verschiedener Weise und jeder Ast trägt ein Sporangium, das des Hauptastes ist dann meist das grösste und zuerst gebildete. - Als ein dicht mit Inhalt erfüllter Schlauch wächst die Fruchthyphe anfangs mit spitzem Ende fort (XXIX $7 \alpha, a)$; bald hört das Spitzenwachsthum auf, die Spitze rundet sich ab $(7 \alpha$ b) und schwillt kugelig an $(7 \beta)$. Die Anschwellung wird immer grösser und dichter mit Inhalt erfültt $(7 \gamma)$, bis sie sich als Sporangium vom Träger trennt. Der Inhalt ist grau bis bräunlich, fein körnig oft durch viele lichte Flecken die zukünftigen Sporen andeutend $(7 \delta)$. Diese werden später gebildet und dann deutlich sichtbar, während die Columella an dem unverletzten Sporangium in der Regel äusserlich nicht zu erkennen ist. Die fertigen Sporangien sind kugelig und ron sehr verschiedener Grösse (XXIX 8, 9, 10), obgleich dabei die Sporen keine entJahrb. f. wiss, Botanik. VIII. 
sprechenden Grössendifferenzen zeigen. Die Sporangien-Membran ist farblos, glatt oder auch mit fein stachligen Erhabenheiten verschen, auch bier wie bei Mucor Mucedo ein nicht constanter Charakter. Bringt man die reifen Sporangien in Wasser, so zerfällt ihre Membran in kleine Körnchen, welche später ganz verselıwinden; die Sporen gehen dabei auseinander. - Die Columella ist hier hoch, meist doppelt so lang als breit (XXIX 11), so in den grösseren Sporangien; in den kleineren wird sie anch kleiner und etwas anders gestaltet ( 13 XXIX). Sie ist breiter, als der benachbarte Theil des Trägers und an der Anhaftungsstelle der Sporangium-Membran (XXIX 11 c) ist daher ein kleiner Vorsprung. Die Columella ist in älteren Culturen oft schwach bräunlich gefärbt und an ihrer Spitze manchmal in $1-3$ kleine Fortsätze ausgewachsen.

Die Sporen dieses Mucor sind in der Regel kugelig nur selten anders geformt, dabei aber in demselben Sporangium ron sehr Perschiedener Grösse, mit einem Durchmesser von 0,0011-66 Mn. Sic siud gewöhulich bräunlich gelb (XXIX 11 a) seltener blasser bis farblos, besonders bei Culturen am Objectglas. Bei 455 facher Vergrösserung zeigen sie meist einen runden Umriss (XXIX 11a), dagegen erscheint derselbe bei noch stärkerer Vergrösserung deutlich pulygonal (XXIX 11b); dann ist auch die Membran als doppelt contourirt zu erkennen, während sie sonst meist einfach aus. sieht. Der Inhalt der Sporen ist homogen ölartig. Im Fruchtsaft keimen die Sporen leicht, dabei vergrössern sie sich zucrst und erhalten einen lichten Inhalt; nawher treiben sie ein bis melirere dicke Keimschlänche, mit zartem Coutour und blassem Inhalt, den einzelne Körnchen cingebettet sind. Die Spore erscheint schwach bräunlich, walırscheinlich ron dem Episporium, das nicbt abgestreift wird (XXIX 15). - Nach 3-4 Tagen ist aus den Sporen wieder ein gleiches Mycelium mit Sporangien entstanden, wie das aus den Pilobolus-Sporen und welches sie erzeugt hattc.

Wir sahen schon oben, dass bereits an sehr jungen Keim. schläuchen unter Deckglas am Linde mancher Aeste mehrere Querwände unmitttelbar hinter einander auftreten; es entstehen so eine Reihe cylindrischer Zellen, nach Inhalt anfangs mit den anderen Theilen des Keimschlauches übereinstimmend. Am fertigen My. celium, das bereits Sporangien entwickelt, finden wir diese Zellen wieder, und zwar meist am Ende der Aeste, einzeln oder bis zu zehn, dabei durch Einschnürungen von einander gesondert, rund 
oder ellipsoïdisch. Sie besitzen einen schwarzen Contour und sind dicht mit einem farblosen, oft glänzenden Inhalt erfüllt, der homogen oder sehr fein granulirt ist (XXIX 16, 17, 18). Ich habe sie Conidien genannt zum Unterschiede von ähnlichen Zellen welche später entstehen, da sie immer zuerst am Mycelium auftreten und

- schon vor den Sporangien ausgebildet sind, die ihnen nachträglich i m mer folgen. Sie sind sonst den Brutzellen von Mucor Mucedo ähnlich; diese entstehen auch hier an älteren Mycelien, indem theils Inhaltspartien sich einzeln durch Querwände zu Zellen absondern oder ganze Theile von Mycelien-Aesten, welche dicht mit Inhalt erfüllt sind, in viele Zellen zerfallen. Diese finden sich immer an älteren Mycelien, aber meist im Verlauf der Aeste und weniger am Ende derselben.

Bringt man Conidien mit den zugehörenden Myceliumtheilen in Fruchtsaft und cultivirt sie unter dem Deckglas auf dem Objectträger, so bilden sie Sprossungen, indem die einzelnen Zellen an verschiedenen Stellen Ausbuchtungen treiben, von theils runder, theils langgestreckter Gestalt, welche ihrerseits wieder welche bilden können (XXX 21, 22). Oft treiben die Conidien auch kurze Schläuche, welche aber meist nicht lang werden, sondern bald in viele Zellen sich theilen (XXX 22b). So stellt Fig. 19.A Taf. XXX ein Stück von einem Keimschlauch dar, der aus einer PilobolusSpore zweiter Generation hervorgegangen war und bereits die Conidien a-f gebildet hatte, die ein feinkörniges, schaumiges Plasma enthielten. Diese Conidien wurden in Fruchtsaft unter Deckglas weiter cultivirt und nach 18 Stunden war daraus Fig. 19 B geworden, wo die ursprünglichen Conidien a-f wieder zu erkennen sind; aber dieselben hatten nicht nur eine grosse Anzahl weitlicher Ausbuchtungen getrieben, sondern $\mathrm{d}-\mathrm{f}$ hatten sich auch isolirt. Indem nun dieser Process sich wiederholt, dass sich theils die seitlich an den Conidien entstandenen Zellen von diesen trennen und ihrerseits wieder Sprossungen bilden, theils dass die ursprünglichen Conidien mit ihren seitlichen Ausbuchtungen als Zellcomplexe von einander und dem Mycelium frei werden, entsteht die sogenannte grosse Kugelhefe (XXX 20a und b), welche auch schon bei anderen Mucorformen beobachtet wurde ${ }^{1}$ ). Sie vermehrte sich unter Deckglas ziemlich rasch und man fand theils isolirte Zellen, theils Complexe von 2-10 und noch mehr Zellen; ob diese Hefe Gäh-

1) Bail in Flora 1857. 
rung bewirkt, kann ich nicht angeben. - Einzelne dieser Hefezellen, sowohl isolirt als im Comp!ex, trieben unter Deckglas auch Kcimschläuche ( $25 \mathrm{XXX}$ ), welche sehr oft am Ende noch ganz kurzer Schläuche gleich wieder Conidien erzeugen (23a XXX) oder sie wachsen mehr in die Länge und verzweigen sich, um aber zuletzt auch an Ende einige Conidien zu bilden (24a XXX), während der andere Theil fast ganz in eine Reihe meist cylindrischer Zellen sich theilt, welche dicht mit einem farblosen, oft glänzenden, homogenen oder sehr fein granulirten Inhalt erfült sind und vielleicht auch eine Form der auch hier, wie bei andern Mucorformen seh. mannigfaltigen Brutzellen darstellen. - Unter Deckglas gelangt die Entwickelung der Kugelhefe nicht weiter, bringt man sie aber in ein Uhrglas mit Fruchtsaft, so treiben die Zellen sogleich Keimschläuche, welche wieder Conidien erzeugen, aber hier auch bis zur Bildung von Sporangien gelangen. Diese sind im allgemeinen kleiner als die früheren, haben eine etwas kugclige Columella und auch kleinere, blasser" gefärbte Sporen (12 XXIX).

Die zuletzt beschriebenen Bildungen entstehen nun aus den Sporen zweiter Generation des P. crystallinus (Form b und c), so zwar, dass die Pilobolus-Sporen ein Mycelium mit Couidien und Mucorsporangien erzeugen; die Mucorsporen geben wieder Conidien und Sporangien; die Conidien entwickeln sich unter Deckglas zu Kugelhefe, welche in mehr Fruchtsaft gebracht auskeimt und abermals Conidien und Sporangien erzeugt.

Diese Bildungen entstanden jedesmal nach 3-4 Tagen, wenn in den Aussaaten das Auskeimen der Pilobolus-Sporen erfolgte, und wurde, wie gesagt, die ganze Entwickelung auf dem Objectträger verfolgt. Es wurden zu diesem $\mathrm{Z}_{\text {wecke einige Sporen mit }}$ der schwarzen Sporangium-Membran, als Marke zum leichteren Auffinden derselben, unter Deckglas in Fruchtsaft gebracht. Die Sporen keimten aus; an den Schläuchen entstanden sogleich die Conidien; das Mycelium wuchs dann weiter unter dem Deckglas hervor und alsbald erschienen um dasselbe die Mucorsporangien. Es ist dabei noch zu beachten, dass in diesem Fall immer zuerst unter dem Deckglas das Mycelium erschien und erst wenn dasselbe unter dem Deckglas hervorgewachsen war erschienen die Sporangien. Unter Deckglas war mehr keine Pilobolus-Spore zu finden, es hatten also alle ausgekeimt. Gleich neben diesem Glase standen andere, ganz gleiche, auch mit Pilobolus-Sporen; hier 
hatte keine einzige ausgekeimt, sich nicht einmal rerändert'), es hatte sich aber, auch kein Mucor gebildet, nicht nur nach vier Tagen nicht, sondern selbst nach zehn Tagen war überhaupt uoch kein Mycelium erschienen und die Pilobolus-Sporen waren noch alle unverändert zu finden. Noch andere Gläser, ohne ausgesäete

- Sporen, verhielten sich wie die letzteren.

Von den mitgetheilten Thatsachen erscheint es für den Anfang etwas befremdend, dass nbgleich die Formen des P. crystallinus (mihi) einen genetisch zusammenhängenden Conplex bilden, doch die Sporen der spontan und der in zweiter Generation entstandenen Form sich in Bezug auf den Mucor, welchen sie im Fruchtsaft entwickeln, verschieden verhalten. Wenn man aber bedenkt, dass, wie oben erörtert, die ersteren sich schon nach Inhaltsbeschaffenheit und nach der Art der Keimung von den letzteren unterscheiden und somit schon in diesen Hauptpunkten sich von einander trennen, so wird es weniger auffallend, dass auch die Produkte wesentlich verschiedener Sporen von einander verschieden sind. Zumal es anderwärts selbst vorkommt, dass ganz gleiche Sporen, doch in verschiedenen Generationen entstanden, sich auch verschieden verhalten. So entwickeln die Schwärmsporen der Saprolegnien und vieler Algen eine Zeit lang nur wieder Schwärmsporen bildende Pflänzchen, während dieselben Schwärmsporen einer späteren Generation Pflanzen mit Geschlechtsorganen bilden; und ähnliche Fälle bei anderen Pilzen mit pleomorphen Fortpflanzungsorganen.

Die Thatsache, dass die Pilobolus-Sporen in Fruchtsaft einen Mucor geben ist für sich betrachtet nur insofern etwas auffallend, als sie noch isolirt und unvermittelt, gleichsam unverstanden dasteht; sie ist eben so auffallend, wie es einst die Pleomorphie der Pilze überbaupt gewesen, so lange sie nur in einzelnen Beispielen bekannt war. - In Folge dieser Thatsache kommt allen Mucorinis eine typische Mucorform zu und wenn nun dadurch bei Pilobolus eine verwandte Sporangienart 2 weimal vorkommt, so müssen wir das nicht sogleich als befremdend auffassen, da wir ja noch nicht wissen, welchen Werth die bis jetzt allein bekannt gewesene Fruchtform des Pilobolus in dessen Entwickelungskreis besitzt.

Nach den bis jetzt bekannten Erfahrungen bei den Mucorinis ist nun wahrscheinlich, dass die Zygosporenbildung dieser Familie

1) Warum in manchen Fällen die Sporen unter Deckglas nicht auskeimten, sich nicht einmal veränderten, kann ich nicht angeben. 
allgemein zukomme und ist dieselbe, wie bekannt, in der Gattung Mucor für einige Fälle bereits nachgewiesen. Was nun Pilobolus anbelangt, so sind hier Zygosporen noch nicht gefunden worden, und nach meinen Erfahrungen wäre ich für jetzt der Meinung, dass solche am Mycelium des Pilobolus im Pferdemist nicht vorkommen, falls sich nicht etwa noch später die Anlagen bei Pilobolus microsporus als Zygosporen, die bei P. crystallinus dagegen als Azygosporen herausstellen sollten, oder dass diese Organe wenigstens Analoga dafür wären. -

Es ist hier zu erwähnen, dass Woronin ${ }^{1}$ ) auf einer über Winter eingetrockneten Cultur von P. crystallinus grosse Zellen fand, welche auf einer blasig-obconischen Erweiterung vertrockneter Myceliumfäden sassen - also wie die Anlagen - und diese entwickelten nach Befeuchtung sogleich die typischen Pilobolus-Fruchtträger. De Bary erwähnt diese Organe als zweifelhafte Zygosporen des Pilobolus. Ich fand auch aut alten Pferdemist, von welchem die Pilobolus-Fruchtträger schon seit längerer Zeit verscbwunden waren, mit freiem Auge sichtbare Zellen, welche wie die Fruchtträger-Anlagen des Pilobolus auf einer obconischen Mycelium-Erweiterung aufsassen, die aber nicht mehr mit dem Mycelium zusanmenhing. Diese Zellen hatten auch sonst theils die Form der Fruchtträger-Anlagen, oder sie waren etwas bisquitformig (XXX 27), dabei aber wie diese dicht mit Inhalt erfüllt, der wie bei den gewöhnlichen Fruchtträger-Anlagen im reflectirten Licht orangegelb erschien. Obgleich ich diese Organe lange cultivirte, eintrocknen liess und wieder befeuchtete, so entwickelten sie doch keine Fruchtträgcr; sondern erhielten sich längere Zeit unverändert, bis sie zu Grunde gingen. Ich halte diese Organe mit den von Woronin beobachteten für analog und für Fruchtträger-Anlagen des Pilobolus, welche in Stande sind nach einer Ruhezeit wieder Fruchtträger zu entwickeln, wie es Woronin beobachtet, während sie bei mir wahrscheinlich zu wenig ausgetrocknet waren, um sich gleich zu verhalten.

Sollten sich diese Organe künftighin nicht als Aequivalente der Zygosporen bei Mucor herausstellen, sondern bloss als Ueberwinterungsstadion von Fruchtträger-Anlagen, so wäre es dann noch möglich und nach Analogie mit Mucor wahrscheinlich, dass der Mucor des Pilobolus unter gewissen Bedingungen und auf be-

1) Citirt in de Bary's Morph. u. Physiol, der Pilze etc. p. 179. 
stimmten Substraten vielleicht auch echte Ziygosporen bilden würde. Darüber müssen weitere Untersuchungen entscheiden und wenn ich so glücklich sein sollte künftighin wieder zı mikroskopischen Untersuchungen zurückkehren zu können, so würde ich auch trachten, die hier angeregten Lücken in der Kenntniss des Pilobolus womöglich auszufüllen.

Nachträglich will ich noch auf Organe zu sprechen kommen, welche von Coemans') als Chlamydosporen des Pilobolus beschrieben wurden, und zwar, da er zweierlei anführt, die grösseren in Fig. 5 seiner genannten Arbeit abgebildeten.

Bei älteren Pilobolus-Culturen findet man oft ein braunes $\mathbf{M y}$ celium-Geflecht, welches den Pferdemist besonders an der Stelle mit der er aufliegt umgiebt. Bei näheror mikroskopischer Untersuchung erkennt man in dem Pilzfäden-Geflecht sogleich die wellig gebogenen, querwandlosen Schläuche des Pilobolus-Myceliums, das bereits abgestorben ist und keinen Inhalt enthält und damit dicht verflochten ein viel zarteres, lebensfähiges Mycelium, das in nicht grossen Entfernungen, aber sonst unregelmässig gestellte Querwände zeigt. Die Zellen sind cylindrisch und tragen an kurzen 1-3zelligen, meist senkrecht zum Hauptast gestellte Aestchen, ellipsoïdische Sporen, mit dicker im reifen Zustand bräunlich-gelber Membran und feinkörnigen Inhalt (XXX 26). Diese Organe sehen nun, soweit eine Vergleichung mit Coemans Abbildung möglich, sehr den genannten Chlamydosporen, nach Form und Grösse ähnlich. Coemans nennt sie „mono- ou biloculaires" und das letztere rührt daher, dass hicr oft die unter der Spore befindliche Zelle des Stieles sich stärker verdickt und nehr mit Inhalt fült, als die übrigen Zellen des Stieles, so dass es bei so schwacher Vergrösserung, wie sie Coemans anwendete, aussieht, als wären die Sporen zweizellig. Sie lösen sich auch, wie Coemans angiebt, sehr schwer vom Stiel und dabei bleibt die unter der Spore be. findliche Zelle des Stieles meist an derselben befestigt, hat aber zu dieser Zeit mehr keinen Inbalt und gehört folglich nicht zur Spore, was auch schon daraus hervorgeht, dass ihre Membran nicht gefärbt ist, wie es bei der Sporenmembran der Fall. Obgleich nun das Mycelium mit diesen Sporen mit dem PilobolusMycelium dicht verflochten vorkam, so habe ich trotz aller Bemühungen doch keinen Zusammenhang nachweisen können und ist

1) Bullet. acad. Belg. 2 Sér. Tom. XVI. p. 75. 
ein solcher bei der so auffallenden Verschiedenheit genannter $\mathbf{M y}$. cclien gar nicht anzunehmen. Diese Organe sind vielmer die Chlamydosporen eines Ascobolus, denn sie gleichen, abgesehen von Grösse, Farbe und Krümmung der sie tragenden Aestchen, ganz den von (Woroniu') bei Ascobolus pulcherrimus aufgefundenen Chlamydosporen. Es spricht dafür nicht nur die Form und das Vorkommen der Sporen auf kurzen meist senkrecht zum Hauptfaden gestellteu Aestchen, sondern besonders das so charakteristische und auffallende Auftreten ron kleinen Oeltropfen beiderseits der Querwände des Myceliums; ebenso sah ich auch ganz ähnliche Copulationen am Mycelium, wie sie Woronin abbildet.

Die besprochenen Chlamydosporen wurden auf Pferdemist aus. gesäet, aber bis jetzt ohne Erfolg, so dass ich volderhand noch nicht angeben kann, welchem Ascobolus sie angehören.

Die übrigen Fruchtorgane, welche Coemans noch dem Pilo. bolus zuschreibt, habe ich nicht beobachtet.

München, 1. Juli 1869.

Nachtrag. Zu rorstehendem Aufsatz mögen hier noch einige nachträgliche Angaben Platz finden.

Die im Pilobolus-Fruchtträger aufyefundenen Krystalloïde hatte ich nochmals Gelegenheit zu untersuchen und erwähne hier, dass dieselben durch Jod gelb bis braun gefärbt werden; durch concentrirte Salpetersäure erscheinen sie nach längerer Einwirkung (12 Stunden) blassgclb, um auf Zusatz von Kali schön goldgelb zu werden. Schwefelsäure allein färbt sie blass rosenroth, welche Farbe auch der Wandbeleg des Pilobolus-Fruchtträgers annimmt. Diese Reactionen zeigen, dass diese Krystalloïde mit den bisher vekannten im Wesentlichen übereinstimmen und auch aus eiweissartigen Stoffen bestehen. - In Folge der Reaction vou Schwefelsäure liess ich es vordem unentschieden, aus welchen Stoffen diese Krystalloïde bestehen; doch wird ja Protoplasma oft durch Schwefelsäure allein schon roth gefärbt, wie es auch beim Wandbeleg des Pilobolus-Fruchtträgers der Fall ist. Durch Kali quellen die Krystalloïde des Pilobolus auch auf und werden bei bestimmter Concentration daron auch aufgelöst; die alkoholische Jodlösung macht

1) Abhandl. d. Senkenberg. Gesellsch. Bd. V. p. 341; besonders Fig. 12 auf Taf. 1V. 
aufgequollene Krystalloïde wieder zusammenschrumpfen. (Siehe übrigens nocb: J. Klein, Ueber die Krystalloïde einiger Florideen in Flora 1871, No. 11).

Betreffend den oben erwähnten Ascobolus mit den zweierlei Sporen bemerke ich, dass ich denselben unterdessen als Ascobolus elegans Klein bereits beschrieben und abgebildet habe. Siehe J. Klein, Mykologische Mittheilungen, in den Verhandl. der zool. bot. Gesel!schaft in Wien. 1870. p. 566.

Während meiner Studien in München hatte ich nicht Gelegenheit gehabt den Pilobolus oedipus auct. auch spontan auftreten zu sehen, sondern wie oben (pag. 360) erwähnt wurde, erhielt ich denselben nach Aussaat der Sporen von Pil. crystallinus auct. Hier in Ofen brachte ich abermals Pferdemist ins Zimmer und hielt ihn feucht. Es erschien darauf der Pilobolus in grosser Anzahl, die Fruchtträger aber waren sehr klein, wie in Fig. 49 und 50 Taf. XXVII und in den Sporangien waren verschieden grosse, aber nur kugelrunde Sporen, sonst zeigten die Fruchtträgcr die Charaktere des echten P. crystallinus mihi. Derselbe kann somit auch spontan in kleiner Form mit kugelrunden Sporen auf Pferdemist erscheinen. Aus Allem geht hervor, dass der P. crystallinus mihi bei spontanem Auftreten entweder grosse Fruchtträger bildet, welche dann meist nur ellipsoïdische Sporen erzeugen ( $P$. crystal. linus auct.), oder in anderen Fällen kleinere Fruchtträger in sehr grosser Anzahl bildet, die ganz runde Sporen zeigen (P. oedipus auct.). -

Ofen, October 1871.

\section{Erklärung der Abbildungen.}

(Die Zahlen in Klammern bedeuten die Vergrösserung).

Taf. XXIII-XXVIII (mit fortlaufender Fig.-Nummer).

Pilobolus crystallinus mihi.

Fig. 1. Partie eines jungen Myceliums, das noch keine Fruchtträger entwickelt a, a, a. System der Hauptäste; ohne Querwände b, b, b, Seitenäste mit Querwänden.

Fig. $2 a$ und 2 b. Partie eines älteren Myceliums, das bereits Fruchtträger bildet. $\mathrm{h}$ Hauptast; $\mathrm{h}^{1}$ zum System der Hauptäste gehörig; a, a, a Seitenäste mit Querwănden; b, b und $b^{1} b^{1}$ nachträglich entstandene Aestchen.

Fig. 3. Mycelium bei A mit einer bereits zum Fruchtträger ausgewachsenen Anlage, bei $B$ eine eben ausgebildete Anlage; h, b, h System der Hauptäste; a, a, a Seitenzweige mit einzelnen Querwänden; 0, o Orte stärksten Wachstbums. 
Fig. 4. Mycelium-Ast der zu einer Fruchtträger-Anlage anzuschwelien beginnt.

Fig. 5. Weiteres Stadium; der Inhalt sammelt sich an.

Fig. 6. Der Inhalt in der Anlage soudert sich, bei a entsteht später eine Scheidewand.

Fig. 7. Eine eben gebildete Anlage.

Fig. 8. Zwei Anlagen A und B in kurz auf einander folgenden Stadien, den Beginn des Auswachsens zum Fruchtträger zeigend. Ende.

Fig. 14. Aus einer Anlage ausgewacbsener Schlauch mit spitzen, farblosem

Fig. 9. Anlage mit ausgewachsenem Schlauch, dessen Ende sich bereits abrundet.

Fig. 10. Weiteres Stadium von Fig. 9. Inhalt beginnt sich im Schlauchende anzusammeln.

Fig. 11. Weiteres Stadium von vorigem.

Fig. 12. Das Schlauchende beginnt zum Sporangium anzuschwellen und füllt sich immer mehr mit Inhalt.

F ig. 13. Weiteres Stadium von vorigem.

Fig. 15. Angelegtes Sporangium, nnch uicht durch eine Querwand vom Träger geschieden; centrale Zellflüssiglieit des letzteren nach oben eben begrenzt.

Fig. 16. Ausgebildetes Sprangium mit farbloser Jlembran; Sporen (nicht ausgeführt) im oberen Theil der Sporangium-Jlembran anliegend, im unteren durch die aufquellende Sporenhülle von derselben zurückgezogen; Columella noch schwach gewölbt; ceutrale Zellflüssigkeit des Trägers nach ohen in einer krummen Linie begrenzt.

Fig. 17. Oberer Theil eines ausgebildeten Fruchtträgers; schwarze SporangiunIlembran, vom Trägers bereits abgerissen, unten die Sporenmasse sichtbar.

Fig. 18. Wie Fig. 16 nur ein älteres Stadium mit bereits stark gewölbter Columella.

Fig. 19. Oberer Theil eines Fruchtträgers, schwarze Membran noch nicht vom Träger abgerissen und mit breiten lichterem Saum durch welchen die Sporen durchleuchten.

Fig. 20. Theil des Sporangiums von Fig. 19 bei stärkerer Vergrösserung; dio fein warzige Sporangien-Membran bei a in die glatte Membran des Trägers übergehend. Sporenmasse durch langes Liegen im Wasser von der Sporangium-Membran zurückgetreten in Folge der aufgequollenen Sporenhülle, diese bei b der Columella autliegend und sich ron der Sporangien-Memhran unten etwas abhebend.

Fig. 21. Theil eines Sporangiums nachlem die schwarze Membran vom Träger sich getrenut, a die Stelle wo sie früber befestigt war; Sporenmasse sichtbar von der aufgequollenen Sporenhülle b umgeben.

Fig. 22a. Unter Deckglas abgeschleudertes Sporangium mit farbloser Sporangium-Membran.

Fig. 22 b. Theil eines unter Deckglas abgeschlenderten Sporangiums; die unten breit aufgequollene Sporenhülle (b) verschmälert sich nach oben zu unter der Sporangien-Membran, wo die Sporen der letzteren eng anliegen.

Fig. 23. Krystalloïde aus dem Inhalt des Fruchtträgers.

Fig. 24-27. Verschiedene Formen der Körper aus oxalsaurem Kalk, welch im Inhalt des Fruchtträgers vorkommen.

Fig. 30-32. Derselbe Fruchtträger in verschiedenen Stadien bei ausnahmsweiser Entwickelung; bis a in Wasser.

Fig. 29. Dieselbe Anlage hat zwei Fruchtträder entwickelt $a$ und $b ; b$ ist an der Spitze c verletzt und abgestorben und hat seitlich den Fruchtträger d entwickelt.

Fig. 33. Zu einer Schlinge gedrebter Fruchtträger mit Sporangium, das sich oben durch eine Wand rom Träger getrennt hatte. 
Fig. 28. Der Theil A in der Fig. 1 Taf. XXIII. bei stärkerer Vergrösserung; bei b hat sich der abgerissene Mycelium-Schlauch durch eine Querwand geschlossen, die sich schon nach Aussen stülpt, bei a ist eine solche Scheidewand ausgewachsen und hat sich an dieser Stelle die Membran stark verdickt.

Fig. 34. Verzweigtes Pilobolus-Pflänzchen, a hat sich nicht weiter entwickelt und hat den Ast b getrieben, der sich zum vollständigen Fruchtträger entwickelte.

Fig. 35. Verzweigter Fruchtträger. 1)ie Spitze a hat aufgehört zu wachsen und unter derselben entstanden $z$ wei Aeste die sich jeder zu einem Fruchtträger ausbildeten.

Fig. 36. Abnormal gebildete Sporen aus einem Sporangium mit farbloser Membran. a. gewöhnliche Form, b. Inhalt ausgeführt abnormale Form.

Fig. 37-39. Verschiedene Columellen.

Fig. 40. Eben angelegte Sporen mit noch feinkörnigen, vacuolenbaltigen Inhalt, a. zu P. microsporus gehörig, b. zu P. crystallinus Form b und c.

Fig. 41. Sporen des P. crystallinus Form a, welche spontan entstanden; in der Mitte einen lichten Fleck zeigend.

Fig. 42. Sporen des P. crystallinus auch spontan entstanden, an beiden Enden einen lichten Fleck zeigend.

Fig. 43. a unveränderte Spore, b lichter Fleck grösser geworden, bei c ist derselbe noch grösser und deutlich als Vacuole zu erkennen, d Spore hat ausgekeimt (in Pferdemist).

Fig. 44. Keimung der Sporen von P. crystallinus. a. in Fruchtsaft. a Spore grösser geworden, b und c Spore rund, Inhalt lichter körnig, d beginnt auszukeimen, e und $f$ Sporen mit kleinen Keimschläuchen, e im Inbalt Vacuolen enthaltend.

Fig. 45. Auskeimende Sporen von P. crystallinus a im Wasser, Inhalt sehr dünn mit grossen Vacuolen, die gelben und rothen Körnchen Bewegung zeigend.

Fig. 46. Fruchtträger in zweiter Generation aus den Sporen des spontan entstandenen $\mathbf{P}$. crystallinus hervorgegangen.

Fig. 47. Sporen wie sie oft in demselben Sporangium vorkommen, der Form angehörig, welche aus den spontan entstandenen Sporen des P. crystallinus entsteht.

Fig. 48 und 49 wie Fig. 46

Fig. 50. Fruchtträger mit lauter kugelrunden Sporen (wie b in Fig. 47) aus den spontan entstandenen Sporen des P. crystallinus hervorgegangen.

Fig. 51. Auskeimende Sporen des in zweiter Generation entstandenen P. crystallinus, erste Art der Keimung mit sehr dünnen Schläuchen.

Fig. 52. Wie Fig 51. Zweite Art der Keimung mit dicken Keimschläuchen bei $\mathbf{a}$ ist $\mathrm{sp}$ die Spore, in den Schläuchen, Inhalt mit Vacuolen, Körnchen $\mathrm{Be}$ wegung zeigend.

\section{Pilobolus microsporus Klein.}

Fig. 53. Mycelium-Theil mit einer sich bildenden Anlage a, einer eben vollendeten $b$ und einer bereits $z u$ einem Fruchtträger ausgewachsenen $c$.

Fig. 54. Anlage mit drei obconischen Mycelium-Erweiterungen beginnt eben zum Fruchtträger auszuwachsen.

Fig. 55. Anlage einen kleinen Schlauch getrieben.

Fig. 56 Aus einer Anlage hervorgewachsener Schlauch mit noch spitzen farblosem Ende.

Fig. 57. Anlage mit ausgewachsenem Schlauch, dieser oben bereits etwas keulig angeschwollen.

Fig. 58. Noch mehr angeschwollenes Schlauchende; Inhalt beginnt sich oben anzuhäufen. 
Fig. 59. Weiteres Stadium, Inhalt in Stränge angeordnet in welchen die Körnchen des Inhalts lebhaft nach oben strömen.

Fig. 60. Sporangium wird angelegt, der angebäufte Inhalt grenzt sich nach unten scharf $a b$.

Fig. 61. Sporangium durch eine Querwand vom Träger abgesondert, a bis b der Theil der später zur blasenförmigen Anschwellung des Trägers wird.

Fig. 62. Ein entwickelter P. microsporus, a die Anlage von zwei obconischen Mycelium-Erweiterungen, b b getragen, c der Stiel des Trägers unten deutlich ron der Anlage gesondert, oben in einen Winkel in die Anschwellung d des Trägers übergehend, welche das Sporangium e trägt (im benetzten Zustand).

Fig. 63. Oberer Theil des Fruchtträgers, in Luft betrachtet.

Fig. 64. Sporangium-Membran vom Trăger abgerissen, in Wasser quillt die Sporenbïlle a hervor, Sporangium hat sich in die Höhe gezogen, darunter die gefärbte Columella sichtbar.

Fig. 65. Oberer Theil eines Trägers ohue Sporangium, die gefärbte schwach gewölbte Columella zeigend.

Fig. 66. Sporen mit einem lichten Fleck in der Mitte.

Fig. 67. Sporen ohne lichten Fleck.

Taf. XXIX u. XXX (mit fortlaufender Fig.-Nummer).

Fig. 1-5 Mucor des spontan entstandenen P. crystallinus.

Fig. 1. Ausgekeimte Spore im Fruchtsaft unter Deckglas.

Fig. $2 \alpha-2 \delta$. Theile eines Präparates. $2 \alpha$. Anfang des Myceliums, a Spore mit den anhaftenden Episporium. 2 $\beta$. Mycelium-Partien mit den nachträglich durch Ausstülpung ontstandenen Aestchen $\mathrm{c} c \mathrm{c}$ und $\mathrm{c}^{\prime}$. $2 \gamma$. Endtheil des Myceliums nit drei Hauptästen; d, d, d junge Astanlagen; c, c, c nachträglich entstandene Ausstülpungen. Ast e bat sich als Fruchthyphe f über die Flüssigkeit erhoben. $2 \delta$. Oberer Theil der Fruchthyphe mit dem Sporangium, g g die Stelle wo die Columella angeheftet ist.

Fig. 3. Sporen aus verschiedenen Sporangien.

Fig. 4. Columella mit netzförmiger Zeichnung, van den Eindrücken der Sporen herrübread.

Fig. 5. Verzweigte Fruchthyphe mit zwei unvollkommenen Sporangion.

\section{Fig. 6-25 Mucordes in zweiter Generation entstandenen P. crystallinus.}

Fig. 6. In Fruchtsaft ausgekeimte Spore sp. Bei c und c bilden sich Conidien. Fig. $\tau \varkappa-\delta$. Fruchthyphen in verschiedenen Stadien zur Sporangienbildung.

Fig. 8. Farbiges grosses Sporangium.

Fig. 9-10. Kleinere Sporangien.

Fig. 11. Columella eines grossen Sporangiums mit den Sporen a und b.

Fig. 12. Columella des Mucor, der aus Kugelhefe entstanden ist

Fig. 13. Columella eines kleinen Sporangiums.

Fig. 14. Ausgekeimte Spore sp.

Fig. 15. Keimende Mucorspore des Pilobolus.

Fig. 16, 17 und 18. Conidien.

Fig. 19. A. Conidien entstanden an einem jungen Keimschlauch aus einer Pilobolus-Spore. B nach 18 Stunden unter Deckglas aus A entstanden, die Coni- 
dien haben viele seitliche Zellen und Ausbuchtungen gebildet. a, b, c, d, e, f die gleichen Theilen bezeichnend.

F ig. 20. a und b aus Conidien entstandene Kugelbefe.

Fig. 21. Cunidien noch am Mycelium befestigt treiben seitliche Zellen.

Fig. 22. Die Conidie a hat seitliche Zellen gebildet und den Schlauch b getrieben, der in mehrere Zellen sich theilte.

Fig. 23. Kugelhefe hat ausgekeimt und bei a wieder Conidien gebildet.

Fig. 24. Unter Deckglas aus Kugelhefe ausgekeimter Schlauch, der am Ende die Conidien a bildete und sich theilweise in kurze Zellen theilte b.

Fig. 25. Unter Deckglas ausgekeimte Kugelhefe.

Fig. 26. Chlamydosporen eines Ascobolus, in Pilobolus-Culturen oft erscheinend. Fig. 27. Ueberwinterungsstadien (?) von Pilobolus-Fruchtträger-Anlagen. 


\title{
Ueber den Bau und die Entwickelung des Pollens bei Ceratozamia longifolia Miq.
}

\author{
Von \\ Prof. Dr. Ludwig Jurányi \\ in Pest
}

(Hierzu Taf. XXXI-XXXIV).

Wie bekannt waren bis jetzt die Entwickelungsverhältnisse der Pollensäcke und der Pollenkörner der Cycadeen kein Gegenstand einer näheren und eingehenderen Untersuchung, selbst die Angaben über den Bau der fertigen, vollständig entwickelten Pollenkörner, und über die Veränderungen welche sie unmittelbar vor oder während der Befruchtung erleiden sind dürftig und lückenhaft. Nur von Schacht ${ }^{1}$ ) besitzen wir bis jetzt einige wenige Angaben über den Pollen der Zamia, deren Werth aber bei ihrer Unvollständigkeit auch noch durch die Wiedersprüche, denen man in ihnen begegnet, herabgemindert wird. -

Um meine Behauptung zu begründen wird es nicht überflüssig Schacht's Angaben hier anzuführen. Er sagt (1. c. p. 145): „Endlich hat Zamia ein kleines Pollenkorn mit einer sehr tiefen Längsfalte, welche sich im Wasser nicht ausgleicht (Taf. XVII Fig. 26, 27). Dieser Falte gegenüber liegt die kleine Tochterzelle, welche erst bei sehr gelungenen Querschnitten sichtbar wird (Fig. 28) und wahrscheinlich wie bei Cupressus nicht zur Ausbildung kommt, während die grössere sich als Pollenschlauch verlängert" u. s. w.; und auf Seite 155: „Bei Nadelhölzern bildet die lntine nicht selbst den Pollenschlauch, es entstehen vielmehr durch Theilung in ihr zwei Tochterzellen von

1) H. Schacht, Ueber den Bau einiger Pollenkörner in Pringshoim's Jahrb. f. wiss. Bot. Bd. IL. p. 144-155. 
Ueber d. Bau und d. Entwickelung d. Pollens bei Ceratozamia longifolia Miq.

ungleicher Grösse, deren grössere entweder direkt zum Pollenschlauche auswächst (Cupressus, Taxus, Arancaria (?), Zamia (?) oder deren kleinere" etc. -

Wenn man nun die hier angeführten Stellen und auch die beigefügten Zeichnungen vergleicht so kann es niemanden entgehen, dass während Schacht behauptet dass die kleine Tochterzelle „erst bei sehr gelungenen Querschnitten sichtbar wird " er sich zugleich durch seine eigene Zeichnungen widerlegt, denn neben der Fig. 28, welche die durchgeschnittene Pollenzelle darstellen und zur Erklärung der soeben erwähnten Angabe dienen soll, finfinden wir auch die Fig. 26, welche eine unverletzte und vollstän. dig entwickelte Zelle zeigt und bei welcher in der Erklärung der 'Tafeln mit dem Buchstaben d die sichtbare kleine Tochterzelle bezeichnet wird. -

Die Unsicherheit dieser Angaben wiederholt sich auch dort, wo über die Bildung des Pollenschlauches die Rede ist, denn auf Seite 145 wird es als eine feststehende Thatsache mitgetheilt, dass von den beiden Tochterzellen die grössere zum Schlauche auswächst, während auf pag. 155 dieselbe Angabe init Fragezeichen begleitet wiedergegeben wird.

Schon aus dieser kurzen Auseinandersetzung erhellt es zur Genüge, dass uns Schacht's angeführte Angaben in jeder Richtung im Unklaren lassen, sogar auch darin, ob die Pollenkörner der Zámia wirklich nur eine kleine Tochterzelle haben, denn die Entscheidung dieser Frage von der Schärfe des Messers abhängig zu machen, bietet meiner unmassgeblichen Meinung nach keine genügende Sicherheit. -

Es sind also noch eine Reihe von Fragen deren Lösung uns allein die lückenlose Kenntuiss theils der Entwickelungsgesetze und des Baues der männlichen Cycadcenblüthe, theils aber auch dic vollständige Kenntniss der verwandtschaftlichen Beziehungen dieser Familie zu den übrigen Phanerogamen einerseits und zu den höheren Kryptogamen andererseits ermöglicht hätte, ungelöst geblieben. -

Unter diesen Umständen war es nun hinreichend begründet, um die mir durch das Blühen der oben genannten männlichen Pflanze gebotene Gelegenheit zu benützen, und die fraglichen Verhältnisse zum Gegenstande meiner Untersuchungen zu machen; und da ich im Laufe derselben zu Ergebnissen gelangt bin die mir wenigstens theilweise unsere bisherigen Kenntnisse zu ergänzen 
geeignet erscheinen, entschloss ich mich, die Resultate meiner Arbeit àer Oeffentlichkuit zu übergeben.

Die Fragen, deren Lösung ich mir zur Aufgabe machte, sind in Folgendem kurz zusanmenzufassen:

1. Wie entstehen die Pollensäcke, und wie differenzirt sich in ihnen das Gewebe zur Bildung der Urmutterzellen der Pollenkörner?

2. Wie entwickeln sich die Mutterzellen der Pollenkörner und diese in jenen?

3. Wie sind die Pollenzellen der Ceratozamia gebaut?

4. Wie verhalten sich die Pollenzellen dieser Pflanze vor und während der Schlauchbildung?

Die erste Entstehung der Pollensäcke konnte ich leider nicht beobachten, - dieses geschieht noch zu der Zeit als die Blüthe noch von den seidig harrigen Schuppen des Stammendes bedeckt und also ihr Vorhandensein nicht zu bemerken ist. Ich habe die Entwickelungsweise der Pollensäcke nur von der Zeit angefangen verfolgen können als sich die Spitze der Blüthenaxe schon etwa $2 \frac{1}{2} \mathrm{Cm}$. hoch über die obersten Schuppen des Stammes erhob. - Zu dieser Zeit sieht man dass die Schuppen dicht gedrängt gestellt und unter einander so fest eingeklemmt sind, dass nur ihre zweibörnige und gedunsene Spitze frei hervorragt, sonst aber sie sich an ihrer ganzen übrigen Oberfläche eng berühren. Wegen dieser Anordnung und wegen ihrer ausserordentlichen Brüchigkeit ist es nun beinahe unmöglich, eine Schuppe unverletzt herauszunehmen, gelingt es aber einen grösseren Theil derselben mittelst der Lanzette herauszuschneiden, so sieht man an ihrer unteren Fläche eine grosse Anzahl von dicht neben einander stehenden kleinen Papillen - die eben die in Entwickelung begriffenen jungen Pollensäcke sind -, denen entsprechend auf der oberen Seite eine jec̉e Schuppe grubig erscheint. -

Macht man während dieses jungen Entwickelungszustandes, während welches die Pollensäcke in ihrer Höhe $\frac{1}{4}-\frac{1}{3}$ Mm. erreicht haben, zarte Quer- oder Längsschnitte durch die Schuppe so wird es dadurch möglich nicht nur über den Bau der jungen Pollensäcke und über den Zusammenhang derselben mit dem Gewebe der Schuppen sich ein klares Bild zu verschaffen, sondern auch über ibre Entstehungsweise eine den Verhältnissen entsprechend richtige Vorstellung zu erlangen. Bei diesem Verfahren findet man folgendes. Vor allem fälit es in die Augen des Beobachters, dass 
ein Theil des Gewebes der Schuppen durch zahlreiche und geräumige Gummigänge durchzogen ist, selbst aber aus zwei differenten und ungleichwerthigen Partien besteht. Derjenige Theil des Gewebes in welchem die eben erwähnten Gummigänge eingebettet sind bestebt durchgängig aus isodiametrischen und gleichförmig gestalteten grossen Zcllen, er erstreckt sich rom kurzen Stiele der Schuppe angefangen bis zu den Hörnern derselben und bildet somit die Hauptmasse des Schuppenkörpers. - Die zweite Gewebspartie ist von geringerer Mächtigkeit und Ausdehnung, sie überzieht als eine aus 6-8 Zelllagen bestehende Schicht die untere Fläche der schildförmigen Schuppe und zwar so dass sie über dem Stiel ihren Anfang nimmt und sich dann bis zu der zu dieser Zeit allein frei hervorragenden gedunsenen Spitze continuirlich ausbreitet. - Ihre Zellen sind klein zartwandig, reich mit protoplasmatischem Inhalte erfüllt und zeigen die Charaktere der Meristemzellen. Dieses letztere Gewebe ist es nun mit welcher die Pollensäcke in unmittelbarem Zusammenhange stehen. -

Die jungen Pollensäcke sitzen zu dieser Zeit mit ziemlich breiter Basis den Schuppen auf, sie sind beinahe cylindrisch, mit abgerundetem stumpfen Eude, umgeben von ziemlich zahlreichen, cinfachen schlauchförmigen Haaren. Durch ihre äussere Erscheinung erinnern sie an mit Paraphysen umgebenen Antheridien, während sie bei einem Längs- oder Querschnitte der Schuppen eine nicht geringe Aetulichkeit mit jungen in Reihen gestellten und in Entwickelung begriffenen Samenknospen zeigen. - Ihr Gewebe hängt wie rorhin erwähnt mit der meristemartigen Gewebspartie der Schuppe zusammen, und bei gut gelungenen Längsschuitten der Pollensäcke sieht man dass sie sich aus diesem Meristeme erheben und dass ihr Gewebe gleichsam lappenförmige Fortsätze desselben bildet. - Der unmittelbare Uebergang des Meristems der Schuppo in das Gewebe des Pollensackes ist um so deutlicher erkennbar, da die Gewebszellen des letzteren besonders an seinem Grunde und unteren Theile, der Grösse und Gestalt nach vollkommen mit den Zellen des Meristems der Schuppe übereinstimmen, ferner da beide eine gemeinsame und ununterbrochene Oberhaut besitzen. -

Es ist durch diese Verhältnisse wie ich glaube zweifellos klar, dass die Pollensäcke ihre Entstehung dem die untere Fläche der Schuppen überziehenden Meristeme verdanken, aus welchem sie 
sich wahrscheinlich als anfangs aus wenigen Zellen bestehende kleine Zellgruppen herrorheben.

Haben nun die Pollensäcke lie oben angegebene Grösse erreicht, so unterliegen sie bei ihrer weiteren Entwickelung Veränderungen, die sich in doppelter Richtung geltend machen, dennindem sie durch das fernere Wachsthum ihre Gestalt und Grösze verändern, beginnen in dem Gewebe derselben Vorgänge, deren Endresultat die Bildung der Pollenkörner ist.

Schon bei sehr jurgen Pollensäcken - den jüngsten die ich intersuchen konnte - war zu bernerken, dass ihr Gewebe nicht durchgängig aus gleichartigen Zellen bestand. Diese Ungleichartigkeit der Zellen aber war nicht sowohl dureh die abweichende Form als rielmehr durch dir Terechicdenbeit der Grössc der Guwebszellen brmerkinr; denn wähend die unteren und die periphorisch gelegenen Zellen de: jungen Pollensuckes in Grösse und G(stalt ron Wrin Zellen des Meristens der. Schuppe kaum eine geringe Abweichung zejgten, waren die central gelegenen Zellen besonders tureh ihre überwiegende Grösse von den übrigen sie umgebenien Zellen ausgezeichnet. (Taf. XXXI. Fig. 16).

Während d reh diese Verschiedenheit der Grösse der centralen Zullen ihr abweichendes Verhalten in Wachsthum und Vermehrung dentlich ausgesprochen erscheint, ist uns dadurch zugleich die Gelegenhcit geboten in ihr den Anfaug der Differenzirung des Gewebes zu erkennen.

$\mathrm{Da}$ sich nun diese zuerst grösser gewordenen Zellen nur in langsamer Folge theilen und kurz nach ibrem Auftreten auch die übrigen Zellen des Gewebes - mit Ausnahme der zwei oder drei äussersten Zellreihen, deren Aufgahe die Bildung der Wand des Pollensackes ist - sich den centralen Zellen entsprechend zu verhalten beginnen, so wird durch diesen Vorgang in Innern des Pollensuckes ein aus grosses isodiametrischen Zcllen bestehendes Gewebz entwickelt, welches durch dic späteren Theilungen-seiner Zellen die Urmutterzellen, und mittelbar die Specialmutterzellen der Pollenkörner hervorzubringen berufen ist.

Die differenzirten Zellen theilen sich zu dem Zwecke - vachdem sie ihre volle Grösse erreicht haben - rasch nacheinander und in jeder Richtung bis durch die letzten Theilungen die Urmutterzellen des Pollens angelegt werden, welche nun das Innere des Pollensackes erfüllen. (Taf. XXXl Fig. 2).

lhrer Gestalt nach sind sie fast cubisch, sie besitzen sehr 
zarte Wände und sind mit protoplasmatischem Inhalte, in welchem der grosse Kern eingebettet liegt, vollständig erfüllt. - Der Zusammenhang dieser Zellen ist so stark, dass sie sich nicht unverletzt trennen lassen. - Wenn nun die Urmutterzellen in ihrer Entwickelung so weit vorgeschritten sind, um ferneren Entwickelungsprozesseu zuin Ausgangspunkte dienen zu können, so sieht man in ihnen plötzlich eine senkrechte, d. h. mit der Längsachse des Pollensackes parallel laufende Wand auftreten, wodurch sie in je zwei nebeneinander stehende Zellen zerfallen (Taf. XXXI Fig. 3bb). Dieser Theilung folgt dann in beiden dieser Schwesterzellen eine zweite Theilung durch eine Querwand, so dass nun die ursprüngliche Mutterzelle in vier zu zweien übereinander gestellten Zellen getheilt erscheint (XXXI Fig. $4 q$ ).

Die so entstandenen Zcllen bilden aber noch nicht unmittelbar die Speciulnutterzellen der Pollenköruer, sie sind zu diesem $Z_{w e c k e}$ noch einer Theilung unterworfen, die durch eine senkrechte aber die erste Theilungsebene kreuzende Waud erfolgt (XXXI Fig. 5 b $b_{1} b_{1}$ ).

Durch diese letzte Theilung sind nuu die Specialmatterzellen der Pollenkörner angelegt, indem eme jede der zuletzt entstandenen Zelleu die Grundlage einer solchen bildet. Nach ihrer Entstehung trennen sich nämlich diese Zellen von einander - so wie wir es auch bei den übrigen Phanerogamen finden - und treten dann als îreie, isolirte Zellen vor. - Sie liegen aber gleich nach ihrer Sonderung im Pollensacke dicht gedrängt neben einander und behalten auch einige Zeit ihre gegenseitige Lagerung (Taf. XXXI Fig. 6). Sie stellen meistens elliptische oder auch ovale Zellen vor, die ungemein zartwandig und mit einem hellen grossen Kerne im reichen plasmatischen Inhalte versehen sinci. - Mit ihrem Grösserwerden erleiden sie hauptsächlich nur die eine Verände rung, dass ihre Wandung dicker wird unu in Folge dessen später doppelt contourirt erscheint. - In Wasser gelegt zeigen diese Specialnutterzelleu alle jene Erscheinungen, welche man an äbnlichen jungen Zellen zu beobachten gewohnt ist.

Wäbrend der Entwickelungsgang bis zu der Bildung der Specialmutterzellen ein auffallend langsamer ist, folgen nun die fortschreitenden Veränderungen in diesen rasch aufeinander. - Bald nach. dem die Specialmutterzellen ihre volle Grösse erreicht haben, schicken sie sich zur Bildung ibrer Tochterzellen beziehungsweise der Pollenkörner an. Der Vorgang wird damit begonnen, dass der grosse Kern der Specialmutterzelle verschwindet und statt 
desselben nun $z$ wei neue aber kleinere Kerne in der Zelle erscheinen. Das Auftreten dieser neuen Kerne erfolgt in der Längs. achse der meist elliptischen Zellen an denjenigen Stellen, wo sie dann während und einige Zeit auch nach der ersten Theilung der Specialmutterzelle verbleibend, die Centra der zunächst entstehenden Tochterzellen bilden (Taf. XXXI Fig. 8, 9, 10x).

Nach dem Auftreten der neuen Kerne bleiben die Special. mutterzellen nur kurze Zeit unverändert, denn bald erfolgt die Theilung derselben durch eine Scheidewand, mit deren Auftreten auch die gleichzeitige Snnderung des Inbaltes in zwei Parthien zu beobachten ist.

Dass die Trennung des Plasmas in zwei Theile nicbt vor dem Auftreten der Scheidewand sondern gleichzeitig mit derselben erfolgt, wird auch durcb den Umstand bestätigt, dass bei diesen Spccialmutterzellen nach dem Auftreten der secundären Kerne das Érsclicinen einer körnerlosen hyalinen Plasmaplatte nicbt nachweisbar ist. - Wohl kommt es ror, dass man zuweilen Specialnutterzellen mit zwei Kernen antrifft, deren Inhalt in zwei vollständig getrennte Parthien gesondert erscheint und $\mathrm{zwar}$ so, dass die Richtung ihrer Trennung mit der Theilungsebene der Zelle zusammenfält (Taf. XXXI Fig. 9). - Dieser Erscheinung kann man aber um so weniger die Kraft eines Beweises zuschreiben, da es leicht zu beobachten ist, dass diese Trennung des plasmatischen Inhaltes in den sonst unter sich vollkommen gleich entwickelten Specialmutterzellen bald eintritt, bald aber das gerade Gegentheil erfolgt, inden der I I halt der Zelle sich im mittleren Theile derselben, also zugleich auch in der ersten Theilungsebene zusammenballt ( $\mathrm{Taf}$. XXXI Fig. 10). - Die entsprechenden Verhältnisse sind auch bei solchen Specialmutterzellen leicht aufzufinden, bei welcher die Entwickelung der Scheidewand begonnen hat (Taf. XXXI Fig. 11, 12). Nach dem eben gesagten muss ich also diese Erscheinung als eine zufällige und mit dem Entwickelungsgange dieser Zellen in keinem nothwendigen Zusammenhange stehende betrachten.

Die Richtung der ersten Theilung dieser Specialmutterzellen liegt in einer Ebene, welche indem sie die Längsachse der sich theilenden Zelle senkrecht schneidet, dieselbe zugleich in $\mathrm{zwei}$ gleich lange Hälften theilt; der Peripherie dieser Ebene entsprechend erfolgt nun die Bildung der die Theilung vollziehenden Scheidewand; sie erscheint als ein plattes breites die Zelle gürtelförmig umlaufendes Band (Taf. XXXI Fig. 13w), welches im opti- 
schen Durchschnitte der Zelle als ein sehr kleiner keilförmiger Vorsprung in dieselbe hineinragt (XXXI Fig. 14w). - Die auf diese Weise auftretende junge Scheidewand wächst nun so lange in die Zelle hinein bis sie dieselbe in $\mathrm{zwei}$ rollständig getrennte Tochterzellen getheilt hat. Gleich rom Beginue ihrer Entwickelung zeigt sie eine rasche und kräftige Zunahme in ihrer Dicke, so dass sie in Folge dessen zu Anfang der Theilung in Dicke und Breite gleichmässig zu wachsen scheint; bald aber wird ihr Wachsthum in die Dicke von dem in die Breite überholt und sie erscheint dann, wenn sie ungefähr schon zwei Drittel ihrer Breite erreicht hat, als ein auf breitem Grunde aufsitzender, mehr oder weniger stumpfer Kegel (Taf. XXXII Fig. 1w, 2w), welcher von nun an vorwiegend nur an seiner Spitze wachsend und sich so zu einer ziemlich dünnen Membran gestaltend die Theilung vollendet (Taf. XXXII Fig. $3 w, 4 w, 5 w)$.

Während der Entwickelung der Scheidewand verdickt sich auch die Wand der Mutterzelle im allgemeinen wohl nur unbeträchtlich, dort aber, wo sich die Scheidewand an die Wand der Mutterzelle ansetzt geht das Dickenwachsthum in so hohem Grade vor sich, dass dadurch die Bildung eines die Zelle scheinbar von aussen ringförmig umschliessenden scharfen kammförmigen Wulstes bewirkt wird (Taf, XXXII Fig. 1-15).

Kurz nach Vollendung dieser ersten Theilung erfolgt die Theilung der entstandenen Schwesterzellen. Der Scheidewandbildung geht auch hier das Auftreten der neuen Zellkerne voran, und fast unmittelbar darauf ist die Verdickung des mittleren dünneren Theiles der ersten Scheidewand zu beobachten (Taf. XXXII Fig. 6w). Sind die neuen Zellkerne schon entwickelt, so bemerkt man, dass sie in den Schwesterzellen meistens nicht in entsprechender Lage sind, und es sind eben in Folge dessen in dieser Beziehung zwei Fälle zu unterscheiden; in dem einen sind alle vier Kerne der beiden Schwesterzellen in einer und derselben Ebene gelegen, folglich auch auf einmal und mit gleicher Deutlichkeit zu senen (Taf. XXXII Fig. 5x), während in dem anderen Falle die Ebenen in welchen die Kerne gelagert waren sich unter rechtem Winkel kreuzten, d. h. die Zellkerne waren in diesem Falle den Ecken eines Tetraëders entsprechend gestellt (Taf. XXXII Fig. 6x).

Da nun durch die Lage der Kerne in den sich zur Theilung vorbereitenden Zellen meistens anch die Richtung mit Sicherteit angegeben ist, in welcher das Wachsthum der Scheidewand zu cr. 
folgen hat; so war es auch in diesen Fällen möglich schon vor Beginn der Scheidewandbildung die Verschiedenheit in den Thei. lungsrichtungen der beiden Tochterzellen zu erkennen. - Gemäss dieser Anordnung der Kerne sind also die sich entwickelnden oder die schon fertigen Scheidewände der Tochterzellen entweder so gestellt, dass sie in beiden in derselben Ebene liegen (Taf. XXXII Fig. 7, 11, 15 bei $\mathrm{k}$ ), oder so dass inden die Scheidewand der einen Tochterzelle mit sammt der ersten Theilungsrichtung der Specialmutterzelle auf die Unterlage senkrecht steht, die Theilungsebene in der zweiten Tochterzelle, :nit derselben parallel läuft (Taf. XXXII Fig. 8, 9, 10 l. k.).

Die Bildung der Scheidewände in den angegebenen Richtungen erfolgt bald nach dem Auftreten der Kerne. Ihre Entwickelung geht im allgemeinen sehr rasch vor sich so dass bei dieser Theilung Mittelzustände nur selten und schwer anzutreffen sind. Am leichtesten gelingt es noch solche am Anfange der Theilung aufzufinden, wo dann die jungen Scheidewände als mebr oder weniger breite stramı ausgespannte un l sichelförmig in die Zelle hineinragende mit scharfem Rande endigende Membranen erscheinen (Taf. XXXII Fig. 8, 9, 10 1.). - Es sei bier noch erwähnt dass die Theilung in beiden Tochterzellen fast ausnahmslos gleichzeitig vor sich geht, und dass ich nur eine Specialmutterzelle fand bei welcher die eine Tochterzelle der anderen in dieser Hinsicht zurorkam (Taf. XXXII Fig. 12).

Bevor ich zur Schilderung der nach der Theilung der Specialmutterzellen eintretenden Entwickelungsvorgänge übergehe sei es mir gestattet, früher noch eine Eigenthuinlichkeit derselben kurz zu erwähnen. - Es ist dies die hochgradige Quellbarkeit ihrer Wände, welche sich vorwiegend in radialer Richtung und besonders während der Bildung der ersten Scheidewand zeigt. - Lässt man nämlich diese Zellen einige (5-8) Stunden in Wasser liegen, so erreicht die Quellung ihrer Wände einen so hohen Grad, dass sie sich endlich in zwei bis drei Lamellen spaltec (Taf. XXXII Fig. 16, 17). Die Trennung in einzelne Lamellen beginnt immer in der nächsten Nähe der in Entwickelung begriffenen jungen Scheidewand, und von hier breitet sie sich dann auf die übrige Zellwand aus. Es ist nun bei dieser Spaltung der Zellwand noch zu bemerken, dass sie - wenigstens in den von mir beobachteten Fällen - niemals gleichmässig in der ganzen Ausdehnung der Zellwand erfolgt, vielmehr ist sie nur auf die eine oder die andere 
Seite ?er Zelle beschränkt, und tritt in grösserer oder geringerer Ausdehnung auf. - Die Quellbarkeit der Wände der Specialmutterzellen wird nach der Tbeilung ihrer Tochterzelleu im allgesneinen geringer, es tritt aber bei ihnen zu dieser Zeit ein Verbalten auf, welches während oder nach der Entwickelung der ersten Scheidenicht zu beobachten ist. Nach der Entwickelung der secundären Scheidewände wird näılich die Wand der Specialmutterzelle an jener Stelle am meisten quellbar, wo sich ihr die Scheidewand ansetzt. - Die Quellbarkeit der Zellwand an dieser Stelle ist so hochgradig und mächtig, dass in Folge dessen die Scheidewand schon nach kurzem liegen in Wasser entweder plötzlich abreisst (Tuf. XXXII Fig. 12, 14 bei n) ohne dass die Spaltung der Zellwand in Lamellen erfolgen würde, - oder aber es schrcitet lie Quellung langsamer vor und in diesem Falle trent sich mit der sich los!ösenden Scheidewand auch die Zellwand mehr oder weniger in zwei Lamellen, von welchen die innere mit der Scheidewand auf beiden oder nur auf einer Seite in Verbindung bleibt (Taf.XXXII Fig. 11, 13, 15 bei g). Der Theil der Wandung der Specialnutterzelle, von welcher sich die Scheidewand losgetrennt hat, breitet sich nach der Trennung gewöhnlich aus und stellt dann ein rerschieden dickes aber immer zartes Membranstück vor, welches die dickeren und nicht zerspalteten Theile der Zellwand gleichsam überbrückt. -

Nach Vollendung der Theilungen der Specialmutterzelle entstehen aus dem Inhalte ihrer Tochterzellen die Pollenkörner. Die Bildung derselben und nach ihrem Zustandekommen die Auflösung und das Zerfallen der Wände der Specialmutterzelien geht ungemein rasch vor sich, wenigstens spricht dafür der Uustand, dass es mir trotz der angewendeten Mühe und Aufmerksamkeit kein einziges Mal gelang, junge Pollenkörner enthaltende Specialmutterzellen zu finden.

Kurz nach ihrer Befreiung aus den Mutterzellen sind die kugeligen jungen Pollenkörner einzellig, besitzen eine zarte doppelt contourirte und glatte Wand. Ibr Inhalt besteht aus ungemein feinkörnigem Plasma in welchem der grosse und belle Zellkern eingebettet liegt; Stärkekörner oder andere geformte Bestandtheile des Zellinhaltes sind nicht vorhanden. - In Wasser quellen sie wenig auf, in Folge der Wasseraufnahme treten in ihrem Inhalte, und zwar in unmittelbarer Nähe des Zellkcrnes mehrere kleine Vacuolen nacheinander auf, welche sich daun zu grösseren vereinigen und 
so heran wachsen, dass sie die Anordnung des Inhaltes zerstören und auch die Schrumpfung desselben bewirken können (Taf. XXXII Fig. 18 a, b, c). - Mag aber die Aufnahme des Wassers noch so reichlich sein, so ist bei diesen Pollenkörnern - und zwar sowobl bei jungen als bei vollkommen reifen - das bei anderen Pollenzellen so allgemein vorkommende Aufplatzen in Wasser nicht zu beobachten.

Die Pollenzellen verharren nicht lange in ihrem einzelligen Zustande, denn bald darauf als ibre Intine - welche bei ganz jungen Körnern nicht zu unterscheiden ist - in die Erscheinung tritt, sieht man in ihnen plötzlich eine Scheidewand auftreten, welche das Innere des Kornes in zwei Zellen von ungleicher Grösse theilt. In beiden durch diese Theilung entstandenen Zellen jst im Inhalte der Zellkern - in der grösseren der beiden Zellen bedeutend grösser als in der kleineren - klar und deutlich wahrzunehmen. -

Die kleinere Tochterzelle des Pollenkornes wächst nach ihrem Zustandekommen rasch und so lange in das Innere ihrer Schwesterzelle hinein, bis sie in ihrer Höhe ungefäbr den dritten Theil des Durchmessers des Pollenkornes erreicht hat, und nun eine stumpfe kegelförmige der Wand des Pollenkornes aufsitzerde Zelle bildet (Taf. XXXIII Fig. 1a).

Da die beiden Tochterzellen des Pollenkornes ungleichwerthig sind, so sind auch jene Veränderungen, welchen sie fernerhin unterworfen sind, ron einander verschieden.

Nachuem die kleinere Tochterzelle schor vollkommen ausgewachsen ist, theilt sie sich durch eine zarte Querwand und $\mathrm{zwar}$ nahe zu ihrem Gruvile so, dass sic hierdurch in eine kleinere an die Wand des Pollenkornes anliegende und eine grössere balbkugelförmige obere Zelle zerfällt (Taf. XXXIII Fig. $2 w, 3 w$ ). Unmittelbar wach ihren Auftreten ist die junge Scheidewand so dünn, dass man sich ron ihrem Vorhandensein nur schwer überzeugen kann. - In solchen Fällen und auch überhaupt um zweifellos nachzu. weisen, dass die kleinere Tochterzelle wirklich durch Scheidewandbildung in zwei Zellen zerfällt ist es vortheilhaft, diese Zellen der Einwirkung solcher Mitteln auszusetzen, welche die langsame Contraction des Inhaltes bewirken können. Man sieht dabei vorerst die Schrumpfung der Zellkerne eintreten, welcher dann die $\mathrm{Zu}$ sammenziehung des Inhaltes aller drei Zellen folgt und nun die vorhaudene dünne Scheidewand klar erkeunen lässt. - Es ist hier 
noch zu bemerken, dass der Inhalt der grössten Tochterzelle bei ihrer Zusammenziehung auch die Intine mit sich fübrt und von ihr bekleidet wird; sie hat dann das Aussehen einer starken Hautschichte, von welcher sie sich aber schon durch ibre grössere Consistenz und in Folge dessen auch dadurch unterscheidet, dass sie sich bei Schrumpfung des Inhaltes wohl mit welliger sonst aber mit glatter Oberfiäche und von allen Punkten der Zellwand trennt und derselben nirgends angeheftet bleibt, es ist also die Bildung von an die Wand des Pollenkorues anklebenden Klumpen oder fadenförmigen Plasmastrahlen nicht zu beobachten (Taf. XXXIII Fig. 4, 5).

Die meisten Pollenkörner sind nun in diesem Entwickelungszustande geschlechtsreif und erleiden auch bis zur Zeit der Befruchtung keine weiteren Veränderungen. - Oft begegnet man aber Pollenkörnern die auf dieser Stufe der Entwickelung nicht stehen bleiben sonderu einen Schritt weiter gehen indem in der oberen halbkugelförmigen Tochterzelle die Theilung noch einmal eintritt, so dass also in diesen Fällen im Innern des Pollenkornes ein dreizelliger kleiner Zelliörper zu finden ist (Taf. XXXIII Fig. 8, 9, 10, 11). Vor dieser Theilung wächst die obere Zelle bedeutend in die Höhe, so dass sie über die Hälfte des Durchmessers des Kornes in die grosse Tochterzelle hineinragt (Taf. XXXIII Fig. 7c). Durch die Theilung zerfällt sie in beinahe gleiche Hälften, welche zugleich ungefähr dieselbe Grösse besitzen wie die basale Zelle, welche sie trägt (Taf. XXXIII Fig. 8). Später wachsen beide und besonders die Endzelle weiter, so dass letztere - indem sie vorwiegend an Breite zunimmt - als eine mehr oder weniger abgeplattete und ausgebreitete Blase der mittleren Zelle aufsitzt (Taf. XXXIII Fig.11d).

Sind die Pollenkörner schon vollkommen ausgebildet, so behalten sie im trockenen Zustande ihre kugelförmige Gestalt nicht, sie ziehen sich nämlich zusammen und zwar so dass die dadurch verursachte Einstülpung im höchsten Grade an der dem Zellkörper gegenüberliegenden Seite erfolgt und hierdurch eine Längsfalte gebildet wird welche das nun kahnförmige Korn in zwei fast gleiche Hälften theilt (Taf. XXXII Fig. 19f).

In diesem Zustande sehen nun diese Pollenkörner jener Zeich. nung die Schacht, l. c. in seiner Fig. 26 Taf. XVII uber Zamia mittheilt, ähnlich. -

Diese Längsfalte soll sich nach Schacht's Angaben niemals rollkommen ausgleichen, so dass also eine Längsfurche an den Pollenzellen der Zamia immer nachweisbar ist. Bei Ceratozamia 
ist dies nun nicht der Fall; die Läugsfalte der Pollenzellen dieser Cycadee verschwindet nämlich in dem Maasse als der Inhalt des Kornes sich mit Wasser sättigt, bis das Aufquellen den höchsten Grad erreicht und lie Zelle wieder vollkommen glatt und kugelig wird (Taf. XXXII Fig. 20, 21 ff.). Im trockenen Zustande sind natürlich auch die Zellen des kleinen Zellkörpers stark zusamınengefallen, so sehr dass man sie gleich am Anfange des Aufquellens kaum wahrnehmen kann; mit der fortschreiteuden Wasseraufnahme dchnen sie sich aber auch langsam aus und dann erscheinen ihre Umrisse als sehr zarte wellig hin und her gebogene Linien, die sich nach und nach ausstrecken und abrunden (Taf. XXXIII Fig. 6, 9, 10).

Um die Schlauchbildung zu studiren habe ich nach mehreren misslungenen Versuchen dic Pollenkörner auf ziemlich saftige Birnenstücke ausgesäet und diose Wahl war eine glückliche, denn während bei allen übrigen Versuchen die Pollenkörner nur bis zum Aufquellen gebracht werden konnten, zeigten diese Körner schon in 24 Stunden solche Veränderungen, die das Gelingen des Versuches hoffen liessen. - Die erste Aussaat wurde den 9. März 1870 gemacht und einen 'T'ag später war an den ausgesäeten Pollenkörnern folgendes zu beobachten. Alle Pollenkörner waren stark aufgequollen, sic zuigteu in ihrem plasmatischen Inbalte zahlreiche Körperchen von verschiedener Grösse, die sich durch die Einwirkung von Jod als Stärkekörner bestinmt erkennen liessen (Taf. XXXIII Fig. 13, 14 bei s). Die Intine erschien mit seltener Klarheit und Deutlichkeit, und es war an ihr leicht zu bemerken, dass sie an Dicke zugenommen hat.

Während die für die Pollenkörner der Coniferen so charak. teristische Erscheinung des Abstreifens der Exine bei den Pollenkörnern der Ceratozamia bis zu diesem Entwickelungszustande nicht zu beobachten ist, tritt sie nun auch bei diesen auf aber in einer für sie eigenen Weise. Mit der Zunahme an Dicke erlangt nämlich die Intine zugleich eine hochgradige Quellbarkeit, welche sich aber nicht sowohl in radialer als vielmebr und vorwiegend in tangentaler Richtung geltend macht. Die Richtung der grössten Ausdehnung bei ihrem Aufquellen ist also die ihrer Fläche; in Wasser gebracht dehnt sie sich dem gesagten entsprechend ungemein rasch aus und indem sie durch den grossen Druck den sie durch ihre rasche Zunahme an die Exine ausübt, letztere an der der im trockenen Zustande des Kornes sichtbaren Längsfalte entsprechenden Stelle aufreisst, tritt sie entweder mit ihrem grössten Theile aus 
der Exine heraus und bekommt dann eine mehr oder weniger birnenförmige Gestalt (Taf. XXXIII Fig. 13, 14) oder platzt sie ınit der Exine fast zugleich und entleert dann ibren Inhalt (Taf. XXXIII Fig. 12); das letztere kommt sehr selten und wahrscheinlich nur bei solchen Pollenkörnern vor, deren Intine noch nicht den höchsten Grad der Quellbarkeit erreicht hat.

Es ist hier noch zu bemerken, dass die Intine au der Stelle wo die Basalzelle des kleinen Zellkörpers der Exine aufsitzt von der letzteren nur ausnahmsweise losgelöst wird sonst aber in der Regel ihr angeheftet bleibt, und dass gerade dieser Umstand es mit sich führt dass einerseits die Exine nicht abgestreift wird und andererseits dass die platt: scheibenförmige Gestalt der Basalzelle in eine stumpf kegelförmige umgewandelt wird. - Uebrigens bleiben die inneren Zellen des Pollenkornes auch dann - wenigstens theilweise - in der Exine eingeklemmt, wenn sie von letzterer an allen Punkten losgelöst wurden, so dass also das vollständige Herausschlüpfen derselben nicht $\mathrm{zu}$ beobachten ist. -

Mit den eben erwähnten Eigenschaften versehen hat nun das Pollenkorn die Fähigkeit zur Bildung des Pollenschlauches erreicht.

Bevor sie noch den Schlauch zu entwickeln beginnen, werden in ihnen die Stärkekörner immer zahlreicher und grösser, und diese Zunahme an Zahl und Grösse erreicht einen so hohen Grad, dass sie beinahe allein das Innere des Kornes einzunehmen scheinen.

Der Pollenschlauch wird nun durch die grosse Tochterzelle

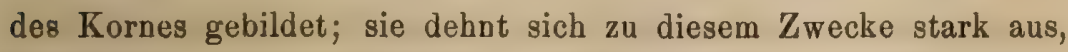
und indem sie die Exine an der der Längsfalte entsprechenden Stelle aufreisst, tritt sie mit stumpfem Ende aus derselben hervor. - Schon vor dem Austreten der schlauchbildenden Zelle ist es wahrnehmbar, dass sich das Protoplasma vor der Austrittsstelle ansammelt, und dadurch die zahlreichen Amylonkọrner zurückdrängt; dabei wird auch der grosse Zellkern sichtbar, welcher seine Stellung nicht verändert hat und jetzt gerade vor der Austrittsstelle des Schlauches gelegen ist (Taf. XXXIV Fig. 1x). Die weitere Entwickelung des Schlauches geht ziemlich schnell vor sich; die Schlauchzelle vergrössert sich anfangs nach allen Richtungen sehr stark und in Folge dessen tritt sie auch nicht selten mit ibrem grössten Theile aus der Exine heraus, welche sie dann nur theilweise von einer Seite umschliesst ('Taf. XXXIV Fig. 2e). Von nun an beschränkt sich das Wachsthum auf das zuerst ausgetretene stumpfe Ende der Zelle, welche sich allmälig verlängernd den mehr 
oder weniger cylindrischen Pollenschlauch bildet; sie wächst dabei entweder in gerader Richtung, oder sie krümmt sich zuerst nach der einen oder anderen Seite des Kornes hin, und fängt erst dann an zum Schlauche auszuwachsen. - Die Länge der entwickelten Schläuche war sehr verschieden, sie endigten entweder einfach oder stumpf ohne an ibrem Ende eine Verengerung oder Érweiterung zu zeigen, oder aber war ihr Ende ku;elig aufgetrieben, oder endlich zeigten sie auch eine Neigung sich zu verzweigen (vergl. die Fig. auf Taf. XXXIV).

Während des Längenwachsthumes des Schlauches gehen im Innern des Kornes Veränderungen vor sich, welche die Aufmerksamkeit des Beobacbters in Anspruch nehmen. - Man bemerkt nämlich einerscits, dass in dem Maasse als sich der Pollenschlauch verlängert, der Inhalt der zwei oder drei kleinen inneren Zellen immer mehr abnimint bis er zuletzt beinahe völlig verschwindet, während andererseits im Inhalte des wachsenden Schlauches die Zahl der Stärkekörner immer kleiner wird bis im Schlauche zuletzt nur wenige zurückbleiben (Taf. XXXIV vergl. Fig. 3-12). Das merkwürdigste und hier für uns unstreitig das wichtigste ist das Verhalten des Zcllkernes. Derselbe liegt, während der Schlauch schon ziemlich in die Länge gewachsen ist, noch immer an jener Stelle wo der cylindrische Theil des Schlauches seinen Anfang nimmt, hat also seine Lage gar nicht oder nur unbedeutend verändert (Taf. XXXIV Fig. 8x); hat aber der Schlauch eine bestimmte Länge erreicht, so verschwindet er dort bald darauf (Taf. XXXIV Fig. 9) um dann gegen das Ende iles Schlauches zu wieder aufzutreten und sich auch zu verdoppeln (Taf. XXXIV Fig. 10x, 11x, 12x). Die Verdoppelung der Kerne habe ich nur in den zwei auch hier abgebildeten Schläucben beobachtet, während ich das Auftreten eines einzelnen Kernes bei fünf oder sechs Fällen gesehen habe.

So weit gelang es mir die Entwickelung der Schläuche zu verfolgen, und es sei bier nur noch erwähnt, dass diese Zellen meist bald nach dem Auftreten der Kerne zu Grunde gegangen sind, und dass die allermeisten in ihrer Entwickelung nicht dazu gekommen sind um an ihrem Ende wenigstens einen Kern auftreten zu lassen.

Ueberblickt man nun die hier mitgetheilten Thatsachen, so kann man das Resultat dieser Arbeit in Folgendem kurz zusammenfassen. 
Die Pollensäcke der Ceratozamia entstehen auf der Unterseite der Schuppen in der Form kleiner Papillen aus einem meristemăhnlichen Gewebe, dessen lappenförmige F'ortsätze oder Erhebungen sie bilden.

Während die Differenzirung des Gewebes und die Bildung der Specialnutterzellen im Pollensacke auf dieselbe Weise wie bei den Mono- und Dicotyledonen vor sich geht, zeigen die Specialmutterzellen ein solches Verhalten, wodurch sie einigermassen zwischen diese beiden Klassen gestellt werden; denn während sie einerseits durch die Eigenschaft dass sie nach ihrem Zustandekommen noch lange Zeit und zwar fast bis zum Beginne ihrer Theilungen dicht gedrängt neben einander liegen, den Typus der Dicotyledonen befolgen: nähern sie sich andererseits durch ibre succedane Theilung den Monocotyledonen an.

Die aus ihren Specialmutterzellen frei gewordenen Pollenkörner sind einzellig, sie zeigen aber bei ihrer weiteren Ausbildung und in ihrem Baue solche Eigenschaften, welche bis jetzt als Charaktere der Coniferen betrachtet werden. Wie wir aber bei den Pollenkörnern dieser Pflanzen in Bezug auf den Bau, und auf die. Weise der Pollenschlauchbildung zwei Typen unterscheiden, so finden wir in den Pollenkörnern der Ceratozamia die Charaktere beider Typen vereinigt. Während sie nämlich in der Zahl der Zellen ihres Zellkörpers dem Typus von Larix entsprechen, schliessen sie sich dadurch, dass nicht die Fndzelle des kleinen Zellkörpers, sondern die durch die erste Theilung entstandene grosse Tochterzelle sich zum Pollenschlauche entwickelt dem Typus von Cupressus an. -

In Bezug auf den Bau der Pollenkörner hat sich noch ergeben, dass die Intine der Pollenkörner der Ceratozamia nur dann jene hochgradige Quellbarkeit - welche für die Coniferen so charakteristisch ist - besitzt, wenn sie sich schon zur Bildung des Pollenschlauches anschickt; die grösste Ausdehnung bei ihrem Aufquellen erfährt sie nicht - wie bei den Coniferen - in radialer, sondern in tangentaler Richtung.

Die Frage ob sich während der Befruchtung im Pollenschlauche der Ceratozamia - so wie dies Hofmeister für die Coniferen angegeben - Zellen bilden, oder ob dieser Process entsprechend den neuesten Angaben Strasburgers - über die Befruchtung der Coniferen - unterbleibt, kann nach den vorliegenden Beobachtungen nicht beantwortet werden. Der Umstand, dass ich am Ende der Schläuche mehrmals Zellkerne angetroffen habe, liesse 
wohl die Deutung zu Gunsten der Angaben $\mathrm{H}$ ofmeisters nicht unbegründet erscheinen, doch muss diese Frage durch die directe Beobachtung des Befruchtungsrorganges entschieden werden, und eben darum kann und darf ich hier das Eintreffen jenes Vorganges nur als eine Wahrscheinlichkeit andeuten, deren Beweis aber künftigen Untersuchungen vorbehalten bleibt. -

\section{Erklärung der Abbildungen.}

Taf. XXXI.

Fig. 1. Junger Pollensack, Längsschnitt. $a$ meristemähnliches Gewebe der Schuppe, $b$ die differenzirten jnneren Zellen, deren allmäliger Uebergang zu $a$ deutlich wahmehmbar ist. $h$ einfache Haare. Vergröss. 220.

Fig. 2. Ein älterer Pollensack. Längsschnitt. Nach einer Zeichnung bei 456maliger Vergrösserung viermal verkleinert dargestellt. a Wand des Pollensackes. $b, b$ Urmutterzellen durch deren Theilung die Specialmutterzellen entstehen.

Fig. 3-5. Bildung der Specialmutterzellen. Fig. 3 drei Urmutterzellen im Querschnitt; von diesen die Zelle $d$ noch ungetheilt, während die Zellen $a$ und $c$ Lei $b, b$ durch die senkrechte Wand getheilt erscheinen. Fig. 4 Urmutterzelle im Längsschuitt, bei $b$ die senkrechte bei $q$ die quere Scheidewand sichtbar. In der Fig. 5, Querschnitt, sind bei b, b, b, b beide senkrechte Scheidewände zu sehen.

Fig. 6. Junge Specialmutterzellen unmittelbar nach ihrer 'Trennung, ihre Wand einfach contourirt, bei $\mathrm{x}$ der Zellenkern.

Fig. 7. $a$ eine schon vollkommen ausgebildete Specialmutterzelle mit doppelt contourirter Wand, bei $\mathrm{x}$ der grosse helle Zellkern. 6 Specialmutterzelle in dem Alter wie $a$. Nach längerem Liegen im Wasser zieht sich der Inbalt zusammen; der Kern ist geronnen bei $x$.

Fig. 8. Eine Specialmutterzelle mit zwei Zellkernen bei $\mathbf{x}, \mathbf{x}$; unmittelbar vor dem Eintritte der ersten Theilung.

Fig. 9-12. Specialmutterzellen mit je zwei Kernen. 9 und 10 vor 11 und 12 während der Bildung der Scheidewand. 9 und 12 mit in zwei Parthien gesondertem, 10 und 11 mit in der Mitte der Zelle zusammengezogenem Inhalte.

F ig. 13, 14. Specialmutterzellen am Anfange der Bildung der ersten Scheidewand. Fig. 13 von der Oberfläche der Zelle gesehen erscheint die junge Scheidewand bei w bandförmig breit. - Die Zelle in Fig. 14 ist im optischen Durchschnitte gezeichnet, bei w, w die junge Scheidewand.

Anmerkung. Auf dieser Tafel sind die Fig. 3-14 alle bei 456 maliger Vergrösserung gezeichnet.

\section{Taf. XXXII.}

Die Figuren 10 und 15 sind bei 852 -alle übrigen bei $456 \mathrm{maliger}$ Vergrösserung gezeichnet.

Fig. 1-3. Specialmutterzellen während der ersten Theilung; bei w, w, w sind die verschiedenen Entwickelungszustände der Scheidewand zu sehen.

Fig. 4. Eine Specialmutterzelle nach Vollendung der ersten Theilung. 
Fig. 5, 6. Specialmutterzellen nach Vollendung der ersten Theilung; in den Tochtezzellen das Auftreten neuer Kerne. - In Fig. 5 liegen die Kerne alle in einer Ebene; in Fig. 6 sind die Kerne in den $\mathrm{z}$ wei Tochterzellen nach den Ecken eines Tetraëders gelagert. Die Kerne überall mit x bezeichnet.

Fig. 7, 11, 14, 15. Specialmutterzellen nach ihren Theilungen. Die secundären Scheidewände bei $k$, $k$ liegen in beiden Tochterzellen in derselben Ebene.

Fig. 8, 9, 10. Specialmutterzellen während der Entwickelung der secundären scheidewände. Bei allen diesen Specialmutterzelleu kreuzen sich die Theilungsebenen ihrer Tochterzellen, bei $\mathrm{k}, \mathrm{k}$ die auf die Fläche der Tafel senkrecht stehenden Scheidewände von olien gesehen; bei l, l die riit der Tafelfläche parallel laufenden Scheidewände, deren freier Rand deutlich zu sehen ist; letztere in der Mittelebene gezeichnet. Die Kerne überall mit $\mathrm{x}$ bezeichnet.

Fig. 12. Eine Specialmutterzelle in welcher die eine Tochterzelle sich früher theilte als die andere.

Fig. 11-15. Trennung der ersten Scheidewand von der Zellmembran. $11 \mathrm{~m}$ Anfang der Trennung. Fig. 12, 14 bei $\mathrm{n}$ hat sich die Scheidewand abgerissen. In den Fig. 11, 13, 15 hat sich die Membrau bei Tremung der Scheidewand in zwei Lamellen gespaltet, die innere Lamelle ist in Fig. $13 \mathrm{~g}$ von beiden in den Fig. 11 und $15 \mathrm{gg}$ nur von einer Seite mit der Scheidewand in Verbindung geblieben. -

Fig. 16, 17. Specialmutterzellen während der ersten Theilung nach längerem Liegen in Wasser. Die Membran derselben hat sich in Fig. 17 in zwei, bei Fig. 16 in drei Lamellen gespaltet.

Fig. 18. Junge Pollenkörner im einzelligen Zustande. x Zellkeru. ve Vacuolen.

Fig. 19. Ein vollkommen ausgebildetes Pollenkorn in trockenem Zustande. $f$ die Längsfalte.

Fig. 20, 21. Fertige Pollenkörner in Wasser, sie quellen auf, die Längsfalte gleicht sich langsam aus. Fig. 20 Pollenkörner mit ihrer Längsfalte dem Beoúachter zugekehrt; in Fig. 21 standen die Polleukörner mit ihrer Längsfalte senkrecht auf dem Objectträger. -

\section{Taf. XXXIII.}

Alle Figuren bei 850 maliger Vergrösserung gezeichnet.

Fig. 1. Ein Pollenkorn welches durch Theilung in zwei Torbterzellen zerfallen ist: $a$ die kleine, $b$ die grosse Tochterzelle.

Fig. 2, 3. Die kleine Tochterzelle getheilt in $a$ und $c$ : Pollenkorn dreizellig.

Fig. 4, 5. Pollenkörner nach Einwirkung von stark gewässertem Alkohol. $x$ Zellkern, $e$ Exine, $i$ Intine. w Scheidewand der kleinen Zellen.

F ig. $7,8,11$. In Fig. 7 sieht man $c$ stark vergrössert, in Fig. 8 erscheint $c$ getheilt, Zellkörper hesteht aus a, c, d, somit dreizellig; b die grosse Tochterzelle. Fig. 11 bei $d$ vollkommen ausgebildete Endzelle des Zellkörpers. - Zellkern überall mit $\mathrm{x}$ bezeichnet.

Fig. 6, 9, 10. Pollenkörner während des Aufquellens in Wasser, die kleinen Zellen des Zellkörpers dehnen sich langsam aus, ihre Umrisse erscheinen als hin und her wellig gebogene Linien.

Fig. 12, 13, 14. Pollenkörner nach 24 stündigem Liegen auf saftigen Birnenstücken; es haben sich Stärkekörner gebildet s, s; die Intine stark quellbar reisst die Exine und tritt aus derselben, Fig. 13, 14; in Fig. 12 ist auch die Intine gesprungen. - 


\section{Taf XXXIV.}

Die Fig. $2-5$ und Fig. 11 sind bei 655 , alle übrigen Figuren bei $456 \mathrm{maliger}$ Vergrösserung gezeichnet. In allen Figuren bedeutet $t$ den Schlauch, $e$ die Exine, $a$ die basale, $c$ die zweite, $d$ die dritte Zelle des Zellkörpers, $s$ die Stärkekörner, $x$ den Zellkern. Alle hier abgebildeten schlauchtreibenden Pollenkörner waren während der Beobachtung und Zeichnung unter sehr verdünnter Zuckerlösung um die Schrumpfung des Inhaltes zu verhindern.

Fig. 1. Anfang der Schlauchbildung; nach kurzem Liegen in Wasser gezeichnet. Der austretende Schlauch zog sich zusammen, und entfernte sich theilweise von der Exine.

Fig. 2-5. Stärker entwickelte Schläuche. Die Schlauchzelle überall sehr stark aufgequollen, ihr Ende beginnt cylindrisch zu werden. In Fig. 2 und 4 der Schlauch seitlich gekrümmt, in Fig. 4 der Zellkern unverrückt, in Fig. 2 und 4 der 2 weizellige Zellkörper deutlich zu sehen. Fig. 3 eine schlauchtreibende Zelle von ibrer Oberfläche gesehen, bei $r$ der Rand der aufgerissenen Exine. Fig 5 der Inhalt des Schlauches zog sich znsammen, er entferute sich von der Exine; man sieht hier wie auch in Fig. 9, dass nicht die kleinen Zellen sondern die grosse Tochterzelle zum Schlauche sich entwickelt.

Fig. 6, 7, 8. Schlauchtreibende Pollenkörner mit zweizelligem Zellkörper. Der Schlauch in Fig. 6 scheint bei $z$ einen Zweig zu treiben; in Fig. 7 ist das Ende des Schlauches kugelig aufgetrieben; in Fig. 8 der Zellkern vor der Mündung des Schlauches.

Fig. 9-12. Mit stark entwickelten Schläuchen. In Fig. 9 war der Zellkern nicht nachweisbar, in Fig. 10 ist ein, in den Fig. 11 und 12 sind je zwei Kerne am Ende des Schlauches zu sehen. -

Anmerkung. Die vorläufige Mittheilung über den Inhalt dieser Arbeit wurde in der Sitzung der Math. Naturwiss. Klasse der Ungarischen Akademie der Wiss. den 11. April 1870 vorgelegt, und die Abbandlung in der Sitzung am 27. Juni 1870 vom Verfasser vorgetragen. Die deutsche Bearbeitung des Gegenstandes war schon druckfertig und nur noch die Tafeln zum deutschen Texte uuvollendet, als mir die Arbeit des Herrn Prof de Bary "Notizen über die Blüthen einiger Cycadeen“, Bot. Ztg. No. 36 1870, zngekommen ist. Diese Umstände mögen entschuldigen, dass im Texte diese Arbeit unberücksichtigt geblieben ist. -

Pest, den 25. September 1870. 


\title{
Ueber die Grösse der Holzzellen bei der gemeinen Kiefer (Pinus silvestris).
}

\author{
Von
}

Dr. Karl Sanio.

Ueber die Grösse der Holzzellen in Stamm und Wurzel, namentlich speciell der Nadelhölzer, hat zuerst Schacht $\left.{ }^{1}\right)$ Mittheilungen gemacht. Derselbe giebt an, dass im Holze der Wurzel aller ihm bekannten Coniferen die Holzzellen 2-4 Mal so breit als im Stamme seien.

Diese Angabe wurde darauf von $\mathbf{M o h l ^ { 2 }}$ ) angegriffen und nachzuweisen gesucht, dass der Unterschied ein viel geringerer wäre.

Aus der darauf folgenden Controverse ${ }^{3}$ ) ergab sich, dass die Holzzellen in Aesten einen geringeren Durchmesser als im Stamme hätten.

Beide Beobachter gingen von der Annahme aus, dass die Grösse der Zellen in sämmtlichen Schichten des Stammes, resp. der Wurzel eine gleiche wäre; ich ${ }^{4}$ ) zeigte darauf, dass dies nicht der Fall sei, dass vielmehr in den meisten Fällen die Grösse der Holzelemente im Zunehmen begriffen sei, bis das Maximum erreicht ist, worauf die Grösse constant bleibt. Diese Zunahme findet statt durch mehrere Jahrringe.

Ich hatte bei meinen damaligen Untersuchungen nur die Weite der Zellen im Auge gehabt, die Länge nicht berücksichtigt, obwohl schon a priori anzunehmen war, dass wenigstens gewisse Elementarorgane, nemlich die von faserartiger Form, mit der $\mathrm{Zu}$ nahme an Weite sich verlängern. Um dieses genauer nachzuweisen, wählte ich das Kiefernholz und untersuchte im März 1867 eine

\footnotetext{
1) Schacht, Anat. u. Physiol. II. p. 174.

2) Bot. Ztg. 1862 . p. 233.

3) cfr. Bot. Ztg. 1862. p. 461.

4) Bot, Ztg. 1863, p. 126 u. 396 .

Jahrb, f. wiss. Botanik. VIII.
} 
67jährige Stanmscheibe aus dem Zopfende in Querschnitten und an durch Maceration in die einzeluen Zellen aufgelöstem Material durch alle Jahrringe hindurch. Meine Annahme, dass neben der Weite auch die Länge der Holzzellen bedeutend zunimmt, bis sie constant wird, bestätigte sich vollständig.

Nachdem ich diese mühsame Arbeit ausgeführt, trat mir die Frage entgegen, ob die erreichte constante Grösse in allen Höhen (les Stammes eine gleiche wäre, oder ob vielleicht die constante Grösse nach der Höhc eine Aenderung erleidet. Eine vorläufige Untersuchung bestätigte letztere Vermuthung, welche ich erst im November 1867 wieder weiter verfolgte und bis zu der Gewissheit eines constanton Gesetzes erhob.

Else ich die speciellen Messungen anführe, will ich dic dabei gewonnenen Gesetze voranschicken, um das Interesse an den nachfolgenden Zahlen zu erhöhen:

1. Die Holzzellen nehmen in den Stamm- und Asttheilen überall von Innen nach Aussen durch eine Anzahl von Jahrringen hindurch zu, bis eine bestimmte Grösse erreicht ist, welche dann für die folgenden Jahrringe constant bleibt.

2. Die endliche constante Grösse der Holzzellen ändert sich im Stamı (Hochstamm) in der Weise ab, dass sie stetig von Unten nach Oben zunimmt, in bestimmter Höhe ihr Maximum erreicht und dann nach dem Wipfel zu wieder abnimmt.

3. Die endiche Grösse der Holzzellen in den Aesten ist geringer als im Stamm, hängt aber von diesem in der Weise ab, dass diejenigen Aeste, welche in solcher Stammhöhe entspringen, in der die Holzzellen grösser sind, auch grössere Zellen haben, als die Aeste, welche an solchen Stammhöhen entspringen, an denen die constante Zellengrösse cine geringere ist.

4. Auch in den Aesten nimmt dic constante Grösse in den äusseren Jahrringen nach der Spitze zu, um dann wieder zu fallen. Bei dem unregelmässigen, knorrigen Wachsen der Wipfeläste kommen indess Unregelmässigkeiten vor; so beobachtete ich bei einem Aste, den ich durch eine beträchtliche Länge hindurch näher untersuchte, ein zweimaliges Steigen und Fallen. Die regelmässig wachsenden Acste altcr Kusselfichten würden hier wohl eine feste und ahnliche Regel wie in Stamme nachweisen, doch habe ich dergleichen noch nicht untersucht.

5. In der Wurzel nimmt auf dem Querschnitte die Weite der Zellen zuerst zu, fällt dann wieder, um wieder zu steigen, bis die 
constante Grösse erreicht ist. Auch nach der Länge der Wurzel findet eine Grösscnzunahme statt, doch habe ich diese Frage aus Mangel an geeignetem Material noch nicht genauer untersucht.

Im Folgenden lasse ich die speciellen Messungen folgen. Ich führte dieselben mit einem Ocularmicrometer aus, bei dem ich den Werth der Theilungen mittelst eines Objectivmicrometers bestimmt hatte. Da der Werth der einzelnen Theilung sich nach der Grösse des zu messenden Gegenstandes ändert, so habe ich für solche Messungen den Werth der ganzen Scala bestimmt und dadurch die Fehlerlerquelle möglichst verringert. Die Grössendifferenzen sind übrigens so bedeutend, dass dieser Apparat vollkommen ausreicht, das Gesetz zu ermitteln; an der Ermittelung einer constanten Grösse kann überhaupt nicht gelegen sein, da dieselbe gesetzlich sich so bedeutend abändert.

Da sich die Grösse der Zellen in den ersten Jahrringen über der Wurzel nicht bequem an alten Stämmen messen lässt, so untersuchte ich zuerst junge Pflanzen. Die Breite der Holzzellen, d. h. ihren die Richtung der Markstrahlen rechtwinklig schneidenden Querdurchmesser maass ich stets in der Herbstgrenze 1, die Länge der Zellen an macerirtem Holze. Die Zahlen bedeuten natürlich Mittelwerthe. Im Folgenden soll „M.PBr." die mittlere Breite, "M.-L." die mittlere Länge bezeichnen.

I. Zweijährige Pflanze.

Einjähriger Trieb.

Spitze.

M.-Br. $=0,011^{\mathrm{Mm}}$.

M.L. $=0,75$.

1) Die für die tangentiale Breite angegebenen Zahlen bedeuten übrigens nicht die Mittelwerthe des grössten Querdurchmessers der Holzzellen, sondern geben vielmehr an, wie viel Raum auf dem Querschnitte je eine Zelle im Mittel einnimmt. Es wurden nåmlich auf Querschnitten tangentiale Reihen von Zellen in der Herbstgrenze gemessen, daraus das Mittel gezogen, und aus einer Anzahl von Mittelwerthen das endliche Mittel berechnet. Da auf jedem Querschnitte die Holzzellen in verschiedener Höhe ihres Längendurchmessers durchschnitten sind, sich neben in der Mitte ihrer Länge durchschnittenen Zellen auch solche finden, die an der Spitze durchschnitten sind, da ferner die Zellen der Herbstgrenze spindel- oder besser faserförmig nach der Spitze verjüngt sind, so kann die angegebene Methode nur anzeigen, wie viel Zellendurchschnitte im Mittel auf einen gegebenen Raum kommen oder mit andern Worten, wie gross der Raum ist, den jede Zelle auf dem gegehenen Querschnitte einnimmt. Wollte man den Mittelwerth des grössten Querdurchmessers finden, so müsste man tangentiale Langsschnitte untersuchen und jede einzelne Zelle für sich messen, was die Untersuchung bedeutend erschweren würde, obne deshalb zweckdienlicher $2 u$ sein. 
Basis.

M. $-\mathrm{Br} .=0,012^{\mathrm{Mm}}$.

M.L. $=0,59$.

\section{Zweijähriger Trieb.}

1. Jahrring.

M. $\cdot \mathbf{B r} .=0,010^{\mathrm{Mm}}$.

2. Jahrring.

M.-Br. $=0,011^{\mathrm{Mm}}$.

M.-L. $=0,61$.

Mitte des 2 jährigen Cauliculus.

1. Jahrring.

$\mathrm{M} \cdot \mathrm{Br} .=0,012^{\mathrm{Mm}}$.

M.-L. $=0,56$.

2. Jahrring.

M.-Br. $=0,012^{\mathrm{Mm}}$, also eben so breit, als im ersten Jahrringe; diese seltsame Thatsache erklärt sich dadurch, dass die Herbstzellen im Verhältniss zu den Frühlingsholzzellen enger sind. Letztere sind im 2. Jahrringe in Wirklichkeit breiter, als die Herbstzellen des 1. Jahrringes.

M.L. $=0,58$.

Hauptwurzel.

$!^{\prime \prime}$ unter dem Wurzelhalse.

1. Jahrring.

M. $\cdot \mathrm{Br} \cdot=0,017^{\mathrm{Mm}}$.

2. Jahrring.

M.Br. $=0,017 \mathrm{Mm}$.

M.L. $=0,83$ -

3. unter dem Wurzelhalse.

1. Jahrring.

M. $\cdot \mathrm{Br} \cdot=0,020^{\mathrm{Mm}}$.

2. Jahrring.

M. - Br。 $=0,020^{\mathrm{Mm}}$.

$11^{\prime \prime}$ unter dem Wurzelhalse.

1. Jahrring.

M.-Br. $=0,022^{\mathrm{Mm}}$.

2. Jahrring.

M.-Br. $=0,021 \mathrm{Mm}$.

M. L. $=1,69$. 
$2 \frac{1}{4}$ " unter dem Wurzelhalse.

1. Jahrring.

M. $\cdot \mathrm{Br} .=0,016$ Mm.

2. Jahrring.

M. $\cdot \mathrm{Br} .=0,022^{\mathrm{Mm}}$.

M.L. $=1,74$ -

4" unter dem Wurzelhalse.

1. Jahrring.

M.-Br. $=0,015 \mathrm{Mm}$.

2. Jahrring.

$\mathrm{M} \cdot \mathrm{Br} \cdot=0,025^{\mathrm{Mm}}$.

M.L. $=3,60$.

$6^{\prime \prime}$ unter dem Wurzelhalse.

2. Jahrring.

M. $-\mathrm{Br} .=0,034 \mathrm{Mm}$.

M.-L. $=3,43^{\mathrm{Mm}}$. nach einer andern Messung $=3,82^{\mathrm{Mm}}$.

Auf die Längenmessungen lege ich hier weniger Gewicht, weil es kaum möglich ist, die schmalen Jahrringe auseinander zu halten. Es wird wohl auffallen, dass die mittlere Breite der Holzzellen im ersten Jahrringe je weiter nach unten, nachdem sie zuerst gestiegen, wieder fällt. Es erklärt sich dies aber aus der geringen Entwickelung des ersten Jahrringes in dem fadenförmigen Wurzelende. Dass hier eine Vergrösserung wirklich stattfindet zeigt die bedeutendere Grösse der Holzzellen im zweiten Jahrringe, obwohl derselbe viel schmäler ist, als in den obern Theilen der Wurzel.

II. Sechsjährige Pflanze.

Sechster 1jähriger Jahrtrieb.

M.-Br. $=0,013$ Mm. M.-L. in der Mittelschicht $=0,75 \mathrm{Mm}$.

M.-L. in der Herbstschicht $=0,81^{\mathrm{Mm}}$.

also zusammen im Mittel $=0,78^{\mathrm{Mm}}$.

Fünfter 2jähriger Jahrtrieb.

1. Jahrring.

M. $\cdot \mathrm{Br} .=0,012^{\mathrm{Mm}}, \quad$ M. $\cdot$ L. $=0,78 \mathrm{Mm}$.

2. Jahrring.

M. $\cdot \mathrm{Br} .=0,014^{\mathrm{Mm} .} \quad$ M. $\cdot \mathrm{L} .=1,00^{\mathrm{Mm}}$.

Vierter 3 jähriger Jahrtrieb.

1. Jahrring.

M. $\cdot \mathrm{Br} .=0,012^{\mathrm{Mm}} \quad$ M. $\cdot$ L. $=0,69^{\mathrm{Mm}}$.

2. Jahrring.

M.-Br. $=0,013^{\mathrm{Mm}} . \quad$ M.-L. $=0,75^{\mathrm{Mm}}$. 
3. Jahrring.

$$
\begin{gathered}
\mathrm{M} \cdot \mathrm{Br} .=0,016^{\mathrm{Mm}} \quad \text { M.L. }=1,00 \mathrm{Mm} . \\
\text { Dritter } 4 \text { jähriger Jahrtrieb. } \\
\text { 1. Jahrring. }
\end{gathered}
$$

M.Br. $=0,011 \mathrm{Mm}$.

2. Jahrring.

M. $\cdot B r \cdot=0,013^{\mathrm{Mm}} . \quad$ M. $\cdot \mathrm{L} \cdot=0,68 \mathrm{Mm}$.

3. Jahrring.

M. $-B r .=0,014$ Mm。 $\quad$ M. $-L_{1}=0,78 M$ Mm.

4. Jahrring.

M. $\cdot \mathrm{Br} .=0,015^{\mathrm{Mm}} \quad$ M. $-\mathrm{L} .=1,00 \mathrm{Mm}$. Zweiter 5jähriger Jahrtrieb.

1. Jahrring.

M. Br. $=0,011^{\mathrm{Mm}} \cdot \quad$ M.L. $=0,55^{\mathrm{Mm}}$

2. Jahrring.

M. Br. $=0,012 \mathrm{Mm} . \quad$ M.L. $=0,57 \mathrm{Mm}$.

3. Jahrring.

M. Br. $=0,013 \mathrm{Mm} . \quad$ M. $\cdot \mathrm{L} \cdot=0,71 \mathbf{M m}$.

4. Jahrring.

M.-Br. $=0,014^{M m} . \quad$ M. $\cdot$ L. $_{0}=0,75^{\mathrm{Mm}}$.

5. Jahrring.

M. $\cdot B r .=0,016^{M m} . \quad$ M.L. $=1,00^{\mathrm{Mm}}$. Erster, 6 jähriger Trieb.

1. Jahrring.

M. $\cdot \mathrm{Br} .=0,010^{\mathrm{Mm}}$.

2. Jahrring.

$\mathrm{M} \cdot-\mathrm{Br} .=0,012^{\mathrm{Mm}}$.

3. Jahrring.

M. Br. $=0,012^{\mathrm{Mm}}$.

4. Jahrring.

M.-Br. $=0,013^{\text {Mm}}$.

M. $\cdot \mathrm{Br} .=0,014^{\mathrm{Mm}}$.

5. Jahrring.

6. Jahrring.

M. Br. $=0,016^{\mathrm{Mm}}$.

Sechsjähriger Cauliculus.

1. Jahrring.

M. $-B r .=0,012^{M m} . \quad$ M. $\cdot L_{*}=0,43^{M m}$.

2. Jahrring.

$\mathrm{M} \cdot \mathrm{Br} .=0,012^{\mathrm{Mm}}$. 


$$
\begin{aligned}
& \mathrm{M} \cdot \mathrm{Br} .=0,012^{\mathrm{Mm}} \text {. } \\
& \text { 3. Jahrring. } \\
& \text { M. Br. }=0,014^{\mathrm{Mm}} \text {, } \\
& \text { 4. Jahrring. } \\
& \text { 5. Jahrring. } \\
& \text { M.-Br. }=0,014^{\mathrm{Mm}} \cdot \quad \text { M. } \cdot \text { L. }=0,78^{\mathrm{Mm}} \text {. } \\
& \text { 6. Jahrring. } \\
& \text { M. } \cdot \text { Br。 }=0,016^{\mathrm{Mm}} \cdot \quad \text { M.L. }=1,00^{\mathrm{Mm}} .
\end{aligned}
$$

Vergleichen wir diese Zahlen, so bemerken wir soyleich eine Steigerung der Grösse in dem je ersten Jahrring in der Richtung ron Unten nach Oben, so dass der erste (einzige) Jahrring des sechsten Triebes die grössten, der erste Jahrring des ersten Jahrtriebes dic kürzesten Zellen hat. Ferner bemerkt man, dass je weiter nach Oben, desto schneller die Zellengrösse in der Richtung von Inuen nach Aussen zunimmt. Dass vom Cauliculus bis zum fünften Jahrtrieb die Länge der Holzzellen in dem äussersten Jahrringe die gleiche ist, ist eine zufällige Erscheinung; in den vorhergehenden Jahrringen findet diese Congruenz nicht statt.

Die Wurzel derselben 6 jährigen Pflanze.

6 jährige Hauptwurzel $\frac{7}{8} "$ unter dem Wurzelhalse.

1. Jahrring. In diesen drei Jahrringen finden sich die \begin{tabular}{c|l} 
M. Br. $=0,013^{\mathrm{Mm}}$. & längsten Kellen; die längste mass bis $3 \mathrm{Mm}$. Eine \\
2. Jahrring. & Trennung nach den Jahrringen war nicht mög-
\end{tabular}

$\mathrm{M} \cdot \mathrm{Br} .=0,018^{\mathrm{Mn}}$ $\begin{gathered}\text { 3. Jahrring. } \\ \text { M.Br. }=0,018^{\mathrm{Mm}} .\end{gathered} \mid \begin{aligned} & \text { jedenfalls sind die weiten Zellen im Frühlings- } \\ & \text { holze in ihm etwas weiter, als im 3. Jahrringe. }\end{aligned}$

4. Jahrring

M. $\cdot \mathrm{Br} .=0,020 \mathrm{Mm} \cdot{ }^{\prime}$ M. $-\mathrm{L} .=1,30 \mathrm{Mm}$.

5. Jahrring.

M. $\cdot$ Br. $=0,022^{\text {Mm. }} \quad$ M. $\cdot \mathrm{L}_{\bullet}=1,34^{\mathrm{Mm}}$.

6. Jahrring.

M.-Br. $=0,023^{\mathrm{Mm}} \cdot \quad$ M.L. $=1,65^{\mathrm{Mm}}$.

Dass in dieser Wurzel die Grösse der Holzzellen geringer ist, als bei ähnlicher Höhe in den entsprechenden Jahrringen der zweijährigen Pflanze erklärt sich dadurch, dass hier die Wurżel, wie die Pflanze anfangs überbaupt ein geringeres Wachsthum hatte, weshalb hier die ersten Jahrringe schwächer sind. Das stärkste Wachsthum trat in den drei letzten Jahren ein, weshalb die drei letzten Jahrringe unverhältnissmässig stark entwickelt sind. 
Dieselbe Hauptwurzel 2" unter dem Wurzelhalse, mit 4 Jahrringen.

1. Jahrring. M.-L. $=2,52^{\mathrm{Mm}}$ Es wurden nur die weiten M.Br. $=0,022^{\mathrm{Mm}}$. Zellen gemessen, dic also dem 2. Jahrringe 2. Jahrring. angehören. Sie sind also länger als im 3. JahrM. $\cdot \mathrm{Br} .=0,025 \mathrm{Mm}$. ringe.

\section{Jahrring.}

M. Br. $=0,023^{\mathrm{Mm}} \cdot \quad$ M.L. $=2,30^{\mathrm{Mm}}$.

4. Jahrring.

M. $\cdot \mathrm{Br} .=0,019^{\mathrm{Mm}} \cdot \mathbf{M} \cdot \mathbf{L} \cdot=2,00^{\mathrm{Mm}}$.

Vom dritten Jahrringe ab fängt also hier bereits die Grösse der Zellen an zu fallen.

Dieselbe Hauptwurzel $4 \frac{1}{4}$ " unter dem Wurzelhalse, mit 4 Jahrringen.

1. Jahrring.

M. $\cdot \mathrm{Br} .=0,025 \mathrm{Mm}$.

2. Jahrring.

M. Br. $=0,027 \mathrm{Mm}$.

$$
\mathrm{M} \cdot \mathrm{Br} \cdot=0,027 \mathrm{Mm} \text {. }
$$

3. Jahrring.

4. Jahrring.
M. $-\mathrm{Br} .=0,033 \mathbf{M m}$.
M. L. $=1,65^{\mathrm{Mm}}$.

Um die Zunahme der Länge in den äussersten Holzschichten unter dem Wurzelhalse bemerkbar zu machen, stellte ich folgeude Messungen an: $\frac{1}{4}$ " unter dem Wurzelhalse M.-L. $=1,13 \mathrm{Mm}$.

$\frac{1}{2}$ " unter dem Wurzelhalse M.L. $=1,52 \mathrm{Mm}$.

$\frac{7}{8}$ " unter dem Wurzelhalse M.-L. $=1,65^{\mathrm{Mm}}$.

III. Circa $110 \mathrm{jähriger} \mathrm{Hochstamm.}$

Ich habe denselben in vier Absätzen untersucht, wovon der erste vom Stammende kurz über den Seitenwurzeln, der zweite aus dem Zopfende und zwei in verschiedener Höhe aus dem Wipfelstücke entnommen wurden.

1) 21 jährige Scheibe aus dem Wipfel.

1. Jahrring.

- M. $\cdot \mathrm{Br} .=0,016^{\mathrm{Mm}} \quad$ M. $-\mathrm{L} .=0,78^{\mathrm{Mm}}$.

14. Jahrring.

$$
\text { M.-L. }=1,74 \mathrm{Mm} \text {. }
$$

18. Jahrring.

$$
\text { M. L. }=2,21^{\mathrm{Mm}} \text {. }
$$


Ueber die Grösse der Holzzellen bei der gemeinen Kiefer (Pinus silvestris). 409

20. Jahrring.

$$
\begin{aligned}
& \text { M.-L. }=2,91 \mathrm{Mm} . \\
& \text { 21. Jahrring. } \\
& \text { M. Br. }=0,026^{\mathrm{Mm} .} \quad \text { M. } \cdot \mathrm{L} .=2,82^{\mathrm{Mm} .}
\end{aligned}
$$

Mit dem 20. Jahrringe erreichen also hier die Holzzellen die definitive Grösse.

2) 35 jährige Scheibe aus dem Wipfel, über den dicken Aesten der Krone.

1. Jahrring.

$$
\text { M.-Br. }=0,016^{\mathrm{Mm} .} \quad \text { M.L. }=0,80^{\mathrm{Mm}} .
$$

15. Jahrring.

$$
\text { M. }-\mathrm{L} .=2,60 \mathrm{Mm} \text {. }
$$

17. Jahrring.

$$
\text { M.L. }=2,74^{\mathrm{Mm}} \text {. }
$$

18. Jahrring:

$$
\text { M.L. }=2,82 \mathrm{Mm} \text {. }
$$

19. Jabrring.

$$
\text { M.-L. }=2,82^{\mathrm{Mm}} \text {. }
$$

20. Jahrring.

$$
\text { M.L. }=2,82^{\mathrm{Mm}} \text {. }
$$

22. Jahrring.

$$
\text { M. L. }=2,82^{\mathrm{Mr}} \text {. }
$$

35. Jahrring.

$$
\text { M.-Br. }=0,028 \mathrm{Mm} . \quad \text { M.L. }=2,78^{\mathrm{Mm}} \text {. }
$$

3) 72 jährige Scheibe aus dem Zopfende des Stammes, 36 Fuss über dem Boden, mindestens 10 Fuss unter der Krone.

1. Jahrring.

$$
\text { M.-Br. }=0,017 \mathrm{Mm} . \quad \text { M.L. }=0,955^{\mathrm{Mm}}
$$

17. Jahrring.

$$
\text { M.L. }=2,74^{\mathrm{Mm}} \text {. }
$$

19. Jahrring.

$$
\text { M. L. }=3,13^{\mathrm{Mm}} \text {. }
$$

31. Jahrring.

$$
\text { M. }-\mathrm{L} \text {. }=3,69^{\mathrm{Mm}} \text {. }
$$

37. Jahrring.

$$
\text { M. L. }=3,87 \mathrm{Mm} \text {. }
$$

38. Jahrring.

$$
\text { M.L. }=3,91 \mathrm{Mm} \text {. }
$$

39. Jahrring.

$$
\text { M. L. }=4,00 \mathrm{Mm} \text {. }
$$


40. Jahrring.

$$
\text { M.-L. }=4,04^{\mathrm{Mm}}
$$

43. Jahrring.

$$
\text { M. L. }=4,09 \text { Mm. }
$$

45. Jahrring.

$$
\text { M. }- \text {. }=4.21 \mathrm{Mm} \text {. }
$$

46. Jahrring.

$$
\text { M. L. }=4,21 \mathrm{Mm} \text {. }
$$

72. Jahrring.

$$
\text { M.-Br. }=0,032 \mathrm{Mm} . \quad \text { M.-L. }=4,21 \mathrm{Mm} .
$$

nach eiver andern Messung $=0,033^{\mathrm{Mm}}$. Ich habe auch die Zellen des 71. Jahrringes gemessen, da die Querschnitte des 72. Jahrringes mir zu wenig Zellen boten. Da beide Jahrringe glcicbgrosse Zellen führen, so lässt sich die cine Messung bequem auf den andern Jahrring übertragen.

4) 105 jährige Stammscheibe kurz über dem Boden.

$$
\text { 1. Jahrring. }
$$

$\mathbf{M} \cdot \mathbf{B r} \cdot=0,011^{\mathrm{Mm}}$

20. Jahrring.

$$
\text { M. }- \text {. }=1,87 \mathrm{Mm} \text {. }
$$

29. Jahrring.

$$
\text { M. } \mathrm{L}_{\text {。 }}=2,48 \mathrm{Mm} \text {. }
$$

30. Jahrring.

$$
\text { M. L。 }=2,60^{M m} \text {. }
$$

31. Jahrring.

$$
\text { M. }-\mathrm{L} \text {. }=2,65^{\mathrm{Mm}} \text {. }
$$

46. Jahrring.

$$
\text { M. }-\mathrm{L}_{\circ}=2,65^{\mathrm{Mm}} \text {. }
$$

60. Jabrring.

$$
\text { M. L. }=2,65 \mathrm{Mm} \text {. }
$$

80. Jahrring.

$$
\text { M.L. }=2,69 \mathrm{Mm} \text {. }
$$

105. Jahrring.

$$
\text { M. } \cdot \text { Br. }=0,028 \mathrm{Mm} . \quad M_{*} \cdot L 。=2,65 \mathrm{Mm} \text {. }
$$

Diese Zahlen lehren, dass nachdem in der jeweiligen Höhe die Grösse der Zellen das Maximum erreicht, fortan die folgenden Jahrringe gleich grosse Zellen bilden, dass ferner die constante Grösse in der Richtung nach Oben bedeutend zunimmt, ein Maximum erreicht und nach dem Wipfel wieder abnimmt. Das Maximum wird früher an der Basis und im Wipfel erreich ‘, am spätestens in der 
Mitte des Stammes, wo die grössten Zellen liegen. Die Grössenzunahme ist indess in allen Höhen keine gleichförmige, sie erfolgt am langsamsten an der Basis des Stammes, am schnellsten in der Stammmitte. Mit andern Worten: es führt die Mitte des Stammes nicht etwa deshalb grössere Zellen, weil hier die Grössenzunahme am längsten wäbrt (in diesem Falle bis zum 45. Jahre), sondern weil hier daneben die Grösse in stärkeren Proportionen zunimmt, als àn der Basis und im Wipfel.

Diese Thatsachen lehren ferner, dass das Holz aus dem Zopfende, schon deshalb weil es aus weiteren und längeren Zellen besteht, lockerer sein muss, als das Holz rom Stammende, obwohl dieser Faktor keineswegs der hauptsächlichste ist.

Um die allmählige Zunahme und dann wieder Abnahme der constanten Grössen in den äussern Jahrschichten in der Richtung nach Oben näher darzulegen, untersuchte ich einen mehr als 100 jährigen Stamm, der in der Nähe des zuletzt beschriebenen gewachsen war, in kurzen Abschnitten. Ich wählte dazu natürlich den äussersten Jahrring, und wo dieser sebr schmal war, die beiden äussersten. Die gewonnenen Resultate sind folgende:

Uebergangsstelle zwischen Stamm und Seiten-

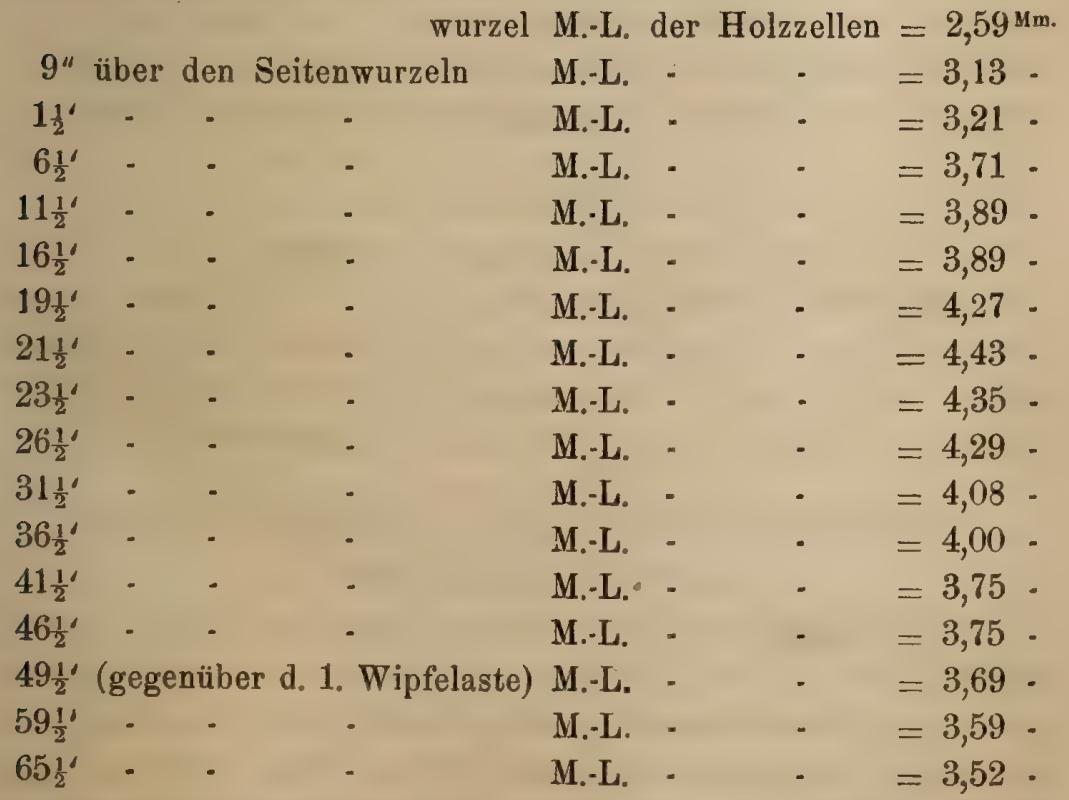

Selbst wenn man zugiebt, dass die hier verzeichneten Mittelwerthe von den wirklichen um $0,10-0,20 \mathrm{Mm}$ abweichen, so ist doch das Gesetz zu ersichtlich, als dass man darüber in Zweifel 
sein könnte. Von dem Seitenwurzelkranze aufwärts steigt zunächst die Grösse sehr schnell, dann etwas langsamer, bis das Maximum erreicht ist. Bekanntlich ist der Kiefernstamm nur in seinem untern Drittel oder Viertel mit graubrauner, festanhaftender Borke bekleidet. Der obere Theil ist glatt, gelbbraun und mit knitternden Korkblättern versehen. Dies rührt nicht etwa davon her, dass im obern Theile die Borkenbildung unterbleibt, sondern daher, dass die gebildeten Borkenblätter jährlich abgeworfen werden, weshalb die Bastschicht nur von einer dünnen Korklage bedeckt ist. Im untern Theile des Stammes gleicht also in der Borkenbildung die Kiefer der Mehrzahl der Holzpflanzen, im obern Theile dagegen von unsern Hölzern der Salix amydalina von fremden der Gattung Platanus. Die Grenze zwiscben diesen beiden Arten von Kork. bildung ist nun der Punkt, an dem die Holzzellen das Maximum der Länge erreichen. Von diesem Punkte an fällt die Länge wieder, aber langsamer, als sie gestiegen war, bis im Wipfel ungefähr dieselbe Länge, wie ron der Basis erreicht ist.

Es wird nicht überflüssig sein zu bemerken, dass man zu dieser Untersuchung glatte Stämme, die sich frühzeitig von Aesten gereinigt haben, also im Schluss aufgewachsen sind, wählen muss. Sind die Aeste stärker geworden, so zeigt der Stamm an der betreffenden Stelle eine Auftreibung und hier kürzcre Zellen, da die Insertion von Aesten auf die Länge der Holzzellen von Einfluss ist.

\section{Die Aeste.}

Ich habe nur Wipfeläste untersucht, weil ich nur diese in hinreichender Stärke erlangen konnte; doch wird das Gesetz so ersichtlich werden, dass man auch auf die untern ohne Weiteres wird schliessen können. Die Aeste sind natürlich sämmtlich ron demselben Stamme, der über 100 Jahre alt war, entnommen.

1) Wipfelast $\left(\mathbf{R}_{1}\right) 52$ Fuss über dem Boden entspringend.

a. Basis mit 55 Jahrringen.

Es ist selbstverständlich, dass wenn man von einem schief in. serirten Aste an der Insertion eine Querscheibe rechtwinklig zur Achse des Astes heransschneidet, ein ziemlich grosses stück von dem untern Astansatze am Stamme bleibt. Da ich nun die Messungen auf der untern stets beträchtlich stärker entwickelten Seite vorgenommen habe, so beziehen sich die gewonnenen Zahlen nicht auf die untere Insertion selbst, sondern auf eine Stelle, die von 
der untern Astinsertion so weit entfernt ist, als das am Stamme zurückgebliebene $\boldsymbol{\Lambda}$ ststück beträgt.

1. Jahrring.

$$
\text { M. } \cdot B r .=0,015^{M m} . \quad \text { M. }-\mathrm{L} .=0,91 \mathrm{Mm} .
$$

31. Jahrring.

$$
\text { M. L. }=2,08^{\mathrm{Mm}} \text {. }
$$

35. Jahrring.

$$
\text { M.-L. }=2,69^{\mathrm{Mm}} \text {. }
$$

37. Jahrring.

$$
\text { M.L. }=2,73^{\mathrm{Mm}} \text {. }
$$

55. Jahrring.

$$
\begin{aligned}
& \text { M.-Br. }=0,025 \mathrm{Mm} . \quad \text { M.-L。 }=2,69 \mathrm{Mm} \text {. } \\
& \text { b. }\left(R_{1}\right) 2^{\prime} \text { von der Basis. }
\end{aligned}
$$

$$
\text { M. L. }=3,21 \mathrm{Mm} \text {. }
$$

c. $\mathbf{R}_{1}$ ca. $6^{\prime}$ von der Basis mit 46 Jahrringen,

$\frac{1}{4}$ " über dem Seitenaste $\left(R_{1}\right)^{2}$ a.

1. Jahrring.

$$
\text { M.-L. }=1,00 \mathrm{Mm} \text {. }
$$

37. Jahrring.

$$
\mathrm{M}_{.}-\mathrm{L}_{\circ}=2,69 \mathrm{Mm} \text {. }
$$

41. Jahrring.

$$
\text { M. L. }=2,82^{\mathrm{Mm}} \text {. }
$$

45. Jahrring.

$$
\text { M. }-\mathrm{L} \text {. }=2,91 \mathrm{Mm} \text {. }
$$

46. Jahrring.

M. $\cdot B r .=0,026 \mathrm{Mm} . \quad$ M. $-L .=2,91 \mathrm{Mm}$.

d. $\mathbf{R}_{1}, 9^{\prime} 6^{\prime \prime}$ von der Basis mit 40 Jahrringen.

38. Jahrring.

$$
\text { M. } \cdot \mathbf{L} .=2,91^{\mathrm{Mm}} \text {. }
$$

40. Jahrring.

M.Br. $=0,023^{\mathrm{Mm}} . \quad$ M.-L. $=2,91 \mathrm{Mm}$. also eben so lang, als $6^{\prime}$ von der Basis.

e. $R_{1}$ ca. $12^{\prime}$ von der Basis nit 31 Jahrringen.

26. Jahrring.

$$
\text { M. }- \text { L. }=2,95 \mathrm{Mm} \text {. }
$$

29. Jahrring.

$$
\text { M. } \cdot \mathbf{L} .=3,17 \mathrm{Mm} \text {. }
$$

31. Jahrring.

M. Br. $=0,030 \mathrm{Mm}, \quad$ M. L. $=3,13^{\mathrm{Mm}}$ 。 
f. $\mathbf{R}_{1}, 13^{\prime} 10^{\prime \prime}$ von der Basis des Astes mit 27 Jahrringen, ca. $\frac{1}{4}$ " über dem Seitenaste $\left(\mathbf{R}_{1}\right)^{2}$ b.

25. Jahrring.

$$
\text { M. }-\mathrm{L}_{\circ}=2,78^{\mathrm{Mm}} \text {. }
$$

27. Jahrring.
M. $\cdot \mathrm{Br} \cdot=0,027 \mathrm{Mm}$
M. $-\mathrm{L} .=2,65^{\mathrm{Mm}}$.

g. $\mathrm{R}_{1}$, ca. 16' ron der Basis mit 21 Jahrringen.

21. Jahrring.

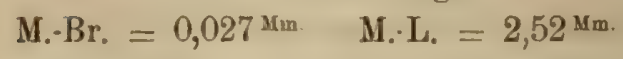

In diesem Aste steigt also die definitive, constante Länge der Holzzellen von Unten nach Oben schnell von $2,69 \mathrm{Mm}$. auf $3,21 \mathrm{Mm}$, fällt dann wieder auf $2,91 \mathrm{Mm}$, bleibt etwas stehen, um dann wieder bis auf $3,13^{\mathrm{Mm}}$. $\mathrm{zu}$ steigen und sebliesslich wieder $\mathrm{zu}$ fallen.

Um das Grössenverhältniss zwischen den Holzzellen des Stammes und des benachbarten Astes klar zu legen, machte ich folgende Untersuchungen:

Stamm 4" unter dem untern Ansatze des Astes $\mathrm{R}_{1}$, ca. $51^{\prime}$ über dem Boden.

Aeusserster Jahrring auf rler dem Aste entsprechenden Seite.

M. Br. $=0,029 \mathrm{Mm}, \quad$ M.Br. im Aste an der Basis $=0,025^{\mathrm{Mm}}$.

M. $-\mathrm{L} .=3,56^{\mathrm{Mm} .} \quad$ M.-L. in Aste an der Basis $=2,69 \mathrm{Mm}$.

Auf der dem Aste entgegengesetzten Seite maassen die Holzzellen des äussersten Stamm-Jabrringes $3,78 \mathrm{Mm}$, also länger, als auf der Astseitc. Der Einfluss des Astes tritt also in der Weise hervor, dass die unter ihm befindlichen Stammparthieen kürzere Zellen führen, als auf der entgegengesetzten vom Aste nicht beeinflussten Seite. Der Uebergang der längeren Stammzellen in die kürzeren Astzellen ist übrigens ein allmähliger, denn 1" übər dem unteren Astansatze maassen die Holzzellen im äussersten Jahrringe $=3,35^{\mathrm{Mm}}$; diese Stelle ist von derjenigen, an welcher die Holzzellen im Aste 2,69 Mm. maassen, um 7" entfernt. Auf die Länge von 7" nahmen also die Holzzellen um $0,566^{\mathrm{Mm} .} \mathrm{ab}$, um dann weiter nach Oben im Aste schnell zu steigen.

Um zu ermitteln, ob der Ast auch auf den darüber befindlichen Theil des Stamnes Einfluss habe (was von von vornherein unwahrscheinlich war), maass ich die Holzzcllen wie äussersten Jahrringe $\frac{1}{4}$ "uber dein oberen Astansatze. Ich fand die mittlere Breite $=0,030^{\mathrm{Mm}}$, M.-L. $=3,74^{\mathrm{Mm}}$. Die Zellen waren also grösser als im Aste und grösser als 4" unter dem unteren Ansatze des 
Astes, zum Beweise dass dieser auf die darunter befindlichen Stammzellen einen Einfluss ausgeübt, denn sonst müssten hier die Zellen, weil niedriger im Stamme, länger sein als über dem Aste. Es geht daraus hervor, dass der Ast nur auf die darunter befindlichen Theile des Stammes Einfluss hat, nicht auf die darüber und anf der entgegengesetzten Seite befindlichen Stammtheile, welche dem allgemeinen Gesetze unterliegen. Deshalb waren auf der dem Astansatze entgegengesetzten Seite des Stammes vier Zoll unter dem unteren Astansatze die Zellen länger, als $\frac{1}{4}$ “ über dem oberen Astansatze, weil die letztere Stelle ca. einen Fuss höher lag, als die erstere.

Untersuchen wir nun die Seitenäste und Zweige des Wipfelastes $\mathbf{R}_{\text {, }}$.

1* Seitenast $\left(\mathbf{R}_{1}\right)^{2}$ a des Wipfelastes $\left(\mathbf{R}_{1}\right), 6^{\prime} 2^{\prime \prime}$ von dessen Basis entspringend.

a. 46jährige Astscheibe, 1" ron der Basis. Untere, stärkere Seite:

46. Jahrring.

M. Br. $=0,021 \mathrm{Mm} . \quad$ M.L. $=1,73^{\mathrm{Mm}}$. Diese Grösse ist schon definitiv, da ich dieselbe auch schon im 44. Jahrringe fand.

Im Seitenaste ist also an der Basis die Länge und Breite der Holzzellen geringer, als in Hauptaste $R_{1}$ an gleicher Stelle, wo die Breite $=0,026^{\mathrm{Mm}}$, die Länge $=2,91^{\mathrm{Mm}}$. beträgt.

$\beta$. Derselbe Seitenast $3^{\prime} 9^{\prime \prime}$ von seinem Ursprunge, $\frac{1}{4}$ " über dem Seitenzweige $\left(R_{1}\right)^{3}$ a mit 36 Jahrringen.

Stärkere Seite:

36. Jahrring.

M. Br. $=0,024 \mathrm{Mm} . \quad$ M.-L. $=2,26 \mathrm{Mm}$. Diese Länge ist schon definitiv, da sich dieselbe bereits im 33. Jahrringe findet.

Wie im Hauptaste steigt also auch im Seitenaste die Länge von Unten nach Oben.

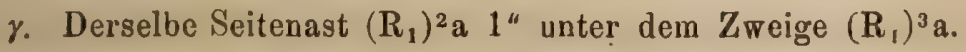
Stärkere Seite: Aeusserster Jahrring.

M.Br. $=0,025^{\mathrm{Mm} .}$ M.-L. $=2,69^{\mathrm{Mm}}$, also grösser als $3^{\prime \prime}$ höher, während im Stamme das Grössenverhältniss umgekehrt war. Wenn also der Seitenzweig auf den Seitenast eincn Einfluss ausübt, so reicht dieser doch nicht weit, da bereits 1 " unter dem Zweigansatze davon Nichts mehr nachzuweisen war. 
d. Derselbe Seitenast $\left(\mathrm{R}_{1}\right)^{2}$ a $4^{\prime} 10^{\prime \prime}$ von seiner Basis.

Stärkere Seite:

Aeusserster Jahrring.

M.-Br. $=0,026^{\mathrm{Mm}} . \mathrm{M}_{.} \cdot \mathrm{L} .=2,48^{\mathrm{Mm}}$. Die Grösse hat also wieder etwas zugenommen.

$2^{*}$ Seitenast $\left(R_{1}\right)^{2}$ b des Wipfelastes $R_{1}, 13^{\prime} 9^{\prime \prime}$ von dessen Ansatze entspringend. 26 jährige Astscheibe $3^{3}$ " von der Basis.

Stärkere Seite:

26. Jahrring.

M.-Br. $=0,020 \mathrm{Mm} . \quad$ M.-L. $=1,69 \mathrm{Mm}^{\mathrm{m}}$

In dem Hauptaste $\mathbf{R}_{1}$ betrug an der Ursprungsstelle des Seitenastes $\left(R_{1}\right)^{2} \mathrm{~b}$ die Breite $=0,027^{\mathrm{Mm}}$, dic Länge $=2,65 \mathrm{Mm}$, also ist auch hier im Seitenaste die Grösse geringer, als im Hauptaste; sie ist aber auch geringer als im Seitenaste $\left(\mathbf{R}_{1}\right)^{2} \mathrm{a}$, weil die Grösse der Zellen des Hauptastes an der Ursprungsstelle des Seitenastes $\left(R_{1}\right)^{2}$ a bedeutender war, als dort, wo sich der Seitenast $\left(R_{1}\right)^{2}$ b abzweigte.

$3^{* *}$ Seitenzweig $\left(R_{1}\right)^{3} a$ des Seitenastes $\left(R_{1}\right)^{2} a, 3^{\prime} 8^{\prime \prime}$ von dessen Ansatze entspringend. 34jährige Astschcibe, $1 \frac{1}{4} "$ übcr der Basis des Seitenzweiges. Stärkere Seite:

34. Jahrring.

M.-Br. $=0,0: 8^{\mathrm{Mm}} \quad$ M. $-\mathrm{L} .=1,65^{\mathrm{Mm}}$. (Dic Grösse war schon constant).

Dic Grösse ist also geringer, als im Tragaste $\left(R_{1}\right)^{2} a$ an gleicher Stelle, wo die Breite $=0,024^{\mathrm{Mn}}$, die Länge $=2,26 \mathrm{Mm}$. betrug. Der Basis des Seitenzweiges näher, nämlich $\frac{1}{2}$ " über dem unteren Astansatze, maassen die Holzzellen der äussersten Jahrringe auf der unteren Seite $=1,43^{\mathrm{Mm}}$, also kürzer, $6^{\prime \prime}$ von der Basis dagegen $1,83^{\mathrm{Mm}}$, also länger als an der Basis. Wie in den Haupt- und Seitenästen fängt also auch im Seitenzweige die Grösse geringer an, um zunächst schnell zu steigen.

2. Wipfelast $\left(\mathbf{R}_{5}\right), 61^{\prime}$. 5" über dem Boden, $9^{\prime} 5^{\prime \prime}$ über $\mathbf{R}_{1}$. 43 jährige Astscheibe, $1^{\prime \prime}$ von der Basis. Untere Seite.

43. Jahrring.

M.-Br. $=0,021 \mathrm{Mm} \cdot$ M.-L. $=1,78 \mathrm{Mm}$, also beträchtlich kürzer, als im Hauptaste $\left(R_{1}\right)$, was daher rührt, dass hier im Stamme die Zellen schon kürzer waren, als an der Ansatzstelle von $R_{1}$. $\frac{1}{2}$ “ über dem Aste $\left(\mathbf{R}_{5}\right)$ betrug nämlich die Länge der Stammholzzellen = $2,95 \mathrm{Mm}$, über dem Aste $\left(R_{1}\right)$ dagegen $3,74 \mathrm{Mm}$. 
3. Wipfelast $\left(R_{6}\right)$, 11' über $R_{1}$, ca. $1_{2}^{\prime \prime}$ über $R_{5}$. Astscheibe ca. 1" vom unteren Astansatze entfernt. Untere Seite. Aeusserster Jahrring.

M. Br. $=0,019$ Mm. M.L. $=1,74^{\mathrm{Mm}}$, also kleiner, als im Aste $\left(R_{5}\right)$. Derselbe Ast $\left(R_{6}\right) 4^{\prime} 3^{\prime \prime}$ von seinem Ansatze, ca. $1^{\text {"über den }}$ Seitenaste $\left(R_{6}\right)^{2}$ a. Ueber dem Seitenaste befindliche Seite: Aeusserster Jahrring.

M. Br. $=0,024 \mathrm{Mm} . \quad$ M. $-\mathrm{L} .=2,17 \mathrm{Mm}$. Die Grösse ist also gestiegen, sie ist aber geringer, als in Aste $\left(R_{1}\right)$ in gleicher Entfernung von seinem Ansatze.

Seitenast $\left(\mathbf{R}_{6}\right)^{2}$ a des Wipfelastes $\left(\mathbf{R}_{6}\right)$, $4^{\prime}$ von dessen Ansatze entfernt entspringend. Astscheibe 1" von der Basis. Untere Seite: A eusserster Jahrring.

M. $\cdot \mathrm{Br} .=0,022^{\mathrm{Mm}} \cdot \mathbf{M} \cdot \mathrm{L} .=1,56^{\mathrm{Mm}}$, also kleiner als im Tragaste $\left(\mathbf{R}_{6}\right)$.

4. Wipfelast $\left(\mathrm{R}_{\imath}\right)$, ca. $15^{\prime}$ über $\mathrm{R}_{1}$. 29jährige Scheibe. 1" von der Basis. Untere, stärkere Seite:

29. Jahrring.

M. Br. $=0,017^{\mathrm{Mm} .} \quad$ M.-L. $=1,60^{\mathrm{Mm}}$, also kürzer als in den unteren Aesten.

Der äusserste Jahrring des Stammes 1 “ über $R_{\gamma}$ zeigte auf der Seite des Ansatzes von $R_{7}$ folgende Grössen der Holzzellen:

M.-Br. $=0,025 \mathrm{Mm} . M_{.}-L_{*}=2,48 \mathrm{Mm}$, also kürzer, als im Stamme über $R_{5}$ und länger, als in der Basis des Astes $R_{7}$.

Diese Untersuchungen genügen vollständig, um dæs Gesetz über die constante Grösse der Astholzzellen aufzustellen:

1) Die Grösse an der Basis der Aeste und Zweige ist stets geringer als an der Ansatzstelle im Stamme oder Tragaste.

2) Sie hängt in der Weise von der Grösse der Holzzellen des Stammes ab, dass da, wo diese grössere Zellen fübren, auch der Ast oder Zweig mit grösseren Zellen an seiner Basis beginnt.

3) Von der Basis steigt zunächst (wie im Stamme über den Seitenwurzeln) die Grösse schnell und dann langsamer bis zu einem Maximum, um dann wieder zu fallen. Doch kommen hier wegen des unregelmässigen Wachsens der Aeste Unregelmässigkeiten vor. Bei einem in grösserer Länge untersuchten Aste beobachtete ich ein zweimaliges Steigen und Fallen.

\section{Die Wurzel.}

Ich habe aus Mangel an geeignetem Material vorläufig nur eine Seitenwurzel aus dem oberen Wurzelkranze und diese auch 
nur an einer Stelle untersucht, doch will ich meine Messungen mittheilen, da durch dieselben eine wesentliche Abweichung von den Grössenverhätnissen im Stamme und den Aesten nachgewiesen wird. Die untersuchte Seitenwurzel ist derselben Kiefer entnommen, deren Stamm oben sub III. untersucht wurde. Die Querschcibe war $1 \frac{1}{2}$ Fuss vom Ursprunge der Seitenwurzel herausgeschnitten und zählte 93 Jahrringe.

Ich theile blos die Längenmaasse mit, obwohl mir vollständige Reihen von Querschnitten zu Gebote stehen. Der Querdurchmesser andert natürlich in gleicher Weise, wie die Länge.

$$
\begin{aligned}
& \text { 1. Jahrring M.-L. }=2,78 \mathrm{Mm} \text {. } \\
& \text { 6. }-8 \text {. - }=6,60 \text {. } \\
& \text { 13.--14. - - }=6,60 \text {. } \\
& \text { 18. - - }=5,43 \text {. } \\
& \text { 20. - - }=4,74 \text {. } \\
& \text { 21. - - }=4,17 \text {. } \\
& \text { 22. - }=4,13 \text {. } \\
& \text { 23. - - }=3,69 \text {. } \\
& 25 . \quad \text { - }=3,13 \text {. } \\
& \text { 28. - } \quad-\quad=2,95 \text { - } \\
& \text { 29. - - }=2,78 \text {. } \\
& \text { 30. . }=2,69 \text {. } \\
& \text { 31. - } \quad=2,58 \text {. } \\
& 32 . \quad \therefore=2,87 \text {. } \\
& \text { 40. - * }=2,95 \text {. } \\
& \text { 61. - - }=2,95 \text { - } \\
& 93 \text {. - - }=2,91 \text {. }
\end{aligned}
$$

In der Wurzel steigt also zuerst die Grösse der Holzzellen, erreicht das Maximum (hier $\mathrm{z}$ wischen dem 8. und 13. Jahrringe), fällt dann wieder, erreicht in diesem Falle mit dem 30. Jahrringe das Minimum um dann zu steigen und nach Erreichung einer bestimmten Grösse constant zu bleiben.

In welcher Weise die Grösse der Holzzellen nach der Länge der Wurzel abändert, kann ich noch nicht bestimmt angeben, doch kann ich so viel mit Sicherheit mittheilen, dass je weiter zur Spitze das erste Steigen der Grösse desto länger anhält, weshalb ziemlich dicke Wurzeln in ihrem weiteren Verlaufe aus weiten und langen Zellen bstehen. Jedenfalls wird mit diesem Steigen auch eine Zunahme der constanten endlichen Grösse nach dem zweiten Steigen eintreten, doch fehlen darüber noch nähere Erfahrungen. 
Schliesslich führe ich noch an, dass nur die weiten langen Zellen beim ersten Steigen und Fallen zweireihige Töpfel führen; in diesem Falle hörte die Zweireihigkeit mit dem 18. Jahrringe auf. Die Zellen der folgenden Jahrringe sind dann den Holzzellen des Stammes ähnlich.

Schliesslich bleibt noch die Frage zu erörtern, ob die Grössenzunahme der Hulzzellen auf jedem gegebenen Querschnitte von einer Vergrösserung der Cambiumzellen herrührt, oder ob die Grösse der letzteren unverändert bleibt und nur durch nachträglichə Verlängerung der jungen Holzzellen die bedeutende Länge erreicht wird. Nach einem schon an anderm Orte von mir erörtertem Ge. setze ist der Unterschied in der Grösse zwischen Cambium- und Holzzellen ein nur geringer, wenn letztere im ausgebildeten $\mathrm{Zu}$ stande eine deutliche Anordnung in radiale Reihen erkennen lassen. Dieses trifft nun beim Kiefernholze zu, weshalb man a priori annehmen kann, dass je länger die Holzzellen werden, desto länger auch die Cambiumzellen, aus denen jene entstehen, geworden sind. Die Beobaehtung bestätigt dieses Resultat. Die Cambiumzellen nehmen in der That sowohl an tangentialer Breite als auch an Länge in den aufeinander folgenden Jahren bedeutend zu, bis sie eine constante Grösse erreicht haben. Von der Verlängerung und Erweiterung der Cambiumzellen rührt also die Vergrösserung der Holzzellen her.

- Aber nicht allein die Grösse, sondern auch die Wanddicke der Holzzellen nimmt von Innen nach Aussen zu, bis sie, die durch die Beschaffenheit der Jahre bedingten Abänderungen ausgenommen, constant wird. Namentlich bezicht sich dies auf das Herbstholz. Im ersten Jahrringe sind hier die Zellen nicht dickwandiger als im Frühlingsholze und von den Zellen des letztern nur durch Abnahme des radialen Durchmesser verschieden; allmählig nimmt in den aufeinander folgenden Jahren die Dicke $\mathrm{zu}$, bis sie gleichartig wird.

Lyck, im Januar 1871.

Nachschrift. - Die constante Länge der Holzzellen in den äusseren Jahrringen des Stammes ist keineswegs bei allen Stämmen gleich, sondern scheint beträchtlichen Abweichungen unterworfen, wenn auch das allgemeine Gesetz davon nicht beeinträchtigt wird. 
Eine an einem anderen melır als 100 jährigen Stamme ausgeführte Messung der Zellenlänge in den äussersten Jahrringen ergab viel kleinere Mittelzahlen, nämlich:

$6^{\prime \prime}$ vom Boden M.-L. $=2,74^{\mathrm{Mm}}$.

\begin{tabular}{|c|c|c|c|c|}
\hline $1^{\prime}$ & - & - & - & $=3,13$ \\
\hline $5^{\prime}$ & - & - & - & $=3,34$ \\
\hline $10 \frac{1^{\prime}}{2}$ & $\cdot$ & - & - & $=3,39$ \\
\hline $15^{\prime}$ & - & - & - & $=3,60$ \\
\hline $20^{\prime}$ & - & - & - & $=3,69$ \\
\hline $24^{\prime}$ & $\cdot$ & - & - & $=3,55$ \\
\hline $28^{\prime}$ & - & - & - & $=3,30$ \\
\hline $32^{\prime}$ & - & - & - & $=3,13$ \\
\hline $37^{\prime}$ & - & - & - & $=3,26$ \\
\hline $42^{\prime}$ & - & - & - & $=3,26$ \\
\hline $47^{\prime}$ & - & - & - & $=3,22$ \\
\hline $52^{\prime}$ & - & - & - & $=3,22$ \\
\hline $57^{\prime}$ & - & - & - & $=2,96$ \\
\hline $62^{\prime}$ & - & - & - & $=2,83$ \\
\hline
\end{tabular}

Lyck, im Februar 1872 .

(an einer anderen Maceration = $3,39 \mathrm{Mm} \cdot)$. 


\section{Ueber eigenthümliche Sphaerokrystalle in der Epidermis von Cocculus laurifolius.}

Von

\section{Gregor Kraus.}

(Hierzu Taf. XXXV).

An einem alten in Glycerin liegenden Epidermispräparat von Cocculus laurifolius fand ich vor einiger Zeit in den Zellen merkwürdige Bildungen, die mit den von $\mathrm{Sachs}^{1}$ ) entdeckten Sphaerokrystallen des Inulins eine auffallende Aehnlicbkeit hatten.

In den Zellen der ober- und unterseitigen Blattepidermis auf der Unterseite besonders in der Umgebung der Spaltöffnungen - befand sich ein kuglicher, ellipsoidischer oder ein aus kuglichen Theilen zusammengesetzter Körper, $0,012-0,015^{\mathrm{Mm}}$ gross, von starker Lichtbrechung und gelblicher Färbung, der von einem Centrum mehr oder weniger deutlich ein strahliges Gefüge orkennen liess (Taf. XXXV Fig. 1). Noch gewöhnlicher war eine in Kugelform geordnete Masse spiessiger Krystalle vorbanden, die, bald dichter bald weniger dicht zusammengelagert, im ersteren Fall nicht selten in der Mitte einen das Licht röthlich brechenden Raum liessen, $\nabla 0 n$ dem zwischen den Nadeln scheinbar Risse verliefen. Selten sassen nadelförmige Krystalle büschelförmig und strahlig an der Seitenwand der Zelle, in benachbarten Zellen cinander gegenüber.

Alle diese Bildungen waren unter dem Polarisationsapparat doppelbrechend, also wirkliche Krystalle.

Die Untersuchung der frischen Blätter ergab zunächst, dass die Gebilde im natürlichen Zustande in den Zellen nicht vorkommen:

1) Ueber Sphaerokrystalle des Inulins und clessen mikroskopische Nachweisung in den Zellen. Bot. Ztg. 22. Jahrg. No, 12 und 13, mit einer Tafel. 
die Zellen der Epidermis haben im ersten Moment einen durchaus wasserhellen Inhalt (Taf. XXXV Fig. 2). Liegen die Schnitte in Wasser, so verändert sich derselbe alsbald. Am Rande, wo die Zellen, angeschnitten, ihren Inhalt sogleich mit Wasser vermischen, schlägt sich aus demselben alsbald eine bräunlich aussehende krümliche Masse nieder. In den weiter nach Innen liegenden Zellen, wo das Wasser einc langsame Exosmose bewirkt, treten scharf umschriebene kugliche Körperchen auf. gewöhnlich zu zwei zusammenliegend; noch weiter nach Innen erscheinen zwei oder mehr Kügelchen, zu zwillings- oder maulbeerartigen Figuren zusammentretend, alle stark lichtbrechend, gelblich von Farbe und glatter Oberfäche (Fig. 3). Wo dicselben grösser sind, sieht man mitunter einen höhlenartigen Raum und undeutlich strahliges Gefüge. Dabei kann man zusehends das Wachsthum unter dem Mikroskop verfolgen und mit der Grösse ein deutlich strahliges Gefüge eintreten sehen. Es lässt sich dabei leicht feststellen, dass das Wachsthum durch Anlagerung ron Aussen stattfindet, indem unter den Augen kugliche Körper durch Anlegung neuer Substanz zu Drillings;, Vierlingskörpern werden. Eime concentrische Schichtung gewahrt man nur sclten in For'n eines am Rande gleich breit laufenden Saumes (Fig. 4). Die Primordialschläuche haben sich indess von der Zellwand zurückgezogen und umbüllen die Sphaerokrystalle wie feinkörnige Säcke, öfter mit einem Krystalle einseitig einer Wand ansitzend.

Der ganze Vorgang zeigt, dass die in Rede stehende Substanz im Zellsaft gelöst, im Wasser aber unlöslich ist, und bei Wassereinwirkung krystallinisch niederfällt.

In rascherer, aber wenig abweichender Wcise erhält man die Krystalle durch Zusatz von Alkohol. Auch diesmal treten in den Randzellen die aus winzigen Körperchen bestehenden bräunlichen, wolkigen Massen auf, weiterhin aber gewöhnlich nadel- oder stabförmige kleine Bildungen, die mitunter aus zwei sehr schlanken Octaëderchen zusammengesetzt scheinen. Innen die oben beschriebenen grossen einfachen oder Doppelkugeln ( maulbeerartige Concretionen u. s. W., theils frei, theils an der Wand, glatt oder mit stumpfen Höckern versehen, deutlich radiär gestreift.

Langsam und Schritt für Schritt lässt sich die Erscheinung des Auskrystallisirens verfolgen, wenn man einem eben in Wasser gelegten Präparat dickes Glycerin zusetzt. Abgesehen von den oben beschriebenen Randerscheinungen (Fig. 5a) zieht sich in den 
inneren Zellen allmählich scheinbar der ganze Inhalt in Form eines stark lichtbrechenden, gelb und ölartig erscheinenden, scharf umschriebenen Tropfens zusammen (Fig. 5b), der vorläufig einfach brechend ist. Nach Verfluss von $\frac{1}{2}$ Stunde und mehr ist derselbe auf das Maass eines gewöhnlichen Sphaerokrystalls zusammengezogen (Fig. 5c), homogen geblieben, oder mit Höhle, Rissen und radiären Streifen versehen, stets doppelbrechend. Jetzt gewahrt man auch die zusammengezogenen Primordialschläuche als Hülle (Fig. 5 c).

Eine eigenthümliche, auch den Sphaerokrystallen des Inulins eigene Erscheinung zeigt sich in der Vertheilung der Krystalle, wenn man ganze Blätter in Alcohol legt. Während bei der Reaction auf Schnitten in jeder Zelle ein Krystall erscheint, treten dieselben jetzt gruppenweise in benachbarten Zellen auf ${ }^{1}$ ), so dass etwa 6-8 und mehr zusammenliegende Zellen an den einander zugekehrten Wänden mit Krystallen besetzt sind, während eine Anzahl zwischen liegender Zellen frei bleibt. Auf der oberseitigen Epidermis lässt sich eine Auswahl des Ortes dieser Gruppen nicht erkennen, auf der Unterseite sind es die Zellen um die Spaltöffnungen, in welchen sich die Krystalle gruppiren (Fig. 6). Zu bemerken ist dabei, dass in den Schliesszellen selbst niemals die Krystalle auftraten, und dass sehr gewöhnlich in den zunächst liegenden Zellen spiessige Krystalle statt der Kugeln vorhanden waren, die auf den den Schliesszellen zugewendeten Seiten sassen und auf die Spaltöffnung wie ein gemeinschaftliches Centrum gerichtet waren (Fig. 7). Uebrigens sind auch in den sonstigen Zellen die Sphaerokrystalle nicht selten noch von spiessigen Krystallen umstellt.

Färben sich die Blätter, was öfter der Fall ist, beim Liegen in Alcohol schmutzig braungrün, so bleiben die Sphaerokrystalle farblos, wogegen sich in diesem Falle die gebräunten Primordialschläuche besonders schön zeigen.

In den Parenchymzellen des Blattes fehlen die Sphaerokrystalle, finden sich aber wiederum in der Epidermis des Stengels und der Blüthenblätter. In den Laubblättern treten sie schon zu einer Zeit auf, wo sie noch nicht $5^{\mathrm{Mm}}$. Grösse erreicht haben.

1) vgl. Sachs, a. a. 0. und Prantl, Das Inulin. München 1870. S. 14. 
In dem bisherigen Verhalten zeigten die Körper grosse Aehnlichkeit mit den Sphaerokrystallen des Inulins; gegen die gewöhnlichen microchemischen Mittel reagiren sie jedoch gänzlich abweichend.

1. Die in Weingeist niederguscblagenen Krystalle lösen sich weder in heissem, noch in kochendem Wasser. Selbst durch 1 Stunde fortgesetztes Kochen liess dieselben ganz intakt.

2. Färbende Mittel, Jod und Karmin, dringen in dieselben • zwar ein, verursachen aber (mit Säuren rerbunden) weder eine Quellung, noch werden sie in beträchtlicher Weise gespeichert. In concentrirter Jodkaliumjodlösung nehmen die Krystalle, die frei liegen und der dünnen Randparthien des Schuitts eine von der des Mediums selbst kaum unterscheidbare Färbung an; tiefer im Schnitt liegende, $\nabla$ on Plasma und Primordialschlauch umhüllte Körper erscheinen gewöhnlich sehr tief braun gefärbt. Allein die Einstellung auf die Mitte des strabligen Krystalls zeigt, dass die Färbung hauptsächlich der protoplasmatischen Umgebung angehört.

3. Aetzammoniak färbt dieselben ohne weitere Aenderung schön goldgelb, tagelanges Liegen und mehrmaliges Kochen damit riefen ebenfalls keine Veränderung hervor.

4. Verdünnte Kalilauge löst dio Krystalle allnählig, sie zerfallen dabci zunächst, indem ihre strahlige Struetur deutlicher wird, in eine Anzahl Bündel, die, nach und nach an Breite und Länge abnehmend, schmelzen. In concentrirtem Kali zerschmelzen sie sofort unter Gelbfärbung - ohne jegliche Quellung. Mitunter bleibt eine feinkörnige Masse, die sich mit Jod gelb färbt, zurück - ein protoplasmatischer Kern.

5. Kalte und kochende Essigsäure (10 Minuten) greift die Nadeln nicht merklich an; ebenso wenig die Phosphorsäure.

6. Concentrirte Salzsäure färbt goldgelb, ohne zu lösen. Nach Kochen von 1 Minute treten an manchen Körpern hellere Säume auf, einzelne scheinen angegriffen und in der Lösung von Aussen her begriffen. Nach 10 Minuten langem Kochen sind viele gelöst und an ihrer Statt kleine tropfenähnliche Körperchen vorhanden, andere beträchtlich kleiner geworden und von Tröpfchen umgeben.

7. In concentrirter Schwefelsäure färben sie sich goldgelb und lösen sich, wo es langsam geschieht, deutlich von Aussen nach Innen abschmelzend. Man sieht dabei häufig scheinbar eine Hülle zurückbleiben; man kann sich aber durch Jodzusatz überzeugen, 
überzeugen, dass es blos die Grenze der Lücke im protoplasmatischen Inhalte der Zelle ist, in welcher der Krystall gelegen.

8. Kalte starke Salpetersäure bewirkt nach 12 Stunden ein deutlicheres Herrortreten der radiären Streifung und Auftreten einer concentrischen Randschicht. Nach mehrtägigem Liegen theilweise Lösung. Einfaches Erwärmen führt keine Aenderung herbei. Unterbrochenes Kochen zeigt wie ciie Körner unter Gasentwickelung ron Aussen nach Innen abschmelzend sich lösen.

9. Erhitzt man trockene Schnitte bis sie sich gelblich färben, so sind die Körper intact; ist der Schnitt tief braun geworden, so sind die Körper verschwunden. Sie sind flüchtig oder zersetzbar.

Aus diescn Reactionen ist wit Sicherheit zu schliessen, dass der Körper ein organischer ist (Reaction 9 nebst den Löslichkeitsverhältnissen); welcher Gruppe unter den mikro-chemisch bekannten Körpern derselbe zuzurechnen sei, lässt aber das Vorstehende nicht ersichtlich werden. Es ist nicht festzustellen, ob er stickstoffhaltig sei, oder nicht. Soviel nur ist gewiss, dass er Inulin nicht sein kann. Dies löst sich in kochendem und heissem Wasser, in allen Mineralsäuren, sicher beim Erwärmen, in kaltem Kali. Unser Körper wird von kalter Salz- und Salpetersäure, von Phosphor- und Essigsäure nicht einmal bei einmaligem Kochen angegriffen. Er ist in Wasser ganz unlöslich und verschwindet in der Hitze, während Inulin verkohlt. Es sei auch hervorgehoben, dass weder der normale Zellinhalt, noch die in Säure gelösten Körper auf die Zuckerprobe reagiren.

Eine besondere Erwähnung verdient noch die Färbung in Alkalien und Säuren. Wie bemerkt wird der Körper von den genannten Mitteln gelb gefärbt. Es ist möglich, dass diese Färbung nicht ihm selbst, sondern gleichzeitig vorhandenem Gerbstoff zukommt, der bekanntlich wenigstens in Alkalien diese Färbung annimmt, und der in diesem Falle beim Niederschlagen des Krystalls in denselben mit eingeschlossen würde. Sicher ist, dass man mit eisenchloriđhaltigem Glycerin deutlich braungrün gefärbte Sphaerokrystalle erhält, und dass der intacte Zellinhalt mit Eisensalzen eine ebensolche Färbung und mit Kali bichromicum den bekannten Niederschlag, allerdings in geringerem Grade, giebt. -

Es scheint demnach nicht, dass die Sphaerokrystalle mit einem der mikrochemisch bereits bekannten Körper in der Pflanzenzelle 
identificirt werden können; es ist mir aber auch nicht gelungen, anderwärts einen Stoff zu finden, mit dem sich die Substanz und Form der Sphaerokrystalle vereinigen liesse, insbesondere will ich noch herrorheben, dass die mit ähnlichen Krystallformen ausge. statteten Körper, die in Funke's Atlas der physiol. Chemie (1858) Taf. IV oder in Robin et Verdeil, Traité de Chimie anatomique et physiologique (Paris 1853) beispielsweise Pl. XLII abgebildet sind, ihren Reactionen nach, ron einem Vergleiche mit unseren Sphaerokrystallen ausgeschlossen sind.

Muss nun auch die chemische Constitution dieser Sphaerokrystalle einstweilen auf sich beruhen, so sind dieselben doch nichts destoweniger schon deshalb ron Interesse, weil sie uns zeigen', dass aus dem blossen Auftreten und der Form der Sphaerokrystalle ein Schluss auf die Natur des Körpers nicht gemacht werden kann.

Erlangen, 1. Juli 1870.

Nachschrift.

Uober Eiweisskrystalloide in der Epidermis von Polypodium ireoides Lam.

Die Zeitereignisse brachten es mit sich, dass dâs Vorstehende liegen blieb. Indess habe ich in der Epidermis des eben genannten Farnkrautes krystallinische Bildungen aufgefunden, welche der Reihe der Krystalloide angehören, und die ich hier um so mehr erwähnen will, als diese allerliebsten Dinger als prächtige, leicht beschaffliche Demonstrationsobjecte empfohlen werden können².

Auf jedem Schnitt der ober- oder unterseitigen Epidermis der Wedel sieht man in jeder Zelle einen (selten mehr) stark lichtbrechenden, gelblichen Körper, 6-12 Micromillimeter und etwas darüber gross, und von scharfen Ecken und Kanten begrenzt. Gewöbnlich sind es scharf ausgeprägte Doppelpyramiden (reguläre Octaëder?), seltener stumpf endende oder mit der Pyramide combinirte kurze Prismen. Am seltensten fand ich Zwillingsoctaeder,

1) vgl. auch Prantl, a. a, Q. S. 60.

2) Leider scheinen dieselben nicht constant in allen Exemplaren vorzukommen. Nachtr. Bem. 
die mit ihren langen Achsen zusammen hingen, kreuzweise zusammengelegte Prismen und Pyramiden, oder dem Kalkoxalat ähnliche Drusen. Eine nähere Bestimmung der Form wurde nicht rorgenommen und ich lasse dahin gestellt, ob dieselben (nach dem Paranuss-Krystalloide zu schliessen) dem rhomboedrischen Systeme angehören, oder dem tesseralen; allerdings habe ich die Krystalle nur einigemal ganz schwach doppelbrechend, gewöhnlich bei gekreuzten Nicols auf dem dunkeln Felde nicht wahrgenommen.

Bei Zusatz ron Jod färben sich dieselben mit derselben Intensität, wie die Zellkerne, tief gelbbraun.

In kaltem Wasser sah ich auch nach mehrtägigen Liegen keine Aenderung an denselben; dagegen giebt das Erwärmen in Wasser über die Natur derselben Aufschluss. Bis zum einmaligen Blasenwerfen erwärmt erscheinen die Krystalloide bei wohl erhaltener Form mit einer hellen Randschicht versehen; aus den Randparthien ist die stark lichtbrechende Substanz verschwunden, und dem Ansehen nach die Masse substanzärmer, weniger dicht geworden, während im Innern, die Krystallform nachahmend, die stark glänzende Substanz noch vorhanden ist. Bei weiterer Einwirkung wird der helle Saum breiter, die glänzende Substanz kleiner und rundlich und verschwindet endlich ganz. Dabei wird auch das Skelett der zurïckbleibenden Substanz abgerundet und verblasst, während eine feine, schon vorher mehr oder weniger deutliche oft körnelige Haut zurückbleibt, um schliesslich ebenfalls spurlos zu vergehen.

Sehr instructiv wirkt ziemlich concentrirte $\mathrm{Phosphorsäure.}$ Abgesehen ron den Veränderungen im übrigen Zellinhalt sieht man die Krystalloide zunächst quellen: ihr Volum nimmt merklich zu, dabei verändern sich die Winkel, die der Nebenachsen, wie es scheint, stets beträchtlicher, der Körper nimmt bald, unter Beibehaltung der spitzen Winkel der Hauptachse, Spindelform an, und wird, indem auch diese Ecken verschwinden, zu einer länglichen, schliesslich runden Kugel. Alles das geht gewöhnlich so langsam vor sich, dass man nicht etwa an ein plötzliches Flüssigwerden denken könnte. Die in ihrem Lichtbrechungsvermögen von dem Krystall nicht verschiedene Kugel, verharrt eine Zeit lang, allmählig verblasst sie mehr und mehr unter Zurücklassung der oben genannten Haut, die am Ende ebenfalls verschwindet.

Die Erscheinungen bei der Einwirkung ron Salzsäure (ziemlich concentrirt) sind ähnlich. Ich sah aber in der kugelich ge- 
wordenen Masse sehr gewölnlich Vacuolen ähnliche Räume auftreten, und noch häufiger ein Körnigwerden des Inhalts, eine Lösung desselben ron Aussen nach Innen, wie es oben für die stark lichtbrechende Innenmasse bei der Wirkung des Wassers beschrieben wurde.

In concentrirter Schwefel- und Essigsäure, Kali- und A mmoniaklauge lösen sich die Körper sogleich. In rerdünntem Kali gewahrte ich ähnliche Erscheinungen, wie bei der Erwärmung in Wasser. -

Die rorstehenden Erscheinungen stimmen so sehr mit dem überein, was Nägcli (Sitzb. Münchn. Acad. 11. Juli 1862. p. 128 ff.) von den Paranusskrystalloiden gesagt hat, dass unsere Krystalloide, mit diesen, wenn nicht identische, doch ganz nah rerwanaite Körper sind.

Erlangen, 8. December 1870.

\section{Erklïrung der Abbildungen.}

Taf. XXXV (300malige Vergrösserung).

Fig. 1. Zellen des Präparatev mit verschiedenen Formen der Sphaerokrystalle.

Fig. 2. Die frischen Epidermiszellen von der Oberseite des Blattes.

Fig. 3. Dieselben mit Wasser behandelt.

Fig. 4. Ein Sphaerolrrystall ans in Präparat Fig. 3; der sowohl die radiäre Streifung, als eine concentrische Raudschicht zeigte.

Fig. 5. Frische Epidermis mit Gilycerin behandelt:

a. Rand des Präparates.

b. erste Einwirkung des Glycerins.

c. fertige Sphaerokrystalle, rechts vom Primordialschlauch umbüllt.

Fig. 6. Gruppirte Sphaerokrystalle von der Unterseite des Blattes.

Fig. 7. Nadelförmige Krystalle um die Spaltöffnung als Centrum gerichtet. 
den Bau trockner Pericarpien, mit Taf. VIII-XI. - J. Walz. Beitrag zur Morphologie und Systcmatik der Gattung Vaucheria DC., mit Taf. XII-XIV. A. B. Frank. Ueber die anatomische Bedeutung und die Entstehung der vegetabilischen Schleime, mit Taf. XV-XVI. - I. de Bary. Ueber die Keimung einiger crosssporiger Flechten, mit Taf. XVII-XIX. - Mar Reess. Zur Entwicklungsgeschichte des Polypodeaceensporangiums, mit Taf. XX - XXII. C. Mliliep. Untersuchung über den Sitz des Alcaloide in der Cinchonarinde, mit Taf. XXIII-XYIV. - §. J. C. Miiller. Das Wachsthum des Vegetationspunktes von Pflanzen nit ecussirter Blattstellung, mit Taf. XXV-XXXIV. - E. Strasburyer. Ein Beitrag zur Entwicklungsgeschichte der Spaltuffnungen, mit Taf. XXXV-XLII. - F. Ilildebrand. Ueber die Befruchtung von Aristolochia Clematitis und einiger anderer Aristolochia-Arten, mit Tafel XLIII. - $k$. Ilidelurand. Ueber die Nothwendigkeit der Insektenhülfe bei der Befruchtung von Corydalis cavil. - L. Kuy. Ueber Bau und Entwickelung der Riccien, mit Taf. XIIV-XLVI. - N. J. C. Miller. Untersuchungen über die Vertheilung der Harze, ütherischen Oele, Gummi und Gummiharze, und die Stellung der Secretionsbehälter im Pflanzenkorper, mit Taf. XI,VII-LIII. - A. Famintziu. Die Wirkung des Lichtes auf Algen lind einige andere ibnen nahe verwandte Organismen, mit Taf. I-III. - A. Fauintzin. Die Wirkung des Lichts auf das Ergrünen der Pflanzen. 1. Frnniutzir. Die Wirkung des Lichts und der Dunkelheit auf die Vertheilung der Clorophyllkirner in den Blättern von Mnium sp.? - N. Th. Cieyler. Ueber den Gifüssbündelıerlauf in den Liaublattregionen der Coniferen, mit Taf. IV-IX. - Ir. Keess. Zur Entwickejungsgeschichte der stammspitze von Equisctum, mit Taf. X-XI. - I. J. Miiller. Die Entwickelungsgeschichte der Kapsel von Ephemerum, mit Taf. III-XIV. - f.lli!łebrad. Nykologische Beituäge, mit Taf. XV-TVII. - (i. Hilger's. Leber das Auftreten der Krystalle von nxalsaurem Kialk in Parenchym einiger Jlonocotylen. - E. Pfitzer. Urber die Schutzscheide der deutschen Equisetaceen, mit Taf. XVIII-XX. - P. b. Lorentz. Grundlinien zu tiner vergleichenden Anatomie der Laubmoose, mit Taf. XXI-XXVIII. 5. Lnew. Ueber Demation pullulans de Bary, mit Taf. XXIX und XXX. 1. C. Miiller. Untersuchungen über die Diffusium der atmosphärischen Gase in der Pflanze und die Gasausscheidung unter verschiedenen Beleuchtungsbedingungen, mit Taf. XXXI. - Hermant liral zu solms-Lanliach. Ueber den Bau und die Entwickelung der Ernïhrungsorgane parasitischer Phancrogamen, mit Taf. XXXII-XXXIX. - J. Baranetzly. Beitrag zur Kenntniss des selbstständigen Lebens wer Flechtengonidien, mit Taf. I. - Fr. Burhennu. Ueber die Richtung der Samenkuospe bei den Alismaceen, mit Taf. II. - Clir. Luerssen. Zur Controverse über die Einzelligkeit oder Mehrzelligkeit des Pollens der Onagrariern, Cucurbitaceen und Corylaceen, mit Taf.IV. - VI. - A. Fischer v. Waldhein. Beiträge zur Biologie und Entwickelungsyeschichte der Ustilagineen, mit Taf. VII-XII. - N. J. C. Biitler, Untersuchungen über die Difrusion atmos!hürischer Gase in der Pflanze und die Gasausscheidung unter verschiedenen Beleuchtumgsbedingungen, II. Theil, nit Til. III. - X. J. C. Hiiller, Ueber den I)urchgang von Wa-serdampf durch die geschlossene Epidermiszelle - 1. J. C. Mïller, Notiz übex die F'arhstoffe im Chloroplyjll. - 6. Kirsts. Ceber die Ursachen der Fi, mänderungen etiolirender Pflanzen. - Julius Silurioder. Beitrag zur Kenntniss der Frühahrsperiode des Ahorns (Acer platanoides) mit Taf. XIII-XX. - El. Bor cow. Ucher gegitterte Parenchymzellen in der Rinde des Stengels ron Ceropegia aphylia und deren Beziehung zu den Milchsaftgefässen, mit Tafel XXI. - H. Leitgel. Neue Saprolegnicen, mit Taf. XXII-XXIV. - E. Strashuruer. Die Befruchtung bei den Farrenkräutern, mit Taf. XXV und XXVI - E. Strasburger, Die Geschlechtsorgane und die Befruchtung bei Marchantia polymorpha, mit Taf. XXVII und XXVIII - F. Ilildehrimu. Ueber die Betiubungstorrichtungen bei den Fumariaceen, mit Taf. XXIX-XXXI. - E. Lnew. Zur Entwicklungsgeschichte von Penicillium mit Tafel XXXI-XXXIV. - G. Kraus. Einige Beobachtungen über den Einfluss des Lichts und der Warme auf die Stärkeerzeugung im Chlorophyll, mit 'l'afel XXXV. - $\because$. Pfitzer Beiträge zur lienntniss des Hautgewebes der Pflanzen, mit Taf. XXXVI-XXXVII. I. Ueher die Spaltöftuung n der Gräser nebst einigen Bemerkungen üher die erstaren in Aljgemeinen. II Teiır die Ilautgewebe einiger Restionaceen. 


\section{Inhalt des vorliegenden Hefts 3, Band VIII.}

Seire

J. Kloill. Zur Kenntniss des Pilobolus mit Taf. XXIII-XXX . . . . . 305

L. Jurinyi. Ueber den Bau und die Entwickelung des Pollens bei Ceratozamia longifolia.Miq. mit Taf XXXI-XXXIV . : . . . . 382

k. Sanin. Leber die Grüse der Holzzellen bei der gemeinen Kiefer (Pinus silvestris) . . . . . . . . . . . . .

G. hraus. Ueber cigentthümliche Snhaerokrystalle in der Epidermis von Cocculus laurifolius mit Taf. XXXV . . . 421

- - Ueber Eiweisskrystalloide in der Fpidermis von Polypodium ireoides Lam. 426

\section{Inhalt des vorhergehenden Heftes 1 u. 2, Band VIII.}

Seite.

I. Kıy. Beiträge zur Entwickelungsgeschichte der Farrenkräuter mit Taf.I - III. 1

E. Plitzer. Beiträge zur Kenntniss der Hautgewebe der Pflanzen mit Taf. VI. 16 III. Leber mehrchichtige Epidemis und das Hypoderma.

N. J. C. Miiller. I) ie Anatomie und Mechanik der Spaltúffnungen mit Taf. IV u. V. 75

III. Wirkung der Wärme iunerhalb der Temperaturgrenzen des gewöhnlichen Lebens.

J. Peyritsel. Ueber Bildungsabweichungen hei Cruciferen mit Taf, VII-IX. 11 T

6. Kritus. Die Entstehung der F'arbstoflkörper in den Beeren von Solanum Pseudocapsicum mit Taf. X . . . . . . . . . .

1. Dodul. Der Uebergang des Dicotyledonen-Stengels in die Pfahlwurzel, mit Taf. XI-XVIII . - .

W. Pfefler. Zur Blüthenentwicklung der Primulaceen und Ampelideen, mit

1. Frank. Ueber die Veränderung der Lage der Chlorophyllkörner und des Protoplasmas in der Zelle, und deren innere und aussere Ursachen . 216

Die ,Jahrbücher für wissenschaftliche Botanik" erscheinen in unterzeichneter Verlagsbuchhandlung in-zwanglosen Heften von 8-12 Bogen Text mit Ablildungen, und wird der Verleger bestrebt sein, die typographische wie artistische Ausstattung der Zeitschrift zu einer müglichst vollkommenen zu gestalten.

Vier Hefte bilden einen Band, doch kann jedes Heft auch einzeln bezogen werden und richtet sich der Preis jedes einzelnen Heftes nach Umfang und nach Anzahl der beigegebenen Tafeln.

Geeignete Beiträge wolle mau gefälligst an den Herrn Herausgeber (in Berlin, Bendlerstrasse 13) oder an den unterzeichneten Verleger senden, welcher letztere alle zur Aufuahme angenommenen Aufsätze mit 10 Thlr. pro Druckbogen honorirt.

Bestellungen auf die „Jahrbücher für wissenschaftliche Botanik ${ }^{\varkappa}$ nehmen alle Buchhandlungen des In- und Auslandes entgegen.

Leipzig, im October 1864.

Die Verlagshandlung. Wilhelm Engelmann.

Redigirt unter Verantwortlichkeit von Dr. Wilh. Engelmann in Leipzig. 


\section{JAHRBÜCHER}

für

\section{wissenschaftliche Botanik.}

Herausgegeben

$\operatorname{ron}$

Dr. N. Pringsheim.

Achter Band. Viertes Heft.

Mit 4 zum Theil farbigen Tafeln.

\section{Leipzig, 1872.}

Verlag von Wilh. Engelmann. 


\section{Inhalt der ersten sieben Bände.}

N. Pringsheim. Beiträge zur Morphologie und Systematik der Algen. I. Morphologie der Oedogonieen, mit Taf. I-VI. - W. Ilofmeister. Neuere Beubachtungen über Embryobildungen der Phanerogamen, mit Taf. VII-X. - X. Pringsheint. Ceber das Austreten der Sporen ron Sphaeria Scirpi aus ihren Schliuchen; hierzu Taf. XXIV. A. - II. Schacht. Ueber die Pflanzenbefruchtung, mit 'Taf. $\mathrm{XI}-\mathrm{XV}$. - Juh. Hanstein. Ueber den Zusammenhang der Blattstellung mit dem Bau des dicotylen Holzringes, mit Taf. XVI-XVIII. - X. Priussheim. Beiträge zur Morphologie und Systematik der Algen. II. Die Saprolegnieen, mit Taf. XIX-XXI. - Al. Braun. Leber den Bluthenbau von Delphinium, mit Taf. XXII und XXIII. - I. ('ienkunsk). Die Pseudogonidien; hierzu Tat. XXIV. B. R. ('ispary. Die Hydrilleen (Anacharideen End) mit T'af. XXV-XXIX. - J. (irönland. Einige Worte über die Bastardbildungen in der Gattung Aegilops, mit Taf. XXX. - I. Pringshrum. Beiträge zur. Horpholngie und Systematik der Algen. III. Die Choleochateen, mit Taf. I-VI. - ('. Annin. Vergleichende Untersuchungen uber den Bau und die Entwickelung des Korkes, mit Tafel VII-XIII. ii. Nchacht. Ueber den Bau piniger Pulfenkörner. mit Taf. XIV-XVIIL. 1. dr Bary. Einige neue Satprolegnien, mit Tat. XIX-XXI. - N. Wichurn, Beiträge zur Physiologie der Lauhmoose. - X. Prinzshriu. Beiträge zur Iforphologie und Srstematik der Algen. IV. Nachtrïge zur MIurphologie der Saprolegnieen, mit Tat. XXII-XXV. - W. Hnfineister. Ueber die Beugungen saftrcicher PHanzentheihe nach Erschutterung. - II Hollinant. Lntrsuchungen ubrr die Keimung der Pilzsporen, mit Taf. XXVI bis XXXII. - J. Sarhs. P'hysiologische Untersuchungen über die . Ibhängkgeit der Keimung ron der Temperatur. - W. Hofmeivir. Teber die Kntwickelung der sporen des Tuber aestivum Vittad., mit Taf. XXXIII-XXX1: - Jul. Ulaustrin. Versuche iber die Leitung des Saftes durch die Rinde und Folgerungen daraus. - N. Priusheim. Nachtrag zur Kritik und Geschichte der Untersuchungen über das Algengeschlecht - A. Wirand. Zur Morphologie und Systematik der Gattungen Trichia und Arçria, nit Taf. I-III. - r. Illduhand. Anatomische Untersuchungen über die Farben der Blithen, mit Taf. IV. - W. Hofmeister, Ueber die durch die Schwerkraft bescimmten Richtungen von Pflanzentheilen. - A. Wimabul. Ueber die Desorganisition der Pflanzenzelle, insbesondere über die physiologische Bedeutung ron Gummi und Harz, mit Taf. V-VII. - J. Sachs. Uelere die Stoffe, welche das Material zum Wachsthum der Zellhäute liefern. - W. Infimeister. Zusitze und Berichtigungen zu den 1851 verötfentlichten Untersuchungen der Entwickelung höherer lírytogamen, mit Taf. VIII. - I. Prinslım. Ueber die Vorkeime und die nacktfussigen Zweige der Charen mit Taf. IX-XIII. - L. ('irnkunsky. Zur Entwicklungsgeschichte der Mixonyceten. - II. Schachit Ueber die Zelistofffaden in der vorderen Aussackung des Embryosackes von Pedicularis sylvatica, mit Taf. XIV und XV. - II. Silhicht. Ueber ein neues Secretionsorgan im Wurzelstock ron Nephrodium Filix mas, mit Tat. XVI. - W. Kibsch. Untersuchungen über die chemische Beschaffenheit der Pflanzengewebe. - L. (iłnkowsy. Las Plasmodium. mit Taf. XVII-XXI. - II Schacht. Ceber die Veränderung durch Pilze in abgestorbenen Pflanzenzellen, mit Taf. XXII-XXIII, - \$. Pringsheim. Zur Morjhologie der Salvinia natans, mit Taf. XXIV-XXIX. - I. Schacht. Die Blüthe und die Befruchtung von Santalum allom, mit Taf. I-IV. - F. Thomas. Zur vergleichenden Anatomie der coniferen-Laubblätter. - L. Kny. Beiträge zur Entwickelungsgeschichte der laubigen Lebermouse, mit Taf. V-VII. - R. Caspary. Bemerkungen uber die Schutzscheide und die Bildung des Stammes und der Wurzel; hierzu Taf. VIII und IX. - A. Neiss. Untersuchungen über die Zahlenund Grössenverhältnisse der Spaltöffnungen. - J. Haustein. Die Befruchtung und Entwicklung der Gattung Marsilia, mit Taf. X-XIV. - Th. Will. Beiträge zur Entwicklungsgeschichte der Orchideen-Blüthe, mit Taf. XV-XVIII. - Gir. Kraus. Ueber den Bau der Cycadeeufiedern, mit Taf. XIX-XXIII. - Al. Fischer v. Waldheim. Ueber die Entwickelung der Falusporen, mit Taf. XXIV his XXVII. F. Buchenan. Der Blüthenstand der Juncaceen, mit Taf. XXVIII-XXX. - S. Rnsanff. Zur Kenntniss des Baues und der Entwicklungsgeschichte des Pollens der Mimoseae, mit Taf. XXXI-XXXII. - F. Ilildebrand. Ueber die Befruchtung der Silviaarten, mit Hülfe von Insecten, Taf. XXXIII. - Th. Geyler. Zur Kenntni s der Sphacelarieen, mit Taf. XXXIV-XXXVI. - Alex. v. Wolkufi. Einige Untersuchungen über die Wirkung des Lichtes von verschiedener Intensität alıf die Ausscheidung der Gase durch Wasserpflanzen, mit Taf. I-III. A. Vogl. Beiträge zur Kenntniss der Milchsaftorgane der Pflanzen, mit Taf. IV. - S. Kosanoff. Morphologisch-embryologische Studien, mit Taf. V-VII. - Gr. Kraus. Ueber 


\section{I n h a $1 \mathrm{t}$ des vorliegenden Heftes 4, Bd. VIII.}

IV. Pfeffer. Untersuchungen über die Proteinkörner und die Bedeutung des Asparagins beim Keimen der Sarnen . . . . . . . . . . , 429

Proteinkörner ohne Krystalloide . . . . . . . . . . 434

Proteinkörner mit Krystalloiden . . . . . . . . . 450

Die Einschlüsse . . . . . . . . . . . . . . 464

Die Grundmasse . . . . . . . . . . . . . . . . 478

Allgemeines . . . . . . . . . . . . . . . . . 486

Die Ursachen der Löslichkeit der Proteinkörner . . . . . . 491

Die Proteinkörner von Paeonia . . . . . . . . . . 499

Bildung der Proteinkörner . . . . . . . . . . . 506

Silybum marianum . . . . . . . . . . . . . 511

Lupinus polyphyllus und luteus . . . . . . . . . 513

Phaseolus vulgaris . . . . . . . . . . . 515

Ricinus communis . . . . . . . . . . . . 516

Veränderung der Proteinkörner beim Keimen . . . . . . . 525

Die Bedeutung des Asparagius beim Keimen . . . . . . . 530

Historisches . . . . . . . . . . . . . . . 565

Erklärung der Abbildungen. Taf. XXXVI-XXXVIII . . . . . 571

J. Wiesner. Untersuchungen über die Farbstoffe einiger für chlorophyllfrei ge-

haltenen Phanerogamen. . . . . . . . . . . . . 575

Erklärung der Figurentafel XXXIX . . . . . . . . 594 



\title{
Untersuchungen über die Proteïnkörner und die Be- deutung des Asparagins beim Keimen der Samen.
}

\author{
Von \\ Dr. W. Pfeffer. \\ Privatdocenten in Marburg.
}

(Mit Taf, XXXVI-XXXVIII.)

In dem ruhenden Samen, aber auch in anderen ruhenden, Reservestoffe führenden und austrocknenden Vegetationsorganen finden sich körnige, dem Stärkemehl dem Ansehen nach gleichende Gebilde, welche Hartigl), ihr Entdecker, Aleuron oder Klebermehl nannte, für welche indess die von $\mathrm{v} . \mathrm{H}$ olle ${ }^{2}$ ) zuerst gebrauchte Bezeichnung "Proteïnkörner" aus gleich anzuführenden Gründen entschieden vorzuziehen ist. Nach Hartig bestehen die Proteinkörner wesentlich aus eiweissartigen Stoffen, spätere Forscher, Trécul, ${ }^{3}$ ) $\mathrm{Sachs}^{4}$ ) und $\mathrm{Gris}{ }^{5}$ ), suchen indess zu beweisen, dass sich auch Fett an der Constitution der Proteinkörner betheiligen oder auch der fast ausschliessliche Bestandtheil werden könne. In diesem Falle würde dann freilich einfach an Stelle der Stärke nur ein anderer stickstofffreier Reservestoff, das Oel, getreten sein; allein meine Untersuchungen haben ergeben, dass in der That die Proteinkörner, von gewissen fremdartigen Einschlüssen abgesehen, aus Proteinstoffen bestehen, denen höchstens selr unbedeutende und nicht sicher nachzuweisende Mengen anderer Pflanzenstoffe beigemengt sind. Uebrigens geht aus den entsprechenden Kapiteln

1) Hartig, Bot. Zeitung 1855, p. 881 ; ibid. 1856, p. 257 und Entwicklungsgeschichte des Pflanzenkeims 1858, p. $108 \mathrm{ff}$.

2) v. Holle, Neues Jahrb. f. Pharmacie von Walz und Winkler 1858, Bd. X, p. 2 d. Separatabzugs.

3) Trécu l, Annal d. sc, natur. IV ser, T X, 1858, p. 355.

4) Sachs, Bot. Zeitung 1862, p, 242 (Dattel); ibid. 1863, p. 56 (Allium Cepa); Lehrb. d. Bot. II. Aufl., p. 52.

5) Gris, Annal. d. sc. natur. V ser, T. II, 1864, p. 98.

Jahrb. f. wisa, Botanik. VIII. 
in den nevesten Hand- und Lehrbüchern der Botanik ${ }^{1}$ ) zur Genüge hervor, wie sehr die Proteinkörner einer erneuten Untersuchung bedürfen; Bildung und Rückbildung derselben bein Reifen und Keimen, worüber auch verschiedene Forscher, Hartig, Maschke, Trécul und Gris schrieben, finden wir ganz mit Stillschweigen über̈gangen.

Meine Untersuchungen beschränken sich auf die Proteinkörner der Samen, deren schon angedeutete Zusammensetzung aus eiweiss. artigen Stoffen an etwa 150 untersuchten Samen aus den verschiedensten Pflanzenfamilien übereinstimmend gefunden wurde. Eine gleiche Constitution kommt aber auch den immer nur sehr kleinen Proteinkörnern zu, welche ich aus ruhenden Wurzeln und Rhizomen untersuchte. Es ist aber die Bezeichnung "Proteïnstoffe“, seitdem Mulder's Ansichten über das Proteïn historisch geworden, zum generischen Begriff erhoben ${ }^{2}$ ), während man unter Kleber einen einzelnen oder wenigstens eine Gruppe eiweissartiger Körper versteht, welche keineswegs die einzigen sind, welche an dem Aufbau der Proteïnkörner sich betheiligen. Desshalb ist aber auch die Bezeichnung "Proteïnkörner" der als „Klebermehl" vorzuzichen und auch zutreffender als der Ausdruck "Albumin- oder Eiweisskörner", da man unter Albumin oder Eiweis einen einzelnen Proteïnstoff versteht.

Es wurden schon fremdartige Einschlüsse erwähnt, die in der That auch keinem grösseren Proteïnkorn fehlen, aber von zweierlei Art vorkommen. Die einen bestehen aus oxalsaurem Kalk und sind immer krystallisirt, sei es nun dass sie als Drusen, gut kenntliche Einzelkrystalle oder als Nadeln vorkominen; sie sollen als krystallinische Einschlüsse oder kurzweg als Krystalle bezeichnet werden (XXXVIII, 1a; XXXVII, 13 u. 14b) ${ }^{3}$ ). Es sind diese aber nur beschränkt verbreitet, während die $\mathrm{zweite}$ Art ron Einschlüssen, welche ich "Globoide" nennen werde, in keinem Samen fehlt. Diese sind kugelige, biscuitförmige, traubenförmige u. s. w. Gebilde, (XXXVIII, 1b u. 9) welche keine Spur einer krystallinischen Struktur erkennen lassen; sie sind das Magnesia und Kalksalz einer gepaarten Phosphorsäure, deren organischer Paarling noch nicht sicher bestimmt wurde. Beide sind schon durch ihre Form, dann

1) Ho fmeister, Pflanzenzelle 1867, p. 391. Sachs, Lehrbuch II, p. 51.

2) z. B. Limpricht, organ. Chem. 1862 , p. 1237, Kolbe, ausführl. Lehrb. d. organ. Chem. III. Bd., 2. Abth., 1868, p. 403.

3) Durch römische Zahlen wird die Tafel, durch arabische die Figur bezeichnet. 
aber auch durch ihr Verhalten gegen Essigsäure leicht zu unterscheiden, denn in dieser ist bekanntlich oxalsaurer Kalk unlöslich, während die Globoide sich sehr leicht auflösen. Es sei hier gleich bemerkt, dass die Globoide eine relativ ansehnliche Grösse erreichen können und dann in Einzahl oder zu wenigen in einem Pro. teïnkorn sich finden; aber man findet auch die Globoide von fast unmessbarer Grösse und dann zuweilen in sehr grosser Menge in der ganzen Masse eines Proteïnkorns vertheilt. Die Krystalle treten immer in geringerer Zabl, zuweilen aber in sehr ansehnlicher Grösse in einem Proteïnkorn auf, das aber mit sehr seltnen Ausnahmen nur eine Art von Einschlüssen führt, ja gewöhnlich sind in derselben Zelle nur Globoide oder nur Krystalle zu finden, wenn beide Arten von Einschlüssen in einem Samen vorkommen.

Bei der Mehrzahl der Samen sind die Einschlüsse von anscheinend amorpher Masse umgeben, bei anderen Pflanzen hingegen findet sich ein aus eiweissartigen Stoffen bestehender krystallähnlicher Körper, Krystalloid von Nägeli ${ }^{1}$ ) genannt, der zusammen mit den Einschlüssen von einer immer ziemlich spärlichen amorpher Hüllmasse umgeben ist und so zum Proteïnkorn wird, welches demnach aus dem Einschluss, dem Krystalloid, die beide auch in Mehrzahl vorhanden sein können, und der diese umgebenden Hüllmasse (XXXVII, 2 u. 3) zusammengesetzt ist.

Unsere Krystalloide wurden von $\mathrm{H}$ artig und anderen Autoren Proteïkrystalle genannt, was aber Hartig als Krystalloide oder Flächenkörper bezeichnete sind Krystalle von oxalsaurem Kalk und liegt mit diesem Nachweis natürlich nicht der geringste Grund mehr vor diese Krystalloide zu nennen; auch hat Hartig's Bezeichnung für diese Gebilde nirgends Eingang gefunden. Hartig's Weiskerne (Albine) und Kranzkörper (Globide) sind unsere Globoide, doch hat jener auch Drusen von oxalsaurem Kalk zu seinen Kranzkörpern gezogen. Sind nun von späteren Autoren die Einschlüsse meist Weisskerne genannt, so wurden doch chemisch differente Körper, unsere Krystalle und Globoide zusammengeworfen und desshalb gebe ich jene Bezeichnung auf.

Die Proteïnköner liegen innerhalb der Zelle in einer „Grund-

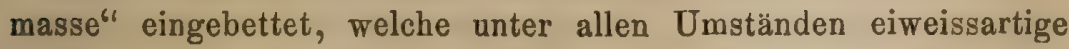
Stoffe enthält, die freilich bei fettreichen Samen gegen das Oel sehr zurücktreten können.

1) Sitzungsb. d. Münchner Akad, 1862, II, p. 220 ff. 
Nach dieser vorläufigen Orientirung können wir uns nun den Untersuchungen zuwenden, welche zur Aufklärung über die Natur der Poteïnkörner und der Vertheilung von Fett und Eiweissstoffen in ruhenden Samen überhaupt, angestellt wurden. Wie schon gesagt, kommen Proteïnkörner in allen Samen vor, doch sind sie in den rorwiegend stärkeführenden auf winzige Grössen herabgedrückt (XXXVII, 16b) umgekehrt findet man aber auch unter grösseren Proteïnkörnern winzige Stärkekörner und zwischen diesen beiden Extremen alle möglichen Verhältnisse in der relativen Grösse und Menge beider, sofern sie zusammen rorkommen. Die neben Stärke sich findenden Proteïnkörner stimmen aber in jeder Beziehung mit denen stärkefreier Samen überein und so können wir die Proteïnkörner dieser zunächst allein im Auge haben. Später werden wir dann einen Blick auf das Zusammenvorkommen von Stärke und Proteïnkörnern werfen, so wie auch die die Vertheilung, Form u. s. w. dieser betreffenden Verbältnisse behandeln. Hier sei nur noch bemerkt, dass die mittlere Grösse der Proteïnkörner fetthaltiger Samen $z$ wischen 3 und 12 Mikromillimeter grössten Durchmessers liegt, doch kommen auch Proteïnkörner von 55 Mikm. Durchmesser vor, während die kleinsten unter 1 Mikm. herabsinken.

Die Proteïkörner der meisten Samen werden von Wasser mehr oder weniger angegriffen, manche selbst $\nabla$ öllig gelöst. Es ist desshalb nöthig, wenn man die Proteïnkörner unverändert sehen will, Samenschnitte in ein anderes Medium zu tragen, als welches sich Olivenöl oder ein anderes fettes Oel am meisten einpfiehlt. In diesem erfahren die Proteinkörner keine äusserlich sichtbare Veränderung, wenn das Oel bis fast.zum Sieden erhitzt wird; vor wie nachher sind sie spröde und durch Druck auf das Deckglas ziem. lich leicht zu zersprengen. Die Proteïnkörner sind mit wenigen Ausnahmen farblos und manche haben beim Betrachten in Oel eine solche Aehnlichkeit mit Stärkekörnern, dass man erst durch mikrochemische Reaktionen über ihre wahre Natur ins Klare kommen kann. Wo, wie bej Chimonanthus fragrans (XXXVIII, 20) (Calycanthee) Proteïnkörner und Stärkekörner von ziemlich gleicher Grösse und Gestalt nebeneinander vorkommen, ist es, nachdem man schon darauf aufmerksam geworden ist, nicht leicht, die beiden geformten Körper zu unterscheiden. Schnell zum Ziele führt übrigens die Anwendung polarisirten Lichtes, denn die Proteïnkörner erweisen sich bei gekreuzten Nicols nicht doppeltbrechend, während die Stärkekörner mit dem bekannten Kreuze erscheinen. Doch ist die 
Aehnlichkeit der Proteïnkörner mit Stärkekörnern nicht für alle zutreffend, sie gilt besonders für diejenigen, welche wenige und sehr kleine Einschlüsse führen. Wenn nämlich grössere Globoide vorhanden sind, so erscheinen diese in dem stürker lichtbrechendem Oele als Vacuolen, die von der dichteren Proteïnmasse umgeben sind ; Ricinus (XXXVII, 1) ${ }^{1}$ ) und Tragopogon majus (XXXVI, 15) seien hier als auffallende Beispiele genannt. Finden sich aber sehr zahlreiche und zugleich sehr kleine Globoide, dann bekommt das Korn èin granulirtes Ansehen, oder es scheint von kleinen Vacuolen durchsäet zu sein, wenn die Globoide nicht allzu winzig sind (Erodium Gruinum; Allium Cepa; Lupinus varius (XXXVIII, 12) u. a. (Letztere Pflanze zeigt beide Verhältnisse gleichzeitig).

Sehr kleine krystallinische Einschlüsse sind an in Oel liegenden Präparaten oft kaum in den Proteïnkörnern wahrzunchmen; grössere grenzen sich aber als dichtere Masse, wenn auch meist nicht sehr deutlich, in der Proteïnmasse ab. Samenschnitte von Silybum marianum sind hier ein empfehlenswerthes Objekt. In einem grossen Theil der parenchymatischen Zellen des Embryos finden sich nämlich krystallinische Einschlüsse und zwar in einem durch Grösse ausgezeichneten Proteïnkorn eine morgensternförmige Krystalldruse, während die übrigen Proteïnkörner derselben Zelle nadelförmige Krystalle einschliessen, die man in Oel kaum wahrnimmt, während man die Krystalldruse, wenn auch nicht sehr deutlich erblickt (XXXVIII, 1a). Die meisten Zellen in der Mitte des Querschnittes eines Samenlappens von Silybum fübren krystallinische Einschlüsse, während eine einige Zelllagen dicke Randzone in der überwiegenden Zahl ihrer Zellen ein oder einige grössere Globoide in jedem Proteïnkorn aufzuweisen hat. $\mathrm{Da}$ die Globoide bei un. serer Pflanze beinahe oder selbst mehr als die Hälfte des Volumens eines Proteïnornes ausmachen, so erblickt man, im optischen Schnitt gesehen, an in Oel liegenden Präparaten, nur einen oft schmalen Ring von Proteïnstoffen, der das als Vacuole erscheinende Globoid umschliesst. Bei der hier so erheblichen relativen Grösse der Globoide, würde man die Proteïnkörner mit gleichem Rechte nach den Einschlüssen benennen können, allein diese machen der Regel nach nur einen geringen procentischen Werth vorn Gesammtrolumen eines Proteïnkornes aus.

1) Bei eiweissartigen Samen habe ich, wenn ich nicht Näheres bsmerke, immer nur die Proteinkörner des Albumens im Auge. 
Die Aufsicht vieler Proteïnkörner erscheint, wie schon Hartig ${ }^{1}$ ) bemerkte, feingrubig, ähnlich etwa wie die Aufsicht auf einen Fingerhut. Bei den Proteïnkörnern der meisten Samen ist es kaum zu entscheiden, ob dieses Aussehen durch wirkliche Grübchen oder durch ungleich lichtbrechende Partien in der Masse der Körner bedingt ist; bei manchen Proteïnkörnern aber, wie den grossen von Vitis vinifera sind wirkliche Unebenheiten vorhanden, wie der im optischen Schnitt ausgezackte Rand beweist. Es dürfte wohl bei anderen Proteïnkörnern demnach cine gleiche Ursache zu Grunde liegen, ob aber nicht auch ungleich dichte Stellen in anderen Fällen einen ähnlichen Effekt hervorrufen, muss ich dahingestellt sein lassen, da ich diesem Punkte keine besondere Aufmerksamkeit zuwandte.

\section{Proteïnkörner ohne Krystalloide.}

$\mathrm{Ob}$ die Proteïnkörner ganz oder theilweise aus Fett bestehen, hierüber muss ibr Verbalten gegen Lösungsmittel der Fette entscheidend werden, als welche Aether, Benzin, Schwefelkohlenstoff, Chloroform und absoluter Alkobol sich als die bekanntesten darbieten. Unter diesen ist aber bei Untersuchungen über Proteïnkörner fưr die meisten Fälle dem absoluten Alkohol entschieden den Vorzug zu geben, wenn dieser auch von vielen Fetten weniger aufnimmt, als die anderen genannten Flüssigkeiten. Es hat der Alkohol den grossen Vortheil sich mit Wasser in jedem Verbältniss zu mischen und erlaubt desshalb die allmäliche Einwirkung von Wasser und von wässrigen Reagentien bequem studiren zu können. Auch löst der Alkohol von fast allen Oelen genug, um deren Entfernung sicher zu erreichen, wenn man Samenschnitte damit einige Stunden stehen lässt, was man am zweckmässigsten in weithalsigen etwa 10-15 Gramm fassenden Fläschchen thun wird. Dass in der That der Alkohol den Samenschnitten alles Oel entzieht, kann man leicht constatiren, indem man dieselben nach Extraktion mit jenem in Wasser, oder falls die Proteïnkörner sich in diesem nicht ganz lösen, in ein etwas Kali enthaltendes Wasser trägt. Man findet nun, dass Oeltropfen nicht mehr zusammenfliessen und dieses stimmt auch mit der Érfahrung der Chemie überein, dass fetthaltigen Samen alles Oel durch Lösungsmittel entzogen werden kann. Damit ist auch

1) Hartig, Pflanzenkeim 1858, p. 112. 
der etwaige Einwand, dass den Proteïnkörnern vermöge ihrer specifischen Organisation eingeschlossene Fettmassen mit Alkohol oder anderen Medien nicht entzogen werden könnten, sofort entkräftigt; übrigens ist ein solcher Einwand auch an sich haltlos. Gesetzt auch den Proteïnkörnern komme, wie dem Protoplasma im vitalen Zustande eine eigenthümliche Organisation zu, vermöge welcher letzteres z. B. Farbstoffen den Fintritt verwährt, so ist doch auch bekannt, wio leicht das Protoplasma getödtet und farbenspeichernd wird. Gerade der absolute Alkohol ist aber im höchsten Grade ein alles Leben vercichtender Körper und so wenig wie Protoplasma, werden auch Proteïnkörner ihren vitalen Molecularzustand in demselben bewahren, mit dessen Verlust dieselben sich aber in der Pflanzenzelle so wie analoge künstliche oder natürlich vorkommende Gemenge in den Geräthschaften des Chemikers verhalten müssen. Eine chemische Bindung des Fettes, welche dieses den Lösungsmitteln unzugänglich machte, ist, wie es die vollständige Extraktion mit Alkohol und anderen Medien beweist, auch nicht vorhanden.

Bei den Proteïnkörnern zahlreicher Samen habe ich niemals das Herauslösen eines Stoffes, geschweige denn eine vollständige Lösung bei Behandlung mit Alkohol, Aether oder Benzol constatiren können. Nach $\mathrm{Sachs}^{1}$ ) sollen sich nun freilich die Pro. teïnkörner des Samens von Allium Cepa, nach $\mathrm{Gris}^{2}$ ) die von Haselnüssen und Mandeln in Aether lösen, allein diese Resultate beruhen auf einem allerdings sehr verzeihlichen Irrthum, den meine eignen Erfahrungen mit Aether mich bald aufdecken liessen. Aether löst nämlich eine kleine Menge Wasser auf und der käufliche mag wohl häufig ganz mit Wasser gesättigt sein. Wenn nun Schnitte in nicht hermetisch schliessenden Gefässen mit Aether behandelt werden, so scheidet sich in Folge der Verciampfung dieses Wasser aus, das sich am Boden und den Seitenwänden des Gefässes in sich ausbreitenden Tröpfchen absetzt. Mit diesen kommen nun die zu Boden sinkenden Schnitte in Berührung und auf solche Weise wird die Desorganisation und Entfernung der Proteïnkörner bewirkt, sofern diese in Wassor löslich sind, was bei den genannten Samen der Fall ist. Hieraus erklärt sich nun auch sofort warum sowohl bei Sachs, als bei Gris immer nur ein Theil der Protein. körner weggelöst war, eben weil nìcbt alle Theile eines Samenschnittes mit den die Gefässwände bekleidenden Wassertröpfchen

1) Sachs, Bot. Zeitung, 1863, p. 56.

2) Gris, 1. c. p. 98. 
in Contakt kameu. Die abwechselnde Behandlung mit Aether und Oel, welche Gris vornalım, ist natürlich an und für sich gleichgültig und nur insofern von Bedentung, als bei diesen Manipulationen möglichst rielen Stellen der Samenschnitte Gelegenheit gegeben wurde mit den rom Aether ausgeschiedenen Wassertröpfchen in Berührung zu kommen. Ich habe selbst bei Allium Cepa, Amygdalus, Paconia und anderen Samen deren Proteïnkörner in Wasser löslich sind, das theilweise oder auch vollständige Verschwinden djeser beobachten könneu, weun ich Samenschnitte mit gewöhnlichem Acther in nicht völlig schliessenden Gefässen digerirte, dabei waren aber auch die fraglichen Wassertröpfchen immer erschienen. Es bleibt dann ein aus eiweissartigen Stoffen bestehendes Netz, in dem die Proteïnkörner durch Hohlräume ersetzt sind; allein dieses beruht, wie wir noch später erfahren werden, darauf, dass die Grundmasse, auch der fettreichsten Samen, immer ein geringeres oder grösseres Quantum in Wasser und auch in verüuntem Kali unlöslicher Pro. teïnstoffe enthält, denen sich noch ein aus denselben Stoffen bestehendes sehr zartes, die Proteïnkörner umschlicssendes Häutchen aggregirt. Bei Anwendung von völlig wasserfreiem Aether unterblieb mit der Ausscheidung der Wassertröpfchen auch die Auflösung der Proteïnkörner, welche jetzt ebenso unrerändert als bei Anwendung eines anderen Fettlösungsmittels sich erwiesen. Setzte ich dann aber auf das weithalsige Gefäss einen mit Wasser durchtränkten völlig schliessenden Kork, so waren nach einigen Tagen die fraglichen Wassertröpfchen erschienen und damit war denn auch das Verschwinden der Proteiukörner zu constatiren. Hier gab offenbar die, zur Zeit der Anstellung des Experimentes nocb dazu erhebliche Schwankung der Temperatur Veranlassung zur Ausscheidung von Wassertröpfchen unter der Aetherschicht, indem die sinkende Temperatur von dem im Aether aufgelösten Wasser immer einen Theil ausscheiden machte, welcher bei steigender Temperatur nicht wieder völlig gelöst wurde, weil der Aether durch Aufnahme ron Wasser aus der sich über ihm befindlichen dampfgesättigten Atmosphäre scinen jeweiligen Sättigungszustand erreichte oder sich wenigstens diesem nährte.

Das Hauptargument für die Fettnatur gewisser Proteinkörner, die Löslichkeit dieser in Aether, ist damit beseitigt; alle übrigen angefürten Reaktionen sind an und für sich nicht entscheidend und wenn der Zellinhalt dabei eine energische Desorganisation erfährt, so ist es niemals möglich mit Sicherheit zu sagen, ob die 
zusammenfliessenden Oeltropfen aus der Grundmasse oder aus den Proteinkörnern stammen. Bei Lupinus varius folyert Sach s ${ }^{1}$ ) den grössercn Fettgehalt der Proteinkörner gegenüber der Grundmasse auch aus dem Verhalten gegen in absolutem Alkohol gelöstes Jod, durch welches Reagens ein durchschnittenes Proteinkorn sich nicht, die Grundmasse aber sich gelb fürben soll. Wenn ich nun unter diesen Umständen auch dic durchschnittenen Profeinkörner nicht gerade farblos sehe, so ist es allerdings richtig, dass die Grundmasse etwas intensiver gefärbt ist. Wenn man nun aber etwa 70procentigen Alkohol zutreten lässt, so ändert sich plötzlich das Bild, die Proteinkörner werden nun viel intensiver gelb oder gelbbraun als die Grundınasse gefärbt. Demnach müssen die Eiweissstoffe der Grundmasse, welche übrigens auch verschieden von denen der Proteinkörner sind, in höherem Grade die Fähigkeit besitzen, absolutem Alkohol Jod zu entziehen, als die Proteinstoffe, aus welchen die Körner bestehen. Uebrigens enthält die fettarme Grundmasse von Lupinus varius relativ viele eiweissartige Stoffe, wo aber diese bei fettreichen Samen in geringerer Menge vorhanden sind, wird auch die Grundmasse, wie die Körner, von alkoholischer Jodlösung nur sehr schwach gefärbt. Dass bei Einwirkung von concentrirter Schwefelsäure unter Verschwinden der Proteinkörner ein Netz der Grundmasse restirt, hat seinen Grund in der Natur der Proteinstoffe dieser, welche sich zum Theil wie die unlösliche (coagulirte) Modifikation der eiweissartigen Körper verhalten, während sich die Proteinkörner selbst, vom Hüllhäutchen abgesehen, aus in kalihaltigem Wasser löslichen Eiweissstoffen zusammensetzen. Natürlich wird das persistirende Netz der Grundmasse, seiner Zusammensetzung cntsprechend, sich rosenroth färben, da, wenn nicht schon Zucker im Samen vorhanden war, sich dieser aus Kohlehydraten durch Einwirkung der Schwefelsäure bilden kann.

Die Möglichkeit, dass sehr geringe Mengen von Stoffen aus den Proteinkörnern durch Alkohol, Aether oder Benzol gelöst werden, ist freilich nicht ganz zu widerlegen, da es zu diesem Zwecke an absolut genauen Methoden feblt, soweit indess diese reichen, ist auch die Entfernung eines Stoffes aus den Proteinkörnern durch die genannten Lösungsmedien nicht zu constatiren. Legt man mit einem Fettlösungsmittel extrahirte und demselben

1) Sachs, Lehrb., II. Aufl, p. 52. 
Samen unmittelbar entnommene Schnitte in fettem Oele so neben. einander, dass man Proteinkörner beider gleichzeitig übersieht, so ist ein merklicher Unterschied in Form und Lichtbrechung der Körner beider Schnitte nicht zu constatiren. Wenn die Proteinkörner der mit Alkohol behandelten Schnitte im ersten Augenblick etwas weniger glänzend, als die der direkt in das $\mathrm{Oel}$ eingetragenen Schnitte erscheinen, so ist dieses doch nur der innigen Umbüllung mit Fett bei letzteren zuzuschreiben. Denn schon in so kurzer Zeit nach dem Eintragen in Oel kann man die Proteinkörner beider Schnitte nicht mehr unterscheiden, dass unmöglich das Oel die Proteinkörner durchdrungen kaben kann, am wenigsten dann, wenn man ein so dickflüssiges Oel wie Ricinusöl anwendet. $\mathrm{Zu}$ einem gleichen Resultat fülurt aber auch der Vergleich der mit Alkohol oder Aether behandelten und unbehandelten Proteinkörner in Glycerin, wobei man freilich sehr schnell operiren muss, da Glycerin die Proteinkörner sehr vieler Samen verändert, oder wenn dieses nicht der Fall ist, doch desorganisirend auf die fetthaltige Grundmasse der nicht extrahirten Samenschnitte wirkt. Man kann natürlich nur solche Proteinkörner anwenden, welche aus der Grundmasse herausgefallen sind und frei im Glycerin liegen, da ja sonst die Umhüllung mit einem fettreichen Medium unvermeidlich eine andere Lichtbrechung hervorrufen muss. Da ausserdem Beschicken des Präparates und Beobachtung unmittelbar aufeinanderfolgen müssen, so wird es nicht immer gleich yelingen allen Bedingungen zu genügen, bis man durch Uebung gelernt hat, wie durch ein schnelles Herumzerren sehr dünner, dem Samen unmittelbar entnommener Schnitte in Glycerin eine Anzahl Proteinkörner mit ziemlicher Gewissheit isolirt werden kann. Bei solchen vergleichenden Beobachtungen konnte aber das Herauslösen bemerkbarer Mengen, wie schon gesagt, niemals festgestellt werden, obgleich ich solche Proteinkörner in Untersuchung zog, die sich wie die von Paeonia, Tragopopon major etc. in Wasser lösen, oder wie die von Lupinus-Arten, Silybum marianum in Wasser theilweise löslich sind, oder endlich wie die Proteinkörner von Cynoglossum officinale und Empetrum nigrum in Wasser nicht verändert werden.

Dass kein Oel in den Proteinkörnern vorhanden ist, kann man auch noch in anderer Weise bestätigen. Es gelingt beim Herumzerren von Samenschnitten mancher Pflanzen in Glycerin einzelne Proteinkörner so vollkommen zu isoliren, dass auch nicht eine Spur der 
fettigen Grundmasse daran zu erkennen ist. Sind die Proteinkörner in Glycerin löslich, wie die von Paeonia, so schreitet die Lösung ganz allmälich von Aussen nach Innen vor und war das Glycerin, das ich übrigens chemisch rein voraussetze, sehr concentrirt, so findet eine Zersprengung des aus unlöslichen Proteinstoffen bestehenden Hüllhäutchens nicht statt. In dem von diesem umgränzten Raum kann man aber nie ein Oeltröpfchen finden, obgleich, wenn die angewandten Proteinkörner sehr kleine, auch bei mehr als 1000 facher Vergrösserung nur punktförmig erscheinende Globoide einschlossen, diese sich in molecularer Bewegung in der Blase umhertummeln (XXXVI, 2). Freilich sind Proteinkörner mit solchen kleinen kugeligen Einschlüssen nicht gut zu diesem Versuche zu benutzen, da man letztere nicht wohl von Oeltröpfchen unterscheiden kann und das Zutretenlassen von essigsäurehaltigem Glycerin, um die Globoide zu lösen, der hierbei unvermeidlichen Strömung halber immer etwas störend ist. Man wählt deshalb besser Proteinkörner mit krystallinischen Einschlüssen (Paeonia ist zu empfehlen) oder solche, die einzelne grössere Globoide einschliessen. Dieser Versuch ist aber nicht allein für die in Glycerin löslichen Proteinkörner aus. führbar, sondern auch für alle anderen mit gleichem Resultate, wenn man nur dem Glycerin eine Spur von Kali zusetzt, in Folge dessen sich eben alle Proteinkörner auflösen.

Ehe wir überhaupt sicher auf mikrochemischem Wege fortschreiten können, müssen wir wissen, welche Stoffe wir bezüglich der Proteinkörner zu berücksichtigen haben. Es ist allerdings gewiss, dass die Proteinkörner ausser den Einschlüssen noch anorganische Stoffe enthalten und für Kali und Phosphorsäure werden wir noch eine wichtige Bedeutung kennen lernen, allein die Menge dieser Aschenbestandtheile ist doch immer nur eine geringere und wir werden diese auch ganz ausser Acht lassen. Ebenso können und brauchen wir auch die stets in kleiner Menge vorkommenden oder auch nur in Samen einzelner Pflanzen sich findenden Stoffe, wie Glucoside, Farbstoffe, organische Basen und Säuren u. s. w. gar nicht zu berücksichtigen; auch auf Gerbstoffe habe ich meine Untersuchungen nicht gerichtet, da sie in den Samenschalen zwar verbreitet, in dem Samen selbst aber sehr selten sind, wenn sie auch nicht, wie Husemanu') angiebt, ganz fehlen. Die Stoffe aber, welche wir ins Auge zu fassen haben, sind Proteinkörper,

1) Dr. A. u. Dr. Th. Hu semann, die Pflanzenstoffe, 1871, p. 526. 
Oele und Kohlehydrate, von welchen letzteren wir, neben dem ja leicht kenntlichen Stärkemebl, wieder nur arabisches Gummi '), Glycose und Rohrzucker zu berücksichtigen brauchen, denn andere, ron Cellulose natürlich abgesehen, sind im reifen Samen nicht nachgewiesen. Es gilt dieses auch für das Dextrin, welches als Reservestoff niemals vorhanden zu sein scheint und dessen Vorkommen in der Pflanze überhaupt noch nicht so zweifellos ist. ${ }^{2}$ ) Dann sind auch die Pektinstoffe zu nennen, über deren Vorkommen im reifen Samen ich keine sicheren Angaben finden kann, jedenfalls sind sie aber, wenn überhaupt, nur spärlich in Samen vorhanden. Gleiches gilt übrigens selbst für die in Frage kommenden löslichen Kolehydrate, die nur in einzelnen Samen sich in etwas erheblicherer Menge finden.

Alle Proteinstoffe sind nun in absolutem Alkohol unlöslich, auch die, welche sich wie Mucedin und Gliadin (Pflanzenleim) in schwachem Weingeist schon bei gewöhnlicher Temperatur in grösserer Menge lösen. Hier sei denn auch gleich darauf aufmerksam gemacht, dass so ziemlich der ganze Stickstoffgehalt reifer Samen in den Proteinstoffen gebunden ist, denn von Alkaloiden und anderen stickstoffhaltigen Pflanzenstoffen, welche in geringer Menge vorkommen, können wir absehen und salpetersaure Salze oder Ammoniaksalze fehlen ganz oder fast ganz. Auch Rohrzucker und Gummi werden ron absolutem Alkohol nicht aufgenommen und so sind es Glycose und Fett, für die aus dem negativen Verhalten der Proteinkörner beim Extrahiren mit absolutem Alkohol das Fehlen, oder wenigstens das Vorkommen in einer dem Nachweis sich entziehenden Menge in den Proteinkörnern folgt.

An den in reinem Wasser theilweise oder ganz unlöslichen Proteinkörnern lassen sich nun unmittelbar die zur Erkennung von Proteinstoffen gebräuchlichen Reaktionen vornehmen, für die in Wasser löslichen Proteinkörner kann man, indem man sie in Jodglycerin (Jod mittelst wenig Jodkali in Glycerin gelöst) trägt, die Gelbfärbung constatiren. Allein wir wollen diese Reaktionen jetzt nicht näher betrachten und einen anderen Weg einschlagen, um zunächst nachzuweisen, dass auch Gummi, Rohrzucker und Pektin. stoffe vielleicht in manchen Porteinkörnern gar nicht, in anderen jedenfalls in nur sehr geringer Menge vorkommen. Ich be-

1) Bassorin ist aus dem Samen, von Samenschale natürlich abgesehen, nicht bekannt.

2) Husemann, 1. c. p. 585 . 
nutzte hier die Eigenschaft der Proteinstoffe durch Quecksilbersublimat in eine in Wasser unlösliche, übrigens chlorfreie Quecksilberverbindung übergeführt zu werden. Um diese ohne Desorganisation der Proteinkörner zu erhalten, digerire ich die Samenschnitte in kleinen Fläschchen während mindestens 12 Stunden mit einer Lösung von einfach Chlorquecksilber in absolutem Alkohol, auf deren Concentration es nicht gerade ankommt, doch mag ich wohl meist eine etwa zweiprocentige Lösung angewandt haben. Man spült dann die Schnitte in Alkohol ab und trägí sie in Wasser, in dem nur die Proteinkörner aller Samen unlöslich sind. Es ist aus noch anzufuhrenden Gründen nicht zu empfehlen, die Samenschnitte sorgfältig mit Alkohol auszuwaschen; auch mache ich darauf aufmerksam, dass man sich zum Herausnehmen der Schnitte keiner Nadeln oder Skalpelle von Stahl bedienen darf, da Eisen metallisches Quecksilber auf sich niederschlägt, das auch die damit in Berührung kommenden Schnittlächen verunreinigt. Man wird deshalb entweder Glasstäbe oder am bequemsten Nadeln oder kleine Skalpelle von Platina anwenden müssen, welche letzteren man sich $\mathrm{zu}$ diesem $\mathbf{Z}$ wecke einfach herstellen kann, indem man ein entsprechend zugeschnittenes Stück eines Platinbleches in ein Glasrohr einschmilzt.

Die in angegebener Weise mit Sublimat unlöslich gemachten Proteinkörner quellen in Wasser wohl etwas auf, nehmen aber beim Zurücktragen in Alkohol nach einiger Zeit wieder ihr früheres Volumen an. Vergleicht man nun diese Proteinkörner mit solchen, welche direkt aus der Sublimatlösung in Alkohol gelegt wurden, so ist man bei manchen Pflanzen, wie bei Paeonia, Allium Cepa nicht im Stande mit Sicherheit zu erkennen, dass etwas herausgelöst ist, obgleich es manchmal den Anschein hat. Bei Lupinus varius, luteus, Gleditschia triacanthos u. a. ist hingegen eine, wenn auch nur sehr kleine Stoffmenge aus den Proteikörnern herausgelöst, die Zucker, Gummi oder Pektin ${ }^{1}$ ) sein muss, welche mit Sublimat bei der angegebenen Behandlung keine in Wasser unlösliche Verbindung eingehen. In der That zeigt uns eine chemische Analyse des reifen Samens (ohne Schale) von Lupin. luteus, die Beyer ${ }^{2}$ ) ausführte, dass in diesem 17,5 Procent der Trockensubstanz Gummi

1) Ich habe hier Pektin allein im Auge, wie sich andere Pektinstoffe, deren Vorkommen in der lebenden Pflanze indess für die meisten fraglich ist, verhalten, lasse ich dahingestellt.

2) Die Landwirth. Versuchsstation, 1867, Bd. IX, p. 178. 
und Zucker (und Bitterstoff) sind, mehr als die meisten Samen ron diesen Stoffen enthalten. Wie weit nun freilich diese Verbindungen in den Proteinkörnern oder in der Grundmasse enthalten sind, muss ich dahingestellt sein lassen, da ein direkter Nachweis in der Grundmasse auf nicht zu überwindende Schwierigkeiten stösst. Doch müssten die Proteinkörner, falls die gesammte Menge von Zucker und Gummi in ihnen aufgespeichert wäre, an Wasser nach Behandlung mit Sublimat riel mehr abgeben, da selbst, wenn alle Proteinstoffe des Samens der gelben Lupine, nämlich 61,3 Procent der Trockensubstanz, auf die Proteinkörner fiele, was ja nicht der Fall ist, doch schon ungefähr ein Fünftel der Kornmasse aus Zucker und Gummi bestände. Nun wird aber faktisch aus den mit Sublimat behandelten Proteinkörnern so wenig herausgelöst, dass die grösste Menge ron Zucker und Gummi in der Grundmasse vorhanden sein wird. Es sei hier noch bemerkt, dass aus den „unlöslich" genannten Proteinkörnern von Cynoglossum offic., Empetrum nigrum u. a., wenn sie einfach mit Alkohol auggezogen werden, Wasser doch kleine Mengen löst, was nach Behandlung mit Sublimat in alkoholischer Lösung nicht mehr der Fall ist, jedenfalls kann man dann wenigstens das Hinweglösen eines Stoffes nicht mehr mit Sicherheit constatiren.

Das von mir eingeschlagene Verfahren ist also ein rein aualytisches, nur kann man leider durch Veränderung des Lichtbrechungsvermögens das Verschwinden geringer procentischer Mengen nicht annähernd so genau feststellen, wie mit Hülfe der chemischen Wage. Doch haben wir wenigstens das mit Gewissheit erweisen können, dass unbedingt der weit überwiegende Theil der Proteinkörner, bei manchen Samen vielleicht das gesammte Proteinkorn, von den Einschlüssen natürlich immer abgesehen, aus eiweissartigen Stoffen besteht. Denn als solche sind sie schon durch ihr Verhalten gegen Sublimat gekennzeichnet, weil hierin kein anderer der im Pflanzenreich verbreiteten Stoffe mit ihnen übereinstimmt. Zu einem annähernd richtigen Schluss über dio Quantität der Proteinstoffe kann man überhaupt nur auf einem solchen analytischen Wege gelangen, mit den üblichen Reagentien kann man wohl die Anwesenheit eiweissartiger Stoffe, nicht aber deren Quantität erkennen. Makrochemische Untersuchungen können aber auch zu keiner absoluten Gewissheit über die Zusammensetzung der Proteinkörner führen, da durch Schlämmen mit Oel oder anderen Medien, wie es von Hartig und Maschke geschah, eine vollkommene Reindarstellung, 
frei von aller Grundmasse, nicht möglich ist und wenn Maschke (Bot. Zeitung 1859, p. 438) in der Hüllmasse der krystalloidführenden Proteinkörner von Bertholetia kleine Mengen Zucker nachgewiesen zu haben glaubt, so liegt in seinem Verfahren keine Garantie, dass dieselben nicht aus adhärirender Grundmasse stammen. Hartig, welcher in seiner ersten Arbeit (Bot. Zeitung 1856, p. 260) Zucker und Gummi als Bestandtheil des Klebermehls angiebt, erwähnt diese Stoffe später (Pflanzenkeim, p. 112) nicht mehr.

An den mit Sublimat unlöslich gemachten Proteinkörnern lassen sich, wie an den für sich schon in Wasser unlöslichen direkt die Reaktionen eiweissartigen Stoffe erhalten. Doch ist die leichte Löslichkeit, auch der Quecksilberverbindung, schon in sehr verdünnten Alkalien und auch in Säuren immerhin bei vielen Reaktionen hinderlich. Eiweissartige Stoffe gehen aber beim Kochen mit Wasser, vorausgesetzt, dass nicht Alkalien oder deren Phosphate hinderlich sind, in coagulirte Modifikationen über, welche sich in verdünnten Alkalien und Säuren bei gewöhnlicher Temperatur kaum, in concentrirten wenigstens erst allmälich lösen. Freilich ist eine solche unlösliche Modifikation schon bei Glutenfibrin schwierig, noch schwieriger und unvollkommener aber bei Mucedin und Gliadin (unter Zersetzung) herbeizuführen, allein die Erfahrung hat gezeigt, dass alle untersuchten Proteinkörner beim Kochen für sich, oder die in Wasser löslichen beim Kochen der Quecksilberverbindung in Wasser, in verdünntem Kali uulöslich wurden, in diesem jetzt zwar aufquollen, schon durch Auswaschen des Kalis mit Wasser aber auf ihr früheres Volumen zurückkehrten. Nun Iasse ich freilich dahingestellt, ob nicht bei den Proteinkörnern mancher Pflanzen die Masse nur theilweise coagulirt wird, da ich Versuche in dieser Richtung nicht anstellte. Es liesse sich daraus vielleicht die Wahrscheinlichkeit gewinnen, welche übrigens auch schon der chemische Nachweis verschiedener Proteinstoffe in einem Samen, wie noch gezeigt werden wird, unterstützt, dass in einem Proteinkorn mehr als ein eiweissartiger Stoff vorkommt, allein dieses hätte keinen grösseren Werth, da bei der jetzigen Kenntniss der Proteinstoffe Albumin, Legumin u. s. w. eigentlich nur Genusnamen für unter sich in wesentlichen Merkmalen zwar übereinstimmende, aber doch in Nebensachen auch ron einander abweichende Proteinstoffe sind.

Die Ueberführung der Proteinkörner in die unlösliche Modifikation, welche übrigens beim einfachen Kochen mit Alkohol bei den 
meisten Samen nicht gelingt, ist ein weiteres sicheres Argument für die Gegenwart ron Proteinstoffen, denn kein anderer der verbreiteten Pflanzenstoffe zeigt ein derartiges Verlialten. Die in unlösliche Modifikation übergeführten Proteinkörner eignen sich auch am besten für die Proteinreaktionen mit sauren Flüssigkeiten, wenn man überhaupt noch Reaktionen anstellen will, dic eigentlich zum Zweck der Erkennung ron eiweissartigen Stoffen in unserem Falle überfüssig sind. Behandlung mit Salpetersäure, daun mit Kali gibt die gelbe, von Xanthoproteinsäure herrührende Färbung; Zucker und Schwefelsäure erzeugen eine rosenrothe Färbung und das Millon'sche Reagens, dessen Werth ich übrigens für mikrochemische Untersuchungen nicht gerade hoch anschlagen kann, bringt im günstigsten Falle eine ziegelrothe Färbung hervor. Selbstverständlich werden auch Jod und Farbstoffe aufgespeichert, wozu man übrigens auch die nicht in coagulirten Zustand gebrachten Proteinkörner benutzen kann, wenn nur die Lösungen neutral sind. Ich bediene mich gewöhnlich des in Wasser löslichen Anilinblaus, von dem eino Lösung sich schon ein Jahr lang unverändert bält, und mit welcher Proteinstoffe eine, bei kleinen Mengen noch mehr auffallende Färbung, als mit Cochenilleauszug annehmen. Wenn auch nicht nothwendig hierher gehörig, sei doch auch der von Piotrowsky und $\mathrm{Czermak}$ vorgeschlagenen Reaktion gedacht, deren Werth u. a. auch von Nägeli und Schwendener') überschätzt wird. Es bilden allerdings die Proteinstoffe mit Kupfervitriol und Kali eine violette bis blaue Lösung ${ }^{2}$ ), allein dieses ist keine Eigenthümlichkeit eiweissartiger Stoffe, sondern sobald organische Substanzen in Lösung sind, wird die Fällung von Kupferoxyd durch Kali verhindert und eine ähnlich oder ebenso gefarbte Lösung hervorgebracht, wie ja auch die mit weinsauren Alkalien dargestellte bekannte Fehlingsche, zur Zuckerbestimmung dienende Lösung auf dicsem Prinzip beruht. Etwas anderes also sagt die fragliche Reaktion positiven Falles nicht, als dass beliebige organische Stoffe vorliegen, welche die Fällung des Kupferoxydes verhindern, denn wenn auch wirklich leichte Farbenüancen je nach der Natur der Stoffe vorkomınen sollten, so sind doch diese begreiflicherweise für Reaktionen unverwendbar.

Man würde statt des Sublimates auch ein anderes Metallsalz,

1) Nägeli u. Schwender, Mikroskop 1867, p. 530.

2) Diese Lösung enthält übrigens eine Verbindung der Proteinstoffe mit Kupferoxyd. Vergl. Ritthausen in Journal fo prakt. Chemie, 1872, p. 215. 
mit welchem die Protcinstoffe unlösliche Verbindungen eingehen, anwenden können, nur müsste dieses Salz in Alkohol löslich sein, welcher Bedingung z. B. Chlorkupfer genügt. Ein Vortheil wäre indess durch cine solche Substitution nicht gewonnen, da die lästige Seite der Methode, dass immer eine längere Digestion nothwendig ist, damit nicht beseitigt würde. Dic Quecksilberverbindung bildet sich offenbar des gebotenen Wasserausschlusses halber so langsam und man kann auch deren Entstehung dadurch beschleunigen, dass man nach einigen Stunden den starken Alkohol durch einen 60 bis 70procentigen, gleichfalls Sublimat aufgelöst enthaltenden ersetzt, doch möchte das längere Stehenlassen für gewöhnlich einfacher sein. Nach 12 Stunden sind die Proteinkörner in der Regel vollständig unlöslich geworden, doch ist es, wic ich schon bemerkte, immer räthlich, die Schnitte kaum mit Alkohol abzuspülen und dann sofort in Wasser zu legen. Es bleibt so das Proteinkorn mit alkoholischer Sublimatlösung imprägnirt und falls kleine Mengen von Proteinstoffen noch nicht die unlösliche Quecksilberverbindung eingegangen hatten, so geschieht dieses jetzt beim Zutritt des Wassers sogleich. Zucrst dürfte von den Proteinkörnern eine nchr oder weniger dicke Kugelschale in die Quecksilberverbindung verwandelt werden, wenigstens habe ich namentlich bei Paeonia wiederholt beobachtet, dass bei kurzer Digestion und zuvorigem guten Auswaschen der Schnitte mit Alkohol die Proteinkörver in Wasser wohl bis auf das Doppelte ihres Durchmessers aufquollen, während weit klaffeude Risse auftraten, die selbst das ganze Korn in einige Stücke zersprengen konnten. Dabei ist es gerade die innere Masse, welche mächtig aufquillt und dabei zun Theil, zuweilen selbst fast ganz gelöst wird. Die verschiedenen Arten der Rissbildung und Zersprengung näher anzuführen hat hier kein Interesse. Uebrigens sind die in unlösliche Quecksilberverbindung verwandelten Proteinkörner an und für sich spröde und manche, wie die ron Paeonia, zerspringen überhaupt leicht, wenn sie aus Alkohol in Wasser kommen, auch wenn die ganze Proteinmasse in Qnecksilberverbindung verwandelt war.

Um die Wirkung von Wasser oder wässrigen Reagentien auf die Proteinkörner zu studiren, ist es immer von Wichtigkeit das fette Oel zu entfernen, denn abgesehen davon, dass es den Zutritt des Wassers zu den Proteinkörnen erschwert, stören die zusammenfliessenden Oeltropfen in hohem Grade die Beobachtung. Dass Alkohol keine nachweisbaren Mengen aus den Proteinkörnern hin- 
weglöst, haben wir schon kennen gelernt, wir müssen aber auch feststellen, dass das Verhalten der Proteinkörner durch Digestion mit Alkohol nicht rerändert wird. Dies fand ich bei einer Reihe von Parallelversuchen, welche ich mit direkt dem Samen entnom. menen und mit Alkohol extrahirten Schnitten vornahm, vollkommen bestätigt, sowohl für die in Wasser löslichen, als unlöslichen Proteinkörner, welche letzteren in ihrem Verhalten gegen kalihaltiges Wasser und andere lösenden Reagenticn nicht verändert waren. Lagen die Proteinkörner eben gefertigter Samenschnitte ganz frei, so war dic Einwirkung ron Wasser oder Reagentien eine gleich schnelle, wic an mit Alkohol cxtrahirten, wenn indess die Proteinkörner noch ron fettiger Grundmasse umgeben waren, so reranlasste disse, wie lcicht begreiflich, eine etwas langsamcre Lösung. Während zwei- bis dreitägigeu Stehens der Samenschnitte mit absolutem Alkohol habe ich niemals cinc Veränderung der Proteinkörner gefunden, wohl aber waren diese, wenn die Digestion acht 'T'age und länger fortgescizt wurde, bei manchen Samen, z. B. ron Paeonia und Cynoglossum in die unlösliche Eiweissmodifikation übergegangen. Ein solches Resultat konnte übrigens nach den Erfahrungen der Chemic erwartet werden, da man weiss, dass die meisten Proteinstoffe bei längerem Verweilen in absolutem Alkohol in die coagulirte Modifikation rerwandelt werden. Man wird deshalb gut thun, die Samenschnitte nicht über zwei Tage mit Alkohol stehen zu lassen, innerhalb dieser Znit ist aber auch eine Aenderung in den Löslichkeitsverhältuissen nicht zu befürchten. Alle meine auf Löslichkeit bezüglichen Untersuchungen sind mit Schnitten, die mit Alkohol extrahirt worden waren, angestellt, deun gerade darin, dass dieses Medium sich mit Wasser in allen Verhältnissen mischt, ist sein Vortheil gegen andere Lösungsmittel für Fette begründet.

In Alkohol liegend ist das Aussehen der sehr spröden und auf Druck leicht zerspringenden Proteinkörner den in Oel betrachteten ähnlich. Auf Wasserzntritt verhalten sich aber die Proteinkörner verschieden, denn während manche sich nicht lösen und nur etwas quellen, findet bei anderen eine theilweise oder vollkommene Lösung statt. Von den ersteren mögen in der That manche Körner vollkommen unlöslich in Wasser sein, andere hingegen, und zwar desselbon Samenschnittes, geben an dasselbe, wie ich schon früher erwähnte, kleine Mengen von Proteinstoffen ab. Alkohol führt diese unlöslichen Proteinkörner, die u. a. bei Cynoglossum offic., Empetrum nigrum und Clarkia pulchella gefunden werden, wieder mehr oder weniger voll- 
ständig, je nachdem etwas sich herauslöste oder nicht, auf ihr früheres Volumen und Ausschen zurück. Auch die an Wasser grössere oder kleinere Mengen von Substanz abgebenden Proteinkörner verhalten sich in dieser Beziehung nicht immer ganz gleich, selbst die desselben Samenschnittes und selbst derselben Zelle, indess sind die Unterschiede immer nur geringe. Doch ist es sehr möglich, dass sich, wenn man dic Samen von an verschiedenen Stationen gewachsenen Pflanzen dersclben Art vergleicht, grössere Unterschiede in der Löslichkeit finden werden, was auch ganz begreiflich crscheinen wird, wenn wir die Ursachen der Löslichkeit der Proteinkörner kennen gelernt haben.

Von den in Wasser unlöslichen, bis zu den vollkommen löslichen Protcinkörnern finden sich alle Zwischenstufen bei verschiedenen Pflanzen ror und von dem Quantum der Proteinstoffe, welches an Wasser abgegeben wird, hängt nun auch das Aussehen der Proteinkörner ab; wird wenig weggelöst, so werden dieselben meist nur körnig, bei grösseren Substanzverlust treten aber auch Vacuolen auf. Die Samen von Lupinus-Arten, Erodium Gruinum, Tropaeolum majus, Berberis vulgaris seien hier als Beispiele solcher genannt, deren Proteinkörner in Wasser theilweise löslich sind. In Wasser lösliche Proteinkörner kommen u. a. den Samen von Paeonia, Sabal Adansoni, Dipsacus recurvus und Tragopogon major zu, doch ist bei diesen richtiger gesagt meist wohl nur der grösste Theil der Proteinstoffe in Wasser löslich, der andere Theil wird nur mechanisch mit fortgeführt; bei Paeonia scheint übrigens die Lösung in der That vollkommen zu sein. Die Löslichkeit der Proteinkörner ist aber keineswegs in einzelnen Familien eine übereinstimmende, sondern es finden sich in dieser Beziehung auch bei nächst vorwandten Pflanzen polare Gegensätze.

Um die Wasserwirkung auf lösliche Proteinkörner zu beobachten ist Paeonia ein recht geeignetes Objekt, indem man zu den in Alkohol liegenden Schnitten Wasser allmählich zutreten lässt, oder indem man dieselben noch besser in Glycerin legt. Je nach der Concentration dieses schreitet nun die Lösung der Pro. teinmasse schneller oder langsamer centripetal fort, die Kornmasse sclbst wird aber dabei nicht immer ron allen Sciten gleich schnel! gelöst und so kommt es, dass dieselbe während der Lösung verschiedene unregelmässige Formen annehmen kann, auch wohl in mehrere Stücke zerfällt (XXXVI, 2a-c). Bei langsamer Einwirkung wickelt sich gewöhnlich die Lösung innerhalb des zur Kugelform 
sich abrundenden Häutchens $a b$, doch wird auch nicht selten die noch in Lösung begriffene Kornmasse, namentlich bei etwas schnellerer Einwirkung, unter Zerreissung des Häutchens herrorgestossen (XXXVI, f.) In den meisten Zellen des Endosperms von Paeonia finden sich kleire krystallinische Einschlüsse je zu eins oder wenigen in einem Proteinkorn, die entweler bis zuletzt in der in Lösung begriffenen Kornmasse eingeschlossen bleiben, oder, da sie sehr gewöhnlich excentrisch liegen, früher frei werden, ührigens je vach Umständen in dem Hüllbäutchen licgen bleiben oder auch herausgestossen werden (XXXVI e-e). Wie schon bemerkt, scheint sich bei Paeonia die Protcinmasse ziemlich vollständig aufzulösen, bei anderen Proteinkörnern aber rerbreitet sich dieselbe wie eine Wolke in dem Lösungsmedium, indem hier offes:bar nur der grösste Theil des Kornes in Wasser löslich ist, der andere Theil aber nur mechanisch fortgeführt wird. So ist es z. B. bei Allium Cepa und Delphinium Requieni, bei denen indess die sehr kleinen Globoide nicht mit körnigen Proteinstoffen rerwechsclt werien dürfen.

Bei über 10 Jahre alteu Samen rou Paeonia waren die Proteinkörner zwar noch in Wasser löslich, jedoch sehr riel langsamer als bei jüngeren Samen und es verbreitete sich dabei auch eine trübe Wolke im Wasser oder Glycerin. Demnach scheint mit dem Alter ein Theil der Proteinstoffe unlöslich oder wenigstens schwieriger löslich geworden zu sein und hicrmit stimmt altch ganz Ritthausens') Augabe über ältere Hülsenfrüchte, dass nämlich aus denselben beim Extrahiren mit Wasser eine geringere Ausbeute an Legumin erhalten wurde, als aus jüngeren Samen.

Ebenso wie die in Wasser löslichen Proteinkörner verhalten sich auch diejenigen, welche von Wasser gar nicht oder nur theilweise verändert werden, wenn man Glycerin anwendet, dem eine Spur von Kali zugesetzt ist. Auch hicr sind es daun immer nur das Hüllhäutchen und die Einschlüsse, welche ungelöst zurückbleiben. Bei den in Wasser unlöslichen Proteinkörnern ist bei Anwondung von verdünntem wässrigem Kali die Lösung eine centripetal fortschreitende, wenn aber das Wasser nur ein Minimum von Kali enthält, dann beginnt die Lösung Innen und rückt allmählich nach Aussen vor (XXXVI, 4). Das Gleiche geschicht auch bei den in Wasser löslichen Proteinkörnern dann, wenn der Alkohol sehr allmälich wässrig wird und ebenso kann bei den in die unlösliche Queck-

1) Ritthausen, Jouru. f, prakt. Cb. 1868, Bd. 103, p. 275 Anmkg. 
silberverbindung übergeführten Proteinkörnern bei Einwirkung von kalihaltigem Wasser oder auch von sehr verdünnten Säuren ein Auflösen ron Innen nach Aussen verfolgt werden (XXXVI, 3). Hüllbäutchen und Einschlüsse bleiben hierbei immer ungelöst, wenn auch ersteres oft gesprengt wird und dann, in Glycerin liegend, dio Ränder des Risses schwach cinwärts biegt. Bei zu stürmischer Lösung wird allerdings das Häutchen gewöhnlich nicht gefunden, indem es mehrfach zerrissen und fortgeführt wurde. Das immer sehr zarte Häutchen erscheint bei starker Vergrösserungr meist ein wenig körnig und löst sich weder in verdünntem Kali, noch in verdünnten Säuren, wenigstens nicht bei kürzerer Einwirkung dieser Reagentien. Mit Jod, Cochenille und Anilinblau färbt es sich und ebenso habe ich Gelbfärbung mit Salpetersäure und Kali crhalten. Wenn nun auch mit dem ohnedies nicht sehr genauen Millons'schen Reagens eine zweifellose Reaktion nicht zu bekomınen ist, so kann dieses bei der Zartheit des Häutchens nicht auffallen und es folgt daraus nicht, dass das Häutchen, wie es Hartig ${ }^{1}$ ) will, aus anderen als Proteinstoffen zusammengesetzt sei; auch Maschke's ${ }^{2}$ ) Ansicht von der Korknatur dieses Häutchens ist durch keine der von diesem Autor angeführten Reaktionen auch nur wahrscheinlich gemacht. Nach den Farbenreaktionen und der Unlöslichkeit in verdünnten Säuren und Alkalien ist die proteinartige Natur des Hüllhäutchens wohl gewiss, das übrigens nicht den Proteinkörnern eigenthümlich ist, sondern mit dem Primordialschlauch und dem Häutchen übereinstimmt, welches sich auch am todten Protoplasma als Abgrenzung gegen Vacuolen und um Protoplasmatropfen bildet. In den Löslichkeitsverhältnissen stimmt allerdings dieses Häutchen mit coagulirten Eiweissstoffen überein, doch kann es cbensowohl aus einem eigenthümlichen Stoff proteinartiger Natur bestehen, welcher, da er ohne Zerstörung nicht durch Lösungsmittel aufgenommen wird, von den Chemikern bis dahin noch nicht dargestcllt wurde. Während $\mathrm{Nägeli}{ }^{3}$ ) die Entstehung eines solchen Häutchens auf eine eiufache Coagulation eiweissartiger Stoffe bei Berührung mit Wasser zurückfübrt, glaubt

1) Hartig, Pflanzenkeim p. 24 u, 112.

2) Bot. Zeitung, 1859 , p. 410.

3) Nägeli in Zeitschrift f. wiss. Bot. von Nägeli und Schleiden, 1846, Heft 3 und 4 und Pflanzenphys. Unters. Heft I, 1855, p. 9. - Auch die Chlorophyllkörner haben ein derartiges Häutchen, für das v. Mobl die Bezeichnung "pellicula“ vorschlug (Bot. 1855, p. 93). Vergl, übrigens Nägeli und Schwendener, Mikroskop. p. 552 u. K ühne, Unters, über d. Protoplasma 1864, p. 36. 
Monoyer ${ }^{1}$ ) nach scinen Versuchen mit Eiweiss, dass einc diesem beigemengte schleimige Substavz durch Diffusionsströmung an die Oberfläche der Eiweisströpfchen gelange und hier zum Häutchen zusammenschliesse, ohne indess schlagende Gründe für seine Ansicht beizubringen. ${ }^{2}$ )

Wir baben bis dahin die Proteinkörner ohne Krystalloide wcsentlich rom chemischen Standpunkte betrachtet und kennen gelernt, dass sie, von den Einschlüssen abgesehen, aus eiweissartigen Stoffen bestehen, manche vielleicht ganz rollständig, andere indess mit Beimengung schr kleiner Quantitäten fremdartiger, voraussichtlich den Kohlenhydraten zugehörigen Stoffen. Fett liess sich niemals, auch nicht in Spuren in den Proteinkörnern nachweisen, und wenn auch die Genauigkeit der Untersuchungsmethoden allerdings seine Grenzen hat, so ist doch soviel gewiss, dass, wenn überhaupt, Fett nur in höchst mininalen Mengen in den Proteinkörnern vorkommen kann. Wir werden uns nun zunächst zu den Proteinkörnern mit Krystalloiden wenden.

\section{Proteïnkörner mit Krystalloiden.}

In Oel betrachtet gleichen diese Proteinkörner den krystalloidfreien, da man bei den moisten rou dem Krystalloid nichts crblickt (XXXVII, 1). Doch giebt es auch Ausnahinen hiervon und namentlich bei Elaeis guyänensis (XXXVII, 17) kann man schon in Oel dic in Einzahl oder Mehrzahl in einem Korn vorhandenen Krystalloide recht gut wahrnehmen. Hier dürfte der Grund wohl darin zu suchen sein, dass dic ganze Hüllmasse von sehr kleinen Globoiden durchsäet und so deren Lichtbrechung eine andere als die der Krystalloide geworden ist. Andere Proteinkörner Laben mehr oder weniger die Form der cingeschlossenen Krystalloide, indem die Hüllmasse sehr spärlich ist, zuweilen sogar fast vollkommen fehlt, was indess wohl immer nur für eine Anzahl von Proteinkörnern desselben Samens zutrifft, wie z. B. bei Elaeis

1) Bull. d. 1. soc. chim. de Paris. II. Sér. T. V, 1866, p. 444.

2) Die schönen Untersuchungeu Traube's (Archiv f. Physiol. von du Bois Reymond und Reichert 1867) über die Bildung von Niederschlagmembranen dürften wohl geeignet sein, die Entstehung des fraglichen Hüllhäutchens zu erklären, sobald man über die chemische Natur dieses und namentlich über dio des Protoplasmas genügende Kenntniss besitzt. 
(XXXVII, 17a und b), Aethusa Cynapium, Salvia officinalis, Fumaria Vaillantii; dasselbe ist auch bei dem nebenbei stärkeführendeu Samen von Myristica moschata der Fall (XXXVIII, 10 u. 11).

Bei allen untersuchten krystalloidführenden Proteinkörnern fand ich Globoide als Einschlüsse, mit Ausnahme von Aethusa Cynapium, bei wolcher Planze auch krystallinische Einschlüsse, sowohl in Form von Einzelkrystallen als Drusen vorkommen (XXXVII, 13b). Die Globoide, welche, bekanntlich in Oel Vacuolen gleichen, sind oft ron ziemlicher Grösse und nur zu je eins oder wenigen in einem Proteikorn vorhanden und dann meist nur auf einer Seite des Kornes und wie es bei der spärlichen Hüllmasse ja selbstverständlich ist, stark excentrisch gelagert, wie z. B. bei Ricinus (XXXVII, 1, 2 u. 3), Linum usitatissimum, Sesamum orientale u. a. Schon bei dicsen Pflanzen treten aber auch gelegentlich kleinere Globoide in Mehrzahl auf, welche dann auch allseitig um das Krystalloid vertheilt sein können; bei anderen Pflanzen hingegen, wie Sambucus racemosa, Platycodon grandiflorus wird eine grössere Anzahl von Globoiden Regel, die besonders zahlreich, aber auch sehr klein, wie schon erwähnt, in der ganzen Hüllmasse von Elaeis sich finden (XXXVII, 17).

Um die Krystalloide sichtbar zu machen, müssen die Proteinkörner in Wasser gebracht werden, welches die Hüllmasse auflöst oder wenigstens aufquellen macht und so das übrigens auch ein wenig quellende Krystalloid hervortreten lässt. Ich habe hier wohl kaum nöthig zu bemerken, dass die Krystalloide in der That schon in den Proteinkörnern vorhanden, nicht erst durch Wasserzutritt aus diesen vermittelst Formveränderung gebildet werden, wie Trecul ${ }^{1}$ ), die Thatsachen ganz verkennend, gegen $\mathrm{H}$ artig annimmt. Dass man die Krystalloide in Oel nicht wahrnehmen kann, ist eben nur eine Folge des gleichen Lichtbrechungsvermögens von Hüllmasse und Krystalloid, und wo dasselbe, wie bei Elaeis, ein verschiedenes ist, da treten auch die Krystalloide an den in fettem Oele liegenden Proteinkörnern hervor.

An den mit Alkohol extrahirten Schnitten kann man beim Vergleich mit direkt den Samen entnommenen, in der früher für krystalloidfreic Proteinkörner beschriebenen Weise, einen Unterschied in der Lichtbrechung der Proteinkörner beider Schnitte nicht constatiren. Auch ist, wenn man in Oel das Krystalloid

1) Trécul, l. c., p. 369. 
nicht wahrnehmen kann, dieses auch in Alkohol nicht der Fall, zum Berveis, dass nicht etwa allein aus der Hüllnasse ein merkliches Stoffquantum gelöst sein kanu. Bchandelt man aber Samenschnitte mit sublimathaltigem absolutem Alkohol, lässt dann die Schnitte oinige Zeit in Wasser liegen und trägt sie nun in Alkohol zurück, so ist auch nach langem Liegen bei Ricinus und Pinie das zuvor nicht sichtbare Krystalloid, wenn auch cur undeutlich zu bemerken. Wahrscheinlich wurde also eine kleine Menge eines Stoffes, voraussichtlich Gummi oder Rohrzucker herausgelöst, wie wir ja auch bei Lupinus bei der gleichen Behandlung das Verscluwinden eines kleinen Stoffquantums constatirten. Jedenfalls besteht aber auch die Hüllmasse der krystalloidführenden Proteinkörner fast ganz, vielleicht öfter's auch allein, von den Einschlüssen abgesehen, aus Proteinstoffen; dies zeigt die Uebereinstimmung mit allen den Reaktionen, welche früher für krystalloidfreie Proteinkörner angefübrt wurden, unter denen namentlich auch die Ueberführung in eine coagulirte Modifikation herrorgehoben sei. Es ist dieses bei Ricinus, wic schon v. Holle') fand, durch einfaches Kochen in Alkohol möglich, während bei Pinus Pinea, auch bei viertelstündigem Kochen, die Löslichkeitsverhältnisse ron Hüllmasse und Krystalloid nicht verändert sind. Die Coagulation erstreckt sich aber auch bei Ricinus allein auf die Hüllmasse, das Krystalloid löst sich nach wie vor in kalihaltigem Wasser, wobei die Hüllmasse, die Form des Krystalloides noch ziemlich scharf begränzend, mit dem oder den Globoiden zurückbleibt.

Gegen Wasser zeigt die Hüllnasse gleiche Verschiedenheiten wie die Masse der krystalloidfreien Proteinkörner. Bei manchen Pflanzen, wie bei Aethusa Cynapium, Linum usitatissimım, Ricinus findet eine mehr oder weniger vollständige Lösung statt, bei anderen, wie bei Pinus Pinea löst sich nur ein kleiner Theil, bei Opuntia Rafinesquiana und Elaeis guyanensis aber so gut wie gar nichts in Wasser, wohl aber vollkommen, sobald dieses etwas Kali enthält. In allen Fällen bleibt auch hier ein Hüllhäutchen ungelöst zurück, wenn vorsichtig verfahren wird. Die Löslichkeit der Hüllmasse kann aber auch bei nächststehenden Pflanzen eine verschiedene sein, wie denn z. B. bei Benincasa cerifera jene ziemlich voll-

1) v. Holle, Neues Jahrbuch f. Pharmacie von Walz und Winkler, 1858, Bd. X, p. 14 d. Separatabzugs. 
Untersuchungen äber d. Proteinkörner und d. Bedeutung d. Asparagins etc. 453

ständig, bei Cucurbita Pepo aber fast gar nicht in Wasser gelöst wird.

Alle Versuche über die Löslichkeitsrerhältnisse der Hüllmasse und obenso der Krystalloide, sind an durch Alkohol extrahirten Schnitten angestellt, nachdem übrigens auch hier in der schon früher beschriebenen Weise durch Parallelrersuche festgestellt war, dass der Alkohol eine Veränderung nicht herbeiführt. Erst nach melırwöchentlichem Stehen in Alkohol fand ich z. B. bei Ricinus die Hüllmasse sowohl, als Krystalloide in die unlösliche Modifikation der eiweissartigen Stoffe verwandelt. Es mögen übrigens bei anderen Proteinkörnern Hüllmasse oder Krystalloid wohl auch in etwas kürzerer Zeit in die unlösliche Modifkation übergehen, doch habe ich hicrüber keine speciellen Untersuchungen angestellt. Sehr schnell sollen nach Radlkofer ${ }^{1}$ ) die Krystalloide in den Zellkernen ron Lathraea squamaria in den coagulirten Zustand übergeführt werden. Auch die aus Blut dargestellten Bümoglobinkrystalle werden durch Liegen in Alkohol coagulirt.

Während die Hüllmasse in Wasser löslich oder unlöslich sein kann, sind alle untersuchten Krystalloide in Wasser unlöslich. Dadurch hat man, wenn die Hüllmasse von Wasser aufgenommen wird, ein Mittel die Krystalloide von jener zu befreien, wo die Hüllmasse aber nicht oder unvollständig gelöst wird, kann man diese zuweilen wie bei Cactcen, dadurch entfernen, dass man mit einer Lösung von phosphorsaurem Natron behandelt, welche in verdünntem Zustand und bei gewöhnlicher Temperatur viele Krystalloide fast gar nicht angreift, während andere wie die von Aethusa Cynapium und Elaeis guyanensis sich leichter in phosphorsaurem Natron auflösen. Freilich sollen nach früheren Autoren nicht alle Krystalloide der Samen in Wasser unlöslich sein, für die der Paranuss aber hat bereits $\mathrm{Nägeli}^{2}$ ) gezeigt, dass in Wasser weder eine Lösung, noch eine Streifung, noch eine Zerklüftung zu Wege kommt, auch dann nicht, wenn die Krystalloide nach dem Eintrocknen wieder befeuchtet werden. Meine Erfahrungen an anderen Krystalloiden stimmen mit denen Nägeli's für Paranuss überein und da gerade dieser Samen es ist, über welchen die meisten gegentheiligen Angaben vorliegen, so verweise ich auf deren Zusammenstellung bei $\mathrm{Nägeli}$ und unterlasse es die

1) Radlk ofer, Krystalle proteinartiger Körper, 1859, p. 23.

2) Nägeli, Sitzungsber. d. Münchner Akad., 1862, p. 130. 
Löslichkeit anderer Krystalloide betreffende Angaben zu citiren. Diese sind kaum auders zu crklären, uls dass das angewandte Wasser mit einem Lösung bewirkenden Körper verunreinigt war, denn dass vielleicht der Zellinhalt einen durch Alkohol entferubaren Stoff enthielte, welcher Veränderung der Krystalloide bei Wasserzutritt bewirken könnte, hicrgegen spricht der Umstand, dass auch beim unmittelbaren Eintragen von Samenschuitten in Wasser eine Lösung der Krystalloide nicht stattfindet. Die Löslichkeit der Krystalloide in Zellkerne von Lathraca in Wasser, welche Radlkofer angibt, ist auch noch nicht sicher gestellt, weil eben immer der saure Zellsaft mit ins Spiel kam und dieser dic Lösung veranlassen konnte. Indess ist die Möglichkeit der Existenz löslicher Proteinkrystalle keineswegs wegzuläugnen, da wir ja schon in den Hämoglobinkrystallen in Wasser lösliche Krystallo proteinartiger Stoffe kennen.

Die Angaben über Zerklüftung finden vielleicht theilweise ihre Erklärung durch dic Proteinkörner, bei welchen einzelne oder zahlreiche unvollkommene, oft nur wie scharfeckige Bruckstücke erscheinende Krystalloide von einer gemeinschaftlichen Hüllmasse umgeben und so zu einem Proteinkorn vereint sind (XXXVII, 3b und c), das dann Hartigr) als componirtes Klcberkorn bezeichnete. In Ocl bemerkt man; wie schon bekannt, die Krystalloide meist nicht, da sie aber auf Wasserzutritt sichtbar werden, so kann dann wohl der Glauben entstehen, sie seien durch Zerfallen eines Krystalloides entstandeu. Dass dem nicht so ist, beweist z. B. Elaeis, bei welcher Pflanze man die zuweilen in Mchrzahl vorhandenen Krystalloide schon an in Oel liegenden Proteinkörnern sehen kann und dann ist der Umstand entscheidend, dass bci manchen diescr zusammengesetzten Körncr eine trennende, mit der Hüllmasse übereinstimuende Masse zwischen den einzelnen uuvollkommenen Krystalloiden rorhanden ist, die mit der Hüllmasse auch in der Löslichkeit übereinstimmt. Wenn letztere in Wasser löslich ist, so muss man die mit Alkohol und Sublimat behandelten Körner in Wasser liegend betrachten, un dic fragliche Zwischenmasse zu erkennen.

Proteinkörner mit mehreren Krystalloiden finden sich bei manchen Pflanzen, wie Bertholletia, Ricinus (XXXVII, 3b u. c), Sesamum u. a. nur vereinzelt, bei anderen indess, wie Datura Stra-

1) Pflanzenkeim, p. 115. 
monium, Melothria pendula häufiger, oder auch wie bei Adonis autumnalis und Myrica cerifera weit zahlreicher als die mit einem einzelnen Krystalloide, doch scheinen bezüglich der Häufigkeit von einfachen oder componirten Proteinkörnern bei verschicdenen Samen der. selben Species Schwankungen vorzukommen. Sind nur zwei Krystalloide in einem Proteinkorn eingeschlossen, so gleichen diesc gewöhnlich Krystallen, welche sich an der Berührungsfläche an der gegenseitigen Ausbildung hinderten. Bei ciner Mehrzahl von Krystalloiden in einem Korn sieht man meist nur scharfeckige Bruchstücke, an dencn man eine bestimmte Krystallform nicht mehr herauszulesen vermag. So ist es immer, wenn spärliche Zwischenmasse vorhanden ist; bei Elaeis aber, wo diese ansehnlicher wird, können auch die einzelnen Krystalloide vollkommen ausgebildet sein (XXXVII, 17c). Bei dieser Pflanze liegen auch, wie schon erwähnt wurde, dic sehr kleinen Globoide in der ganzen, die cinzelnen Krystalloide umhüllenden Masse, während bei den anderen componirten Körnern Globoide fast nie in der die Krystalloide selbst trennenden Zwischenmasse gefunden wurden.

Nachdem wir uns mit der Art des Vorkommens der Kry. stalloide in den Proteinkörnern vertraut gemacht haben, wollen wir uns den Krystalloiden selbst noch zuwenden. Schon früher wurde gesagt, dass absoluter Alkohol keine nachweisbaren Mengen eines Stoffes aus den krystalloidführenden Proteinkörnern aufnimmt; auch wenn man krystalloidführende Proteinkörner oder die Krystalloide allein, nach dem Entfernen der Hüllmasse durch Wasser, in Glycerin, das eine Spur Kali enthält, sich sehr langsam auflösen lässt, so ist in dem persistirenden Hüllhäutchen das Zusammenfliessen irgend eines Oeltröpfchens so wenig wie bei den krystalloidfreien Proteinkörnern zu constatiren. Natürlich habe ich dabei nicht zuvor mit Alkohol extrahirte Proteinkörner im Auge. Die Vermuthung ron Sachs'), dass.das Krystalloid auch ein wenig Fett enthalte, trifft demnach nicht zu, wohl aber ist die Existenz eines anderen als Proteinstoffes in den Krystalloiden nicht nachzuweisen. Auch haben alle anderen Autoren sowohl die Proteinkrystalloide in den Samen, als in anderen Pflanzentheilen als allein oder wesentlich aus Proteinstoffen bestehend angesprochen. Die Kry. stalloide aller Samen sind durch Kochen leicht in die unlösliche Modifikation der Proteinstoffe zu verwandeln, und sind dann in

1) Sachs, Lehrb. II. Auf, p. 54. 
verdünntem Kali unlöslich, in dem sie, wie es auch die coagulirten Proteinkörner thun, sehr auschnlich quellen, bei Auswaschen des Kalis aber oder bei dessen Neutralisation auf ihr früheres Volumen zurückgchen. Cohn') hat dieses Verhalten bei den coagulirten Krystalloiden der Kartoffel, Crame ${ }^{2}$ ) bei denen der Florideen (dem Rhodospernim Craucl's), dic auch aus unlöslicher Modifikation eiweissartiger Stoffe bestanden, näher beschricben.

Vor der Coagulation lösen sich alle Krystalloide sehr leicht in verduuntem Kali und zwar schreitet dic Lösung vou Aussen nach Innen fort, nur danu, wenn man Wasser verwendet, welches nur cine Spur ron Kali cnthält, gelingt es auch ungekehrt eine Auflösung vou Innen heraus zu crzielen. Letzteres ist leichter mit Salzsäure oder Essigsäure zu erreichen, welche sich aber je wach der Concentration verschieden verhalten, worüber $\mathrm{Nägeli}{ }^{3}$ ) für die Krystalloide von Bertholletia ausführlichere Mittheilungen machte, die ich im wesentlichen auch bei Ricinus und Pinie bestätigen kann (vgl. XXXVII, 7 dic Lösung beim Keimen darstellend).

Wie bei rorsichtiger Lösung immer ein das ganze Proteinkorn umgrenzendes Häutchen bleibt, so hinterlässt auch ein jedes Krystalloid ein solches, wenn die Lösung sehr langsam ror sich ging. Man kann dieses am besten durch $\Delta$ nwendung ron concentrirten Glycerin erreichen, dem man nur ein Minimum von Kali zusetzt. Zucrst löst sich an dem ganzen Proteinkorn von Ricinus z. B. die Hüllmasse auf, danu schrcitet lie Lösung centripetal in dem Krystalloid weiter und dabei kann dann auch die noch in Lösung begriffene Masse in mehrere Portionen zerfallen, wie $\mathrm{Nägcli}$ dieses schon für Wirkung säurehaltigen Glycerins auf die Krystalloide der Peranuss beschrieb (XXXVII, 4a u. b Ricinus). War die Lösung nur äusserst langsam von Statten gegangen, dann findet man innerhalb des von der Hüllmasse herrührenden Aussenlüutchens, wclches die Form des ganzen Proteinkorns ziemlich bewahrte, auch noch das Häutchen, welches rom Krystalloid herrührt und dessen Form mit einiger Abrundung zeigt (XXXVII, 5b u. d). Dieses letztere Häntchen verschmilzt aber, indem es aufquillt oder zerreisst, bei etwas schnellerer Lösung sehr leicht mit dem äusseren Häutchen und

1) Cohn, Ueber Proteinkrystalle in Kartoffeln. Im 37. Jahresb. d. schlesisch. Ges. f. vaterl. Cultur, 1858.

2) Cramer, Das Rhodospermin u. s. w. Vierteljahrschrift d. naturf. Ges. in Zürich, Bd. VII, 1862.

3) $\mathrm{N}$ ägeli, l. c., p. $130 \mathrm{ff}$. 
dann erscheint der Raum, in welchem der oder dic Einschlüsse liegen, ringsum hautartig begränzt (XXXVII, 5a). Auch das äussere Häutchen kann bei schnellerer Lösung an einer oder an mehreren Stellen zerreissen. Man kann übrigens auch die Krystalloide isoliren, indem man z. B. mit Alkohol ausgezogene Samenschnitte in Wasser bringt und durch leichtes Rollen des Deckglases das von der gelösten Hüllmasse gebliebene Häutchen entfernt, um dann am besten mit einer Spur Kali versetztes Glycerin zutreten zu lassen. Auch in dieser Weise ist ein ungelöstes Häutchen zu erhalteu, dessen Reaktionen, welche schon früher beschrieben wurden, die Zusammensetzung aus proteinartigen Stoffen verrathen.

Sind mehrere, aber unmittelbar aneinanderliegende Krystalloide in einem Proteinkorn, dann schreitet die Lösung nicht in jedem einzelnen Krystalloide, sondern gegen den Mittelpunkt des Complexes fort, wohl aber bleibt ein jedem einzelnen Krystalloide ein Häntchen, welches man aber an der früheren Berührungsfläche zweier Krystalloide selten von dem angrenzenden Häutchen getrennt, meist init ihm verschmolzen findet (XXXVII, 5c). Wenn indess bei componirten Proteinkörnern etwas Zwischenmasse vorhanden ist, so kann sich anch ein jedes Krystalloid für sich von Aussen nach Innen in dem Glycerin auflösen. Hat ein Krystalloid Risse, dann breitet sich zuweilen vou diesen aus die Lösung allseitig ans und wenn ein Riss ganz durchgeht, verhält sich jede Theilhälfte wie ein einzelnes Krystalloid, Erscheinungen, die schon von $\mathbf{N a ̈ g e l i}{ }^{1}$ ) beobachtet wurden.

Auf die Gegenwart des membranälnlichen Häutchens legt $\mathrm{Nägeli}{ }^{2}$ ) ein grosses Gewicht, weil er daraus die Unmöglichkeit des Wachsthams durch Apposition für die Krystalloide folgern zu können glaubt. Wenn dieses Argument auch auf den ersten Blick schlagend scheint, so folgt die Werthlosigkeit desselben doch sofort daraus, dass auch echte Krystalle, nämlich oxalsaurer Kalk, wie schon Payen ${ }^{3}$ ) zeigte, mit einem zarten aus Proteinstoffen be. stehenden Häutchen umzogen sind. Auch Sachs ${ }^{4}$ ) fand dieses Häutchen an den grossen Krystallen in den Keimpflanzen ron Phaseolus und ich selbst habe es an allen grösseren krystallinischen Einschlüssen der Proteinkörner, die ich darauf untersuchte, sowohl
1) $\mathrm{Nägeli}$, l. c., p. 133.
2) Nägeli, l. ca, p. 139.
3) Р a yen, Mémoir. présent. p. divers. savents, 1846, T. 9, p. 91.
4) Sachs, Lehrb. II, p. 63 . 
an Einzelkrystallen, als Krystalldrusen nachweisen, und dessen völlige Uebereinstimmung mit den beim Lösen ron Krystalloiden oder Proteinkörnern bleibenden Häutchen feststellen können. Es ist dieses aber den Krystallen so vollständig angeschmiegt, dass man dessen Existenz vor dem Weglösen des oxalsauren Kalkes mit Salzsäure gewöhnlich gar nicht nachweisen kann. Möglich, dass überhaupt alle in eiweisshaltigen Flüssigkeiten liegenden Gebilde sich mit einem solchen Häutchen aus Proteinstoffen umgeben, wie es auch um Protoplasmatropfen sich bildet. Jedenfalls wenigstens würde ein solches Häutchen sich ebenso gut un krystallisirende Proteinstofle, wie um krystallisirenden oxalsausen Kalk bilden. Das fragliche Ï̈utchen trifit man freilich auch schon an den noch nicht ausgewachsenen Krystalloiden von Ricinus, aber, nach allerdings unsollständigen Untersuchungen, auch an noch wachsenden Krystallen von oxalsaurem Kalk und würde dann, wenn dieses richtig, dic Anlagerung neucr Krystallatome unterhalb des IIäutchens stattfinden müssen. Ich lasse freilich ganz unentschieden, ob nicht viclleicht das Häutchen um dic sich noch vergrösserenden Krystalle von oxalsaurem Kalk erst in Folge der Einwirkung ron Wasser oder einem anderen Medium entstand, doch würde eine glciche Möglichkeit ja für die noch wachsenden Krystalloide nicht minder gelten.

Zwei andere für das Wachsthum durch Intussuception geltend gemachte Argumente Nägeli's kann ich auch für die Krystalloide von Ricinus, Aethusa Cynapium und Elacis guyanensis nur bestätigen. Es sind diese die Imbititionsfähigkeit und die grössere Weichheit, d. b. Quellungsfähigkeit, der inneren Masse, welche in der That bei grossen Krystalloiden weicher, als die äussere Partie kleiner Krystalloide zu sein scheint. Aus der Entwicklung der Krystalloide von Ricinus vermag ich auch keine andere Anhaltspunkte, als dic eben genannten, für das Wachsthum durch Intussusception zu finden, sicher treten aber die Krystalloide von Anfang an in Krystallform auf (XXXVII, 10-12), und die Vermuthung $\mathrm{N}$ ägeli's ${ }^{1}$ ), dass jene aus Kugeln sich allmälich zur späteren Krystallform ausbilden möchten, trifft demnach nicht zu. Wenn mir nun auch ein Wachs. thum durch Intussusception aus den vorhin angeführten Gründen nicht unwahrscheinlich scheint, so wage ich doch nicht mich entschieden dafür auszusprechen, jedenfalls würde aber für die in der

1) Nägeli, 1. c., p. 140 . 
Quellungsfähigkeit sich gleich verhaltenden Hämoglobinkrystallen ein gleicher Wachsthumsmodus ebenso wahrscheinlich sein.

Immer aber sind die Unterschiede $\mathrm{zwischen} \mathrm{Krystalloiden} \mathrm{und}$ Krystallen ansehnlich genug. Schon an ausgebildeten Krystallen können die Winkel und ebenso der Parallelismus gegenüber liegenden Flächen, wie $\mathrm{N}$ ïg eli zeigte, um einige Grade von einander abweichen, und beim blossen Befeuchten trockner Krystalle treten Winkelveränderungen von 2 bis 3 Graden ein, die bei Anwendung von Quellungsmitteln selbst anf 15 bis 16 Grade gesteigert werden können. Die Imbibitionsfähigkeit, die Aufnalme ron Wasser in die Molecularinterstition, geht dem echten Krystall ab, welcher undurchdringlich ist und dessen Winkelveränderungen durch Erwärmen nicht der durch Qucllung beim Krystalloid vergleichbar ist. ") Man muss hier entweder den Krystallbegriff erweitern oder einen eijenen Namen für die Krystalloide annehmen, welches letztere zunächst jedenfalls geboten er'scheint. Deun auch die schwache Wirkung der Krystalloide auf polarisirtes Licht unterstützen die Annahme, dass ihre Molecularconstitution nicht mit der der Krystalle, sondern mit der organisirter Gebilde übereinstimmt, welche wir nns, wic $\mathrm{Nageli}^{2}$ ) in seinen klassischen Arbeiten entwickelte, aus krystallänlichen (ans vielen Atomen zusammengesetzten) Molecülen zusammengesetzt zu denken haben.

Es wurde von $\mathrm{N}^{\mathrm{ag}} \mathrm{geli}{ }^{3}$ ) auch der Beweis zu führen gesucht, dass in den Krystallniden der Paranuss, wic in Stärkckörnern zwei verschiedene Stoffe miteinander gemengt seien. Aehnlich wie bei Bertholletia ein schwach säurehaltiges Glycerin, wirkt boi Ricinus schon chemisch reines Glycerin, während ein solches bei Pinus Pinea keine Veränderung hervorruft. Werden mit Alkohol extrahirte Schnitte aus dem Endosperm ron Ricinus in Glycerin getragen, so fivdet man nach längerer Zeit, bei sehr concentrirtem Glycerin sogar erst nach Tagen, manche Krystalloide vollständig bis auf das Hüllıäutchen gelöst, das bei dieser langsamen Einwirkung gewöhnlich frei in dem das ganze Proteinkorn umhüllenden Häutchen licgt (XXXVII, 5a u. b). An solchen Krystalloiden ist auch nach Zusatz von Jodglycerin, oder nach Auswaschen mit Wasser und Färben mit Jod oder Anilin durchaus nichts von einer inncrhalb der Hüllhaut liegenden Masse nachzuweisen. Bei anderen Krystalloiden bemcrkt man aber un-

1) Vgl. Hofmeister, Pflanzenzelle, p. 395, Anmerkung.

2) Vgl. Nägeli, l. c., p. 141.

3) Nägeli, I. c, p. 135. 
mittelbar oder nach Fürbung mit Jod, dass ein kleines, übrigens bestimmt ungleich grosses Quantum eines Stoffes zurückgeblieben ist, welcher das ganze Häutchen als sehr weiche, etwas körnige Masse erfüllt und mit Jod rine gelbe Färbung annimmt (XXXYII, 5d). Aus solchen Bildern schliesst nun Nägeli, dass bei Paranuss die Krystalloide eine Mischung zweier Stuffe seien, von denen der eine weggelöst wurde. Wenn das auch nicht unmöglich ist, so kann ein gleiches Resultat doch auch dann zu Stande kommen, wenn der das Krystalloid aufbauende Stoff eine wirkliche chemische Verbindung ist.

Von dem krystallisirenden Hämoglobin (Hämatokrystallin) wissen wir, dass es eine Verbindung zweier näheren Bestandtheile, des Hämatins und Globulins ist, und in diese schr leicht, schon durch sehr schwache Säuron und Alkalien, sogar schon beim Erwärmen in Wasser gespalten werden kann ${ }^{1}$ ). Etwas Aehnliches könnte nun aber auch bei den Krystalloiden der Pflanien der Fall sein und sobald eines der Spaltungsprodukte sich in Wasser unlöslich erwiese, wäre damit das oben beschriebene Resultat ciner nicht vollkommenen Lösung erzielt, das Krystalloid aber doch von einer wirklichen chemischen Verbindung gebildet. Eine derartige Spaltung kann man sich in verschiedenster Weise vorstellen, selbst ohue dass zwei nähcre organische Verbindungen in Betracht kämen, da auch Phosphorsäure und Alkalien, die wahrscheinlich dem Krystalloid nicht fehlen und deren hohe Bedeutung für Lösung eiweissartiger Stoffe wir noch kennen lernen werden, dabei im Spiele sein könnten. Auch der Umstand, dass in dem einen Falle schon reines, im anderen erst säurehaltiges Glycerin die Spaltung: hervorruft, spricht nicht gegen einen derartigen Vorgang, da verschiedene Verbindungen, die ja möglich sind, auch ungleich resistent sein könncn. Ist doch auch das aus dem Blute verschiedener Thiere gewonnene Hämatokrystallin sowohl in seiner Löslichkeit in Wasser, als in seiner Krystallform, also auch voraussichtlich in seiner Constitution verschieden. Nun will ich freilich eine solche Spaltung für die Krystalloide der Pflanzen nicht ge. radezu behaupten, mir war es eben nur darum zu thun zu zeigen, dass das mit Glycerin oder säurehaltigem Glycerin zu erzielende Resultat noch keineswegs ein entschiedener Beweis dafür ist, dass

1) Kolbe organ Chemie, Bd. III, Abth. 2, 1868, p. 416. Hoppe Seyler, Handbuch d. physiol. u. pathol. chem. Analyse, 1870, p. 218. 
in den Krystalloiden zwei Stoffe, wie Grauulose und Collulose in den Stärkekörnern, miteinander gemengt sind. Es kann hier überhaupt nicht eher eine Entscheidung erwartet werden, bis die Chemie das Dunkel gelichtet hat, welches über diesen krystallisirenden Proteinstoffen noch schwebt. Was die ron Nägeli ${ }^{1}$ ) beschriebenen Farbstoffkrystalloide aus den Früchten von Solanum americanum betrifft, so kann für diese dasselbe, wie für andere Krystalloide gelten, nur dass bei ihnen der mit Alkohol, Aether, verdünnten Säuren oder kochendem Wasser entfernbare Stoff über die eiweissartigen Stoffe überwiegt, welche das eine Spaltungsprodukt sein könnten. Dass allerdings auch fremde Stoffe sich in den Krystalloiden vertheilen können, ist eine nothwendige Folge ihrer Imbibitionsfähigkeit und wird schon durch die natürlich vorkommenden gefärbten Krystalloide erwiesen.

Maschke ${ }^{2}$ ) spricht die Krystalloide der Paranuss als eine chemische Verbindung von Casein und wenig Albumin mit einer unbekaunten Säure an, sein cinziges Argument ist abcr eigentlich die saure Reaktion der isolirten Krystalloide und darauf ist natürlich kein grosses Gewicht zu legen, wenn auch eine der Vermuthung Maschke's entsprechende Zusammensetzung sehr möglich ist, da Ritthausen ${ }^{3}$ ) zeigte, dass der als reines Legumin betrachtete Körper stets sauer reagirt, weil er Phosphorsäure in chemischer Verbindung enthält. Eine chemische Untersuchung der Krystalloide dürfte aber sehr wohl ausführbar sein, da nach Maschke die Krystalloide der Paranuss aus einer wässrigen Lösung wieder in Krystallen zu erhalten sind. Ich muss hier allerdings bererken, dass die Krystalloide, auch die der Paranuss, in Wasser nicht löslich sind, da indess Maschke ausdrücklich ron saurer Reaktion spricht, so mag Säure wohl die Lösung vermittelt haben. Auch Böttcher ${ }^{4}$ ) gibt an, dass er beim Eintrocknen von Samenflüssigkeit und ebenso von Hühnereiweiss mikroskopische, ans einem Eiweisskörper bestehende Krystalle erhalten habe.

Es ist nicht meine Absicht, das Verhalten von Krystalloiden gegen verschiedene lösende Reagentien nähcr zu beschreiben, da

1) Sitzungsb. d. Münchner Akad. 1862, Bd. II, p. 147 ff.

2) Maschke, Journ. f. prakt. Chemie 1858, Bd. 74, p. 436 u. Bot. Zeitung 1859, Nr. 52.

3) Ritthausen, Journal f. prakt. (Lemie 1868, Bd. 10:3, p. 211.

4) Böttcher, Zeitschrift f, analyt. Chemie 1865, p. 749 u. Virchow's Arehiv Bd. 32 , p. 525 . 
sich doch keine wesentlichen Schlüsse daraus ziehen lassen. Was die Einwirkung von Säuren und Alkalien betrifft, so stimmen hier meine Erfahrungen an Ricinus und Pinie wesentlich mit denen ron $\mathrm{Nägeli}$ an Bertholletia überein, anf die ich somit verwcisen kann. Die vielfach abweichenden Angaben anderer Autoren finden, wie schon Nägeli bemerkt, zum Theil wohl ihre Erklärung in dem Concentrationsgrad der angewandten Reagentien, der von wesentlichem Einfluss auf den Verlauf der Reaktion ist und manche denn auch wohl darin, dass bei längerer Aufbewahrung in Aether oder anderen Medien die unlösliche Modifikation der Proteinstoffe ganz oder theilweise entstanden sein mochte.

Auch über Krystallform habe ich keine Untersuchungen angestellt. Wir verdanken hier bekauntlich alle wesentlichen Aufschlüsse den sorgfältigen Untersuchungen Nägeli's, nach welchen die Krystalloide ron Bertholletia höchst wahrscheinlich dem klinorhombischen System angehören, aber eben der Veränderlichkeit der Winkel halber liess sich nicht absolut sicher entscheiden, dass diese Krystalloide dem hexagonalen System nicht zuzutheilen seien. Diesem System soll nach Hartig ein Theil der im Samen vorkommenden Krystalloide, auch die von Bertholletia, angehören, die meisten aber theilt der eben genannte Autor dem tesseralen System $\mathrm{zu}^{\mathrm{r}}$ ), welchem indess von den unter meine Augen gekommenen Krystalloiden aus Samen schwerlich irgend welche angehören dürften, auch nicht die von Ricinus, welche v. Holle ${ }^{2}$ ) hierher zieht. Hingegen gehören die Krystalloide von Myristica moschata, Elacis guyanensis und Acthusa Cynapium wohl sicher dem gleichen Krystallsystem wie die ron Bertholletia an. Die Krystalloide mancher Samen dürften aber auch anderen Krystallsystemen zuzuthcilen sein und dies kann auch um so weuiger auffallen, als aus anderen Pflanzenorganen bereits Krystalloide bekannt sind, welche nicht dem klinorhombischen oder hexagonalen System zugehörer. So sehen die von $\mathrm{Cohn}^{3}$ ) näher beschriebenen Krystalloide der Kartoffel Würfeln täuschend ähnlich, quadratische

1) Hartig, Pflanzenkeim 114.

2) v. Holle, neues Jahrb. f. Pharm. von Walz u. Winkler, 1858, Bd. X, p. 14 des Separatabzugs - Die ührigen beiläufigen Angaben über Krystallform der Krystalloide, auch die Trécul's übergehe ich.

3) Coh n, im 37. Jahresb. d. schles. Ges, für vaterländ. Cultur, 1858, p. 70 ff. 1)iese Krystalloide hat wohl schon Bailey (Amerie. Journ. of Science and Aits 1848, Vol. 48, p. 17) gesehen, aber vermuthet, dass sie ans phosphorsaurem Kalk bestehen. 
Untersuchungen üher die Prnteinkömer und d. Bedentung d. Isparagins etc. 463

Säulen, die nach Sorauer') gleichfalls sich finder, habe ich nicht gesehen, doch lässt die von $\mathrm{Cohn}$ bereits nachgewiesene schwache Doppeltbrechung es allerdings zweifelhaft erscheinen, ob die fraglichen Krystalloide wirklich im tesseralen System urterzubringen sind. Nach $\mathbf{R a d l k o f e r}{ }^{2}$ ) sind die Krystalloide in den Zellkernen von Lathraea dem rhombischen System zuzuzählen und ebenso nach $\mathrm{N}$ ägeli die Farbstoffkrystalloide aus den Beeren von Solanum americanum, die freilich keine eigentlichen Proteinkrystalle sind, sondern nur wenig eiweissartige Stoffe enthalten. Die von Klein ${ }^{3}$ ) jüngst bekannt gemachten Krystalloide aus dem Zellsaft des Fruchttrïgers von Pilobolns-Arten sollen dem quadratischen oder wahrscheinlicher dem tesseralen System angehören. Auch erinnere ich hier daran, dass das aus dem Blute verschiedener Thiere dargestellte Hämatokrystallin in verschiedenen Krystallsystem krystallisirt. Es sind hier auch zugleich dic in anderen Pflanzentheilen bis dahin gefundenen Krystalloide genannt ${ }^{+}$), wenn ich noch die zweierlei Krystalloide anführe, welche $\mathrm{Cramer}^{5}$ ) bei Florideen, die in Weingeist oder Kochsalzlösung aufbervahrt waren, entdeckte und als hexagonales und oktaedrisches Rhodo. spermin unterschied, welches letzteres Cramer geneigt ist, dem klinorhombischen System zuzurechnen. Diese farblosen Krystalloide sind nach $\operatorname{Cohn}^{6}$ ) schon in der lebenden Pflanze enthalten, das karmoisinrothe hexagonale Rhodospermin scheint sich aber erst durch den Einfluss wasserentzichender Medien zu bilden ${ }^{3}$ ).

Trécul ${ }^{8}$ ) bringt mit den Krystalloiden von Sparganium auch

1) Sorauer, Annalen der Landwirthschaft in den Künigl, prenss. Staaten 1871, p. 65 .

2) R adlk ofer, Krystalle etc. 1859, p. 7.

3) Kle in, Verhandhungen d. zool.-bot. Ges. in Wien 1870 , p. 550 und Flora 1871, p. 163.

4) Nach Sorauer (Annal. 1. Landwirthschaft 1868, Bd. 51, p. 11) kommen Krystalloide transitorisch mehrfach in canbialen 'Lellen der Gefässbündel vor und auch in vergänglichen Drüsenhaaren. Was es hierwit für eine Bewandtniss hat, muss ich dahingestellt sein lassen, wie ich auch kein Urtheil über die von Karsten (Pogg. Annal. 1860, Bd. 109, p. 514) als "Zellenki'ystalloille" beschriebenen Körper abgeben kann, welche nach diesem $\Lambda$ utor wabrscheinlich aus eiuem stickstoffhaltigen Stoff bestehen. - Krystalloide aus der Epidermis von Polypodium irevides hat jüngst Kraus (Jahrb. f. wiss. Bot. Bd. VIII., p. 426) bekannt genacht.

5) Cramer, Vierteljahrschrift der naturf. Ges, zu Zürich, 1862, Bu. ViI.

6) Cohn, Schulze's Archiv f. mikroskop. Anatomie 1867, Bd. 3, p. 24.

7) Vgl. Klein, in Flora 1871, p. 168.

8) Trécul, Annal. d. sc. naturelt 1858, IV. Sér., 'T'. 10, p. 61. Anch clie ron Karsten (Flora 1871, p. 360) krystallisirten Zellen verglichenen mul Krystalloide 
Krystalle und Krystalldrusen aus den Blattzellen einiger Orchideen (Pleurothallis circumplexus, Megaclinium maximum, Lepanthes cochlearifolia) unter einen $\mathrm{Hut}$, die indess bestimmt wie bei anderen Orchidecn nur Krystalle ron oxalsaureu Kalk sein dürften; es steht mir leider keine der genannten Speces zu Gebote, um endgültig entscheiden zu können.

An den näher untersuchten Krystalloiden ist, wenn auch immer nur schwache Doppeltbrechung beobachtet worden, so an denen der Kartoffel (Cohn), von Bertholletia (Maschke, Radl. kofer), Sparganium (Radlkofer) und denen in Zellkernen von Lathraea (Radlkofer). Auch die hexagonalen Krystalloide der Florideen, von denen Cramer negatives Resultat angab, sind von diesen später, nach einer Mittheilung Klein's '), doppeltbrechend gefunden worden. Diese Krystalloide bestanden aber aus in die unlösliche Moditikation übergegangenen eiweissartigen Stoffen und da nach Radlkofer ${ }^{2}$ ) die Coagulation der Krystalloide ron Lathraea ihre Wirkung auf das polarisirte Licht aufheben soll, so werden zur Aufklärung dieses Punktes erneute Untersuchungen angestellt werden müssen. Auch die schwache Doppeltbrechung, welche v. $\mathrm{Mohl}^{3}$ ) an den Proteinkörnern von Attalea funifera auffand, dürfte auf die eingeschlossenen Krystalloide zurückzuführen sein, welche sich in diesem mir nicht zugänglichen Samen höclıst wahrscheinlich finden, da sie auch bei nächst verwandten Palınen, Cocos sp. (nach Hartig) und Elaeis guyanensis vorkommen. An anderen Proteinkörnern fand v. Mohl und ebenso Caspary ${ }^{4}$ ) keine Doppeltbrechung und damit stimmen auch meine Resultate an wenigen untersuchten krystalloidfreien Proteinkörnern überein. Jedoch ist zu bemerken, dass die krystallinischen Einschlüsse von oxalsaurem Kalk stark doppeltbrechend sind und wo sie vorhanden, sich auch sofort durch ihr starkes Lenchten bei gekreuzten Nicols bemerklich machen.

genannte Körper aus den Samenlappen von Lupinus luteus sind Krystalle von oxalsaurem Kalk.

1) Flora 1871, p. 162.

2) Radlkofer, 'Krystalle u. S, W., p. 26.

3) v. Mohl, Bot. Zeitung 1858, p. 17.

4) Nacb Hartig, Pflanzenkeim p. 109. 


\section{Die Einschlüsse.}

Einleitend bemerkte ich schon, dass sich in den Proteinkörnern zwei Arten von Finschlüssen finden, die ich als krystallinische Einschlüsse (Krystalle) und kugelige Einschlüsse (Globoide) unterschied, deren erstere einfach aus oxalsaurem Kalk bestehen, während die letzteren eine Verbindung von Magnesia und Kalk mit einer gepaarten Phosphorsäure sind.

Die Globoide, welche in keinem Samen fehlen, sind meist kugelig, kommen aber auch in verschieden gestalteten traubenförmigen Formen vor. Eine sehr schöne Musterkarte verschiedener Formen von Globoiden findet sich in den Proteinkörnern des Endosperms von Vitis vinifera (Rosinenkernen), welche zugleich die grössten mir vorgekommenen Globoide einschliessen, indem diese bis zu 10 Mikromill. Durchmesser erreichen können. Uebrigens sind Globoide nicht in allen Zellen des Endosperms enthalten, da auch krystallinische Einschlüsse bei unserer Pfanze vorkommen. Manche dieser Globoide von Vitis sind vollkommen kugelig (XXXVIII, 7a), an anderen treten aber, sei es nun einseitig oder allseitig, kleine abgerundete Hügel aus der Kugel hervor, welche derart wachsen kömnen, dass den hervorstehenden Kugeln nur noch kleinere Haubenstücke zur völligen Abrundung fehlen. Auch dieses kann wieder auf einer Seite oder auf allen Seiten gleichzeitig geschehen und in diesem Falle bildet dann eine innere Masse gleichsam die Insertionsbasis für die mehr oder weniger weit hervorstehenden Kugeln (XXXVIII, 9). Diese im optischen Sclinitt kranzförmig erscheinenden Globoide sind es, welche Hartig Kranzkörper nannte, unter denen er freilich, wie schon bemerkt wurde, auch manche Drusen von oxalsaurem Kalk unterbrachte. Die einzelnen herrorstehenden Kugeln können nun wieder alle oder theilweise in ähnlicher Weise zusammengesetzt werden und so entstehen verschieden gestaltete drusenförmige Gebilde, welche besonders schön in den Proteinkörnern der Paranuss (XXXVI, 17b u. c) zu finden sind, bei der aber auch einfache Kugeln vorkommen. So gross wie eben beschrieben ist nun freilich der Formenkreis der Globoide in den meisten Samen nicht, sondern, wie schon bemerkt, sind einfache oder wenig componirte Kugeln bei weitem vorherrschend.

Die meisten grösseren Globoide, wie z. B. die von Ricinus, Cotoneaster laxiflora, Portulaca olcracea überschreiten nicht leicht 
einen Durehmesser von 5 Mikromill, bei der Melrzahl der Pflanzen sind sie indess wesentlich kleiner, ja sie sinken nicht selten bis zu fast unmessbarer Grösse herab. Doch schwankt auch die Grösze der Globoide in den meisten Samen erheblich, wenn auch die letztgenannten Extreme nicht häufig vorkommen. Sind zahlreiche Globoide bei krystalloidfreien Proteinkörnern vorhanden, so sind diese durch die ganze Proteinmasse zerstreut oder auch an einzelnen, übrigens beliebigen Stellen des Kornes angehäuft. Auch grössere Globoide können sowohl central als excentrisch liegen, doch ist deren Zahl, wic begreiflich, immer nur gering oder es ist auch nur ein Globoid rorhanden. Finden sich auch Krystalloide in den Proteinkörnern, so ist den Globoiden, da die Hüllmasse immer spärlich ist, einc excentrische Lage vorgeschrieben. Wenn dann cinige Globoide rorhauden sind, so liegen diese gewöbnlich auf derselben Seite des Proteinkorns, doch kommt auch das Gegentheil vor und namentlich sind die schon früher erwähnten Proteinkörner ron Elacis als solche zu nennen, bei denen sehr zahlreiche winzige Globoide in der ganzen Hüllnasse zerstreut sind. Im allgemeinen sind freilich bei krystalloidführenden Proteinkörnern einzelne oder wenige grössere Globoide hänfiger als kleine und zahlreiche, welche bei krystalloidfreien Proteinkörnern wohl ebenso oft als grössere Globoide in geringerer Zahl auftreteu.

Fast immer macht das Gesammtvolumen des cinzelnen oder der zahlreichen Globoide cines Protcinkorns nur cinen geringen, oft sehr geringen Bruchtheil der Proteinmasse aus, doch kommt es auch vor, dass diese dic Globoide kaum überwiegt, oder selbst von der Masse der letzteren ein wenig übertroffen wird. Silybum marianum (XXXVIII, 1b), Coriandrum sativum (XXXVII, 14a), Aethusa Cyuapium (XXXVII, 13a) können hicr als Beispiele genannt werdeu. In demselben Sameu schwankt das relative Verhältniss zwischen Globoiden und Proteinmasse für verschicdene Proteinkörner innerhalb engerer Grenzen, indess gibt es auch Ausnahmen und namentlich findet man manche Samen, in denen ein cinzelnes Proteinkorn durch seine cigene Grösse und auch die relative Grösse zeines Einschlusses sich vor den übrigen Proteinkörnern derselben Zelle auszeichnet, z. B. Vitis vinifera (XXXVIII, 6 u. 7). Für die krystallinischen Einschlüsse gilt bezüglich des relativen Volumens dieser und der Proteinmasse das gleiche wie für Globoide.

Die Globoide sind, abgesehen von ihrer Gestalt, durch ihre 
Löslichkeit in Essigsäure leicht von krystallinischen Einschlüssen zu unterscheiden, die, wic es ja für oxalsauren Kalk bekannt ist, sich nicht in der genannten Säure lösen. Die krystallinischen Einschlüsse finden sich nur bei einer beschränkten Auzahl von Samen, bei denen indess immer Globoide neben diesen vorkommen, indess fübren gewöhnlich alle Proteinkörner einer Zelle entweder kugelige oder krystallinische Einschlüsse (XXXVII, 13 u. 14; XXXVIII, 1), seltener finden sich beide Arten, aber getrennt in besonderen Körnern, in derselben Zelle. Hiervon ist mir nun eine Ausnahme bekannt, nämlich für Vitis vinifera, bei der in einem besonders grossen Proteinkorn, das sich neben vielen kleineren in jeder Zelle des Endosperms findet, entweder ein oder einige Globoide (XXXVIII, 7) liegen oder eine Krystalldruse gefunden wird (XXXVIII, 6), zuweilen kommt aber auch ein aus beiden zusammengesetzter Einschluss vor (XXXVIII, 8 u. 7b). Man findet dann nämlich eine kleinere Krystalldruse oder einen Einzelkrystall, wohl auch einige Kryställchen, von Globoidmasse umhüllt, die man mit Essigsäure weglösen und so den aus oxalsaurem Kalk bestehenden Kern isoliren kann. Nach Hartig ') scheinen bei Cissus antarctica ähnliche Einschlüsse vorzukommen, auch gibt dieser Forscher an, dass bei Corylus avellana Krystalle und Globoide nebeneinander sich finden ${ }^{2}$ ), was wohl möglich ist, wenn ich auch selbst immer nur eine Art von Einschlüssen in demselben Proteinkorn fand.

Für das regelmässige Zusammenvorkommen von Globoiden und Krystallen in derselben Zelle, aber in verschiedenen Proteinkörnern, ist Lupinus luteus ein Beispiel (XXXVIII, 15). In einem, die übrigen Proteinkörner der Zelle an Grösse übertreffenden Pro. teinkorn finden sich nämlich ein oder einige, dann meist zwillingsartig verwachsene tafelförmige Krystalle, während in den übrigen Proteinkörnern kleine Globoide in grosser Anzahl liegen. Bei anderen Pflanzen trifft man gelegentlich einmal in Zellen, die sonst nur Krystalle in den Proteinkörnern führen, ein oder einige, dann meist sehr kleine Proteinkörner mit Globoiden oder umgekehrt neben diesen einzelne Proteinkörner mit krystallinischen Einschlüssen. Dieses ist z. B. bei Acthusa Cynapium häufiger als bei Silybum marianum der Fall. Bei letzterer Pflanze kommen, wie schon früher bemerkt wurde, in den mittleren Zellen eines ieden Samenlappens vorwiegend krystallinische, in einigen äusseren

1) Bot. Zeitung 1856, p, 314.

2) Ebenda, p. 316 und Tafel VIII, Fig. III, 3. 
Zelllagen aber vorwiegend kugelige Eimsehlïsse vor, doch finden sich anch bis in die Epidermis hinein krystallführende Zellen. Aehnlich ist es bei Centaurea Jacea und noch strenger tritt eine solche Vertheilung bei Scorzonera hispanica herror, bei der dann freilich die Epidermiszellen selbst wieder fast nur krystallinische Einschlüsse führen. Bei Tragopogon major tinden sich in allen Zellen Globoide in den Proteinköruern, nur in den Zellen, mit welchen die beiden Samenlappen aneinander liegen, ist oxalsaurer Kalk vorhanden. Alle untersuchten Umbelliferen haben beide Arten von Einschlüssen aufzuweisen, doch sind die Zellen, in welchen dieselben vorkommen, olune bestimmte Ordnung untereinander vertheilt. Hier finden wir auch in Acthusa Cynapium die einzige mir bekannte Pflanze, welche neben Krystalloiden krystallinische Einschlüsse führt (XXXVII, 13), denn den anderen untersuchten Umbelliferen fehlen Krystalloide.

Bei Paconia sind in einigen peripherischen Zelllagen des Endosperms Globoide so gut wie ausschliesslich vorhanden (XXXVI, 5), wälırend in allen mehr inneren Kellen nur kleine Krystalle von oxalsaurem Kalk, und zwar immer nur je einer oder wenige in einem Proteinkorn, sich linden (XXXVI, 1). Der Embryo von Paconia fuihrt nur Globoide, wie auch der von Cephalaria procera, bei welcher P'fanze das Liwciss in allen Zellen kleine krystallinische Einschlïsse und danchen nur vereinzelte Globoide aufzuweisen hat. Lis seien hicr noch Berberis vulgaris, Staphylea pinnata, Helleborus foetidus und Corylus Avellana als weitcre Beispiele solcher Samen genannt, in welchen auch krystallinischo Lin. schlüsse in den Proteinkörnern vorkommen. Jedenfalls ist die meist strenge Localisirung von krystallinischen oder kugeligen Einschliissen auf bestimmte Zellen benerkenswerth, da hicrin ein Hinweis auf ungleiche physiologische 'Thätigkeit der als Reservemagazine dienenden Zellen liegt. His ist aber noch zu bemerken, dass krystallinische Einschlüsse keineswegs allen l'Aauzen derselben Familic zukommen zn brauchen, wic z. B. nicht allen Compositen und Ranunculaceen, während jeno in allen bis dahin untersuchten Umbelliferci enthalten waren, weun es auch schr wohl möglich ist, dass hicr noch Samen ohne krystallinische Einschlüsso gefunden werden.

Dic Form, in welcher die krystallinischen Einschlüsse erscheinen, kann in derselben Zelle variabel sein. Bei Scorzonera hispanica finden sich z. B. spärliche Hendyoeder, die Grundform des mit 
einem Atom $\left(\mathrm{H}^{2} \mathrm{O}\right)$ Wasser krystallisirenden oxalsauren Kalkes $\left.{ }^{1}\right)$, häufiger aber langgestreckt̄e prismatische Gestalten, die selbst bis zur Nadelform vorkommen (XXXVI, 13) und endlich auch morgensternförmige Drusen, welche hier namentlich in den Epidermiszellen der Samenlappen gefunden werden. Häufiger als bei Scorzonera sind Krystalldrusen bei Corylus, Aethusa Cynapium und Athamanta Mathioli, meist trifft man aber nur eine, bei Coriandrum aber auch nicht selten 2 bis 4 Drusen in einem Proteinkorn (XXXVII, 14b). Bei Silybun marianum schliesst ein durch Grösse ausgezeichnetes Proteinkorn eine grosse Krystalldruse ein, während die übrigen Proteinkörner derselben Zelle je eine Anzahl nadelförmiger Krystalle aufuweisen haben (XXXVIII, 1a); gerade so ist es auch bei Centaurea Jacca, wo indess kcin Proteinkorn durch Grösse besonders hervorragt. Die Krystalle, welche bei Lupinus (XXXVIII, 15) in dem grossen Proteinkorn einer jeden Zelle vorkommen, sind klinorhombische Tafeln, häufig mit Abstumpfung der klinodiagonalen oder orthodiagonalen oder beider Kanten und oft zu Berührungs- oder Durchkreuzungszwillingen verwachsen. Ob der mit drei Atomen Wasser im quadratischen System krystallisirende oxalsaure Kalk als Einschluss sich findet, kann ich nicht sagen, da ich ein specielles Augenmerk auf die Krystallform nicht warf. Uebrigens scheinen auch die sehr kleinen Krystalle in den Proteinkörnern von Paeonia und ebenso die Drusen in den Proteinkörnern von Tragopogon, ihrer sehr starken Doppeltbrechung halher, dem klinorhombischen Systeme zuzugehören. Zu diesem rechnet auch Radlk o fer, nach einer Mittheilung H ol z ner's ${ }^{2}$ ), die Krystalldruse, welche sich in einem besonders grossen Proteinkorn in den Zellen der Cotyledonen von Cardiospermum Halicacabum findet. Es ist dieses auch der cinzige Fall, dass Krystalle und überhaupt Einschlüsse der Proteinkörner ihrer Natur nach richtig erkannt wurden. Hartig ${ }^{3}$ ) vermuthet für alle Arten von Einschlüssen eine gleiche Zusammensetzung und zwar scheint ihm ein inulinartiger Körper am wahrscheinlichsten; Maschke ${ }^{4}$ ) sucht dann zu erweisen, dass die Globoide der Paranuss aus Bassorin und einer proteinartigen Substanz zusammengesetzt seien. $\nabla$. Hollo hat zwar die Verschiedenhcit krystallinischer und kugeliger Einschlüsse crkannt,

1) Ho $1 \mathrm{zner}$, Flora 1864, p. $273 \mathrm{ff}$. und 1867, p. $499 \mathrm{ff}$.

2) Holzner, Flora 1867, p. 505.

3) Hartig, Bot. Zeitung 1856, p. 303.

4) Maschke, Bot. Zeitung 1859, p. 421 . 
spricht sich indess ülor die Natur nicht aus, bemerkt nur bei den Krystalldrusen, er halte sie "für krystallinische Bildungen nach der Art der sogenannten Durchwachsungen* "), ist aber über die chemische Zusammensetzung jedenfalls völlig im Unklaren, da er den Namen Krystalloide vorschlägt.

Grössere Protcinkörner habe ich nic obne irgend einen Einschluss gesehen, doch trifft man sehr kleine Körner, welche sich gelegentlich zwischen grösseren Proteinkörnern finden und in den vorwiegend stärkeführenden Samen allein vorkommen, auch frei von Einschlüssen; ebenso kommt es zuweilen vor, dass kleine Einschlüsse nicht in Protciukörnern, sondern in der Grundmasse liegen. Freilich sinken auch die Einschlüsse zu so geringer Grösse berab, dass bei sehr kleinen Proteinkörnern es oft nicht möglich ist, mit aller Sicherheit zu entscheiden, ob nicht dennoch ein winziger Einschluss vorhanden ist.

Zum Zwecke der Untersuchung zicht man zunächst aus Samenschnitten das Oel aus und behandelt dann diese, falls dic Proteinkörner in Whsser löslich sind, mit Wasser, oder in anderen Falle mit sehr verdünntem Kali, welches die Einschlüsse nicht angreift.

Der oxalsaure Kalk ist bekanntlich leicht durch mikroche. mische Realstionen zu erkennen. Schon die Unlöslichkeit der Kristalle in Wasser und Essigsäure schliesst die in der Pflanze vorkommenden anorganischen Säuren aus, da keine dieser mit einer der vorhandenen Basen ein derartiges Salz bildet; von Baryt und Strontian, welche nur in Spuren bei cinigen Planzen gefunden wurden, können wir natürlich absehen. Dass aber die Krystalle eine organische Säure enthalten, geht aus dem Verhalten in der Hitze hervor, denn nach dem Glühen löst sich die rückbleibende Masse unter Brausen in Essigsäure. Von organischen Säuren können aber nur zwei in Betracht kommen, nämlich Oxalsäure und Traubensäure, da dic Salze aller anderen in Pflanzen vorkommenden Säurer in Wasser oder Essigsäure löslich sind. Die Kalksalze der beiden Säuren trennt man in der analytischen Chemie durch mässig concentrirte kalte Kali- oder Natronlage und diese Treunung ist auch mikrochemisch anwendbar, wenn man die Lauge nicht zu concentrirt anwendet. Im anderen Falle nämlich löst sich der oxalsaure Kalk nach einigen Stunden, wie Sanio ${ }^{2}$ )

1) v. Holle, vgl. Unters. d. Proteinkömer etc., neues Jahrb. f. Pharm. von Walz u. Winkler 1859, p. 17 d. Separatabzuges.

2) Monatsb. d. Berl. Akademie 1858, p. 254 Anmerkg. 
nachwies, plötzlich und schmell auf um sich nach kürzerer Zeit wieder in Krystallen auszuscheiden. Indess findet dieses nicht statt, wenn die Lange verdünnter, jedoch concentrirt genug ist, um, wie man sich durch den Versuch überzeugen kann, traubensauren Kalk leicht zu lösen. Dic krystallinischen Einschlüsse aus Proteinkörnern, wclche ich näher untersuchte, gaben sich durch ihre Unlöslichkeit in alkalischer Lauge als oxalsaurer Kalk zu erkenneu. Nach diesen Reactionen, zusammengehaltenen mit der Löslichkeit der Krystalle in Salzsäure, kann überhaupt nur das oxalsaure Salz ron Kalk, oder wohl auch Magnesia vorliegen, auf welches letztere bis dahin keine Rücksicht genommen ist, das indess bei seiner sehr schweren Löslichkeit in Wasser und der grossen Verbreitung von Magnesia in Pflanzen wohl auch vor. kommen dürfte. Die Krystalle aus den Proteinkörnern von Sily. bum marianum, Vitis vinifera und Lupinus luteus, welche ich in dieser Richtung untersuchte, bestanden allerdings aus oxalsaurem Kalk. ') Ich unterlasse es übrigens hicr cine Reihe von Reaktionen anzuführen, welche man zum Zwecke der Erkennung des oxalsauren Kalkes noch anstellen kann. ${ }^{2}$ )

Das beim vorsichtigen Aufösen der Krystalle in Salzsäure ein zartes Häutchen bleibt, welches aus Proteinstoffen besteht, habe ich schon früher mitgetheilt. Die Krystalldrusen haben aber auch in ihrer Mitte, wie schon $\mathrm{Sanio}^{3}$ ) erkanntc, einen aus Proteinstoffen bestehenden Kern, den man häufig ohne weiteres als anders lichtbrechende Masse erkennt, von seiner Gegenwart sich aber am sichersten überzeugt, wenn man die Drusen in verdünnter Salzsäurc auflöst, welcher vortheilhaft etwas Jod zligesetzt ist. Es sei hicr noch erwähnt, dass Hartig dic Krystalldrusen (seine sternförmigen Einschlüsse) als Kranzkörper (eine Form unserer Globoide) betrachtet, deren peripherische Kugeln zu Krystallform ausgebildet seien. Allein Globoide und Krystalle sind chemisch ganz verschieden zusammengesetzt und wenn Hartig ${ }^{4}$ ) angibt, dass aus Krystalldrusen durch Bchandlung mit Millon's Reagens

1) Man kann die Oxalate von Kalk und Magnesia darlurch unterscheiden, dass man mit einer mit Ammoniak versetzten Lösung von Chlorammonium und oxalsaurem Ammoniak digerirt. Die oxalsaure Magnesia löst sich nach längerer Zeit auf, der oxalsaure Kalk nicht.

2) Eine grössere Zahl von Reaktionen findet sich bei Sanio, Monatsb. d. Berl. Akademie 1858, p. 254 ff., auch bei Holzner, Flora 1864, p. $273 \mathrm{ff}$.

3) Monatsb. d. Berl. Akad. 1858, p. 258.

4) Hartig, Pflanzenkeim p. 117. 
ein Kranzkörper (Globoid) entstanden sei, so ist dieses eben ein Irrthuu; möglich dass hierzu der aus eiweissartigen Stoffen bestehende Kern, um welchen die Druse sich bildete, Veranlassung wurde.

Wenden wir uns nun zu Globoiden. Diese sind in kaltem und kochendem Wasser, auch in Weingeist unlöslich, werden aber von allen anorganischen Säuren und ebenso auch von Essigsäure und Weinsäure leicht und obnc Brausen gelöst. Die Lösung geht immer von Aussen nach Innen vor sich und es bleibt hierbei ein zartes, aus Proteinstoffen bestehendes Hüllhäutchen, wie auch bei den Krystallen zurück (XXXVIII, 5 Lösung beim Keimen). Auch in Wasser liegend sind die Globoide spröde und leicht zersprengbar und vehmen weder mit Jod, noch mit Anilin eine Fürbung an. Vou einer krystallinischen Struktur kann man an den Globoiden nichts erkenuen und bei gekreuzten Nicols ist auch keine Doppeltbrechung zu bemerken, ob auch nicht bei Anwendung von Gypsblättchen, habe ich nicht untersucht.

Zunächst ist es wichtig festzustellen, dass dic Globoide unverbrennliche Substanz enthalten. Zu dem Ende bringt man am besten cinen Schnitt aus Samen, welche grosse Globoide enthalten, wie Ricinus, Pinus Pinca, Cotoneaster u. a. in wenig Wasser auf ein starkes Druckglas, nachdem die Proteinstoffe in der schon angegebenen Weise entfernt, das Kali aber jedenfalls vollkom. men ausgewaschen wurde. Beim Hin- und Herbewegen des Schnittes gelingt es dann leicht eine Anzahl Globoide herausfallen zu machen, welche beim Eintrocknon des Wassers frei auf dem Deckglas liegen. Ėrhitzt man nun aber über der Weingeistlampe, so bemerkt mall zunächst, dass dio Globoide sich durch ihre ganze Masse sehr stark schwärzen, ungleich mehr als dieses beim Erhitzen der in Pflanzen vorkommenden Krystalle von oxalsaurem Kalk der Fall ist. Um völlig weiss zu brennen, muss man schon starke Hitze anwenden und desshalb das Deckglas auf ein ebenes Platinblech legen, damit das zu starke Verbiegen jenes vermieden wird. Man erkennt dann die Form der Globoide wieder, indem eine immerhin beträchtliches Quantum amorpher, körnig erscheinender Masse zurückblicb, welche sich nicht in Wasser, wohl aber leicht in den früher genannten Säuren obne merkliches Brausen löst. Dass dabei nun freilich ein matter Fleck auf dem Glase restirt, kann kein Wunder nehmen, da entweder das Glas selbst angegriffen oder etwas Koble zurückgeblieben sein konnte. 
Schon jetzt können wir mit Sicherheit sagen, dass die Asche der Globoide Kalk oder Magnesia, oder beide enthalten muss. Denn die Alkalien bilden mit den in der Pflanze vorkommenden Stoffen keine in Wasser unlösliche Verbindungen, Kieselsäure kann aber bei der Löslichkeit in Säuren nicht vorliegen und die allerdings fenerbeständige Phosphorsäure würde einmal flüssig sein (wenigstens in der Hitze) und ausserdem sich in Wasser lösen. In Verbindung mit Kalk und Magnesia kann natürlich die Phos: phorsäure in der Asche sein und sic ist dieses auch wirklich, wie wir noch erfahren werden.

Es können aber auch Magnesia sowohl als Kalk direkt an den von der Proteinmasse befreiten Globoiden nachgewiesen werden. Lässt man zu Globoiden, welche in der schon beschriebenen Weise isolirt wurden, unter Deckglas eine ammoniakalische Lösung von Chlorammonium und phosphorsaurem Ammoniak treten, so beginnen gleich darauf Krystalle von phosphorsaurer Ammoniakmagnesia sich zu bilden, welche wachsen und sich vermehren, während die Globoide abschmelzen und nach einer halben Stunde oder aucli etwas längerer Zeit verschwunden sind. Vollkommen ausgebildete Kry. ställchen sind, auch weun das Reayens verdünnt angewandt wurde, nicht häufig, doch kommen auch die für die phosphorsanre Ammoniakmagnesia charakteristischen Sargdeckelformen vor, meist freilich treten nur federig oder sternförmig gruppirte Krystalle auf. Eine nähere Beschreibung kann ich übrigens unterlassen, da mau jeden Augenblick die gleichen Kryställchen erhalten kann, wenı man anstatt der Globoide ein wenig schwefelsaure Magnesia oder ein anderes Magnesiasalz in der beschriebenen Weise behandelt. Bei gleicher Behandlung gibt freilich zuweilen aucb ein Kalksalz Kryställchen von phosphorsaurem Kalk, der meist amorph bleibt, dessen Kryställchen man aber auch leicht von denen der phosphorsauren Ammoniakmagnesia unterscheiden kann, wenn man sich durch vergleichende Versuche erst mit den Formen vertraut gemacht hat.

Der Nachweis des Kalkes gelingt mittelst einer ammoniakalischen Lösung von Chlorammonium und oxalsaurem Ammoniak, indem man im übrigen mit der Beschickung wie bei der Erkennung der Magnesia verfährt. Hier geht nun freilich das Verschwinden der Globoide viel langsamer von Statten und nimmt gewöhnlich mehrere Stunden in Anspruch, wesshalb man auch die beschickten Objektträger am besten in cine fenchte Ammoniakatmosphäre bringt, 
welche sehr leicht herstellbar ist, indem man in ein Schälchen etwas Salmiakgeist gibt und diesez, zusammen mit dem Objektträger, unter eine kleine, auf eine geschliffene Glasplatte fest anschliessende Glocke bringt. Als Endresultat findet man dann an, oder wenigstens in der Nähe der Stellen, wo Globoide lagen, Kryställchen ron oxalsaurem Kalk, welche man mit entsprechenden Reagentien näher prüfen kann; die Magnesia ging bei dieser Behandlung in Lösung. Wenn man isolirte Globoide anwandte, so kann natürlich über den Ursprung des Kalkes kein Zweifel herrschen; jedenfalls war aber dessen Menge bei allen untersuchten Globoiden viel geringer als die der Magnesia. In der Asche vieler Samen findet sich mehr Kalk als Magnesia, doch auch das umgekchrte kommt vor und sogar in den Samen derselben, aber an rerschiedenen Stationen gewachsenen Pflanze kann einmal der Kalk, das andermal die Magnesia überwiegen. ${ }^{1}$ ) Es ist desshalb wahrscheinlich, dass auch in den Globoiden die beiden Erden in relatir ungleicher Menge rorkommen, doch mag der Kalk wohl immer in grösserer Menge auch in den Zellhäuten, vielleicht auch anderweitig im Zellinhalt aufgespeichert sein. Der relatir grosse Magnesiagehalt der Samen steht in Zusammenhang mit dem Verhalten der beiden mehrfach genannten Erden beim Reifen der Samen. Nachdem, wie Pierre ${ }^{2}$ ) zeigte, schon zu Eude der Blüthezeit die absolute Menge der Mineralbestandtheile in der Pflanze aufyenominen ist, beginnt weiterhin deren Einwanderung in den reifenden Samen. Dabei ist nun für Kali und Phosphorsäure, nächstdem für Magnesia, die Entleerung der Pflanze eine weitgehende, welche bei dem Weizen nach Heinrich ${ }^{3}$ ) bis zu 91 Procent des Gesammtrorrathes steigen kann, während Kalk in grösscrer Menge in den vegetativen Theilen der Pflanze zurückbleibt.

Man kann übrigens anch, indem man Globoide mit Schwefelsäure behandelt, das Anschiessen von Nadeln beobachten, wolche die Sulphate von Magnesia und ron Kalk sein müssen, die man

1) Ausführliches über Zusammensetzung von Aschen bei $\mathrm{E}$. Wolff, AschenAnalysen landwirthschafticher Produkte 1871. Samen von Rothklee zeigt \%. B. im Mittel $6,4 \% \mathrm{Ca}^{2} \mathrm{O}$ und 12,9\% $\mathrm{MgO}$; Esparsette hingegen $31,58 \%{ }^{\circ}\left(\mathrm{C}^{2} \mathrm{O}\right.$ und $6,65 \%$ $\mathrm{Mg}^{2} \mathrm{O}$. Das einmal $\mathrm{Ca}^{2} \mathrm{O}$, das anderemal $\mathrm{Jg}^{2} \mathrm{O}$, überwiegend wurle 7. B. gefunden bei Secale cereale (p. 14) und Phaseolus vulgaris (p. 53).

2) J. Pierre, Compt. rendus 1869, T. 69, p. 1256 ff.

3) Heinrich, Amal, der Landwirthe haft in den Kgl. preuss. Staten 1871, - $p 31 \mathrm{ff}$. 
indess nicht wobl unterscheiden kann, da beide, wenn auch Gyps schwieriger, bei Wasserzutritt sich lösen. ${ }^{1}$ )

Eine chemische Untersuchung, welche auf meine Bitte mein Freund Dr. Brandau, Assistent am chemischen Laboratorium, vornahm, ergab, wie ich schon mittheilte, dass die genannten Erden an eine mit einem organischen Körper gepaarten Phosphorsäure gebunden sind. Die Analyse wurde, insoweit sie das Isoliren der Globoide bezweckte, mit Ricinussamen in der durch den mikro. chemischen Befund vorgeschriebenen Weise ausgeführt, indem zunächst das $\mathrm{Oel}$, dann mit verdünntem Kali die löslichen Proteinstoffe entfernt wurden, um dann mit verdünnter Essigsäure die Globoide aufzulösen. Das in Arbeit genommene Material war aber nicht ausreichend, um über den Paarling in's Klare zu kommen, indess wird Dr. Brandau die Sache weiter verfolgen; nicht unwahrscheinlich ist es aber, dass die vorliegende Säure Zuckerphosplorsäure ist. Der Gedanke an Glycerinphosphorsäurc, welche ja mit thierischen Albuminstoffen zusammen vorkommt, lag a priori nahe, muss aber fallen gelassen werden, weil die Salze, welche diese Säure mit Erden bildet, als in Wasser lösliche angegeben werden.

Erst nach der chemischen Analyse gelang es mir auch mikrochemisch die Phosphorsäure in den Globoiden nachzuweisen. So nahe der Gedanke an diese Säure von vornherein mir auch lag, so war doch die Löslichkeit der Globoide in einer ammoniakalischen Lösung von Chloraminonium röllig bewcisend, dass das Phosphat der gewöhnlichen Phosphorsäure nicht vorliegen konnte. Denn dieses hätte sich nicht lösen dürfen und wenn auch eine Veränderung möglich war, so hätten doch um die Globoide Krystalle von phosphorsaurer Ammoniakmagnesia anschiessen müssen. Dieses geschah aber gar nicht oder es bildeten sich nur so sehr vereinzelte Kryställchen, dass unmöglich die Globoide Erd. phosphate in irgend erheblicher Menge enthalten konnten. Wohl aber wird dieses Verhalten vollkommen begreiflich mit dem Nachweis der gepaarten Phosphorsäure, da gepaarte Säuren in ihrem Verhalten von den einfachen Säuren ganz abweichend sein können. Ich habe hicr noch zu bemerken, dass die Lösung der Globoide in ammoniakalischem Chlorammonium nur langsam vor sich geht, und man muss desshalb, wenu man auf Objektträgern

1) Gyps ist in schwefelsäurehaltigem Wasser nicht unlöslich, wie Solms angibt (Bot. Zeitung 1871, p. 511), sondem lüst sich im Gegentheil in demselben leichter als in reinem Wasser. 
operiren will, diese in einer feuchten Ammoniakatmosphäre halten, aber auch dann wird man die fortschreitende Lösung erst nach einiger Zeit constatiren und erst nach 8 und melr Stunden vollendet finden. Doch ist die Lösung eine bis auf das Hüllbäutchen vollständige und weun man zuvor mit Alkohol und Kali behandelte Schnitte, an denen nicht geöffnete Zellen rorhanden sind, zwei Tage mit einer grösseren Menge ammoniakalischer Chlorammoniumflussigkeit digerirt, so kann man nach dem Auswaschen der Schnitte Krystalle von phosphorsaurer Ammoniakmagnesia durch die früher angegebene Behandlung nicht mehr erzeugen.

Beim Verbrennen der Globoide wird aber die organische Substanz zerstört und die Asche besteht nun aus den Phosphaten von Magnesia und Kalk. Lässt man nun, indem man das Deckglas auf einen Objektträger legt, ammoniakalische Lösung von Chlorammonium zutreten, so verwandelt sich das unlösliche amorphe Magnesiaphosphat allmälich in phosphorsaure Ammoniakmagnesia, die, wenn auch langsam, unmittelbar an oder auf der Stelle wo Globoide verbrannten in Krystallformen dieses Salzes erscheint. Wir luaben also nun auf mikrochenischem Wege mit Sicherheit Magnesia, Kalk, Phosphorsäurc und organische Substanz in den Globoiden erkannt, und sogar auch dio Gewissheit erlangt, dass eine gewölnliche Phosphorsäure nicht Bestandtheil der Globoide sein kann. Hiernach kann es nun aber auch nicht im Mindesten zweifelhaft sein, dass die auf makrochemischem Wege nachgewiesene gepaarte Phosphorsäure in den Globoiden selbst, nicht etwa anderweitig in den Zellen enthalten ist. Ohnehin ist eine andere Quelle für dic gepaarte Phosphorsäure nicht wohl denkbar, denn beim Behandeln mit Kali wurde mit den eiweissartigen Stoffen auch die in diesen enthaltene Phosphorsäure entfernt.

Es bleiben nun noch einige zur weiteren Charakteristik der Globoide dienende Reaktionen anzuführen, zunächst ihr Verhalten gegen absoluten Alkohol in dem etwas concentrirte Schwefelsïure gelöst ist. Bei längere Zeit fortgesetzter Digestion verschwinden nämlich die Globoide und wenn sie, wie bei Ricinus, nicht zu klein waren, so kann man an dem nun ihre Stelle einnehmenden hohlen Raum eine körnige Masse finden. Es besteht diese aus den Sulphaten von Magnesia und Kalk, welche des Wassermangels halber Krystallform nicht annehmen konnten, sich aber ihrer Zusammensetzung entsprechend in Wasser lösnn. Bei diescr Behandlung 
trat also Schwefelsäure an Stelle der gepaarten Phosphorsäure, welche letztere im Alkohol sich auflöste. Wie Schwefelsäure wirkt auch Oxalsäure in alkoholischer Lösung, man findet dann nach längerer Zeit zuweilen winzige Kryställchen der Oxalate von Kalk und Magnesia an Stelle der Globoide. Demnach übertrifft die Oxalsäure die gepaarte Phosphorsäure an Affinität zu unseren Basen, wenigstens in alkoholischer Lösung, in welcher aber Essigsäure, wie das auch zu erwarten war, die Globoide nicht angreift, weil eben die essigsauren Salze von Kalk und Magnesia, namentlich das Acetat dieser letzteren, in Alkohol löslich sind.

Wenn genügend verdünntes Kali bei gewöhnlicher Temperatur die Globoide nicht verändert, so gilt dieses keineswegs für concentrirtes Kali, das einen Stoff, und zwar von Aussen nach Innen fortschreitend, aus den Globoiden herauslöst, wie dieses übrigens auch nach der chemischen Zusammensetzung sicher zu erwarten war; auch concentrirtes Ammoniak wirkt wie concentrirtes Kali (XXXVII, 6a). Die veränderten Globoide haben ihre frühere Gestalt $\mathrm{zwar}$ bewahrt, erscheinen aber als eine fein granulirte, schwach lichtbrechende Masse, welche Aussen von einer hautartig erscheinenden Schicht, dem Hüllhäutchen umzogen ist. Es wurde eben durch das Kali Phosphorsäure entfernt, und Kalk und Magnesia blieben, und zwar wenn die Lauge nicht zu sehr concentrirt und kohlensäurehaltig war, als kohlensaure Salze zurück, die sich natürlich gleichfalls in verdünnten Säuren lösen. Bemerkenswerth ist aber, dass sich jetzt die ganze Masse der veränderten Globoide mit Jod oder Anilin färbt, also die Anwesenheit eines stickstoffhaltigen, vermuthlich proteinartigen Stoffes zu erkennen gibt. $\mathrm{Ob}$ nun ein Proteinstoff schon in den Globoiden vertheilt war, aber sich vorher nicht durch Färbung verrathen konnte, weil jene nicht imbibitionsfähig sind oder ob erst durch die concentrirte Kalilauge - welche ja immer noch Proteinstoffe des Zellinhaltes löst, auch wenn zuvor mit verdünnter Lauge behandelt war, - ein eiweissartiger Körper in die zurückbleibende Masse der Globoide eingeführt und zurückgehalten wurde, wage ich nicht endgültig zu entscheiden. Es ist indess böchst wahrscheinlich, dass der eiweissartige Körper in der Masse der Globoide bereits vorhancien war; jedenfalls ist dessen Menge aber eine sehr geringe, denn bei noch so vorsichtigem Lösen in verdünnter Salzsäure oder Essigsäure bleibt von Proteinstoffen nur das Hüllhäutchen und manchmal ein 
Körnchen zurück, welches das Centrum des Globoides, ähnlich wie bei einer Krystalldruse, einnahm.

Die restirende Masse der Globoide ist sehr spröde und lässt sich durch Druck auf das Deckglas unschwer zersprengen; auch entstehen schon bei Einwirkung des Kalis zuweilen Sprünge, welche selbst das Zerfallen des Globoides in einige Stücke zur Folge haben können. (XXXVII. 6, b u c.) Ein merkliches Aufquellen findet aber bei Einwirkung des Kalis nicht statt, denn ich konnte bei mit mebr als 1000 facher Vergrösserung vorgenommenen Mes. sungen eine Vergrösscrung des Durchmessers nicht finden und auch die traubenförmigen Globoide der Paranuss z. B., welche bei der Behandlung mit Kali diese Gestalt beibehalten, sprechen gegen eine Quellung.

Kali sowohl als Säuren greifen dic Globoide immer von Aussen an und auch beim Keimen ist eine centripetal fortschreitende Lösung Regel, doch kommt beim Keimen auch Lösung von Innen heraus vor, wobei ich indess nicht sicher bin, ob dann nicht feine Risse in Globoide Verablassung waren, da ich solche einigemal bestimmt auffand.

\section{Die Grundmasse.}

Nachdem erwiesen, dass die Proteinkörner keine nachweisbaren Fettmengen enthalten, ist damit auch entschieden, dass das in den Samen sich findende Oel in der Grundmasse vertheilt sein muss. Bei fettreichen Samen, wie denen von Bertholletia, Ricinus und Paeonia kann man schon, wenn man einfach trockene Samenschnitte unter das Mikroskop bringt, sich ron dem bohen Fettgehalt der Grundmasse durch den Augenschein überzeugen. Lässt man dann Benzol oder Aether - welche sich hierzu besser als absoluter Alkohol eignen, weil sie Fett leichter lösen - zu den Schnitten treten, so ist das Weglösen des Fettes leicht zu verfolgen, wobei indess von der Grundmasse, auch der fettreichsten Samen, immer etwas ungelöste Substanz zurückbleibt, welche als fein granulirte oft freilich sehr spärliche Masse zwischen den Proteinkörnern liegt (XXXVII. 2, 13 u. 14).

Sehr schön lässt sich der Fettgehalt der Grundmasse durch Färbung mit Alkannaroth sichtbar machen. Dieser in Alkohol und Oel lösliche, in Wasser aber unlösliche Farbstoff wird zwar auch 
von coagulirtem Hühnereiweiss aus alkoholischer Lösung aufgenommen und lässt sich dann dem Eiweiss weder durch Alkohol noch durch Oel, auch bei mehrtägigem Stehen, nicht wieder ganz entziehen, allein um aufgenommen zu werden, muss eben der Farbstoff sich in Lösung befinden, während Oel, weil es Lösungsmittel ist, sich auch färbt, wenn es mit fein vertheiltem Farbstoff in Berührung kommt. Um nun dieses Verhalten zur Reaktion zu verwenden, bediene ich mich eines tief gefärbten, mit etwa 70 bis 80 procentigem Weingeist dargestellten Auszuges von Alkannawurzel, schwenke in diesem einen Samenschnitt einigemal herum, spüle ihn nur oberflächlich mit schwachem Weingeist ab und lege ihn sogleich in concentrirtes Glycerin. Der in Alkohol gelöste Farbstoff drang in der kurzen Zeit innerbalb der er mit den Proteinkörnern in Berührung kam, nicht in diese ein, in Glycerin aber scheidet sich der in alkoholischer Lösung dem Schnitt anhängende Farbstoff unlöslich ab, wird aber von dem Fette der Grundmasse, mit dem er so in innige Berührung kommt, schnell aufgelöst und sich in demselben vertheilend, wird die Grundmasse fettreicherer Samen in kürzerer Zeit schön blutroth gefärbt. (XXXVIII, 21.) Selbst wenn die Grundmasse sehr tief gefärbt ist, erscheinen die Proteinkörner doch ganz farblos, auch wenn sie ganz isolirt liegen. Die Samen von Cynoglossum Paeonia, Silybum marianum können u. a. zu diesem Experimente empfohlen werden, aber auch andere Samen, welche viel fettärmer als die genannten sind, geben noch entscheidende Reaktion, wenn auch die Färbung viel schwächer ausfällt. So ist bei Lupinus lateus, dessen Embryo nach Beyer ${ }^{2}$ ) nur 6 Procent Fett enthält, dieses noch sicher durch die Alkannareaktion zu erkennen, welche aber bei noch wesentlich geringerem Fettgehalt nicht mehr zum Ziele führt.

Die Anwendung eines schwächeren Weingeistes ist nöthig, damit keine grösseren Fettmengen aus den Samenschnitten gelöst werden und ist besonders dann geboten, wenn das Oel, wie z. B. das von Ricinus, in Alkohol leicht löslich ist. Man kann auch in der Weise verfahren, dass man den weingeistigen Auszug von Alkanna zu etwa gleichen Theilen mit Glycerin versetzt, die Schnitte einen Augenblick in diese Mischung und dann in concentrirtes Glycerin bringt. Auch ist zu beachten, dass die Proteinkörner mancher Samen sich in Glycerin allmälich lösen und sind desshalb

1) Die landwirthschaftl .Versuchsstationen 1867, Bd. IX., p. 173. 
solche Samen, bei denen dieses nicht der. Fall ist, für die fragliche Reaktion im Allgemeinen vorzuziehen.

Bei dem sehr fettreichen Samen von Paeoonia kann man sich auch in anderer Weise überzeugen, dass die Grundmasse allein Fett enthält. Trägt man nämlich Samenschnitte, namentlich solche aus mehrere Jahre altem Samen, in Glycerin, so lösen sich die Proteinkörner allmälich auf und an ihre Stelle ist nun Flüssigkeit getreten, in der die Einschlüsse, aber keine Fettropfen schwimmen. Die Grundmasse hat sich dabei getrübt, ohne dass indess Fetttropfen in dersclben entstanden wären, welche erst nach längerer Zeit sich in derselben bilden, und zwar so, dass man über ihren Ursprung nicht in Zweifel sein kann.

Die Proteinkörner liegen bei den fettreichen Samen im Allgemeinen weiter ron einander entfernt als bei fettarmen (Vergl. XXXVI., 16 u. XXXVII., 1 mit XXXVIII, 13 u. 15), lass aber auch bei den fettreichsten Samen der Hohlraum zwischen den Körnern hinreicht, um die analytisch gefundene Oelmenge aufunchmen, zcigt folgende einfache Rechnung. Wenn man einen Würfel, dessen Höhe =s, in beliebig viele gleich grosse Würfel, deren Seite $n$ genannt sei, zerlegt und in jeden einzelnen ein grösste Kugel eingeschrieben denkt, so muss natürlich die Summe aller Hohlräume zusammen genommen gleich sein dem Hohlraum, welcher bleibt, wenn dem grossen Würfel mit der Scite s eine grösste Kugel eingeschrieben ist, weil der procentische Werth des Hohlraumes in jedem einzelnen $W$ ürfel derselbe bleibt. Es geht dieses übrigens auch ohne weiteres aus der aufzustellenden Formel hervor, denn der Kubikinhalt aller Kugeln wäre $=\mathrm{n}^{3} \cdot \frac{4}{3}\left(\frac{\mathrm{s}}{2 \mathrm{n}}\right)^{3} \pi=\frac{\mathrm{s}^{3}}{6} \pi$ worin also $\mathrm{n}$ verschwunden ist. Der bleibende Hohlraum aber würde sein $=\mathrm{s}^{3}\left(1-\frac{\pi}{6}\right)$ d. h. $=47,6 \ldots$ Procent des Wür. felinhaltes. ') In diesem Falle stiessen die Kugeln noch unmittelbar aneinander, wenn man aber in übrigens unveränderter Lage je zwei um ein Drittel eines einzelnen Radius von einander abstehen lässt, so dass also nun der Kugelradius um $\frac{1}{6}$ kleiner als die halbe Höhe eines Würfels ist, dann ergibt sich ein Hohlraum

1) Bei der denkbar günstigsten Lagerung der Kugel würde der Hohlraum freilich auf etwas mehr als die Bälfte herabsinken. 
von $69,7 \ldots$ Procent des Rauminhaltes des $W_{\text {ürfels }}{ }^{1}$ ), melir also als selbst sehr fettreiche Samen an Oel enthalten.

Fällt nun auch für den Zellinhalt der Oelgehalt etwas höher aus, als ihn Analysen, bei welchen die Zellhäute mitgerechnet sind, angeben, so ist z. B. die gegenseitige Entfernung der mehr oder wenige eiförmigen oder ellipsoidischen Proteinkörner von Ricinus doch noch grösser als in der letzten Rechnung für Kugeln angenommen wurde, so dass jedenfalls das Fett sowohl, als die beigemengten kleinen Quantitäten von Proteinstoffen zwischen den Proteinköruern genügenden Raum finden. ${ }^{2}$ )

Wie schon gesagt, finden sich in der Grundmasse immer eiweissartige Stoffe, die aber bei fettreichen Samen gegen das Oel sehr zurücktreten, während bei fettarmen, wie bei Lupinus, die Proteinstoffe sogar überwiegen dürften. Doch liegen bei letzteren Samen die Proteinkörner weniger von einander entfernt, so dass der absolute Gehalt der Grundmasse an eiweissartigen Stofien auch hier kein bedeutender ist. Man bemerkt diese Proteinstoffe der Grundmasse, wie auch schon gesagt wurde, nach Entfernung des Oeles mit irgend einem Lösungsmittel zwischen den Proteinkörnern, als feinkörnige Masse, welche sich in Wasser immer nur theilweise, meist wohl zum geringsten Theil auflöst. Will man aber die Gesammtmenge der Proteinstoffe der Grundmasse unlöslich zurückbehalten, um entsprechende Reaktionen zur Constatirung ihrer chemischen Natur anzustellen, dann ist es am besten Samenschnitte in der früher beschriebenen Weise mit alkoholischem Sublimat zu behandeln (XXXVIII., 1, XXXVII., 2, 13 u. 14.). Man hat es nun in der Gewalt durch Jod oder Anilin die Proteinstoffe der Grundmasse deutlicher sichtbar zu machen und weun dieselben auch dann bei sehr fettreichen Samen nur als einzelne Körnchen erscheinen, so sind diese doch unbedingt durch freilich sehr weiche Masse mit einander verbunden, weil sie sonst unvermeidlich, wie ja das auch noch viel grössere isolirte Körnchen thun, Molecularbewegung zeigen müssten. Die Proteinstoffe und das Fett befanden sich also in der Grundmasse in innigster Mengung und nach Entfernung des letzteren bleiben jene gleichsam als ein Gerüst zurück, man kann

1) Die Formel würde sein $s^{3}\left[1-\frac{\pi}{6}\left(\frac{5}{6}\right)^{3}\right]$

2) Vergl. Sachs, Lehrb. II. Aufl, p. 54. 
die Grundmasse gewissermaassen mit Protoplasma vergleichen, in dem Wasser durch Oel ersetzt ist. Um zu entscheiden, ob auch andere Pflanzenstoffe, wie z. B. lösliche Kohlhydrate sich in der Grundmasse finden, reichen die zu Gebote stehenden Methoden nicht aus, doch ist mir dieses aus schon früher angegebenen Gründen sehr wahrscheinlich.

Bei allen Samen lässt sich nach Ausziehen des Fettes und dann folgerde Behandlung mit Wasser oder mit Kali ein, Grundmassennetz erbalten, in welchem an Stelle der Proteinkörner Hohlräume getreten sind. Dieses Netz verhält sich seinen Reaktioner nach ebenso wie die Häutchen, welche bcim Auflösen von Proteinkörnern zurückbleiben, doch kaun unan hier, wo eine grössere Menge von Proteinstoffen vorliegt, auch mit Millon'schem Reagens die Proteinreaktion erzielen (XXXVIII., 2; XXXVI., 14). Während bei vielen Pflanzen selbst bei Anwendung eines ziemlich concentrirten Kali's das Grundmassennetz immer erhalten wird, ist dieses bei anderen, selbst fettärmeren Samen, wie z. B. Tetragonolobus purpureus und Erodium Gruinum nicht der Fall und man muss hier die Proteinkörner mit Wasser, welches nur eine Spur Kali enthält, weglösen, wenn man ein vollkommenes Netz erhalten will Ist dieses aber einmal dargestellt, so ist es gegen Kali etwas resistenter, doch ergeben sich auch hier, wie bei den Hüllhäutchen Unterschiede, und während manche Netze von mässig concentrirter Kalilauge unter theilweiser Lösung leicht zerstört werden, wiederstehen andere, wic die von Paconia sehr lange. Bei sehr fettreichen Samen sind, wie schon bekannt, dem Oele der Grundmasse nur relativ geringe Mengen von Proteinstoffen beigemengt, und desshalb ist ein vollkommenes Grundmassennetz nichtimmer leicht darzustellen. Doch gelingt dieses z. B. bei Ricinus noch recht wohl, wenn man mit Alkohol ausgezogene Samenschnitte vorsichtig zuerst mit Wasser und dann mit sehr verdünntem Kali behandelt und endlich, zur besscren Sichtbarmachung des Grundmassennetzes, nach Auswaschen des Kalis mit Jod färbt. Doch ist bei Paranuss und bei Elaeis auch bei vorsichtigster Behandlung das Grundmassennetz fast immer nur in Bruchstücken zu erhalten. Uebrigens ist die Darstellung des Netzes bei den meisten Samen auch so möglich, dass man dem Samen unmittelbar entnommene Schnitte in kalihal. tiges Wasser wirft und orst nachher das Fett mit einem Lösungs. mittel entfernt.

Erinnern wir uns nun, dass beim Auflösen von einem jeden 
Proteinkorn ein Hüllhäutchen zurückbleibt, ein solches aber in den Maschenräumen nicht isolirt gefunden wird, so folgt hieraus sofort, dass auch das fragliche Hüllhäutchen an dem Aufbau des Grundmassennetzes participirt. Die Hoblräume in diesem sind, wie es ja auch zu erwarten ist, rings geschlossen, was daraus hervorgeht, dass die Einschlüsse bei hervorgebrachten Wasserströmungen in den ungeöffneten, Maschenräumen berumtanzen, aber wenn sie auch noch so klein sind, nicht hinausgespült werden können. Wenn man zu Samenschnitten, deren Proteinkörner in Wasser löslich sind, (Paeonia, Tragopogon u. a.) langsam Wasser treten lässt, sobewahren die Hohlräume zicmlich die Form der Proteinkörner und man erkennt nun als Begränzung jener eine hautartige Schicht, welche viel dichter als die übrige sehr weiche Substanz der Grundmasse ist; wir haben hier ein den Protoplasmabändern ganz ähnliches Bild vor uns. Ein gleiches Bild, nur dass jetzt die hautartige Begrenzung der Grundmasse vielleicht etwas weniger mächtig ist, erhält man aber auch, wenn man solche Stellen zur Beobachtung wählt, an welchen die Proteinkörner selbst herausgefallen waren, und so haben wir denn hier den schlagenden Beweis vor uns, dass das Grundinassennetz nicht von den Hüllhäutchen der Proteinkörner allein gebildet wird. Dieses wäre bei der Mächtigkeit des Netzes ohnchin nicht möglich und zudem wissen wir ja schon, dass die Proteinstoffe der Grundmasse wohl zum grössten Theil solche sind, welche sich in sehr verdünntem Kali nicht lösen. Bei den in Wasser nicht oder nur theilweise löslichen Proteinkörnern kommt man übrigens, wenn man deren Lösung mit kalihaltigem Wasser bewirkt, zu ganz gleichem Resultate, nur ist dann die Form des Hohlraumes nicht immer so genau die des Proteinkorns, was in noch geringerem Grado der Fall ist, wenn man das Maschennetz mit etwas Essigsäure behandelt und dann mit Jod färbt.

Man kann bei manchen Samen, wie bei Paeonia, Tragopogon, Cynoglossum, die hautartige Begrenzung der Grundmasse schon bemerken, wenn man Schnitte direct in Oel trägt, und solche Stellen zur Beobachtung wählt, wo Proteinkörrer herausgefallen sind. Auch lässt sich constatiren, dass diese hautartige Begrenzung der Grundmasse unmittelbar an die Proteinkörner anstösst, denn wenn auch durch die Strahlenbrechung an der Peripherie Zweifel entstehen könnte, so ist doch der Umstand entscheidend, dass man beim Bewegen des Deckglases Proteinkörner isoliren kann, an denen 
kleine Stücke der Grundmasse fest adhäriren. Gegen die Zellwand ist die Grundmasse gleichfalls hautartig begrenzt und zwar, wie die Entwicklungsgeschichte ergibt, durch den ursprünglichen Primordialschlauch der Zelle.

Bis dahin schwieg ich gänzlich von dem Zellkern, dessen desorganisirten Reste man bei allen untersuchten Samen als eine unregelmässig geformte Masse mehr oder weniger deutlich findet und zwar in dem Maschencetz wie eine Spinne in ihrem Netze hängend (XXXVI., 14, XXXVIII., 2 bei $n$ ). Dass dieses so sein muss, ist übrigens leicht verständlich und ich will hier auch nur die später durch die Entwicklungsgeschichte zu erhärtende Bemerkung machen, dass der eigentliche Protoplasmaleib der Zelle zwar in die Grundmasse aufgenommen, abcr keineswegs diese selbst ist. Bei vielen Samen ist es nicht schwer den Zellkern als zusammengeschrumpfte Masse zwischen den Proteinkörnern zu finden, sowohl wemu man Samenschnitte in Oel, als nach Behandlung mit Alkohol und Sublimat in Wasser liegend betrachtet, bei anderen Samen allerdings, wie bei Lupinus Arten, muss man schon sorgfältig suchen, bis man sich auch hier überzeugt, dass ein Zellkern vorhanden ist. Auch beweist ja die zurückbleibende, allerdings desorganisirte Masse des Zellkerns sogleich, dass dieser im Gegensatz zu den Proteinkörnern, zum guten Theil aus Proteinstoffen besteht, welche sich wie die unlösliche Modifikation verhalten. Einzelne grosse Proteinkorner, deren schon bei den Einschlüssen Èrwähnung geschah, haben gleichfalls nichts mit dem Zellkeru zu thun, den ich ebenso auch neben den krystalloidführenden Protcinkörnern nachweisen konnte. Nur bei Sparganium ramosum, dessen Endospermzellen dicht mit Stärke erfült sind und zwischen dieser nur ein grosses, mit wenig Hüllmasse umgebenes Krystalloid erkennen lassen, fand ich eincu Zellkern nicht. Es soll denn auch hier nach Trécul') das Krystalloid in oder aus dem Zellkern gebildet werden, was allerdings so gut wie bei Lathraea möglich ist, jedoch wohl sicher nicht in der von Trécul angegebenen Weise, dass das einemal das Kernkörperchen, das anderemal der ganze Zellkern sich zum Krystalloid umbildet. Auch in den stärkeführenden Samen der Gräser Leguminosen u. a. ist der Zellkern immer zwischen den Stärkekörnern nachzuweisen. In dem eingeschrumpften Zellkern habe

1) Annal. d. sc. natur. 1858, IY. ser. T. x. p. 57. 
ich aber niemals derartige Einschlüsse, wie sie sich in den Proteinkörnern finden, mit Sicherheit nachweisen können, es sei denn dass bei Sparganium das Krystalloid wirklich in dem Zellkern entstehe, was freilich noch durchaus zweifelhaft ist, denn hier finden sich allerdings in der spärlichen Hüllmasse einige kleine Globoide.

Bei manchen sehr fettreichen Samen kommt in Krystallen ausgeschiedenes Fett in der Grundmasse vor, was Hartig I) bereits in dem Samen einer unbestimmten Palmenart, ich selbst bei Elaeis guyanensis, Bertholletia und Myristica moschata beobachtete. Jn den Samen der beiden erstgenannten Pflanzen sind die schmalen Nadeln büschelig gruppirt oder liegen wie Bündel von Raphiden mehr oder weniger parallel nebeneinander und erreichen zuweilen cine solche Länge, dass sie die ganze Zelle durchsetzen (XXXVI. 16). Dabei können sie etwas hin und her gebogen sein, wodurch es ihnen eben möglich wird, zwischen den, bei den fraglichen Samen allerdings ziemlich weit auseinander liegenden Proteinkörnern, sich von einer Zellwand zur anderen zu erstrecken. Von der Fettnatur dieser Krystalle kann man sich leicht durch das Schmelzen beim Erwärmen und durch die Löslichkeit in Benzol überzeugen. Zahlreicher sind noch die Fettkrystalle bei Myristica moschata, bei welcher die Zellen des Albumens gleichfalls krystalloidführende Proteinkörner, von denen eines besonders gross ist, ausserdem aber auch Stärkekörner enthalten. Zwischen diesen geformten Körpern ist nun die Grundmasse förmlich zu büschelig oder strahlig gruppirten Nadeln erstarrt (XXXVIII. 10). Dieses hat denn auch zur Folge, dass auf frische Samenschnitte Wasser nur sehr langsam desorganisirend wirkt, wenn man nicht durch Erwärmen das Schmelzen des Fettes herbeiführt.

Da man aus der chemischen Analyse die in den betreffenden Samen vorkommenden Glyceride der Fettsäure kennen kann, so würde man hieraus schon einen Schluss auf die nähere Zusammensetzung der Fettkrystalle ziehen und sich dann durch Bestimmung des Schmelzpunktes völlige Gewissheit verschaffon können, doch hat dieses nur so geringes physiologisches Interesse, dass ich nicht näher darauf eingehe. Sicherlich wird man aber auch in manchen fettreichen Samen, bei denen bei mittlerer Temperatur sich kein auskrystallisirtes Fett findet, solches durch Temperaturerniedrigung erzeugen können.

1) Hartig. Bot. Zeit. 1856. p. 304. Hartig nennt diese Fettkrystalle Stearopten, doch versteht man meines Wissens unter diesem Namen nur den erstarrenden Theil äetherischer Oele oder überhaupt feste ätherische Oele. 


\section{Allgemeines.}

Ueber die Gestalt der Proteinkörner ist nicht viel zu sagen. Im allgemeinen sind sie rundlich, ellipsoidisch oder eiförmig, dabei mehr oder weniger polygonal und dieses durchschnittlich um so mehr, je ärmer an Oel und Grundmasse ein Same ist. Längliche Proteinkörner finden sich u.a. bei Scorzonera hispanica (XXXVI. 13) zwischen anderen, und bei Gramineen blciben zuweilen bei Einwirkung von Wasser einige der sehr kleinen Proteinkörner perlschnurartig aneinander gereiht. Fast alle Proteinkörner sind farblos, gelblich bis braunroth gefärbte fand ich in der Toncobohne, etwas grünliche bei Pistacia und dem Samen einer Weidenart; gelb gefärbte Krystalloide bietet Myristica. Nach Hartig*) kom. men blaue Proteinkörner in den äusseren Zellen des Samens bei einer Varietät von Cheiranthus annuus, bei Panax und Knautia, ebenso nach Trécul ${ }^{2}$ ) bei Mathiola incana und parviflora vor. Auch rosenrothe Proteinkörner führt Hartig von einigen Pflarzen an.

Schon eingangs theilte ich mit, dass die Mittelgrösse der Proteinkörner etwa zwischen 3 und 12 Mikromill. sich bewegt, aber auch sehr kleine Körner, von weniger als ein Mikromill. Durchmesser sich finden. Namentlich sind die Proteinkörner der vorwiegend stärkeführenden Samen von geringer Grösse, doch finden sich auch in ölreichen Samen neben grösseren Proteinkörnern solche von winziger Grösse, entweder häufiger, wie bei Coriandrum (XXXVII., 14), Vitis, (XXXVIII., 6), Scorzonera, oder auch nur gelegentlich und nicht in allen Zellen. Ferner kann die Grösse der Proteinkörner derselben Zelle sich in engeren Grenzen bewegen oder auch, wie dies schon mehrfach bemerkt wurde, ein Korn durch besondere Grösse ausgezeichnet sein und z. B. bei Vitis bis 40 (XXXVIII, 6), bei den krystalloidführenden Proteinköruern ron Elaeis sogar bis 55 Mikromill. grössten Durchmesser erreichen. Ein solches grosses Proteinkorn kann auch, wie das schon früher bemerkt wurde, durch die Gestalt seiner Einschlüsse von den kleineren Körnern abweichen oder auch mit diesen übereinstimmen. Für beides liefert u. a. der Samen von Vitis (XXXVIII, 6) und von Silybum (XXXVIII.,

1) Hartig, Pflanzenkeim, p. 109.

2) Trécul, l. c. p. 354 . 
1) Beispiele, indem hier in manchen Zellen die grossen Proteinkörner grosse Krystalldrusen, die kleineren Einzelkryställchen einschliessen, in anderen Zellen hingegen in allen Proteinkörnern Globoide gefunden werden. Da sich das grössere Korn weder seinem Ursprung, noch seinem physiologischen Werth nach nicht von den anderen Proteinkörnern unterscheidet, so liegt auch kein Grund vor, demselben einen eigenen Namen beizulegen, wie dies Hartig, welcher es Solitär bezeichnet, gethan hat Dieses ist um so weniger gerechtfertigt, als sich bei manchen Samen, z. B. Lupinus polyphyllus in verschiedenen Zellen des Samenschnittes ein durch Grösse ausgezeichnetcs Proteinkorn finden oder auch fehlen kann. Uebrigens trifft man solche durch Grösse hervorragende Körner sowohl bei krystalloidführenden, als krystalloidfreien Proteinkörnern. Ich habe natürlich hier nur wirkliche Proteinkörner im Auge gehabt. Es kommt aber bei kleinen Proteinkörnern vor, dass sie vom Zellkern an Grösse übertroffen werden, der dann offenbar auch als Solitär von Hartig bezeichnet wurde. Dieses ist häufig der Fall bei sehr kleinen Embryonen eiweisshaltiger Samen, aber auch bei vielen Samen in den peripherischen Zellen des Albumcns und ebenso des Embryos eiweissloser Samen, da in diesen Zellen die Proteinkörner oft nur klein sind. Der Umstand, dass die Proteinstoffe des eingetrockneten Zellkerns sich immer nur zum Theil in verdünntem Kali lösen, erlaubt den auch habituell abweichenden Zellkern immer von Proteinkörnern zu unterscheiden.

Hier muss ich auch die von Hartig seinen Solitären angereihten Füllkörner erwähnen, obgleich sie faktisch mit den Proteinkörnern gar nichts zu thun haben. Von diesen sollen sie sich nach Hartig') in mancher Beziehung unterscheiden, namentlich auch dadurch dass sie in vereinzelten, Reihen bildenden Zellen vorkommen und meist gefärbt sind. Bei Theobroma Cacao sind manche Zellen fast ganz mit stahlblauer Masse erfüllt, welche sich beinahe ganz in Wasser löst und neben Farbstoff wohl wesentlich gummiartiger Natur sein mag; hingegen dürtten die goldgelben Massen in manchen Zellen der Aussenschicht der Cotyledonen von Laurus Pichurin wohl wesentlich ein Gummiharz sein und die Füllkörner bei Myrtus Pimenta sind die, eine Schicht un.ter der Epidermis der Samenlappen bildenden, oelführenden Räume.

1) Hartig, Botanische Zeitung, 1856, p. 266 und 330. Pflanzenkeim p. 110. 
Bei Juglans und Dipterix odorata, welche Hartig auch aufführt, kann ich nichts, was auf dessen Füllkörner passte, finden. Einer näheren Prüfung habe ich übrigens diese, den Proteinkörnern so fremden Zellcontenta nicht unterzogen.

Vorhin schon erwähnte ich, dass die Proteinkörner der äusser. sten oder einiger äusseren Zellschichten des Endosperms gewöhnlich kleiner sind und ebenso ist es auch in den Cotyledonen eiweissloser Samen, bei denen im hypocotylen Glied und dem Ẅürzelchen die Proteinkörner meist von geringerer Grösse gefunden werden als in den Samenlappen. Im Embryo eiweisshaltiger Samen sind die Proteinkörner immer sehr klein, wenn jener eine relativ geringe Grösse hat (Ranunculaceen, Convallaria, Umbelliferen u. a.), gewöhnlich wachsen aber die Proteinkörner, wenn der Embryo zunimmt und wenn dieser und das Albumen nicht zu sehr in ihrer Grösse abweichen, so gilt dieses auch meist für die Proteinkörner (Cephalaria procera, Plantago arenaria, Pinus Pinea). Die grössten Proteinkörner finden sich wohl bei solchen Samen, deren Embryo oder Albumen umfangreich ist; doch ist es keineswegs Regel, dass Grössenabnahme der Organe auch eine Verkleinerung der Protein. körner mit sich bringt; so sind z. B. die Proteinkörner von Linum usitatissimum viel grösser als die der Wallnuss. Innerhalb derselben Familie trifft man aber öfters die Proteinkörber mit der Grössenzunahme des Samens wachsend, obne dass dieses übrigens eine durchgreifende Regel wäre.

Das bis dahin Gesagte gilt sowohl für die Proteinkörner mit als ohne Krystalloide. Letztere sind keineswegs bestimmten Familien eigenthüınlich, denn wenn auch z. B. bei Euphorbiaceen Coniferen und Cucurbitaceen alle von mir untersuchten Pflanzen Krystalloide aufzuweisen hatten, so ist dieses doch bei anderen Familien keineswegs der Fall. Ich erwähne hier nur Aethusa Cynapium, welche allein von sechs untersuchten Umbelliferen Kry. stalloide besass und Sabal Adansoni, welche Pflanze frei von Krystalloiden ist, die sich bei Elaeis und anderen Palmen in so ausgezeichneter Weise finden.

Soweit ich darauf untersuchte, kommen krystalloidführende Proteinkörner im Embryo und Albumen, wenn solches vorhanden, gleichzeitig ror, und bei Opuntia Rafinesquiana feblen die Krystalloide in dem sehr stärkereichen Eiweiss. Uebrigens schliesst die Anwesenheit von Stärke die Möglichkeit der Existenz von Proteinkörnern nicht aus, wie Myristica moschata und Sparganium ramosum 
beweisen- - Wo Krystalloide vorhanden, da trifft man diese der Regel nach in allen grösseren Proteinköruern, indess kommen solche bei Aethusa Cynapium auch frei von Krystalloiden vor. Sehr kleine krystalloidfreie Proteinkörner werden häufiger neben krystalloidführenden gefunden.

Die grosse Verbreitung der Krystalloide in Samen zeigt das nachstehende Verzeichniss der Pflanzen, bei welchen solche bis jetzt beobachtet wurden. Die Familie ist dann einfach genannt, wenn aus derselben keine Pflanze ohne Krystalloide, wenigstens aber drei mit Krystalloiden bekannt sind. Nach eigenen Beobachtungen habe ich nun folgende Pflanzen und $\mathrm{Fa}$ milien zu rerzeichnen: Euphorbiaceae, Sesameae, Solaneae, Cacteae, Papareraceae, Cucurbitaceae, Conifereae, Salvia sp., Fumariaceae, Linum usitatissimum, Celtis australis, Viola sp., Campanulaceae, Myrica cerifera, Myristica moschata, Plantago arenaria, $\mathbf{P a}$ rietaria erecta, Passiflora vespertilio, Sparganium ramosum, Ruta graveolens, Bertholletia excelsa. - Aus solchen Familien, bei denen einzelne Arten Krystalloide enthielten, anłere aber frei davon waren, sind anzuführen: Potentilla sp., Aethusa Cynapium, Valerianella Auricula, Elaeis guyanensis, Cocos sp., Asphodelus fistulosus. - Nach Hartig kommen ausserdem Krystalloide vor bei: T'ournefortia, Saussurea, Cladium, Carex Grayana, Marica, Vaccinium, Arbutus, Casuarina, Morus, Ulmus, Nyssa, Vinca, Magnoliaceae; nach Trécul ferner noch bei Sideroxylon spinosum, Myristica sebifera und Basella alba, und noch von Holle bei: Urtica, Typhaceae, Menispermum canadense, Caprifoliaceae, Polygaleae.

Es wurde schon mehrfach des Zusammenvorkommens von Stärke und Proteinkörnern gedacht und zwar treffen wir in dem relativen Verhältniss alle möglichen Abstufungen bei verschiedenen Samenarten von winzigen Stärkekörnern (XXXVIII., 19, vergl. auch XXXVIII., 20) zwischen grossen Proteinkörnern bis zu dem umgekehrten Extreme, welches u. a. Phaseolus (XXXVII., 16b) und andere Leguminosen, sowie die Gramineen darbieten. Bei diesen ist dann die Vertheilung der stickstofffreien und stickstoffhaltigen Reservestoffe gerade die umgekehrte wie bei ölreichen Samen, indem hier die Stärkekörner gleichsam an Stelle der Proteinkörner lagern, welche sich in winziger Grösse zwischen jenen finden. Namentlich sind bei manchen Gräsern, wie Zea, Eleusine Coracana die Proteinkörner sehr klein und zwischen den oft sehr dicht gelagerten Stärkekörnern kann von. eigentlichen Proteinkörnern 
nicht mehr die Rede sein, indem die eiweissreichen Stoffe einfach zu einer etwas körnigen $\mathrm{Z}$ wischenmasse eintrockneten. Uebrigens verhalten sich auch die kleinen Proteinkörner von Gräsern und Leguminosen denen fettreicher Samen gleich, doch scheinen den winzigen Proteinkörnern öfters Einschlüsse zu fehlen, welche bei anderen als sehr kleine Globoide zu erkennen sind.

Da Proteinkörner in keinem Samen fehlen, so könnte natürlich nur eine Uebersicht über ihr Vorkommen mit und ohne Stärke ein Interesse haben. Ueber die Vertheilung der Stärke in den Samen besitzen wir aber durch Nägeli ${ }^{1}$ ) sehr ausführliche Mittheilungen, auf die ich einfach verweisen kann; ich erwähne nur, dass nach den Untersuchungen dieses Forschers die Samen vou ungefähr $9 / 10$ aller Phanerogamen frei von Stärke sind.

Dass auch inncrhalb derselben Familie stärkefreie und stärkehaltende Samen vorkommen können, ist z. B. für die Leguminosen bekannt, es trifft sich aber auch ausnahmsweise dass ein sonst stärkehaltiger Samen frei davon ist. So fand ich es einmal bei Phragmites communis, in dessen Endospermzellen mittelgrosse Proteinkörner in fettreicher Grundmasse lagen und Nägeli ${ }^{2}$ ) führt noch mehrere Gräser mit ansnahmsweise stärkefreiem Albumen an. Die ein oder zwei äussersten Zellschichten des Endosperms der Gräser scheinen übrigens immer frei von Stärke zu sein. ${ }^{3}$ )

Gewöhnlich ist bei eiweisshaltigen stärkeführenden Samen der Embryo frei von Stärke und enthält kleine Proteinkörner in fettreicher Grundmasse. Stärke findet sich aber im Schildchen von Zea Mais, jedoch nicht in dem an das Endosperm stossenden $\mathrm{Cy}$. linderepithel, nach v. Holle ${ }^{4}$ ) auch bei Sorghum sacharatum, ferner auch im Ėmbryo von Viscum album und dann nach Nägeli ${ }^{5}$ ) bei den Cycadeen und meisten Erythroxyleen. Höchst selten kommt aber Stärke im Embryo vor wenn das Eiweiss stärkefrei ist, ich kenne hier nur die Angaben $\mathrm{N}$ äge elis ${ }^{6}$ ) für Forestiereen u. Erycibeen.

1) Nägeli, Stärkekōiner, p. 385 ff.

2) Nägeli, 1. c, p. 536.

3) Vergl. auch Saclıs, Bot. Zeitung 1862, p. 145 für Zea Mais:

4) v. Holle, Vergl. Uebersicht etc., 1. c, p. 39 d. Separatabzugs.

5) Nägeli, loc., p. 386.

6) Nägeli, I. c., p. 386 . 


\section{Die Ursachen der Löslichkeit der Proteinkörner.}

Durch seine zahlreichen, auf alle bekannten pflanzlichen Proteinstoffe, das Albumin ausgenommen, sich erstreckende Untersuchungen hat Ritthausen ${ }^{1}$ ) gezeigt, dass Legumin und die verwandten eiweissartigen Körper (Conglutin, Glutencasein), Glutenfibrin und Mucedin im reinen Zustand in Wasser so gut wie unlöslich sind; nur der Pflanzenleim (Gliadin) löst sich in höchst geringer Menge in kaltem Wasser. Die genannten Proteinkörper sind es nun gerade, welche in den Samen ganz vorwiegend als Reservestoffe gefunden werden, während das Albumin der eiweissartige Körper ist, welcher in der lebensthätigen Pflanze überwiegend auftritt, in den Samen indess, soweit vorliegende Untersuchungen ein Urtheil erlauben, in geringerer Menge vorkommt, wohl auch gänzlich fehlen kann. Das Albumin kann man demnach, wie es auch Mayer ${ }^{2}$ ) schon gethan, als functionirenden Proteinstoff den übrigen eiweissartigen Körpern, den Reserveproteinstoffen, gegenüber stellen.

Albumin soll auch in reiner Form in Wasser löslich sein, wie Hoppe-Seyler ${ }^{3}$ ) den gegentheiligen Angaben von Denis gegenüber mit aller Sicherheit für das thierische Albumin angibt, welches dem pflanzlichen höchst nahe steht, wenn nicht damit identisch ist.

Wenn nun dennoch Wasser aus Samen von den für sich unlöslichen Proteinstoffen oft sogar sehr grosse Mengen auflöst, so muss jedenfalls ein lösendes Vehikel im Spiele sein und in der That wurde eine schon von v. Liebig und Rochleder ausgespro-

1) Die Untersuchungen Ritthausens sind der Bearbeitung der betreffenden Proteinstoffe bei "Husemann, die Pflanzensioffe 1871, p. $619 \mathrm{ff}^{\text {«. }}$. zu Grunde gelegt und ist hier auch die Literatur nachgewiesen. Das Legumin oder Pflanzencasein früherer Autoren wurde von Ritthausen in Legumin, Conglutin und Glutencasein unterschieden, doch gebrauche ich hier die Bezeichnung Pflanzencasein oder Legumin in ihrem früheren Umfang. - Die Angabe Mayers, (Lehrb. der Agrikulturchemie 1871, p. 206) dass das Legumin in Wasser sich löse, ist nicht richtig, da nach Ritthausen (Journ. f. prakt. Chemie, Bd. 103, p. 215) reines Legumin in Wasser beinahe ganz unlöslich ist. Auch wird reines Legumin beim Kochen mit Wasser in eine unlösliche Modifikation verwandelt.

2) A. Mayer, Lehrb. d. Agriculturchemie, 1877. p. 191.

3) Hoppe-Seyler, Handb. der physiol. u. pathol. chem. Analyse, 1870. p. 200. Zu vergl. auch Gautier, Chem Centralblatt 1871, p. 583. 
chene Ansicht, von Ritthausen ${ }^{1}$ ) in neuerer Zeit zunächst für das Lepumin erwiesen, dass nämlich die Löslichkeit dieses durch phosphorsaures Kali und Kali bedingt, der Menge dieser Körper, welche in den wässrigen Auszug der Samen übergeheu, proportional sei. Gleiches gilt nun offenbar aber auch für die anderen als Reserveproteinstoffe bezeichneten eiweissartigen Körper und Ritthausen schreibt auch deren Uebergang in die wässrigen Auszüge der Samen dem lösenden Einfluss von phosphorsaurem Kali und Kali zu.

Wir erfuhren oben, dass die Proteinkörner sich gegen Wasser sehr verschieden verhalten, die mancher Samen sich in demselben ganz oder theilweise lösen, während andere Proteinkörner von Wasser gar nicht angegriffen werden. Da diese Verschiedenheiten in der Löslichkeit auch bei den Proteinkörnern solcher Samen vorkommen, welche sicher kein Albumin enthalten, so kann man schon hieraus folgern, dass die verschiedene Löslichkeit der Proteinkörner in Wasser in solchen Fällen von dem ungleichen Vorrath an phosphorsaurem Kali und Kali abhänge. Der Beweis hierfür lässt sich aber auch auf mikrochemischem Wege führen, sobald wir nur Mittel und Wege finden, die genannten, die Lösung vermittelnden Körper zu entfernen oder wenigstens unschädlich zu machen. Letzteres ist mir denn auch auf sehr einfache Weise gelungen, indem ich Samenschnitte mit absolutem Alkohol, welchem ein wenig concentrirte Schwefelsäure zugesetzt ist einige Zeit digerire. Es kommt dabei auf den Schwefelsäuregehalt nicht genau an, ich habe meist auf etwa $15 \mathrm{CC}$. Alkohol 4 bis 5 Tropfen concentrirte Schwefelsäure angewandt. Phosphorsaures Kali, welches in Alkohol unlöslich ist, wird bei gleichzeitiger Gegenwart von Schwefelsäure zerlegt in gleichfalls in Alkohol unlösliches schwefelsaures Kali und in Phosphorsäure, welche von dem Alkohol aufgenommen wird; aber auch das Kali, welches mit den Proteinstoffen allenfalls in Verbindung ist, wird in schwefelsaures Kali verwandelt werden. Durch Einlegen der Schnitte in reinen Alkohol wird dann Phosphorsäure und Schwefelsäure völlig entfernt, das zurückbleibende schwefelsaure Kali wirkt aber in keiner Weise lösend auf Proteinkörper cin; vom schwefelsauren Natron ist es ja sogar bekannt, dass man durch concentrirte Lösungen dieses Salzes manche eiweissartigc Körper aus ihren Auflösungen abscheiden kann.

1) Ritthausen, Jouru. f. prakt. Chemie, 1868. Bd. 103, p. 275. 
Der Erfolg entsprach vollkommen der theoretischen Schlusgfolgerung, denn bei einigen 20 Samen, deren Proteinkörner in Wasser ganz oder theilweise löslich waren, blieben diese nach der angegebenen Behandlung immer in Wasser erbalten; es gilt dieses anch für die löslichen Hüllmassen bei krystalloidführenden Proteinkörnern. Keineswegs war aber hierbei die unlösliche Modifikation der Proteinstofie entstanden, denn auch nur eine Spur von Kali enthaltendes Wasser brachte die unlöslich gemachten Proteinkörner ebenso leicht in Auflösung wie die an sich unlöslichen anderer Samen, natürlich immer das schon bekannte Hüllbäutchen zurücklassend. Doch wird durch die Behandlung mit schwefelsäurehaltigem Alkohol die Entstehung der unlöslichen Modifikation eiweissartiger Körper sehr beschleunigt, weil eben Alkalien und phosphorsaure Alkalien die Herbeiführung des coagulirten 'Lustandes, sowohl durch Hitze, als wasserentziehende Mittel, erschweren, oder auch ganz verhindern können. Desshalb darf auch die Digestion nicht zu lange fortgesetzt werden; meist sind 3 bis 5 Stunden ausreichend und eine Ausdehnung über 24 Stunden ist nicht räthlich, da dann bei manchen Proteinkörnern die Bildung der unlöslichen Modifikation begonnen haben kann. Ob dieses geschehen, kann man $\mathrm{ja}$ in allen Fällen durch das Verhalten gegen sehr verdünntes Kali entscheiden.

Bei der Digestion mit Alkohol und Schwefelsäure verschwinden aber auch, wie schon früher mitgetheilt wurde, die Globoide, indem die gepaarte Phosphorsäure vom Alkohol aufgenommen wird, und körnige Massen der Sulphate von Magnesia und Kalk bleiben, welche indess oft gar nicht oder kaum wahrzunehmen sind; die Krystalle von oxalsaurem Kalk erfahren aber bei kürzerer Digestion keine Veränderung. Die Proteinkörner mit Globoiden haben desshalb auch schon in Alkohol liegend ein fremdartiges Aussehen durch das Verschwinden ihrer Einschlüsse angenommen, wo diese aber Krystalle sind, da ist kein Unterschied, auch in der Lichtbrechung, gegen solche Proteinkörner zu constatiren, welche mit Alkohol allein behandelt wurden. Wenn man nun solche Samenschnitte, in denen in Wasser lösliche Proteinkörner mit krystallinischen Einschlüssen vorhanden sind, nach Behandlung mit schwefelsäurehaltigem Alkohol und sorgfältigem Abwaschen mit Alkohol in Wasser bringt, dann nach einiger Zeit in Alkohol zurückträgt und nach längerem Liegen mit anderen Schnitten vergleicht, die ans dem schwefelsäurehaltigen Alkohol unmittelbar in reinen $\mathrm{Al}$ - 
- kohol kamen, so schcint ein klciner Unterschied in der Lichtbrechung zu Ungunsten der mit Wasser behandelten Körner immer rorhanden zu sein (Lupinus varius, Silybum, Coriandrum sativum, Cephalaria procera, Vitis vinifera u. a). Doch war diese Differenz bei allen untersuchten Samen stets eine äusserst geringe, so dass ich vielfach nicht einmal mit Sicherheit entscheiden konnte, ob wirklich ein Unterschied vorliege und ob Eiweissstoffe hinweggelöst wurden, wage ich nicht zu bchaupten. Denn einmal müssen die auch nur in höchst minimalen Mengen in gewissen Proteinkörnern sich findenden löslichen Kohlehydrate (und Pectinstoffe?) bei den vorgenommenen Operationen durch das Wasser entfernt sein und dann kann wan nicht wissen, ob die etwas aufquellenden Proteinkörner durch Alkohol wieder ganz rollkommen auf ihr früheres Aussehen zurückgeführt werden. Die nur sebr kleincn Mengen von schwefelsaurem Kali (aus phosphorsaurem Kali und Kaliverbindungen der Proteinstoffe stammend), welche in Wasser sich auflösen, kann man übrigens ruhig vernachlässigen. Da die Proteinstoffe der krystallinische oder kugelige Einschlüsse fühıcnden Proteinkörner in jeder Beziehung vollkommen übereinstimmen, so kann das erhaltene Resultat auch ohne Bedenken auf die Proteinkörner mit Globoiden übertragen werden, um so mehr als man auch an 'diesen die Gewissheit gewinnt, dass ein irgend erhebliches Quantum von Proteinstoffen nach Behandlung mit Alkohol und'Schwefelsäure jedenfalls nicht durch Wasser gelöst wird.

Die hier eingeschlagene Methode erlaubt zwar nicht direkt Phosphorsäure und Kali zu erkennen, aber auf den, auf chemischem Wege erhaltenen Resultaten fussend, ist sie durchaus beweisend. Denn die Chemie lehrt uns, dass die Reserreproteinstoffe für sich in Wasser unlöslich sind, aus den Samen aber nur desshalb durch Wasser in kleineren oder grösseren Mengen aufgenommen werden, weil phosphorsaures Kali und Kali die Lösung vermitteln, welche Körper aber durch unser Verfahren in solche Verbindungen ühergeführt werden, dass sie nicht mehr lösend wirken können. Es ergibt sich nun auch, dass die genannten Lösungsvehikel in den Proteinkörnern selbst enthalten sind, denn wenn diese völlig isolirt sind, so lösen sie sich ebenso gut, als wenn sie in der Grundmasse liegen, vorausgesetzt natürlich, dass sie überhaupt in Wasser löslich sind. Auch geht aus unseren Resultaten hervor, dass erhebliche Mengen von Pflanzenalbumin nicht in den untersuchten Proteinkörnern rorhanden waren, wenn weuigstens die 
Untersuchungen über d. Proteinkörner und d. Bedeutung d. Asparagins etc. 495

chemischen Angaben richtig sind, dass das Albumin sich auch im reinen Zustand im Wasser löst.

Wir haben nun zu erörtern, wie sich die bei manchen Samen sogar starke saure Reaktion mit der Rolle verträgt, welche dem phosphorsauren Kali und dem Kali bezüglich der Lösung der Reserveproteinstoffe zugeschrieben wurde. $\mathrm{Zu}$ dem $\mathrm{Zwecke}$ müssen wir uns zunächst mit dem Verhalten des Kalialbuminates und des Caseins gegen Säuren bei Anwesenheit phosphorsaurer Alkalien vertraut machen und wenn auch hier die Untersuchungen mit thierischen Proteinstoffen vorgenommen wurden, so kann es doch nicht zweifelhaft sein, dass sich die gleichnamigen Eiweisskörper des Pflanzenreichs gleich verhalten, da sie ja denen des Thierreichs so nahe verwandt sind, dass sie vielfach für identisch gehalten wurden und wohl auch noch werden. Wird Casein mit möglichst wenig Kali gelöst, so scheidet sich auf Zusatz von wenig Säure sofort wieder Casein aus, nicht aber, wenn phosphorsaures Natron oder Kali zugegen ist, denn dann entsteht sauer phosphorsaures Alkali und nicht eher wird bei vorsichtigem $\mathrm{Zu}$ satz der Säure das Casein ausgefällt, bis alles Alkaliphosphat in saures Salz verwandelt und noch ein kleiner Ueberschuss von Salzsäure oder Essigsäure zugegeben ist. Ganz gleich verhält sich aber, wie Rolle ${ }^{1}$ ) zeigte, das Kalialbuminat nach Versetzung

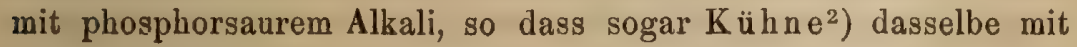
dem Casein der Milch identisch hält. Wir erfahren hieraus, dass die Kaliverbindung von Eiweissstoffen auch in einer Lösung existiren kaun, welche durch sauer phosphorsaures Alkali sehr stark sauer reagirt und dass die Kaliverbindung erst dann durch Säure bei Gegenwart von Alkaliphosphaten zersetzt wird, wenn diese vollkommen in saures Salz verwandelt sind. Nun wissen wir aber in der That, dass der wässrige Auszug der Samen stark sauer reagirt und dabei doch erhebliche Mengen von löslichen Proteinstoffen enthalten kann, wie denn z. B. Wasser aus den Samen der gelben Lupine 10,9 Procent von den 61,3 Procent der vorhandenen Eiweissstoffe aufninmt. ${ }^{3}$ ) Jedenfalls kann in diesem Falle die Lösung der Proteinstoffe nicht durch basisch phosphorsaures Alkali ge-

1) Rollet, Sitzungsber. d. Wiener Akademie 1860, Bd. 39, p. 547.

2) Kühne, Lehrbuch d. physiol. Chemie 1867. p. 277 u. 565.

3) Nach Beye r, Landwirthschftl. Versuchsstationen 1867, Bd. 9, p. 173. 
schehen, wie Ritthausen ${ }^{1}$ ) auch für die Samen der Lupine annimmt, indess wäre es ja denkbar, dass freie Säuren als Lösungsmittel dienten. Nun kommen allerdings Aepfelsäure und Oxalsäure $^{2}$ ) in der gelben Lupine vor, allein diese können nicht das lösendo Mittel sein, denn auch nach dem Ausziehen ron Samenschnitten mit Alkohol, in dem sich die genannten Säuren, wie auch die anderen im Pflanzenreich bäufiger vorkommenden organischen Sauren lösen, ${ }^{3}$ ) nimmt $W$ asser aus den Proteinkörnern des Samens unserer Pflanze ebenso viel als zuvor auf. Es wird aber auch durch Erschöpfen gepulverter Samen mit Alkohol die saure Reaktion des Rückstandes nicht aufgehoben, kann also jedenfalls nicht oder wenigstens nicht allein von freion organischen Säuren herrühren. Möglich dass saure in Alkohol unlösliche Salze dieser vorhanden sind, allein von solchen ist es nicht bekannt, dass sie Lösungsmittel für Proteinstoffe sind und so kommen wir denn nothwendig auf saures phosphorsaures Kali zurück, welches sich ja ohnehin bildet, wenn Säuren, auch Oxalsäure oder Aepfelsäure, mit Alkaliphosphaten in Berührung kommen; dass aber Kali und Phosphorsäure immer hohe Procentsätze von Samenaschen ausmachen ist bekannt.

Dass bei Lupinus die Proteinkörner selbst sauer reagiren ist an und für sich nicht sehr entscheidend, da auch reines Legumin nach Ritthausen ${ }^{4}$ ) eine sauer reagirende phosphorsäurehaltige Proteinverbindung ist. Indess muss das saure Alkaliphosphat bei Lupinus schon in den Proteinkörnern selbst enthalten sein, da sich diese bezüglich ihrer Löslichkeit in Wasser ganz gleich verhalten, gleichviel ob sie ganz isolirt oder in der Grundmasse liegen, was doch gewiss nicht der Fall sein könnte, wenn in letzterer etwa organische Säuren oder saure Salze dieser aufgespeichert wären, welche erst bei Zutritt vou Wasser die Entstehung von saurem phosphorsaurem Kali veranlassten, dessen Existenz in dem wässrigen Auszug aber absolut sicher ist.

Erst jetzt tritt die Bedeutung der Phosphorsäure für die Lösung der Proteinstoffe in das rechte Licht; wir können nicht, wie es Ritthausen that, sagen dass immer basisch phosphorsaure Alkalien die Lösung der Proteinstoffe aus Samen vermitteln,

1) Journ. f. prakt Chemie 1868, Bd. 103, p. 215.

2) Ritthausen, Journ. f. prakt. Chemie 1871, II. Reihe, Bd. 3, p. 339 ff.

3) Anorganische Säuren kommen nicht im freien Zustande in Samen vor.

4) Rittbausen, Journ. f, prakt. Chemie 1868, Bd. 103, p. 211. 
denn wenn dieses auch in concreten Fällen möglich ist, so ist es doch für andere Samen, wie Lupinus und Paeonia, ebenso gewiss, dass saures Kaliphosphat die lösende Wirkung ausübt. Fraglich ist es nun freilich ob dabei die Proteinstoffe der Körner Kaliverbindungen sind oder nicht. Man könnte dieses vielleicht folgern, wenn man für einen gegebenen Fall die Natur der Pro. teinstoffe der Körner kennen würde und dann wüsste ob etwa der fragliche reine Proteinstoff nicht, wohl aber dessen Kaliverbindung in sauer phosphorsaurem Kali löslich ist. Doch bier hat die Chemie noch nicht vorgearbeitet, wenn aber dieses geschehen, dann wird es auch gelingen noch weiter mit mikrochemischen Methoden in die angeregten Fragen einzudringen. Es gibt noch einen weiteren schlagenden Beweis, dass saures Kaliphosphat die Lö* sung der Proteinkörner veranlassen kann. Wenn man nämlieh Samenschnitte von Paeonia oder Allium Cepa mit absolutem Alkohol digerirt, welchem statt der Schwefelsäure Phosphorsäure zugesetzt ist, so sind auch nach mehrtägigem Stehen die Proteinkörner nach wie vor in Wasser löslich, obgleich hier unter allen Umständen basisches Phosphat in saures verwandelt wurde und da anzunehmen, dass Kaliverbindungen von Eiweisskörpern hierbei zerlegt werden, so scheint es allerdings, dass gewisse Proteinstoffe für sich in saurem Kaliphosphat löslich sind. Da ich indess nicht auf sicherem chemischen Boden stehe, so nehme ich hier von allen Schlussfolgerungen Abstand, die man vielleicht daran knüpfen könnte, dass Digestion mit phosphorsäurehaltigem Alkohol bei Delphinium Requieni die Proteinkörner zum Theil, vielleicht auch ganz unlöslich macht. Wenn sich auf mikrochemischem Wege nach weisen liess, dass die lösenden Vehikel in den Proteinkörnern selbst enthalten sind, so ist es doch Sache der Chemie festzustellen, ob die Kaliphosphate wirkliche chemische Verbindungen mit den Proteinstoffen eingehen oder nicht, auf welche Frage noch keine entschiedene Antwort gegeben ist.

$\mathrm{Da}$ alle Samen in der Asche hohe Procentsätze von Phosphorsäure und Kali enthalten, so kann also das Fehlen dieser Stoffe nicht die Ursache sein, dass die Proteinkörner gewisser Pflanzen in Wasser unlöslich sind. Es ist hier einmal möglich, dass die nicht mit Kali verbundenen Proteinstoffe in phosphorsaurem Kali nicht löslich sind, wie das nach Ritthause ${ }^{1}$ ) bei dem aus dem Maissamen

1) Ritthausen, Journ. f. prakt. Chemie, Bd. 106, pag. 471. 
dargestellten Pflanzenfibrin der Fall ist, oder Kali und Phosphorsäure sind in Verbindungen gebracht, welche nicht lösend auf die eiweissartigen Stoffe wirken können, wie das für die Phosphorsäure gilt, welche mit einem organischen Stoff gepaart und an Magnesia und Kalk gebunden, die Globoide bildet. Wenn Kaliphosphat mit einem löslichen Magnesia. oder Kalksalz in neutraler oder alkalischer Lösung zusammentrifft, so werden dieselben sich unbedingt in lösliches Kalisalz und in unlösliche phosphorsaure Magnesia umsetzen und bei genügender Zufuhr der Erdsalze kann es ja dahin kommen, dass sämmtliche an Kali gebundene Phosphorsäure unlösliche Erdphosphate liefert, während ja die mit anderen Säuren gebildeten Kalisalze nicht lösend auf Proteinstoffe wirken. Dass in den Globoiden eine gepaarte Phosphorsäure vorkommt, thut hier nichts zur Sache, denn dieselbe mag ja wohl schon als Kalisalz vorhanden gewesen sein. Jedenfalls sehen wir aber leicht ein, wie es möglich ist, dass trotz Gegenwart ron Kali und Phosphorsäure die Proteinkörner ganz unlöslich in Wasser sein können. Ferner ist es klar wie Samen selbst derselben Species bei gleichem absoluten Phosphorsäuregehalt ungleich lösliche Proteinkörner einschliessen können, z. B. indem eine stärkere Zufuhr von Erdsalzen, die $j a$ an verschiedenen Standorten möglich ist, Veranlassung zur Ueberführung einer grösseren Menge von Phosphorsäure in unlösliches Salz geben kann, freilich nicht durchaus muss '). Natürlich wird auch eine Herabdrückung der absoluten Menge von Phosphorsäure oder Kali dic Löslichkeit der Proteinkörner vermindern können und in einer dieser Ursachen, oder in beiden zugleich, ist es begründet, dass die Samen derselben, aber an verschiedenen Stationen gewachsenen Pflanzenart auch wohl ungleiche Mengen von eiweissartigen Stoffen an Wasser abgeben.

$\mathrm{Da}$ die Proteinkörner mit Einschlüssen von oxalsaurem Kalk in ihrem Verhalten gegen Wasser mit denen, welche Globoide einschliessen übereinstimmen, so findet also eine $\mathrm{An}$. häufung von Kaliphosphat auch bei jenen nicht statt und wo sich in einzelnen Zellen nur krystallinische Einschlüsse finden, wird in diesen die Menge der Phosphorsäure des Fehlens der Globoide halber geringer sein, als in den Zellen, in welchen die letztgenannten Einschlüsse auftreten.

Nach unseren Betrachtungen ist es nun auch ganz selbstrer-

1) So nicht in sauren Flüssigkeiten, in denen sich das Erdphosphat löst. 
Untersuchungen über d. Proteïnkörner und d. Bedeutung d. Asparagins etc. 499

ständlich, dass die ungleiche Löslichkeit der Proteinkörner verschiedener Samenarten in Wasser, nicht auf verschiedene Proteinstoffe schliesson lässt, ja selbst das differente Verhalten gegen lösende Reagentien erlaubt dieses nicht einmal, was ich hier auszuführen unterlasse. Gleiches gilt auch für die ungleiche Coagulirbarkeit der Proteinkörner, denn Alkalien und ebenso deren Phosphate können unter Umständen die Coagulirbarkeit der Eiweisskörper ganz aufheben oder doch wesentlich modificiren.

\section{Die Proteinkörner von Paeonia.}

Wenn Samenschnitte aus dem Endosperm von Paeonia humilis oder peregrina nach Digestion mit schwefelsäurehaltigem Alkohol und nachfolgendem kurzen Auswaschen mit Alkohol in Wasser gebracht werden, so treten Schichtungen auf, welche an die der Stärkekörner erinnern. Es finden sich diese aber fast allein an denjenigen Proteinkörnern, welche als Einschluss meist ein, selten mehr als drci Kryställchen führen, (XXXVI, 1), die mit Globoiden versehenen Proteinkörner (XXXVI, 5), welche einige peripherische Zelllagendes Endosperms occupiren, zeigen höchstens zuweilen Andeutungen solcher Schichtunger. Wesentlich ist es übrigens die Digestion mit dem schwefelsäurehaltigen Alkohol nicht lauge, am besten etwa sechs Stunden fortzusetzen, da sich schon nach 12 Stunden einzelne Proteinkörner in unlösliche Modifikation verwandelt haben können und dann an diesen keine Schichtung mehr auftritt.

Die grösste Zahl von Schichten, welche ich beobachtete, waren vier harte Schichten, die mir aber nur wenigemal vorkamen; öfters schon traf ich drei harte Schichten, indess sind so auffallende Bilder wie Fig. 7n (Taf. XXXVI) nicht bäufig. Es können nun einzelne weiche Schichten ringsum gehen oder auch unvollkommene Blasen sein und dann trifft man meist das Proteinkorn excentrisch geschichtet. Wie nun auch einzelne Schichten einfach auf Spalten reducirt vorkommen und ebenso von den Proteinkörnern mit zwei harten Schichten: geben die Figuren (XXXVI, $7 \mathrm{a}-\mathrm{n}$ ) eine genügende Vorstellung, um mich weiterer Worte zu überheben; eine unvollkommene harte Schicht in einer weichen ist mir nicht vorgekommen. Hier sei noch aufmerksam gemacht auf die Proteinkörner, deren weiche Schichten nach zwei Seiten liegen (XXXVI, $7 \mathrm{k}$ u. l) und dann auch auf solche ohne Schichtung, 
welche wohl an jedem Samenschnitt in kleinerer oder grösserer Zahl gefunden werden. Bei diesen wird die innere weiche Masse entweder allmälig nach ausscn dichter (XXXVI, 7 a) oder es ist eine äussere härtere Kugelschale scharf abgegrenzt (XXXVI, 7b). Ebenso ist es auch mit dem ron dichterer Masse umhüllten weichen Kern, der entweder nur klein oder auch von erheblicher Grösse sich als Schichtungscentrum bei den geschichteten Körnern findet. In diesem Kern können auch die Kryställchen liegen (XXXVI, $7 \mathrm{e}, \mathrm{f}, \mathrm{m}, \mathrm{n})$, welche indess in anderen Falleu in einer harten oder auch in einer weichen Schicht eingebettet sind (XXXVI, $7 \mathrm{~h} \mathrm{u.} \mathrm{k).}$ Auch in den ungeschichteten Proteinkörnern mit scharf abgegrenzter dichterer Kugelschale trifft man die Kryställchen sowohl in dieser, als in der weichen Innenmasse.

Die weichen Schichten sind so substanzarm, dass man in der That in Zweifel gerathen kann, ob sie nicht vollständige Hohlräume sind. Doch bemerkt man, namentlich nach Färbung mit Anilin bei sehr starker Vergrösserung (Gundlach Immersion VII) öfters feinkörnige Masse zwischen den harten Schichten und völlig entscheidend sind die Proteinkörner, bei welchen in einer weichen Schicht ein oder mebrere Kryställchen liegen. Denn dieseliegen durchaus unbeweglich, während sie, sobald man die Proteinstoffe mit Kali hinweggelöst hat, sofort moleculare Bewegungen beginnen. Ebenso zeigen auch diejenigen Körner, bei denen eine weiche Schicht ringsum geht, die innere Masse aber unbeweglich liegt, dass die weichen Schichten von einer wenn auch noch so schwach lichtbrechenden Masse erfüllt sind.

Dass die Proteinkörner von Paeonia weder in Alkohol noch in Oel geschichtet erscheinen dürfte nicht auffallen, da ja auch an trockenen Stärkekörnern keine Schichtung wahrzunehmen ist. In Wasser lassen sich aber unsere Proteinkörner, ihrer Leichtlöslichkeit in diesem Medium halber, nicht ohne weiteres betrachten, wenn man sie aber nach Behandlung mit alkoholischem Sublimat in Wasser trägt, kann man keine oder nun ganz unbestimmte Andeutungen von Schichtung an den nun unlöslichen und, wie früher bemerkt, leicht zerspringenden Proteinkörnern bemerken. Schon hiernach wird es wahrscheinlich, dass aus den geschichteten Proteinkörnern ein Stoff herausgelöst wird, dass dieses aber erst beim Eintragen in Wasser geschieht zeigt der folgende Versuch sehr schlagend. Hat man nämlich Samenschnitte mit schwefelsäurehaltigem Alkohol so lange stehen gelassen, bis beim Eintragen 
in Wasser die Proteinkörner geschichtet werden und bringt man nun diese Samenschnitte in sublimathaltigen Alkohol, so erscheinen nach einiger Digestion beim Eintragen der Schnitte in Wasser die Proteinkörner ganz so wie die allein mit sublimathaltigem Alkohol behandelten.

Das Verhalten der geschichteten Proteinkömer von Paennia gegen Alkohol beweist nun vollends die Herauslösung eines Stoffes, denn in Alkohol getragen verringern sie zwar ihren Durchmesser etwas, die Schichtung verschwindet aber in keinem Falle wieder, bleibt rielmehr vollkommen deutlich. Entständen aber die weichen Schichten durch starkes Aufquellen entsprechender Zonen, dann müssten sie in Alkobol auch wieder verschwinden und ebenso auch beim Einlegen der mit sublimathaltigem Alkohol behandelten Schnitte in Wasser auftreten, weil es mehr als unwahrscheinlich ist, dass ungleich quellungsfähige Schichten diese Fähigkeit mit dem Uebergang in die Quecksilberverbindung einbüssen sollten, welche doch auch quellungsfähig ist. Das Verhalten der mit Sublimat unlöslich gemachten Proteinkörner schliesst aber auch die Möglichkeit aus, dass der sich herauslösende Stoff Fett oder ein lösliches Kohlehydrat sein könnte, da ersteres schon durch Alkohol, letzteres aber durch Wasser entfernt worden wäre. So ist schon hieraus zu folgern, dass der sich lösende Stoff ein Proteinstoff sein muss; völlig entscheidend werden aber die durch längere Digestion mit schwefelsäurehaltigem Alkohol in die unlösliche Modifikation verwandelten Proteinkörner. Denn da nun beim Eintragen der Schnitte in Wasser die Proteinkörner nicht mehr geschichtet werden, so folgt hieraus, dass der sich weglösende Stoff unlöslich wurde und dieses ist bei der eingeschlagenen Behandlung unter allen Pflanzenstoffen nur für die der Coagulation fähigen eiweissartigen Körper möglich.

Es ist also nun mit Sicherheit erwiesen, dass in den weichen Schichten der Proteinkörner von Paeonia zwei, bei Digestion mit schwefelsäurehaltigem Alkohol sich verschieden verhaltende Eiweisskörper gemengt sind. Diese sind nun entweder zwei wirklich verschiedene Proteinstoffe oder es könnten wohl auch verschiedene Verbindungen desselben Proteinstoffes, etwa mit Alkalien oder Phosphaten sein, von denen bei der eingeschlagenen Behandlung die eine schwieriger zersetzt wird. Diese letztere Möglichkeit verliert aber alle Wahrscheinlichkeit dadurch, dass einzelne Proteinkörner zuweilen nach zwei, selbst drei Tagen noch 
nicht coagulirt sind und dann auch beim Eintragen in Wasser Schichtungen, wie die nur kürzere Zeit mit schwefelsäurehaltigem Alkohol in Berührung gewesenen Proteinkörner ausbilden. Wir werden also nothwendig zu der Annahme gedrängt, dass der sich weglösende Proteinstoff ein solcher ist, welcher für sich, auch olne Beihülfe von Alkalien oder deren Phosphaten, in Wasser löslich ist und hier entsinnen wir uns, dass das reine Albumin in Wasser löslich sein soll und in der That findet sich Pflanzenalbumin, wie ich mich selbst überzeugte, in dem wässrigen Aus zug der geschälten Samen von Paeonia. Ich werde also hier der Einfachheit halber den fraglichen Proteinstoff Albumin nennen, auch auf die Gefahr hin, dass es ein vielleicht chemisch verschiedener Proteinstoff ist, welcher mit dem Eiweiss darin übereinstimmt, dass er im reinen Zustand in Wasser löslich ist. Man könnte wohl auch an Pflanzenleim denken, welcher in reinem Wasser, wenn auch nur in Spuren löslish ist, allein jener geht nur änsserst schwer und dann doch nur unvollkommen in einen unlöslichen Zustand über, so dass dieser unmöglich schon bei eintägiger Digestion mit schwefelsäurehaltigem Alkohol erreicht werden kann und wenn dieses nicht der Fall, dann müssten beim Eintragen in Wasser die Proteinkörner, deren übrige Proteinmasse coagulirte, geschichtet erscheinen. Die leichte Coagulirbarkeit der. Proteinkörner von Paeonia spricht aber nur zu Gunsten des Albumins, da dieses unter allen Proteinstoffen der am leichtesten in die unlösliche Modifikation übergehende ist.

Wir haben aber nur für die weichen Schichten die Anwesenheit zweier Proteinstoffe erwiesen und wenn sich dasselbe für die harten Schichten nicht durch direkte Beobachtung ermitteln lässt, so ist es doch wabrscheinlich, dass auch in diesen zwei Proteinstoffe miteinander gemengt ${ }^{1}$ ) sind. Es wurde' früher erwähnt, dass eine variable Anzahl von Proteinkörnern an jedem Samenschnitte ungeschichtet gefunden wird, obgleich dieselben nicht coagulirt sind und auch an Grösse den geschichteten nicht nachzustehen brauchen. Wenn man aber solche Schnitte zurück in Alkohol trägt und dann die Proteinkörner mit anderen vergleicht, welche nur mit schwefelsäurehaltigem Alkohol behandelt wurden, so lässt sich an jenen

1) Es könnte freilich auch eine chemische Verbindung zweier Proteinstoffe miteinander vorliegen, wie ich das bei den Krystallen erörterte, doch sehe ich davon $a b$, weil sich über diesen Punkt keine Entscheidung gewinnen lässt. 
mit Wasser behandelten Körnern das Herauslösen eines wonn auch nur kleinen Stoffquantums constatiren, das augenscheinlich auch grösser ist als die schr kleine Stoffinenge, welche nach Ueberführung in die unlösliche Quecksilberverbindung Wasser aus den Proteinkörnern ron Paeonia löst. Da nun aber gar keine Wahrscheinlichkeit dafür vorliegt, dass verschiedene sonst ganz übereinstimmende Proteinkörner derselben eine ungleiche Znsammensetzung haben sollten, so muss anden ungeschichteten Körnern der für sich in Wasser lösliche Proteinstoff in dem ganzen Proteinkorn mit dem anderen im reinenZustand unlöslichen Eiweisskörper innig gemengt sein. Eine quantitativ ungleiche Mengung beider Proteinstoffe ist schon in jenen Körnern vorhanden, an denen eine äussere härtere Kugelschale sich mehr oder weniger deutlich von der inneren weichen Masse abgrenzt und die fortschreitende Dissociation der beiden eiweissartigen Stoffe wirả durch die verschiedene Zahl und Ausbildung der weichen und harten Schichten repräsentirt. Wie aber in ersteren die beiden Proteinstoffe immer noch miteinander gemengt blieben, so wird es wohl sicher auch, natürlich in dem umgekehrten relativen Verhältniss, in den harten Schichten der Fall scin und die Mengung der beiden Proteinstoffe ist dann eine der Mengung von Granulose und Cellulose in den Stärkekörnern entsprechende.

Bei den geschichteten Proteinkörnern ist der Durchmesser meist mehr als bei ungeschichtet bleibenden gewachsen. Dieses findet wohl darin seine Erklärung, dass die harten Schichten vorwiegend in tangentialer Richtung aufquellen, wie sich das auch in den freilich sehr seltenen Rissen zu erkennen gibt, welche sich nach Aussen auskeilen. Wenn aber aus den, an den geschichteten Proteinkörnern weich erscheinenden Zonen der eiweissartige Körper nicht weggelöst wird, was ja an den coagulirten oder an den mit Sublimat unlöslich gemachten Proteinkörnern der Fall ist, verhindert die Cohäsion die äusseren concentrischen Schichten ihrem tangentialen Quellungsbestreben freien Lauf zu lassen, während diesem etwas geringere Hindernisse in den Weg stehen, wenn durch Weglösen eines grösseren Stoffquantums aus gewissen concentrischen Zonen diese weicher werden. Jedenfalls kann in der endosmotischen Spannung, welche der sich lösende aber sicher nur sehr schwer durch die umgrenzenden harten Schichten diosmirende Proteinstoff ${ }^{1}$ ) hervorrufen wird, nicht die

1) Das endosmotische Aequivalend der Eiweisstoffe ist sehr gering, fast gleich 100. Vergl, Kühne, Lehrb. d. physiol. Chemie. 1868, p. 49. 
einzige Ursache des Aufquellens liegen, denn in diesem Falle würde man gewiss auch harte Schichten aufgesprengt finden, was ich niemals antraf. Wohl möglich ist es aber, dass die in den weichen Schichten entwickelte endosmotische Spannung das tangentiale Aufquellen der harten Schichten unterstützt.

Mit der ungleichen quantitativen Mengung zweier Stoffe geht bei den Proteinkörnern ron Paeonia nicht eine ausgesprochene Differenzirung in harte und weiche Schichten Hand in Hand, wie es bei den Stärkekörnern der Fall ist. Doch macht sich eine solche Differenzirung zuweilen bemerklich, indem an ganz vereinzelten, sowobl an durch Sublimatbehandlung, als an durch Coagulation in Wasscr unlöslich gewordenen Proteinkörnern, unbestimmte Andeutungen von Schichtung zu bemerken sind. Deutlicher sind dann und wann Schichtungen zu erzielen, wenn man zu in Alkohol liegenden Proteinkörnern ganz allmälich Wasser treten lässt, doch gelingt es auch auf diese Weise keineswegs jedesmal und dann immer nur an sehr vereinzelten Körnern Schichtungen sichtbar zu machen. Wie früher mitgetheilt wurde, werden in Wasser lösliche Proteinkörner bei selr langsamer Einwirkung jenes von Innen heraus aufgelöst, und nur solche Proteinkörner von Paeonia, die im Innern schon theilweise gelöst oder auch nur gequollen waren, sind es, an denen in der äusseren Zone einzelne, höchstens vier sehr schmale weiche Schichten bemerkbar werden, welche durch gleichfalls nur schmale harte'Schichten getrennt sind. (XXXVI, 8.) Diese weichen Schichten können ringsum gehen oder auch unvollständig sein, immer aber sind sie nur schmal, wenn auch im günstigsten Falle vollkommen deutlich. Bei den durch Behandlung unit schwefelsäurehaltigem Alkohol und Eintragen in Wasser geschichtet werdenden Proteinkörnern wird also jedenfalls auch ein erhebliches Quellen der Masse stattfinden, welche nach Weglösen des Albumins in den weichen Schichten zurückbleibt, da diese oft ansehnliche Breite erreichen.

Jedenfalls aber erfahren wir durch die Seltenheit mit der Schichten, sowohl beim langsamen Aufquellen der Proteinkörner von Paeonia in verdünntem Weingeist, als nach dem Unlöslichmachen derselben durch Sublimat oder durch Coagulation auftreten, dass die albuminreichen Schichten nicht so, wie die granulosereichen der Stärkekörner eine besondere Neigung zur Aufnahme grösserer Wassermengen als die harten albuminarmen Schichten besitzen. Freilich gibt es auch Stärkekörner an denen keine Schichtung zu erkennen ist 
Untersuchnngen über d. Proteinkörner und d. Bedeutung d. Asparagins etc. 505

und das sind nicht nur sehr kleine, für die das Unzureichende der Hülfsmittel zur Erklärung ansreicht, sondern auch grössere wie z. B. die von Zingiber officinale ${ }^{1}$ ). In diesen könnten nun einmal Granulose und Cellulose in gleichförmiger Mengung sein, wie dieses ja an den auch bei Behandlung mit schwefel. säurehaltigem Alkohol ungeschichtet bleibenden Proteinkörner augenscheinlich der Fall ist, oder aber es sind beide Stoffe in gleicher Weise wie bei anderen Stärkekörnern gemengt, aber die granulosereichen Schichten nehmen nicht wesentlich mehr Wasser auf als die granulosearmen Schichten ${ }^{2}$ ). Unsere geschichteten Proteinkörner (wenn nicht näher bezeichnet, meine ich immer die durch schwefelsäurehaltigen Alkohol gewonnenen) sind aber immer den Celluloseskeletten der Stärkekörner zu vergleichen, da ja ein der Granulose analog zu betrachtender Stoff hinweggelöst wurde.

Leider konnte ich bei gleicher Behandlung mit schwefelsäurehaltigem Alkohol aus keinem anderen Samen geschichtete Proteinkörner wie bei Paeonia erzielen, nur dann und wann wurden einzelne weiche Stellen bemerkt. Ebenso suchte ich vergebens an in Wasser für sich schon unlöslichen Proteinkörnern nach Schichtung, die auch an diesen, sowie auch an den mit schwefelsäurehaltigem Alkohol unlöslich gemachten Proteinkörnern nicht durch Behandlung mit verdünntem Weingeist erzielt werden konnte. Ich versuchte dieses, weil einige Proteinstoffe in verdünntem Weingeist löslich sind. Ob Proteinkörner anderer Samen aus zwei oder mehreren Proteinstoffen bestehen, lässt sich mikrochemisch nicht nachweisen, doch ist dieses für viele Samen ziemlich gewiss, in denen die chemische Analyse zwei oder mehrere Proteinstoffe in grösserer Menge nachgewiesen bat. Denn da die Proteinkörner derselben und ebenso verschiedener Zellen keinen Unterschied in ihren Reaktionen erkennen lassen, so ist nicht anzunehmen, dass

1) Nägeli, Stärkekörner. p. 18.

2) In letzterem Falle würde aus diesen ungeschichteten Stärkekörnern ein Celluloseskelett wie aus anderen Stärkekörnern erhältlich sein und damit wäre dann auch sehr schlagend gezeigt, dass in der chemischen Differenz der constituirenden Stoffe nicht der Grund zur Bildung ungleich grosser Molecüle liegt. Wie Nägeli in seinem Meisterwerke über Stärkekörner nachwies, sind die Molecüle der weichen Schichten kleiner, als die der harten Schichten, denn unter beiderlei Annahmen, das Wasser werde von der Masse oder von der Oberfläche angezogen, muss die aus kleineren Molecülen bestehende Schicht wasserreicher sein, als die aus grossen Molecülen zusammengesetzte Schicht (Stärkekörner p. 333 ff.). 
die fraglichen Eiweisskörper getrennt und in verschiedenen Zellen vertheilt sind.

Nach Hartig') sollen nach Auswaschen mit Wasser beim Betrachten in Jodalkobol die Proteinkörner von Camellia oleifera Schichtenbildung erkenuen lassen, Samen dieser Pflanze stehen mir aber nicht zu Gebote. Auch muss ich der Körnchen Erwähnung thun, welche nach $\mathrm{Caruel}^{2}$ ) sich aus dem Milchsaft von Ficus carica absetzen und etwas excentrisch geschichteten Stärkekörnern mit nur wenig Schichten gleichen sollen. Zwar hat sich der genannte Autor über die Natur dieser Körnchen nicht ausgesprochen, doch sollen dieselben mit Jod gelbe Färbung annehmen, mit Zucker und Schwefelsäure allerdings keine Eiweissreaktion geben, da sie aber als in Kali unlöslich angegeben werden, so können sie unseren Proteinkörnern nicht unmittelbar verglichen werden. Mir stand kein genügendes Material von Ficus Carica zur Verfügung um Milchsaft in einiger Quantität zu gewinnen, an Milchsafttröpfchen aber, welche ich unmittelbar auf Objektträger gal, kounte ich ausser Tröpfchen, welche wesentlich aus Fett oder Hairz bestehen nur einzelne kleine, mit Jod sich bläuende Stärkekörnchen finden, für die ich aber nicht festgestellt habe, ob sie nicht aus angeschnittenen Parenchymzellen stammen. Geschichteten Stärkickörnern und also auch den geschichteten Proteinkörnern von Paeonia sind dem Ansehen nach ähnlich die corpuscula amylacea, welche früher (Virchow, Nägeli) ihrer Jodreaktion halber für einen der Stärke nahestehenden Stoff angesehen wurden, indess wenigstens der Hauptsache nach wohl sicher aus einem eiweissartigen Körper gebildet werden, wie auch diese Zusammensetzung für die amorphe amyloide Substanz durch chemische Analysen erwiesen ${ }^{3}$ ) und damit zugleich dargethanjwurde, dass Blaufärbung mit Jod ${ }^{4}$ ) auch Proteinstoffen zukommen kann.

\section{Bildung der Proteinkörner.}

Als erstes Beispiel für die Entstehung der Proteinkörner will ich die des Endosperms von Paeonia peregrina wählen und mit

1) Hartig, Bot. Zeitung 1856, p. 317.

2) Caruel, Bull d. 1. soc. bot. de France 23. Juni 1865, Separatabzug.

3) Vgl. Kühne, physiol. Chemie 1868, p. 413. - Hoppe-Seyler, Handbuch d. physiol, u. pathol. chem. Analyse 1870, p. 211.

4) Nach Wiesner und A. Ungerer (Wiesner, mikroskop. Unters. 1872 p. 22) soll das Protoplasma in den Bastfasern von Böhmeria nivea u. tenacissima mit Jod eine bläuliche Farbe annchmen. Mir steht das Objekt nicht zu Gebote. 
dem Zeitpunkt beginnen, in welchem die Einwanderung der Reservestoffe in den Samen seinen Anfang nimmt. Wenn dieser etwa die Hälfte seiner endlichen Grösse erreichte und die Samenschale sich eben zu färben beginnt, ist Zellinhalt und Protoplasma in bekannter Weise angeordnet. Der von der Hüllmasse sich nicht besonders gut abgrenzende Zellkern ist durch Fäden und Bänder, welche in das Wandprotoplasma übergehen, wie ãie Spinne in ihrem Netz aufgehangen ${ }^{3}$ ) oder liegt auch in dem Wandprotoplasma selbst; auch habe ich Zellkerne in der von Hanstein beschriebenen Weise einigemal in Theilung gefunden ${ }^{2}$ )

Während noch die Zellen des Endosperms in Vermehrung be. griffen sind treten Stärkekörnchen in dem Zellsaft auf und gleichzeitig beginnt dessen Trübung, die zum guten Theil jedenfalls durch eiweissartige Stoffe veranlasst wird, welche auch durch die Jodfärbung sich in dem Zellsaft erkennen lassen. Trübung der Zellflüssigkeit, sowie Grösse und Zahl der Stärkekörner vermehren sich während der Samen heranwächst und wenn dieser etwa das Maximum der Grösse, im frischen Zustande gedacht, erreichte, sind die Endospermzellen mit Stärkekörnern von annähernd gleicher oder auch variabeler Grösse angefüllt, welche bis zu 17 Mikrom. Durchmesser gefunden werden und zwischen denen sich eine trübe, an Liweiss. stoffen sehr reiche metaplasmatische ${ }^{3}$ ) Flässigkeit befindet (XXXVI, 9). Die Stärkekörner selbst sind mehr oder weniger kugelig und mit Ausnahme der kleinsten zwei bis achtzählig zusammengesetzt. $\left.{ }^{4}\right)$

Hiermit hat die Stärkebildung ihren Höhepunkt erreicht und nun beginnt die Umwandlung der Stärke in Oel, welche vollendet ist, wenn die zuvor hellblutroth gefärbte Samenschale ein dunkles Roth angenommen hat. Der Same steht nun freilich auch in dem letzten Reifestadium, denn der Nabelstrang, welcher bis dahin Stärke und Zucker in den parenchymatischen Zellen des Grundgewebes, Proteinstoffe in den langgestreckten Zellen des Basttheiles des Gefässbündels zuleitete,

1) Vgl. d. Fig. Taf. XXXVI, 8 u. 15 von Ricinus u. Phaseolus.

2) Die zuerst von Brücke (Wiener Akad. Berichte 1861, Bd. 44, p. 401 ff.) geltend gemachte Anschauung des Protoplasmakörpers als eines invidualisirten Organismus wurde neuerdings von Hanstein (Sitzungsb. d. niederrhein. Gesellsch. 19. Dec. 1870) mit Glück weiter ausgeführt. Ich kann mich den Ansichten dieses Forschers in den wesentlichsten Punkten nur anschliessen.

3) Es ist jedenfalls geboten den Protoplasmaleib und die im Zellsaft liegenden assimilirten Stoffe gesondert zu halten und adoptire ich für letztere die von Hanstein vorgeschlagene Bezeichnung „Metaplasma“ (Bot. Ztg. 1868, p. 710 Anmerkg.)

4) Vgl. Nägeli, Stärkekörner, p. 391 u. 561. 
beginnt jetzt saftlos zu werden. Der Same hat nunmehr seine Reservestoffe aufgenommen, er trocknet nun einfach ein und damit beginnt dann auch erst die Bildung der Proteinkörner.

Unmittelbar nach der Umwandlung der Stärke in Oel erfüllt eine körnige und sehr trübe Masse die Zellen des Endosperms in der man nicht einmal imner den Zellkern finden kann und nur im günstigsten Falle einen Thcil der Protoplasmastränge überblickt (XXXVI, 10), wenn man feine Schnitte im eignen Zellsaft betrachtet, was aber durchaus geboten ist, weil selbst in Glycerin oder Oel der Zellinhalt schnell desorganisirt wird. Zicht man Schnitte mit Alkohol aus und bringt sie dann vorsichtig in Wasser, so gelingt es aber den Protoplasmaleib besser za “übersehen und man kann sich danı überzeugen, dass wenigsters relativ die Anzahl der Bänder und Fäden, gegenüber jugendlicheren Endospermzellen, nicht zugenommen hat. Die Einschlüsse, deren Bildung übrigens schon vor der Stärkeverwandlung begonnen hatte, sind in dem ganzen Zellinhalt vertheilt; in den mebr inneren Zellen des Endosperms finden sich die kleinen Kryställchen, welche wohl schon volle Grösse erreicht haben mögen und in einigen äusseren Zelllagen die jedenfalls ihrer vollen Grösse sehr nahestehenden Globoide, auf die ich in diesem Falle keine weitere Rücksicht nehmen will.

Gleich nach der Stärkeverwandlung treten auch in dem trüben Zellinhalt mehr oder weniger kugelige aus Proteinstoffen bestehende Massen auf, in welchen man gewöhnlich sofort eine, zwei, auch bis drei Krystallkörnchen des oxalsauren Kalkes bemerkt (XXXVI, 10 u. 11). Diese jugendlichen Proteinkörner wachsen, während gleichzeitig neue entstehen und so kommt denn endlich ein Bild zu Tage, wie es der reife trockene Samen gewährt (XXXVI, 12), doch ist die Grundinasse jetzt, offenbar durch Wassergehalt, noch sehr trübe und klärt sich dem entsprechend bei dem fortschreitenden Eintrocknen des Samens auf.

Dass die als jugendliche Proteinkörner bezeichneten Gebilde aus eiweissartigen Stoffen bestehen, ergibt sich wenn man Samenschnitte in Alkohol wirft; namentlich kann man, wenn man sublimathaltigen Alkohol anwandte, an den nun unlöslich gewordenen, zuvor aber in Wasser löslichen Proteinkörnern, gleiche Reaktionen wie an den Körnern trockener Samen vornehmen. Sobald die Proteinkörner zur Beobachtung gross genug geworden waren, konnte auch bei langsamer Wasserwirkung die Lösung von Innen heraus und ebenso 
das restirende Hüllläutchen, ganz so wie es früher für die Proteinkörner trockener Samen beschrieben wurde, constatirt werden. Die jugendlichen Proteinkörner enthalten aber immer ein nicht unerhebliches Quantum Wasser und schrumpfen desshalb in Alkohol etwas, wobei ihre Contouren mebr oder weniger wellig werden. Das gleiche, jedoch in geringerem Maasse, findet auch dann statt, wenn der Zellinhalt der reifenden Samen ein dem trockenen Samen ähnliches Bild erreich hat, die Proteinkörner sind dann entschieden schon procentisch ärmer an Wassergehalt geworden. Wohl aber sind die Körner jetzt noch weich, jedoch bis zu einem gewissen Grade elastisch, da die beim leichten Drücken auf das Deckglas erzielte Formveränderung nur so lange als der Druck andavert. Die Gestalt dieser grösseren Proteinkörner ist nicht nur die einer Kugel, sondern kann auch eine eiförmige oder ellipsoidische sein, auch kommt wohl eine schwach polygonale Form, wie im trockenen Samen, zu Stande, wenn ein ähnliches Bild wie letzterer es bezüglich der Anordnung von Körnern und Grundmasse bietet erreicht ist. Die Kryställchen von oxalsaurem Kalk scheinen gleichsam als Anziehungscentrum für die in Ausscheidung aus der trüben Emulsion begriffenen Protein. stoffe zu dienen, ob aber immer nur um ein oder einige Kryställchen ein Jugendanfang eines Proteinkornes entsteht oder ob in das wachsende Korn auch nachträglich Kryställchen aufgenommen werden, dieses sicher'zu entscheiden erlaubte ausser der Kleinheit des Objektes vor allen Dingen der so sehr trübe Zellinhalt nicht. Doch glaube ich, dass auch in jugendliche Proteinlzörner Kryställchen noch eintreten können, denn jene gleichen in der Verschiebbarkeit der Theilchen einem sehr substanzreichen Protoplasma und ich habe bei Anwendung ron Druck unter meinen Augen zwei noch kleine Proteinkörner sich vereinen und zusammen eine der Kugelform sich nähernde ellipsoidische Gestalt annehmen sehen; bei grösser und wasserärmer gewordenen Proteinkörnern ist mir solches nicht mehr gelungen. Soviel steht aber fest, dass fast alle Kryställchen in Proteinkörner eintreten und nur höchst vereinzelt in der Grundmasse liegen bleiben.

Eine durch den Wasserverlust des Samens bedingte Trennung der zuvor zu inniger Emalsion gemengten Stoffe hat also die Entstehung der Proteinkörner zurFolge, welche fast nur aus solchen eiweissartigen Stoffen, von den Einschlüssen abgesehen, gebildet sind die sich in verdünnten Alkalien löscn. Stets aber wird anch in dem Fette 
der Grundmasse eine kleinere oder grössere Menge von Proteinstoffen zurückgehalten, welche immer zum Theil solche sind, die sich in verdünnten Alkalien nicht auflösen. Der Protoplasmaleib ist bei diesur Dissociation nicht unmittelbar betheiligt, es ist aber selbstverständlich dass die Protoplasmastränge in die Grundmasse zu liegen kommen müssen. In dieser gehen sie aber keineswegs auf, sondern trocknen mit dem Wasserverlust des Samens ein, wie der Umstand beweist, dass man dann und wann an in Oel liegenden Schnitten mancher trockener Samen, z. B. Tragopogon (XXXVI, 15), die Protoplasmastränge, wenn auch immer nur auf kürzere Strecken verfolgen kann. Wenn dieses so selten der Fall ist, so erklärt sich das daraus, dass die von Oel durchtränkten Protoplasmastränge der Grundmasse, welche ja auch aus Proteinstoffen und Fett zusammengesetzt ist, an Lichtbrechung sehr nahe stehen. Auch der Zellkern trocknet einfach aus; der ganze Protoplasmaleib erwacht aber beim Keimen des Samens wieder zu neuem Leben. Das Grundmassennetz, das man aus Schnitten reifer Samen in früher angegebener Weise darstellen kann, muss natürlich mit dem Zellkern in Continuität stehen, aber es ist dieses Netz, wie ich schon damals bemerkte, nicht der Protoplasmaleib, sondern dieser ist nur in ihm aufgenommen und der Primordialschlauch bildet die Grenze gegen die Zellwand.

Es wurde schon mitgetheilt, dass die Einwanderung der Reservestoffe in die Samen von Paeonia zum allergrössten Theil vollendet ist, wenn das Maximum der Stärkebildung erreicht wurde. Nimmt man solche Samen aus den Carpellen und lässt sie an der Luft trocknen, so geht die Verwandlung von Stärke in Oel dennoch ror sich und die Proteinkörner bilden sich ähnlich wie in den völlig zur Reife gelangten Samen aus, auch sind jene Samen keimfähig. ${ }^{1)}$ Das kleine Deficit an Reservestoffeu macht sich aber doch bei den an der Luft getrockneten Samen dadurch bemerklich, dass die Zellwände der Endospermzellen, je nach dem Ausfall an plastischen Stoffen stärker oder schwächer gewellt

1) Dass auch nicht ganz reife Samen keimen können ist schon lange bekannt. Eine Zusammenstellung hierüber, sowie auch eigene Beobachtungen theilt Cohn mit (Symbola ad semin. physiologiam. Inaugurald. 1847, p. 39 ff.). Nach diesem Autor scheinen sogar Samen eines mittleren Reifestadiums schneller zu keimen als völlig reife. 
sind, $\left.{ }^{1}\right)$ während dieses an dem völlig gereiften Samen nicht der Fall ist, ausgenommen freilich die an die centrale Hrhlung, in welcher der Embryo liegt, stossenden Zellen, deren Wände buchtig und zusammengefallen sind, weil der Zellinhalt beim Eintrocknen zu wenig feste Substanz hinterliess. Mag nun hierbei der Embryo auch mitbetheiligt sein, so ist doch der Hauptgrund darin zu suchen, dass die peripherischen Zellen des Endosperms den inneren Zellen in der Füllung mit Reservestoffen vorauseilen, wie dieses ganz besonders an den nur unvollkommen gereiften, an der Luft getrockneten Samen dadurch hervortritt, dass die Wände der Zellen um so stärker wellig werden, je weiter man nach Innen zu im Endosper'm vorrückt.

Die Entwickelung der Proteinkörner in dem kleinen Embryo, in welchem gleichfalls transitorische Stärkebildung auftritt, habe ich nicht verfolgt; hier sei nur noch bemerkt, dass sämmtliche Proteinkörner des Embryos nur Globoide einschliessen.

Im Endosperm von Veratrum album und ebenso in den Embryonen der eiweisslosen Samen von Agrimonia Eupatoria und Geranium nodosum wickelt sich die Bildung der Proteinkörner in allen wesentlichen Zügen wie bei Paeonia ab. Auch bei den Samen, welche nur wenig Stärke transitorisch bilden, liegt eben der Unterschied hierin, nicht in der Bildung der Proteinkörner selbst. Doch müssen wir noch einige Samen bezüglich der Entwickelung der Proteinkörner betrachten und wende ich mich zunächst zu:

\section{Silybum marianum.}

Der Protoplasmaleib der Zellen des jugendlichen Embryos dieses bekanntlich eiweisslosen Samens ist ähnlich gestaltet wie es bei Paeonia angegeben wurde (XXXVIII, 3). Die Trübung des zuvor klaren Zellsaftes beginnt mit der bräunlichen Färbung der Samenschale und dann trifft man auch schon im Zellsaft sehr kleine Globoide, welche übrigens der Form nach den bei Silybum im ausgewachsenen Zustand ziemlich grossen Globoiden gleichen. Wie unter diesen solche gefunden werden, welche gleichsam aus $\mathrm{zweien}$ oder einigen componirt sind und biscuit- oder traubenförmige Gestalten vorstellen, so treten auch schon die jugendlichen Globoide

1) Vergl. XXXVIII, 14 u. 13 aus den Cotyledonen reifer und unreifer Samen von Lupinus polypyllus. 
in gleichen Formen auf. Ob nicht auch die componirten Globoide dadurch entstehel können, dass zwei oder mehrere aneinanderstossende Einzel-Glowoide durch Umbüllung mit sich ausscheidenGloboidmasse zu einem organischen Ganzen rereint werden, wage ich nicht zu entscheiden, wenn mir es auch nicht unmöglich scheint. Die Globivide nehmen nun fortwährend an Grösse zu und scheinen erst mit Beginn der Bildung der Proteinkörner ihr Wachsthum aufzugeben. Dieses geschieht aber sicher dur Apposition, da wir die fertigen wie jugendlichen Globoide nicht imbibitions. und quellungsfähig finden.

Wie schon bekannt trifft man aber in anderen Zellen des reifen Embryos ron Silybum krystallinische Einschlüsse und $\mathrm{zwar}$ in einem durch Grösse ausge\%cichneten Proteinkorn cine Druse, in den anderen Körnern derselben Zelle eine Anzahl Nadeln von oxalsaurem Kalk. Gleichzeitig mit den! ersten Auftreten der Globoide ist in den fraglichen Zellen auch sehou oxalsaurer Kalk in winzigen Kryställchen nachuweisen, die Druse wird aber erst in etwas älteren Embryonen sichtbar, um dann wie auch die anderen Kry. ställehen allmälig zu wachsen, was bei diesen krystallinischen Einschlüssen bis zur beginnenden Bildung der Proteinkörner fortdauert. In jedem Samen sind aber Globoide wie Krystalle immer nur im Zellsaft zu finden und jedenfalls ziemlich vollständig ausgewachsen, wenn die Entstehung der Proteinkörner ihren Anfang nimmt.

Bald nach der begonnenen Trübung des Metaplasmas in den Zellen cier noch jugendlichen Embryonen tritt ganz vorübergehend eine sehr geringe Menge kleinkörniger Stärke auf. Fortwährend aber nimmt die Mengedes Futtes und der Proteinstoffe in den Zellen des heran wachsendeu Embryos zu, bis der Samen das Maximum sciner Grösse erreichte, womit das Einwandern der Reservestoffe so ziemlich vollendet ist. Wie bei Paeonia ist der ctwas leichter zu überselende Protoplasmaleib auch jetzt ähnlich wie in jugendlichen Zellen gestaltet, Lildet aber auch hier keine Chlorophyllkörner aus. Die Einschlüsse sind in dem ganzen Metaplasma vertheilt, die Krystallnadeln wohl auch schon gruppenweise vereint und jetzt beginn mit dem Wasserverlust des Samens die Entstehung der Proteinkörner, welche sich um dic Einschlüsse bilden und schon in Jugendzuständen mehrere Krystallnadeln enthalten können (XXXVIII,3). $\mathrm{Da}$ aber in anderen Proteinkornanfängen auch nur eine Krystallnadel zu bemerken ist, in den Proteinkörnern des trockenen 
Samens aber immer mehrere sich finden, so müssen wohl in jugendliche Proteinkörner krystallinische Einschlüsse noch nachträglich aufgenommen werden, wie ich dieses auch bei Paeonia schon wahrscheinlich machte. Durch Ansammeln von Proteinmasse um die Krystalldruse entsteht das durch seine Grösse hervorragende Korn (Hartig's Solitär). Ein solches grosses Korn kommt wohl auch in den Globoide führenden Zellen vor und wird hier entweder dadurch gebildet, dass sich um einen besonders grossen Globoid die eiweissartigen Stoffe ansammeln oder dass ein Proteinkorn stärker als die übrigen wächst. Im Uebrigen wickelt sich die Sache wie bei Paeonia ab.

\section{Lupinus polyphyllus und lateus.}

Die Lupinus-Arten bilden schon in sehr jugenálichen Embryonen Chlorophyll, welches in kleinen, meist länglichen Formen in dem Wandprotoplasma, den Protoplasmasträngen und der Hüllmasse des Zellkerns auftritt'), namentlich in den nach Aussen liegenden Zellen der Samenlappen. Bei Lupinus luteus ist die Chlorophyllbildung reichlicher als bei Lupinus polyphyllus, welche letztere Pflanze ich in Folgendem zunächst allein im Auge labe.

Auch bei Lupinus beginnt die Bildung der Globoide schon frühzeitig, die aber hier klein bleiben, während fortwährend neue bis zu dem Punkte entstehen, wo die Bildung der Proteinkörner selbst ihren Anfang nimmt. Die Proteinkörner entwickeln sich wie in den schon beschriebenen Fällen, doch geht ihre Bildung hier sebr schnell ron Statten, so dass man Mittelstufen zwischen dem ersten Auftreten und der vollen Grösse der Proteinkörner nicht häufig findet. In den jugendlichen Proteinkörnern sind, wie in den älteren, die kleinen Globoide in der ganzen Masse mehr oder weniger gleichförmig vertheilt.

Die ausgewachsenen Proteinkörner sind, wie ja auch im trockenen Samen, durch ziemlich spärliche Grundmasse von einander getrennt und öfters weiter von der Kugelgestalt abweichend, als dieses bei Paeonia und anderen fettreichen Samen der Fall ist; gewöbnlich sind sie mehr oder weniger polygonal. Da die Protoplasmastränge in die Grundmasse aufgenommen werden, so erblickt man in den sclumalen Streifen

1) Fig. 18 auf Taf. XXXVIII aus keimender Lupinus luteus kann zur Veranschauligung dienen. 
dieser stellenweise Chlorophyllkorner (XXXVIII, 16) und diese Bilder von Lupinus kønnen allerdings auf den ersten Blick die Vorstellung erwecken, dass der Protoplasmaleib zu einem gleichsam parenchymatischen Netze geworden sei, dessen Maschenränme formbestimmend für die einwandernden metaplasmatischen Stoffe wurden. Allein die Entwickelungsgeschichte widerlegt auch bei Lupinus eine solche Ansicht, indem man, während die Proteinkör. ner in Bildung begriffen sind, nachweisen kann, dass die Zahl der Protoplasmastränge keine gegen früher vermehrte ist.

Bei Lupinus luteus entstehen gleich nach dem ersten Auftreten der Globoide, wenn die Embryonen etwa ein Viertel ihrer endlichen Grösse erreicht haben, im Zellsaft einer jeden Zelle ein oder zwei Krystalle von oxalsaurem Kalk, ') welche bis zur Bildung der Proteinkörner wachsen. Un diese Krystalle bildet sich das durch Grösse hervorragende Proteinkorn, welches aus dem trockenen Samen unserer Pflanze schon bekannt ist (XXXVIII, 15) ${ }^{2}$ ) und welches, wie auch die Krystalle, bei Lupinus polyphyllus und varius fehlt.

Sowohl bei Lupinus polyphyllus, als bei L. luteus tritt in dem Zellsaft nur eine sehr geringe transitorische Stärkebildung auf, wobl aber produciren die Chlorophyllkörnchen in ihrem Innern Stärkekörnchen, welche erst beim Eintrocknen des völlig reifen Samens verschwinden, indem sie voraussichtlich Oel l:efern. Die Chlorophyllkörner verlieren in dem trockenen Samen ihre Farbe, doch ist die zusammengeschrumpfte Protoplasmamasse derselben noch erhalten, da man bei vorsichtiger Darstellung eines Grundmassennetzes in diesem aus eiweissartigen Stoffen bestehende kugelige oder längliche kleine Ballen findet, welche wohl gewiss auf die Chlorophyllkornmasse zurückzuführen sind.

Entnimmt man nicht vollkommen reife Samen ron Lupinus der Hülse und lässt sie an der Luft eintrocknen, so entstehen die

1) Hartig (Pflanzenkeim p. 139) hat das frühzeitige Auftreten des von ihm seiner Natur nach nicht erkannten Krystalles bemerkt, doch soll dieser sich weiterhin auflösen und der im Solitär vorkommende Krystall aus einem Kernkörperchen hervorgehen und wie ein solches verschiedene Inhaltsgebilde der Zelle produciren. Diese Theorien stimmen nun freilich mit der Wirklichkeit in Nichts überein.

2) Vergl. XXXVIII, 18. Aus heimender Lupiuns luteus, woselbst der Zellinhalt, auch bezüglich des Krystalls, dem in den Zellen reifenden Embryonen ganz ähnlich ist. 
Proteinkörner wesentlich wie in völlig reifen Samen, doch sind auch hier die Zellwände des Ausfalles an Reservestoffen halber mehr oder weniger wellig geworden. Hierbei wird aber die vorhandene spärliche Stärke wohl zum Theil in Fett verwandelt, ein Theil der Stärkekörnchen indess bleibt erhalten und findet sich nun zwischen den Proteinkörnern. Gerade so verhält sich auch Cynoglossum officinale ${ }^{1}$ ) und wohl gewiss noch zahlreiche andere Samen, bei denen man in solchen, welche man berechtigt ist für nicht völlig reife zu halten, Stärkekörnchen findet, welche anderen vollkommen gereiften Samen fehlen. ${ }^{2}$ ) Bei solchen Samen ist also die totale Verwandlung der Stärke an völlige Reife gebunden, während auch ohne diese bei Paeonia und gewiss noch anderen Samen die Transmutation der Stärke eine durchaus vollkommene ist.

Phaseolus vulgaris.

Würde in dem Samen von Paeonia die Stärke nicht in Oel verwandelt, während aus der zwischen jener liegenden eiweissreichen Masse Proteinkörner entständen, so wäre damit ein gleiches Bild erreicht, wie es die vorwiegend stärkeführenden Samen z. B. der Bohne und der Gramineen darbieten. Bei Phaseolus vulgaris findet man, wenn die Embryonen eine Länge von 2 bis 3 Millim. erreichten, vom Zellkern ausstrablend ziemlich kräftige Strombänder, in denen schon jetzt, wie zuweilen auch in der Hüllmasse des Zellkerns einzelne kleine Stärkekörnchen sich finden. Weiterhin, wenn der Embryo 4 bis 6 Millim. lang geworden ist, tritt auch Stärke in dem sich trübenden Zellsaft auf (XXXVII, 15) in welchem die Körner allmälich grösser und endlich denen reifer Samen ähnlich werden, während die im Protoplasma eingebetteten Stärkekörner immer klein bleiben und wahrscheinlich bis zur Reife ganz verschwunden sind. Es ist dieses nicht leicht zu entscheiden, da sich die Protoplasmastränge in der an eiweissartigen Stoffen reichen und trüben, zwischen den Stärkekörnerı befindlichen Masse nur schlecht abgrenzen, doch ist der Zellkern gewöhnlich nicht zu schwer aufzufinden (XXXVII, 16a). Sind die Reservestoffe fertig eingewandert, ${ }^{3}$ ) so beginnt der Funiculus und

1) Nägeli's Angabe (Stärkekörner p. 391) dass Cynoglossum niemals im Samen Stärke bilde, ist nicht richtig.

2) Vergl. Nãge li, Stärkekörner, p. 387. Ueber Entstehung von Oel aus Stärke vergl. Sachs, Experimentalphysiol. p. $348 \mathrm{ff}$.

3) Näheres bei Sachs, Jahrb. f. wiss. Bot. Bd. III, 1863, p. 232. 
dann auch der Samen einzutrocknen, und hierbei entstehen aus der zwischen den Stärkekörnern ergossenen eiweissreichen Masse die kleinen Proteinkörner (XXXVII, 16b), deren Bildung der geringen Grösse halber nicht näher verfolgt werden kann, indess wohl sicherlich mit der in anderen Samen übereinstimmt. Der beschränkte Raum gestattet eine erhebliche Grössenzunahme der Proteinkörner hier ohnehin nicht, dass aber die geringe Grössenentwicklung derselben nicht auch dem fast gänzlichen Mangel des Oeles zugeschrieben werden kann, folgt daraus, dass die Proteinkörner sehr fettreicher Samen, wie z. B. von Juglans, viel kleiner als die der fettarmen Samen von Lupinus sind.

Kocht man Samenschnitte trockener oder auch annähernd reifer frischer Samen mit Wasser, welches etwas Schwefelsäure enthält, so werden die Stärkekörner unter Verwandlung in Dextrin und Glycose gelöst und es restirt ein aus Proteinstoffen gebildetes Netz in dem an Stelle der Stärkekörner Hohlränme gefunden werden. In diesem Netz, in dem der Protoplasmaleib aufgenommen ist, kann man auch den desorganisirten Zellkeru bemerken.

Ricinus communis.

Die Entwicklung krystalloidführender Proteinkörner untersuchte ich im Endosperm von Ricinus, mit dem Euphorbia segetalis vollkommen übereinstimmt.

Noch während die Samenschale ungefärbt ist beginnt die Trübung des Zellinhaltes und die Entstehung ron Krystalloiden und Globoiden, die, wie auch dic weitere Entwicklung derselben, in dem unteren Theil des Albumens, und hier wieder in den peripherischen Zellen immer roraus ist; namentlich aber ist in den ersten Entwicklungsphasen die Differenz eine erhebliche. Dieses bat den Vortheil, dass man in demselben Samen verschiedene Ertwicklungsstufen der Krystalloide gleichzeitig findet und man braucht desshalb auch die Untersuchung erst mit solchen Samen zu beginnen deren Schale schon rothbräunliche Färbung annahm.

Die beginnende Trübung des Zellsaftes wird wobl wesentlich durch Oeltröpfchen, aber auch nehenbei durch eiweissartige Stoffe veranlasst. Diese körnig erscheinenden Stoffe sind im Zellsaft gleichförmig vertheilt, oder auch um die Protoplasmastränge und 
den Zellkern ${ }^{1}$ ) vorwiegend angehäuft. Gleich darauf trifft man dann im Zellsaft eine geringe Menge kleiner Stärkekörnchen, welche aber bald wieder verschwinden (XXXVII, 8). Diese transitorische Stärkebildung, welche von einigen Forschern übersehen wurde, ist übrigens schon von $\mathrm{Maschke}{ }^{2}$ ) bemerkt worden. Mit der Stärke gleichzeitig treten auch andere Körperchen auf, welche sich mit dem Verschwinden jener ein wenig vergrössert haben und nun der Beobachtung schon besser zugänglich sind. (XXXVII, 9.) Man unterscheidet dann kugelige Gebilde, die Globoide, und die auch jetzt scharfeckig erscheinenden Kry. stalloide, an denen man sobald sie etwas grösser geworden sind, erkennt, dass sie in der Form mit den Krystalloiden reifer Samen übereinstimmen ${ }^{3}$ ) und dasselbe gilt auch für ibr. Verhalten gegen Lösungsmittel (XXXVII, 10 u. 11). In Alkohol behalten die jugendlichen Krystalloide, sowie ältere, ihre Krystallform bei, wenn auch erstere vielleicht ein wenig weicher sind und in Folge dessen eine erheblichere Verringerung ihres Volumens erfahren. Das Behandeln der Samenschnitte mit Alkohol ist jedenfalls zu empfehlen, wenn man Reaktionen über Globoide und Krystalloide anstellen will, um aber deren Entstehung im Zellinhalt zu verfolgen, muss man nothwendig die Schnitte im eigenen Zellsaft betrachten und noch dazu sehr schnell operiren, da baldigst Desorganisation erfolgt; dazu erschwert dann noch der äusserst trübe Zellinhalt die Beobachtung im hohen Grade.

Die mit der fortschreitenden Reifung des Samens allmälig wachsenden Globoide und Krystalloide liegen unmittelbar in dem fettreichen und sehr trüben Zellsaft. Meist liegen die beiden geformten Gebilde so nebeneinander, wie es auch bei Proteinkörnern reifer Samen der Fall ist (XXXVII, 10-12), ja sie können sogar mit einer|gewissen Energie aneinander adhäriren, urd schwimmen dann im desorganisirten Zellinhalt herum obne sich leicht von einander zu trennen. Durch dieses unmittelbare Aneinanderliegen kommt es auch, dass

1) Der Protoplasmaleib ist hier, wie anch in anderen schon beschriebenen Samen ausgebildet. Die Abbildungen welche Gris (Annal. d. sc. naturell, V ser. T. II, Taf. 1, Fig. 6) gibt sind nicht ganz correkt. Die Stränge sind zu zart gezeichnet, die Hüllmasse des Zellkerns und das Wandprotoplasma aber sind ganz übersehen.

2) M a schke, Bot. Zeitung 1859, p. 429. - A. Gris, Annal. d. sc, waturell. V ser., T II, 1864, p. 38. - Ueber das Einwandern der stickstofffreien Stoffe in den Samen von Ricinus vergl. Sachs, Jahrb. f. wiss. Bot. 1863, B̈d. III, p. 234.

3) Schon bemerkt von Hartig, Pflanzenkeim p. 116. 
die Krystalloide reifer Samen an der Stelle wo die Globoide sie berühren zuweilen eine entsprechende Einbuchtung zeigen. Viele Globoide entfermen sich aber auch bei Desorganisation des Zellinhaltes von den unausgewachsenen Krystalloiden und beide scheinen in Jugendzuständen auch weiter von einander entfernt liegen zu können. Das Nebeneinanderlagern der Krystalloide und Globoide findet vielleicht dadurch seine Erklärung, dass mit der Bindung von Phosphorsäure an Kalk und Magnesia die Ausscheidung derjenigen Proteinstoffe veranlasst wird, welche zum Wachsthum der Krystalloide verwandt werden.

Krystalloide und Globoide vergrössern sich allmälich und haben ihre volle Grösse etwa dann erreicht, wenn der Funiculus auszutrocknen beginnt. Bis dahin war von einer Hüllmasse nicbts zu bemerken, welche nun um die einander genähert oder unmittelbar aneinander liegenden Globoide und Krystalloide sich ausscheidet (XXXVII, 12). Dieses gesclieht aber erst während des Austrocknens der Samen, in Folge dessen auch die wasserärmere Grundmasse sich etwas zu klären beginnt. Dass Wasserentziehung die Entstehung der Hüllmasse veranlasst, zeigen evident noch nicht völlig gereifte Samen, welche man nach Entfernung der Schale einige Stunden an der Luft austrocknen lässt. Denn nun findet man eine Hüllmasse, welche in dem Samen zuvor nicht vorhanden war, gebildet. Ueber den Bau der fertigen Proteinkörner wurde schon früher das nöthige mitgetheilt; auch erfuhren wir dort, dass manche Proteinkörner von Ricinus mehrere unvollkommen ausgebildete Krystalloide umschliessen. Es entstehen diese Körner dadurch, dass zwei oder mehrere kleine Krystalloide unmittelbar aneinanderliegen und sich gegenseitig an der Ausbildung verhindern, wie es ja auch bei Krystallen vorkommt, lund dann zusammen mit den anliegenden Globoiden von Hüllmasse umgeben werden.

Die Angaben von Maschke') und $\mathrm{Gris}^{2}$ ), dass die Krystalloide und Globoide innerhalb Vacuolen (Schleimbläschen Ma schke's) entstehen, sind irrig und durch Beobachtung an desorganisirtem Zellinhalt gewonnen, wie denn Gris seine Präparate durch Quetschung erhielt, wobei die Desorganisation ganz unvermeidlich

1) Bot. Zeitung 1859 , p. 430.

2) Annal. d. sc. natur. 1864, V. ser. T. II, p. 39. 
erfolgt. Diese hat zur Folge, wie man namentlich schon an den aus zerschnittenen Zellen hervorquellenden Inhalt sehen kann, dass Vacuolen entstehen, welche zur Zeit wo die Krystalloide und Glo. boide noch sehr klein sind sich ansehnlich vergrössern und endlich nur noch durch ziemlich schmale Streifen getrennt sind, die aus einer mit Proteinstoffen gebildeten fettreichen Emulsion bestehen. Werden die Zellen inhaltsreicher, dann werden die Vacuolen weniger gross, die trennende Masse nimmt hingegen an Mächtigkeit zu. Dem Gesagten entsprechen aber auch genau die von Gris gelieferten Abbildungen. ${ }^{1}$ )

Die Entstehung krystalloidfreier Proteinkörner begann bei allen untersuchten Pflanzen erst in dem letzten Reifungsstadium des Samens und schreitet, während dieser Wasser verliert, ibrem Ende entgegen. ${ }^{2}$ ) Ebenso verhalten sich die Hüllmassen krystalloidführende Proteinkörner, keineswegs aber die Krystalloide selbst, die schon unmittelbar nach Beginn der Einwanderung der Reservestoffe auftreten und gleichzeitig mit dem Fortschreiten derselben wachsen. Da wir Entstehung und Wachsthum der Globoide und Krystalloide gleichzeitig beginnen und fortschreiten sehen, so liegt der Gedanke nahe, dass beide eine genetische Beziehung zu einander haben und ist dieses auch im höchsten Grade wahrscheinlich, wenn wir das früher über die Bedeutung des Kaliphosphates für die Löslicbkeit der Proteinkörner und über die Bildung der Globoide Gesagte berücksichtigen. Bei der Doppelzersetzung von löslichen Magnesia oder Kalksalzen und phosphorsauren Alkalien sind in der That die Bedingungen für das Wachsthum der beiden fraglichen Gebilde gegeben, denn mit der Beseitigung des Kaliphosphates werden die Proteinstoffe in Wasser unlöslich werden und können nun zum Wachsthum der Krystalloide verwandt werden, während das entstehende Erdsalz der gepaarten Phosphorsäure zur Vergrösserung der Globoide dient. Hier drängt sich uns aber die Frage auf, ob dann das Erdsalz und das Kaliphosphat erst in den Endospermzellen zusammentreffen dürfen. Diese Frage muss verneint werden, da, wenigstens in sauren Lö sungen ${ }^{3}$ ) beide Salze nebeneinander bestehen können, wenn es immerhin

1) L. c. Tafel I, Fig. 10-13.

2) Es könnten vielleicht auch Samen gefunden werden bei denen die Bildung der Proteinkörner nicht von dem Wasserverlust des Samens abbängig, sondern durch das Unlöslichwerden von Proteinstoffen bedingt wäre, etwa indem die Phosphorsäure als unlösliches Erdsalz gebunden würde.

3) Dass der Inhalt sauer reagirender Parenchymzellen Magnesia und Phosphorsäure enthält, konnte ich mittlerwe ile auf mikrochemischem Wege feststellen. 
auch möglich ist, dass die fraglichen Salze sich in besonderen Zellenzügen zu dem Samen bewegen. Wir wissen hierüber noch gar nichts, doch wird gewiss eine grössere Menge von Kaliphosphat dem Samen auf demselben Wege wie die Eiweissstoffe zugeführt, welche in den dünnwandigen langgestreckten Zellen des Gefässbündels durch Samenleiste und Funiculns in den Samen einwandern. ") Bei der Einwanderung der Protcinstoffe in den reifenden Samen spielt Asparagin keine rermittelnde Rolle; auch bei den Leguminosen ist zu keiner Zeit Asparagm in jenem zu finden, obgleich hier der genannte Stoff, wic wir noch kennen lernen werden, die Translocation der Proteinstoffe beim Keimen der Samen vermittelt.

Wir haben bis dahin die Entstehung der krystalloidfreien Proteinköruer nur den rein äusseren Erscheinungen nach betrachtet, ohne uns Rechenschaft über die Art ihres Wachsthums zu geben. Dass dieses aber weder durch Apposition, noch durch Intussusception, genau in der Weise wic bei Stärkekörnern, geschehen kann, lässt sich aus der Verthcilung der Einschlüsse in jugendlichen und ausgewachsenen Proteinkörnorn folgern. Wenn zahlreiche Linschluisse in einem fertigen Proteinkorn vorkommen, was bei Globoiden sehr häufig ist, dann sind dieselben oft in der ganzen Masse des Kornes gleichformig vertheilt oder man trifft wohl auch in dem Centrum, in der Peripherie oder an irgend einer Seite eine grössere Menge von Globoiden. Ẻs kann z. B. Lupinus varius 'als gutes Objekt empfohlen werden, da hier die übrigens an Grösse rariabeln Globoide meist gross genug sind, um in Oel als Vacuolen zu erscheinen. Nun trifft man auch schon in jugendlichen Proteinkörnern Globoide und wo die Grösse dieser nicht zu gering ist, kann man sicher nachwcisen, dass in der Grundmasse kaum noch irgend eiu Globoid rorhanden ist, wenn die Proteinkörner noch lange nicht ihre volle Grösse erreichten. So ist es z. B. bei Cynoglossum, in dessen reifen Samen man auch annähernd kugelige Proteinkơrner auffindet, bei welchen von den in mässiger Zahl vorhandenen Globoiden einzelne fast geradezu an die hautartige Begrenzung stossen; und zwar kann dieses gleichzeitig an

1) Die mehrfach aufgetauchte Behauptung dass der Stickstoff in den Pflanzen in einem bestimmten Verbätniss zur Phosphorsüure stehe, scheint mir nicht wahrscheinlich. Die für eine solche Relation angeführten Zahlen zeigeu doch immer eine ansebuliche Amplitude und neuerdings gibt u. a. auch Schroeder direkt an, dass er ein hestimmtes: Verbilltniss zwischen Phosphorsäure und Stickstoff bei der Schminkbohue nicht gefunden habe (Landw: Versuchs-Stat. Bd. X, 1868, p. 501.) 
zwoi gerado entgegengesetzten Seiten oder auch an verschiedenen Stellen des Proteinkornes der Fall sein. Da die Globoide schon sicher in dem Proteinkorn eingeschlossen waren, ehe dieses seinen halben Durchmesser erreichte, so ist ein Wachsthum durch Apposition hier einfach ausgeschlossen, denn ein solches hătte böchstens an den Seiten stattfinden können, an welchen nicht die der Aussenzone eingebetteten Globoide lagen. Wuchs das Proteinkorn an zwei entgegengesetzten Sciten, so würde dasselbe einmal eine mehr oder weniger längliche F'orm angenommen haben und die Verbindungslinie der beiden Globoide hätte den Durchmesser des jugendlichen Proteinkorns nicht überschreiten können.

Bei jugendlichen Proteinkörnern von Lupinus varius fand ich, dass die noch kaum ein Viertel des endlichen Durchmessers erreicht haben. den Körner sehr zahlreiche Globoide ebenso im ganzen Korn vertheilt einschlossen, wie es bei den Proteinkörnern des reifen Samens der Fall ist. Ein Wachsthum durch Intussusception in der Weise wie bei Stärkekörnern hätte aber dahin führen müssen, dass, sei es nun eine centrale oder excentrisch gelegene innere Kornmasse frei von Globoiden blieb. Ich hebe hier noch hervor, dass an eine Neubildung der Globoide in der Proteinmasse des Korns nicht gedacht werden kann, weil zur Zeit, in welcher die Entstehung der Proteinkörner ihren Anfang nimmt, die Vollzahl der Globoide ganz augenscheinlich erreicht ist, wie auch ein Wachsthum schon vorhandener nicht mebr zu bemerken ist.

Aus den rorauggegangenen Betrachtungen folgt aber auch, dass die neu aufgenommenen Substanzmelocüle zwischen denen des wachsenden Proteinkorns sich vertheilen müssen, sei es nun, dass diese Vertheilung völlig oder nur annähernd gleichförmig in derganzen Masse des Kornes stattfindet. Dieses ist aber ohne weiteres bei einer Verschiebarkeit der Molecüle möglich, wie sie den noch wachsenden Proteinkörnern ja wirklich zukommt, da man dieselben beim Aneinanderpressen zum Ineinanderfliessen bringen kann, so wie es ja auch bei Protoplasmamassen und selbst Chlorophyllkörnern geschieht. ${ }^{1}$ ) Auch in dem Hinstreben der Proteinkörner zur Kugelform, so lange sie sich nicht durch gegenseitigen Druck abmodeln, spricht sich die Verschiebbarkeit der Molecüle aus. Wie sich die Proteinkörner ihrer Zusammensetzung aus eiweissartigen Stoffen

1) Nägeli und Schwendener, Mikroskop. 1867, p. 554 . 
nach den Protoplasmagebilden näheren, so thuen sie es auch in der Verschiebbarkeit der Molecüle und zunächst möchte man wohl einen Vergleich der Proteinkörner mit den Clorophyllkörnern anstellen, namentlich wenn diese ärmer an Wasser sind und eine Zähflüssigkeit besitzen, wie sie in höherem Grade auch den wachsenden Proteinkörnern nicht zukommt. Freilich muss dieser Vergleich durchaus nur auf Aeusserlichkeiten sich beziehen, denn nicht nur in der physiologischen Bedeutung ist ein himmelweiter Unterschied zwischen Proteinkörnern und Chlorophyllkörnern, sondern auch in der chemischen Constitution, selbst der Proteinstoffe, da die Chlorophyllkörner zum guten Theil aus in verdünntem Kali unlöslichen eiweissartigen Stoffen zusammengesetzt sind, welche sich überhaupt in allen protoplasmatischen Gebilden in grösserer Menge zu finden scheinen. Die fremdartigen Linschlüsse haben die Pro. teinkörner vor dem Protoplasma nicht roraus, da sich auch in diesem u. a. oxalsaurer Kalk in Krystallen findet und bekannt ist es ja, dass die Myxomyceten in ihrem beweglichen Zustand Körnchen beliebiger Stoffe in sich aufnehmen können, wie es ja auch mehr als wabrscheinlich ist, dass in noch sehr jugendliche Proteinkörner, namentlich wo die Globoide zahlreich sind, Einschlüsse nachträglich eindringen.

Früher lernten wir die Proteinkörner von Paeonia genauor kennen, in denen wenigstens zwei Proteinstoffe gleichformig, aber auch in ungleich quantitativem Verhältniss gemischt sein können, in welchem letzteren Falle eine der Granulose und Cellulose in den geschichteten Stärkekörnern analoge Vertheilung vorliegen kann. Wenn nun auch hier die immer nur in höchst geringer Zahl vorhandenen krystallinischen Einschlüsse einen Beweis gegen das Wachsthum durch Intussusception nach Art und Weise der Stärkekörner, nicht zu erbringen erlauben, so zeigt doch der Unstand, dass man zwei in Wachsthum begriffene Proteinkörner zum Ineinanderfliessen bringen kann, dass auch bei Paeonia die Molecuile wie bei den übrigen Proteinkörnern gegenseitig verschiebbar sind. Dabei ist es ja aber auch möglich, dass die chemisch verschiedenen Proteinstoffe sich in der fraglichen Weise gruppiren, wenn wir über die bedingende Ursache auch nichts Bestimmtes aussagen können. Leider versäumte ich seiner Zeit sicher zu stellen, ob schon die noch wachsenden Proteinköroer beim Behandeln mit Alkohol und Schwefelsäure Schichtung annehmen.

Die grössere Weichheit der inneren Masse der Proteinkơrner 
kann gegen die beigebrachten Argumente nicht für ein Wachsthum durch Intussuception nach der Art der Stärkekörner sprechen, um so weniger, als bei allen protoplasmatischen Gebilden die innere Masse weicher zu sein scheint. In gleicher $W$ eise sind auch aus eiweissartigen Stoffen gebildete kugelige Massen im Innern weicher, welche entstehen, wenn die unvollständig mit Reservestoffen angefüllten Samenlappen von Lupinus, sowohl die reifender als keimen. der Samen, in Alkohol gelegt werden. Dabei können sich diese aus Proteinstoffen bestehenden Kugeln auch um Globoide, bei Lupinus luteus auch um den schon mehrfach erwähnten, in jeder Zelle sich findenden Krystall von oxalsaurem Kalk sammeln. Ob die fraglichen, auch bezüglich der Lờslichkeitsverbältnisse den Proteinkörnern gleichenden Kugeln jenen gleichwerthig zu betrachten sind, lasse ich dahin gestellt, weil ja möglicherweise ein eigenthümlicher vitaler Zustand der Proteinkörner existiren könnte, wie ein solcher für das Protoplasma bekannt ist. Freilich habe ich keine bestimmten Anhaltspunkte für einen solchen vitalen Zustand der Proteinkörner finden können, was indess auch sehr schwierig sein dürfte, weil, auch wenn die Proteinkörner unlöslich sind, doch die Grundmasse sofort durch Wasser desorganisirt wird.

Die in Wasser unlöslichen Proteinkörner genügen den Postulaten, welche Nägeli und Schwedener') bezüglich der Quellungsfähigkeit an organisirte Substanzen stellen und die in Wasser ganz oder theilweise löslichen thuen dieses, sobald die Kaliphosphate, welche die Lösung vermitteln, entfernt sind. Demnach sind aber die Proteinkörner als organisirte Körper zu betrachten, deren Wesen eben in den aus zahlreichen Atomen zusammengesetzten Molecülen und der mit dieser Molecularconstitution Hand in Hand gehenden Imbibitionsfähigkeit beruht. ${ }^{2}$ ) Dass in den wachsenden Proteinkörnern die Molecüle ihre relative Lage leicht ändern ist kein Grund gegen Organisation, denn auch in dem allgemein als organisirt betrachteten Protoplasma sind die Molecüle leicht verschiebbar. Auch der Unstand, dass Wasserentziehung die Bildung der Proteinkörner veranlasst, spricht nicht gegen Organisation; wissen wir doch," dass langsames Austrocknen an dem Protoplasmakörper der Myxomyceten Gestaltungs- und Bildungsvorgänge veranlassen oder begünstigen kann und dann kann man wohl auch

1) Nägeli und Schwendener Mikroskop 1867, p. 417.

2) Ebenda, p. 420. Vergl. auch p. 552 Anmerkung. Ich gebrauche die Worte "Molecül" und "Atom" in gleichem Sinne wio Nägeli. 
an freilich unorganisirte Körper, die Krystalle, erinnern, welche bei Entziehung des lösenden Mediums anschiessen. Ferner ist nicht zu vergessen, dass alles Wachsthum organisirter Körper nur unter Vermittelung gelöster Stoffe möglich ist. Hier sei denn noch speciell darauf aufmerksam gemacht, dass Organisation nur specifisch vitaler Zustand, wie wir ihn an Protoplasma kennen, nicht verwechselt werden dürfen. Auch das todte Protoplasma ist, vorausgesetzt, dass es noch aus Molecülen aufgebaut ist, ein organisirter Körper, und die dem lebenden Protoplasma eigenthümlicken Eigenschaften werden wohl nur durch eine specifische Anordnung der Molecuile bedingt sein.

Ueber die Gestalt der Molecüle, sowohl der Proteinkörner als der Protoplasmagebilde, ist nichts Bestimmtes bekannt. Wenn Sachs ${ }^{1}$ ) eine nicht kugelige Form der Molecüle vermuthet, weil das Protoplasma nach verschiedenen Richtungen hin verschiedene Kräfte geltend mache, so lassen sich hieryegen doch manigfache Bedenken anführen. Dagegen spricht bei den geschichteten Proteinkörnern von Paeonia gegen eine kugelige Gestalt der Molecüle der Umstand, dass in den harten Schichten, wie entstehende Risse zeigen, Quellung in Richtung der Tangenten rorwiegt. Wie $\mathbf{N} a ̈ g \in \mathrm{li}^{2}$ ) zeigte, muss sich aber ein Molecül in Richtung seines kleinen Durchmessers mit einer dickeren Wasserhülle umgeben, als in Richtung seines grösseren Durchmessers. Prülung im polarisirten Licht gibt sowohl mit Proteinkörnern, als mit Protoplasinagebilden negatives Resultat, doch sind hierdurch krystallinische Substanzmoleculle noch nicht unmöglich geworden, weil deren Anorùnung eine solch $\mathrm{e}$ sein kaun, dass keine nachweisbare Gesammtwirkung zu Stande kommt, oder auch die krystallinischen Molecüle dem regulären System angehören könnten.

Die Hüllmasse krystalloidführeuder Proteinkörner stimmt mit der Proteinmasse krystalloidfreier Proteinkörner übercin, den Krystalloiden hingegen kommen krystallinische Molecüle zu deren ho. mologe Achsen gleich gerichtet sind, ${ }^{3}$ )

Auch die Grundenasse, in der Proteinstoffe und Fett innig gemengt sind, kann man vielleicht als organisirten Körper ansehen. Ich verglich jene schon früher einem Protoplasma, in welchem das Wasser durch $\mathrm{Oel}$ ersetzt ist, welcher Vergleich übrigens ein rein bildlicher sein soll.

1) Sachs, Experimentalphys., p. 445.

2) Nã geli, Stärkskörner p. 334 u. 355.

3) Nägeli, Sitzungsber. der Münchener Acal. 1862, Bd. II., p. 142. 
Untersuchungen über d. Proteinkörner und d. Bedeutung d. Asparagins etc. 525

Veränderung der Proteinkörner beim Keimen.

Beim Keimen der Samen werden die metaplasmatischen Stoffe unter Aufösung der Proteinkörner wieder in innige Mischung zurückgeführt und bilden eine ähnliche trübe Emulsion, wie sie der Entstehung der krystalloidfreien Proteinkörner vorausging. Wir wollen diesen Vorgang zunächst bei Lupinus luteus, mit welchcr Pflanze übrigens andere Arten dieser Gattung übereinstimmen ins Auge fassen.

Bei der mit Aufquellen rerbundenen Wassereinsaugung des Samens nehmen die Proteinkörner wieder die zähflüssige $\mathrm{Be}$ schaffenheit an, welche dieselben vor dem Austrocknen des reifenden Samens besassen.(XXXV1II, 16) und ihre Mischung mit der Grundmasse beginnt schon während die Wurzel hervorbricht. Die Proteinkörner sclımelzen hierbei sehr gewöhnlich gleichsam von Aussen ab, sei es nun dass dieses gleichförmig geschicht oder dass einzelne Stellen wie angefressen erschcinen; an anderen Körnern beginnt aber auch die Lösung im Innern (XXXVIII,17). Dabei kommt nun freilich kein faktischer Hohlraum im Innern zu Stande, sondern es entsteht hier nur eine sehr weiche Masse, voraussichtlich weil eben bei der Verschiebbarkeit der Molecüle anch bei alsfälliger totaler Lösung der Innenmasse Ersatz von angrenzenden äusseren Kugelschalen des Proteinkornes geleistet werden kann Die Verschiebbarkeit der Molecüle ist offenbar auch der Grund wesshalb die Proteinkörner, welche von Aussen abzuschmelzen scheinen, meist eine kugelige Furm bewahren und man kann hier auch nicht behaupten, dass die Lösung wirklich genau von äusseren zu inneren Molecularschichten des Proteinkorns vorrücke; denn es könnte ebenso gut aus der ganzen Masse des Kornes Substanz entfernt werden, während die zurückbleibende Masse vermöge der Verschiebbarkeit ihrer Theilchen näher zusammen. rückt und sich zur Kugelform abrundet. Noch ehe die Samenschale abgestreift wurde, sind aber die Reservestoffo zu trüber Emulsion gemengt, während mittlerweile auch schon anderweitige Veränderungen vorgingen (XXXVIIl, 18).

Schon vor dem Hervorbrechen der Wurzel zeigen sich einzelne Stärkekörnchen in der Grundmasse und noch lange ehe die Lösung der Proteinkörner vollendet ist, entstehen kleine Chlorophyllkörner, die vielleicht einfach eine Regeneration der im reifenden Sa- 
: en vorhandenen Chlorophyllkörner sind, da ja deren protoplasmatische Grundlage in auggetrockneter Form im Samen erhalten blieb. Durch direkte Beobachtung ist hierüber kaum Gewissheit zu erlangen; jedenfalls entstehen aber noch ausserdem Chlorophyllkörner. da es u. a. auch rorkommt, dass um Stärkekörner, ähnlich wic bei Kartoffeln, sich ergrünende Masse sammelt. ${ }^{1}$ ) Die Chlorophyllkörner treten auch hier nur in dem Protoplasma auf, sowohl in der Hülmasse des Zellkerns, als auch in den Strängen und dem Wandprotoplasma, wie man sich überzeugen kann sobald die Lösung; der Proteinkörner weiter fortgeschritten oder rollendet ist. Denn dann gelingt es in dem trüben Zellinhalt, wenn auch immer nur schwierig, den Protoplasmaleib einigermaassen zu übersthen, welcher den in reifenden Samen ähnlich gestaltet ist (XXXYII, 18). Schon bei dem Aufquellen des Samens kehrt der cingeschrumpfte Zellkern zu der Gestalt zurück, welche er im reifen Samen hatte und hiernach kann kein Zweifel sein, dass überhaupt der gauze eiugetrocknete Protoplasmaleib, welcher ja faktisch in der Grundmasse vorhanden ist, wieder lebensthätig wird, womit ihm dann natürlich auch die Fähigkeit der Gestaltsveränderung wieder zukommt.

In dem Zelliwhalt tritt, in dem Maasse als er durch Entleerung der Reservestoffe durchsichtiger wird, der Protoplasmaleib deutlicher hervor und später sind dann nur noch in dem Wandprotoplasma Chlorophyllkörner zu finden, welche in den entfalteten Cotyledonen durch ihre eigene assimilirende Thätigkeit geschaffene Stärkekörner einschliesseu. Die Globoide haben sich allmälich aufgelöst, doch erlaubt ihre geringe Grösse bei Lupinus nicht die Auflösung näher zu verfolgen; die tafelförmigen Krystalle von oxalsaurem Kalk trifft man aber zu allen Zeiten in den Samenlappen, wenn sie auch Spuren von Auflösung zeigen können (XXXVIII, 18).

Das Hüllhäutchen der Proteinkörner ist später nicht mehr in dem Zellsaft aufzufinden, es wird also aufgelöst werden oder sich wenigstens in dem Zellsaft vertheilen.

Aehnlich wie bei Lupinus sind die Veränderungen welche bci Silybum marianum die Proteinkörner erfahren und auch hier sind die Reservestoffe schon vor dem Abstreifen der Samenschale zu trüber Emulsion gemengt. Gleich mit der ersten Regung des

1) Vergl. Sachs, Experimentalphys. p. 315 u. 316. 
Keimens sammelte sich eine dickere Schicht von Wandprotoplasma an, welche schon dann hervortritt, wenn die Auflösung der Proteinkörner noch nicht weit vorgeschritten ist, was übrigens erst nach Behandlung von Samenschnitten mit Alkohol und kalihaltigem Wasser gut zu bemerken ist. Man erhält jetzt noch in dieser Weise ein mehr oder weniger vollständiges Netz, in dem an Stelle der Proteinkörner Hohlräume erscheinen, in welchem aber die $\mathrm{Zu}$ nahme der Wandprotoplasmas sehr wohl zu erkennen ist. Ist die Auflösung der Proteinkörner weiter vorgerückt, so kann ein Grundmassennetz natürlich nicht mehr erhalten werden, wohl aber gelingt es nun bei gleicher Behandlung den Protoplasmaleib, wenn auch gewöhnlich nur unvollständig freizulegen. In dem ansehnlichen Wardprotoplasma beginnt schon ehe die Proteinkörner völlig gelöst sind die Bildung von Chlorophyllkörnern, welche dem Embryo in reifenden Samen fehlen. (Vgl. XXXVIII, 4.)

Die Einschlüsse liegen nach Verschwinden der Proteinkörner anfangs wohl noch gruppenweise zusammen, vertheilen sich aber bald beliebig in dem Zellsaft. An den Globoideu beginnt sehr zeitig eine Lösung, welche schon mit Entfaltung der Samenlappen bemerklich, mit dem Hervortreten einiger Laubblätter des Keimpflänzchens vollendet ist. Die Lösung schreitet gewöhnlich von A ussen nach Innen fort, wobei das zarte Häutchen bestehen bleibt (XXXV1II, 5), innerhalb dessen der sich lösende Kern vor dem völligen Verschwinden wohl auch in einige Stiucke zerfallen kann. Statt eines zarten Häutchens kann der in Lösung begriffene innere Theil des Globoides auch von einer mächtigeren Kugelschale umgeben sein, welche alicr nicht aus der unveränderten Masse einer äusseren Kugelschale des Globoides besteht, sondern im Ansehen den bei Einwirkung von concentrirtem Kali zurückbleibenden kohlensauren Erden gleicht. Andere Globoide werden von einzelnen Stellen aus angegriffen und bei manchen beginnt die Veränderung im Innern. Dann konnte ich zuweilen zarte oder gröbere Spalten an dem Globoide finden (XXXVIII, 5), in anderen Fällen war dieses allerdings nicht möglich, doch dürften auch hier wohl sehr feine Risse vorhanden gewesen sein, da ohne diese ein Beginn der Lösung in Centrum der nicht imbibitionsfähigen Globoide unverständlich wäre.

Die krystallinischen Einschlüsse hingegen werden bei Silybum gar nicht verändert (XXXVIII, 4) und finden sich noch in den absterbenden Cotyledonen grösser gewordener Pflanzen, in denen 
übrigens Kryställchen von oxalsaurem Kalk noch neu gebildet sind. Demnach ist der oxalsaure Kalk hier, wie nach Holzner ${ }^{1}$ ) ïberall. Auswurfsstoff, während derselbe nach $\mathrm{Aé}^{2}$ ) in der Pflanze wieder aufgelöst und dann die darin enthaltene Oxalsäure weiter rerwandt werden soll. Allgemein gilt dieses nun ganz gewiss nicht, ob aber nicht in anderen Fällen eine Lösung des oxalsauren Kalkes rorkommt, lasse ich dahin gestellt; Spuren von Lösung konnten, wie schon bemerkt wurde, an den Krystallen in den Samenlappen blühender Pflanzen ron Lupinus luteus bemerkt werden. Jedenfalls kann man die Auflösung des oxalsauren Kalkes nicht a priori für unmöglich erklären, weil keine der organischen Säuren, welche in der Pflanze allein im freien Zustand vorkommen werden, Kalkoxalat aufzulösen vermag, denn bekanntlich werden in der Pflanze viclfache Entbildungen und Bildungen ausgefülurt, welche die Chemic bis jetzt nicht nachzuahmen' vermag. Es muss aber auch im Auge behalten werden, dass, wie ich früher bemerkte, die für oxalsauren Kalk gehaltenen Krystalle auch aus oxalsaurer Magnesia bestehen könnten, welche sich, wenn auch nur in sehr geringer Menge, in Wasser auflöst.

Die oben betrachteten Samen waren solche in denen Stärke bcim Keimen nur spärlich, in den Samenlappen wenigstens, auftritt, während andere Samen, wie Delphinium Requieni und Conrolvulus tricolor massenhaft Stärke in allen Organen, die erstgenannte Pflanze auch im Endosperm produciren. Bei Delphinium Requieni beginnt die Stärkebildung aber erst nachdem Oel und Eiwcissstoffe sich zu trüber Emulsion rereinten und wenn auch bei Convulvulus Aufösung der Proteinkörner nnd Stärkebildung gleichzeitig stattfinden, so rerwandelt sich doch niemals ein Proteinkorn in ein Stärkekorn, wie dieses nach $\mathrm{Hartig}{ }^{3}$ ) bei manchen Pflanzen vorkommen soll. Eine solche direkte Umwandlung ist ganz nndenkbar, wenn die Möglichkeit auch vorliegt, dass durch Spaltung aus Proteinstoffen ein Kohlehydrat nebenbei entsteht, wie ja im thierischen Organismus Fett aus eiweiss. artigen Stoffen gebildet wird. Ebenso wenig wird jemals aus einem Proteinkorn, indem dieses einfach ergrünt ein Chlorophyllkorn; schon der Umstand, dass das Chlorophyll stets dem Protoplasma

1) Holzner, Flora 1867, p. 515 ff.

2) Aé, Flora 1869, p. 183 ff.

3) Hartig, Pflanzenkeim p. 126. 
die Proteinkörner aber immer dem Metaplasma angehören, kann hier zur Widerlegung dienen. Wie aber diese rückschreitenden Verwandelungen der Proteinkörner niemals vorkommen, entstehen dieselben auch nie aus Stärke- oder Chloroplıyllkörnern, was H artig gleichfalls behauptet. Uebrigens ist schon $\mathrm{Gris}^{1}$ ) der ganz und gar irrigen Ansicht Hartig's entgegen getreten.

Die Veränderungen, welche krystalloidführende Proteinkörner beim Keimen erfahren, verfolgte ich namentlich in dem Endosperın von Ricinus. Gleich bei der Wassereinsaugung durch den Samen mischt sich die gelöst werdende Hüllmasse mit der Grundmasse zu einer trüben Emulsion und damit ist das Bild regenerirt, welches der reifende Samen unmittelbar vor Entstehung der Hüllmasse darbot. Dann beginnt aber auch bald die Lösung der Krystalloide, welche sich in verschiedener Weise abwickeln kann. Oft nimint die Lösung innerhalb einer nur dünnen oder auch etwas mächtigeren Schicht ihren Anfang, die später aber selbst bis auf das Hüllhäutchen verschwindet, und schreitet centripetal fort, wobei dann der in Lösung begriffene Kern solid bleiben oder auch in zwei oder mehrere Stücke zerfallen kann (XXXVII, 7, a-c). ${ }^{2}$ ) In anderen Fällen beginnt die Lösung im Inneren unã rückt nach Aussen vor, bis hier, wie auch endllich bei dem erst beschriebenen Modus nur ein zartes Häutchen bleibt (XXXVII, 7, e u.g) Aebnlich wie bei den Stärkekörnern ${ }^{3}$ ) innerhalb der Pflanze, findet also auch bei den Krystalloiden bald centripetal bald centrifugal fortschreitende Lösung statt, und ist bald die erstere, bald die letztere Lösungsart überwiegend. Ausserdem können aber auch die Krystalloide von einer oder einigen Stellen aus angegriffen werden (XXXVII, 7, f) und von hieraus setzt sich dann die Lösung, im Innern sich ausbreitend, fort. Liegen zwei oder einige Krystalloide in einem Proteinkorn unmittelbar aneinander, so können dieselben zusammen bei der Lösung sich wie ein einzelnes Krystalloid verhalten, oder auch in jedem einzelnen Korn schreitet die Lösung, sei es nun von Innen oder von Aussen fort. Die äussere ungelöste Zone bewahrt mehr oder weniger die Gestalt des Krystalloides, während das endlich allein restirende Hüllhäutchen eine grössere oder geringere Alurundung erfährt. Man kann die beschriebenen

1) Gris, Annal. d. scienc. naturell. 1864, V ser. T II, p. 62.

2) Solche Krystalloide sind es, welche Gris abbildet, 1. c. Taf. I, Fig. 16.

3) Nägeli, Stärkekörner, p. 93. 
Lösungserscheinungen in dem trüben Zellinhalt nur schwieriger studiren, kommt aber leicht zum Ziele, wenn man Samenschnitte mit Alkohol auszieht und dann in Wasser betrachtet.

Etwa gleichzeitig mit dem Herrorbrechen der Wurzel des Embryos beginnt die Lösung der Krystalloide im Endosperm und zwar zuerst in dem inneren Theile, in welchem auch die Entwickelung der Krystalloide im reifenden Samen vorauseilte. Die Auflösung der Krystalloide sowohl, als auch der Globoide ist längst vollendet ehe die Samenlappen aus dem Endosperm hervortreten. ${ }^{1}$ ) Wenn dieses geschieht hat das Zusammenschrumpfen des Endosperms schon begonnen und in seinen Zellen findet man sehr wässrigen Inhalt, in dem neben dem theilweise in Desorganisation begriffenen Protoplasmaleib nur spärlich Eiweissstoffe gelöst sind, welche zu kleinen Kugeln zusammenwandern, wenn das ganze Endosperm in Alkohol gelegt wird.

Die Auflösung der Hüllmasse, der Krystalloide und Globnide geht bei Cucurbita Pepo in gleicher Weise wie bei Ricinus vor sich. Bei Curcurbita beginnt die Lösung in Wurzel und hypocotylem Gliede, darauf auch gleich in der Basis der Cotyledonen, von wo aus sie nach der Spitze dieser vorrückt und bier fast vollendet ist, wenn die Samenschale eben abgestreift wird. Auch tritt gleich mit dem Keimen in den parenchymatischen Zellen der Samenlappen ein dichtes Wandprotoplasma auf und noch ehe die Auflösung der Krystalloide ganz vollendet ist, beginnt jenes durch Zcrfällung Chlorophyllkörner zu bilden. ${ }^{2}$ )

Die Bedeutung des Asparagins beim Keimen.

Betrachteten wir eben die Auflosung der Proteinkörner der äusseren Erscheinung nach, so werden wir jetzt einen beim Keimen aus den Eiweisskörpern entstehenden Körper, das Asparagin, ins Auge fassen, welches, wenigstens bei den Papilionaceen, wie ich zeigen werde, eine höchst wichtige Rolle bei der Translocatiou der Proteinstoffe spielt.

Dass das Asparagin, welches als ein beim Keimen von Samen

1) Ueber die Keimung von Ricinus vergl. Sachs, Lehrbuch II. Aufl, p. 603.

2) Ueber Keimung von Cucurbita siehe Sachs, Bot. Ztg. 1859, p. 186 und Jahrb. f. wiss. Bot. III, p. 214. 
Untersuchungen über d. Proteinkörner und d. Bedeutung d. Asparagins etc. 531

häufiger auftretender Körper bckannt ist, notbwendig aus den Proteinstoffen entstehen muss, lässt sich aus den bekannten Thatsachen ohne weiteres folgern. Wie es als durchaus sichergestellt anzusehen ist, dass Pflanzen atmosphärischen Stickstoff nicht assimiliren können, ${ }^{1}$ ) so wurde auch durch eine schr exakte Untersuchung von Boussingault ${ }^{2}$ ) gezeigt, dass keimende Pflanzen ihren absoluten Stickstoffgehalt nicht verändern, vorausgesetzt natürlich, dass assimilirbarer gebundener Stickstoff (Salze von Ammoniak oder Salpetersäure) nicbt zugeführt wird. Anderseits wissen wir aber, dass fast der ganze hobe Stickstoffgehalt der Samen in den Proteinstoffen enthalten ist, denn Salze des Ammoniaks oder der Salpetersäure finden sich nicht im Samen und wenn andere stickstoffhaltige Körper, wie Alkaloide, gewisse indifferente Stoffe u. s. w. vorkommen, so ist dieses doch einmal nicht in allen Samen der Fall und dann ist deren Menge nur sehr gering, so dass der so gebundene Stickstoff immer nur einen sehr kleinen Bruchtheil von dem hohen Stickstoffgehalt des reifen Samens ausmacht. Wenn aber nun beim Keimen mancher Samen, bei unverändertem absoluten Stickstoffgehalt, Asparagin in Menge entsteht, welches selbst reicher an Stickstoff als die Proteinstoffe ist, ${ }^{3}$ ) so muss dasselbe ganz nothwendig aus den als Reservestoffe aufgespeicherten eiweissartigen Körpern hervorgegangen sein. Damit ist natürlich nicht gesagt, dass dieses durch glatte Reaktionen geschehen muss, und wenn auch, so bleibt die Aufstellung von Zersetzungsgleichungen doch Sache der Chemie, die einen genetischen $\mathrm{Zu}-$ sammenhang $\mathrm{zwischen}$ Asparagin und Proteinstoffen noch nicht aufgeklärt hat. Das einzige hier Bekannte ist, dass, wie Ritt.

1) Siehe Sachs, Exphys, p. 133. - Meyer, Lehrb. der Agrikulturchemie 1871 , p. 154 ff.

2) Boussingault, Agronomie, Chimie agr. et Physiol. 1868, Bd. IV, p. 245 ff. H. K arsten, (Landwirthschafti. Versuchsstationen 1871, Bd. 13, p. 193) behauptet, dass die Schminkbohne beim Keimen einen ansehnlichen Verlust im absoluten Stickstoffgehalt erfahre, doch halte ich einstweilen an den Resulten der durch ihre Exaktheit bekannten Untersuchungen Boussingault's fest. Karsten hat sich übrigens in der citirten Arbeit ganz unrichtige Schlussfolgerungen zu Schulden kommen lassen, worüber ich später noch eine Notiz bringen werde.

3) Nach Kolbe, organ. Chemie, Bd. III, 1868, p. 402 schwankt der procentische Stickstoffgehalt der verschiedenen Proteinstoffe (von Emulsin mit 11,5 Procent abgesehen) zwischen 15,6 und 18,2 Procent; Asparagin enthält 21,2 Procent Stickstoff. 
hausen und Kreusler') nachwiesen, alle untersuchten Eiweissstoffe beim Kochen mit verdünnter Schwefelsäure, neben anderen Zersetzungsprodukten, Asparaginsäure lieferten, welche aber auch, neben schwefelsaurem Ammoniak, aus dem Asparagin beim $\mathrm{Be}$ handeln mit Schwefelsäure entsteht.

Aber auch ohne dass die Chemie die genetischen Beziehungen anfgeklärt hat, kann für gewisse Körper die Pflanzenplysiologie dennoch ihre Aufgabe bis zu einem gewissen Grade lösen, nämlich die in der Pflanze vorkommenden Stoffe als Mittel und Zweck der Lebensthätigkeit kennen $\mathrm{zu}$ lernen. Ich brauche hier nur an die $\mathrm{Be}$ ziehungen zwischen Oel, Stärke und löslichen Kohlehydraten einer seits nnd der Zellhaut andererseits zu erinnern; was aber jene für diese sind, das ist das Asparagin beim Keimen der Leguminosen für die eiweissartigen Inhaltsstoffe der Zellen. Das Asparagin geht nämlich aus den Reserve-Proteinstoffen herror, wandert zu den wachsenden Organen und wird hier zu Eiweissstoffen regenerirt.

Die Entstehung des Asparagins aus Proteinstoffen und umgegekebrt wurde bereits von $\mathrm{Hartig}^{2}$ ) angenommen, indess durch kein sicheres Argument gestützt und die Ansichten des genannten Autors über die Rolle des Asparagins sind theilweise durchaus unklar und falsch, so die Annahme dass auch Oel aus dem Asparagin gebildet werde. Da Hartig das Asparagin nur mikro. chemisch nachwies, ohne irgend welche Studien zum Aufhellen der physiologischen Bedeutung anzustellen, so konnte er hierüber auch keine bestimmten Schlüsse ziehen, so wenig als dieses aus dem makrochemischen Nachweis des Asparagins in Pflanzen, die mit Haut und Haaren der Analyse unterworfen wurden, möglich ist. Hartig selbst indentifizirt nun freilich die Krystalle, welche er erhielt indem er zu Schnitten Alkohol treten oder diese in Ocl austrocknen liess, nicht mit dem Asparagin, sondern nennt dieselben Gleis, und glaubt dass sie aus einem stickstoffhaltigen, dem Asparagin verwandten Stoff bestehen, Es kann aber keine Frage scin, dass Hartig wirkliche Asparagin-Krystalle unter Augen gehabt hat, doch dürfte er auch andere Kryställchen, welche vor-

1) Ritthausen, Journ. f. prakt. Chemie 1869, Bd. 107, pag. 218. - Ritthausen u. Kreusler, ebenda 1871 (II), Bd. 3, p. 314 . Nachzutragen ist, dass später auch von Hlasiwetz und Habermann (Annal. d. Chem. u. Pharm. 1871, Bd. 139, p. 329) durch Einwirkung von Brom auf Proteinstoffe Asparaginsäure neben anderen Zersetzungsprodukten gewonnen wurde.

2) $\mathrm{H}$ artig, Pflanzenkeim p. 128. 
Untersuchnngen über d. Proteinkörner und d. Bedeutung d. Asparagins etc. 533

aussichtlich aus verschiedenen Salzen anorganiseher und organischer Säuren bestehen, mit seinem Gleis verwechselt haben und so zu der irrigen Ansicht von der allgemcinen Verbreitung des Asparagin's (Gleis) gekommen sein; doch davon später.

Eine quantitative analytische Arbcit über die Keimung der gelben Lupine, die für uns sebr werthvoll werden wird, theilte Beyer ${ }^{1}$ ) mit, welcher keine eigene Ansicht über die physiologische Bedeutung des Asparagins ausspricht, sondern sich auf einfache Mittheilung der Anschauung Hartig's beschränkt.

Sachs ${ }^{2}$ ) vermuthet nur dass ans Asparagin auch wieder Eiweissstoffe entstehen; über die physiologischen Functionen jenes spricht er sich nicht aus, wie dieses auch auf Grund der vorliegenden Arbeiten nicht möglich war. ${ }^{3}$ ) Wenn aber Boussingault*) das Asparagin als ein Nebenprodukt des Stoffwechsels betrachtet, und dem thierischen Harnstoff vergleicht, so sind hier seine Schlussfolgerungen unrichtig, denn aus dem von unserem Autor selbst gelieferten Nachweis, dass der absolute Stickstoffgehalt beim Keimen der Samen sich nicht verändert und der Kenntniss, dass A sparagin in den am Licht wachsenden Pflanzen versch windet, folgt zunächst, dass es jedenfalls weiter in der Pflanze rerwendet wird.

Um über die Bedeutung der Asparagins bei Translocation der Proteinstoffe in's Klare kommen zu können, war es durchaus nothwendig jenes mikrochemisch nachweisen zu können, was mittelst absoluten Alkohols, in dem das Asparagin fast ganz unlöslich ist, gelingt Wenn sich Asparagin in grösserer Menge findet, wie dieses zu gewissen Zeiten bei keimenden Lupinen und anderen Papilionaceen der Fall ist, kann man es unmittelbar in den Zellen in Krystallen niederschlagen, indem man Schnitte von solcher Dicke dass nicht alle Zellen geöffnet sind in absoluten Alkohol, welcher sich in Uhrschälchen befindet wirft und durch Herumschwenken das Eindringen des Alkohols befördert. Dass dieses schnell geschieht ist wichtig, weil sonst viel Asparagin aus den Zellen diosmirt, welches sich theilweise wohl auf den Schnittflächen ausscheidet, zum Theil aber auch ganz austritt und sich in Kryställchen an den Wänden des Uhrschälchens absetzt.

1) Beyer, Die Laniwirthschaftl. Versuchsstationen 1867, Bd. 9, p. $186 \mathrm{ff}$. auch Archiv f. Pharmacie 1867, p. 201 ff.

2) Sachs. Lehrb. II. Aufl. p. 593, Experimentalphysiol. p. 344.

3) Auch Ma yer (Lehrb. d. Agrikulturchemie 1871, p. 210) erklärt, dass über die physiol. Functionen des Asparagins nichts bekannt sei.

4) Boussingault, Agron, Chim. agr. et Physiol. 1868, Bd. IV, p. 265. 
Aus den angegebcuen Gründen ist es aucb nicht räthlich die Schnitte ron zu grosser Dicke anzuwenden. Sind aber die Gcwebe zu arm an Asparagin, so gelingt dessen Nachweis in der angegebenen Weise nicht mehr, wohl aber indem man mässig dicke Schnitte auf den Objektträger legt und nun zu diesem Alkohol treten lässt. Dabei bedarf es indess, namentlich wenn es sich um kleine Mengen von Asparagin handelt, einiger Uebung; denn einmal darf der Alkohol nicht zu sclinell in die Zellen eindringen, damit das Asparagin aus denselben heraus diosmirt, und doch darf auch der Alkohol in der Umgebung des Schnittes nicht zu rerdünnt werden, weil sich dann kein Asparayin ausscheidet. ${ }^{1}$ ) Bei höherer Sommertemperatur wird durch das Verdunsten des Alkohols ein öfteres Nachgeben nothwendig und dieses reicht gewöhnlich gerade aus um ein günstiges Resultat zu crzielen. Andernfalls wird man aber gut thun einen sehr langsamen Strom von Alkohol durch ein wenig aufgelegtes Fliespapicr unter dem Deckglas zu unterhalten. Auf diese Weise kann man bei genügender Uebung noch sehr kleine Mengen Asparagin nachweisen; die ron Hartig auch angewandte Methode, Samenschnitte längere Zeit untcr Oel liegen zu lassen, ist weniger genau und noch dazu schr langsam ausführbar. Bei der letzt angegebenen Behandlung mit Alkohol schiesst das Asparagin in der Näho des Schnittes oder auch auf demselben in leicht kenntlichen Krystallen an, welche bei nicht zu geringer Menge erhebliche Grösse erreichen können.

Die Grundform der Asparagin-Krystalle ist ein, rhombisches Prisma, an dem sehr charakteristische hemiedrische Abstumpfungen der Kanten der Endflächen vorkommen. Es sind nämlich je zwei opponirte, an den beiden Endflächen aber gerade die entgegengesetzten Kanten durch Pyramidenflächen mehr oder weniger abgestumpft, ${ }^{2}$ ) durch deren Vergrösserun Raumes ein rhombisches Sphenoid entstehen würde.

Die genannten so schr charak teristischen Formen sind an den innerhalb oder ausserhalb der Pflanzenzellen crhaltenen Krystallen nicht häufig und öfters sind dann an denselben Ecken durch Pyramidenflächen oder Seitenkanten durch Domaflächen abgestumpt. Die Prismen können säulen- oder tafelförmig sein, in welcher letzterer

1) Nach Biltz lösen 500 Theile 60 procentigen Weingeistes 1 Theil Asparagin.

2) Pasteur, Annal. d. chim. et d. phys. 1851, III ser., Bd. 31, p. 72 und Taf. I, Fig. 1 u. 2. 
Form, oft mit Abstumpfung der makrodiagonalen Kante, man sie namentlich erhält, wenn man zu ein wenig reiner Asparaginlösung auf dem Objektträger plötzlich Alkohol treten lässt. Ferner kommen auch rhombische Syhenoide vor und häufig auch einfache oder mehrfache Durchkreuzungs-Zwillinge, welche beim Präciptiren reiner Asparaginlösung auf dem Objekträger immer nur spärlich auftreten. Die genanuten, sowie noch andere abgeleitete Formen und auch unvollkommene Krystallgestalten treten nebeneinander oder auch einzelne vorherrschend auf, ohne dass man die Ërzeugung bestimmter Formen in der Gewalt hat. Wenn bei Verwendung ron Schnitten aus Keimpflänzchen oft vorwiegend Formen anschiessen, welche man aus reiner Asparaginlösung bei Behandlung mit Alkohol auf dem Objektträger nur selten erhält, so kann dieses nicht weiter auffallen, da für thierische Flussigkeiten ein analoges Verhalten bei zahlreicheren Körpern bekannt ist. Doch wird man beim Vergleich der aus reiner Asparaginlösung und aus Pflanzentheilen niedergeschlagenen Krystalle über die Identität beider nicht in Zweifel bleiben.

Die erhaltenen Asparaginkrystalle sind ohne Asche unter Verkohlung verbrennhar. Schon desshalb könnte von den häufiger in den Pflanzen vorkommenden Stoffen nur noch Rohrzucker vorliegen, welcher beim Behandeln mit Alkohol nur sehr schwer in Krystallen erhalten wird und zudem den meisten Pflanzen fehlt. Die häufigeren organischen Säuren der Pflanze sind in freien $Z_{11}$. stand in Alkohol löslich, ebenso Glycose, während Gummi, Dextrin und Pektin nicht krystallisiren. Auch kann man das lasurblaue Asparagin-Kupferoxyd unter Deckglas, wenn auch nicht leicht, darstellen, indem man alkoholische Lösung von neutralem essigsaurem Kupferoxyd zu Pflanzenschnitten treten lässt. Leider eignet sich diese in Wasser fast unlösliche Kupferverbindung nicht wohl zum Nachweis des Asparagins in den Pflanzen, denn einmal entsteht sie nicht immer sogleich und dann löst sie sich sehr leicht in verdünnten Säuren oder Alkalien. Der flüssige Inhalt parenchymatischer Zellen reagirt aber bei allen untersuchten Papilionaceen stark sauer. Krystallform, Verbrennlichkeit und die Kupferverbindung lassen aber über die Identität des fraglichen Körpers mit Asparagin um so weniger $\mathbf{Z}_{\text {weifel, als wir wissen, dass dieses }}$ bei den keimenden Leguminosen in Menge entsteht.

Wenn man Schnitte aus Pflanzentheilen unter Deckglas mit Alkohol behandelt, so schiessen neben dem Asparagin, wenn solches 
vorhanden ist, auch noch Kryställchen an, die aber immer nur sehr klein bleiben und schon desshalb mit dem Asparagin, dessen Krystalle erheblichere Grösse erreichen, durchaus nicht verwechselt werden können. Diese Kryställchen sind bestimmt verschiedene Salze auorganischer Basen, jedenfalls mit verschiedenen Säuren, die theilweise wohl organisch sind, doch kommt wohl sicher auch Salpetersäure namentlich in schon etwas älteren Pflanzen vor. Trotz der sehr geringen Grösse babe ich doch für die fraglichen Kryställchen einen feuerbestäudigen Rückstand immer nachweisen können; nur manche Kryställchen vegetirender Gewächse scheinen ganz flüchtig zu sein und könnten wobl aus Ammoniaksalzen bostehen.

Wenden wir uns nun zur Keimung des Samens der gelben Lupine, welche sich zum Studium über die physiologische Bedeutung des Asparagins vortrefflich eignet und uns den Vortheil gewährt, dass für zwei jugendliche Keimungsstadien quantitative Bestimmungen der Pflanzenstoffe durch Beyer vorliegen.

Der ruhende Samen, welcher schon oft erwähnt wurde, enthält in den Zellen, in nicht zu reichlicher und fettärmerer Grundmasse, mchr oder weniger polygonale Proteinkörner, von denen ein durch Grösse ausgezcichnetes Korn einen Krystall von oxalsaurem Kalk einschliesst, während die anderen Köner zablreiche und sehr kleine Globoide führen. Den hohen Gehalt unseres Samen an Proteinstoffen zeigt die Lier folgende Aualyse Beyer's '), welche sich auf bei $100 \mathrm{C}$. getrocknete, von den Samenschalen befreite Einbryonen bezieht.

$$
\begin{aligned}
& \text { Mineralstoffe . . . . . 4,22 } \\
& \text { Fettes Oel .. . . . . 6, 6, 62 } \\
& \text { Zucker und Bitterstoff . . 10,61 } \\
& \text { Gummi . . . . . . 6,92 } \\
& \text { Zellstoff, Pektinkörper (Stärke) 10,96 } \\
& \text { Eiweisskörper . . . } \frac{61,27}{100,0}
\end{aligned}
$$

Aus den über zwei noch näher zu bezeichnende Keimungsperioden vorliegenden Analysen Beyer's, welche ausser den eben genannten Pflanzenstoffen auch das gebildete Asparagin berücksichtigen, theile ich hier den Gebalt an Eiweisskörpern, Asparagin und absoluter Stickstoffmenge mit, sowohl für 1000 Stück bei $100 \mathrm{C}$. getrocknete Keimpflänzchen, als für 100Theile Trockensubstanz dieser.

1) Die Landwirthschaftl. Versuchsstationen 1867, Bd. 9, p. 173. 
In 1000 Stück bei $100^{\circ}$ getrockneter Samen sind enthalten in Grammen:

\begin{tabular}{|c|c|c|c|c|c|c|c|}
\hline & \multirow{2}{*}{ 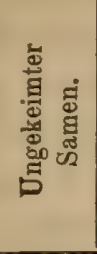 } & \multicolumn{3}{|c|}{ I. Periode. } & \multicolumn{3}{|c|}{ II. Periode. } \\
\hline & & 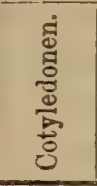 & 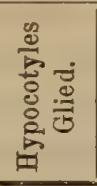 & 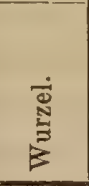 & 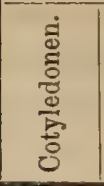 & 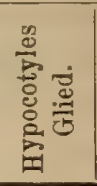 & 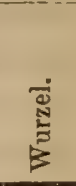 \\
\hline Eiweisskörper . . . & 49,07 & 44,25 & 1,49 & 0,54 & 40,26 & 1,81 & 1,03 \\
\hline Asparagin ....... & - & - & 0,52 & 0,22 & 0,96 & 0,98 & 0,67 \\
\hline $\begin{array}{c}\text { Absoluter Stickstoff- } \\
\text { gehalt ....... }\end{array}$ & 7,85 & 7,08 & 0,35 & 0,13 & 6,65 & 0,50 & 0,31 \\
\hline
\end{tabular}

In 100 Theilen bei $100^{\circ}$ getrockneter Substanz sird enthalten:

\begin{tabular}{r|r|r|r|r|r|r|r}
\hline Eiweisskörper ... & 61,27 & 60,76 & 30,00 & 25,48 & 60,45 & 27,08 & 23,00 \\
$\begin{array}{l}\text { Asparagin . . . . } \\
\text { Absoluter Stickstoff- }\end{array}$ & - & - & 10,5 & 10,6 & 1,45 & 14,65 & 14,99 \\
gehalt $\ldots . .$. & 9,80 & 9,72 & 7,02 & 6,32 & 9,98 & 7,44 & 6,86 \\
\hline
\end{tabular}

Ueber die äussere Erscheinung des Keimens der eiweisslosen Samen von Lupinus sei hier nur bemerkt, dass einige Zeit nach dem Hervorbrechen der Wurzel das hypocotyle Glicd sich zu strecken beginnt und so die noch in der Samenschale steckenden Cotyledonen über die Erde gehoben werden. Kurze Zeit darauf wird die Samenschale abgestreift und die schon im Ergrünen begriffenen dickfleischigen Cotyledonen entfalten sich nun als assimilirende Organe, an denen auch Spaltöffnungen gebildet werden.

Noch vor dem Hervorbrechen der Wurzel beginnt in dieser und dem hypocotylen Glied eine sehr energische Stärkebildung; während in den Zellen der Samenlappen, mit Ausnahme der die Gefässbündel umgebenden Zellen, nur wenig Stärke producirt wird. Asparagin findet sich in diesem Stadium so wenig wie im ruhenden Samen und wird erst dann in mässiger Menge nachweisbar, wenn die Wurzel etwa 12 , das hypocotyle Glied 2 bis 4 Millim. Länge erreichte. In diesen Organen und ausserdem auch noch im unteren Theil des Stiels der Samenlappen, ist jetz.t Asparagin, einmal der 
geringen Menge und dann auch der stärker erfüllten Zellen halber, nur indirekt ${ }^{1}$ ) nachzuweisen.

Wir wollen nun eine Keimpflanze ins Auge fassen, welche dem ersten ron Beyer untersuchten Keimungsstadium entspricht, ${ }^{2}$ ) nämlich eine solche deren Wurzel 30 bis 40 Mill. Länge erreichte, während das hypocotyle Glicd immer nur noch einige Mill. lang jst und desshalb auch die Cotyledonen noch nicht wesentlich über die Erde herrorgehoben sind. Wie es ja allgemein Regel, wurde in den sich streckenden Theilen der Hauptwurzel die Stärke spärlich, ${ }^{3}$ ) welche jetzt schon mehrere Mill. vor dem punc. tum regetations cndet, aufwärts dann nur in vereinzelten Körnchen in der Stärkescheide auftritt, um erst im oberen Theil der Wurzel und in hypocotylen Glied, doch auch in diesem rorwiegend in der Stärkescheide, in reichlicherer Menge aufzutreten. In dem Stiel der Cotyledonen ist namentlich um das Gefässbündel Stärke reiclulich zu finden; in den Samenlappen selbst hat sich deren Vertheilung gegen das erste Keimungsstadium nicht geändert und bleibt hier auch wahrend der ganzen Entlecrung die gleiche. Glycose ist jetzt in deu parenchymatischen Rindenzclleu des hypocotylen Gliedes reichlich, im Marke nur spärlich nachuweisen, in der Wurzel erstreckt sie sich mit abnebmender Menge bis einige Mill. vor den Vegetationspunkt; auch im Stiel der Cotyledonen tritt Glycose in des Parenchynzellen auf, während sic in den Cotyledonen selbst nicht sicher zu erkeunen ist. ${ }^{4}$ )

1) Weun das Asparagin nur dalurch zu erkemen ist, dass man unter Deckglas zu den Schnitten Alkohol treten lïsst, so werde ich dieses als indirekten Nachweis bezeichneu, lisst es sich aber in den Zellen sellst in Krystallen uiederschlagen sn nenne ich dieses den direkten Nachweis.

2) Wurzel und hypocotyles Glied zusammen waren 1 bis $1 \frac{1}{2}$ Zoll lang.

3) Sachs, Bot Ztg. 1859, p. 177. In derW' urzelhaube findet sich aber auch hier Stirke.

4) Die Metbode des Zuckernachweises, wie sie Sachs auwandte, hat den Nachtheil, dass damn, wenn ein Ueberschuss von Kupfervitriol in die Zellen eingedrungen war, durch das heisse Kali schwarzes Kupferoxyd gefällt und die Reaktion getrübt werden kann. Weudet man hingegen weinsaures Kupferoxyd an, so ist der Uebelstand völlig beseitigt, auch kaun man zum Ueberfuss noch weinsaures Alkali (am handlicbsten dürfte das weinsaure Natron-Kali, der 'Tartarus natronatus der Apotheken sein) dem Kali zusetzen. Da es auf chemische Reinheit des weinsauren Kupferoxyds nicht ankommt, so kann man sich dieses für unsere $Z$ wecke einfach dadurch darstellen, dass man Lösungen ron Kupfervitriol und einfach weinsaurem Kali mischt und von dem ausgeschiedenen schwerer löslichen schwefelsauren Káali abfiltrirt. Es kommt dabei natürlich auf einen Ueberschuss eines der beiden Salze nicht an, bei Anwendung von 5 Theilen Kupfervitriol auf 9 Theile weinsaures Kali ist übrigens derselbe nur gering. - Uebrigens bemerke ich hier, dass ich mit der Bezeichnung "Glycose" nur gesagt haben will, dass Kupferoxydul reducirende Substanz vorhanden ist. Für unsere physiologischn Zwecke kommt es auf eine Unterscheidung der mit solcher Eigenschaft begabten Zuckerarten ja gar nicht an. 
Der Vertheilung der Glycose schliesst sich die des Asparagins unmittelbar an. In den Rindenzellen des hypocotylen Gliedes ist dasselbe direkt nachzuweisen, fehlt aber in dem Marke; auch im oberen Theil der Wurzel lassen sich Asparaginkrystalle in den Zellen niederschlagen, während dieses weiter abwärts nicht mehr der Fall ist und wenige Mill. vor dem Vegetationspunkt, in gleicher Höhe mit dem Verschwinclen der Glycose, gelingt auch der indirekte Nachweis des Asparagins nicht mehr. Der Wurzelhaube fehlt das Asparagin, wie auch die Glycose. Auch im Stiele der Cotyledonen kann man Asparagin nur im unteren Theile erkennen. Es stimmt also der mikrochemische Befund mit den Resultaten der Analysen Bey er's für das erste Keimungsstadium (I. Periode auf Seite 537) völlig überein, da auch diese das Fehlen des Asparagins in den Samenlappen zeigen, während dasselbe in Beziehung auf Trockensubstanz in dem hypocotylen Glied und in der Wurzel in procentisch gleicher, in letzterer aber in absolut geringerer Menge gefunden wird.

Auch in dem zweiten von Beyer untersuchten Keimungsstadium stimmte die mikrochemisch festgestellte Stoffvertheilung mit den chemischen Analysen ganz überein; es sind hier Keimpflänzchen berücksichtigt, welche eine Länge von 2 bis 3 Zoll (54 bis 83 Mill.) erreichten. Das Asparagin hat sich jetzt, wie auch Glycose, im Stiel der Cotyledonen reichlich eingefunden und ist bis etwa in die Mitte dieser indirekt nachzuweisen, fehlt aber noch in der oberen Hälfte der Samenlappen. Im hypocotylen Glied ist Stärke spärlicher geworden, Asparagin hingegen wie auch Glycose sind reichlicher aufgetreten. Die chemische Analyse zeigt, dass jetzt in dem hypocotylen Glied und der Wurzel das Asparagin fast 15 Procent der Trockensubstanz ausmacht und in der Wurzel ist beinahe die Hälfte des totalen 6,86 Procent betragenden Stickstoffgehaltes im Asparagin gebunden, denn 14,99 Theile Asparagin entsprechen 3,18 Theilen Stickstoff. In den Samenlappen ist die absolute Menge des Asparagins ziemlich eben so gross wie im hypocotylem Gliede, indess gegenüber der Trockensubstanz sehr viel geringer und ungefähr nur der 32. Theil der totalen Stickstoffmenge fällt auf das vorhandene Asparagin. ${ }^{1}$ )

Die Asparaginmenge nimmt aber bei weiterer Entwickelung der Keimpfänzchen noch entschieden zu und solchePfänzchen derenSamen-

1) 1,45 Procent Asparagin enthalten 0,31 Procent Stickstoff, wäbrend die totale Stickstoffmenge 9,98 Procent beträgt 
lappen halb entfaltet sind, während sich zwischen diesen die zwei ersten noch zusammengefalteten Blätter auf kurzem Stiel erheben, werden wir jetzt näher ins Auge fassen. Bei diesen Keimpflänzchen hatte das Stämmchen eben begonnen in die Länge zu wachsen, das hypocotyle Glied misst etwa 12 , die Wurzel, welche noch keine Seitenwurzeln producirte, etwa 90 bis 100 Millimeter.

In allen Zellen der Samenlappen, auch denen der Epidermis, ist jetzt Asparagin in einiger Quantität enthalten, doch gelingt der direkte Nachweis in dem an Proteinstoffen noch sehr reichen Zellinhalt nicht immer leicht; frei von Asparagin sind wie überall die Gefässbündel und auch die mit Stärkekörnern erfüllten Schliesszellen der Spaltöffinungen scheinen keins zu enthalten, doch ist letzteres nicht sicher zu entscheiden. Nach der Basis der Cotyledonen nimmt das Asparagin entschieden an Menge zu, reichlicher wird es noch in dem Stiel der Samenlappen und zwar gegen deren Insertionsstelle um so reichlicher, je ärmor dic Zelllüssigkeit an Proteinstoffen wird. In allen parenchymatischen Zellen des Samenlappenstieles lässt sich das Asparagin unınittelbar niederschlagen, doch ist seine Menge auf der Innenseite des halbmondförmigen Gefässbündelkreises, in den zwischen diesem und der Rinne des Blattstieles liegenden Zellen, wesentlich geringer, als in den übrigen Zellen. In den parenchymatischen Zellen der Samenlappen ist nun auch Glycose in geringer Menge zu finden, nur im Umkreis der Gefässbündel ist dieselbe reichlicher und nimmt abwärts zu, bis sie im Stiel der Cotyledonen massenhaft in den $\mathrm{Pa}$ renchymzellen nachzuweisen ist. Stärke ist in dem Stiel der Sa. meulappen jetzt fast nur noch in der Stärkescheide vorhanden und dasselbe gilt für das hypocotyle Glied, in dessen Parenchymzellen, wie auch in denen des unteren Theiles des Samenlappenstieles, der übrigens an Strömungsbändern nicht reiche Protoplasmaleib einen durchsichtigen wässrigen Zellsaft einschliesst, in dem nur ein geringes Quantum eiweissartiger Stoffe gelöst ist. Es zeigt dieses schon die schwache Jodfärbung, am besten wirft man aber ganze Stücke des hypocotylen Gliedes in Alkohol und fertigt dann dünnere Schnitte an, welche man einige Zeit in sublimathaltigem Alkobol liegen lässt. Beirn Eintragen in Wasser löst sich dann das ausgeschiedene Asparagin, während die spärlichen Eiweissstoffe des Zellinhaltes, welche beim langsamen Eindringen des Alkohols in Kügelchen zusammenwanderten, ungelöst bleiben und sich näher durch Reagentien crkennen lassen. In dieser Weise 
kann man sich auch überzeugen, dass die langgestreckten dünnwandigen Zellen der Gefässbündel in allen Organen des Keimpflänzchens von Lupinus, wie bei allen Pflanzen, einen an eiweissartigen Stoffen reichen Zellinhalt führen.

In den Rindenzellen des hypocotylen Gliedes ist das Asparagin jetzt noch reichlicher als früher vorhanden, doch enthalten die peripherischen Zellen etwas weniger als die inneren, unter denen aber die Stärkescheide jedenfalls nur arm an Asparagin ist, welches sich in den Gefässbündeln, wie auch im Marke nicht nachweisen lässt. Es bedarf um dieses festzustellen freilich besonderer Vorsicht, da auch bei den schärfsten Messern sich wohl immer ein wenig Zellflüssigkeit verbreitet und desshalb auf der Schnittfläche der Gefässbündel und des Markes einige Asparaginkrystalle erscheinen können. Man muss desshalb nicht an der Schnittfläche, sondern an einem etwas unterhalb derselben genommenen optischen Schnitt beobachten. Auch Glycose, welche in der Rinde sehr reichlich ist, findet sich im Marke in etwas geringerer Menge.

In der Wurzel verschwindet die in der Stärkescheide immer spärlicher werdende Stärke etwa 10 bis 12 Millim. vor der Spitze ganz, während Zucker und Asparagin, freilich zuletzt in geringer Menge sich bis ungefähr 5 Mill. vor dem Vegetationspunkt der Wurzel nachweisen lassen. Von da ab sind dann aber die noch in Streckung begriffenen Zellen reichlicher mit Protoplasma und eiweissartigen Stoffen überhaupt versehen. Man wird, auch zum indirekten Nachweis des Asparagins in der Wurzel, der langestreckten Zellen halber, besser Längs- als Querschnitte anwenden.

Das epicotyle Stämmchen unserer Pflanze ist in dem fraglichen Keimungsstadium nur noch wenig verlängert, steht aber jetzl gerade auf dem Punkte, ein energisches Längenwachsthum zu beginnen. Die beiden ersten, etwa 10 Mill. langen, aber noch zusammengefalteten Blättchen erheben sich auf einem ungefähr 2 Mill. langen Blattstiel, ausserdem sind übrigens noch einige Blättchen unterhalb des Vegetationspunktes angelegt. Etwa so weit als die deutliche Differenzirung der Gewebeformen geht, erstrecken sich im Stämmchen Zucker und Asparagin und in der Stärkescheide auch Stärke, und alle diese Stoffe verschwinden, nachdem sie zuvor allmälich spärlicher geworden, dicht unterhalb des Urmeristems. Im epicotylen Glied ist aber das Asparagin, wie auch die Glycose, im Marke ebenso reichlich als im Rindengewebe vorhanden. Auch 
in den parenchymatischen Zellen des kurzen Blattstieles kann Glycose und Asparagin bis an die Basis der zusammengefalteten Fiederblättchen und zuweilen auch in jener noch erkannt werden, wie auch Stärke in der Gefässbündelscheide sich bis zur Insertion der Fiederblättchen zieht. An dem Ursprung dieser kann das A sparagin nur indirckt erkannt werden, etwas weiter abwärts im Blattstiel lässt es sich aber unnittelbar in den Zellen niederschlagen.

War früher die Wurzel das lebhaftest wachsende Organ des Keimpflänzchens, so ist dieses jetzt das Stämmchen geworden und dem entsprechend wendet sich jetzt der Hauptstrom von Glycose und Asparagin in dieses. Die Vertheilung der beiden massenhaft in den Parenchymzellen auftretenden Stoffe (auch der Stärke) bleibt hierbei die eben erst beschriebene, ebenso gilt dieses für die Blätter, in denen Zucker und Asparagin auch noch an eben entfalteten Blättern sich bis an die Basis der Fiederblättchen verfolgen lassen. Wenn das Stämmchen etwa 12 Mill. Länge errcichte, dann ist in dem hypocotylen Gliede und in der Wurzel Asparagin wie Zucker zwar noch reichlich, jedoch entschieden relativ spärlicher als zuror und auch spärlicher als in den epicotylen Gliedern zu finden. Mittlerweile entstanden auch Seitenwurzeln, - in die sich Zucker und Asparagin in gleicher Weise hineinziehen, wie für die Hauptwurzel beschrieben wurde, an welcher letzteren, die jetzt langsamer in die Länge wächst, etwa schon 8 bis 10 Mill. vor dem Vegetationspunkt die Möglichkeit des Nachweises von Glycose und Asparagin erlischt.

In dem Stiele der Cotyledonen ist jetzt das Asparagin noch ebenso massenhaft wie zuvor zu finden, auch in den Samenlappen selbst ist dessen Menge nicht verringert, wohl aber ist der grösste Theil der Reserveproteinstoffe verschwunden und der Zellinhalt hat sich dem entsprechend schon sehr aufgehellt. Da die tief grünen Cotyledoven assimiliren, so brauchen die stickstofffreien Substanzen, Stärke und Glycose, welche wir gleichfalls wie früher in den Co. tyledonen und dem Blattstiel vertheilt finden, nicht mehr aus Reservestoffen zu stammen, ja sind sogar zum Theil bestimmt durch die Thätigkeit des Chlorophylls neugebildet.

Die völlige Entleerung der Reserve-Proteinstoffe aus den Samenlappen geht aber nur langsam vor sich und ich traf dieselbe noch nicht ganz vollendet bei an einem Südostfenster erwachsenen Pflanzen, deren hypocotyles Glied 40, deren Stämmchen 80 Mill. maassen und welche 7 Laubblätter vollkommen entfaltet hatten. 
Untersuchungen über d. Proteinkörner und d. Bedeutung d. Asparagins etc. 549

Es fand sich jetzt immer noch etwas Asparagin in den Samenlappen und in dem Stiele derselben, zwar viel weniger als früher, doch noch soviel, dass es zuweilen in den Zellen selbst niedergeschlagen werden konnte. In dem epicotylen Stamme ist jetzt im unteren Theile das Mark zerrissen und in den Gefässbündeln hat schon ziemliche Verdickung der Zellwände der entsprechenden Elementarorgane stattgefunden, in dem Rindengewebe trifft man aber noch Asparagin, wenn auch hier dessen Nachweis fast immer nur indirekt möglich ist. Weiter aufwärts fehlt auch das Asparagin dem noch saftigen Marke nicht und wird sogar anscheinend in diesem, ebenso wie in der Rinde, gegen den Vegetationspunkt hin etwas reichlicher, jedoch nicht so, dass man es jedesmal mit Sicherheit in den Zellen niederschlagen kann Doch ist Asparagin, wie auch Glycose, bis dicht unter das Urmeristem zu verfolgen. Auch in den Stielen der in Entfaltung begriffenen und noch nicht lange entfalteten Blätter kann man Asparagin indirekt nachweisen, während dieses bei den ältesten Laubblättern nicht mehr möglich ist. In der Rinde des hypocotylen Gliedes ist das Asparagin eher noch spärlicher als im unteren Theil des Stämmchens, doch kann man sehr kleine Mengen auch noch im oberen Theile der Wurzel und ebenso in den sich hier abzweigenden Nebenwurzeln erkennen; weiter abwärts aber gelingt weder in diesen, noch in der Hauptwurzel der Nachweis des Asparagins.

In diesem Stadium ist die Flüssigkeit in den Zellen der Samenlappen kaum reicher an Proteinstoffen, als die beliebiger saftiger Parenchymzellen und nachdem also jetzt die in Reserve aufgespeicherten eiweissartigen Stoffe entleert sind, 1) verschwindet auch das Asparagin ziemlich bald in allen Theilen der Pflanze. Wenn diese eben begann, an der Hauptachse den Blüthenstand anzulegen, so konnte ich weder an den in Töpfen cultivirten noch den im freien Lande gewachsenen Pflanzen Asparagin nachweisen. Auch bei Bildung ron Achselsprossen war in keinem Entwickelungsstadium dieser Asparagin zu erkennen. Dieses Ergebniss stimmt

1) Völlig werden die Zellen der Reservestoffbehälter niemals entleert, auch dann, wenn diese abgestorben sind, finden sich noch grössere Mengen von Proteinstoffen darin. (Vergl. für Schminkbohne Schröder, landwirth. Versuchsstationen 1868, Bd. X, p. 505). Dieses erklärt sich schon daraus, dass die Eiweissstoffe des Protoplasmas in den Zellen theilweise, wenn nicht ganz, zurückbleiben. Mit den Proteinstoffen wandern Kali und Phosphorsäure zum grössten Theile aus den Reservebehältern, bei der Schminkbohne wird nach Schröder (l. c.) auch die Magnesia zu 2/3 entleert, während der Kalk zum grössten Theil in den Samenlappen bleibt 
nun auch völlig mit den von Chemikern gewonnenen Resultaten. Denn nach Piria ${ }^{1}$ ) lieferten blühende Wicken nur sehr wenig, fruchtende aber gar kein Asparagin, $\mathrm{P}$ asteu $\mathrm{r}^{2}$ ) bingegen konnte aus 200 Liter Saft, welcher aus dem Blühen nahen Wicken gepresst war, keine Spur von Asparagin erhalten.

Bis zu dem Punkte, wo drei Laubblätter vollkommen entfaltet und die epicotylen Glieder zusammen eine Länge von etwa 35 Mill. erreichten, sind alle meine mikrochemischen Versuche mit ganz gleichem Erfolge sowohl mit solchen Pflanzen gemacht, welche in gewöbnlicher Gartenerde gezogen waren, als auch solchen, welche in wässeriger Nährstoftösung cultivirt wurden, in der sich alle nothwendigen Aschenbestandtheile fanden, während gebundener Stickstoff (ein Salz von Ammoniak oder Salpetersäure u. s. w.) nicht zugegen war. ${ }^{3}$ ) Bis zu dem genannten Stadium waren auch diese Pflanzen kräftig gewachsen und ich wage, da ich keine Controllversuche machte, nicht zu entscheiden, ob ihr etwas schwächliches Ansseben der Wassercultur oder dem Mangel an gebundenem Stickstoff unter den Nährstoffen zuzuschreiben ist; übrigens ist es bei dem so sehr hohen Stickstoffgehalt der Lupinen leicht verständlich, dass sich auch unter diesen Verbältnissen die Pflanzen ziemlich weit normal entwickeln können. Dabei wurde aber die absolute Stickstoffmenge nicht vermehrt, die gesammte Masse des Asparagins musste also aus Reserve-Proteinstoffen stammen, während bei den in Gartenerde cultivirten Pflanzen assimilirbarer Stickstoff aufgenommen wurde und Asparagin auch aus diesem sich hätte bilden können, sei es nun als Vorläufer veu entstehender Eiweissstoffe oder durch Spaltung dieser. Da wir aber sehen, wie das Asparagin verschwindet, wenn die Reserve-Proteinstoffe aus den Samenlappen entleert sind und in den weiter entwickelten Pflanzen gänzlich fehlt, obgleich doch die Neubildung von Eiweissstoffen hier fortschreitet, so kann also weder bei dieser, noch bei der Translocation der formirten Eiweissstoffe das Asparagin irgend eine Rolle spielen. Desshalb aber auch müssen wir schliessen, dass das Asparagin bei der Lupine und, wie wir seben werden, ebenso anderen Papilionaceen, ausschliesslich die Fordwanderung der Reserveproteinstoffe vermittelt, womit alle Thatsachen im vollsten Einklang stehen.

1) Piria, Annal d. Chim. et d. Phys 1848, III. ser, T. 22, p. 163.

2) Pasteur, Annal, d. Chim. et d. Phys. 1851, III ser, T. 31, p. 72.

3) Vergl Sachs, Experimentalphys. p. 122. 
Wie einer der verbreitetsten und beim Keimen der meisten Samen auftretender Zellhautbildner, die Glycose, bestimmte Gewebeformen von den Reservemagazinen aus bis zu den Orten des Ver. brauches erfüllt, so thut es bei Lupinus auch das Asparagin, welches hier mit dem Zucker ganz Hand in Hand geht, mit diesem gleichzeitig unter den wachsenden Vegetationspunkten endet. Was der Zucker für die Zellhäute, das ist hier das Asparagin für die eiweissartigen Inhaltsstoffe der Zellen; wie jener verschwindet, weil aus ihm u. a. Cellulose hervorgeht, so thut es dieses, weil die eiweissartigen Inhaltsstoffe der Zellen aus ihm regenerirt werden. Und wie dauernde Zufuhr von Zellhautbildnern nöthig ist, weil diese zu Neubildung und Wachsthum von Zellwänden verwandt werden, so müssen ja auch Eiweisskörper oder deren Bildner fortwährend zugeleitet werden, da ja in jeder Zelle ein Quantum proteinartiger Stoffe zurückbleibt. Wie Glycose in den Zellen des Urmeristems ver. muthlich desshalb verschwindet, weil hier der Verbrauch so energisch ist, dass eine durch unsere Reagentien nachweisbare Menge sich nicht anzusammeln vermag, so kann es auch mit dem Asparagin sein, doch ist dieses nicht unbedingt nothwendig, weil dem Urmeristem auch ebensogut Proteinstoffe zugeführt werden könnten, welche schon unterhalb desselben aus Asparagin gebildet wurden. Es bleibt hier. bei natürlich nicht ausgeschlossen; dass in den langgestreckten dünnwandigen Zellen der Gefässbündel ein Theil der eiweissartigen Stoffe als solche den Verbrauchsorten zuwandert, so gut wie es ja auch für die stickstofffreie Substanz bekannt ist, dass sie in verschiedener Gestalt, so als Oel, Stärke und Glycose wandern kann. Bei Lupinus ist indess die Asparaginbildung dauernd eine so massenhafte, dass wohl jedenfalls die ganz überwiegende Menge der stickstoffhaltigen Reservestoffe als Asparagin translocirt wird, bei manchen anderen Papilionaceen, wie Wicken und Erbsen, bei denen das Asparagin meist nicht ganz so reichlich wie bei Lupinus auftritt, kann ja möglicherweise ein relativ grösseres Quantum der stickstoffhaltigen Reservestoffe in den Gefässbündeln in Form von eiweissartigen Stoffen wandern. Nach meinen Argumenten habe ich nicht zu fürchten, dass $\mathbf{Z}$ weifel an der nachgewiesenen Bedeutung des Asparagins bei der keimenden Lupine erhoben werden, doch will ich zum Ueberfluss auch nochmals darauf aufmerksam machen, dass ja ganz nothwendig aus dem Asparagin wieder Eiweissstoffe gebildet werden müssen, weil ersteres in der Pflanze später ganz verschwindet und auch dann, von Salzen der Salpeter- 
säure und des Ammoniaks abgeschen, die aus dem Boden aufgenomnen werden, andere stickstoff haltige Stoffe in namhafter Menge vorhanden sind. Aber auch bei den Pflanzen, welche bei Ausschluss von gebundenem Stickstoff in wässeriger Nährstofflösung cultivirt wurden, bei denen also der absolute Stickstoffgehalt gleich blieb, habe ich das allmäliche Verschwinden des Asparagins an den kränkelnden Pflanzen festgestellt.

Wie massenhaft das Asparagin in gewissen Keimungsstadien in manchen Organen des Pflänzchens, z. B. in Parenchymzellen des hypocotylen Gliedes und des Stämmchens auftritt, wurde schon früher betont und es muss sich in der That zu gewissen Zeiten mindestens eine nahezu gesättigte Lösung in den fraglichen Zellen finden, da unmittelbar nach dem Ausfliessen des Saftes zerschnittener Zellen auf dem Objekträger Asparaginkrystalle anzuschiessen beginnen, in den Zellen lebender Planzen aber das Asparagin nur gelöst vor. kommt. Ja es wäre sogar möglich, dass sich eine übersättigte Lösung in den Zellen findet, da nach Dessaignes und Chautard ') ein Liter aus im Dunklen gekeimten Wicken ausgepressten Saftes im Maximum 40 Gramm Asparagin licfertc, dieses zu der Flüssigkeit also im Verbältniss von 1: 24 stand, während nach Henry und Plisson erst 58 Theile Wasser von 13 C. 1 Theil Asparagin lösen. Bei der angegebenen Temperatur war also die Lösung, ein nicht chemisch gebundenes Asparagin vorausgesetzt, unter allen Umständen übersättigt und wenn auch bei höherer Temperatur die Löslichkeit des Asparagins gesteigert wird, so ist doch nicht zu vergessen, dass das Asparagin localisirt ist und in den Zellen, in welchen es vorwiegend angehäuft ist, müsste dann auch bei hoher Sommertemperatur bestimınt Uebersättigung rorhanden sein. Dieses gilt natürlich nur unter der Voraussetzung, dass der sauer reagirende Saft der Parenchym. zellen etwa, indem eine leicht zerlegbare Verbindung entsteht, die Löslichkeit des Asparagins nicht vermehrt, was sehr leicht mög. lich ist, da das Asparagin faktisch mit Säuren noch wenig untersuchte Verbindungen eingeht. Das Inulin, an welches wir bei dieser Gelegenheit erinnert werden, kommt in dem Pflanzensafte bekanntlich auch nur gelöst vor, während es einmal ausgeschieden durch Wasser von gewöhnlicher Temperatur fast gar nicht aufge-

1) Husemann, die Pflanzenstoffe 1871, p. 672. - Leider gibt Beyer (I. c.) nicht das Frischgewicht der von ibm untersuchten Keimptlanzen und ihrer Theile an, so dass man über das Verhältniss des Asparagins zur Gesammtmenge der Flüssigkeit in den betreffenden Organen nichts folgern kann. 
nommen wird, hier haben aberDragendorf $\mathrm{f}^{1}$ ) und $\mathrm{Pop} \mathrm{p}^{2}$ ) gezeigt, üass es eine lösliche Modifikatinn des Inulins gibt, in welcher dasselbe in den Pflanzen sich auch findet.

In allen wesentlichen Zügen mit Lupinus luteus übereinstimmend verhalten sich bezüglich des Auftretens, der Wanderung und des endlichen Verschwindens des Asparagins Lupinus varius, Medicago tuberculata und Tetragonolobus purpureus, deren Cotyledonen gleichfalls ergrünen und sich entfalten. Bei der letztgenannten Pflanze ist das Asparagin zu allen Zeiten spärlicher in den Samenlappen als bei Lupinus, während im Stiel der Samenlappen das Asparagin wohl ebenso reichlich als bei der gelben Lupine auftritt. Ob bei Medicago tuberculata das Asparagin im Mark des hypocotylen Gliedes fehlt, lasse ich dahin gestellt, bei den beiden andern genannten Pflanzen ist dieses aber, wie bei Lupinus luteus der Fall.

Von solchen Papilionaceen, deren Samenlappen nur Reservestoffbehälter sind und beim Keimen weder ergrünen, noch sich entfalten, ${ }^{3}$ ) habe ich Vicia sativa und Pisum sativum näher bezüglich des Asparagins untersucht, beides Pflanzen, die bekauntlich grosse Mengen Stärke als Reservenahrung einschliessen.

Hat das Würzelchen bei keimenden Samen von Vicia sativa eine Länge von etwa 8 Mill. erreicht und haben sich die Samen: lappenstiele soweit gestreckt, dass zwischen ihnen die plumula eben hervortreten will, so findet man in dem kurzen hypocotylen Glied und in der Wurzel kleine Mengen von Asparagin, die sich des stärkereichen Zellinhaltes halber nur indirekt nachweisen lassen. Die Streckung des Würzelchens, und damit das Verschwinden fast aller Stärke in den fraglichen Theilen, geht nun in üblicher Weise vor sich, damit wird aber das Asparagin reichlicher und tritt nun alich in dem Stiel der Samenlappen in ziemlicher Menge auf. Wenn das Stämmchen boi an einem Südfenster erwachsenen Pflanzen etwa 15 bis 20, das Würzelchen 60 bis 80 Mill. Länge erreicht hatte, schien das Maximum der Asparaginbildung eingetreten. zu sein. In dem Stämmchen, das mit Ausnahme der Gefässbündelscheide kaum Stärkekörner enthält, liess sich jetzt das Asparagin direkt in den Zellen niederschlagen, doch war dessen Menge bei verschiedenen Keimpflänzchen desselben Entwicklungsstadiums entschieden variabel, anscheinend aber nie ganz so gross (relativ) wie

1) Dragendorff, Materialen zu einer Monographie des Jnulins Petersburg 1871.

2) Popp, Archiv f. Phamacie 1871, Bd. 196, p. 40.

3) So auch Vicia Faba, wofür Abbildung bei Sachs Lehrbuch II. Aufl, p. 524, 
bei Lupinus. Die Gefässbündel sind bei Vicia, wie anch bei Pisum frei von Asparagin, ob aber das spärliche Mark solches enthält, habe ich nicht sicher festgestellt. Schon rtwa 4 Mill. unterhalb des Vegetationspunktes gelingt es nicht mehr Asparagin nachzuweisen, allein hier hat die Streckung der Zellen in einer weit längeren Zone unterhalb des Vegetationspunktes, als bei Lupinus, noch nicht recht begonnen und bis an diese niedrigeren, mit Protoplasma dicht erfüllten Zellen ist auch das Asparagin zu verfolgen, dessen Verschwinden mit dem der Glycose zusammenfällt. In der Wurzel lässt sich das Asparagin im oberen Theile auch in den Zellen niederschlagen, weiter abwärts geht dieses nicht mehr und etwa 6 Mill. vor der Spitze ist es nicht mehr nachzuweisen.

In dem immer viel Stärke in seinen Parenchymzellen führenden Stiel der Samenlappen erschwert eben jene den direkten Nachweis des Asparagins, welches übrigens reichlich in diesem Organe vorhanden ist. Auch am Grund der Cotyledonen kann man wohl noch eine Spur von Asparagin entdecken, ausserdem ist es aber in jenen zu keiner Zeit nachzuweisen. So lange die Samenlappen noch nicht alle Stärke, und damit auch noch nicht die Reserve-Proteinstoffe entleerten, ist auch Asparagin in dem Stiele der Cotyledonen zu erkennen und ebenso, ähnlich wie bei Lupinus, in Stengel und Wurzel der Keimpflanze. Allmälich wird aber das Asparagin spärlicher und wenn 5 bis 6 Fiederblättchen entfaltet sind, kann man dasselbe in keinem Theile der Planze mehr finden. ${ }^{1}$ ) Ganz übereinstimmend mit Vicia satira fand ich das Verhalten des Asparagins bei der Keimung von Pisum satirum.

$\mathrm{Ob}$ nun vielleicht bei allen Papilionaceen, deren Cotyledonen nicht ergrünen, in diesen keine nachweisharen Mengen von Asparagin gebildet werden, lasse ich dahin gestellt, jedenfalls liegt aber hierin kein Anstoss gegen die Bedeutung, welche ich für das Asparagin beim Keimen der Samen der genannten Familie kennen lernte. Denn einmal wäre es möglich, dass erst an der Basis der Samenlappen und im Stiele derselben aus Eiweissstoffen Asparagin entstände oder dieses könnte inmer so schnell aus den Samenlappen abfliessen, dass es stets in zu geringer Menge vorhanden ist, um

1) Es bilden sich bei Vicia, wie auch Pisum, in dem beranwachsenden Pfänzchen in manchen Zellen in der Nähe der Gefassbüudel grössere Krystalle von oxalsaurem Kalk, die nicht mit Asparagin verwechselt werden dürfen, übrigens durch ihre Un. öslichkeit in Wasser sich leicht unterscheiden lassen. 
mikrochemisch nachweisbar zu sein. Ebenso lässt sich auch bei Phaseolus multiflorus nach Sachs ${ }^{1}$ ) Glycose in den Cotyledonen nicht nachweisen, obgleich sie in dem Keimplänzcher selbst reichlich sich findet; ob auch bei Vicia und Pisum in den Samenlappen kein Zucker auftritt, habe ich nicht untersucht. Da ausser den von mir untersuchten Pflanzen von Dessaignes und Chautard ${ }^{2}$ ) in den Keimpflanzen von noch anderen zehn Papilionaceen Asparagin in grosser Menge nachgewiesen wurde, so ist nicht daran zu zweifeln, dass bei allen Pflanzen dieser Familie das Asparagin dieselbe Rolle bei der Fortwanderung der Reserve-Proteinstoffe spielt. Wie es sich bei den nahe verwandten Caesalpineen und Mimoseen verhält, ist noch festzustellen.

In welcher Weise Asparagin aus Proteinstoffen entsteht und wieder zu denselben regenerirt wird, darüber kann man sich keine bestimmte Vorstellung machen, da, wie schon früher bemerkt wurde, die Chemie die Beziehungen zwischen den fraglichen Stoffen noch nicht aufgedeckt hat. Es ist desshalb aber doch nicht ohne Interesse, die Zusammensetzung des Legumins, des Proteinstoffes im Samen der Papilionaceen, und des Asparagins untereinander zu vergleichen. Letztere ist hier procentisch angegeben, während das Legumin ${ }^{3}$ ) auf 21,2 Stickstoff, den procentischen Werth dieses Elementes im Asparagin berechnet wurde.

$\begin{array}{lcc}\text { Legumin. } & \text { Asparagin. } & \text { Differenz. } \\ \text { C. } 64,9 & \text { C. } 36,4 & +28,5 \\ \text { H. } 8,8 & \text { H. } 6,1 & +2,7 \\ \text { N. } 21,2 & \text { N. } 21,2 & 0 \\ \text { O. } 30,6 & \text { O. } 36,4 & -5,8\end{array}$

Wir sehen hier sofort, dass wenn bei der Bildung des Asparagins sämmtlicher Stickstoff des Legumins verwandt würde, wie es nicht unwahrscheinlich ist, eine ansehnliche Menge Kohlenstoff, auch etwas Wasserstoff, vom Legumin abgespalten würde, während Sauerstoff aufgenommen werden müsste. Was aus jenem Kohlenstoff

1) Sachs, Sitzungsb. d. Wiener Akad. 1859, Bd. 37. Jabrb. f. wiss. Bot. III, p. 210.

2) Dessaignes und Chautard, Journal d. pharmacie 1848, T. XIII, p. 245 ff. Aufgezählt auch bei Husemann, die Pflanzenstoffe 1871, p. p. 671.

3) Die procentische Zusammensetzung d. Legumins ist nach Ritthausen C. 51,48; H. 7,02; N. 16,$77 ; 0.24,33 ;$ S. 0,40 . 
wird, das muss nun freilich dahin gestellt bleiben; es ist denkbar, dass durch weitere Metamorphosen Pflanzenstoffe, vielleicht gar Kohlebydrate aus ihm hervorgehen, er könnte aber auch vollständig zu Kohlensäure, wie auch der Wasserstoff zu Wasser verbrannt werden. ${ }^{1}$ ) Letzteres ist, wie wir aus Beyer's Analysen ent. uehmen können, wenigstens nicht unmöglich. In der zweiten von diesem Forscher untersuchten Keimungsperiode machte nämlich das Asparagin 3,36 Procent der gesammten Trockensubstanz aus und wenn eine solche Menge von Asparagin aus Legumin unter Verwendung des ganzen Stickstoffs dieses entstände, so würden, wie sich aus der eben für 100 Theile angeführten Bilanz ergibt, nur 0,96 Theile Kohlenstoff und 0,09 Theile Wasserstoff disponibel werden, während der ja auf diese beiden Stoffe fallende totale Ge. wichtsverlust, welchen die gekeimten Pflänzchen durch Athmung erfahren, nach Beyer 2,95 Procent der Trockensubstanz ausmachte. Natürlich denke ich nicht daran, eine solche einfache Zersetzung nun desshalb behaupten zu wollen, es könnten ja gerade so gut bei der Zersetzung auf irgend eine Weise aus dem abgespaltenen Kohlenstoff und Wasscrstoff Pflanzenstoffe hervorgehen. ${ }^{2}$ ) Dieses wäre dann ein der Zersetzung, welche Proteinstoffe im thierischen Organismus erfahren können, insofern analoger Vorgang, als hierbei Fett unter Bildung eines freilich vicl stickstoffreicheren Körpers als es das Asparagin ist, des Harnstoffs, entsteht, welcher aber Excret ist, während das Asparagin wieder zur Neubildung ron Eiweissstoffen dient. Sicherlich würde das Asparagin, wie es für den Hefepilz bereits nachgewiesen ist, ${ }^{3}$ ) auch denn, wonn es dureh die Wurzeln in die Pflanze

1) Ob und wie solche Vorgänge sich mit den durch die Produkte repräsentirten chemischen Spannkräfteu vertragen, lasse ich unerörtert, da ohnehin durch die Athmung der PHanze eine Kraftıuelle immer zu Gebote steht.

2) Dass aus Proteinstoffen beim Kieimen Koblehydrate entstehen sollen, wurde in neuester Zeit von $\Pi$. Karsten (Laudwirth. Versuchstat. 1871, Bd. 13, p. 193) behauptet, indess nicht im mindesten erwiesen, auch nicht einmal durch die rorliegenden Versuche wahrscheinlich gemacht. Karsten vergisst u. a., dass seine am Licht erzogenen Bohnen (entsprechend der Fig. 5 auf Taf, I, bei Sachs, Keimung d. Schminkbohnen Wien. Akad. Bericht. 1859) Blätter entfalteten und in Folge dessen assimilirten, hierdurch aber auch die vermehrte Trockensubstanz procentisch ärmer an Stickstoff als bei im I unklen gleich lang cultivirten Pflanzen wirl. Für diese wird hier. durch der höhere Procentgehalt an Proteinstofien selistverständlich, unbegreiflich aber ist es, wie Karsten hieraus für die Entstehung von Kohlehydraten Argumente gewinnen will. Uebrigens kömte ich noch andere falsche Schlussfolgerungen Karsten's aufdecken, worauf ich bier verzichte.

3) A. M a yer, Untersuchungen über die alkohol. Gährung 1869, dessen Lehrb. d. Agrikulturch. 1871, p. 174 . 
gelangte, so gut wie Harnstoff, Leucin, Glycocoll ${ }^{r}$ ) und noch anlere stickstoffhaltige organische Stoffe zur Bildung von Protein- toffen verwandt werden können.

Umgekehrt muss bei der Entstehung eines Proteinstoffes aus deḿ Asparagin Kohlenstoff au.genommen werden müssen und es wis $J$ hie: also voraussichtlich die Zersetzung eines stickstofffreien Pflauzenstoffes mit im Spiele sein, wie ja dieses auch bei der Bildung der Eiweissstoffe aus den durch die Pflanze aufgenommenen Salzen des Ammoniaks und der Salpetersäure einerseits und den stickstofffreien assimilirten Stoffen anderseits der Fall ist. Es dürfte aber aus dem Asparagin nicht wieder Legumin, sondern Albumin entstehen, da dieser Proteinstoff in der lebensthätigen Pflanze der verbreitetste ist, während Legumin vielleicht ganz fehlt ${ }^{2}$ ) und auch beim Keimen von Samen der Papilionaceen Albumin aus Legumin entstehen soll. ${ }^{3}$ )

Ueber die Bedeutung des Lichtes bei Bildung und beim Verschwinden des Asparagins liegen ganz entgegengesetzte Angaben von Seiten der Chemiker vor. So behaupten Dessaignes und Chautard, ${ }^{4}$ ) ebenso auch Piria, ${ }^{\text {) }}$ dass sie aus Wicken, die im Dunklen oder am Licht gekeimt waren, gleichviel Asparagin erhalten hätten, $\mathrm{Pasteur}^{6}$ ) hingegen konnte in dem Blühen nahestehenden Wicken überhaupt kein Asparagin finden. Die Ansicht Sullivan's, ${ }^{7}$ ) dass das Asparagin wohl reichlicher im Dunklen gebildet, am Licht aber schnell wieder umgewandelt werde, theilt auch Boussingault, ${ }^{8}$ ) welcher namentlich auch eine direkte Begünstigung der Asparaginbildung durch Lichtentziehung annimmt.

Wir haben schon kennen gelernt, dass bei den am Licht sich entwickelnden Pflanzen der Papilionaceen die Reserve-Proteinstoffe der Samenlappen in Form von Asparagin entleert werden und hieraus folgt ja, dass das Licht die Bildung des Asparagins nicht verhindert, der Rückwandlung des Asparagins in Proteinstoffe steht indess, wie ich zeigen werde, in Beziehung zu dem Lichte. Eine

1) Vergl. Mayer, Lehrb. d. Agrikulturchemie 1871, p. 172.

2) Ma ye r, Lehrb. d. Agrikulturch. 1871, p. 202.

3) Theoretische Erörterungen über die Bildung des Legumins aus Albumin gibt Theile in Jenaischer Zeitschrift f. Medicin u. Natnrwiss. 1868, p. 280.

4) Dessaignes n Chautard, Journal d. pharmacie, 1848, T. XIII, p. 246.

5) Piria, Annal d. Chim. et de Physique 1848, III ser, Bd. 22, p. 163.

6) Pasteur, ebenda 1851, III ser, Bd. 31, p. 72.

7) Sullivan, Annal d. scienc. naturell. 1858, IV ser, Bd. IX, p. 290.

8) Boussingault, Agronom, Ch. agr, et. Physiol. 1868, Bd. IV, p. 265. 
im Dunklen keimende Pflanze der Papilionaceen stimmt in der Vertheilung des Asparagins in den ersten Entwicklungsstadien völlig mit den am Licht keimenden Pflanzen überein, weiterhin aber häuft sich in den etiolirten Pfanzen das Asparagin an. Untersucht man eine bei Lichtabschluss erzogene Pflanze von Lupinus oder Tetragonolobus, wenn dieselbe schon im Absterben begriffen ist, so findet man das Asparagin noch in allen parenchymatischen Geweben in Menge vor. Bei Vicia sativa und Pisum sativum ist das Gleiche der Fall, nur scheint hier das Asparagin bei mikrochemischem Nachweis nicht so massenhaft vorhanden zu sein, weil es sich eben bei diesen, beim Etioliren eine so sehr beträchtliche Länge erreichenden Pflanzen auf eine sehr grosse Menge von Zellflüssigkeit vertheilt, ${ }^{1}$ ) während die Längsstreckung des vergeilten hypocotylen Gliedes bei Lupinus und Tetragonolobus eine mässige ist, und die epicotyle Achse hier kaum zur Entwicklung kommt.

Es ist nun die Frage zu entscheiden, ob das Licht direkt bei der Rückwandlung des Asparagins oder in irgend einer Weise indirekt betheiligt ist. Für letzteres spricht schon der Umstand, dass bei den am Licht erwachsenen Pflanzen auch in den tief im Boden steckenden Wurzeln das Asparagin verschwindet, entscheidend aber zeigt Tropaeolum majus, dass das Verschwinden des Asparagius auch im Dunklen möglich ist. Diese Pflanze pro. ducirt nämlich, wie wir noch erfahren werden, nur in ihrem ersten Keimungsstadium ein Quantum Asparagin, welches aber sowoll im Licht als im Dunkeln bald wieder verschwunden ist. Auch ist die Menge des Asparagins, welche sich in vergeilten, sich nicht mehr weiter entwickelnden Pflanzen findet, unbedingt geringer, als die Gesammtmenge des Asparagins, welche während der Entleerung der Reserveproteinstoffe am Lichte gebildet wird. Da wir aber wissen, dass Dunkelheit die Produktion ron Asparagin nicht beeinträchtigt, so wird folglich nur ein Theil des überhaupt entstandenen Asparagins nicht wieder rückverwandelt werden.

Ein indirekter Einfluss des Lichtes auf die Rückwandlung des Asparagins ist auch sehr leicht verständlich, wenn wir nur festhalten, dass jedenfalls bei der fraglichen Metamorphose Kohlenstoff addirt werden muss. Dieser wird aber jedenfalls von zersetzt werdender stickstofffreier Substanz entnommen, denn an eine derartige Spaltung des Asparagins, dass einerseits die stickstoff-

1) Es dürfte aber doch auch die absolute Menge des Asparagins bei Vicia u. Pisum kleiner als bei Lupinus ausfallen. 
Untersuchungen über d. Proteinkörner und d. Bedeutung d. Asparagins etc. 559

ärmern Proteinstoffe, anderseits ein stickstoffreicherer Körper entsteht, ist nicht zu denken, weil ein solcher sich nicht in den Keimpflänzchen bildet, denn von der sehr kleinen Menge von Ammoniak, welche nach Hosaeus ${ }^{1}$ ) beim Keimen producirt wird, kann man schon absehen. Dass aber der absolute Stickstoffgehalt in Keimpfänzchen unverändert bleibt, ist durch die Untersuchungen Boussingault's nachgewiesen. Bei den im Dunklen keimenden Pflanzen werden nun die stickstofffreien Reservestoffe mehr und mehr aufgezehrt und wenn dieses vielleicht auch niemals ganz vollkommen geschieht, so werden die bleibenden Reste doch wohl ebensogut, wie sie nicht zur Produktion von Cellulose oder anderweitig Verwendung finden, auch unfäbig sein können, den nöthigen Kohlenstoff und Wasserstoff zur Regeneration von Proteinstoffen aus dem Asparagin herzugeben. Bei Tropaeolum, wo Asparagin nur im ersten Keimungsstadium entsteht, findet dieses jetzt auch noch reichliche Mengen von stickstofffreien Reservestoffen vor und damit ist jenem auch die Möglichkeit zur Rückbildung in Eiweissstoffe gegeben. Auch erklärt es sich nun, warum in den ersten Keimungsstadien bei den Leguminosen im Dunklen keine grösseren Mengen von Asparagin in den Pflänzchen zu entstehen scheinen, als am Licht und die Anhäufung dieses Stoffes erst weiterhin stattfindet, wenn eben die stickstofffreien Reservestoffe verbraucht oder wenigstens spärlicher geworden sind. Natürlich gilt hierbei für die stickstofffreien Pflanzenstoffe, welche allenfalls aus dem Legumin bei der Abspaltung des Asparagins entstehen können, dasselbe, wie für andere stickstofffreien Stoffe. Dass in der That in jüngeren Keimungsstadien die am Licht oder im Dunklen erwachsenen Pflanzen von Wicken gleichviel Asparagin enthalten, zeigten Dessaignes und $\mathrm{Ch}$ autard, wie auch Piria in ihren früher citirten Arbeiten, und dass $\mathrm{P}$ a steur aus am Licht erwachsenen Wickenpflanzen kein Asparagin erhalten konnte, hat seinen Grund einfach darin, dass dieser nicht, wie die erstgenannten Forscher jüngere Keimpflanzen, sondern schon dem Blühen nahe stehende Pflanzen verwandte. Man darf demnach auch erwarten, dass je nach dem Verhältniss, welches zwischen Proteinstoffen, resp. dem producirten Asparagin und den stickstofffreien Reservestoffen der Samen besteht, eine grössere oder geringere Menge von Asparagin nicht in Eiweissstoffe wieder rückverwandelt wird. Die vorliegenden chemischen Arbeiten erlauben

1) Archiv f.' Pharmacie 1868, Bd. 135 , p. $42 \mathrm{ff}$. 
bier nicht einmal einen Wahrscheinlichkeitsschluss, doch Łönnte nach dem mikrochemischen Befunde bei Vicia und Pisum die in vergeilten Pflanzen zurückgebliebene Menge von Asparagin, gegenüber dem überhaupt producirten kleiner als bei Lupinus sein.

Wie wir kennen lernten, wird bei den Papilionaceen die Bildung des Asparagins durch Lichtabschluss offenbar nicht begünstigt, wie Boussingault will, welcher das Asparagin überbaupt als ein Produkt aller im Dunklen keimenden Samen ansieht. Dies ist indess keinenfalls der Fall, denn schon Dessaignes und Chautard (1. c.) konnten in den bei Lichtabschluss erzogenen Keimpflänzchen von Kürbis, Buchweizen und Hafer kein Asparagin nachweisen. Bei anderen keimenden Gramineen ist allerdings etwas Asparagin, nämlich im Mais von Boussingault (1. c.) und im Gerstenmalz ron Lermer, ${ }^{1}$ ) nachgewiesen und wenn es demnach zweifelhaft erscheinen muss, ob nicht auch Hafer Asparagin producirt, so ist es doch jedenfalls gewiss, dass dann dieses nur in sehr geringer Menge geschieht. Mikrochemisch suchte ich sาwohl an im Dunklen, als am Licht erzogenen Keimpflänzchen ron Cucurbita Pepo, Ricinus, Specularia speculum und Brassica Rapa in verschiedenen Entwicklungsstufen vergeblich nach Asparagin. Doch schliesst dieses negative Resultat nicht aus, dass faktisch kleine Mengen vorhanden sind, welche sich dem Nachweis bei der angewandten Methode entziehen und zudem könnte sich das Asparagin $\mathrm{ja}$ in der Pflanze in Verbindungen finden, welche durch Alkohol überhaupt nicht in Krystallform ausgeschieden würden. Demnach müssen jedenfalls chemische Untersuchungen zunächst entscheiden, bei welchen Samen Asparagin entsteht, jene sind aber ausser bei zahlreichen Papilionaceen nur mit den wenigen schon genannten Samen zu dem fraglichen Zwecke vorgenommen.

Als ein Samen, welcher beim Keimen Asparagin producirt, wurde schon der von Tropaeolum majus genannt. Die fleischigen Cotyledonen der eiweisslosen Samen dieser Pflanze, xelche nur Reservestoffbehälter sind, bleiben immer in der Samenschale stecken und führen Proteinkörner und eine mässige Menge von Oel in der Grundmasse. Beim Keimen tritt reichliche Bildung von Stärke auf und als solche oder als Glycose, welche übrigens in den Samenlappen selbst immer fehlt, wandern die stickstofffre'en Reservestoffe in das Keimpflänzchen. Dieses wird durch die Streckung

1) Lermer, Dinglers polytechn. Journal 1866, Bd. 179, p. 71. 
des Stieles der Cotyledonen aus der Samenschale hervorgeschoben und zugleich entwickelt sich die Wurzel, während einige Zeit nachher das nun sein Wachsthum beginnende Stämmchen nach der an. deren Seite zwischen den Samenlappenstielen hervortritt. Noch bevor dieses geschieht, kann man kleine Mengen ron Asparagin in dem Pfänzchen nachweisen und wenn bei Entwicklung am Licht das Stämmchen etwa 9 und die Wurzel 20 Mill. erreichte, scheint das Maximum der Asparaginbildung eingetreten zu sein. Im unteren Theil des Stämmchens, im oberen Theil der Wurzel und auch im Stiele der Cotyledonen gelingt es jetzt sogar zuweilen Asparaginkrystalle unmittelbar in den parenchymatischen Zellen niederzuschlagen, wenn auch bei weitem nicht in solcher Menge wie bei entsprechenden Keimungsstadien der Papilionaceen. Etwa 5 Mill. vor dem Vegetationspunkt des Stämmchens und ungefähr 10 Mill. vor dem der Wurzel hört die Möglichkeit Asparagin nachzuweisen auf, in den Cotyledonen selbst ist aber überhaupt nie Asparagin zu finden.

Hiernach würde jetzt unsere Pflanze, wenn wir von der Quantität des Asparagins absehen, mit einem correspondirenden Keimungsstadium ron Vicia sativa übereinstimmen. Nun aber wird das Asparagin auffallend schnell spärlich und wenn das erste Laubblatt eben entfaltet ist, kann, wie auch in älteren Pflanzen, Asparagin nicht mehr nachgewiesen werden. In den Samenlappen finden sich jetzt noch Stärke und Proteinstoffe in ziemlicher Menge und deren Entleerung wird erst weit später vollendet. Wie die am Licht gezogenen, so verhalten sich aber auch die im Dunklen cultivirten etiolirten Pflanzen.

Auch bei Silybum marianum fand ich Asparagin, welches einige Zeit nach dem Hervorbrechen der Wurzel auftritt, am reichlichsten aber dann rorhanden ist, wenn die Cotyledonen daran sind die Samenschale abzustreifen oder dieses eben thaten. Es gelingt nun wohl im hypocotylen Glied und in dem oberen Theil der Wurzel Asparagin direkt nachzuweisen, doch scheinen bezüglich der Menge dieses in demselben Topf erwachsene Pflanzen gleicher Entwicklungsstufe sich verschieden verhalten zu können. Im unteren Theil des Stieles der Samenlappen lässt sich Asparagin noch erkennen, in diesen selbst indess nicht. In allen Theilen des Pflänzchens suchte ich aber vergebens nach Asparagin, nachdem die Cotyledonen entfaltet und die beiden ersten Laubblätter theilweise hervorgetreten waren. Auch bei Silybum verschwindet das Asparagin noch vor völliger Entleerung der Reservestoffe. 
Wie Silybum verhält sich Helianthus tuberosus und such im Mais konnte ich Asparagin erkennen, doch ist auch bei diesem dessen Auftreten gleichfalls nur ein vorübergehendes. Bei allen den genannten Pflanzen entsteht auch im Dunklen nicht mehr Asparagin, als am Licht; auch verschwindet dasselbe bei Lichtabschluss so gut wie bei Tropaeolum.

Bei allen diesen Pflanzen spielt das Asparagin also jedenfalls bei der Fortwanderung der Reserve-Proteinstoffe nur eine beiläufige Rolle, da es ja schon lange vor vollendeter Entleerung derselben verschwinden kann, während es bei den Papilionaceen so lange neugebildet wird, bis die aufgespeicherten Proteinstoffe, aus denen das Asparagin entsteht, verschwunden sind. Die Bedeutung des Asparagins für die Translocation der Reserre-Proteinstoffe, welche wir bei den Papilionaceen kennen lernten, bleibt also auf diese 2unächst beschränkt, ob sie vielleicht auch auf einige andere Pflanzenfamilien auszudehnen ist, müssen weitere Untersuchungen lehren.

Ausser in keimenden Pflanzen ist Asparagin auch in verschiedenen Theilen regetirender Pflanzen gefunden worden, seine physiologische Bedeutung aber in keinem Fall ermittelt. So ist es ja bekannt, wie Asparagin in den Spargeln vorkommt, in denen es auch entdeckt wurde. In Wurzeln und Rhizomen wurde Asparagin mehrfach nachgewiesen, ${ }^{1}$ ) so z. B. bei Symphytum officinale und Scorzonera hispanica, reichlich soll es sich nach Hlasiwetz in den Wurzeln von Robinia Pseud-Acacia finden. Besonders bemerkenswerth ist auch die Art des Vorkommens des Asparagins beiStigmaphyllon jatrophaefolium, einer brasilianischen Malphigiacee, die im Garten zu Pisa von Mitte April bis Mitte Norember vegetirt und dann bis auf die perennirenden Knollen abstirbt. Diese wurden im Januar von Luca und Ubaldin ${ }^{2}$ ) einer Untersuchung unterworfen und Asparagin nachgewiesen. Sollte äieses nun hier vielleicht als Reservestoff vorhanden sein und findet ähnliches auch bei anderen Pflanzen statt, deren unterirdische Theile perenniren? In den Wurzeln (soll wohl heissen Rhizomen) und dem Kraut zugleich ist das Asparagin bei Convallaria majalis aufgefunden und hier konnte ich auch mikrochemisch an jungen, noch nicht ans der Erde hervorgebrochenen Sprossen sehr kleine Mengen von Asparagin erkennen. Anführen will ich hier auch noch, was bei

1) Eine Aufzählung der bekannten Vorkommnisse des Asparagins bei Huse mann, die Pflanzenstoffe 1871, p. 671.

2) Luca u. Ubaldini, Annal. d. sc. naturell. 1864, V ser, Bd. II, p. 380. 
H usemann nicht erwähnt ist, dass Beyer ') aus dem Frühjahrssaft einiger Bäume sehr kleine Mengen von Asparagin darstellte.

Der allgemeinen Verbreitung, welche Hartig ${ }^{2}$ ) dem Asparagin zuschreibt, wurde schon Erwähnung gethan, es soll dasselbe sich in den Früjahrstrieben aller untersuchten Pflanzen finden und auch bei der Weiterentwicklung vieler Wurzeln, Knollen und Zwiebeln auftreten. Für die im Dunklen sich entwickelnden Kartoffeltriebe ist aber das Fehlen des Asparagins makrochemisch festgestellt, doch wäre es hier freilich möglich, dass, wie auch Boussingault ${ }^{3}$ ) vermuthet, das Asparagin von Solanin vertreten wird. Bei anderen Pflanzen, auch in den Achselsprossen der Leguminosen (wie bei Lupinus luteus, Caragana macrophylla, Astragalus sp. u. a.) habe ich in den verschiedensten Bildungs- und Entwicklungsstufen vergebens nach Asparagin gesucht. In gleicher Weise konnte ich auch bei Comarum palustre, Syringa persica Filia parvifolia und einigen anderen Pflanzen kein Asparagin beim Austreiben der Knospen nachweisen. Wohl aber erzielte ich bei allen genannten Pflanzen die schon früher erwähnten Kryställchen in grösserer oder geringerer Menge, welche wohl jedenfalls verschiedene Salze mit anorganischer Basis sind und dürfte diese wohl Hartig mit seinen Gleiskrystallen verwechselt haben.

Für die Translocation der eiweissartigen Stoffe stellte S a ch s $^{4}$ ) als allgemeine Regel auf, dass die dünnwandigen gestreckten Zellen der Gefässbündel (Cambiform, Gitterzellen, Siebröhren) der Fortleitung der eiweissartigen Körper dienen, in den parenchymatischen Zellen der Rinde und des Markes aber die stickstofffreien plastischen Stoffe wandern. Die Leguminosen machen hier aber eine Ausnahme, indem ein Proteinstoff-Bildner, das Asparagin, gerade in den parenchymatischen Zellen aus den Reservebehältern, den Cotyledonen, zu den Verbrauchsorten wandert. Dass nun freilich auch hier die langgestreckten dünnwandigen Zellen der Gefässbündel eiweissartige Stoffe führen, wurde schon mitgetheilt und so ist es wahr-

1) Beyer, Archiv f. Pharmacie 1868, Bd, 143, p. 221. - In diesem, wie auch in manchen anderen Fällen, kann die Entstehung des Asparagins aus Proteinstoffen nicht behauptet werden, da es auch auf anderem Wege, etwa aus Aepfelsäure und Ammoniak gebildet werden kōnnte.

2) Hartig, Pflanzenkeim, p. 127.

3) Boussingault, Agron,, Ch. agr. et Phpsiol. 1868, Bd. IV, p. 265. Das Solanin scheint aber doch nach den Angaben der Chemiker allzu spärlich in den Kartoffeltrieben sich zu finden.

4) Sachs, Experimentalphys. p. 380. 
scheinlich, dass auch diese eiweissartige Stoffe fortleiten, deren Menge indess gegenüber der in Form von Asparagin wandernden stickstoffbaltigen Substanz wohl sicher nur gering ist, da eben das Asparagin so sehr massenhaft producirt wird. Doch mögen sich in dieser Beziehung schon unter den Papilionaceen Unterschiede geltend machen und bei Tropaeolum z. B. wird sicher nur ein kleiver Theil der Reserve-Proteinstoffe in Form von Asparagin translocirt.

Der Vortheil der Asparaginproduktion zum Zwecke der Fortwanderung der stickstoffhaltigen Reservestoffe bei den Leguminosen liegt klar auf der Hand, wenn man erwägt, dass das Asparagin cine Krystalloidsubstanz ist und ausserdem dessen Regeneration zu Proteinstoffen an den Verbrauchsorten einen dauernden Nachstrom des in den Samenlappen neu producirten Asparagins sichert. Die Proteinstoffe hingegen diosmiren fast gar nicht; ibr endosmotisches Aequivalent ist nahezu 100') und dieser Punkt muss in der 'That es fraglich erscheinen lassen, ob die eiweissartigen Stoffe faktisch als solche die Zellwände durchsetzen, welches ja, die nicht bei allen Pflanzen vorkommenden Siebröhren ausgenommen, auch bei Canbiform und Gitterzellen der Fall sein müsste. Wir könnten hier analog wie bei der Stärke daran denken, dass sich die Proteinstoffe in einen diosmirenden Körper verwandelten, aus dem dann jene jedesmal nach Durchsetzung der Zellwand sofort wieder regenerirt würden. Allein zu einer solchen Annahme liegen noch keine zwingenden Gründe vor, da wir einmal nicht wissen, wie sich die eiweissartigen Stoffe gegen die Wände lebender Zellen verhalten und es auch Verbindungen oder Lösungen der Proteinstoffe geben könnte, deren endosmotisches Aequivalent ein viel geringeres als das der reinen Körper wäre. Wir werden hier an Verbindungon der Proteinstoffe mit Kaliphosphat und Kali erinnert und wenn auch hier eingehendere Studien über die angeregte Frage meines Wissens noch nicht angestellt wurden, so ist doch soviel gewiss, dass Kalialbumin durch Mfembranen in viel grösserer Menge dringt als reines Albumin. ${ }^{2}$ )

Dic erst von Sachs richtig interpretirten Versuche des Ringelschnittes zeigen aber evident, dass an den untersuchten Objekten

1) Kühne, physiol. Chemie 1868, p. 49. Fick, Physik des Menschen 1860, p. 406.

2) Vergl. If opje-Seyler, Ilawbuch der physiologisch u. pathologisch chem. Analyse 1870, p. 208 gelegentlich der Darstellung des Kalialbuminats. - Ueber Mucin siehe Eichwald, Annal d. Chem. u. Phys. 1865, Bd. 134, p. 177. 
die eiweissartigen Stoffe faktisch in den Siebröhren, den Gitterzellen und im Cambiform wandern, denn der einfache Nachweis dieser Stoffe in den genannten Zellformen ist nicht völlig entscheidend, weil ja auch in den parenclymatischen Zellen Proteinstoff-Bildner sich bewegen könnten, welche nicht gerade Asparagin, sondern auch andere stickstoffhaltige Körper sein könnten. Für die Kartoffeltriebe wird man sich hier des Solanins erinnern und wenn auch für viele andere Pflanzen sticksoffhaltige Stoffe, die man als analog betrachten könnte, nicht bekannt sind, so darf man doch nicht vergessen, dass die Möglichkeit einer Zerspaltung der Proteinstoffe unter Bildung von Ammoniak oder Salpetersäure nicht unmöglich ist, welche letzteren dann an die Verbrauchsorte geleitet, wieder zur Regeneration von Eiweissstoffen dienen könnten. So sehr unwahrscheinlich dieses auch ist, so kann es doch nicht als absolut unmöglich bezeichnet werden, denn die Bildung einer geringen Menge von Ammoniak aus Proteinstoffen ist beim Keimen von Samen bereits durch Hosaeus nachgewiesen worden. Vielleicht findet aber bei den vegetirenden Pflanzen Translocation der Proteinstoffe überhaupt nur in sehr untergeordneter Weise statt, indem dieselben immer erst an den Stellen des Bedarfes aus den entfernteren Baustoffen, clen Salzen von Ammoniak oder Salpetersäure einerseits und stickstofffreier assimilirter Substanz anderseits, entstehen. Auch dieses kann als unmöglich nicht verworfen werden, da wir durch Pasteurs ${ }^{1}$ ) Versuche wissen, dass auch von chlorophyllfreien Pilzzellen die Proteinstoffe aus den genannten entfernteren $\mathrm{Be}$. standtheilen gebildet werden können und die Salze von Ammoniak oder Salpetersäure ${ }^{2}$ ) oder beide gleichzeitig in vegetirenden Pflanzen allgemein verbreitet sind. Es muss zukünftigen Forschungen überlassen bleiben, über die vorgefübrten Fragepunkte zu entscheiden.

\section{Historisches.}

Die Proteinkörner wurden, wie ich schon früher erwähnte, von Hartig entdeckt, welcher nach einer vorläufigen Notiz im

1) Vergl. Sachs, Experimentphys. p. 345; auch A. Mayer, Untersuchungen über die alkoholische Gährung 1869.

2) Zahlreiche Angaben bei Sullivan, Annal. d. scienc. natur. 185s, IV ser, Bd. IX, p. 293 ff.; ebenso bei Hosaeus, Zeitschrift f. deutsche Landwirthe 1864 bis 1866. Ferner sei noch genannt $\mathrm{H}$ of $\mathrm{fman}$ n, Arch. f. Pharmacie 1865, Bd. 122, p. 193. 
Jahre $1855,{ }^{1}$ ) in den folgenden Jahren zwei ausführliche Arbeiten über diesen Gegenstand publicirte. ${ }^{2}$ ) Die Proteinkörner (Aleuron oder Klebermehl Hartigs) denkt sich unser Autor ganz nach dem von ihm aufgestellten Zellenschema aufgebaut und zwar sollen hier die doppelten Schlauchhäute (Ptychode und Ptychoide) unmittelbar aneinander liegen, in den meisten Fällen aber an einer Stelle auseinanderweichen, um zwischen sich die Einschlüsse, die Aequivalente des Zellkerns aufzunehmen, während der übrige, dem Zellsaft in den Zellen entsprechende Raum, mit Proteinmasse erfüllt sei, welche entweder amorph oder auch zum Theil oder ganz krystallisirt vorkommen könne, in welchem letzteren Falle also krystalloidfülurende Proteinkörner rorliegen. Die Ansicht Hartigs bezüglich seiner Schlauchhäute bedarf keiner Widerlegung und es ist schwer begreiflich, wie sie von ilhrem Autor aufgestellt werden konnte, da sie in den Fällen wo zahlreiche Einschlüsse in dem ganzen Proteinkorn zerstreut liegen geradezu unmöglich wird. Wie fern aber die Einschlüsse einem Zellkern oder Kernkörperchen stehen, zeigt der ron mir gelieferte Nachweis, dass jene Salze mit anorganischer Basis sind. Hatte auch Hartig die Aufspeicherung von eiweissartigen Stoffen in den Proteinkörnern richtig erkannt, so sind seine Ansichten über den Aufbau dieser doch ebenso verfehlt, wie über deren Bildung. Die Proteinkörner sollen nämlich durch direkte Umwandlung von Chlorophyllkörnern oder Stärkekörnern oder auch unmittelbar aus der Inhaltsmasse (Kernstoffkörpern Hartigs) des Zellkerns gebildet werden und beim Kcimen der Samen auch eine gleiche Rückbildung in Stärke und Chlorophyll erfahren können; faktisch entstehen aber, wie ich zeigte die Proteinkörner ganz unabhängig von den genannten Gebilden. Richtig ist aber Hartigs Angabe, dass aus den eiweissartigen Stoffen der Proteinkörner Gleis (Asparagin) entstehe, für welchen Körper indess $\mathrm{Hartig}$, wie mitgetheilt wurde, unrichtigerweise eine sehr allgemeine Verbreitung in Anspruch nimmt.

An Hartigs Arbeiten schliessen sich die von Holle's ${ }^{3}$ ) unmittelbar an, welcher Forscher geneigt ist, die doppelte Schlauchhaut Hartigs auf ein einfaches Häutchen zu reduziren. Wesent-

1) Hartig, Bot. Zeitung 1855 , p. 881 .

2) Hartig, Bot. Zeitung 1856, p. 257 und Entwicklungsgeschichte des Pfianzenkeims 1858, p. 108 ff.

3) v. II olle, Mehrere Publikationen im neuen Jahrbuch für Pharmacie von Walz und Winkler 1858 und $1859, \mathrm{Bd}$. X, XI, u. XII. 
lich neue Ansichten konmen bei von Holle nicht vor', der in seiner letzten Arbeit Mittheilungen über das Vorkommen der Proteinkörner bei 111 deutschen Pflanzenfamilien macht, welche ein näheres Eingehen nicht erfordern, weil ja die Proteinkörner in allen Samen sich finden.

$R$ auwe $n$ h of $f$ scheint sich in einer Arbeit, die ich nur aus einem kurzen Referat kenne, ${ }^{1}$ ) nach diesem zu urtheilen, den Resultaten H artigs anzuschliessen, jedoch statt Klebermebl den Namen "Proteinmehl" vorzuschlagen; übrigens bezeichnete auch $\nabla$. Holle in demselben Jahre die Aleuronkörner Hartigs als Proteinkörner.

Von $\mathbf{N} \ddot{g} g \mathrm{el}^{2}$ ) wurden gelegentlich seiner Untersuchungen über Stärke in manchen Samen aus eiweissartigen Stoffen bestehende Gebilde gesehen, die er Plasmakörper nannte, welche, wie es scheint, Krystalloide, vielleicht aber auch in Wasser unlösliche Proteinkörner waren. Nägeli's Beobachtungen fallen wohl vor Hartigs Publikationen, während die Veröffentlichung nach diesen datirt.

Bei Trécul ${ }^{3}$ ) begegnen wir zuerst der Ansicht, dass die Proteinkörner ausser Proteinstoffen auch theilweise oder ganz aus Fett bestehen könnten; übrigens sieht dieser Autor die Proteinkörner als Bläschen mit einfacher Membran (paroi) an. Die Kry. stalloide sollen nach Trécul nicht präformirt in dem Proteinkorn enthalten sein, sondern erst durch Krystallisation des Kornes bei Wassereinwirkung sich bilden. Ebenso wie diese Ansicht, sind auch die Angaben Tréculs über die Globoide verfehlt, dass näm. lich unter diesen auch in Wasser lösliche, wie auch mit Jod sich färbende vorkommen; beides trifft selbst bei den von Trécul namhaft gemachten Samen nicht zu. Die Entstehung der Proteinkörner führt Trécul zum Theil auf eine Metamorphose von Stärkemehl zurück, andere sollen aber unabhängig von diesem in der Zellflüssigkeit sich heranbilden. Bezüglich der Entwicklung der Krystalloide von Sparganium muss ich auf das früher Gesagte verweisen.

Die nächsten ausführlicheren Untersuchungen über Proteinkörner, welche namentlich Entwicklungsgeschichte und Rückbildung beim Keimen im Auge haben, rühren von $\mathrm{Gris}^{4}$ ) her. Dieser

1) Jahresbericht d. Chemie für 1858, p. 491. Das Original befindet sich in Scheikundige Verbandelingen en Onderzoekingen II deel, 2 stuk, 1858.

2) $\mathrm{Nägeli,} \mathrm{die} \mathrm{Stärkekörner} \mathrm{1859,} \mathrm{p.} 406$ u. 541.

3) Trécul, Des formations vesiculaires etc., Annal d. sc. natur. 1858, IV ser, Bd. 10, p. 20 ff., p. 127 ff. und p. $205 \mathrm{ff}$.

4) Gris, Recherches sur la germination, Annal d. sc. naturell. 1864, V ser, Bd. II, p. 1 ff. 
zeigte, dass die Proteinkörner nicht durch eine Umwandlung run Stärke- oder Chlorophyllkörnern gebildet werden und die Darstellung der Entwicklung jener ist im Allgemeinen richtig; bei Ricinus sind aber die Vacuolen, in denen die Krystalloide sich bilden sollen, wie ich zeigte, Artefakte. Auch die Rückbildung der Proteinkörner beim Keimen hat Gris, soweit es äusserliche Erscheinungen betrifft, im wesentlichen richtig erkannt. Seine Ansicht über die chemische Constitution der Proteinkörner ist die Trécul's, während er das Hüllhäutchen nicht finden konnte, übrigens die Proteinkörner bezüglich der Struktur den Chlorophyllund Stärkekörnern vergleicht.

Auch Sachs') glaubt, dass dic Proteinkörner ganz oder theilweise aus Fett bestehen können, doch habe ich schon früher die Gründe angegeben, welche bier zu einer Täuschung Veranlassung gaben. Ueber die Grundmasse, welche man bis dahin meist einfach für Fett gehalten zu haben scheint, hat sich Sachs zuerst präciser ausgesprochen und betont, dass sie ein Gemenge von Fett und Eiweissstoffen sei, in welchem die letzteren dominiren.

Ausserdem haben wir noch über Krystalloide aus Samen Arbeiten von $\mathrm{Masch}$ he und $\mathrm{N}$ äg eli zu verzeichnen. Nach ersterem ${ }^{2}$ ) sind die Proteinkörner des Samens ron Bertholletia von einem aus Korksubstanz bestehenden Häutchen umgeben, Hüllmasse aber wie Krystalloid bestehen aus sehr kleinen Bläschen, deren Inhalt beim Krystalloid krystallinische Beschaffenkeit angenommen hat; die Globoide sollen aus Bassorin und einer proteinartigen Substanz zusammengesetzt sein. Bezüglich der Ansicht $\mathrm{M}$ aschke's, dass die Krystalloide eine Verbindung von Casein mit einer unbekannten Säure seien, verweise ich auf früher Gesagtes. In der mitgetheilten Entwicklungsgeschichte der Proteinkörner von Ricinus theilt Maschke, wie es auch Hartig thut, dem Zellkern eine Hauptrolle zu, die Hülle dieses soll wiederholt platzen und die Inhaltsmasse (Parablasten Maschke's, Kernstoffkörper Hartigs) sich in den Zellraum ergiessen, wo sich dann in Vacuolen (Schleimbläschen Maschke's), bezüglich derer das schon bei Gris Gesagte gilt, die Krystalloide und Globoide bilden würden.

1) Sachs, Keimung der Dattel, Bot. Zeitung 1862, p. 242 . Keimung,von Allium Cepa daselbst 1863, p. 56 und Lehrbuch. II. Aufl, p. 52.

2) Maschke, Ueber Bau und Bestandtheile der Kleberbläschen in Bertholletia. Bot. Zeitung 1859, Nr. 49-52. 
Untersuchungen über d. Proteïnkörner und d. Bedentung d. Asparagins etc. 569

Nägeli's $\left.{ }^{1}\right)$ Untersuchungen über die Krystalloide der Paranuss wurden im Verlaufe meiner Arbeit vielfach erwähnt, denn jenen verdanken wir wesentlich unsere Kenntniss über krystallähnliche Proteinstoffe.

Zum Schluss fasse ich die Hauptergebnisse kurz zusammen:

Die Proteinkörner finden sich in allen reifen Samen; sie bestehen, von gewissen Einschlüssen abgesehen, wesentlich nur aus Proteinstoffen, welche entweder anscheinend amorph oder zum Theil als Krystalloid vorhanden sind.

Die Einschlüsse sind zweierlei Art, Globoide oder Krystalle. Letztere bestehen aus oxalsaurem Kalk, die Globoide aber sind das Magnesia- und Kalksalz einer gepaarten Phosphorsäure mit organischem Paarling. Die Globoide fehlen in keinem Samen, während die Krystalle nur beschränkt verbreitet sind.

Alle Krystalloide sind in Wasser unlöslich; die diese um. gebende Hüllmasse und ebenso die krystalloidfreien Proteinköruer können in Wasser unlöslich, aber auch ganz oder theilweise löslich sein. Die constituirenden Proteinstoffe sind für sich in Wasser unlöslich; ihre Löslichkeit beruht auf in der Proteinmasse enthaltenem Kaliphosphat. Ob dabei die eiweissartigen Stoffe immer Kaliverbindungen sind, bleibt unentschieden.

In den Proteinkörnern des Endosperms von Paeonia finden sich zwei verschiedene Proteinstoffe entweder gleichförmig oder in der Art wie Granulose und Cellulose in den Stärkekörnern miteinander gemengt.

Das Fett der Samen gehört der Grundmasse an, in der es immer mit einem, wenn auch oft nur geringen Quantum von Pro* teinstoffen gemengt ist. Diese sind stets zum Theil solche, welche sich gegen Lösungsmittel wie in die unlösliche Modifikation übergegangene Eiweissstoffe verhalten.

Die krystalloidfreien Proteinkörner bilden sich durch Dissociation aus einer Emulsion von Fett und Eiweissstoffen erst dann, wenn der gereifte Samen auszutrocknen begann; die Krystalloide treten aber schon in dem noch unreifen Samen und zwar sogleich in Krystallform auf. Ebenso werden die Einschlüsse, Globoide und Krystalle, schon frühzeitig sichtbar und gelangen während des Heraureifens des Samens allmälich zur definitiven Grösse.

1) Năgeli, Ueber die aus Proteinsubstanzen bestehenden Krystalloide in der Paranuss, Sitzungsber. der Münchner Akad. 1862, Bd. II, p. 120. 
Der Protoplasmaleib ist bei der Bildung der Proteinkörner nicht unmittelbar betheiligt. In dem ruhenden Samen ist er mit seinem Zellkern einfach ausgetrocknet, um beim Keimen wieder zu neuem Leben zu erwachen.

Bei den keimenden Papilionaceen vermittelt Asparagin die Fortwanderung der Reserve-Proteinstoffe. Das Asparagin wandert hier nicht in Elementen des Gefässbündels, sondern in dem parenchymatischen Grundgewebe.

Beleuchtung und Verfinsterung sind für die Bildung des Asparagins indifferent, doch ist Beleuchtung bei der Regeneration der Eiweissstoffe, wenn auch nur mittelbar betheiligt.

Marburg, Ende October 1871. 


\section{Erklärung der Abbildungen.}

(Die eingeklammerten Zahlen geben die Vergrösserung an.)

\section{Tafel XXXVI.}

Fig. 1-12 bezieben sich a p Paeonia humilis und peregrina.

Fig. 1. Zelle aus dem Endosperm in Oel gesehen; die Proteinkörner haben Kryställchen als Einschlüsse. n der Zellkern $\left(\frac{500}{1}\right)$.

Fig. 2a-f. In Glycerin sich auflösende Proteinkörner $\left(\frac{800}{1}\right)$.

Fig. 3. Ein durch Sublimat unlöslich gemachtes Proteinkorn, dessen Lösung durch kalihaltiges Wasser von Innen heraus geschah. $\left(\frac{800}{1}\right)$.

Fig. 4a-c. Beim Verdünnen von Alkohol sich von Innen heraus lösende Proteinkörner $\left(\frac{800}{1}\right)$.

- Fig. 5. Proteinkörner aus den peripherischen Zellen des Endosperms, deren Einschlüsse Globoide sind $\left(\frac{1000}{1}\right)$.

Fig. 6. Ein Proteinkorn wie Fig. 5, dessen Globoid nach Behandlung mit schwefelsäurehaltigem Alkohol verschwand.

Fig. 7a-n. Proteinkörner mit krystallinischen Einschlüssen nach Behandlung mit schwefelsäurehaltigem Alkohol in Wasser getragen $\left(\frac{1000}{1}\right)$.

Fig. 8. Proteinkörner, welche beim Verdünnen von Alkohol Schichtung zeigten $\left(\frac{1000}{1}\right)$.

Fig. 9. Aus dem Endosperm eines nicht ganz reifen Samens. Im Metaplasma liegen zusammengesetzte Stärkekörner $\left(\frac{500}{1}\right)$.

Fig. 10. Aus einem etwas älteren Samen als Fig. 11. Die Stärke hat sich in Oel verwandelt und die Bildung von Proteinkörnern begann $\left(\frac{500}{1}\right)$.

Fig. 11 u. 12. Weitere Entwicklung der Proteinkörner $\left(\frac{500}{1}\right)$.

Fig. 13. Zellen aus den Samenlappen von Scorzonera hispanica. Es sind diese nach oinem in $0 \mathrm{el}$ liegenden Präparate gezeichnet und desshalb treten die krystallinischen Einschlüsse nicht sehr deutlich hervor $\left(\frac{500}{1}\right)$.

Fig. 14 u. 15. Tragopogon major. Fig. 14 ist das nach Behandlung mit Alkohol und Wasser dargestellte Grundmassennetz, in dessen Maschenräumen noch die Globoide liegen. Fig. 15 stellt eine in 0 el liegende Zelle vor, bei der man in der Grundmasse Theile der Protoplasmastränge sieht. n ist der Zellkern $\left(\frac{500}{1}\right)$. 
Fig. 16. Eine Zelle aus den Simenlappen von Bertholletia excelsa in Oel liegeud. Die Krystalloide, welche man eigentlich baum sieht, sind in den Proteinkörnern leicht angedeutet; die langen Nadeln sind Fettkrystalle $\left(\frac{300}{1}\right)$.

Fig. 17. Einzelne Proteinkörner desselben Samens wie Fig. 16, nach Behandlung mit sublimathaltigem Alkohol in Wasser liegend. $\left(\frac{500}{1}\right)$

\section{Tafel XXXVII.}

Fig. 1-12. Aus dem Endosperm von Ricinus communis.

Fig. 1 stellt eine in Oel liegende;

Fig. 2 eine nach Behandlung mit sublimatbaltigem Alkohol in Wasser getragene Zelle vor $\left(\frac{400}{1}\right)$.

Fig. 3 a-c. Einzelne Proteinkörner nach gleicher Behandlung wie für Fig. 2 angegeben $\left(\frac{800}{1}\right)$.

Fig. 4a u.b. In etwas kalihaltigem Glycerin sich aufösende Proteinkörner $\left(\frac{800}{1}\right)$.

Fig. 5. Proteinkörner mit Alkohol extrahirter Schnitte nach mebrtägigem Liegen in chemisch reinem Glycerin. In Fig. $a, b$ und $c$ ist die Inhaltsmasse der Krystalloide gelöst, während in d eine geringe Menge das ganze Krystalloid erfüllender Substanz zurückblieb $\left(\frac{800}{1}\right)$.

Fig. 6. Globoide mit concentrirtem Kali behandelt. a während, b und c nach Vollendung der Einwirkung $\left(\begin{array}{c}1000 \\ 1\end{array}\right)$.

Fig. 7 a-g. Lösung der Krystalloide beim Keimen des Samens $\left(\begin{array}{c}800 \\ 1\end{array}\right)$.

Fig. 8. Aus dem reifenden Samen. Die kugeligen Gebilde im Zellsaft sind Stärkekörnẹ: $\left(\frac{400}{1}\right)$.

Fig. 9. Etwas älter als Fig. 8. Die Stärke ist verschwunden, die Bildung der Krystalloide und Globoide begann $\left(\frac{400}{1}\right)$.

Fig. 10 u. 11. Fortbildung der Krystalloide und Globoide $\left(\frac{400}{1}\right)$.

Fig. 12. Bildung der Hüllmasse um die ausgebildeten Krystalloide und Globoide $\left(\frac{400}{1}\right)$.

Fig. 13. Zellen aus dem Endosperm von Aethusa cynapium nach Behandlung mit sublimathaltigem Alkohol im Wasser liegend. In Zelle a haben die krystalloidführenden Proteinkörner kugelige, in b krystallinische Einschlüsse $\left(\frac{500}{1}\right)$.

Fig. 14. Zellen aus dem Endosperm von Coriandrum sativum nach gleicher Behandlung wie bei Fig. 13 angegeben. In a sind die Einschlüsse der Proteinkörner Globoide, in b Krystalle. $\mathrm{n}$ ist der Zellkern $\left(\frac{500}{1}\right)$. 
Untersuchungen über d. Protenkörner und d. Bedeutung d. Asparagins ete. 573

Fig. 15. Aus dem Samenlappen eines jugendlichen Eimbryous von Phaseolus vulgaris. Im Protoplasma und Metaplasma finden sich Stärkekörnchen $\left(\frac{400}{1}\right)$.

Fig. 16a. Eine Zello aus den Cotyledonen vou Phaseolus vulgaris unmittelbar vor Bildung der Proteinkörner. - 16 b. Aus dem ruheuden Samen derselben Pflanze; die kleinen Körner sind Proteinkörner, die grossen Stärkekörner $\left(\frac{400}{1}\right)$.

Fig. 17. Einzelne Proteinkörner von Elaeis guyanensis in 0el liegend $\left(\frac{500}{1}\right)$.

\section{Tafel XXXVIII.}

Fig. 1-5. Silybum marianum.

Fig. 1. Bei a ist eine Zelle mit krystallinischen, bei b eine solche mit kugeligen Einschlüssen dargestellt. Es sind diese einem Schnitt aus dem Samenlappen eines ruhenden Samens extnommen, welcher nach Behandlung mit sublimathaltigem Alkohol in Wasser getragen wurde $\left(\frac{500}{1}\right)$.

Fig. 2. Das Netz der Grundmasse durch Behandlung mit verdünntem Kali und Salzsäure dargestellt. Das Präparat stammt aus einem Cotyledon des ruhenden Samens. n Zellkern $\left(\frac{500}{1}\right)$.

Fig. 3. Eine Zelle aus dem Samenlappen eines fast reifen Samens, in welcher die Bildung der Proteinkörner eben begann $\left(\frac{500}{1}\right)$.

Fig. 4. Zellen aus den Cotyledonen keimender Samen, welche eben die Samenschale abstreiften. Die Proteinkörner sind verschwunden, die Einschlüsso aber noch vorhanden $\left(\frac{500}{1}\right)$.

F ig. 5. In Lösung begriffene Globoide aus Samenlappen keimender Samen $\left(\frac{800}{1}\right)$.

Fig. 6. Zelle aus dem Endosperm von Vitis vinifera" in Oel liegend $\left(\frac{500}{1}\right)$.

Fig. 7. Vitis vinifera. Grosse Proteinkörner, deren Einschlüsse Globoide sind. Bei b findet sich in dem Globoid eine Krystalldruse von oxalsaurem Kalk, ebenso wie in Fig. 8, der Abbildung zweier Globoide, woselbst das andere Globoid einen Einzelkrystall einschliesst $\left(\frac{500}{1}\right)$.

Fig. 9. Globoide von Vitis vinifera $\left(\frac{500}{1}\right)$.

Fig. 10. Eine Zelle aus der Muskatnuss in Oel liegend. In der Grundmasse liegen sehr zahlreiche Fettkryställchen. Die bellgelassenen Körner sind die oft componirten Stärkekörner, die anderen die krystalloidführenden Proteinkörner. Das einzelne durch Grösse hervorragende Proteinkorn hat fast gar keine Hüllmasse, welche sich aber an dem in Fig. 11 dargestellten grossen Proteinkorn einer anderen Zelle findet $\left(\frac{500}{1}\right)$.

Fig. 12. Ein einzelnes Proteinkorn von Lupinus varius in Oel liegend. Dio bellgelassenen Stellen sind Globoide $\left(\frac{800}{1}\right)$. 
Fig. 13. Eine Zelle aus dem Samenlappen eines nicht völlig reifen Embryos von Lupinus polyphyllus, welcher langsam austrocknete $\left(\begin{array}{c}500 \\ 1\end{array}\right)$.

Fig. 14. Von derselben Species wie Fig. 13, aber dem ruhenden völlig gereiften Samen entnommen. Beide Präparate lagen in 0 el $\left(\frac{500}{1}\right)$.

Fig. 15. Zellen aus einem Samenlappen von Lupinus luteus in Oel liegend. In dem durch Grösse hervorragenden Proteinkorn liegt ein Krystall von oxalsaurem Kalk $\left(\frac{500}{1}\right)$.

Fig. 16. Aus einem Cotyledon des reifenden Samens von Lupinus polyphyllus, die Proteinkörner haben volle Grösse erreicht. n ist der Zellkern $\left(\frac{500}{1}\right)$.

Fig. 17. In Lösung begriffene Proteinkörner des keimenden Samens von Lupinus luteus $\left(\frac{500}{1}\right)$.

Fig. 18. Zelle, welche einem Cotyledon des keimenden Samens von Lupinus luteus unmittelbar vor dem Abstreifen der Samenschale entnommen wurde. In dem Metaplasma liegt der aus dem grossen Proteinkorn stammende Krystall $\left(\frac{500}{1}\right)$.

Fig. 19. Aus den Samenlappen des ruhenden Samens von Tetragonolobus purpureus. Das Präparat wurde nach Behandlung mit sublimathaltigem Alkohol mit Jod gefärbt. Die Proteinkörner sind gelb, die Stärkekörnchen blau gefärbt $\left(\frac{600}{1}\right)$.

Fig. 20. Ein in der eben angegebenen Weise behandeltes Prăparat aus den Samenlappen von Chimonanthus fragrans, Die blauen Körner sind hier, wie in Fig. 19, Stärke-, die gelben Proteinkörner $\left(\frac{600}{1}\right)$.

Fig. 21. Die Alkannareaktion an einer Zelle aus dem Endosperm von Paeonia $\left(\frac{500}{1}\right)$. 


\title{
Untersuchungen über die Farbstoffe einiger für chloro- phyllfrei gehaltenen Phanerogamen.
}

Von

\author{
Julius Wiesner. ${ }^{1}$ )
}

Beim Studium des anatomischen Baues der Neottia Nidus avis Rich., welches mich in diesem Frühlinge (1871) gelegentlich beschäftigte, lernte ich, und zwar ganz zufällig, einige Eigenschaften des Farbstoffes dieser Orchidee kennen, die mir so merkwürdig und interessant und einer näheren Untersuchung so werth schienen, dass ich mich zur Durchführung der vorliegenden Arbeit gedrängt fühlte.

Als ich nämlich ein von anhängender Erde mittelst Wasser gereinigtes Exemplar der Neottia Nidus avis zum Zwecke der Conservirung in Alkohol einlegte, bemerkte ich zu meinem Erstaunen, dass die in allen ihren Theilen licht bräunliche Pflanze, besonders aber die oberirdischen Organe, alsbald eine grüne Farbe annahmen. Nach kurzer Zeit hatte sich der Weingeist deutlich grün gefärbt. Ein durch die Flüssigkeit geleiteter Lichtkegel zeigte einen röthlichen Schimmer- Als ich hierauf aus der im Mörser zerquetschten Pflanze durch Aufguss von absolutem Alkohol ein Extract bereitete, nahm ein durch dasselbe geleiteter Lichtkegel darin eine blutrothe Farbe an. Es zeigte sich ein Fluorescenzphänomen, wie es dem Chlorophyllextract eigenthümlich ist. Auch in Aether und Benzin erfolgte ein rasches Ergrünen der genannten Pflanze. Etwas länger dauerte das Grünwerden bei Anwendung von Schwefelkohlenstoff.

Diese Wahrnehmungen mussten mir um so mehr auffallen, als ich in keiner Gewebsregion der genannten Pflanze Chlorophyllkörner oder ergrüntes Plasma auffinden konnte. Ich versuchte nunmehr die bekannten Reactionen des Chlorophylls an dem weingeistigen Extracte der N. n. a. vorzunehmen und exhielt durch-

1) Vorlăufige Mitth. hierüber s. botan. Zeit. 1871, p. 619 . 
wegs positire Resultate. Der durch Eracuiren erhaltene Rückstand des Extractes löste sich in allen bekannten Lösungsmitteln des Chlorophylls. Das weingeistige Extract gab ferner mit Alaunlösung eine Fällung. Durch Kalkwasser bildete sich ein Niederschlag, welcher durch Salzsäure zersetzt, beim Ausschütteln mit Aether eine grüne Lösung gab. Wasserstoff in st. nasc. entfärbte das Extract. - Obwohl sich Chlorophyll in der genannten Pflanze optisch nicht nachweisen lässt, unterliegt es nach den vorstehenden Versuchen wohl kcinem Zweifel, dass sie, mit den Lösungsnitteln für Chlorophyll behandelt, Chlorophyll liefert.

Diesc Beobachtungen waren es nun zunächst, welche mich bestimmten, die in der N. n. a. vorkommenden Farbstoffe genauer z untersuchen und auch einige andere für chlorophyllfrei gebaltenen Phanerogamen nach derselben Richtung zu studiren. Ausser N. n.a. untersuchte ich noch: Orobanche cruenta Bert., O. rubens Wallr., 0 . Galii Duby und 0 . epithymum DC.

Ich habe hicr über dreierlei Farbstoffe abzuhandeln, über die in deu bräunlichen Theilen der genannten Pfanzen rorkommenden geformten Pigmente, über einen rothen aufgelöst vorkommenden Farbstoff, und endlich über zwei die Zellwinde gewisser Gewebe der aufgeführten Pflanzen tingirende Körper.

1) Dic braunen Farbstoffkörperchen der Neottia $\mathrm{Nidus}$ avis. (Fig. 1-4). Sowohl in den Hautgeweben, als auch in Grundgewebe aller Organe dieser Pflanze finden sich licht bräunlich gefärlte Farbstoffkörperchen vor, meist von zweispitziger aber auch von rundlicher Form, die entweder im farblosen Zellsafte suspendirt sind, oder in farblosen Plasmasträngen liegen, oder aber - und dies ist der häufigste Fall - den Zellkern ganz oder theilweise bedecken, und dann manchmal in denselben bineinragen. ${ }^{1}$ )

Diese Farbstoffkörper haben zumeist die schon an ähnlichen Gebilden mehrfach (von H. v. Mohl, Trécul, A. Weiss, G. Kraus u. A.) beschriebene zweispitzige Form, welche, nach den vorliegenden Beobachtungen, in Blütben und Früchten sehr häufig vorzukommen

1) Gregor Kraus (Die Entstehung der Farbstoffkörper in der Beere von Solanum Pseudocapsicum. Jahrb. f. wiss. Bot. VIII. p. 134 ff.) hat im Fruchtfleische von Sul. P's. ebenfalis zweispitzige Farbstonkürperthen beobachtet, welche häufig deu Zellkern hedeckiten, und manchmal in das Imnere des letzteren hineingeschoben erscheinen. 
Untersuch. über d. Farbstoffe einiger f. chlorophyllfrei gehaltenen Phanerogamen. $\quad 577$

scheint. ${ }^{1}$ ) Die Länge dieser Farbstoffkörper schwankt bei der genannten Pflanze zwischen 0.016-0.032, die grösste Breite zwischen $0.001-0.006$ Millim. Erstere beträgt meist 0.023 Millim. Die Enden laufen meistens fadenförmig aus. Alle Formen sind seitlich abgeplattet. Nicht selten haften mehrere dieser Körperchen mit den spitzen Enden aneinander. Manchmal bemerkt man am Contour leichte Einbuchtungen. - Ausser den zweispitzigen Farbstoffkörpern bemerkt man in manchen Zellen auch linsenförmige Gebilde, welche - abgesehen von der Form - in allen Eigenschaften mit den erstgenannten übereinstimmen. Der grösste Durchmesser der linsenförmigen Körperchen gleicht dem Breitendurchmesser der zweispitzigen Formen, oder ist etwas grösser.

An all' den genannten Farbstoffkörperchen lassen sich keinerlei Structurverhältnisse wahrnehmen. Mit starken Vergrösserungen (Hartnack Im. Syst. Nr. 11. Oc. holost.) betrachtet, erscheinen mir bloss die älteren derartigen Gebilde ausgesprochen körnig. Jugendzustände sind entweder völlig hyalin oder überaus feinkörnig. Eine membranartige Hülle konnte ich nicht auffinden. Wohl aber habe ich auf das bestimmteste in manchen dieser zweispitzigen runden Formen grössere Körnchen gesehen, welche sich bei mebrfachen Versuchen als Stärkekörnchen erwiesen.

Gegen Reagentien zeigen diese Körperchen folgendes Verbalten. Wasser ändert sie nicht. Ein gleiches gilt für fette Oele. In concentrirter Zuckerlösung werden sie undeutlich und verfliessen darin. Alkohol färbt sie grün. Bei längerer Einwirkung von hochprocentigem Alkohol werden sie farblos und verfliessen schliess. lich im Reagens. Gegen Aether und Benzin verhalten sie sich in gleicher Weise. Ammoniak macht sie dunkler und körnig. Durch Salzsäure werden sie aufangs goldgelb, später grünlich. Eisenchlorid bringt keine Aenderung hervor. Durch concentrirte Schwefelsäure verfliessen sie alsbald unter Annahme einer blaugrünen bis tief blauen (nur an einzelnen Körnern zu beobachtenden) Farbe. Durch Kali- oder Natronlösung werden sie grüngelb und schliesslich gelöst.

In Betreff des Vorkommens dieser bräunlichen Farbstoffkörperchen ist der obigen Bemerkung, dass mit Ausschluss des Gefässbündelgewebes, selbe in den übrigen Geweben der oberund unterirdischen Organe der Neottia Nidus avis auftreten, noch folgendes anzufügen. An reichlichsten finden sich diese Körper-

1) Ueber das Vorkommen derartig geformter Farbstoffkörner s. die Citate in Kraus' genannter Arbeit auf p. 131. 
chen in der Oberhaut der Blüthentheile und des Stengels vor, aber auch im Epiblem der unterirdischen Theile sind sie nachweisbar. Am schönsten ausgeprägt fand ich sie in der Oberhaut des Fruchtknotens, wo sie meist dicht um den Kern gelagert sind, denselben kranzförmig überdeckend, oder an einzelnen Abschuitten seiner Oberfläche, bäufig diametral gegenüber, angehäuft vorkommen. In diesen Zellen fand ich sio nur selten im Zellsafte schwebend. Auch im Grundgewebe des Stengels und im Parenchym der Blüthentheile kommen die Körperchen mehr oder minder reichlich vor, auch hier gerne am Zellkerne angelehnt, oder selbst in denselben theilweise eingesenkt. Das Markgewebe enthält weniger von diesen Gebilden als jene Partie des Grundgewebes, welche zwischen der Oberhaut und dem Gefässbündel gelegen ist. In jugendlichen Stengeltheilen und Blättern treten sie spärlicher als in herangewachsenen und alternden Organen auf. In den völlig ausgebildeten Bracteen des Blüthenstandes kommen sie hauptsächlich im unteren Theile vor. Der obere T'heil des Blattes führt hingegen viel Sturke.

Das Vorkommen der Farbstoffikörperchen im Grundgewebe des Stengels rerdient besondere Beachtung. Während ich in den übrigen Geweben der Pflanze die Farbstoffkörnchen im Zellsaft flottirend, dem Zellkern angefügt, oder in Plasmaströme eingebettet beobachtet habe, bemerkte ich hier auf das Bestimmteste, dass viele dieser Farbstoffgebilde in scharf individualisirten Räumen des Zellinhaltes vorkommen. (Fig. 4.) Ich hatte hier entschieden jenes Vorkommen vor mir, welches an ähnlichen Farbekörperchen schon mehrfach und zwar von A. Weiss ${ }^{1}$ ) und Gr. Kraus ${ }^{2}$ ) beobachtet wurde. Weiss hat diese Räume als Bläschen, Kraus als Vacuolen gedeutet. Ich halte mich hier nur strenge an meine an N. N. a. gemachten Beobachtungen. Ich habe hier stets eine so feste Verbindung dieser Räume mit dem Zellinhalte gesehen, und bemerkte niemals eine membranartige Umhüllung dersclben, so dass ich sie nur als für Vacuolen und nicht für Bläschen erklären kann.

Meine Wahrnehnungen über die Entstehungsgeschichte dieser Farbestoff körperchen haben mich nur wenig befriedigt. Obgleich ich Jugendzustände aller Organe der N. N. a. vor mir hatte, konnte ich doch nur wenige Anhaltspunkte zur Feststellung der

1) A. Weiss. Untersuchungen über die Entwicklungsgeschichte des Farlıstoffes in Pflanzenzellen. Sitzungsber. d. kais. Akad. d. Wiss. B: 54. Juliheft.

2) E. c. p. 145. 
Entwicklungsgeschichte dieser Gebilde finden. Die ausserordentliche Aehnlichkeit der in der genannten Pflanze vorkommenden Farbstoffkörperchen mit ähnlichen Gebilden in Früchten und Blüthen, wie uns solche durch Trécul, A. Weiss, Gr. Krausu. A. bekannt geworden sind, lässt eine ähnliche Entstehungsgeschichte vermuthen. Aber ich bin nicht so glücklich gewesen, wie die genannten Beobachter, welche ein directes Hervorgehen dieser Farbstoffgebilde aus Chlorophyllkörnchen beobachteten. Auch jene Entwickelungsweise, welche von A. Weiss für einige derartige Gebilde angegeben wurde, und darin besteht, „dass sich um die Amylumkörner junger Zellen Plasmaballen lagern, und während diese ersteren immer nach und nach verschwinden, ein Pigment diese Ballen immer intensiver färbt, welches kaum anders als durch Stoffmetamorphose des Amylums entstanden ist" "), konnte ich an den Farbstoffkörperchen der N. N. a. nicht aufinden. Die Entstehung aus Chlorophyllkörnern kommt hier nicht weiter in Betracht, da diese Körper in der N. N. a. nicht vorkommen. Stärke findet sich in allen jungen Theilen der genannten Planze vor, und zwar sowohl im Haut-als im Grundgewebe. Die Stärkekörnchen sind zumeist sehr klein, einfach oder componirt. Ich kann sehr bestimmt aussagen, dass in jugendlichen Organen viel Stärke vorkommt nnd erst mit dem Verschwinden des Amylums die Farbstoffkörperchen in grösserer Masse auftreten. Auch eine Umlagerung der Stärkekörnchen von einer überaus feinkörnigen blassbräunlichen Masse habe ich gesehen. Wenn ich nun für die Entstehung der Farbekörperchen einen Zusammenhang der Stärkesubstanz mit der Substanz der Körperchen nicht ausschliesse, kann ich doch nach dem von mir Gesehenen keineswegs ein Hervorgehen dieser Gebilde aus Amylumkörnchen durch directe chemische Metamorphose der letzteren für richtig halten. Ich finde, dass die Farbstoffkörperchen durch Individualisirung einzelner Partieen des Plasma's entstehen, welche einige Zeit hindurch ein selbständiges Wachsthum, und zwar vornehmlich an den Spitzen zu haben scheinen. Ich werde unten nachweisen, dass die Substanz des Chlorophylls in den Geweben des N. N. a. vorkommt, und bin der Meinung, dass diese Substanz bei der Entstehung der Farbstoffkörperchen betheiligt ist. - Die Entstehung von spindelförmigen Farbstoffkörperchen in Zellen, welche keine Chlorophyllkörner führen, regt die Frage an, ob nicht

1) A. W eiss 1. e. Separatabdruck p. 79. 
boi der Entstehung derartiger Gebilde in chlorophyllführenden Zellen das Chlorophyll in einer anderen als in der ron Trécul, Weiss und Kraus angegebenen Weise betheiligt ist. Nach der überein. stimmonden Meinung dieser Beobachter ist allerdings das zugespitzte Farbstoffkörperchen ein Theil des chemisch metamorphosirten Chlorophyllkorns selbst. Die Entstehung dieser Furbstoffgebilde aus Chlorophyllkörnern wird hingegen ron den genanuten Autoren keineswegs übereinstimmend geschildcrt. Aber hiermit nicht genug. Ein so ausgezeichncter Beobachter wie Hofmeister ${ }^{1}$ ) hat eine von den Darlegungen der mehrfach angeführten Botaniker röllig verschiedene Ansicht über die Lntstehung dieser zweispitzigen Farbstoffkörperchen ausgesprochen, welche darauf hinauslauft, dass im Gelbwerden begriffene Chloroplyyllkörner sich durch Spitzenwachsthum in die genannten Farbstoffyebilde umformen sollen. Die Entwicklungsgeschichte der Farbstoffkörperchen in den Pflanzenzellen scheint mithin erneuter Untersuchungen werth zu sein.

2) Das Torkommen ron Chlorophyll in den Geweben der Neottia Nidus aris. Dic oben angeführten Beobachtungen über las Ergrünen der genannten Pflanze bei der Einwirkung von Reagentien regt die Frage an, ob dieser für chlorophyllfrei gehaltene Humusbewohner nicht Chlorophyll in einer bestimmten Form enthält. Obgleich weder Chlorophyllkörner, noch ergrüntes Plasna, noch gelöstes ('hlorophyli²) in den Geweben der N. N. a. vorkommt, so bleibt dennoch kcin Zweifel darüber übrig, dass in der That eine bestimmte Form des Chlorophylls in der genannten Pflanze enthalten ist. Auf den ersten Blick möchte es, namentlich in Anbetracht des Unstandes, dass sich in der N. N. a. die Gegenwart des Chlorophylls direct im Mikroskope nicht erweisen lasst, scheinen, als wäre in den Geweben dieser Pflanze eine dem Chlorophyllfarbstoff nahestehende Verbindung vorhanden, welche erst durch die Einwirkung der oben angeführten Reagentien in Chlorophyll übergeht. Die wasserentziehende Wirkung des absoluten Alkohols und der Schwefelsäure, welche die N. N. a. ebenfalls zum Ergrünen bringt, regt dic Frage an, ob nicht die grüne Farbe durch Wasserentziehung aus einer in den Geweben der genannten Pflanze vorhandenen Verbindung entstanden sei. Diese Frage muss aber sofort verneint werden, wenn man erwägt, dass ein so energisch wasserentziehendes Mittel wie concuntrirte Zuckerlösung kein Ergrünen hervorbringt,

1) Pflanzenzelle p. 377.

2) S. u. A. Weiss l, c. p. 48. 
und dass Substanzen wie Aether oder Benzin, welche, wie oben gesagt wurde, ebenfalls ein Grünwerden der N. N. a. hervorrufen, nicht wasserentziehend wirken. Der Umstand, da ss nur solche Reagentien, welche Lösungsmittel für Chlorophyll sind, ein Ergrünen der N. N. a. bedingen, zwingen zu der Annahme, dass in dieser Pflanze das Chlorophyll als solches'vorhanden und mit einer Substanz gemengt sein müse, welche in dengenannten Lösungsmitteln schwerer als dieses loslich oder unlöslich ist. Verfolgt man das Auftreten des Chlorophylls in den Geweben der N. N. a. mikroskopisch, so findet man, dass es lediglich die beschriebenen lichtbräunlichen, zumeist zweispitzigen Farbstoffkörperchen sind, welche als Träger des Chlorophylls in der genannten Pflanze fungiren, denn nur diese sind durch die genannten Mittel zum Lrgrünen zu bringen. In diesen eine plasmatische Grundlage besitzenden Farbstoffgebilden muss das Chlorophyll, gemengt mit einem anderen Farbstoff ${ }^{2}$ ), auftreten.

Mit dem Alter zerfallen die Farbstoffkörperchen in eine feinkörnige, bräunliche Masse, welche in den genannten Flüssigkeiten nur mehr schwach ergrünt. So kömmt es, dass ältere, schon in Fruchtbildung begriffene Exemplare da N. N. a in Alkohol nur mehr eine schwach grüne Farbe annahmen.

3) Das Pigment in der verholzten Zellmembranen des Gefässbündels der Neottia Nidus avis. Die Membranen der aus den Cambiumzellen hervorgehenden Holzzellen, Holzparenchymzellen und Spiralgefässe zeigen in Jugendzuständen die bekannten Cellulosereactionen. Später tritt in ihnen Holzsubstanz auf, wie sich durch Anwendung von schwefelsaurem Anilin erweisen lässt. ${ }^{1}$ ) Die schon ganz deutlich verholzten Zellen und Gefässe besitzen noch ungefärbt erscheinende Membranen. Erst nach dem Eintritt der Verholzung entwickelt sich, und zwar durch chemische Metamorphose von Stoffen der Zellmembran, ein die Zellwand gelblich färbendes Pigment. In fettem Oel, kaltem und heissem Wasser, in Weingeist, Aether und Schwefelkohlenstoff ändert sich die Farbe der Zellwand gar nicht. Das Pigment scheint in diesen Flüssigkeiten völlig unlöslich zu sein. Alkalien färben die Zellwände etwas lebhafter. Die Farbe zieht daun etwas in's Bräun-

1) Ueber diese Reaction s. Wiesner, Technische Mikroskopie p. 64.

2) Der aber selbst wieder ein Gemenge sein kann. 
liche. Säuren (Salzsäure und Schwefelsäure) rufen eine sehr lebhafte gelbgrüne Farbe hervor. In diesen Säuren ist das Pigmat der Zell- und Gefässwände unlöslich. Chromsäure übt anfänglich eine ähnliche Wirkung auf die Membranen der rerholzten Gewebstheile aus; nach einiger Zeit zerstört sie das Pigment röllig.

In einzelnen Zellen der Hautgewebe der N. N. a ist ein rother Farbstoff gelöst, welcher genan dasselbe Verhalten, wie das in Orobanchen sehr häufig vorkommende, gelöste Pigment zeigt, über welches noch weiter unten ausführlich abgehandelt werden wird.

4) Die Farbstoffkörperchen der Orobanchen. (Fig. 5-7.) In jungen Lxemplaren der oben genannten Orobanchen habe ich, wie in den Geweben der Neottia Nidus aris, dreierlei Pigmente angetroffen. 1) Farbstoffkörperchen, 2) einen rothen im Zellsaft gelösten Körper, und 3) ein in der Membran der verholzten Elemente rorkommendes, gelbliches Pigment. In alternden Exemplaren tritt eine, den Membranen der Oberhaut angehörige hraunschwarze bis tiefschwarze Substanz auf.

Im Haut- und Grundgewebe der ober- und unterirdischen Theile aller von mir untersuchten Orobauchen finden sich kleine, anfänglich grünliche, alsbald gelblich werdende Körnchen vor, welche im Vorkoumen und in den morphologisehen Verlältnissen eine auffällige Aehnlichkeit mit Chlorophyllkörner zeigen. Die Körnchen sind zumeist rundlich und etwas abgeplattet, also von der Form der Chlorophyllkörnchen. In den Zellen der Köpfchenhaare habe ich sie deutlich zweispitzig gefunden, ebenso in den gelbgefärbten Blüthenblättern, wo sie häulig genau das Aussehen der Farbekörper der Neottia Nidus avis haben. Ihre Grösse variirt ziemlich bedeutend, etwa 2 wischen $0.0029-0.006$ Millim.; seltener steigt sio darüber. Wie die Chlorophyllköruchen zeigen auch sie eine farbige Hülle und einen ungefärbten Kern; manchmal umschliessen sie sogar melırere farblose Inhaltskörper. Häufig gelang es mir, nachzuweisen, dass die Einschlüsse Stärkekörnchen sind. So z. B. in den Farbstoffkörnchen, welche im Parenchym der Blüthenblätter von Orobanche cruenta und in den Spaltơffnungszellen der Stengeloberhaut aller von mir untersuchten Orobanchen auftreten ${ }^{1}$ ). Die

1) Bis jetzt hat man meines Wissens die Stengeloberhaut der Orobanchen für spaltüfnungsfrei gebalten. (Vgl. Herm. Graf zu Solms-Laubach: Ueber den Bau und die Entwickelung der Erä̈hrungsorgane parasitischer Phanerogamen. Jahrb, für wiss. Bot. Bd. VI. p. 522.) An der unteren Stengelpartie der Orobanche rubens 
in den ebenherangewachsenen Spaltöffnungszellen vorkommenden Farbstoffkörner machen in Farbe und Form und Structur lebhaft den Eindruck der Chlorophyllkörner. Wie in dem übrigen Gewebe der Orobanchen vergilben sie auch hier rasch.

Die Farbstoffkörner der Orobanchen verhalten sich gegen Reagentien genau so wie Chlorophyllkörner oder wie solche Farbstoffkörper, welche aus Chlorophyll hervorgehen. In Wasser und Oel bleiben sie ungeändert. Weingeist entfärbt sie, die vergilbten rascher, die grünen langsamer, unter Zurücklassung der Stärkeeinschlüsse. Dem Entfärben der Farbstoffkörner durch Weingeist geht inanchmal ein stärkeres Ergrünen voraus. Ich habe dies namentlich an den schon genannten zweispitzigen Formen beob. achtet. Sehr bemerkenswerth erscheint mir das Verhalten der Farbstoffkörner gegen concentrirte Schwefelsäure. Junge, lebhaft grüne Farbstoffkörner werden durch diese Sžure smaragd- bis blaugrün, ältere vergilbte Körner indigblau gefärbt. Ein Blauwerden durch Schwefelsäure hat auch Kraus ${ }^{1}$ ) an den Farbstoffkörperchen von Solanum Pseudocapsicum constatirt. Ich erinnere hier auch daran, dass es eine lange bekannte Eigenschaft der Chlorophyllkörner ist durch concentrirte Schwefelsäure eine smaragd- oder spahngrüne Farbe anzunehmen.

Ueber das Vorkommen der Farbstoffkörner in den Geweben der Orobanchen bemerke ich folgendes. Die Farbstoffkörner treten am häufigsten, an die Zellwand angelegt, auf, doch habe ich sie auch im Zellsafte schwimmend (in den Köpfchenhaaren), und in Plasmastränge eingebettet gesehen. Ein Vorkommen dieser Gebilde in Vacuolen oder eigenen Bläschen habe ich in den Geweben der Orobanchen niemals beobachtet. Die Oberhaut ist sehr reich an Farbstoffkörperchen. Das ausserhalb des Gefässbündelkreises gelegene Grundgewebe ist reicher daran, als das Mark.

Ueber die Entstehung und Entwickelung der Farbstoffkörner in den Geweben der Orobanchen haben mir junge Blüthen-

fand ich auf $1 \square$ Millim. 6, am mittleren Stengeltheile auf $1 \square$ Millim. 30, in der Nähe der Blüthenspindel, auf $5 \square$ Millim. bloss 3 Spaltöffnungen. Auch in der Oberhaut der schuppenförmigen Blätter, des Stengels, der Kelchblätter und der Bracteen, treten Spaltöffnungen auf. Hier haben sie eine ziemlich regelmässige Gestalt. Die auf der Stengeloberhaut auftretenden Spaltöffnungen zeigen hingegen häufig eine verzerrte Gestalt; die von der Spalte abgewendeten Contouren der Schliesszellen sind nicht selten polygonal. Die Axe der Spaltöffnungen divergirt hier häufig mit der Richtong der benachbarten Oberhautzellen.

1) 1. c. p. 132. 
thcile und die über alle oberirdischen Organe verbreiteten Køpfchenhaare die besten Aufschlüsse gegeben. Sowohl im Haut- als im Grundgewebe der Blüthentheile und in den Zellen der Kopfchenhaare (Drüsenhaare) habe ich ein Entstehen der Farbstoffkörpercben aus wachsenden und völlig individualisirten Plasmakörperchen gesehen. In den Haaren geht die Bildung des Farbstoffkörperchen vor sich, ehe darin noch Stärkekörner auftreten. Diese Farbstoffkörperchen entstehen mithin hier keineswegs aus Stärke, sondern gehen unmittelbar aus dem Plasma hervor. Es lassen mich auch alle anderen an Orobanchen angestellten einschlägigen Beobachtungen eine gleiche Entstehung für die übrigen Farbstoffkörperchen dieser Pflanzen rermuthen. Das massenhafte Auftreten von Stärke ${ }^{1}$ ) in allen jungen Organen der Orobanchen und das so häufige Verschwinden des Amylums bei der Bildung der Farbstofflörperchen macht allerdings auf den ersten Blick ein Hervorgehen. del letzteren aus dem ersteren wahrscheinlich. Diese Auffassung kann jedoch den directen Beobachtungen nicht Stand halten.

Dass die in den Farbstoffkörnchen der Orobanchen vorkommenden Stärkekörnchen darin entstehen, ist für mich nicht $\mathrm{zweifel}$ haft ${ }^{2}$ ). Auf diese Weise lässt sich jedoch nur die Entstehung eines kleinen Theils des Amylums der Orobanchen erklären. Grosse Massen von Stärke sind in dem jungen Gewebe dieser Pflanzen oft schon vorhanden (Grundgewebe des Stengels) bevor noch die Farbstoffkörperchen entstanden sind. Die grösste Masse der Stärke, wolche wir in den Orobauchen finden, wird entschieden der Nährpflanzo entnommen.

Dic Farbstoffkörperchen zerfallen häufig in eine bräunliche, körnige Masse. (Fig. 7 c).

5) Das Vorkommen von Chlorophyll in den Orobanchen. Dic Orobanchen sind bis jetat als chlorophyllfrei angesehen worden. Aber schon die im vorangegangenen Theile dieser Ab.

1) Stärke kommt in verschiedener Form und Grösse in allen jungen Organen der Orobanchen und zwar massenweise vor. Sie findet sich nicht nur im Parenchym, sondern auch in der Oberhaut. Die Stärkekörnchen der oberirdischen Organe sind nur klein, die des Stammgrundes hingegen gross. Die letzteren sind meist zusammengesetzt und bestehen, ähnlich wie die bekannten Sagostärkekörnchen aus einem grossen und mehreren kleinen Theilkörnern. Die grossen Theilkörner erreichen manchmal einen Durchmesser von 0.042 Millim.

2) Ich balte es auch für wabrscheinlich, dass die in den Farbstoffloörperchen der Neottia Nidus avis manchmal vorkommenden Stärkekörncheu in denselben ontstanden sind. 
handlung angeführten Beobachtungen über die Farbekörperchen der Orobanchen machen es im hohen Grade wahrscheinlich, dass diese Farbstoffgebilde nichts anderes als Chlorophyllkörner sind. Ich habe an den genannten Pflanzen keinerlei dieser Vermuthung widersprechende Wahrnehmung gemacht. Wohl aber kann ich den schon oben mitgetheilten Thatsachen noch einige neue anfügen, welche meine Voraussetzung zur Gewissheit erheben. In den Stielund Köpfchenzellen der Drüsenhaare lässt sich vor dem Auftreten der Farbstoffkörperchen ein Ergrünen des Plasmas constatiren. Man hat in diesen Fällen einen gefärbten Plasmakörper vor sich, der sich von dem sogenannten "Chlorophyllkörper" in gar nichts unterscheidet. Dieser ergrünte Plasmakörper zerfällt manchmal bald und verwandelt sich dann in eine gelbliche, später bräunliche, feinkörnige Masse. Häufig aber bilden sich in dem Plasmakörper grüne Körnchen mit Stärkeeinschlüssen aus, welche Niemand von echten Chlorophyllkörnern zu unterscheiden im Stande ist. Junge herangewachsene Stengel und Blüthen von Orobanchen ergrünen allerdings etwas in Alkohol. Aber in dem Extracte will es nicht gelingen, die Gegenwart des Chlorophylls nachzuweisen. Aber durch Auswahl wenig gerötheter Exemplare von Orobanchen und Ausscheidung der roth gefärbten Theile ist es mir doch gelungen, ein alkoholisches Extract darzustellen, welches schwach röthlich fluorescirte, und die oben angeführten Reactionen einer Chloroplyylllösung zeigte. Noch besser gelang mir die Herstellung eines mit allen Eigenschaften einer Chlorophylllösung ausgerüsteten alkoholischen Extractes durch Verwendung von Stengelspitzen junger Orobanchen. Die benutzten Exemplare hatten eine Höhe von 3-6 Centimeter. Die Species liess sich selbstverständlich nicht bestimmen. Ihre Wirthe waren Galium-Arten und Papilionaceen. Die Stengelspitze dieser jungen Individuen hatte so wie die zugehörigen Blättchen eine gelblichgrüne Färbung. Das Extract war ausgesprochen grün, fluorescirte röthlich und ergab die oben angegebenen Reactionen des Blattgrüns. - Nach allen meinen a f die Frage bezüglichen Beobachtungen muss ich die Orobanchen für chlorophyllhaltige Pflanzen halten, wie ich auch Neottia Nidus avis für ein blattgrünführendes Gewächs erklären musste. Die Menge des in den Geweben der Orobanchen vorkommenden Chlorophylls ist allerdings - im Vergleiche mit grünen Gewächsen - keine grosse. Auch verfällt das Chlorophyll der Orobanchen bald, es wird rasch 
gelb. Die Orobanchen sind mithin chlorophyllhaltig, in dem Sinne etwa, wie die bunten Blüthenblätter, in denen ja auch nur wenig und rasch verfallendes Chlorophyll auftritt.

6) Der rothe Farbstoff der Orobanchen. Die rothen Stellen der Orobanchen-Stengel, ferner der Corollen von Orobanche cruenta, rubens, epithymum, Galii und der Narben der zwei zuletztgenannten Species verdanken ihre Farbe einem in Zellsafte der betreffenden Gewebe aufgelöst vorkommenden Farbstoffe. An den Stengeln ist die Oberhaut, an den Blüthen die am innern, manch. mal anch die am äusseren Theile der Coralle gelegene Oberhaut und das darunterliegende, von kleinen Intercellularräumen durchsetzte Parenchym der Sitz dieses Pigmentes.

Ein Vergleich des Vorkommens und der Reactionen dieses Farbstoffes mit den gewöhnlichen, von roth bis blau gelegenen, im Zellsafte aufgelöst vorkommenden Blüthenfarbstoffen, macht es gewiss, dass man es auch hier mit nichts anderem als dem Anthocyan zu thun habe. Da aber die Eigenschaften dieses so ausserordentlich häufig im Pflauzenreiche und zwar in Laubblättern, Stengeln, Blüthen, Früchten und selbst unterirdischen Organen vorkommenden Farbstoffs noch immer Gegenstand der Controverse sind, so will ich den sich mir darbietenden Anlass benutzen, um einige meiner erneuten Beobachtungen über diesen Körper hier in Kürze mitzutheilen. -- Diese Beobachtungen beziehen sich nicht nur auf sogenannte chlorophyllfreie, sondern auch auf mehrere gewöhnliche, grüne Planzen. Ein Theil dieser Mittheilungen scheint auf den ersten Blick nicht genau in den Rahmen dieser Abhandlung zu passen. Es wird sich jedoch herausstellen, dass ein richtiges Verständniss der an Orobanchen vorkommenden Verhältnisse sich nur dann erzielen lässt, wenn auch auf andere Vorkommnisse des Anthocyan's Rücksicht genommen wird.

In Betreff der Reactionen des Anthocyans (Cyanin) wird von einer Seite ${ }^{1}$ ) behauptet, dass es durch Säuren geröthet, durch Alkalien grün gefärbt werde. Von anderer Seite ${ }^{2}$ ) wird ausgesagt, dass dieser Farbstoff, im (saueren) Zellsafte gelöst, durch Alkalien zuerst blau und dann grün werde. Ich habe durch eine Reihe von Beobachtungen darzulegen versucht ${ }^{3}$ ), dass das Anthocyan durch

1) Frémy et Cloèz. Journ, de Pharm. XXV. 249.

2) Wigand. Botan. Zeitsch. 1862. p. 124.

3) Botan. Zeitung. 1862. p. 389 ffd. 
Alkalien stets gebläut wird, und nur wenn es im Zellsafte mit einer Substanz gleichzeitig vorkommt, die von Alkalien gelb gefärbt wird, durch letztern Körper in Grün übergeht, welches als Mischfarbe entsteht. Die durch Alkalien sich gelbfärbende Substanz habe ich als einen eisengrünenden Gerbstoff erklärt. - Nach Nägeli und Schwendener ${ }^{1}$ ) ist es eine das Anthocyan characterisirende Erscheinung, dass es bei saverer Reaction des Zellsaftes, also roth gefärbt, durch Alkalien blau wird und dann in Grün übergeht. Die Richtigkeit meiner oben kurz dargelegten Anschauung wird von $\mathrm{Nägeli}$ und $\mathrm{Sch}$ wendener nicht zugegeben und zwar auf Grund von Beobachtungen, die an Gentiana verna und Pelargonium zonale angestellt wurden. - Ich habe über den Blüthenfarbstoff beider Pflanzen genaue Untersuchungen angestellt, deren Ergebnisse zur Lösung der Frage über die Eigenschaften des Anthocyans geeignet sein dürften.

a. Gentiana verna. In meiner oben citirten Abhandlung habe ich über den Blüthenfarbstoff dieser Pflanze nichts gesagt. Nägeli und Schwendener behaupten, dass die Blüthenblätter dieser Pflanze frei sind von eisengrünendem Gerbstoff, aber trotzdem durch Alkalien eine grüne Farbe annehmen; und ziehen daraus den Schluss, dass diese durch Alkalien hervorgebrachte grüne Färbung dem blauen Blüthenfarbstoff eigenthümlich sei. Es wird ferner die Behauptung aufgestellt, dass in den Blumenblättern ein eisenbläuender Gerbstoff vorkommt, von dem ich a. a. O. aussagte, dass er die Reaction des Anthocyans nicht beeinflusse. Würden sich diese Behauptungen bewahrheiten, so wäre meine Auffassung der Farbenreactionen des Anthocyans entweder irrthümlich oder doch nicht allgemein geltend.

Vor allem werde ich nachweisen, dass zur Zeit der Blüthe, nicht nur in allen Theilen der Blüthe, sondern in allen ober- und unterirdischen Organen dieser Pflanze eine im Wasser lösliche Substanz vorkommt, welche durch Ammoniak oder durch Alkalien eine intensiv gelbe Farbe annimmt. - Ich habe zahlreiche Exemplare der Gentiana verna, im völlig frischen Zustande, sorgfältig in folgende Theile getheilt: Wurzel, hypocotyle Stengelglieder, Blätter, Internodien, Kelche, farblose Theile der Blumenkrone, blau gefärbte Theile der Blumenkrone, Filamente, Stempel. Jede Partie wurde im Mörser mit destillirtem Wasser übergossen, zerdrückt

1) Mikroskrop. $501 \mathrm{ffd}$. 
und filtrirt. Alle Filtrate waren klar, fast röllig farblos, und nahmen mit Alkalien sofort eine intensiv gelbe Farbe an. Selbst die Pollenkörner zeigten deutlich diese Reaction. Verfolgt man die sich mit Alkalien gelbfärbende Substanz in den Geweben der Pflanze, so ergiebt sich, dass rornchmlich die Elemente der Oberhaut und der Fibrovasalstränge die Träger dieses Körpers sind.

Durch Alkohol lässt sich diese Substanz aus allen Theilen noch leichter, als durch kaltes Wasser entziehen. - Dieser Körper, in zahlreichen Blüthen von mir aufgefunden, ist a. a. O. von mir als eisengrünender Gerbstoff gedeutet worden, da ich jedes. mal, wenn ich mich durch Ammoniak von seiner Gegenwart überzeugte, durch chemisch reines, keine überschüssige Säuere führendes Eisenchlorid eine schwarzgrüne Trübung oder Fällung erhielt. Ich habe säımtlicbe oben genannte wässerige Auszüge mit Eisenchlorid behandelt, und habe mit Sicherheit constatirt, dass in allen Theilen, auch in den Blüthen, ein eisengrünender Gerbstoff vorhanden ist. Welche näheren Eigenschaften diese durch Alkalien sich gelbfärbende, durch Eisenoxydsalze schwarzgrün fällbare Substanz hat, konnte ich nicht feststellen. Immerhin ist es aber erlaubt, sie nach ihren Löslichkeitsverhältnissen, und nach dem Verhalten gegen Eisensalze, in die allerdings chemisch nicht genau definirte Gruppe der eisengrünenden Gerbstoffe zu stellen. Für die folgende Betrachtung ist es erwähnenswerth, dass grösscre Quantitäten dieses Körpers mit essigsauerem Bleioxyd nach anhaltendem Kochen eine schwefelgelbe Fällung geben.

Das von $\mathrm{N}$ ägeli und $\mathrm{Schwendener} \mathrm{angegebene} \mathrm{Vorkommen}$ von eisenbläuendem Gerbstoff in den Blüthenblättern von Gentiana verna kann ich nicht bestätigen. Weder in den wässerigen, noch weingeistigen oder ätherischen Extracten der Stengel, Blätter, Blüthen u. s. w. der Gentiana verna konnte ich durch Eisensalze eine blaue Färbung, oder einen blauen Niederschlag erhalten. Es ist eben in gar keinem Theile der genaunten Pflanze zur Zeit der Blüthe ein eisenbläuender Gerbstoff vorhanden.

Ich führe hier einige Reactionen des Anthocyans an, welche nicht nur zur Characterisirung dieses Farbstoffes, sondern auch dazu dienen werden, zu erklären, wie Nägeli und Schwendener dazu kamen, in den Blüthen der Gentiana verna einen eisenbläuenden Gerbstoff anzunehmen.

Bringt man die blauen Blüthentheile der genannten Pflanze in einen Kolben und säuert man sie mit salzsäurehaltigem Wasser an, 
Untersuch. über d. Farbstoffe einiger f. chlorophyllfrei gehaltenen Phanerogamen. 589

so werden sie alsbald, besonders rasch in der Wärme intensiv roth. Wäscht man sie hierauf auf einem Filter mit destillirtem Wasser aus, bis die ablaufende Flüssigkeit nicbt mehr sauer ist, so kann man an ihnen dann folgende Reactionen hervorrufen. Mit einer chemich reinen Eisenchloridlösung zusanımengebracht, werden die Blüthen intensiv blau. Diese Reaction war es, welche die beiden genannten Forscher verleitete, die Anwesenbeit eines eisenbläuenden Gerbstoffes in den Blüthen der Gentiana verna anzunehmen. Da aber, wie oben gezeigt wurde, ein solcher Gerbstoff in der Blüthe nicht vorkommt, so wird die Annahme nahegelegt, dass diese Farbenreaction dem Farbstoff ihr Entstehen verdanke. Versucht man das Anthocyan nach der von Fremy und Cloëz ${ }^{1}$ ) angegebenen Weise darzustellen, wobei jedoch - es sei dies nebenher bemerkt - noch keine chemisch reine Substanz gewonnen wird, so kann man sich von der Richtigkeit meiner Vermuthung überzeugen. Das Anthocyan geht eben mit Eisenoxyd eine blaue gefärbte Verbindung ein, welche in Wasser schwer löslich ist. Eine ebenso intensiv blau gefärbte Verbindung wie mit Eisenoxyd geht das Anthocyan mit Bleioxyd ein. Die angesăuerten, in Folge dessen gerötheten, und hierauf rein ausgewaschenen Blüthentheile von Gentiana verna werden mit essigsauerem Bleioxyd intënsiv blau. Eine ähnliche Farbe nimmt das möglichst rein aus Gentianablüthen dargestellte Anthocyan mit Bleizuckerlösung an. Ich erinnere hier daran, dass der eisengrünende Gerbstoff, welcher sich den Blüthen durch Wasser, Weingeist oder Aether entziehen lässt, mit Bleizuckerlösung einen in Wasser schwerlöslichen citrongelben Niederschlag liefert, - Die Verbindungen des Anthocyans mit Metalloxyden sind meist lebhaft gefärbt. So fand ich, dass auch die Kupferverbindung blau ist. Die Verbindungen mit Silber, Zink und Mangan liegen in der Farbe zwischen roth und blau.

Die Löslichkeitsverhältnisse jener durch Alkalien sich gelb färbenden Substanz der Gentiana-Blüthen und der übrigen Organe dieser Pflanze, welchen Körper ich in die Gruppe der eisengrünenden Gerbstoffe einzureihen mich für berechtigt halte, weichen nicht viel von jenen des Anthocyans ab; auch die Löslichkeitsverhältnisse der mir bekannt gewordenen Verbindungen des Anthocyans mit Basen stimmen so nahe mit den analogen Verbindungen des in

1) 1. c. 
Gentiana verna vorkommenden eisengrünenden Gerbstoffes überein, so dass es mir nicht möglich war, die beiden Körper völlig von einander zu trennen. Ich konnte desshalb bei den gossen Mengen von eisengrünendem Gerbsteff, welche in den Blüthen von Gentiana verna vorkommen, nicht den directen Beweis herstellen, dass das Anthocyan durch Alkalien blau und nicht grün wird, und dass die grüne Farbe bloss durch Beimengung ron eisengrünendem Gerbstoffe zu Stande kommt. Allein die Anwesenheit des letztgenannten an sich farblosen durch Alkalien sich gelb färbenden Körpers in den blauen Theilen der Blumenblätter, der Umstand, dass man an blauen (oder rothen) Blüthen je nach der Menge dieses Körpers durch Alkalien alle Nuançen zwischen reinem Blau und Smaragdgrün hervorrufen kann, lassen schliessen, dass das Anthocyan als solches in saueren Flüssigkeiten als rother, in alkalischen als blauer Körper erscheint.

Ein völlig gleiches Verhalten, sowohl in Bezug auf den Blüthenfarbstoff als auf das Vorkommen und die Eigenschaften des als eisengrünenden Gerbstoff erkannten Chromogens fand ich an zahlreichen Pflanzen mit blauen Blüthen auf, z. B. an Ajuga reptans, Muscari racemosum, Veronica, Myosotis ${ }^{\text {I) }}$ u. s. w.

Sehr bemerkenswerth ist die Thatsache, dass der eisengrünende Gerbstoff der Blüthenblätter gegen Eisenoxyd- und Bleioxydsalze nicht so empfindlich als das Anthocyan reagirt. Während blaue Blüthen mit sehr geringem Gerbstoffgehalte durch Alkalien schon eine grüve Farbe annehmen, werden dieselben bei schwach sauerer Reaction durch Eisen- oder Bleisalze noch rein blau. Blüthen hingegen mit grossem Gehalt an Gerbstoffen, werden auch durch Eisenund Bleisalze, alsbald grün, z. B. die Blüthen von Myosotis. Das Grün ist auch hier nichts als Mischfarbe aus Blau und Gelb: das Blau ist der Verbindung des Anthocyans mit Eisen- oder Bleioxyd, das Gelb der Verbindung des Gerbstoffes mit diesen Basen eigen.

b. Pelargonium zonale. Von den scharlachrothen Blüthen des Pel. zon. habe ich a. a. O. ausgesagt, dass sie durch Alkalien blau gefärbt werden, und dass nur eine kleine Menge jener Substanz, welche durch Alkalien sich gelb färbt (eisengrünender Gerbstoff) vorhanden ist. Die Reaction des Anthocyans wird also in diesem Falle durch eine nebenher auftretende Substanz

1) Vgl. hierüber meine oben (p. 586) citirte Abhandlung. 
keineswegs gestört. Darum also die Blaufärbung der Blüthen durch Alkalien ${ }^{1}$ ). Auch orwähnte ich in der genannten Abhandlung, dass vor dem Verblassen der Pelargonium - Blüthes in Alkalien eine schmutzig rothe Farbe bemerklich wird, eine Thatsache, die ich nur ganz nebenher bemerkte und die mit meinen dort gegebenen Schlussfolgerungen in keinerlei Zusammenhang stand.

Nägeli und Scwendener, welche, wie oben bemerkt, behaupten, dass das Anthocyan aus Blau in Grün durch Alkalien übergeht, scheinen in den Pelargonium-Blüthen gar kein Anthocyan anzunehmen, da es ihnen nicht gelingen wollte, den Farbstoff dieser Blüthen durch Alkalien in Grün überzuführen. L. c. p. 503 heisst es: "Woher es kommt, dass gewisse Farbstoffe unter keinen Umständen in Grün üborgehen, wollen wir dahingestellt sein lassen." Diese Stelle bezieht sich auf die Blüthen von Pelargonium zonale.

Die nachfolgenden Beobachtungen werden lehren, dass der Farbstoff der Blüthen ron Pelargonium zonale (ein gleiches gilt auch für Pel. inquinans) sich in gar nichts von dem Anthocyan, also z. B. vom Blüthenfarbstoff der Gentiana verna unterscheidet.

In allen Theilen des Pelargonium zonale lässt sich zur Zeit der Blüthe eine Substanz nachweisen, die in wässeriger oder alkoholischer oder ätherischer Lösung durch Alkalien gelb wird, und die ganz und gar mit jener Substanz von Gentiana verna übereinstimmt, die wir als eisengrünenden Gerbstoff angesprochen haben. Die scharlachrothen Pelargonium-Blüthen führen aber nur eine sehr geringe Quantitä dieses Körpers. Sie lässt sich hier durch Ammoniak ziemlich sicher, durch Eisenchlorid aber nui schwer nachweisen. Hingegen enthalten, und dies ist für die nachfolgende Betrachtung von Wichtigkeit, die blassrothen Varietäten der beiden Pelargonien bedeutend grössere Mengen dieses Körpers, welche sich im wässerigen Extracte der Blüthen schon durch Eisen. chlorid leicht nachweisen lassen.

Wie ich schon a. a. O. angab, werden die scharlachrothen

1) Ich betone hier nochmals. dass die von Wigand aufgestellte Behauptung, dass rothe Zellsäfte durch Alkalien zuerst blau und dann grün werden, sich für alle die Fälle nicht bewahrheitet, wenn im Zellsafte grössere Mengen von eisengrünendem Gerbstoff vorhanden sind. Blüthen von Clinopodium vulgare, Lamium purpureum, maculatum und amplexicaule, reich an eisengrünendem Gerbstoffe, werden durch Alkalien genau so intensiv grün, wie etwa blaue Enzianblüthen. 
Blüthen von Pelargonium zonale durch Alkalien blau; eben so auch der daraus dargestellte Farbstoff. Die blassrotben Blüthen der genannten Pelargonien werden durch Alkalien sofort blaugrün und nach einiger Zeit grün, was nach den oben angeführten Beobachtungen über das Vorkommen von eisengrünendem Gerbstoff eben so wenig befremden kann, wie die Thatsache, dass die scharlachrothen Blüthen durch Alkalien blau werden. Extrahirt man die scharlachrothen Blüthen sammt den an eisengrünendem Gerbstoff reichen Kelchen mit heissem Wasser, wobei sowohl der Farbstoff als der Gerbstoff in Lösung geht, und dampft man im Wasserbade bis zur Trockene ein, so erbält man einc rothe Substanz, welche durch Alkalien grün wird.

Eisenoxyd- und Bleioxydsalze geben mit dem Farbstoff blaue Verbindungen, welche sich genau so wie die analogen Verbindungen des Farbstoffes der Gentiana-Blüthen verhalten, sich in Wasser lösen, aus der kochenden Lösung herausfallen, und durch Säueren geröthet werden. Auch das Verhalten gegen Kupfer-, Zink;, und Mangansalze ist genau dasselbe, wie wir es bei den durch Ansäuerung gerötheten Blüthen von Gentiana rerna kennen lernten.

Die angeführten Beobachtungen zeigen auf das Deutlichste, dass der Farbstoff der Gentiana rerna und des Pelargonium zonale völlig miteinander übereinstimmen, dass derselbe nichts anderes ist als Anthocyan, eine durch Säueren sich röthende, durch Alkalien bläuende Substanz, und dass die durch Anthocyan tingirten Blüthen von Gentiana verna nur wegen gleichzeitiger Anwesenheit von einer farblosen, durch Alkalien sich gelbfärbenden Substanz (eisengrünender Gerbstoff) durch Alkalien eine grüne Farbe - eine Mischtarbe von Blau und Gelb - annehmen.

Ich muss schliesslich noch bemerken, dass ich a. a. 0 . das Zustandekommen der blauen Färbung an mit Eisenchlorid behandelten Pelargonien-Blüthen als Reaction eines eisenbläuenden Gerbstoffes deutete. Es ist dies aber, wie schon oben auseinandergesetzt wurde, eine dem Anthocyan eigenthümliche Reaction, welche man auch durch andere Salze, z. B. durch Bleioxydsalze hervorzubringen im Stande ist. Das Anthocyan geht eben sowohl mit Eisenoxyd als Bleioxyd blaue Verbindungen ein. Ich verfiel in denselben Fehler, in welchen später Nägeli und Schwendener verfielen, als sie in den angesäuerten Blüthen der Gentiana verna eisenbläuenden Gerbstoff nachzuweisen rermeinten. Erneute und auf sehr zahlreiche Blüthen ausgedehnte Untersuchungen haben 
in keinem einzigen Falle die Anwesenheit von eisenbläuenden Gerb. stoff ergaben. Hingegen habe ich bis jetzt keine einzige Blüthe gefunden, in welcher nicht zum mindesten kleine Quantitäten von eisengrünendem Gerbstoff vorhanden gewesen wären.

c. Orobanche-Arten. Nach den Auseinandersetzungen über den Blüthenfarbstoff der Gentiana verna und des Pelargonium zonale wird es keine Schwierigkeiten machen, nachzuweisen, dass das Pigment der Orobanchen vom Anthocyan nicht verschieden ist.

Durch Säueren wird der rothe Zellsaft der Orobancb sn äusserst lebhaft roth (fuchsin- bis zinnoberroth), durch Alkalien sofort intensiv spahngrün gefürbt. Eisenoxydsalze bringen eine bläulich grüne, essigsaures Bleioxyd eine lebhaft grüne Färbung hervor. Das Verhalten der rothen Blüthengewebe gegen Eisenoxydsalze und Bleizucker weicht ziemlich auffällig ron dem Verhalten der gewöhnlichen blauen, violetten oder rothen Zellsäfte der Blumenblätter gegen die genannten Salze ab. Diese Verschiedenheit wird abel sofort erklärlich, wenn man erwägt, dass die Menge jener in den rothen Blüthentheilen vorkommenden Substanz, welche durch Alkalien eine gelbe Farbe annimint, und die nach allen übereinstimmenden Beobachtungen ein eisengrünender Gerbstoff ist, bei ‘.en Orobanchen eine auffällig grosse ist '). Ein farbloses wässeriges Extract, aus Orobanchenblüthen bereitet, gicbt mit essigsauerem Bleioxyd eine reichliche Menge eines citronengelben Niederschlags. Das Grün, welches Bleizuckerlösung in den rothen Theilen der Orobanchenblüthen hervorruft, ist ebenso eine Mischfarbe, wie die Farbe, welche die Blumenkrone vom Gentiana verna durch Alkalien erleidet. Im ersteren Falle entsteht die Mischfarbe aus alkalisch gemachtem Anthocyan (blau) und der genannten gelben Bleiverbindung; im letzteren Falle aus alkalisch gemachtem Anthocyan und der vielerwähnten gelben Alkali- (oder Ammoniak-) Verbindung. ${ }^{2}$ )

7) Die Farbstoffe der Zellmembranen einiger Gewebe der Orobancben.

1) Aehnlich wie in den Blüthen von Myosotis.

2) Die Verbindungen, welche das Anthocyan mit Metalloxyden, namentlich mit Eisenoxyd eingeht, legen die Frage nahe, ob nicht manche der blauen Blüthenfarben durch derartige Verbindungen hervorgerufen werden. Ich werde vielleicht später Gelegenheit haben, hierüber analytische Belege geben zu künnen. Hier will ich nur erwähnen, dass die bis jetzt von mir untersuchten blauen Blüthen mehrerer Labiaten einen grösseren Gehalt an Eisen als die bis dahin geprüften rothen Labiatenblüthen ergaben. 
Diø verholzten Elemente des Gefässbündels der Orobanchen enthalten in der Zellwand ein Pigment, welches genan dasselbe Verhalten zeigt, wie die schon oben näher besprochene, in den Membranen der verholzten Zellen des Gefässbündels der Neottia Nidus avis vorkommende gefärbte Substanz.

Die Oberhautzellen des unteren Stengeltheiles der Orobanchen haben häufig dunkle, beinahe schwärzliche Membranen. In Alkohol werden die Zcllwände etwas lichter und nimmt das betreffende Gewebe in diesem Reagens eine schwärzlichgrüne Farbe an. Durch Salzsäure werden diese Zellmembrane zuerst rostbraun und schliesslich lichtbräunlich. Chromsäure entfärbt diese Zellwände, deren dunkles Pigment zweifelsolne durch chemische Metamorphose aus Substanzen der Zellwand entstanden ist.

\section{Erklärung der Figurentafel XXXIX.}

Fig. 1. Oberhautzellen vom Fruchtknoten der Neottia Nidus avis. z. Zellkern; f. f.' runde, fo" spindelförmige Farbstoffkörperchen.

Fig. 2. Farbstoffkörperchen aus der Stengeloberhaut der Neottia Nidus avis: a. runde, b. zweispitzige, c. desgleichen mit Stärkeeinschlüssen.

Fig. 3. Oberhautzellen vom Stengel der Neottia N. a. z. Zellkern f. f. Farbstoftkörperchen.

Fig. 4. Parenchymzellen aus dem Stengel von Neottia Nidus avis. z. Zellkern. o. Vacuolen mit Farbstoffkörperchen.

Fig. 5. Oberbaut vom Stengel der Orobanche rubens. S. Spaltöffnung. f. Farbstoffkörperchen mit Stärkeeinschluss. $\mathrm{f}^{\prime} \mathrm{f}^{\prime}$. Farbstoffkörperchen.

Fig. 6. Haare von den Kelchblätteru der Orobanche rubens, a. jung mit noch farblosen, b. mit ergrünendem Plasma, c. herangewachsenes Köpfchenhaar, p. ergrüntes Plasma, f. Farbstoffkörperchen, z. Zellkern.

Fig. 7. Farbstoffkörper aus Orobanche rubens, stark vergrössert; a a' mit Stärkeeinschlüssen nach Behandlung mit Jodlösung, b. junge; c. alternde Formen. d. Ein mit concentrirter Schwefelsäure behandeltes stärkeführendes Farbstoffkörperchen. Die blaue Hülle entspricht dem farbigen Theile des Farbstoffkörpers, der durch Schwefelsäure ledig blau wird. 
den Bau trockner Pericarpien, mit Taf. VIII-XI. - J. Walz. Beitrag zur Morphologie und Systematik der Gattung Vaucheria DC., mit Taf. XII-XIV. A. B. Yrank. Ueber die anatomische Bedeutung und die Entstehung der vegetabilischen Schleime, mit Taf. XV-XVI. - A. de Bary. Ueber die Keimung einiger grosssporiger Flechten, mit Taf. XVII-XIX. - Max Reess. Zur Entwicklungsgeschichte des Polypodiaceensporangiums, mit Taf. XX-XXII. C. Müller. Untersuchung über den Sitz der Alcaloide in der Cinchonarinde, mit Taf. XXIII-XXIV. - N. J. C. Mïller. Das Wachsthum des Vegetatiunspunktes von Pflanzen mit decussirter Blattstellung, mit Tat. XXV-XXXIV. - E. Strasburger. Ein Beitrag zur Entwicklungsgeschichte der Spaltiffnungen, mit Taf. XXXV-XLII. - F. Hildebrand. Ueber die Befruchtung von Aristolochia Clematitis und einiger anderer Aristolochia-Arten,mit Tafel XLIII. -- F. Hildelinand. Ueber die Nothwendigkeit der Insektenhülfe bei der Befruchtung von Corydalis cavis. - L. Kin. Ueber Bau und Entwickelung der Riccien, mit Taf. XİIV-XLVI. - I. J. C. Miille:. Untersuchungen über dic Vertheilung der Harze, ätherischen Oele, Gummi und Gummiharze, und die Stellung der Secretionshehälter im Pflanzenkorper, mit Taf. XLVII - LIII. - A. Famintzin. Die Wirkung des Lichtes auf Algen und einige andere ibnen nahe verwaudte Organismen, mit Taf. I-III. - A. Fanintıin. Die Wirkung des Lichts auf das Eirgrünen der PHanzen. A. Fanintzin. Die Wirkung des Lichts und der Dunkelheit auf die Vertheilung der Cloro,hyllkörner in den Blittern von Mnium sp.?. - It. Th. fieyler. Ueber den Gefassbündelverlauf in den Laubblattregionen der Coniferen, mit Taf. IV-IX. - M. K.ess. Zur Entwickelungsgeschichte der Stammspitze von Equisetum, mit Taf. X-XI. - I. J. Millpr. Die Entwickelungsgeschichte der Kapsel von Ephemerum, mit Taf. XII-XIV. - F. Hildebrand. Mykolıgische Beiträge, mit Taf. XV-XVII. - fi. llilgers. Leber das Auftreten der Lirystalle ron ixalsaurem Kalk im Parenchym einiger Monocotylen. - E. Pfit»er. Ueber die Schutzscheide der deutschen Equisetaceen, mit Taf. XVIII-XX. - P. (i. Lorentz. Grundlinien zu einer vergleichenden Anatomie der Laubmoose, nit Taf. XXI-XXVIII. E. Loew. Ueber Dematium pullulans de Bary, mit Taf. XXIX und XXX. N. C. Mïlleı. Untersuchungen uber die Diftusion der atmosphärischen Gase in der Pflanze und die Gasausscheidung unter verschiedenen Beleuchtunisberlingungen, mit Tatf. XXXI. - Herltann hrat' zu Solms-Lanbach. Ueber den Bau und die Entwickelung der Ernährungsorgane parasitischer Phanerogumen, mit Taf. XXXII-XXNIX. - J. Baranetzliy. Beitrag zur Kenntniss des selbstständigen Lebens der Flechtengonidien, mit Taf. I. - Fr. Buchenau. Ueber die Richtung der Samenknospe bei den Alismaceen, mit Taf. II. - Clip lnerssen. Zur Controverse über die Einzelligkeit oder Mehrzelligkeit des Yollens ler Onagrarieen, Cucurbita. ceen und Corylaceen, mit Taf. IV. - VI - A. Fischep v. Waldheim. Beiträge zur Biologie und Entwickelungsgeschichte der Ustilagineen, mit Taf. VII-XII. - \. I. ('. Miiller, Untersuchungen über die Diffusion atmosphirischer Gase in der Pflanze und die Gasausschcidung unter verschiedenen Belcuchtungsbedingungen, II. Theil, mit Taf. III. - N. J C. Ililler, Ueber den Durchgang von Wasserdampf durch die geschlossene Epidermiszelle - 1. J. C. Miiller, Yotiz über die Farbstoffe im Chloropbyil. - li. Kírus. Ueber die Ursachen der Formänderungen etiolirender Pflanzen. - Julims Schröder. Beitrag zur Kenntniss der Frühjahrsperiode des Ahorus (Acer platanuides) mit Taf. XIII-XX. - BI. Bors cow. Ceber gegitterte Parenchynzellen in der Rinde des Stengels von Ceropegia aphylia und deren Beziehung zu den Milchsaftgefässen, mit Táfel XXI. - II. Leitøeh. Neue Saprolegnieen, mit Taf. XXII - XXIV. - I. strasburger. Die Befruchtung bei den Farrenkräutern, mit Taf. XXV und XXVI. - E. Strasburger, Die Geschlechtsorgane und die Befruchtung bei Mirchantia polymorpha, mit Taf. XXVIr und XXVIII - F. liildehrand Ueber die Bestiubungsvorrichtungen bei den Fumariaceen, mit Taf. XXIX-XXII. - E. Loew. Zur Entwichlungsgeschichte von Yenicillium mit Tafel XXXI-XXXIV. - G. Kraus. Einige Beobachtingen über d'n Einfluss des Lichts und der Wärme auf die Stärkeerzeugung im Chlorophyll, mit Tafel XXXV. - E. Plitzer Beiträge zur Kenntniss des Hautgewebes der Pflanzen, mit Taf. XXXVI-XXXVII. I. Ueber die Spaltöffnungen der Gräser nebst einigen Bemerkungen über die ersteren im Allgemeinen. II. Ueber die Hautgewebe einiger Restionaceen. 


\section{Inhalt des vorliegenden Hefts 4, Band VIII.}

W. Pfeffer. Untersuchungen üler die Proteinkörner und die Bedeutung des Asparagins beim Keimen der Samen mit Tafel XXXVI-XXXVIII.

J. Wiesuer. Lintersucbungen über die Fart: tofie einiger für chtorophyllfrei gehaltener Phanerogamen mit Taf. XXXIX . . . . . . . . 575

\section{Inhalt der vorhergehenden Hefte 1, 2 u. 3, Band VIII.}

I.. Kur. Beiträge zurEntwickelungsgeschichte der Farrenkriuter mit Taf.I -III. 1

E. Pfitzer. Beiträge zur Kenntniss der Hautgewebe der Ptlanzen mit Taf. VI. 16

III. Ceber dic mehrschichtige Epidermis und das IIynoderma.

i. J. C. Miller. Die Anatomie und Mechanik der Spaltöfinungen mit Taf. IV u. V.

III. Wirkung der Wärme innerhalb der Temperaturgrenzen des gewöhnlichen Lebens.

J. Peyritsch. Leber Bildungsabweichingen hei Cruciferen mit Taf. VII-IX. 117

f. Kralls. Die Entstehung der Farbstofikürper in den Beeren von Solanum Pseudocapsicum mit Taf. $\mathbf{X}$

1. Dodal. Der l'ebergang des Dicotyledonen-Stengels in die Pfablwurzel, mit Taf. XI-XVIII . . . . . . . . . . . ?

W. Pfefleer. Zur Blüthenentwicklung der Primulaceen und Ampelidcen, mit Taf. XIX-XXII . . . . . . . . . . .

B. Frank. Ueber die Veränderung der Lage der Chlorophyllkörner und des Protoplasmas in der Zelle, und deren innere und aussere Ursachen . 216

J. Kleiı. Zur Kenntniss des Pilobolus mit Taf. XXIII-XXX . . . . 305

L. Jurányi. Ueber den Ban und die Entwickelung des Yollens bei Ceratozamia longifolia Miq. mit Taf XXXI- XXXIV . . . . . . .

K. Sanio. Ueber die Grusse der Holzzellen bei der gemeinen Kiefer (Pinus silvestris) . . . . . . . . . . . .

G. Krats. Cuber eigenthümliche Sphaerokrystalle in der Epidermis von Cocculus laurifolius mit Taf. XXXV . . . . . . . 421

- - Ueber Eiweisskrystalloide in der Fpidermis von Polypodium ireoides Lam. 426

Die ,Jahrbücher für wissenschaftliche Botanik" erscheinen in unterzeichneter Verlagsbuchhandlung in zwanglosen Heften von 8-12 Bogen Text mit Abbildungen, und wird der Verleger bestrebt sein, die typographische wie artistische Ausstattung der Zeitschrift zu einer muglichst vollkommenen zu gestalten.

Vier Hefte bilden einen Band, doch kann jedes Heft auch einzeln bezogen werden und richtet sich der Preis jedes einzelnen Heftes nacl Umfang und nach Anzahl der beigegebenen Tafeln.

Geeignete Beiträge wolle man gefälligst an den Herrn Herausgeber (in Berlin, Bendlerstrasse 13 ) oder an den unterzeichneten Verleger senden, welcher letztere alle zur Aufnahme angenommenen Aufsätze mit 10 Thlr. pro Druckbogen hooorirt.

Bestellungen auf die ,Jabrbücher für wissenschaftliche Botanik" nehmen alle Buchhandlungen des In- und Auslandes entgegen.

Leipzig, im October 1864.

Die Verlagshandlung. Wilhelm Engelmann.

Redigirt unter Verantwortlichkeit von Dr. Wilh. Engelmann in Leipzig. 

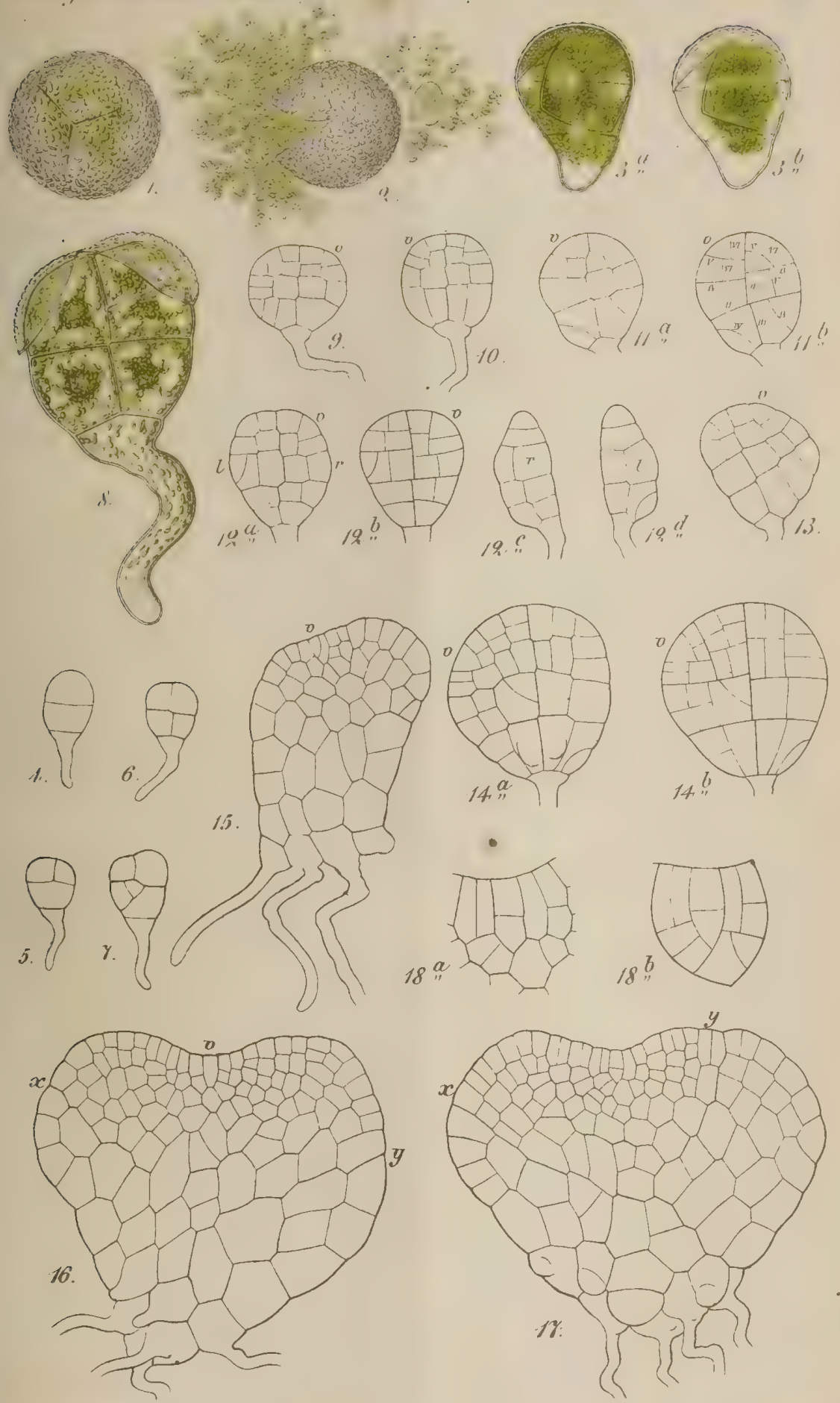



\section{.}

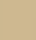



Jahrb. f m. Botanik, IIII. Bd.

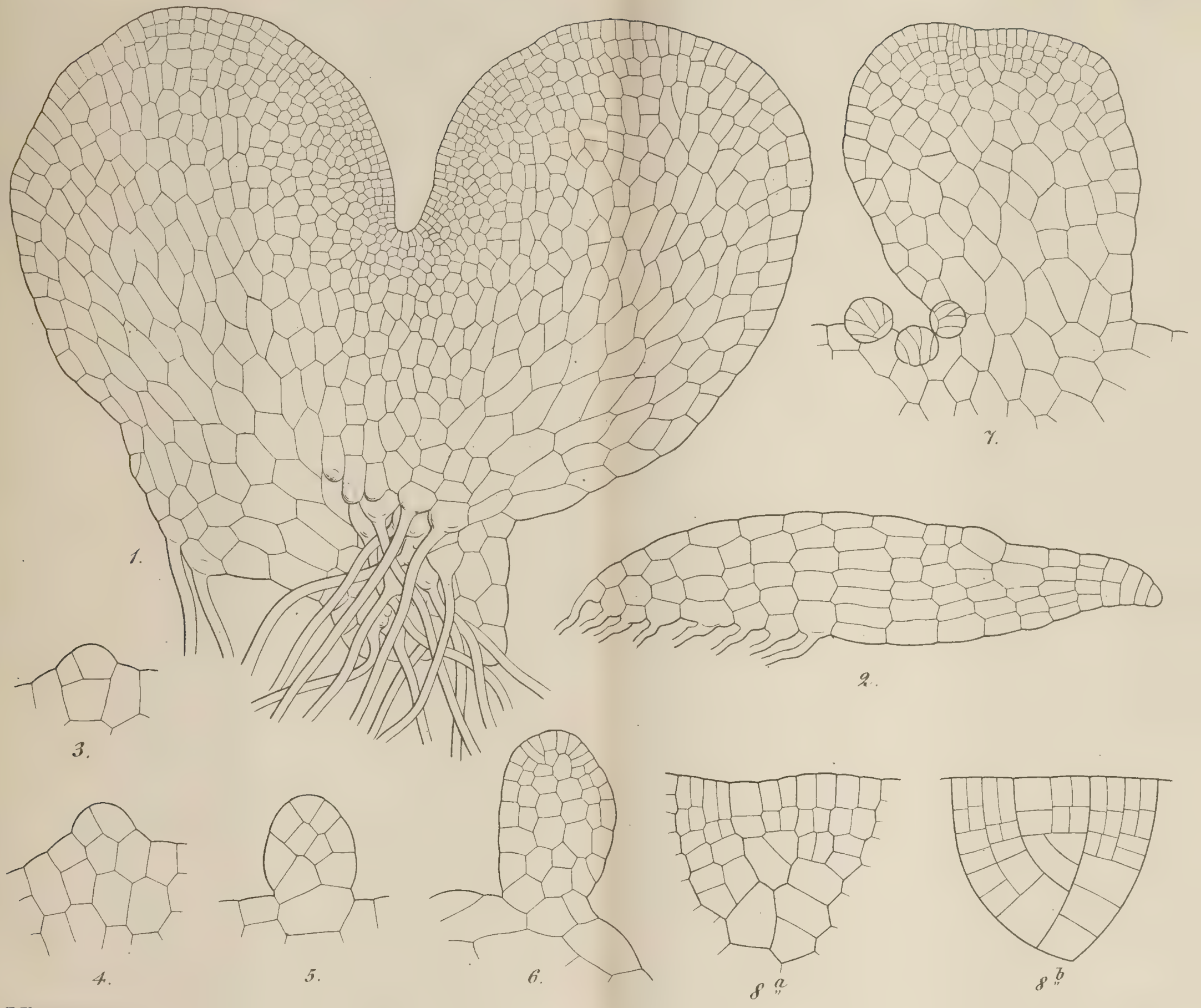

I. Kriö ad nat del. 



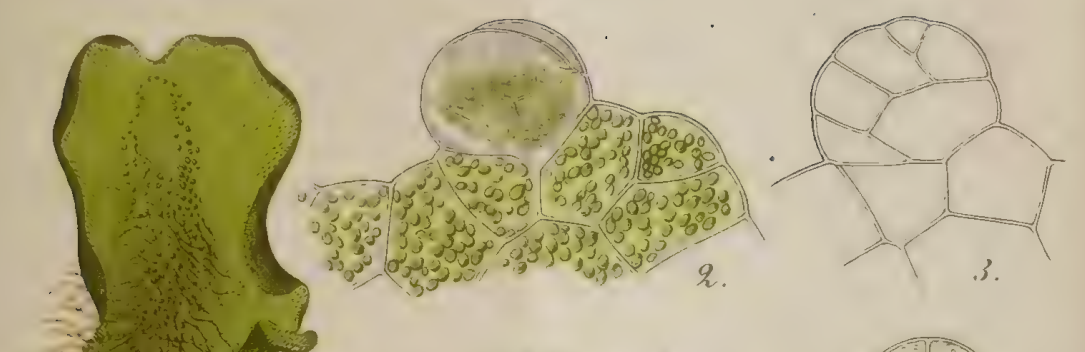

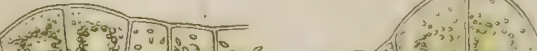

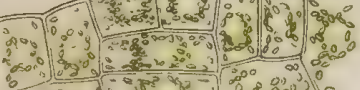
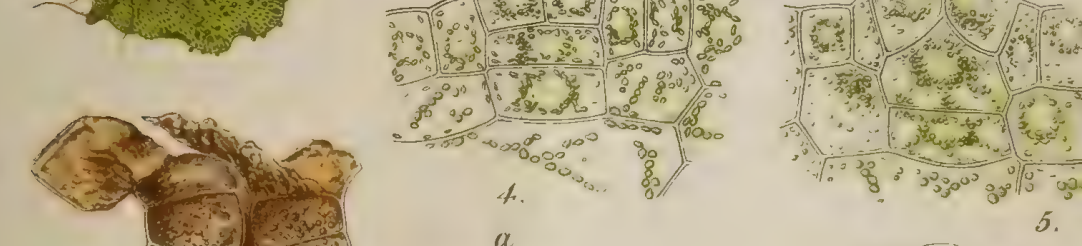
$\therefore-16 \cos 3$

6 os entist

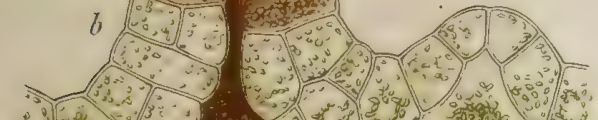

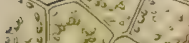
(a) - 30 , a.

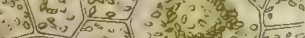

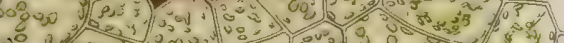

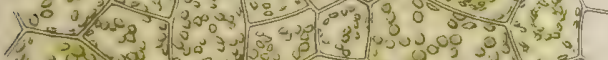
गए प्रा

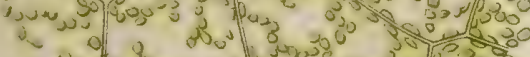

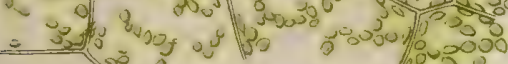

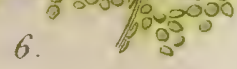
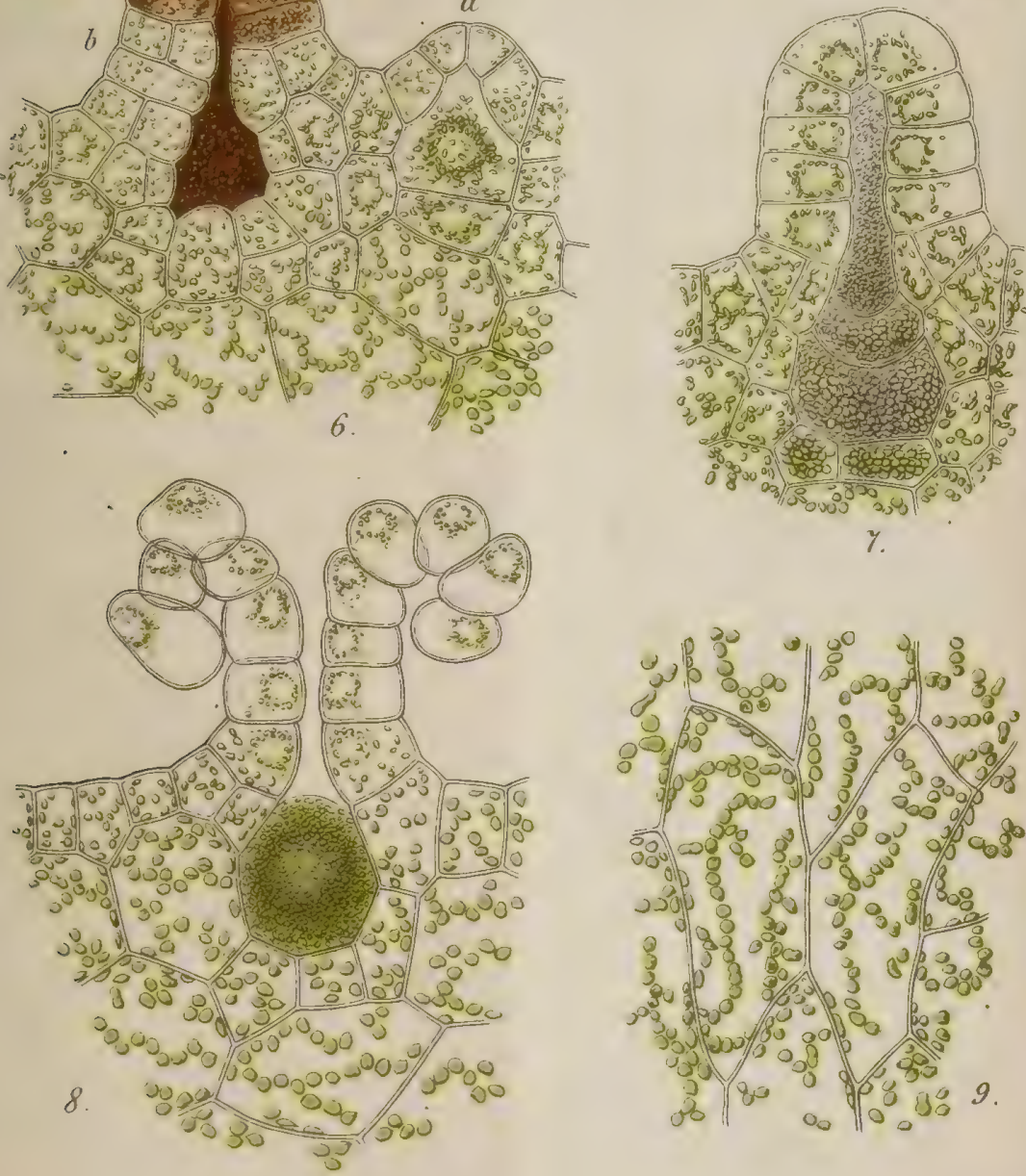

5.

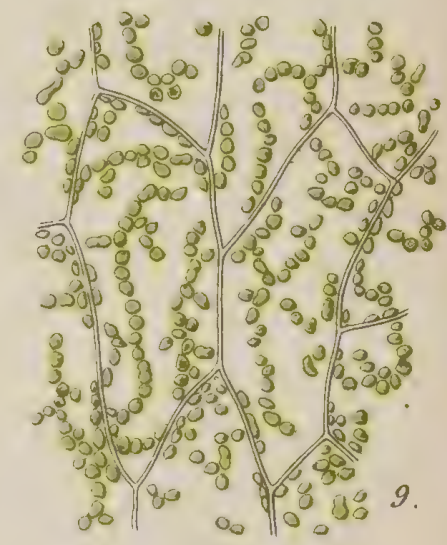




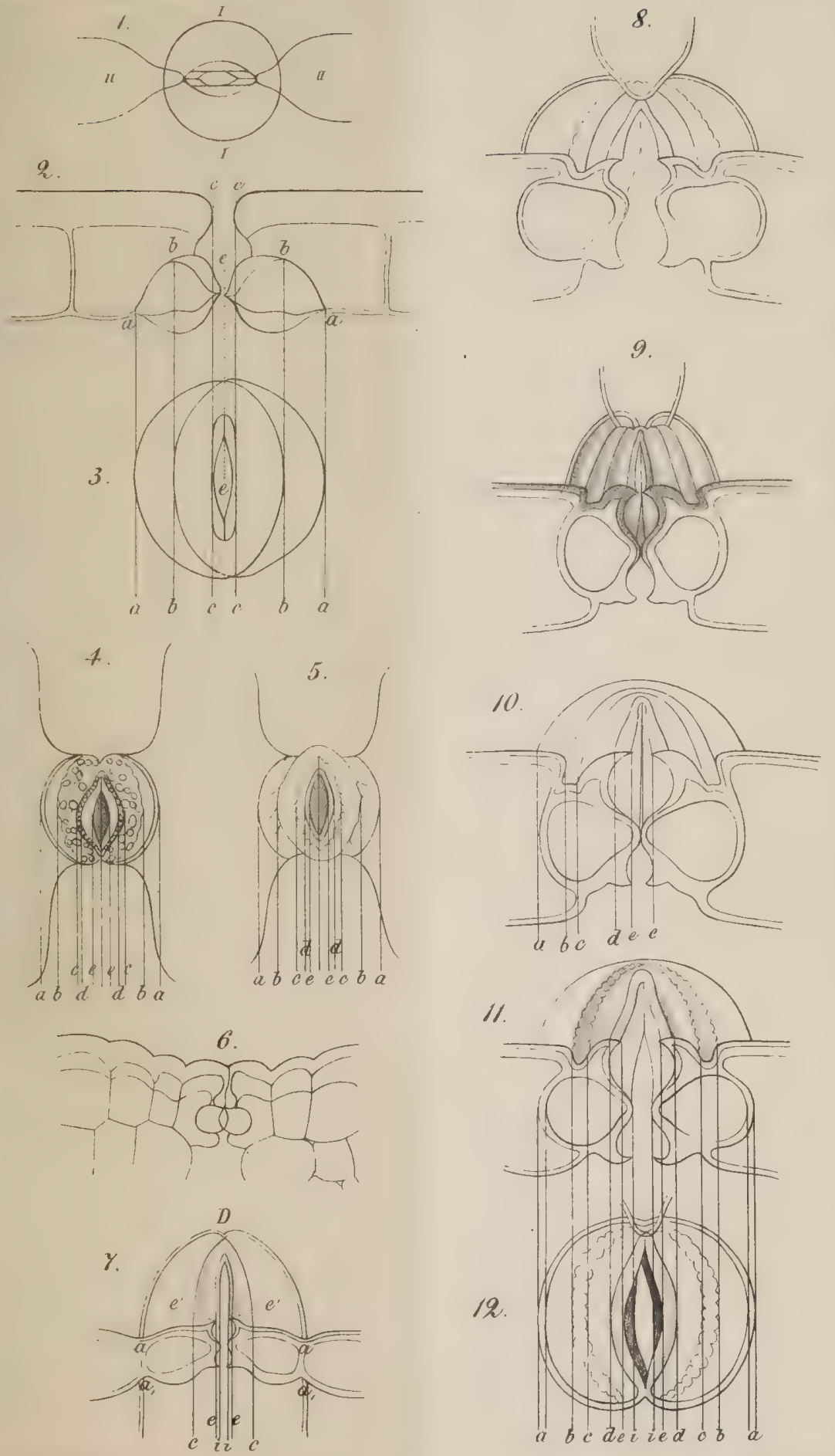

C. Laue lith 



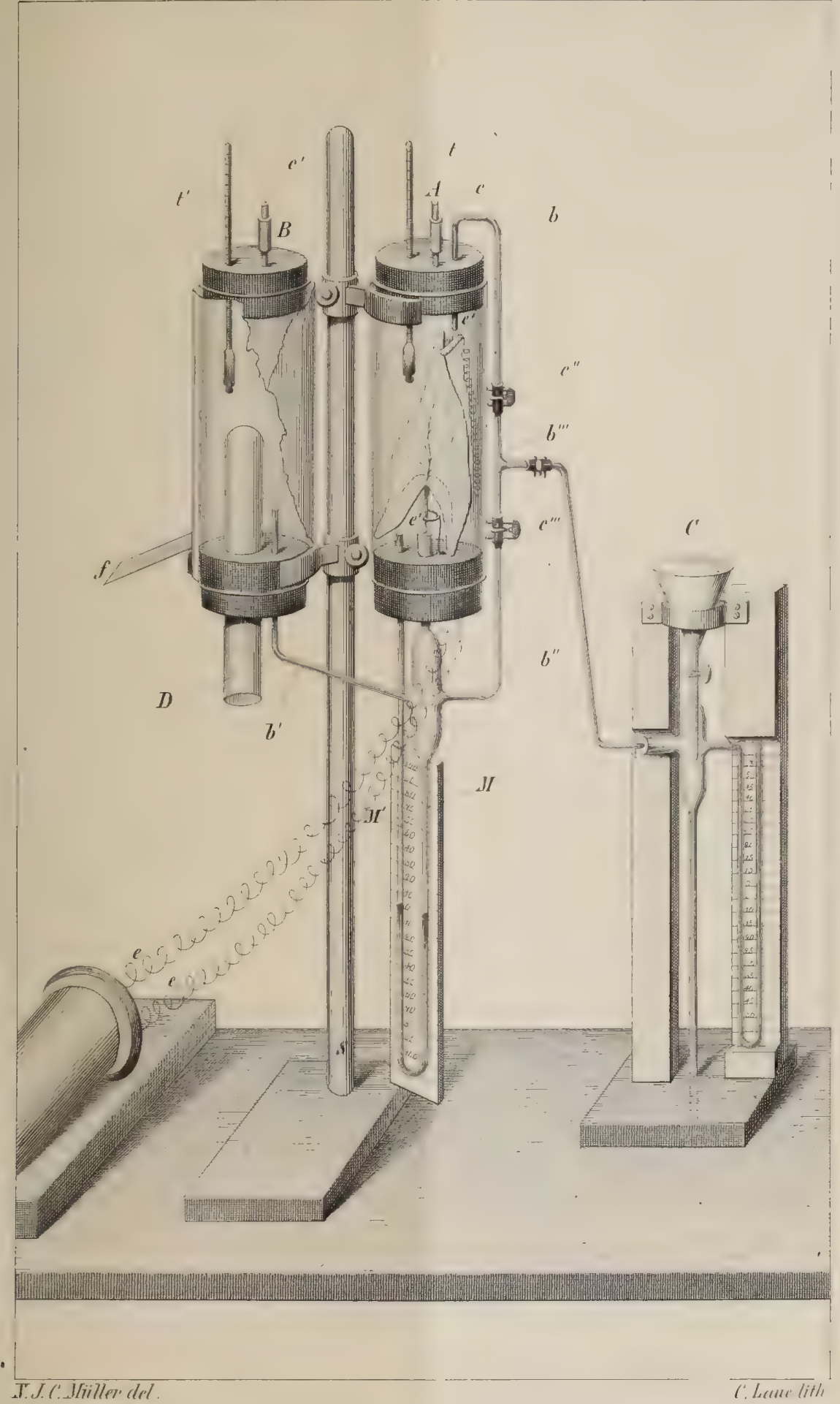



Irahol, fir Botumik, ITII. Bat.
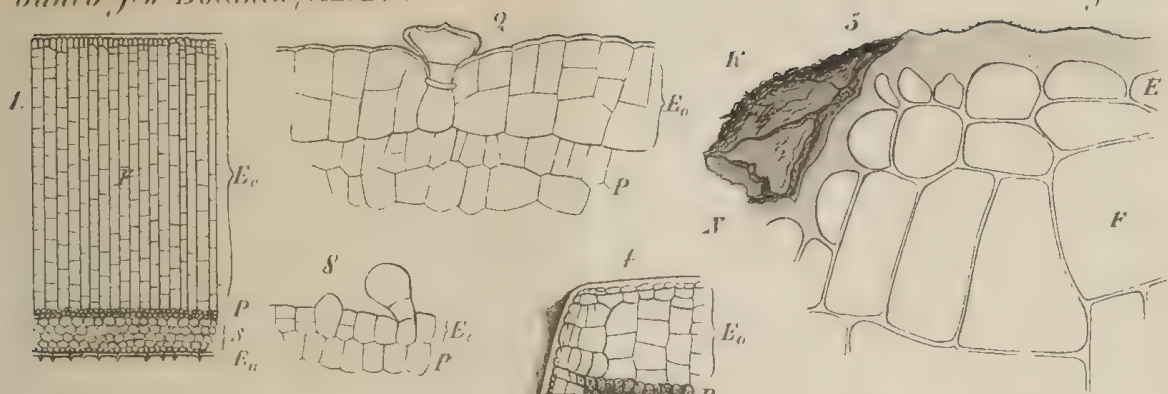

Hing
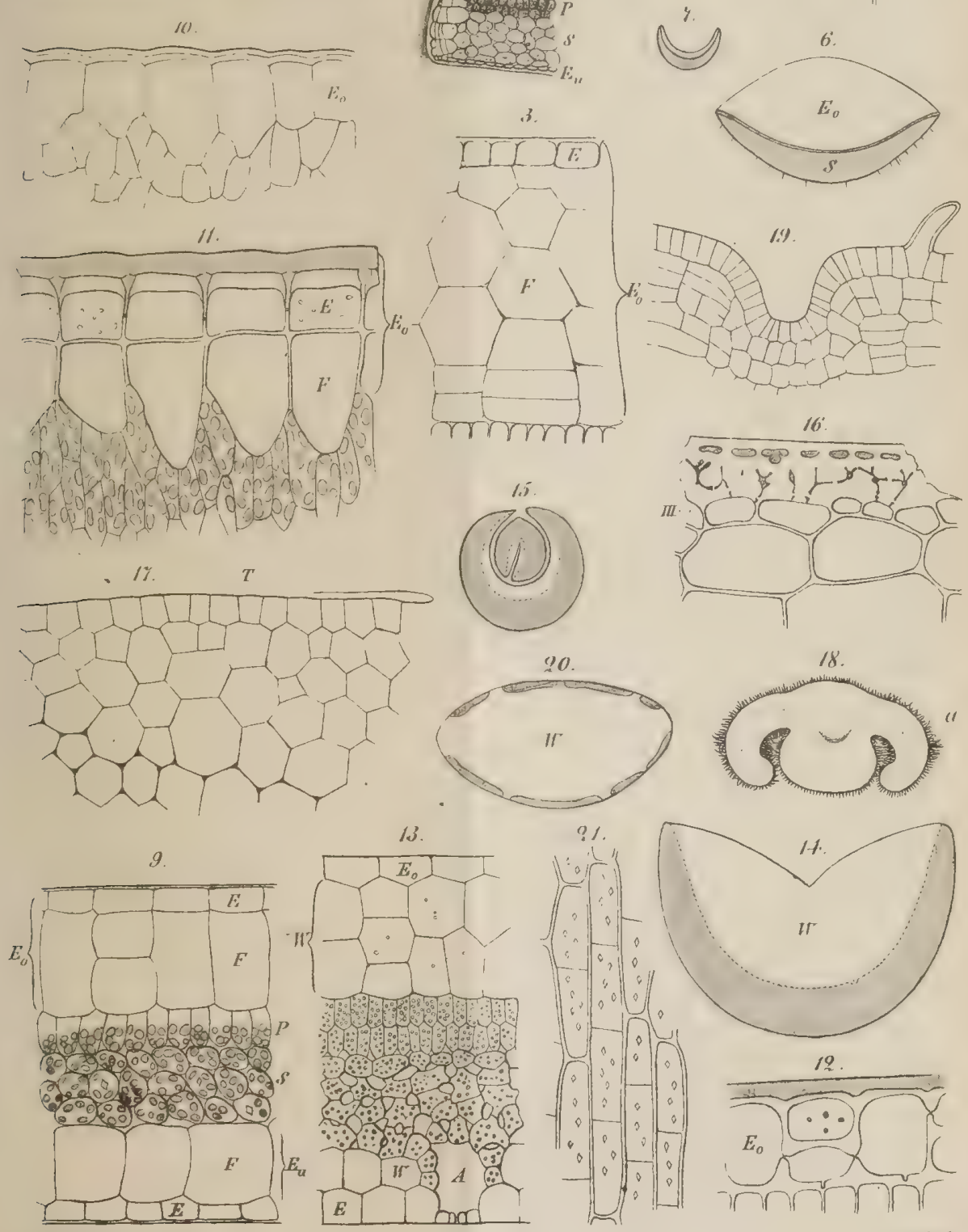

E. Pfitxer ad nat.del.
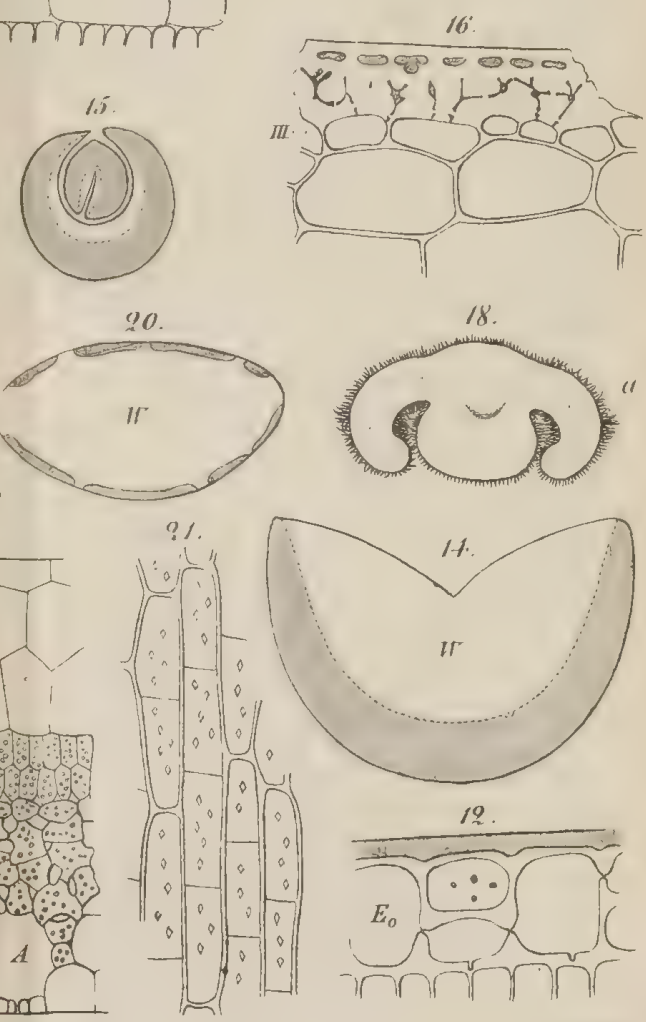

('Lane hethe. 

Jaherb. fro. Botanik, ITII. Bd. "
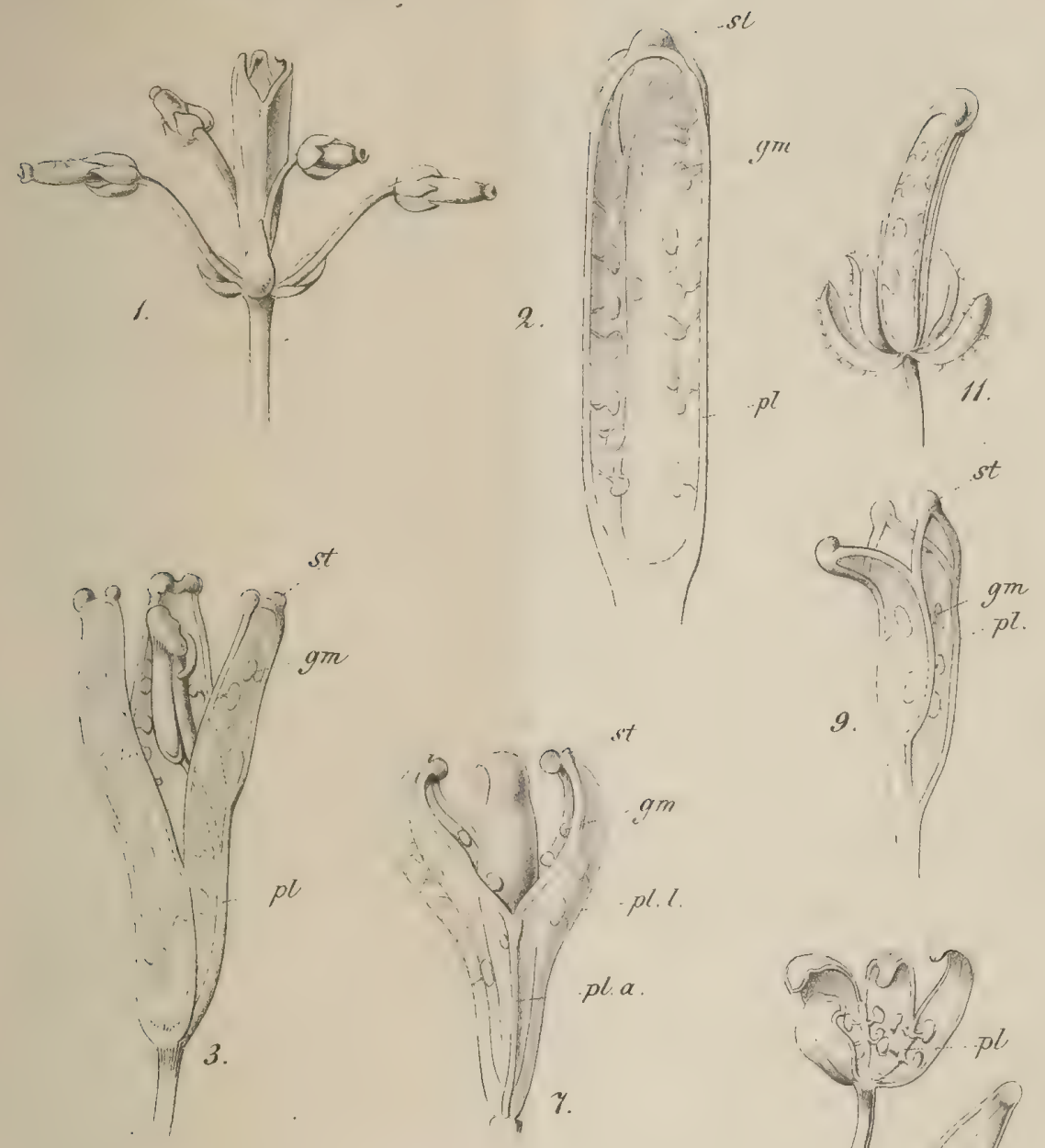


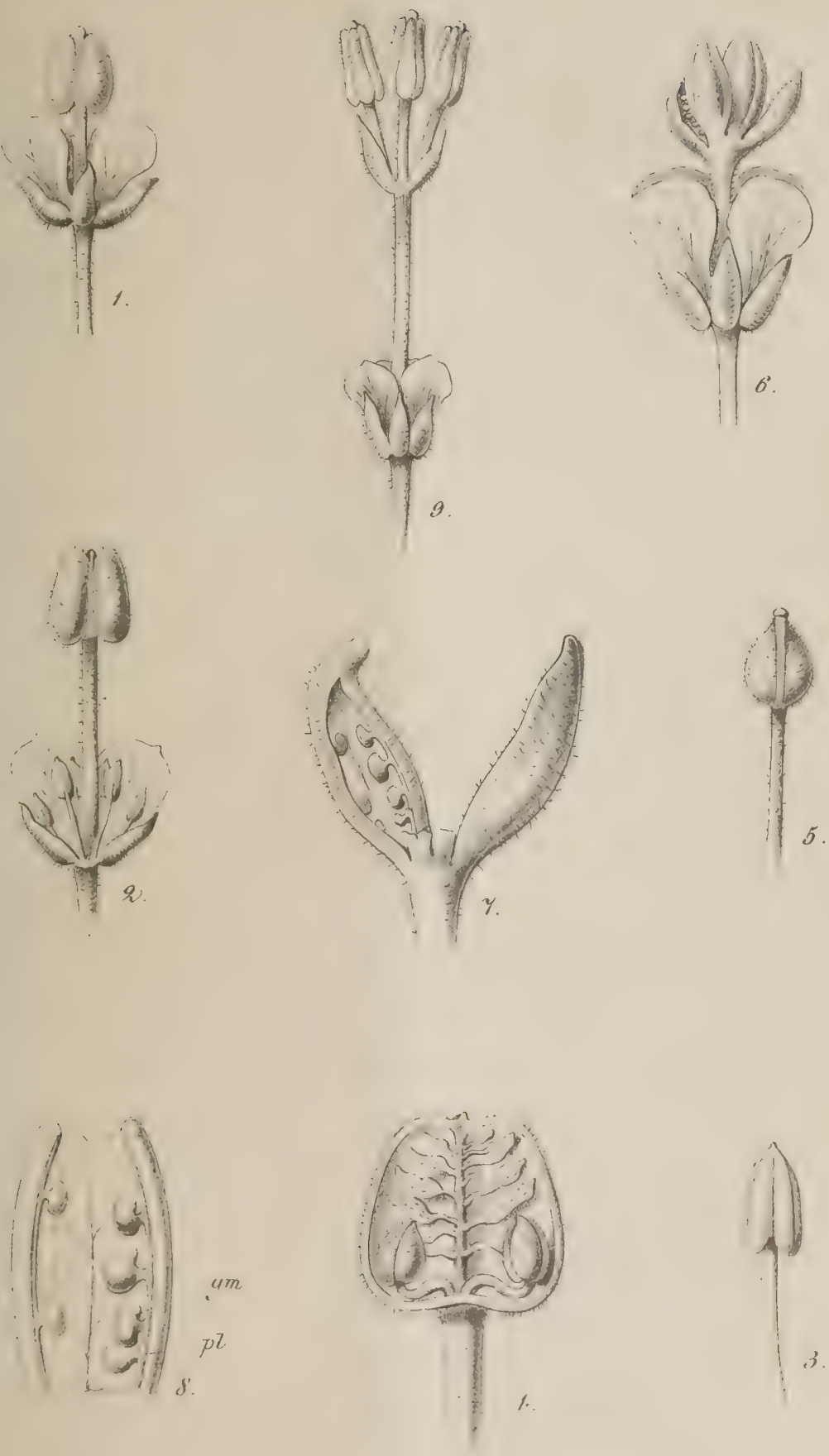

Jahrb f. mo. Bolanils, VIII. Bd.
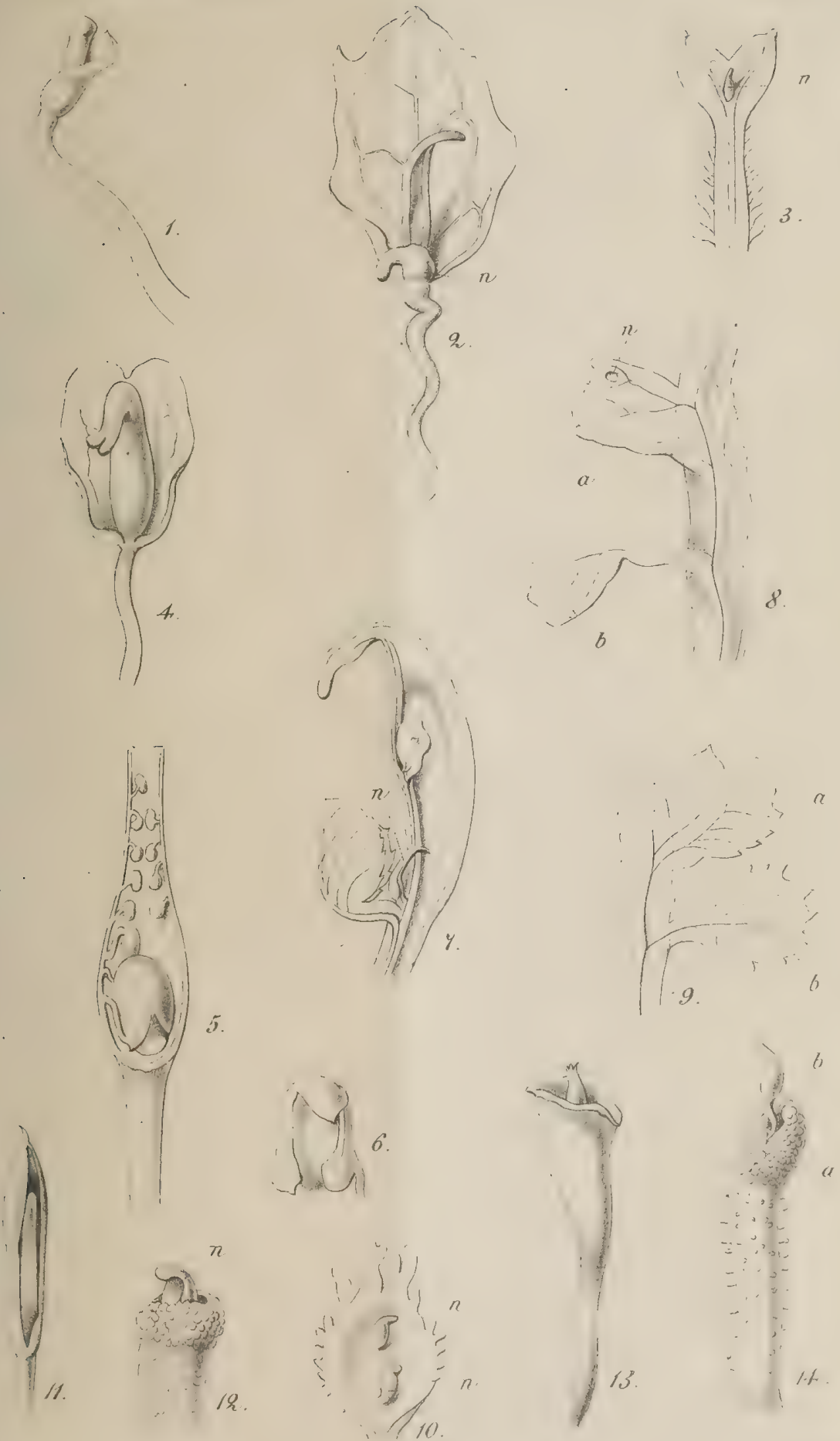

Jahrb. f. m. Botanit, IIII. Bd.

figg. 3.

\section{fing 1. \\ 008}

Fig $/ a: f_{b} f^{\prime} x^{h}$
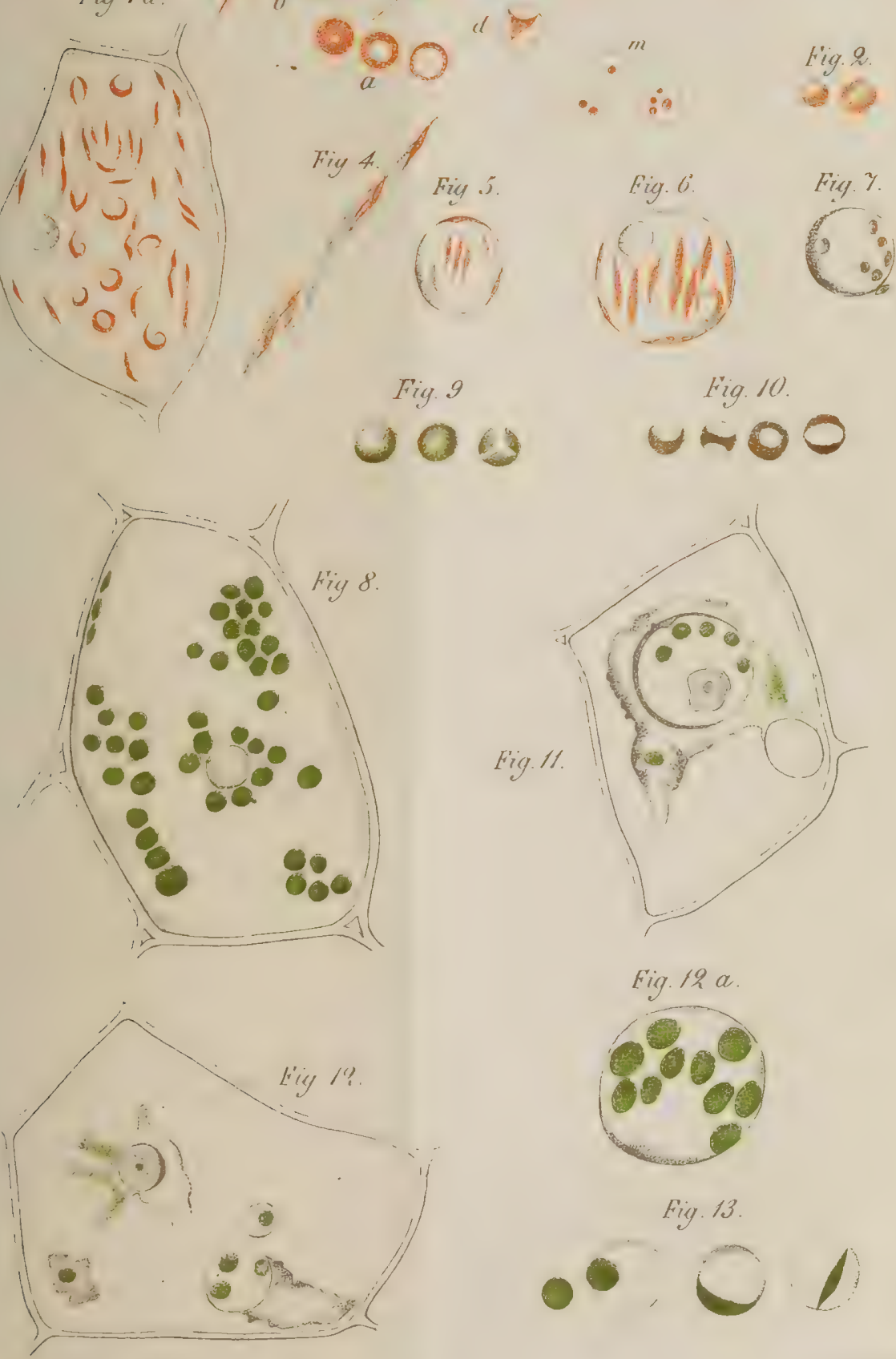

Fig. IR a

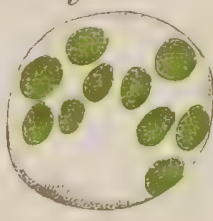

Fig. 13

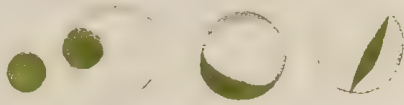





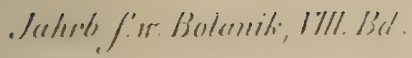
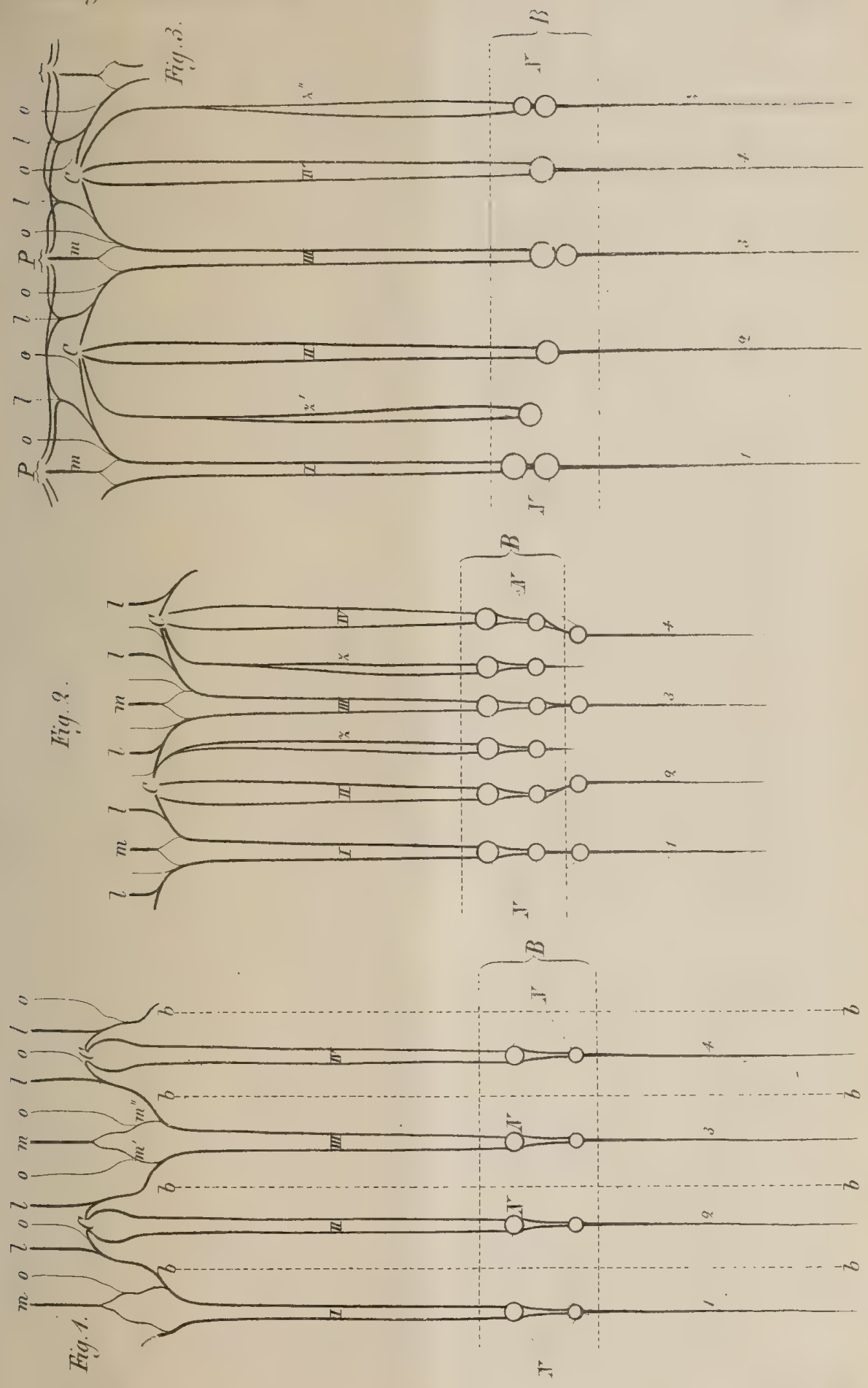

Jahrbl. f.n. Botanit, IIII. Bal.

Tif:TIT.

Fig. 8 .

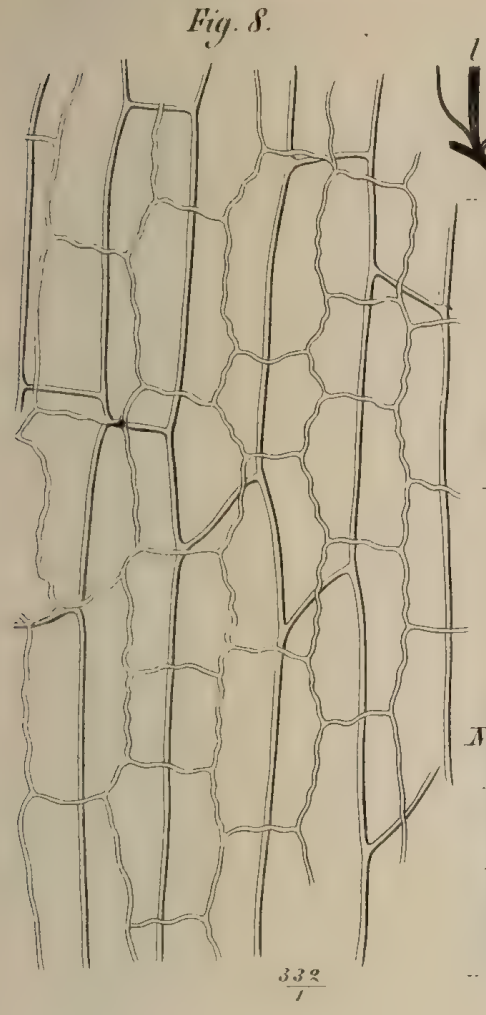

Fig. 5.
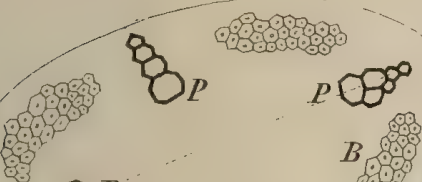

$\sigma^{P}{ }_{B} Q_{B}$
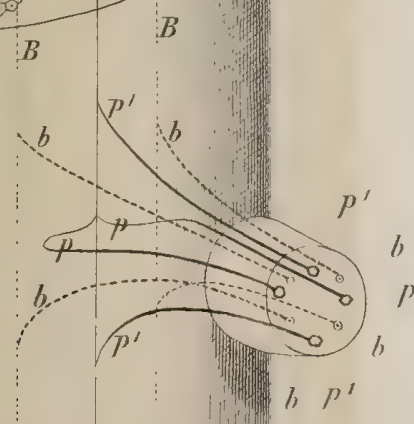

B $P \quad B$

Fing.t.
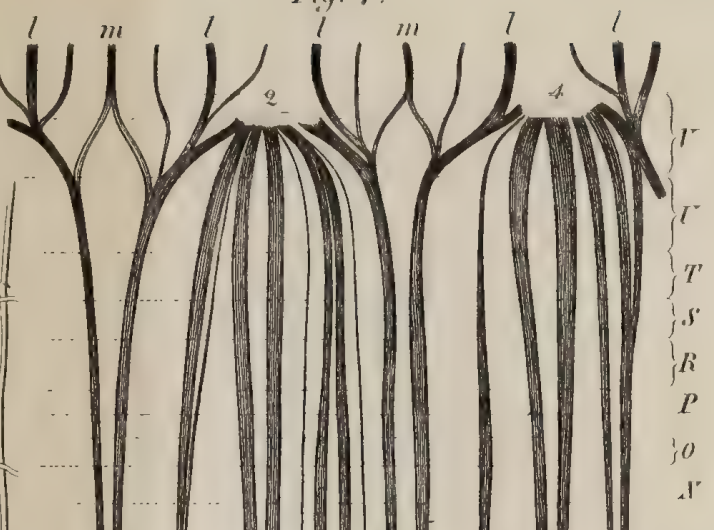

(1) $x \underbrace{1}$
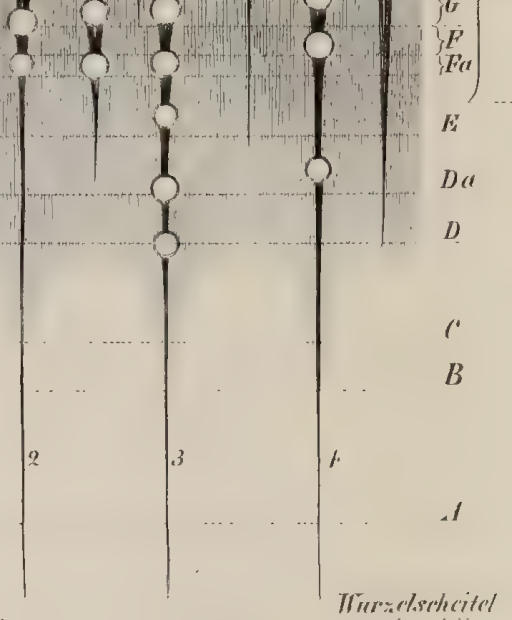

Five. 1.5.
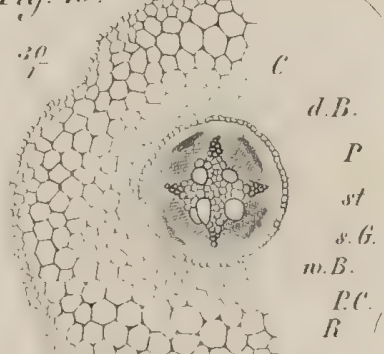



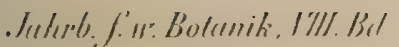

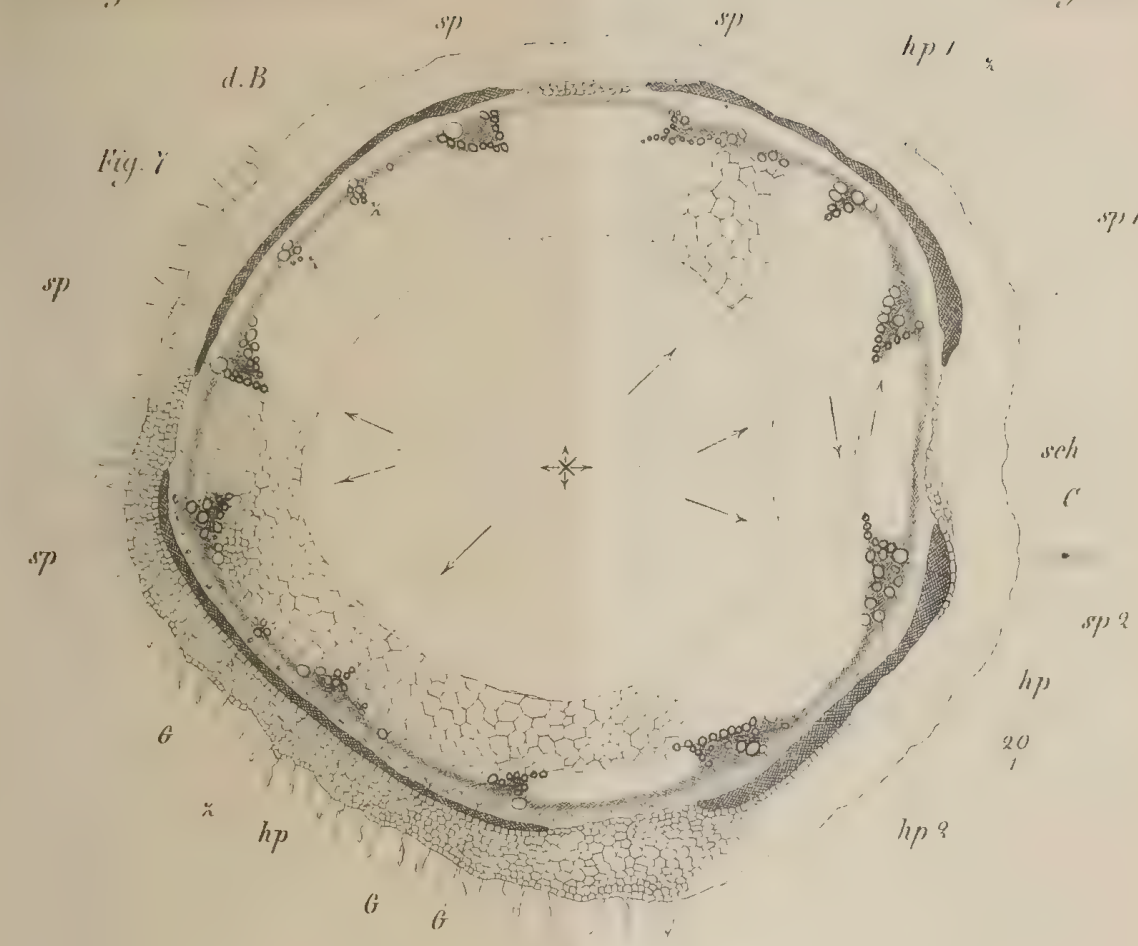

$.7 \% 1$

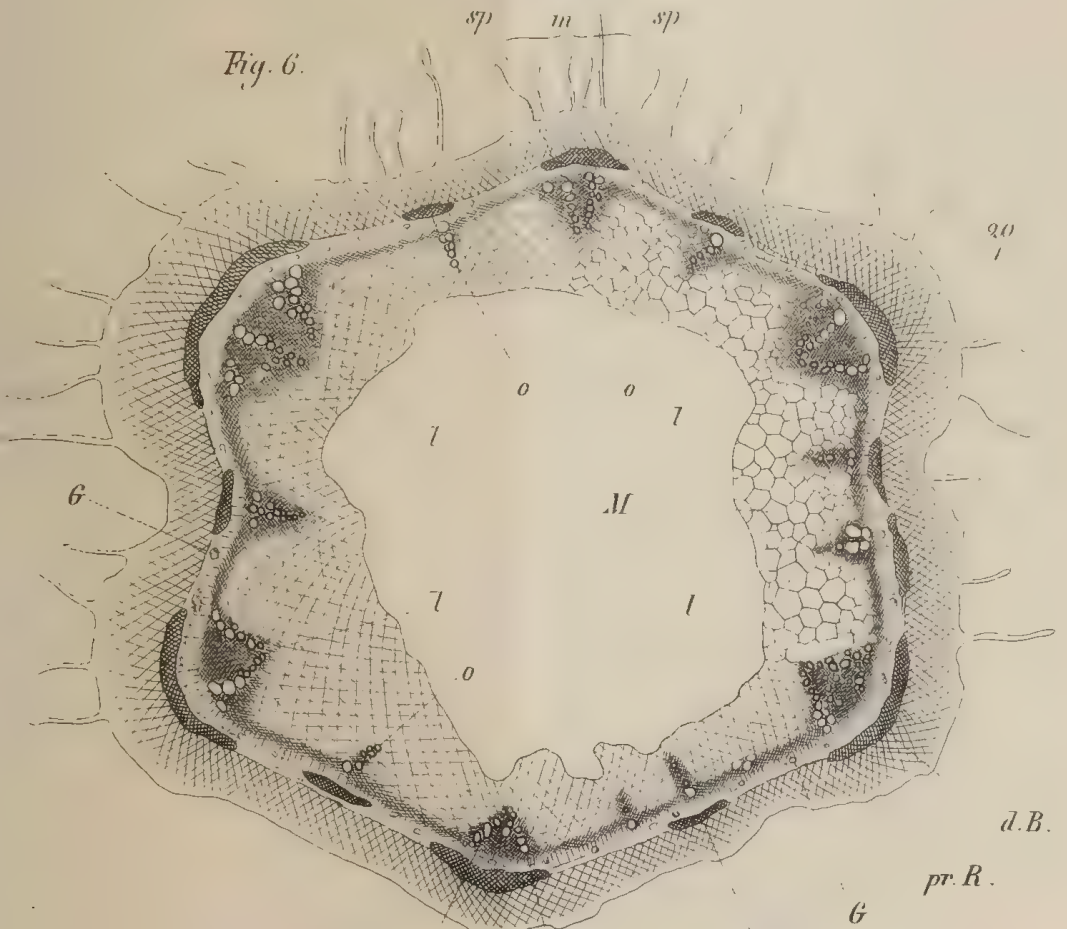

d.B. 



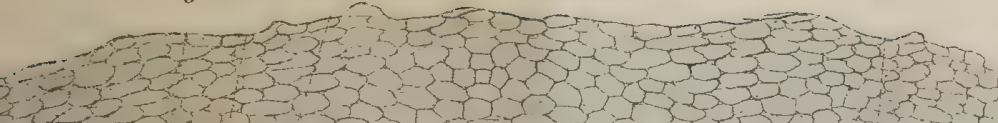

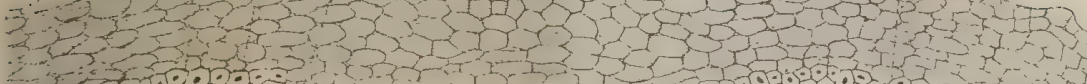

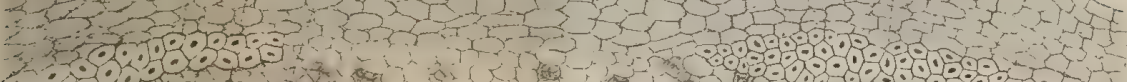
- 0.00 on (1)

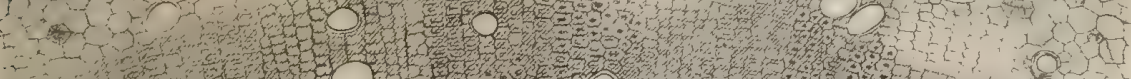

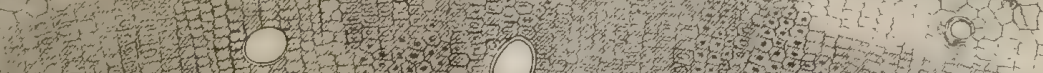

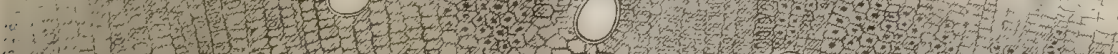

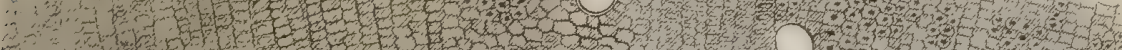

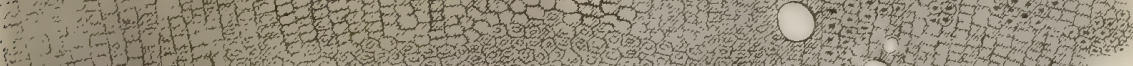

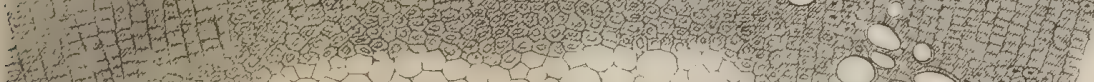

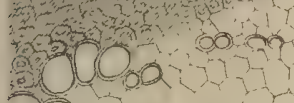
और 000

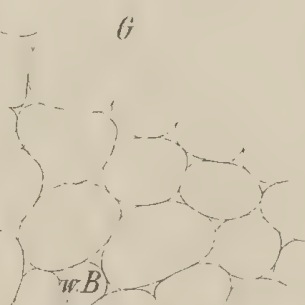

Frig. 10

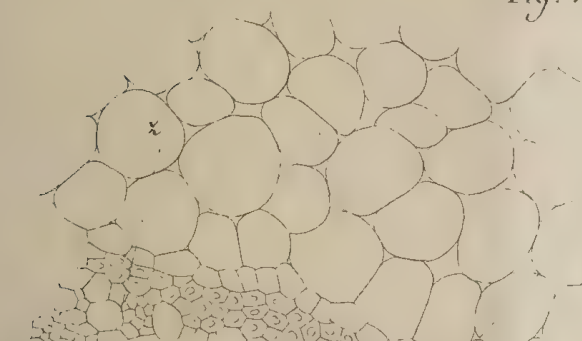

$$
86
$$

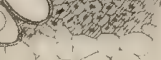



Juhlit, f.n. Botanik, IIII. Bd.

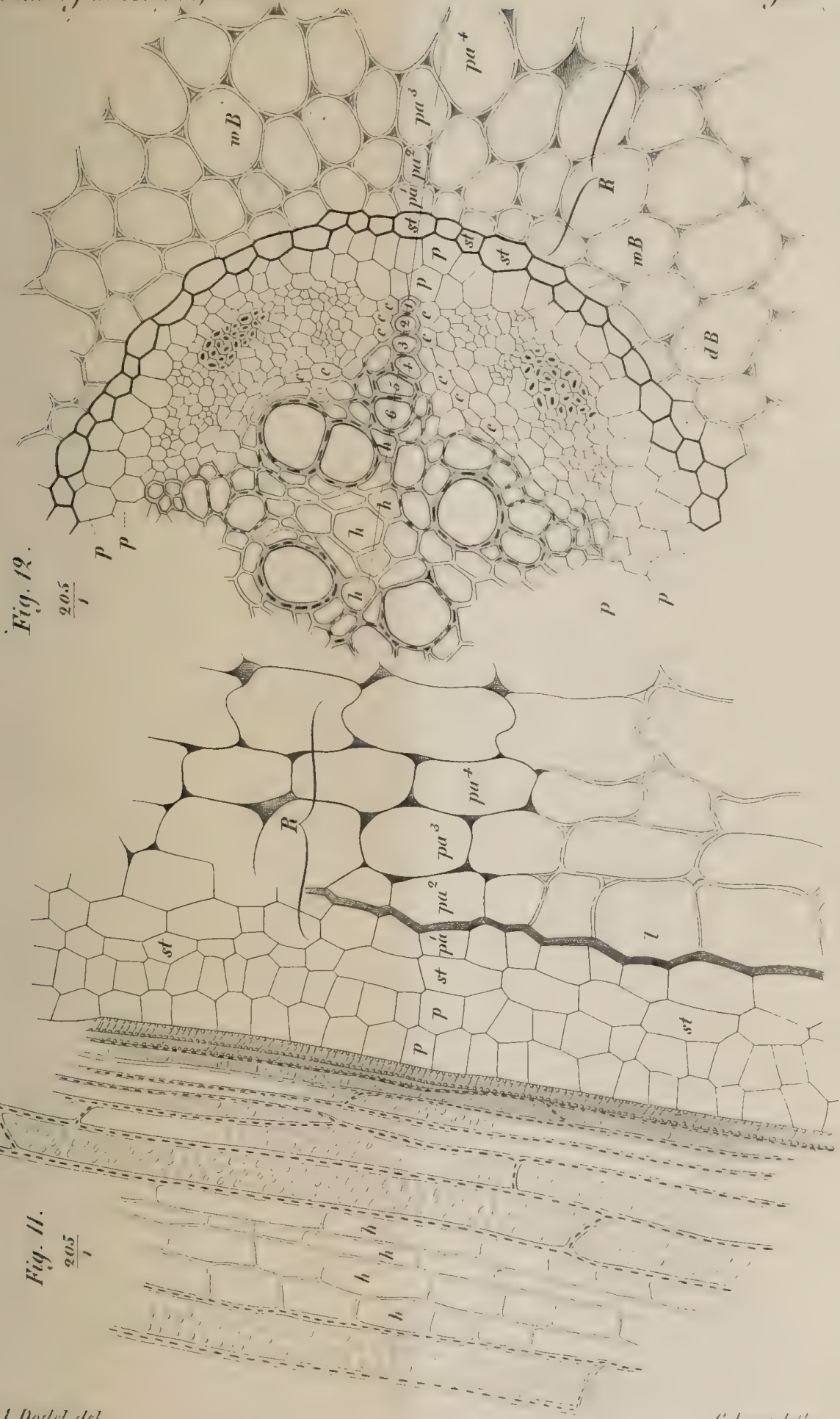




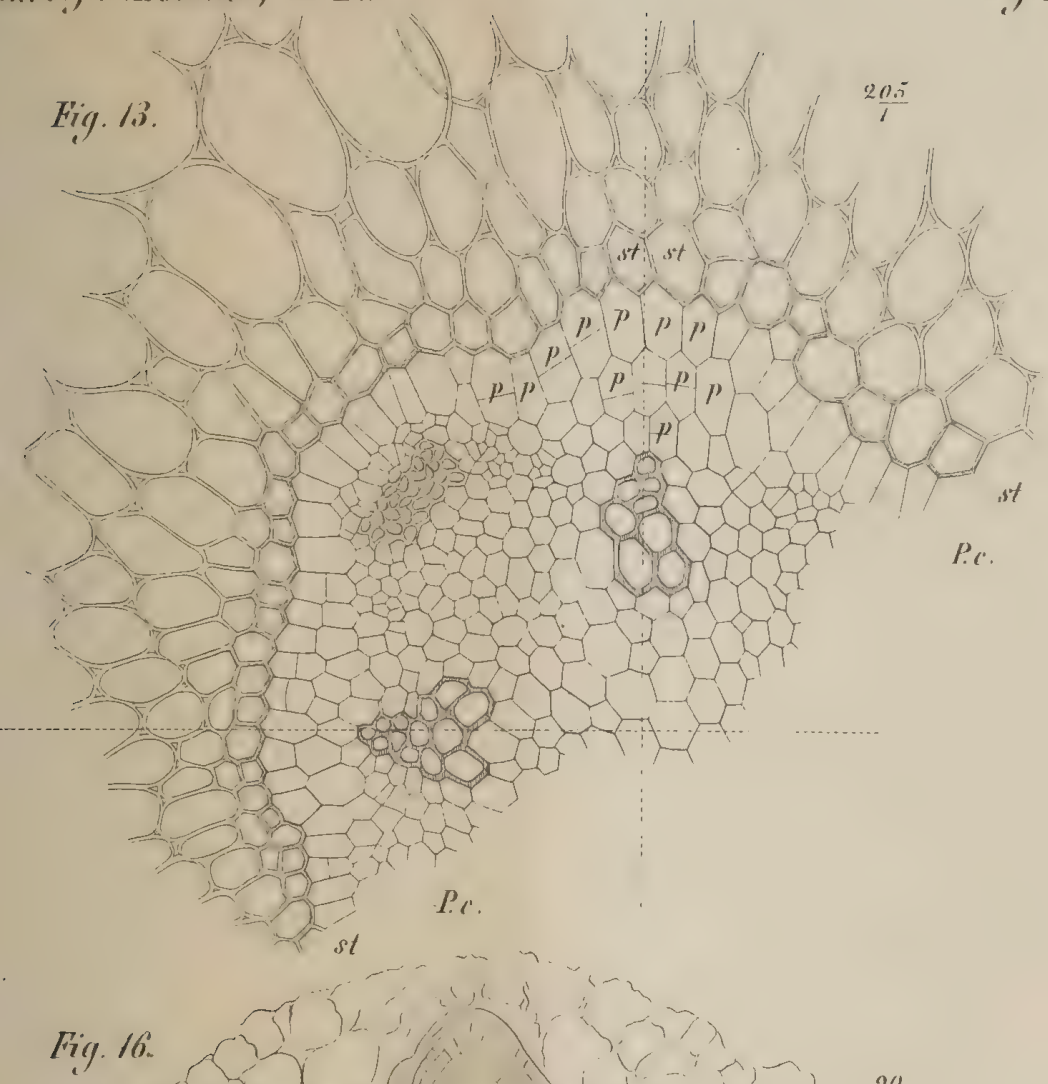



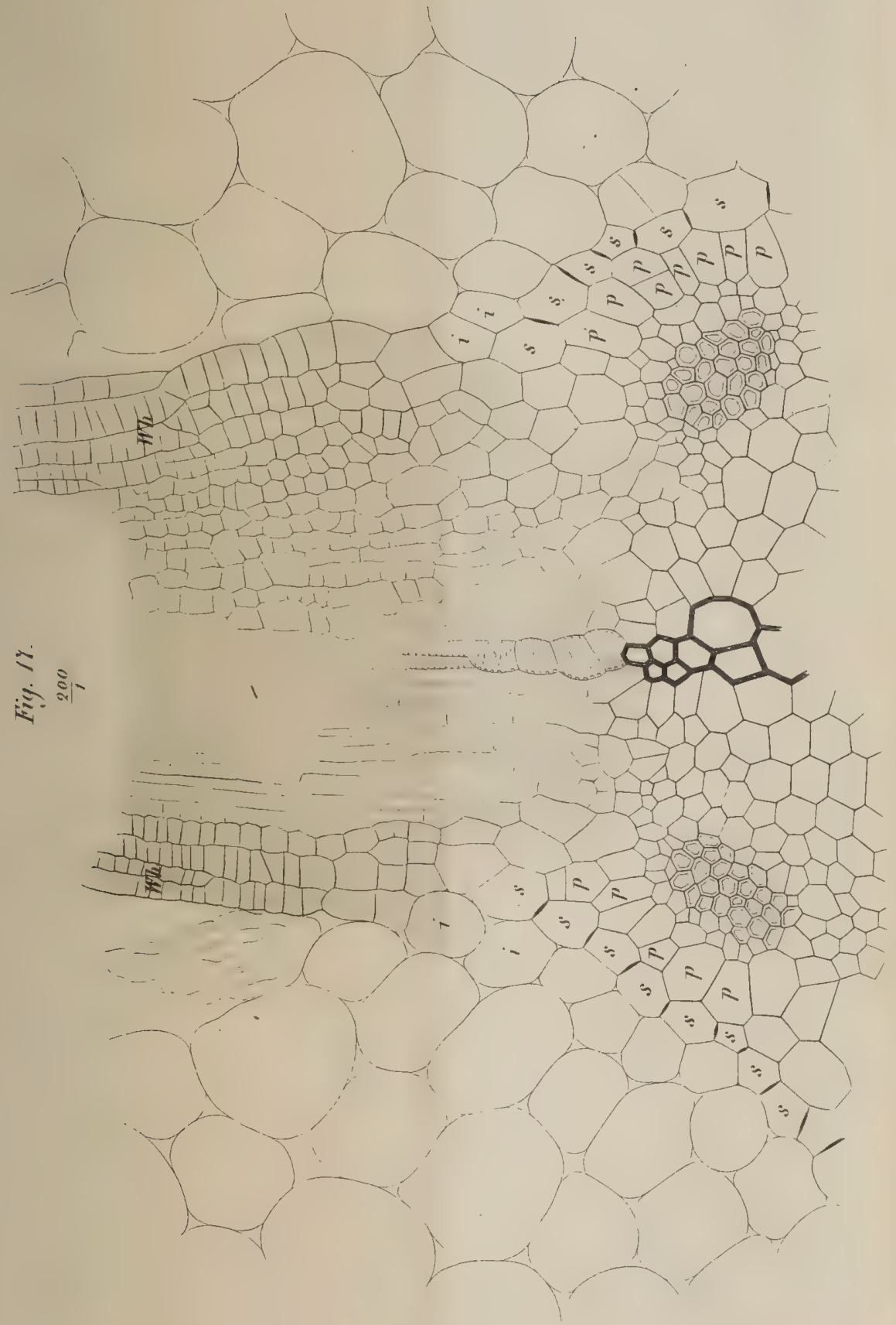





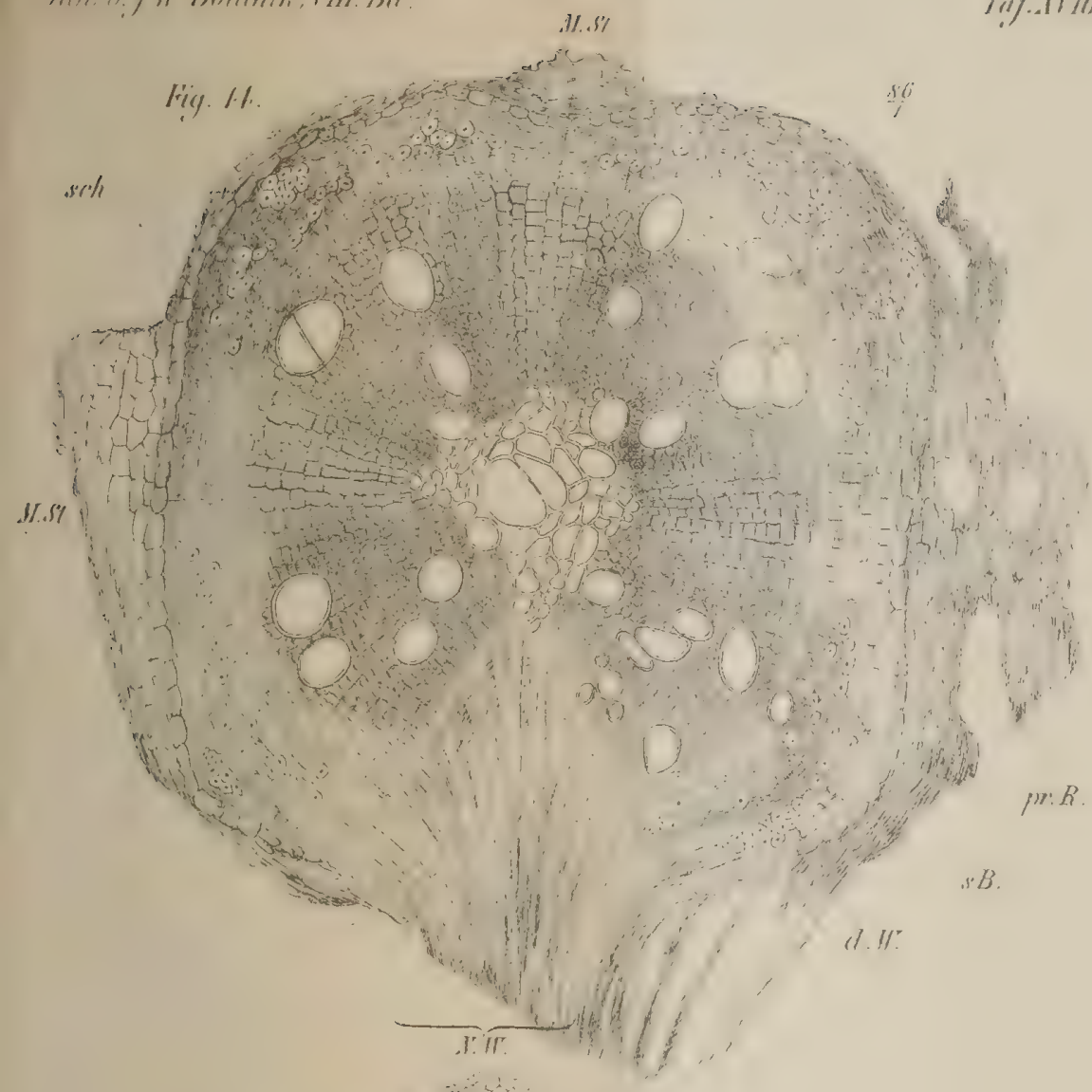

Fin. 18 .

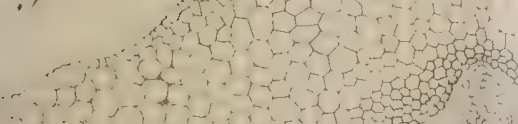

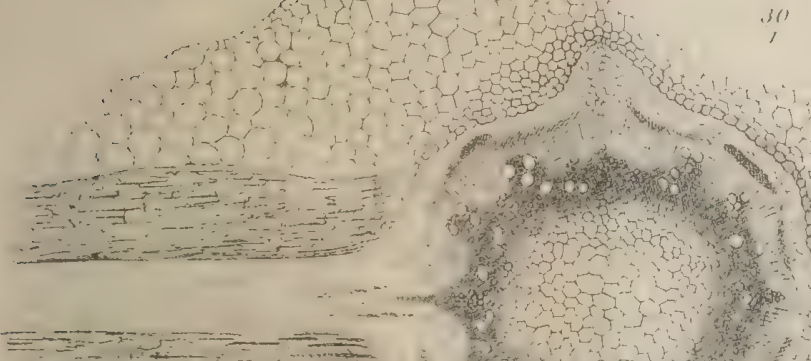





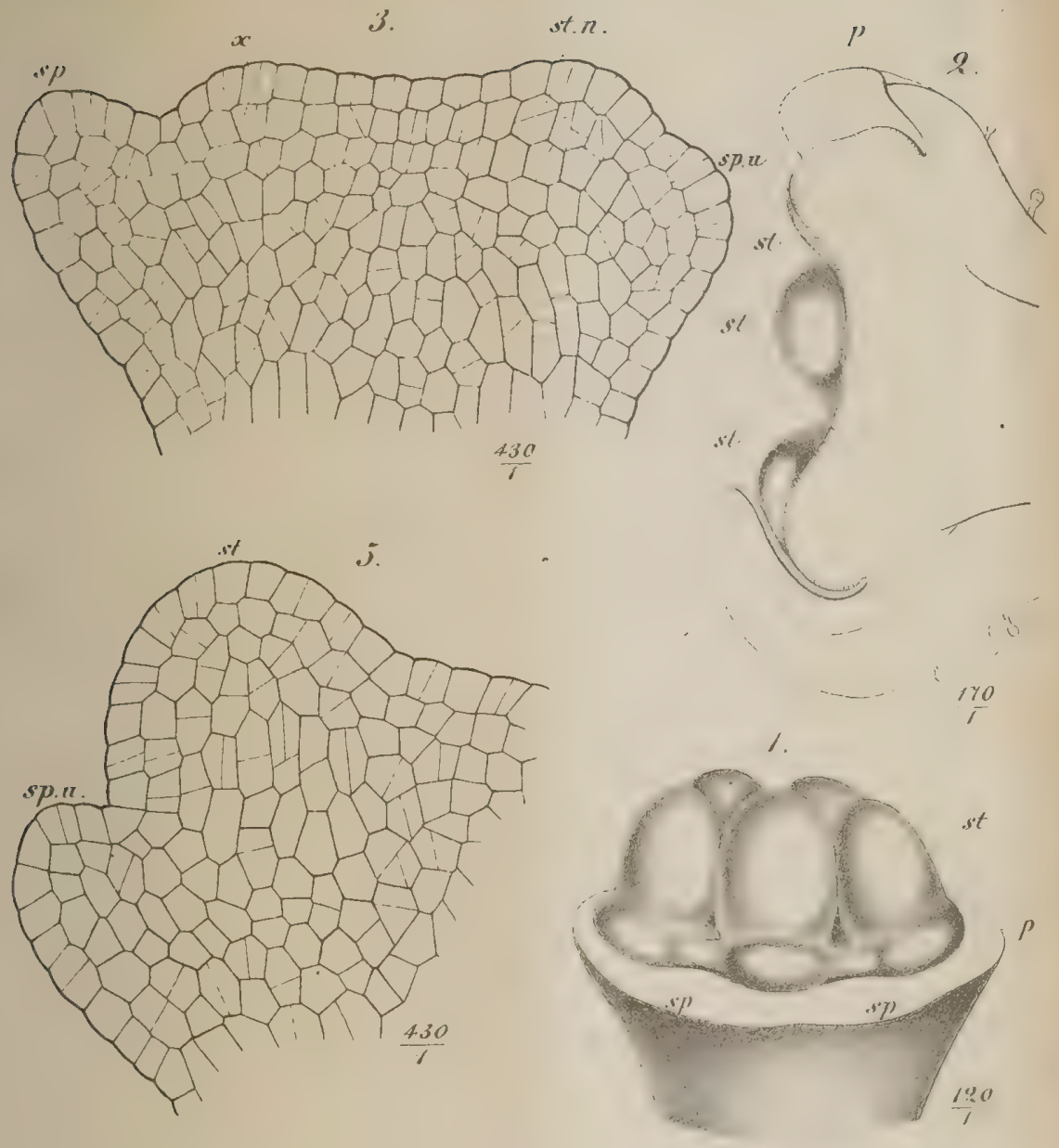

t.

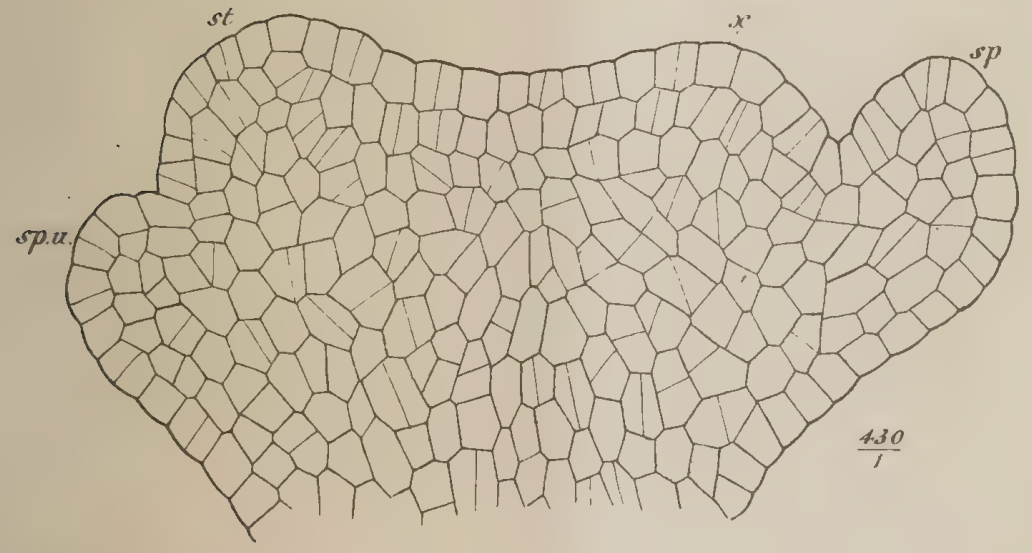






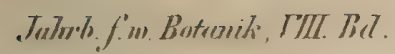
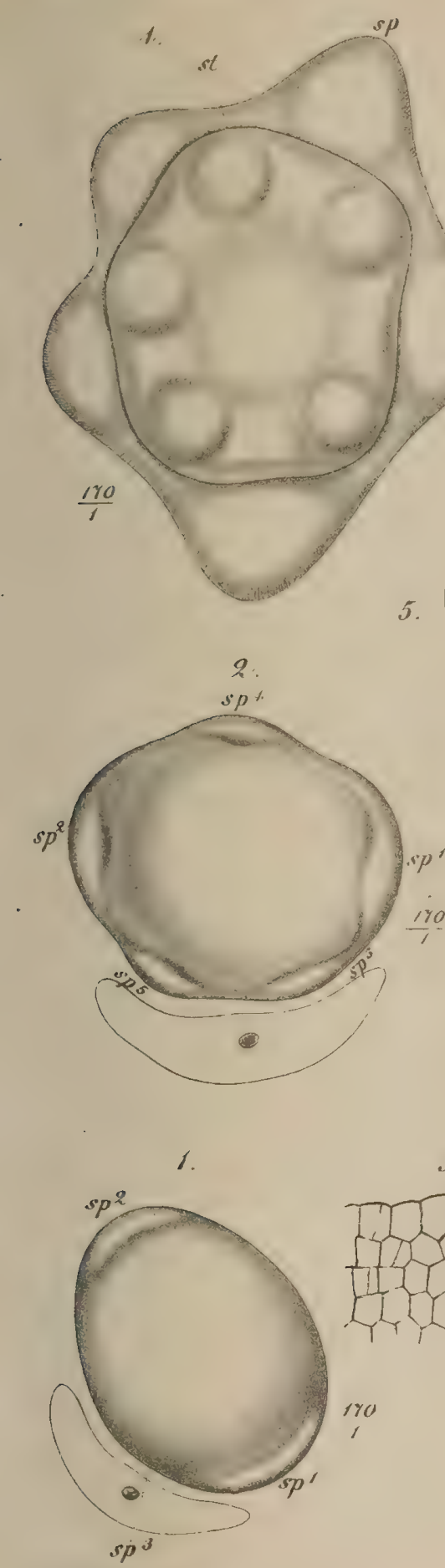

Pfeffer ad not:del
Iny. A.I\%
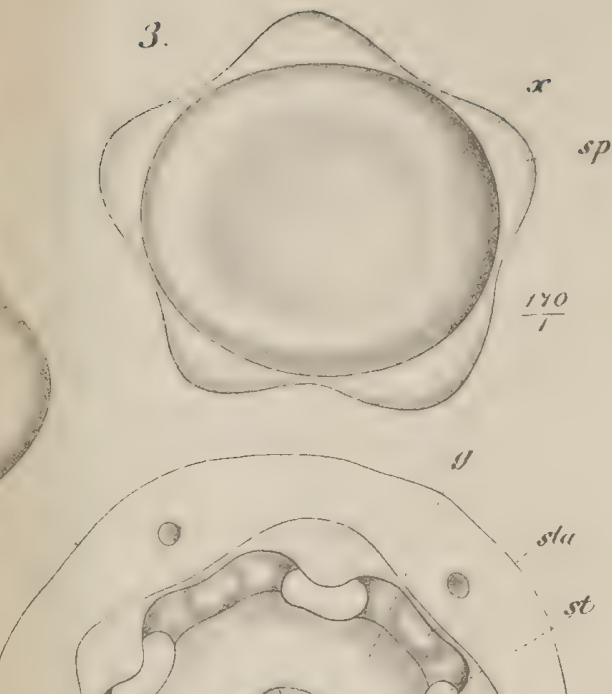

i).

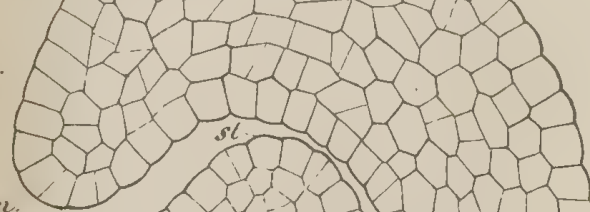

9.12.

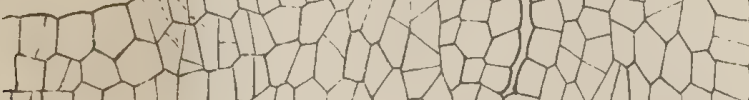

120
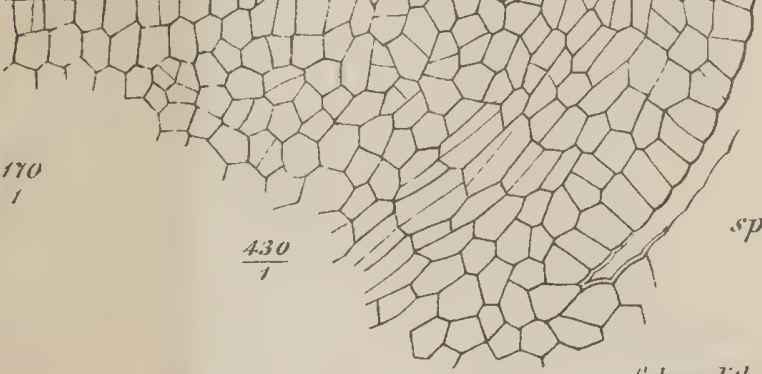

c' liaue bith 


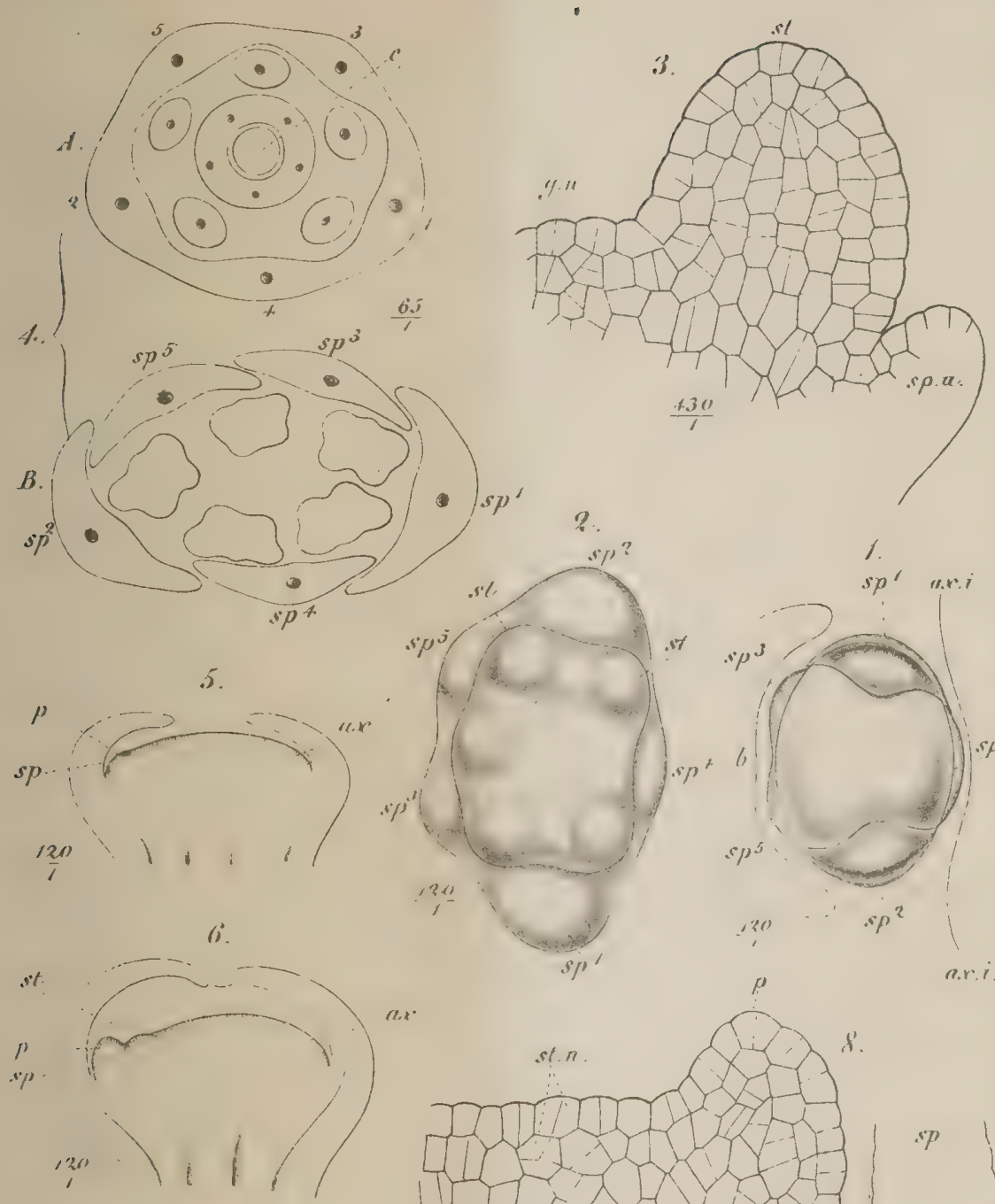

, ?क
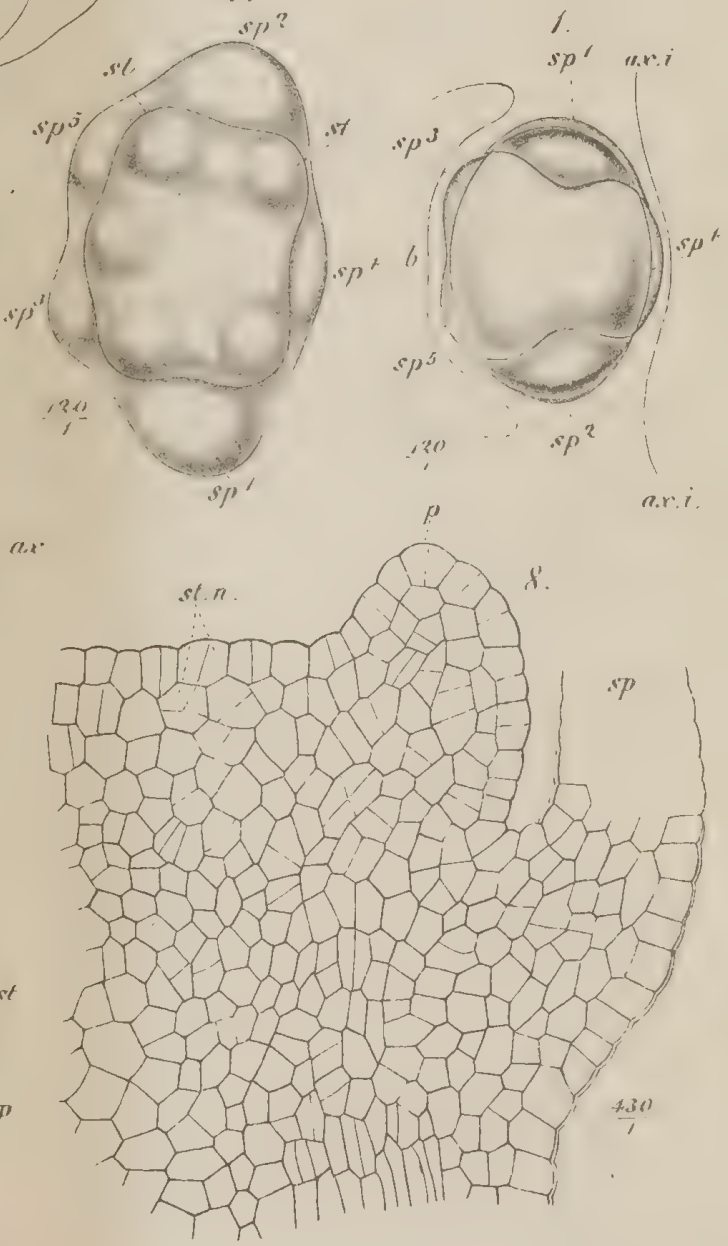

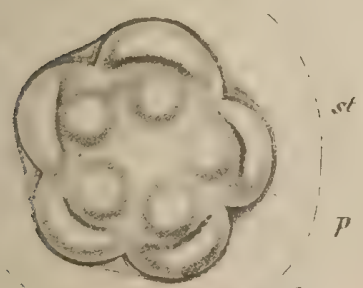

$\frac{120}{1}$

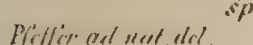





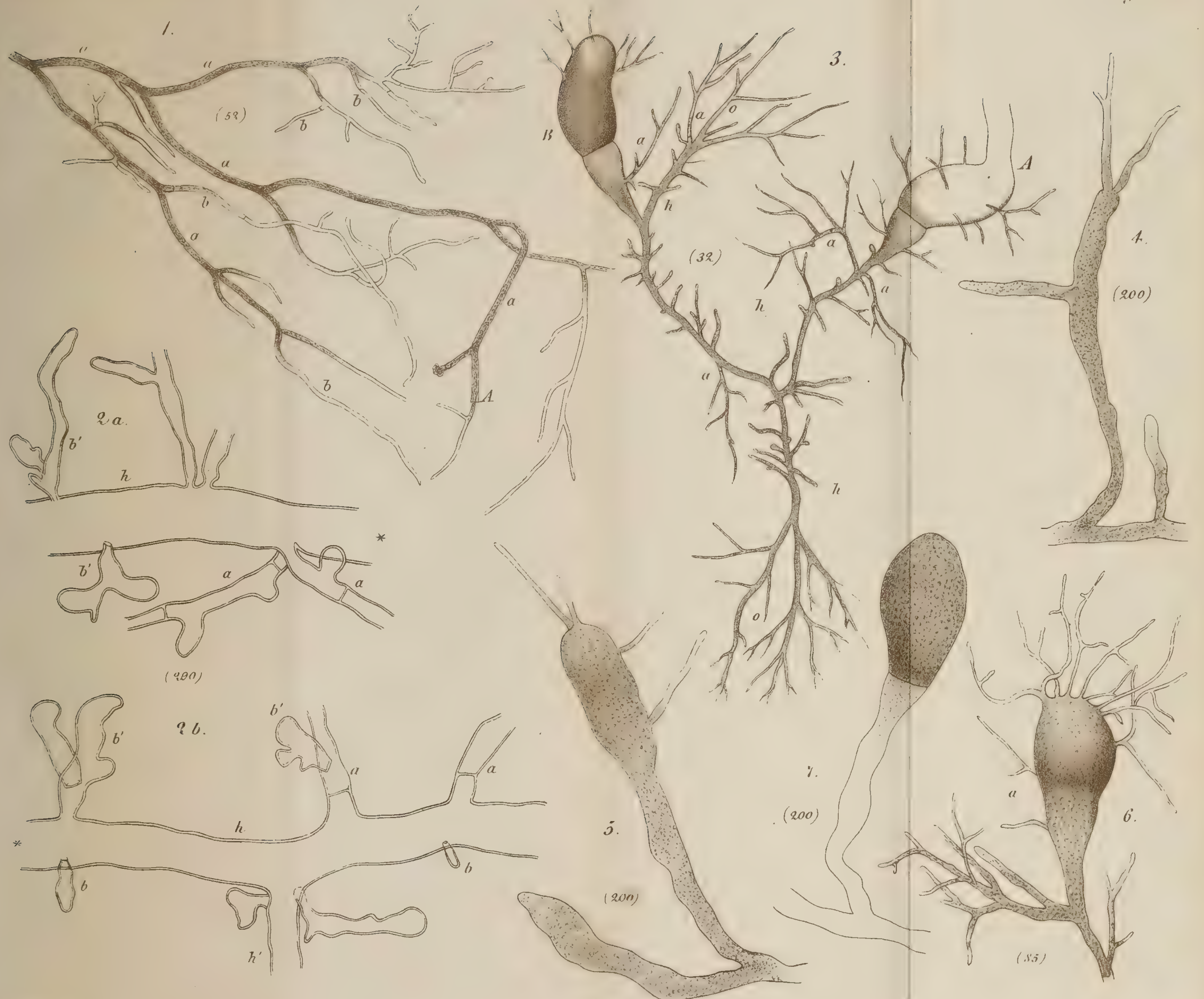





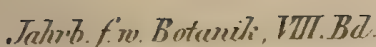

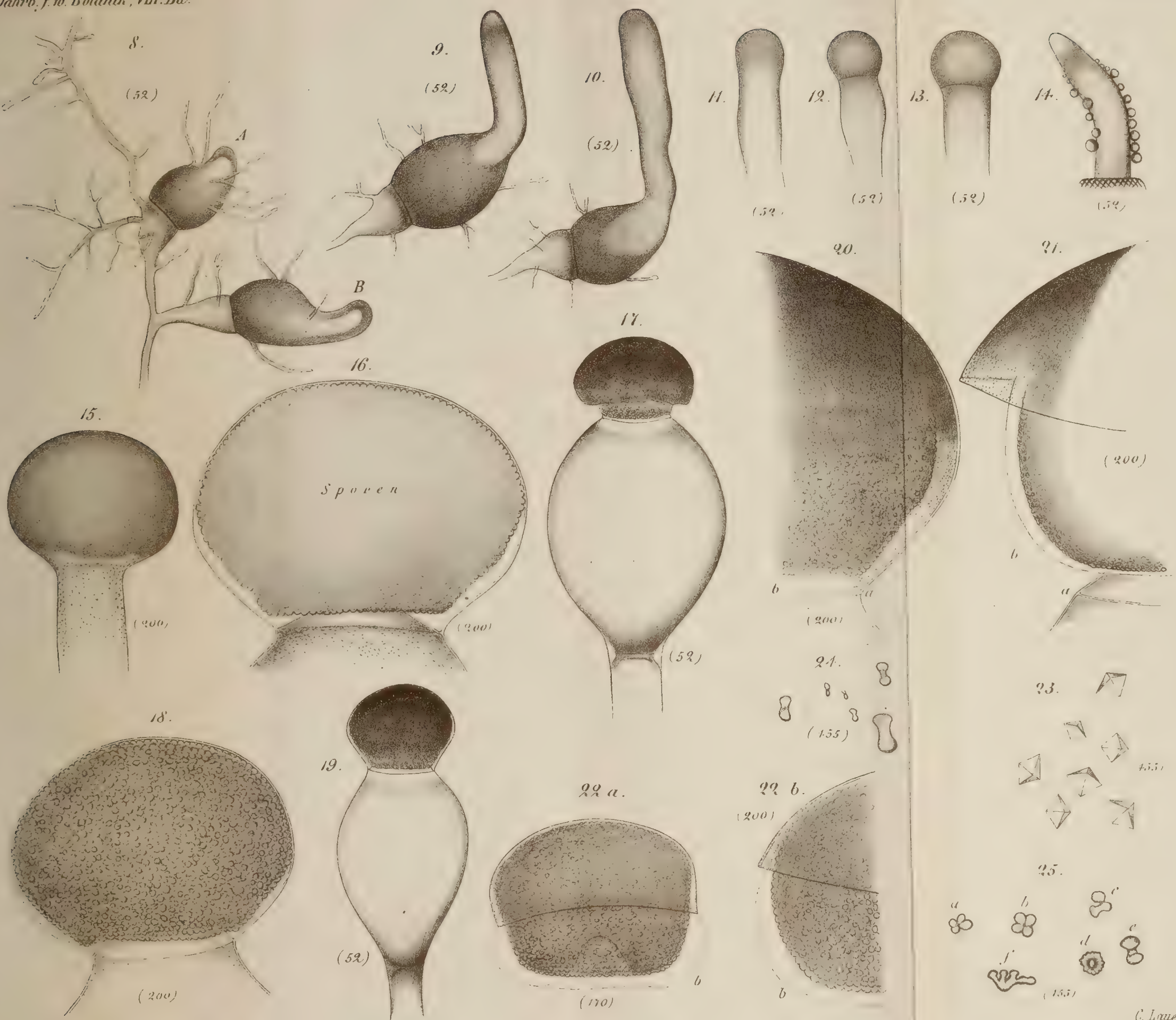

$J$ Klein ad nat. det. 



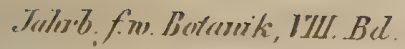

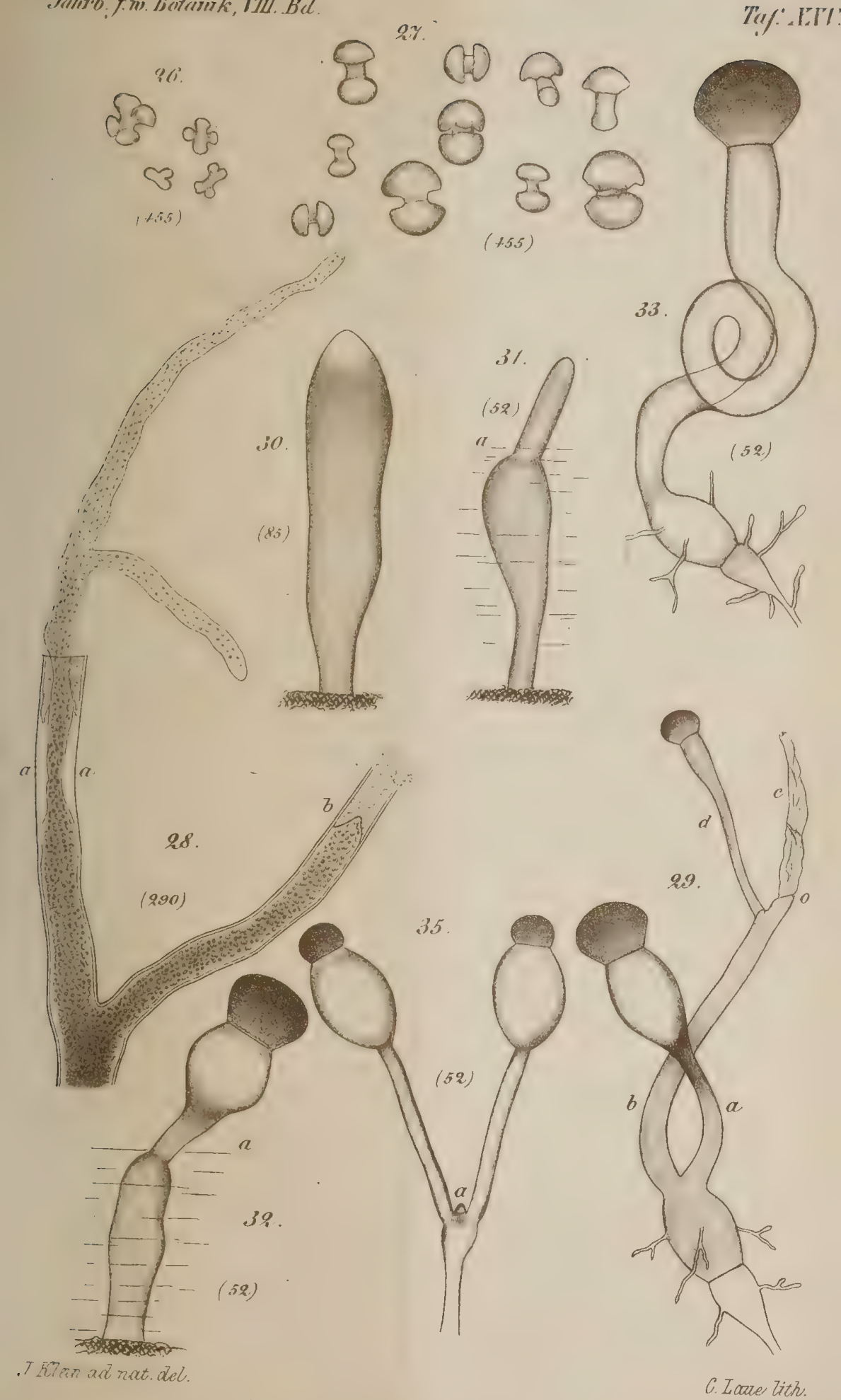



.Taturb, f' w. Botanik, IIII. Bd.

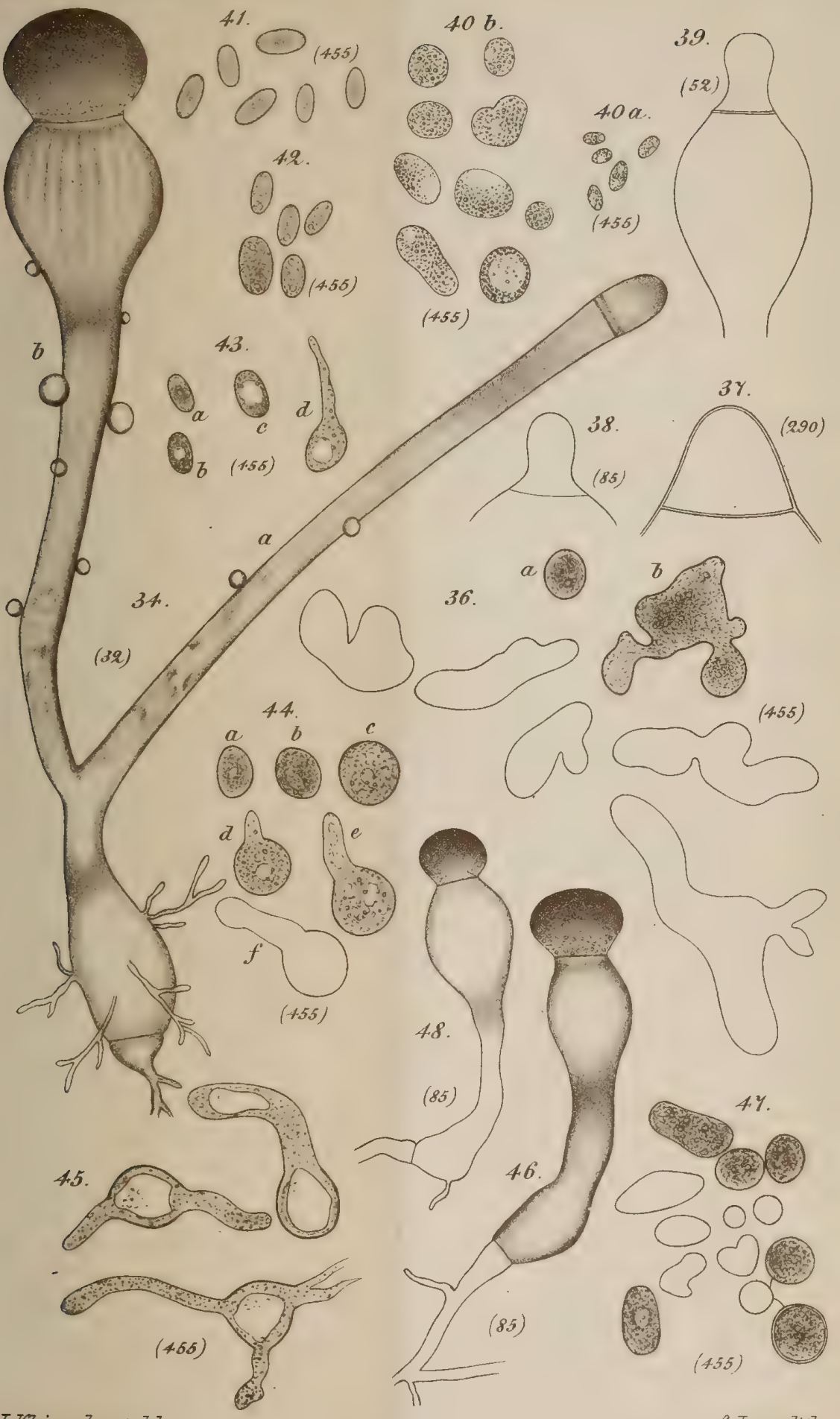




Jahrb. f'ro. Bolanik, IIII. Bd.
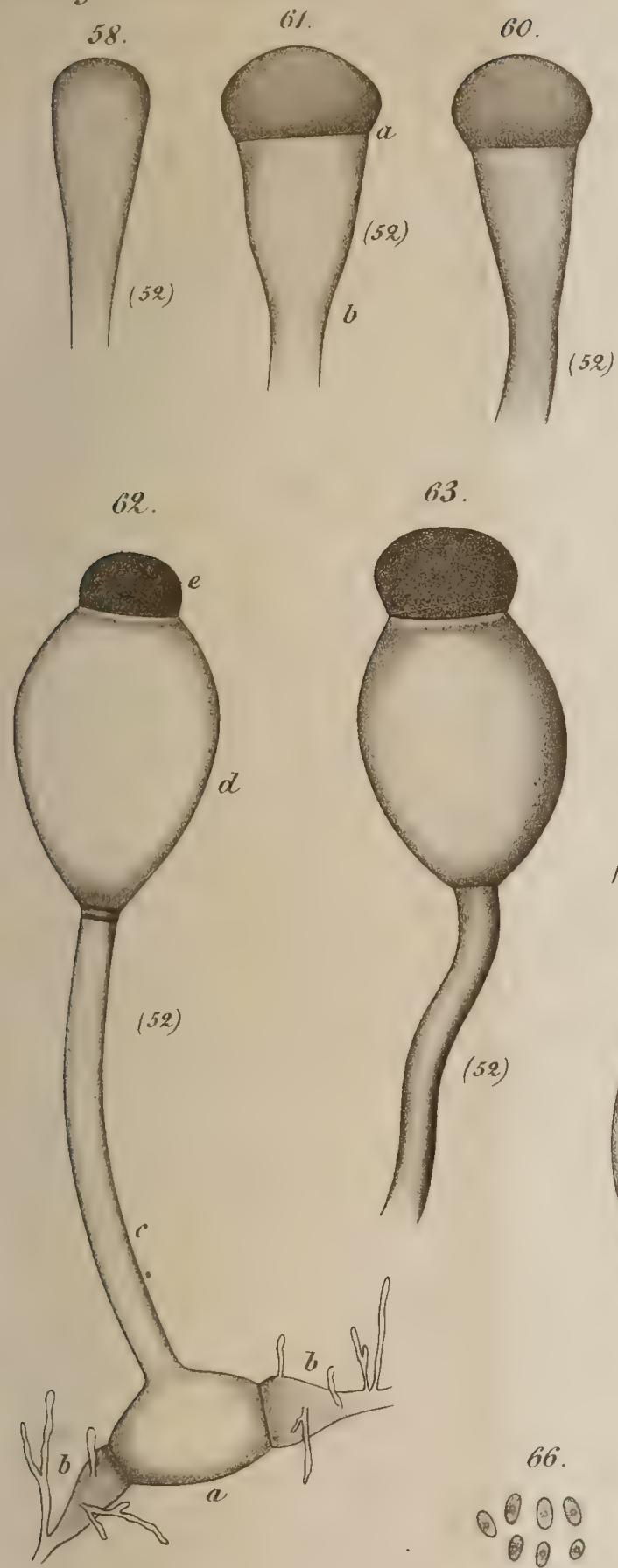

63.
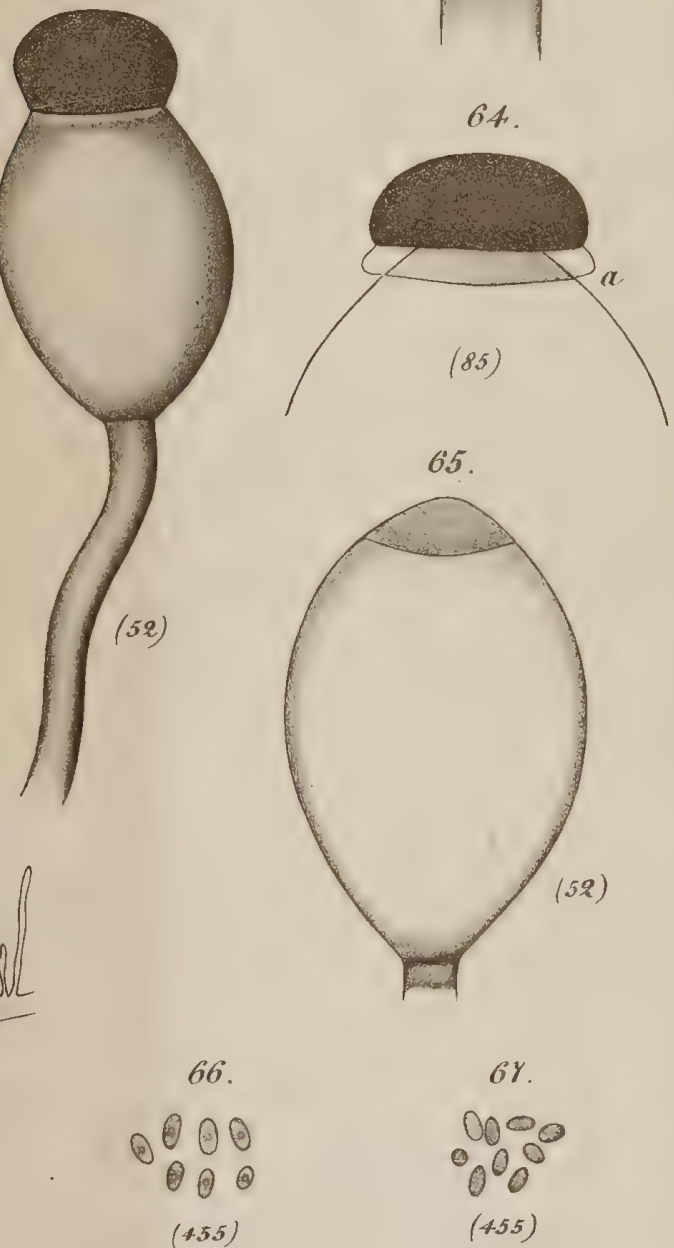

Jahirb. f.n. Botanik, VIII. Bd.

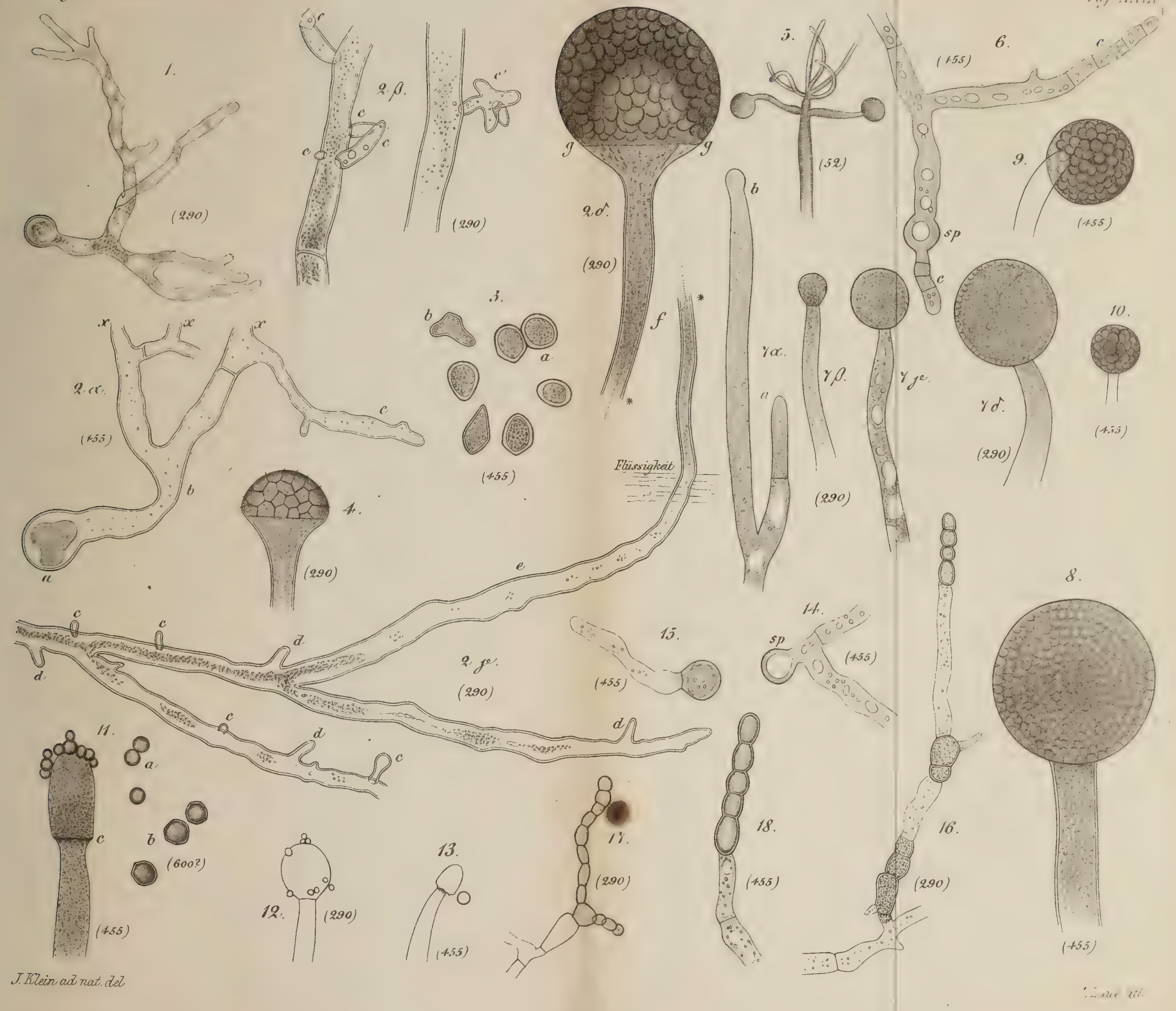



Jaherb. f'r Botarite, IIII. Bel.

TIIf: LET:

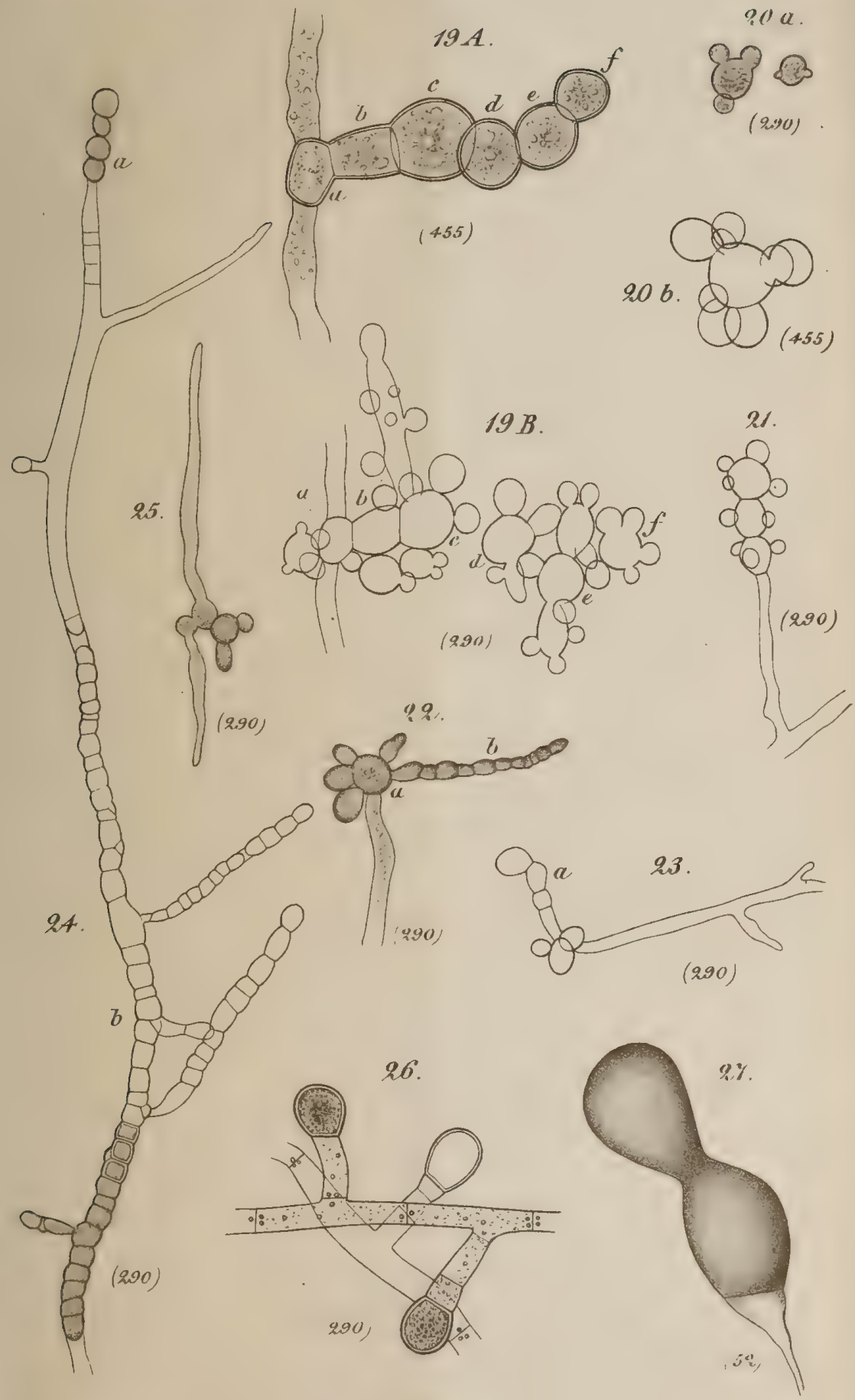

Tizeris chitrut iel. 


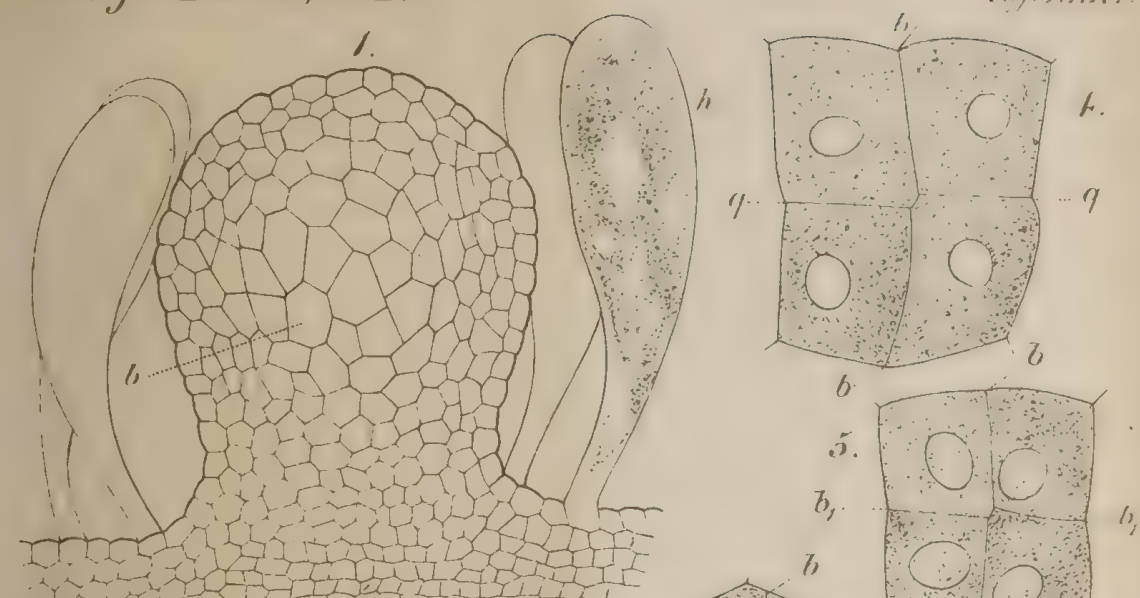

"थ

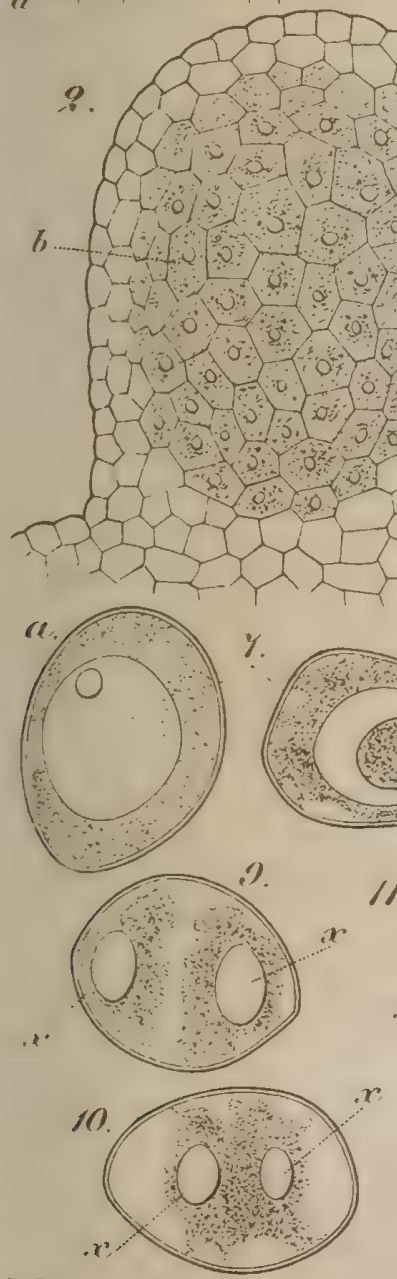

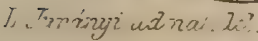

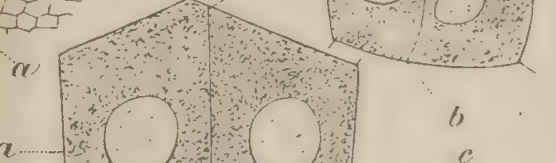

6

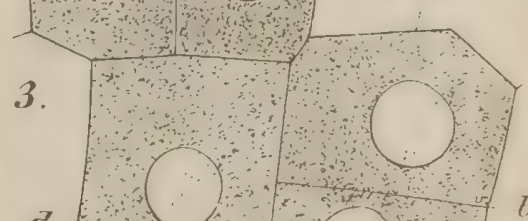

$d-3=0$

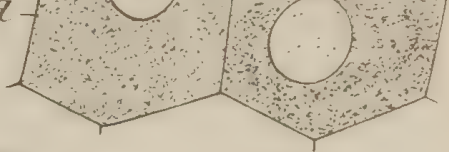

12
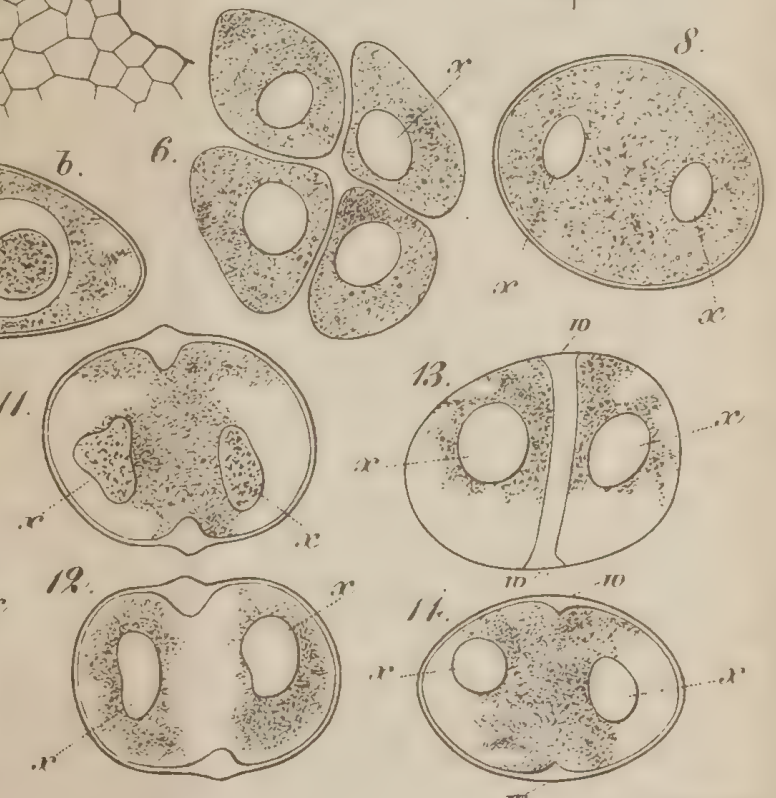

CTourebich 



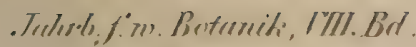

Ti, I.ETH
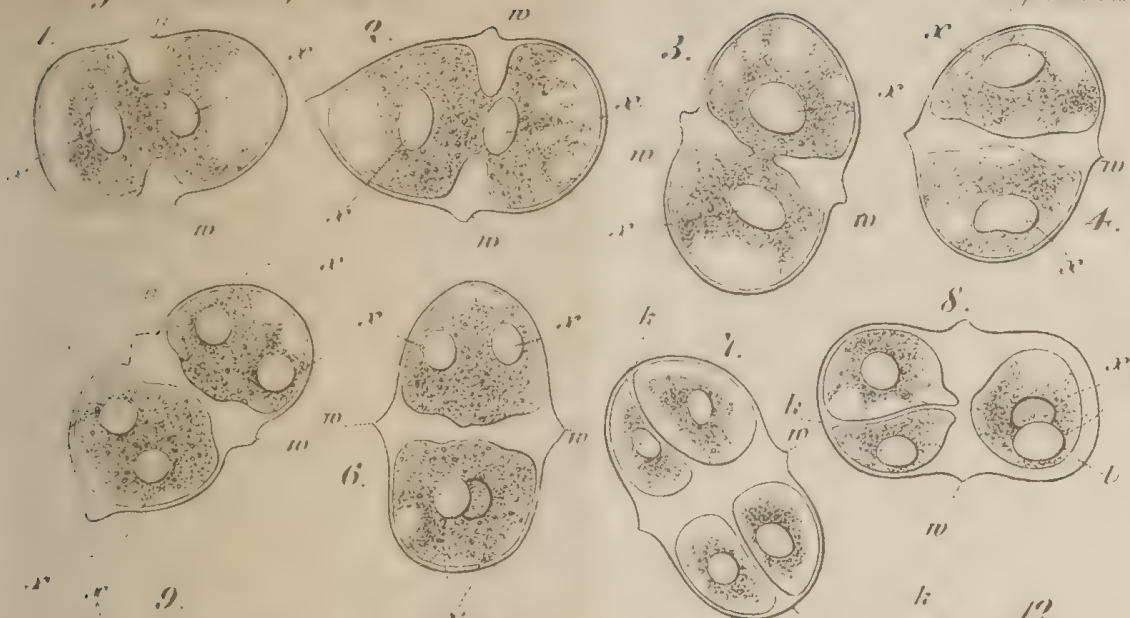

s'.
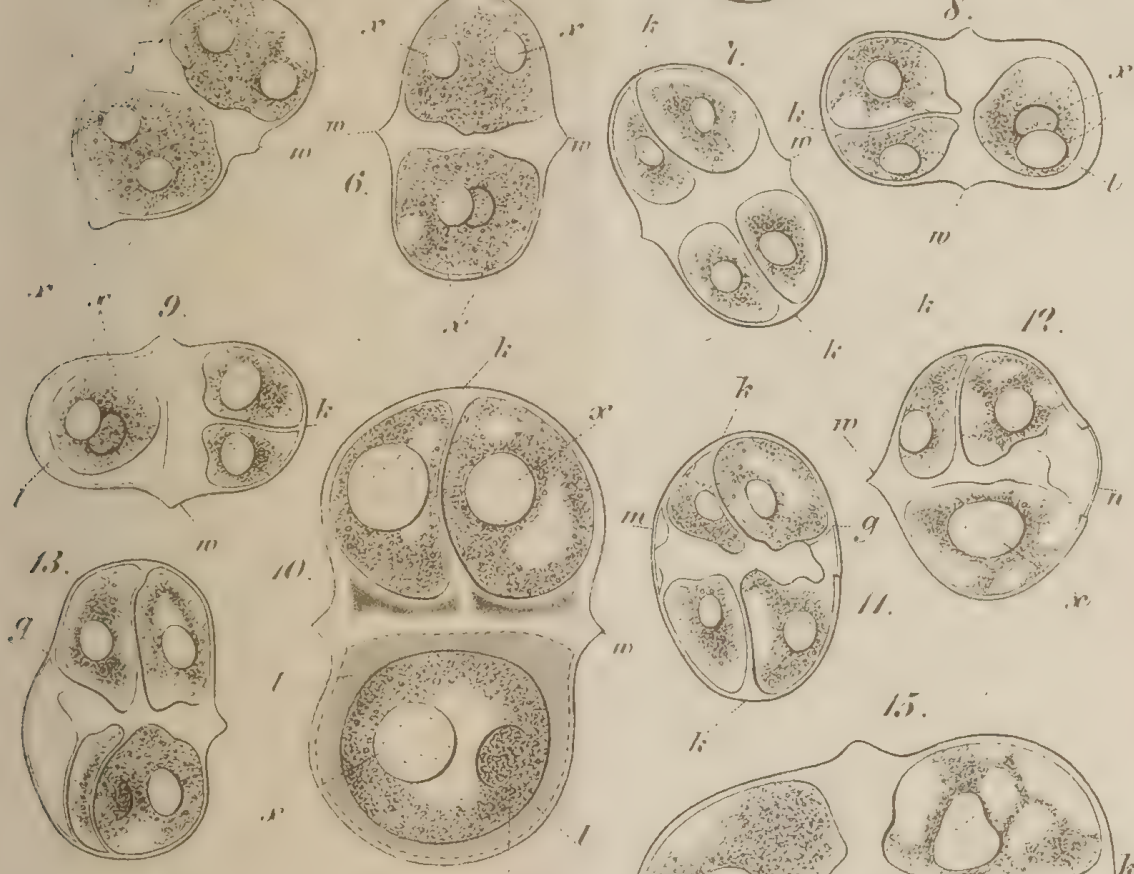

I.
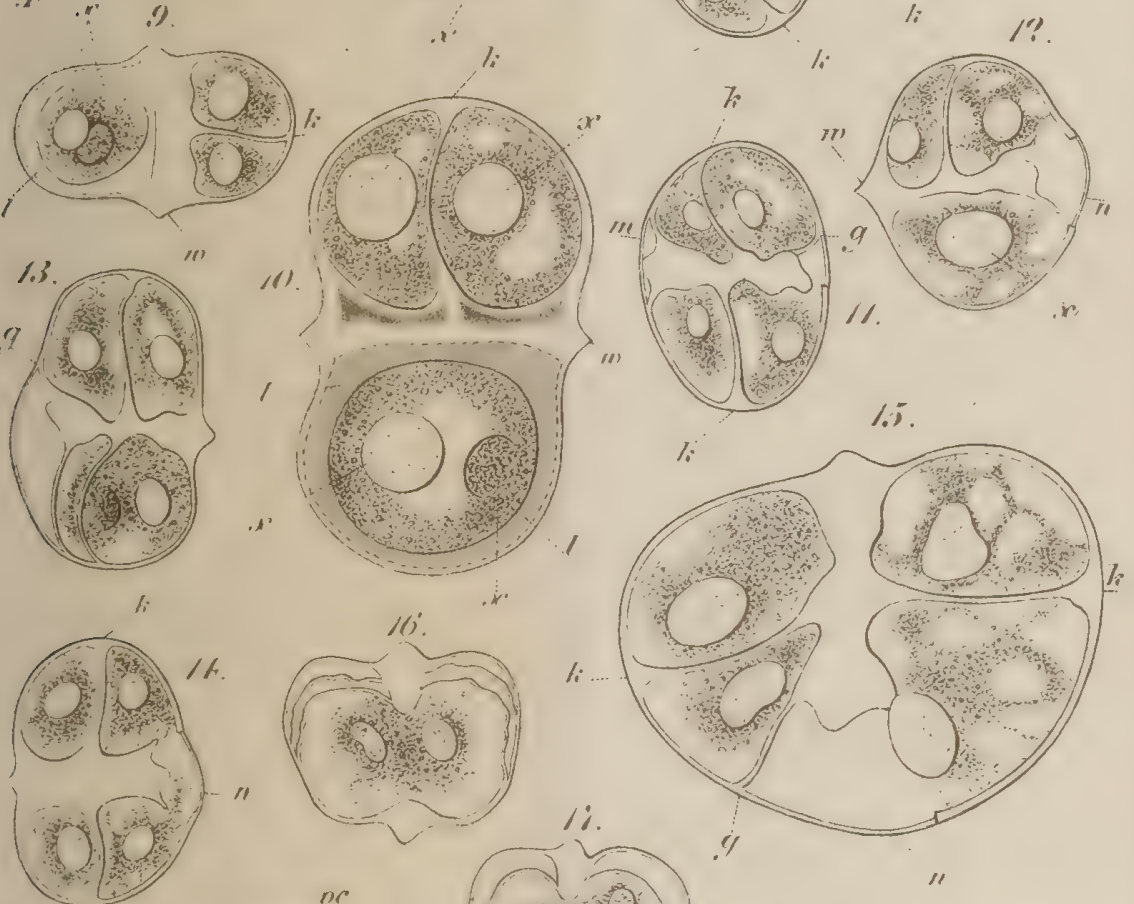

1.5
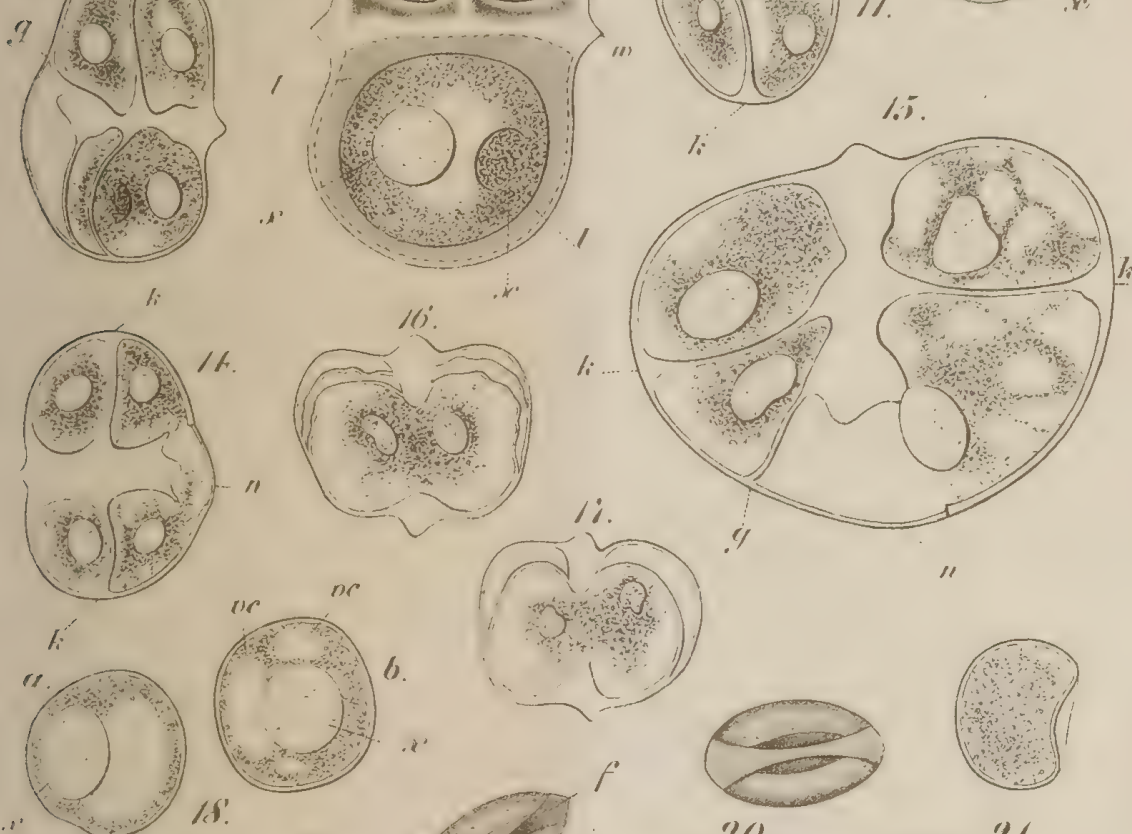

i.

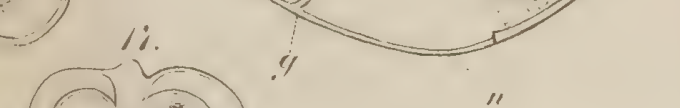

or. 00
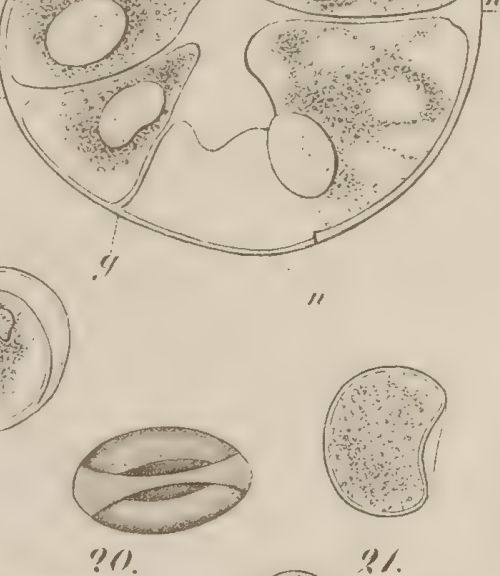

?\%
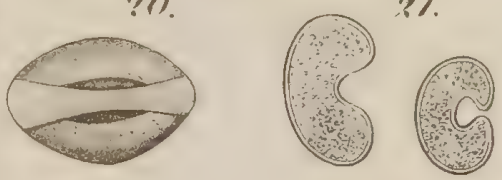

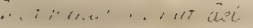

C. Laut tilic. 



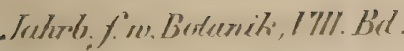
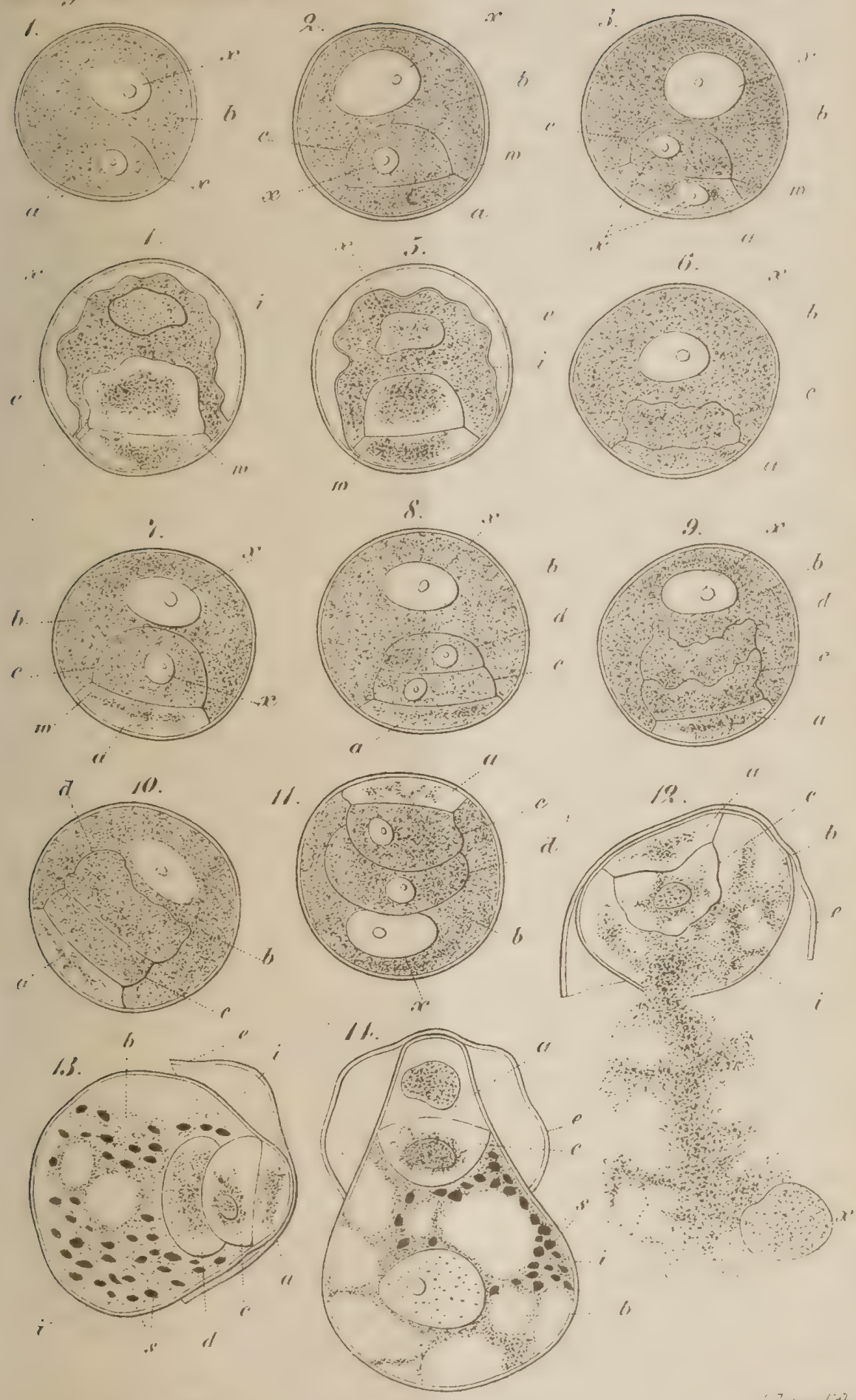

L. Ireranyi aà nat del. 

. Tuholl, f'm. Brtureik, l'Ill. Lid.
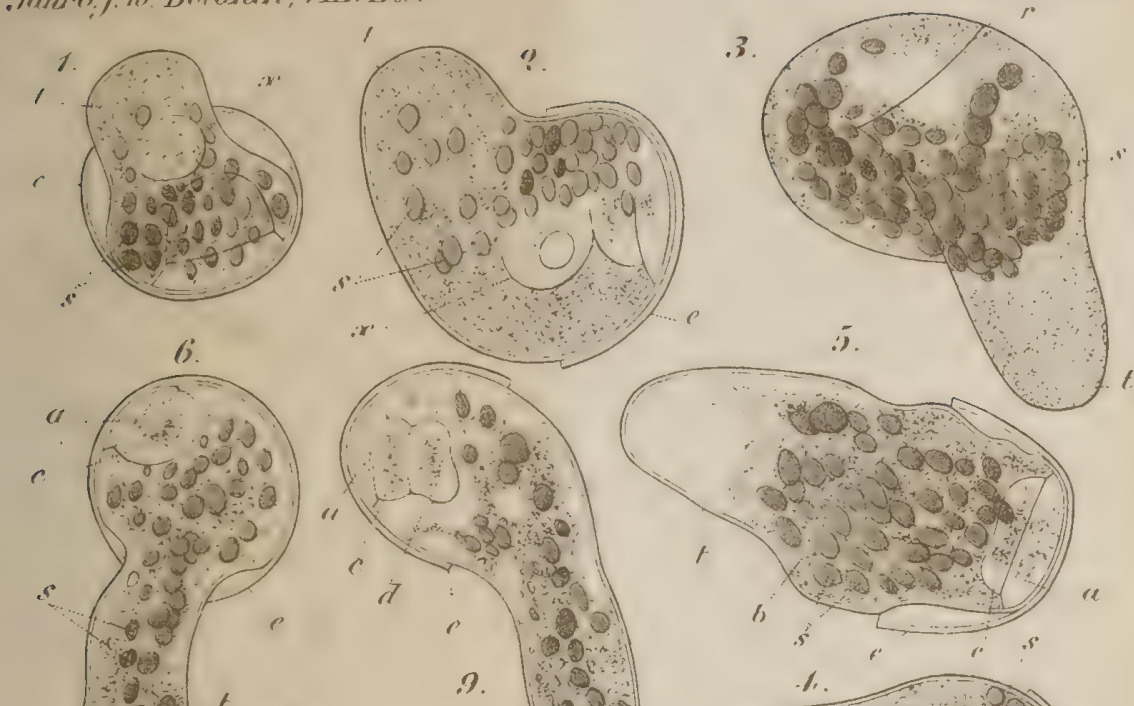

$\%$

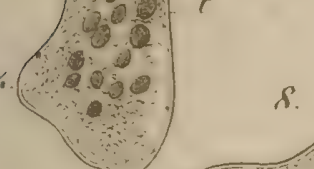

f.

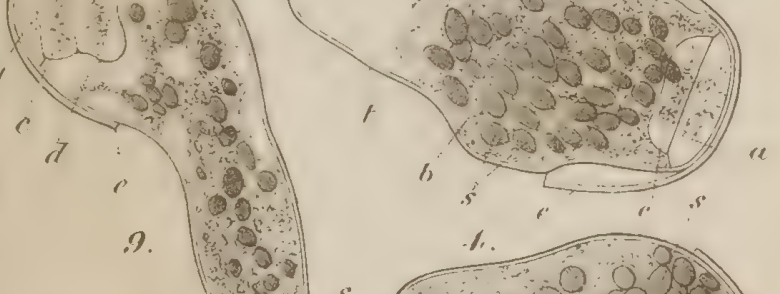

2
3
3

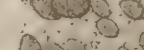

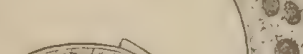
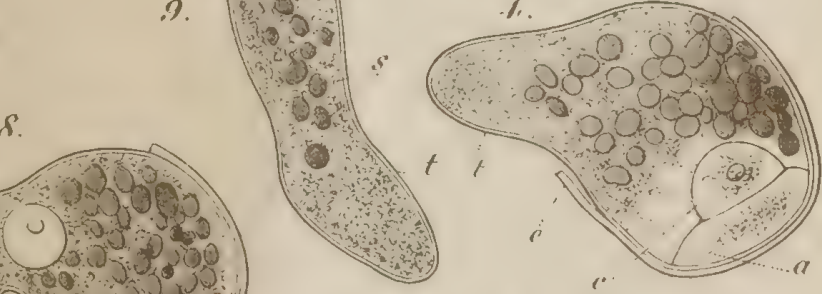


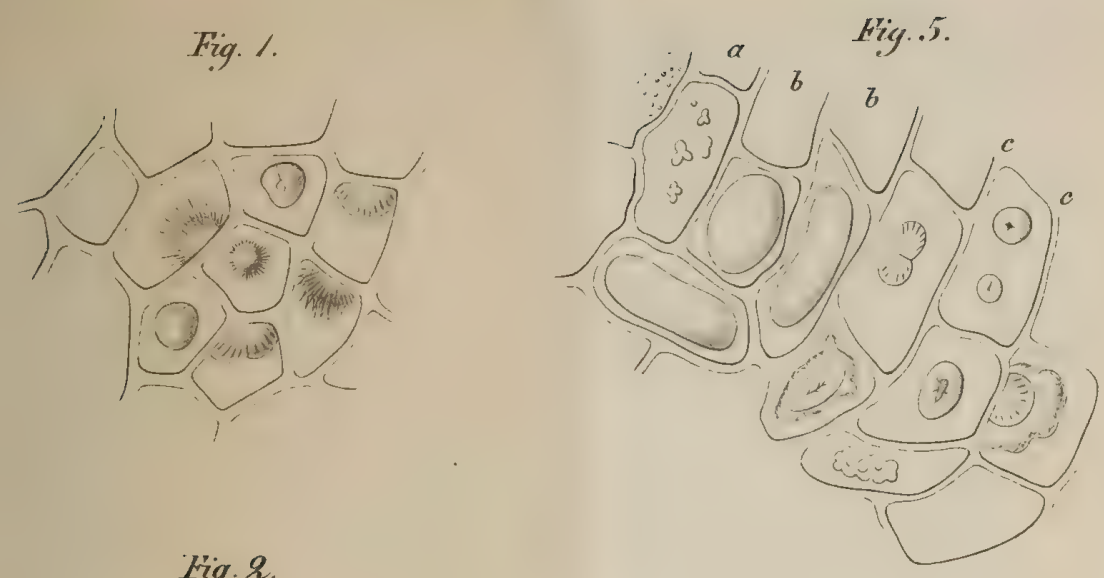

Fig. 2 .

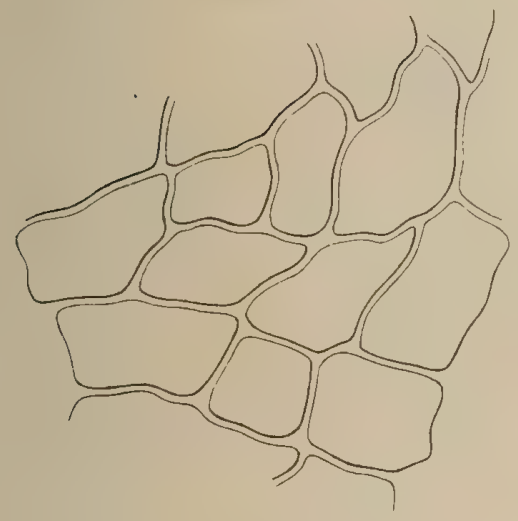

Fig. 6.

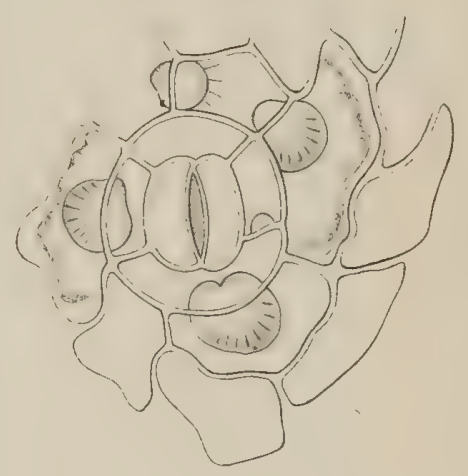

Fig. 3.

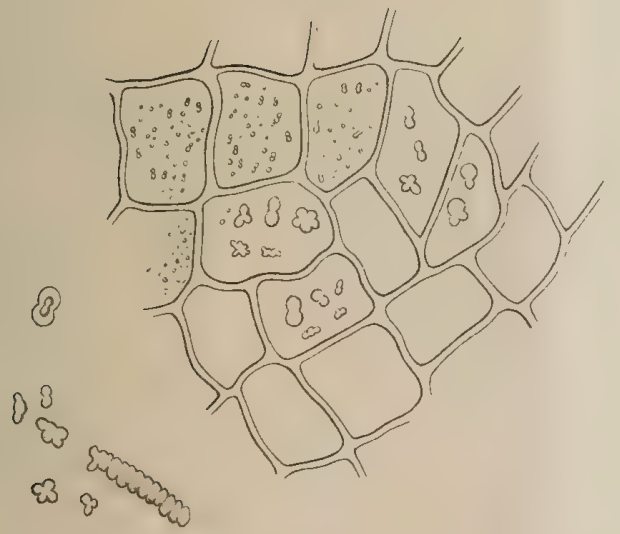

Fig. A.

Fig. \%

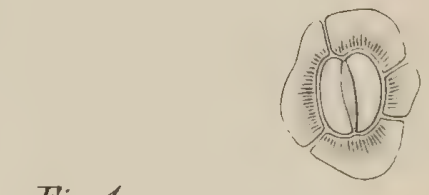

G. Troans ad nat. det.

r. Iraze lith 

Jahrb. fro. Botanik, VIII. Bd.
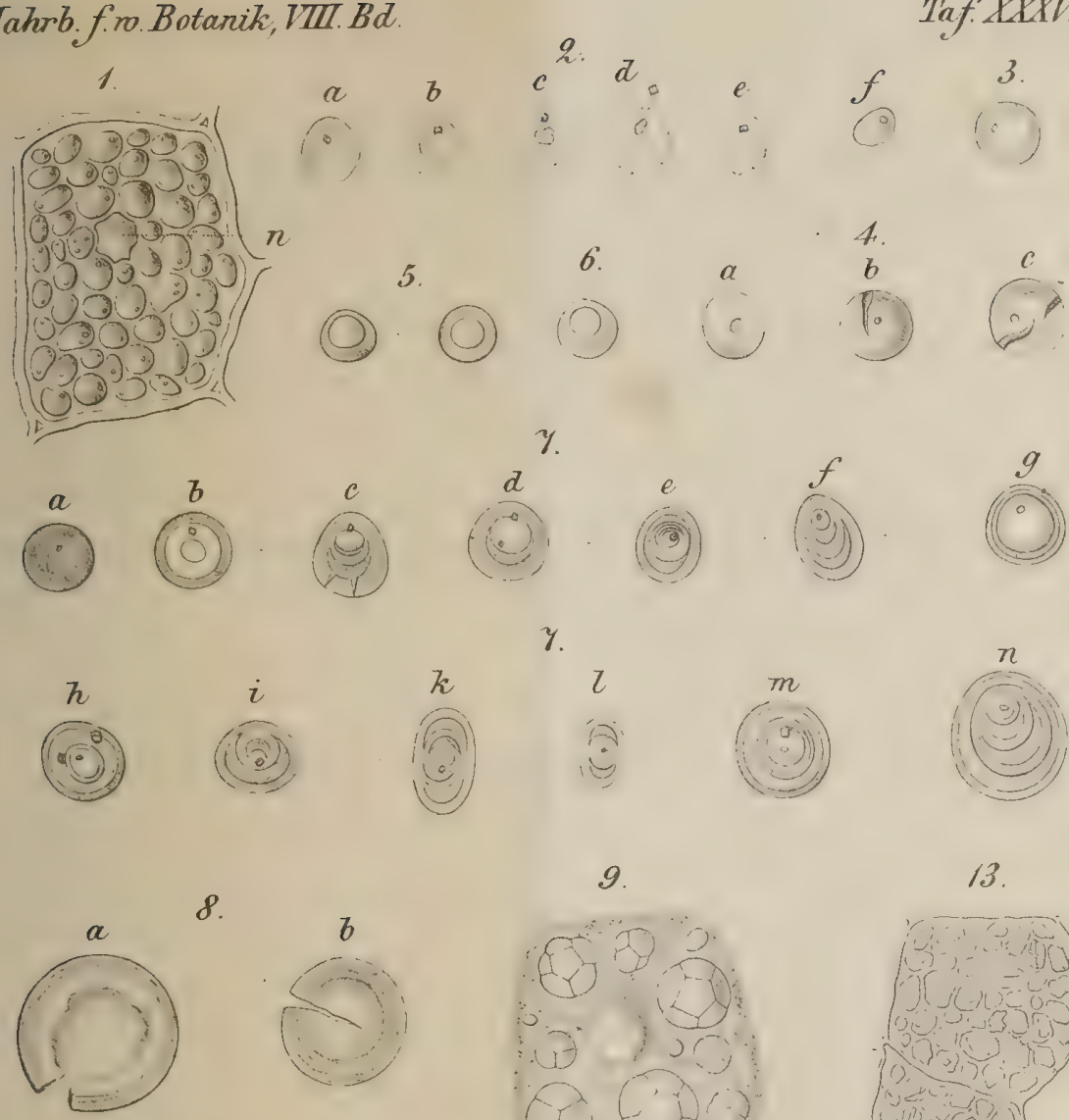

9.

13.
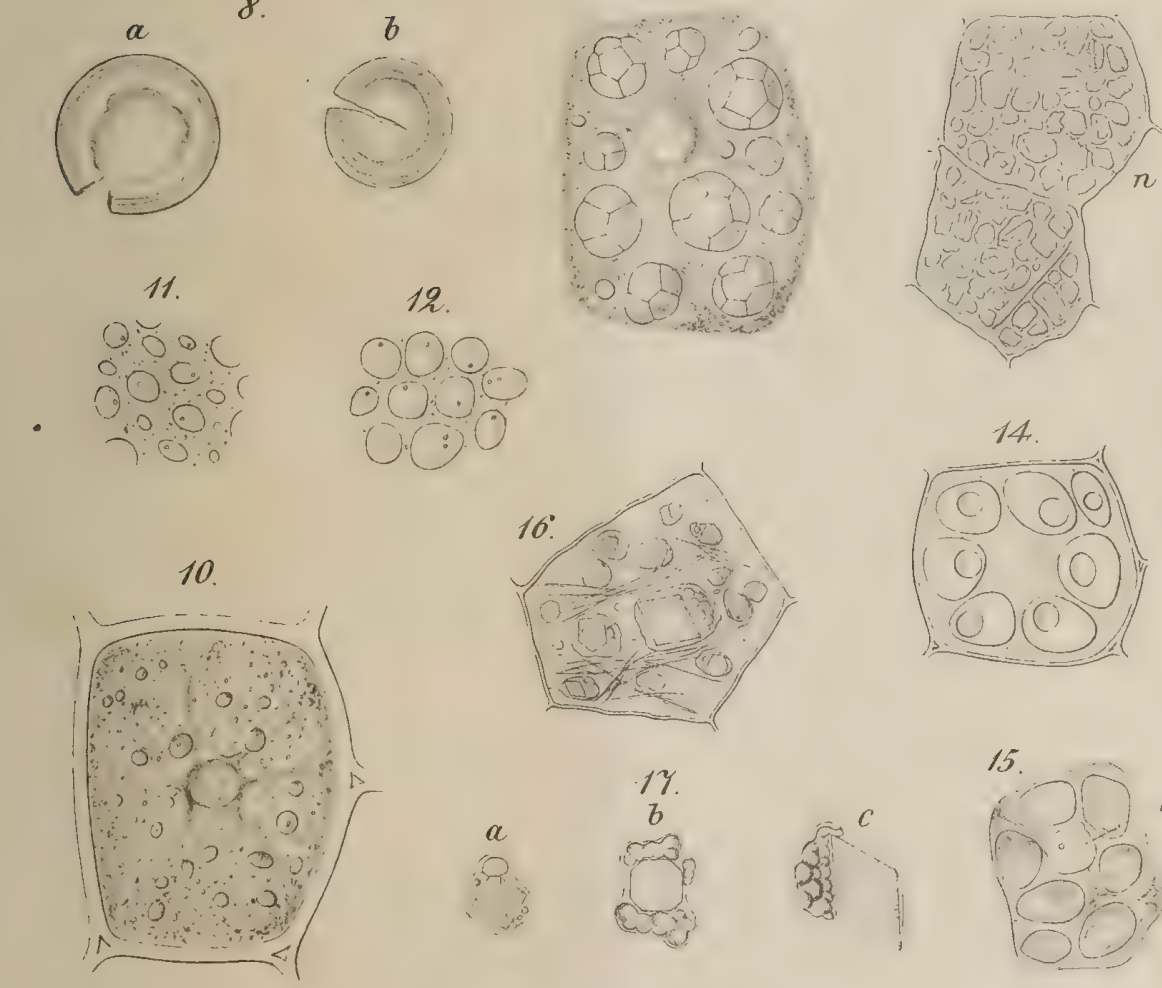

W. Pfeffer ad nat. del.

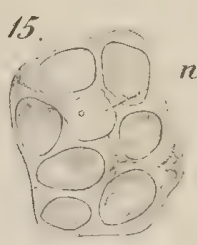

C Iorue lith 


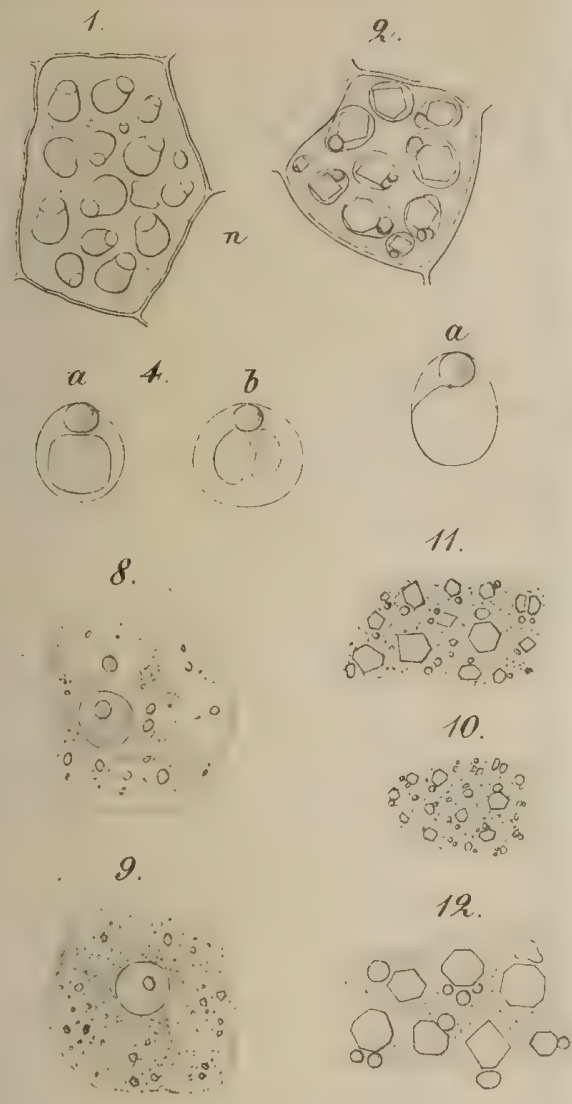

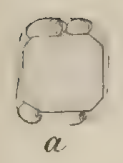

con

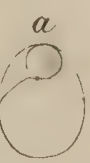

5

b

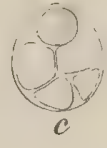

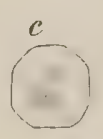

Taf. IXXVII.
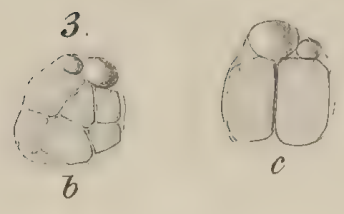

6 .

$\therefore b$ $\sqrt{3}$

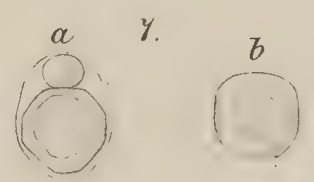

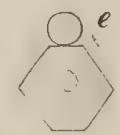
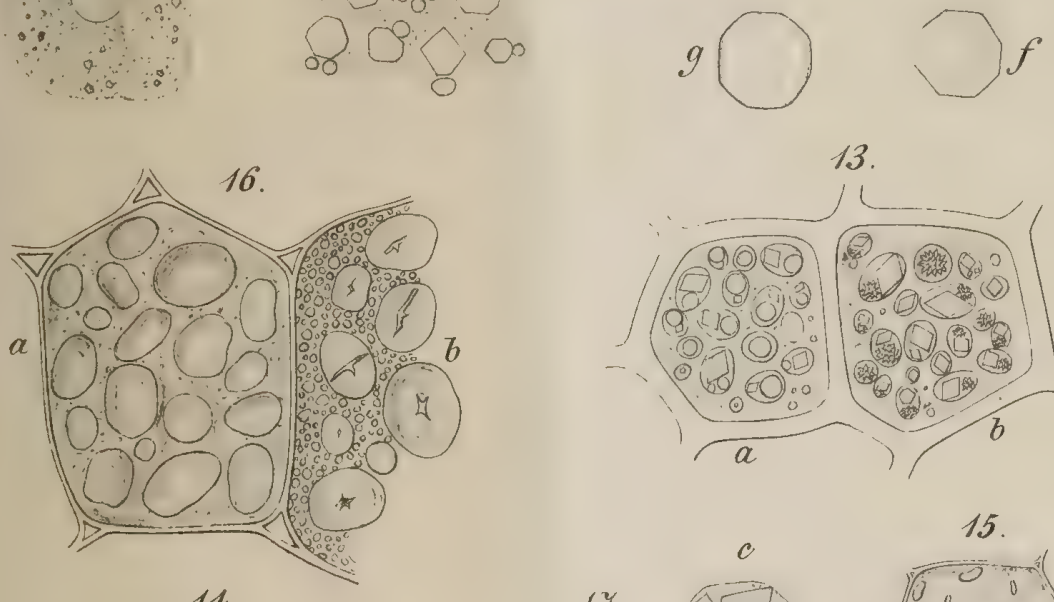

14.

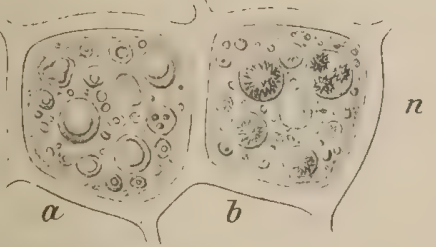

W. Pfeffer ad nat del.

13.
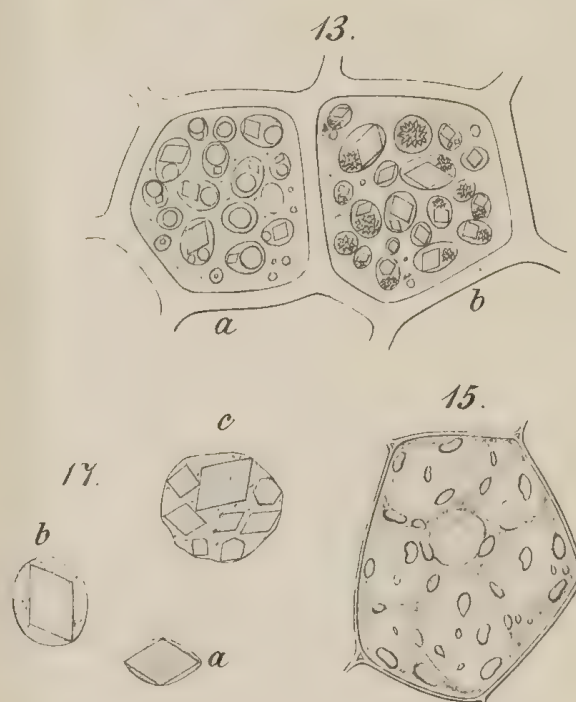

15.

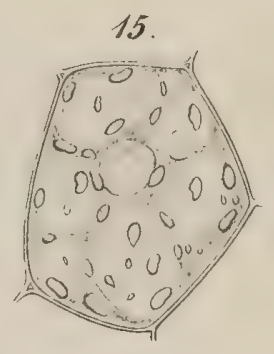

C. Taue lith 

Jahrb. f.r. Botanik, VIII. Bd.

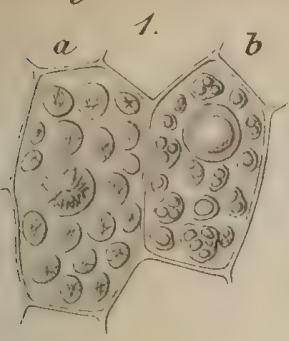

3
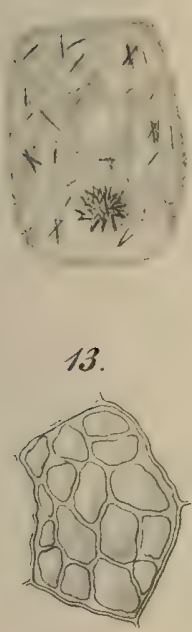

14.

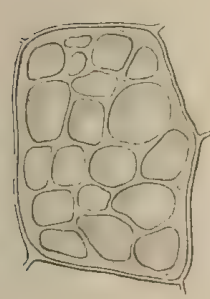

15.

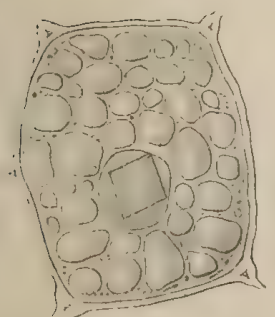

W.Pfiffer ad nat. del.

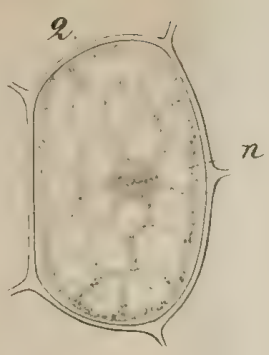

5.

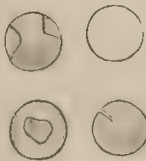

10.

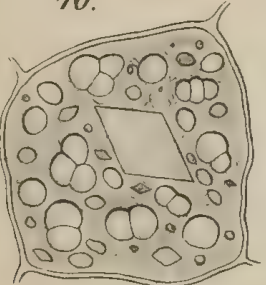

Q

9.
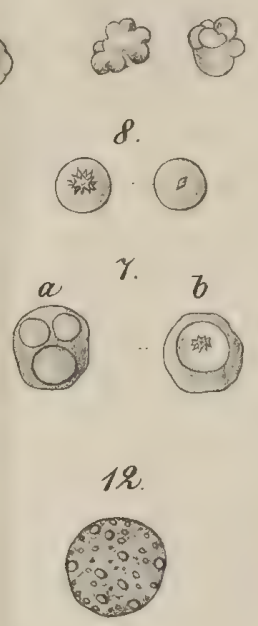

18

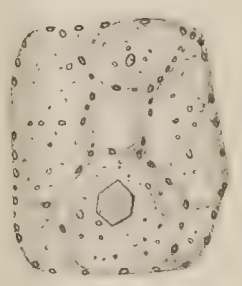

Taf. XXXVIII.

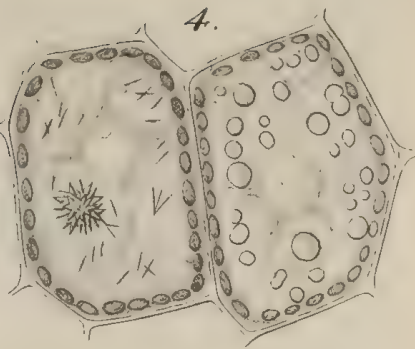

6.

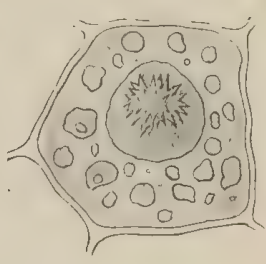

19.

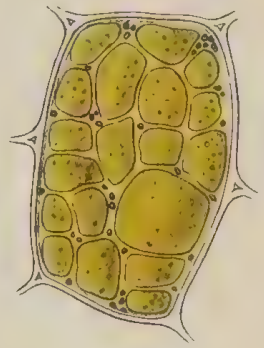

20.

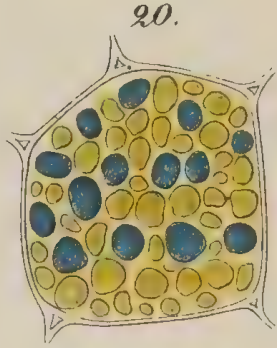

16

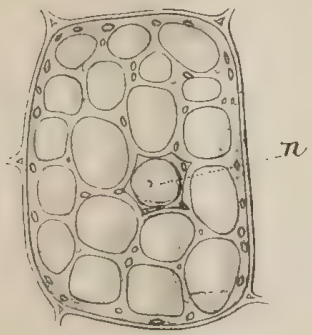

21.

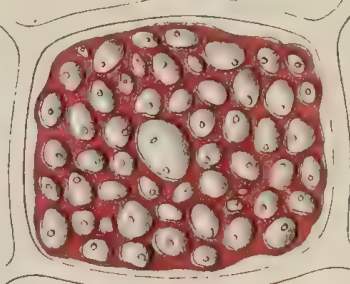

C. Iane lith 

. Thliot. f.m. Botanits, VIII. Bd.

Fig. 1.

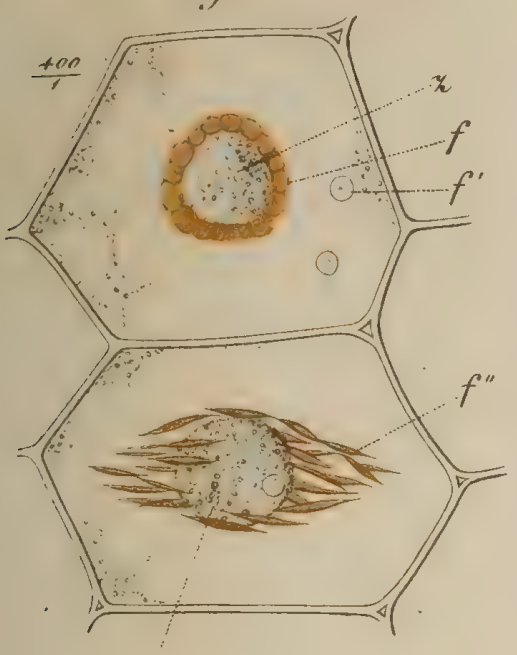

$z$

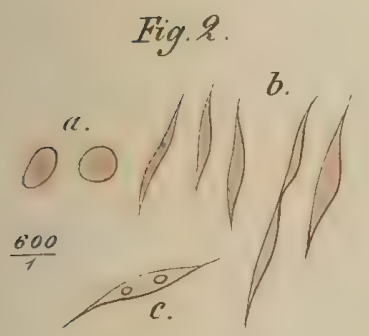

Fig. 5.
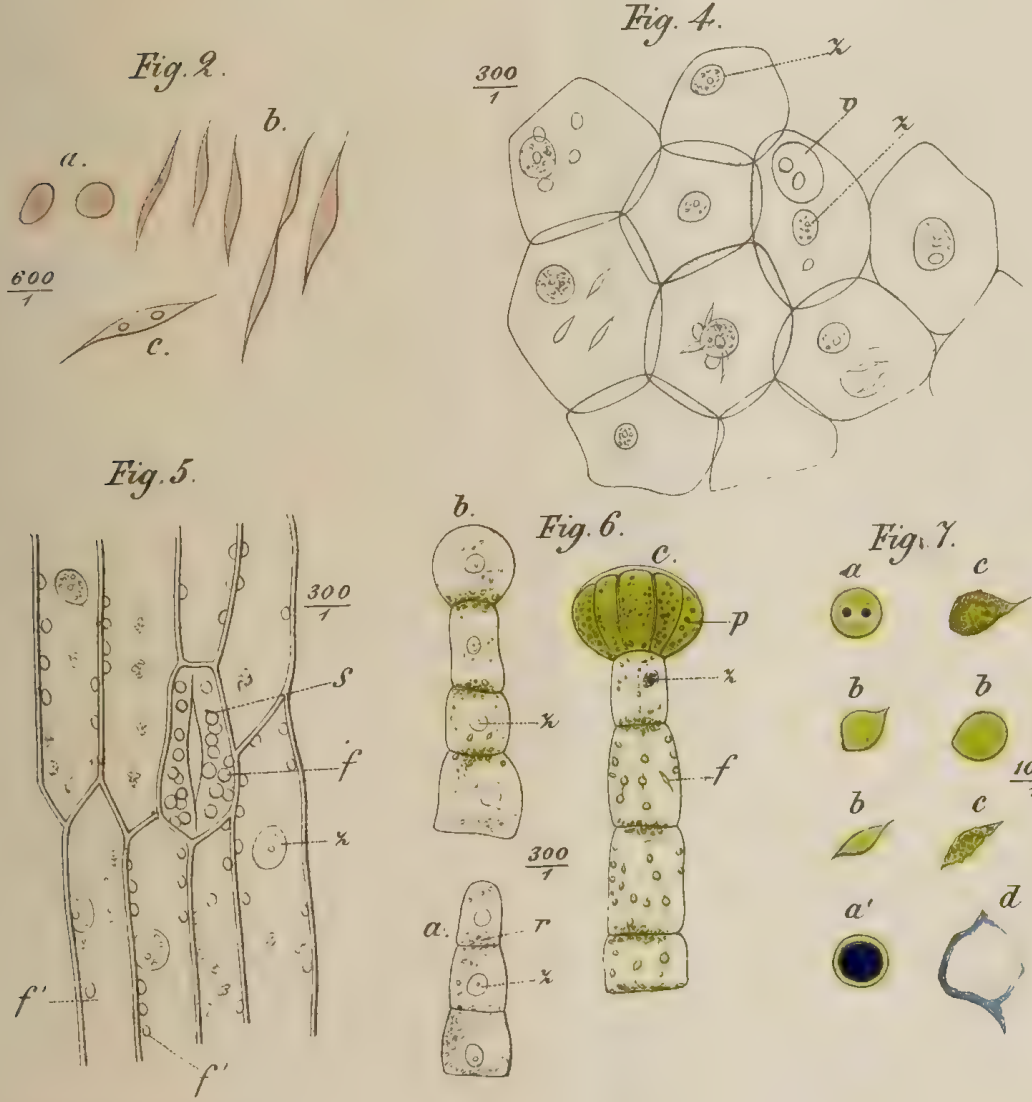

Taf. $\triangle X X I X$.

Fig. 3 .

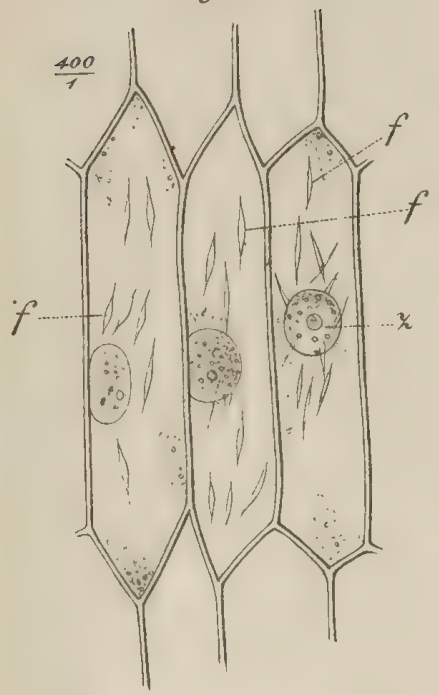

Fig. A. 




